NUREG-1368

\title{
Preapplication Safety Evaluation \\ Report for the Power Reactor \\ Innovative Small Module (PRISM) \\ Liquid-Metal Reactor
}

\section{Final Report}

Manuscript Completed: January 1994

Date Published: February 1994

Office of Nuclear Reactor Regulation

U.S. Nuclear Regulatory Commission

Washington, DC 20555-0001

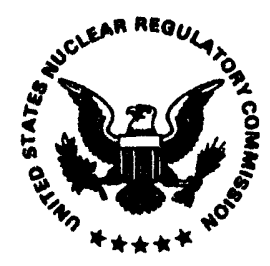




\begin{abstract}
This preapplication safety evaluation report (PSER) presents the results of the preapplication design review for the power reactor innovative small module (PRISM) liquidmetal (sodium)-cooled reactor, Nuclear Regulatory Commission (NRC) Project No. 674. The PRISM conceptual design was submitted by the U.S. Department of Energy (DOE) in accordance with the NRC's "Statement of Policy for the Regulation of Advanced Nuclear Power Plants" (51 Federal Register 24643). This policy provides for the early Commission review and interaction with designers and licensees. The PRISM reactor design proposed by DOE is for a small, modular, pool-type, liquid-metal (sodium)-cooled reactor. The standard plant design for the PRISM consists of three identical power blocks with a total electrical output rating of $1395 \mathrm{MWe}$. Each power block comprises three reactor modules, each with an individual thermal rating of $\mathbf{4 7 1}$ MWt. Each module is located in its own below-grade silo and is connected to its own intermediate heat transport system and steam generator system. The reactors utilize a metallic-type fuel, a ternary alloy of U-Pu-Zr. The design includes passive reactor shutdown and passive decay heat removal features.
\end{abstract}

ABSTRACT

The review approach and criteria used by the staff are directed toward meeting the guidance in the Commission's Advanced Reactor Policy which states that advanced reactors must, as a minimum, provide at least the same degree of protection for the public and the environment that is required for current-generation LWRs. The staff has interpreted current-generation LWRs to be those evolutionary designs currently under review as standard plant designs, such as the advanced boiling water reactor. Further, the policy states that the Commission expects advanced designs to provide enhanced margins of safety.
Accordingly, in the review of the PRISM design, the staff proposes to use and build on applicable existing regulations and guidelines for safety developed for application to LWRs, to develop additional criteria when necessary to address the unique characteristics of these designs, and to require that they be assessed for enhanced safety. Additionally, the staff created further criteria following the guidance provided by the Commission in the Staff Requirements Memorandum dated July 30, 1993, that dealt with key policy' issues for the advanced reactors. In the application of the existing regulations and guidelines, the staff, in some cases, has had to interpret the guidance developed for LWRs for application to the PRISM concept and for issues under review. In making such interpretations, the staff has directed its approach toward maintaining limits and criteria at least equivalent to those of LWRs for quality design, construction, and operation, and for the release of radiation, maintaining defense in depth, providing for conservatisms to account for plantspecific uncertainties in the designs, and maintaining consistency with the guidance under development of future LWRs for the treatment of severe accidents.

The PSER is the NRC staff's preliminary evaluation of the safety features in the PRISM design, including the projected research and development programs required to support the design and the proposed testing needs. Because the NRC staff review was based on a conceptual design, the PSER did not result in an approval of the design. Instead it identified certain key safety issues, provided some guidance on applicable licensing criteria, assessed the adequacy of the preapplicant's research and development programs, and concluded that no obvious impediments to licensing the PRISM design had been identified. 


\section{CONTENTS}

Page

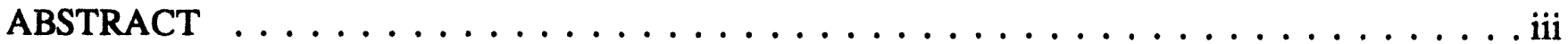

EXECUTIVE SUMMARY $\ldots \ldots \ldots \ldots \ldots \ldots \ldots \ldots \ldots \ldots \ldots \ldots \ldots \ldots$

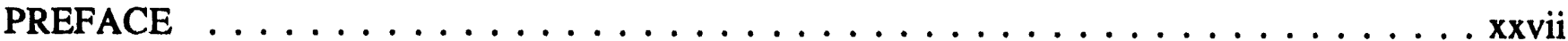

ACKNOWLEDGEMENTS $\ldots \ldots \ldots \ldots \ldots \ldots \ldots \ldots \ldots \ldots \ldots \ldots \ldots \ldots \ldots$

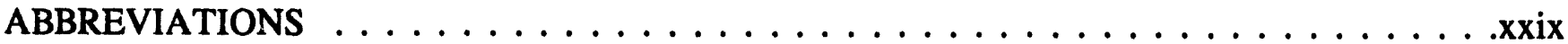

1 INTRODUCTION AND SUMMARY $\ldots \ldots \ldots \ldots \ldots \ldots \ldots \ldots \ldots \ldots$

1.1 Introduction $\ldots \ldots \ldots \ldots \ldots \ldots \ldots \ldots \ldots$

1.2 PRISM Approach and Objectives . . . . . . . . . . . . . . . . 1-1

1.3 General Plant Description . . . . . . . . . . . . . . . . . . . . . . 1-2

1.4 Comparison With Other Liquid-Metal Reactors . . . . . . . . . . . . . . . . . . . 1-6

1.5 Program Status Overview and Research and Development (R\&D) . . . . . . . . . . 1-14

1.6 Scope of the Review . . . . . . . . . . . . . . . . . . . . . . 1-17

1.7 Review Approach and Criteria . . . . . . . . . . . . . . . . . . . 1-18

1.8 References . . . . . . . . . . . . . . . . . . . . . . . . . 1-19

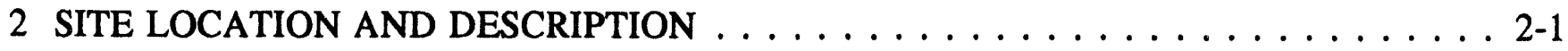

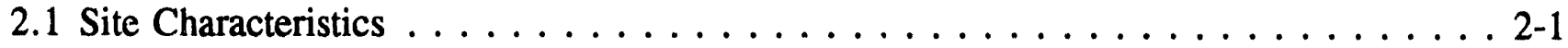

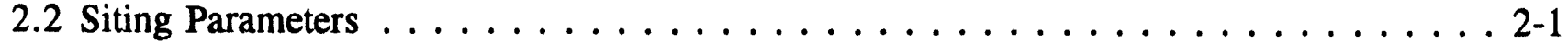

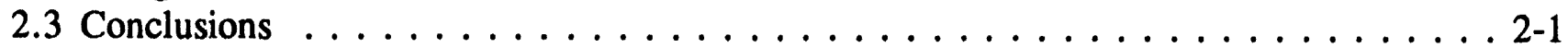

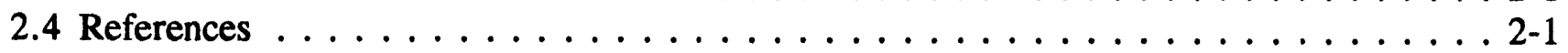

3 REVIEW APPROACH AND CRITERIA . . . . . . . . . . . . . . . . 3-1

3.1 Review Criteria . . . . . . . . . . . . . . . . . . . . . . . . . 3-1

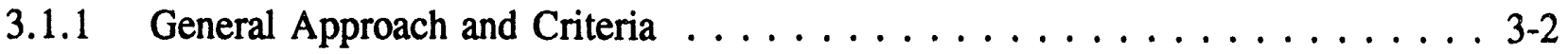

3.1.2 Proposed Licensing Criteria From SECY-93-092 (Ref. 3.1) . . . . . . . . . . 3-3

3.2 Conformance With General Design Criteria . . . . . . . . . . . . . . . . . . 3-13

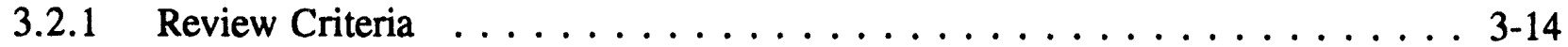

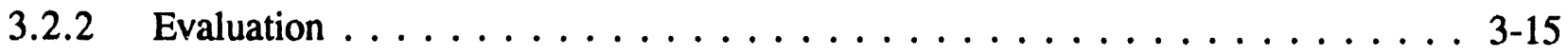

3.2.3 Comparison to the GDC in 10 CFR Part $50 \ldots \ldots \ldots \ldots \ldots \ldots$. . . . . . . . . . .

3.2.4 Additional GDC Proposed for the PRISM Design Not in 10 CFR Part 50 . . . 3-55

3.2 .510 CFR Part $52 \ldots \ldots \ldots \ldots \ldots \ldots \ldots \ldots \ldots \ldots$

3.2.6 Commission's Advanced Reactor Policy Statement . . . . . . . . . . . . . . 3-58

3.2.7 Review of Clinch River Breeder Reactor Plant (CRBRP) . . . . . . . . . . 3-58

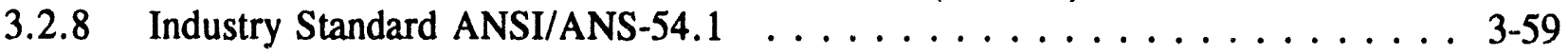

3.2 .9 Advanced Reactor Design Policy Issues . . . . . . . . . . . . . . . . . 3-59

3.2 .10 Conclusions . . . . . . . . . . . . . . . . . . . . . . 3-59

3.3 Seismic Design . . . . . . . . . . . . . . . . . . . . . . . . 3-59

3.3.1 Seismic Input, Plant System Analysis, and System Seismic Analysis . . . . 3-59

3.3 .2 Seismic Instrumentation $\ldots \ldots \ldots \ldots \ldots \ldots \ldots$. . . . . . . . . . . . . . . . . . . . .

3.3.3 Seismic Base Isolation System . . . . . . . . . . . . . . . . . . 3-62 


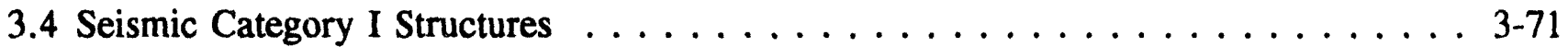

3.4.1 Design Description and Safety Objectives . . . . . . . . . . . . . . 3-71

3.4 .2 Scope of Review . . . . . . . . . . . . . . . . . . . . 3-71

3.4 .3 Design Criteria . . . . . . . . . . . . . . . . . . . 3-72

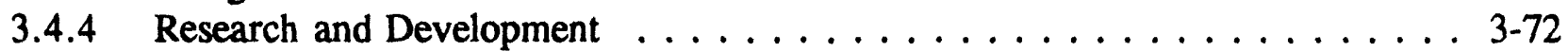

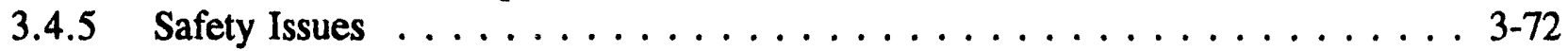

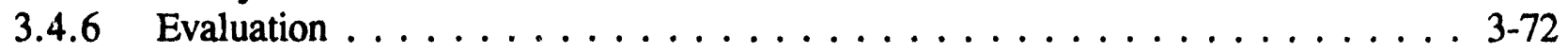

3.4 .7 Conclusions . . . . . . . . . . . . . . . . . . 3-73

3.5 Mechanical Systems and Components . . . . . . . . . . . . . . . . . 3-73

3.5.1 Design Description and Safety Objectives . . . . . . . . . . . . . . 3-73

3.5 .2 Scope of Review . . . . . . . . . . . . . . . . . . . . . . 3-73

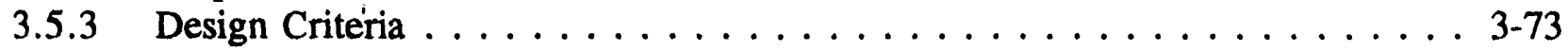

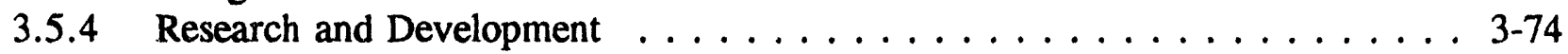

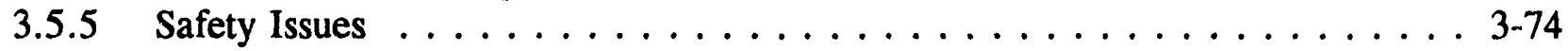

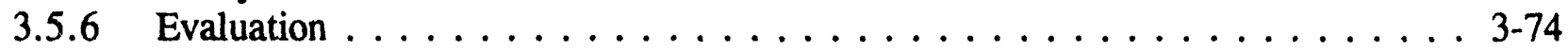

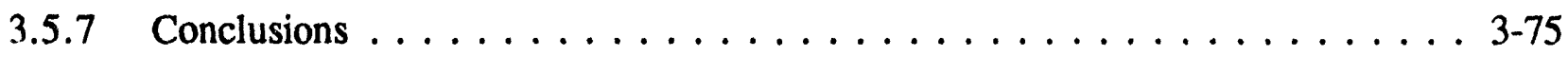

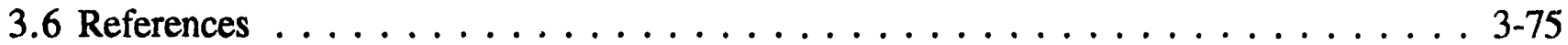

4 REACTOR SYSTEM . . . . . . . . . . . . . . . . . . . . 4-1

4.1 Summary Description . . . . . . . . . . . . . . . . . . . 4-1

4.2 Fuel System . . . . . . . . . . . . . . . . . . . . . . 4-1

4.2.1 Design Description and Safety Objectives .................. . . . .

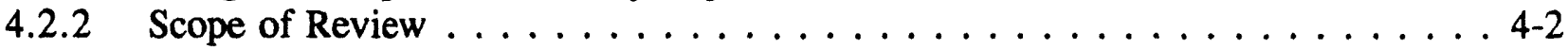

4.2 .3 Design Criteria ............................ . . . . . . . . .

4.2.4 Research and Development ... . . . . . . . . . . . . . . 4-3

4.2 .5 Safety Issues $\ldots \ldots \ldots \ldots \ldots \ldots \ldots \ldots \ldots \ldots \ldots$

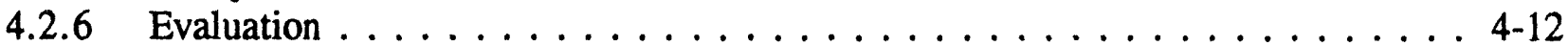

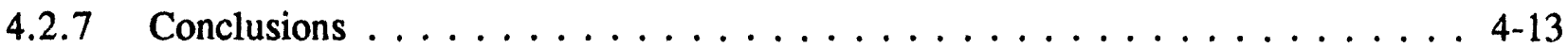

4.3 Nuclear Design . . . . . . . . . . . . . . . . . . . . . . . . . . . . . . . . . . . .

4.3.1 Design Description and Safety Objectives . . . . . . . . . . . . . . . 4-15

4.3 .2 Scope of Review . . . . . . . . . . . . . . . . . . . . 4-16

4.3 .3 Review Criteria ........................ 4-16

4.3.4 Research and Development ..................... 4-16

4.3.5 Safety Issues - Identification and Evaluation . . . . . . . . . . . . 4-17

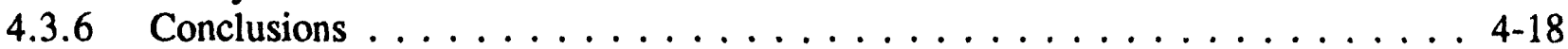

4.4 Thermal and Hydraulic Design . . . . . . . . . . . . . . . . . . . . . 4-19

4.4.1 Design Description and Safety Objectives . . . . . . . . . . . . . . . 4-19

4.4 .2 Scope of Review . . . . . . . . . . . . . . . . . . . . 4-20

4.4 .3 Review Criteria . . . . . . . . . . . . . . . . . . . . 4-20

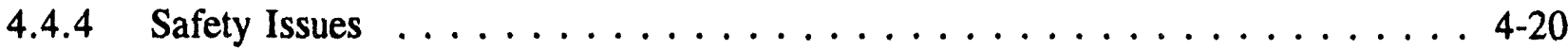

4.4 .5 Evaluation . . . . . . . . . . . . . . . . . . . 4-20

4.4.6 Research and Development ................... 4-22

4.4. Conclusions . . . . . . . . . . . . . . . . . . . . 4 4-22

4.5 Active Reactivity Control and Shutdown System . . . . . . . . . . . . . . . . 4-23

4.5.1 Design Description and Safety Objectives ... . . . . . . . . . . . 4-23

4.5 .2 Scope of Review ... . . . . . . . . . . . . . . . . 4-23

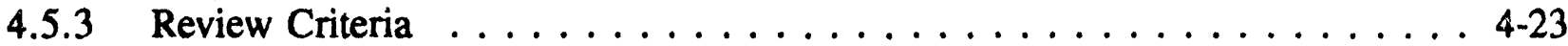




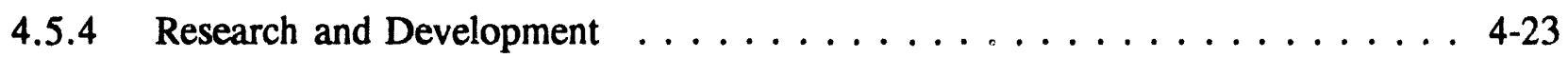

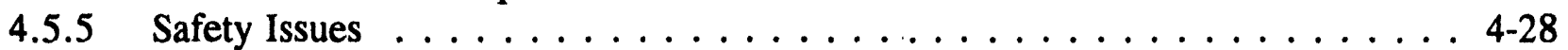

4.5 .6 Conclusions . . . . . . . . . . . . . . . . . . . . . . 4-28

4.6 Passive Safety System Design . . . . . . . . . . . . . . . . . . . . . . . . . 4-29

4.6.1 Design Description and Safety Objectives . . . . . . . . . . . . . . . . . 4-29

4.6 .2 Scope of Review . . . . . . . . . . . . . . . . . . . . . 4-30

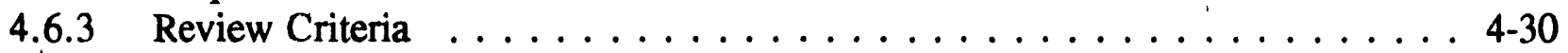

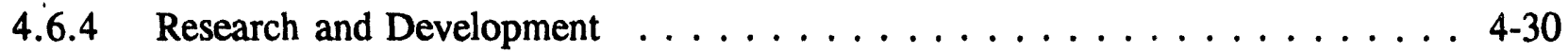

4.6 .5 Safety Issues and Evaluation . . . . . . . . . . . . . . . . . . . . 4-30

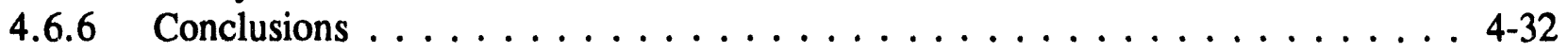

4.7 References . . . . . . . . . . . . . . . . . . . . . . 4-32

5 REACTOR COOLANT SYSTEM AND CONNECTED SYSTEMS $\ldots \ldots \ldots \ldots \ldots$

5.1 Summary Description . . . . . . . . . . . . . . . . . . . 5-1

5.2 Reactor Vessel and Closure Head . . . . . . . . . . . . . . . . . . 5-6

5.2 .1 Design Description and Safety Objectives . . . . . . . . . . . . . . . 5-6

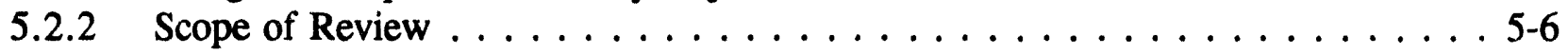

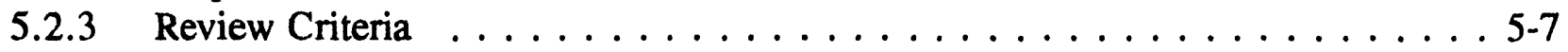

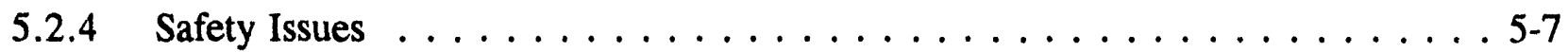

5.2 .5 Evaluation ............................... . . . . . . . . . .

5.2 .6 Research and Development $\ldots \ldots \ldots \ldots \ldots \ldots \ldots$

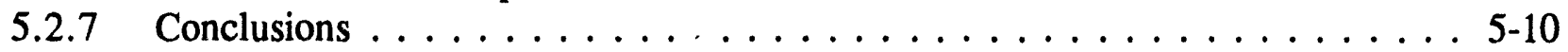

5.3 Reactor Internal Structures . . . . . . . . . . . . . . . . . . . . 5-11

5.3.1 Design Description and Safety Objectives . . . . . . . . . . . . . 5-11

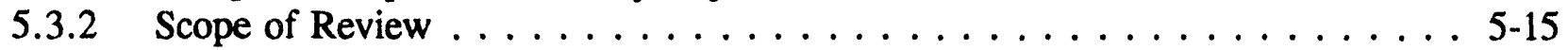

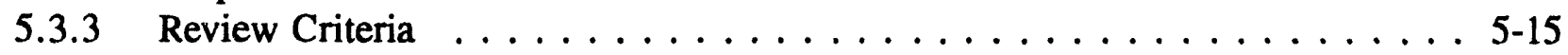

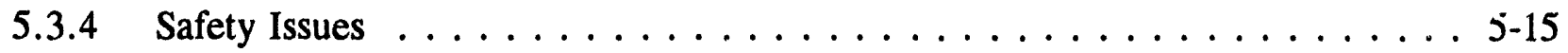

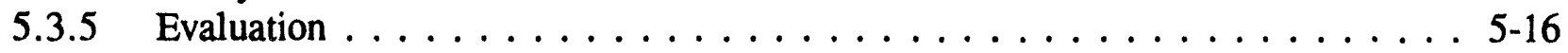

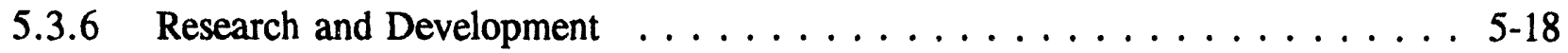

5.3 .7 Conclusions . . . . . . . . . . . . . . . . . . . 5-18

5.4 Primary Heat Transport System . . . . . . . . . . . . . . . . . . . . . 5-19

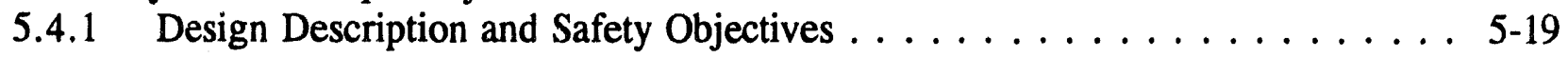

5.4 .2 Scope of Review ........................... 5-21

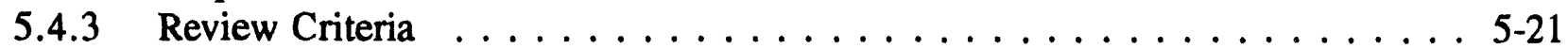

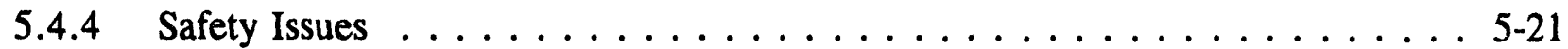

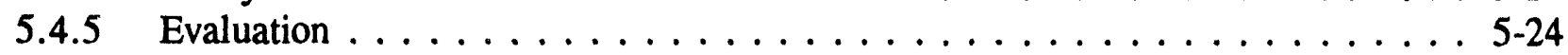

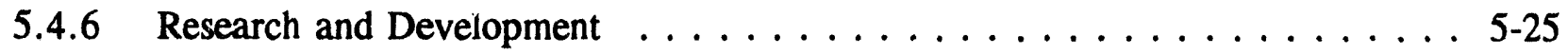

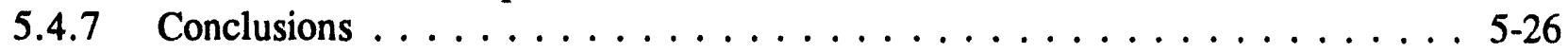

5.5 Intermediate Heat Transport System . . . . . . . . . . . . . . . . . 5-26

5.5 .1 Design Description and Safety Objectives . . . . . . . . . . . . . . 5-26

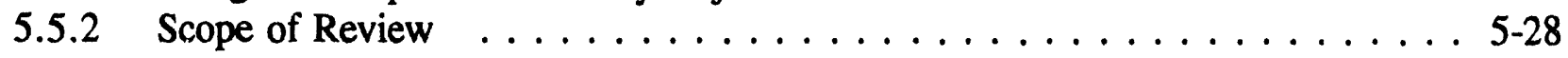

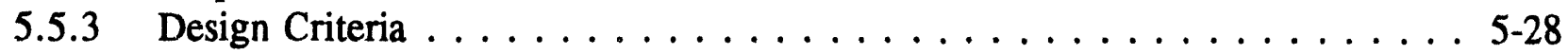

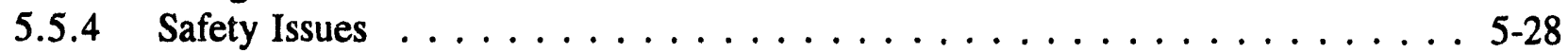

5.5 .5 Evaluation . . . . . . . . . . . . . . . . . . . . . 5 5-28

5.5 .6 Research and Development . . . . . . . . . . . . . . . . . . . 5-29

5.5 .7 Conclusions . . . . . . . . . . . . . . . . . . . . . . . 5-29 
5.6 Steam Generator System _. . . . . . . . . . . . . . . . . . . . . . 5 5-29

5.6 .1 Design Description and Safety Objectives . . . . . . . . . . . . . . 5-29

5.6 .2 Scope of Review . . . . . . . . . . . . . . . . . . . 5 5-32

5.6 .3 Design Criteria ........................... . . . . . . . . . . .

5.6 .4 Research and Development ... . . . . . . . . . . . . . . 5-34

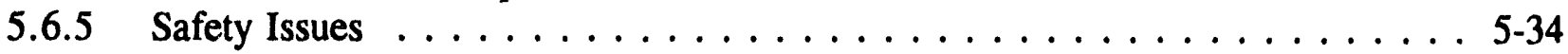

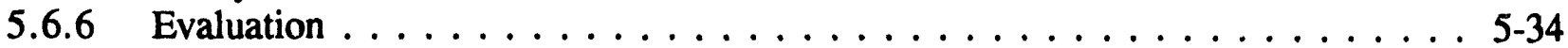

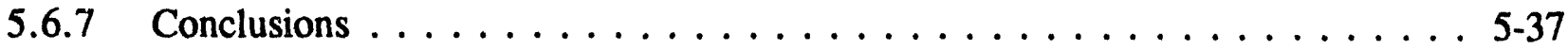

5.7 Residual Heat Removal Systems . . . . . . . . . . . . . . . . . . . 5-37

5.7 .1 Design Description and Safety Objectives . . . . . . . . . . . . . 5-37

5.7 .2 Scope of Review ... . . . . . . . . . . . . . . . . 5-39

5.7 .3 Review Criteria ... . . . . . . . . . . . . . . . . 5-39

5.7 .4 Discussion of Safety Issues $\ldots \ldots \ldots \ldots \ldots \ldots \ldots \ldots \ldots$

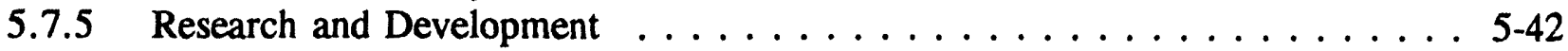

5.7 .6 Conclusions ............................ 5.42

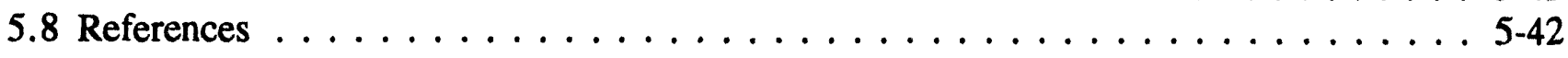

6 ENGINEERED SAFETY FEATURES $\ldots \ldots \ldots \ldots \ldots \ldots \ldots \ldots \ldots$

6.1 Design Description and Safety Objectives . . . . . . . . . . . . . . 6-1

6.1 .1 Containment System . . . . . . . . . . . . . . . . . . 6 6-1

6.1 .2 Containment During Maintenance $\ldots \ldots \ldots \ldots \ldots \ldots \ldots$

6.1 .3 Source Term and Site Suitability Analysis .................. 6-3

6.1 .4 Containment Performance ...................... 6.5

6.1 .5 Guard Pipes ............................. . . . . . . .

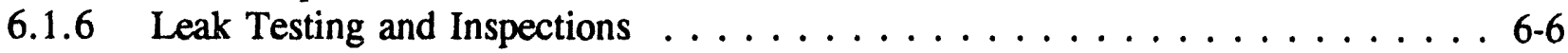

6.2 Scope of the Review . . . . . . . . . . . . . . . . . . . 6 6 6

6.3 Design Criteria . . . . . . . . . . . . . . . . . . . . 6 6-7

6.4 Research and Development . . . . . . . . . . . . . . . 6-7

6.5 Safety Issues . . . . . . . . . . . . . . . . . . . . . . . . . 6-8

6.5 .1 Response to Challenges . . . . . . . . . . . . . . . . . . . 6-8

6.5.2 Containment Atmosphere and Combustible Gas Control . . . . . . . . . . . 6 6-8

6.5 .3 Containment During Maintenance . . . . . . . . . . . . . . . . 6 6-9

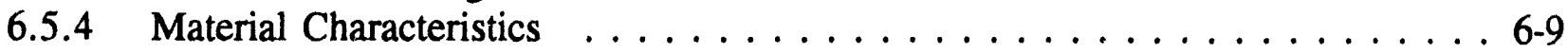

6.5 .5 Source Term . . . . . . . . . . . . . . . . . . . . . 6-9

6.5 .6 Containment Isolation . . . . . . . . . . . . . . . . . . 6 6-9

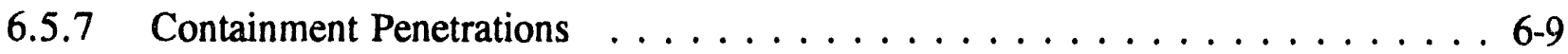

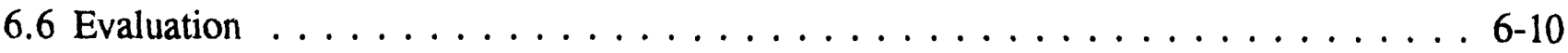

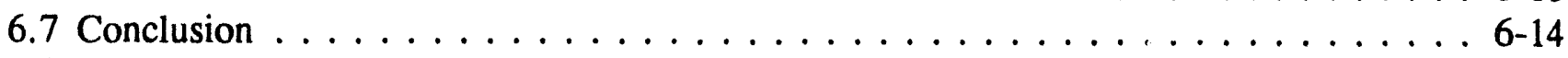

6.8 References ............................... . . . . . . . . . .

7 INSTRUMENTATION AND CONTROL $\ldots \ldots \ldots \ldots \ldots \ldots \ldots \ldots$

7.1 Reactor Protection . . . . . . . . . . . . . . . . . . 7-1

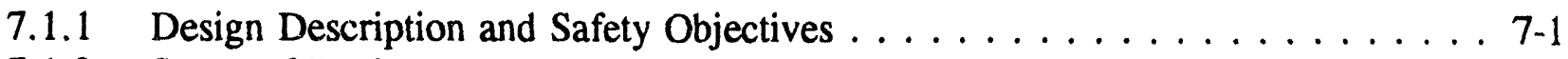

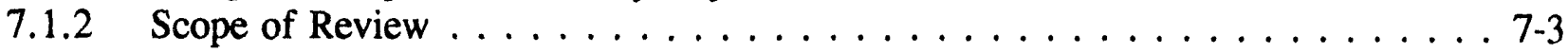

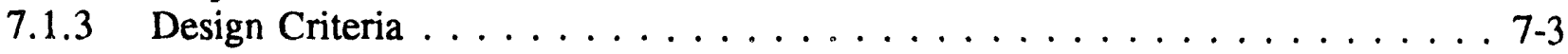

7.1 .4 Research and Development (R\&D) . . . . . . . . . . . . . 7-5

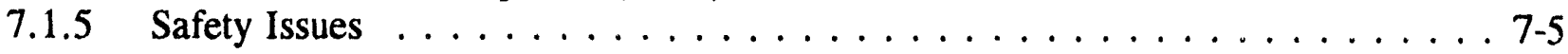


7.1 .6 Evaluation ........................ $7-7$

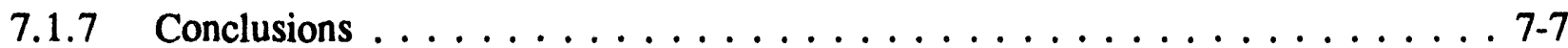

7.2 Safety-Related Instrumentation . . . . . . . . . . . . . . . 7-7

7.2.1 Design Description and Safety Objectives . . . . . . . . . . . . 7-7

7.2 .2 Scope of Review . . . . . . . . . . . . . . . . . 7-11

7.2 .3 Design Criteria . . . . . . . . . . . . . . . . . 7-11

7.2 .4 Research and Development $\ldots \ldots \ldots \ldots \ldots \ldots \ldots \ldots \ldots$. . . . . . . . .

7.2 .5 Safety Issues $\ldots \ldots \ldots \ldots \ldots \ldots \ldots \ldots \ldots \ldots \ldots \ldots \ldots \ldots \ldots \ldots \ldots .12$

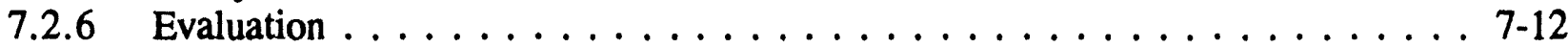

7.2 .7 Conclusions . . . . . . . . . . . . . . . . . . . 7-14

7.3 Other Instrumentation and Monitoring Systems . . . . . . . . . . . . . . 7-14

7.3.1 Design Description and Safety Objectives . . . . . . . . . . . . 7 7-14

7.3 .2 Scope of Review . . . . . . . . . . . . . . . . 7-14

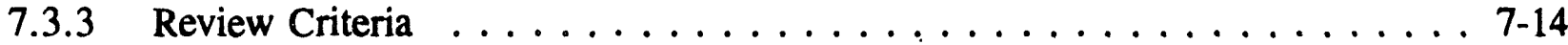

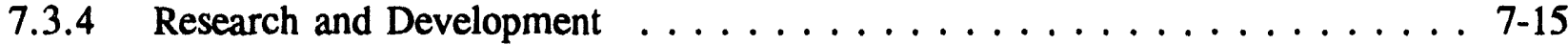

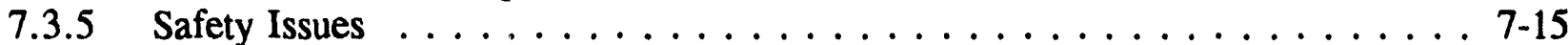

7.3 .6 Evaluation ..................... 7-15

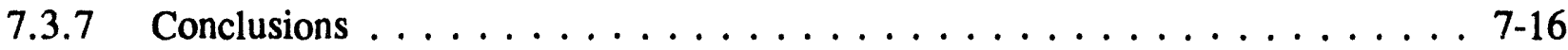

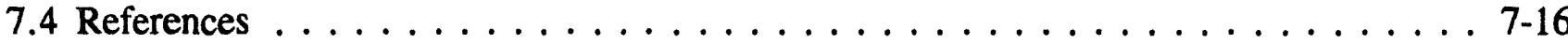

8 ELECTRICAL SYSTEMS $\ldots \ldots \ldots \ldots \ldots \ldots \ldots \ldots \ldots \ldots \ldots$. . . . . . . . . . . .

8.1 Overall Electrical System . . . . . . . . . . . . . . . . . . 8-1

8.2 Safety-Related Electrical Power System . . . . . . . . . . . . 8 8-1

8.2.1 Design Description and Safety Objectives . . . . . . . . . . . 8 8-1

8.2.2 Scope of the Review . . . . . . . . . . . . . . . . 8-1

8.2.3 Design Criteria . . . . . . . . . . . . . . . . . . 8-2

8.2.4 Research and Development $\ldots \ldots \ldots \ldots \ldots \ldots \ldots \ldots$. . . . . . . . .

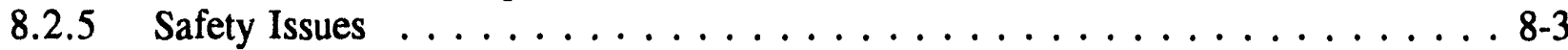

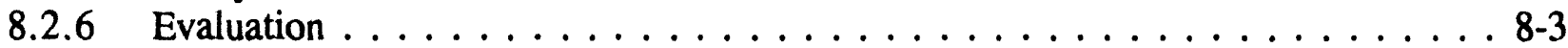

8.2.7 Conclusion . . . . . . . . . . . . . . . . . . . . 8-4

8.3 Electromagnetic Pump Power System . . . . . . . . . . . . . . . . . . 8-4

8.3.1 Design Description and Safety Objectives . . . . . . . . . . . . 8-4

8.3.2 Scope of Review . . . . . . . . . . . . . . . . . 8-7

8.3.3 Design Criteria . . . . . . . . . . . . . . . . . . . 8 8-7

8.3.4 Research and Development $\ldots \ldots \ldots \ldots \ldots \ldots \ldots \ldots . \ldots \ldots$

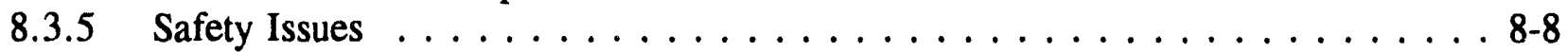

8.3 .6 Evaluation . . . . . . . . . . . . . . . . . . 8-9

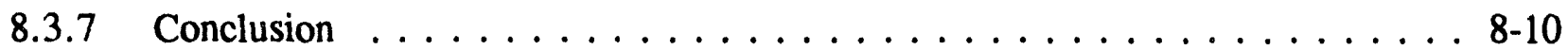

8.4 References . . . . . . . . . . . . . . . . . . . . 8-10

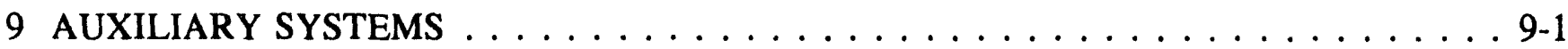

9.1 Summary Descriptions . . . . . . . . . . . . . . . . . . . 9-1

9.1 .1 Fuel Handling and Storage System $\ldots \ldots \ldots \ldots \ldots \ldots \ldots \ldots . \ldots \ldots$

9.1 .2 Water System . . . . . . . . . . . . . . . . . . 9-1

9.1.3 Process Auxiliaries . . . . . . . . . . . . . . . . . . 9-1

9.1.4 Heating, Ventilation, and Air Conditioning System . . . . . . . . . 9-1

9.1.5 Auxiliary Liquid-Metal System . . . . . . . . . . . . . . . . . 9-1 
9.1.6 Sodium Piping and Equipment Heating and Insulation System . . . . . . . . 9-2

9.1.7 Other Auxiliary Systems . . . . . . . . . . . . . . . . . . . . . . . 9-2

9.2 Fuel Handling and Storage System (Reactor Refueling System) . . . . . . . . . . . . . . 9-2

9.2.1 Design Description and Safety Objectives . . . . . . . . . . . . . . . . . 9-2

9.2.2 Scope of Staff Review . . . . . . . . . . . . . . . . . . . 9-2

9.2 .3 Design Criteria . . . . . . . . . . . . . . . . . . . 9.3

9.2.4 Research and Development Plans ..................... . . . . . . . . . . . . .

9.2.5 Discussion of Safety Issues $\ldots \ldots \ldots \ldots \ldots \ldots \ldots \ldots$

9.2 .6 Evaluation . . . . . . . . . . . . . . . . . . . . $9-3$

9.2 .7 Conclusions . . . . . . . . . . . . . . . . . . . . . . . 9-4

9.3 Water System . . . . . . . . . . . . . . . . . . . . . . . . . . . . . . . . . . . . . . .

9.3.1 Design Description and Safety Objectives . . . . . . . . . . . . . . . . . . . . . . . . . . . . . . . . . . . . . .

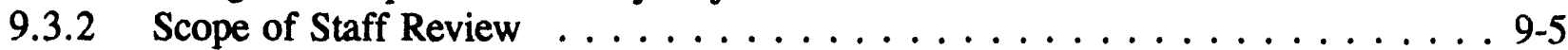

9.3.3 Design Criteria . . . . . . . . . . . . . . . . . . . . . 9-5

9.3.4 Research and Development Plans . . . . . . . . . . . . . . . . . . 9-5

9.3.5 Discussion of Safety Issues . . . . . . . . . . . . . . . . . . . . 9-5

9.3 .6 Evaluation .......................... . . . . . .

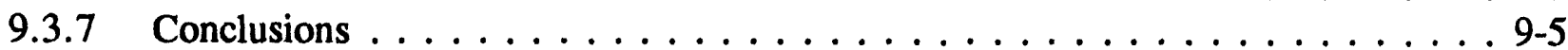

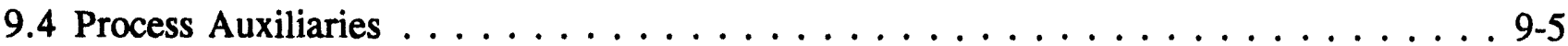

9.4.1 Design Description and Safety Objectives . . . . . . . . . . . . . . 9-5

9.4.2 Scope of Staff Review . . . . . . . . . . . . . . . . . . . 9-6

9.4.3 Design Criteria . . . . . . . . . . . . . . . . . . . . . 9.7

9.4.4 Research and Development Plans . . . . . . . . . . . . . . . 9.8

9.4.5 Discussion of Safety Issues $\ldots \ldots \ldots \ldots \ldots \ldots \ldots$

9.4 .6 Evaluation . . . . . . . . . . . . . . . . . . . 9 9.8

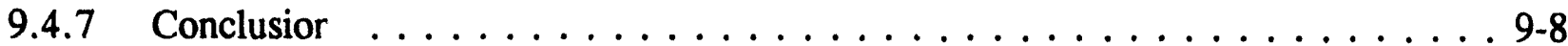

9.5 Heating, Ventila $n$, and Air Conditioning System . . . . . . . . . . . 9-8

9.5.1 Design Description and Safety Objectives . . . . . . . . . . . . . . . . 9-8

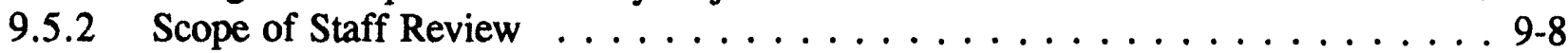

9.5 .3 Review Criteria $\ldots \ldots \ldots \ldots \ldots \ldots \ldots \ldots \ldots$

9.5 .4 Design Criteria . . . . . . . . . . . . . . . . . . . . . . 9-9

9.5.5 Discussion of Safety Issues . . . . . . . . . . . . . . . . . . . 9 9-9

9.5 .6 Evaluation . . . . . . . . . . . . . . . . . . . . . . . . . .

9.5.7 Research and Development Plans . . . . . . . . . . . . . . . . . . . . . . . . . . . . . . . . .

9.5 .8 Conclusions . . . . . . . . . . . . . . . . . . . . . . . . . . . . . . . . . . . . . . . . . . .

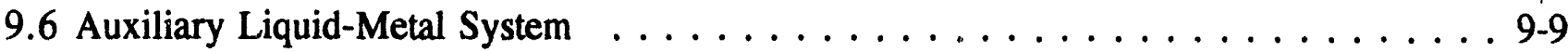

9.6.1 Design Description and Safety Objectives . . . . . . . . . . . . . . . . . . . 9-9

9.6.2 Scope of Staff Review . . . . . . . . . . . . . . . . . . . . . . . 9-10

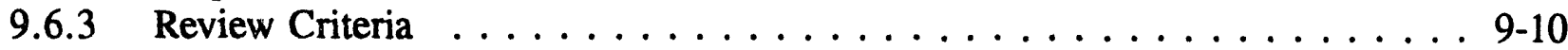

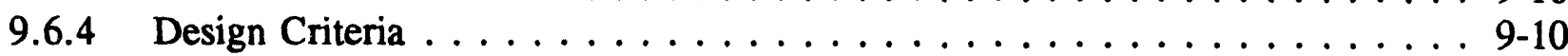

9.6.5 Discussion of Safety Issues . . . . . . . . . . . . . . . . 9-10

9.6 .6 Evaluation . . . . . . . . . . . . . . . . . . . . . 9-10

9.6.7 Research and Development Plans . . . . . . . . . . . . . . . . 9-10

9.6 .8 Conclusions . . . . . . . . . . . . . . . . . . . . . . . 9 9-10

9.7 Sodium Piping and Equipment Heating and Insulation System . . . . . . . . . . . . 9-10

9.7.1 Design Description and Safety Objectives . . . . . . . . . . . . . . . . . 9-10

9.7.2 Scope of Staff Review $\ldots \ldots \ldots \ldots \ldots \ldots \ldots \ldots \ldots \ldots$ 
9.7.3 Design Criteria . . . . . . . . . . . . . . . . . . . 9-11

9.7.4 Discussion of Safety Issues $\ldots \ldots \ldots \ldots \ldots \ldots \ldots \ldots \ldots \ldots \ldots . \ldots \ldots$

9.7 .5 Evaluation . . . . . . . . . . . . . . . . . 9-12

9.7.6 Research and Development Plans . . . . . . . . . . . . 9-12

9.7.7 Conclusions . . . . . . . . . . . . . . . . . . . . 9-12

9.8 Plant Fire Protection System . . . . . . . . . . . . . . . . . . 9-12

9.8.1 Design Description and Safety Objectives . . . . . . . . . . . . . . . 9-12

9.8.2 Scope of Staff Review . . . . . . . . . . . . . . . . . . 9-12

9.8.3 Design Criteria . . . . . . . . . . . . . . . . . . 9-13

9.8.4 Discussion of Safety Issues $\ldots \ldots \ldots \ldots \ldots \ldots \ldots \ldots \ldots . \ldots \ldots$

9.8.5 Evaluation . . . . . . . . . . . . . . . . . 9-13

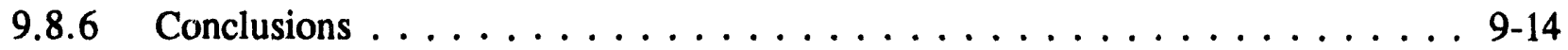

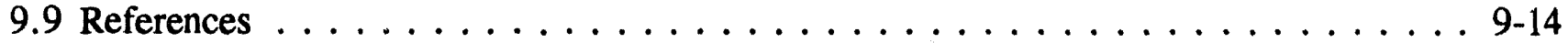

10 STEAM AND POWER CONVERSION SYSTEMS $\ldots \ldots \ldots \ldots \ldots \ldots \ldots$. . . . . . .

10.1 Design Description and Safety Objectives . . . . . . . . . . . . . . . . 10-1

10.1.1 Summary Description . . . . . . . . . . . . . . . 10-1

10.1.2 Turbine Generators . . . . . . . . . . . . . . . . . 10-1

10.1.3 Main and Auxiliary Steam Systems $\ldots \ldots \ldots \ldots \ldots$ 10-1

10.1.4 Feedwater and Condensate System . . . . . . . . . . . . . . 10-3

10.1.5 Water Chemistry Control $\ldots \ldots \ldots \ldots \ldots \ldots \ldots \ldots$ 10-3

10.2 Scope of the Review . . . . . . . . . . . . . . . . . 10-3

10.3 Design Criteria . . . . . . . . . . . . . . . . . . . . . . 10-3

10.4 Research and Development . . . . . . . . . . . . . . . . . . 10-3

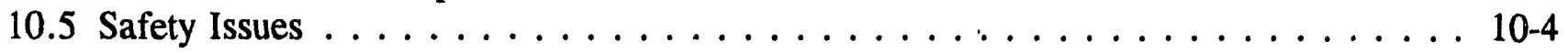

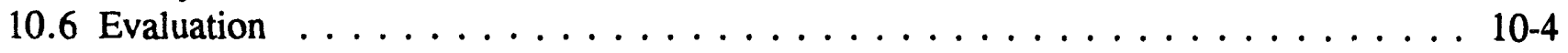

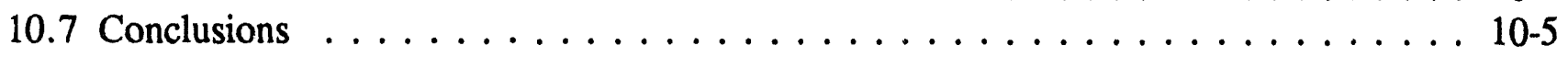

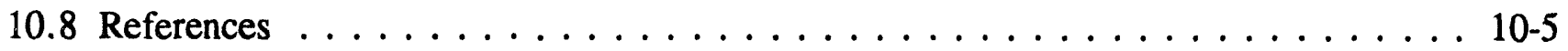

11 RADIOACTIVE WASTE MANAGEMENT $\ldots \ldots \ldots \ldots \ldots \ldots \ldots \ldots \ldots$ 11-1

11.1 Source Terms . . . . . . . . . . . . . . . . . . . . . 11-1

11.2 Liquid Waste Management Systems . . . . . . . . . . . . . . . 11-1

11.3 Gaseous Waste Management Systems . . . . . . . . . . . . . . . . . 11-1

11.4 Solid Waste Management System . . . . . . . . . . . . . . . . . . 11-2

11.5 Process and Effluent Radiological Monitoring Instrumentation and Sampling Systems 11-2

11.6 References . . . . . . . . . . . . . . . . . . . . . 11-2

12 RADIATION PROTECTION . . . . . . . . . . . . . . . . . . . . 12-1

12.1 Ensuring That Occupational Radiation Exposures Are ALARA . . . . . . . . 12-1

12.1.1 Policy Considerations . . . . . . . . . . . . . . . . . 12-1

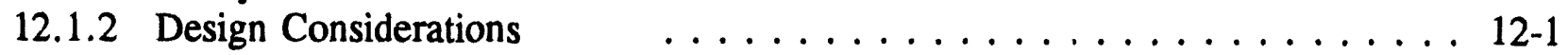

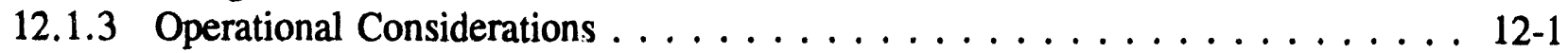

12.2 Radiation Sources . . . . . . . . . . . . . . . . . . . . . 12-2

12.3 Radiation Protection Design Features . . . . . . . . . . . . . 12-2

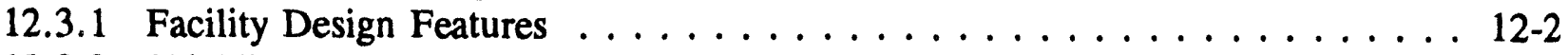

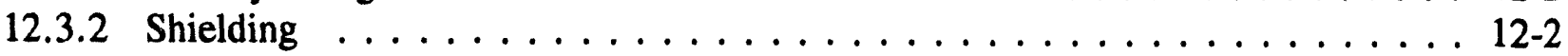


12.3.3 Ventilation System . . . . . . . . . . . . . . . . . . . 12-3

12.3.4 Area Radiation and Airborne Radioactivity Monitoring Instrumentation . . . 12-3

12.4 Dose Assessment . . . . . . . . . . . . . . . . . . . . . . . . 12-3

12.5 Operational Radiation Protection Program . . . . . . . . . . . . . . . 12-3

12.6 References . . . . . . . . . . . . . . . . . . . . . . . 12-4

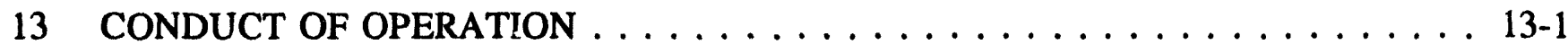

13.1 Radiological Emergency Planning . . . . . . . . . . . . . . . . . . 13-1

13.1.1 Preapplicant's Proposed Planning . . . . . . . . . . . . . . . . 13-1

13.1.2 Scope of the Review ......................... 13-2

13.1 .3 Discussion ............................ 13-2

13.1 .4 Evaluation ........................... 13-3

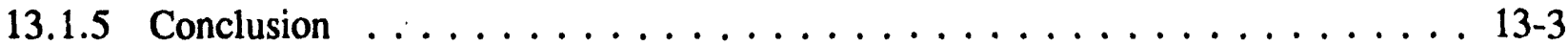

13.2 Plant Operations $\ldots \ldots \ldots \ldots \ldots \ldots \ldots \ldots \ldots \ldots$

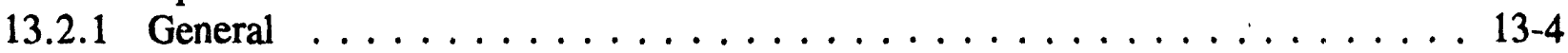

13.2.2 Operating Modes . . . . . . . . . . . . . . . . . . . 13-4

13.2.3 Control Room and Remote Shutdown Facility . . . . . . . . . . . . . . . 13-5

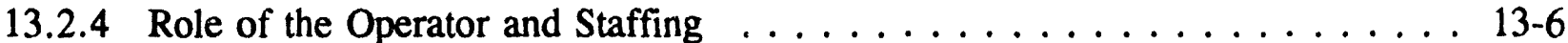

13.2.5 Multi-Module Control . . . . . . . . . . . . . . . . . . 13-7

13.2.6 Conclusion . . . . . . . . . . . . . . . . . . . 13-7

13.3 Safeguards and Security . . . . . . . . . . . . . . . . . . 13-7

13.3.1 Design Description and Safety Issues . . . . . . . . . . . . . . 13-7

13.3.2 Scope of the Review . . . . . . . . . . . . . . . . . . 13-10

13.3 .3 Conclusions . . . . . . . . . . . . . . . . . . . . 13-10

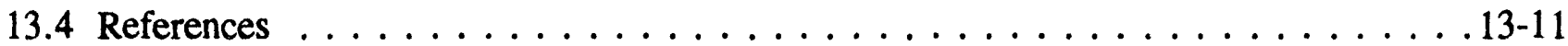

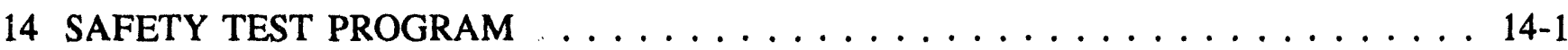

14.1 Design Description and Safety Objectives . . . . . . . . . . . . . . 14-1

14.1.1 Safety Test Program . . . . . . . . . . . . . . . . . . 14-1

14.2 Scope of Review . . . . . . . . . . . . . . . . . . . . . . . 14-4

14.3 Review Criteria . . . . . . . . . . . . . . . . . . . . . . . 14-4

14.3.1 10 CFR Part $52 \ldots \ldots \ldots \ldots \ldots \ldots \ldots \ldots \ldots$

14.3.2 Commission's Advanced Reactor Policy Statement . . . . . . . . . . . . . . 14-5

14.3.3 Commission Paper SECY-91-074 . . . . . . . . . . . . . . . . . 14-5

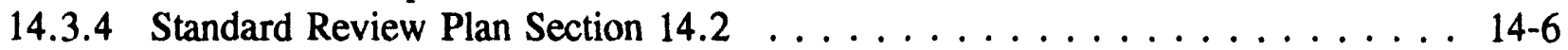

14.4 Research and Development . . . . . . . . . . . . . . . . . . . . . . 14-7

14.5 Safety Issues . . . . . . . . . . . . . . . . . . . . . . . . . . 14-8

14.5.1 Risks Associated With the Prototype Tests . . . . . . . . . . . . . . . . 14-8

14.5.2 Lack of Detail on the Safety Test and R\&D Programs . . . . . . . . . . . . . 14-8

14.5.3 Justification of the Single-Module Prototype . . . . . . . . . . . . . . . . . . 14-9

14.5.4 Justification of the Systems for the Prototype . . . . . . . . . . . . . . . 14-9

14.5.5 Additional Development or Testing in the R\&D Program . . . . . . . . . . 14-9

14.6 Evaluation . . . . . . . . . . . . . . . . . . . . . . . . 14-9

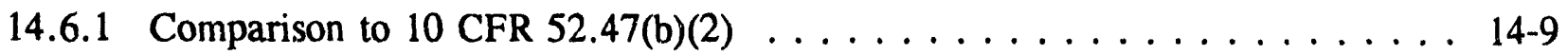

14.6.2 Comparison to the Commission's Advancer Reactor Policy . . . . . . . . . . . 14-12

14.6.3 Comparison to Commission Paper SECY-91-074 . . . . . . . . . . . . . 14-12

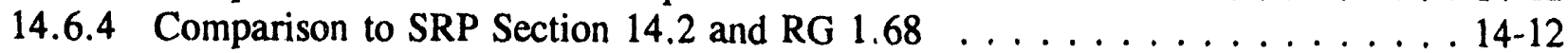


14.6.5 ALMR Technology Development Requirements Plan . . . . . . . . . . . . . 14-13

14.6.6 Changes to the Standard PRISM Design . . . . . . . . . . . . . . . 14-13

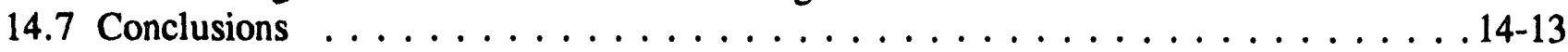

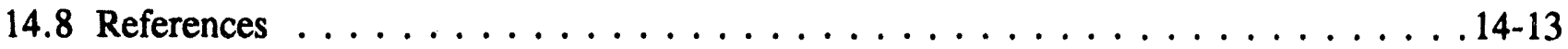

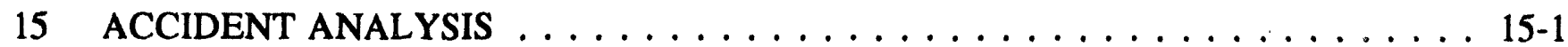

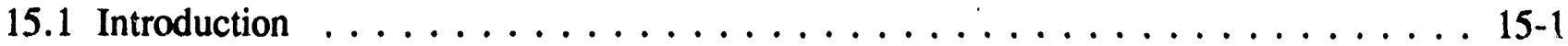

15.1.1 Design Description and Safety Objectives . . . . . . . . . . . . . . . 15-1

15.1.2 PRISM Approach to Safety ... . . . . . . . . . . . . . . 15-1

15.1.3 Safety Evaluation Procedure . . . . . . . . . . . . . . . . . . 15-2

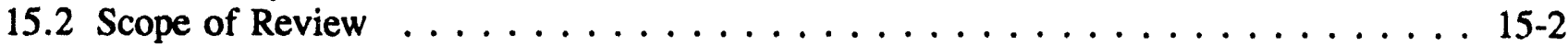

15.3 Design Criteria $\ldots \ldots \ldots \ldots \ldots \ldots \ldots \ldots \ldots \ldots \ldots$

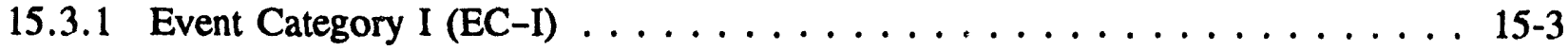

15.3 .2 Event Category II (EC-II) $\ldots \ldots \ldots \ldots \ldots \ldots \ldots \ldots \ldots \ldots$

15.3 .3 Event Category III (EC-III) $\ldots \ldots \ldots \ldots \ldots \ldots \ldots \ldots \ldots \ldots$

15.3.4 Bounding Event Selection . . . . . . . . . . . . . . . . . 15-4

15.3.5 Source Term and Radiological Consequences . . . . . . . . . . . . . 15-7

15.4 Research and Development . . . . . . . . . . . . . . . . . . . 15-9

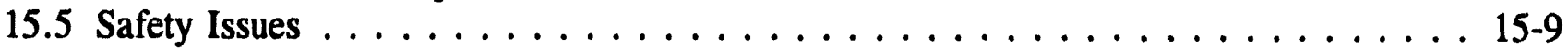

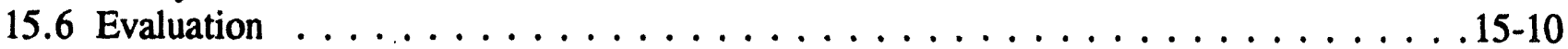

15.6.1 Reactivity Insertion DBEs . . . . . . . . . . . . . . . . . . 15-10

15.6.2 Undercooling DBEs (Loss of Normal Shutdown Cooling) . . . . . . . . . . . 15-11

15.6.3 Fuel Failure (Local Fault) Tolerance . . . . . . . . . . . . . . . . . . . 15-14

15.6.4 Primary Sodium Spills . . . . . . . . . . . . . . . . . 15-15

15.6.5 Fuel-Handling and Storage Accidents . . . . . . . . . . . . . . 15-16

15.6.6 Other Design-Basis Events (Cover Gas Release) . . . . . . . . . . . . . . . . 15-17

15.6.7 Bounding Events . . . . . . . . . . . . . . . . . . . . . . . . 15-17

15.6.8 Hypothetical Core Disruption Accident (HCDA) . . . . . . . . . . . 15-21

15.6.9 Severe Core Accident Considerations . . . . . . . . . . . . . . . 15-27

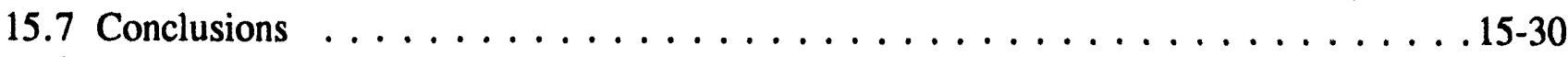

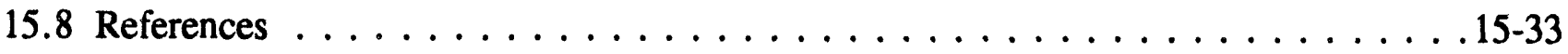

16 TECHNICAL SPECIFICATIONS $\ldots \ldots \ldots \ldots \ldots \ldots \ldots \ldots \ldots$

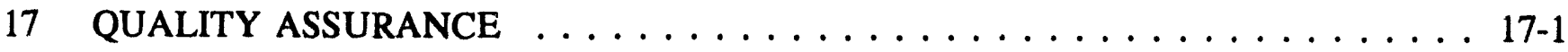

17.1 Quality Assurance Program . . . . . . . . . . . . . . . . 17-1

APPENDIX A PROBABILISTIC RISK ASSESSMENT

A.1 Purpose and Objectives of the Conceptual PRISM Probabilistic Risk Assessment (PRA)

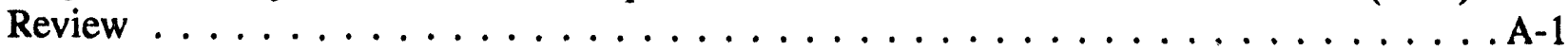

A.2 Introduction $\ldots \ldots \ldots \ldots \ldots \ldots \ldots \ldots \ldots \ldots \ldots \ldots \ldots \ldots \ldots \ldots$

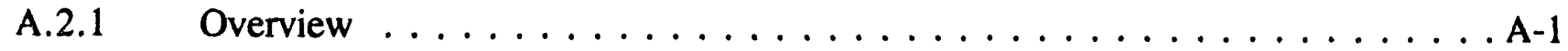

A.2.2 Description of 1990 Design Changes $\ldots \ldots \ldots \ldots \ldots \ldots \ldots \ldots \ldots$

A.2.2.1 Increase in Reactor Power Level and System Power Production . . . . A-1

A.2.2.2 Ultimate Shutdown System (USS) . . . . . . . . . . . . A-1

A.2.2.3 Gas Expansion Modules (GEMs) $\ldots \ldots \ldots \ldots \ldots \ldots \ldots$ 
A.2.2.4 Mechanical Stops on Control Rods $\ldots \ldots \ldots \ldots \ldots \ldots \ldots$. . . . . A-2

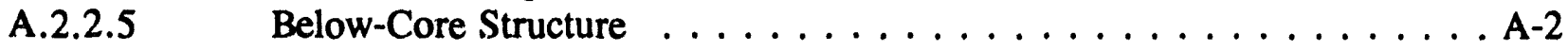

A.2.2.6 Accommodation of Hypothetical Core Disruptive Accident (HCDA) . . A A-2

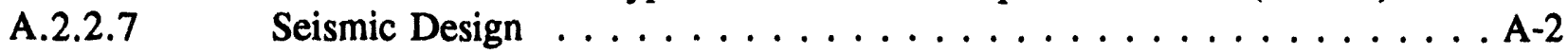

A.2.2.8 Containment Improvements and Dome . . . . . . . . . . A-2

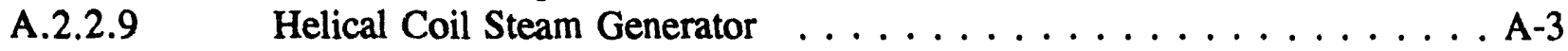

A.2.2.10 IHTS Auxiliary Cooling System (ACS) Modifications . . . . . . . . . . . A-3

A.2.2.11 Reactor Fuel Redesign .....................A-3

A.2.2.12 Impact of Changes on PRA ................... . . . .

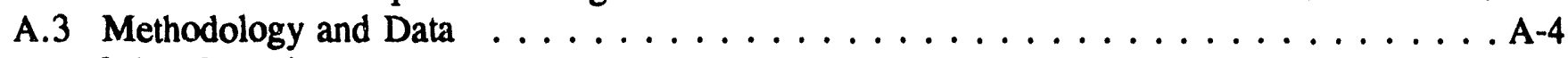

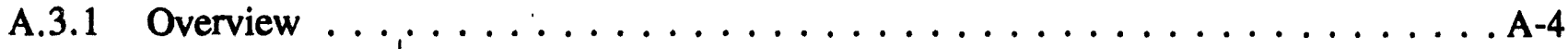

A.3.2 Initiating Events $\ldots \ldots \ldots \ldots \ldots \ldots \ldots \ldots \ldots \ldots \ldots$

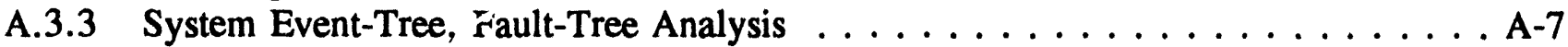

A.3.4 Sensitivity Study on Initiating Event Frequencies . . . . . . . . . . . . . A-8

A.4 System Analysis . . . . . . . . . . . . . . . . . . . . . A A $\ldots \ldots$

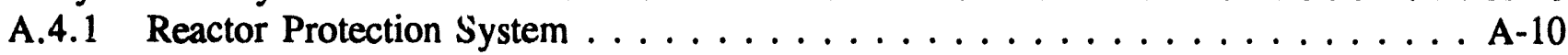

A.4.2 Primary Pump Coastdown System ..................... . A-10

A.4.3 Shutdown Heat Removal System . . . . . . . . . . . . . . . . A-11

A.4.4 Reactivity Control and Shutdown System . . . . . . . . . . . . . . . . . . A A-12

A.4.5 Seismic Isolator System . . . . . . . . . . . . . . . . . . . . A-12

A.4.6 Passive Reactivity Feedback . . . . . . . . . . . . . . . . . A-12

A.4.7 Sensitivity Studies on Frequency of Accident Types . . . . . . . . . . . A-13

A.5 Phenomenological Analysis . . . . . . . . . . . . . . . . . A-13

A.5.1 Core Response Event Trees . . . . . . . . . . . . . . . . . A-13

A.5.2 Containment Response Event Trees . . . . . . . . . . . . . . . A-15

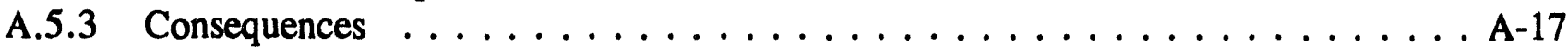

A.6 Summary . . . . . . . . . . . . . . . . . . . . A A-18

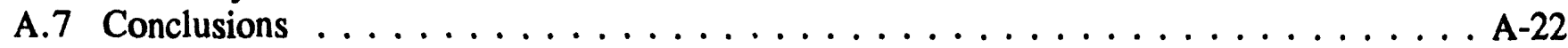

A.7.1 Overview .............................. A $\ldots \ldots$

A.7.2 Assessment of 1990 Design Changes . . . . . . . . . . . . . . . . . A-22

A.7.2.1 Increase in Reactor Power Level and System Power Production . . . A-22

A.7.2.2 Ultimate Shutdown System (USS) . . . . . . . . . . . . . . A-22

A.7.2.3 Gas Expansion Modules (GEMs) $\ldots \ldots \ldots \ldots \ldots \ldots \ldots \ldots$. . . . . A-23

A.7.2.4 Mechanical Stops on Control Rods $\ldots \ldots \ldots \ldots \ldots \ldots \ldots \ldots$

A.7.2.5 Below-Core Structure .................... A-23

A.7.2.6 Accommodation of Hypothetical Core Disruptive Accident (HCDA) . . A-23

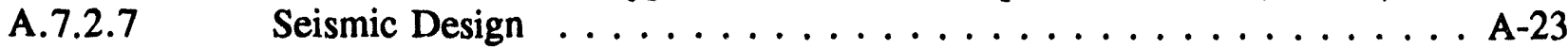

A.7.2.8 Containment Improvements, Including the Containment Dome . . . . A-24

A.7.2.9 Helical Coil Steam Generator . . . . . . . . . . . . . . A A-24

A.7.2.10 IHTS Auxiliary Cooling System (ACS) Modifications . . . . . . . . . . . A-24

A.7.3 Impact of 1990 Design Changes . . . . . . . . . . . . . . . . . . . . . A A-24

A.7.3.1 Seismic Isolation of the Synchronous Machines . . . . . . . . . . . . A-24

A.7.3.2 Strengthening Buildings and Enclosures . . . . . . . . . . . . A-24

A.7.3.3 Gas Expansion Modules (GEMs) . . . . . . . . . . . . . . A A-24

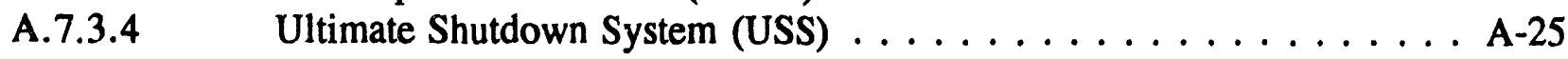

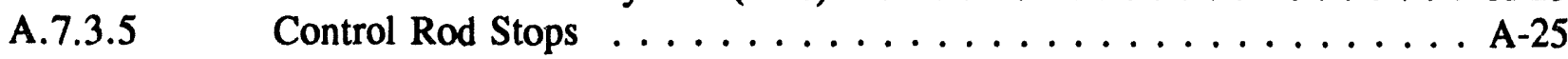

A.7.3.6 Designing To Accommodate HCDAs . . . . . . . . . . . A-25 
A.7.3.7 Designing To Accommodate Core Meltdown . . . . . . . . . A-25

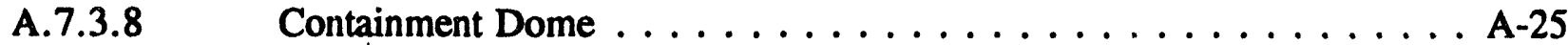

A.7.3.9 Sensitivity Studies $\ldots \ldots \ldots \ldots \ldots \ldots \ldots \ldots \ldots \ldots \ldots$

A.8 References

A-26

APPENDIX B INDEPENDENT ANALYSES OF SELECTED EVENTS ANALYZED BY GE

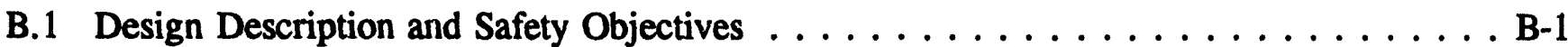

B.1.1 Gas Expansion Modules (GEMs) . . . . . . . . . . . . . . . . . B-1

B.1.2 Control Rod Stops ........................... . . . .

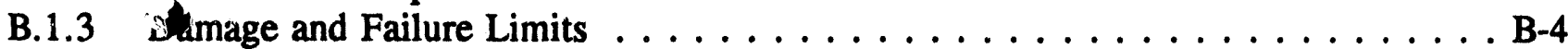

B.2 Summary and Interpretation of GE's Revised Analyses . . . . . . . . . . . . . . . . B-5

B.2.1 BE-1A: All-Rods Withdrawal Without Scram, With Normal Cooling . . . . . . . . B-5

B.2.2 BE-1B: Ail-Rods Withdrawal Without Scram, With RVACS Cooling Only . . . B-5

B.2.3 BE-2: Unprotected Loss of Flow, Loss of Heat Sink, for 36 Hours . . . . . . . . . B-7

B.2.4 BE-3: Loss of Decay Heat Removal Capability . . . . . . . . . . . . . . . . . B-7

B.2.5 BE-4: Unprotected Loss of Flow, Loss of Heat Sink, With Seizure of One

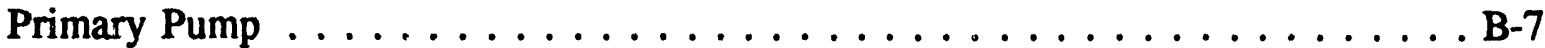

B.2.6 Summary ................................ . . . .

B.3 Independent Analyses of Selected Bounding Events . . . . . . . . . . . . . B-10

B.3.1 Analytical Approach $\ldots \ldots \ldots \ldots \ldots \ldots \ldots \ldots \ldots$

B.3.2 SSC Modeling . . . . . . . . . . . . . . . . . . . . B-10

B.3.3 MINET Representation . . . . . . . . . . . . . . . . . . . B-11

B.3.4 Unprotected Transient Overpower Events $\ldots \ldots \ldots \ldots \ldots \ldots \ldots \ldots \ldots \ldots$. . . . . . . . . . . . .

B.3.4.1 BE-1A: UTOP With Normal Cooling . . . . . . . . . . . . . . . . . . B-13

B.3.4.2 BE-1B: UTOP With Only RVACS Cooling . . . . . . . . . . . . . . . B-23

B.3.4.3 Variation on BE-1: UTOP With LOF . . . . . . . . . . . . . . . . . B-23

B.3.4.4 Peak UTOP Temperatures . . . . . . . . . . . . . . . . . . . . . . . . . B-24

B.3.5 BE-2: Loss of Electric Power . . . . . . . . . . . . . . . . . . . . . . . B-24

B.3.5.1 Loss of Power With Scram . . . . . . . . . . . . . . . . . . . . . . B-24

B.3.5.2 Loss of Power Without Scram - Variant Cases . . . . . . . . . . . . . . . . B-24

B.3.5.3 Combined ULOF/LOHS . . . . . . . . . . . . . . . . . . . . . . . B-29

B.3.5.4 ULOF Only . . . . . . . . . . . . . . . . . . . . . . . . . . . B-29

B.3.5.5 ULOHS Only . . . . . . . . . . . . . . . . . . . . B-35

B.3.5.6 Comparing the ULOF and ULOHS Cases . . . . . . . . . . . . . . . . . . . . . . . . . . . . . . . . . . . . . . . .

B.3.6 LOHS Events With Partial Blockage of RVACS Ducting . . . . . . . . . . . B-36

B.3.6.1 75-percent Blockage of Air-Flow Ducting . . . . . . . . . . . . . B-36

B.3.6.2 Full Blockage of Ducting for 12 Hours, Then 25 Percent Reopened . . . . . B-36

B.3.7 LOF Events With Coastdown Failures . . . . . . . . . . . . . . . . . B-36

B.3.7.1 ULOF on Three of Four Pump Coastdowns . . . . . . . . . . . . . . . . B-40

B.3.7.2 Instantaneous Stoppage of One Pump Without Scram . . . . . . . . . . . . B-47

B.3.7.3 Instantaneous Stoppage of All Pumps Without Scram . . . . . . . . . . . . B-47

B.3.7.4 Cross-Comparison of ULOF Variations . . . . . . . . . . . . . . . . . B-53

B.4 Research and Development . . . . . . . . . . . . . . . . . . B-53

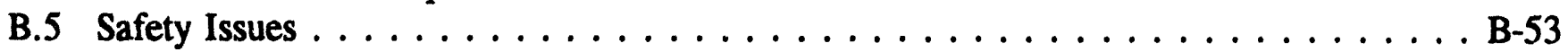

B.6 Evaluation $\ldots \ldots \ldots \ldots \ldots \ldots \ldots \ldots \ldots \ldots \ldots \ldots \ldots \ldots$ 
B.6.1 Can the GE Analyses for the PRISM Be Replicated? . . . . . . . . . . . B-55

B.6.2 Do We Agree With the GE Interpretation of the Analyses? . . . . . . . . . . B-55

B.6.3 Have Key Events Been Overlooked? . . . . . . . . . . . . . . . B-55

B.6.4 Gas Expansion Modules . . . . . . . . . . . . . . . . . B-55

B.6.5 Control Rod Stops $\ldots \ldots \ldots \ldots \ldots \ldots \ldots \ldots \ldots \ldots$

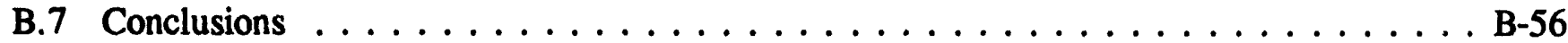

B.8 References . . . . . . . . . . . . . . . . . . . . . . . B-57

APPENDIX C ADVISORY COMMITTEE ON REACTOR SAFEGUARDS LETTER

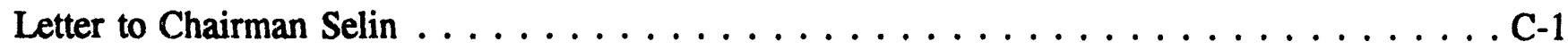

Figures

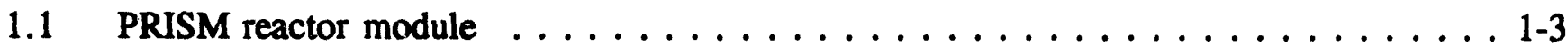

1.2 PRISM standard power plant -1395 MWe . . . . . . . . . . . . . . . . . . 1-4

$1.3 \quad$ PRISM power block -465 MWe . . . . . . . . . . . . . . . . . . . 1-5

$1.4 \quad$ PRISM seismic isolation system $\ldots \ldots \ldots \ldots \ldots \ldots \ldots \ldots \ldots$

1.5 PRISM reactor containment design $\ldots \ldots \ldots \ldots \ldots \ldots \ldots \ldots \ldots \ldots$

1.6 PRISM reactor closure head with rotatable plug . . . . . . . . . . . . . . . 1-9

1.7 PRISM reference metal core . . . . . . . . . . . . . . . . . . . 1-10

1.8 PRISM main power system . . . . . . . . . . . . . . . . . . . . . 1-11

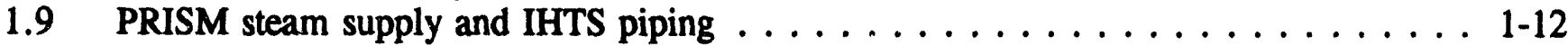

1.10 PRISM plant control and protection system concept . . . . . . . . . . . . . 1-13

1.11 PRISM technology development schedule .................... . . . . . . . .

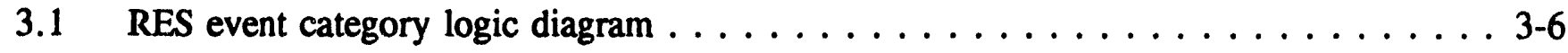

4.1 IFR technology demonstration schedule $\ldots \ldots \ldots \ldots \ldots \ldots \ldots$

$4.2 \quad$ PRISM control rod scram system . . . . . . . . . . . . . . . . . . . . 4-24

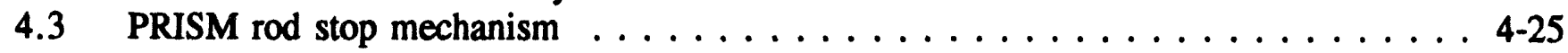

4.4 PRISM ultimate shutdown system (USS) . . . . . . . . . . . . . . . . . . 4-26

4.5 PRISM ultimate shutdown system assembly actuation . . . . . . . . . . . . 4-27

$5.1 \quad$ PRISM cooling systems and associated systems $\ldots \ldots \ldots \ldots \ldots \ldots \ldots$

$5.2 \quad$ PRISM internal structures . . . . . . . . . . . . . . . . . . . 5-3

5.3 PRISM primary sodium flow circuit - normal operation $\ldots \ldots \ldots \ldots \ldots$

5.4 PRISM reactor internal components . . . . . . . . . . . . . . . . . 5-12

$5.5 \quad$ PRISM reactor internal structures $\ldots \ldots \ldots \ldots \ldots \ldots \ldots \ldots \ldots \ldots \ldots$

5.6 PRISM intermediate heat exchanger (IHX) $\ldots \ldots \ldots \ldots \ldots \ldots \ldots \ldots$

5.7 PRISM primary sodium EM pump ... . . . . . . . . . . . . . . . 5-22

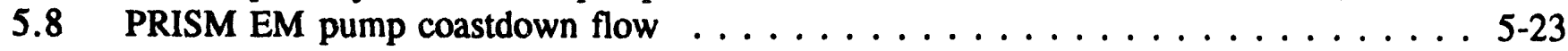

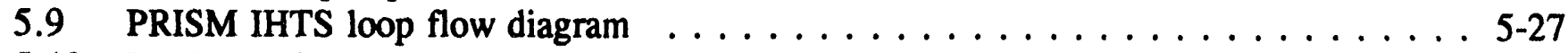

5.10 PRISM helical coil steam generator . . . . . . . . . . . . . . . . 5-31

5.11 PRISM sodium-water reaction pressure relief system (SWRPRS) . . . . . . . . . 5-33 
5.12 PRISM shutdown heat removal system $\ldots \ldots \ldots \ldots \ldots \ldots \ldots \ldots \ldots$ 5-38

5.13 Alternative flow model for blockage of RVACS inlets $\ldots \ldots \ldots \ldots \ldots \ldots$. . . . .

6.1 PRISM reactor containment $\ldots \ldots \ldots \ldots \ldots \ldots \ldots \ldots \ldots \ldots$ 6-2

6.2 PRISM reactor refueling system arrangement $\ldots \ldots \ldots \ldots \ldots \ldots \ldots \ldots$

7.1 PRISM reactor protection system (RPS) configuration $\ldots \ldots \ldots \ldots \ldots \ldots$ 7-2

7.2 PRISM reactor module and RVACS monitoring instrumentation $\ldots \ldots \ldots \ldots \ldots 7-8$

7.3 PRISM accident monitoring system diagram $\ldots \ldots \ldots \ldots \ldots \ldots \ldots \ldots$

10.1 Steam and power conversion systems schematic $\ldots \ldots \ldots \ldots \ldots \ldots$ 10-2

15.1 PRISM LOHS with RVACS performing normally $\ldots \ldots \ldots \ldots \ldots$ 15-12 $\ldots \ldots \ldots$

15.2 RVACS parametric study on air flow resistance . . . . . . . . . . . . 15-13

15.3 Predicted adiabatic expansion work versus reactivity insertion rates for a metal-fuel core . . . . . . . . . . . . . . . . . . . . . . . . 15-23

15.4 PRISM reactor changes to enhance accident mitigation capability . . . . . . . 15-28

15.5 PRISM temperature distributions in the melt and the core support bottom plate . . . 15-31

A.1 PRISM risk structure model $\ldots \ldots \ldots \ldots \ldots \ldots \ldots \ldots$. . . . . . . . .

A.2.A SMART results for moderately stable weather (Type F) $\ldots \ldots \ldots \ldots \ldots \ldots$. . . . . . .

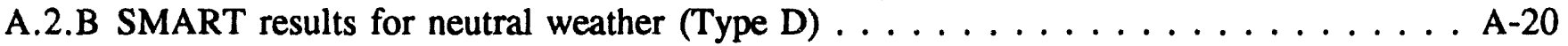

A.2.C SMART results for extremely unstable weather (Type A) $\ldots \ldots \ldots \ldots \ldots \ldots$ A-20

B.1 Operation of the gas expansion module tested in the Fast-Flux Test Facility . . . . . B B-2

B.2 Summary of GE Bounding Events $1 \mathrm{~A}, 1 \mathrm{~B}, 2^{\prime}$, and $4 \ldots \ldots \ldots \ldots \ldots$ B-9

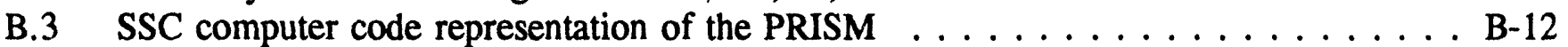

B.4 MINET computer code representation of the PRISM . . . . . . . . . . . B-12

B.5 Relative power prediction from the SSC computer code for the PRISM during a $40 \mathrm{C}$ UTOP for assumptions similar to the ARIES computer code . . . . . . . . . . . . B-15

B.6 Average core outlet temperature prediction from the SSC computer code for the PRISM during a 40C UTOP for assumptions similar to the ARIES computer code . . . . . . .

B.7 Reactivity feedbacks (total, ACLP, grid plate) predicted for the 40C UTOP from the SSC computer code using conditions similar to the ARIES computer code . . . . . . B-16

B.8 Reactivity feedbacks (Doppler, control rod, GEMs) predicted for the 40C UTOP from the SSC computer code using conditions similar to the ARIES computer code . . . . B B-16

B.9 Reactivity feedbacks (radial expansion, density, axial expansion) predicted for the $40 \mathrm{c}$ UTOP from SSC using conditions similar to the ARIES . . . . . . . . . . . .

B.10 Predicted fuel temperature distribution from the SSC computer code for the third node from the top (i.e., $0.898 \mathrm{~m}-0.674 \mathrm{~m}$ ) for a $40 \mathrm{c}$ UTOP using nominal ternary fuel

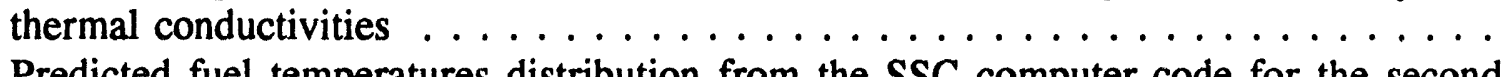

B.11 Predicted fuel temperatures distribution from the SSC computer code for the second node from the top (i.e., $1.122 \mathrm{~m}-0.897 \mathrm{~m}$ ) for a $40 \mathrm{c}$ UTOP using nominal ternary fuel thermal conductivities $\ldots \ldots \ldots \ldots \ldots \ldots \ldots \ldots \ldots \ldots \ldots \ldots \ldots$

B.12 Predicted fuel temperature distribution from the SSC computer code for the top $0.224 \mathrm{~m}$
(i.e., $1.346 \mathrm{~m}-1.122 \mathrm{~m}$ ) of the fuel pin for a 40C UTOP using nominal ternary fuel thermal conductivities 
B.13 Predicted fuel temperatures distribution from the SSC computer code for the third node from the top (i.e., $1.122 \mathrm{~m}-0.897 \mathrm{~m}$ ) for a $40 \mathrm{c}$ UTOP using reduced ternary fuel thermal conductivities $\ldots \ldots \ldots \ldots \ldots \ldots \ldots \ldots \ldots$

B. 14 Predicted fuel temperature distribution from the SSC computer code for the top $0.224 \mathrm{~m}$ (i.e., $1.346 \mathrm{~m}-1.122 \mathrm{~m}$ ) of the fuel pin for a $40 \mathrm{c}$ UTOP using reduced ternary fuel thermal conductivities

B.15 Predicted sodium saturation temperature margin from the SSC computer code for a $40 \mathrm{C}$ UTOP using reduced ternary fuel thermal conductivities $\ldots \ldots \ldots \ldots \ldots$

B.16 Predicted sodium level in the GEMs from the SSC computer code for a 40C UTOP using reduced ternary fuel thermal conductivities $\ldots \ldots \ldots \ldots \ldots$

B.17 Predicted fuel temperature distribution from the SSC computer code for the third node from the top (i.e., $0.897 \mathrm{~m}-0.673 \mathrm{~m}$ ) during a 40 c UTOP/LOF . . . . . . . . . . .

B. 18 Predicted fuel temperature distribution from the SSC computer code for the top $0.224 \mathrm{~m}$ (i.e., $1.346 \mathrm{~m}-1.122 \mathrm{~m}$ ) during a $40 \mathrm{c}$ UTOP/LOF $\ldots \ldots \ldots \ldots \ldots \ldots$

B.19 Predicted sodium saturation margin from the SSC computer code for a $40 \mathrm{c}$

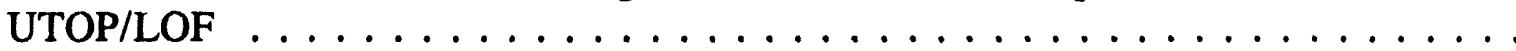

B.20 Predicted sodium level in the GEMs from the SSC computer code for a $40 \mathrm{c}$ UTOP/LOF

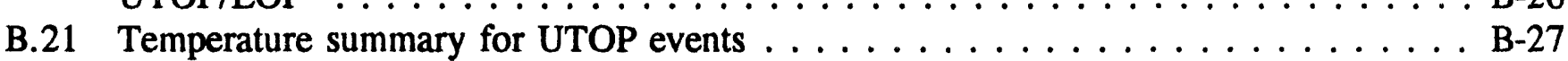

B.22 PRISM LOHS with RVACS performing normally (Bounding Event 3A) . . . . . . .

B.23 PRISM LOHS with RVACS air flow ducting 75-percent blocked (Bounding

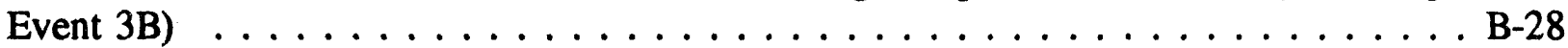

B.24 Predicted relative power and core flow from the SSC computer code during a ULOF/LOHS

B.25 Predicted average core outlet temperature from the SSC computer code during a ULOF/LOHS

B.26 Predicted total, above-core load pad and core support grid plate reactivity feedback from the SSC computer code during a ULOF/LOHS . . . . . . . . . . . . . .

B.27 Predicted radial expansion, sodium density, and axial expansion reactivity feedback from the SSC computer code during a ULOF/LOHS

B.28 Predicted Doppler, control rod expansion, and gas expansion module reactivity feedback from the SSC computer code during a ULOF/LOHS . . . . . . . . . . . .

B.29 Predicted sodium level in the GEMs from the SSC computer code during a

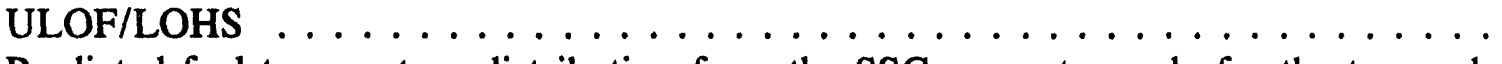

B.30 Predicted fuel temperature distribution from the SSC computer code for the top node (i.e., $1.346 \mathrm{~m}-1.122 \mathrm{~m}$ ) during a ULOF/LOHS . . . . . . . . . . . . . . B-33

B.31 Predicted sodium saturation margin from the SSC computer code during a ULOF/LOHS

B.32 Predicted relative power from the SSC computer code for a ULOF with and without

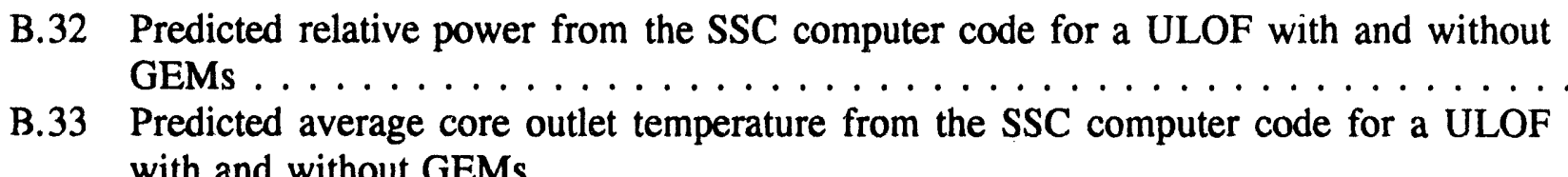

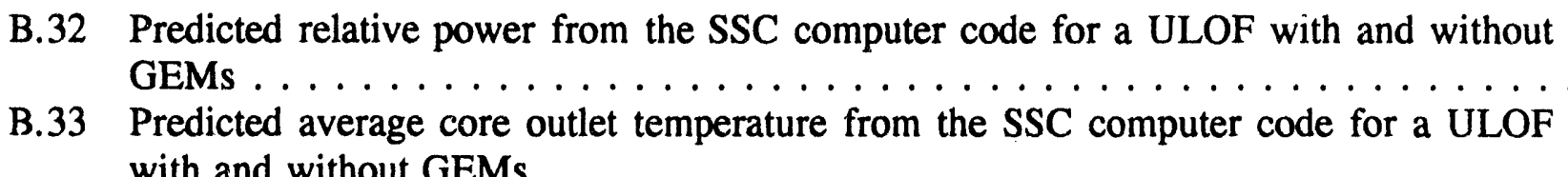
with and without GEMs

B.34 Predicted fuel temperature distribution from the SSC computer code for the third node from the top (i.e., $0.897 \mathrm{~m}-0.673 \mathrm{~m}$ ) for a ULOHS . . . . . . . . . . . B-37

B.35 Predicted fuel temperature distribution from the SSC computer code for the top node (i.e., $1.346 \mathrm{~m}-1.122 \mathrm{~m}$ ) for a ULOHS . . . . . . . . . . . . . . . . B-37

B.36 Temperature summary for unprotected loss-of-flow and/or loss-of-heat-sink events . . B-38 
B.37 Temperature summary for unprotected loss-of-heat-sink with RVACS only events . . B-39

B.38 Predicted pump flow rate from the MINET computer code for a ULOF/LOHS with four EM pumps . . . . . . . . . . . . . . . . . . . . B-41

B.39 Predicted pump flow from the MINET computer code for a ULOF/LOHS with a pump

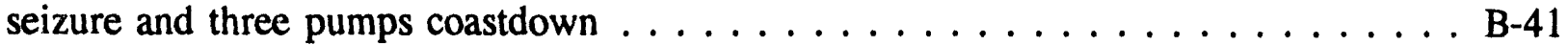

B.40 Predicted flow in a seized EM pump for a ULOF/LOHS with three pumps

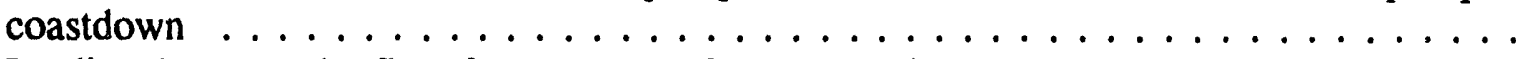

B.41 Predicted core outlet flow from MINET for a ULOF/LOHS with one pump seizure and three pumps coastdown $\ldots \ldots \ldots \ldots \ldots \ldots \ldots \ldots \ldots$. . . . . . . . . . . . . . . . . .

B.42 Predicted relative power and normalized core flow from the SSC computer code for a

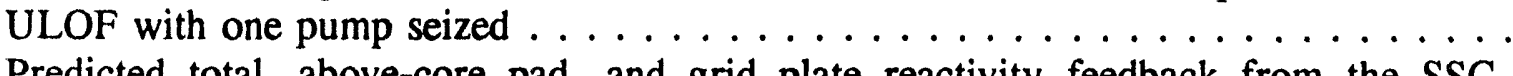

B.43 Predicted total, above-core pad, and grid plate reactivity feedback from the SSC computer code for a ULOF with one pump seized $\ldots \ldots \ldots \ldots \ldots$

B.44 Predicted core radial expansion, sodium density, and axial expansion reactivity feedback from the SSC computer code for a ULOF with one pump seized . . . . . . . . . . . .

B.45 Predicted Doppler, control rod drive line thermal expansion and GEM reactivity feedback from the SSC computer code for a ULOF with one pump seized . . . . . . .

B.46 Predicted fuel temperature distribution for the third from the top node (i.e., $0.897 \mathrm{~m}-0.673 \mathrm{~m}$ ) of a fuel pin from the SSC computer code for a ULOF with one

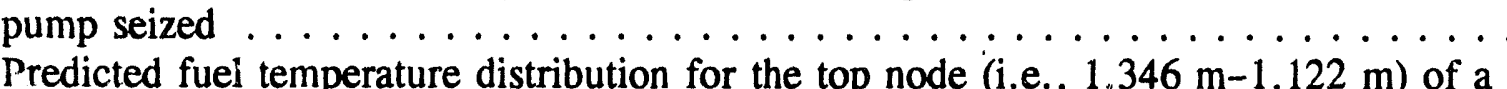

B.47 Predicted fuel temperature distribution for the top node (i.e., $1.346 \mathrm{~m}-1.122 \mathrm{~m}$ ) of a fuel pin from the SSC computer code for a ULOF with one pump seized . . . . . . . .

B.48 Predicted margin to sodium saturation from the SSC computer code for a ULOF with one pump seized $\ldots \ldots \ldots \ldots \ldots \ldots \ldots \ldots \ldots \ldots \ldots \ldots \ldots \ldots \ldots$

B.49 Core exit average sodium temperature from the SSC computer code for a ULOF with one pump seized $\ldots \ldots \ldots \ldots \ldots \ldots \ldots \ldots \ldots \ldots \ldots \ldots$

B.50 Predicted relative power and normalized core flow from the SSC computer code for a

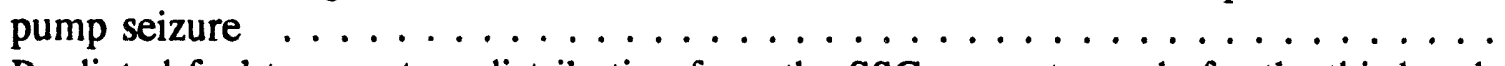

B.51 Predicted fuel temperature distribution from the SSC computer code for the third node from the TOP (i.e., $0.897 \mathrm{~m}-0.673 \mathrm{~m}$ ) for a pump seizure . . . . . . . . . . . B-48

B.52 PRISM core sodium flow from the SSC computer code for a total EM pump failure . B-49

B.53 Predicted relative power and normalized core flow from the SSC computer code for a total EM pump failure . . . . . . . . . . . . . . . . . . . . . . . B-49

B.54 Predicted total, above-core pad and core-support grid plate reactivity feedback from the SSC computer code for a total EM pump failure . . . . . . . . . . . . . . .

B.55 Predicted core radial'expansion, sodium density, and axial expansion reactivity feedback from the SSC computer code for a total EM pump failure . . . . . . . . . . . . .

B.56 Predicted Doppler, control rod drive line thermal expansion, and GEM reactivity feedback from the SSC computer code for a total EM pump failure . . . . . . . . . .

B.57 Predicted sodium level in the GEMs from the SSC computer code for a total EM pump

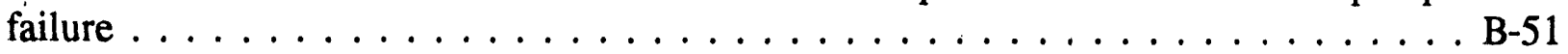

B.58 Predicted fuel temperature distribution from the SSC computer for the third node from the TOP (i.e., $0.897 \mathrm{~m}-0.673 \mathrm{~m}$ ) for a total EM pump failure . . . . . . . . . . B-52

B.59 Channel exit sodium temperature from the SSC computer code for a total EM pump

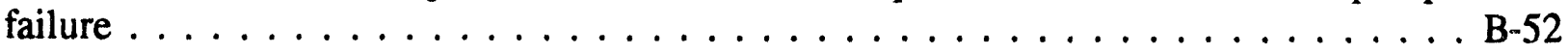

B.60 Temperature summary for loss-of-flow events $\ldots \ldots \ldots \ldots \ldots \ldots \ldots$. . . . . . . . . . . . . . 
Tables

Page

$1.1 \quad$ PRISM plant characteristics and design data $\ldots \ldots \ldots \ldots \ldots \ldots \ldots \ldots$

1.2 Major world LMRs (operating or under construction) . . . . . . . . . . . . . . . . 1-14

2.1 Components of GE's proposed site suitability source term . . . . . . . . . . . . . . 2-2

2.2 Proposed PRISM siting parameters . . . . . . . . . . . . . . . . . . . . . 2-2

3.1 GDC applicable to the PRISM design, by GDC number . . . . . . . . . . . . . 3-16

3.2 Summary evaluation of GDC . . . . . . . . . . . . . . . . . . . . . 3-17

3.3 Summary of (1) changes proposed for and (2) recommended additional general design

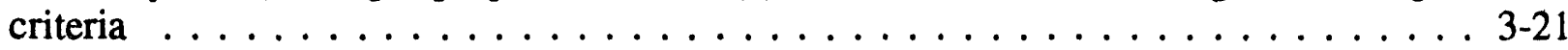

3.4 Characteristics of the ALMR seismic isolation system . . . . . . . . . . . . . 3-63

3.5 Response of the Rancho Cucamonga - San Bernandino County Law and Justice Center to various earthquakes . . . . . . . . . . . . . . . . . . . . . 3-65

3.6 Response of the Los Angeles - 2 Story Fire Command-Control Building to various

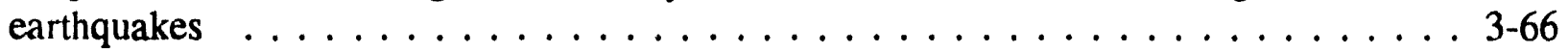

3.7 Response of the Los Angeles - 7 Story University Hospital to various earthquakes . . 3-66

3.8 Planned in-service inspection program . . . . . . . . . . . . . . . . 3-70

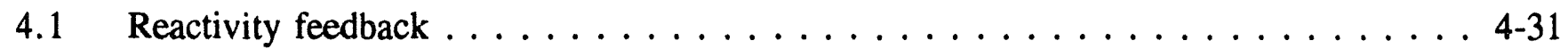

5.1 ALMR steam generator design specifications $\ldots \ldots \ldots \ldots \ldots \ldots$

6.1 Source term used for design-basis analysis $\ldots \ldots \ldots \ldots \ldots \ldots$

6.2 Dose estimates for the first 8 hours $\ldots \ldots \ldots \ldots \ldots$

8.1 EM pump performance monitoring parameters . . . . . . . . . . . . . . . . . 8-5

8.2 Synchronous coastdown machine performance monitoring parameters . . . . . . . . 8 8-5

8.3 Power conditioning unit performance monitoring parameters . . . . . . . . . . . . . 8-6

8.4 EM pump synchronous coastdown machine failure modes . . . . . . . . . . . . 8-8

9.1 Safety-related equipment and structures for reactor refueling systems . . . . . . . . 9-4

9.2 Safety-related equipment and structures for the process auxiliary systems . . . . . . . . 9-7

9.3 Safety-related equipment and structures for the auxiliary liguid-metal system . . . . . . 9-11

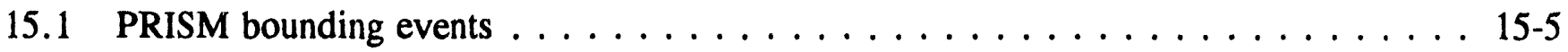

15.2 Bounding events specification $\ldots \ldots \ldots \ldots \ldots \ldots \ldots$

15.3 Summary of evaluation criteria $\ldots \ldots \ldots \ldots \ldots \ldots \ldots \ldots$

15.4 Evaluation criteria - PRISM core conditions . . . . . . . . . . . . . . . 15-8

15.5 PRISM RVACS performance $\ldots \ldots \ldots \ldots \ldots \ldots \ldots \ldots \ldots \ldots$

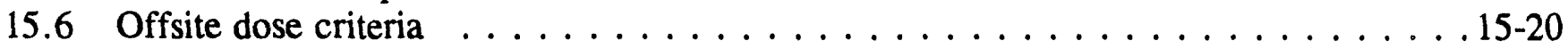

A.1 Initiating event frequency and mean time to recover $\ldots \ldots \ldots \ldots \ldots$

A.2 Risk sensitivity to uncertainty in initiating event frequencies . . . . . . . . . . . . A A-9

A.3 Risk sensitivity to uncertainty in accident-type frequencies . . . . . . . . . . . . . A-14 
A.4 Conditional probability of eutectic formation and sodium boiling . . . . . . . A-16

A.5 Release categories for $\mathrm{GE}$ bounding calculation . . . . . . . . . . . . . A A-19

B.1 Summary of peak temperatures reached during bounding events $\ldots \ldots \ldots \ldots$ B-6

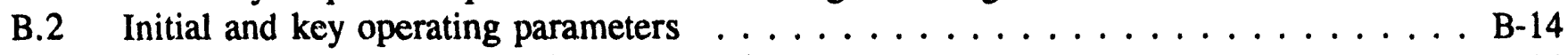

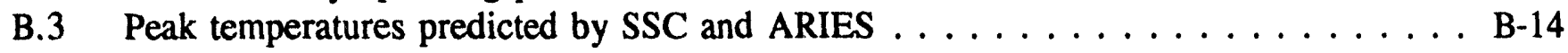

B.4 Referenced thermal conductivities .................... B-20

B.5 Peak values for UTOP variant case $\ldots \ldots \ldots \ldots \ldots \ldots \ldots \ldots \ldots \ldots$ B-20 


\section{EXECUTIVE SUMMARY}

The staff of the U.S. Nuclear!Regulatory Commission (NRC) has prepared this preapplication safety evaluation report (PSER) to document its review of the Department of Energy's (DOE's) submittal of a conceptual design for the Power Reactor Innovative Small Module (PRISM), as part of DOE's advanced liquid-metal reactor program. PRISM is a small, modular, pool-type, liquid-metal (sodium)-cooled reactor producing $471 \mathrm{MWt}$ power. Three reactor modules constitute a power block, and up to three power blocks can be combined for a 1,395-MWe station. The reactor modules would be a standard design that would be built in a factory and shipped by rail to a site. PRISM also uses an advanced metal-fuel (a plutonium-uranium-zirconium alloy) concept. Chapter 1 of this PSER summarizes the plant, the reactor module, and the reactor core designs.

The Preliminary Safety Information Document (PSID) (Ref. E.1) for the PRISM design was submitted by DOE in November 1986, for NRC review in accordance with the NRC's "Regulation of Advanced Nuclear Power Plants; Statement of Policy" published in the Federal Register (Ref. E.2). The three primary objectives of the Commission's advanced reactor policy statement are the following:

- to encourage the earliest possible interaction of applicant, vendors, and government agencies, with NRC;

- to provide all interested parties, including the public, with the Commission's views concerning the desired characteristics of advanced reactor designs, and;

- to express the Commission's intent to issue timely comment on the implications of such designs for safety and the regulatory process.

The staff developed NUREG-1226, "Development and Utilization of the NRC Policy Statement on the Regulation of Advanced Nuclear Power Plants," (Ref. E.3) in response to the advanced reactor policy statement to provide guidance to designers and the staff in performing preapplication reviews. The NRC staff reviewed the PRISM PSID according to the process and guidelines outlined in NUREG-1226.

The review approach and criteria used by the staff are directed toward meeting the guidance in the Commission's advanced reactor policy statement which states that advanced reactors must, as a minimum, offer the same degree of protection for the public and the environment as is required for current-generation light-water reactors (LWRs). The staff has interpreted "current-generation" LWRs to be those evolutionary designs currently under review as standard plant designs, such as the advanced boiling water reactor. Further, the policy states that the Commission expects advanced designs to provide enhanced margins of safety. The following nine desired characteristics of advanced reactor designs were identified in the advanced reactor policy statement:

- Highly reliable and less complex shutdown and decay heat removal systems. The use of inherent or passive means to accomplisk this objective is encouraged (negative temperature coefficient, natural circulation).

- Longer time constants and sufficient instrumentation to allow for more diagnosis and management prior to reaching safety system challenges and/or exposure of vital equipment to adverse conditions.

- Simplified safety systems which, where possible, reduce required operator actions, equipment subjected to severe environmental conditions, and components needed for maintaining safe shutdown conditions. Such simplified systems should facilitate operator comprehension, reliable system function, and more straight-forward engineering analysis.

- Designs that minimize the potential for severe accidents and their consequences by providing sufficient inherent safety, reliability, redundancy, diversity and independence in safety systems.

- Designs that provide reliable equipment in the balance of plant (or safety-system independence from balance of plant) to reduce the number of challenges to safety systems.

- Designs that provide easily maintainable equipment and components.

- Designs that reduce potential radiation exposure to plant personnel.

- Designs that incorporate defense-in-depth philosophy by maintaining multiple barriers against radiation release, and by reducing the potential for and consequences of severe accidents.

- Design features that can be proven by citation of existing technology or which can be satisfactorily established by commitment to a suitable technology development program.

The staff published its preliminary findings in a draft PSER (NUREG-1368) in September 1989 (Ref. E.4). Early in 1990, DOE, in conjunction with the designer, General Electric (GE), amended the PRISM PSID in 
response to staff comments in the draft PSER. In responding to some of these concerns, design changes were made and Amendments 12 and 13 were submitted, forming a new Appendix G. These design changes are described in Section A.2.2 of Appendix A of this PSER.

In response to a Commission staff requirements memorandum (SRM) (Ref. E.5), the staff committed to identify those policy and technical issues that require Commission guidance or staff resolution for design certification. The staff identified these issues during this preapplication review, and discussed the issues with the Advisory Committee on Reactor Safeguards (ACRS) and the preapplicant. In a paper to the Commission (SECY-93-092) (Ref. E.6), the staff listed eight PRISM design features that deviated significantly from current LWR regulatory requirements. For these issues, either existing regulations do not apply to the design or the preapplicant has proposed criteria that difter significantly from the current regulations. These issues are (1) accident evaluation, (2) calculation of source term, (3) containment performance, (4) emergency planning, (5) operator staffing and function, (6) residual heat removal, (7) positive void reactivity coefficient, and (8) design of control room and remote shutdown area. In an SRM dated July 30, 1993 (Ref. E.7), the Commission approved the staff recommendations concerning these issues. This PSER reflects those recommendations.

In its review of the PRISM design, the staff has used and built on applicable existing regulations and guidelines for safety that were developed for application to LWRs to develop additional criteria when necessary to address the unique characteristics of the design, and to assess the design for enhanced safety. In the application of the existing regulations and guidelines, the staff, in some cases, has had to interpret the guidance developed for LWRs for application to the PRISM concept and for issues under review. In making such interpretations, the staff has directed its approach toward maintaining limits and criteria at least equivalent to those of LWRs for quality, design, construction, and operation, and for the release of radiation, maintaining defense in depth, providing for conservatisms to account for plant-specific uncertainties in the design, and maintaining consistency with the guidance being developed for future LWRs for the treatment of severe accidents.

The staff assessment presented here is based on the designer's expectations of systems and metal-fuel performance in response to transient and accidents, including a hypothetical core-disruptive accident. In evaluating the systems and fuel performance expectations, the staff has reviewed supporting information submitted by the designer, and has also performed independent analyses of a wide range of bounding events. Areas in which additional information is needed to support the expectations are noted as either being covered by current, ongoing research and development efforts or by the planned prototype reactor. Guidance is also given on the information that will need to be addressed during design certification.

This PSER constitutes a record of the staft's evaluation of the conceptual design of the PRISM reactor. In Chapter 3 , the staff identifies the key policy issues pertaining to the PRISM design, and assesses the designer's proposed criteria which, in the designer's judgment, apply to the design. The staff also reviewed confirmatory research and development programs and plan for prototype testing. In Chapter 4, the staff assesses he planned research and development programs in support of the metal-fuel design. In Chapter 14, the staff assesses the planned safety testing program for the PRISM. In Appendix A, the staff reviews the probabilistic risk assessment performed by the preapplicant, including the 1990 design changes. Appendix B records the staff's independent analyses of selected bounding events that were used to assess the enhanced safety margin in the PRISM conceptual design that are responsive to the Commission's expectation as stated in the advanced reactor policy. This PSER also discusses those areas in which additional information will be required to support design certification and indicates where in the PSID the information either appears to support the designer's proposed criteria or where additional work may be needed to strengthen those positions. This PSER focuses on licensability issues and does not cover all aspects of a full design, including balance of plant and areas in which the technologies to be used are consistent with operating sodium-cooled, fast reactor designs.

The staff discussed this PSER with the ACRS on November 4, 1993. In a letter of November 10, 1993 (see Appendix C), the ACRS agreed that the staff should publish this report and supply DOE with its assessment of the licensability of the PRISM concept. On the basis of the review performed, the staff, with the ACRS in agreement, concludes that no obvious impediments to licensing the PRISM design have been identified. The ACRS letter is reproduced in Appendix $C$ of this PSER.

The preapplicant (GE) commented on the PSER in a letter of November 29, 1993 (Ref. E.8). The comments add some information, raise no new safety concerns, and are generally editorial in nature. GE also clarified the DOE requirement, in the Energy Policy Act of 1992, to submit an application to the NRC for preliminary design approval of a standard plant design by September 30, 1996. GE 
noted that this date will precede an application for design certification by many years. In this PSER, the staff uses the term "design certification" to denote the review stage at which it expects the designer to address the concerns identified. The staff expects that the designer will address the concerns when DOE submits an application to the NRC for preliminary design approval of a standard plant design. The staff has incorporated the comments from GE, as appropriate, into the report.

The staff's review of PRISM is based on a conceptual design, that continues to evolve and for which confirmatory research and development programs must be completed. This PSER does not, nor is it intended to, approve the design. For that approval, a formal application must be submitted for Commission review.

\section{References:}

E.1 General Electric, PRISM-Preliminary Safety Information Document, GEFR-00793 UC-87Ta, November 1986.

E.2 U.S. Nuclear Regulatory Commission, "Regulation of Advanced Nuclear Power Plants; Statement of Policy (10 CFR Part 50)," Federal Register, Vol. 51, No. 130, July 8, 1986, pp. 24643-24648.

E.3 U.S. Nuclear Regulatory Commission, "Development and Utilization of the NRC Policy Statement on the Regulation of Advanced Nuclear Power Plants, " NUREG-1226, June 1988.
E.4 U.S. Nuclear Regulatory Commission, "Draft Preapplication Safety Evaluation Report for Power Reactor Inherently Safe Module Liquid Metal Reactor," NUREG-1368, September 1989.

E.5 U.S. Nuclear Regulatory Commission, memorandum from S.J. Chilk to J.M. Taylor, "Staff Requirements - SECY-89-197 - Issuance of Draft Safety Evaluation Report (SER) for the Power Reactor Inherently Safe Module (PRISM)," September 12, 1989.

E.6 U.S. Nuclear Regulatory Commission, "Issues Pertaining to the Advanced Reactor (PRISM, MHTGR, and PIUS) and CANDU 3 Designs and Their Relationship to Current Regulatory Req'irements," SECY-93-092, April 8, 1993.

E.7 U.S. Nuclear Regulatory Commission, memorandum from S.J. Chilk to J.M. Taylor, "Staff Requirements - SECY-93-092 - Issues Pertaining to the Advanced Reactor (PRISM, MHTGR, and PIUS) and CANDU 3 Designs and Their Relationship to Current Regulatory Requirements, " July 30,1993.

E.8 J.E. Quinn, General Electric, letter to S.P. Sands, NRC, "GE Comments on NUREG-1368 Preapplication Safety Evaluation Report for the Power Reactor Innovative Small Module (PRISM) Liquid-Metal Reactor, " November 29, 1993. 


\section{PREFACE}

This preapplication safety evaluation report (PSER) for the power reactor innovative small module (PRISM) liquidmetal reactor is being issued to document the review performed by the Nuclear Regulatory Commission (NRC) staff. This review was performed at the request of the U.S. Depariment of Energy (DOE) consistent with the NRC's advanced reactor policy statement (51 Federal Register 24643).

This report presents the NRC staff's evaluation of the safety features of the PRISM design, including the projected research and testing needs. In addition, this report presents criteria proposed by the NRC staff to judge the acceptability of the PRISM design and, where possible, includes statements on the potential of the PRISM design to meet these criteria. However, it should be recognized that final conclusions in all matters discussed in this report require approval by the Commission.

Major differences in criteria proposed by the preapplicant and the PRISM designers, which deviate from current light-water reactor guidance for the revitw of designs, were identified in a staff policy issue paper to the Commission (SECY-93-092, April 8, 1993). The Commission approved the staff's recommendations contained in the policy issue paper in a staff requirements memorandum, July 30, 1993, which was released to the public on August 16, 1993. At the time the PRISM design is submitted for design certification, it will be necessary for the staff to identify the data, analyses, acceptance criteria, confirmatory research, and program plans in much greater detail in order that the Commission, the designers, and the public are more fully aware of the technical regulatory requirements for prototype demonstration and design certification.

The staff has reviewed this design placing emphasis on those unique features in the design that accomp'.sh key safety functions for reactor shutdown, decay heat removal, and the containment of radioactive materials.

\section{ACKNOWLEDGEMENTS}

The Office of Nuclear Reactor Regulation would like to acknowledge the following individuals for their contributions and efforts in the review, development, and preparation of this PSER.

\section{NRC Office of Nuclear Reactor Regulation Staff:}

T.H. Cox

J.E. Donoghue

J.E. Dyer

E.F. Goodwin

P.B. Moore

D.E. Roth

M.M. Slosson

A.P. Ulses
R. DePriest

J.N. Donohew

G.R. Golub

R.M. Kenneally

R.C. Pierson

S.P. Sands

E.D. Throm

B.A. Wetzel
NRC Office of Nuclear Requlatory Research (RES) Staff:

RES staff developed the 1989 draft preapplication safety evaluation report (PSER) which provided the foundation for this final report. RES also provided additional support and technical assistance that facilitated the completion of this report.

\section{BNL Contractors:}

J. Rodnizki, G.C. Slovik, G. VanTuyle

Editing and Typing:

S.A. Adams, L.O. Lessler, L.L. Luther, P.M. Magnanelli, R.F. Sanders, P.W. Shea, B.J. Toms 


\section{ABBREVIATIONS}

ABWR advanced boiling-water reactor

ACLP above core load-pad

ACRS Advisory Committee on Reactor

\section{Safeguards}

ACS auxiliary cooling system

AISI American Iron and Steel Institute

ALARA as low as is reasonably achievable

ALMR

ALTAP

ALWR

ANL

ANS

ANSI

AO

AOO

ASCE

ASHRAC

ASM

ASME

ASTM

ATWS

B

BDBE

$\mathrm{BE}$

BNL

BOP

BTP

BTU

BWR

C

$\begin{array}{ll}\text { CCTV } & \text { closed-circuit television } \\ \text { CFR } & \text { Code of Federal Regulations } \\ \text { CRBR } & \text { Clinch River Brueder Reactor } \\ \text { CRBRP } & \text { Clinch River Breeder Reactor Project } \\ \text { CRD } & \text { control rod drive } \\ \text { CRSS } & \text { control rod stop system } \\ \text { CSMIP } & \text { California Strong Motion } \\ & \text { Instrumentation Program }\end{array}$

\begin{tabular}{|c|c|}
\hline DBA & design-basis accident \\
\hline DBE & design basis event \\
\hline DDL & $\begin{array}{l}\text { detergent and decontamination liquid } \\
\text { system }\end{array}$ \\
\hline DHR & decay heat removal \\
\hline HTS & data handling and transmission system \\
\hline DN & delayed neutron \\
\hline DINB & departure from nucleate boiling \\
\hline DNM & delayed neutron monitor \\
\hline DOE & Department of Energy \\
\hline & isplacements per atom \\
\hline
\end{tabular}

$\mathbf{E}$

\begin{tabular}{|c|c|}
\hline $\mathrm{EAB}$ & exclusion area boundary \\
\hline EBR-II & Experimental Breeder Reactor-II \\
\hline EC & event category \\
\hline ECC & emergency core cooling \\
\hline ECCS & emergency core cooling system \\
\hline EM & electromagnetic \\
\hline EOP & emergency operating procedure \\
\hline EP & emergency planning \\
\hline EPA & Environmental Protection Agency \\
\hline EPRI & Electric Power Research Institute \\
\hline EPZ & emergency planning zone \\
\hline ERDA & $\begin{array}{l}\text { Energy, Research, and Development } \\
\text { Administration }\end{array}$ \\
\hline EQ & environmental qualification \\
\hline ETEC & Energy Technology Engineering Center \\
\hline
\end{tabular}

FBTA fuel behavior test apparatus

FCF fuel cycle facility

FCI fuel-coolant interaction

FEDAL fuel element detection and location

FFTF

FHC

FP

FR

FRSS

FRSSS
Fast Flux Test Facility

fuel handling cell

fission product

Federal Register

floor response spectrum

fuel recieving, storage and shipping

system 


\section{GDC general design criteria/criterion \\ GE General Electric \\ GEFR General Electric technical report \\ designation \\ GEM gas expansion module \\ GESSAR General Electric Standard Safety \\ Analysis Report \\ GRWS gaseous radioactive waste system}

H

$\begin{array}{ll}\text { HAA } & \text { head access area } \\ \text { HCDA } & \text { hypothetical core disruptive accident } \\ \text { HEDL } & \text { Hanford Engineering Development } \\ \text { HFEF } & \text { Laboratory } \\ \text { hot fuel exmaination facility } \\ \text { HTGR } & \text { high-temperature gas-cooled reactor } \\ \text { HVAC } & \begin{array}{l}\text { heating, ventilation, and air } \\ \text { conditioning }\end{array}\end{array}$

I

\begin{tabular}{|c|c|}
\hline $\begin{array}{l}\text { IALL } \\
\text { ICC }\end{array}$ & $\begin{array}{l}\text { intermediate-activity-level liquid system } \\
\text { inadequate core cooling }\end{array}$ \\
\hline IEEE & $\begin{array}{l}\text { Institute of Electrical and Electronics } \\
\text { Engineers }\end{array}$ \\
\hline IFR & integral fast reactor \\
\hline IGRPS & $\begin{array}{l}\text { inert gas receiving and monitoring } \\
\text { system }\end{array}$ \\
\hline IHTS & intermediate heat transport system \\
\hline IHX & intermediate heat exchanger \\
\hline INEL & Idaho National Engineering Laboratory \\
\hline ISA & Instrument Society of America \\
\hline ISI & inservice inspection \\
\hline ISPS & $\begin{array}{l}\text { intermediate sodium processing } \\
\text { subsystem }\end{array}$ \\
\hline $\begin{array}{l}\text { IVHM } \\
\text { IVTM }\end{array}$ & $\begin{array}{l}\text { in-vessel fuel handling machine } \\
\text { in-vessel transfer machine }\end{array}$ \\
\hline
\end{tabular}

$\mathbf{L}$

LALL low-activity-level liquid system

LMFBR liquid-metal fast breeder reactor

LMR liquid-metal reactor

LOCA loss-of-coolant accident

LODHR loss of decay heat removal

LOF loss of flow

LOHS loss of heat sink

LOSHR loss of shutdown heat removal

LPMS loose parts monitoring system

LWR light-water reactor
MPCA maximum permissible concentration in air

MSIV main steam isolation valve

MTTR mean time to recover

$\mathbf{N}$

$\begin{array}{ll}\text { NFPA } & \begin{array}{l}\text { National Fire Protection Association } \\ \text { nuclear island }\end{array} \\ \text { NRC } & \text { Nuclear Regulatory Commission } \\ \text { NRR } & \text { Office of Nuclear Reactor Regulation } \\ \text { NSFPS } & \text { non-sodium fire protection system } \\ \text { NSMH } & \text { Nuclear Systems Material Handbook } \\ \text { NSSS } & \text { nuclear steam supply system } \\ \text { NUREG } & \text { NRC technical report designation }\end{array}$

OBE operating-basis earthquake

OSHA Occupational Safety and Health

Administration (U.S. Department of Labor)

$\mathbf{P}$

PAG

PAM

PCS

PFPS

PFR

PHTS

PRA

PSAR

PSER

PSID

PSPS

PV

PWR

Q

QA Quality assurance

QC

QG protective action guideline

postaccident monitoring

plant control system

plant fire protection systein

Prototype Fast Reactor primary heat transport system probabilistic risk assessment preliminary safety analysis report preapplication safety evaluation report preliminary safety information document

primary sodium processing subsystem pressure vessel

pressurized-water reactor quality group 
RAI

RBCB

RCIC

RCPB

RCS

RFHS

RG

RHR

RO

RP

RPS

RPST

RRS

RSF

RSS

RTD

RTE

RVACS request for additional information

run-beyond-cladding-breach

reactor core isolation cooling

reactor coolant pressure boundary

reactor coolant system

reactor fuels handling system

regulatory guide

residual heat removal

reactor operator

rotatable plug

reactor protection system

reaction products separator tank

reactor refueling system

remote shutdown facility

rod stop system

resistance temperature detector

residual total elongation

reactor vessel auxiliary cooling system
TH

TID

TMI

TS

$\mathbf{U}$

$\begin{array}{ll}\text { UBC } & \text { Uniform Building Code } \\ \text { UHAA } & \text { upper head access area } \\ \text { UIS } & \text { upper internal structure } \\ \text { ULOF } & \text { unprotected loss of flow } \\ \text { ULOHS } & \text { unprotected loss of heat sink } \\ \text { UPS } & \text { uninterruptable power supply } \\ \text { USS } & \text { ultimate shutdown system } \\ \text { UTOP } & \text { unprotected transient overpower }\end{array}$

UBC Uniform Building Code

UHAA upper head access area

UIS

ULOF

ULOHS

USS

UTOP thermal hydraulic

USAEC technical report designation

Three Mile Island

transport system

$\mathbf{S}$

SAFR

SDT

SECY

SER

SFPS

SG

SHRS

SJAE

SPE

SRM

SRO

SRP

SRTS

SSC

SSE

SWR

SWRPRS sodium advanced fast reactor

sodium dump tank

Secretary of the Commission, Office of the (NRC)

safety evaluation report

sodium fire protection system

steam generator

shutdown heat removal system

steam jet-air detector

steam packing exhauster

staff requirements

memorandum/memoranda

senior reactor operator

Standard Review Plan

sodium recieving and transfer

subsystem

structures, systems, and components

safe-shutdown earthquake

sodium-water reaction

sodium-water reaction pressure relief

system
W

WHC Westinghouse Hanford Corporation

WPF whole pin furnace

7

ZPPR zero power plutonium reactor 


\section{INTRODUCTION AND SUMMARY}

\subsection{Introduction}

The staff of the U.S. Nuclear Regulatory Commission (NRC) has prepared this preapplication safety evaluation report (PSER) to document its review of the Department of Energy's (DOE's) submittal of a conceptual design for the Power Reactor Innovative Small Module (PRISM), as part of DOE's advanced liquid-metal reactor (ALMR) program. In response to a Commission staff requirements memorandum (SRM) (Ref. 1.1), the staff committed to identify those policy and technical issues that require Commission guidance or staff resolution for design certification. The staff identified these issues during this preapplication review in a paper to the Commission (SECY-93-092) (Ref. 1.2) which discussed eight PRISM design features that deviated significantly from current light-water reactor (LWR) regulatory requirements. In these issues, either existing regulations did not apply to the design or the preapplicants have proposed criteria that differ significantly from the current regulations. These issues, information on current LWR requirements, preapplicant-proposed approaches, staff considerations, and staff recommendations are discussed in Section 3.1 of this report.

The Preliminary Safety Information Document (PSID) (Ref. 1.3) for the PRISM design was submitted by DOE, for NRC review and interaction in accordance with the NRC's "Statement of Policy for the Regulation of Advanced Nuclear Power Plants" published in the Federal Register (Ref. 1.4). The DOE submitted the initial design documentation in November 1986. The NRC staff reviewed the PSID according to the process and guidelines outlined in NUREG-1226, "Development and Utilization of the NRC Policy Statement on the Regulation of Advanced Nuclear Power Plants" (Ref. 1.5). The staff's preliminary findings in a draft PSER (NUREG-1368) were published in September 1989 (Ref. 1.6). Early in 1990, the DOE, is conjunction with the designer, General Electric (GE), amended the PRISM PSID in response to staff comments in the draft PSER. Amendments 12 and 13 were submitted, forming a new Appendix G. The staff has reviewed the first five volumes of the original PSID and Appendix G (Vol. 6) in conducting its evaluation $c^{\prime}$ the PRISM design for this final PSER.

The design submitted by the DOE is for a small, modular, pool-type, liquid-metal (sodium)-cooled reactor producing $471 \mathrm{MWt}$ power. The reactor modules are a standard design that would be built in a factory and shipped by rail to a site. The PRISM design concept was selected because it emphasizes
- passive safety characteristics

- passive shutdown and decay heat removal reatures that permit simplification

- modularity for reduced costs

- a reduced number of safety-related systems

The significant design revisions submitted in Appendix G to the PSID in response to concerns raised by the staff in NUREG-1368 have changed some of the conclusions in the draft PSER. Among these design changes are the following:

- addition of the ultimate shutdown system (USS) and the containment dome

- addition of the gas expansion modules (GEMs)

- increase in reactor power to $471 \mathrm{MWt}$

- switch to a single-wall-tube, helical-coil steam generator design

The first two design changes are believed to represent significant safety improvements, the latter two may have changed some of the safety margins and will need to be evaluated in greater detail.

This PSER does not constitute an approval of the PRISM design but rather documents a preapplication review for the purpose of providing guidance early in the design process on the acceptability of the design. This PSER is intended to aid the preapplicant and the designer in developing further documentation to support licensing of the PRISM concept; however, the Commission can make a licensing determination only after the preapplicant has submi ted the PRISM design to the staff for design certification. The preapplicant will have to comply fully with the administrative processes of nuclear reactor licensing, including public notification and participation, as required by Part 52 of Title 10 of the Code of Federal Regulations (CFR), "Energy."

\subsection{PRISM Approach and Objectives}

The objectives of the PRISM project, as proposed by the preapplicant, are to develop an advanced reactor design with passive safety characteristics, which will be reliable, economical, and competitive w/ith alternative electric power generation sources available to the electric utility industry 
for large power plant complexes and will also be deployable in smaller incremental power additions.

The design characteristics of the PRISM design, coupled with its smaller reactor size make it practical to construct and operate a full-scale prototypic safety test. The safety test would not only provide the means to demonstrate PRISM's safety performance, but would also serve as the vehicle to obtain valuable operational experience necessary to support design certification. Data from the safety test, together with supporting analyses, would help to facilitate the staff safety review during the design certification process.

\subsection{General Plant Description}

The PRISM reactor design proposed by the designer, GE, is for a small, modular, pool-type, liquid-metal (sodium)cooled reactor producing $471 \mathrm{MWt}$ power. Figure 1.1 is a cut-away view of the reactor module. The standard plant design consists of three identical power blocks (Figure 1.2) of $465 \mathrm{MWe}$, for a total electrical rating of $1395 \mathrm{MWe}$.
Each power block (Figure 1.3) comprises three reactor modules, each with an individual thermal rating of $471 \mathrm{MWt}$. Each module is located in its own below-grade silo and is connected to its own intermediate heat transport system (IHTS) and steam generator system. The steam generator and secondary system hardware are located in a separate building and are connected by a below-grade pipeway. All the reactors on the site share a common control center, reactor maintenance facility, remote shutdown and radwaste facility, and assembly facility. Each power block of three reactor modules, would share a sodium service vault containing sodium purification equipment. The facility is being designed to permit siting at 90 percent of existing continental United States sites. The designer has proposed a 60-year design life for the facility. The major plant characteristics are listed in Table 1.1.

Each reactor module has its own steam generator which is combined with the two other steam generators in each power block by a common header to feed a single turbine

Table 1.1 PRISM plant characteristics and design data

\begin{tabular}{|l|c|}
\hline Overall Plant & 3 \\
\hline Number of reactors per power block & $1 / 2 /$ or 3 \\
\hline Number of power blocks & $465 / 930 /$ or $1395 \mathrm{MWe}$ \\
\hline Net electrical output & $32.9 \%$ \\
\hline Net station efficiency & \\
\hline Turbine throttle conditions & \\
\hline Reactor Module & $6653 \mathrm{kPa} / 555 \mathrm{~K}\left(965 \mathrm{psia} / 540^{\circ} \mathrm{F}\right)$ \\
\hline Thermal Power & $471 \mathrm{MWt}$ \\
\hline Primary sodium inlet/outlet temp. & $611 \mathrm{~K} / 758 \mathrm{~K}\left(640^{\circ} \mathrm{F} / 905^{\circ} \mathrm{F}\right)$ \\
\hline Primary sodium flow rate & $174,128 \mathrm{~L} / \mathrm{min}(46,000 \mathrm{gpm})$ \\
\hline Intermediate sodium inlet/outlet temp. & $555 \mathrm{~K} / 716 \mathrm{~K}\left(540^{\circ} \mathrm{F} / 830^{\circ} \mathrm{F}\right)$ \\
\hline Intermediate sodium flow rate & $156,148 \mathrm{~L} / \mathrm{min}$. (41,250 gpm) \\
\hline Reactor Core & \\
\hline Fuel & \\
\hline Refueling interval & Metallic \\
\hline Breeding ratio & 18 months \\
\hline
\end{tabular}

* Reference design, see Reference 1.12 
Introduction and Summary

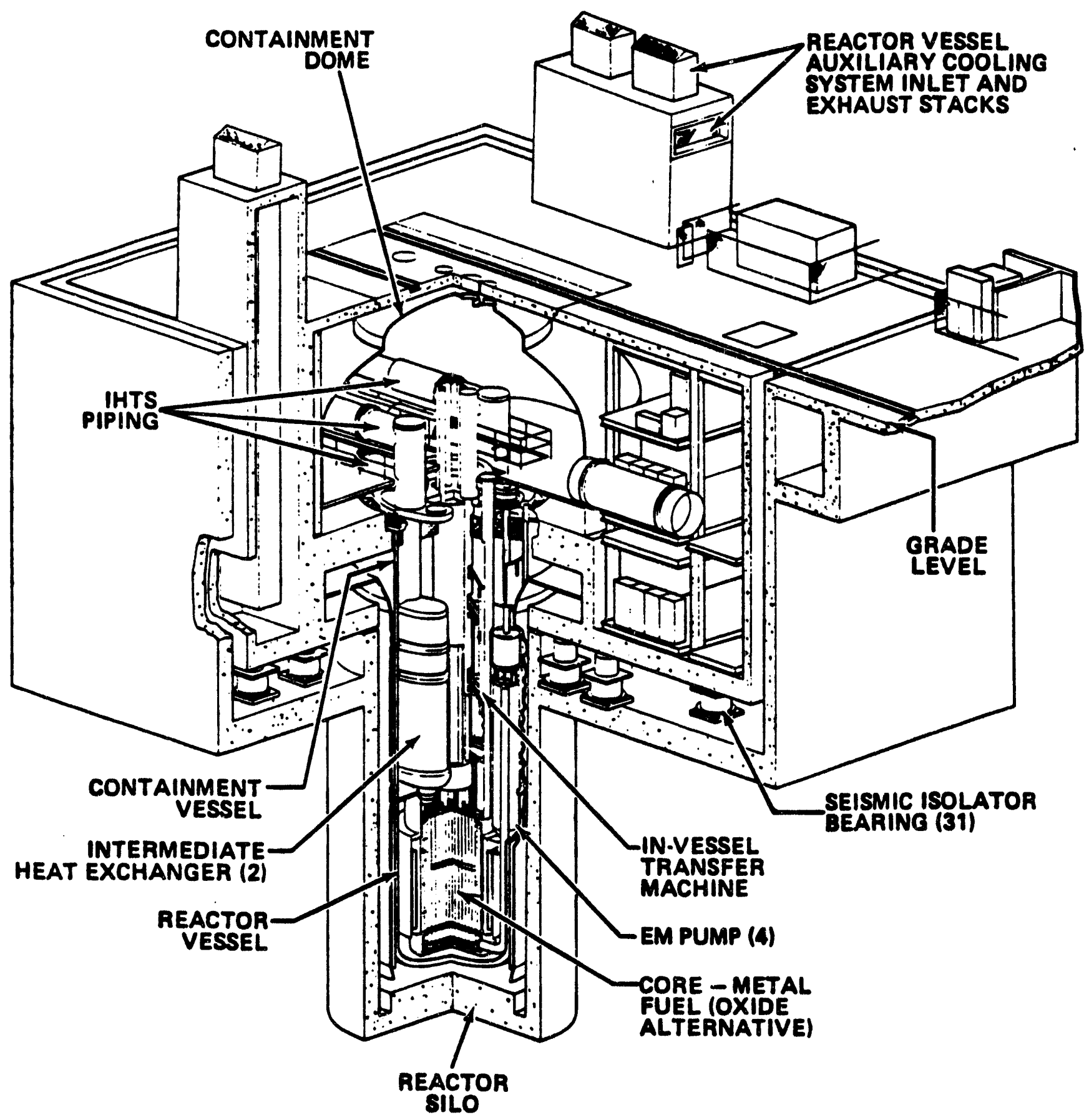

Figure 1.1 PRISM reactor module 
孞

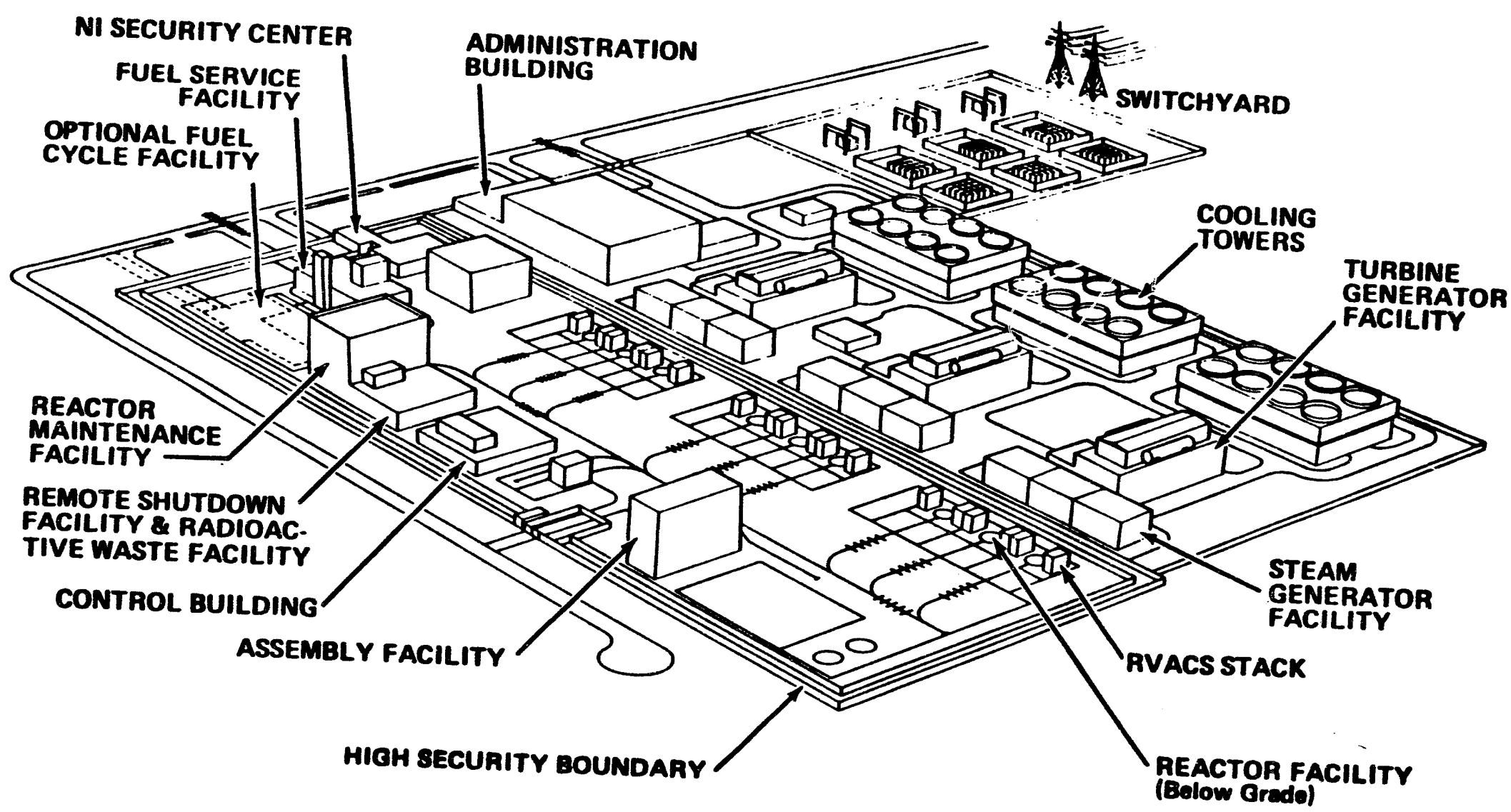

Figure 1.2 PRISM standard power plant - 1395 MWe 


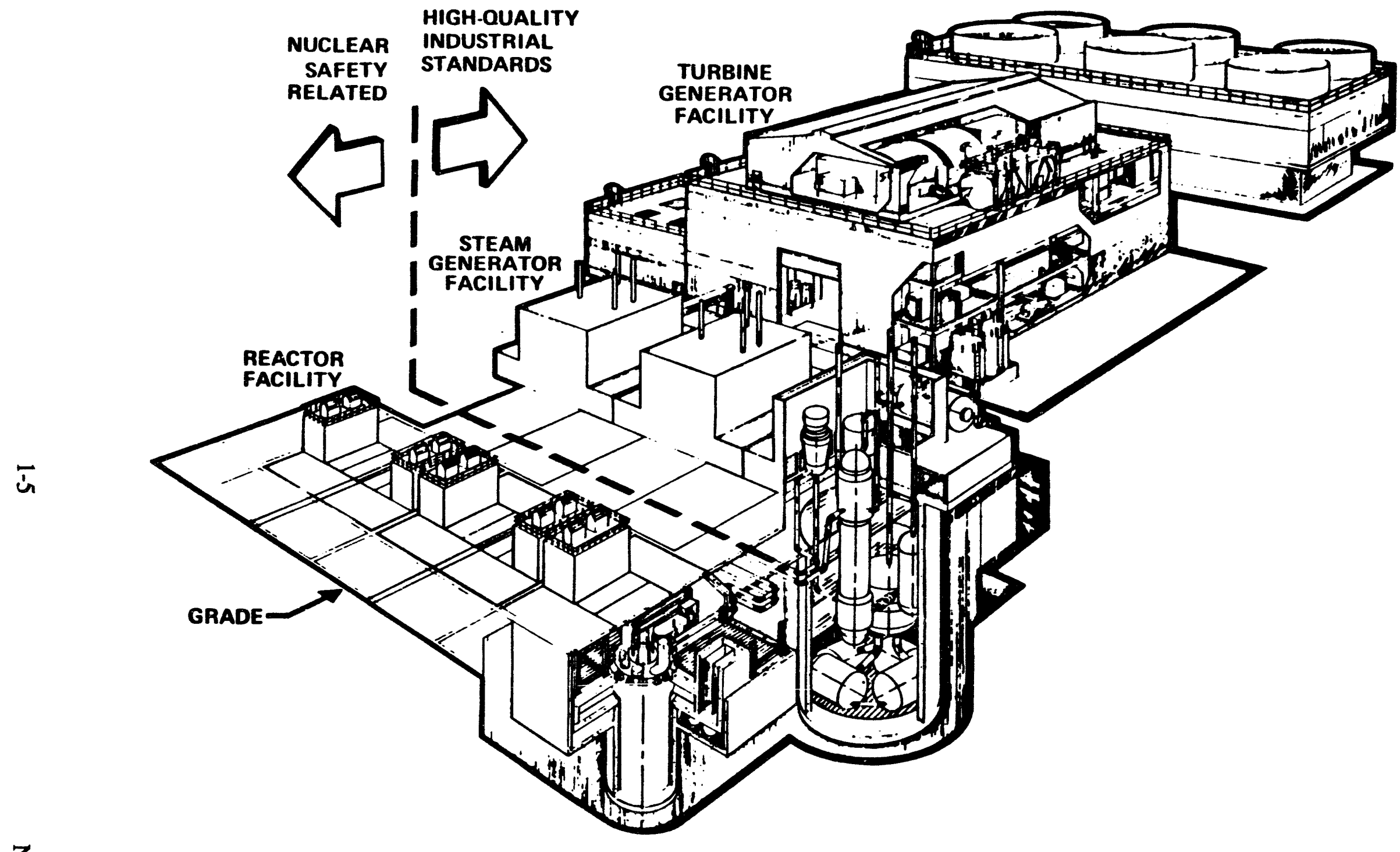

Figure 1.3 PRISM power block - 465 MWe 
generator. The reactor module is approximately $19 \mathrm{~m}$ $(62 \mathrm{ft})$ high and about $6 \mathrm{~m}(20 \mathrm{ft})$ in diameter and is in a silo below grade level. The reactor module and its associated components are seismically isolated to reduce horizontal oscillations (Figure 1.4). The reactor module enclosure consists of the reactor vessel, the containment vessel, and the reactor closure head. The reactor vessel is a $5.08-\mathrm{cm}$ (2 in.)-thick stainless steel vessel, $5.74 \mathrm{~m}$ (18.83 ft) in diameter and $16.9 \mathrm{~m}$ (55 $\mathrm{ft} 7 \mathrm{in}$.) high. The reactor containment vessel is a $2.5-\mathrm{cm}$ (1-in.)-thick stainless steel vessel approximately $6.04 \mathrm{~m}(19.83 \mathrm{ft})$ in diameter (Figure 1.5). A 15.2-cm (6 in.) diametral gap filled with argon gas exists between the reactor vessel and the containment vessel. The vessels are designed to permit inservice visual inspection of the two vessels. The gap between the two vessels is also intended to contain a primary coolant leak without resulting in core uncovery. The reactor closure head is common to both vessels. The closure head is a $0.3-\mathrm{m}(1 \mathrm{ft})$-thick steel plate with a rotatable plug (Figure 1.6) for refueling, and with penetrations for the primary coolant pumps, the intermediate heat exchanger system, and instrumentation and hardware. The system is designed so that all containment penetrations only penetrate through the closure head.

The PRISM core (Figure 1.7) is designed to use metallic fuel rather than oxide fuel. The core is designed to have a $21 \mathrm{c}$ reactivity swing during the fuel cycle. Reactivity and power are controlled by six independently regulated absorber assemblies (control rods). Any one of the six absorber assemblies is capable of shutting down the reactor and maintaining the core in a hot-shutdown condition. In addition, the reactor core is designed to utilize passive reactivity feedback mechanisms to give a negative reactivity coefficient for all design-basis transients. Three GEMs, on the core periphery, insert negative reactivity (approximately -69f) following a loss-of-flow event. The GEMs are discussed in detail in Section 4.3.5.6. An ultimate shutdown system is located in the center of the core to provide an alternative means of reaching coldshutdown conditions if control rods cannot be inserted.

The main power system is displayed in Figure 1.8. The primary coolant is forced through the core by four electromagnetic (EM) pumps. During normal operations, the EM pumps receive power from the non-Class $1 E$ ac distribution system. Should the preferred ac distribution system fail, the secondary offsite power supply system could also power the EM pumps. If the preferred and secondary offsite supplies are lost, the plant, and therefore the EM pumps, have no emergency ac power system (see Section 8.3). However, power is supplied to the EM pumps to provide coastdown, similar to a centrifugal pump, by four synchronous motor/generator machines.
The heat removed from the core is transferred from the primary coolant to an intermediate sodium loop through the intermediate heat exchanger. The IHTS piping is connected to the steam generator through a below-grade pipeway (Figure 1.9). The IHTS piping is enclosed in a guard pipe to contain possible sodium leaks. The shutdown heat is removed by three systems: (1) the main condenser, (2) the auxiliary (steam generator to air) cooling system (ACS), and (3) the safety-grade passive reactor vessel auxiliary cooling system (RVACS).

The control system for the PRISM is a state-of-the-art, hierarchical distributed microprocessor-based digital control system. An overview of the plant control system (PCS) concept is shown in Figure 1.10. Plant operations from 0 -to-25 percent power are semiautomatic (manually initiated, but automatically implemented). This control mode involves a progression through a series of hold points or plant verification states. Operation from 25-to 100-percent power is fully automated. Each of the nine reactor modules has an independent reactor protection system (RPS) located in the reactor vault, but isolated from the reactor module. The RPS is a digital system entirely independent of the PCS. The RPS is a quad-redundant protection system.

According to the designer, GE, the PRISM design features have been chosen to pievent core- melt/core-damage events that previous LMR designs have traditionally been designed to accommodate. Accordingly, traditional containment and emergency planning have not been proposed for the PRISM design because, it is suggested, the likelihood of events occurring needing such mitigation features has been reduced below that which needs to be considered in the design.

\subsection{Comparison With Other Liquid-Metal Reactors}

The PRISM design has considered worldwide LMR experience to date. This experience base is from operation of a number of facilities. The major facilities are listed in Table 1.2. Each of these facilities uses a unique combination of shutdown systems, shutdown heat removal, and containment/confinement. Operating experience with the more recent smaller facilities such as Experimental Breeder Reactor-II (EBR-II), Fast Flux Test Facility (FFTF), and Phenix has been very good. The largest facility, Super Phenix, has had some operational problems in recent years since full-power operation began. In general, the PRISM designers have attempted to incorporate the lessons learned from the worldwide experience into the design. 
Introduction and Summary

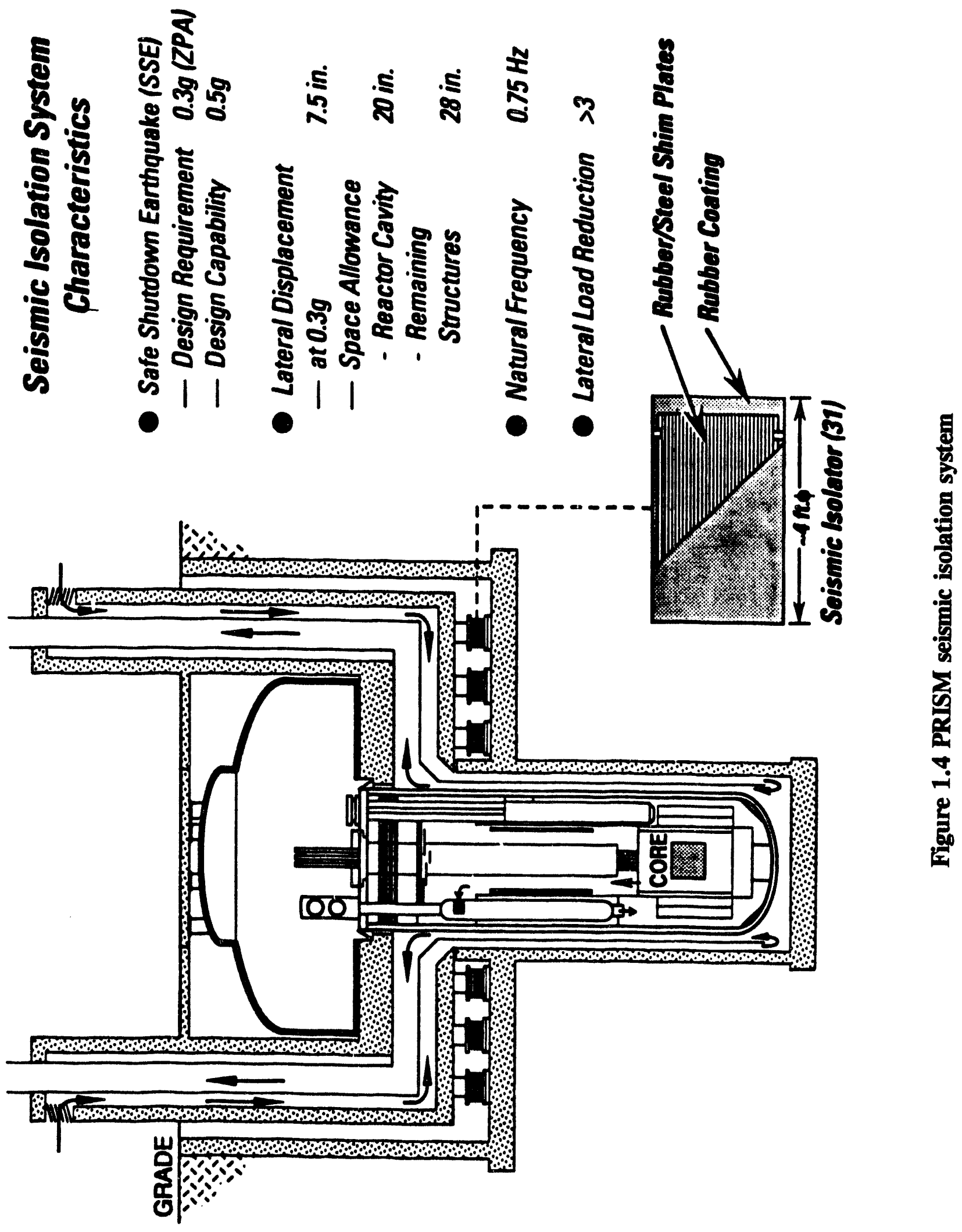




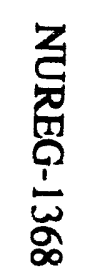

$\vec{\infty}$

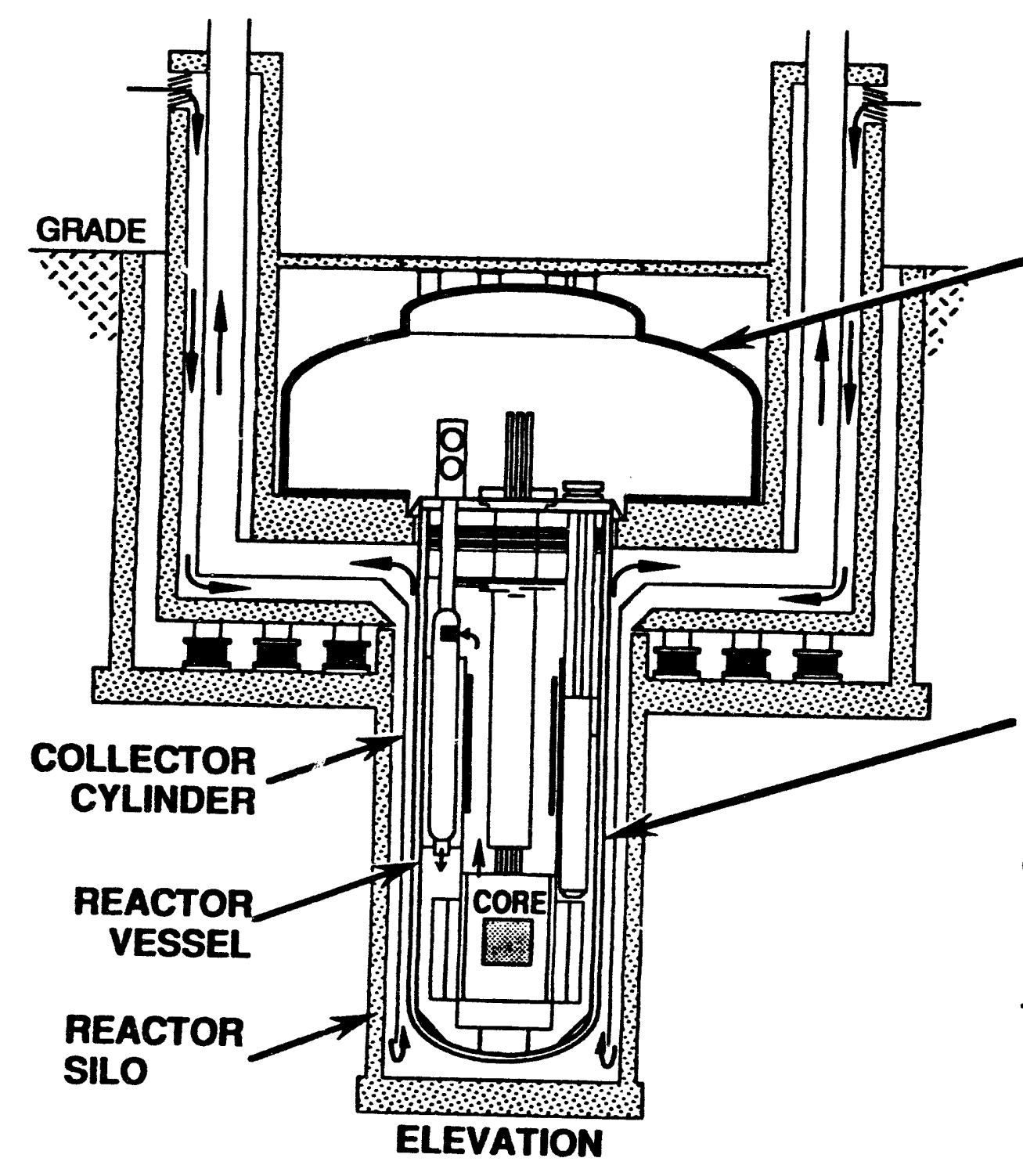

Containment Dome

- ASME Section III, Div. 1, Class MC

- Material - SA 516 Grade 70

- Design Requirements:

$<1 \%$ / day at 25 psig/700 of

Containment Vessel

- ASME Section III, Div. 1, Class MC*

- Material - 2 1/4 Cr - 1 Mo

- Design Requirements: Zero Leak Rate at 60 psig/800 of

* - Reference 1.12 states that the containment vessel will be designed to ASME Section AI, Div. 1, Class 1.

Figure 1.5 PRISM reactor containment design 
Introduction and Summary

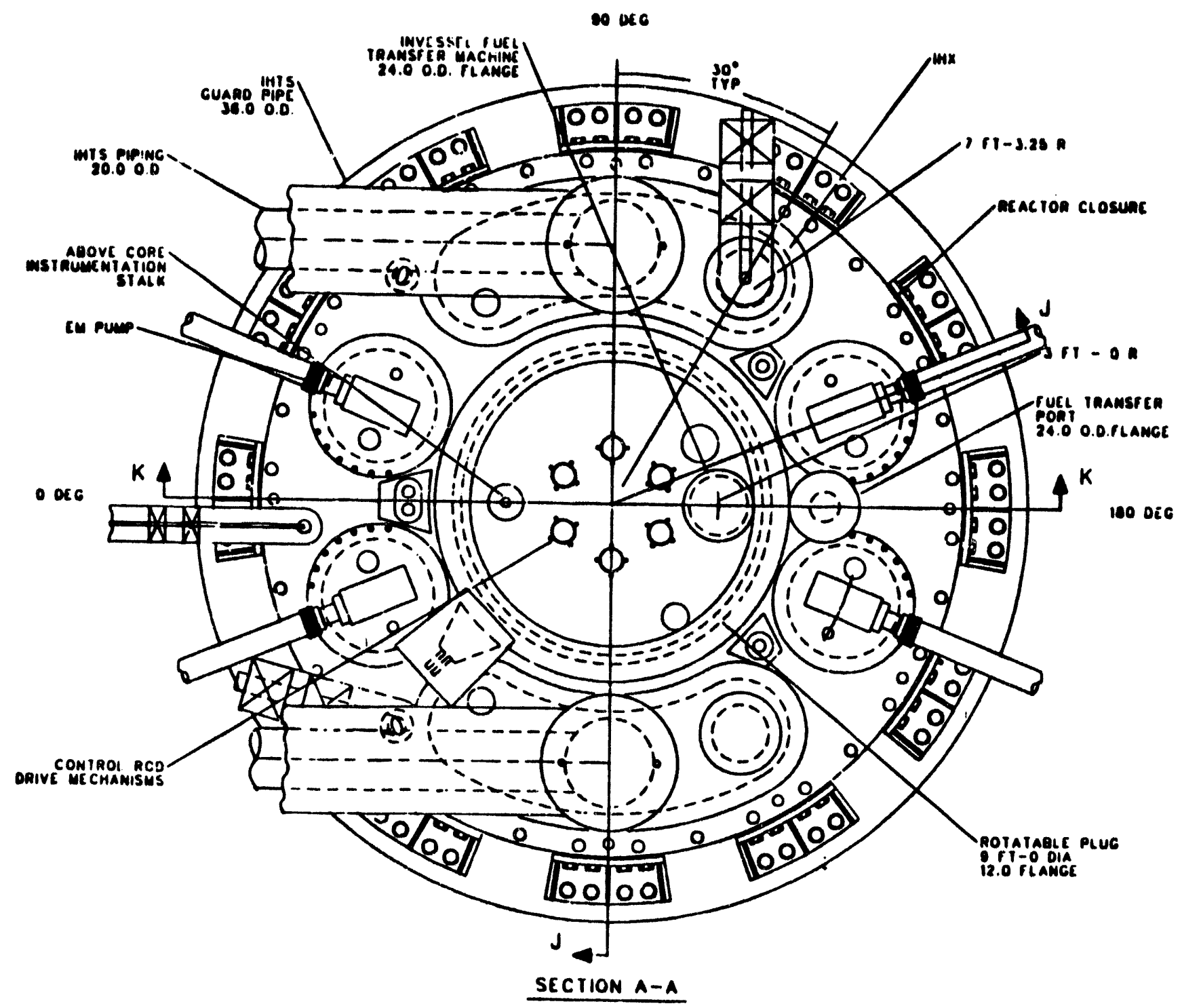

Figure 1.6 PRISM reactor closure head with rotatable plug 

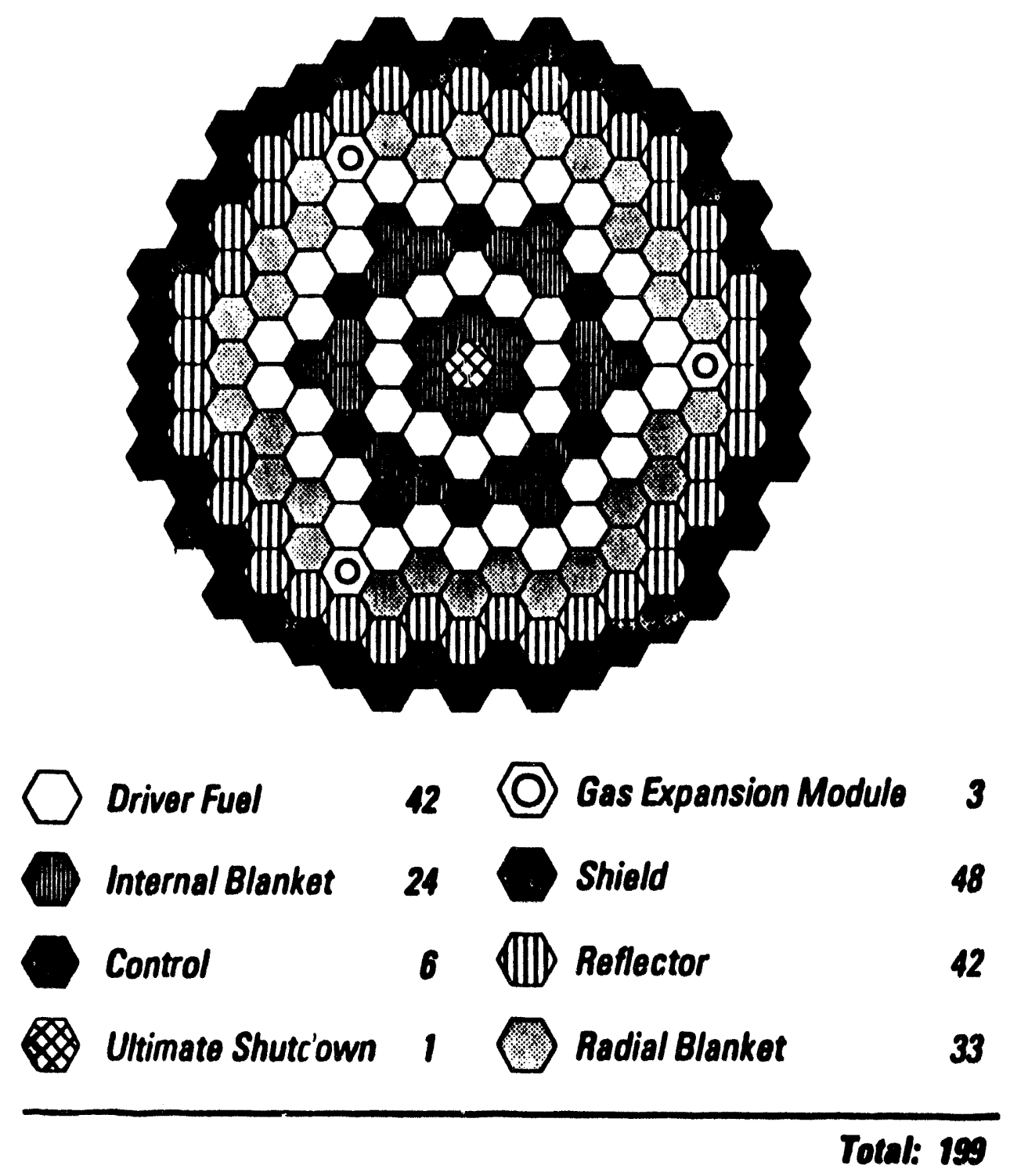

Figure 1.7 PRISM reference metal core 


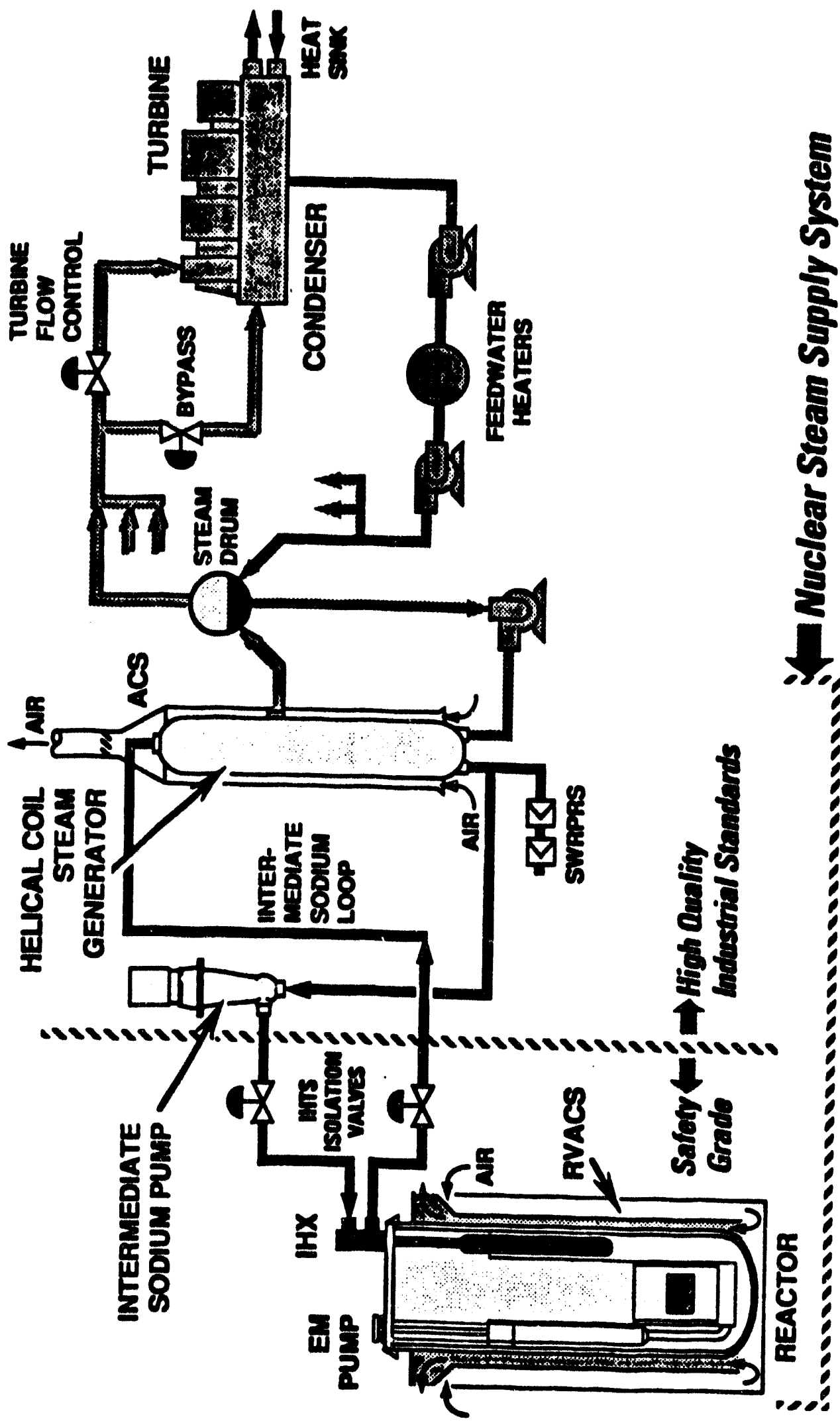

是 


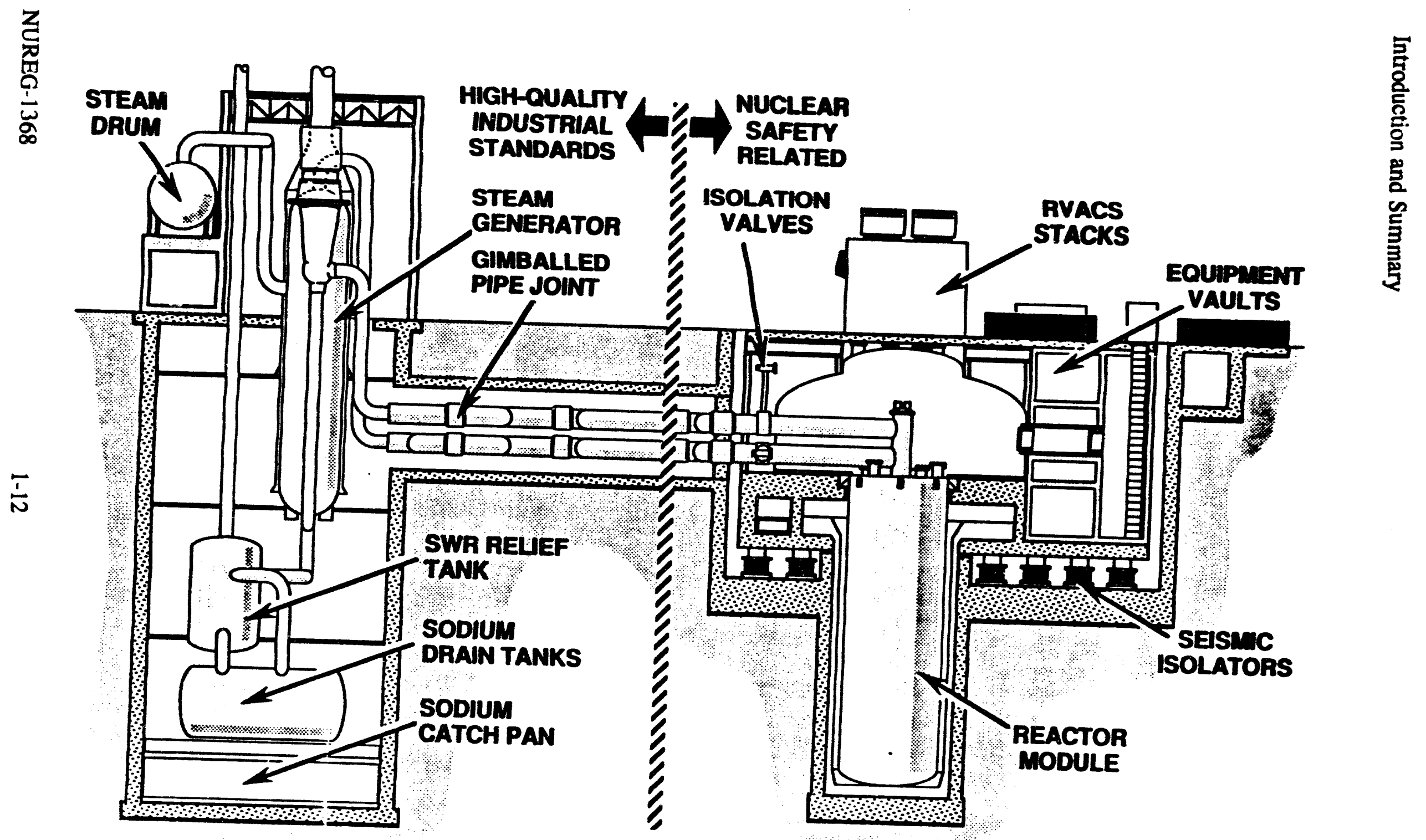

Figure 1.9 PRISM steam supply and IHTS piping 


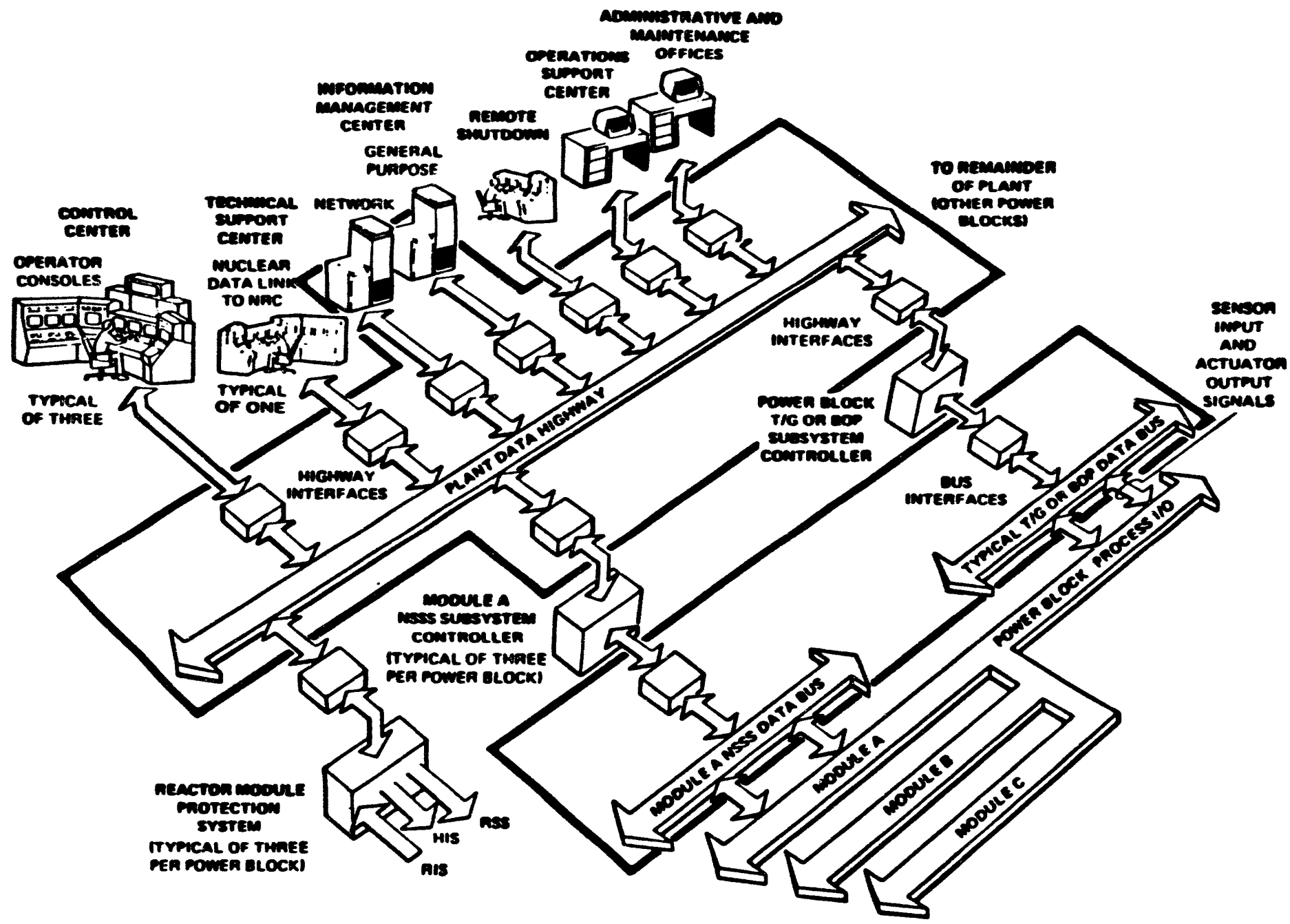

Figure 1.10 PRISM plant control and protection system concept 
Table 1.2 Major world LMRs (operating or under construction)

\begin{tabular}{||l|c|c|c|c||}
\hline \multicolumn{1}{|c|}{ Reactor } & $\begin{array}{c}\text { Thermal } \\
\text { Power }\end{array}$ & $\begin{array}{c}\text { Pool/loop } \\
\text { Design }\end{array}$ & $\begin{array}{c}\text { Date } \\
\text { Critical }\end{array}$ & Country \\
\hline EBR-II & $62.5 \mathrm{MW}$ & Pool & 1963 & U.S. \\
\hline Joyo & $100 \mathrm{MW}$ & Loop & 1977 & Japan \\
\hline FFTF & $400 \mathrm{MW}$ & Loop & 1980 & U.S. \\
\hline PFR & $559 \mathrm{MW}$ & Pool & 1974 & U.K. \\
\hline Phenix & $563 \mathrm{MW}$ & Pool & 1973 & France \\
\hline Monju & $714 \mathrm{MW}$ & Loop & - & Japan \\
\hline SNR 300 & $736 \mathrm{MW}$ & Loop & - & FRG \\
\hline BN-350 & $1000 \mathrm{MW}$ & Loop & 1973 & USSR \\
\hline BN-600 & $1470 \mathrm{MW}$ & Pool & 1980 & USSR \\
\hline Super Phenix & $3000 \mathrm{MW}$ & Pool & 1983 & France \\
\hline
\end{tabular}

\subsection{Program Status Overview and Research and Development (R\&D)}

The technology development work for the PRISM was identified in four phases; these phases relate to major phases in the ALMR design development program (Figure 1.11):

- Phase I (1985-1988)

Feasibility tests (conceptual design)

- Phase II (1989-1993)

Key features tests (advanced conceptual design)

- Phase III (1994-1997)

Components and subsystems tests (preliminary and detailed design)

- Phase IV (1998-2001)

Systems tests with prototype reactor module

During Phase I, which coincided with the initial conceptual design phase, a series of feasibility tests was performed to confirm that the innovative design features selected for the PRISM would produce the expected enhancement of safety characteristics. A series of demonstration tests carried out by Argonne National Laboratories (ANL) with the EBR-II clearly showed the capability of a small metal-fuel core to accommodate unprotected loss-of-flow and loss-of-heat- sink events with benign consequences. These types of events were previously considered as typical initiators for hypothetical core-disruptive accidents. From these tests, ANL showed that core outlet or inlet temperature increases lead to negative reactive feedbacks so that a stable neutronic, near-shutdown condition was reached at an elevated but structurally acceptable temperature. Similar tests were successfully conducted in the FFTF from 50percent power at 100-percent flow for a mixed-oxide core with nine GEMs located at the periphery of the core to enhance neutron leakage following the loss of core inlet pressure.

The capability for air natural circulation cooling of the reactor vessel for shutdown heat removal was demonstrated with tests in the FFTF interim decay storage tank facility and additional full length channel tests conducted at ANL using an annular segment of the RVACS. Pertinent heat transfer correlations were established. Limits of the system performance were evaluated by testing the flow channel with a blocked inlet. It was demonstrated that significant heat removal capability is retained.

Seismic isolation is included in the ALMR design to protect the reactor module and its safety equipment from potentially damaging ground motions during earthquakes by transforming the range of high-energy seismic input motions into low-frequency harmonic motions thereby reducing horizontal accelerations. The feasibility of the concept has been demonstrated in many civil structures as 


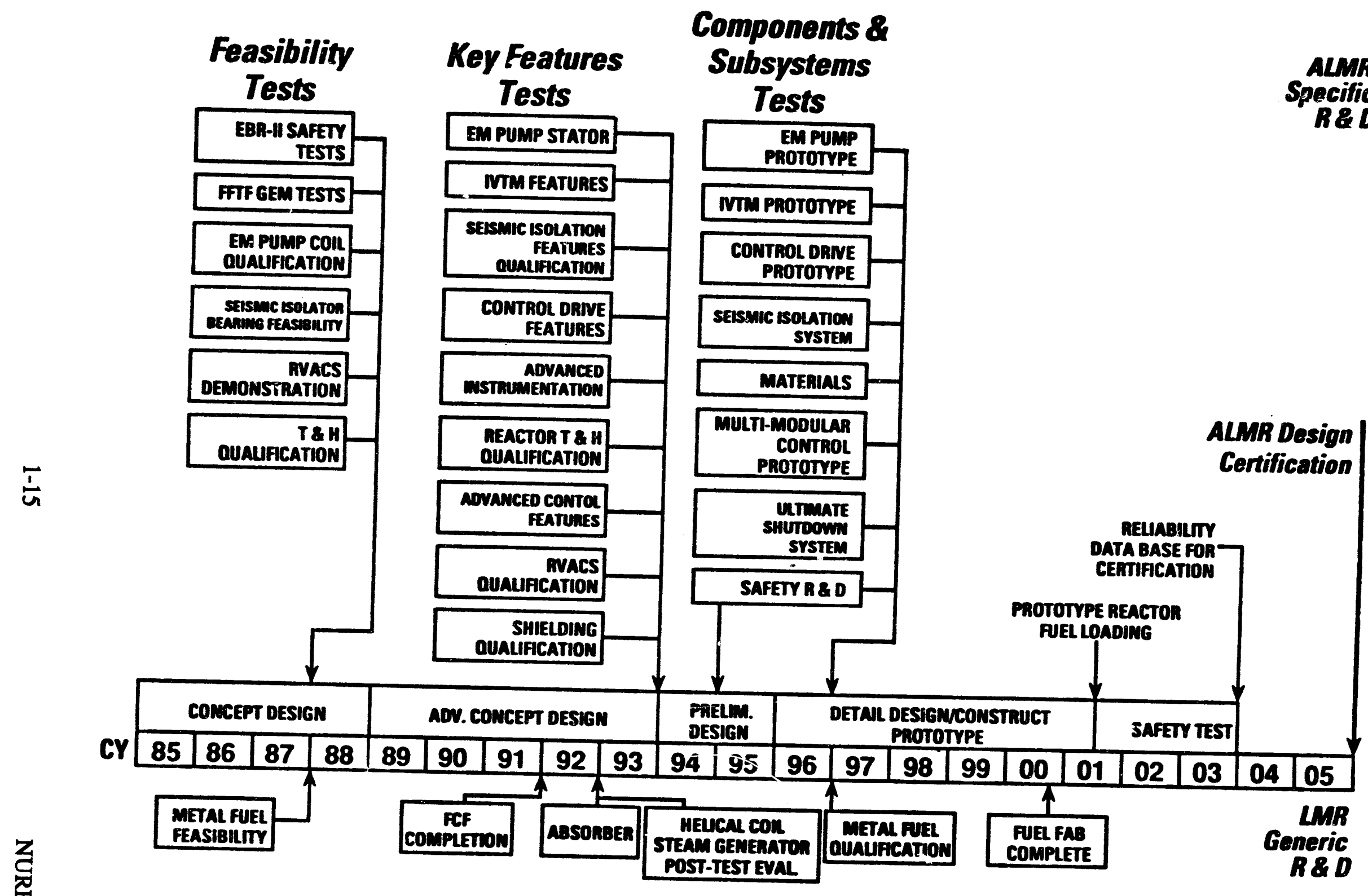

Figure 1.11 PRISM technology development schedule 
well as by testing scale-size, high-damping, steel-laminated elastomer bearings to displacements corresponding to more than three times the predicted safe-shutdown earthquake (SSE) displacement without failure.

A self-cooled EM pump is included in the design consistent with the approach to hermetically seal the reactor during operation. Since the reactor sodium is used to cool the pump coils, the electrical insulation operates at elevated temperatures (near $811 \mathrm{~K}\left(1000^{\circ} \mathrm{F}\right)$ ). Specimens tested in ovens indicated potential insulation operating life in excess of 60 years at the peak insulation temperature expected under normal reactor operation.

The reactor thermal-hydraulic characteristics for natural circulation and transient conditions were verified in a 1/5scale water-flow model at ANL. The flow stratification in the upper and lower plenum was examined.

In Phase II of the technology development program, which coincides with the ALMR advanced conceptual design phase, key feature tests of components and systems were scheduled. Significant progress has been made in selected areas; however, some areas lag. Among the major sccomplishments are the following:

- completion of Phases I and II of a mechanical performance test of a 1/4-length, full- diameter segment of the EM pump

The improved Phase II test module was exposed to a maximum sodium temperature of $739 \mathrm{~K}\left(870^{\circ} \mathrm{F}\right)$ for more than 3000 hours and completed more than 30 startup/shutdown cycles without failure.

- accelerated aging tests of EM pump electrical insulation bar specimens and full-size coils continued to show long-term, high-temperature performunce

The test operations exceeded 40,000 hours (at $953 \mathrm{~K}$ $\left(680^{\circ} \mathrm{C}\right)$ ) for bar specimons and 35,000 hours (at $823 \mathrm{~K}\left(550^{\circ} \mathrm{C}\right)$ ) for the full-size coils.

- completion of automated controller development for turbine bypass and testing of this feature in EBR-II

- completion of development of supervisory technique for module power allocation

- completion of static and dynamic testing of 1/2-size and 1/4-size seismic isolation bearings to determine structural characteristics, failure modes, and performance margins
The environmental characterization of bearings include the exposure of rubber specimens to low gammairradiation at the EBR-II sodium purification cell.

- testing of a 70-MWt helical coil steam generator unit at the Energy Technology Engineering Center (ETEC) after 16,000 hours of operation at various power levels

A post-test examination program was initiated to verify the structural performance. The water side examinations and sodium cleaning are completed.

- testing of the passive fission gas monitor

Testing was initiated at ENEA-Brasimone to demonstrate the diffusion characteristics of fission gas species (Xe-133) in helium under typical reactor temperature and sodium environment conditions.

- removal of two flexible piping bellows from the hot leg of the EBR-II IHTS after 5 years of testing

A post-test evaluation program is ongoing consistent with ALMR data needs.

The additional work planned in Phase II will complete the key features tests. Information on these tests is not available at this time; however, the following accomplishments are expected

- completion of testing of a 1/4-length segment of a double-stator-type EM pump and completion of the electrical insulation material qualification effort including insulation lifetime predictions

- demonstration of performance characteristics of key features of the in-vessel transfer machine (IVTM), including shaft seals, bearings under sodium, and gripper assembly

- demonstration of performance characteristics and margins of the seismic isolation system with single bearing tests and shake table tests using multiple bearings to support a simple reactor simulation model, as well as completion of the environmental qualification of seismic isolation bearings

- evaluation of the performance characteristics of key reactor shutdown system components including latch solenoids and bellows in a prototypical environment and verification of the performance of the absorber release mechanism 
- post-test examination of the 76-MWt helical coil steam generator unit, including visual and structural/metallurgical examinations, demonstration of tube removal and tube sheet hole-plugging operations in the field, and specification of supplementary key features tests

- performance demonstrations of the passive fission gas monitor, delayed neutron monitor, high-temperature source-range flux monitor, sodium aerosol detector, and pressure sensors in a prototypical environment

- development of a plant system model for advanced controls integration, and validation and completion of the initial controller development effort

- thermal-hydraulic tests using a water simulation model to evaluate flow stability under the range of operating conditions and temperature distributions at various structures, and to determine transient flow conditions, plenum mixing effects, and 3-D effects for the compact ALMR geometry

- RVACS performance demonstration with system model to evaluate degraded systems performance and environmental effects

- reactor shielding evaluations in support of advanced conceptual design

- continuation of the qualification of structural materials for 60-year life

- continuation of flexible bellows testing program

According to the designer, GE, Phase III of the technology development program will include the testing of key ALMR components to verify performance characteristics and safety response in a prototypical environment. This work will be completed during the detailed design phase and some of the prototype components will be refurbished after testing for use in the first prototype reactor module or be kept as spare components. Major accomplishments expected during Phase III include

- performance and safety testing of the seismic isolation system

- performance testing of a prototype EM pump

- performance testing and failure recovery tests for a prototype IVTM

- performance and reliability testing of two control drive prototypes
- performance and reliability testing of the ultimate shutdown system

- completion of structural materials qualification

- performance and reliability testing of automated controls system prototype

- completion of tests supporting the license certification effort

For Phase IV, safety tests have been scheduled with the prototype reactor module as outlined in the PSID. According to the preapplicant, these tests will be performed in support of obtaining a standard design certification for the PRISM. The Phase IV safety testing and performance verification program will include the following tests:

- preoperational, startup, and duty-cycle tests

- safety benchmark tests to demonstrate inherent safety response characteristics, including core reactivity feedback effects and RVACS heat transfer

- safety tests to demonstrate the reactor responses to anticipated transients with scram and with delayed scram, and responses to events simulating the degradation of safety systems

- demonstration of reactor module seismic isolation system performance characteristics with forced vibration and forced displacement/snapback tests

- demonstration of the on-line maintenance and in-service inspection capability of the PRISM module

\subsection{Scope of the Review}

The following major documents were supplied by DOE and were reviewed by the staff:

- Preliminary Safety Information Document (PSID), Volumes 1-5

- PSID Amendments 12 and 13 (Volume 6)

- Probabilistic Risk Assessment (PRA)

- Safety Test Program

These documents, other DOE documents, and information supplied by DOE contractors are formally identified in the section on references at the end of each chapter of this report. Because of the conceptual nature of the PRISM 
design, the review concentrated on those features, issues, and research and development activities considered important to its safety and viability. Because of the differences in design from an $L W R$, certain issues of a policy nature arose that require Commission review and guidance. These policy issues are listed here, and are discussed in detail in Section 3.1 of this report.

- accident evaluation

- calculation of source term

- containment performance

- emergency planning

- operator staffing and function

- residual heat removal

- positive void reactivity coefficient

- control room and remote shutdown area design

These issues were also discussed in a paper sent to the Commission on April 8, 1993 (SECY-93-092). The key policy issues were also reviewed by the Advisory Committee on Reactor Safeguards (ACRS) at a meeting of the full committee on January 6, 1993. The Commission approved the staff's recommendations contained in the policy issue paper in a staff requirements memorandum, July 30, 1993, which was released to the public on August 16, 1993. Many other technical issues also arose from the review of these policy issues. These are addressed in the appropriate sections of this report. Each chapter or major section within each chapter of this report identifies the scope of its review. The staff directed its review principally in the areas of review approach and criteria, nuclear design, reactor physics, reactor vessel integrity, the passive heat removal system, safety analysis, and PRA. Less of an effort was expended in areas of instrumentation, control and electrical systems, auxiliary systems, occupational exposures, human factors, safeguards and security, and balance-of-plant items. Although the staff's review was limited in some of these areas because of the information available, important issues were identified. The staff did not review the areas of mechanical equipment design, the modeling of fissionproduct transport, and other phenomena involving chemical processes for which experimental data are important to the staff acceptance of any models proposed.

\subsection{Review Approach and Criteria}

The guidance used by the staff in reviewing the PRISM design is that provided by the recent Commission policies on advanced reactors (Ref. 1.4), severe accidents (Ref. 1.7), safety goals (Ref. 1.8), and standardization (Ref. 1.9). Further guidance on the use of these policies and on the review process is given in NUREG-1226 (Ref. 1.5). In general, the review approach used by the staff was one that parallels the review approach used on
LWRs. The many factors that contribute to LWR safety (such as coriservative design practices directed toward accident 'prevention, and the use of redundancy and diversity in accomplishing key safety functions) were evaluated to ensure that similar factors or adequate substitutes were provided for the PRISM design. The acceptability of the design was not determined by measurement against a single parameter (such as the safety goals) or by comparing PRA results with LWR results. Although PRA analysis is a useful tool in evaluating a design, the staff does not consider it to be developed to the point where it can be used as the primary measure of reactor safety or acceptability. The staff relied primarily on a deterministic review to ensure that adequate conservatism and defense in depth are maintained in the design. This review also serves as the basis for making a judgment on the potential of the PRISM design to provide protection to the public and the environment at least the equivalent of that provided by current generation LWRs.

Central to the staff's evaluation was the treatment of the policy issues discussed in Sections 3.1 and 3.2. These policy issues resulted from the different approach used in PRISM to accomplish key safety functions. The staff's approach in these areas is demonstrated in Section 3 of this report. Because of the high potential to prevent core damage, a mechanistic analysis of radionuclide releases for a range of low-probability events (equivalent to severe accidents in LWRs) was substituted for the traditional, non-mechanistic, large source term (which is representative of a source term from a core-melt accident) utilized in LWR siting. Guidance from the safety goal policy was used to help define the range of low-probability events that need to be considered. However, provisions were maintained for engineering judgment to bound uncertainties in the selection of these events. Similarly, the review of a design without a conventional containment building was based on a mechanistic analysis of a range of lowprobability events and on the potential for demonstrated capability of the design (via prototype testing) to perform as predicted. Inherent in this approach is a shift in emphasis in defense in depth from accident mitigation to accident prevention and plant protection. With respect to emergency planning, the preapplicant asserts that, given the potential for a long response time before core damage, and given the use of passive reactor shutdown and cooling systems, the PRISM is sufficiently safe so that the emergency planning zone radius can be reduced to the site boundary. The long response time may compensate for certain emergency planning requirements.

Consistent with the above, the review followed the general approach of a construction permit review as described in the Standard Review Plan (SRP) (Ref. 1.10), but was far less comprehensive, emphasizing only items believed to be 
important to feasibility and safety, and deferring to a later stage of review those items judged less significant. The chapter-by-chapter organization of this document, as well as the PSID submitted by DOE, follows generally the organization of the SRP.

The staff's review was aided by independent analyses at Brookhaven National Laboratory (BNL) (Ref. 1.11), directed toward confirming the potential of the key safety features of the design to perform their function and to look for vulnerabilities in the design through sensitivity studies. This independent analysis is summarized in Chapter 15 and in Appendix B. BNL also reviewed selected topics in fuel design, thermal-hydraulics, reactor physics, and safety analysis. These BNL reviews contributed to this report.

In reviewing the PRISM design, the staff defined three event categories (ECs) for the evaluation. These ECs, in general, correspond to traditional LWR event categories as follows:

- EC-I Anticipated Operational Occurrences

- EC-II Unlikely Events

- EC-III Extremely Unlikely Events

These event categories were developed to avoid confusion over which events need to be considered in the design and how they are to be selected. The consideration of EC-III in the design is intended to ensure that low-probability events beyond the traditional design-basis envelope are considered in the design which would provide a sufficient challenge to the plant to allow the use of a mechanistic calculation of siting source terms. This consideration also provides a shift in emphasis from accident mitigation to accident prevention. The events in this category would be selected using engineering judgment, complemented by PRA. The consideration of such events in the design also meets the intent of the Commission's Severe Accident Policy Statement and the Safety Goals for the Operation of Nuclear Power Plants. A description of these event categories and their use can be found in Section 15.3 of this report.

\subsection{References}

1.1 U.S. Nuclear Regulatory Commission, memorandum from S.J. Chilk to J.M. Taylor, "Staff Requirements - SECY-89-197 - Issuance of Draft Safety Evaluation Report (SER) for the Power Reactor Inherently Safe Module (PRISM)," September 12, 1989.

1.2 U.S. Nuclear Regulatory Commission, "Issues Pertaining to the Advanced Reactor (PRISM, MHTGR, and PIUS) and CANDU 3 Designs and
Their Relationship to Current Regulatory Requirements," SECY-93-092, April 8, 1993.

1.3 General Electric, PRISM-Preliminary Safety Information Document, GEFR-00793 UC-87Ta, November 1986.

1.4 U.S. Nuclear Regulatory Commission, "Regulation of Advanced Nuclear Power Plants; Statement of Policy (10 CFR Part 50)," Federal Register, Vol. 51, No. 130, July 8, 1986, pp. 24643-24648.

1.5 U.S. Nuclear Regulatory Commission, "Development and Utilization of the NRC Policy Statement on the Regulation of Advanced Nuclear Power Plants, " NUREG-1226, June 1988.

1.6 U.S. Nuclear Regulatory Commission, "Draft Preapplication Safety Evaluation Report for Power Reactor Inherently Safe Module Liquid Metal Reactor," NUREG-1368, September 1989.

1.7 U.S. Nuclear Regulatory Commission, "Policy Statement on Severe Reactor Accidents Regarding Future Designs and Existing Plants (10 CFR Part 50)," Federal Register, Vol. 50, No. 153, August 8, 1985, pp. 32138-32150.

1.8 U.S. Nuclear Regulatory Commission, "Safety Goals for the Operation of Nuclear Power Plants; Policy Statement (10 CFR Part 50)," Federal Register, Vol. 51, No. 149, August 4, 1986, pp. 28044-28049.

1.9 U.S. Nuclear Regulatory Commission, Code of Federal Regulations, Title 10, "Energy," Part 52, "Early Site Permits; Standard Design Certifications; and Combined Licenses for Nuclear Power Plants, Subpart B, Standard Design Certification."

1.10 U.S. Nuclear Regulatory Commission, "Standard Review Plan for the Review of Safety Analysis Reports for Nuclear Power Plants, LWR Edition, " NUREG-0800, July 1982.

1.11 U.S. Nuclear Regulatory Commission, "Evaluations of 1990 PRISM Design Revisions," NUREG/CR-5815, (BNL-NUREG-52311) March 1992.

1.12 J.E. Quinn, General Electric, letter to S.P. Sands, NRC "GE Comments on NUREG-1368 Preapplication Safety Evaluation Report for the Power Reactor Innovative Small Module (PRISM) Liquid-Metal Reactor," November 29, 1993. 


\section{SITE LOCATION AND DESCRIPTION}

\subsection{Site Characteristics}

The site characteristics for the Power Reactor Innovative Small Module (PRISM) design, as defined in the Preliminary Safety Information Document (PSID) (Ref. 2.1) by the Department of Energy (DOE) and its contractor, General Electric (GE), are an envelope of selected site-related parameters which are designed to include the majority of potential reactor sites available and are independent of the reactor type (e.g., light-water reactor or liquid-metal reactor). This envelope of siterelated parameters establishes the conditions and phenomena that the PRISM is designed to accommodate.

\subsection{Siting Parameters}

The PRISM facility siting parameters have been selected to envelope 90 percent of the existing sites in the continental U.S. The selected siting parameters are identical, with one exception, to those submitted for the GESSAR II (Ref. 2.2) by GE in March 1980. The exception to the GESSAR II envelope is the snow load, $3.83 \mathrm{kPa}\left(80 \mathrm{lb} / \mathrm{ft}^{2}\right)$ for PRISM versus $2.39 \mathrm{kPa}\left(50 \mathrm{lb} / \mathrm{ft}^{2}\right)$ for GESSAR II. The below-grade design of the PRISM and the top structure permit this increased load. Should a proposed site exceed the design conditions, reanalysis would be performed with the appropriate siting conditions.

Site boundaries and public exclusion zones will be determined to satisfy the exposure limit guidelines given in 10 CFR Part 20 (Ref. 2.3), 10 CFR Part 100 (Ref. 2.4), and the U.S. Environmental Protection Agency (EPA) protective action guidelines (PAGs). However, at the conceptual design stage, values of $0.80 \mathrm{~km}(0.5 \mathrm{mi})$ and $3.22 \mathrm{~km}(2.0 \mathrm{mi})$ were used for the exclusion area boundary and low-population zone, respectively. Dose calculations at these distances based on source terms determined from mechanistic analysis of events in Event Categories I through III (EC-I through-III), as well as a GE-proposed enveloping siting source term (see Table 2.1) were calculated. These are discussed in Chapters 6 and 15. The following hazards were excluded from the siting parameter by the preapplicant:

- aircraft impact

- explosion

- flammable vapor clouds

- toxic chemicals

- fires

- collisions with intake structures

- liquid spills
The PRISM siting envelope parameters are summarized in Table 2.2.

\subsection{Conclusions}

The Nuclear Regulatory Commission staff based its review on information that the applicant submitted originally in the PSID. GE submitted no new information in Amendments 12 and 13 for Chapter 2 of the original PSID submittal, which covers site location and characteristics. On the basis of the review performed on the PRISM conceptual design and the approval of the GESSAR II siting envelope, the staff finds that the siting characteristics specified for PRISM are reasonable and meet the intent of Regulatory Guide 4.7 (Ref. 2.6). The acceptability of the proposed siting source term is contingent upon final Commission review of the siting source term policy issue (see Chapter 3). Metropolitan siting was neither proposed by the preapplicant nor considered in the staff review of PRISM.

\subsection{References}

2.1 General Electric, PRISM-Preliminary Safety Information Document, GEFR-00793 UC-87Ta, November 1986.

2.2. General Electric Co., "GESSAR II, BWR/6 Nuclear Island Design," (22A7007, Rev. 21) (Initial issue March 1980).

2.3 U.S. Nuclear Regulatory Commission, Code of Federal Regulations, Title 10, "Energy," Part 20, "Standards for Protection Against Radiation."

2.4 U.S. Nuclear Regulatory Commission, Code of Federal Regulations, Title 10, "Energy," Part 100, "Reactor Site Criteria."

2.5 U.S. Nuclear Regulatory Commission, "Assumptions Used for Evaluating the Potential Radiological Consequences of a Loss-of-Coolant Accident for PWRs," Regulatory Guide 1.4.

2.6 U.S. Nuclear Regulatory Commission, "General Site Suitability Criteria for Nuclear Power Stations," Regulatory Guide 4.7. 
Table 2.1 Components of GE's proposed site suitability source term

\begin{tabular}{||c|c|}
\hline Radio-Nuclides Released to Containment & Assumed Release \\
\hline Noble gases & $100 \%$ \\
\hline Halogens (I \& Br) & $0.1 \%$ \\
\hline Particles (Cs \& Rb) & $0.1 \%$ \\
\hline Transuranics (Pu) & $0.01 \%$ \\
\hline Containment Leak Rate & $0.1 \% /$ day \\
\hline Meteorological Assumptions & RG 1.4 (Ref 2.5) \\
\hline
\end{tabular}

* Representative of large core damage

Table 2.2 Proposed PRISM siting parameters

\begin{tabular}{|c|c|}
\hline Condition & Parameter \\
\hline \multicolumn{2}{|l|}{ Meteorological } \\
\hline Extreme wind & $209.2 \mathrm{~km} / \mathrm{hr}(130 \mathrm{mph})-9.1 \mathrm{~m}(30 \mathrm{ft})$ above ground \\
\hline Tornado & $\begin{array}{l}579.3 \mathrm{~km} / \mathrm{hr}(360 \mathrm{mph}) \text { maximum wind speed } \\
466.7 \mathrm{~km} / \mathrm{hr}(290 \mathrm{mph}) \text { maximum rotational } \\
112.7 \mathrm{~km} / \mathrm{hr}(70 \mathrm{mph}) \text { maximum translational } \\
8.0 \mathrm{~km} / \mathrm{hr}(5 \mathrm{mph}) \text { minimum translational } \\
20.7 \mathrm{kPa}(3 \mathrm{psi}) \mathrm{pressure} \text { drop } \\
13.8 \mathrm{kPa} / \mathrm{sec}(2 \mathrm{psi} / \mathrm{sec}) \text { rate of pressure drop }\end{array}$ \\
\hline $\begin{array}{l}\text { Short-term }(2 \mathrm{hr}) \\
\text { dispersion conditions }\end{array}$ & $\chi / Q=2 \times 10^{-3} \mathrm{sec} / \mathrm{m}^{3}(5 \%)$ \\
\hline Temperature range & $233 \mathrm{~K}\left(-40^{\circ} \mathrm{F}\right)$ to $319 \mathrm{~K}\left(115^{\circ} \mathrm{F}\right)$ \\
\hline \multicolumn{2}{|l|}{ Hydrological } \\
\hline Ground water level & $0.61 \mathrm{~m}(2 \mathrm{ft})$ below grade \\
\hline Flood level & $0.30 \mathrm{~m}(1 \mathrm{ft})$ below grade \\
\hline Maximum rainfall rate & $10.16 \mathrm{~cm} / \mathrm{hr}(4 \mathrm{in} . / \mathrm{hr})$ \\
\hline Maximum snow load & $3.83 \mathrm{kPa}\left(80 \mathrm{lb} / \mathrm{ft}^{2}\right)$ \\
\hline $\begin{array}{l}\text { Maximum cooling water } \\
\text { temperature }\end{array}$ & $311 \mathrm{~K}\left(100^{\circ} \mathrm{F}\right)$ \\
\hline \multicolumn{2}{|l|}{ Seismological } \\
\hline $\begin{array}{l}\text { Safe-shutdown earthquake } \\
\text { (SSE) }\end{array}$ & $\begin{array}{c}0.3 \mathrm{~g} \text { horizontal and vertical free-field as } \\
\text { measured at grade level }\end{array}$ \\
\hline Operating-basis earthquake & $0.15 g \quad 1 / 2$ SSE \\
\hline
\end{tabular}




\section{REVIEW APPROACH AND CRITERIA}

\subsection{Review Criteria}

The review approach and review criteria applied to the Power Reactor Innovative Small Module (PRISM) design are, in some cases, different from those applied to conventional light-water reactors (LWRs) because of the unique design characteristics of the PRISM. Major differences in criteria proposed by the PRISM designers, which deviate from current LWR guidance for the review of designs, were identified in a staff policy issue paper to the Commission (Ref. 3.1). The following areas which depart from current regulatory requirements:

- accident evaluation

- calculation of source term

- containment performance

- emergency planning

- operator staffing and function

- residual heat removal

- positive void reactivity coefficient

- control room and remote shutdown area design

There were two other policy issues, reactivity control system and safety classification, in the staff policy issue paper that did not relate to the PRISM design.

Each of these major differences results from the characteristics of the design which, because of its modular scheme and its use of passive reactor shutdown and decay heat removal systems, are claimed by the Department of Energy (DOE) to prevent fuel damage for a wide range of accident conditions, among which are such very unlikely events as anticipated transients without scram, station blackout, and multiple operator errors. Accordingly, the staff has studied the fundamental technical issues associated with each of these areas and has developed an approach and recommended criteria to address each issue. The approach utilizes the guidance in four documents as the basis for deriving a set of proposed decision criteria against which the PRISM concept was reviewed:

the Commission's Advanced Reactor Policy Statement (51 FR 24643) (Ref. 3.2)

NUREG-1226, "Development and Utilization of the NRC Policy Statement on the Regulation of Advanced Nuclear Power Plants" (Ref. 3.3)

the Safety Goals (Ref. 3.4)

$$
\text { the Severe Accident Policy Statement (Ref. 3.5) }
$$

The review approach and criteria used by the staff are directed toward meeting the guidance in the Commission's Advanced Reactor Policy which states that advanced reactors must, as a minimum, provide at least the same degree of protection for the public and the environment that is required for current-generation LWRs. The staff has interpreted current-generation LWRs to be those evolutionary designs currently under review as standard plant designs, such as the advanced boiling-water reactor (ABWR). Further, the policy states that the Commission expects advanced designs to provide enhanced margins of safety. Accordingly, in the review of the PRISM design, the staff proposes to use and build on applicable existing regulations and guidelines for safety developed for application to LWRs, to develop additional criteria when necessary to address the unique characteristics of these designs, and to require that they be assessed for enhanced safety. In the application of the existing regulations and guidelines, the staff, in some cases, has had to interpret the guidance developed for LWRs for application to the PRISM concept and for issues under review. In making such interpretations, the staff has directed its approach toward maintaining limits and criteria at least equivalent to those of LWRs for quality design, construction, and operation, and for the release of radiation, maintaining defense in depth, providing for conservatisms to account for plant-specific uncertainties in the designs, and maintaining ccisist acy with the guidance under development for future LWRs for the treatment of severe accidents. Each of these considerations is discussed in this first section of Chapter 3. However, because of the fundamental importance of the defense-in-depth principle to reactor safety, its application to the PRISM concept is addressed first.

"Defense in depth" in nuclear power plant safety regulation is a philosophy that ensures that safety is achieved through multiple, diverse, and complementary means to prevent and mitigate radioactive releases. Different aspects of plant safety that are generally categorized as prevention, protection, mitigation, and emergency planning include such features as

(1) plant design that uses conservative assumptions, appropriate codes and standards, and high quality in the design, construction, testing, operation, and maintenance to minimize the potential for accidents

high reliability, redundancy, and diversity in components, systems, and structures to adequately respond to and protect the plant and the barriers to radiation release in the event of an accident

(3) mitigative capability to delay and limit the release of fission products to the environment in the event an accident leads to the failure of one or more barriers to radiation release 
(4) emergency planning for protecting the public in the event radiation released from the plant exceeds acceptable limits

In general, the PRISM designers have attempted to maintain the defense-in-depth concept by addressing the four categories listed above. The PRISM designers have approached plant design and the means of maintaining defense in depth somewhat differently from the approach taken by LWR designers. In general, the PRISM shifts emphasis from mitigation features to highly reliable protection or prevention features. For example, the PRISM designers aim to achieve high reliability and protection through the use of simple and passive reactor shutdown and decay heat removal methods as compared to high reliability through active redundant systems in LWR designs. These passive protection features are directed toward maintaining fuel integrity even for very unlikely events. Mitigation is provided in the PRISM design through a low-pressure/low-leakage containment system, through physical phenomena (fission-product retention, plateout, and holdup), and through use of the long time response of the reactor in accident sequences. This has resulted in a design that proposes to accomplish protection, mitigation, and emergency planning in ways different from LWRs, thus raising the issues discussed in Section 3.1.2 (below). In the development of the criteria discussed in the remaining part of this safety evaluation report (SER), requirements have been included to ensure that each of the four categories of defense in depth listed above is addressed consistent with the unique characteristics of the PRISM design, but with the objective of providing at least equivalent protection, as compared to current LWR, to the public when the defense-in-depth provisions al a considered as a whole. In summary, the criteria directed toward the accident-prevention aspects of defense in depth for the PRISM are intended to require accident prevention capabilities at least equivalent to those required for current LWRs. The criteria directed toward the protection and mitigation aspects of defense in depth are intended to provide protection to the public and the environment, against the release of radiation, at least equivalent to that provided by LWRs. The criteria directed toward emergency planning are intended to provide an equivalent level of protection in consideration of the characteristics of the PRISM design.

In assessing the PRISM design, the staff used the existing general design criteria (GDC) in 10 CFR Part 50 (Appendix A) (Ref. 3.6) as the initial framework for its review. Specific criteria have been proposed for each of several important issues associated with the PRISM concept. The criteria could be applied in the review of any reactor design that was significantly different from current-generation LWRs. It should be emphasized that the proposed criteria were developed with full consideration of technical and policy issues and are directed toward ensuring a level of safety at least equivalent to that of current-generation LWRs. The staff developed the proposed criteria from the perspective of what it believes are required to support design certification.

\subsubsection{General Approach and Criteria}

In reviewing the PRISM advanced reactor concept, the staff used the following general criteria as a framework and an approach for conducting its review. However, it is from the GDC that the staff proposed more specific criteria to address such areas as emergency planning, accident selection, containment, and source term. The staff has structured its review conservatively, so that affirmations about the licensability of the conceptual design during the preapplication review would serve as a reasonable basis for finding the design acceptable at design certification. During the design certification process, some of the conservatism in the staff (or applicant) analyses could be removed if completed research leads to improved understanding of the design and to the development of better analytical tools. Some sources of uncertainty regarding the conceptual design are limited performance and reliability data for passive safety features, lack of final design information, unverified analytical tools used to predict plant response, limited supporting technology and research, limited construction and operating experience, and incomplete information on the proposed metallic fuel.

The proposed GDC stem from criteria the designers must satisfy to ensure a level of safety that is at least equivalent to that of LWRs and are discussed below.

(1) In order to ensure a level of safety at least equivalent to that of LWRs, applicable LWR rules and regulations are interpreted for advanced reactor concepts and applied to the PRISM design. The LWR Standard Review Plan (SRP), GDC, and other regulations or staff positions were reviewed for their applicability to the PRISM design and were supplemented, as necessary, to account for the differences and unique attributes of the design as compared to LWRs. The following major exceptions to existing rules and regulations are proposed by DOE for the PRISM.

- Permit calculation of siting source term based upon mechanistic analysis in lieu of the large nonmechanistic source term applied to LWRs such as the TID-14844 (Ref. 3.7) source term used in the $10 \mathrm{CFR}$ Part 100 siting determination. 
- Permit the containment function to be performed differently from that for LWRs.

- Permit offsite emergency planning to be modified to reflect passive plant safety characteristics.

(2) The PRISM design must comply with the intent of the severe accident requirements formulated for LWRs, therefore

- Meet the four procedural criteria for new plants stated in the Commission's Severe Accident Policy Statement (Ref. 3.5).

- Identify important severe events to be considered in the design.

- Evaluate design-dependent features incorporated to prevent severe accidents.

- Evaluate design-dependent features provided for mitigation and accident management.

(3) The PRISM design must show fission-product (FP) retention capability at least equivalent to that of LWRs, (that is, for equivalent classes of events, criteria associated with FP release - fuel damage limits, primary system integrity, and offsite dose) should require FP retention as good as or better than that for LWRs

(4) To account for the reduced experience, as compared to LWRs, the use of new or innovative features in the PRISM design to perform safety functions must

- Be demonstrated prior to design certification via testing on the first of a kind or prototype plant so that reasonable assurance will exist about the ability of these features to prevent or accommodate accidents. Specifics of plant testing can be determined case by case based on review of the plant-specific safety analysis, probabilistic risk assessment (PRA), and other analyses.

- Utilize additional inspection, surveillance, and in-service testing techniques and programs, as necessary, to ensure that the quality and performance of the new/innovative safety features are maintained within acceptable limits over the life of the plant.

\subsubsection{Proposed Licensing Criteria From SECY-93-092 (Ref. 3.1)}

Within the framework of the general approach described, more-specific criteria are provided for each of the key licensing policy issues where there were differences in the criteria proposed by the PRISM designers. These specific criteria are discussed below.

\subsubsection{Accident Selection and Evaluation}

The staff proposes to develop a single approach for accident evaluation to be applied to all advanced reactor designs during the preapplication review. The approach will have the following characteristics:

- Events and sequences will be selected deterministically and will be supplemented with insights from PRA of the specific design.

- Categories of events will be established according to expected frequency of occurrence. One category of events to be examined is accident sequences of a lower likelihood than traditional LWR design-basis accidents (DBAs). These accident sequences would be analyzed without applying the conservatisms used for DBAs. Events within a category equivalent to the current DBA category will require conservative analyses, as is presently done for LWRs.

- Consequence acceptance limits will be established for core damage and onsite and offsite releases to be consistent with Commission policy guidance.

- Methodologies and evaluation assumptions will be developed for analyzing each category of events consistent with existing LWR practices.

- Source terms will be determined as approved by the Commission and are discussed in Section 3.1.2.2 of this report.

- A set of events will also be selected deterministically to (1) assess the safety margins of the proposed designs,

(2) to determine scenarios to mechanistically determine a source term, and (3) to identify a containment challenge scenario.

- External events will be chosen deterministically on a basis consistent with that used for LWRs.

- Evaluations of multi-module reactor designs will consider whether specific events apply to some or all 


\section{Review Approach and Criteria}

reactors on site for the given scenario for all operations permitted by proposed operating practices.

Consideration in the design of a spectrum of accidents beyond the traditional LWR design-basis accident envelope was considered necessary for the PRISM. Consideration of such a spectrum of accidents (1) ensures that advanced designs comply with the Commission's Safety Goals and Severe Accident Policies (Refs. 3.4 and 3.5), (2) provides a sufficient test of the capability of the design to allow use of mechanistic source terms for siting determinations and for decisions regarding containment and emergency evacuation plans, and (3) ensures that the shift in emphasis in defense in depth from accident mitigation to accident prevention, as compared to LWRs, does in fact provide a design with safety at least equivalent to that of currentgeneration LWRs. Therefore, a set of event categories corresponding to events that must be used for design, siting, and emergency planning purposes was defined. Events to be included in each of these categories were selected deterministically, supplemented by insights gained from a PRA. The events selected will be used as a basis for calculating source terms, evaluating the safety characteristics of the proposed designs, and assessing the adequacy of their containment systems and offsite emergency planning. The staff proposed the following event categories.

Event Category I (EC-I): This category of events for advanced reactors would be equivalent to the current anticipated operational occurrences (AOOs) class of events considered for LWRs. The frequency range for these events is approximately $10^{-2}$ per plant-year, or greater, which corresponds to the frequency of events that may be expected to occur one or more times during the life of the plant. These events would be analyzed in a manner similar to the analysis for LWRs to demonstrate compliance with Appendix I to 10 CFR Part 50 (Ref. 3.6) and 40 CFR Part 190 (Ref. 3.8).

Event Category II (EC-II): This category of events for advanced reactors would be equivalent to the current DBA category for LWRs and would be selected consistent with the selection of an LWR DBA envelope. Specifically, events in EC-II would

(1) Be selected using traditional engineering judgment, complemented by PRA methods, that would include individual internal events down to a frequency of approximately $10^{-4}$ per plant-year $\left(10^{-4} / \mathrm{yr}\right.$ is based upon ensuring that any event expected to occur over the lifetime of a population of reactors -100 reactors operating for 100 years-is included). A lower value of $10^{-5}$ per plant-year will be used by the staff to increase the confidence that the collective risk of most potential DBAs are considered in the design and to account for uncertainties, particularly for a preapplication review. (Currently, GE considers all individual events that might occur at a frequency higher than $10^{-6}$ per reactor-year to be design basis events (DBEs). GE analyzes these events in a conservative manner.)

(2) Include a traditional selection of design-basis external events.

(3) Be subject to the single-failure criterion and other traditional conservatisms (such as no credit for nonsafety-grade equipment). Events within this category would require conservative analysis as is presently done for LWRs.

Event Category III (EC-III): This category of events for advanced reactors corresponds to those severe events beyond the traditional DBA envelope that should be used by designers in establishing the design bases for these reactors. The staff believes that the identification and use of such an event category is consistent with the Commission's Severe Accident Policy statement and is justified for the PRISM design, particularly where the use of a mechanistic calculation of source terms and a shift in emphasis from accident mitigation to accident prevention is proposed. The events in this category would be selected using engineering judgment, complemented by PRA insights. This is consistent with the guidance provided in the Commission's Safety Goal and Severe Accident policies, which encourage the use of PRA methods to supplement engineering judgment and deterministic (nonmechanistic) analyses. Specifically, events in EC-III would

(1) Include events (less-likely internal initiating events plus multiple-failure event sequences) down to an individual sequence frequency of approximately $10^{-7}$ per plant-year. The selection of $10^{7} / \mathrm{yr}$ is based upon ensuring that the cumulative risk of several event sequences below $10^{6} / \mathrm{yr}$ are considered in assessing compliance with the Commission's proposed performance guideline of less than a $10 \% / \mathrm{yr}$ frequency of a large release of radioactive material to the environment. The inclusion of external events beyond those in EC-II would be consistent with their application to future LWRs, which is currently being developed as part of the implementation of the Commission's Severe Accident Policy.

(2) Include, based on engineering judgment, additional bounding events to account for plant-specific 
uncertainties. Selected bounding events for the PRISM design are described in Table 15.1 of this report. Further specification of these events is provided in Table 15.2. The rationale for bounding event selection and use is described in Section 15.3 .4 of this report.

In selecting the events to be included in EC-III, the design would be specifically reviewed to identify those events that have the potential for a large release, core melt, or reactivity excursion, to ensure that adequate prevention or protection is furnished for these events. EC-III events should be analyzed on a best-estimate basis, rather than on a known conservative basis as would be done for EC-ll.

PRISM Bounding Event Selection: In evaluating the PRISM design, the staff was faced with the task of defining the range of events that should be considered in the design. This task was made particularly important because PRISM was proposing a design with containment and emergency planning features significantly different from those applied to conventional LWRs, and because the primary justification for these features was the proposed capability of PRISM to provent accidents that could lead to significant core damage and offsite release of radioactive material. The bounding events are discussed in greater detail in Section 15.3.4 of this report.

The Office of Nuclear Regulatory Research (RES) has developed a sequence categorization scheme which relies on the type and number of system, component, or operator failures to bin sequences by qualitative risk based on the likelihood of an initiating event. Subsequent failure probabilities are not needed to determine the sequence endstate (or event category).

The sequence information resulting from the solution of event trees can be used to (1) clarify each sequence, (2) identify the systems significant to safety, and (3) identify key operator actions. Each sequence in the event tree can be evaluated to determine its event category (EC) as a function of its initiating event frequency and the type and number of failures in the event tree. RES defined four ECs designated as EC-I, EC-II, EC-III, and EC-IV. These ECs were defined to help identify scenarios to be analyzed by an applicant for design certification. The ECs definitions are

- The RES EC-I category was defined to include scenarios that might occur at least once in the lifetime of a given plant. Scenarios similar to those in this category might be selected by the staff as anticipated operational occurrences for analysis by an applicant.
- The RES EC-Il category was defined to include low frequency initiators and single component or operator failures. These scenarios might occur once in the lifetime of a population of plants. Some of these scenarios might later be selected as design-basis accidents for analysis by an applicant.

- The RES EC-III category was defined to include very low probability scenarios, some with multiple failures which would be typical of severe accidents. Such scenarios might be analyzed in probabilistic safety assessments to determine licensing source terms and to assess containment (or mitigative) capabilities.

- The RES EC-IV category was defined to include scenarios of such low probabilities that detailed analysis would probably not be worthwhile. These are referred to by RES as "residual risk" scenarios.

The criteria for categorizing a particular sequence is demonstrated in Figure 3.1. As indicated, each categorization bin would be individually identified to relate a sequence to its initiating event frequency.

The staff has not applied the RES event categorization to the PRISM preapplication evaluation presented in Chapter 15 of this report. However, for comparative purposes RES EC-I would be equivalent to the PRISM classification of both "normal operation" (frequency $\geq 10^{-1}$ per reactor-year) and "anticipated event" $\left(10^{-1}>\right.$ frequency $z$ $10^{-2}$ per reactor-year); RES EC-II would be equivalent to the PRISM classification of "unlikely event" $\left(10^{-2}>\right.$ frequency $\geq 10^{-4}$ per reactor-year); RES EC-III would be equivalent to the PRISM classification "extremely unlikely event" $\left(10^{-4}>\right.$ frequency $\geq 10^{-6}$ per reactor-year); and RES EC-IV would be equivalent to the PRISM classification of a beyond design basis event (frequency below $10^{-6}$ per reactor-year). The proposed criteria presented in Chapter 15 are similar to the RES categorization but the lower bound frequencies in EC-II and EC-III would be an order of magnitude lower to account for uncertainties in the conceptual design phase. The RES method does not rely on a frequency estimate to categorize any given scenario.

\subsubsection{Siting Source Term}

Source term development for advanced reactors could be based on mechanistic analysis if

- The performance of the reactor and fuel under normal and off-normal conditions is sufficiently well understood to permit a mechanistic analysis. Sufficient data should exist on the reactor and fuel performance through the research, development, and testing 


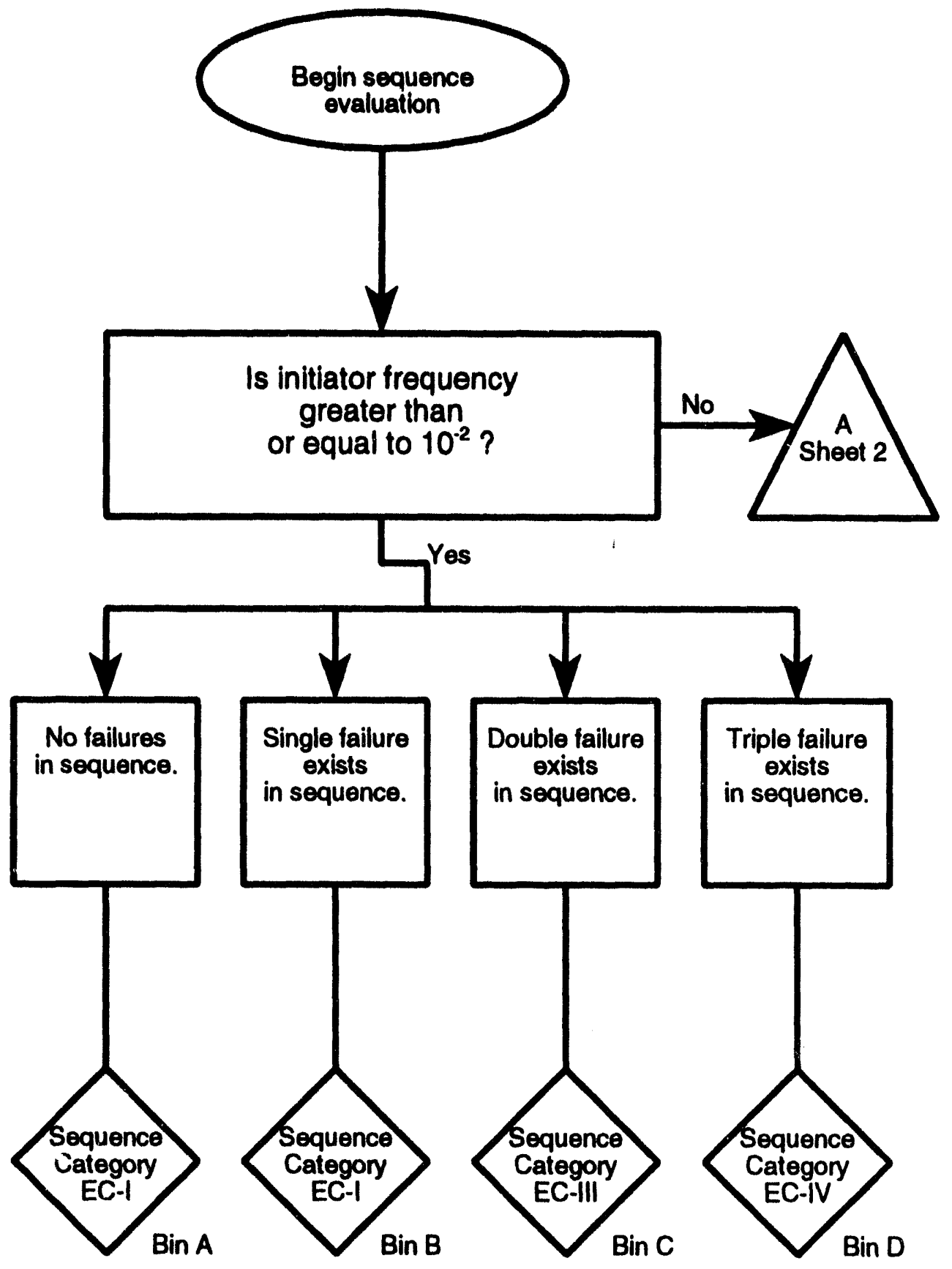

Notes: Single failure denotes one component failure or one operator error.

Double fallure denotes one system failure or two component failures or two operator errors or combination component failure / operator error.

Triple failure denotes multiple failures which exceed the criteria for double failure.

Sheet 1 of 3

Figure 3.1 RES event category logic diagram 


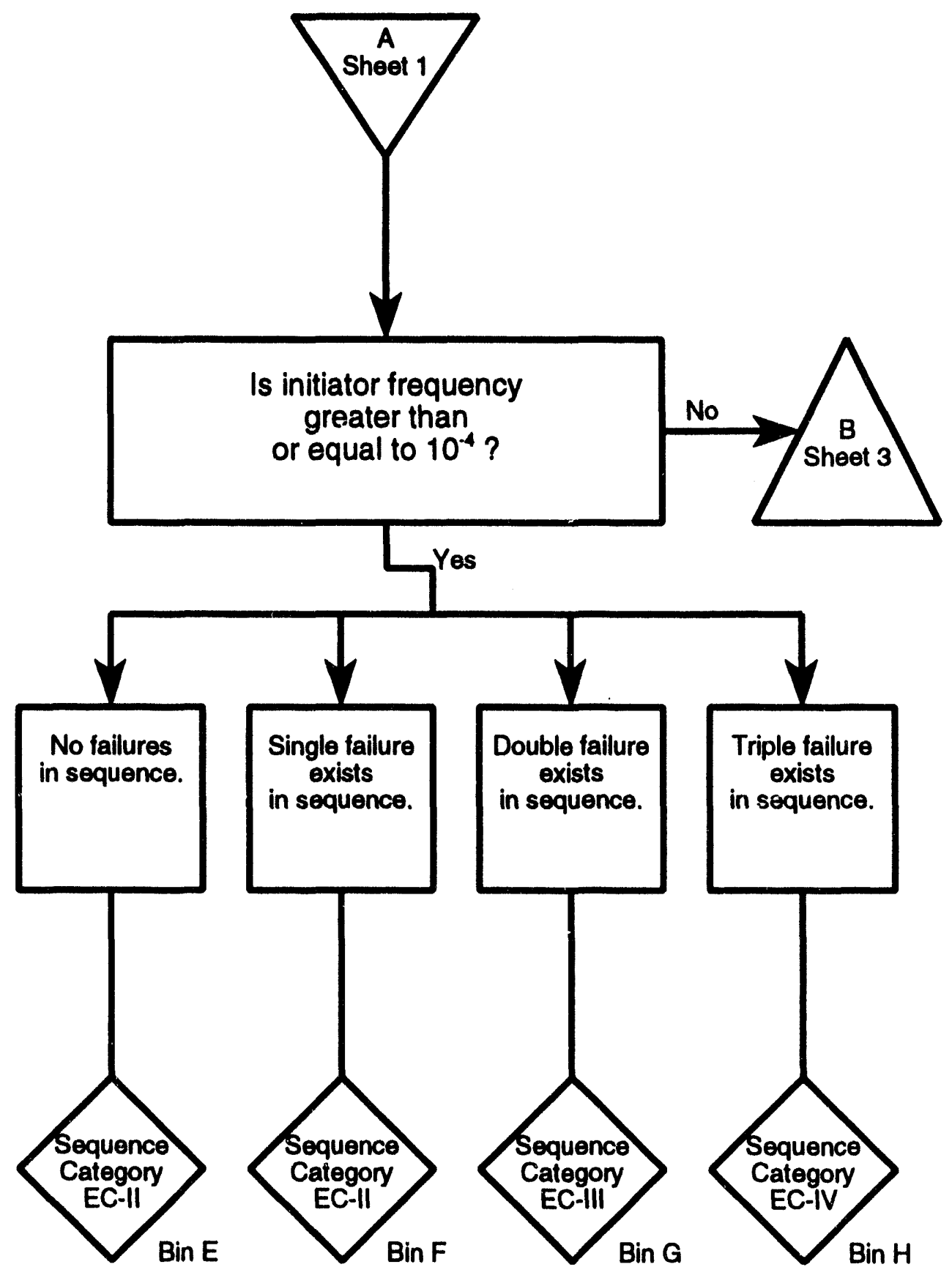

Notes: Single fallure denotes one component failure or one operator error.

Double failure denotes one system failure or two component failures or two operator errors or combination component failure / operator error.

Triple fallure denotes multiple failures which exceed the criteria for double failure.

Sheet 2 of 3

Figure 3.1 (continued) RES event category logic diagram 
Review Approach and Criteria

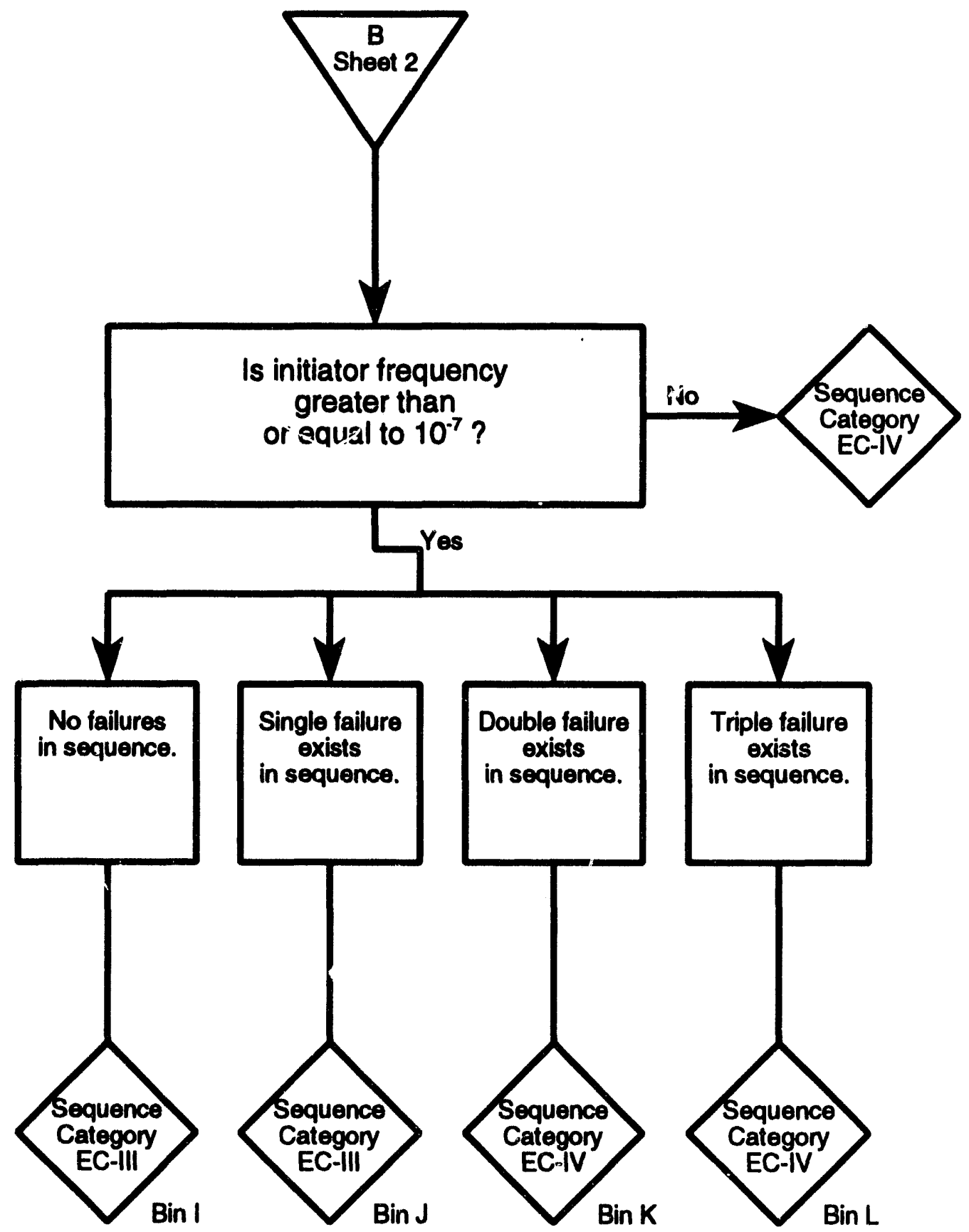

Notes: Single failure denotes one component failure or one operator error.

Double failure denotes one system failure or two component failures or two operator errors or combination component failure / operator error.

Triplo fallure denotes multiple failures which exceed the criteria for double failure.

Sheet 3 of 3

Figure 3.1 (continued) RES event category logic diagram 
programs to provide adequate confidence in the mechanistic approach.

- The transport of fission products can be adequately modeled for all barriers and pathways to the environs, including specific consideration of containment design. The calculations should be as realistic as possible so that the values and limitations of any mechanism or barrier are not obscured.

- The events considered in the analyses to develop the set of source terms for each design are selected to bound severe accidents and design-dependent uncertainties.

This would yield a more realistic estimate of source terms and would give designers of advanced reactors incentive to develop designs that minimize radionctive releases. The following criteria are proposed for the preapplication review of the PRISM design for the calculation of a mechanistic siting source term:

- Using the EC-II spectrum perform a conservative evaluation of EC-II scenarios and calculate source.

- Using the EC-III spectrum perform a best-estimate evaluation of EC-III scenarios and calculate source.

- Ensure that sufficient data exist (thrcugh an R\&D program or prototype testing) on reactor and fuel performance under EC-II and EC-III conditions to produce adequate confidence in the mechanistic analysis methods used.

- Ensure that none of the EC-II and EC-III scenarios are on a threshold where a slight change in assumptions or uncertainty can cause an unacceptable change in source.

The dose guideline specified for EC-II events is based upon maintaining a dose guideline equivalent to that for LWRs where mechanistically calculated source terms are used (i.e., where the LWR Standard Review Plan (Ref. 3.9) allows the use of mechanistically calculated source terms in analyzing accidents, it specifies offsite dose must be a small fraction of 10 CFR Part 100 guidelines, which is generally interpreted as $10-25$ percent of the 10 CFR Part 100 dose guidelines). For the preapplication review, the staff has chosen 10 percent of the 10 CFR Part 100 guidelines. The dose guidelines for EC-II is meant to ensure, at this stage of review, that the likelihood of meeting the LWR equivalent of a small fraction of the 10 CFR Part 100 guidelines is high and there is confidence in licensibility at a later review stage.
The dose guideline specified for EC-III events is based upon applying the same siting dose guideline as is applied to LWRs (10 CFR Part 100) to those events that are being analyzed in place of the traditional non-mechanistic LWR source term (i.e., EC-III events are the severe events which in an LWR have traditionally been predicted to result in a core melt and which, for LWRs, led to the establishment of the non-mechanistic TID-14844 (Ref. 3.7) source term).

The staff recognizes that the Safety Goal large release criteria would allow greater release than Part 100 at sufficient low probability. The dose guideline for EC-III is meant to ensure, at the preapplication stage, that the likelihood of meeting the Safety Goals is high and there is confidence that future licensability is assured.

To allow the use of mechanistic analysis for siting sourceterm selection, the staff proposed and GE adopted the following dose guidelines for siting assessment during the preapplication and preliminary design approval review stages.

\begin{tabular}{lll} 
Category & Dose Guideline & Meteorology \\
EC-II & $10 \%$ \& 10 CFR Part 100 & Conservative \\
EC-III & 10 CFR Part 100 & Conservative \\
\hline
\end{tabular}

These proposed criteria on siting source-term calculation and dose guidelines would be used in conjunction with the traditional assersment of site suitability using the guidelines of Regulatory Guide (RG) 4.7 (Ref. 3.11) for such factors as population distribution and meteorology. These criteria are not intended to modify any of the other NRC siting guidelines described in RG 4.7.

The criteria GE uses for the bounding-event evaluations is 10 percent of the 10 CFR Part 100 criteria, based on a conservative analysis.

\subsubsection{Containment}

The PRISM design maintains an accident mitigation approach, part of which includes containment of fission products. The reactor building and containment dome are below grade, offering protection from external hazards. The PRISM containment design is a high-strength steel, low-leakage pressure-retaining boundary, comprising two components, the upper containment dome and lower containment vessel. The upper steel containment dome differs from LWR containments. 
The staff recognizes that reactor designs without traditional containment structures or systems represent a significant departure from past practice on LWRs, and that existing LWR containment structures have proven an effective component of the staff defense-in-depth approach to regulation. New reactor designs that deviate from current practice need to be extensively reviewed to ensure that an equivalent level of safety to that of current-generation LWRs is provided, and that uncertainties in the design and performance are taken into consideration. The staff believes that new reactor designs with limited operational experience require a containment system that provides a substantial level of accident mitigation for defense in depth against unforeseen events, including core damage accidents. Accordingly, the staff proposes to utilize a standard based upon containment functional performance to evaluate the acceptability of a proposed design rather than to rely exclusively on prescriptive containment design criteria. The staff intends to approach this by comparing containment performance with the following accident evaluation criteria:

- The containment design must be adequate to meet the onsite and offsite radionuclide releuse limits for the event categories to be developed as described in the accident evaluation section, Section 3.1.2.1 of this report.

- For a period of approximately 24 hours following the onset of core damage, the specified containment challenge event results in no greater than the limiting containment leak rate used in evaluation of the event categories, and structural stresses are maintained within acceptable limits (e.g., ASME Code Level C requirements (Ref. 3.12) or equivalent). After this period, the containment must prevent uncontrolled releases of radioactivity.

These criteria are intended to maintain at least the same level of protection of the public and environment (by specifying equivalen. dose guidelines and protection) as is provided by current-generation LWRs. In addition, safetyrelated systems, structures, and components should be protected from sabotage and external events at least as well as they are for current-generation LWRs.

\section{3,1.2.4 Offsite Emergency Planning}

Although emergency plans are not required for the issuance of a design certification under 10 CFR Part 52 (Ref. 3.13), they would be necessary for the issuance of a combined license under Part 52 or a license issued under 10 CFR Part 50. According to 10 CFR 50.47, no operating license will be issued unless the NRC finds that there is reasonable assurance that adequate protective measures can and will be taken in the event of a radiological emergency.

The preapplicant claims that the PRISM design, with its passive reactor shutdown and cooling systems, and with core heatup times much longer than those of existing LWRs is sufficiently safe that the emergency planning zone (EPZ) radius can be reduced to the site boundary, and that detailed planning and exercising of offsite response capabilities need not be required by NRC regulation. The designers of the PRISM have objectives of achieving very low probabilities $\left(<1.0 \times 10^{-6}\right.$ per year) of exceeding the Environmental Protection Agency lower-level protective action guidelines (PAGs). The preapplicant also states that this does not imply that no offsite emergency plan would be developed, but rather that such a plan could have fewer details concerning movement of people, and need not contain provisions for early notification of the general public or periodic exercises of the offsite plan on a scale consistent with present licensed reactors.

The NRC staff proposes no changes to the existing regulations governing emergency planning (EP) for advanced reactor preapplicants at this time. The staff will provide regulatory direction at or before the start of the design certification phase so that any EP implications can be addressed. The staff views the incorporation of EP by advanced reactor preapplicants as an essential element in the regulatory philosophy of "defense in depth," which is consistent with the current regulatory approach. This philosophy, briefly stated (1) requires high quality in the design, construction, and operation of nuclear power plants to reduce the likelihood of malfunctions; (2) recognizes that equipment can fail and operators can make mistakes, thus requiring safety systems to reduce the probability that malfunctions will progress to accidents that release fission products from the fuel; and (3) recognizes that, in spite of these precautions, serious fuel damage accidents can occur, thus requiring containments and other safety features to prevent the release of fission products off site. Therefore, adding EP to the defense-in-depth philosophy provides reasonable assurance that emergency protective actions can be taken to protect the population around nuclear power plants, even in the unlikely event of an offsite fissionproduct release.

Once information is obtained from accident evaluations conducted by preapplicants and licensees, it will be factored into the EP requirements for advanced reactor designs. Based in part upon these accident evaluations, the staff will consider whether some relaxation from current requirements may be appropriate for advanced reactor offsite emergency plans. The relaxations the staff may evaluate include, but are not limited to, size of the EPZ, the frequency of exercises, and notification requirements. 


\section{Review Approach and Criteria}

\subsubsection{Operator Staffing and Function}

The NRC established the requirements for control room staffing in 10 CFR 50.54(m)(2)(iii) whicl lists the minimum staffing requirements for an oper ing reactor. The SRP Section 13.1.2, Paragraph II.C, states that at any time a nuclear unit is operated in modes other than cold shutdown, the minimum shift crew shall include two licensed senior reactor operators (SROs), one of whom will be designated as the shift supervisor, two licensed reactor operators (ROs), and two unlicensed auxiliary operators (AOs).

According to the preapplicant, the PRISM control room would contain the instrumentation and controls for up to nine reactor modules and their associated power conversion systems. The minimum number of operating staff for the PRISM design would include one SRO shift supervisor, one SRO assistant supervisor, and one RO per power block (three modules) in the control room, and three roving or plant ROs. This is a minimum of eight licensed operators for nine reactor modules.

Present-day $L W R s$ are required to have a minimum of one shift supervisor, one SRO, and two ROs per reactor. The PRISM preapplicants have stated that the highly automated operating systems, the passive design of safety features, and the large heat capacity of the reactor result in designs that respond to transients in a manner that demands less of the operators than do current operating plants. The PRISM designers assert, that because of passive safety features, operator actions may not be required for several hours to several days following an accident. This design also automates systems that start up, shut down, and otherwise control the reactor. Because of these factors and others, the designers of the PRISM suggest that the plant could be operated with fewer licensed operators which would significantly reduce the training and operating costs to licensees.

The staff believes that operator staffing may be design dependent and intends to review the justification for a smaller crew size for the PRISM design by evaluating the function and task analyses for normal operation and accident management. The function and task analyses must demonstrate and confirm the following through test and evaluation:

- Smaller operating crews can respond effectively to a worst-case array of power maneuvers, refueling and maintenance activities, and accident conditions.

- An accident at a single unit can be mitigated with the proposed number of licensed operators, less one, while all other units could be taken to a cold-shutdown condition from a variety of potential operating conditions, including a fire in one unit.

- The units can be safely shut down with eventual progression to a safe-shutdown condition under each of the following conditions:

- a complete loss of computer control capability

- a complete station blackout

- a design-basis seismic event

- The adequacy of these analyses will be tested and demonstrated. The staff is currently recommending that an "actual control room prototype" be used for test and demonstration purposes.

\subsubsection{Control Room and Remote Shutdown Area Design}

The current LWR requirements for control room and remote shutdown area design are addressed in 10 CFR Part 50, Appendix A (Ref. 3.6), and 10 CFR Part 100 (Ref. 3.10). The GDC require that a control room with adequate radiation protection is provided to operate the plant safely under normal and accident conditions and that there be an ability to shut down the plant from outside the control room. The GDC also require that the electrical system for the control room and the remote shutdown equipment meet the requirements for quality and independence. These requirements are defined as Class $1 \mathrm{E}$ in supporting Institute of Electrical and Electronics Engineers (IEEE) standards. The GDC and 10 CFR Part 100 require that the structures and systems important to safety be designed to seismic Category I standards to withstand the effects of natural phenomena without loss of capability to perform their safety functions.

The current LWR acceptance criteria and guidelines for the remote shutdown area are given in SRP Section 7.4. The SRP states that the area should be separated from the control room as, for example, local control panels. This area should be in communication with the control room, should have Class 1E monitoring instrumentation and controls capable of bringing the reactor down to cold shutdown, and should be designed to meet single-failure criteria and seismic Category I requirements.

The control room for the PRISM design contains the instrumentation and controls for up to nine reactor modules and their power conversion systems. According to the preapplicant and the designers, the control room structure is not considered safety-related and, therefore, is not designed to seismic Category I design requirements. Additionally, the equipment in the control room is not 


\section{Review Approach and Criteria}

safety-grade. A separate, alternate, remote shutdown facility (RSF) with Class 1E safety-grade electronics and displays, is in close proximity to the control room located in the protected area of the reactor service building. The RSF is a seismic Category I structure with operator access provided through a seismic Category II, tornado-hardened underground tunnel connected to the control room.

The staff believes that the operator remains a critical and key element in ensuring reactor plant safety. Operators are most familiar with the control room surroundings and normally manage plant activities from there. At this time, the staff is reluctant to approve any design that would (1) increase the burden on operators managing off-normal operations, (2) increase the frequency of evacuation of the control room during design-basis accident conditions, and (3) possibly hamper the control or monitoring of upset conditions as an event sequence progresses. The staff believes human performance will still play a large role in the safety of the advanced reactor plants and that the quality of support provided by a safety-related, seismic Category I and electrical Class IE control room is appropriate. The staff also believes that any remote shutdown area should be designed to complement the main control room. Sufficient Class $1 E$ instrumentation and controls should be available to effectively manage anticipated accidents that would cause a loss of the control room functions. The location and qualification of the RSF areas should also ensure protection of the remote shutdown operations to the greatest extent possible. Therefore, the staff will apply current LWR regulations and guidance to the review of the PRISM design at this time. This will ensure that plant controls and the operators will be adequately protected so that safe shutdown can be assured in accident situations.

\subsubsection{Positive Void Reactivity Coefficient}

The existence of a positive sodium void coefficient, or any reactivity feedback effect that tends to make a postulated accident more severe, is a significant concern.

In the PRISM design, the maximum sodium void worth, according to the preapplicant, assuming only driver fuel and internal blanket assemblies void, is nominally $\$ 5.50$. If radial blankets are included, the sodium void worth is nominally $\$ 5.26$, which does not include the -69 c from the gas expansion modules (GEMs). Should sodium boiling occur on a core-wide basis, assuming failure-toscram conditions with a total loss of flow without coastdown, the reactor could experience a severe power excursion and core disruption. The predicted temperature reactivity feedback would be approximately $-80 \mathrm{c}$ preceding the onset of sodium voiding. This tends to mitigate, to some extent, the positive reactivity addition. It should be noted that for sodium voiding to occur, redundant and diverse safety-grade systems would have to experience multiple failures.

GDC 11 requires that the reactor core and coolant system be designed so that in the power operating range, the net effect of prompt inherent nuclear feedback characteristics tends to compensate for rapid increases in reactivity. The staff concludes that a positive sodium void coefficient should not necessarily disqualify a particular reactor design. However, the staff is proposing that the PRISM preapplicant analyze the consequences of events (such as anticipated transients without scram (ATWS), unscrammed loss-of-coolant accidents (LOCAs), delayed scrams, and transients affecting reactivity control) that could lead to core damage as a result of the positive void coefficient. When reviewing these analyses, the staff will take into account the overall risk perspective of the designs.

\subsubsection{Residual Heat Removal}

The PRISM design is equipped with three methods for shutdown heat removal. These are (1) condenser cooling in conjunction with the intermediate sodium and steam generator systems, (2) the auxiliary cooling system (ACS) which removes heat from the steam generator by natural convection of air after transport of heat from the core by natural convection in the primary and intermediate systems, and (3) the reactor vessel auxiliary cooling system (RVACS), which removes heat passively from the reactor containment vessel by natural convection of air.

The PRISM design uses the RVACS as the safety-grade system for removing residual heat from the reactor core. Heat generated in the reactor is transferred through the reactor vessel, across an argon gas gap, then to the outer surface of the containment vessel. The containment vessel surface is then cooled by transferring the residual heat by natural circulation in the completely passive RVACS. Cooler air from outside the plant flows downward into the below-grade reactor silo, where it is turned inward and upward to be heated by the outer surface of the containment vessel and a special collector cylinder. The heated air then flows out of the silo and is released to the atmosphere. The RVACS is completely passive and always in operation. The RVACS is proposed as a backup system to normal non-safety-grade cooling through the intermediate heat transport system, the steam generator, and the condenser. If the condenser is not available for cooling, but the intermediate sodium loop remains available, then the non-safety-grade ACS supplements the RVACS. The RVACS design-basis analysis (performed by $\mathrm{GE})$ results in high-temperature conditions, within design 
limits, for an extended period of time even if no other system is operated. However, use of the ACS in conjunction with the RVACS can limit peak coolant temperature for decay heat removal to about $15 \mathrm{~K}\left(27^{\circ} \mathrm{F}\right)$ above normal operating temperatures. According to the designer, the ACS was included in the plant to reduce the number of RVACS transients and to have this system available to cool the plant passively along with RVACS whenever there is sodium in the intermediate heat transport system.

Current LWR criteria (GDC 34) require the RHR to function using only safety-grade systems, assuming a loss of either onsite or offsite power, and assuming a single failure within the safety system. Also Regulatory Guide (RG) 1.139 (Ref. 3.14) augments GDC 34 stating that the RHR function should be capable of bringing the plant to a safe-shutdown condition within 36 hours after reactor shutdown. Branch Technical Position RSB 5-1 also states that the RHR function must be performed in a reasonable period of time following reactor shutdown.

The time required to cool the reactor down to the hot standby temperature of $561 \mathrm{~K}\left(550^{\circ} \mathrm{F}\right)$ is approximately 80 days using RVACS-only cooling, unless the ACS or normal heat removal system is restored. The safety-grade RHR system is completely passive and in continuous operation. Continuous performance monitoring of the passive system is one advantage of constant operation. The high heat capacity of the PRISM design results in longer time periods before exceeding temperature limits. However, relying solely on passive systems may lead to high-temperature challenges to the reactor vessel and reactor internal structures. Passive cooling requires larger temperature differences between the reactor and ultimate heat sink (air in the PRISM), because natural convection and radiation, the passive processes, utilize temperature difference as the driving force, eliminating the necessity for pumps, motors, and associated control equipment. However, temperatures significantly above normal operating values may exist in the vessel and internal structures for long periods of time and, therefore, creep damage may be more likely as a result of the long-term high-temperature transients.

Similar issues were identified for the RHR system of the passive LWR designs. In SECY-93-087 (Ref. 3.15), the staff discussed issues relating to the (1) ability of passive systems to reach safe shutdown, (2) definition of a passive failure, and (3) treatment of non-safety-grade systems that reduce challenges to the passive systems. The staff believes that ultimate reliance on a single, completely passive, safety-related RHR system may be acceptable. Although these issues have not been resolved, the staff proposed recommendations to the Commission for resolving them (Ref. 3.1). In perforning its detailed design evaluation, the staff will ensure that NRC regulatory treatment of non-safety-related backup RHR systems is consistent with Commission decisions on ${ }^{\prime}$ assive LWR design requirements.

\subsection{Conformance With General Design Criteria}

In this section, the staff evaluates the principal design criteria proposed by the preapplicant for the PRISM design. The differences between acceptable criteria for the PRISM design and the GDC for LWRs in Appendix A to 10 CFR Part 50 are discussed. In this section "principal design criteria" refers to the PRISM design and "general design criteria" refers to the criteria in Appendix A to 10 CFR Part 50.

This evaluation is based on a review of the following documents: (1) PSID Section 3.1 and PSID Appendices F.1, F.2, F.3, G.4.1 (containment), and PSID Section G.4.2 (shutdown system) for the PRISM design (Ref. 3.16); (2) the Commission's Advanced Reactor Policy Statement concerning GDC for advanced reactors (Ref. 3.2); (3) ANSI/ANS-54.1, "American National Standard, General Safety Design Criteria for a LiquidMetal Reactor Nuclear Power Plant, " which is an industry standard on GDC for a liquid-metal reactor (LMR) (Ref. 3.17); and (4) NUREG-0968, "Safety Evaluation Report Related to the Construction of the Clinch River Breeder Reactor Plant," dated March 1983, which evaluated the Clinch River Breeder Reactor (CRBR) design including the conformance of the design to the GDC (Ref. 3.18).

The preapplicant has also listed and discussed principal design criteria for the PRISM design in PSID Section 1.2.1. These design criteria are divided into two categories: power generation design criteria and safety design criteria. This review is not concerned with the power generation design criteria. The safety design criteria correspond to the GDC in PSID Section 3.1. They do not include all the GDC considered applicable by the preapplicant to the PRISM design (e.g., GDC 1, quality standards and records, and GDC 3 , fire protection). The safety design criteria do include additional criteria as, for example, protection against sodium/water reactions. These safety design criteria were not reviewed against the preapplicant's proposed GDC or the GDC in 10 CFR Part 50. 


\subsubsection{Review Criteria}

\subsubsection{10 CFR Part 52}

Paragraph 47(a)(1)(i) of Subpart B, "Standard Design Certification, " of 10 CFR Part 52 (Ref. 3.13) identifies the technical information that is required for construction permits and operating licenses. References to 10 CFR Part 20 (Ref. 3.19), Part 50 and its appendices (Ref. 3.6), and Parts 73 and 100 (Refs. 3.20 and 3.10) are incorporated into Part 52. Information that is technically relevant to the design and not site specific is required for an application for a standard design certification.

Section 50.34(a)(3)(i) requires that the preliminary safety analysis report for an LWR nuclear power plant design include the principal design criteria for the proposed facility. The principal design criteria establish the necessary design, fabrication, construction, testing, and performance requirements for structures, systems, and components (SSCs) of the plant design which are important to safety. These are the SSCs that provide reasonable assurance that the plant can be operated without undue risk to the health and safety of the public. The GDC in Appendix A to 10 CFR Part 50 established minimum requirements for the principal design criteria for LWR nuclear power plants similar in design to plants for which construction permits have been issued by the Commission (i.e., the current-generation of LWRs).

\subsubsection{Commission's Advanced Reactor Policy Statement}

The Commission stated, in its final policy statement (Ref. 3.2) on advanced reactors, that (1) the advanced reactors are to have at least the same degree of protection of the public and the environment that is required for current-generation LWRs, (2) the advanced reactor designers are encouraged to propose design criteria, and (3) the GDC for the advanced reactor designs should use LWR regulations where they are applicable to the design. In the Commission's response to Question 4 in the Final Policy Statement, the Commission stated that it intended to use existing LWR regulations where they are applicable to the designs. The advanced reactor designers were also encouraged to propose specific criteria and novel regulatory approaches which apply to their designs.

The PRISM design is not an LWR design. It is an advanced liquid-metal reactor (LMR) design. The PRISM design is considered an advanced reactor because it is significantly different from the then-current-generation LWRs under construction or in operation, and uses simplified inherent or other innovative means to accomplish safety functions. The Commission's final policy statement and matters such as the use of the GDC for the advanced reactor designs are discussed in NUREG-1226 (Ref. 3.3).

The preapplicant, in PSID Section 3.1, has proposed principal design criteria for the PRISM design. These principal criteria were compared to the GDC to show where the GDC are applicable to the PRISM design and where they are not applicable. This comparison also assisted the staff in determining if the PRISM design has at least the same degree of protection that is required of current-generation LWRs (i.e., Item (1) above).

\subsubsection{Clinch River Breeder Reactor Plant Review}

Before the Commission issued the Advanced Reactor Policy Statement, the principal Commission statement on advanced reactor review policy was given in the introduction to the GDC. In this introduction, it is stated that the GDC are considered to be generally applicable to nuclear power plants other than LWRs and are intended to provide guidance in establishing the principal design criteria for such other plants. This led to the "comparable level of safety" philosophy under which non-LWR designs were reviewed by NRC before the Advanced Reactor Policy Statement; that is, a comparable level of safety would be established for all reactor types, with the recognition that the licensing criteria for the non-LWR reactors would be developed using the criteria for LWRs to the extent practicable. The wording "comparable level of safety" is the same as the later "same degree of protection" used in the Commission's Advanced Reactor Policy Statement.

The implementation of the "comparable level of safety" philosophy in reviews of non-LWR designs by NRC took three forms with respect to the GDC: direct adoption, suitable adaptation, and recognition of the need for and development of new specialized criteria. Direct adoption of the existing criteria has been possible in many instances and has provided a means of ensuring a comparable level of safety for new reactor designs.' An example of such a review of a non-LWR design is the NRC review of the sodium-cooled Clinch River Breeder Reactor Plant (CRBRP), even though the plant was never constructed. The CRBRP, like the PRISM design, is a sodium-cooled LMR. A safety evaluation report (Ref. 3.18) documented the evaluation by the staff of the CRBRP design, including the conformance of the CRBRP design to the GDC.

The positions proposed by the preapplicant for the PRISM principal design criteria were compared in this report to the positions taken by the NRC staff on the principal 


\section{Review Approach and Criteria}

design criteria for the CRBRP design in NUREG-0968. This comparison was performed to use applicable work completed by the staff on principal design criteria for another LMR to assist in determining if the PRISM design has the "same degree of protection" required by the Commission's Advanced Reactor Policy Statement.

\subsubsection{Industry Standard ANSI/ANS-54.1}

The nuclear industry standard, ANSI/ANS-54.1-1989 (Ref. 3.17), was written to establish GDC (Criteria 3.1.1 to 3.6.5) for large-loop and pool-type LMRs as well as small modular reactors. The standard was developed with the emphasis placed on retaining the GDC wherever the criterion is applicable to the LMR design. Changes and deletions to the GDC were made only to reflect the unique characteristics of the LMRs. The CRBRP licensing experience and the passive heat removal systems being developed for the PRISM design have been factored into the standard.

The approach taken in ANSI/ANS-54.1 is consistent with the approach taken by the Commission in its Advanced Reactor Policy Statement. Because the standard applies to LMRs similar to the modular, pool-type PRISM design, and because it incorporates the CRBRP licensing experience and the passive heat removal systems of the PRISM design, the standard is applicable to the PRISM design. The preapplicant's proposed principal design criteria for the PRISM design have been compared to the positions taken in this standard.

\subsubsection{Evaluation}

The evaluation of the preapplicant's proposed principal design criteria for the PRISM design provides guidance for a set of principal design criteria. These criteria would express broad requirements that the designer must meet to ensure that the safety of the PRISM design would be at least that required of the current-generation LWRs. As discussed in Section 3.1.1 of this report, this would be only one set of requirements that the designer must meet to ensure this minimum level of safety. The resulting criteria would then represent the minimum requirements for principal design criteria acceptable to the staff for the
PRISM design and would provide the point of departure for the development of detailed engineering criteria for the final PRISM design.

The preapplicant compared the GDC to the specific PRISM design and decided whether or not a system was needed for the design to meet the criteria. If it was determined that no system was required, then the preapplicant concluded that the GDC was not applicable to the PRISM design. The staff took a broader view and considered whether the GDC should be applicable to any LMR design or to a possible revised PRISM design where the systems were changed.

The preapplicant's proposed principal design criteria for the PRISM are compared to the GDC, the criteria in NUREG-0968, and ANSI/ANS-54.1-1989. Because the minimum design requirements for the current-generation LWRs are the GDC, the results of this comparison will provide one part of the basis for the NRC staff to conclude that the PRISM design will or will not provide at least the same degree of protection that is required of currentgeneration LWRs. This comparison will not be sufficient in itself because the PRISM design (1) may require additional GDC to those provided in 10 CFR Part 50 and (2) will require a review of margins in the design compared to LWRs as, for example, fuel design and earthquake design limits, and the potential consequences of postulated accidents. See the discussion in Section 3.1.1 of this report on the criteria directed toward ensuring a level of safety for the PRISM design at least equivalent to that of LWRs.

In some cases, NUREG-0968 and ANSI/ANS-54.1-1989 have additional criteria not in the GDC. The preapplicant will be requested to address why the additional criteria are not included in the principal design criteria for the PRISM design.

The preapplicant's proposed principal design criteria will be considered in the order of the GDC and discussed in terms of the exceptions taken by the preapplicant for the PRISM design to the requirements in the GDC. A summary of this evaluation is given in Tables 3.1 through 3.3. 
Review Approach and Criteria

Table 3.1 GDC applicable to the PRISM design, by GDC number

\begin{tabular}{|c|c|c|}
\hline GDC Categories & $\begin{array}{l}\text { Staff Evaluations by } \\
\text { GDC Number }\end{array}$ & $\begin{array}{c}\text { Preapplicant Proposal } \\
\text { by GDC Number }\end{array}$ \\
\hline $\begin{array}{l}\text { GDC directly } \\
\text { applicable }\end{array}$ & $\begin{array}{l}1,2,3,5,10,11,12,13,14 \\
16,18,20,21,22,24,29,30 \\
32,42,43,52,53,54,56,60 \\
62, \text { and } 63\end{array}$ & $\begin{array}{l}1,2,3,5,10,11,12,13, \\
14,15,16,17,18,20,21, \\
22,23,24,25,26,29,30, \\
31,32,34,38,40,52,53, \\
54,56,60,61,62,63,64\end{array}$ \\
\hline GDC applicable but needing changes & $\begin{array}{l}4,15,17,19,23,25,26,27 \\
28,31,34,36,37,38,39,40 \\
41,44,45,46,50,51,55,57 \\
61, \text { and } 64\end{array}$ & $4,19,27,28,39,50$, and 51 \\
\hline GDC not applicable & $33^{19}$ and 35 & $\begin{array}{l}33,35,36,37,41,42,43 \\
44,45,46,55, \text { and } 57\end{array}$ \\
\hline Possible additional criteria & $\begin{array}{l}\text { Sections 3.2.4.1, 3.2.4.2, and } \\
\text { 3.2.4.6 }\end{array}$ & None \\
\hline $\begin{array}{l}\text { GDC for which the NRC staff agrees with } \\
\text { the preapplicant }\end{array}$ & $\begin{array}{l}1,2,3,5,10,11,12,13,14 \\
16,18,20,21,22,24,29,30 \\
32,35,39,51,52,53,54,56 \\
60,62, \text { and } 63\end{array}$ & \\
\hline $\begin{array}{l}\text { GDC for which the NRC staff requests the } \\
\text { preapplicant to address changes to its position } \\
\text { during the preliminary design phase on the } \\
\text { GDC }\end{array}$ & $\begin{array}{l}4,15,17,19,23,25,26,27 \\
28,31,33^{14}, 34,36,37,38 \\
40,41,42,43,44,45,46,50 \\
55,57,61, \text { and } 64\end{array}$ & \\
\hline
\end{tabular}


Table 3.2 Summary evaluation of GDC

\begin{tabular}{|c|c|c|c|c|}
\hline GDC Number/Title & $\begin{array}{c}\text { GDC } \\
\text { Directly } \\
\text { Applicable }\end{array}$ & $\begin{array}{c}\text { GDC } \\
\text { Applicable } \\
\text { With } \\
\text { Revisionssiv }\end{array}$ & $\begin{array}{c}\text { GDC } \\
\text { Not } \\
\text { Applicable }^{\text {Iy }}\end{array}$ & $\begin{array}{c}\text { Staff/ } \\
\text { Preapplicant } \\
\text { Position } \\
\text { on the } \\
\text { GDC } \\
\end{array}$ \\
\hline & Staff/Preapp. & Staff/Preapp. & Staff/Preapp. & \\
\hline \multicolumn{5}{|l|}{ I Overall Requirements; } \\
\hline 1-Quality Standards and Records & $x / x$ & & & Agreement \\
\hline $\begin{array}{l}2 \text { - Design Bases for Protection Against } \\
\text { Natural Phenomena }\end{array}$ & $\mathbf{x} / \mathbf{x}$ & & & Agreement \\
\hline 3- Fire Protection & $x / x$ & & & Agreement \\
\hline $\begin{array}{l}4 \text { - Environmental and Dynamic Effects } \\
\text { Design Bases }\end{array}$ & & $x / x$ & & Disagreement \\
\hline $\begin{array}{l}5 \text { - Sharing of Structures, Systems, and } \\
\text { Components }\end{array}$ & $x / x$ & & & Agreement \\
\hline \multicolumn{5}{|l|}{$\begin{array}{l}\text { II Protection by Multiple } \\
\text { Fission Product Barriers: }\end{array}$} \\
\hline 10 - Reactor Design & $\mathbf{x} / \mathbf{x}$ & & & Agreement \\
\hline 11 - Reactor Inherent Protection & $\mathbf{x} / \mathbf{x}$ & & & Agreement \\
\hline $\begin{array}{l}12 \text { - Suppression of Reactor Power } \\
\text { Oscillations }\end{array}$ & $x / x$ & & & Agreement \\
\hline 13 - Instrumentation and Control & $x / x$ & & & Agreement \\
\hline 14-Reactor Coolant Pressure Boundary & $x / x$ & & & Agreement \\
\hline 15 - Reactor Coolant System Design & $1 x$ & $\mathrm{x} /$ & & Disagreement \\
\hline 16 - Containment Design & $x / x$ & & & Agreement \\
\hline 17 - Electric Power System & $1 x$ & $\mathbf{x} 1$ & & Disagreement \\
\hline $\begin{array}{l}18 \text { - Inspection and Testing of Electric Power } \\
\text { Systems }\end{array}$ & $x / x$ & & & Agreement \\
\hline 19 - Control Room & & $x / x$ & & Disagreement \\
\hline
\end{tabular}


Table 3.2 (continued) Summary evaluation of GDC

\begin{tabular}{|c|c|c|c|c|}
\hline GDC Number/Title & $\begin{array}{c}\text { GDC } \\
\text { Directly } \\
\text { Applicable }{ }^{\text {Iy }}\end{array}$ & $\begin{array}{l}\text { GDC } \\
\text { Applicable } \\
\text { With } \\
\text { Revisions }^{(n)}\end{array}$ & $\begin{array}{c}\text { GDC } \\
\text { Not } \\
\text { Applicable }\end{array}$ & $\begin{array}{c}\text { Staff/ } \\
\text { Preapplicant } \\
\text { Position } \\
\text { on the } \\
\text { GDC } \\
\end{array}$ \\
\hline & Staff/Preapp. & Staff/Preapp. & Staff/Preapp. & \\
\hline \multicolumn{5}{|l|}{$\begin{array}{l}\text { III Protection and Reactivity Control } \\
\text { Systems }\end{array}$} \\
\hline 20 - Protection System Functions & $x / x$ & & & Agreement \\
\hline $\begin{array}{l}21 \text { - Protection System Reliability and } \\
\text { Testability }\end{array}$ & $x / x$ & & & Agreement \\
\hline 22 - Protection System Independence & $x / x$ & & & Agreement \\
\hline 23 - Protection System Failure Modes & $1 x$ & $\mathbf{x} 1$ & & Disagreement \\
\hline $\begin{array}{l}24 \text { - Separation of Protection and Control } \\
\text { Systems }\end{array}$ & $\mathbf{x} / \mathbf{x}$ & & & Agreement \\
\hline $\begin{array}{l}25 \text { - Protection System Requirements for } \\
\text { Reactivity Control Malfunctions } \\
\end{array}$ & / $x$ & $\mathbf{x} /$ & & Disagreement \\
\hline $\begin{array}{l}26 \text { - Reactivity Control System Redundancy } \\
\text { and Capability }\end{array}$ & / $x$ & $\mathbf{x} 1$ & & Disagreement \\
\hline $\begin{array}{l}27 \text { - Combined Reactivity Control Systems } \\
\text { Capability }\end{array}$ & & $x / x$ & & Disagreement \\
\hline 28 - Reactivity Limits & & $\mathbf{x} / \mathbf{x}$ & & Disagreement \\
\hline $\begin{array}{l}29 \text { - Protection Against Anticipated } \\
\text { Operational Occurrences }\end{array}$ & $\mathbf{x} / \mathbf{x}$ & & & Agreement \\
\hline \multicolumn{5}{|l|}{ IV Fluid Systems } \\
\hline $\begin{array}{l}30 \text { - Quality of Reactor Coolant Pressure } \\
\text { Boundary }\end{array}$ & $x / x$ & & & Agreement \\
\hline $\begin{array}{l}\text { 31 - Fracture Prevention of Reactor } \\
\text { Coolant Pressure Boundary }\end{array}$ & / $x$ & $\mathbf{x} /$ & & Disagreement \\
\hline $\begin{array}{l}32 \text { - Inspection of Reactor Coolant Pressure } \\
\text { Boundary }\end{array}$ & $x / x$ & & & Agreement \\
\hline 33 - Reactor Coolant Makeup & & & $\mathbf{x} / \mathbf{x}$ & Disagreement \\
\hline 34 - Residual Heat Removal & $1 x$ & $\mathbf{x} 1$ & & Disagreement \\
\hline
\end{tabular}


Table 3.2 (continued) Summary evaluation of GDC

\begin{tabular}{|c|c|c|c|c|}
\hline GDC Number/Title & $\begin{array}{c}\text { GDC } \\
\text { Directly } \\
\text { Applicablely }\end{array}$ & $\begin{array}{l}\text { GDC } \\
\text { Applicable } \\
\text { With } \\
\text { Revisions' }^{\text {M }}\end{array}$ & $\begin{array}{c}\text { GDC } \\
\text { Not } \\
\text { Applicable }{ }^{\top}\end{array}$ & $\begin{array}{c}\text { Staff/ } \\
\text { Preapplicant } \\
\text { Position } \\
\text { on the } \\
\text { GDC } \\
\end{array}$ \\
\hline IV Fuid Systems_(cont.) & Staff/Preapp. & Staff/Preapp. & Staff/Preapp. & \\
\hline 35 - Emergency Core Cooling & & & $x / x$ & Agreement \\
\hline $\begin{array}{l}36 \text { - Inspection of Emergency Core Cooling } \\
\text { System }\end{array}$ & & $\mathbf{x} 1$ & $/ x$ & Disagreement \\
\hline $\begin{array}{l}37 \text { - Testing of Emergency Core Cooling } \\
\text { System }\end{array}$ & & $\mathbf{x} /$ & / $x$ & Disagreement \\
\hline 38 - Containment Heat Removal & $1 x$ & $\mathbf{x} 1$ & & Disagreement \\
\hline $\begin{array}{l}39 \text { - Inspection of Containment Heat } \\
\text { Removal System }\end{array}$ & & $x / x$ & & Agreement \\
\hline $\begin{array}{l}40 \text { - Testing of Containment Heat Removal } \\
\text { System }\end{array}$ & / $x$ & $\mathbf{x} /$ & $1:$ & Disagreement \\
\hline 41 - Containment Atmosphere Cleanup & & $\mathbf{x} 1$ & $1 x$ & Disagreement \\
\hline $\begin{array}{l}42 \text { - Inspection of Containment Atmosphere } \\
\text { Cleanup Systems }\end{array}$ & $\mathbf{x} /$ & & / $x$ & Disagreement \\
\hline $\begin{array}{l}43 \text { - Testing of Containment Atmosphere } \\
\text { Cleanup Systems }\end{array}$ & $\mathbf{x} /$ & & $1 \mathrm{x}$ & Disagreement \\
\hline 44 - Cooling Water & & $\mathbf{x} 1$ & $1 \mathrm{x}$ & Disagreement \\
\hline 45 - Inspection of Cooling Water System & & $\mathbf{x} 1$ & $1 x$ & Disagreement \\
\hline 46 - Testing of Cooling Water System & & $\mathbf{x} /$ & $1 \mathrm{x}$ & Disagreement \\
\hline \multicolumn{5}{|l|}{ y Reactor Containment: } \\
\hline 50 - Containment Design Basis & & $\mathbf{x} / \mathbf{x}$ & & Disagreement \\
\hline $\begin{array}{l}51 \text { - Fracture Prevention of Containment } \\
\text { Pressure Boundary }\end{array}$ & & $x / x$ & & Agreement \\
\hline $\begin{array}{l}52 \text { - Capability for Containment Leakage } \\
\text { Rate Testing }\end{array}$ & $\mathbf{x} / \mathbf{x}$ & & & Agreement \\
\hline $\begin{array}{l}53 \text { - Provisions for Containment Testing } \\
\text { and Inspection }\end{array}$ & $\mathbf{x} / \mathbf{x}$ & & & Agreement \\
\hline
\end{tabular}


Table 3.2 (continued) Summary evaluation of GDC

\begin{tabular}{|c|c|c|c|c|}
\hline GDC Number/Title & $\begin{array}{c}\text { GDC } \\
\text { Directly } \\
\text { Applicable }{ }^{\prime y}\end{array}$ & $\begin{array}{l}\text { GDC } \\
\text { Applicable } \\
\text { With } \\
\text { Revisions }\end{array}$ & $\begin{array}{c}\text { GDC } \\
\text { Not } \\
\text { Applicable }\end{array}$ & $\begin{array}{l}\text { Staff/ } \\
\text { Preapplicant } \\
\text { Position } \\
\text { on the } \\
\text { GDC } \\
\end{array}$ \\
\hline V Renctor Containment (cont.): & Staff/Preapp. & Staff/Preapp. & Staff/Preapp. & \\
\hline 54 - Piping Systems Penetrating Containment & $x / x$ & & & Agreement \\
\hline $\begin{array}{l}55 \text { - Reactor Coolant Pressure Boundary } \\
\text { Penetrating Containment } \\
\end{array}$ & & $\mathbf{X} /$ & I $\mathrm{x}$ & Disagreement \\
\hline 56 - Primary Containment Isolation & $x / x$ & & & Agreement \\
\hline 57 - Closed System Isolation Valves & & $\mathbf{x} 1$ & $1 x$ & Disagreement \\
\hline \multicolumn{5}{|l|}{ VI Iuel and Radioactive Control: } \\
\hline $\begin{array}{l}60 \text { - Control of Releases of Radioactive } \\
\text { Materials to the Environment }\end{array}$ & $\mathbf{x} / \mathbf{x}$ & & & Agreement \\
\hline $\begin{array}{l}61 \text { - Fuel Storage and Handling and } \\
\text { Radioactivity Control }\end{array}$ & I $x$ & $\mathbf{X} /$ & & Disagreement \\
\hline $\begin{array}{l}62-\text { Prevention of Criticality in Fuel Storage } \\
\text { and Handling }\end{array}$ & $x / x$ & & & Agreement \\
\hline 63 - Monitoring Fuel and Waste Storage & $x / x$ & & & Agreement \\
\hline 64 - Monitoring Radioactivity Releases & $1 x$ & $\mathbf{x} /$ & & Disagreement \\
\hline
\end{tabular}

-An " $\mathrm{X"}$ " indicates that the staff and/or the preapplicant have concluded that there is a basis to consider that the specific GDC of 10 CFR Part 50 is in the category represented by the column.

"Agreement" indicates that the staff and the preapplicant are in agreement with the applicability of the GDC to the PRISM design and all the changes that have been proposed for the GDC: "Disagreement" means that the staff and the preapplicant are NOT in agreement. 
Table 3.3 Summary of (1) changes proposed for and (2) recommended additional general design criteria

\begin{tabular}{|c|c|c|}
\hline GDC Number/Title & $\begin{array}{l}\text { Staff/Preapplicant } \\
\text { Position on the } \\
\text { GDC }\end{array}$ & $\begin{array}{c}\text { Changes Proposed by NRC Staff } \\
\text { to Revise the GDC }\end{array}$ \\
\hline \multicolumn{3}{|l|}{ I Overall Requirements: } \\
\hline $\begin{array}{l}\text { 4- Environmental and Dynamic } \\
\text { Effects Design Bases }\end{array}$ & Disagreement & $\begin{array}{l}\text { Delete the last sentence of the GDC, add a phrase at } \\
\text { the end of the first sentence stating "including the } \\
\text { effects of sodium and its aerosols and combustion } \\
\text { products," and delete the phrase "including loss-of- } \\
\text { coolant accidents" from the sentence. }\end{array}$ \\
\hline \multicolumn{3}{|l|}{$\begin{array}{l}\text { II Protection by Multiple } \\
\text { Fission Product Barriers: }\end{array}$} \\
\hline $\begin{array}{l}15 \text { - Reactor Coolant System } \\
\text { Design }\end{array}$ & Disagreement & $\begin{array}{l}\text { Add the phrase, "sodium heating system," to the list } \\
\text { of systems associated with the reactor coolant system. }\end{array}$ \\
\hline 16 - Containment Design & Agreement & $\begin{array}{l}\text { Incorporate the Commission's decision on the } \\
\text { containment leak rate policy issue submitted in Policy } \\
\text { Issues Paper }{ }^{(1)} \text {. }\end{array}$ \\
\hline 17 - Electric Power System & Disagreement & $\begin{array}{l}\text { Add the phrase "normal operation, including" to the } \\
\text { words "anticipated operational occurrences" in Item } \\
\text { (1) of the GDC. }\end{array}$ \\
\hline 19 - Control Room & Disagreement & $\begin{array}{l}\text { Delete the phrase "including loss-of-coolant } \\
\text { accidents" after accident conditions in the first } \\
\text { sentence, delete the word "adequate" from the phrase } \\
\text { "adequate radiation protection shall be provided," add } \\
\text { the phrase "including those conditions from sodium } \\
\text { reactions" to the first sentence, and revise the } \\
\text { reference to cold shutdown in Item (2) of the GDC. }\end{array}$ \\
\hline \multicolumn{3}{|l|}{$\begin{array}{l}\text { III Protection and Reactivity } \\
\text { Control Systems: }\end{array}$} \\
\hline $\begin{array}{l}23 \text { - Protection System Failure } \\
\text { Modes }\end{array}$ & Disagreement & $\begin{array}{l}\text { Add the phrase "sodium and sodium reaction } \\
\text { products" to the list of adverse environments in the } \\
\text { GDC. }\end{array}$ \\
\hline $\begin{array}{l}25 \text { - Protection System } \\
\text { Requirements for Reactivity } \\
\text { Control Malfunctions }\end{array}$ & Disagreement & $\begin{array}{l}\text { Delete the phrase "(rod ejection or dropout)" of } \\
\text { control rods in the last line of the GDC. }\end{array}$ \\
\hline
\end{tabular}




\section{Review Approach and Criteria}

Table 3.3 (continued) Summary of (1) changes proposed for and (2) recommended additional general design criteria

\begin{tabular}{|c|c|c|}
\hline GDC Number/Title & $\begin{array}{c}\text { Staff/Preapplicant } \\
\text { Position on the } \\
\text { GDC }\end{array}$ & $\begin{array}{c}\text { Changes Proposed by NRC Staff } \\
\text { to Revise the GDC }\end{array}$ \\
\hline \multicolumn{3}{|l|}{$\begin{array}{l}\text { III Protection and Reactivity } \\
\text { Control Systems (cont.): }\end{array}$} \\
\hline $\begin{array}{l}26 \text { - Reactivity Control System } \\
\text { Redundancy and Capability }\end{array}$ & Disagreement & $\begin{array}{l}\text { Incorporate the Commission's decision on the control } \\
\text { rods policy issue submitted in Policy Issues Paper }{ }^{111} \text {, } \\
\text { delete the phrase "(including xenon burnup)" in the } \\
\text { second sentence and the second to the last sentence of } \\
\text { the GDC, replace the phrase "cold conditions" in the last } \\
\text { sentence to that of conditions where the coolant } \\
\text { temperature is lower than normal operating conditions, } \\
\text { and add additional sentences discussed in } \\
\text { Section 3.2.4.22. }\end{array}$ \\
\hline $\begin{array}{l}27 \text { - Combined Reactivity } \\
\text { Control Systems Capability }\end{array}$ & Disagreement & $\begin{array}{l}\text { Delete the phrase "in conjunction with poison addition } \\
\text { by the emergency core cooling system" }\end{array}$ \\
\hline 28 - Reactivity Limits & Disagreement & $\begin{array}{l}\text { Delete the words "rod dropout" and "steam line rupture" } \\
\text { from the list of postulated accidents listed in the last } \\
\text { sentence and replace "rod ejection" and "cold water } \\
\text { addition" by "accidental withdrawal of control rod(s)" } \\
\text { and "cold sodium addition" in the list of postulated } \\
\text { accidents, of the GDC. }\end{array}$ \\
\hline \multicolumn{3}{|l|}{ IV Fluid Systems: } \\
\hline $\begin{array}{l}\text { 31 - Fracture Prevention of } \\
\text { Reactor Coolant Pressure } \\
\text { Boundary }\end{array}$ & Disagreement & $\begin{array}{l}\text { Add the phrase "effects of coolant chemistry" to the } \\
\text { phrase "effects of irradiation on material properties" in } \\
\text { the list of four items at the end of the GDC, and add the } \\
\text { words "service degradation of properties, creep, fatigue, } \\
\text { stress rupture" between "service temperature" and "other } \\
\text { conditions of the boundary material" in the second } \\
\text { sentence of the GDC. }\end{array}$ \\
\hline 33 - Reactor Coolant Makeup & Disagreement & $\begin{array}{l}\text { Replace the GDC by Criterion } 27 \text { in NUREG- } 0968^{[3]} \\
\text { and Criterion 3.4.1 of ANSI/ANS-54.1-1989 }\end{array}$ \\
\hline
\end{tabular}


Table 3.3 (continued) Summary of (1) changes proposed for and (2) recommended additional general design criteria

\begin{tabular}{|c|c|c|}
\hline GDC Number/Title & $\begin{array}{c}\text { Staff/Preapplicant } \\
\text { Position on the } \\
\text { GDC }\end{array}$ & $\begin{array}{c}\text { Changes Proposed by NRC Staff } \\
\text { to Revise the GDC }\end{array}$ \\
\hline \multicolumn{3}{|l|}{ IV Fluid Systems (cont.): } \\
\hline 34 - Residual Heat Removal & Disagreement & $\begin{array}{l}\text { Incorporate the Commission's decision on single, } \\
\text { passive safety-related systems which is a policy issue } \\
\text { submitted in Policy Issues Paper }{ }^{(1)} \text {, add the phrase } \\
\text { "under all plant shutdown conditions following } \\
\text { normal operation, including anticipated operational } \\
\text { occurrences, and postulated accidents conditions" to } \\
\text { the second sentence, add the phrases "a passive } \\
\text { boundary shall normally separate reactor coolant from } \\
\text { the working fluids of the reactor residual heat } \\
\text { extrication system" and "any fluid in the residual heat } \\
\text { extrication system that is separated from the reactor } \\
\text { coolant by a single passive barrier shall not be } \\
\text { chemically reactive with the reactor coolant" to the } \\
\text { first paragraph, and add a statement that the working } \\
\text { fluid of the residual heat extrication system will be at } \\
\text { a higher pressure than the reactor coolant system. }\end{array}$ \\
\hline 35 - Emergency Core Cooling & Agreement & $\begin{array}{l}\text { To consider this GDC is not applicable to } \\
\text { LMR/PRISM designs, GDC } 34 \text { must be revised to } \\
\text { add a reference to the residual heat removal system } \\
\text { being designed for postulated accidents. }\end{array}$ \\
\hline $\begin{array}{l}36 \text { - Inspection of Emergency Core } \\
\text { Cooling System }\end{array}$ & Disagreement & $\begin{array}{l}\text { Replace the references to emergency core cooling, } \\
\text { including the title, to that of residual heat removal } \\
\text { system, and change the list of important components. }\end{array}$ \\
\hline $\begin{array}{l}37 \text { - Testing of Emergency Core } \\
\text { Cooling System }\end{array}$ & Disagreement & $\begin{array}{l}\text { Replace the references to emergency core cooling, } \\
\text { including the title, to that of residual heat removal } \\
\text { system, and delete the phrase "and the operation of } \\
\text { the associated cooling water system". }\end{array}$ \\
\hline 38 - Containment Heat Removal & Disagreement & $\begin{array}{l}\text { Replace the reference to LOCAs by a references to } \\
\text { postulated accidents. }\end{array}$ \\
\hline
\end{tabular}


Table 3.3 (continued) Summary of (1) changes proposed for and

(2) recommended additional general design criteria

\begin{tabular}{|c|c|c|}
\hline GDC Number/Title & $\begin{array}{l}\text { Staff/Preapplicant } \\
\text { Position on the } \\
\text { GDC }\end{array}$ & $\begin{array}{c}\text { Changes Proposed by NRC Staff } \\
\text { to Revise the GDC }\end{array}$ \\
\hline \multicolumn{3}{|l|}{ IV Fluid Systems (cont.): } \\
\hline $\begin{array}{l}39 \text { - Inspection of Containment } \\
\text { Heat Removal System }\end{array}$ & Agreement & $\begin{array}{l}\text { Delete references to a torus and sumps and add } \\
\text { pumps to the list of examples of important } \\
\text { components. }\end{array}$ \\
\hline $\begin{array}{l}40 \text { - Testing of Containment Heat } \\
\text { Removal System }\end{array}$ & Disagreement & $\begin{array}{l}\text { Delete the word "water" from the phrase "cooling } \\
\text { water system." }\end{array}$ \\
\hline $\begin{array}{l}41 \text { - Containment Atmosphere } \\
\text { Cleanup }\end{array}$ & Disagreement & $\begin{array}{l}\text { Add the phrases "sodium aerosols" and "combustion } \\
\text { products," and add the phrase that the containment } \\
\text { cleanup systems should consider "the effects of } \\
\text { sodium leakage and its potential reaction with oxygen } \\
\text { and its potential for hydrogen generation when in } \\
\text { contact with concrete," to the first sentence of the } \\
\text { GDC. }\end{array}$ \\
\hline 44 - Cooling Water & Disagreement & $\begin{array}{l}\text { Change the title to "structural and equipment cooling" } \\
\text { and add the phrase "as necessary" to the end of the } \\
\text { first sentence of the GDC. }\end{array}$ \\
\hline $\begin{array}{l}45 \text { - Inspection of Cooling Water } \\
\text { System }\end{array}$ & Disagreement & $\begin{array}{l}\text { Change the title to "inspection of structural and } \\
\text { equipmant cooling" and delete the word "water" from } \\
\text { the phrase "cooling water system" in the first } \\
\text { sentence of the GDC. }\end{array}$ \\
\hline $\begin{array}{l}46 \text { - Testing of Cooling Water } \\
\text { System }\end{array}$ & Disagreement & $\begin{array}{l}\text { Change the title to "testing of structural and } \\
\text { equipment cooling," delete the word "water" from the } \\
\text { phrase "cooling water system" in the first sentence, } \\
\text { and delete the phrase "for reactor shutdown and for } \\
\text { loss-of-coolant accidents" in Item } 3 \text { of the GDC. }\end{array}$ \\
\hline \multicolumn{3}{|l|}{ V Reactor Containment: } \\
\hline 50 - Containment Design Basis & Disagreement & $\begin{array}{l}\text { Delete reference to } 10 \text { CFR } 50.44^{(2)} \text { in Item } 1 \text { replace } \\
\text { reference to LOCAs with "postulated accidents, " and } \\
\text { replace metal-water and other chemical reactions } \\
\text { from a degraded ECCS with "fission products, } \\
\text { potential spray or aerosol formation, and potential } \\
\text { exothermic chemical reactions" at the end of Item } 1 \\
\text { of the GDC. }\end{array}$ \\
\hline
\end{tabular}


Table 3.3 (continued) Summary of (1) changes proposed for and

(2) recommended additional general design criteria

\begin{tabular}{|c|c|c|}
\hline GDC Number/Title & $\begin{array}{l}\text { Stafr/Preapplicant } \\
\text { Position on the } \\
\text { GDC }\end{array}$ & $\begin{array}{c}\text { Changes Proposed by NRC Staff } \\
\text { to Revise the GDC }\end{array}$ \\
\hline \multicolumn{3}{|l|}{ V Reactor Containment (cont.): } \\
\hline $\begin{array}{l}51 \text { - Fracture Prevention of } \\
\text { Containment Pressure } \\
\text { Boundary } \\
\end{array}$ & Agreement & $\begin{array}{l}\text { Replace the phrase "ferritic materials" with "metallic } \\
\text { materials." }\end{array}$ \\
\hline $\begin{array}{l}55 \text { - Reactor Coolant Pressure } \\
\text { Boundary Penetrating } \\
\text { Containment } \\
\end{array}$ & Disagreement & $\begin{array}{l}\text { Add the phrase "or the reactor cover gas boundary" } \\
\text { to the first sentence of the GDC. }\end{array}$ \\
\hline $\begin{array}{l}57 \text { - Closed System Isolation } \\
\text { Valves }\end{array}$ & Disagreement & $\begin{array}{l}\text { Add the phrase "or cover gas boundaries" to the end } \\
\text { of the phrase "neither part of nor directly connected } \\
\text { to the reactor coolant pressure boundary" in the first } \\
\text { sentence of the GDC. }\end{array}$ \\
\hline \multicolumn{3}{|l|}{$\begin{array}{l}\text { VI Fuel and Radioactivity } \\
\text { Control: }\end{array}$} \\
\hline $\begin{array}{l}61 \text { - Fuel Storage and Handling } \\
\text { and Radioactivity Control }\end{array}$ & Disagreement & $\begin{array}{l}\text { Add a sentence that "The fuel handling and its } \\
\text { interfacing systems shall be designed to minimize the } \\
\text { potential for fuel handling errors that could result in } \\
\text { fuel damage." }\end{array}$ \\
\hline $\begin{array}{l}64 \text { - Monitoring Radioactivity } \\
\text { Releases }\end{array}$ & Disagreement & $\begin{array}{l}\text { Delete the phrase "spaces containing components for } \\
\text { recirculation of loss-of-coolant accident fluids." }\end{array}$ \\
\hline \multicolumn{3}{|l|}{ Possible New Criteria: } \\
\hline $\begin{array}{l}\text { Criterion 3.2.5.1 - Protection } \\
\text { Against Sodium Reactions }\end{array}$ & & $\begin{array}{l}\text { This criterion would involve designing the SSCs to } \\
\text { limit the consequences of chemical reactions resulting } \\
\text { from a sodium leak. It should reference ANS 54.8- } \\
1988^{[3]} \text {. This is Criterion } 4 \text { of NUREG-0968 } \\
\text { Criterion } 3.1 .4 \text { of ANSI/ANS-54.1-1989 } \\
\text { C. }\end{array}$ \\
\hline
\end{tabular}


Table 3.3 (continued) Summary of (1) changes proposed for and (2) recommended additional general design criteria

\begin{tabular}{|c|c|c|}
\hline GDC Number/Title & $\begin{array}{c}\text { Staff/Preapplicant } \\
\text { Position on the } \\
\text { GDC }\end{array}$ & $\begin{array}{c}\text { Changes Proposed by NRC Staff } \\
\text { to Revise the GDC }\end{array}$ \\
\hline $\begin{array}{l}\text { Section 3.2.5.2 - Sodium } \\
\text { Heating System }\end{array}$ & & $\begin{array}{l}\text { This criterion would concern heating systems needed } \\
\text { to maintain the coolant in liquid form and to prevent } \\
\text { aerosols from condensing and plugging flow paths } \\
\text { important to safety. This is Criterion } 7 \text { of } \\
\text { NUREG-0968 }{ }^{[/]} \text {and Criterion } 3.1 .7 \text { of } \\
\text { ANSI/ANS-54.1-1989 }\end{array}$ \\
\hline \multicolumn{3}{|c|}{$\begin{array}{l}\text { U.S. Nuclear Regulatory Commission, "Policy Issue," SECY-93-092, April 8, } 1993 . \\
\text { Code of Federal Regulations, Part 50, "Energy," January 1993. } \\
\text { American Nuclear Society, ANS 54.8-1988, "Liquid Metal Fire Protection in LMR Plants." } \\
\text { U.S. Nuclear Regulatory Commission, NUREG-0968, "Safety Evaluation Report Related to the } \\
\text { Construction of the Clinch River Breeder Reactor Plant," March 1983. } \\
\text { American National Standards Institute/American Nuclear Society, ANSI/ANS-54.1-1989, "General Safety } \\
\text { Design Criteria for Liquid Metal Reactor Nuclear Power Plants," April 1989. }\end{array}$} \\
\hline
\end{tabular}

Table 3.1 presents the GDC by numbers (i.e., the titles of the GDC are not given) that would be in one or more of the following categories:

(1) GDC directly applicable to an LMR/PRISM design without any changes to the criteria

(2) GDC applicable to an LMR/PRISM design but changes are needed to the criteria

(3) GDC not applicable to an LMR/PRISM design

(4) GDC for which the staff and the preapplicant are in agreement

(5) GDC for which the staff and the preapplicant are in disagreement

(6) recommended additional GDC for an LMR/PRISM design

Table 3.2 presents the GDC by titles for the first five categories above; the first three categories above are represented by the second, third, and fourth columns in Table 3.2, and the fourth and fifth categories above are represented by the fifth column in the table. The recommended additional GDC for an LMR/PRISM design are not given in this table. The letter " $\mathrm{X}$ " in a column means that the staff or the preapplicant concluded that the GDC is in the category represented by the column.

Table 3.3 summarizes the following:

- changes proposed for GDC to apply to an LMR/PRISM design

- additional design criteria that may be needed

The details for the changes discussed in Table 3.3 are given in Sections 3.2.3 and 3.2.4. In some cases, the GDC are involved with the key policy issues on the PRISM design. These key issues are discussed in Section 3.2.3.10 below and in the appropriate GDC in the next section.

\subsubsection{Comparison to the GDC in 10 CFR Part 50}

This evaluation provides GDC that are acceptable at the preapplication stage for the PRISM design in terms of the GDC and possible additional criteria. The abbreviation "GDC: refers to the GDC in Appendix A to $10 \mathrm{CFR}$ Part 50. The preapplicant's review was directed toward the applicability of the GDC to only the PRISM design and the staff's review was directed toward the applicability of the GDC to any likely LMR design, which would include the PRISM design. 


\section{GDC 1: Quality Standards and Records}

This criterion requires (1) a safety classification system to classify SSCs according to their importance to the safety of the plant, (2) the designing, building, and testing of the SSCs to quality codes and standards commensurate with their safety function, (3) a QA program which ensures that the SSCs will satisfactorily perform their safety function, and (4) the maintenance of the appropriate records of these SSCs for the life of the plant.

No exceptions were proposed to this GDC. Safety classification criteria and SSCs important to safety (i.e., safety-related) for the PRISM design are discussed and listed by the preapplicant in PSID Section 3.2. Recognized codes and standards are stated to apply to ensure a quality product consistent with the safety classification. The total QA program, including contractor programs, is discussed in PSID Chapter 17 and is stated to satisfy the qualityrelated requirements of $10 \mathrm{CFR}$ Part 50, including Appendix B. Documents to demonstrate that all the requirements of the QA program are satisfied would be maintained for the life of the plant.

The requirements in GDC 1 are independent of the plant design and the staff agrees with the preapplicant that the criterion is directly applicable to the PRISM design. GDC 1 is consistent with Criterion 1 of NUREG-0968 and Criterion 3.1.1 in ANSI/ANS-54.1-1989. GDC 1 is, therefore, acceptable as written for the PRISM design.

In some cases, the staff disagrees with the preapplicant's decisions on the safety classification of certain systems or components. For example, the preapplicant classifies the control room and the equipment as non-safety-related and the control room operators are considered not to have a safety function. The staff does not agree with the preapplicant's positions, as discussed in Section 13.2.3 of this report.

\section{GDC 2: Design Bases for Protection Against Natural Phenomena}

This criterion requires that a plant be designed with an adequate margin of safety to withstand the natural phenomena that could affect the ability of the plant's safety-related SSCs to perform their safety function for the proposed site area.

No exceptions were proposed to this GDC. The preapplicant stated that the PRISM design is a standard plant design in accordance with 10 CFR Part 52 for which a specific site is not part of the design. PSID Chapter 2 discusses the site characteristics for which the PRISM was designed and PSID Table 2.1-1 summarizes the PRISM siting-related envelope. The preapplicant stated that the PRISM will be designed for a majority of the potential sites in the contiguous United States.

The requirements in GDC 2 are independent of the plant design. The staff agrees with the preapplicant that the criterion is directly applicable to the PRISM design. GDC 2 is consistent with Criterion 2 of NUREG-0968 and Criterion 3.1.2 of ANSI/ANS-54.1-1989. GDC 2 is, therefore, acceptable as written for the PRISM design.

The staff will require a PRA-based analysis of seismic margins in order to evaluate the robustness of the PRISM design to withstand seismic events beyond the design basis. This requirement is part of assessing the plant response to severe accident sequences, as discussed in Chapter 15 of this report.

\section{GDC 3: Fire Protection}

This criterion requires that a plant be designed and constructed to (1) minimize the probability and effects of fires and explosions on plant SSCs important to safety and (2) prevent fire-fighting systems from adversely affecting these SSCs.

No exceptions were proposed to this GDC. The preapplicant stated that the SSCs considered important to safety shall be located to minimize the probability and effects of fires and explosions. Fire protection subsystems shall be in compliance with requirements for improved risk classif -tion as defined by the Energy, Research, and Development Administration (ERDA) Industrial Fire Protection Manual, Chapter 0552, and by applicable National Fire Protection Association (NFPA) codes. PRISM is to follow guidelines in Appendix R to 10 CFR Part 50 (Ref. 3.6) and SRP Section 9.5.1 of NUREG-0800 (Ref. 3.9).

PRISM is different from LWRs in that it contains large quantities of sodium that reacts vigorously with water and oxygen, and could cause fires that would not occur at LWRs. The preapplicant stated that special precautions will be taken for sodium fires. The plant will be designed with special consideration given to detection and mitigation of sodium leaks and reactions. The steam generator system will have sodium-water reaction pressure systems to detect sodium or water leakage, to relieve the pressure pulses from sodium-water reactions, and to collect and vent the reaction products.

Even though the presence of sodium in the PRISM design presents additional problems compared to LWRs with respect to fire protection, the overall requirements for fire protection are independent of the design of the plant. The 
staff agrees with the preapplicant that this criterion is directly applicable to the PRISM design. GDC 3 is consistent with Criterion 3 in NUREG-0968 and Criterion 3.1.3 of ANSI/ANS-54.1-1989. GDC 3 is, therefore, acceptable as written for the PRISM design.

\section{GDC 4: Environmental and Dynamic Effects Design Bases}

This criterion requires that the plant be designed and constructed so that SSCs important to safety can withstand environmental conditions and dynamic effects, including missiles and pipe whip, without losing their ability to perform their safety function.

The preapplicant's proposed Criterion 4 would exclude the last sentence in GDC 4 that states "However, dynamic effects associated with postulated pipe ruptures in nuclear power units may be excluded from the design basis when analyses reviewed and approved by the Commission demonstrate that the probability of fluid system piping rupture is extremely low under conditions consistent with the design basis for the piping." This has allowed for pipe leak before pipe break in LWRs. It is not being considered by the preapplicant for PRISM because the reactor coolant is a low-pressure system. Therefore, the proposed criterion is more conservative than GDC 4.

The preapplicant stated that safety-related SSCs will be protected from the worst potential environmental conditions and a wide spectrum of credible missiles, including tornado generated missiles. Spontaneous and massive ruptures of the sodium piping are not considered credible by the preapplicant because the piping is in low-pressure and low-stressed systems. The dynamic effects of pipe rupture (i.e., pipe whip) are not included in the PRISM design.

Although sodium presents additional problems in PRISM compared to LWRs with respect to plant environmental conditions and dynamic effects, the requirements for this criterion are independent of the plant design. The staff agrees with the preapplicant that this criterion is applicable to the PRISM design.

As proposed by the preapplicant, GDC 4 is consistent with Criterion 5 of NUKEG-0968 and Criterion 3.1.5 of ANSI/ANS-54.1-1989 with the following three exceptions which involve only NUREG-0968. First, to account for the presence of sodium, NUREG-0968 adds the following phrase on protection against sodium reactions at the end of the first sentence of GDC 4: "including the effects of sodium ... and [its] ... aerosols and combustion products. " The intent of this additional phrase is to require that the plant be designed and constructed with special consideration given to the effects of sodium. Because of the high chemical activity of sodium, leaks and spills can lead to chemical reactions, fires, and reaction products not possible in LWRs and, therefore, special measures need to be taken. The preapplicant should address why the additional phrase on protection against sodium reactions should not be included in the GDC 4 for the PRISM design.

Second, NUREG-0968 has deleted the phrase "including loss-of-coolant accidents," which follows the words "postulated accidents, " from the first sentence of GDC 4. The staff did not consider LOCAs an important class of accidents for the CRBRP design and they were, therefore, not specifically referred to in the GDC. The reference to postulated accidents will cover all the important accidents for LMRs. This exception is considered important for the PRISM design and the preapplicant should address why the phrase "including loss-of-coolant accidents" should not be deleted from GDC 4.

The third exception would add the same phrase "including anticipated operational occurrences" to the first sentence of GDC 4 to ensure that the criterion would apply to all desigu-basis events. It is not considered necessary to include "anticipated operational occurrences" for LMRs among the design basis events because the design basis events will determine the environmental and dynamic design bases for the plant.

The proposed GDC 4, with the modifications discussed above, appears to be acceptable for tine PRISM design.

\section{GDC 5: Sharing of Structures, Systems, and Components}

This criterion requires that SSCs important to safety shall not be shared among nuclear power units unless it can be shown that such sharing will not significantly impair their ability to perform their safety functions, including, in the event of an accident in one unit, an orderly shutdown and cooldown of the remaining units.

No exceptions were proposed to this GDC. The SSCs important to safety for each module are not shared between modules; however, the control room and primary sodium processing subsystem (PSPSS) will be shared among modules in a plant. The preapplicant does not classify the control room, which is shared among all the nine modules, as a safety-related structure and control system. The staff's evaluation of the control room is given in Section 13.2.3 of this report.

Although the preapplicant has classified the PSPSS as safety-related, it is shared among the three modules of a 


\section{Review Approach and Criteria}

power block. As discussed in PSID Section 9.5, the PSPSS is not used during power operation. The PSPSS is designed to remove impurities from the sodium in the reactor vessel during refueling and hot standby conditions and from the sodium in the primary sodium storage vessel. It is not designed to shut down a module, cool a module, or mitigate the consequences of an accident involving a module. Althnugh the sharing of the PSPSS in a power block appears to meet GDC 5, the preapplicant should specifically address why the sharing of the safety-related PSPSS meets the requirements in GDC 5.

The requirements in GDC 5 are independent of the design of the plant. The staff agrees with the preapplicant that this criterion is directly applicable to the PRISM design. GDC 5 is consistent with Criterion 6 of NUREG-0968 and Criterion 3.1.6 of ANSI/ANS-54.1-1989. GDC 5, therefore, is acceptable as written for the PRISM design.

\section{GDC 10: Reactor Design}

This criterion requires that there be assurance in the plant design that fuel design limits will not be exceeded during normal operation and anticipated operational occurrences.

No exceptions were proposed to this GDC. The preapplicant stated that maintenance of fuel rod structural integrity with design limits is a design requirement for normal and anticipated operational occurrences. Although the preapplicant does not refer to control and protection systems to ensure that fuel design limits are not exceeded in its discussion of GDC 10, these will have to be designed with adequate margin if they are being relied upon by the PRISM designers. The fuel research and development program discussed in Chapters 4 and 14 is designed to provide the fuel normal operating and limiting condition parameters necessary to define normal and off-normal operating limits.

The requirements in this criterion are independent of the design of the plant. The staff agrees with the preapplicant that this criterion is directly applicable to the PRISM design.

GDC 10 is consistent with Criterion 8 of NUREG-0968 and Criterion 3.2.1 of ANSI/ANS-54.1-1989 with two exceptions. The first is that NUREG-0968 deletes the word "core" following the word "reactor" in the first sentence so that GDC 10 would not be limited to the reactor core. The staff concludes that this is not important for the PRISM design.

Exception two is that ANSI/ANS-54.1-1989 adds several paragraphs of requirements to GDC 10 for LMRs. After reviewing these paragraphs in ANSI/ANS-54.1-1989, the staff believes that these additional requirements, although unique to LMRs, are details that are contained within the generalities of GDC 10 of 10 CFR Part 50. Therefore, these additional paragraphs need not be added to the GDC 10 for the PRISM design.

Therefore, GDC 10 is acceptable as written for the PRISM design.

\section{GDC 11: Reactor Inherent Protection}

This criterion requires that the nuclear characteristics of the core provide a prompt negative reactivity feedback to positive reactivity insertions while the plant is in a transient during any operating mode in the power operating range.

No exceptions were proposed to this GDC. The preapplicant stated that the fuel Doppler effect for the PRISM core provides prompt and strongly negative reactivity feedback which is needed to mitigate the effects of reactivity transients. The analysis of accident conditions will use conservative values of the Doppler coefficient. The core expansion and fuel assembly bowing are predicted to provide additional negative reactivity feedback for transients. These reactivity effects will be verified in the prototype testing of the Safety Test Program for PRISM, discussed in Chapter 14 of this report.

The requirements in this criterion are independent of the design of the plant. The staff agrees with the preapplicant that this criterion is directly applicable to the PRISM design. GDC 11 is consistent with Criterion 9 of NUREG-0968 and Criterion 3.2.2 of ANSI/ ANS-54.1-1989. GDC 11 is, therefore, acceptable as written for the PRISM design.

In the PRISM design, a failure to scram and a total loss of flow without coastdown could result in sodium boiling, and a severe power excursion and core disruption. The staff is, therefore, concerned that there are certain events that could lead to sodium boiling and, thus, the PRISM design may not meet GDC 11. The question of whether a reactor design can be acceptable if its overall inherent reactivity tends to increase under specific conditions or accidents, even though the conditions require the multiple failures of redundant and diverse safety-grade systems, is a policy issue that was presented to the Commission (Ref. 3.1). See Section 3.1.2 of this report. The preapplicant should address the staff's concern about whether the design neets GDC 11.

\section{GDC 12: Suppression of Reactor Power Oscillations}

This criterion requires that the core and associated systems be designed to ensure that power oscillations cannot exceed 
fuel design limits or that the oscillations can be reliably detected and suppressed.

No exceptions were proposed to this GDC. The preapplicant stated that the PRISM core is small compared to the average neutron mean free path and, therefore, the core is tightly coupled neutronically which will prevent spatial instability. The strong fuel Doppler coefficient has been shown by analysis to ensure a stable response to reactivity perturbations at full power.

The requirements in this criterion are independent of the design of the plant. The staff agrees with the preapplicant that this criterion is directly applicable to the PRISM design. GDC 12 is consistent with Criterion 10 of NUREG-0968 and Criterion 3.2.3 of ANSI/ ANS-54.1-1989. GDC 12 is, therefore, acceptable as written for the PRISM design.

\section{GDC 13: Instrumentation and Control}

This criterion requires sufficient instrumentation and controls to monitor and maintain system variables within their prescribed operating ranges throughout normal operation, anticipated operational occurrences, and accidents.

No exceptions were proposed to this GDC. The preapplicant stated that instrumentation and controls are provided to monitor and control neutron flux, control rod position, chemical composition, temperatures, pressures, flows, and levels as necessary to ensure that adequate plant safety can be maintained for normal operating conditions, anticipated operating conditions, and accidents.

The requirements in this criterion are independent of the design of the plant. The staff agrees with the preapplicant that this criterion is directly applicable to the PRISM design. GDC 13 is consistent with Criterion 11 of NUREG-0968 and Criterion 3.2.4 of ANSI/ANS-54.11989. GDC 13 is, therefore, acceptable as written for the PRISM design.

\section{GDC 14: Reactor Coolant Pressure Boundary}

This criterion requires a high integrity for the reactor coolant pressure boundary (RCPB) and a low probability of gross rupture of this boundary.

No exceptions were proposed to this GDC. The preapplicant stated that the RCPB will be designed and constructed to applicable sections of the American Society of Mechanical Engineers (ASME) Boiler and Pressure
Vessel Code and Code Case N-47 for elevated reactor vessel temperatures. Because of the low operating pressure and high operating temperatures, and because the RCPB components are fabricated of highly ductile stainless steel material, the potential for rapidly propagating failure of the RCPB is considered negligible. Seals in the RCPB are monitored for leakage.

The requirements in this criterion are independent of the design of the plant. The staff agrees with the preapplicant that this criterion is directly applicable to the PRISM design. GDC 14 is consistent with Criterion 12 of NUREG-0968 and Criterion 3.2.5 of ANSI/ ANS-54.1-1989. GDC 14 is, therefore, acceptable as written for the PRISM design.

\section{GDC 15: Reactor Coolant System Design}

This criterion requires that the reactor coolant system and its associated systems are designed with sufficient margin to prevent the design conditions from being exceeded during normal conditions and anticipated operational occurrences.

No exceptions were proposed to this GDC. The preapplicant stated that the reactor coolant system and associated auxiliary, control, and protection systems are designed with sufficient margin to ensure that GDC 14 is met. Consistent with the safety classification, the systems and components will be designed to the appropriate sections of the ASME Code and code cases. The normal operating conditions and the nature and frequency of anticipated operational occurrences will be included in the design analyses.

The requirements in this criterion are independent of the design of the plant. The staff agrees with the preapplicant that this criterion is directly applicable to the PRISM design.

GDC 15 is consistent with Criterion 13 of NUREG-0968 and Criterion 3.2.6 of ANSI/ANS-54.1-1989, except that both documents added the phrase "sodium heating system" to the list of systems associated with the reactor coolant system. The addition of the sodium heating system to the GDC for the PRISM is discussed in Section 3.2.4.2 below. The preapplicant should address why the additional phrase "sodium heating system" should not be accepted for the PRISM design for this GDC.

A modified GDC 15 adding the phrase "sodium cooling system" to the list of systems is acceptable for the PRISM design. 


\section{GDC 16: Containment Design}

This criterion requires that a reactor containment and associated systems be provided to establish an essentially leak-tight barrier against uncontrolled release of radioactivity to the environment and ensure that important containment design conditions are not exceeded during postulated accidents.

No exceptions were proposed to this GDC. The preapplicant stated in PSID Section G.4.1 that the PRISM containment design is an upper containment dome above the reactor closure head and a lower containment vessel connecting to the closure head. The containment dome and the containment vessel are designed to have a design leakage during accidents no greater than 1.0 percent and 0.1 percent volume per day, respectively. The upper and lower containment regions have different design leakage requirements because the upper region is not required to contain primary sodium leaks, as is the case for the lower region. The containment pressure boundary will be designed to meet NRC containment boundary requirements.

The requirements in this criterion are independent of the design of the plant. The staff agrees with the preapplicant that this criterion is directly applicable to the PRISM design.

GDC 16 is consistent with Criterion 14 of NUREG-0968 and Criterion 3.2.7 of ANSI/ANS-54.1-1989 except that ANSI/ANS-54.1 refers to confinements in addition to containments and an "effectiye" barrier instead of a leaktight barrier. These exceptions change GDC 16 as follows: (1) relaxes the requirement for an essentially leaktight structure that is typical for LWRs and (2) allows filtered, vented containments (these may have higher leak rates than current LWRs, but will meet the same requirements on dose consequences as these LWRs).

The staff does not make a distinction between containment and confinement structures; therefore, the word "confinement" is not used in the GDC. The issue of permitting containments to have a design and tested leakage greater than "essentially leaktight" in GDC 16 is a policy issue that was presented to the Commission (Ref. 3.1). See Sections 3.1.2.3 and 3.2.10 of this report. The Commission approved the staff's recommendation to restrict the leakage of the containment to be less than that needed to meed the acceptable onsite and offsite dose consequence limits (Ref. 3.46). Therefore, the Commission agreed that the containment leakage for advanced reactors, similar to and including PRISM, should not be required to meet the "essentially leaktight" statement in GDC 16.
Therefore, GDC 16 is acceptable as written for the PRISM design. The Commission's decision on the containment policy issue discussed above may relax the current requirements.

In PSID Section G.4.1, the preapplicant stated that the refueling enclosure would be part of the containment pressure boundary during refueling. This is discussed in Section 6.6 of this report; however, the preapplicant has not explained how the GDC 16 for the PRISM design may affect the design of this enclosure.

\section{GDC 17: Electric Power Systems}

This criterion requires a highly reliable onsite and offsite electric power system to ensure that electric power will be available to the systems and components important to safety. The reliability of the electric power is to ensure that the SSCs will be able to perform their safety functions.

No exceptions were proposed to this GDC. The preapplicant described the onsite and offsite electric power systems for the PRISM design in PSID Sections 3.1.2.8, 8.2, and 8.3.

The requirements in this criterion are independent of the design of the plant. The staff agrees with the preapplicant that this criterion is directly applicable to the PRISM design.

GDC 17 is consistent with Criterion 15 of NUREG-0968 and Criterion 3.2.8 of ANSI/ANS-54.1-1989 with the following two exceptions:

(1) The words "normal operation, including" have been added in front of "anticipated operational occurrences" in Item (1) of the GDC in NUREG-0968.

(2) Requirements for station blackout are specified in a separate paragraph in ANSI/ANS-54.1-1989.

The first exception is to include normal operating conditions with anticipated operational occurrences in assuring that "specified acceptable fuel design limits and design conditions of the reactor coolant boundary are not exceeded." The staff believes that the preapplicant should address why the additional phrase on normal operation, as given in NUREG-0968, should not be included in this GDC for the PRISM design.

The second exception is to add a paragraph with requirements for station blackout. After reviewing this paragraph, the staff believes these additional requirements 
are details that are contained within the generalities of GDC 17 of 10 CFR Part 50 and, therefore, are not needed.

Therefore, a modified GDC 17 with the phrase "normal operation, including" added to the criterion is acceptable for the PRISM design.

\section{GDC 18: Inspection and Testing of Electric Power Systems}

This criterion requires that the electric power system for the plant be designed to allow for periodic inspection and testing to ensure that electric power will be available to the systems and components important to safety.

No exceptions were proposed to this GDC. The preapplicant stated that the alternating current (ac) and direct current (dc) systems will be designed to be tested during plant operation in accordance with the IEEE Standard 338-1977 and NRC RG 1.118 (Ref. 3.21).

The requirements in this criterion are independent of the design of the plant. The staff agrees with the preapplicant that this criterion is directly applicable to the PRISM design. GDC 18 is consistent with Criterion 16 of NUREG-0968 and Criterion 3.2.9 of ANSI/ ANS-54.1-1989. GDC 18 is, therefore, acceptable as written for the PRISM design.

\section{GDC 19: Control Room}

This criterion requires that (1) a control room be designed to permit access and occupancy under all normal and postulated accident conditions and (2) the maximum occupational exposure to operators under accident conditions be 5 rem whole body or its equivalent. In addition, equipment at appropriate locations outside the control room shall be provided with a (1) design capability for prompt hot shutdown of the reactor, including necessary instrumentation and controls to maintain the unit in a safe condition during hot shutdown, and (2) potential capability for subsequent cold shutdown of the reactor through the use of suitable procedures.

The following two changes were proposed to this GDC: (1) delete the phrase ", including loss-of-coolant accidents" after "accident conditions" in the last part of the first sentence in the GDC and (2) delete the word "adequate" from the phrase "adequate radiation protection shall be provided." These changes are not discussed by the preapplicant; however, the first acknowledges the reduced importance of LOCAs for the low-pressure, pool-type PRISM design and still requires that the control room will be maintained in a safe condition under all "accident conditions." The second change does not alter the radiation exposure limits for operators in the control room during an accident; therefore, the radiation protection necessary to meet this limit is still required. The preapplicant does not propose to delete the reference to "cold shutdown" of the reactor, where the refueling temperature for the PRISM design is at least $478 \mathrm{~K}$ $\left(400^{\circ} \mathrm{F}\right)$ to prevent the sodium from freezing.

The preapplicant stated that equipment needed to operate and shut down the plant, and to maintain safe control of the reactor modules, will be located in the control room; however, because the inherently safe design responds to accidents without any need for operators, special protection features have not been provided for the operators. In the event the control room must be vacated, the reactor modules can be maintained in a hot shutdown condition for an extended time using the remote shutdown facilities located in either the reactor service building or the individual reactor module.

Except for the reference to "cold shutdown," these requirements are independent of the plant design. The staff agrees with the preapplicant that GDC 19 is applicable to the PRISM.

The preapplicant's proposed GDC 19 for the PRISM design is consistent with Criterion 17 of NUREG-0968 and Criterion 3.2.10 of ANSI/ANS-54.1-1989 with the following exceptions:

(1) Consistent with NUREG-0968 and ANSI/ANS54.1-1989, the phrase "including loss-of-coolant accidents" after the words "accident conditions" in the first sentence of GDC 19 is deleted. The phrase ", including those conditions from sodium ... reactions" has been added.

(2) The word "postulated" has been added twice to modify the words "accident conditions" in both documents.

The entire Item 2 of the second paragraph in the GDC has been deleted in both documents to remove the reference to cold shutdown, which is not applicable to sodium-cooled reactors, and the phrase "and with a design capability for subsequent control of the reactor at any coolant temperature lower than that during the hot shutdown" was added in NUREG-0968.

(4) The phrase ", including anticipated operational occurrences" has been added after the words "under normal condition" in the first sentence of GDC 19 in ANSI/ANS-54.1-1989. 
For the first exception, the phrase ", including the loss-ofcoolant accident" should be deleted from GDC 19 and the phrase ", including those conditions from sodium ... reactions" should be added. The intent of this additional phrase, as in GDC 4 above, is to require that the plant be designed and constructed with special consideration given to the effects of sodium. Because of the high chemical activity of sodium, leaks and spills can lead to chemical reactions, fires, and reaction products not possible in LWRs and, therefore, special measures need to be taken. The preapplicant should address why the additional phrase on protection against sodium reactions should not be included in the GDC 19 for the PRISM design.

For the second and fourth exceptions, the use of the word "postulated" in the phrase "postulated accident conditions" and the addition of the phrase ", including anticipated operational occurrences" to modify "normal operation" are not considered important and the preapplicant does not have to address these changes. The word "postulated" does not need to be added to the phrase "accident conditions" for the appropriate accident conditions to be applied to the design. It is also not necessary to include "anticipated operational occurrences" with normal conditions when GDC 19 requires the control room to be designed for accident conditions.

In the third exception, the reference to "cold shutdown" should be modified for the PRISM because an equivalent LWR reactor condition of "cold" shutdown is not applicable to sodium-cooled reactors. The PRISM design has a hot shutdown temperature of about $589 \mathrm{~K}\left(600^{\circ} \mathrm{F}\right)$ and a refueling temperature of about $478 \mathrm{~K}\left(400^{\circ} \mathrm{F}\right)$. The applicant should address whether Item 2 in GDC 19 should be revised to refer to these lower temperature conditions.

The preapplicant's safety classification for the control room, and the equipment therein, disagrees with the position of the staff and is discussed in Section 13.2.3 of this report. The use of safety-grade equipment to reduce $p$ wer to hot shutdown and perhaps refueling is discussed in Section 5.7 of this report. This is one of the policy issues that the staff presented to the Commission (Ref. 3.1). See Sections 3.1.2.6 and 3.2.10 of this report.

The preapplicant's proposed GDC is acceptable for the PRISM design.

\section{GDC 20: Protection System Functions}

This criterion requires that the RPS automatically respond (1) to prevent the fuel from exceeding its design limits and

(2) to initiate appropriate systems and components important to safety and that may be needed to mitigate accidents.

No exceptions were proposed to this GDC. The preapplicant stated that the reactor protection system (RPS) trips will (1) release all control rods and operate rod drive-in motors, assuring full rod insertion, not exceeding design fuel limits and (2) initiate primary sodium coolant pump coastdown, containment isolation, and plant control system adjustments to respond to the reactor trip. The RPS will be designed to accepted codes and standards to be highly reliable and testable with redundant input and output channels, separated logic elements, and single-failure capability.

The requirements in this criterion are independent of the plant design. The staff agrees with the preapplicant that this criterion is directly applicable to the PRISM design. GDC 20 is consistent with Criterion 18 of NUREG-0968 and Criterion 3.3.1 of ANSI/ANS-54.1-1989. GDC 20 is, therefore, acceptable as written for the PRISM design.

\section{GDC 21: Protection System Reliability and Testability}

This criterion requires a highly reliable RPS which has a single-failure capability and can be tested with the reactor at power without loss of its safety function.

No exceptions were proposed to this GDC. The preapplicant stated that the RPS includes automated on-line testing and that all channels used during power operation are sufficiently redundant so that individual channel testing and calibration can be performed with the reactor at power without loss of either the RPS shutdown function or singlefailure capability. Information will be available to the operator on the status of the RPS.

The requirements in this criterion are independent of the plant design. The staff agrees with the preapplicant that this criterion is directly applicable to the PRISM design. GDC 21 is consistent with Criterion 19 of NUREG-0968 and Criterion 3.3.2 of ANSI/ANS-54.1-1989. GDC 21 is, therefore, acceptable as written for the PRISM design.

\section{GDC 22: Protection System Independence}

This criterion requires that the RPS be designed to (1) prevent loss of its safety function resulting from the effects of natural phenomena, normal operation, maintenance, testing, and accidents, and (2) include aspects of diversity in the performance of its safety function.

No exceptions were proposed to this GDC. The preapplicant stated that the RPS has defenses against the loss of the protection function from such natural 
phenomena as tornado, flood, earthquake, and fire. It is tested and qualified for extreme environmental conditions, and the equipment cabinets, tests, and maintenance will prevent failure from normal wear, dust, or dirt. The RPS will be designed with redundant logic trains and reactor trip devices, and engineered safety feature actuation devices are physically separated and electrically isolated. Functional diversity will be included in the RPS.

The requirements in this criterion are independent of the plant design. The staff agrees with the preapplicant that this criterion is directly applicable to the PRISM design. GDC 22 is consistent with Criterion 20 of NUREG-0968 and Criterion 3.2.3 of ANSI/ANS-54.1-1989. GDC 22 is, therefore, acceptable as written for the PRISM design.

\section{GDC 23: Protection System Failure Modes}

This criterion requires the RPS to be designed so that, if the system fails or is in a faulted condition, it will fail into a safe state for the reactor.

No exceptions were proposed to this GDC. The preapplicant stated that the RPS is designed with consideration of the most probable failure modes of the components. Where practical, channel and logic circuit failures will result in a reactor trip. Fault-tolerant circuit architecture is incorporated in the design of the RPS to minimize adverse effects of faults, on-line channel monitoring and testing to detect channel failures, and divisional redundancy to prevent single-failure loss of the safety function. Failure modes and effects analyses will be performed to assess the faulted performance capabilities of the design to perform its safety function.

The requirements in this criterion are independent of the plant design. The staff agrees with the preapplicant that this criterion is directly applicable to the PRISM design.

GDC 23 is consistent with Criterion 21 of NUREG-0968 and Criterion 3.2.4 of ANSI/ANS-54.1-1989 except that both documents add the phrase "sodium and sodium reaction products," to the list of postulated adverse environments in GDC 23. Sodium and sodium reaction products are additional adverse environments that the PRISM design should address. The preapplicant should address why this phrase should not be added to the GDC 23 for the PRISM design.

Therefore, a modified GDC 23, with the addition of the phrase "sodium and sodium reaction products, " is proposed for the PRISM design.

\section{GDC 24: Separation of Protection and Control Systems}

This criterion requires sufficient separation of the two systems so that a failure, or taking out of service, of any single component or channel, either within the control system or common to the RPS, will not prevent the RPS from meeting its reliability, redundancy, and independence requirements and performing its safety function. Because the RPS and the control system need the same process information to perform their functions, the systems may share components and channels.

No exceptions were proposed to this GDC. The preapplicant stated that the components common to both the RPS and the control system are the RPS sensors and signal conditioning equipment. The RPS is separate and distinct from the control system, and the control system input signals are transferred from the RPS by RPS optical isolators which are designed to isolate the RPS from the control system. No credible failure at the isolator will prevent the corresponding RPS channel from performing its safety function, and adequacy of this system separation under faulted conditions will be tested. The control system is designed so that a single failure of a sensor will not cause a control system malfunction requiring the RPS to function. The RPS will be designed to appropriate codes and standards.

The requirements in this criterion are independent of the plant design; thus, the staff agrees with the preapplicant that this criterion is directly applicable to the PRISM design. GDC 24 is consistent with Criterion 22 of NUREG-0968 and Criterion 3.3.5 of ANSI/ANS-54.11989. GDC 24 is, therefore, acceptable for the PRISM design.

GDC 25: Protection System Requirements for Reactivity Control Malfunctions

This criterion requires that the RPS be designed to prevent fuel design limits from being exceeded during any anticipated operational occurrence involving a single reactivity control system malfunction.

No exceptions were proposed to this GDC. The preapplicant stated that the inherent shutdown capability of the PRISM design, coupled with the safety-grade heat removal system (reactor vessel air cooling system), will ensure that fuel design limits are not exceeded for a postulated single control rod withdrawal without a reactor trip. However, the RPS would detect the reactivity change associated with the rod withdrawal and would shut down the reactor, to prevent the fuel design limits from being exceeded. 
The requirements in this criterion are independent of the plant design. The staff agrees with the preapplicant that this criterion is directly applicable to the PRISM design.

GDC 25 is consistent with Criterion 23 of NUREG-0968 and Criterion 3.3.6 of ANSI/ANS-54.1-1989, except that NUREG-0968 did not include the phrase "(rod ejection or dropout)" of control rods in the last line of GDC 25. These words were deleted from the criterion in NUREG-0968 because they were not considered applicable to the CRBRP design. The preapplicant should address why this phrase should not be deleted from its proposed GDC 25 for the PRISM design.

A modified GDC 25 with the deletion of rod ejection and dropout is acceptable for the PRISM design.

\section{GDC 26: Reactivity Control System Redundancy and Capability}

This criterion requires that there be at least two independent reactivity control systems of different design principles for diversity of control in responding to normal operation and off-normal conditions, without exceeding fuel design limits. One system shall use control rods, the other shall be capable of holding the core subcritical under cold conditions.

No exceptions were proposed to this GDC. The preapplicant stated in PSID Section G.4.2.2 that the PRISM design has multiple and diverse means for reactivity control and reactor shutdown. Although, as discussed above for GDC 19, an equivalent LWR reactor condition of cold shutdown is not applicable to the PRISM design, the preapplicant did not propose deleting the reference to "cold conditions" in the last line of the criterion.

The requirements in this criterion, except for the reference to "cold shutdown," are independent of the plant design. The staff agrees with the preapplicant that this criterion is applicable to the PRISM design.

GDC 26 is consistent with Criterion 24 of NUREG-0968 and Criterion 3.3.7 of ANSI/ANS-54.1-1989 with the following exceptions:

(1) Both documents delete the statement that "one of the two systems shall use control rods, preferably including a positive means for inserting the rods," and the phrase "(including xenon burnup), "in the second sentence and in the second-to-the-last sentence, respectively, of the criterion.
NUREG-0968 changed the requirements in the criterion for one system to reliably control reactivity changes and the other system to reliably control the rate of reactivity changes, both to prevent fuel design limits from being exceeded, to the requirements that both systems independently and reliably sense and respond to off-normal conditions with one system to prevent fuel design limits from being exceeded and the other system to ensure that the capability of cooling the core is maintained.

ANSI/ANS-54.1-1989 adds the sentences that "Suitable independence and diversity shall be provided to assure adequate protection against common cause failures." and "Each of the means of reactivity control shall be capable of performing its nuclear safety function with a single active failure."

NUREG-0968 adds the following sentence: "Each system has sufficient worth, assuming failure of any single active component, to shut down the reactor from any operating condition to zero power and maintain subcriticality at the hot shutdown temperature of the coolant, with allowance for the maximum reactivity associated with any anticipated operational occurrence or postulated accident."

Both documents replace the reference to "cold conditions" in the last sentence of the criterion to a reference to conditions where the coolant temperature is lower than normal operating temperatures.

The first exception, deleting the statement that "one of two systems shall use control rods, " has not been proposed by the preapplicant. There is also no reference to xenon burnup in NUREG-0968 and ANSI/ANS-54.1-0968 because the higher flux spectrum in LMRs significantly reduces the importance of xenon in LMR cores compared to LWRs. The preapplicant should address why this reference should not be deleted from the GDC 26 for the PRISM design.

The issues of permitting an advanced reactor design which does not have control rods was presented to the Commission. The staff concluded that a reactivity control system without control rods should not necessarily disqualify a reactor design. The Commission approved the staff's position regarding this requirement (Ref. 3.46).

For the second exception, NUREG-0968 revised GDC 26 to require that both reactivity control systems independently and reliably sense and respond to off-normal conditions. One system is used to prevent fuel design 
limits from being exceeded and the other system is used to ensure that the capability of cooling the core is maintained. As stated in NUREG-0968, the intent of the revised GDC 26 was to require two independent reactivity control systems of different design principles, each capable of responding to off-normal events. One system was to maintain the fuel within design limits; the other system was to maintain core coolability. These requirements are a more conservative criterion to account for inherent differences in nuclear characteristics between LWRs and the CRBRP design. The preapplicant does not have to address these changes.

The third and fourth exceptions (listed above) are to add sentences to GDC 26 . These changes state more clearly requirements for the reactivity control systems concerning single failures in the system. The preapplicant should address why these changes should not be added to the GDC 26 for the PRISM design.

The fifth exception treats the fact that the LWR equivalent of cold shutdown or cold condition does not apply to LMRs with coolants that freeze above the boiling temperature of water. This is also discussed under GDC 18 and GDC 25. The preapplicant should address why the reference to "cold conditions" should not be revised in the GDC 26 for the PRISM design.

A modified GDC 26 with the addition of these more clearly stated requirements for the reactivity control system, the deletion of the reference to "xenon burnup" and "cold shutdown," and the additional sentences from NUREG-0968 and ANSI/ANS-54.1-0968 is acceptable for the PRISM design.

The GDC 26 requirement for an independent and diverse means of reactivity control is provided in the PRISM design by the inherent reactivity feedback of the design which, according to the designers, brings the reactor to zero power upon loss of flow or loss of a normal heat removal path, even if there is a failure to scram. This is acceptable to the staff as a means of meeting GDC 26 and the minimum level of safety criteria discussed in Section 3.1.1 of this report, provided that rertain conditions can be met (see Section 7.2.5.1). Adequacy of the pruposed design to meet the purpose of this GDC through passive feedbacks should be demonstrated by prototype testing before the design certification stage.

\section{GDC 27: Combined Reactivity Control Systems Capability}

This criterion requires that the reactivity control systems be designed to have a combined capability, in conjunction with poison addition from the emergency-core cooling system (ECCS), of reliably controlling core reactivity changes to ensure, under postulated accident conditions and with margin for stuck control rods, the capability to maintain a cooled core.

The exception proposed to this GDC is to delete the words "in conjunction with poison addition by the emergency core cooling system." The preapplicant stated that poison addition by the ECCS is not a design feature for the PRISM as it is for LWRs. A system of active control rods is supplied for the PRISM core. This system has redundant and diverse core shutdown methods designed to shut down the reactor and bring the core to refueling temperatures (1) with the single highest worth rod withdrawn from the core (including rod worth uncertainties and the additional shutdown margin) and (2) with only one of six rods inserted, not including the additional shutdown margin.

GDC 27 was written for LWRs where boron addition from the ECCS is used to control reactivity changes during accidents. The PRISM design, a pool-type reactor, does not rely on the addition of poison and the PRISM design does not have an ECCS. Deleting the references to poison addition and the ECCS from GDC 27 would still require that the reactivity control systems are designed "to have a combined capability of reliably controlling reactivity changes to assure that under postulated accideni sonditions and with appropriate margin for stuck rods the capability to cool the core is maintained."

ut the reference to a system of poison addition by the , the requirements on the reactivity control systems us revised criterion are independent of the plant design. The staff agrees with the preapplicant that this criterion is applicable to the PRISM design.

The preapplicant's proposed GDC 27 for the PRISM design is consistent with Criterion 25 of NUREG-0968 and Criterion 3.3.8 of ANSI/ANS-54.1-1989 in that both documen's have deleted the requirement for poison addition by the ECCS, but with the following exceptions:

ANSI/ANS-54.1 states that "each of the reactivity control [systems] shall be designed to independently prevent fuel damage limits from being exceeded ... assuming failure of any single active component."

NUREG-0968 revises the statement that the reactivity control systems shall be designed to have "a combined capability ... of reliably controlling reactivity changes" to state "an independent capability of reliably sensing and responding to offnormal conditions." 
The first exception repeats the requirements in the revised GDC 26 that two independent reactivity control systems are required. These requirements do not have to be repenied in GDC 27.

The second exception was required for the CRBRP design because of the inherent differences in nuclear characteristics between LWRs and the CRBRP design. The preapplicant should address why this exception should not be added to the GDC 27 for PRISM.

The proposed GDC 27 with the addition of requirements on reliably sensing and responding to off-normal conditions is acceptable for the PRISM design.

\section{GDC 28: Reactivity Limits}

This criterion requires that the reactivity control systems be designed to prevent the potential amount and rate of reactivity increase in postulated reactivity accidents from significantly damaging the reactor coolant pressure boundary and impairing the capability to cool the core. The list of accidents to be considered, however, include two specific to LWRs and not applicable to the PRISM design: steam line rupture and cold water addition.

The preapplicant proposed an exreption to this GDC to delete the phrases "steam line rupiure" and "cold water addition" from the postulated reactivity accidents listed in the last sentence of the GDC. The preapplicant stated that these two accidents are specific to LWRs and are not applicable to the PRISM design. These are not significant accidents for the design because there is an intermediate heat exchanger between the steam generator and the core, and the reactor coolant is sodium, not water.

The reactivity control system is designed to reliably control normal reactor operations and the reactor protection sysiem is designed to reliably detect off-normal events. Rod ejection is prevented by a mechanical control driveline and mechanism, and by having the rod bundle weight greater than the uplift force of the core flow. The core support structures, vessel, and internal components are also designed for the anticipated rates and magnitudes of temperature changes that are calculated to occur in postulated reactivity accidents.

After deleting references to steam line break and cold water addition, the requiremeats in this revised criterion are independent of the plant design. The staff agrees with the preapplicant that this criterion is applicable to the PRISM design.
The preapplicant's proposed GDC 28 is consistent with NUREG-0968 and Criterion 3.3.9 of ANSI/ANS-54.11989 with the following exceptions:

In listing accidents, ANSI/ANS-54.1 also deletes "rod dropout," revises rod ejection to "accidental withdrawal of control rod(s)," and changes cold water injection to "cold sodium addition."

(2) NUREG-0968 has replaced GDC 28 with two additional criterion concerning the heat transport system design and adequate reactor coolant inventory, which are unique to the CRBRP design.

The first exception concerns the postulated reactivity accident: that are applicable to the PRISM design, instead of to an LWR. Rod dropout is not applicable to the PRISM design. Withdrawal of control $\operatorname{rod}(\mathbf{s})$ is more applicable than rod ejection. Cold sodium addition is more applicable than cold water addition. The preapplicant should address why these changes should not be made to the GDC 28 for the PRISM design.

The second exception is the addition of two criteria to the PRISM design concerning the heat transport system and adequate reactor coolant inventory. See the discussion on GDC 29 (below). These additional criteria are discussed in Section 3.2.4 on an additional criterion to the GDC on the heat transport system and in the discussion (below) on GDC 33, reactor coolant makeup, respectively.

The proposed GDC 28, with the additional changes concerning rod dropout, withdrawal of rods, and cold sodium addition, is acceptable for the PRISM design.

\section{GDC 29: Protection Against Anticipated Operational Occurrences}

This criterion require that the RPS and tae reactivity control system be designed to assure a high probability that they will accomplish their safety functions.

No exception is proposed to this GDC. The preapplicant stated that both the RPS and the plant reactivity control system are being designed with sufficient redundancy, testability, and reliability to provide assurance that the systems will perform their intended functions. The systems contain fault-tolerant architec ure and on-line testing and monitoring. The reactivity control system will take protective actions to automatically keep the reactor within its safe operating range. The RPS will independently act to shut down the reactor if the control system does not shut it down. The reactivity control system is designed to reliably control normal reactor operations and the reactor protection system is designed to 
reliably detect off-normal events. See also the discussions of the RPS and the reactivity control systems in sections on GDC 20 to GDC 28, above.

The requirements in this criterion are independent of the plant design. The staff agrees with the preapplicant that this criterion is directly applicable to the PRISM design. GDC 29 is consistent with Criterion 32 of NUREG-0968 and Criterion 3.3.10 of ANSI/ANS-54.1-1989, except for the following:

(1) ANSI/ANS-54.1 adds a paragraph on requirements to protect against anticipated transients without scram (ATWS), an anticipated operational occurrence.

(2) NUREG-0968 lists two additional criterion, Criteria 26 and 27, which are unique to the CRBRP design concerning the heat transport system design and adequate reactor coolant inventory.

The first exception concerns possibly additional requirements on ATWS being listed in the revised GDC 29 for the PRISM design. It is not considered necessary to add these requirements to the current GDC 29 because ATWS are just one group of anticipated operational occurrences. GDC 29 applies to all anticipated operational occurrence, including ATWS. The preapplicant does not have to address this exception.

The second exception which is also discussed under GDC 28 (above), is the addition of two criteria to the PRISM design concerning the heat transport system and adequate reactor coolant inventory. These additional criteria are discussed (below) in Section 3.2.4 on an additional criterion to the GDC on the heat transport system and in the discussion below on GDC 33, reactor coolant makeup, respectively.

Therefore, GDC 29 is acceptable as written for the PRISM design.

GDC 30: Quality of Reactor Coolant Pressure Boundary

GDC 30 requires that the reactor coolant pressure boundary (RCPB) be designed, fabricated, erected, and tested to the highest quality standards practical and that means be provided to detect and locate, if practical, leaks from the RCPB. The reactor cover gas space for LMRs, including the PRISM design, is considered within the RCPB and is also discussed in the sections on GDC 32, 55,56 , and 57 .
No exception is proposed to this GDC. The preapplicant stated that the RCPB comprises the reactor vessel, intermediate heat exchanger (IHX), and reactor closure. This boundary will be designed, fabricated, erected, and tested to the highest quality standards. Monitoring instruinentation in the reactor vessel/containment annulus and in the reactor closure head will provide continuous boundary leak detection. Reactor vessel coolant level instrumentation will detect leaks in the IHX.

Internal components of the refueling machine will become part of the RCPB during refueling. The preapplicant has not addressed how this criterion and GDC 31 and 32 will affect the design of the machine. The use of this machine outside of the upper dome containment differs from the use of refueling machines for LWRs.

The requirements in GDC 30 are independent of the design of the plant; thus, the staff agrees with the preapplicant that this criterion is directly applicable to the PRISM design. GDC 30 is consistent with Criterion 28 of NUREG-0968 and Criterion 3.4.2 of ANSI/ ANS-54.1-1989, except that the second sentence of GDC 30, which requires the detection and location of RCPB leaks, is not included in Criterion 3.4.2. However, ANSI/ANS-54.1-1989 does have this requirement (for detection and location of RCPB leaks) as a criterion for RCPB inspection and surveillance. The requirement for detection and location of RCPB leaks should remain in GDC 30; the preapplicant does not need to address this exception.

Therefore, GDC 30 is acceptable as written for the PRISM design.

\section{GDC 31: Fracture Prevention of Reactor Coolant Pressure Boundary}

This criterion requires that the RCPB be designed with sufficient margin and with consideration of certain conditions (i.e., service temperatures, conditions of the boundary material, and uncertainties in material properties, effects of irradiation, internal stresses, and size of flaws) to avoid brittle and rapidly propagating fractures thus minimizing the likelihood of RCPB leaks greater than those assumed in the design basis.

No exception is proposed to this GDC. The preapplicant stated that the reactor vessel, IHX, and reactor closure head will be fabricated of materials capable of meeting the deformation and fatigue failure modes in accordance with the specifications of ASME Code Service Levels A, B, and C (except for the closure head which never exceeds $700 \mathrm{~K}$ $\left(800^{\circ} \mathrm{F}\right)$ ) as defined in Appendix $\mathrm{T}$ to ASME Code Case N-47, "Safety Class 1 Components." The purity of the 


\section{Review Approach and Criteria}

coolant will be maintained to prevent material damage, sodium freezing, and plugging. The RCPB is sufficiently shielded or separated from the core that the effects of neutron fluence on material properties over the life of the plant should be negligible.

The requirements in this criterion and the list of conditions are independent of the design of the plant; thus, the staff agrees with the preapplicant that this criterion is directly applicable to the PRISM design.

The proposed GDC 31 for the PRISM design is consistent with Criterion 29 of NUREG-0968 and Criterion 3.4.13 of ANSI/ANS-54.1-1989 except for the following:

Both documents added the phrase "effects of coolant chemistry" to the phrase "effects of irradiation on material properties" io the second item in the list of four items in the last sentence of GDC 31 for which uncertainties must be considered in the design of the RCPB.

NUREG-0968 added the phrase "service degradation of material properties, creep, fatigue, stress rupture, " between "service temperatures" and "and other conditions of the boundary material, " to reflect what the design shall consider, in the first part of the second sentence of GDC 31 .

(3) ANSI/ANS-54.1-1989 added the phrase "and those parts of other coolant boundaries that use the leak before break principle to define design basis leaks" after "the reactor coolant pressure boundary" in the first sentence to describe what parts of the RCPB are affected by GDC 31 .

Both documents replace the phrase "under operating" in the first and second sentences of GDC 31 with the phrase "under normal operations, including anticipated operational occurrences."

The first and second exceptions would add the phrase "coolant chemistry" and "service degradation of properties, creep, fatigue, stress rupture" to address unique concerns of CRBRP because of the high design and operating temperatures of the RCPB and the use of sodium as the coolant. The preapplicant should address why these phrases should not be added to GDC 31 for the PRISM design.

The preapplicant is not taking credit for leak before break in the design of the piping for the PRISM reactor coolant system. See the section on GDC 4. Therefore, the addition of the phrase referring to components designed for leak before break (in the third exception above) would not apply to the PRISM design and the preapplicant does not need to address this exception.

The fourth exception would replace the phrase "under operating" with the phrase "under normal operations, including anticipated operational occurrences"; however, this is not considered important for the PRISM design and the preapplicant does not have to address this exception.

Therefore, a modified GDC 31 with additions concerning coolant chemistry, service degradation, creep, fatigue, and stress rupture is acceptable for the PRISM design.

Internal components of the refueling machine will become part of the RCPB during refueling. The preapplicant will have to address how this criterion and GDC 30 and 33 will affect the design of the machine. The use of this machine outside of the upper dome containment is different from the use of refueling machines for LWRs.

\section{GDC 32: Inspection of Reactor Coolant Pressure Boundary}

This criterion requires that the RCPB be designed to allow for periodic inspections and an appropriate material surveillance program.

No exception is proposed to this GDC. The preapplicant stated that the RCPB comprises the reactor vessel, IHX, and reactor closure head. The RCPB will be inspected in accordance with the appropriate sections of the ASME Code. The preapplicant will use what is considered an alternative examination method in the code and will include a combination of continuous monitoring and remote visizal video techniques. Because the external walls of the reactor vessel and the annulus between the reactor vessel and containment vessel will be continuously monitored, they are designed with inspection access ports for remote visual inspection. The annulus space between the sodium level and reactor closure head will be continuously monitored and periodically inspected. The experience at test facilities and experimental reactors with the continuous monitoring devices being considered for the PRISM indicated that the devices were sensitive to sodium leaks. The preapplicant did not address the materials surveillance program for the reactor vessel.

The requirements in this criterion are independent of the design of the plant; therefore, the staff agrees with the preapplicant that this criterion is directly applicable to the PRISM design. GDC 32 is consistent with Criterion 30 of NUREG-0968 and Criterion 3.4.3 of ANSI/ ANS-54.1-1989, except that the latter document extended the criterion to include the reactor cover gas boundary and added a requirement concerning detecting and locating RCPB leakage. 
The extension of the proposed GDC to the reactor cover gas boundary is not necessary because this cover gas region is considered within the RCPB for the PRISM and CRBRP designs. The addition of a requirement to provide detection and location of RCPB leakage is also not necessary because this requirement is in GDC 30 , as discussed above. The preapplicant does not need to address these exceptions.

Therefore, GDC 32 is acceptable as written for the PRISM design. Also, the use of remote visual video techniques as an alternative examination method for meeting the requirements of GDC 32 for the PRISM design appears to be acceptable. This will be reviewed in detail at the PSAR review stage.

Internal components of the refueling machine will become part of the RCPB during refueling. The preapplicant will have to address how this criterion and GDC 31 and 32 will affect the design of the machine. The use of this machine outside of the upper dome containment differs from how refueling machines are used for LWRs.

\section{GDC 33: Reactor Coolant Makeup}

This criterion requires a reactor coolant makeup system for the RCPB to prevent leakage or flow from small pipe breaks from uncovering the core or causing coolant circulation in the core to be lost, and thus cooling to be lost.

The preapplicant proposed an exception to this GDC to delete the phrase "and for offsite electric power system operation (assuming onsite power is not available)" from the third sentence of the GDC. The preapplicant stated that a reactor coolant makeup system is not required for the PRISM because of the low operating pressure of the RCPB and the existing sodium pool. In effect, the preapplicant is stating that this criterion is not applicable to the PRISM design.

The requirements in this criterion are not unique to LWRS; however, because of the LMR of srating conditions of low coolant pressure, this criterion is not as important for LMRs as it is for LWRs. For LWRs, the high coolant pressure allows small breaks to release significant quantities of the coolant in a short time which could uncover the core. There is no GDC 33 for LMRs in either NUREG-0968 or ANSI/ANS-54.1-1989, and the staff agrees with the preapplicant that GDC 33 should not be applied to the PRISM design.

However, there is an alternative to GDC 33, "Assurance of Adequate Reactor Coolant Inventory," in Criterion 27 of NUREG-0968 and Criterion 3.4.1 of
ANSI/ANS-54.1-1989 for the PRISM design. This is a criterion for the assurance of adequate reactor coolant inventory, the intent of which would be to require that the RCPB, associated components, and control and protection systems be designed to maintain an adequate inventory of coolant for the heat transport system to perform its safety functions. The preapplicant should address why this alternative GDC 33 should not be applied to the PRISM design.

The preapplicant stated that the RCPB for PRISM is designed to limit the loss of coolant so that an adequate inventory is available at all times for the residual heat removal system to perform its safety functions. The containment vessel ensures that the core will not be uncovered and the core can be cooled even if the reactor vessel leaks.

Therefore, the alternative GDC 33 is acceptable for the PRISM design.

\section{GDC 34: Residual Heat Removal}

This criterion requires a reliable means of removing reactor residual decay heat to maintain the fuel and RCPB within design limits assuming loss of offsite and onsite electric power concurrent with a single failure. This system is required to have suitable redundancy, leak detection, and isolation capabilities.

No exception is proposed to this GDC. The preapplicant stated that each PRISM reactor module has its own independent, passive, safety-grade, siutdown heat-removal system-the reactor vessel air cooling systen (RVACS). This system is designed to maintain conditions within the fuel and RCPB design limits without operator action and during design-basis events, including natural phenomena. The RVACS functions by the natural circulation of outside air over the containment vessel. The RVACS has no moving parts and is operating all the time. Furthermore, no operator action could shut it down or keep it from functioning.

The requirements in this criterion are independent of the design of the plant; therefore, the staff agrees with the preapplicant that this criterion is directly applicable to the PRISM design.

GDC 34 is consistent with Criterion 35 of NUREG-0968 and Criterion 3.4.7 of ANSI/ANS-54.1-1989 with the following exceptions:

(1) Both documents added the phrase "to ultimate heat sinks under all plant shudown conditions following normal operation, including anticipated operational 
occurrences, and postulated accident conditions" in the second sentence in the GDC to describe the heat flow from the reactor coolant system.

(2) Both documents added the word "reliably" to the second sentence to describe the act of heat removal from the reactor coolant system.

(3) NUREG-0968 deleted the phrase "such that specified acceptable fuel design limits and the design conditions of the reactor coolant pressure boundary are not exceeded."

(4) Both documents added two additional requirements to the first paragraph, that "a passive boundary shall normally separate reactor coolant from the working fluids of the reactor residual heat extraction system" and "any fluid in the residual heat extraction system that is separated from the reactor coolant by a single passive barrier shall not be chemically reactive with the reactor coolant." ANSI/ANS-54.1-1989 added another requirement to keep the working fluid of the heat removal system at a higher pressure than the reactor coolant system, if there is a single passive barrier, so that leakage would be into the reactor coolant system.

(5) Both documents added the phrase "independence and diversity in systems" as additional capabilities of the heat removal system in the second paragraph,

(6) Both documents added the requirement for having at least two flow paths available for residual heat removal.

ANSI/ANS-54.1-1989 added a paragraph to the criterion to specify acceptable methods to address anticipated transient; without scram and station blackout.

The first exception (above) explains that (1) the heat flow is from the reactor coolant system to the ultimate heat sinks and (2) the residual heat removal system should be designed for "all plant shutdown conditions following normal operation, including anticipated operational occurrences, and postulated accident conditions." It is not necessary to refer to the ultimate heat sink in GDC 34 because this requirement is in GDC 44. However, adding the phrase on plant shutdown conditions including postulated accidents would only be adding the same woids to GDC 34 that already exist in other GDC. The preapplicant should address why Item 2 above should not be included in the GDC 34 for the PRISM design.
Exceptions 2, 5, and 6 (above) potentially add requirements to GDC 34 on reliability, independence, and diversity, and require two flow paths for the residual heat removal system. Because GDC 34 refers to suitable redundancy in components and features, and suitable interconnections so that even with loss of electric power and a single failure, the system can still perform its safety function, the existing words in GDC 34 are adequate to include these requirements from NUREG-0968 and ANSI/ANS-54.1-1989 and, therefore, these additional words are not considered necessary for GDC 34.

For the third exception, the GDC 34 requirement that the fuel and RCPB design limits should not be exceeded is important and should not be deleted from the GDC; therefore, this exception from NUREG-0968 should not be included in the revised GDC 34 for the PRISM design.

The fourth exception (above) concerns additional requirements on the residual heat removal system: a passive barrier may be needed between the reactor coolant and the working fluid of the residual heat removal system, the fluid in the heat removal system with a single passive barrier shall not react with the reactor coolant, and the fluid in the residual heat removal system with a single passive barrier will be at a higher pressure than the reactor coolant. NUREG-0968 states that the barrier will normally exist in the plant design and ANSI/ANS-54.1-1989 requires the barrier.

It is not obvious that the residual heat removal system for any design would have a different working fluid from the reactor coolant system; however, this might be true for LMRs. Therefore, the preapplicant should address why the additional requirements (in the fourth exception) on passive barriers, working fluids, and working fluid pressure should not be included in a revised GDC 34 for the PRISM design.

For the seventh exception (above), ANSI/ANS-54.1-1989 added a paragraph to specify acceptable methods to address ATWS and station blackout. This detail is not necessary for GDC 34 because this criterion would apply to all plant shutdown conditions following normal operation, including anticipated operational occurrences, and postulated accidents. See the first exception discussed above. ATWS and station blackout are examples of anticipated operational occurrences and thus would be considered in applying GDC 34 to a reactor design without specifically identifying them in the criterion.

Therefore, a modified GDC 34 with the addition of the phrases concerning the (1) removal of heat during all plant shutdown conditions including accidents and (2) passive barriers between the residual heat removal system fluid and 
the reactor coolant, as discussed above, is acceptable for the PRISM design.

There is an issue of whether the RVACS, the single, passive, safety-related, residual heat removal system for the PRISM design, meets the "suitable redundancy in components and features, and suitable interconnections" of GDC 34. This is discussed in Section 5.7 of this report. This is one of the policy issues the staff presented to the Commission in SECY-93-092 (Ref. 3.1). The Commission approved the staff's recommendations (see Section 1.6 of this report) contained in SECY $-93-092$ (Ref. 3.46).

\section{GDC 35: Emergency Core Cooling}

This criterion requires that a heat removal system to supply emergency core cooling be provided and that the system be designed to prevent fuel and cladding damage and significant clad metal-water reaction from a loss of coolant that could interfere with continued effective core cooling. This system is required to have suitable capabilities for redundancy, leak detection, and isolation. For LMRs, however, LOCAs and effect on claciding from metal-water reactions are not important.

The preapplicant stated that GDC 35 is not applicable to the PRISM design because a LOCA is prevented by the containment vessel. The preapplicant is narrowly interpreting GDC 35 to require that a system be provided only for a LOCA, which is very important for LWRs but not important for LMRs, and, concluding, because the PRISM design does not have such a system, that this GDC is not applicable to the PRISM design.

The requirements in this criterion, except for the references to LOCAs and metal-water reactions, are independent of the plant design and are important requirements for the protection of the core. However, there is no GDC 35 for LMRs in NUREG-0968 and ANSI/ANS-54.1-1989. Both these documents also concluded that GDC 35 does not apply because, as stated in NUREG-0968, the emergency core cooling function is provided by the reactor residual heat removal system and this system is addressed under GDC 34 in Criterion 35 in NUREG-0968 and Criterion 3.4.7 in ANSI/ANS-54.1-1989.

The residual heat removal system of GDC 34 is designed to remove decay heat to maintain the fuel and RCPB within design limits for conditions that do not include a postulated accident. The ECCS of a revised GDC 35 would be designed to prevent fuel and cladding damage that could interfere with continued effective core cooling during postulated accidents. These two design requirements on providing sufficient cooling to the core are equivalent because not exceeding fuel design limits is the same as maintaining effective core cooling to prevent fuel and cladding damage and vice versa; however, the requirements on the residual heat removal system in GDC 34 are not directed toward postulated accidents as they are for the emergency core cooling system in GDC 35. The requirements on suitable redundancy, leak detection, and isolation capabilities in GDC 34 and 35 are the same.

For LWRs, the residual heat removal system is designed for low-pressure conditions because the RCPB will be depressurized when the system is used; the ECCS is designed for high-pressure conditions because the RCPB may not be depressurized when the ECCS is used. Therefore, for LWR designs, the residual heat removal system and the ECCS are two different systems, and there are two separate GDC. For LMR designs, the RCPB is at low pressure, and only one system and one GDC are needed.

If the criterion for the design of the residual heat removal system applied to all reactor conditions including postulated accidents, then all the criteria in GDC 35 for an emergency core cooling system would be included in the revised GDC 34. As discussed under GDC 34, Criterion 35 of NUREG-01968 and Criterion 3.4.7 of ANSI/ANS-54.1-1989 added a phrase to the GDC to include "all plant shutdown conditions following normal operation including ... postulated accidents." This phrase would be sufficient to have the revised GLC 34 include the requirements in GDC 35 on accidents.

The staff proposes to accept the approach taken in both NUREG-0968 and ANSI/ANS-54.1-1989, to eliminate GDC 35 for emergency core cooling and add references to postulated accidents in GDC 34 for residual heat removal, for the PRISM design. This agrees with the preapplicant's position that GDC 35 is not applicable to the PRISM design.

\section{GDC 36: Inspection of Emergency Core Cooling System}

This criterion requires that the ECCS be properly designed for periodic inspection of the important components of the system, such as spray rings and water injection nozzles. Because the ECCS function for PRISM is provided by the residual heat removal system, these inspection requirements, which are important to safety, should be applied to the latter system and the important components of this system should be listed. 
The preapplicant stated that GDC 36 is not applicable to the PRISM design because the PRISM does not require an ECCS. The preapplicant is narrowly interpreting GDC 36 for an LMR design to require inspection of a system designed ouly for LOCAs and concluding, because the PRISM design does not have an ECCS, that this GDC is not applicable to the PRISM design.

The title of GDC 36 should be changed to "Inspection of Residual Heat Removal System" because, as discussed under GDC 35, the ECCS function for LMRs is provided by the residual heat removal system.

The inspection requirements in this criterion, except for the reference to the ECCS and specific components of the ECCS, are not unique to LWRs. GDC 36 should reference the residual heat removal system, not the ECCS and the list of specific important ECCS components should be deleted. The revised GDC 36 should require the capability to inspect the residual heat removal system. The preapplicant should further address this criterion and its application to the PRISM design.

There is no GDC 36 for ECCS inspection for LMRs in either NUREG-0968 or ANSI/ANS-54.1-1989; however, the ECCS function is provided by the residual heat removal system and the inspection of this system is required in Criterion 36 of NUREG-0968 and Criterion 3.4.8 of ANSI/ANS-54.1-1989.

The revised GDC 36 with the reference to residual heat removal and deletion of specific important ECCS components would be consistent with Criterion 36 of NUREG-0968 and Criterion 3.4.8 of ANSI/ANS-54.11989 except for the following:

Both documents referred to important components, as heat exchangers and piping, other than the specific ones listed for an LWR ECCS.

ANSI-54.1-1989 added a requirement that means shall be provided to detect leakage from the system.

The first exception (above) is to account for the fact that the residual heat removal system for the LMR design provides both the emergency core cooling and residual heat removal functions for the LMR design, and to list the components important to inspect in LMRs. Therefore, the preapplicant should address why these changes should not be made to the GDC 36 for the PRISM design.

The second exception (above) would require leak detection of the residual heat removal system. This requirement is in the revised GDC 34; therefore, this requirement does not have to be included in GDC 36.
A revised GDC 36, replacing references to emergency core cooling with references to residual heat removal, and changing the title, and making a change in the list of important system components, could be acceptable for the PRISM design.

\section{GDC 37: Testing of Emergency Core Cooling System}

This criterion requires that the ECCS be properly designed for periodic pressure and functional testing of the important components. Because the ECCS function is provided by the residual heat removal system, these testing requirements, which are important to safety, should be applied to the latter system.

The preapplicant stated that GDC 37 is not applicable to the PRISM design because an ECCS is not required. The preapplicant is interpreting GDC 37 too narrowly for an LMR design to require testing of a system designed only for a LOCA and concluding, because the PRISM design does not have an ECCS, that this GDC is not applicable to the PRISM design.

The title of GDC 37 should be changed to "Inspection of Residual Heat Removal System" because, as discussed under GDC 35, the ECCS function for LMRs is provided by the residual heat removal system.

The testing requirements in this criterion, except for the reference to the ECCS, are not unique to LWRs. Because the ECCS function for LMRs is provided by the residual heat removal system, GDC 37 should also be revised to change references to the ECCS to refer to the residual heat removal system. With this change, the staff does not agree with the preapplicant that this criterion is not applicable to the PRISM design. The revised GDC 37 would require the capability to test the residual heat removal system. The preapplicant should further address why this criterion should not apply to the PRISM design.

There is no specific GDC for ECCS testing for LMRs in either NUREG-0968 or ANSI,ANS-54.1-1989; however, the ECCS function is performed by the residual heat removal system, and testing of this system is required in Criterion 37 of NUREG-0968 and Criterion 3.4.9 of ANSI/ANS-54.1-1989.

The revised GDC 37 is consistent with Criterion 37 of NUREG-0968 and Criterion 3.4.9 of ANSI/ANS-54.11989 except for the following:

(1) Both documents delete the phrase "and the operation of the associated cooling water system" in addition to deleting the reference to emergency cure cooling. 
(2) ANSI-54.1-19189 adds a requirement that "passive systems shall be designed to permit performance demonstration, under conditions as close to design as practical, to assure operability of the systems."

For an LMR design, the first exception (above) takes into account that (1) the residual heat removal system also performs the emergency core cooling function, which is discussed above, and (2) water systems for cooling the RCPB should be avoided. Therefore, references to "emergency core cooling" and "cooling water" should be deleted from GDC 37 for the PRISM design. The preapplicant should address why these changes should not be made to the GDC 37 for the PRISM design.

The second exception, the addition of the requirement that "passive systems shall be designed to permit performance demonstration, under conditions as close to design as practical, to assure operability of the systems" repeats the requirement in Item 3 of GDC 37 that the system be designed so that the operability of the system as a whole can be tested; thus, this change does not need to be made to GDC 37 .

Therefore, a revised GDC 37 with the deletion of the references to emergency core cooling and water cooling systems, is acceptable for the PRISM design.

\section{GDC 38: Containment Heat Removal}

This criterion requires that a containment heat removal system be provided and be designed to ensure that the containment design temperature and pressure limits are not exceeded following any LOCA. This system is required to have suitable redundancy, leak detection, and isolation capabilities. Because the RCPB of an LMR is at low pressure, the LOCA is not an important accident for the containment design of LMRs, as it is for LWRs.

No exceptions were proposed to this GDC. The preapplicant stated that each reactor module has its own independent and passive shutdown heat removal system, the RVACS, to ensure that the peak containment vessel temperature does not exceed the ASME Code Level C limit. The preapplicant should address the effect on this GDC of the changes made to the containment in PSID Section G.4.1, which added the upper dome containment.

The design requirements in GDC 38, except for the reference to a LOCA, are independent of the plant design; therefore, the staff agrees with the preapplicant that this criterion is applicable to the PRISM design.

There is no specific GDC on the design of a containment heat removal system for LMRs in NUREG-0968 and
ANSI/ANS-54.1-1989. The former document concludes that GDC 38 does not apply to the CRBRP design because postulated design-basis events did not cause the CRBRP containment to exceed its design temperature or pressure limits, and a containment heat removal system was not required for the design. However, the preapplicant has proposed a containment heat removal system for PRISM.

Equivalent to GDC 38 for LMRs are ANSI/ANS-54.1-1989, Criterion 3.4.10, "Structural and Ec, lipment Cooling," which applies to safety-related structures in general, and Criterion 3.5.1, "Reactor Containment/Confinement System Design Basis," which applies to containments. The preapplicant's proposed GDC 38 was compared to Criterion 3.4.10 since the proposed GDC 38 requires cooling for containments because they are safety-related structures, and to Criterion 3.5.1 because that criterion requires the containment to be designed to accommodate the calculated pressure and temperature conditions from postulated accidents. Therefore, ANSI/ANS-54.1-1989 supports having a GDC 38 on the design of containment heat removal systems for LMRs and also does not include references to a LOCA. The preapplicant should address why the specific reference to a LOCA should not be replaced by a general reference to postulated accidents.

Therefore, a revised GDC 38, with the reference to LOCAs being replaced by a reference to postulated accidents, is acceptable for the PRISM design.

\section{GDC 39: Inspection of Containment Heat Removal System}

This criterion requires that the containment heat removal system be designed to permit periodic inspection of such important components as the torus, sumps, spray nozzles, and piping. The torus and sumps are not important to LMRs. The requirement to be able to inspect the containment heat removal system is important and should be required for LMRs.

The preapplicant's proposed exceptions to this GDC would delete the reference to a torus and sumps, and add a reference to pumps, as examples of important components of a containment heat removal system. The preapplicant stated that the RVACS for each reactor module will be (1) continuously monitored by measuring air flow and exit air temperature, (2) monitored for water intrusion, radiation, and fire and smoke, and (3) periodically examined by remote visual means for blockage of the flow passages and system integrity. The preapplicant should address the effect on this GDC of the changes to the containment in PSID Section G.4.1, which added ne upper dome containment to the PRISM design. 
The inspection requirements in GDC 39, except for the reference to the torus and sumps as important components, are independent of the plant design. The proposed exceptions are only a list of important components of the containment heat reinoval system and do not affect the requirements on those components or the system. Therefore, the staff agiees with the preapplicant that this criterion is applicable to the PRISM design.

There is no specific GDC on the inspection of an LMR containment heat removal system in either NUREG-0968 or ANSI/ANS-54.1-1989. The former document concludes that GDC 39 does not apply to the CRBRP design because postulated design-basis events did not cause the containment to exceed its design temperature or pressure limits and a containment heat removal system was not required for the design. However, this GDC may apply to LMRs in general. The PRISM design includes a containment heat removal system.

ANSI/ANS-54.1-1989, Criterion 3.4.11, "Inspection of Structural and Equipment Cooling," which applies to safety-related structures, would also apply to the containment structure. Therefore, this document supports having a GDC 39 on inspection of the containment heat removal system for LMRs. The preapplicant's proposed GDC 39 is in agreement with Criterion 3.4.11 in that this criterion also does not refer to components of LWR systems.

Therefore, the proposed GDC 39, which has the deletion of the reference to a torus and sumps, and the addition of a reference to pumps, to a list of important LMR components in the GDC, is acceptable for the PRISM design.

\section{GDC 40: Testing of Containment Heat Removal System}

This criterion requires the containment heat removal system to be designed to permit periodic pressure and functional testing of important components. The reference to "cooling water systems" comes from the GDC applicability to LWRs. LMR designers would avoid the use of water and would likely use cooling systems other than cooling water in an LMR.

No exception was proposed to this GDC. The preapplicant stated that periodic testin the RVACS for each resctor module is not required because the system is operating continuously (i.e., there are no means for an operator to start up or shut down this system) and any significant degradation of the system would be detected by the inspections of the system discussed under GDC 39 above. The preapplicant does not discuss the effect of changes to the containment in PSID Section G.4.1, which added the upper containment dome to the PRISM design.

The testing requirements in GDC 40 are not unique to LWRs, except for the reference to the "associated cooling water system," but are independent of the plant design; therefore, the staff agrees with the preapplicant that this criterion is applicable to the PRISM design.

There is no specific GDC for testing LMR containment heat removal systems in either NUREG-0968 or ANSI/ANS-54.1-1989. The former document concluded that GDC $\mathbf{4 0}$ does not apply to the CRBRP design because a containment heat removal system was not required for the design. The PRISM design has a containment heat removal system (i.e., RVACS), and this system will be tested through inspections to assure its operation as designed. See discussion under GDC 39 (above).

Criterion 3.4.12 of ANSI/ANS-54.1-1989, "Testing of Structural and Equipment Cooling," applies to safety-related structures and, thus, would apply to the containment structure. Therefore, this document supports having a GDC 40 on testing of the containment heat removal system for LMRs. GDC 40 is consistent with Criterion 3.4.12, except that this criterion does not state that the test of the full operational sequence includes "the operation of the associated cooling water system." In the ANSI/ANS document, references to water have been removed and the preapplicant should address why this should not also be done for the GDC 40 for the PRISM design.

Therefore, a modified GDC 40, with the deletion of the word "water" from the phrase "cooling water system," is acceptable for the PRISM design.

\section{GDC 41: Containment Atmosphere Cleanup}

This criterion requires that systems be provided as necessary to control the amount of combustible gases to ensure containment integrity, and to reduce the amount of fission products in the containment atmosphere following postulated accidents. These systems are required to have suitable redundancy, leak detection, and isolation capabilities. These design requirements are important to safety, because they would ensure that containment integrity will not be compromised during accidents.

The preapplicant stated that GDC 41 is not applicable to the PRISM design because the containment volume is sisficiently small that natural processes will remove aerosols and "systems" are not needed. The recovery from accidents that release fission products to the 
containment is proposed to be accomplished through the gaseous waste processing system. The preapplicant does not discuss the effect on GDC 41 of changes to the containment discussed in PSID Section G.4.1.

These design requirements are independent of the plant design; therefore, the staff believes that GDC 41 is applicable to the PRISM design even though the compliance of the PRISM design with the criterion may be assured by means other than "systems." Also, GDC 41 states that systems shall be provided "as necessary," which means that a reactor design may not need any containment atmosphere cleanup systems. This position is consistent with Criterion 49 in NUREG-0968 and Criterion 3.5.11 in ANSI/ANS-54.1-1989 on the design of containment atmosphere cleanup systems for LMRs. Therefore, the preapplicant should further address why this criterion is not applicable to the PRISM design. Also, the preapplicant should discuss the effect of changes to the containment in PSID Section G.4.1 on this GDC.

GDC 41 is consistent with Criterion 49 in NUREG-0968 and Criterion 3.5.11 in ANSI/ANS-54.1-1989 with only the following exceptions:

(1) Both documents add the phrases "sodium aerosols" and "combustion products" to the list of things to be controlled by the containment cleanup systems in the first sentence.

(2) Both documents add that the containment cleanup systems should consider "the effects of sodium leakage and its potential reaction with oxygen and its potential for hydrogen generation when in contact with concrete" to the first sentence.

(3) ANSI/ANS-54.1-1989 also refers to both confinements and containments.

The first and second exceptions (above) refer to important containment cleanup problems that are unique to LMRs, except for the reference to combustion products; therefore, the preapplicant should address why these changes should not be made to the GDC 41 for the PRISM design.

The third exception would add words to refer to both confinements and containments; however, the GDC do not distinguish between containments and confinements and do not address a confinement system; therefore, the staff believes such an addition is not warranted in a GDC 41 for the PRISM design.

Therefore, a modified GDC 41, with the addition of a reference to sodium aerosols, combustion products, and the consideration of the effects of sodium leakage, is acceptable for the PRISM design. GDC 42: Inspection of Containment Atmosphere
Cleanup Systems

The requirements in GDC 42, including the list of important system components, are independent of the plant design; therefore, the staff believes that this criterion is still applicable to the PRISM design even though the compliance of the PRISM design with GDC 41 may be assured by means other than containment atmosphere cleanup systems. Inspection of these "other means" may be needed. Therefore, the preapplicant should further address why GDC 42 is not applicable to the PRISM design.

The preapplicant stated that GDC 42 is not applicable to the PRISM design because the design does not require such a system. If the system is not required, the inspection of the system is also not required. See the discussion above under GDC 41.

Compliance with GDC 41 would require containment atmosphere cleanup systems if they are needed. GDC 42 would require that these systems be designed to permit periodic inspections of such important components as filter frames, ducts, and piping, to ensure the integrity and capability of the systems.

This position on the applicability of GDC 42 to LMRs is consistent with criteria on the inspection of containment atmosphere cleanup systems for LMRs in NUREG-0968 and ANSI/ANS-54.1-1989. GDC 42 is consistent with Criterion 50 of NUREG-0968 and Criterion 3.5.12 of ANSI/ANS-54.1-1989, with the only addition, from ANSI/ ANS-54.1-1989, to also refer to both confinements and containments. As discussed under GDC 41, this change should not be included in a GDC 42 for the PRISM design.

Therefore, GDC 42 is acceptable as written for the PRISM design.

\section{GDC 43: Testing of Containment Atmosphere Cleanup Systems}

The requirements in GDC 43 are independent of the plant design; therefore, the staff believes that this criterion is still applicable to the PRISM design even though the compliance of the PRISM design with GDC 41 may be assured by means other than containment atmosphere cleanup systems. Testing in the same manner of these "other means" may be needed. Therefore, the preapplicant should further address why GDC 43 is not applicable to the PRISM design. 
The preapplicant stated that GDC 43 is not applicable to the PRISM design because the design does not require a containment atmosphere cleunup system and, if the system is not required, then testing of the system must also not be required. See tho discussion under GDC 41.

Compliance with GDC 41 would require containment atmosphere cleanup systems if they are needed. GDC 43 would require that these systems be designed to allow periodic testing of important components to ensure the operability and functionality of the systems.

This position on the applicability of GDC 43 to LMRs is consistent with criteria on the testing of containment atmosphere cleanup systems for LMRs in NUREG-0968 and ANSI/ANS-54.1-1989. GDC 43 is consistent with Criterion 51 in NUREG-0968 and Criterion 3.5.13 of ANSI/ANS-54.1-1989, except that ANSI/ANS-54.1-1989 also refers to both confinements and containments. As discussed under GDC 41, this change should not be included in a GDC 43 for the PRISM design.

Therefore, GDC 43 is acceptable as written for the PRISM design.

\section{GDC 44: Cooling Water}

GDC 44 requires a cooling water system to transfer heat from SSCs important to safety to the ultimate heat sink(s) with suitable redundancy, leak detection, interconnections, and isolation capabilities and assuming loss of offsite or onsite power, and normal or accident conditions. This criterion, however, should not be restricted to only cooling water systems, and the reference to water in the title of the criterion should be deleted.

No exception is proposed to this GDC; however, the preapplicant stated that the PRISM design does not require a safety-related cooling water system. The staff concludes that the preapplicant believes that this GDC is not applicable to the design. See discussion under GDC 45 (below).

There are systems to transfer heat from structures, systems, and components (SSCs) by condenser water and air to the ultimate heat sinks under normal operating and accident conditions; however, for accidents involving the loss of the condenser or steam generator feedwater, heat is stated to be rejected to the air only. The preapplicant has also stated, without justification, that the leak detection and isolation capabilities requirement in the GDC are not applicgble to the PRISM design, but the preapplicant did not propose to delete this requirement from the GDC. The preapplicant did not address redundancy in components, featnres, and interconnections.
For LMRs, the title of this criterion should be changed to "Structural and Equipment Cooling" to eliminate the reference to water and to modify this GDC to cover any cooling systems used to transfer heat from SSCs important to safety to the ultimate heat sink(s). This would include the heat transfer from the residual heat removal system and the containment heat removal system, which are also covered by GDC 34 through 40 , to the ultimate heat sink(s). GDC 34 through 40 are not concerned with the ultimate heat sink(s). The new title is also used in NUREG-0968 and ANSI/ANS-54.1-1989.

The GDC 44 requirements, under the proposed revised title, are independent of the plant design and are the only general design requirements concerned with the rejection of heat, from SSCs important to safety, to the ultimate heat sink(s). Even though the preapplicant concluded that leak detection and isolation capabilities are not needed for the PRISM design, other safety-grade cooling systems may be added to the design requiring leak detection and isolation and the GDC only states that "suitable" leak detection and isolation capabilities are required. Therefore, this criterion should remain and should retain the requirements for having suitable leak detection and isolation capabilities, and the preapplicant should further address why GDC 44 and this requirement should not be applicable to the PRISM design.

GDC 44 is consistent with Criterion 38 in NUREG-0968 and Criterion 3.4.10 in ANSI/ANS-54.1-1989, except that both documents have made the following changes:

(1) The phrase "In addition to the heat rejection capability provided by the reactor residual heat extraction system," now begins the first sentence.

(2) The phrase ", as necessary" have been added to the end of the first sentence.

(3) The phrase ", including anticipated operational occurrences," has been added to the phrase "under normal operation" and the word "postulated" has been added in front of to the word "accident, " near the end of the second sentence.

The first exception was made to exclude the residual heat extraction or removal systen for LMRs from GDC 44, because this system is covered in GDC 34,36 , and 37 . This exclusion could also apply to the containment heat removal systems by the fact that GDC 38 through 40 exist; however, GDC 44 applies to transferring heat from systems to the ultimate heat sinks and GDC 34 through 40 do not. Therefore, these systems should not be excluded from GDC 44 and this phrase should not be added to GDC 44. 
The second exception would add the phrase ", as necessary" to the statement in GDC 44 that a system to transfer heat from SSCs shall be provided. Because this GDC may be interpreted to require a system, the addition of "as necessary" will show that providing a system to transfer heat from SSCs is not a requirement. See discussion of GDC 41. The preapplicant should address why this phrase should not be added to the GDC 44 for the PRISM design. The third exception is not considered sufficiently important to be added to the GDC and the preapplicant does not have to address it.

Therefore, a modified GDC 44 with the change in the title and the addition of the phrase "as necessary" is acceptable for the PRISM design.

\section{GDC 45: Inspection of Cooling Water System}

This criterion requires that the cooling water systems to transfer heat from SSCs important to safety to the ultimate heat sink(s) should have provisions for periodic inspections of important components to ensure the integrity and capability of the system. The LMR systems that perform the same function are not referred to as cooling water systems, but are important to safety, and this criterion should be applied to these systems.

The preapplicant has stated that GDC 45 , inspection of the cooling water systems that are covered in GDC 44 , is not applicable because the design does not require any safetyrelated cooling water systems. The staff concludes that the preapplicant has also concluded that GDC 44 is not applicable to the design.

For LMRs, the title of this criterion should be changed to inspection of "structural and equipment cooling system" to eliminate the reference to water and because this GDC should be applicable to any cooling system used to transfer heat from SSCs important to safety to the ultimate heat $\operatorname{sink}(\mathrm{s})$. This would include the transfer of heat from the residual heat removal system and the containment heat removal system, which are also covered by GDC 34 through 40 , to the ultimate heat $\operatorname{sink}(s)$. GDC 34 through 40 do not address the ultimate heat sink(s). This new title is also used in NUREG-0968 and ANSI/ANS-54.1-1989.

The GDC 45 requirements, without the reference to water, are independent of the plant design. The staff believes that the modified criterion is applicable to the PRISM design because GDC 45 is the only GDC concerned with inspection of the means to reject heat from SSCs important to safety to the ultimate heat sink(s). GDC 45 is consistent with Criterion 39 in NUREG-0968 and Criterion 3.4.11 in ANSI/ANS-54.1-1989, except that both documents also delete the word "water" from "cooling water system" in the first sentence of the criterion. The preapplicant should further address why this modified GDC 45 should not be applicable to the PRISM design. Therefore, a modified GDC 45 with the deletion of the word "water" and the change in the title is acceptable for the PRISM design.

\section{GDC 46: Testing of Cooling Water System}

This criterion requires that the cooling water systems to transfer heat from SSCs important to safety to the ultimate heat sink(s) should have provisions for periodic testing of important components and the system. This criterion should not be restricted to cooling water systems.

The preapplicant has stated that GDC 46, testing of the cooling water systems that are covered in GDC 44, is also not applicable because the PRISM design does not require any safety-related cooling water systems.

For LMRs, the title of this criterion should be changed to inspection of "structural and equipment cooling system" to eliximate the reference to water and to make this GDC applicable tc any cooling system used to transfer heat from SSCs important to safety to the ultimate heat $\operatorname{sink}(\mathrm{s})$. This would include the transfer of heat from the residual heat removal system and the containment heat removal system, which are also covered by GDC 34 through 40 , to the ultimate heat sink(s). GDC 34 through 40 do not address the ultimate heat sink(s). This new title is also used in NUREG-0968 and ANSI/ANS-54.1-1989.

The GDC 46 requirements, except for the reference to "cooling water" and the LOCA, are independent of the plant design. The staff believes that the modified criterion is applicable to the PRISM design because GDC 46 is the only GDC concerned with the testing of the means to reject heat from SSCs important to safety to the ultimate heat $\operatorname{sink}(\mathrm{s})$. The preapplicant should further address why this criterion should not be applicable to the PRISM design.

GDC 46 is consistent with Criterion 40 in NUREG-0968 and Criterion 3.4.12 in ANSI/ANS-54.1-1989, except that both documents have made the following changes:

(1) The word "water" in the phrase "cooling water system" was deleted.

(2) The phrase "for reactor shutdown and for loss-of-coolant accidents" in the middle of Item 3 of the criterion was deleted.

The first exception would delete the reference to water, as discussed above. The preapplicant should address why this 
reference should not be deleted from the GDC 46 for the PRISM design.

The second exception would delete a restriction to testing the performance of the full operational sequence that brings the cooling system into operation only "for reactor shutdown and for loss-of-coolant accidents." The preapplicant should address why this restriction should not be deleted from the GDC 46 for the PRISM design.

A modified GDC 46 with the deletion of the word "water" and the phrase "for reactor shutdown and loss-of-coolant accidents," and a change in the title, is acceptable for the PRISM design.

\section{GDC 50: Containment Design Basis}

This criterion requires that the containment structure, internal compartments, and associated penetrations be designed with sufficient margin to accommodate, without exceeding the design leakage rate, the potential energy releases during any LOCA. The margin shall reflect certain specified considerations, including 10 CFR 50.44 requirements on energy from metal-water reactions. This criterion, however, should not be restricted to metal-water reactions and LOCAs which are important to LWRs but not to LMRs.

The only exception proposed to this GDC is deletion of the reference to 10 CFR 50.44 in Item 1 of the criterion. The preapplicant stated that the containment is designed with margin to accommodate the calculated pressure and temperature conditions under normal operation and designbasis events, including coolant leakage into the containment. The containment for the PRISM design is the containment vessel and the upper dome containment. The preapplicant did not address the effect on compliance with GDC 50 from the changes to the containment design discussed in PSID Section G.4.1.

The requirements in GDC 50, with the deletion of the references to the LOCA, 10 CFR 54.44, and metal-water reactions, are independent of the design of the plant. The LOCA is not an important accident for the LMR containment design, 10 CFR 50.44 is not applicable to an LMR, and metal-water reactions will not be important for LMRs with a minimum of water inside containment. Therefore, the staff agrees witn the preapplicant that a modified criterion is applicable to the PR:SM design; however, the staff has considered additional modifications to the criteria that are in NUREG-0968 and ANSI/ANS-54.1-1989.

The preapplicant's proposed GDC 50 for the PRISM design, with the deletion of the reíerence to
10 CFR 50.44, is consistent with Criterion 41 in NUREG-0968 and Criteria 3.5.1 ("Containment/Confinement Design Basis"), $\quad 3.5 .2$ ("Containment Design Basis"), and 3.5.3 ("Confinement Design Basis") in ANSI/ANS-54.1-1989, with the following exceptions:

(1) NUREG-0968 replaces the phrase "the containment heat removal system" with the phrase " if necessary, in conjunction with additional postaccident heat removal systems including exvessel systems" in the list of systems, in the first sentence, that the criterion applies to.

(2) Both documents replace the phrase "loss-of-conlant accident" with the phrase "normal operation, including anticipated operational occurrences, and any of the postulated accidents" and ANSI/ANS-54.1-1989 adds the phrase, "assuming failure of a single active component" at the end of the first sentence.

(3) Both documents replace the phrase "such as energy in steam generators and as required by [10 CFR] 50.44 energy from metal-water and other chemical reactions that may result from degradation but not total failure of emergency core cooling functioning" with the phrase "such as decay heat in released fission products, potential spray or aerosol formation, and potential exothermic chemical reactions" at the end of Item 1 in the second sentence.

(4) ANSI/ANS-54.1-1989 adds a requirement that the containment or confinement or both stiall be designed to limit the release of radioactivity so that established guidelines (i.e., 10 CFR Part 100) are not exceeded for postulated accidents.

ANSI/ANS-54.1-1989 does not refer to the "containment heat removal system."

(6) ANSI/ANS-54.1-1989 adds requirements for confinement systems concerning provisions for operation at an internal negative pressure, recirculation rates, mixing, and filtration efficiency,

The first exception has the criterion refer to a more general "postaccident heat removal system" rather than to the more specific "containment heat removal system." This criterion should, for conservatism, refer only to the systems designed to remove heat from the containment (i.e., the containment heat removal systems) and not to other heat removal systems within the containment that are, for example, ren. iving heat from the reactor coolant. 
This exception and the fifth exception (above) from ANSI/ANS-54.1-1989 should not be made to the GDC 50 for the PRISM design.

In GDC 50, the containment is required to be designed for the LOCA; however, the LOCA is important to the design of containments for LWRs but not for LMRs. The second exception would replace the reference to LOCAs in the criterion with the phrases "normal operation, including anticipated operational occurrences, and any of the postulated accidents" and ", assuming failure of a single active component." Because the limiting design conditions for containments are not normal operation, including anticipated operational occurrences, but are postulated accidents, the phrase "loss-of-coolant accident" in GDC 50 should be replaced by "postulated accident." The proposed inclusion of the phrase about a single failure during a postulated accident is unnecessary. The specific postulated accidents used to determine the containment design conditions would be selected during the review of the design. These proposed changes do not change the fundamental principle of GDC 50, but ensure that accidents important to the containment design for the PRISM, or for any LMR, are considered. The preapplicant should address why these changes should not be made to the GDC 50 for the PRISM design.

The third exception would replace the phrase "such as energy in steam generators and as required by [10 CFR] 50.44 energy from metal-water and other chemical reactions that may result from degradation but not total failure of emergency core cooling functioning" with the phrase "such as decay heat in released fission products, potential spray or aerosol formation, and potential exothermic chemical reactions." As explained above, the reference to 10 CFR 50.44 and metal-water reactions that may result from emergency core cooling (ECC) degradation is incorrect for LMRs. The reference to energy into containment from decay heat from fission products, spray or aerosol formation, and exothermic chemical reactions is important to LMRs, and exothermic chemical reactions is another way of stating "other chemical reactions" in GDC 50. Although steam generators are typically placed outside the containment to reduce the size of the containment as in the PRISM design, they were placed inside the containment for the CRBRP design and, thus, a reference to the energy from steam generators should remain in GDC 50. Therefore, for the PRISM designs, the phrase "50.44 energy from metalwater reactions and other chemical reactions from degradation but not total failure of emergency core cooling functioning" should be replaced by a reference to energy from fission products, spray or aerosol formation, and exothermic chemical reactions. The preapplicant should address why these changes should not be made to the GDC 50 for the PRISM design.

The fourth exception would add a requirement that the containment or confinement or both shall be designed to limit the release of radioactivity so that established guidelines are not exceeded for postulated accidents. GDC 50 requires that the containment shall be designed not to exceed its design leakage rate during an accident. The leak rate of the containment during an accident limits the release of radioactivity from the containment to acceptable dose consequences. The design leak rate must be less than that which $w^{r}$.ld limit dose consequences for the postulated accident to acceptable values. Therefore, it is not necessary to add this requirement to the GDC 50 for the PRISM design.

The sixth exception would add requirements for confinement systems. The GDC do not address a confinement system, and the staff believes such an addition is unwarranted, and should not be included in the GDC 50 for the PRISM design.

Therefore, this proposed GDC 50 with the additional replacement of (1) LOCAs by postulated accidents and (2) metal-water and other chemical reactions from a degraded ECC by fission products, potential spray or aerosol formation, and exothermic chemical reactions is acceptable for the PRISM design.

\section{GDC 51: Fracture Prevention of Containment Pressure Boundary}

This criterion requires that the containment boundary structure be designed with sufficient margin to avoid brittle fracture under all postulated loading conditions, including postulated accidents. Replacing the phrase "ferritic materials" with "metallic materials" broadens the application of the GDC to all likely containment materials rather than to only ferritic metals.

The only exception proposed to this GDC is to change the phrase "ferritic materials" to "metallic materials" in the first sentence of the GDC. The preapplicant stated that the containment is designed with sufficient margin to ensure, under plant operation, maintenance, testing, and postulated accidents, that its metallic materials, which include metallic materials other than ferritic materials, will behave in a nonbrittle manner, and that the probability of rapidly propagating fracture is minimized. The preapplicant stated that the containment will be shop fabricated to better ensure material and fabrication quality of the structure compared to building it on site. 


\section{Review Approach and Criteria}

The requirements in this criterion with the proposed change are independent of the design of the plant; therefore, the staff agrees with the preapplicant that this criterion is applicable to the PRISM design.

The preapplicant's proposed GDC 51 is consistent with Criterion 42 in NUREG-0968 and Criterion 3.5.4 in ANSI/ANS-54.1-1989, except that both documents replace the word "operation" with the phrase "normal operation, including anticipated operational occurrences" in the first and second sentences. This change is not considered important for the PRISM design and the preapplicant does not have to address it. Both documents also replaced the phrase "ferritic materials" with "metallic materials" in the first sentence of the criterion.

Therefore, the proposed GDC 51 which replaces "ferritic materials" by "metallic materials" is acceptable for the PRISM design.

\section{GDC 52: Capability for Containment Leakage Rate Testing}

This criterion requires that the containment and applicable equipment be designed for periodic integrated leakage rate testing at the containment design pressure. The requirements are independent of the design of the plant; therefore, the staff agrees with the preapplicant that this criterion is directly applicable to the PPISM design.

No exceptions were proposed to this GDC. The preapplicant stated that the containment is designed for periodic leakage rate testing; however, the preapplicant did not specify pressure for the tests.

GDC 52 is consistent with Criterion 43 in NUREG-0968 and Criterion 3.5.5 in ANSI/ANS-54.1-1989, except that ANSI/ANS-54.1-1989 does not have the requirement that the leakage rate testing be done at the containment design pressure. This difference is not based on the unique characteristics of the LMRs and would reduce requirements because GDC 52 requires that the testing be done at the containment design pressure. Therefore, this difference should not be included in the GDC 52 for the PRISM design.

The current GDC 52 is acceptable as written for the PRISM design. GDC 53: Provisions for Containment Testing and
Inspection

This criterion requires that the containment be designed for periodic inspections of all important areas, such as the penetrations, including the leaktightness at containment design pressure of the penetrations which have resilient seals and expansion bellows. These requirements are independent of the design of the plant, and penetrations with resilient seals and further expansion bellows could exist in LMR plants. The staff agrees with the preapplicant that this criterion is directly applicable to the PRISM design.

No exceptions were proposed to this GDC. The preapplicant stated that the containment will be subjected to (1) a structural integrity test in accordance with Article CC-6600 of Division 2, Section III of the ASME Code (Ref. 3.22) and (2) a program of preoperational and periodic leakage rate verification tests similar to that required for LWRs in Appendix J to 10 CFR Part 50. The containment and internal equipment and structures will be designed to accommodate these tests.

GDC 53 is consistent with Criterion 44 in NUREG-0968 and Criterion 3.5.6 in ANSI/ANS-54.1-1989, except that ANSI/ANS-54.1-1989 added words concerning confinement systems. As discussed previously, these additional words are not considered necessary for GDC 53.

Therefore, GDC 53 is acceptable as written for the PRISM design.

\section{GDC 54: Piping Systems Penetrating Containment}

This criterion requires that piping systems penetrating the containment have leak detection, isolation, and containment capabilities with redundancy, reliability, and performance consistent with the importance to safety of isolating the piping system. The piping systems shall have the capability to also periodically test the operability of the isolation valves and allow the determination that the valve leakage is within acceptable limits.

No exceptions were proposed to this GDC. The preapplicant stated that piping systems penetrating the containment are designed to have leak detection, isolation, and containment capabilities with redundancy, reliability, and performance capabilities that reflect the importance to safety of isolating these piping systems, while allowing for periodic testing of operability and the determination that leakage is within acceptable limits.

The requirements in this criterion are independent of the design of the plant; therefore, the staff agrees with the preapplicant that this criterion is directly applicable to the PRISM design.

GDC 54 is consistent with Criterion 45 in NUREG-0968 and Criterion 3.5.7 in ANSI/ANS-54.1-1989, with the following exceptions: 
(1) ANSI/ANS-54.1-1989 replaced the phrase "which reflect the importance to safety of isolating these piping systems" with the phrase "as required to meet the containment safety function" at the end of the first sentence.

\begin{abstract}
ANSI/ANS-54.1-1989 replaced the phrase "having redundancy, reliability, and performance capabilities" in the first sentence of the criterion with the sentence "See criteria contained in [Criteria] 3.5.8, 3.5.9, and 3.5.10 for the redundancy, reliability, and performance requirements."
\end{abstract}

For both exceptions, there are no substantive differences between the requirements in the two phrases being deleted and the requirements in the phrase and sentence being added. Therefore, these changes should not be made to the GDC 54 for the PRISM design.

Therefore, GDC 54 is acceptable as written for the PRISM design.

\section{GDC 55: Reactor Coolant Pressure Boundary Penetrating Containment}

GDC 55 requires two containment isolation valves near the containment pressure boundary on lines penetrating primary containment and connecting directly to the RCPB. Acceptable combinations of automatic isolation valves and locked-closed valves are specified in the criterion. A simple check valve may not be used as the automatic isolation valve outside the containment. The "other appropriate requirements" discussed in the criterion are to minimize the probability or consequences of an accidental rupture of such lines that could potentially release fluids from the RCPB which are normally very radioactive.

The preapplicant stated that GDC 55 does not apply to the PRISM design because all the primary sodium is within the reactor vessel during reactor operation, and the core is inside a pool of sodium. However, the preapplicant has also stated that the primary sodium service system piping is open to the sodium pool but will have containment isolation in accordance with GDC 56 instead of GDC 55.

The PRISM design has piping that is directly connected to the RCPB and that penetrates the containment. The preapplicant stated that the primary sodium service system which is used during reactor shutdown has piping open to the sodium pool and, therefore, to the RCPB. The fact that the system would not be used during reactor operation should not relieve the system from the requirements of GDC 55. Because the requirements for containment isolation valves are the same for GDC 55 and 56 (i.e., the preapplicant would apply GDC 56 to these lines), one might conclude that it does not matter which GDC is applied to this system; however, the "other appropriate requirements" in the last paragraph of GDC 55 could result in additional requirements on this system if it is designed in accordance with GDC 55 instead of GDC 56.

The requirements in this criterion are independent of the design of the plant and impose important restrictions of containment isolation that do not exist elsewhere in the GDC. Also, even if having no systems within the PRISM design fall within GDC 55, does not mean that GDC 55 should not apply to the design. Therefore, the staff believes that this criterion is directly applicable to the PRISM design. The preapplicant should further justify why GDC 55 should not apply to the PRISM design.

GDC 55 is consistent with Criterion 46 in NUREG-0968 and Criterion 3.5.8 in ANSI/ANS-54.1-1989, with the following exceptions:

(1) Both documents add the phrase "or directly connected to" to the description of the applicable piping systems in the first sentence of the criterion.

ANSI/ANS-54.1-1989 adds the phrase "or the reactor cover gas boundary" to the description of the applicable piping systems in the first sentence.

The first exception modifies the description of the applicable piping systems to include such supporting systems as drain lines and purification system lines (e.g., the primary sodium service system piping in the PRISM design) under GDC 55 because they are connected to and contain the primary sodium coolant. However, these systems should already be included in the existing statement that GDC 55 applies to systems "that are part of the RCPB"; therefore, it is not necessary to add this phrase to the GDC.

The second exception seems to address the question of whether the piping which is directly connected to the reactor cover gas space should be considered under GDC 55 for piping that is part of the RCPB or under GDC 56 for piping connected directly to the containment atmosphere. Because the cover gas space is in direct contact with the coolant and is not part of the containment atmosphere, GDC 55 should apply to this piping. This change would clarify which systems should be subject to GDC 56 because of the unique design of LMRs and would not add new requirements to the criterion; therefore, the preapplicant should further justify why this phrase is not added to the GDC 55 for the PRISM design. 
The modified GDC 55, with the additional words concerning the reactor cover gas space, is acceptable for the PRISM design.

\section{GDC 56: Primary Containment Isolation}

This criterion requires two containment isolation valves near the containment pressure boundary on lines penetrating the primary containment and connecting directly to the containment atmosphere. Acceptable combinations of automatic isolation valves and lockedclosed valves are specified in the criterion. A simple check valve may not be used as the automatic isolation valve outside the containment. These requirements are independent of the design of the plant; therefore, the staff agrees with the preapplicant that this criterion is directly applicable to the PRISM design. GDC 56 is consistent with Criterion 47 in NUREG-0968 and Criterion 3.5.9 in ANSI/ANS-54.1-1989.

No exceptions were proposed to this GDC. The preapplicant stated that during operation all gaseous service system lines that penetrate the primary reactor containment boundary are closed and that redundant isolation valves are located as close as practical to the reactor closure head. The gaseous service lines are open to the reactor coolant cover gas space and the designer considers them part of the containment atmosphere. The preapplicant has not addressed the changes to its implementation of GDC 56 in response to the addition of the upper dome containment in PSID Section G.4.1 which places the containment boundary at the upper dome. The primary sodium service lines and cover gas piping are shown with double isolation valves located near the upper dome containment boundary in PSID Figure G.4.1-5. The preapplicant did not address the type of isolation valves to be used for the penetrations.

Therefore, GDC 56 is acceptable as written for the PRISM design.

\section{GDC 57: Closed System Isolation Valves}

GDC 57 requires a single containment isolation valve, which is either automatic (but not a simple check valve), or locked closed, or capable of remote manual operation, for piping that penetrates the containment but is neither part of the RCPB nor connected directly to the containment atmosphere. The valve shall be outside the containment and located as close as practical to the containment.

The preapplicant stated that GDC 57 does not apply to the PRISM design because there is no piping of this type, that is, piping that penetrates the containment but is neither part of the RCPB (i.e., piping under GDC 55) nor connected directly to the containment atmosphere (i.e., piping under
GDC 56). This may have been correct before PSID Section G.4.1 of Amendment 13 was issued, when the upper dome containment was added to the containment design to enclose the reactor closure head and the IHX. In addition to the piping from the IHX to the steam generator penetrating the upper dome, there is the upper dome containment cooling system piping that penetrates the upper dome but is neither part of the RCPB nor is it connected directly to the containment atmosphere. GDC 57 should apply to this piping for both systems.

It also appears that the IHX piping that lies within the reactor coolant system should be considered part of the RCPB (i.e., the outside of the single wall piping is part of the RCPB) and that aspects of GDC 55 concerning "other appropriate requirements" may apply to this system for piping which penetrates containment. This is discussed in Section 6.6 of this report.

The requirements in GDC 57 are independent of the design of the plant and apply to piping not covered by GDC 55 and 56. Such a GDC should be retained for LMRs. Even though the PRISM design may not have this type of piping, this should not mean that the requirements should not exist and should not apply to the design, because this type of piping may be added to the design in the future. This criterion is directly applicable to the PRISM design. If none of this type of piping exists in a design, then the requirements of the GDC would not be imposed on the design. Therefore, the preapplicant should further justify why GDC 57 should not apply to the PRISM design.

GDC 57 is consistent with Criterion 48 in NUREG-0968 and Criterion 3.5.10 in ANSI/ANS-54.1-1989, with the following exceptions:

(1) Both documents replace the phrase "part of the reactor coolant pressure boundary" with either the phrase "part of nor directly connected to the reactor coolant pressure boundary" (NUREG-0968) or the phrase "part of nor directly connected to the reactor coolant or cover gas boundaries" (ANSI/ANS-54.1-1989).

(2) Both documents add the phrase ", unless it can be demonstrated that containment isolation provisions for a specific class of lines are acceptable on same other defined basis" after the phrase "at least one containment isolation valve."

The first exception (considering first only the NUREG-0968 proposal) would exclude systems that penetrate the containment and contain primary coolant because these systems are addressed in GDC 55. Because GDC 55 applies to piping that is "part of the reactor 
coolant pressure boundary" and GDC 57 applies to piping that is not "part of the reactor coolant pressure boundary," there should be no confusion about the piping covered by either GDC and it is not necessary to include this change to GDC 57 for the PRISM design.

The addition of the phrase "or cover gas boundaries" in the first exception would include the cover gas space within the reactor coolant pressure boundary. As discussed under GDC 55, some may question whether the piping that is directly connected to the reactor cover gas space should be considered to be part of the RCPB or to be connected directly to the containment atmosphere (i.e., under GDC 55 or 56). Because the cover gas space is in direct contact with the coolant and is not part of the containment atmosphere, such piping is part of the RCPB. This addition would clarify GDC 57 for LMRs but would not add new requirements to the design of nuclear power reactors. The preapplicant should address why this phrase should not be added to the GDC 57 for the PRISM design.

The second exception would allow an alternate approach to containment isolation to the one specified in the GDC. The additional phrase is a relaxation of GDC 57 which might provide flexibility to the designer in meeting the GDC and is currently stated in GDC 55 and 56 . However, because this is a relaxation of the GDC which is not based on the unique characteristics of the LMR, it should not be applied to the PRISM design.

Therefore, a modified GDC 57, with the addition of the phrase "or cover gas boundaries" to the RCPB, is acceptable for the PRISM design.

\section{GDC 60: Control of Releases of Radioactive Materials to the Environment}

This criterion requires the plant to have provisions for the controlled release of gaseous, liquid, and solid radwaste from the plant during normal reactor operation and anticipated operational occurrences. Sufficient holdup capacity shall be provided for gaseous and liquid radwaste. The preapplicant did not address anticipated operational occurrences, sufficient holdup capacity, and the waste gas system for the reactor system cover gas in the PSID. This information should be provided at a later design review stage.

No exceptions were proposed to this GDC. The liquid radioactive waste system is divided into intermediate and low-level waste streams. Normal operation liquids are released to the environment within Federal guidelines, after discharge and dilution. The solid and gaseous radioactive waste systems are provided by the onsite fuel cycle facility. Solid waste will be shipped in approved containers.

The requirements of this criterion are indeperflent of the design of the plant. LMRs have gaseous, liquid, and solid radwaste; therefore, the staff is consistent with the preapplicant that this criterion is directly applicable to the PRISM design. GDC 60 is consistent with Criterion 52 of NUREG-0968 (Ref. 3.18) and Criterion 3.6.1 of ANSI/ANS-54.1-1989 (Ref. 3.17) and is acceptable as written for the PRISM design.

\section{GDC 61: Fuel Storage and Handling and Radioactivity Control}

This criterion requires that systems that store and handle fuel, radwaste systems, and other systems containing radioactivity be designed for periodic inspection, testing, shielding, adequate coolant inventory, confining or filtering, and cooling to ensure adequate safety under normal and postulated accident conditions.

The preapplicant proposed no exceptions to this GDC. The sections discussing fuel handling and radioactive waste management provided details on the design basis of these systems.

The requirements in GDC 61 are independent of the design of the plant; therefore, the staff is in agreement with the preapplicant that this criterion is directly applicable to the PRISM design. GDC 61 is consistent with Criterion 53 in NUREG-0968 and Criterion 3.6.2 in ANSI/ANS-54.11989 , with the following exceptions:

A sentence is added at the end of each criterion that "The fuel handling and its interfacing systems shall be designed to minimize the potential for fuel management errors that could result" in either "fuel rod failure" (NUREG-0968) or "fuel damage limits being exceeded" (ANSI/ANS-54.1-1989).

(2) In the first sentence of each criterion, a phrase ", including anticipated operational occurrences" is added after "normal operation".

The first exception clarifies the reference to adequate safety in GDC 61 for fuel handling and the interfacing systems so that they be designed to minimize fuel management errors that could result in fuel damage. This could also be applied to LWRs because it is not based on the unique characteristics of LMRs; however, it is not considered a new requirement. Therefore, the preapplicant should address why this clarification should not be added to the GDC 61 for the PRISM design. 
The second exception, would add the phrase ", including anticipated operational occurrences" to modify "normal operation" in the criterion. This is not considered important for the PRISM design because it is not necessary to include "anticipated operational occurrences" with normal operation when GDC 61 requires that fuel storage and handling, radioactive wastes, and other systems be designed for accident conditions. The preapplicant does not have to address it.

Therefore, a modified GDC 61, with the addition of a sentence on the design of the fuel handling system, is needed for the PRISM design.

\section{GDC 62: Prevention of Criticality in Fuel Storage and Handling}

This criterion requires physical systems or processes, preferably by geometrically safe configurations, to prevent criticality in handling and storing fuel. The requirements are independent of the design of the plant; therefore, the staff finds this criterion directly applicable to the PRISM design. GDC 62 is consistent with Criterion 54 in NUREG-0968 and Criterion 3.6.3 in ANSI/ANS-54.11989 , and it is acceptable as written for the PRISM design.

No exceptions were proposed to this GDC. The preapplicant stated that means will be provided to prevent criticality among fuel assemblies using poison columns in the interstices between the fuel storage positions. These positions are also spaced to ensure a geometrically safe configuration.

\section{GDC 63: Monitoring Fuel and Waste Storage}

This criterion requires systems to monitor fuel and radwaste storage areas to ensure adequate heat removal and acceptable radiation levels. This is independent of the plant design; thus, the staff agrees with the preapplicant that GDC 63 is directly applicable to the PRISM design. GDC 63 is consistent with Criterion 5.5 in NUREG-0968 and Criterion 3.6.4 in ANSI/ANS-54.1-1989, and it is acceptable as written for the PRISM design.

The preapplicant proposed no exceptions to this GDC. The PSID states that a means has been provided for monitoring fission gas release from fuel in the fuel handling cell. The preapplicant did not state if this would also be true for the fuel storage facility, radioactive waste systems, and fuel handling areas, and how this monitoring would detect conditions that may result in loss of residual heat removal.

\section{GDC 64: Monitoring Radioactivity Releases}

This criterion requires means to monitor the containment atmosphere, spaces containing components for recirculation of LOCA fluids, effluent discharge paths, and the plant environs for radioactivity that may be released from the plant during normal operations and postulated accidents.

No exceptions were proposed to this GDC. The preapplicant stated that means have been provided for monitoring radioactivity releases resulting from normal and anticipated operational occurrences. The preapplicant did not state if this would be true for releases during postulated accidents, as also required in GDC 64 . This information should be provided at a later design review stage.

The requirements in this criterion are independent of the design of the plant, except for the reference to "spaces containing components for recirculation of loss-of-coolant accident [LOCA] fluids" which is specific to LWRs. LMR designs, including CRBRP and PRISM, do not allow for collection and recirculation of coolant lost from the RCPB. Therefore, the staff agrees with the preapplicant that this criterion is applicable to the PRISM design; however, the phrase concerning spaces for recirculation of LOCA fluids should be deleted frotn this criterion for the PRISM design.

GDC 64 is consistent with Criterion 56 in NUREG-0968 and Criterion 3.6.5 in ANSI/ANS-54.1-1989 in that the two documents also delete the phrase "spaces containing components for recirculation of loss-of-coolant accident fluids" from the criterion. The preapplicant should address why this phrase should not be deleted from the GDC 64 for the PRISM design.

Therefore, a modified GDC 64, with the deletion of the phrase "spaces containing components for recirculation of loss-of-coolant accident fluids," is needed for the PRISM design.

\subsubsection{Additional GDC Proposed for the PRISM Design Not in 10 CFR Part 50}

There are additional proposed GDC in NUREG-0968 (the staff's safety evaluation report on the CRBRP design, including the conformance of the design to the GDC), and in the industry's standard (ANSI/ANS-54.1-1989), for GDC for LMRs, for which there is no directly corresponding criterion in the GDC in Appendix A to 10 CFR Part 50. The additional GDC that are discussed in Sections 3.2.4.1 through 3.2.4.9 are the following: 
- protection against sodium reactions

- sodium heating systems for the liquid-metal coolant

- heat transport system design

- assurance of adequate reactor coolant inventory

- design of the intermediate coolant system that interfaces with the RCPB

- reactor and intermediate coolant, and cover gas purity control

- inspection and testing of the residual heat removal system

- protection against fuel rod failure propagation

- protection against coolant flow blockage

\subsubsection{Protection Against Sodium Reactions}

NUREG-0968 and ANSI/ANS-54.1-1989 (i.e., Criterion 4 and Criterion 3.1.4, respectively) propose what would be a new criterion for LMR reactor designs. This new criterion concerns designing structures, systems, and components to limit the consequences of chemical reactions resulting from a sodium leak. The intent of the criterion is to require that the plant be designed and constructed with special consideration given to the effects of sodium, including the detection, consequences, and mitigation of sodium reactions and spills. Because of the high chemical activity of sodium, leaks or spills can lead to chemical reactions, fires, and combustion products not possible in LWRs. Therefore, requirements that special measures be taken to prevent contact of sodium with water, concrete, and oxygen, and to extinguish any sodium fires that occur need to be considered in the design. In addition, means to detect sodium spills and to protect plant equipment and personnel from the corrosive and potentially radioactive corrosion products are required.

Because there is no similar design criterion in the GDC to account for the high chemical activity of sodium with such common plant materials as water, air, and concrete, a GDC covering the sodium coolant for LMR designs warrants developing. Therefore, the preapplicant should address the development of an additional criterion for the PRISM design on protecting the plant against sodium reactions similar to those developed in NUREG-0968, ANSI/ANS-54.1-1989, and ANS 54.8, "Standard for Liquid Metal Fire Protection in LMR Plants" (Ref. 3.23).
This criterion appears to be one of the safety design criteria presented by the preapplicant in PSID Section 1.2.1.2.2.

\subsubsection{Sodium Heating Systems}

NUREG-0968 and ANSI/ANS-54.1-1989 (i.e., Criterion 7 and Criterion 3.1.7, respectively) propose what would be a new Criterion 7 for LMR reactor designs. This criterion concerns heating systems needed to maintain sodium in liquid form and to prevent sodium aerosols from condensing and plugging flow paths; it would be unique for LMR designs. The intent of the criterion is to require that systems important to safety, and which contain sodium or sodium aerosols and require a controlled temperature for the system to perform its safety function, be designed and maintained to preclude overheating (creating aerosols) and underheating (condensing aerosols and freezing sodium) the system. Because the physical properties of sodium are significantly different from those of water, and because sodium freezes above the boiling point of water, special measures should be taken for LMR designs that are not needed for LWR designs.

An LWR design feature similar to the sodium heating system in LMRs is the heat tracing of high-concentration boric acid and water lines outside buildings where the temperature is below the freezing point of water. Requirements for system features similar to those listed in SRP Section 9.3.4, Item III.A.9 (Ref. 3.9), should be developed for sodium systems in LMRs.

The preapplicant should address the development of an additional criterion on sodium heating systems for the PRISM design similar to those developed in NUREG-0968 and ANSI/ANS-54.1-1989.

\subsubsection{Heat Transport System Design}

The intent of Criterion 26 of NUREG-0968 is to ensure the system that transports heat from the reactor to the turbine generator or ultimate heat sink will be designed to (1) provide sufficient cooling to not exceed the fuel design limits for normal operation and anticipated operational occurrences, (2) maintain the integrity of the RCPB to provide adequate core cooling for postulated accidents with at least two flow paths available, and (3) have at least two independent flow paths. There is no corresponding criterion in ANSI/ANS-54.1-1989.

This criterion is the same as GDC 34, "Residual Heat Removal"; GDC 35, "Emergency Core Cooling"; and GDC 44, "Cooling Water," for LWRs. As discussed above for GDC 34 and 35, a revised GDC 34 which was also for (1) all reactor conditions including postulated 
accidents and (2) preventing fuel and clad damage that could interfere with continued effective core cooling, would cover the design of the residual heat removal system, the emergency core cooling system, and the heat transport system. In the discussion on GDC 44 , it is stated that GDC 44 provides the general design requirements for systems transferring heat to the ultimate heat sinks. Therefore, the revised GDC 34 and GDC 44 encompass the requirements proposed in Criterion 26 of NUREG-0968 and it is not necessary to have an additional criterion on the heat transport system.

\subsubsection{Assurance of Adequate Reactor Coolant Inventory}

The intent of Criterion 27 of NUREG-0968 and Criterion 3.4.1 of ANSI/ANS-54.1-1989 is to ensure the heat transport system provides for retention of sufficient sodium inventory to ensure adequate decay heat removal capability. This is discussed under GDC 33, "Reactor Coolant Makeup." A revised GDC 33 using the words from Criterion 27 of NUREG-0968 and Criterion 3.4.1 of ANSI/ANS-54.1-1989 is proposed for the LMR and the PRISM design instead of the GDC 33 for LWRs.

\subsubsection{Design of the Intermediate Coolant System}

Criteria 31 through 33 of NUREG-0968 and Criteria 3.4.5 and 3.4.6 of ANSI/ANS-54.1-1989 are concerned with the design of the intermediate coolant istem between the reactor coolant system and the st a generator for the LMRs. There are equivalent criteria in the GDC for LWRs regarding the cooling water systems for SSCs important to safety (i.e., GDC 44 to 46). The LWR intermediate cooling system is between the safety-related SSCs and the ultimate heat sink. Another equivalent system for LWRs would be the steam generator for pressurized water reactors (PWRs) for which GDC 14, 15, 31 , and 32 are applicable.

The requirements in Criterion 31, "Intermediate Coolant System, " and Criterion 33, "Inspection and Surveillance of Intermediate Coolant System," of NUREG-0968 are consistent with requirements imposed in the GDC for equivalent systems in LWRs or add new requirements which come from the differences between sodium and water. Criteria 3.4.5 and 3.4.6, respectively, of ANSI/ ANS-54.1-1989 correspond to these criteria. The preapplicant should address why these two criteria are not included with the GDC for the PRISM design.

The requirements in Criterion 32, "Fracture Prevention of Intermediate Coolant Boundary, " of NUREG-0968 are not consistent with requirements imposed in the GDC for equivalent systems in LWRs. In SRP Section 5.4.2.1,
"Steam Generator Materials," it is stated that GDC 31 on fracture prevention of the reactor coolant pressure boundary is applied up to the steam line isolation valves and not beyond, however, Criterion 32 of NUREG-0968 appears to be applied to the entire intermediate coolant system up to the steam generator.

The GDC 31 for LMRs, discussed above, should require that the intermediate coolant system be designed for fracture prevention up to the isolation valves and not beyond. Therefore, there should not be a need for a separate criterion on fracture prevention of the intermediate coolant system and Criterion 32 of NUREG-0968 should not be considered as a GDC for the PRISM design.

\subsubsection{Reactor and Intermediate Coolant, and Cover Gas Purity Control}

This is Criterion 34 of NUREG-0968 and Criterion 3.4.4 of ANSI/ANS-54.1-1989 which require that systems shall be provided to monitor and maintain reactor coolant, intermediate coolant, and cover gas purity within acceptable limits. A corresponding system for LWRs is the reactor water cleanup system for boiling water reactors (BWRs). In SRP Section 5.4.8, "Reactor Water Cleanup System," the system is required to be capable of maintaining acceptable reactor water purity in normal operation and anticipated operational occurrences in accordance with GDC 14, "Reactor Coolant Pressure Boundary." Therefore, as discussed under GDC 14 (above), a similar extension for LMRs should require that there be LMR systems to keep the reactor coolant, intermediate coolant, and cover gas purity within acceptable limits for LMR designs; however, it would be more explicit to have a specific GDC for LMR designs.

Therefore, the preapplicant should address the development of an additional criterion for the PRISM design similar to Criterion 34 in NUREG-0968 and Criterion 3.4.4 in ANSI/ANS-54.1-1989.

\subsubsection{Inspection and Testing of the Residual Heat Removal System}

The intent of Criteria 36 and 37 of NUREG-0968 and Criteria 3.4.8 and 3.4.9 of ANSI/ANS-54.1-1989 is to ensure that the residual heat removal system is designed for periodic inspection and testing of principal components important to safety. This is discussed above for GDC 36, "Inspection of Residual Heat Removal System," and GDC 37, "Testing of Residual Heat Removal System." The revised GDC 36 and 37 with the deletion of the references to emergency core cooling and water, and a change in the list of important components would have the 
requirements given in Criteria 36 and 37 of NUREG-0968 and Criteria 3.4.8 and 3.4.9 of ANSI/ANS-54.1-1989.

\subsubsection{Protection Against Fuel Rod Failure Propagation}

Criterion 59 of NUREG-0968 which requires features to limit propagation of stochastic fuel rod failures which could lead to a disruption of a significant fraction of the core, and to monitor for fuel pin failures. This criterion was originally proposed for CRBRP because of design differences between CRBRP fuel and LWR fuel and the limited experience compared to LWR fuel.

There is presently no Section 50.44 and Appendix $\mathrm{K}$ to 10 CFR Part 50 for LMR designs; however, as discussed in SRP Section 4.2, "Fuel System Design, " GDC 10, 27, and 35 impose requirements on the reactor design, including fuel, reactivity control, and emergency core cooling, respectively, to limit fuel damage during normal operation and postulated accidents to avoid losing the ability to cool the core effectively. SRP Section 4.2 also requires on-line fuel failure monitoring and post-irradiation surveillance to detect anomalies or confirm that the fuel has performed as expected. Although there are differences between LMR fuel and LWR fuel, there does not seem to be a need to add a new GDC for the PRISM design to properly address the fuel beyond the GDC 10,27, and 35 for the PRISM design. These criteria are discussed under GDC 10, 27, and 35 above.

\subsubsection{Protection Against Coolant Flow Blockage}

Criterion 60 of NUREG-0968, requires the reactor and core assembly designs to incorporate features to minimize the potential for flow blockage while the fuel assemblies are in the reactor core so that flow blockage can be eliminated as a design-basis event. Because the core assemblies in CRBRP were ducted assemblies, blockages or restrictions at the inlet of an assembly affect flow through the entire assembly and could cause fuel failure such as occurred at the Fermi-1 reactor.

The applicant discusses flow blockage events for the PRISM design in PSID Section G.4.6 and in Section 4.4.6.4 of this report. This GDC should be considered for the PRISM design.

\subsubsection{CFR Part 52}

Section 50.34(a)(3)(i) of 10 CFR Part 50 requires that the preliminary safety analysis report for an LWR nuclear power plant design include the principal design criteria for the proposed facility. The preapplicant met this requirement by submitting GDC for the PRISM design.
This is in PSID Section 3.1. These proposed criteria were evaluated in Section 3.2.3 ("Comparison to the GDC in 10 CFR Part 50"), and Section 3.2.4 ("Additional GDC Proposed for the PRISM Design Not in 10 CFR Part 50"). The preapplicant was requested to address changes to its proposed criteria in these two sections.

\subsubsection{Commission's Advanced Reactor Policy Statement}

As discussed in Section 3.2.1.2 above, the preapplicant proposed GDC for the PRISM design in PSID Section 3.1 and has compared these criteria to the GDC to show where the GDC are applicable to the PRISM design. The preapplicant has, therefore, complied with Items 2 and 3, listed in Section 3.2.1.2 above, of the Commission's Advanced Reactor Policy Statement on the GDC.

The preapplicant's proposed GDC for the PRISM design were evaluated against the GDC for LWRs in Section 3.2.3 ("Comparison to the GDC in 10 CFR Part 50"), and Section 3.2.4 ("Additional GDC Proposed for the PRISM Design Not in 10 CFR Part 50"). The preapplicant was requested to address changes to its proposed criteria in these two sections. With the resolution of these changes, the staff would conclude that the PRISM design has complied with one part of the Commission's policy statement that the advanced reactor should provide at least the same degree of protection that is required of current-generation LWRs (i.e., Item 1 of Section 3.2.1.2 above), that is the GDC for the PRISM design would require at least the same degree of protection that is required in the GDC for the LWR designs. The other parts would come from the review of the specific margins in fuel design limits, containment design limits, and so forth, of the PRISM design compared to the current LWR designs.

\subsubsection{Review of Clinch River Breeder Reactor Plant (CRBRP)}

In the evaluation of the GDC proposed by the preapplicant for the PRISM design, the proposed criteria were compared to the GDC for the CRBRP in Section 3.1 of NUREG-0968. The comparison is discussed in Section 3.2.3 ("Comparison to the GDC in 10 CFR Part 50"), and Section 3.2.4 ("Additional GDC Proposed for the PRISM Design Not in 10 CFR Part 50"). Where GDC for the CRBRP were relevant to the PRISM design and not part of the criteria proposed by the preapplicant, the preapplicant was requested to address why these criteria are not included in the GDC for the PRISM design. 


\subsubsection{Industry Standard ANSI/ANS-54.1}

In the evaluation of the GDC proposed by the preapplicant for the PRISM design, the proposed criteria were compared to the GDC for an LMR design in the industry standard ANSI/ANS-54.1-1989. The comparison is discussed in Section 3.2.3 ("Comparison to the GDC in 10 CFR Part 50"), and Section 3.2.4 ("Additional GDC Proposed for the PRISM Design Not in 10 CFR Part 50"). Where GDC for an LMR design in the standard were relevant to the PRISM design and not part of the criteria proposed by the preapplicant, the preapplicant is requested to address why these criteria are not included in the GDC for the PRISM design during the preliminary design phase.

\subsubsection{Advanced Reactor Design Policy Issues}

In the Commission policy paper (SECY-93-092) dated April 8, 1993 (Ref. 3.1), the staff presented ten key policy issues bearing on the future advanced reactor designs, including the PRISM design, to request guidance from the Commission on these issues. These key issues are the following: accident evaluation, source term, containment performance, emergency planning, reactivity control, operator staffing, residual heat removal, positive void coefficient, control room design, and safety classification. These issues are discussed in the GDC: GDC 1 (safety classification, operator staffing, accident evaluation, and source term), GDC 11 (positive void coefficient), GDC 16 (containment performance), GDC 19 (control room design), GDC 26 (reactivity control), and GDC 34 (residual heat removal). These key issues were made available to the preapplicant and the puivlic by a Commission paper dated April 8, 1993. The key policy issues were also reviewed by the ACRS at a full-commitice meeting on January 6, 1993. The Commission approved the staff's recommendations contained in SECY-93-092 in an SRM, July 30, 1993, which was released to the public on August 16, 1993.

\subsubsection{Conclusions}

The preapplicant proposed GDC for the PRISM design in PSID Section 3.1. These criteria were evaluated against the requirements in 10 CFR Part 52, the Commission's Policy Statement on advanced reactors, the GDC for the CRBRP design, and the GDC for an LMR design in ANSI/ANS-54.1-1989. The preapplicant was requested (1) to address why certain additional changes, not proposed by the preapplicant, should not be included in the proposed GDC for the PRISM design and (2) to provide additional justification why certain GDC should be considered not applicable to the PRISM design. Additional requirements were identified that may be needed for the GDC for the PRISM design, and the applicant was requested to address why these additional requirements should not be included in the GDC for the PRISM design.

With the resolution of the changes identified in these two sections above, the staff would conclude that the PRISM design has met one part of the Commission's policy statement that the advanced reactor should provide at least the same degree of protection to the public and the environment that is required of current-generation LWRs. The other parts, as discussed in Section 3.1.1 of this safety evaluation, would come from the review of the specific margins in fuel design limits, containment design limits, and so forth, of the PRISM design compared to the current LWR designs.

\subsection{Seismic Design}

The seismic design consists of the specification of the seismic input to the plant, plant system analysis, system seismic analysis, seismic instrumentation, and the seismic base isolation system.

3.3.1 Seismic Input, Plant System Analysis, and System Seismic Analysis

\subsubsection{Design Description and Safety Objectives}

The seismic input described the generic site characteristics (including soil properties and shear wave velocities), vibration spectra, site validation, damping values, and time-history development. The plant system analysis described embedded structures analysis, development of floor response spectra, interaction of structures, and incrorporation of torsional effects. System seismic analysis Jescribed analysis and qualification-by-test of mechanical and electrical components; and piping; heating, ventilation, and air conditioning (HVAC) ducts; electrical raceways; buried pipes; and tunnels analysis.

\subsubsection{Scope of Review}

This review focused on information submitted in PSID Chapter 3, as modified by Amendments 12 and 13 to the PSID.

\subsubsection{Design Criteria}

GDC 2 of Appendix A to 10 CFR Part 50 requires, in part, that nuclear power plant structures, systems, and components important to safety be designed to withstand the effects if such natural phenomena as earthquakes, tornadoes, f oods, tsunamis, and seiches without loss of capability to verform their safety functions. 
It is the purpose of Appendix A to 10 CFR Part 100 to give the principal seismic and geologic considerations to guide the Commission in its evaluation of the suitability of proposed sites for nuclear power plants, and in the design suitability of the plant for a particular site. Appendix A of 10 CFR Part 100 applies primarily to LWRs, but is also applicable to other types of reactors.

\subsubsection{Research and Development}

Applicant-sponsored R\&D was not described or reviewed at this time.

\subsubsection{Safety Issues}

The design used to ensure that the required safety functions are maintained during and after the vibratory ground motion associated with the safe-shutdown earthquake (SSE) shall involve the use of either a suitable dynamic analysis or a suitable qualification test.

The analysis or test shall take into account soil-structure interaction at various typical sites and should include structure-to-structure interaction between modules, variability in soil properties, and the expected duration of vibratory motion. It is permissible to design for strain limits in excess of yield strain in some of these safetyrelated structures, systems, and components during the SSE and under the postulated concurrent conditions, provided that the necessary safety functions are maintained.

\subsubsection{Evaluation}

The evaluation is limited to discovering potential safety problems with the design and identifying information the applicant is expected to submit at the next licensing stage.

In PSID Section 3.7.1.1, "Generic Site Characteristics," the applicant should submit a discussion on liquefaction potential either generically or specifically in the next submittal. Also, seismic classification of structures, systems, and components important to safety should be indicated, as should any component that could affect a safety-related system.

SRP Sections 2.5.2, 3.7.1, 3.7.2, and 3.7.3 were revised in 1989 as part of the resolution of Unresolved Safety Issue A-40, "Seismic Design Criteria." The applicant should review applicable sections of the PRISM PSID as appropriate, to reflect new staff positions on the location of the seismic input motion control point, variability in soil properties, and design time-history options, or should submit technical justifications in support of the deviations.
The procedures and criteria used for piping analysis, HVAC duct analysis, electrical raceway analysis, and buried pipe and tunnels should be included in the next submittal.

\subsubsection{Conclusion}

Unless specified above, the information in the PSID is considered to be sufficient at this stage of the review to conclude that the seismic response of nuclear power plant features important to safety can be determined promptly.

\subsubsection{Seismic Instrumentation}

When an earthquake occurs, it is important to assess immediately the affects on a nuclear power plant. Suitable instrumentation shall be provided so that the seismic response of features important to safety can be determined promptly, and the response can be compared with the design-basis response. Such a comparison is needed to decide whether the plant can continue to be operated safely and to permit appropriate and timely response.

\subsubsection{Design Description and Safety Objectives}

It is important to determine quickly whether or not seismic design conditions were exceeded. The seismic instrumentation system should supply in a readily usable form the information for making the determination.

A typical instrumentation system consists of a tri-axial time-history accelerograph and a tri-axial response spectrum recorder to measure directly the input timehistory and response spectra. Additional time-history accelerographs, response spectrum recorders, peak accelerographs, seismic switches, and response spectrum switches are recommended to measure the responses of structures, equipment, and components at selected locations.

The time-history accelerograph measures and records absolute acceleration as a function of time during an earthquake. This may be a self-contained instrument or it may consist of acceleration sensors that detect absolute acceleration and transmit the data to a remote central recorder. From the resulting time-history records, the peak accelerations and response spectra can be determined.

The response spectrum recorder measures and records spectral accelerations at specified frequencies during an earthquake.

A peak accelerograph (which requires no power) detects and records peak acceleration. 


\section{Review Approach and Criteria}

A seismic switch sends an immediate signal to indicale if a specified acceleration has been exceeded. It consists of an acceleration sensor and a switch closure. A response spectrum switch can send an immediate signal to indicate if a specified spectral acceleration has been exceeded.

\subsubsection{Scope of Review}

This review focused on a comparison of the proposed seismic instrumentation presented in PSID Chapter 3 with the seismic instrumentation guidelines of RG 1.12 (Ref. 3.24).

\subsubsection{Design Criteria}

Technical specifications are required by 10 CFR 50.36 to include surveillance requirements to ersure that the necessary quality of systems and components is maintained, that facility operation will be within safety limits, and that the limiting conditions of operation will be met. Appendix A to 10 CFR Part 100 requires a suitable program for implementing the requirements of 10 CFR 50.36 to determine the response of plant features. RG 1.12 gives applicants the necessary guidance for implementing the cited regulations.

\subsubsection{Research and Development}

Preapplicant-sponsored R\&D was not described or reviewed at this stage.

\subsubsection{Safety Issues}

Paragraph V(a)(2) of Appendix A to 10 CFR Part 100 indicates that if vibratory ground motion exceeds that of the operating-basis earthquake (OBE), then the nuclear power plant must be shut down. Before resuming operations, the applicant will be required to demonstrate that those reatures necessary to protect the health and safety of the public have not been functionally damaged.

The seismic instrumentation needs to be designed to withstand the conditions of reactor vessel auxiliary cooling system (RVACS) operation, or, if not so designed, it needs to be replaced following RVACS operation.

\subsubsection{Evaluation}

The evaluation is limited to identifying potential safety problems with the design and information the applicant will be expected to submit at the next licensing stage. In addition, current staff activities (for instance, the proposed revision of Appendix A to 10 CFR Part 100) have been identified so that the applicant will be aware of these changes and can take appropriate action coincident with the next licensing stage.

The seismic instrumentation program is consistent with RG 1.12 with the following exceptions and clarifications:

- A permanently installed response spectrum analyzer is provided, rather than a response spectrum recorder. Data from the strong-motion accelerometers are fed into the response spectrum analyzer to produce immediately earthquake spectra following an earthquake. The response spectrum analyzer is located in an electrical and instrumentation vault in the reactor building; readout is in the control room.

- Accelerometers are located at the top of the operating floor, the head access area enclosure, the basement, and the top of the reactor silo basemat.

- Only one complete set of seismic instrumentation is required for a given site, since the expected seismic response is the same for all units. However, the first two reactor buildings on a PRISM site will be instrumented to allow for one set of instruments being out of service.

Consistent with RG 1.12, instruments are located at the top of the radioactive waste building basemat and in the free field. The remainder of the seismic instrumentation program is similar to that used for current nuclear plants.

The PRISM facility will use seismic-base isolation to reduce the response to an earthquake relative to a fixedbase building. Therefore, it is recommended that accelerometers be placed on both the rigid and isolated portions of the structures at approximately the same elevations. The additional instrumentation will allow a comparison of response between the isolated and non-isolated portions of the structure. This is consistent with the NRC staff position taken in Draft RG DG-1016 (Ref. 3.25).

\subsubsection{Conclusion}

Except as specified above, the information in the PSID is considered to be sufficient to conclude that adequate seismic instrumentation will be provided so that the seismic response of nuclear power plant features important to safety can be determined promptly.

Because of the continuous enhancements in seismic instrumentation and the proposed revisions to Appendix A to 10 CFR Part 100 and to RG 1.12, conformity with instrumentation guidelines in existence at the time of an individual licensee application will be required. This is 
consistent with the NRC staff position taken in the SER for the advanced boiling-water reactor (ABWR).

\subsubsection{Seismic Base Isolation System}

A seismic basi? isolation system is a system installed between a structure and its foundation which reduces the ground motion transmitted to the structure. This relatively new technology is being used in numerous applications worldwide to reduce the acceleration of buildings and their contents.

\subsubsection{Design Description and Safety Objectives}

The PRISM ALMR design uses horizontal seismic isolation. The seismic base isolator system transforms the high-energy horizontal ground motions into reduced horizontal accelerations, at a lower natural frequency, thereby allowing for a rigid body response of the structures; relative displacements between the isolated and nonisolated portions of the facility are increased, however, and the design must accommodate this.

Seismically isolated equipment in the plant design includes the reactor module, containment, RVACS, head access area (HAA) components, the safety-related reactor instrumentation, and EM pump synchronous machines.

The seismic base isolation system consists of 31 highdamping, steel-laminated, elastomeric bearings arranged in a separate vault with access for inspection and maintenance. The seismic bearings are supported on a 2.1-m (7-ft)-thick basemat. The bearings support a platform $21.9 \mathrm{~m}(72 \mathrm{ft})$ wide and $24.8 \mathrm{~m}$ (81.5 ft) long. The bearings are positioned below the major loads supported by the seismic platform; each bearing carries a vertical load of about $2 \mathrm{MN}$ (500 kips). Within the seismic bearing vault, a $0.76-\mathrm{m}(2.5-\mathrm{ft})$-thick continuous circular shield wall located adjacent to the reactor module shields the bearings from radiation.

The seismic isolator bearing is $1.32 \mathrm{~m}$ ( $52 \mathrm{in}$.) in diameter and $0.59 \mathrm{~m}$ ( $23.1 \mathrm{in}$.) high, and consists of 30 layers of $12.7-\mathrm{mm}(1 / 2-$ in. $)$-thick elastomer and 29 steel shim plates, $3.2 \mathrm{~mm}(1 / \mathrm{sin}$ ) thick. A 76.2-mm (3-in.)-thick layer of elastomer is added to the circumferential surface area of the bearing as a protective barrier against harsh environmental conditions. There are 25.4-mm ( 1 -in.)-thick steel plates forming the top and bottom surfaces of the seismic isolator bearing which interface with the connecting structures. All steel and rubber layers are vulcanized together into a composite structure.
The elastomeric compound used in the seismic isolator bearings is formed from natural rubber filled with a damping material. To control the relative displacements between the ground and the building, and to attenuate the small component of the earthquake energy which coincides with the natural frequency of the isolator, sufficient damping must be built into the isolators. Damping is desired to provide energy absorption characteristics, thereby reducing the maximum relative displacement magnitudes.

Lateral displacement between the top and bottom bearing plates results from the horizontal shear forces applied through the flexible rubber layers. The load is applied on the bearings through dowels that connect the top and bottom plates to the superstructure and the basemat, respectively. A different method than the use of dowels is under consideration. The bearings are bolted to both the basemat and the isolated platform. One feature of this design is the more positive connection between bearings and support structures.

The isolation system should be stiff enough to avoid perceptible vibrations under low-level lateral loads, such as wind loads, small seismic events, and normal operational loads. Also, to minimize amplifications in vertical response due to the vertical flexibility of the isolators, a high vertical-to-horizontal stiffness ratio is provided.

Table 3.4 summarizes the performance characteristics of the ALMR seismic isolator system.

The service lifetime of these bearings is expected to extend beyond the 60-year design life of the ALMR. Experience has shown that natural rubber retains its physical characteristics for many years when protected from ozone and high temperatures. Radiation effects are a concern in the ALMR application and radiation shielding has been provided. The rubber material is expected to retain its properties if its accumulated radiation dose is kept below $20 \mathrm{kGy}$ ( $2 \mathrm{Mrad})$. An in-service inspection program has been planned to monitor the condition of the bearings. The bearings will be examined in place every refueling interval, and every 12 years, two bearings will be removed for testing (and replaced with qualified spare bearings). The isolated platform will be jacked up locally to support the vertical load while bearings are being removed and replaced. If any bearing condition is found to be outside of operating limits, the bearing will be replaced. Adequate space is available to transport the bearings to and from the surface. 
Table 3.4 Characteristics of the ALMR seismic isolation system

\begin{tabular}{||c|c||}
\hline Safe shutdown earthquake (SSE) & \\
\hline Design requirement & $0.3 \mathrm{~g}$ \\
\hline Design capacity & $0.5 \mathrm{~g}$ \\
\hline Operating basis earthquake (OBE) & \\
\hline Design capacity & $0.17 \mathrm{~g}$ \\
\hline Seismic platform to ground relative displacement & \\
\hline At $0.3 \mathrm{~g}$ & $21.6 \mathrm{~cm}(8.5 \mathrm{in})$. \\
\hline At $0.5 \mathrm{~g}$ & $35.6 \mathrm{~cm}(14 \mathrm{in})$. \\
\hline At bearing limit & $76.2 \mathrm{~cm}(30 \mathrm{in})$. \\
\hline Seismic platform natural frequencies & \\
\hline Horizontal & $0.75 \mathrm{~Hz}$ \\
\hline Vertical & $>20 \mathrm{~Hz}$ \\
\hline Reactor horizontal seismic load reduction factor & \\
\hline Horizontal & None \\
\hline Vertical & \\
\hline
\end{tabular}

\subsubsection{Scope of Review}

This review focused on the seismic isolator system's design rationale, characteristics, operational experience, and qualification program described in PSID Section 3.7.5 and PSID Section G.4.4; the ALMR Technology Development Requirements Plan (Refs. 3.26 and 3.27); and material presented to the NRC staff on October 25, 1990, and October 16, 1991, (Refs. 3.28 and 3.29).

\subsubsection{Design Criteria}

The design criteria are the same as those given in Section 3.3.1.3, above.

\subsubsection{Research and Development}

The practice of placing buildings on seismic isolation bearings is relatively new. However, this approach to protecting important structures from the effects of earthquakes is receiving considerable worldwide attention. In the United States, the practice was first applied to the Foothill Communities Law and Justice Center located in the municipality of Rancho Cucamonga in San Bernardino County, California. Other applications include the Fire Command-and-Control Building and University Hospital in Los Angeles, California. The earthquake response of these buildings is monitored by the California Department of Conservation, Division of Mines and Geology, as part of the California Strong Motion Instrumentation Program (CSMIP).

The French applied seismic isolation concepts to a two-unit nuclear power plant on a common basement at Koeberg, South Africa (commercial operation began in 1987) and a four-unit standardized design located at Cruas-Meysse in the Rhone Valley of France. An extensive test program is being conducted in Japan to develop more information for this new technology.

In support of the PRISM ALMR, a technology development program supports the qualification of a seismic isolation system for the ALWR. The qualification program includes

- testing high damping rubber bearings 


\section{Review Approach and Criteria}

- qualifying gimbaled expansion joints for the secondary heat transfer system piping

- conducting tests on large buildings with prototypical isolators

- testing scale models of reactor structures with isolators on a shake table

- developing analytical models

- optimizing and qualifying bearing materials

- developing seismic isolation guidelines

- assessing seismic margins

\subsubsection{Safety Issues}

Although seismic base isolation appears to offer significant benefits for nuclear power plants, there are a number of issues and concerns that must be considered and resolved before seismic isolation can be accepted for such plants. These issues include such items as the effects of long period earthquake ground motion; the effects, other than horizontal, of isolation systems on vertical, rocking, and torsional responses of isolated structures; non-linear effects during beyond-design basis earthquakes; and the effects of non-ideal conditions.

The natural frequencies of seismically isolated structural systems are lower than those of non-isolated systems; the effects of long period ground motions become more important. The resulting relative displacements between isolated and non-isolated portions of the plant or the ground must be adequately considered in the design. In addition, specific design problems, such as fluid sloshing, must be evaluated.

Detailed modeling of structures with isolation systems indicates that vertical motion, rocking, and torsional motion may be induced in the isolated structure. These modes may be significant for the isolated structure or components therein; for example, rocking could lead to a reactivity control problem.

Analytical capabilities need to be enhanced so that there is a better correlation between experiments and analysis. For example, for beyond-design-basis earthquakes, numerical computations have not revealed the high frequency response in secondary systems shown to exist during laboratory tests of isolated structures. Multiple degrees-offreedom representation of the isolator, structure, and secondary systems in revised computational models are needed to predict and evaluate coupling or interferences. Prototypical models and computational methodologies need to be validated by tests for both static and dynamic environments.

Concerns related to such effects as non-ideal field conditions, as-built tolerances, differential settlements, aging, inspection and maintenance, and replacement need to be evaluated.

\subsubsection{Evaluation}

The evaluation focuses on discovering potential safety problems with the design and identifying information the applicant is expected to submit at the next licensing stage. In addition, current staff activities (for instance, the proposed revision of Appendix A to 10 CFR Part 100) have been identified so that the applicant will be aware of these changes and can take appropriate action coincident with the next licensing stage.

\section{Experience With Seismic Isolation of Structures}

The responses of the Foothill Communities Law and Justice Center (in San Bernardino County), the Fire Command-and-Control Building (in Los Angeles), and University Hospital (in Los Angeles) buildings to various earthquakes are given in Tables 3.5, 3.6, and 3.7. Data from the tables can be used to compare horizontal and vertical accelerations at the basement (above the isolators) to those at the foundation (below the isolators). Also the amplification or attenuation of the roof acceleration can be examined.

One-half of the horizontal accelerations above the isolators were lower in magnitude than those below the isolators, approximately 33 percent of the time the accelerations were equal, and 17 percent of the time they were greater in magnitude. A similar comparison for the vertical direction showed that approximately 17 percent of the time accelerations above the isolators were lower in magnitude than the accelerations below the isolators, 58 percent of the time they were equal, and 25 percent of the time they were greater.

In general, the roof acceleration was twice the basement (above the isolators) acceleration. It is also apparent that, in some cases, there was a rocking or torsional response. In six cases the maximum acceleration on the basement was from a sensor in a different location or orientation than the foundation level sensor. 
Table 3.5 Response of the Rancho Cucamonga - San Bernandino County Law and Justice Center to various earthquakes

\begin{tabular}{|c|c|c|c|c|c|c|c|c|c|}
\hline \multicolumn{10}{|c|}{$\begin{array}{r}\text { RANCHO CUCAMONGA - SAN BERNARDINO COUNTY } \\
\text { CSMIP Station No. } 23497 \\
\text { Isolation type: Elastomeric bear }\end{array}$} \\
\hline \multicolumn{3}{|c|}{ Earthquake } & \multicolumn{2}{|c|}{ Freefield } & \multicolumn{2}{|c|}{$\begin{array}{c}\text { Foundation } \\
\text { Below Isolators } \\
\end{array}$} & \multicolumn{2}{|c|}{$\begin{array}{c}\text { Basement" } \\
\text { Above Isolators }\end{array}$} & \multirow{2}{*}{$\begin{array}{c}\text { Roof } \\
\begin{array}{c}\text { Horiz. } \\
(g)\end{array} \\
\end{array}$} \\
\hline Date & $\begin{array}{l}\text { Name, [Magnitude-M } M_{\downarrow} \text {, } \\
\text { (Ref. No.) }\end{array}$ & $\begin{array}{l}\text { Dist. } \\
(\mathrm{km})\end{array}$ & $\begin{array}{l}\text { Horiz. } \\
(g)\end{array}$ & $\begin{array}{l}\text { Vert. } \\
(g)\end{array}$ & $\begin{array}{l}\text { Horiz. } \\
(g)\end{array}$ & $\begin{array}{l}\text { Vert. } \\
(g)\end{array}$ & $\begin{array}{l}\text { Horiz. } \\
(g)\end{array}$ & $\begin{array}{l}\text { Vert. } \\
(g)\end{array}$ & \\
\hline $10 / 2 / 85$ & $\begin{array}{l}\text { Redlands, [4.9], } \\
\text { (Ref. 3.35) }\end{array}$ & 31 & 0.04 & N.A. & 0.04 & N.A. & N.A. & N.A. & 0.03 \\
\hline $7 / 8 / 86$ & $\begin{array}{l}\text { Palm Springs, [5.9], } \\
\text { (Ref. 3.36) }\end{array}$ & 90 & 0.02 & N.A. & 0.02 & 0.02 & 0.02 & 0.02 & 0.04 \\
\hline $10 / 1 / 87$ & $\begin{array}{l}\text { Whittier, [6.1], } \\
\text { (Ref. 3.37) }\end{array}$ & 47 & 0.06 & 0.04 & 0.03 & 0.03 & 0.03 & 0.03 & 0.06 \\
\hline $2 / 28 / 90$ & $\begin{array}{l}\text { Upland, [?], } \\
\text { (Ref. 3.38) }\end{array}$ & 12 & 0.26 & 0.19 & 0.15 & 0.10 & $\begin{array}{l}0.06 \\
0.08\end{array}$ & 0.12 & 0.16 \\
\hline $6 / 28 / 91$ & $\begin{array}{l}\text { Sierra Madre, [5.8], } \\
\text { (Ref. 3.39) }\end{array}$ & 43 & 0.04 & 0.03 & 0.03 & 0.02 & 0.04 & 0.02 & 0.08 \\
\hline $6 / 28 / 92$ & $\begin{array}{l}\text { Landers, [7.5 M } \\
\text { (Ref. 3.40) }\end{array}$ & 106 & 0.12 & 0.05 & 0.11 & 0.05 & 0.10 & 0.07 & 0.19 \\
\hline $6 / 28 / 92$ & $\begin{array}{l}\text { Big Bear, [6.6 M } \mathrm{s} \text {, } \\
\text { (Ref. 3.41) }\end{array}$ & 70 & 0.05 & 0.04 & 0.06 & 0.04 & $\begin{array}{l}0.02 \\
0.05\end{array}$ & 0.04 & 0.07 \\
\hline
\end{tabular}

* If two acceleration values are given, the first is from the basement sensor in the same location and orientation as the foundation sensor; the second value is the maximum value on the foundation. 
Table 3.6 Response of the Los Angeles - 2 Story Fire Command-Control Building to various earthquakes

\begin{tabular}{||c|c|c|c|c|c|c|c|c||}
\hline \multicolumn{8}{|c|}{ LOS ANGELES - 2 STORY FIRE COMMAND/CONTROL BUILDING - CSMIP Station No. 24580 } \\
Isolation type: Laminateri steel and rubber bearings
\end{tabular}

* If two acceleration values are given, the first is from the basement sensor in the same location and orientation as the foundation sensor; the second value is the maximum value on the foundation.

Table 3.7 Response of the Los Angeles - 7 Story University Hospital to various earthquakes

\begin{tabular}{|c|c|c|c|c|c|c|c|c|c|}
\hline \multicolumn{10}{|c|}{$\begin{array}{l}\text { LOS ANGELES - } 7 \text { STORY UNIVERSITY HOSPITAL - CSMIP Station No. } 24605 \\
\text { Isolation type: Laminated steel and rubber bearings with lead cores }\end{array}$} \\
\hline \multicolumn{3}{|c|}{ Earthquake } & \multicolumn{2}{|c|}{ Freefield } & \multicolumn{2}{|c|}{$\begin{array}{c}\text { Foundation } \\
\text { Below Isolator }\end{array}$} & \multicolumn{2}{|c|}{$\begin{array}{l}\text { Basement" } \\
\text { Above Isolator }\end{array}$} & \multirow{2}{*}{$\begin{array}{c}\text { Roof } \\
\begin{array}{c}\text { Horiz. } \\
(\mathrm{g})\end{array} \\
\end{array}$} \\
\hline Date & $\begin{array}{l}\text { Name, [Magnitude-M } \\
\text { (Ref. No.) }\end{array}$ & $\begin{array}{l}\text { Dist. } \\
(\mathrm{km})\end{array}$ & $\begin{array}{c}\text { Horiz. } \\
(g)\end{array}$ & $\begin{array}{c}\text { Vert. } \\
(g)\end{array}$ & $\begin{array}{l}\text { Horiz. } \\
(g)\end{array}$ & $\begin{array}{l}\text { Vert. } \\
(g)\end{array}$ & $\begin{array}{l}\text { Horiz. } \\
(g)\end{array}$ & $\begin{array}{l}\text { Vert. } \\
(g)\end{array}$ & \\
\hline $6 / 28 / 91$ & $\begin{array}{l}\text { Sierra Madre, [5.8] } \\
\text { (Ref. 3.39) } \\
\end{array}$ & 29 & 0.16 & 0.07 & 0.09 & 0.04 & $\begin{array}{l}0.04 \\
0.05 \\
\end{array}$ & $\begin{array}{l}0.04 \\
0.06 \\
\end{array}$ & 0.09 \\
\hline $4 / 22 / 92$ & $\begin{array}{l}\text { Desert Hot Springs, } \\
\text { [6.1], (Ref. 3.42) }\end{array}$ & 173 & 0.02 & 0.01 & N.A. & N.A. & N.A. & N.A. & 0.04 \\
\hline $6 / 28 / 92$ & $\begin{array}{l}\text { Landers, }\left[7.5 \mathrm{M}_{\mathrm{S}}\right] \\
\text { (Ref. 3.40) }\end{array}$ & 163 & 0.05 & 0.03 & 0.04 & 0.02 & 0.04 & 0.02 & 0.09 \\
\hline $6 / 28 / 92$ & $\begin{array}{l}\text { Big Bear, }\left[6.6 \mathrm{M}_{\mathrm{S}}\right] \\
\text { (Ref. 3.41) }\end{array}$ & 127 & 0.06 & 0.02 & 0.05 & 0.02 & 0.03 & 0.02 & 0.06 \\
\hline
\end{tabular}

* If two acceleration values are given, the first is from the basement sensor in the same location and orientation as the foundation sensor; the second value is the maximum value on the foundation. 
In an October 25, 1990, meeting (Ref. 3.28) with staff from the NRC, General Electric, Department of Energy, and Argonne National Laboratory the response of the Foothills Communities Law and Justice Center to the Upland earthquake (Ref. 3.30) was discussed. It was noted that some amplification was observed at the top floor. This was attributed to the relatively higher stiffness of the bearings for earthquakes smaller than maximum design earthquakes. For the maximum earthquake, a predominant rigid body mode response with no horizontal top floor amplification is predicted.

The applicant must demonstrate an understanding of how the ALMR facility will respond to a wide range of earthquakes. This range should include levels both below and beyond the maximum design earthquake.

\section{Seismic Isolator Qualification Program}

A research and development program (Refs. 3.26 and 3.27) has been established for the use of the seismic base isolation system to provide adequate system characterization and qualification for certification. The program is supported by the Energy Technology Engineering Center, the Argonne National Laboratory, the University of Southern California, the University of California at Berkeley, the California Institute of Technology, the General Electric Company, Rockwell International, and Bechtel National, Inc..

Unless otherwise noted, for this stage of the licensing review, the program appears adequate. Revisions to the plan reflecting new issues and experience obtained through plan implementation should be provided to the NRC staff for review and comment. The plan is summarized below.

\section{- Testing of High-Damping Rubber Bearings}

Steel-laminated high-damping natural rubber bearings (similar to the bearings used in the Foothill Communities Law and Justice Center building) will be used. More than 50 bearings at scales ranging from one-fourth to full size will be tested to characterize; the horizontal static and dynamic stiffness; the vertical stiffness; damping; the vertical load and horizontal displacement margins; and the failure modes which include horizontal shear, vertical tension and compression, or combinations of these. Tests will include sustained compression/creep tests, cyclic tests at various frequencies, self-centering tests, and buckling tests.

Results from the first series of these tests on half-size seismic bearings follow.
The bearings demonstrated large margins for accommodating relative horizontal displacements and vertical loads. The bearings are designed for a shear strain of 50 percent (maximum relative horizontal displacement divided by bearing height of 0.5 ); the maximum displacement is associated with ground acceleration of $0.3 \mathrm{~g}$ (an SSE event). While carrying a load of $1.9 \mathrm{MN}$ (420 kips), the bearings were subjected to movement and distortion of four times the expected maximum value. At this relative displacement, the limit of the test rig, substantial warping of the bearing end plates and some disengagement of the dowel occurred but failure could not be induced. Followup tests showed the bearing load-deflection behavior was unchanged from initial tests up to 50 percent shear strain.

The stiffness of the bearing increases at high strains due to stiffening of the elastomer, even though yielding of the end plates results in lower stiffness than if the plates were rigid. The resulting benefit is a further limiting effect on relative displacements during extreme events.

In an attempt to determine the ultimate load-carrying capability of the bearings, a bearing was loaded vertically to the maximum capacity of the testing machine; the maximum of the machine is $20 \mathrm{MN}(4000$ kips). The bearing sustained no apparent damage to either the elastomer or internal steel plates. Failure would be anticipated to occur by tensile failure of the steel plates under the vertical load.

Two bearings were stacked, then a load was applied in a ramp fashion. Note that the bearing end plates were free to move laterally. The buckling load was reached at 28 times the design load.

\section{- Gimbaled Expansion Joints Qualification}

Programs have been conducted in the U.S. and Japan to evaluate the performance characteristics of flexible piping joints. The joints could be used in the heattransfer system piping of a liquid-metal reactor for accommodation of differential thermal expansion and relative seismic motions. Work in that area led to the specification of the American Society of Mechanical Engineers (ASME) Code Case N-290-1. The code provides guidelines for design analyses and required supplementary performance tests of flexible piping. The present experimental data base appears sufficiently advanced to allow a modification of the code case for design by analysis only, rather than by analysis and testing. 
Section III Code Case N-290-1 and its application to the ALMR was discussed in the October 25, 1990, meeting with the staff (Ref. 3.28). The IHTS is a nonsafety-grade system designed to ASME Code Section VIII. However, the ASME Code rules developed for Section III Code Case N-290-1 will be used.

The qualification testing of the reference gimbaled expansion joint will include an evaluation of the available U.S. and Japanese (PNC) data base to establish requirements for supplemental full-size flexible-expansion-joint tests for accommodation of seismic displacements. The $25-\mathrm{mm}$ (10 in.)-diameter flexible piping bellows tested in the hot-leg piping of the Experimental Breeder Reactor II (EBR-II) intermediate heat transport system will also be evaluated. Tests to characterize safety margins beyond the design basis for seismic events will be performed as needed.

The gimbaled joints should be qualified at temperature and pressure, and should include the effects of aging. In addition, the potential for creep damage combined with seismic considerations should be considered.

\section{- Large Building/Prototypic Reactor Module Tests}

Seismic base isolation systems installed in buildings with seismic instrumentation will be used to gain information on response characteristics for a comparison with analytical predictions. Four types of tests will be conducted to verify large structure responses: (1) vibration tests with counter-rotating oscillators to provide uni-directional excitation, (2) static displacement tests to a maximum displacement, (3) tests of insiantaneous releases from a maximum displacement, and (4) measurement of building responses to natural seismicity.

A prototype reactor module test will be performed to verify system performance characteristics, if required to support utility approval and licensing certification.

A prototype test of the reactor module will be required. The test configuration should also include the gimbaled expansion joints to verify system-structure interaction during earthquake excitation. In commercial applications of base isolation, the interfaces between the isolated and rigid portions of buildings, particularly at the higher elevations, are kept to a minimum. For example, water and sewer service lines enter the building through the foundation and basement where the accelerations and displacements are the smallest. Stairways between the sidewalk and building are cantilevered from the building to avoid a friction point that may introduce a torsional response or inhibit the performance of the isolator system. Inclusion of the gimbaled expansion joints and applicable piping onto the large building tests (at the appropriate elevation) will verify that interfaces between the isolated and rigid portions of the ALMR can be adequately modeled and that the resulting responses are understood.

\section{- Systems Tests}

Shake-table tests using simple structural representations of the ALMR structure (an approximate mass distribution of the reactor system modeled by a steel frame structure) mounted on multiple bearings (four bearings or more) will be performed to characterize system responses under a range of earthquake timehistories and different acceleration levels, including high-energy waves (representative of El Centro) and low-frequency waves (representative of Hachinohe, Akita). Responses to excitations approaching the isolation frequency will be evaluated. The tests will also characterize the effects of coupling, torsion, rocking, and uplift. System safety margins will be established and tests to failure or near-failure conditions will be used to verify analysis tools and demonstrate their effectiveness in predicting the response of isolated structures.

Foundation level response spectra from the eight earthquakes noted in Tables 3.5 to 3.7 should be developed and compared to the dynamic characteristics (such as fundamental frequency) of the CSMIP monitored buildings. The earthquake time-histories used in the seismic isolator qualification program should be selected so that there is a similar relationship between the frequency content of the seismic input and the fundamental building frequency. The variation of earthquake magnitude should range from very low level to beyond the design-basis conditions. The mass of the test specimen should be varied to validate analytical predictions of amplification or attenuation of seismic responses in the structures.

- Development of Numerical Models and Model Validation

Existing dynamic analysis computer programs will be evaluated. To establish licensable evaluation models, data obtained from the system tests and the large building or prototypic reactor module tests (as modified to incorporate NRC staff comments) will be used to verify the computer programs and demonstrate the accuracy of the computed response. The analysis models will be used to evaluate the effects of torsion, 
rocking, and basemat uplift of the rectangular portion of the foundation. Additionally, the effects of soilstructure interaction on the isolated response, including basemat flexibility, spatial variatiou of ground motion, and ground settlement, will be studied. Threedimensional large displacement finite element models will be used to support the evaluation of bearing tests, specification of parameters and allowable defects or deviations in design guidelines, and further optimization of the isolation bearing properties and geometry, if required to enhance the bearing performance characteristics.

- Bearing Material Characterization and Environmental/Aging Assessment

Required materials performance parameters are: (1) adequately high damping ( $>10 \%)$, (2) acceptable temp7erature sensitivity of compound in the design range, including temperature dependence of shear modulus, etc., (3) acceptably low creep for the high shape factor bearing, (4) consistent good bonding to steel plates with a bond strength greater than the rubber strength, and (5) long-life capability.

Seismic bearings will be characterized for expected environmental conditions; for example, temperature variations, low gamma radiation, ozone, and fires.

Selected tests will be performed with rubber compound specimens to determine the effects of the environment on such key properties as tensile strength, stiffness, compression creep, and rubber elongation. Constitutive materials equations will be established as needed for analytical models. Full-size bearing tests under controlled environmental conditions are not presently being considered.

Performance data will be collected over a long period of time as subscale bearings stored under vertical compressive loads to demonstrate aging characteristics of the seismic bearings. Potential degradation effects will be established by performing periodic testing under benchmark vertical loads in combination with horizontal displacements.

- Seismic Isolation Design Guidelines

Support is provided for the American Society of Civil Engineers (ASCE) development of guidelines for seismic isolated nuclear facilities. Specific guidelines include (1) definition of ground motions, (2) design requirements and analysis methods for isolated buildings and isolated support structure, (3) design and performance requirements for overall seismic isolation systems, (4) design requirements and analysis methods for isolated structures, systems, and components, (5) design requirements and analysis methods for interface components, (6) design requirements for individual isolation devices, (7) qualification of seismic isolation bearings, (8) acceptance testing of isolator bearings, (9) seismic safety margin assessment, and (10) seismic monitoring.

- Soil-Structure Interaction Development

Maintain awareness of soil-structure-interaction experiments being carried out to verify computer programs that account for embedment and foundation flexibility and other soil-related effects. Soil-silo interactions will be evaluated, if required, using an underground expansion test approach.

This scope will be redefined after a specific site selection has been selected.

\section{In-service Inspection Program}

The in-service inspection program summarized in Table 3.8 (PSID Table G.4.4-2) has been planned to frequently monitor the condition of the bearings. The frequency of the inspections and the number of bearings that are inspected or tested for each category must be justified. In addition, the criteria used to determine acceptability or failure (for instance, acceptable range of bearing stiffness, location for the hardness measurement points, limits on vertical height) for each inspection or testing activity and action to be followed if the criteria are not met must be identified and justified.

Procedures similar to those recommended in Draft Regulatory Guides (RGs) DG-1017, "Pre-Earthquake Planning and Immediate Nuclear Power Plant Operator Post-Earthquake Actions" (Ref. 3.31), and DG-1018, "Restart of a Nuclear Power Plant Shut Down by a Seismic Event" (Ref. 3.32), should be noted in Table 3.8, Category IV, "Following an OBE." The NRC staff is developing a similar, voluntary position on exceeding the OBE of operating plants. 
Table 3.8 Planned in-service inspection program

\begin{tabular}{|c|c|c|c|c|c|}
\hline Category & Frequency & $\begin{array}{l}\text { Type of } \\
\text { Inspection }\end{array}$ & $\begin{array}{l}\text { Component } \\
\text { Inspected/Tested }\end{array}$ & $\begin{array}{l}\text { Inspection/Testing } \\
\text { Activity }\end{array}$ & $\begin{array}{c}\text { Number of } \\
\text { Bearings } \\
\text { Inspected } \\
\text { or Tested }\end{array}$ \\
\hline \multirow[t]{3}{*}{ I } & \multirow[t]{3}{*}{$\begin{array}{l}\text { Every } 18 \\
\text { Months }\end{array}$} & \multirow[t]{2}{*}{ Visual } & $\begin{array}{l}\text { Bearing Rubber } \\
\text { Cover }\end{array}$ & $\begin{array}{l}\text { - Check for obvious surface cracks or } \\
\text { tears } \\
\text { - Check for surface bulges which may } \\
\text { be indicative of bond failure } \\
\text { between the rubber and steel shim } \\
\text { plate }\end{array}$ & \multirow[t]{2}{*}{$\begin{array}{l}\text { All } 31 \\
\text { bearings }\end{array}$} \\
\hline & & & Bearing & - Verify vertical height [1] & \\
\hline & & Testing & $\begin{array}{l}\text { Bearing Rubber } \\
\text { Cover }\end{array}$ & $\begin{array}{l}\text { Measure hardness (indicative of } \\
\text { shear modulus) at } 6 \text { points using } \\
\text { Durometer }\end{array}$ & 16 bearings [2] \\
\hline II & $\begin{array}{l}\text { Every } \\
4-1 / 2 \\
\text { years }\end{array}$ & $\begin{array}{l}\text { Additional } \\
\text { tests to } \\
\text { determine } \\
\text { aging } \\
\text { effects }\end{array}$ & $\begin{array}{c}\text { Bearing } \\
\text { Specimens [3] }\end{array}$ & $\begin{array}{l}\text { Perform vertical static compression } \\
\text { tests to determine vertical bearing } \\
\text { stiffness } \\
\text { - Perform horizontal static tests to } \\
\text { determine horizontal bearing } \\
\text { stiffness }\end{array}$ & $\begin{array}{l}\text { Perform } \\
\text { vertical } \\
\text { and horizontal } \\
\text { tests on } 5 \text { test } \\
\text { specimens }\end{array}$ \\
\hline III & $\begin{array}{l}\text { Every } \\
12 \text { years }\end{array}$ & $\begin{array}{l}\text { Additional } \\
\text { testing }\end{array}$ & Bearing & $\begin{array}{l}\text { Perform vertical static compression } \\
\text { tests to determine vertical bearing } \\
\text { stiffness } \\
\text { - Perform horizontal static tests to } \\
\text { determine horizontal bearing } \\
\text { stiffness }\end{array}$ & $\begin{array}{l}\text { Replace and } \\
\text { test } \\
2 \text { bearings [4]. } \\
\text { vertical and } \\
\text { horizontal tests } \\
\text { performed on } \\
\text { both bearings }\end{array}$ \\
\hline \multirow[t]{2}{*}{ IV } & \multirow[t]{2}{*}{$\begin{array}{l}\text { Following } \\
\text { an OBE }\end{array}$} & $\begin{array}{l}\text { Visual/ } \\
\text { testing }\end{array}$ & Same as Category I & $\begin{array}{l}\text { Repeat all Category I inspections } \\
\text { and tests }\end{array}$ & $\begin{array}{l}\text { Same as } \\
\text { Category } 1\end{array}$ \\
\hline & & $\begin{array}{l}\text { Additional } \\
\text { Visual }\end{array}$ & Bearing & $\begin{array}{l}\text { Verify no permanent horizontal } \\
\text { displacement of bearings [5] }\end{array}$ & $\begin{array}{c}\text { All } 31 \\
\text { bearings }\end{array}$ \\
\hline
\end{tabular}

\section{NOTES:}

[1] Any vertical height reduction represents bearing shortening and its effect on continued bearing performance is evaluated against established limits.

[2] Different bearings are tested after each inspection until all 31 of the bearings have been tested; then the process is repeated.

[3] Five 1/4-scale (or smaller) bearing specimens subjected to equivalent vertical design loads are aged during storage in the seismic bearing vault. At 4-1/2 year intervals all 5 bearing specimens are removed from storage and tested. After testing, the bearing specimens are returned to storage for further aging in the loaded condition. Any deterioration in bearing stiffness based on test results is used to evaluate degradation effects of all bearings due to aging.

[4] Select bearings for testing on a random basis; replacement bearings are qualified spares. After testing, tested bearings become qualified spares.

[5] Following an earthquake, the bearings are expected to return to their approximate horizontal starting position. The effects of any permanent displacement on continued bearing performance is evaluated against established limits. 
Experience With Seismic Base Isolation of Nuclear Power Plants

The French have applied seismic base isolation concepts to a two-unit nuclear power plant at Koeberg, South Africa. This facility began commercial operation in 1987. Data about isolator performance and their in-service inspection program should be obtained. The applicant should address comparison of measured to predicted responses of the plant to actual earthquakes; comparison of measured to expected stiffness of the seismic isolators measured during in-service i.spections (after several years operation); general comments on the in-service inspection program (frequency of inspections, evaluation criteria) and major differences.

\section{Required Operating-Basis Earthquake Ground Motion Analysis}

Consistent with Appendix A to 10 CFR Part 100, the OBE for the ALMR is $1 / 2$ of the SSE; an analysis is required. Proposed Appendix S, "Earthquake Engineering Criteria for Nuclear Power Plants," to 10 CFR Part 50 would allow the value of the $\mathrm{OBE}$ ground motion to be set at onethird or less of the SSE ground motion, where the requirements associated with this $O B E$ can be satisfied without the applicant performing explicit response or design analyses. An applicant may voluntarily select an OBE greater than one-third of the SSE; however, analysis and design must be performed to demonstrate that the requirements associated with this $O B E$ are satisfied. The elimination of the OBE analysis may not be applicable to the PRISM. The supplemental information to the proposed regulation (published October 20, 1992, 57 FR 47802, Item $\mathrm{V}(\mathrm{B})(6)$ ) includes the following statement: "More than one earthquake response analysis for a seismic base isolated nuclear power plant design may be necessary to ensure adequate performance at all earthquake levels. Decisions pertaining to the response analysis associated with hase isolated facilities will be handled on a case-bycase basis."

\subsubsection{Conclusions}

Unless specified above, the information provided in PSID Section 3.7.5 and PSID Section G.4.4, as supplemented by material presented to the NRC staff on October 25, 1990, and October 16, 1991, is considered to be sufficient at this stage of the review to conclude that adequate testing and analysis is being performed or planned in support of seismic isolator licensing.

Revisions to the Seismic Isolator Qualification Program reflecting new issues or experience obtained through plan implementation should be submitted to the NRC staff. Research results from the specific topics in the plan will receive a detailed review at a later stage in the design review.

\subsection{Seismic Category I Structures}

The design of seismic Category I structures includes specifying and complying with the following:

- applicable codes, standards, specifications, and regulations

- methods and criteria for loads and load combinations

- design and analysis procedures

- structural acceptance criteria

- materials

- testing and inservice inspection requirements

- standards for quality assurance

\subsubsection{Design Description and Safety Objectives}

Applicable codes, standards, specifications, and regulations contain information pertaining to design, fabrication, construction, testing, and surveillance of seismic Category I structures. The loads and load combination descriptions describes the normal, severe environmental, extreme environmental, and abnormal loads, and identifies how these independent loads are combined in the design of reinforced-concrete and structural steel structures. The analysis and design description describes the mathematical representation of the buildings and foundation and references applicable industry standards. The structural acceptance criteria describe the design limits imposed on the various parameters that serve to quantify the structural behavior of each structure and its components; specifically stresses, strains, gross deformations, and factors of safety against structural failure were included. For each load combination specified, allowable limits are compared with acceptable limits. The materials description describes the properties of concrete and the foundation (soil or rock type and thickness), grade of reinforcement and structural steel, anchors, and other pertinent information. If applicable, any post-construction testing and inservice surveillance programs are described. Standards for quality assurance are to be identified.

\subsubsection{Scope of Review}

This review focused on information submitted in the PRISM PSID, Sections 3.8.1 through 3.8.6, and Appendix F (Ref. 3.16). 


\subsubsection{Design Criteria}

Appendix A of 10 CFR Part 50, lists the GDC applicable to construction and operation of light-water reactor plants. The following identifies those considered applicable to the structural design of ALMR seismic Category I structures.

GDC 1, "Quality Standards and Records," and 10 CFR 50.55: require safety-related structures to be designed, fabricated, erected, and tested to quality standards commensurate with the importance of the safety function to be performed.

GDC 2, "Design Bases for Protection Against Natural Phenomena," requires that nuclear power plant structures, systems, and components important to safety be designed to withstand the effects of natural phenomena such as earthquakes, tornadoes, floods, tsunamis, and seiches without loss of capability to perform their safety functions.

GDC 4, "Environmental and Dynamic Effects Design Basis," requires that safety-related structures be capable of withstanding the dynamic effects of equipment failures, including missiles and blowdown loads associated with the loss-of-coolant accidents.

GDC 5, "Sharing of Structures, Systems, and Components," requires sharing of structures important to safety not be done unless it can be shown that such sharing will not significantly impair the validity to perform their safety functions.

GDC 16, "Containment Design," requires the containment to act as a leaktight membrane to prevent the uncontrolled release of radioactive effluents to the environment.

GDC 50, "Containment Design Basis," requires containment internal structures be designed with sufficient margin of safety to accommodate appropriate design loads.

\subsubsection{Research and Development}

Applicant-sponsored R\&D was not described or reviewed at this time.

\subsubsection{Safety Issues}

The design of seismic Category I structures must ensure that safety-related structures are properly classified, designed, fabricated, erected, constructed, tested, and inspected to quality standards commensurate with their safety function.

The designer must ensure that safety-related structures will withstand the $0.3 \mathrm{~g}$ ground motion spectra discussed in RG
1.60 at all sites considered for design certification with sufficient margin, and the combinations of the effects of normal and accident conditions with the effects of environmental loadings of earthquakes and other natural phenomena.

Safety-related structures must be capable of withstanding the dynamic effects associated with missiles, pipe whipping, and discharging fluids.

Safety-related structures, systems, and components may not be shared between units or any sharing will not impair the ability to perform intended safety function.

The containment must be an essentially leaktight barrier to prevent the uncontrolled release of radioactive effluents to the environment.

Furthermore, the designer must ensure that the containment will have sufficient margin to accommor'ste the leak rate, pressure, and temperature resulting from accident conditions, and that appropriately defined design conditions are not exceeded during the full course of the accident condition.

\subsubsection{Evaluation}

The evaluation is limited to discovering potential safety problems with the design and identifying information the applicant is expected to submit at the next licensing stage.

The majority of the NRC RGs cited in Section 3.8.1.2 of the PRISM PSID do not pertain to the design of seismic Category I structures. Although the following RGs are not cited in the PSID, they are applicable to the design of seismic Category I structures:

- RG 1.57, "Design Limits and Loading Combinations for Metal Primary Reactor Containment System Components" (Ref. 3.43)

- RG 1.94, "Quality Assurance Requirements for Installation, Inspection and Testing of Structural Concrete and Structural Steel During the Construction Phase of Nuclear Power Plants" (Ref. 3.44)

- RG 1.142, "Safety-Related Concrete Structures for Nuclear Power Plants" (Ref. 3.45)

The applicable sections of the ASME Boiler and Pressure Vessel Code should be included. Also, the designer should use the latest revision of applicable codes, standards, and specifications. Note that the NRC Office of 
Nuclear Regulatory Research is presently evaluating a number of recsint codes for use in future plants.

The load combination equations and structural stability factors of safety given in PSID Tables 3.8-1 to 3.8-3 was not reviewed at this stage of the review.

Before the next licensing stage, the applicant should thoroughly review applicable SRP sections and RGs, and should submit technical justification for deviations from those documents.

\section{Leak Before Break}

The application of leak-before-break technology is proposed for moderate energy piping systems. However, because there are no postulated ruptures in moderate energy piping, leak-before-break technology cannot be implemented in this case. Postulated leakage cracks in moderate energy lines used to determine environmental qualification of safety equipment cannot be eliminated by leak-before-break technology. In GDC 14, the NRC staff states: "the reactor coolant pressure boundary shall be designed...so as to have an extremely low probability of abnormal leakage..." Inservice inspection (ISI) is applicable to the detection of random cracks or flaws of finite size and unknown origin, and, therefore, conflicts with the basic intent of the criterion; its intent is to preclude the initiation of cracks due to known causes. Furthermore, Supplements 1 and 2 of NRC Bulletin 88-08 (Ref. 3.33) show that ISI is not always reliable for detecting flaws before they develop into leaking cracks.

In the final broad-scope rule to modify GDC 4 , the staff states that the leak before break concept cannot be used in ferritic steel piping when operating temperatures exceed $644 \mathrm{~K}\left(700^{\circ} \mathrm{F}\right)$, and in austenitic steel piping when the operating temperature exceeds $700 \mathrm{~K}\left(800^{\circ} \mathrm{F}\right)$ (Ref. 3.34). These limitations reflect uncertainties in creep behavior after long service times. These limits may be lower than PRISM operating temperatures. Use above these operating temperatures can be approved only when concerns with creep, creep rupture, and creep fatigue after a 60-year service life are addressed.

The preapplicant's reference to the Clin's River Breeder Reactor Plant (CRBRP) in PSID Section 3.6.2.1 is m.jleading. Leak-before-break technology, as presently understood, was not applied to this design. Instead, because the double-end guillotine break was unacceptable in terms of core physics, guard pipes and guard vessels were used to reduce the consequences of pipe rupture. No proof was developed that the probability of pipe rupture is extremely low, although such proof is mandated by present rules. However, it is likely that if such measures as the use of guard pipes are implemented for the PRISM, pipe ruptures could be eliminated from design consideration. The pipe ruptures were not considered in CRBRP and the Fast Flux Test Facility (FFTF) due to the use of guard pipes. Not only dynamic effects design bases are affected in such a case, but also requirements for emergency core cooling systems and environmental qualification.

\subsubsection{Conclusions}

Unless specified above, the information in the PSID is considered to be sufficient at this stage of the review to conclude that seismic Category I structures will be adequately designed and analyzed.

\subsection{Mechanical Systems and Components}

The design of mechanical systems and components includes specifying and complying with the analytical methods used for all components and component supports covered by the American Society of Mechanical Engineers Boiler and Pressure Vessel Code Class 1, 2, and 3. Further, it is necessary to define specifications for components not covered by the ASME Code.

\subsubsection{Design Description and Safety Objectives}

In the ASME Code, Class 1 components and component supports are categorized as low-temperature components or elevated-temperature components, and are described by inelastic and limit analyses. ASME Code Class 2 and 3 components and component supports are described by component operating conditions and design loading conditions, design stress and pressure limits, analytical and empirical methods for design of pumps and valves and design and installation criteria for pressure-relieving devices and component and piping supports. In addition, core components and the control rod system which are not covered by the ASME Code are described.

\subsubsection{Scope of Review}

This review focused on information in PSID Sections 3.9.1 through 3.9.3.

\subsubsection{Design Criteria}

Appendix A of 10 CFR Part 50 lists the requirements used to design and evaluate light-water nuclear plants. Each of the requirements is referred to as a GDC. Certain of these are considered generally applicable to ALMRs (see Section 3.2 of this report) and were used to evaluate the preapplicant's structural design of mechanical systems and components for the PRISM design. 
Both 10 CFR 50.55a and GDC 1, "Quality Standards and Records," require safety-related structures to be designed, fabricated, erected, and tested to quality standards commensurate with the importance of the safety function to be performed.

GDC 2, "Design Bases for Protection Against Natural Phenornena, " requires that nuclear power plant structures, systems, and components important to safety be designed to withstand the effects of such natural phenomena as earthquakes, tornadoes, floods, tsunamis, and seiches without losing their capability to perform safety functions.

GDC 4, "Environmental and Dynamic Effects Design Basis, " requires that safety-related structures be capable of withstanding the dynamic effects of equipment failures, including missiles and blowdown loads associated with loss-of-coolant accidents.

GDC 14, "Reactor Coolant Pressure Boundary," requires that the reactor coolant pressure boundary be designed, fabricated, erected, and tested to have an extremely low probability of abnormal leakage, rapidly propagating failure, and gross rupture.

GDC 15, "Reactor Coolant System Design," requires that the reactor coolant system be designed with sufficient margin to ensure that the design conditions are not exceeded.

\subsubsection{Research and Development}

Preapplicant-sponsored R\&D was not described or reviewed at this time.

\subsubsection{Safety Issues}

The design of mechanical systems and components must ensure that systems and components important to safety are designed to quality standards commensurate with their importance to safety and that these systems can accommodate such events as loss-of-coolant accidents and earthquakes. The specified design and service combinations of loadings as applied to ASME Code Class 1, 2, and 3 pressure-retaining components in systems designed to meet seismic Category I standards are such as to provide assurance that in the event of an earthquake or other service loadings due to postulated events or system operating transients, the resulting combined stresses imposed on system components will not exceed allowable stress and strain limits for materials of construction.

The designer must ensure that overpressure relief devices are designed to standards commensurate with their safety functions, and can accommodate the effects of discharge due to normal operation and such events as LOCAs and the dynamic effects resulting from the ground motion of an SSE. The reactor coolant pressure boundary design limits for normal operation and anticipated operational occurrences must not be exceeded. The criteria used in the design and installation of ASME Class 1, 2, and 3 overpressure relief devices must provide adequate assurance that the stresses resulting from discharge will not exceed allowable stress and strain limits.

Component supports important to safety must be designed to quality standards commensurate with their safety functions, and the designer must ensure that they can accommodate the effects of discharge due to normal operation as well as such postulated events as LOCAs and the dynamic effects resulting from the ground motion of an SSE. The combination of loadings (including system operating transients) considered for each component support within a system, including the designation of the appropriate service stress limit for each combination, has met applicable NRC staff positions and criteria. The specified design and service loading combinations used for the design of ASME Code Class 1, 2, and 3 component supports in systems classified as seismic Category I provide assurance that in the event of an earthquake or other service loadings due to postulated events or system operating transients, the resulting stresses imposed on system components will not exceed allowable stress and strain limits for the materials of construction.

\subsubsection{Evaluation}

The evaluation is limited to discovering potential safety problems with the design and identifying the information the applicant will be expected to submit at the next licensing stage.

It is stated in PSID Section 3.9.1 that inelastic and limit analysis methods may be used in conjunction with the dynamic analysis, provided that the designer observes the stress and deformation limits established by the ASME Code (Section III and Code Case N-47, "Class 1 Components in Elevated Temperature Service, Section III, Division 1"). The components associated with the reactor system (reactor vessel, primary control rod driveline, upper internal structure, etc.) and the heat transport system (steam generators, intermediate heat exchanger, etc.) for which inelastic analysis has been performed or is being considered are listed in PSID Table 3.9-1.

At this time, the staff has not endorsed Code Case N-47 and, in general, has not accepted the application of inelastic stress and deformation limits in the initial design evaluations. Therefore, at the next licensing stage, the applicant should anticipate considerable discussion and 


\section{Review Approach and Criteria}

correspondence with the NRC staff pertaining to the application of this code case and inelastic analysis to the PRISM design.

A thorough review of the load combination equations and stress criteria listed in PSID Tables 3.9-2 through 3.9-6 was not performed at this stage of the licensing review.

\subsubsection{Conclusions}

Except as described in "Evaluation" above, the information provided in the PSID is considered to be sufficient at this stage of the review to conclude that adequate design and analysis of mechanical systems and components will be performed.

\subsection{References}

3.1 U.S. Nuclear Regulatory Commission, "Issues Pertaining to the Advanced Reactor (PRISM, MHTGR, and PIUS) and CANDU 3 Designs and Their Relationship to Current Regulatory Requirements," SECY-93-092, April 8, 1993.

3.2 U.S. Nuclear Regulatory Commission, "Regulation of Advanced Nuclear Power Plants; Statement of Policy," 51 Federal Register, 24643, July 8, 1986.

3.3 U.S. Nuclear Regulatory Commission, "Development and Utilization of the NRC Policy Statement on the Regulation of Advanced Nuclear Power Plants, " NUREG-1226, June 1988.

3.4 U.S. Nuclear Regulatory Commission, "Safety Goals for the Operation of Nuclear Power Plants," 51 Federal Register, 28044, August 4, 1986.

3.5 U.S. Nuclear Regulatory Commission, "Policy Statement on Severe Reactor Accidents Regarding Future Designs and Existing Plants," 51 Federal Register, 32138, August 8, 1985.

3.6 U.S. Nuclear Regulatory Commission, Code of Federal Regulations, Title 10, "Energy," Part 50, "Domestic Licensing of Production and Utilization Facilities."

3.7 U.S. Atomic Energy Commission, "Calculation of Distance Factors for Power and Test Reactors Sites," Technical Information Document TID14844, March 1962.

3.8 U.S. Environmental Protection Agency, Code of Federal Regulations, Title 40, "Protection of
Environment, " Part 190, "Environmental Radiation Protection for Nuclear Power Operations."

3.9 U.S. Nuclear Regulatory Commission, "Standard Review Plan for the Review of Safety Analysis Reports for Nuclear Power Plants, LWR Edition," NUREG-0800, July 1982.

3.10 U.S. Nuclear Regulatory Commission, Code of Federal Regulations, Title 10, "Energy," Part 100, "Reactor Site Criteria."

3.11 U.S. Nuclear Regulatory Commission, "General Site Suitability Criteria for Nuclear Power Stations," Regulatory Guide 4.7.

3.12 American Society of Mechanical Engineers (ASME), Boiler and Pressure Vessel Code, Section III, Division I, Subarticle NE-3220, "Service Level C Limits," New York, 1980.

3.13 U.S. Nuclear Regulatory Commission, Code of Federal Regulations, Title 10, "Energy," Part 52, "Early Site Permits; Standard Design Certification; and Combined Licenses for Nuclear Power Plants, Subpart B, Standard Design Certification."

3.14 U.S. Nuclear Regulatory Commission, "Guidance for Residual Heat Removal," Regulatory Guide 1.139 .

3.15 U.S. Nuclear Regulatory Commission, "Policy, Technical, and Licensing Issues Pertaining to Evolutionary and Advanced Light-Water Reactor (ALWR) Designs," SECY-93-087, April 2, 1993.

3.16 General Electric, PRISM-Preliminary Safety Information Document, GEFR-00793 UC-87Ta, November 1986.

3.17 American National Standards Institute/American Nuclear Society, ANSI/ANS-54.1-1989, "General Safety Design Criteria for a Liquid Metal Reactor Nuclear Power Plant," ANS, La Grange Park, Illinois.

3.18 U.S. Nuclear Regulatory Commission, "Safety Evaluation Report Related to the Construction of the Clinch River Breeder Reactor Plant," NUREG-0968, Volume 1, March 1983.

3.19 U.S. Nuclear Regulatory Commission, Code of Federal Regulations, Title 10, "Energy," Part 20, "Standards for Protection Against Radiation." 
3.20 U.S. Nuclear Regulatory Commission, Code of Federal Regulations, Title 10, "Energy," Part 73, "Physical Protection of Plants and Materials."

3.21 U.S. Nuclear Regulatory Commission, "Periodic Testing of Electric Power and Protection Systems," Regulatory Guide 1.118.

3.22 American Society of Mechanical Engineers (ASME), Boiler and Pressure Vessel Code, Section III, Division 2, Subarticle CC-6000, "Structural Integrity Test for Concrete Containments," New York, 1992.

3.23 American National Standards Institute, Inc., American Nuclear Society, ANSI/ANS 54.8-1989, "Standard for Liquid Metal Fire Protection in LMR Plants," American Nuclear Society, La Grange Park, Illinois.

3.24 U.S. Atomic Energy Commission, "Instrumentation for Earthquakes," Regulatory Guide 1.12.

3.25 U.S. Nuclear Regulatory Commission, "Nuclear Power Plant Instrumentation for Earthquakes," Draft Guide 1016 (MS 140-5, Proposed Revision 2 to Regulatory Guide 1.12), July 1981.

3.26 Gluekler, E.L., et. al., "Seismic Isolation Development for the U.S. Advanced Liquid Metal Reactor Program," First International Seminar in Seismic Base Isolation of Nuclear Power Facilities, San Francisco, California, August 21-22, 1989.

3.27 Energy Technology Engineering Center, et al., "ALMR Technology Development Requirements Plan," GEFR-00845, Revision 3, June 1992.

3.28 E.D. Throm, U.S. Nuclear Regulatory Commission, letter to C.E. Alder, "Summary of October 25-26, 1990 Meetings with GE, DOE, and Argonne National Laboratories on Advanced Liquid Metal Reactor PRISM Design," November 15, 1990.

3.29 Proceedings from the meeting with General Electric, Bechtel Corporation, and the Department of Energy on the Power Reactor Innovative Small Module, "Discussion of Seismic Response and the Use of Seismic Isolators for the PRISM Design," 16-17 October 1991.

3.30 California Department of Conservation, Division of Mines and Geology, Office of Strong Motion Studies, "Quick Report on CSMIP Strong-Motion
Records From the February 28, 1990 Earthquake Near Upland, California," August 1991.

3.31 U.S. Nuclear Regulatory Commission, "PreEarthquake Planning and Immediate Nuclear Power Plant Operator Post-Earthquake Actions," Draft Guide 1017.

3.32 U.S. Nuclear Regulatory Commission, "Restart of a Nuclear Power Plant Shutdown by a Seismic Event, " Draft Guide 1018.

3.33 U.S. Nuclear Regulatory Commission, "Thermal Stresses in Piping Connected to Reactor Coolant Systems," Bulletin 88-08, Supplement 3, April 1989.

3.34 U.S. Nuclear Regulatory Commission, "Modifications of General Design Criterion 4 Requirements for Protection Against Dynamic Effects of Postulated Pipe Ruptures, " 52 Federal Register, 41291, October 1987.

3.35 California Department of Conservation, Division of Mines and Geology, Office of Strong Motion Studies, Preliminary Data Report OSMS 85-02, "Selected Accelerograms from Redlands, California Earthquake of October 2, 1985 (Including First Records from a Base-Isolated Building), " 8 October 1985.

3.36 California Department of Conservation, Division of Mines and Geology, Office of Strong Motion Studies, Report OSMS 86-05, "CSMIP StrongMotion Records from the Palm Springs, California Earthquake of 8 July 1986," 6 August 1986.

3.37 California Department of Conservation, Division of Mines and Geology, Office of Strong Motion Studies, Report OSMS 87-05, CSMIP StrongMotion Records from the Whittier, California Earthquake of 1 October 1987," October 31, 1987.

3.38 California Department of Conservation, Division of Mines and Geology, Office of Strong Motion Studies, "Quick Report on CSMIP Strong-Motion Records from the February 28, 1990 Earthquake near Upland, California, " March 2, 1990.

3.39 California Department of Conservation, Division of Mines and Geology, Office of Strong Motion Studies, Report OSMS 91-03, "CSMIP StrongMotion Records from the Sierra Madre, California Earthquake of 28 June 1991," August 8, 1991. 
3.40 California Department of Conservation, Division of Mines and Geology, Office of Strong Motion Studies, Report OSMS 92-09, "CSMIP StrongMotion Records from the Landers, California Earthquake of June 28, 1992," August 5, 1992.

3.41 California Department of Conservation, Division of Mines and Geology, Office of Strong Motion Studies, Report OSMS 92-10, "CSMIP StrongMotion Records from the Big Bear, California Earthquake of June 28, 1992," August 21, 1992.

3.42 California Department of Conservation, Division of Mines and Geology, Office of Strong Motion Studies, Report OSMS 92-03, "Quick Report on CSMIP Strong-Motion Records from the April 24, 1992 Desert Hot Springs, California Earthquake," April 24, 1992.

3.43 U.S. Nuclear Regulatory Commission, "Design Limits and Loading Combinations for Metal
Reactor Containment System Components," Regulatory Guide 1.57.

3.44 U.S. Nuclear Regulatory Commission, "Quality Assurance Requirements for Installation, Inspection, and Testing of Structural Concrete and Structural Steel During the Construction Phase of Nuclear Power Plants, " Regulatory Guide 1.94.

3.45 U.S. Nuclear Regulatory Commission, "SafetyRelated Concrete Structures for Nuclear Power Plants (Other than Reactor Vessels and Containments), " Regulatory Guide 1.142.

3.46 U.S. Nuclear Regulatory Commission, Staff Requirement Memorandum, "SECY-93-092, Issues Pertaining to the Advanced Reactors (PRISM, MHTGR, and PIUS) and CANDU 3 Designs and Their Relationship to Current Regulatory Requirements," July 30, 1992. 


\section{REACTOR SYSTEM}

\subsection{Summary Description}

The PRISM reactor is designed to use a heterogeneous metal-alloy core. The conceptual design is for a ternary fuel, that comprises uranium with $26 \mathrm{wt}$. \% plutonium and 10 wt. \% zirconium, (U-26wt. \% Pu-10wt. \% Zr), clad with the ferritic steel alloy HT9, and arranged in 42 fuel assemblies, each consisting of $\mathbf{3 3 1}$ fuel rods. The core will also contain 24 internal blanket assemblies, 33 radial blanket assemblies, 42 reflector assemblies, 48 radial shield assemblies, and 6 control and shutdown assemblies. Three peripheral assembly locations, in the radial blanket, are replaced with gas expansion modules (GEMs). An ultimate shutdown system (USS) assembly is at the center of the core. The present core is designed for $471 \mathrm{MWt}$ $(155 \mathrm{MWe})$ power output per reactor module. A full ninemodule plant site is rated at 1,395 MWe. The bulk sodium temperature is expected to increase in the core by $148 \mathrm{~K}\left(265^{\circ} \mathrm{F}\right)$, with an inlet temperature of $610 \mathrm{~K}$ $\left(640^{\circ} \mathrm{F}\right)$ and a bulk outlet temperature of $758 \mathrm{~K}\left(905^{\circ} \mathrm{F}\right)$. The active height of the fuel is 1.35 meters ( 53 inches). Fuel life is 4.5 years with refueling intervals of 18 months. Spent fuel will be stored in the reactor vessel for one fuel cycle.

The core internal structural material is HT9, the same as the fuel rod cladding. This tempered martensitic stainless steel material was selected for its low-swelling characteristics upon irradiation.

The control and shutdown system is designed to operate with six control rods. The six control rods provide scram diversity and shutdown redundancy. Rod positioning during normal operation is accomplished through a stepping motor, controlled by the plant control system (PCS), which actuates a lead screw to insert and withdraw the absorber. The PCS actuates only one control rod at a time. Each control rod unit consists of a drive mechanism, a driveline, and a control assembly (absorber bundle and outer duct). Each unit has two diverse means of scramming the absorber bundle. For rapid emergency shutdown (scram), the Class IE reactor protection system (RPS) causes the electromagnets on all six control rod assemblies to deenergize, thus opening the mechanical latches and allowing the absorbers to drop into the core. Unlatch time is less than 0.2 seconds and full stroke insertion takes atrout 2 seconds. The second means is by an irreversible, high-speed drive-in motor controlled by the RPS from an uninterruptible power supply. The highspeed drive-in is initiated at the same time as the latch release and exerts up to 8,900 newtons $(2,000$ pounds force). Fast drive-in produces full stroke insertion in 18 seconds. Each control rod has sufficient worth for reactor shutdown, a 6:1 redundancy.
A Class $1 \mathrm{E}$, electronically positioned, mechanical rod stop system (RSS) prevents the unprotected rod withdrawal event from exceeding $40 \mathrm{C}$ reactivity insertion, with uncertainties. Components in the RSS include a redundant Class $1 \mathrm{E}$ controller, a rod stop drive selector (only one rod may be repositioned at a time), and a single limitedcapacity power supply that controls power to each of the six rod stop adjustment motors, one motor for each control rod.

Three GEMs are located at the periphery of the active core. A GEM is the same external size and configuration as the ducts on the other core assemblies. The GEMs are filled with inert gas and sealed at the top. Each GEM communicates with the core inlet plenum through an opening in the nose piece. With the primary pumps running, the pressure in the core inlet plenum compresses the gas captured in the GEMs and raises the sodium level in the GEMs to a height above the active core. When the pumps are turned off, the core inlet plenum pressure drops and the gas expands, displacing the sodium in the GEMs to a level below the active core. This change in the sodium level introduces significant negative reactivity and limits the peak temperatures attained during loss-of-flow events. The GEMs also enhance the PRISM capability to safely withstand severe undercooling accidents without scram, including loss of all cooling by the intermediate heat transport system (IHTS) from a full-power condition.

The USS is a diverse, independent means of bringing the reactor to cold shutdown. The USS is operator activated to release neutron-absorbing spheres containing fully enriched boron-10 (B-10) in the form of boron carbide $\left(B_{4} C\right)$ from a container at the closure head of the reactor vessel; these fall into an open assembly in the center of the reactor core.

\subsection{Fuel System}

\subsubsection{Design Description and Safety Objectives}

The fuel and blanket subassembly design and operational parameters are presented in Chapter 4 and Appendix $G$ of the Preliminary Safety Information Document (PSID) (Ref. 4.1), and are not repeated here. The fuel design uses a ternary metal-alloy made of uranium (U) that contains 26wt.\% of plutonium $(\mathrm{Pu})$ and $10 \mathrm{wt} . \%$ of zirconium ( $\mathrm{Zr}$ ), the blanket design specifies $\mathrm{U}-10 \mathrm{wt} . \%$ of zirconium. The plutonium source assumed for the PRISM design is light-water reactor (LWR) recycle plutonium. Both fuel and blanket are clad with low-swelling HT9 steel, and the subassembly ducts are also fabricated of HT9. The fuel and blanket assemblies are designed for a 4.5-year and 7.5-year lifetime, respectively, with fuel discharged with a peak burnup of $135 \mathrm{MWd} / \mathrm{kg}$ and a 
blanket with a peak burnup on the order of $55 \mathrm{MWd} / \mathrm{kg}$. During this period of operation, considering normal and anticipated duty-cycle events which include load following and run beyond cladding breach operation, no more than 0.01 percent of the pins in the (equilibrium) core are expected to fail. In addition, the system is designed to tolerate a set of design-basis accidents with allowable consequences ranging from no significant degradation of expected fuel lifetime to maintenance of a coolable geometry.

The reactor core subsystem performs the following functions:

- Generates thermal power through controllet nuclear fission and transfers it to the liquid sodium of the primary heat transport system.

- Contains and confines within the core, the fissile and fertile materials and the solid and gaseous fission products to prevent excessive contamination of the coolant.

- In conjunction with the reactor structures, shields permanent structures peripheral to the core subsystem to prevent excessive nuclear irradiation damage during the plant design life.

- Supports safety goals and requirements through the use of passive (inherent) reactivity feedback mechanisms.

- Performs an initial cleanup of the primary heat transport system sodium with special non-fueled assemblies which also have the capability for hydraulic characterization of the core components during preoperational testing. Core special assemblies also contain the startup neutron source for the initial core loading.

The core is comprised of removable components. The structural design requirements for these components are determined by cladding and assembly integrity and by duct interaction requirements. These requirements are explicitly embedded within the operational and reliability requirements for fuel failure probability and duct interactions based on applicable materials properties, applicable duty cycles, and applicable liquid-metal reactor (LMR) core analytical computer programs.

\subsubsection{Scope of Review}

The metal-fuel system (U-Pu-Zr fuel with HT9 cladding) is a new concept with little operational experience. A research and development (R\&D) program sponsored by the Department of Energy (DOE) and being implemented by Argonne National Laboratory (ANL) as part of the Integral Fast Reactor (IFR) Fuel Performance Program is currently supporting the PRISM fuel and core design (Ref. 4.2). Despite many years of successful operation with metal fuel in the Experimental Breeder Reactor-II (EBR-II), the differences in material, geometry, and operating conditions are such that direct application of that experience to the PRISM design is difficult without additional fuel and material testing, safety tests, and analytical model development. The review presented here was carried out with the recognition that a new technology is under development and, although much research has already been done in support of the program, much remains to be done.

The staff review consisted of an assessment of the current state of knowledge with respect to the PRISM fuel system concept and a review of the R\&D effort planned within the IFR program. Final determination regarding the ability of the PRISM design to meet the design criteria of 10 CFR Part 50 (Ref. 4.3) and the objectives given above must await a detailed review of the results of the R\&D program. Thus, the limited objective of this review was to identify potential problems in the design that could be ascertained at this early date and that might have the potential to be major safety-related problems. A second objective was to determine whether the R\&D program would lead to development of the experimental data base and analytical tools that will eventually be required to support licensing of the PRISM design.

The review was carried out using published literature as a basic resource, and the ANL IFR collection of reports. It must be noted that these reports are subject to the DOE applied technology provisions under 10 CFR Part 810 , which restricts their general availability. This literature was supplemented by several information exchange meetings presented by the ANL staff to Brookhaven National Laboratory (BNL) and NRC personnel. In addition, a series of written exchanges in the form of questions and answers provided useful clarifications.

\subsubsection{Design Criteria}

Section 4.2, "Fuel System Design," of the Standard Review Plan (SRP) (Ref. 4.4) discusses the criteria to be used in performing fuel system safety reviews. The objectives of the review are derived from 10 CFR Part 50, General Design Criterion (GDC) 10. The reactor core and associated coolant, control, and protection systems shall be designed with appropriate margin to ensure that specified acceptable fuel design limits are not exceeded during any condition of normal operation, including the effects of anticipated operational occurrences. The objectives of the fuel safety review are to assure the following: 
- The fuel system is not damaged as a result of normal operation and anticipated operational occurrences.

- Fuel system damage is never so severe as to prevent control rod insertion when it is required.

- The number of fuel rod failures is not underestimated for postulated accidents.

- Coolability is always maintained.

The general requirements for maintaining control rod insertability and core coolability appear repeatedly in the light-water reactor (LWR) GDC.

In GDC 27, it is stated that "The reactivity control systems shall be designed to have a combined capability, in conjunction with poison addition by the emergency core cooling system, of reliably controlling reactivity changes to assure that under postulated accident conditions and with appropriate margin for stuck rods the capability to cool the core is maintained."

The chemical poison system requirement in GDC 27 is not applicable to the PRISM design. Excess negative reactivity requirements, including uncertainties, to obtain cold shutdown with the highest worth control rod stuck out will be maintained in the design.

In GDC 35, it is stated that

A system to provide abundant emergency core cooling shall be provided. The system safety function shall be to transfer heat from the reactor core following any loss of reactor coolant at a rate such that (1) fuel and clad damage that could interfere with continued effective core cooling is prevented and (2) clad metal-water reaction is limited to negligible amounts. Suitable redundancy in components and features, and suitable interconnections, leak detection, isolation, and containment capabilities shall be provided to assure that for onsite electric power system operation (assuming offsite power is not available) and for offsite electric power system operation (assuming onsite power is not available) the system safety function can be accomplished, assuming a single failure.

The PRISM design, a low-pressure pool reactor with no piping or fittings below the surface of the pool and with a containment (guard) vessel surrounding the reactor vessel, precludes a large loss-of-coolant accident (LOCA) and does not require an emergency core cooling system similar to those in current-generation LWRs. GDC 35, is therefore, not applicable to the PRISM design.

With minor changes in wording, the PRISM PSID uses the appropriate GDCs as guidance for its reactor and fuel system design criteria. These are stated in Section 3.1 of the PRISM PSID.

\subsubsection{Research and Development}

Analytical tools and a supporting experimental data base, are being developed for use in analyzing the fuel system response to the anticipated range of design and exposure conditions. EBR-II can serve as an extensive irradiation experience data base for the metal fuel concept (Refs. 4.5 and 4.6). The Mark-Il uranium-fissium driver fuel clad with austenitic Type 316 stainless steel, which has had many years of experimental and analytical development, has been successfully irradiated to burnups close to the PRISM design limit, which is 15 atomic percent (at.\%) peak burnup. Such experience lends support to the metal fuel concept proposed by PRISM.

Peak burnups achieved in EBR-II with ternary metal fuel (as of mid-1991) include

- 18.4 at. \% burnup with U-8wt. \%Pu-10 wt.\%Zr with HT9 cladding

- 16.2 at. \% burnup with U-19wt. \%Pu-10wt. \% Zr with HT9 cladding

- 4.1 at. \% burnup with U-22wt. \%Pu-10wt.\% Zr with HT9 cladding

- 4.1 at. \% burnup with U-26wt. \%Pu-10wt. \% Zr (PRISM specific fuel) clad with HT9

There is also a large amount of data for ternary metal fuels with Type 316 stainless steel cladding and D9 cladding, and also for binary (U-Zr) metal fuel.

The basic materials, geometry, and exposure conditions for most of the ternary metal fuels irradiated in the EBR-II are different from the PRISM fuel design. Because of these differences, analytical models are used to extrapolate the EBR-II data to the PRISM design concept. Much prototypic experimental data remain to be developed in order to verify the models and to establish the basic relationships regarding material compatibility between fuel, cladding, and sodium.

Eight PRISM ternary fuel rods (U-26wt. \% Pu-10wt. \% Zr with HT9 cladding) have been in the EBR-II irradiation 
program since November 1988. In January 1990, specimens were removed, with an accumulated burnup of 2.3 at. \%, for ex-reactor testing (Ref. 4.7).

In order to meet the NRC safety criteria for the proposed design, analytical tools and supporting experimental data are required in two broad areas: (1) fuel design and performance based on the specified duty cycle of the system and (2) response of the fuel to transients. The development efforts in progress are discussed briefly below.

\section{Fuel and Cladding Fabrication Technology}

The PRISM plant is designed to accommodate fuel reprocessing in the form of a commercial-scale fuel cycle facility that includes fabrication, reprocessing, and waste treatment. At the end of its reactor lifetime, fuel can be reprocessed using a pyrometallurgical technique to separate out fission products. This processing technique has been demonstrated on a laboratory scale. The development work leading to engineering-scale demonstration of the technique is being done at the present time (Ref. 4.8). The ability of the reprocessing technique to produce $\mathrm{U}-\mathrm{Pu}-\mathrm{Zr}$ fuel with the requisite quality assurance standards of uniform composition from batch to batch has yet to be demonstrated on a commercial scale. There will no doubt be "fissium" products remaining in the fuel. The final composition of the reprocessed fuel, however, has yet to be determined.

If spent fuel from LWRs is to be used to make fuel for the advanced liquid-metal reactor (ALMR), and if pyroprocessing of the LWR oxide fuel is to be utilized, then the minor actinides are going to come along with the plutonium. The minor actinides will also build up from the planned recycling of the ALMR fuel. The minor actinides increase the decay heat load and add further complications to the metal fuel, which would become approximately U-26wt. \% Pu-1wt. \% Np-2wt. \%Am-0.2wt\% - Cm-10wt. \% Zr. There is significant uncertainty in the cross-sections for the minor actinides, so calculations regarding burnups and reactivity feedbacks would contain more uncertainly than is presently the case.

HT9 steel has been chosen as the reference cladding material because of its demonstrated low-swelling characteristics at neutron fluences of interest to the ALMR program. The staff notes that, although this material may have potentially favorable properties, little is known about its structural response to the extended irradiation planned in the PRISM design. More data, including response characteristics data, are anticipated as experience with this material is gained through the EBR-II and Fast Flux Test Facility (FFTF) irradiation programs. As planned, the irradiation programs appear to be adequate to produce the needed information in a timely manner consistent with the proposed PRISM schedule. This steel alloy is relatively new and its uniformity of composition and thermomechanical properties from batch to batch have not yet been adequately demonstrated. In addition, techniques have only recently been developed to weld and fabricate this alloy.

Since the technology is new, particular attention needs to be paid to quality assurance of material supply and fabrication and welding techniques.

\section{Fuel Desien and Performance Methodology}

A program of analytical model development, irradiation performance testing, out-of-pile materials testing and experimental verification is in progress as part of the ANL IFR program. This program contains the essential research efforts required to develop the technology to support the PRISM design. The brief review of the major elements of the program (below) points out several phenomenological issues that are of sufficient importance to the success of the metal-fuel program to require that close attention be given to future research.

The LIFE-METAL computer code (Ref. 4.9) is the analytical tool being developed at ANL to model the response of the metal fuel and blanket elements to steady-state and operational transient conditions. The code, which is used as the fuel design tool, has been adapted from earlier versions that were used to analyze oxide, carbide, and nitride fuel systems. It is fully operational in its application to metal fuel at this time. It concains preliminary models or correlations of the relevant physical phenomena and incorporates the latest ayailable thermophysical property data on metal fuels. The staff has not reviewed the LIFE-METAL code modeling; however, analysis done by ANL using this code indicates good agreement with experimental data. The staff should assess the LIFE-METAL code in subsequent ALMR reviews.

At the present time, ANL believes that the fuel lifetime is limited by the mechanism of creep rupture of the HT9 cladding under internal loading caused by fission gas plenum pressurization. Cladding wastage resulting from fuel-cladding chemical-exchange processes is also considered. It is believed that, because of the properties of the highly porous fuel and the high strength of the cladding, the fuel-cladding mechanical interaction component of cladding loading is a physical mechanism of the second order. Confirmatory investigations that deal with all of the relevant mechanisms involved in predicting fuel failure within the bounds of this scenario are in progress. 
The global aspects of fission gas release from metal fuels have been studied and characterized to the extent that models are available to predict fission gas release and plenum pressurization. Local effects along the fuel pin axis are currently under investigation. Fission gas retention and swelling on a local basis are also under investigation. Models for fuel swelling and radial versus axial fuel strain are being developed. The LIFE-METAL code modeling of these phenomena is supplemented by more-detailed modeling in the STARS code (Ref. 4.10). Early indications were that axial fuel strain terminated after approximately 5 at. \% burnup; more-recent evidence, however, suggests that axial strain may continue to increase up to 10 at. \% burnup. This evidence has a strong influence on the control characteristics of the reactor system. Close attention should be paid to research in this area.

Significant fuel restructuring has been observed to occur as a result of irradiation. There is also some evidence that plutonium may redistribute at high burnups. Since the fuel melting characteristics are dependent upon alloy composition, these effects could strongly influence the fuel element design, both in terms of geometry and in terms of maximum operating power density. The mechanisms of migration within fuel elements are not well understood at present. Available evidence indicates that restructuring occurs with ternary fuels of all compositions, and also in $\mathrm{U}-\mathrm{Zr}$ fuel. The experimental observations of migration are used as empirical input to the LIFE-METAL code at the present time in order to estimate the effects on the thermal and mechanical responses of the fuel elements.

Multi-phase boundaries present in the fuel during operation lead to annular zones that differ in swelling properties and metallurgical composition. This zone structure is most prominent in observations from 19wt. \% Pu fuel. By 2 at. \% burnup, an interchange between the zirconium and uranium occurs. Depending on the fuel temperature, this leaves either a $\mathrm{Zr}$-depleted shell $(<2 w t . \% \mathrm{Zr})$ at mid-radius surrounding a $\mathrm{Zr}$-rich core (a two-ring structure) or a $\mathrm{Zr}$-depleted nugget at slug center encircled by $\mathrm{Zr}$-rich fuel (a three-ring structure). Wedge-shaped cracks appear in the early stages of burnup, but are completely "healed" by 10 at. \% burnup.

Three issues relate to performance effects that preferential radial redistribution can have on $\mathrm{U}-\mathrm{Pu}-\mathrm{Zr}$ fuels. These are

If plutonium should redistribute preferentially to the outer radius of the fuel elements, then there are potential effects on the expected fuel-cladding-chemical interaction. U.Pu-Fe phase diagrams indicate that fuel-cladding would melt at a lower temperature if plutonium is concentrated near the fuel-cladding interface. This effect would limit the allowable fuel-cladding temperatures, especially during off-normal events of long duration.

(2) If plutonium concentrates in the $\mathrm{Zr}$-depleted areas (mid-radius in high-temperature fuel), then the fuel melting temperature could be further reduced (increased $\mathrm{Pu}$ and decreased $\mathrm{Zr}$, or both, reduce the fuel solidus temperature). This could potentially lower the limiting fuel temperatures during off-normal events. There is currently no evidence that during steady-state operation the $\mathrm{Zr}$-depleted zone would form at a location where temperatures approach the fuel solidus temperature. The secondary imposition of an off-normal event would, however, not allow time for additional fuel redistribution, and the fuel could melt at a pre-existing low- $\mathrm{Zr}$ area if temperatures were high enough.

(3) Plutonium redistribution can also potentially redistribute the local fission density, changing the radial temperature distribution in a fuel element. The potential negative secondary effects are then increased in the fuel center, the issues being similar to those just discussed in item 2 .

Having reviewed the data available to date, ANL has summarized the U-Pu- $\mathrm{Zr}$ redistribution characteristics as follows:

- At low burnup ( $<6$ at. \%) there is no significant radial variation in plutonium concentration (by at. \%).

- At high burnup ( $>10$ at. \%) there is some evidence of slight increases in plutonium concentration in zones enriched with zirconium. These are the inner and outer zones in three-ring structures, and the outer ring in two-ring structures. The influence of fission products could affect this, but the exact correlation is not known. Likewise, the statistical significance of the plutonium variations are not documented, as the influence of porosity variations on the experimental results could be significant for these small amounts of possible segregation, and the porosity influence is not currently known. The influence of the observed plutonium variations on solidus temperature or fuel-cladding interaction should be insignificant compared to uranium and zirconium migration effects.

It is clear that significant uranium and zirconium redistribution occurs in U-Pu-Zr fuel. At low burnup, the plutonium distribution (at. \%) appears essentially unchanged across the fuel radius. Analysis of high-burnup fuel shows 
some indication of slight plutonium redistribution to high- $\mathrm{Zr}$ portions of the tuel. Effects of this plutonium distribution are difficult to predict as a result of the degree of segregation when compared to the potential experimental errors or those errors involved in modeling the fuel elements. DOE plans to investigate this phenomenon. Currently there are several high-plutonium experiments in progress to gain steady-state performance data and to produce irradiated fuel for ex-reactor testing.

In addition to fuel restructuring, irradiation and fission gas release are observed to lead to the development of a nonuniform porous fuel structure with porosities observed in excess of 60 percent on a local basis. Although the mechanisms of fission gas release are understood and preliminary models are available, porosity distributions cannot be predicted at present. Models for porosity distribution are being developed and evaluated.

The effects of fuel restructuring and porosity have a strong influence on the thermal-mechanical behavior of the ALMR fuel element. The local thermal conductivity of the fuel depends strongly on both the local elemental concentration and the local porosity. The behavior of bond sodium, in possibly filling some of the porosity, is an additional unknown and is being investigated. The creep properties of the fuel depend on the porosity as well, although local effects may not be important. Since, at present, neither phenomenon is well understood, experimental observations are being used to specify the material and porosity distributions in calculations of the thermal response of the fuel element. The computed temperature distribution within the fuel element must be compared with the local alloy solidus temperature in order to determine reasonable design limits for power density and possible modifications of fuel design. These areas are crucial for future decisions regarding maximum operating power.

Although the current hypothesis is that the porous and spongy nature of the fuel leads to negligible fuel-cladding mechanical interaction loading of the cladding, this area still requires additional research. Work at ANL will address the creep behavior of the porous fuel structure so that models for LIFE-METAL may be verified. Additional questions relate to possible fuel growth due to the presence of solid fission products and to the possibility that near the end of life, some of the porosity will be closed by the solid fission products.

Cladding breach criteria are being developed for implementation into the LIFE-METAL code. Preliminary models have been incorporated in the LIFE-METAL code. The models are based on out-of-pile HT9 tube burst data developed at Hanford Engineering Development
Laboratory (HEDL). Little in-pile data relevant to failure of HT9 tubes are currently available. Models developed will eventually be verified against in-pile fuel-cladding performance data.

An extensive program of fuel-cladding compatibility experiments is in progress to characterize the chemical exchange processes at the fuel-cladding interface. An out-of-pile facility is used to test fresh and irradiated fuel samples over a range of prototypic temperatures. Although the current data base for HT9 is not extensive, additional data are anticipated. A correlation developed for the cladding penetration rate has been implemented in the LIFE-METAL code. At present, it is believed that the penetration rates are small enough to have no influence on fuel lifetime. Since this phenomenon has a potentially significant impact on fuel lifetime, it is important to keep track of developments.

The ternary metal fuel and the HT9 cladding are in a developmental stage at present and little data are available at significant burnups $(>10$ at. $\%)$. Therefore, temperature limits, such as eutectic formation, are not well known. There are several areas where more data is required to address concerns with the metal-fuel concept. These include

- Fuel-cladding chemical interaction forms the eutectic with the minimum melting temperature at the fuel-cladding interface, caused mainly by iron $(\mathrm{Fe})$ diffusion into the fuel. This effect is compounded by the migration of lanthanide, plutonium, zirconium, and the kinetics at the fuel-cladding interface. The minimum eutectic temperature must be determined for the prototypical PRISM fuel design.

- The maximum fuel-cladding liquid penetration rate from the eutectic formation must be determined from irradiated fuel, taking into account the lanthanide, plutonium, and zirconium migration, the iron diffusion, and the kinetics of potential transients (time at temperature).

The fuel-cladding eutectic temperature limit is currently thought to be $980 \mathrm{~K}\left(1,300^{\circ} \mathrm{F}\right)$ based on available experimental data from $\mathrm{U}-10 \mathrm{wt} . \% \mathrm{Zr}$ and ternary fuel with less than $26 \mathrm{wt} . \%$ Pu clad in D9, Type 316 stainless steel, or HT9. There are limited data on unirradiated fresh fuel typical of the PRISM design that indicates that the eutectic temperature may be as low at $903 \mathrm{~K}\left(1,165^{\circ} \mathrm{F}\right)$. The test does not include surface effects, irradiation effects, or kinetic factors. Recently completed testing on low-burnup (2.3 at.\%) PRISM fuel (Ref. 4.7) indicates that no fuel-cladding interaction occurs for temperatures below $1,025 \mathrm{~K}\left(1,385^{\circ} \mathrm{F}\right)$. Additional data are needed to 
establish a fuel design limit for use in licensing the PRISM design.

The IFR Fuel Performance Program for fuel assembly irradiations and post-test examinations supports the analytical model development program described above. A very strong program has been carried out and is planned for the future in the EBR-II, which will be converted to the ternary fuel. Additional experiments are currently being carried out in the FFTF using experimental metalfuel assemblies (Ref. 4.11). Consideration is also being given to eventually utilizing metallic fuel elements in the FFTF, although this appears to be the binary U-Zr system for the present. Ternary fuels will, however, be tested in the FFTF as experimental assemblies. Thus, a substantial data base will be developed over the next 5 years relevant to the behavior of metal fuel systems. At present, most of the available in-pile ternary fuel irradiation data have been obtained using D9 cladding. Data from HT9 fuel-cladding systems are being obtained at the present time. One fuel assembly in EBR-II has successfully achieved 9 at.\% burnup in ternary and binary fuel clad with HT9.

\section{Transient Fuel Response}

Research is in progress to develop a set of computer codes to predict the behavior of ALMR fuel subject to transient overpower and other transient events. The FPIN2 (Ref. 4.12) code is a detailed thermal-mechanical model of an individual fuel element used for analyses of fuel performance under transient conditions. The code has been modified from earlier versions used to model oxide fuel. It is currently operational using the latest thermal-mechanical properties of the metal-fuel-cladding system and has undergone some verification through comparisons with the transient overpower $\mathbf{M}$-series of Transient Reactor Test Facility (TREAT) experimental data. Supporting the FPIN2 computer code are more detailed codes, currently under development, for modeling fission-product retention and swelling in $\mathrm{U}-\mathrm{Pu}-\mathrm{Zr}$ alloy fuels during steady-state irradiation (STARS code) and for modeling the transient fission gas bubble gas distribution in solid and molten fuel (FRAS3 code). A less-detailed model for the fuel element thermal-mechanical response is being developed in the DEFORM-5 (metal fuel) module, a more recent version of the DEFORM-4 (oxide fuel) module from the SAS4A computer code (Ref. 4.13), for use as the fuel behavior model in the SASSYS (Ref. 4.14) whole-core-response computer code. Both of these codes are designed to predict transient events to the time of cladding rupture. In particular, the codes will provide predictions of fuel failure location and timing. However, neither contains the capability for ex-pin fuel motion modeling. A peer review of these codes may be necessary for future reviews.
Models are being developed, implemented, and tested in the transient response codes for cladding rupture based on the HEDL test data for HT9. Fission-gas retention and distributions are obtained from more detailed STARS calculations and from experimental data. Fuel-swelling rate is calculated using a model of gas-bubble growth. The creep behavior of the porous fuel is modeled using an empirically based correlation.

The fuel-cladding interaction rate at elevated temperatures is treated empirically using data obtained from both in-pile and out-of-pile experiments. Data from experiments using HT9 samples are now being obtained. These data appear to be making a consistent picture when combined with earlier information.

The results from the FPIN2 code and DEFORM-5 module are being compared with the results of the $M$-series of TREAT experiments (M2-M7) performed using both fresh and irradiated fuel elements. Comparison of code calculations with the data is leading to an understanding of the behavior of the EBR-II fuel elements with U-fissium fuel and, more recently, with ternary fuel with both D9 and HT9 (M7) cladding. The comparisons of code results with the data have provided an understanding of the mechanisms of failure of these fuel elements during "slow" overpower transients. Experiments and analyses indicate that, under the "slow" overpower conditions of the experiments, the fuel pins fail near the top of the fuel column, where the molten fuel is released into the coolant channel. Experiments indicate that the molten fuel is swept downstream from the failure location, presumably by the movement of the flowing sodium. Although the arguments appear plausible, they should be verified by experiments using fuel elements more prototypical of the PRISM fuel. Additional experiments should be performed with higher burnup fuel.

The modeling and fuel failure arguments that have been applied to the $M$-series of overpower experiments should be tested with experim/snts using fuel elements that are closer to the PRISM d/sign than are the EBR-II elements. This means that th; fuel elements irradiated in the FFTF should eventually be tested to build confidence in the models and in the irterpretation of results. Consideration is currently being given to such testing as part of the IFR program. Other experiments that simulate more-rapid transients are not planned at the present time. This decision appears reasonable for simulating rod-withdrawal accidents. Faster transients are, however, needed for simulating accidents under conditions of large reactivity insertion due to sodium boiling, a hypothetical core disruption accident (HCDA). 
Fuel motion during an HCDA is the mechanism that limits the energy release that the reactor vessel and structures need to be capable of absorbing. Rapid prefailure (before the reactor fails) extrusion of the molten fuel into the plenum fission gas volume and out of the active core region during the power excursion results in a negative reactivity feedback which, in turn, limits the overpower excursion. FFTF data based on oxide fuel have heen used to estimate the upper bound on the maximum excursion that could be developed in the PRISM design. The FFTF reactivity ramp rates, which could exceed $\$ 100$ per second, and the energy release, which reaches a few hundred megajoules (MJ), are considered to be higher than would occur in a metal-fuel core and, therefore, conservative when applied to PRISM. A 500-MJ energy release is currently being used by GE in the PRISM design studies. GE believes this to be a conservative upper bound for the primary boundary assessment.

The behavior of molten fuel during a power excursion, particularly the extrusion mechanism, needs to be verified by appropriate testing. Such tests are expected to be complex and costly. The IFR test program includes a series of TREAT experiments to develop the needed data base for postulated severe accidents and core disruption events. These data will be used to validate the SAS4A code.

In general, the use of TREAT tests to determine the transient response appears to be acceptable. Plans to use TREAT tests are currently being developed for investigating such factors as rapid eutectic formation and cladding penetration, fuel melting and motion characteristics, and more prototypical pin and transient tests. Modeling uncertainties remain, many of which are the uncertainties that have already been discussed in this section. Research is in progress to reduce the modeling uncertainties. Transient overpower data will be available to verify the modeling. However, the staff believes that additional experiments using fuel elements more prototypic of the PRISM design are appropriate, as discussed above. It should be noted that current analyses of transient events rely largely on system response simulations and eutectic formation versus time and temperature correlations. Generally, detailed analyses of fuel pin dynamics are not performed.

Experiments performed thus far using breached metal-fuel elements bave indicated good compatibility of the metalfuel system with sodium. Little erosion of metal has been observed. Additional run-beyond-cladding-breach (RBCB) experiments are planned in EBR-II with the ternary fuel system (Ref. 4.15). The data produced should allow assessment of the potential for problems related to erosion or corrosion product formation.

Future analyses to determine that fuel coolability will be maintained under operational and anticipated transients will be developed in the IFR fuel research programs. Although HT9 is not expected to swell under extended irradiation, the fuel irradiation performance program should produce the experimental data necessary to establish whether ballooning will close the coolant channels and to study issues related to ensuring that the control rods will insert.

One possible weakness in the program involves experimental verification of the claim that no more that 0.01 percent of the PRISM fuel pins in the (equilibrium) core will fail during normal and transient conditions. The FFTF irradiations will be the closest to prototypical PRISM conditions. The number of planned ternary fuel elements to be irradiated, to produce an adequate data base for a statistical analysis, remains an open item along with how the differences in geometry and other relevant characteristics will be accounted for in such a statistical analysis. Prototypical fuel fabrication processes, fuel composition, fuel geometry, and irradiation typical of anticipated end-of-cycle burnups need to be accounted for in the testing program.

Planned Metal-Fuel System Research and Development Program

The metal-fuel system to be used in the PRISM reactor is still under development, and a significant R\&D program, the IFR program, is in place at ANL. Figure 4.1 shows the current IFR technology development schedule. The IFR is a complete advanced reactor concept which capitalizes on the unique characteristics of metallic fuel and liquid-metal cooling; it aims for significant improvements in reactor safety, reactor operations, fuel cycle economics, environmental protection, and safeguards.

The IFR technology R\&D program consists of three phases:

- Phase I - Technical Feasibility (1985-1986)

- Phase II - Technology Development (1987-1990)

- Phase III - Technology Demonstration (1991-1995) 
Figure 4.1 IFR technology demonstration schedule

\begin{tabular}{|c|c|c|c|c|c|c|c|c|c|c|c|}
\hline & 85 & 86 & 87 & 88 & 89 & 90 & 91 & 92 & 93 & 94 & 95 \\
\hline & \multicolumn{2}{|c|}{$\begin{array}{c}\text { PHASE } \\
\text { I } \\
\text { Technical } \\
\text { Feasibility }\end{array}$} & \multicolumn{4}{|c|}{$\begin{array}{l}\text { PHASE } \\
\text { II } \\
\text { Tochnology } \\
\text { Development }\end{array}$} & \multicolumn{5}{|c|}{$\begin{array}{c}\text { PHASE } \\
\text { III } \\
\text { Technology } \\
\text { Demonstration }\end{array}$} \\
\hline $\begin{array}{l}\text { Technology } \\
\text { Development }\end{array}$ & \multicolumn{6}{|c|}{$\begin{array}{l}\text { Fuel performance, safety, core design, } \\
\text { pyro-process development, fuel cycle } \\
\text { development }\end{array}$} & \multicolumn{5}{|c|}{$\begin{array}{l}\text { Licensing database, waste } \\
\text { treatment technology }\end{array}$} \\
\hline EBR-II & \multicolumn{6}{|c|}{ EBR-II core conversion } & \multicolumn{5}{|c|}{ Recycle fuel demonstration } \\
\hline $\begin{array}{l}\text { Fuel Cycle } \\
\text { Facility }\end{array}$ & & & \multicolumn{5}{|c|}{ HFEF/S facility refurbishment } & \multicolumn{4}{|c|}{$\begin{array}{c}\text { Fuel cycle } \\
\text { demonstration }\end{array}$} \\
\hline $\begin{array}{l}\text { Advanced } \\
\text { LMR Design }\end{array}$ & \multicolumn{4}{|c|}{ Conceptual design } & \multicolumn{3}{|c|}{$\begin{array}{l}\text { Advanced } \\
\text { conceptual design }\end{array}$} & \multicolumn{4}{|c|}{$\begin{array}{l}\text { Define private sector } \\
\text { and international interest }\end{array}$} \\
\hline & 85 & 86 & 87 & 88 & 89 & 90 & 91 & 92 & 93 & 94 & 95 \\
\hline
\end{tabular}

Major accomplishments during Phase I include

- feasibility demonstration of electrorefining on a laboratory scale

- passive safety demonstration tests in EBR-II

- adaptation of the IFR concept to the PRISM and SAFR (sodium advanced fast reactor) designs

Major accomplishments during Phase II include

- demonstration of high-burnup potential and fuel performance characterization

- engineering-scale demonstration of electrorefining
- development of safety data to support the PRISM design team licensing interactions with the NRC

- EBR-II core conversion to the IFR metallic U-Zr and U-Pu-Zr fuels

- refurbishment of the original EBR-II fuel cycle facility

The major goals of Phase III include

- demonstration of performance of recycled IFR fuel up to the $150,000 \mathrm{MWd} / \mathrm{T}$ burnup level

- demonstration of the passive (inherent) safety potential of the IFR concept through actual EBR-Il plant tests with recycled IFR fuels 


\section{Reactor System}

- demonstration of the entire IFR fuel cycle on a prototype scale

- definition and characterization of the IFR waste package

- demonstration of actinide recycle capability

- developing a licensing data base in support of the ALMR project interactions with the NRC (PRISM review)

The objective of the Phase III safety program is to perform safety research and development activities to develop the data base and the validated analysis tools to support the licensing of a demonstration reactor near the turn of the century. Validation of these analysis tools requires an experimental data base. Testing in the TREAT reactor, in EBR-II, and out-of-pile experiments in the whole pin furnace (WPF) facility, and the fuel behavior test apparatus (FBTA), is necessary to validate the analytical tools. The methods are largely in place to facilitate the evaluation of design options and to proceed with licensing activities in several areas of IFR safety technology, for example, sodium void reactivity, decay heat removal, loss of primary sodium, sodium fires, and sodium-water reaction in the steam generators.

The safety technology areas requiring significant additional development to support licensing are

- anticipated transients without scram

- local faults

- containment function

A brief summary of the IFR fuel-related R\&D program is given.

\section{In-Reactor Experiments}

Transient tests in the TREAT reactor produce two types of validation data:

- data on fuel element failure mechanisms and fuel element margins to failure (These data are necessary for the evaluation of the IFR-based reactor to respond to all transients, including anticipated transients without scram (ATWSs), without fuel failure.)

- integral experiment data on post-failure fuel dynamics using multipin experiments to allow validation of the SAS4A code for severe core disruption events
Other issues, such as local faults phenomenology and fission-product release and transport characteristics, may also be addressed depending upon their need.

The following four series of tests, in TREAT, are planned during Phase III:

\section{Cladding Failure Mechanisms and Margins to Eailure}

The first series will be a continuation of the previous M-series of tests to obtain data on fuel failure mechanisms and failure margins for combinations of fuel, cladding, and burnup for which the current data base is now deficient. One test will investigate fuel damage, cladding failure, and prefailure fuel expansion of IFR reprocessed fuel or unreprocessed $26 \mathrm{wt} . \% \mathrm{Pu}$ fuel, or both. Use of the high-Pu-content fuel should demonstrate the expected insensitivity of fuel behavior to plutonium content. One other test in this series will be performed on longer fuel ( 92 centimeters (36 inches)), to confirm the adequacy of existing models to the prediction of full-length fuel and demonstrate the absence of any phenomenon peculiar to longer fuel.

\section{Post-Failure Fuel Motion}

The second series will specifically address fuel disruption and post-failure fuel dynamics in pin-bundle geometry. Transient heating and flow conditions that are characteristic of the principal, hypothetical, severe-accident scenarios will be included in the tests. These tests will address conditions pertaining to loss-of-flow (LOF) and loss-of-heat sink (LOHS) ATWS events.

\section{Local Faults}

The third series will determine the outcome of certain local fault situations. These tests will address the consequences of undetected internal blockage, or an enrichment error in fuel fabrication.

\section{Fission-Product Source Term}

The fourth series of tests will investigate the release and transport of fission products during hypothetical fuel disruption sequences. The basic goal of these tests will be to obtain data that gives a quantitative understanding of the phenomenology of the transport and retention of fission products and actinides following a core-melt accident. Two 
general classes of transport mechanism appear to be important: radionuclide transport by the sodium flow through the above-core sodium pool, and fission gas-driven transport in large gas bubbles. The data to be obtained includes

- the quantity of radionuclides released to the cover gas region

- the nature of this release, particularly the aerosol portion

- the deposition of aerosols on surfaces in the cover gas region

- the aerosol behavior within the cover gas region

- retention within the above-core sodium

- deposition on surfaces within the above-core sodium

Two tests using seven-pin bundles are planned, one to simulate transient overpower conditions and one to simulate loss-of-flow conditions.

\section{Ex-Reactor Experiments}

These experiments involve furnace testing of irradiated metal alloy fuel pins in a hot cell under simulated accident conditions. Additional tests are planned with unirradiated metallic fuel to study severe-accident phenomenology.

\section{- Irradiated Fuel Pin Tests}

Out-of-pile tests on EBR-II-irradiated fuel pins are being performed in the WPF system. The objectives of these tests are to (1) study the behavior of irradiated fuel pins under simulated reactor accident conditions of relatively long duration (minutes to days) typical of loss-of-flow and loss-of-heat-sink events, and (2) to generate data for the validation of the FPIN2 and LIFE-METAL codes. The WPF tests fill that gap between the short-term (on the order of seconds) transient overpower experiments in the TREAT reactor and the relatively low-temperature, inherent safety demonstration experiments in EBR-II.

The recently completed WPF test, FM-3, was performed on low-burnup (2.3 at.\%) U-26wt. \% Pu-10wt. \% Zr fuel samples.

Current tests are related to the licensing needs of the IFR EBR-II Mark V core (U-19wt.\%Pu-10wt.\%Zr) to demonstrate safety margins under (1) accident transients like loss- of-flow without scram and (2) high-temperature operating conditions.

Testing beyond FY-1993 will emphasize higher-burnup Mark V fuels, recycled fuels, and the PRISM reactor design fuel. Details of these tests will be developed later depending on the availability of appropriate irradiated fuel pins.

\section{- Unirradiated Fuel Tests}

Previous ex-reactor tests confirm that there is no energetic interaction between molten uranium alloy fuel and sodium for the fuel and sodium temperatures typical of a core-melt accident. These tests also indicated that, in the event of a core melt, the core debris should be coolable in the reactor vessel by single-phase natural convection cooling of the sodium.

There is a need to address hypothetical core-melt accidents to gain assurance of containment integrity. Tests are planned to address the following broad issues: (1) melt relocation in the subassembly region; (2) melt breakup, quench, and the extent of solidification in the sodium-filled region of the lower internals and bottom head, including the effects of iron (from structures) in the melt composition from U-Fe to various compositions of $\mathrm{U}-\mathrm{Fe}-\mathrm{Zr}$; (3) the coolability of core debris accumulated on horizontal surfaces (lower core support structure) in the sodium pool; (4) melt penetration into substrates; (5) fuel dispersal in a transient overpower event; and (6) the retention of fuel and fission products within the sodium. The objectives of these tests are to (1) develop validated models for the melt progression in the SAS4A code and (2) demonstrate that in-vessel retention and low radiological release can be achieved, given continuing availability of reactor vessel heat rejection.

\subsubsection{Safety Issues}

Although all major problems are currently being addressed, much research remains to be performed in order to establish the safety and reliability of the specific fuel concept to the burnups planned. The data base to support the metal-fuel system to be used in the PRISM design needs to be developed. The data needed to support the establishment of the fuel design limits and the fuel damage limits for licensing, and for the validation of the analytical tools for licensing evaluations, include

- the uniformity of quality (for example, the composition, thermophysical properties, and strength characteristics) resulting from production and fabrication technologies for the fuel and cladding 
- behavior and extent of fuel restructuring and porosity characteristics as a function of burnup ( $>10$ at. \%); the development of $\mathrm{Zr}$-depleted regions and potential plutonium distribution; and the axial strain limits

- fuel-cladding eutectic formation temperature; cladding wastage, or penetration rate, as a function of temperature; cladding failure mechanism(s); and run-beyond-cladding-breach data

- data for fast, rapid reactivity insertion, transients to quantify the axial extrusion reactivity feedback to establish the energetics of a hypothetical core disruptive accident, and the behavior of molten fuel during a power excursion

- the statistical data base to support the claim of $<0.01$ percent fuel failures

- the conclusions drawn with respect to the behavior of the PRISM fuel system under "slow" overpower transients to be verified in experiments with fuel elements of prototypic geometry

- source term data: fission-product release from fuel matrix, the transport and holdup in the sodium pool, the transport and holdup in the cover gas region above the sodium pool, and the transport and holdup within the containment boundary

- a peer review of the analytical tools (LIFE-METAL, FPIN2, STARS, FRAS3, DEFORM-5, SAS4A, and SASSYS), the ANL IFR program needs to be monitored periodically to follow the progress of the metal fuel system development

\subsubsection{Evaluation}

In general, the staff considers the planned IFR program of fuel performance irradiation to be satisfactory. The list of planned experiments is extensive and involves irradiation in EBR-II, FFTF, and testing in TREAT. The program should provide a very substantial data base for the modeling efforts described above. One possible weakness in the program has to do with experimental verification of the claim that no more that 0.01 percent of the PRISM fuel pins in the (equilibrium) core will fail during normal and transient conditions. The FFTF irradiations will be the closest to prototypical PRISM conditions. The number of planned ternary fuel elements to be irradiated, to gain an adequate data base for a statistical analysis, remains an open item along with how the differences in geometry and other relevant characteristics will be accounted for in such a statistical analysis.
On the basis of the preceding discussion, the present DOE R\&D program seems capable of providing the relevant analytical tools and supporting data base to support the PRISM design. Although many uncertainties exist, there appears at present to be no major problem in the area of fuel performance that is likely to prevent ultimate acceptance of the basic ternary fuel concept, and the IFR program should confirm the expected performance characteristics of the PRISM fuel.

One important series of tests, recently performed on low-burnup PRISM-specific fuel, reinforces the metal-fuel concept and tends to support the performance characteristic expected by the designers on the basis of their previous experiences with other metal-fuel designs (of various alloy weight percentages and various cladding materials).

A series of ex-reactor heating tests on low-burnup (2.3 at.\%) U-26wt. \% Pu-10wt. \% Zr metallic fuel for the PRISM reactor was conducted to evaluate the fuel-cladding metallurgical interaction and its effect on cladding integrity at elevated temperatures (Ref. 4.7). The test specimens were irradiated in EBR-II from November 1988 until January 1990.

Although these tests are limited in scope and only address low burnups, the results tend to support the metallic fuel concept and are consistent with expected behavior based on previous, tests of a lower weight percentage of plutonium and tests with other cladding materials, D9, and Type 316 stainless steel.

The results of these tests are summarized as follows:

- Fuel-Cladding Reaction Mechanism: At an elevated temperature, above $1,075 \mathrm{~K}\left(1,470^{\circ} \mathrm{F}\right)$, the HT9 cladding constituents, mainly iron, that diffuse into the U-Pu-Zr fuel cause the fuel to liquefy, forming a solid-liquid two-phase mixture. At these high temperatures, cladding dissolution (wastage) by the molten fuel-cladding alloy also occurs. At a lower temperature, such as the 1.0 -hour $1,025 \mathrm{~K}\left(1,380^{\circ} \mathrm{F}\right)$ test, there was no fuel liquefaction and, therefore, no fuel-cladding interaction. These results are consistent with the expected behavior of the fuel based on previous studies with alternate metal fuel system designs.

- Cladding Penetration Rates: The deepest penetration in the 1.0-hour $1,075 \mathrm{~K}\left(1,475^{\circ} \mathrm{F}\right)$ test was $55 \mu \mathrm{m}$ which corresponds to a penetration rate of $1.5 \times 10^{-2} \mu \mathrm{m}$ per second. This rate, and the "null" rate for the $1,025 \mathrm{~K}$ test, is substantially below the existing penetration rate correlation current in use for design and modeling purposes. This indicates that the PRISM metal-fuel 
system has larger margins to failure (longer time at temperature) than measured with previous metal-fuel systems designs.

- Fuel Behavior During Siniulated PRISM UTOP and NRC Bounding Events: The PRISM unprotected transient overpower (UTOP) event was simulated in the FBTA, 2 minutes at $1,090 \mathrm{~K}\left(1,510^{\circ} \mathrm{F}\right)$. The fuel surface liquefaction and the fuel-cladding interaction were minimal, with a maximum cladding penetration of $19 \mu \mathrm{m}$. Bounding Event 1B (UTOP with LOHS) was simulated in the FBTA by following the UTOP test with a 36-hour hold at $975 \mathrm{~K}\left(1,290^{\circ} \mathrm{F}\right)$. Apparently due to the sluggishness of iron diffusion into the fuel at the "modest" LOHS temperature, there was no substantial additional surface liquefaction. However, the maximum cladding penetration was $121 \mu \mathrm{m}$, sbout 28 percent of the initial cladding thickness. This amount of cladding wastage is considered to be moderate for the extreme severity of the event.

- Pin Cladding Integrity Margin: A WPF test (FM-3) was conducted at a peak cladding temperature of $1,090 \mathrm{~K}\left(1,510^{\circ} \mathrm{F}\right)$ until the cladding breached 146.7 minutes into the test. Since the duration of events terminated by the plant protection system and the duration of ATWS events are typically on the order a few minutes, this test demonstrated a large cladding integrity margin. Pre-test analyses with FPIN2 and LIFE-METAL predicted failure times of 93 minutes and 217 minutes, respectively. The FM-3 test data are being used to refine the predictive capabilities of both codes.

- Pin Cladding Breaching Mode and Mechanism: Post-test neutron radiographs indicated that the cladding failed near the top of the fuel column where the cladding temperature was highest during the test. Once-molten fuel debris, released from the breach and trapped in the gap between the pin cladding and the test capsule wall, was apparent at the top of the column. The cladding breach mode was a benign crack, not a burst rupture. At the breach site, nearly 80 percent of the original cladding thickness had reacted with the fuel, indicating that fuel-cladding interaction played the dominant role in the cladding breach, with fission-gas pressure loading causing the final rupture of the thinned cladding. The fuel failure mechanism, cladding wastage, and cladding thinning with cladding breach due to the internal fission-product gas pressure, is consistent with previous findings for other metal-fuel system designs.

\subsubsection{Conclusions}

Section 4.2, "Fuel System Design, " of the SRP discusses the criteria to be used in fuel system safety reviews. The objectives of the review are derived from 10 CFR Part 50, GDC 10, "Reactor design"; GDC 27, "Combined reactivity control systems capability"; and GDC 35, "Emergency core cooling."

Fuel design limits - temperature, burnup, fluence, and cladding strain - considering normal and anticipated duty cycle events, which include load following and run beyond cladding breach operation, will be established to ensure a failure rate of no more than 0.01 percent of the pins in the (equilibrium) core.

Fuel damage limits - cladding strain, amount of fuel melting, amount of cladding deformation or melting, and fractional fuel failure beyond which accident consequences are unacceptable - will be established from a set of design-basis accidents with allowable consequences ranging from no significant degradation of expected fuel lifetime to mainter ance of a coolable geometry.

The chemical poison system requirement in GDC 27 is deemed by the staff to be unique to light-water reactors and is not applicable to the PRISM design. Excess negative reactivity requirements, including uncertainties, to obtain cold shutdown with the highest worth control rod stuck out will be maintained in the design.

The PRISM design, a low-pressure pool reactor with no piping or fittings below the surface of the pool and with a containment (guard) vessel surrounding the reactor vessel, precludes a large LOCA and does not require an emergency core cooling system similar to those in currentgeneration light-water reactors. GDC 35 is, therefore, not applicable to the PRISM design.

The PRISM fuel system, U-Pu-Zr fuel clad with HT9, is a new concept. Many of the basic design principles have been developed from EBR-II metal-fuel experience. However, because of differences in material, geometry, and exposure conditions, this experience must be extrapolated to the PRISM design through the use of analytical tools that characterize the operational history and transient responses of the fuel system. Experimental data must be obtained both to support the model development efforts and to verify the integrated computer codes.

At this stage of the design, the staff review was carried out with the limited objective of identifying potential problems 
in the fuel system design that could be ascertained at this early date and that could potentially lead to major safety-related problems. A second objective was to determine whether the R\&D program currently in place would lead to the development of the experimental data base and analytical tools that will eventually be required to support licensing of the PRISM design.

Although no new major safety-related problems in the proposed PRISM fuel system design were identified, many phenomenological uncertainties must be resolved in order to develop a set of analytical tools and a supporting experimental data base necessary for licensing. These include

- The uniformity of quality (for example, the composition, thermophysical properties, and strength characteristics) resulting from production and fabrication technologies for the fuel and cladding needs to be established. The ability of the reprocessing technique to produce $\mathrm{U}-\mathrm{Pu}-\mathrm{Zr}$ fuel with the requisite uniformity from batch to batch has yet to be demonstrated on a commercial scale. There will no doubt be "fissium" products remaining in the fuel. The final composition of the reprocessed fuel, however, has yet to be determined. Since the technology is new, particular attention needs to be paid to quality assurance of material supply, fabrication, and welding techniques.

- Behavior of and the extent of fuel restructuring and porosity characteristics as a function of burnup needs to be confirmed. These phenomena are as yet poorly understood, although first-order estimates of their effects based on experimental evidence have been made. Although early indications were that axial fuel strain terminated after approximately 5 at. \% burnup, more recent evidence suggests that axial strain may continue to increase up to 10 at. \% burnup. This evidence has a strong influence on the control characteristics of the reactor system. Close attention should be paid to research in this area. The fuel-cladding eutectic temperature limit is currently thought to be $980 \mathrm{~K}\left(1,300^{\circ} \mathrm{F}\right)$ based on available experimental data from $\mathrm{VJ}-10 \mathrm{wt} . \% \mathrm{Zr}$ and ternary fuel with less than 26wt. \% Pu clad in D9, 316SS, or HT9. At this time, there is limited data on unirradiated fresh fuel typical of the PRISM design that indicate that the eutectic temperature may be as low at $903 \mathrm{~K}$ $\left(1,165^{\circ} \mathrm{F}\right)$. The test does not include surface effects, irradiation effects, or kinetic factors. Recently completed testing on low-burnup (2.3 at.\%) PRISM fuel indicates that no fuel-cladding interaction occurs for temperatures 2 . . $1,025 \mathrm{~K} \quad\left(1,385^{\circ} \mathrm{F}\right)$. Additional data are we sed to establish a fuel design limit and for burnups greater than 10 at. $\%$ for use in licensing the PRISM design.

- The behavior of prototypical fuel at high burnup ( $>10$ at. \%) in prototypic geometry needs to be established. Among concerns that need to be addressed are the closure of porosity due to solid fuel swelling and, perhaps, the effect of the weight of the fuel column. The computed temperature distribution within the fuel element must be compared with the local alloy solidus temperature in order to determine reasonable design limits for power density and possible modifications of fuel design. These areas are crucial for future decisions regarding maximum operating power. A correlation that was developed for the cladding penetration rate has been implemented in the LIFE-METAL code. At present, it is believed that the penetration rates are small enough to have no influence on fuel lifetime. Since this phenomenon has a potentially significant impact on fuel lifetime, it is important to keep track of developments. Additional data are needed to establish fuel damage limits for use in licensing the PRISM design.

- The behavior of molten fuel during a power excursion, particularly the extrusion mechanism, needs to be verified by appropriate testing. It is expected that such tests will be complex and costly. The IFR test program includes a series of TREAT experiments to develop the needed data base for postulated severe accidents and core disruption events. These data will be used to validiate the SAS4A code.

- The statistical data base to support the claim of less than 0.01 percent fuel failures needs to be developed using ternary fuel of prototypical geometry.

- The conclusions drawn with respect to the behavior of the PRISM ruel system under "slow" overpower transients must be verified in experiments with fuel elements of prototypical geometry.

- The run-beyond-cladding-breach and potential for fuel failure propagation needs to be experimentally established.

- Research is in progress to develop a set of computer codes to predict the behavior of ALMR fuel subject to transient overpower and other transient events. The LIFE-METAL computer code is the analytical tool being developed at ANL to model the response of the metal fuel and blanket elements to steady-state and operational transient conditions. The FPIN2 code is a detailed thermal-mechanical model of an individual fuel element used for analyses of fuel performance under 
transient conditions. Supporting the FPIN2 computer code are more detailed codes, currently under development, for modeling fission-product retention and swelling in U-Pu- $\mathrm{Zr}$ alloy fuels during steady-state irradiation (STARS) and for modeling the transient fission gas/bubble gas distribution in solid and molten fuel (FRAS3). A less-detailed model for the fuel element thermal-mechanical response is being developed in the DEFORM-5 (metal fuel) module, a more recent version of the DEFORM-4 (oxide fuel) module from the SAS4A computer code, for use as the fuel behavior model in the SASSYS whole-core response computer code. Both of these codes are designed to predict transient events to the time of cladding rupture. In particular, the codes will offer predictions of fuel failure location and timing. However, neither has the capability for ex-pin fuel motion modeling. A peer review of these codes may be necessary to support future reviews.

It is the staff's opinion that DOE has in place the programs related to fuel system characterization, both operational and transient, that will lead toward resolution of the technological uncertainties and development of the appropriate analytical tools.

The staff considers the planned IFR program of fuel performance irradiation to be satisfactory. The list of planned experiments is extensive and involves irradiation in EBR-II and FFTF, and testing in the TREAT. The staff believes that the program will produce a very substantial data base for the modeling efforts described above. The FFTF irradiations will be the closest to prototypical PRISM conditions. The number of planned ternary fuel elements to be irradiated, to produce an adequate data base for a statistical analysis, remains an open item along with how the differences in geometry and other relevant characteristics will be accounted for in such a statistical analysis.

\subsection{Nuclear Design}

\subsubsection{Design Description and Safety Objectives}

The PRISM reactor core was designed to meet several objectives: to limit peak fuel burnup to $135 \mathrm{MWD} / \mathrm{kg}$; to limit the burnup reactivity swing to $-21 \mathrm{c}$; and to permit an 18-month refueling interval, a 54-month life for the fuel and a 90-month life for the blankets. One of the most significant design goals is to provide sufficient negative reactivity feedback to withstand almost all failure-to-scram events without fuel damage. This passive safety characteristic is described further in Section 4.6.
The PRISM reactor core uses a heterogeneous ternary metal-alloy-fueled core of uranium, $27 \mathrm{wt} . \%$ plutonium, and $10 \mathrm{wt} . \%$ zirconium. The core contains 199 assemblies: 42 fuel assemblies, 24 internal blanket assemblies, 33 radial blanket assemblies, 42 reflector assemblies, 48 shield assemblies, 3 gas expansion modules, 6 control assemblies, and 1 ultimate shutdown assembly. In the metallic fuel, the zirconium imparts structural strength to the fuel while being relatively transparent to the neutron spectrum. The reactor is termed a fast reactor because the macroscopic fast-absorption cross-sections are much smaller than the macroscopic fast-scattering crosssections. Therefore, most neutrons are absorbed or leak from the core before slowing down and the flux at or below epithermal level energies is negligible.

Forty-two reflector assemblies are located at the core perimeter. The reference core has been designed with reflectors and without axial blankets so that excess plutonium is not produced; breeding in the reference core is close to break even. The core is designed for the addition of more fertile material to increase breeding should the design goals be changed.

The initial design submittal for the PRISM had a plant rating of $1245 \mathrm{MWe}$ and plant core power rating of $425 \mathrm{MWt}$. The most recent design descriptions have increased these numbers to $1395 \mathrm{MWe}$ and $471 \mathrm{MWt}$. The power fraction in each region of the core in the initial design submittal was predicted to vary from the beginning to end of equilibrium core from 72 percent to 65 percent in the driver fuel, while the inner blanket shifts from 10 percent to 16 percent. The radial blankets shift power fractions from 17 percent to 18 percent during the same period. No estimates of the power fraction shifts in the separate regions of the core have been given for the revised design, which is an open issue. The power generation is shifted to the blankets during a fuel cycle because fissile plutonium is being bred from the depleted uranium in the blankets. This allows the design to have a minimal reactivity swing during a fuel cycle, which permits operation throughout core life with the control rods almost fully withdrawn. The initial design submittal for the PRISM reactor has a burnup reactivity swing of $-21 \mathrm{c}$. Such operation limits the amount of reactivity available for insertion in a rod withdrawal accident and contributes to the passive safety characteristics of the PRISM design. Also, fast reactors are insensitive to xenon, therefore, total rod worth needed is essentially limited to only that amount of reactivity needed to overcome the Doppler effect, the power defect. This contributes to the passive safety characteristics.

Each of the six control rods has two diverse methods of insertion: a gravity-driven rod drop and a powered drive- 
in. Shutdown redundancy is provided by designing each of the six control rods with sufficient worth to shut down the reactor from hot full power to a cold shutdown condition. Total rod scram worth of all six rods using natural $\mathrm{B}_{4} \mathrm{C}$ is $\$ 20.43$. The reactivity control and shutdown system is described further in Section 4.5. The use of metal fuel is another important feature since the metal fuel operates at a relatively low centerline temperature, thus limiting the stored reactivity (power reactivity decrement) which the negative reactivity feedbacks would need to overcome during an ATWS event.

The PRISM nuclear design for passive shutdown is described in more detail in Section 4.6 of this report and Appendix $G$ of the PSID.

\subsubsection{Scope of Review}

The review of Section 4.3 focused on the reactor design calculations, reactivity feedback estimations, and uncertainties associated with each. GE, the preapplicant, used an extensive package of computer codes, but many of these codes are standard in scope and methods. The staff did not prepare a detailed independent calculation of reactor characteristics during the current review, but this will need to be done. BNL's analyses of the design are presented and discussed further in References 4.16 and 4.17.

\subsubsection{Review Criteria}

GDC 11 and 12 (10 CFR Part 50, Appendix A) requires that the reactor core be designed so that, in the power operating range, (1) the net reactivity nuclear feedback characteristics compensate in the event of a reactivity insertion and (2) there are no power oscillations that can result in exceeding fuel design limits.

GDC 13 requires that instrumentation will monitor variables in their anticipated ranges to ensure adequate safety and that appropriate controls will maintain the variables and their systems within prescribed operating ranges.

The requirements of GDC 25 through 29 were used to assess the diverse methods for inserting control rods, the limitations for withdrawing control rods, and the use of passive feedback effects to provide a diverse means of shutdown.

SRP Section 4.3, "Nuclear Design, " provided guidance for this review. This SRP specifically requires that the review of the nuclear design is carried out to aid in confirming that fuel design limits will not be exceeded during normal operation or anticipated operational occurrences, and that the effects of postulated reactivity accidents will not cause significant damage to the reactor coolant pressure boundary or impair the capability to cool the core and to ensure conformance with the requirements of GDC 10, 11, 12 , $13,20,25,26,27$, and 28 .

The staff used design standards proposed by ANSI/ANS-54.1-1989, General Safety Design Criteria for a Liquid Metal Nuclear Power Plant (Ref. 4.18), to acquire more specific guidance for review of areas involving unique characteristics of the PRISM. These criteria supplement the required general design criteria (GDCs) contained in 10 CFR Part 50 (Appendix A).

Several design guidelines proposed by the Advanced Light Water Reactor Utility Requirements Document (ALWR Passive Plant) (Ref. 4.19) were referred to in this review. Although intended to address LWR safety or operability issues, these guidelines warrant consideration for their potential for reducing PRISM safety systems challenges. These points do not reflect regulatory positions, but are intended to provide early indication of expected industry design objectives for standard plants.

\subsubsection{Research and Development}

Most of the R\&D support will be in the metal-fuels area, specifically at a hot fuel examination facility (HFEF/South) and additional testing in EBR-II. These planned R\&D activities are discussed in more depth in Section 4.2 of the PSID and in this report. Additional R\&D is planned via full-scale critical experiments in the Zero Power Plutonium Reactor (ZPPR) to confirm power distribution, control rod worths, and reactivity feedbacks, and to validate analytical tools. The preapplicant intends to develop and construct a prototype PRISM reactor, which will be ready for startup around the year 2005. System tests performed with the first prototype will quantify and characterize passive safety features and safety-enhancing mechanisms, including passive reactivity reduction and the passive shutdown heat removal. The preapplicant has stated that agreement will be reached with the NRC on the scope of these safety tests. The preapplicant has conducted tests on passive reactivity reduction and passive shutdown heat removal. The details and results of these tests are discussed in Section 4.6 .4 of this report. The R\&D program planned by the preapplicant appears to be adequate. The NRC will review the scope and depth of the prototype testing to be performed after the prototype reactor has been built. 


\subsubsection{Safety Issues - Identification and Evaluation}

\subsubsection{Analytical Methods}

The package of computer codes used by GE were standard in scope and methods. The nuclear evaluation process was initiated by the generation of region-wide microscopic cross-sections utilizing a technique based upon the TDOWN data processing code. All fuel cycle calculations were carried out with the three-dimensional flux solution code, DIF3D. Control worth calculations were carried out with six neutron energy groups, three-dimensional hexagonal-Z geometry, and nodal approximation in DIF3D flux solutions. Reactivity feedback coefficients and neutron kinetics parameters were calculated by a series of computer codes. These computer codes include DIF3D, SN2D, SNPERT, and SNASS (a develop-mental code at $G E)$, and were used to perform the neutron flux and adjoint solution calculations, perturbation computations, and data manipulations. The program ORIGEN-2 was utilized for the irradiation and decay heat calculations. The designer validated the analytical methods and computer codes against critical experiments and other analytical approaches. ANL performed some PRISM analysis and the GE methods compared well with the ANL analytical approach. The NRC staff did not perform a detailed independent calculation of reactor characteristics. Independent calculations and verifications will be required during future reviews of the PRISM design.

\subsubsection{Physics Calculations During Voiding}

For the present, the staff reviewed the GE calculational process and concluded that the $G E$ calculations are credible, but that GE's estimates of the uncertainties may be inappropriately small. In addition, since the passive shutdown characteristics are based on reactivity feedbacks, it is important to properly determine the values of such key feedbacks as radial expansion, axial expansion, Doppler, sodium density, and control rod drive line expansion. Therefore, scoping calculations were done as part of the review to verify these reactivity feedbacks as being reasonably accurate. Sodium density feedback was the most difficult parameter to estimate. However, judging from other LMR designs, the overall sodium void reactivity worth appears to be reasonable. Additional discussion of the staff's review in this area is provided in Section 4.6.

\subsubsection{Reactivity Coefficients}

Although the nominal values presented for the various reactivity coefficients appear to be in the range of what is expected for a liquid-metal reactor of this design, a more accurate analysis defining their magnitude, dependencies, and variation over core burnup and region will need to be performed when the final design application is submitted. These predictions will also need to be qualified and verified on a prototype plant. The role of passive reactivity feedbacks in an ATWS event in combination with the USS needs to be thoroughly evaluated. To this end, the reactivity coefficient for sodium voiding must be accurately calculated and portrayed in all accident scenarios.

The positive sodium void coefficients result in certain EC-III events having the potential to lead to positive reactivity insertion events (see Chapter 15). The positive sodium void reactivity coefficient is a concern to the staff and efforts should be made to reduce its magnitude, as much as practical, even if the likelihood of sodium boiling is so reduced that no events that could lead to sodium boiling are in the EC-III probability events.

In Appendix $G$ to the PSID, GE presented a study on core design alternatives to reduce the void worth. The following criteria were applied for the study:

- The total positive sodium void reactivity worth of the core must be reduced to less than $50 \mathrm{c}$.

- The impact of the design changes on the passive performance characteristics of the core must be acceptable.

- The impact on the economics of power production must be acceptable.

A core height study was performed and resulted in a reduction from $\$ 5.26$ to about $\$ 4.20$, or about a 15 to 20 percent reduction. In addition, the burnup swing would increase to a value between $\$ 2$ and $\$ 3$.

Studies involving (1) composition changes at fixed core layout encompassing changes in steel, sodium and void volume fractions and the addition of $\mathrm{BeO}$ and $\mathrm{B}_{4} \mathrm{C}$; (2) changes to height to diameter ratios at fixed assembly design; and (3) changes to core layout encompassing axial heterogeneous, radial heterogeneous, annular and coupled cores were also performed. The following conclusions were reported:

- Sodium void worth can be reduced to near zero or even made negative, but the result will be an unfavorable change in one or more of the performance parameters considered.

- There is no universal best way to reduce sodium void worth because the relative importance of the several 
other performance changes will depend upon the specific design criteria.

GE concluded that design changes required to reduce the sodium void worth adversely impact other safety and economic performance parameters. A 25 to 35 percent reduction could be achieved, but would be of little safety significance. Therefore, GE concluded that because (1) significant reductions in sodium void worth impact other safety parameters, (2) significant reductions in sodium void worth require reactor designs which increase the cost of power reduction, (3) it can be shown that sodium voiding is highly improbable, and (4) it can be shown that the consequences of sodium voiding are tolerable if it were to occur, no design changes to reduce sodium void worth should be made.

\subsubsection{Core Power Fractions}

Similar to the reactivity coefficients, the core power fractions and their shift over the burnup of the core must be determined and presented in the final design application along with a more accurate calculation of reactivity swing over the fuel cycle.

\subsubsection{Reactor Instrumentation}

Appropriate instrumentation should be chosen to ensure that fuel integrity is maintained. The final design application should address the following:

- spatial variations of core flux, flow, and temperature, and the significance of these effects

- a description of the instrumentation that is safety grade and provides input into the reactor protection system

- calibration and calculation methods to be used for all reactor system instrumentation

- limits and setpoints for actions, alarms, or scram signals for all reactor process instrument systems

- translation of the design limits, uncertainties, operating limits, instrument requirements, and setpoints into technical specifications and instrumentation setpoints

\subsubsection{Gas Expansion Modules (GEMs)}

Three GEMs have been added to the core which contribute significantly to the mitigation of postulated unscrammed events involving loss of pumps. Because of the GEMs, the passive shutdown now appears to work much better for the unprotected loss-of-flow (ULOF) events. The GEMs are located at the periphery of the active core and are the same size and cosfiguration as the ducts on the other core assemblies. They are filled with inert gas and are sealed at tie top. Under full pumping conditions, the gas is compressad enough that sodium occupies the portion of the GEM that resides in the active core, while the gas is trapped above the core. When the pumps stop and the system pressure falls, the gas region expands into the core, speeding the decrease in reactor power through increased leakage of neutrons. The change in sodium level introduces significant negative reactivity and limits the peak temperatures attained during loss-of-flow events.

Some potential risks are associated with the GEMs. If some of the gas leaks out during normal operation and the GEM fills with sodium, the GEM could fail to operate when required during a loss-of-flow event. Alternately, if the pumps are turned on only after the reactor is critical, power would increase significantly. The addition of GEMs also raises questions about shielding (more neutrons escape through the gas) and possible reactivity insertions should the gas escape and migrate into the central regions of the core. These potential risks suggest a need for continuous monitoring of GEM level, either directly or indirectly. This is an issue that needs further evaluation at the design certification stage of review.

A major unknown that needs resolution is the worth of GEMs in PRISM. The GE prediction is $69 \mathrm{C}$ at full-power conditions. However, that estimate was performed using a diffusion theory code, and Hanford Engineering Development Laboratory (HEDL) has determined that diffusion theory should not be used for initial estimates. This is discussed further in Reference 4.20, "Assessment of the Pump Restart Tests in FFTF Using SSC." The streaming effect of the neutrons requires the use of transport theory or Monte Carlo methods. GEM worth and insertion rate are functions of temperature, because of the sodium level within the device. The worth of the GEM was also measured to be different in each FFTF fuel cycle. The accumulation of fission products might be the cause of this phenomena. The vendor needs to specify the worth as a function of burnup and temperature within the fuel cycle, along with the cold-shutdown and hot-standby condition.

\subsubsection{Conclusions}

The PRISM reactor nuclear design appears to be at an appropriate stage, given the status of the metal-fuel program and other R\&D. While there are uncertainties associated with the reactivity feedbacks, it appears that the GE/ANL projections are plausible, although perhaps slightly on the optimistic side, and that the approach to the core nuclear design and its supporting R\&D is generally acceptable. The results of further in-reactor experiments, 
critical experiments, and prototypical testing (see Chapter 14) should be followed closely and will be required to support final acceptance. Further effort should, however, be applied to making the positive sodium void coefficient more negative.

\subsection{Thermal and Hydraulic Design}

\subsubsection{Design Description and Safety Objectives}

This section addresses thermal and hydraulic design considerations of such reactor vessel internal components as fuel, blanket and control assemblies; the core support structure; upper internals structure; core former rings; thermal liner; and the core barrel. Information pertaining to structural design and material selection of the reactor vessel and internal components is in Chapter 5 of this report.

The PRISM design is a pool-type system, with the entirety of the primary heat transport system (PHTS) contained within the reactor vessel. During normal operation, the level of primary sodium is maintained at $1.22 \mathrm{~m} \mathrm{(4} \mathrm{ft)}$ below the level of the closure head, and circulating sodium is maintained within the liner. In transient operation, sodium heatup causes the level to rise to the reactor vessel auxiliary cooling system (RVACS) overflow slots, located

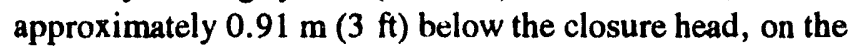
reactor vessel liner. Instrumentation for primary flow measurement is located in the upper internals structure (UIS). The boundary between the hot and cold sides of the PHTS is formed by the support cylinder and seal plate. The flow path for the PHTS goes from the hot pool above the core through the intermediate heat exchangers (IHXs) where it is cooled; the sodium exits the IHX at its base and enters the cold pool. The cold pool sodium is then drawn through the fixed shield assemblies into the pump inlet manifold. The four electromagnetic (EM) pumps take suction from the cold pool sodium through a manifold and discharge into the high-pressure core inlet plenum through the piping connecting each manifold to the plenum. The sodium is then heated as it flows upward through the core and back into the hot pool.

The PRISM reactor has inlet orifices for each assembly, to ensure proper cooling in all channels, which results in a relatively flat core outlet temperature, particularly at end of life, when breeding has resulted in higher fission rates in the blanket assemblies. The 11 orifice zones are 5 for driver fuel, 4 for internal blanket regions, and 2 for radial blanket regions.

Blockage of flow assemblies is a concern; a flow blockage event at the Fermi LMR led to partial fuel melt in 1966. Amendment 13 to the PRISM PSID describes design features and analyses related to the issue of fuel assembly flow blockage. GE also plans to use mechanical key discriminators on the assembly nosepieces to preclude misloading of assemblies, for example, the placement of fuel assemblies in a blanket region. Furthermore, the core inlet plenum and nozzles (at the bottom of the assemblies) are designed so that it is difficult to block all flow to any given channel. Multiple entrance holes all around the inlet plenum and assembly nozzles make it unlikely that any credible form of blockage will block all of the entrance holes. Furthermore, the PRISM designer has specified delayed neutron detectors in the IHXs which will detect flow blockage by detecting a molten fuel-cladding interaction with the flowing sodium. Although no in-core instrumentation is presently specified for the design to confirm no blockage, the preapplicant is evaluating methods to verify in-reactor flow and orificing for the inlet modules.

One concern raised during the review involved flotation of the absorber assemblies during refueling. In Appendix G of the PSID, the preapplicant has presented an analysis demonstrating that flotation is not likely. Assemblies are held down in two ways: mechanical (snap-rings) and hydraulic (core bypass flow) to increase core outlet pressure. Furthermore, in an analysis discussed later in this section, the preapplicant has stated that under full-flow conditions, the weight of the assemblies is sufficient to keep an assembly from being lifted from the grid plate even if other means of hold-down are lost. Hold-down of the assemblies is important to avoid flow bypass of the core in the event one should lift up. In addition, holddown of the moveable absorber bundles is important to preclude reactivity additions during refueling.

The reactor thermal-hydraulic design also facilitates adequate cooling under natural circulation conditions (such as would occur if there were a station blackout) for the conditions where a successful scram or a successful "shutdown" via the passive reactivity feedback process has occurred. Such a capability is present in most sodiumcooled systems; however, its use under passive reactivity shutdown conditions is new and needs to be reviewed.

One objective of the preapplication review is to ensure that the conceptual thermal and hydraulic design of the PRISM reactor coolant system (RCS) has been carried out using appropriate methods. The RCS should provide acceptable margins of safety from conditions that would lead to fuel damage during normal operation and anticipated operational transients. Other objectives include meeting the intent of current guidelines, in particular Regulatory Guide (RG) 1.68 (Ref. 4.21), governing startup testing, and RG 1.133 (Ref. 4.22), which covers loose-parts detection systems. 


\section{Reactor System}

\subsubsection{Scope of Review}

Thermal-hydraulic design of the PRISM RCS was reviewed to examine the design basis, system design, analytical methods and codes, performance evaluation, tests, inspections, and instrumentation where applicable. Structural/materials evaluation of RCS components is in Chapter 5 of this report. Acceptance of PRISM thermalhydraulic methods at the design certification stage will partly depend on (1) independent computer calculations to substantiate designer analysis, (2) the preapplicant's use of experimental data to verify design principles, and (3) independent comparison to data from experimental programs. Further guidance is given in areas of possible design weaknesses, and in other areas where the design may conflict with possible future regulatory guidance concerning LMRs. System design for the reactor vessel, closure head, and rotatable plug is provided by the designer in Section 4.4 of the PSID and Appendix G of the PSID, which contains modifications to the reference design. Other sources of material reviewed are supplemental reports issued by the designer, and responses to staff requests for additional information (Refs. 4.23, $4.24,4.25,4.26)$.

Computer calculations performed by GE and the NRC staff to evaluate postulated scrammed and unscrammed events consistently showed adequate natural circulation cooling as long as the power production was at or near decay heat levels. Many of the staff calculations were performed using SSC (a BNL code), which was developed for the NRC to evaluate natural circulation cooling in the Clinch River design (Ref. 4.27).

\subsubsection{Review Criteria}

The following regulatory guidance was reviewed for general applicability to the PRISM design. However, current SRPs and regulatory guides were developed specifically for LWRs. Similar guidance for liquid-metal reactors has not been developed.

(1) SRP Section 4.4, "Thermal and Hydraulic Design" - This SRP gives guidance for acceptable design methods for the reactor coolant systems of LWRs. The SRP is applied to PRISM, where possible, in a manner consistent with the intent of the SRP toward LWRs.

(2) RG 1.68, "Initial Test Programs for Water-Cooled Nuclear Power Plants"

(3) RG 1.133, "Loose-Part Detection Program for the Primary System of Light-Water-Cooled Reactors"
(4) 10 CFR Part 50, Appendix A, General Design Criterion (GDC) 10 - This GDC states that fuel design limits must not be exceeded during any condition of normal operation, including anticipated operating occurrences.

\subsubsection{Safety Issues}

During the review, a number of issues were addressed by the staff as having significant importance at either the preapplication stage or the design certification stage, as noted. These issues are thermal and hydraulic analysis, initial testing plans, loose-parts monitoring system, flow blockage, sloshing, protection against inadequate core cooling, and natural circulation cooling, and absorber bundle flotation. These issues are discussed in the sections that follow.

\subsubsection{Evaluation}

\subsubsection{Thermal and Hydraulic Analysis}

To satisfy GDC 10 , the preapplicant will be required, at the design certification stage, to submit more information on methods used for the thermal and hydraulic analysis. Empirical confirmation of analytical relationships for PHTS components of unusual geometry should also be submitted. The staff must confirm that appropriate and adequate methods are used for meeting the intent of GDC 10 governing thermal and hydraulic design. More particularly, flow correlations used in the PRISM thermalhydraulic analysis, justification for the temperature limits that are mentioned in the PSID, the basis for flow velocities and pressure losses listed in the PSID, and flow correlations for determining fuel and cladding temperatures should be submitted. Uncertainties associated with the data and correlations should also be examined.

For the design certification review, supporting analysis should be submitted pertaining to hot-channel factors that are used in determining margins to fuel failure and evaluating natural circulation. The factors should be demonstrated to be conservative.

\subsubsection{Initial Testing Plans}

SRP Section 4.4 specifies that initial testing plans for the thermal-hydraulic design aspects of the PHTS are to be evaluated. The SRP refers to RG 1.68 as a satisfactory method of planning and carrying out initial and startup testing programs. The designer has committed to complying with the intent of RG 1.68 and the associated subsections that govern initial and preoperational testing of boiling-water reactor (BWR) feedwater and condensate systems, remote shutdown capability, and instrument and 
control air systems. At the design certification stage, the designer should submit more detailed information pertaining to administrative details and control of initial test programs and also preoperational test plans for RCS components and other related components.

\subsubsection{Loose-Parts Monitoring System (LPMS)}

SRP Section 4.4 specifies review procedures for the looseparts monitoring system. The SRP states that the design criteria, instrument types, location, and mounting for the LPMS be reviewed at the construction permit stage. Under 10 CFR Part 52 licensing, this information would be required at the design certification stage. In the design of the LPMS, the designer has committed to complying with the intent of RG 1.133, "Loose-Part Detection Program for the Primary System of Light-Water-Cooled Reactors." The LPMS is mentioned in PSID Section 7.6.7; however, at the design certification stage, more information is required on the PRISM LPMS, particularly with respect to the time required after a loosepart alert to detect the location and cause of the problem, and its effects. Early detection can provide the time required to take appropriate actions to avoid or mitigate damage to or malfunctions of safety-related equipment and primary system components.

\subsubsection{Flow Blockage}

Amendment 13 to the PSID describes design features and analyses related to the issue of fuel assembly flow blockage. The designer describes the startup sequence for the PRISM which brings the reactor sodium flow to that corresponding to 100 percent power before withdrawing control rods. Power is to be increased to 25 percent over no less than 30 minutes. After a short hold time, the power is ramped to 100 percent at a maximum rate of I percent per minute. Starting with reactor sodium flow at 100 percent will provide maximum cooling to the surrounding assemblies in the event of a blocked fuel assembly. Full flow also ensures that the time that it takes molten fuel to activate delayed neutron monitors (DNMs) will be minimized. The DNM will be an important source of information for determining how much fuel is in the sodium. However, at a later stage, the designer will be required to submit more information on post-melt behavior of the fuel, particularly experimental data on reactivity insertions due to molten fuel and the basis for judgments made in the PSID that "fuel movement will probably result in a less reactive core state." The designer should also substantiate claims that fuel movement will be away from the core center, and that pin failures will be limited to the blocked assembly. Phase III of the IFR fuel development program at ANL will address these issues, as is discussed in Section 4.4.7 of this report.
To ensure that margin is retained in the design to accommodate a blocked assembly, the staff requests that the following commitments discuseed in Amendment 13 be maintained:

- Technical specification limits are provided that require establishing full reactor sodium flow before withdrawal of control rods and limit the startup rate to less than 1 percent per minute.

- Technical specification limits are provided on DNM operability and alarm setpoints sufficient for rapid detection of fuel melting.

\subsubsection{Sloshing}

In LMR systems, both pool and loop-type reactors can experience some sloshing of a free surface (Ref. 4.28); this is applicable to the PRISM PHTS interface with the argon cover gas in the reactor vessel. Sloshing involves movement of the sodium free surface, possibly in response to seismic events. Seismic events have the potential to cause input frequencies near the resonant frequencies of PRISM internal components, particularly the UIS, reactor closure, and support cylinder. The pertinent resonant frequencies and possible seismic input frequencies are both on the order of 1 hertz $(\mathrm{Hz})$. Because sloshing may have an important effect on the seismic and structural design of the PRISM, further information should be submitted on this topic at the design certification stage.

\subsubsection{Protection Against Inadequate Core Cooling}

SRP Section 4.4 on thermal and hydraulic design gives guidance for ensuring that preapplicants have an acceptable program for incorporation of instrumentation and procedures for detection and recovery from conditions of inadequate core cooling. Although this guidance is not a requirement and was intended for LWRs, the PRISM designers chould address this issue in a manner analogous to LWRs. This means that the PRISM should have temperature monitors that are useful up to the sodium boiling temperature. It appears that the PRISM has adequate temperature detection above the core; however, the range of this instrumentation has not been confirmed. At the design certification review, the designers will need to determine whether operating procedures for detection and recovery from inadequate core cooling (ICC) are needed. If the determination is made that procedures are not needed, the designers will have to justify that finding.

\subsubsection{Natural Circulation Cooling}

Although natural circulation cooling has been shown to be viable in LMR systems (Ref. 4.29), the adequacy must be 
confirmed for the PRISM. Instabilities or flow oscillations that may exist during the transition to natural circulation during reactor heatup transients should also be examined, particularly low flow and possible flow reversal that may exist in the transition to natural circulation cooling. This is an important issue, but it appears that natural circulation cooling will work well in the PRISM design and can be tested during prototype testing. Startup testing of the PRISM should involve verifying primary coolant flow values given in the PSID, as stated in SRP Section 4.4.

\subsubsection{Absorber Bundle Flotation}

An issue raised during the review involved inadvertent ejection or flotation of absorber rods during refueling. An absorber bundle design requirement is that the bundle not be lifted (floated) by hydraulic forces when the driveline is disconnected and the pumps are operated at full flow, and also that the absorber bundle be able to fall into the core in a few seconds against full flow following a reactor scram. The inadvertent pump startup accident is most likely to happen during refueling if the operator accidentally starts the pumps. The pressure drop across the bundle required to lift the bundle is $45.5 \mathrm{kPa}(6.6 \mathrm{psi})$, considerably higher than the lifting force from full flow of $5 \mathrm{kPa}(0.72 \mathrm{psi})$. Periodic scram testing will ensure absorber bundle drop against full flow. Analysis involved with this issue is not complicated and designer expectations should be relatively easy to verify at a later review stage.

\subsubsection{Research and Development}

The ultimate testing of the orificing and the core thermalhydraulic design will be done during the safety tests performed on the first reactor module.

Phase III of the ANL IFR testing program (Ref. 4.24) involves significant experimental and analytical work. Inreactor experiments will establish a data base for validation of fuel disruption analysis capability for both transient overpower and loss-of-flow sequences by running multi-pin bundle transient tests in TREAT. Safety analysis and model development will complete development of models of metallic fuel response to severe-accident conditions. Ex-reactor experiments will investigate core-melt phenomena in detail, including melt relocation, behavior of fission gas in molten fuel, effect of iron in melt composition, and fuel dispersal. As mentioned earlier, studies should include substantiation of claims that fuel movement will be away from the core center, that pin failures will be limited to blocked assemblies if such blockage occurs, and that fuel movement will result in a less-reactive core state.

\subsubsection{Conclusions}

It appears that the thermal and hydraulic design has the potential to satisfy the intent of important LWR regulations and guidelines, including GDC 10, SRP Section 4.4, Three Mile Island (TMI) Action Plan requirements (Ref. 4.33), and regulatory guides covering loose-parts detection and startup testing. However, the preapplicant will need to give more consideration to a number of the areas, listed below, before a final safety judgment can be made.

\subsubsection{Thermal and Hydraulic Analysis}

At the design certification stage, the applicant should present more detailed information on the flow correlations used in the thermohydraulic analysis, the basis for temperature limits used in the PSID, and the basis for flow velocities and pressure losses also listed in the PSID. Hotchannel factur analyses should also be submitted.

\subsubsection{Initial Testing Plans}

At the design certification stage, the designer should submit more-detailed information pertaining to administrative details and control of initial test programs and also pre-operational test plans for RCS components and other related components.

\subsubsection{Loose-Parts Monitoring System}

The designer has committed to comply with the intent of RG 1.133 on the LPMS. At the design certification stage, more information is required on the PRISM LPMS, particularly with respect to the time required after a loosepart alert to detect the location and cause of the problem, and its effects.

\subsubsection{Flow Blockage}

To ensure that margin is retained in the design to accommodate a blocked assembly, the following commitments discussed in Amendment 13 are to be maintained: (1) technical specification limits are provided which require establishing full reactor sodium flow before withdrawal of control rods and limit the startup rate to less than 1 percent per minute, and (2) technical specification limits are provided on DNM operability and alarm setpoints sufficient for rapid detection of fuel melting. The IFR Phase III molten-fuel testing at ANL will also be important to making a final safety judgment on the issue of flow blockage. The preapplicant should substantiate claims made on fuel performance during the ANL testing. 


\subsubsection{Sloshing}

Because sloshing may have an important effect on the seismic and structural design of the PRISM, and because little information has been submitted on the topic, further information should be submitted at the preliminary design application.

\subsubsection{Protection Against Inadequate Core Cooling}

At the design certification review, the designers will need to determine whether operating procedures for detection and recovery from ICC are needed. If the determination is made that such procedures are not needed, the designers will have to justify that finding.

\subsubsection{Natural Circulation Cooling}

Various aspects associated with the transient and steadystate performance of natural circulation in the PRISM will need to be verified during prototype testing. In particular, the transition to natural circulation during transient operation should be examined.

\subsection{Active Reactivity Control and Shutdown System}

\subsubsection{Design Description and Safety Objectives}

The primary safety-grade reactivity control and shutdown system consists of six absorber bundles that are used for power control, burnup compensation, and reactor shutdown in response to demands from the plant control system, from the plant protection system, or from loss of electric power. Each bundle consists of an array of tubes containing $\mathrm{B}_{4} \mathrm{C}$. The absorber material moves within a hexagonal duct, similar to FFTF (Ref. 4.30) and the Clinch River Breeder Reactor (Ref. 4.27). The control rod system regulates reactivity during startup, power operation, shutdown, and scram. Any one of the six rods can insert sufficient negative reactivity to achieve cold shutdown with the remaining five rods at their operational positions.

For scram diversity, each control rod unit has features to ensure absorber insertion in the event of a scram signal. Each unit has a latch that releases the rod from the drive line when the scram coil is deenergized, allowing the rod to drop into the core. Each drive mechanism also has a drive-in motor that can drive the rods in and can exert 8,896 newtons $(2,000 \mathrm{psi})$ of drive-in force to overcome astuck rod, if necessary. The control rod scram system is illustrated in Figure 4.2.
In order to limit the amount of reactivity insertion due to an uncontrolled rod withdrawal event, a rod stop system (RSS) (Figure 4.3) has been added to the control rod design. Through the use of a motor-driven movable stop and a computerized controller, the RSS provides for a physical limitation to control rod withdrawal. The rod stops will have to be periodically reset to compensate for reactivity changes to the core during the fuel cycle.

Diverse shutdown is provided in the PRISM by the USS and the passive negative feedback characteristics discussed in Section 4.6 of this report. The USS consists of $\mathrm{B}_{4} \mathrm{C}$ spheres contained in a canister above the core. Upon manual actuation, the spheres drop into a hexagonal channel in the center of the core to provide enough negative reactivity to achieve cold shutdown. The system is designed for an unscrammed unprotected loss-of-flow (ULOF), unprotected loss-of-heat sink (ULOHS), or unprotected transient overpower (UTOP) event in which the inherent passive negative reactivity feedback characteristics would greatly reduce the power of the core until the USS could be activated either by energizing actuation circuitry or manually shearing hinge pins on the ball release door. The USS is illustrated in Figure 4.4 and Figure 4.5.

\subsubsection{Scope of Review}

The PRISM reactivity control and shutdown system was reviewed for compliance with the GDCs and SRP Sections 4.3 and 4.5. Reactivity worths of the control rods have not been independently verified at this stage of the review. Also, the design was evaluated for similarity to the FFTF and CRBR reactivity control designs which have been extensively tested.

\subsubsection{Review Criteria}

10 CFR Part 50, Appendix A, Section III, "Protection and Reactivity Control Systems, " GDCs 25 through 29 require the protection system to sense accident conditions, actuate automatically, and have sufficient capability to reliably control reactivity changes under postulated accident conditions to maintain the specified acceptable fuel design limits, with enough margin to account for stuck rods.

\subsubsection{Research and Development}

Extensive irradiation testing of $\mathrm{B}_{4} \mathrm{C}$ absorber pins has already been performed (these pins are used in the FFTF) (Ref. 4.30), and additional testing is not expected to be necessary. The latch design was extensively evaluated and tested for use in the secondary control rod system in the CRBR design. No additional R\&D programs have been identified at this stage of review. 


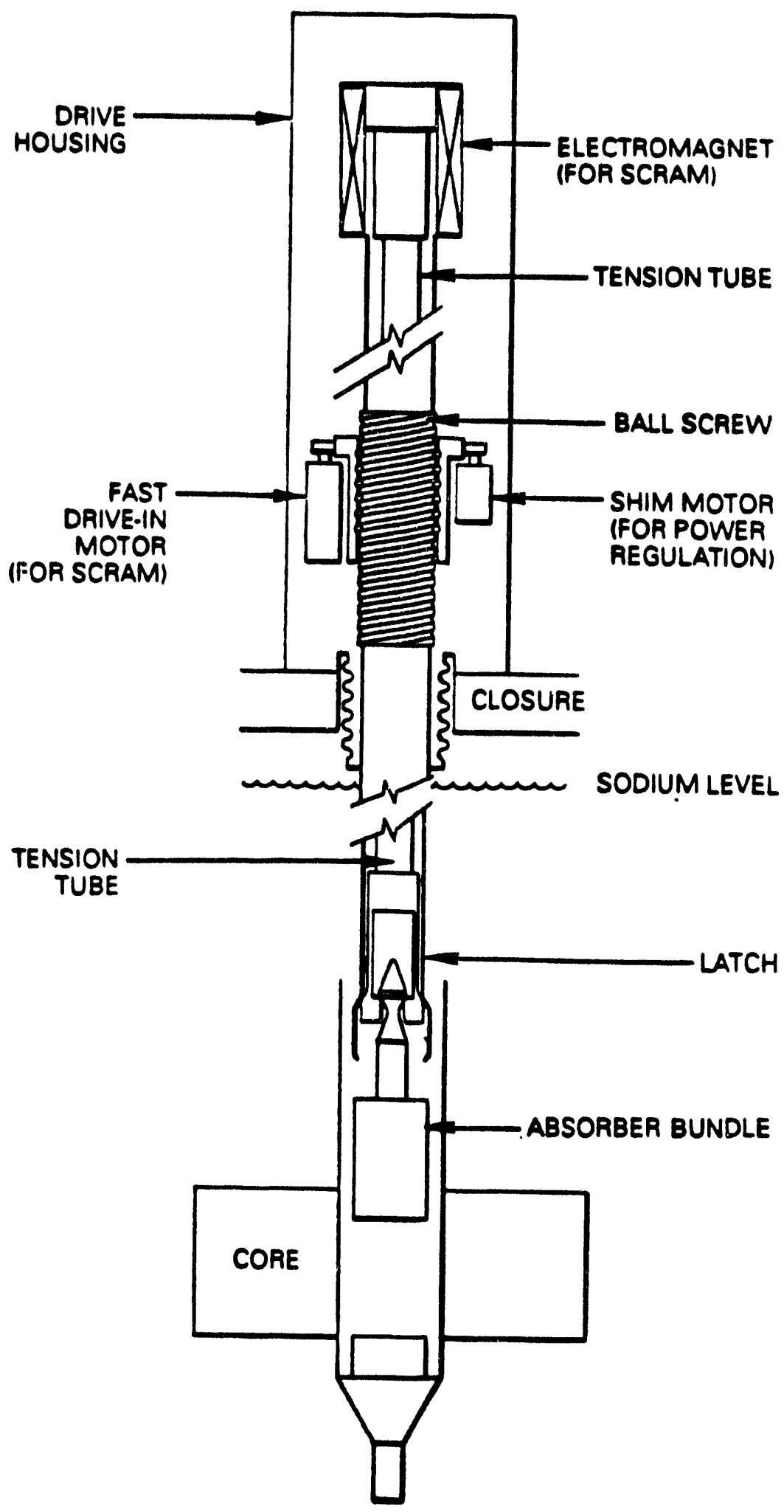

Figure 4.2 PRISM control rod scram system 

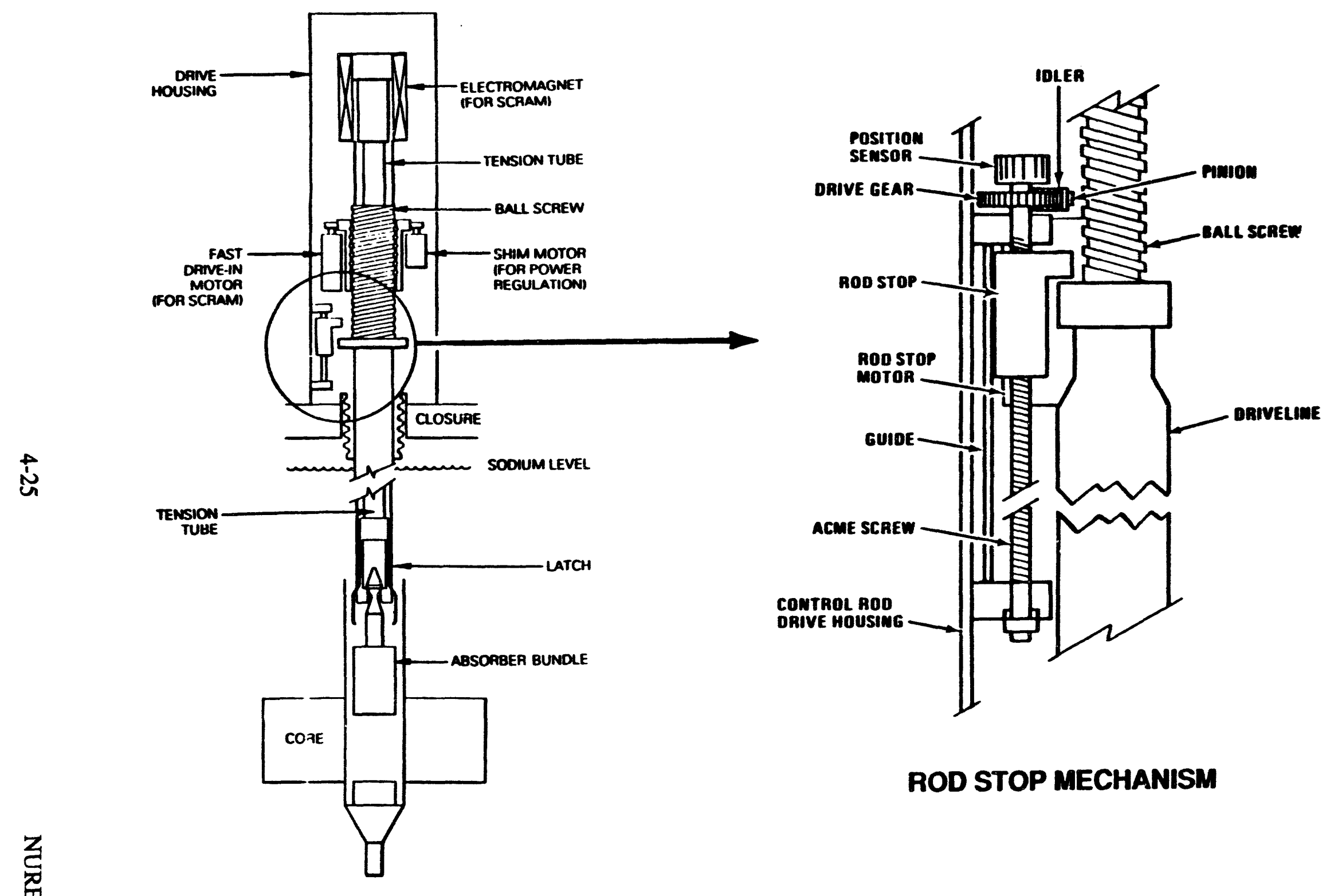

Figure 4.3 PRISM rod stop mechanism 


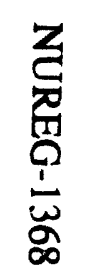

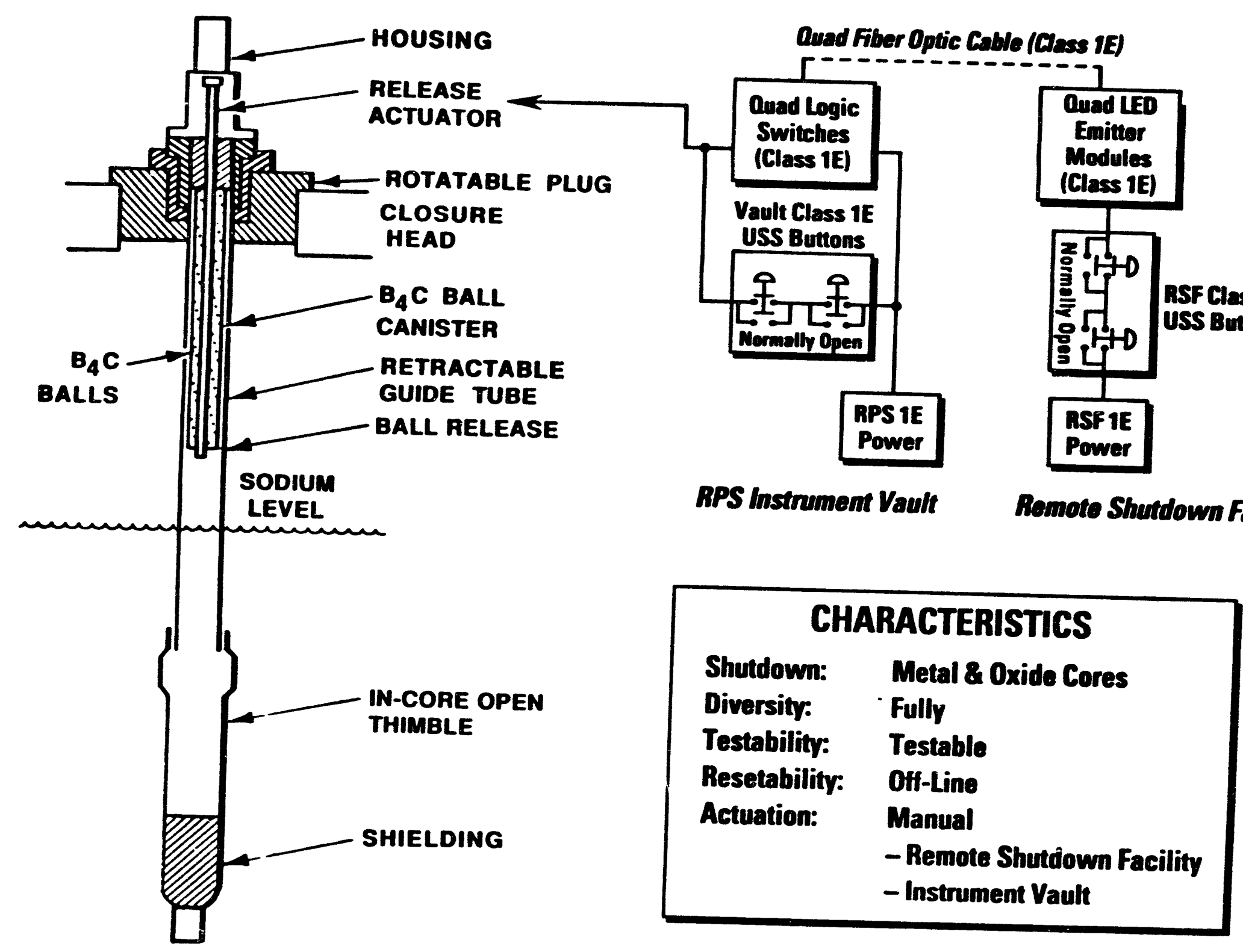

Figure 4.4 PRISM ultimate shutdown system (USS) 


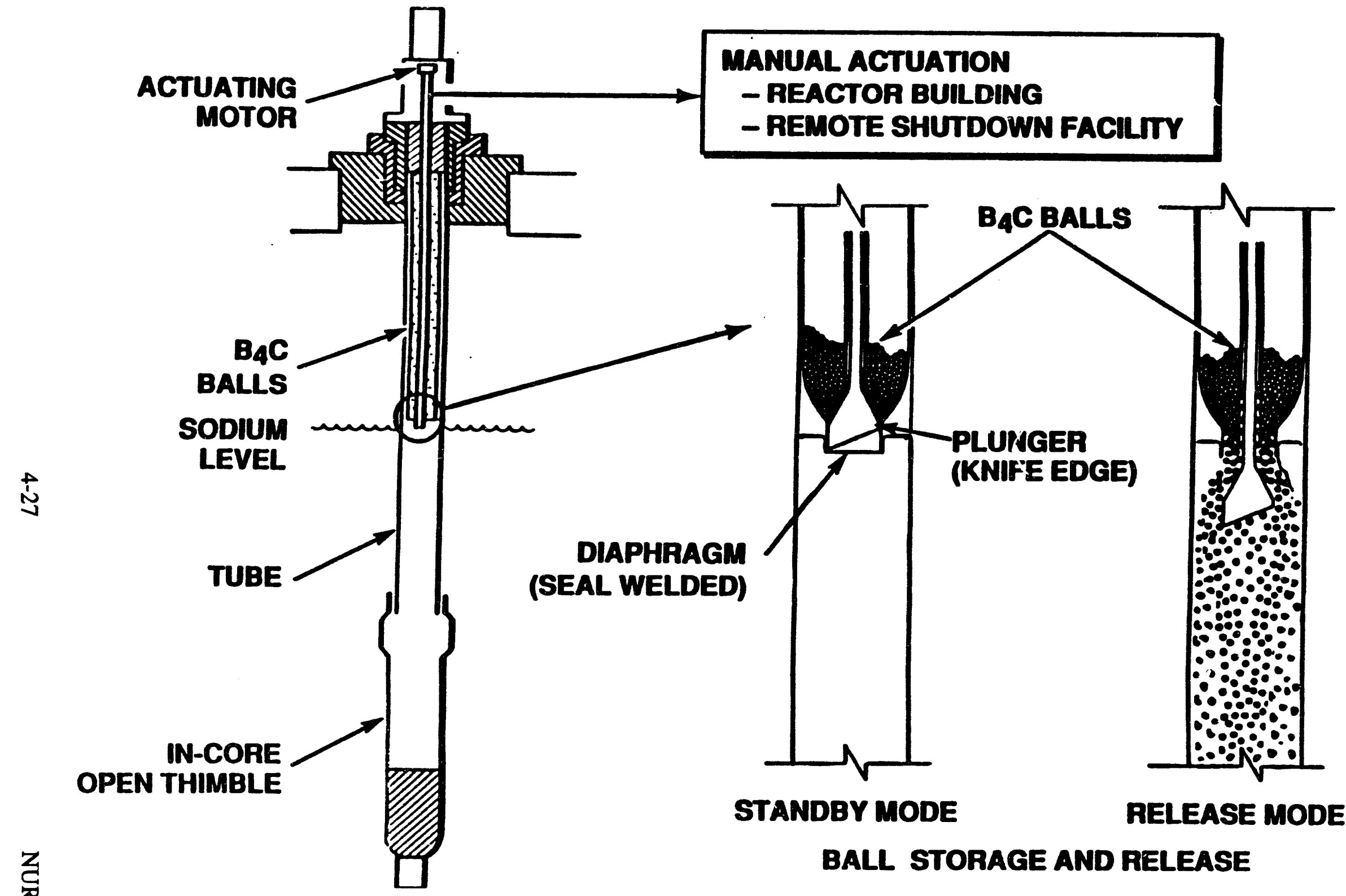

Figure 4.5 PRISM ultimate shutdown system assembly actuation 
The need for additional R\&D on components of the system will be determined preceding the design certification application. It is expected that, if needed, any such R\&D would not be extensive, consisting at most of full-scale life-cycle testing under prototypical conditions.

\subsubsection{Safety Issues}

\subsubsection{Ultimate Shutdown System}

The NRC staff position on the design of the USS is that it should be safety grade if it is to be considered as the second diverse means of reactor shutdown. The integrity of the center core assembly into which the $\mathrm{B}_{4} \mathrm{C}$ spheres are dropped and held must be ensured for all postulated events requiring actuation of the USS. Actuation of the USS is an active process requiring electrical power with a manual backup accomplished by shearing a hinge bar with the actuator bar above the reactor. This manual actuation process must be adequately developed to ensure the ability to achieve shutdown following an unscrammed event with a loss of electrical power. Employment of the USS as a diverse means of shutdown is acceptable pending review of the final design when the design certification application is submitted.

\subsubsection{Support Systems}

All essential support systems (i.e., systems that provide cooling for the control rod drive housing) necessary to ensure the proper function of the control rod drive system and the USS should be identified and analyzed preceding design certification application to develop performance criteria and address single-failure and commonmode-failure conditions.

\subsubsection{Structural Materials}

The properties of the materials used in the control rods and the support systems will need to be reviewed before final design approval to ensure adequate performance throughout the design life of the component within the design environment.

\subsubsection{Control Rod Stops}

Electromechanical control rod stops are used to minimize the reactivity insertion from an unplanned control rod withdrawal event. The rod stops will be adjusted over the fuel cycle of the reactor to account for bumup. Adjustments must be performed by a licensed operator five to six times per fuel cycle. The present design of the RSS would limit the potential inadvertent reactivity insertion to less than 30c. The designer has added a $10 c$ reactivity margin to account for uncertainties in the safety analyses.

The designer has proposed the rod stops as a safety-grade system. However, their importance as a means of mitigating a rod withdrawal event suggests that the rod position should be reliably known. The prespplicant should consider a diverse means of verifying rod stop position to prevent any mispositioning. The preapplicant should address this item in the next stage of review. The positioning of the rod stops will need to be accomplished using safety-grade equipment with reliable information obtained through the RPS or some similar safety-grade system. Rod stop position calculation should also be redundant and diverse to guard against common-mode failures occurring in data acquisition systems. Administrative procedures and verification of rod stop positioning activities will need to be described in a surveillance and testing program for the rod stops. The actual design of the system will be reviewed when the design certification application is submitted.

\subsubsection{CRD Drive-in Motors}

The control rod drive motors are designed to exert 8,896 $\mathbf{N}(2,000 \mathrm{psi})$ of driving force to overcome a stuck rod, if necessary, in the event of a scram signal. The design of this system will need to be addressed preceding application for design certification to assess the possibility that forcing a stuck rod into the core may result in damage to the fuel that would compromise an important barrier to fissionproduct release.

\subsubsection{Conclusions}

The reactivity control and shutdown system discussed in this section has much internal redundancy and calculations of rod worth appear satisfactory. The rod worth calculations and the system as a whole will be more closely reviewed following a formal license application. The design appears to be well supported by existing data and experience. The overall design of the control rod system, its essential support systems, structural materials, rod stops, and drive-in motors, will be reviewed upon receipt of an application for preliminary design approval of a standard plant design.

The USS appears to be an acceptable approach to provide for a diverse scram capability and will be reviewed further upon receipt of an application for preliminary design approval of a standard plant design. The contribution of the inherent negative reactivity feedback toward the function of the USS will require prototype testing to characterize and quantify this effect. 


\subsection{Passive Safety System Design}

\subsubsection{Design Description and Safety Objectives}

Passive safety refers to the inherent negative temperature coefficient of reactivity of PRISM that results in a reduction in reactor power when the reactor core average temperature increases. An ULOHS involves a failure of the reactor scram system concurrent with a failure of the heat removal system (e.g., failure of the intermediate heat transport system pumps; or a reduction in feedwater flow to, or steam flow from, the steam generator), causing the primary sodium system to heat up without insertion of negative reactivity by an active system. The resulting thermal expansions tend to reduce core power as the coolant and core heat up. This type of reactor response is sometimes referred to as "inherent shutdown," but this term can cause confusion. Depending upon the relative magnitudes of the structural and fuel feedbacks, the core may be either stably critical or subcritical. After a period of time, thermal equilibrium is established between core power generation and primary loop heat removal capacity (i.e., RVACS). Thus, the core appears to achieve thermal equilibrium without any operator intervention. However, to reach a zero-power, subcritical condition, at least one of the control absorbers (control rods) must enter the core. The inherent shutdown characteristics of the PRISM reactor core were considered by the preapplicant as a diverse and independent means of shutdown in addition to the control rod scram. This passive feature is composed of several reactivity feedback properties. The main components of this feedback follow.

Doppler Effect. As the fuel temperature rises, the fuel captures more neutrons in non-fission events. This has the effect of removing active neutrons from the core and reducing reactivity. Doppler feedback is also the fastest acting feedback mechanism. Fuel temperature is instantly affected by core power level and is a practically instantaneous indicator $\because$ rower excursions. Doppler feedback removes reactivity as the temperature rises and can thus help limit the extent of power-increase excursions. As the fuel temperature drops with the power reduction, the Doppler effect adds reactivity and tends to increase the core fission power.

Sodium Density/Void. For a small liquid-metal-cooled reactor (such as EBR-II) this is a negative feedback due to dominance of leakage effects, and is helpful. For the larger PRISM reactor, this is a positive feedback. As long as the sodium is subcooled, the positive reactivity contribution is small. If the sodium thermally expands, there are fewer sodium atoms within and surrounding the core. The reduced density surrounding the core results in fewer neutrons being scattered back into the core, and produces a small negative feedback effect by increasing the leakage around the periphery. However, the dominant effect is to reduce the collisions between neutrons and sodium atoms, which increases the average neutron energy and yields a net positive reactivity feedback. If the sodium boils, this feedback becomes large and prompt (approximately $\$ 5$ positive reactivity for total core void within a few seconds). The prevention of sodium voiding or sufficient mitigation of its effects is the most significant issue regarding the passive reactivity effects of the PRISM reactor.

Axial Fuel Expansion. Metal fuel expands significantly when it heats up. Axial expansion within the cladding increases the core size and decreases the effective density of the core materials. This increases the probability that neutrons will escape from the core, creating a significant negative reactivity feedback. The size of this feedback changes sfter about 2 percent burnup, when the fuel swells into contact with the cladding. The axial expansion is then controlled by the expansion rate of the cladding, since metal fuel has little strength. Fuel axial expansion and the Doppler effect are the dominant negative feedbacks, with fuel axial expansion being slightly more negative than the Doppler feedback at all power levels, as illustrated in Appendix F4, page 52, of the PRISM PSID.

Radial Expansion. The radial dimension of the core is determined largely by the assembly spacing. This spacing is determined by the grid plate below the core and by two sets of load pads above the core. When the structures heat up and expand, the core expands radially and the core density reduces, which increases leakage and thereby reduces the net reactivity.

Bowing. When a fuel or blanket assembly is heated more on one side than the other, the heated side will expand more than the other side, and the center of the assembly will bow toward the hotter direction. This type of behavior occurs in the PRISM fuel and blanket assemblies. It has some reactivity contribution, but it is difficult to calculate accurately. The PRISM uses a limited free bow restraint system, which limits the importance of bowing and makes the contribution negative under conditions of interest.

Control Rod Drive Line Expansion. The control rod drive lines, which are fixed in the upper internal structure, expand dow ward when they are heated. This inserts the control rods further into the core and adds negative reactivity.

Reactor Vessel Expansion. Since the control rod drives are attached to the top of the vessel and the reactor core attaches to a point much lower along the vessel wall, the 
expansion of the vessel wall as it heats up pulls the control rods out. This is a positive feedback, but is not an immediate factor because it is quite slow to act.

\subsubsection{Scope of Review}

In performing this review, the staff analyzed test data from existing sodium fast reactors to approximate the performance of the PRISM core under normal and accident conditions. Independent analysis of the reactivity feedbacks has been limited to scoping calculations and comparison against values for similar designs.

\subsubsection{Review Criteria}

10 CFR Part 50, Appendix A, GDC 11 requires that the reactor core and associated coolant system be designed so that in the power operating range the net effect of the prompt inherent nuclear feedback characteristics tends to compensate for a rapid increase in reactivity. The requirements of 10 CFR Part 50, Appendix A, GDC 27 through 29 were used to assess the use of passive feedback effects to provide a diverse means of shutdown.

Design standards proposed by ANSI/ANS-54.1-1989, "General Safety Design Criteria for a Liquid Metal Nuclear Power Planit, " were used to provide more specific guidance for review of areas involving unique characteristics of the PRISM. These criteria supplement the required design criteria contained in 10 CFR Part 50, Appendix A.

Standard Review Plan Section 4.3, "Nuclear Design," provided guidance for this review. This SRP specifically requires that the review of the nuclear design is carried out to aid in confirming that the effects of postulated reactivity accidents will not cause significant damage to the reactor coolant pressure boundary or impair the capability to cool the core and to ensure conformance with the requirements of GDC 10, 11, 12, 13, 20, 25, 26, 27, and 28 .

\subsubsection{Research and Development}

The DOE/GE approach for the PRISM is to build a prototype reactor test facility. The characterization and qualification of the passive safety features and safety enhancing mechanisms, including passive reactivity reduction and the passive shutdown heat removal, will be completed by performing systems tests on the prototype reactor. A series of unscrammed transients will be performed to test the passive response of the reactor. This is discussed in Chapter 15 of the PSID. Given the uncertainties in the reactivity feedbacks and the degree to which these feedbacks are dependent on the design of the reactor, this is clearly the preferred approach.
Tests involving passive reactivity have already been performed. Integral transient tests to demonstrate the inherent shutdown characteristics have been completed in EBR-II for a small metallic core and in FFTF for a mixed-oxide core. The transients involved loss-of-flow and loss-of-heat-sink conditions without reactor scram and were previously considered to potentially result in core disruptive events. For EBR-II, the results were benign, either a short-term temperature peak of $978 \mathrm{~K}\left(1300^{\circ} \mathrm{F}\right)$ for less than 100 seconds or a temperature increase in the core support structure of $300 \mathrm{~K}\left(80^{\circ} \mathrm{F}\right)$. For FFTF, nine gas expansion modules were included to perform loss-offlow tests from 100-percent flow and 50-percent power. A sodium outlet temperature increase of $339 \mathrm{~K}\left(150^{\circ} \mathrm{F}\right)$ in 90 seconds reduced the fission power to zero. Details of R\&D in this area are further discussed in the PSID.

\subsubsection{Safety Issues and Evaluation}

\subsubsection{Adequacy of Reactivity Feedbacks}

The negative feedbacks maintain the reactor at a safe, stable state at an elevated temperature, but the reactor may still be critical if none of the reactor control rods have been inserted. The ultimate shutdown system has been added to bring the reactor to a subcritical state. Independent analysis of the reactivity feedbacks has been limited to scoping calculations and comparison against values for similar designs. Details of the independent analyses are discussed in BNL's, "Summary of Advanced LMR Evaluations - PRISM and SAFR" (Ref. 4.16). The reactivity coefficients given by GE for the PRISM design were obtained using the three-dimensional flux solution code DIF3D and the fuel management and burnup code FUMBLE. The independent review estimated the radial expansion feedback within 5 percent of that cited by GE, and extrapolation to axial expansion follows. All other feedbacks are clearly within reasonable ranges. As a result of this review, the staff considers the feedbacks cited by GE to be achievable, although they contain uncertainties which at this time appear to be in the 10-25 percent range.

The preapplicant designed the PRISM to achieve reactor power runback ("shutdown") in response to reductions in both heat removal and reactor sodium flow rate without the intervention of any active safety systems. NRC concerns about the magnitude and characteristics of the passive reactivity feedbacks prompted the preapplicant to modify the design with the addition of the USS. Because the designer has provided an additional means with which to shut down the reactor using the USS, the passive reactivity characteristics are no longer being directly relied upon to effect a reactor "shutdown." Although this reduces the importance of the inherent reactivity feedbacks from an 
accident analyses standpoint, these reactivity feedbacks still play a crucial role in the transient behavior of the reactor.

The key reactivity feedback parameters estimated by GE for the PRISM have been compared to the equivalent feedbacks for SAFR, Super Phenix, EBR-II, and FFTF (the latter two were measured, that is, estimated from experimental data, as is shown in Table 4.1). The PRISM and the SAFR have strong similarities, EBR-II is much smaller, and FFTF and Super Phenix use oxide fuel. According to Hummel and Okrent, (Ref. 4.31), the Doppler feedhack for an oxide core should be about three times larger than that for a metal core. Sodium density worth depends largely on core geometry (leakage). Radial and axial expansion are very similar in all five reactors, as shown in the Table 4.1.

These data were obtained from NUREG-1369 (Ref. 4.32). Because of the consistency in the various feedback parameters, it appears likely that the values cited by the designer are correct. However, the fact that EBR-II is obviously quite different from the other cores decreases one's confidence in extrapolating from the EBR-II test series. Analyses consistently indicate that the "passive shutdown" will work as designed in the PRISM, but a series of safety tests using a prototype reactor is needed for confirmation.

The preapplicant has committed to developing a test program to verify the adequacy of the inherent reactivity feedback, as described in the PSID Appendix G.4.2-33. The inggnitude and nature of the feedback will be verified during the ALMR prototype safety test and, periodically, during the subsequent long-term power demonstration phase. An in-service testing program will also be developed for the commercial ALMR to verify the adequacy of the core feedback. ANL has developed a method by which the feedback can be measured on an operating liquid-metal reactor. This technique will be initially demonstrated during the full-size ALMR prototype safety test.

\subsubsection{The Positive Void Worth}

The positive sodium void worth is a concern in the passive safety argument. Because of it, one must qualify any characterization of the PRISM reactor response as "passively safe" by pointing out that this is conditional on the sodium remaining below the boiling temperature. Should sodium boiling begin on a core-wide basis under failure-to-scram conditions, the reactor would be likely to experience a severe power excursion and a potential HCDA. GE states that the PRISM reactor vessel and closure can safely accommodate the anticipated HCDA loads without loss of structural integrity, disengagement of the rotatable plug from the reactor closure, or expulsion of sodium.

Due to the highly diverse reactor shutdown systems and the reactive feedback-based passive reactor runback mechanism, wide-scale sodium voiding is highly unlikely, though not impossible. The loss of all EM pump flow without adequate EM pump coastdown has the potential to lead to sodium boiling and will require further study before the acceptability of the PRISM design can be determined. Mitigation of this event using the submitted design details for the GEMs system needs further study.

Table 4.1 Reactivity feedback

\begin{tabular}{||l|r|r|r|r|r||}
\hline \multicolumn{5}{|c||}{ Reactivity Feedbacks, $\delta \mathbf{k} / \delta \mathrm{T}(\mathbf{K}),\left[\times 10^{-6}\right]^{*}$ [Referenced to nominal conditions] } \\
\hline & PRISM & \multicolumn{1}{|c|}{ SAFR } & EBR-II & FFTF & SuPhx \\
\hline Doppler & -6.1 & -4.2 & -0.4 & -14.6 & -12.0 \\
\hline Na Density & 6.7 & 5.9 & -8.7 & -0.7 & 6.0 \\
\hline Radial Expansion & -6.9 & -9.7 & -9.3 & -22.0 & -10.0 \\
\hline Axial Expansion & -2.7 & -2.9 & -4.8 & -1.8 & -2.0 \\
\hline Based on 1986-1987 design data. & & & & \\
\hline
\end{tabular}




\subsubsection{Reactivity Swing Due to Burnup}

Changes in the magnitude of the reactivity effects must be accounted for over the fuel cycle for the PRISM reactor. A test and surveillance program to measure the magnitude and nature of the feedbacks over the reactor life will need to be established. The actinide content of the fuel also has a bearing on the reactivity coefficients and should be addressed.

\subsubsection{Ultimate Shutdown System Activation}

Concerns that the inherent core characteristics, while placing the core in a safe hot standby but still critical condition, would not take the core to cold shutdown led the preapplicant to incorporate an additional active shutdown system in the PRISM design. This USS is designed to release spheres of $\mathrm{B}_{4} \mathrm{C}$ into a channel in the reactor core, which will bring it to a subcritical state. Similar to the liquid poison shutdown systems in LWRs, it is not as rapid as a control rod scram and is manually initiated. The inherent negative reactivity of the PRISM core would still play a role in an unscrammed event in limiting the extent of the transient until the USS is activated. The worth of the USS absorber inserted into the core is sufficient to bring the reactor from 135 percent of full power to a cold shutdown.

The USS is activated from the RPS vaults or the remote shutdown facility (RSF). Unlike the control rods, the time response of the USS must take into account delays associated with decisional protocol to activate the USS and in the transit time for an operator to proceed to the RPS vaults or the RSF to initiate the USS. Upper limits on the total time to initiate must be determined in order to complete the transient analysis of the PRISM reactor core. It is possible that the staff may insist on a safety-grade actuation from the control room at a later date.

\subsubsection{Rod Stop System}

An RSS limits control rod withdrawal so as to bound the amount of reactivity that can be added to the core as a result of an uncontrolled rod withdrawal event. This feature makes possible the passive accommodation of events that are precipitated by one or more control rod withdrawals accompanied by a failure to scram. The rod stop physically limits the withdrawal stroke of the control rod drives. The RSS is designed to limit the reactivity insertion possible from all control rods being withdrawn from the normal power banked position until stopped by the limiter to $40 c$ ( $30 c$ from rods and $10 c$ for uncertainty) worth of reactivity. Analyses of transient overpower events indicate that the PRISM core can accommodate up to $40 \mathrm{C}$ of reactivity insertion from full power without scram, and still meet EC-III limits. However, if the RSS were to fail to perform its intended function during a UTOP event, the preapplicant has estimated the maximum reactivity insertion to be $\$ 1.65$. Details are discussed further in BNL's, "Evaluations of 1990 PRISM Design Revisions" (Ref. 4.18). Under such conditions, c ladding failure and fuel dispersion could occur in less than one minute. The staff will review a UTOP event with RSS failure in more detail during the design certification phase.

\subsubsection{Gas Expansion Modules}

GEMs are devices designed to passively insert negative reactivity during loss-of-primary-flow events. GEMs significantly enhance the negative reactivity feedback during the loss-of-flow without scram. The GEM design and its potential weaknesses are discussed in detail in Section 4.3.5.6 of this report.

\subsubsection{Conclusions}

The passive response of the PRISM reactor is not a true reactor shutdown mechanism as it does not place the reactor in a subcritical condition leading to cold shutdown. However, the reactivity feedbacks play a very important role in the transient response of the reactor. The addition of the USS precludes the reliance on passive reactivity feedback as a diverse and independent means of achieving reactor shutdown. The need to characterize and qualify these reactivity feedbacks still exists and should come from safety tests performed in a prototype reactor.

\subsection{References}

4.1 General Electric, PRISM-Preliminary Safety Information Document, GEFR-00793 UC-87Ta, November 1986.

4.2 Till, C.E., et al., "Progress and Status of the Integral Fast Reactor (IFR) Fuel Cycle Development," Proceedings of the International Conference on Fast Reactors and Related Fuel Cycles, October 28 - November 1, 1991, Kyoto, Japan.

4.3 U.S. Nuclear Regulatory Commission, Code of Federal Regulations, Title 10, "Energy," Part 50, "Domestic Licensing of Production and Utilization Facilities."

4.4 U.S. Nuclear Regulatory Commission, "Standard Review Plan for the Review of Safety Analysis Reports for Nuclear Power Plants, LWR Edition," NUREG-0800, July 1982. 
4.5 Sackett, J.I., "Operating and Test Experience of EBR-II," Proceedings of the International Conference on Fast Reactors and Related Fuel Cycles, October 28 - November 1, 1991, Kyoto, Japan.

4.6 Pahl, R.G., et al., "Irradiation Experience with HT9-Clad Metallic Fuel," Proceedings of the International Conference on Fast Reactors and Related Fuel Cycles, October 28 - November 1, 1991, Kyoto, Japan.

4.7 Tsai, H., et al., "Behavior of Low-Burnup Metallic Fuels for the Integral Fast Reactor at Elevated Temperatures in Ex-Reactor Tests," Proceedings of the International Conference on Fast Reactors and Related Fuel Cycles, October 28 - November 1, 1991, Kyoto, Japan.

4.8 Rosen, S., "The ALMR as a Future Energy Source for the United States," Proceedings of the International Conference on Fast Reactors and Related Fuel Cycles, October 28 - November 1, 1991, Kyoto, Japan.

4.9 Billone, M.C., "LIFE-METAL Analysis of U-Pu-Zr Fuel Performance," 89th Annual Meeting Abstracts, American Ceramics Society, April 26-30 1989, 15-N-87, p. 282, and Billone, M.C., et al., "Status of Fuel Element Modeling Codes for Metallic Fuels," Proceedings of the American Nuclear Society, International Conference on Reliable Fuels for Liquid Metal Reactors, September 7-11, 1986, Tucson, AZ, pp. 5-77 to 592.

4.10 Argonne National Laboratory, "The STARS Model for Fission-Gas Behavior: I. Steady State Behavior," ANL-IFR-58, December 1986.

4.11 Bridges, A.E., et al., "Advanced Liquid Metal Reactor Fuel and Blanket Designs Using HT9," Proceedings of the International Conference on Fast Reactors and Related Fuel Cycles, October 28 November 1, 1991, Kyoto, Japan.

4.12 Hughes, T.H. and J. M. Kramer, "The FPIN2 Code - An Application of the Finite Element Method to the Analysis of the Transient Response of Oxide and Metal Fuel Elements, " Proceedings of the International Conference on the Science and Technology of Fast Reactor Safety, May 12-16, 1968, Guernsey, U.K., British Nuclear Engineering Society.
4.13 Miles, K.J. and D. J. Hill, "DEFORM-4: Fuel Pin Characterization and Transient Response in the SAS4A Accident Analysis Code System," Proceedings of the International Conference on the Science and Technology of Fast Reactor Safety, May 12-16, 1968, Guernsey, U.K., British Nuclear Engineering Society.

4.14 Dunn, F.E., et al., "The SASSYS-1 LMFBR Systems Analysis Code," Proceedings, of the International Topical Meeting on Fast Reactor Safety, CONF-850410, pp. 999-1006, Knoxville, TN, April 1985.

4.15 Pahl, R.G., et al., "The Characterization and Monitoring of Metallic Fuel Breaches in EBR-II," Proceedings of the International Conference on Fast Reactors and Related Fuel Cycles, October 28 November 1, 1991, Kyoto, Japan.

4.16 U.S. Nuclear Regulatory Commission, "Summary of Advanced LMR Evaluations - PRISM and SAFR, " NUREG/CR-5364(BNL-NUREG-52197), October 1989.

4.17 U.S. Nuclear Regulatory Commission, "Evaluations of 1990 PRISM Design Revisions," NUREG/CR-5815 (BNL-NUREG-52311), March 1992.

4.18 American National Standards Institute, Inc./American Nuclear Society, ANSI/ANS-54.11989, General Safety Design Criteria for a Liquid Metal Nuclear Power Plant, " American Nuclear Society, LaGrange Park, Illinois, 1989.

4.19 Electric Power Research Institute-Advanced Light Water Reactor Utility Requirements Document, Vol. III, "ALWR Passive Plant," 1990.

4.20 Brookhaven National Laboratory, "Assessment of the Pump Restart Tests in FFTF Using SSC," Department of Nuclear Energy, November 25, 1992.

4.21 U.S. Nuclear Regulatory Commission, "Initial Test Program for Water-Cooled Nuclear Power Plants, " Regulatory Guide 1.68.

4.22 U.S. Nuclear Regulatory Commission, "Loose-Part Detection Program for the Primary System of Light-Water-Cooled Reactors," Regulatory Guide 1.133 . 
4.23 Sands, S., U.S. Nuclear Regulatory Commission, memorandum to file, "Telecon Request for Additional Information (RAI) to General Electric Company for Specific Information Related to the PRISM PSID," March 10, 1992.

4.24 Argonne National Laboratory, "Integral Fast Reactor Program Plan," April 1991.

4.25 General Electric, "Thermal Hydraulic Analysis," (GEFR-00833), October 1988.

4.26 General Electric, "Reactor Structural and Thermal Hydraulic Evaluation," (GEFR-00894), September 1991.

4.27 U.S. Nuclear Regulatory Commission, "Safety Evaluation Report Related to the Construction of the Clinch River Breeder Reactor Plant," NUREG0968, March 1983.

4.28 Takakuwa, M., K. Amano, M. Yamakawa, and M. Naitou, "Three-Dimensional Analysis Method for Sloshing Behavior of Fast Breeder Reactor and its Application to Uni-Vessel Type and Multi-Vessel
Type FBR," Proceedings of the International Conference on Fast Reactors and Related Fuel Cycles, Japan, October 28 - November 1, 1992, Kyoto, Japan.

4.29 American Nuclear Society, "Thermal Analysis of Liquid Metal Fast Breeder Reactors," LaGrange Park, Illinois, 1978.

4.30 U.S. Nuclear Regulatory Commission, "Fast Flux Test Facility Safety Evaluation Report," NUREG0358, August 1978.

4.31 American Nuclear Society, "Reactivity Coefficients in Large Fast Power Reactors," LaGrange Park, Illinois, 1978.

4.32 U.S. Nuclear Regulatory Commission, "Preapplication Safety Evaluation Report for the Sodium Advanced Fast Reactor (SAFR) LiquidMetal Reactor," NUREG-1369, December 1991.

4.33 U.S. Nuclear Regulatory Commission, "Clarification of Three Mile Island (TMI) Action Plan Requirements," NUREG-0737, November 1980. 


\section{REACTOR COOLANT SYSTEM AND CONNECTED SYSTEMS}

\subsection{Summary Description}

The reactor coolant system and connected systems contain the heat removal systems for the PRISM conceptual design. Included are all systems and components needed for removing and transporting reactor heat to the steam generator and systems responsible for removing residual heat. The principal components discussed herein include the following:

- reactor vessel and closure head

- reactor internal structures

- primary heat transport system

- intermediate heat transport system

- steam generator system

- residual heat removal systems

The containment vessel and dome, reactor vessel and closure head, and all of the reactor vessel internal make up the reactor module. The heat transported from each reactor module is used to produce steam in the steam generator. A general description of each system and corresponding design requirements is given in this section. In subsequent sections of Chapter 5, the PRISM reactor coolant systems are evaluated against present guidelines and regulations. Figure 5.1 gives an overview of major components of PRISM cooling systems and associated systems.

\section{Reactor Vessel and Closure Head}

The reactor vessel is located directly inside the containment vessel. It is separated from the containment (or guard) vessel by a 5-inch annular region that is filled with argon. The reactor vessel has no penetrations and provides the support for all of the internal components, along with all primary sodium and part of the intermediate heat transport system (IHTS). The reactor vessel is suspended from the reactor closure head, and the reactor closure head is supported by the containment vessel flange.

The reactor closure head is the top head of the reactor vessel, and contains all penetrations for instrument lines, IHTS piping, sodium-processing equipment, and other monitoring equipment. The closure head, which includes a rotatable plug for access to the internal reactor vessel, and the shell side of the intermediate heat exchanger (IHX) form the boundary for the primary sodium coolant system.

The reactor vessel and closure head are reviewed in Section 5.2 below.

\section{Reactor Internal Structures}

The principal function of the reactor internal structures is to provide the mechanical support and restraint of the reactor core. The internal structures also provide restraint for the primary coolant system components, direct primary system flow, and supply in-vessel radiation shielding. Some of the internal structures are shown in Figure 5.2. Below are listed internal structural /support components that were reviewed; the primary functional requirements are also listed.

- Core Support Structure

Prode lateral and vertical restraint of the core.

- Support Cylinder

Provide thermal separation of hot and cold sides of the primary heat transport system (PHTS).

- Fixed Shielding

Limit activation of sodium coolant and air flowing through the reactor vessel auxiliary cooling system (RVACS) air, and limit irradiation of reactor vessel.

- Electromagnetic (EM) Pump Inlet Manifold Provide direction for PHTS flow from the fixed shielding to the EM pumps.

- Reactor Vessel Liner and Seal Plate Mitigate effects of thermal transients on reactor vessel; the seal plate is a large portion of the boundary between hot and cold primary sodium.

- Pump Discharge Manifold and Seals The outlets of the EM pumps are onnected to two manifold assemblies that distribute the discharge flow into eight pipes that lead to the core inlet plenum.7

- IHX Seals and Supports

Provide a seal at the IHX penetration of the seal plate and the reactor closure head; provide vertical support of the IHX at the reactor closure head.

- In-Vessel Fuel Storage Racks

Provide support for spent fuel assemblies.

- Core Assembly Transfer Station

Used to move fuel assemblies during refueling.

- Hot Pool Thermal Insulation

Miize heat transfer from hot to cold primary sodium near the level of the core outlet. 


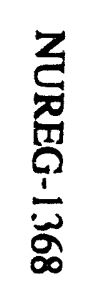

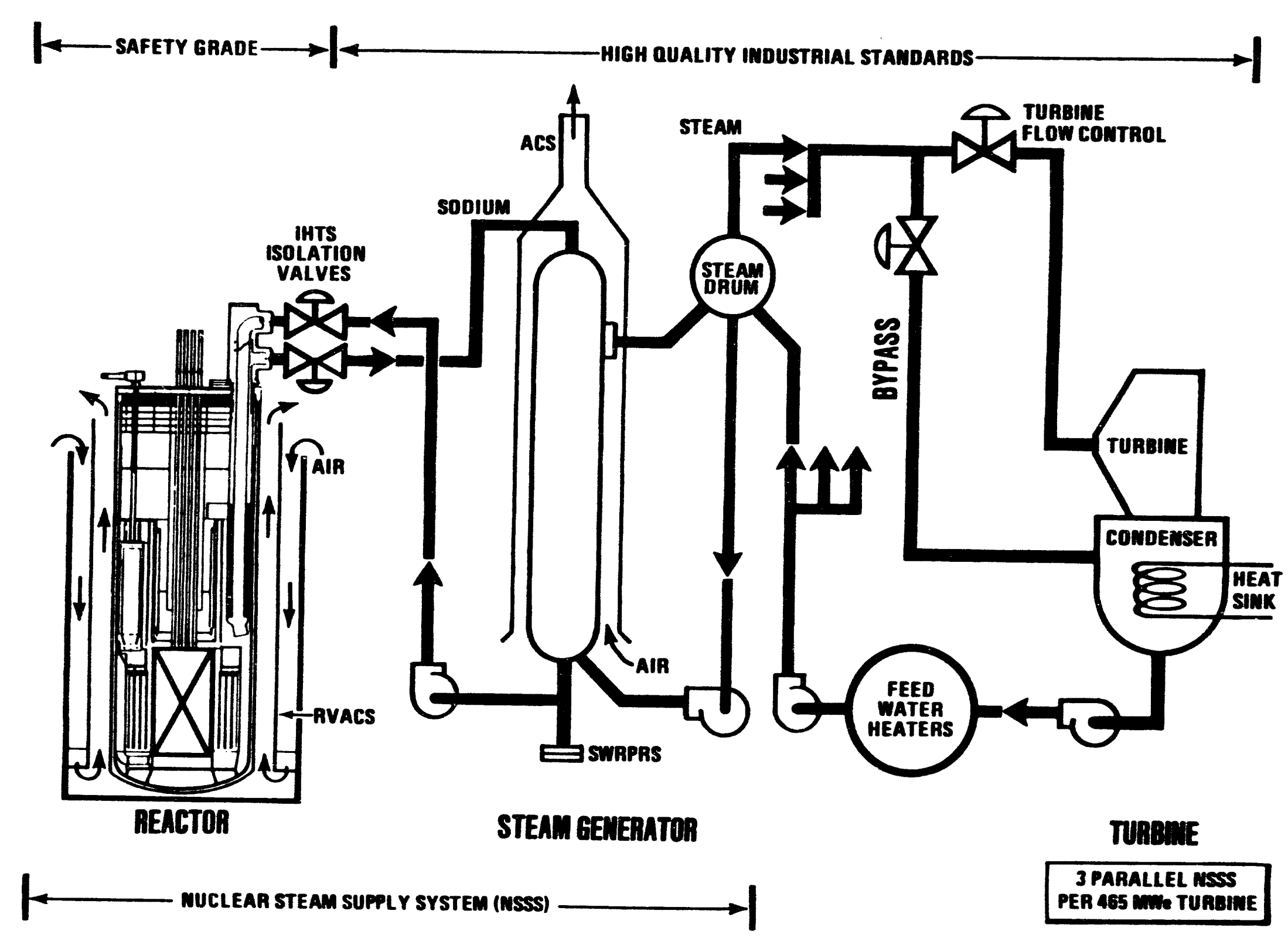

Figure 5.1 PRISM cooling systems and associated systems 


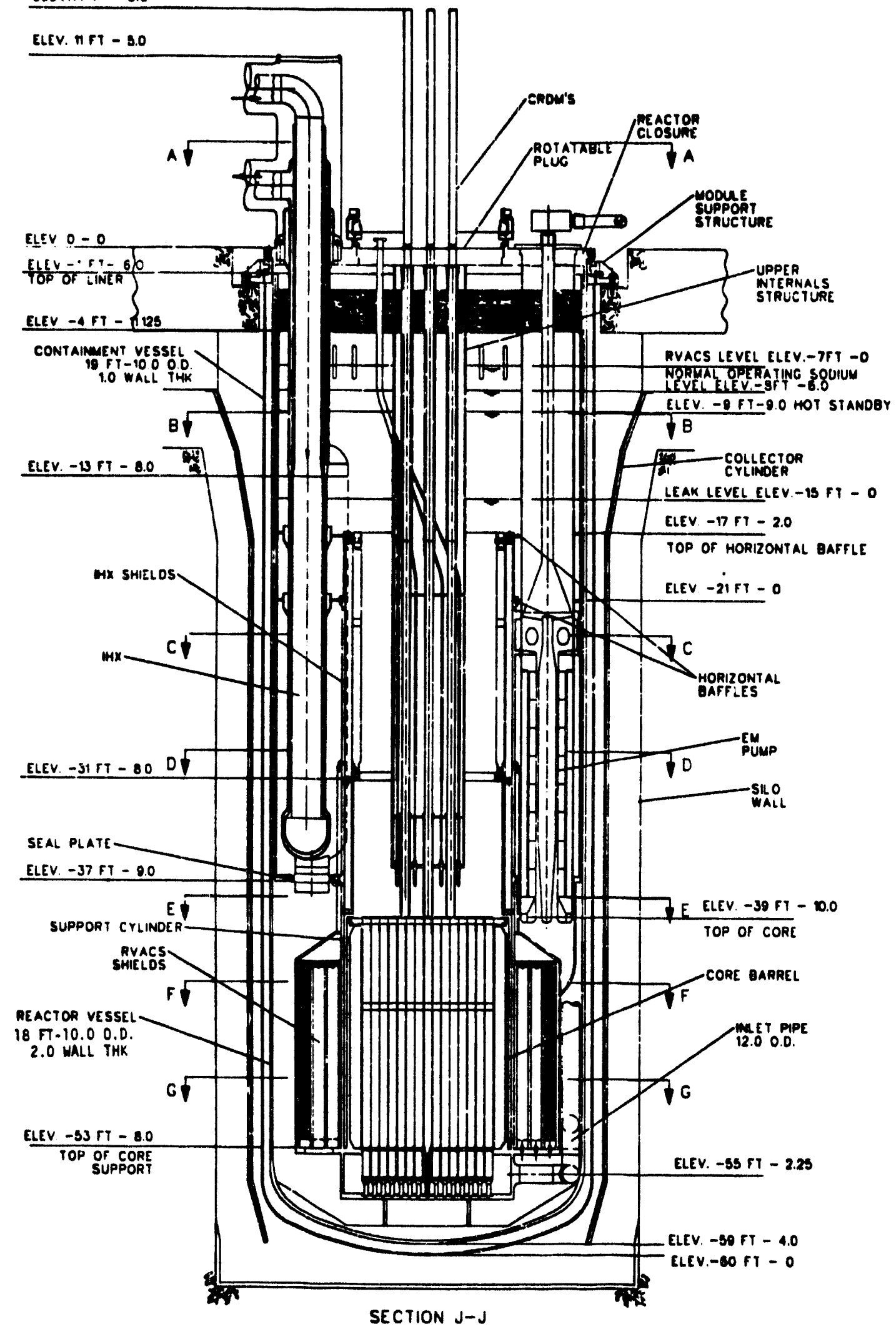

Figure 5.2 PRISM internal structures 
- Upper Internals Structure (UIS) Provide support for instrumentation lines and control rod drivelines.

Reactor internal structures are reviewed in Section 5.3 which follows.

\section{Primary Heat Transport System}

The PHTS is contained entirely within the reactor vessel. Primary sodium flows from the core outlet to the upper plenum, IHX shell side to the cold pool, pump inlet manifold, EM pump and pump discharge, to the core inlet plenum. This process is shown in Figure 5.3.

The four EM pumps circulate the primary sodium coolant. The pumps have no moving parts, are cooled by the sodium coolant, and are suspended from the reactor closure head. Because of the high temperature of the sodium coolant, research is being performed to select an electrical insulating material for the power supply to the EM pumps. Because the EM pumps have no moving parts and, therefore, no stored kinetic energy, a synchronous coastdown machine is required for each pump to provide coastdown flow of the coolant upon loss of power.

The heat from the PHTS is transferred to the IHTS through the IHX. Two IHXs per module are suspended from the reactor closure head. The design has the primary sodium coolant on the shell side and the intermediate sodium coolant on the tube side.

The PHTS is reviewed in Section 5.4 of this report.

\section{Intermediate Heat Transport System}

The IHTS transfers heat to the water-steam system through the steam generator during both normal operation and upset conditions. The main components are the tube side of the IHX, the shell side of the steam generator, the intermediate sodium pump with an auxiliary pony motor, the IHTS piping, and the IHTS isolation valves. The isolation valves close to isolate the reactor from pressure surges from the $6895 \mathrm{kPa} 1000$ psi water-steam system that may occur during sodium-water reactions due to steam generator tube ruptures. The sodium-water-reaction pressure-relief system (SWRPRS) is connected to the steam generator and produces an IHTS isolation signal.

The SWRPRS is reviewed in Section 5.6 of this report, and the IHTS is reviewed in Section 5.5.

\section{Steam Generator System}

Each reactor module has an independent steam generator, which supplies saturated steam to the turbine. The steam generator is also linked to the SWRPRS. The SWRPRS initiates isolation and blowdown of the water-steam system and reactor scram in the event of sodium-water reactions. The steam generator is used for residual heat removal (RHR) by the auxiliary cooling system (ACS). The ACS serves as a non-safety-grade backup RHR system. The ACS operates by air (natural circulation) cooling of the steam generator and is only useful when intermediate sodium is circulating through the steam generator, either by forced or natural circulation.

The steam generator system is discussed in Section 5.6 of this report, and ACS is discussed in Section 5.7.

\section{Residual Heat Removal Systems}

Three systems can perform the RHR functions in the PRISM design: normal condenser cooling, the auxiliary cooling system, and the reactor vessel auxiliary cooling system. The first two systems are non-safety-grade; RVACS is the only safety-grade RHR system.

The ACS removes heat by air circulation past the steam generator outer shell while sodium is available in the steam generator. Airflow dampers can be opened by the operators to permit air to flow by natural circulation around the steam generators when the water supply is lost. In this mode, heat is removed by natural convection to the air. The ACS can operate with forced or natural circulation of the intermediate sodium.

Should the operators be unable to open the airflow dampers or should the IHTS flow or IHTS sodium inventory be lost, the residual heat will be removed by natural circulation airflow around the reactor containment vessel using atmospheric air through the RVACS. Heat will transfer from the reactor vessel to the containment vessel (by radiation) and then to the air surrounding the containment vessel (by convection), and then to a collector cylinder (by radiation). The heat transferred to the collector cylinder will be removed by convection to the air.

Of the three cooling mechanisms, only the RVACS functions continuously and does not require operator action or supply of coolant by an engineered system. Although heat is constantly being removed by the RVACS, the rate of heat removal increases to a significant level in the absence of the normal heat removal mechanisms because of the increased temperature in the containment vessel. 


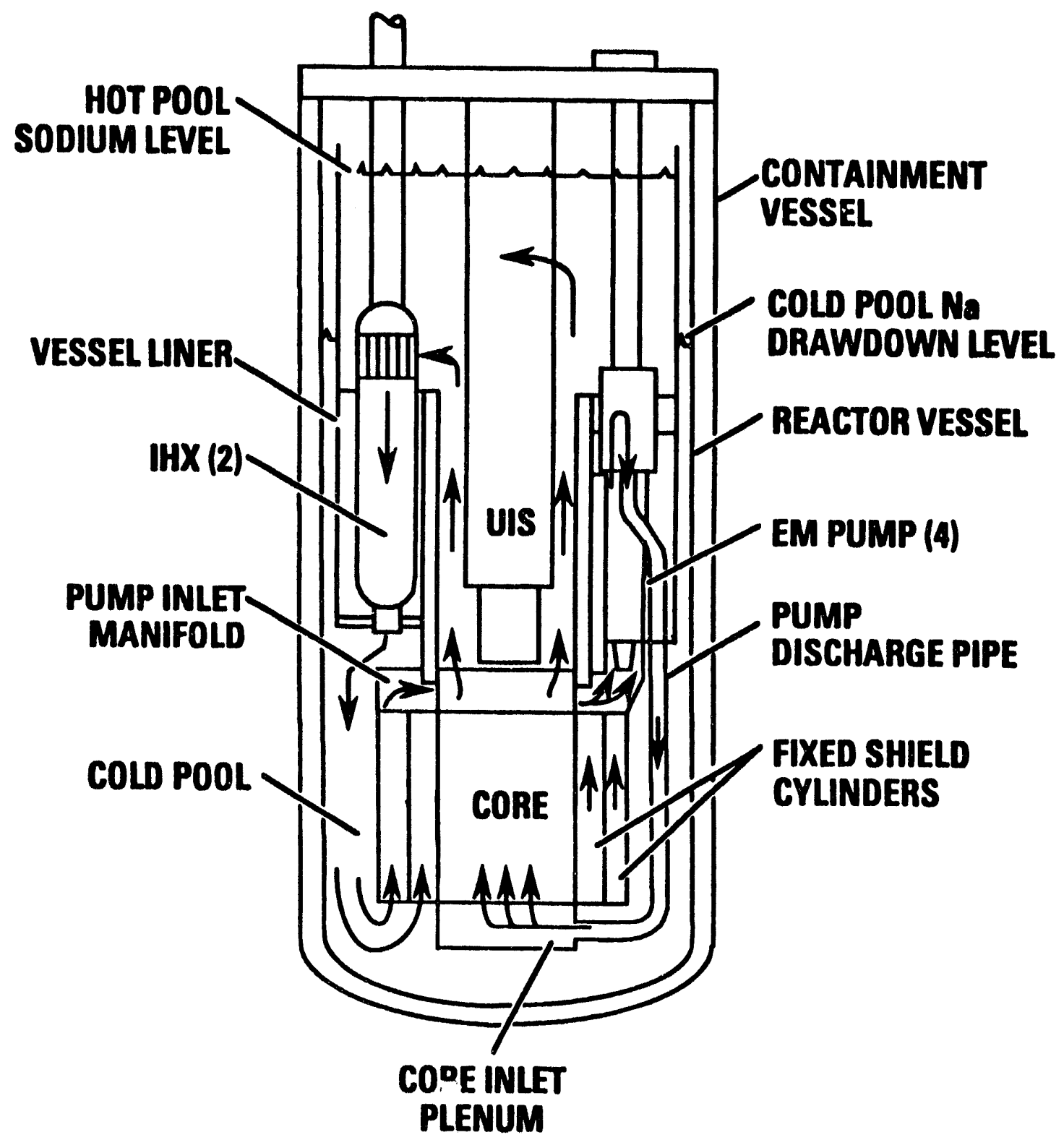

Figure 5.3 PRISM primary sodium flow circuit - normal operation 
Residual heat removal is evaluated in Section 5.7 of this report.

\subsection{Reactor Vessel and Closure Head}

\subsubsection{Design Description and Safety Objectives}

The reactor vessel for the PRISM supports the core and related components, the reactor internal structures, fixed shielding, EM pumps, intermediate heat exchangers, the reactor liner and support cylinder, the in-vessel transfer machine (IVTM), control rod drives, and all primary sodium and part of the intermediate sodium inventories. The reactor vessel has an outer diameter of $5.74 \mathrm{~m}$ (18 ft-10 in.) and a 5.08-cm (2-in.) wall thickness, and is constructed of Type 316 stainless steel. The components supported by the reactor vessel weigh 391 metric tons (431 tons) for the reactor internals, 76 metric tons ( 84 tons) for the core, and 220 metric tons ( 242 tons) for internal sodium from the primary and secondary loops.

The reactor vessel is supported by the top flange of the containment vessel. The containment vessel closely surrounds the reactor vessel, and the $12.7 \mathrm{~cm}$ (5-in.) annular gap between the two cylindrical vessels contains argon to minimize the effects of sodium-air-water reactions that may arise from reactor vessel leakage to the containment vessel. The PRISM reactor has a leakage detection system, comprising contact detectors and sodium aerosol detectors, to monitor sodium leakage out of or into the reactor vessel. The leakage detection system also monitors cover gas pressures in the containment vessel and reactor vessel to detect leakage of gases between the two vessels.

A vessel liner protects the reactor vessel during normal operation from the high temperature of the circulating primary sodium $758 \mathrm{~K}\left(905^{\circ} \mathrm{F}\right)$, and maintains sodium that is in contact with the vessel below $700 \mathrm{~K}\left(800^{\circ} \mathrm{F}\right)$. Relatively low operating temperatures compared to other liquid-metal reactors (LMRs) also help to minimize creep in the vessel during normal operation. During heatup scenarios, natural circulation sodium flow is induced, by sodium thermal expansion, in the annular gap between the vessel and the vessel liner, and reactor vessel temperatures rise considerably. Such high temperatures are reached in the vessel under these abnormal scenarios, that the hightemperature ASME Code Cases N-47 through N-51 are required for determining material stress limits for such time-independent and time-dependent forms of failure as ductile rupture, creep rupture, creep fatigue, and ratcheting. At present, the high-temperature code cases have not presently been approved by the Nuclear Regulatory Commission (NRC) for use in the design of nuclear power plant components, and will need to be reviewed for acceptance at a later stage in the review process.

The closure tead is the top head of the reactor vessel. Its basic component is a 30.5 -cm (12-in.)-thick stainless steel

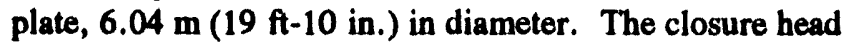
provides support for control rod drive (CRD) lines, the IVTM, penetrations for IHX lines, sodium and cover gas processing lines, a port for in-service inspection (ISI), ports for inspection conduits and the rotatable plug (RP). Penetrations for the six CRD lines, the IVTM, and ISI lines are within the RP. In addition, the RP has suspended from its underside the UIS. During power operation, to hermetically seal the RP, it will be welded to the closure head.

The closure head and the RP are designed to operate at relatively low temperatures, from 367 to $422 \mathrm{~K}$ (200 $300^{\circ} \mathrm{F}$ ). The 30.5 -cm (12-in.)-thick reactor closure head is insulated from the circulating sodium coolant by 22 horizontal layers of stainless steel plate (each 15.9-mm-thick) supported beneath the closure head plate. The high-temperature code cases are, therefore, not required for the closure head or the RP stress evaluation. The containment vessel and the connected dome exist primarily to serve as a barrier against release of radioactive materials. The containment vessel also serves as the surface for radiative heat transfer to the RVACS collector surface during an RVACS transient. The functional design of the containment is reviewed in Chapter 6 of this report.

The reactor vessel, containment vessel, reactor closure head, and rotatable plug will be designed in accordance with ASME Boiler and Pressure Vessel Code (ASME Code), Section III, and will all be seismic Category I. They are also being designed for the 60-year life of the plant.

\subsubsection{Scope of Review}

The reactor vessel, closure head, and the rotatable plug were reviewed in terms of the design basis, system design, performance evaluation, tests, inspections, and instrumentation. The functional requirements of the reactor vessel and closure head were reviewed in terms of satisfying structural/support, material, and instrumentation requirements. Compliance with codes, proposed research and development, and system performance were also evaluated where applicable. System design for the reactor vessel, closure head, and rotatable plug appear in PSID Section 5.2 and PSID Appendix G (Ref. 5.1) which contains modifications to the reference design. Other 
sources of material that were reviewed include highlights of Advisory Committee on Reactor Safeguards (ACRS) meetings with the designer (Ref. 5.2).

\subsubsection{Review Criteria}

The staff reviewed the following regulatory guidance for general applicability to the PRISM design. However, current standard review plan (SRP) and regulatory guides were developed specifically for light-water reactors (LWRs). Similar regulatory guidance for liquid-metal reactors has not been developed.

The following SRP (Ref. 5.3) sections were considered in this review:

- 5.2.1.1, "Compliance With the Codes and Standards Rule, 10 CFR Part 50.55a"

- 5.2.3, "Reactor Coolant Pressure Boundary Materials"

- 5.3.1, "Reactor Vessel Materials"

The following regulatory guides were considered in this review:

- 1.44, "Control of the Use of Sensitized Stainless Steel" (Ref. 5.4)

- 1.87, "Guidance for Construction of Class 1 Components in Elevated Temperature Reactors," (Ref. 5.5)

\subsubsection{Safety Issues}

The staff concentrated its review of the PRISM reactor vessel on areas in which the design departs from LWR design, and where design weaknesses may exist in comparison to accepted standards and practices.

\subsubsection{High-Temperature Environment - Stress Corrosion}

The high temperatures realized, particularly during Level $C$ and D transients, in the austenitic stainless steel of the PRISM vessel, can lead to stress corrosion cracking, particularly near welded areas of the reactor vessel. At a later stage, the designer should develop manufacturing, quality control, and quality assurance plans that will minimize sensitization of any part of the vessel that leals to stress corrosion cracking.

\subsubsection{Flowing Sodium Environment}

Degradation of the vessel can also occur with exposure to a flowing sodium environment, which initiates migration of carbon and nitrogen from the vessel surface and can lower the strength of the vessel. Erosion of the vessel wall during transient situations also should be examined at a later stage in the design review.

\subsubsection{Neutron Embrittlement}

The PRISM reactor vessel is one of the components to be designed for a 60-year lifetime. Over this extended time period, the vessel is exposed to neutron irradiation, which decreases ductility and fracture resistance. The effects of neutron embrittlement need to be accounted for in the final design and safety analyses.

\subsubsection{Stress Analysis/Time-Dependent Failures}

At a later stage of review, the designer should submit a more detailed analysis, to include the following:

- verification of component temperatures in Level $A / B$ to allow usage of Section III-NB of the ASME Code

- Level D analysis which utilizes the safe-shutdown earthquake (SSE)

- consideration of all types of time-dependent failures detailed in Code Case N-47

\subsubsection{In-Service Inspection}

The reactor vessel and closure head ISI will be performed in accordance with Section XI, Division 3, of the ASME Boiler and Pressure Vessel Code, "Rules for In-Service Inspection and Testing of Components of Liquid Metal Cooled Plants." Among particular problems that may arise are converting inspection requirements from 40 to 60 years, and visual inspection plans for the reactor vessel. More information should also be submitted on inspection of the inner surface of the reactor vessel, particularly following an RVACS transient heatup of the reactor vessel and internal components.

\subsubsection{High-Temperature Code Cases}

At a later stage, the applicant's use of Code Cases N-47, $\mathrm{N}-48, \mathrm{~N}-49, \mathrm{~N}-50, \mathrm{~N}-51$, and N-201 (Ref. 5.6) in the PRISM design must be approved by the NRC. 


\subsubsection{Vessel Closure-Rotatable Plug}

The rotatable plug is a non-integral, but mechanically attached, part of the reactor closure, governed by the closure design criteria. The basic structure of the RP is much the same as that of the stationary part of the closure having a $30.48-\mathrm{cm}$ (12-in.)-thick load-carrying plate with 22 layers of insulating plate underneath and thermal insulation on top. The RP has six penetrations for the CRD lines, a port for the IVTM, an ISI port, and a port for a cluster of above-core instrumentation conduits. In addition to these penetrations, the RP has the UIS and the IVTM suspended from the underside. The vessel closure head, including the RP, shall conform to the ASME Boiler and Pressure Vessel Code, Section III, Subsections NCA and NB, and also Code Cases $\mathrm{N}-47, \mathrm{~N}-48, \mathrm{~N}-49, \mathrm{~N}-50$, and N-51. The designer has stated that the closure head and the RP fall under the jurisdiction of the ASME Code, Section III, for nuclear power plant components, and shall be designed to accommodate the load combination prescribed therein without producing total combined stresses in excess of those allowed by the code. ASME Class 1, Class MC, or seismic Category I shall be designed to withstand the concurrent loadings associated with Service Level B conditions and the vibration effects of 50 percent of the SSE.

\subsubsection{Evaluation}

\subsubsection{High-Temperature Environment - Stress Corrosion}

Type 316 stainless steel is specified for the reactor vessel. Type 316 is an austenitic sensitized stainless steel, so stress corrosion cracking of the reactor vessel becomes important (Ref. 5.7). The PRISM retains the circulating sodium at temperatures that exceed $700 \mathrm{~K}\left(800^{\circ} \mathrm{F}\right)$ inboard of the reactor vessel liner during normal operation so that sodium in contact with the vessel walls remains below $700 \mathrm{~K}$ $\left(800^{\circ} \mathrm{F}\right)$. However, during certain transient heatups of the vessel, internal components, and the core, the primary sodium in the vessel will expand and rise above the level of openings in the liner. Natural circulation flow is established between the vessel and the liner, and temperatures near the vessel wall will approach core outlet temperatures, which increase to between $867 \mathrm{~K}\left(1100^{\circ} \mathrm{F}\right)$ and $978 \mathrm{~K}\left(1300^{\circ} \mathrm{F}\right)$ in these transients. Because stress corrosion becomes more likely at elevated temperatures, the designer will have to submit more complete information at a later stage of the design review about stress corrosion of the vessel, particularly with respect to the core support structure welded to the reactor vessel. Guidelines for the allowable stress limits of welds in the vessel are being developed as part of ASME Code Case
$\mathrm{N}-47$, and will be reviewed as more design information becomes available. More work is planned for extrapolating of $\mathrm{N}-47$ applicability from 34 years to 60 years, and the basis of extrapolation methods should be submitted at a later date. The designer should develop steps to minimize sensitization of stainless steel components, particularly near welded components, including appropriate heat treatments and processes during. fabrication, and quality assurance and quality control programs. The PRISM design also specifies a low oxygen level ( $2 \mathrm{ppm}$ ) and core outlet temperatures that will help to minimize corrosion of the vessel.

\subsubsection{Dynamic Sodium Environment}

As a consequence of exposure to a dynamic sodium environment, the vessel can experience two different types of degradation: erosion-corrosion and property changes. Erosion-corrosion decreases the effective load-carrying thickness of austenitic stainless steels; property changes can decrease time-dependent strength properties and properties not dependent on time. This issue is also considered in Section 5.3 (below) on reactor internals.

Erosion-corrosion rates are given in the Nuclear Systems Materials Handbook (Ref.5.8), as shown in PSID Figure G.4.3-12. This type of erosion or corrosion will be more pronounced during reactor vessel heatup transients, possibly in scenarios when only passive heat removal is available. Because sodium in contact with the vessel is stationary during normal operation, erosion of the vessel should not be a major concern. This issue is further discussed in Section $\mathbf{5 . 3}$ of this report.

Exposure to flowing sodium also produces changes in material properties (Refs. 5.9 and 5.10). Two types of effects that cause the changes are important: surface effects and interstitial effects. Surface effects may involve, depending on the operating temperatures, transfer of certain metallic elements from hotter to cooler regions of the system. This phenomenon essentially changes the surface of components from having austenitic properties to having ferritic properties by removal of chromium, nickel, and molybdenum, with an accompanying decrease in rupture strength. The designer has estimated that rupture strength will decrease 1 percent in response to surface effects; however, it is not clear that this analysis applies to the reactor vessel, which is in contact with stationary sodium during normal operations. Therefore, it seems that this is a concern only for reactor internals, as discussed in Section 5.3 of this report. Interstitial effects involve the sodium transfer of carbon and nitrogen from hotter to cooler regions. Structural analysis by the designer has estimated carbon loss from less than $0.5 \mathrm{~mm}(0.02 \mathrm{in}$.) of 
Reactor Coolant System and Connected Systems

the surface layer of the vessel. This phenomenon is more dependent on time and temperature than on sodium velocity, so this effect is important for the reactor vessel. At a later stage of the design review, the designer should more fully describe the effects of carbon loss on the properties of the stainless steel.

\subsubsection{Neutron Embrittlement}

The PRISM reactor vessel is one of the components to be designed for 60-year use. Degradation of the vessel material properties over this extended period is a consequence of neutron irradiation. Neutron exposure decreases ductility and fracture resistance. Embrittlement of the vessel is measured by the designer using displacements per atom (dpa) methods, and is a way of measuring reductions in ductility and fracture resistance. The dpa limit is set at a value that ensures 10-percent residual total elongation (RTE) in load-bearing components and 5-percent RTE in non-load-bearing components. The RTE is a measure of the remaining ductility of a certain material. The designer has estimated dpa values in the reactor vessel, and these are within design limits that ensure the required RTE, a measure of ductility, and include such conservatisms as accounting for uncertainties in neutron flux and energies at the reactor vessel. However, the PSID contains no information on the justification for choosing the 10-percent and 5-percent RTE limits. The justification for the RTE limits should be submitted at a later review stage. This analysis has not been independently verified and no tests have been performed in real time to determine the effects of neutron irradiation for this length of time; therefore, the validity of not using real-time test specimens should be examined. It appears that the PRISM design can satisfy 10 CFR Part 50, Appendix H (Ref. 5.36) requirements by using permanent and replaceable shielding outside the core and shielding at the level of the IHX to minimize neutron irradiation of the reactor vessel to a stated level of $6.8 \times 10^{12}$ neutrons per square centimeter, which is well below the level of $1.0 \times 10^{17}$ stated in Appendix $\mathrm{H}$. However, consideration should be given to the fact that the fast neutron spectrum of PRISM can cause more damage than thermal neutrons for a given fluence. Furthermore, the Clinch River Breeder Reactor (CRBR) Plant Safety Evaluation Report (Ref. 5.11) stated that, for fluences less than $1.0 \times 10^{21}$ neutrons per square centimeter, the effects of neutron irradiation are not significant. If neutron irradiation levels are verified at a later stage of the review, it appears that the PRISM design can achieve a low level of neutron embrittlement of the reactor vessel.

\subsubsection{Stress Analysis in Design-Basis Scenarios - Time-Dependent Failures}

Utilizing elastic and simplified inelastic analysis methods, GE performed a steady-state thermal stress analysis in the reactor vessel using the ANSYS 4.2 finite element code. Temperature distributions were calculated for the top half of the reactor vessel, where thermal stresses are expected to be the highest. Normal operating temperatures in the PRISM are low enough that time-independent stress limits of the ASME Code are limiting values. Results from the designer's stress analysis list reactor vessel stresses that are below the allowable stress limits stated in Section III-NB of the ASME Boiler and Pressure Vessel Code, with maximum radial and circumferential reactor vessel stresses of 222.7 $\mathrm{MPa}(32,300 \mathrm{psi})$ and 106.7 $\mathrm{MPa}(15,400 \mathrm{psi})$, respectively. The designer will need to demonstrate that Section III-NB can be used, because PRISM vessei temperatures exceed the limit for using III-NB. These thermal stresses were combined with the stresses from gravity, system pressure, and the operating-basis earthquake (OBE) loads and compared with the ASME Code Service Level A/B stress limits to assess the adequacy of the reactor vessel and internal components. The results generally exhibited large margins to Level $A / B$ limits with a minimum 25-percent margin in stress limits in the vessel at the level where the sodium meets the cover gas. Exceeding design stress limits might cause outward ratcheting of the vessel. Gross distortion of the vessel and other components due to ratcheting in this manner is considered in Code Case $\mathrm{N}-47$, but has not been addressed by the designer. Other time-dependent failure modes, including creep rupture and creep-fatigue failure, have been analyzed as part of the station blackout analysis submitted by the designer, and as part of Code Case N-47 analysis requirements. As part of the Level A/B service life of the PRISM, the operating temperatures are low enough that time-independent stress levels are more restrictive than time-dependent limits, and the PRISM appears to be within the more restrictive values. In Level $C / D$ analysis, creep and fatigue damage also are well below the total allowable damage limits, as shown in PSID Section G.4.17. Cumulative creep and fatigue values are low enough that damage limits do not appear attainable for any reasonable frequency of Level $C$ and $D$ events that have the potential to cause creep or fatigue damage at elevated temperatures (station blackout). Presently, the designer is using four Level $\mathrm{C}$ events and one Level D event over the lifetime of the reactor module for design analyses. 
Therefore, at a later stage of review, the designer should submit a more detailed analysis, to include the following:

- verification of component temperatures in Level $A / B$ to allow usage of Section III-NB of the code

- Level D analysis that utilizes the SSE

- consideration of all types of time-dependent failures raised in Code Case $\mathrm{N}-47$, such as outward ratcheting of the vessel

\subsubsection{In-Service Inspection}

At a later stage of review, the designer will be required to submit more detailed information on the ISI and testing of the reactor vessel and closure head. The designer has stated that for nuclear-class components, which include the reactor vessel and closure head, ISI will be performed in accordance with Section XI, Division 3, of the ASME Boiler and Pressure Vessel Code, "Rules for In-Service Inspection and Testing of Components of Liquid Metal Cooled Plants." Particular problems that may arise include converting inspection requirements from 40 to 60 years and preparing visual inspection plans for the reactor vessel. More information should be submitted on inspection of the inner surface of the reactor vessel, particularly following an RVACS transient heatup of the reactor vessel and internal components.

\subsubsection{High-Temperature Code Cases}

When a design certification is applied for, the NRC staff will review the elevated-temperature ASME Code Case N-201 used for the PRISM design for acceptability. The code case is not currently considered among the approved high-temperature code cases as listed in the regulatory guides. Other high-ternperature code cases $(\mathrm{N}-48, \mathrm{~N}-49$, N-50, N-51) may also need to be reviewed. Code Case $\mathrm{N}-47$, also used for guidance in design of elevatedtemperature components, has not been accepted by the NRC. The extrapolation of allowable structural linits to 60 years from the present 34 years is also an open issue.

\subsubsection{Vessel Closure - Rotatable Plug}

Type 304 stainless steel is used for all components of the closure head. The closure head is not predicted to reach the high temperatures of the reactor vessel or its internal components. The closure head is also not in contact with the sodium environment. For these reasons, creep and corrosion are not expected to be a problem in the closure head. Thermal stresses in the closure head are expected to be considerably smaller than in the reactor vessel, and will have large design margins.

\subsubsection{Research and Development}

The designer is continuing to test the thermal stresses of the vessel and closure head during normal and abnormal conditions. The finite-element computer code ANSYS 4.2 is used in the analysis of thermal stresses. Seismic analysis of the reactor vessel and closure head is being done so that the vessel and closure will be able to meet the requirements for ASME Class 1 components. The vessel is to withstand the SSE and remain able to perform its safety function. This analysis will be required at a later review stage. Research is also being performed at Oak Ridge National Laboratory to validate extrapolation of ASME Code Case N-47 to 60 years.

\subsubsection{Conclusions}

The quality group and safety classification for the PRISM reactor vessel and the closure head are commensurate with the importance of the safety function to be performed by these components.

Quality control will be very important in fabrication of the reactor vessel to minimize stress corrosion of the vessel. More information will be required at the design certification stage on the quality control, quality assurance, and processes used in fabrication of the reactor vessel and the attached core-support structure.

For the design certification review, the designer should more fully describe the process and the effect of carbon loss on the strength of the stainless steel vessel. Analysis of erosion rates using data from the Nuclear Systems Materials Handbook, should also include the consequences of increased erosion during transient temperature excursions.

The designer should submit an analysis of the damage due to neutron embrittlement, the analysis and summary of testing programs for dpa limits, and the total exposure of the vessel. Also, the basis for RTE limits as specified in the PSID should be submitted. Furthermore, the designer should determine the validity of not using real-time specimens in determining dpa limits.

At a later stage of review, the designer should submit a more detailed analysis, important to final acceptance of the structural analysis, which is to include (1) verification of component temperatures in Level $A / B$ to allow usage of Section III-NB of the code, (2) Level D analysis which utilizes the SSE, and (3) consideration of all types of time- 
dependent failures detailed in Code Case $\mathbf{N}-47$, such as outward ratcheting of the vessel.

The preapplicant has stated that for nuclear-class components, which include the reactor vessel and closure head, ISI will be performed in accordance with Section XI, Division 3, of the ASME Boiler and Pressure Vessel Code. However, the designer will be required to submit, at the design certification stage, more detailed information on the ISI and testing of the reactor vessel and closure head.

Regarding elevated temperature, the NRC staff will review the ASME code cases used for the PRISM design upon receipt of a design certification application.

For the certification review, the preapplicant should submit a more complete analysis pertaining to failure modes for the reactor vessel, addressing the importance of all failure modes described in Code Case N-47, as well as synergistic effects that may occur as a result of a combination of the various failure and degradation modes.

\subsection{Reactor Internal Structures}

\subsubsection{Design Description and Safety Objectives}

The principal function of the reactor internal structures is to provide the mechanical support and restraint of the reactor core, reactor instrumentation, fuel transfer equipment, and in-vessel stored fuel. Reactor internals also provide restraint of the primary coolant system components, direction for primary system flow, and invessel radiation shielding. The reactor internal structures also contain features to prevent the hydraulic fluid forces from levitating core assemblies. All internal components are classified as safety-grade. Most reactor internal structures are specified for a 60 -year service life. Items that cannot reasonably be expected to last 60 years will be designed to be easily replaceable. Key internal components are shown in Figure 5-4.

\subsubsection{Core Support Structure}

The core support structure consists of eight radial beams welded to the bottom of the reactor vessel. This weldment supports the primary sodium inlet plenum, the core iarrel, and core restraint rings. Taken together, these structures restrain the core laterally and vertically.

The core is restrained laterally by the restraint rings located near the top of the core and inboard of the core barrel, and by the assembly nosepieces that meet the inlet plenum. One restraint ring is provided at the top of the assemblies. The inner surface contour of the restraint ring will closely match that of the outermost row of core assemblies. Load pads are in place between the restraint rings and the core assemblies. As lateral support is provided only near the top and bottom of the assembly, the core assemblies will be free to bow as dictated by temperature differences and their metallurgical condition.

The primary sodium inlet plenum, located directly below the core and above the radial support beams, contains 199 penetrations for the assembly nosepieces, and also contains eight inlets from the EM pump discharge. Structurally, the inlet plenum is comprised of upper and lower horizontal flat plates, a large-diameter cylinder that seals the two plates of the plenum, and six small-diameter sleeves inside the plenum that support the upper plate. The assembly receptacles are in the upper plate; the eight inlet holes from the pump discharge are on the outer cylinder. The lower plate serves as the vertical support for the assemblies.

\subsubsection{Support Cylinder}

The support cylinder extends upward from its connection at the upper plate of the core inlet plenum to the upper portion of the reactor hot plenum (Figure 5.5). The cylinder supports all internal components except the core, and also provides pressure and temperature separation between the hot and cold sides of the primary system. The functions supported by the support cylinder are discussed in the sections that follow. The cylinder has a 3.04-m (10-ft) outside diameter and 5.08-cm (2-in.) thickness at its lower end, and 2.54-cm (1-in.) thickness over its top

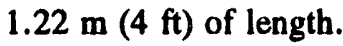

\subsubsection{Fixed Shielding}

Fixed shielding is used in the PRISM design to limit activation of RVACS air and secondary sodium in the IHX, to provide an adequate environment for neutron flux monitors, and to limit secondary fissioning in the stored fuel due to thermal neutrons in the hot plenum. Near-core fixed shielding is carried out by four cylinders, two made from steel and two made with $\mathrm{B}_{4} \mathrm{C}$. The two steel shields and one of the $\mathrm{B}_{4} \mathrm{C}$ shields are located immediately outboard of the core barrel. The other $\mathrm{B}_{4} \mathrm{C}$ shield is located inside the core barrel, to mitigate radiation damage to the barrel. The core barrel shielding is exposed to the highest neutron flux and so has been designed as removable shield assemblies which can be replaced before problematical deterioration of the $\mathrm{B}_{4} \mathrm{C}$. All fixed shielding is supported by the support cylinder. Additional shielding just inside the support cylinder at the level of the IHXs prevents activation of the intermediate sodium. The design 

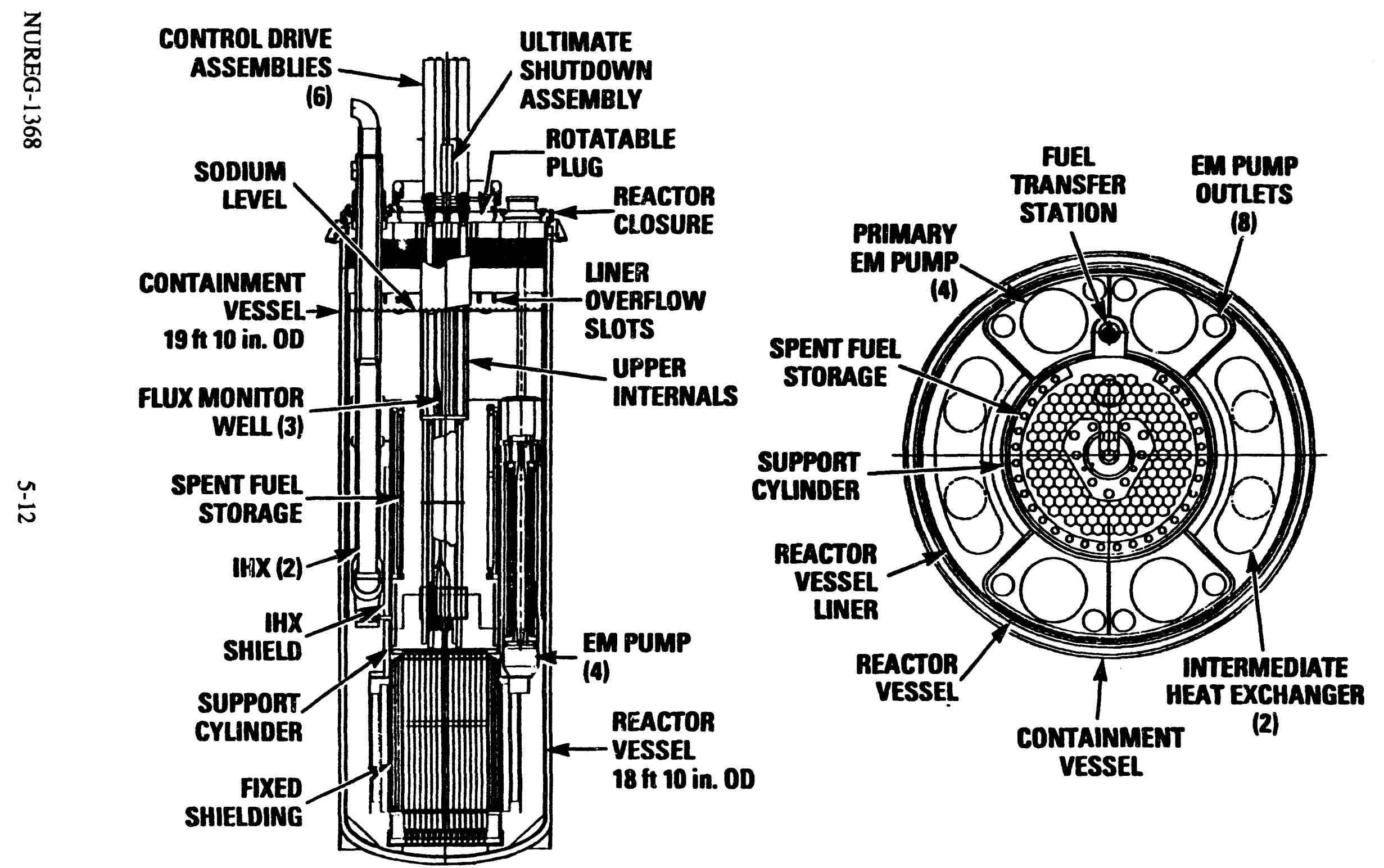

Figure 5.4 PRISM reactor internal components 
Reactor Coolant System and Connected Systems

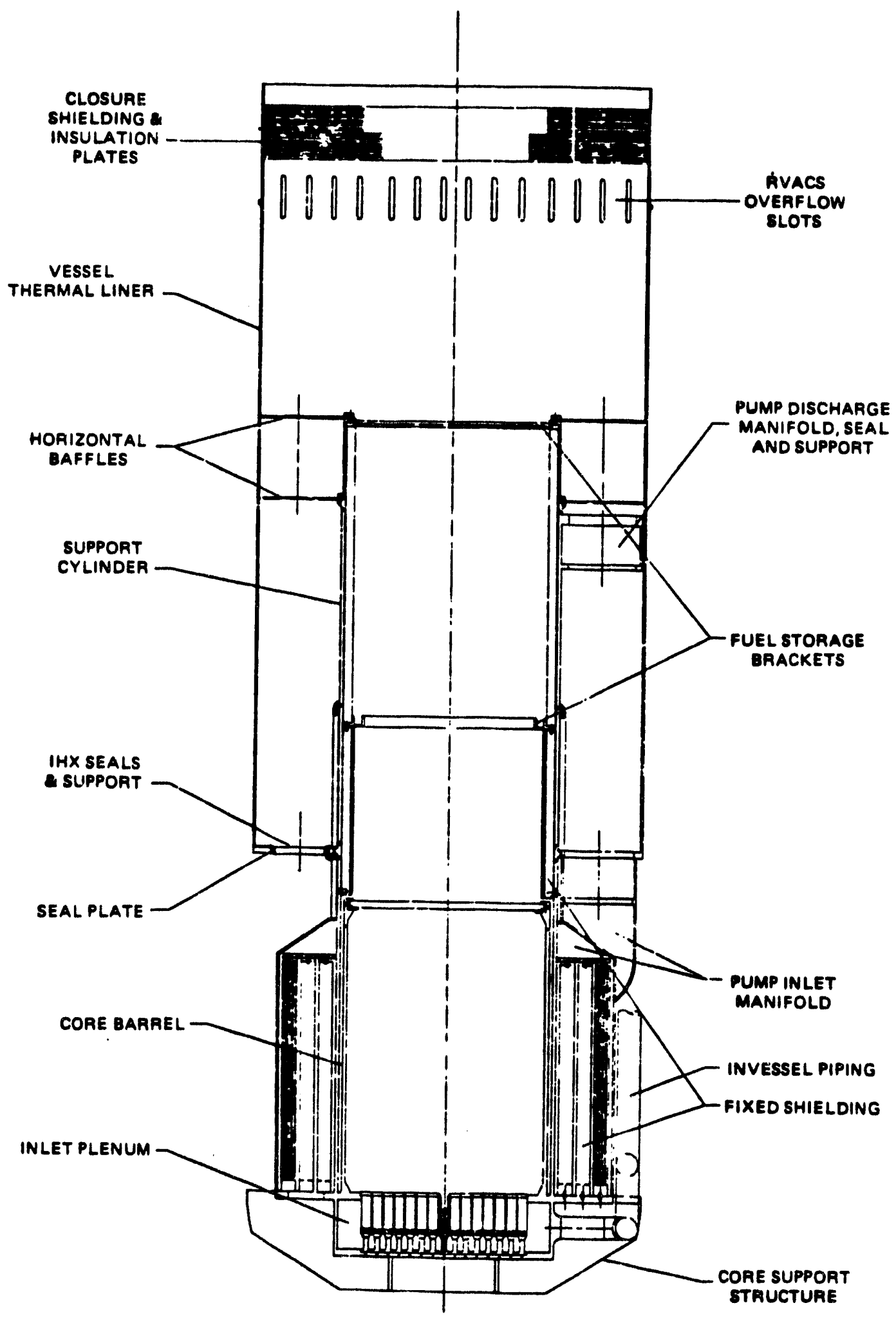

Figure 5.5 PRISM reactor internal structures 
of the $\mathrm{B}_{4} \mathrm{C}$ shielding is similar to the design employed for the control assemblies. $\mathrm{B}_{4} \mathrm{C}$ powder is compressed into pellets at 70 percent of theoretical density. The pellets are loaded into stainless steel pins $2.54 \mathrm{~cm}(1 \mathrm{in}$.) in diameter which support the shielding and prevent the $\mathrm{B}_{4} \mathrm{C}$ from leaking into the primary sodium.

\subsubsection{Electromagnetic Pump Inlet Manifold}

The pump inlet manifold directs primary sodium from flow across the fixed shielding to the pump inlet. The manifold is located directly above the shielding, with the support cylinder forming the inner annular boundary of the manifold and a conical flow guide forming the outer boundary of the inlet manifold. The conical extension of the manifold extends to and ends at the EM pump inlet. The manifold is sealed from the hot plenum at the level of the seal plate with an Inconel 718 piston ring. Sealing this area ensures that sodium entering the pump is coming from the fixed shielding flow, not from the cold leg of the primary system.

\subsubsection{Reactor Vessel Liner and Seal Plate}

The reactor vessel liner provides steady-state and transient thermal protection for the vessel and forms a portion of the boundary between hot and cold sides of the primary system. The liner also supports the 22 steel plates that provide thermal insulation for the underside of the reactor vessel closure head. A horizontal seal plate also forms a large portion of the boundary between the hot and cold plenums. The seal plate connects the vessel liner and the support cylinder at the level of the IHX discharge.

The vessel liner is cylindrical and is located $3.81 \mathrm{~cm}$ $(1.5 \mathrm{in}$.$) inside the reactor vessel and runs from the seal$ plate up above the normal sodium level in the hot plenum. The seal plate is welded to the liner and the support cylinder to complete the boundary between the hot and cold legs of the primary system. Near the top of the liner, which is about $30.48 \mathrm{~cm}$ (12 in.) above the normal operating level of primary sodium, are overflow slots which allow natural circulation of sodium to the reactor vessel wall during overheating events. Natural circulation becomes effective when thermal expansion raises the sodium level to the overflow slots, and the natural circulation consequently increases the effectiveness of RVACS heat removal. The liner will also insulate the vessel from normal rapid temperature changes which limits

\subsubsection{Pump Discharge Manifold and Seals}

The EM pumps discharge to two manifold assemblies (Ref. 5.37) that distribute the primary flow into eight pipes leading to the core inlet plenum. Each manifold consists of a closed annular shaped $\left(90^{\circ}\right.$ arc length) chamber and accommodates two of the EM pumps. Horizontal plates on the pump discharge manifold are $1.07 \mathrm{~m}(3.5 \mathrm{ft})$ apart, forming the upper and lower boundary of the manifold plenum. The discharge pipes that lead down to the core are sealed to the discharge plenum using Inconel 718 seals.

\subsubsection{IHX Seals and Supports}

Seals for the IHX are located at its penetration of the seal plate and the reactor closure head. The seals of the primary discharge of the IHX at the seal plate are Inconel 718 piston rings that interface with the stellite surface of the seal plate. The primary boundary is then sealed at the interface between the IHX mounting flange above the closure head and the closure head. At this interface are metallic O-rings which are compressed when the IHX flange is bolted down. The IHX flange is also seal-welded to the reactor closure to produce a hermetically sealed pressure boundary. The $1 \mathrm{HX}$ is supported vertically at the reactor closure head by the mounting flange bolted to the closure head.

\subsection{1. \& In-Vessel Fuel Storage}

The PRISM is designed to store spent fuel assemblies within the reactor vessel during operation to allow them to decay to power levels low enough to permit handling and storage outside the vessel with only dry natural cooling. The decay power level of blanket assemblies is sufficiently low that the blanket assemblies do not require in-vessel storage. There is space for 22 assemblies in the outlet plenum above the reactor core. The support cylinder supports the assemblies. The assemblies are mounted inboard of the support cylinder at a level above the core outlet. The assemblies are supported at their top and bottom by the cylinder to keep them from moving.

\subsubsection{Core Assembly Transfer Station and In-Vessel Transfer Machine}

Core assemblies are transferred into and out of the reactor vessel with a straight push-pull thimble device operating through a fixed port in the reactor closure head just outside of the rotatable plug. A station below the transfer station enables the fuel transfer bucket, which moves assemjlies into and out of the transfer station, to park there temporarily. The spent fuel is placed into the fuel transfer bucket by the IVTM. The thimble is supported vertically by the reactor closure head and laterally by interfacing structures connected to the support cylinder. The thimble will be designed for a 60-year life. The IVTM will be 
used to move fuel assemblies and other core components between the core, storage racks, and transfer station for removal from the reactor vessel.

\subsubsection{Hot Pool Thermal Insulation}

Insulation will minimize the heat passing from the hot plenum to the cold side of the primary loop, bypassing the IHX. The insulation is attached to the support cylinder, and is made up of two types of material. The first type is $\mathrm{B}_{4} \mathrm{C}$ radiation shielding at the level of the IHX, and the other comprises three stainless steel liner plates. Between the level of the bottom of the IHX and the top of the core, $\mathrm{B}_{4} \mathrm{C}$ shielding is on the inside and outside of fir support cylinder. Stainless steel plates near the reactor outlet increase the effectiveness of insulation at the point of greatest difference between hot and cold temperatures, and also protect the $\mathrm{B}_{4} \mathrm{C}$ shielding from thermal striping.

\subsubsection{Upper Internals Structure}

The UIS is attached at its upper end to the rotatable plug of the reactor closure head and hangs downward into the reactor hot pool, terminating at a point $5-\mathrm{cm}(2$-in.) above the top of the core. The UIS is a Type 316 stainless steel cylindrical structure (O.D. $1.32 \mathrm{~m}$ (52 inches); $11.79 \mathrm{~m}$ (38 $\mathrm{ft}-8 \mathrm{in}$.) long) that gives lateral support to and protects the control rod drivelines, and supports instrumentation lines. The control rod drivelines each include a shroud tube inside the UIS, made up of a Type 316 stainless steel upper tube, an Inconel 718 lower tube, and an Inconel 718 bushing. The Inconel bushing is positioned within the shroud tube to restrain and support the control rods. Inconel is used in the lower parts of the shroud tubes because it has the ability to sustain the thermal striping and thermal shock conditions that are the greatest near the core outlet. The shroud tubes extend the full length of the UIS and are welded to both ends of it.

\subsubsection{Scope of Review}

The staff reviewed the internal components of the reactor vessel with respect to the design basis, system design, performance evaluation, tests, inspections, and instrumentation. The reactor internal structures were reviewed on the basis of information presented in the PSID, particularly in Section 5.3, and the design changes in PSID Appendix G. Other sources of information were meeting summaries between the ACRS and the designers (Ref. 5.34 and 5.35).

\subsubsection{Review Criteria}

The staff reviewed the following SRPs for general applicability to the PRISM design:

- 5.2.1.1, "Compliance With the Codes and Standards Rule, 10 CFR Part 50.55a"

- 5.2.1.2, "Applicable Code Cases"

- 5.2.3, "Reactor Coolant Pressure Boundary Materials"

\subsubsection{Safety Issues}

Review of the PRISM reactor internal components concentrated on areas where the design departs from LWR design, or where possible design weaknesses exist in comparison to applicable regulations, codes, and standards, such as the ASME Boiler and Pressure Vessel Code.

\subsubsection{Stress Analysis in Design-Basis Events}

For Level D analysis, the SSE will be included as part of the mechanical stress. The designer should submit stress analysis of the PRISM including mechanical and thermal stresses.

\subsubsection{Dynamic Thermal Loads}

Among the most important thermal loads on the internal structures are thermal striping during normal operation, and thermal shock (low-cycle fatigue) during transient operation on the components directly exposed to the core exit coolant. Since the thermal stress studies were based on preliminary information, the staff will need to evaluate this in greater detail during the next stage of review.

\subsubsection{Structural Design: UIS}

More specific information about the current UIS design should be submitted at a later review stage. If it becomes necessary to increase UIS diameter to diminish deflections, the staff will need to evaluate thermal stress, and aging of the UIS may become a safety concern because of changes to sodium flow patterns.

\subsubsection{The Environment of Flowing Sodium}

Reactor internal components degrade when they are exposed to a flowing sodium environment. Such exposure initiates migration of carbon and nitrogen from the vessel surface and can weaken the vessel. Erosion of the vessel wall during transient situations also should be examined as a mode of degradation. Surface effects may involve 
transfer of certain metallic elements from hotter to cooler regions of the system, with an accompanying decrease in rupture strength. Interstitial effects involve the sodium transfer of carbon and nitrogen from hotter to cooler regions.

At a later stage of review, the designer should more fully describe the process and consequences of surface and interstitial property changes. Analysis of erosion rates using data from the Nuclear Systems Materials Handbook, should consider the consequences of increased erosion during transient temperature excursions.

\subsubsection{In-Service Inspection}

The plan for inspecting internal components and primary system piping will follow Section XI, Division 3, of the ASME Boiler and Pressure Vessel Code, "Rules for InService Inspection and Testing of Components of Liquid Metal Cooled Plants." Among the problems that may arise are converting inspection requirements from 40 to 60 years, and visual inspection problems associated with the opaque nature of the sodium coolant.

\subsubsection{Use of Stellite}

The PSID stated that stellite would be used, on the surface of the hardfaced cylinder that contacts the Inconel 718 seals, in the PRISM EM pump design. The staff had concerns about the amount of cobalt -60 in the stellite that could escape from the reactor vessel pressure boundary. However, the designer stated, in Reference 5.37, that stellite has been eliminated from the PRISM design. The PSID was not revised to reflect this change. This resolves the staff's concerns about the use of stellite.

\subsubsection{High-Temperature Code Cases}

Use of Code Cases N-47, N-48, N-49, N-50, N-51, and $\mathrm{N}-201$ in the PRISM design must be approved by the NRC at a later stage.

\subsubsection{Evaluation}

The main purpose of the internal components is to provide a support and restraint function for the core and other invessel components, and to guide the coolant flow. The major in-vessel components (IHX, EM pumps) are supported by the closure head, as discussed in Section 5.2 of this report. Other internal components are supported by the support cylinder. However, high operating temperatures and a dynamic sodium environment lead to various modes of degradation of the internal components, including creep/fatigue failures, corrosion/erosion processes, and thermal striping.

\subsubsection{Stress Analysis in Design-Basis Events}

Stress analysis of the PRISM will include analysis of mechanical and thermal stresses. The maximum mechanical stresses in the internal components were examined by the designer by simultaneously considering gravity, a 689-kPa (100-psi) primary coolant pressure, and the effects of the SSE. The SSE has a maximum ground acceleration of $0.30 \mathrm{~g}$. The equivalent load of the SSE is then combined with gravity and coolant pressure to determine maximum mechanical stress, which can then be combined with thermal stresses for the total stress. Total stress must be examined because the internal components must perform their safety functions while withstanding the effects of the SSE. Total stress has not been analyzed in the PSID, although analysis was done to determine the maximum mechanical stresses, which included equivalent seismic loads for the SSE. The results of the analysis showed large margins to the allowable stress limits for the Type 304 stainless steel internal components.

In a related analysis done by the designer, thermal stresses were combined with mechanical loads and the operating basis earthquake (OBE), which is based on an earthquake with half the ground acceleration magnitude of the SSE, and is used in Level A/B analysis (expected events). The SSE is to be used for Level D analysis. This analysis used calculated temperature distributions from the COMMIX code (Ref. 5.12). For steady-state operation, the maximum stresses from this analysis are well within Level A/B design limits. However, the SSE will be considered at a later design stage as part of the total stress during Level D events.

\subsubsection{Dynamic Thermal Loads}

On the basis of the thermal stress studies discussed above and preliminary thermal mapping of primary coolant system operating temperatures, some general conclusions can be drawn about the importance of thermal loads on the reactor's internal components. Among the most important thermal loads on the internal structures are thermal striping (Ref. 5.13) during normal operation and thermal shock (low-cycle fatigue) during transiert operation on the components directly exposed to the core exit coolant, which include the lower portion of the UIS and instrument posts, the support cylinder, and the shielding/thermal insulation n:ar the support cylinder. Analogously, thermal stresses in components away from the core outlet, such as the core support structure in the cold plenum, are small compared to components mentioned above. 
The UIS experiences relatively high thermal stress at its lower end near the core outlet. In response to the high temperatures and flow rates at the bottom of the UIS, Inconel 718 is specified for the bottom plate of the UIS above the core outlet. It is also used for the instrumentation posts near the bottom of the UIS. Inconel 718 has excellent corrosion resistance and high resistance to thermal striping during normal operation, and should offer satisfactory protection against thermal shock during transients. However, for application in the PRISM, further information must be submitted in two areas. First, the performance of Inconel 718 in high-radiation environment needs to be evaluatod; second, radiation effects need to be considered simultaneously with thermal striping to determine the overall acceptability of Inconel 718. Thermal striping stresses have been estimated by the designer to be highest in the UIS shroud tube and instrument posts at the UIS bottom surface. At a later review stage, analytical methods and attenuation factors used in determining the magnitude of thermal striping stresses should be submitted. For transient operation with a reactor trip at full power with minimal decay heat, the designer has stated that thermal transients in the PRISM are expected to produce ramp rates of $9 \mathrm{~K}$ per second (15 ${ }^{\circ} \mathrm{F}$ per second) for lower UIS structures. This is lower than UIS rates predicted for the CRBR and the Large-Scale Prototype Breeder, so thermal shock in PRISM should fall within material design limits.

It may also be necessary to move to a more corrosionresistant material for the support cylinder, where structural temperatures are above the ASME Code low-temperature design limit of $700 \mathrm{~K}\left(800^{\circ} \mathrm{F}\right)$. The support cylinder serves as a major portion of the boundary between hot and cold legs of the PHTS, and its degradation can have a major impact on how effectively the PHTS will remove heat. Material for the support cylinder will have to be evaluated at a later stage in the review process, taking into account the extent of thermal striping and the magnitude of other high-temperature effects.

\subsubsection{Structural Design - UIS}

Another issue associated with development of the UIS is structural design. The UIS is required to limit seismic deflections of the control rods to a level that is sufficiently small to preclude interference between a driveline and its guiding components which would interfere with scram performance. The designer analyzed UIS deflections during an SSE. Deflections are given for combinations of UIS dimensions of $1.14-\mathrm{m}$ (45-in.) and $1.83-\mathrm{m}$ (72-in.)-diameter and 1.27-cm (0.5-in.) and 2.54-cm (1.0-in.)-thickness, and the deflections were also measured at isolation frequencies of 0.5 and $1.0-\mathrm{Hz}$ (isolation frequency for the PRISM is $0.75 \mathrm{~Hz}$ ), so that the analysis is for a range of values near the present design values of PRISM. Analysis on the 1.14-m (45-in.)-diameter UIS gave values that exceeded allowable deflection at the 1.0-Hz frequency. Furthermore, it is difficult to determine from the analysis whether the deflection limit would be exceeded for the $1.32 \mathrm{~m}$ (52 in.) diameter cylinder. On this basis, more specific information about the UIS design should be submitted at a later review stage. If it becomes necessary to increase UIS diameter to diminish deflections, thermal stress and aging of the UIS may need to be reevaluated because of the larger diameter, which changes sodium flow patterns.

\subsubsection{The Environment of Flowing Sodium}

Degradation of the reactor internal structures is a consequence of exposure to a dynamic sodium environment, and is the source of two different types of degradation: erosion-corrosion and property changes. Erosion-corrosion decreases the effective load-carrying thickness of austenitic stainless steels; property changes are the decrease of both time-dependent and time-independent strength properties.

Erosion-corrosion rates are given in the Nuclear Systems Materials Handbook, as shown in PSID Figure G.4.3-12. Erosion caused by a sodium environment will be more pronounced during transients involving reactor vessel heatup, possibly in scenarios when only passive heat removal is available. The designer should submit more information justifying selected worst-case erosion rates, and whether increased erosion during transient heatups is possible.

Exposure to flowing sodium also produces changes in material properties. Two types of effects that cause the changes are important: surface effects and interstitial effects. Depending on the operating temperatures, surface effects may involve transfer of certain metallic elements from hotter to cooler regions of the system. This phenomenon essentially begins to change the surface of components from having austenitic properties to having ferritic properties by removal of chromium, nickel, and molybdenum, with an accompanying decrease in rupture strength. The designer has estimated that rupture strength will decrease 1 percent because of the altered surface. This area requires further review upon submittal of more detailed information about this process. Interstitial effects involve the sodium transfer of carbon and nitrogen from hotter to cooler regions. Having performed a structural analysis, the designer estimates carbon loss of less than $0.5 \mathrm{~mm}(0.02 \mathrm{in}$.) of the surface layer of reactor components. At a later stage of the design review, the 
designer should describe in detail the effects of carbon loss on the properties of the stainless steel.

\subsubsection{In-Service Inspection}

The designer must submit more detail on the in-service inspection and testing programs for the reactor internal components. The designer has stated that for nuclear-class components, which include the reactor internals and primary system piping, ISI will be performed in accordance with Section XI, Division 3, of the ASME Boiler and Pressure Vessel Code, "Rules for In-Service Inspection and Testing of Components of Liquid Metal Cooled Plants." Among the particular problems that may arise are converting inspection requirements from 40 to 60 years, and visual inspection problems associated with the opaque sodium coolant. The designer will have to justify the visual inspection plan used for the PRISM, particularly the plan for detecting cracks and erosion by means of remote visual examination equipment. Continuous monitoring of pressures and temperatures will not produce enough information about these modes of degradation.

\subsubsection{Use of Stellite}

Although the PSID stated that stellite would be used for sealing joints on the seal plates and on EM pump manifold joints, the designer stated, in Reference 5.37, that stellite has been eliminated from the PRISM design. The PSID, however, was not revised to reflect this change. This addresses the staff's concerns about the use of stellite.

\subsubsection{Use of ASME High-Temperature Code Cases}

The elevated-temperature ASME Code Case N-201 used for the PRISM design will need to be reviewed by the NRC staff upon receipt of a design certification application. The code case is not currently considered among the acceptable high-temperature code cases cited in the regulatory guides. Other high-temperature code cases (N 48, N-49, N-50, N-51) may also need to be reviewed. Code Case $\mathrm{N}-47$, also used for guidance in design of components exposed to elevated temperatures, has not been accepted by the NRC. The extrapolation of allowable structural limits to 60 years from the present 34 years is an open issue.

\subsubsection{Research and Development}

The designer is continuing to test thermal stresses of the reactor internal components during normal and abnormal conditions. The finite-element computer code ANSYS 4.2 is used in the analysis of thermal stresses.

\subsubsection{Conclusions}

Using the ANSYS code, GE performed a stress analysis to estimate the magnitude of maximum mechanical stress in the reactor internal structures. The conservative analysis showed that there were large margins in the allowable stress. Final acceptance of the internal components will depend on the designer's stress analysis that will need to combine the thermal stresses evaluated in the PSID with the effects of the SSE, as part of the design basis of the PRISM.

Among the most important thermal loads on the internal structures are thermal striping during normal operation and thermal shock (low-cycle fatigue) during transient operation on the components directly exposed to the core exit coolant. Inconel 718 is specified for the UIS bottom in order to protect against thermal striping. Two areas require further information to be submitted: first, the performance of Inconel 718 in a high-radiation environment needs to be evaluated; second, radiation effects need to be considered simultaneously with thermal striping to determine the overall acceptability of Inconel 718 at the UIS bottom. Furthermore, at a later review stage, analytical methods and attenuation factors used in determining the magnitude of thermal striping stresses should be submitted. The required material for the support cylinder will have to be determined at a later stage in the review process, based on the extent of thermal striping and the magnitude of other high-temperature effects.

More specific information about the current UIS design will be required for the design certification review. If it becomes necessary to increase UIS diameter to diminish control rod deflections, thermal stress and aging effects of the UIS may need to be reevaluated because of the changed sodium flow patterns. The designer should confirm that deflection magnitudes do not exceed limits for safe insertion of the control rods.

For the design certification review, the designer will need to more fully describe the process and consequences of surface and interstitial property changes. Analysis of erosion rates using data from the Nuclear Systems Materials Handbook, should also include the consequences of increased erosion during transient temperature excursions. The designer should submit more information on whether the erosion rate is the same for all internal components.

The designer will also be required to submit more detail on the in-service inspection and testing programs for the reactor internal components at the design certification stage. The designer has stated that for nuclear-class 
components, which include the reactor internals and primary system piping, ISI will be performed in accordance with Section XI, Division 3, of the ASME Boiler and Pressure Vessel Code.

The elevated-temperature ASME Code cases used for the PRISM design will need to be reviewed by the NRC staff upon receipt of a design certification application.

For the design certification review, the designer should submit a more complete analysis pertaining to failure modes for reactor internal components, addressing the importance of all failure modes described in Code Case $\mathrm{N}-47$, as well as synergistic effects that may occur as a result of a combination of the various failure and degradation modes.

\subsection{Primary Heat Transport System}

\subsubsection{Design Description and Safety Objectives}

The PRISM PHTS is contained entirely within the reactor vessel and removes heat directly from the core and delivers it to the secondary (intermediate) sodium loop at the IHX. The rated heat removal capacity of the PRISM is $471 \mathrm{MWt}$. The flow rate for the primary system is $2507 \mathrm{~kg}$ per second (5527 lb per second). All PHTS components are submerged in a large volume of sodium within the reactor vessel. The PHTS loop consists of the reactor core, the hot pool at the core outlet, two IHXs, the cold pool below the reactor core inlet plenum, four EM pumps, eight EM pump discharge piping lines, and the core inlet plenum. Primary sodium flows from the core outlet plenum to the shell side of the IHX, down through the IHX, through the near-core shielding to the EM pump, and from the pump discharge down to the core inlet plenum. All components in contact with the PHTS are made of austenitic stainless steel and, except for the EM pumps, have a 60-year service life as the design basis. A 30-year life is specified for the EM pumps. The designer has stated that PHTS components that may not last 60 years shall be either sufficiently redundant or shall be designed to be easily replaceable. The primary flow patterns are shown in Figure 5.3. All components of the PHTS are classified safety Class 1 , and seismic Category I.

The safety objective of the PHTS is to maintain a primary sodium flow rate for keeping reactor temperatures within design limits that preclude damage to the reactor vessel, the fuel, and reactor internal components. The four EM pumps are required to provide adequate coolant flow for the reactor in normal and abnormal conditions. Synchronous coastdown machines will provide electrical power to ensure coastdown flow in the EM pumps if the primary power source fails. The IHX is the heat sink for the heat generated by the reactor. All structures and components of the PHTS are to be capable of withstanding the effects of $O B E$ accidents without losing their capability to remain functional, and perform their safety functions during a SSE.

\subsubsection{Intermediate Heat Exchanger}

There are two IHXs per reactor module (Fig. 5.6). They are located at a level just above the top of the core and outboard of the module support cylinder. Primary sodium enters the shell side of the IHX and transfers heat to the intermediate (secondary) sodium loop at the IHX. The tubes of the IHX form a portion of the primary coolant boundary and their integrity must be ensured. This is particularly true with respect to challenges resulting from steam generator tube ruptures and the sodium-water reaction (SWR) that would follow. The IHX tubes are designed to withstand a (internal) 6895-kPa (1000-psi) pulse, which is also the pressure of the steam system. This pressure would be applied to the intermediate sodium loop if a steam generator tube ruptured. Higher pressures that may result from SWRs are addressed in Section 5.6 of this report. In addition, during normal operation, the pressure in the intermediate system is maintained higher than pressure in the primary system, to prevent any leakage of radioactive primary sodium outside the primary system should an IHX tube rupture. Intermediate sodium enters through a central downcomer in the IHX, rises from the lower plenum through the tube bundles, and exits through the upper plenum to an annular flow riser coaxial with the downcomer. Both flowpaths exit from the primary boundary at the closure head. The downcomer and riser are separated by an inert gas-filled annular section to minimize regenerative heat transfer to the entering intermediate sodium. Although the entirety of the IHX is planned for a 60 -year life, the tube bundles of the IHX, each with 2139 tubes, are cesigned to be replaceable if necessary. The IHX is supporied by, and hangs from, the reactor vessel closure head and is constructed from Type 304 austenitic stainless steel. Expansion bellows are located at the top of the downcomer assembly (upper end) of the IHX. These bellows allow for the differential thermal expansion between the tube bundle and the IHX downcomer.

\subsubsection{Electromagnetic Pump}

The EM pumps are located above the core elevation and are just outboard of the support cylinder which surrounds the core, so that two EM pumps separate the IHXs on each side, with the IHXs $180^{\circ}$ apart. 


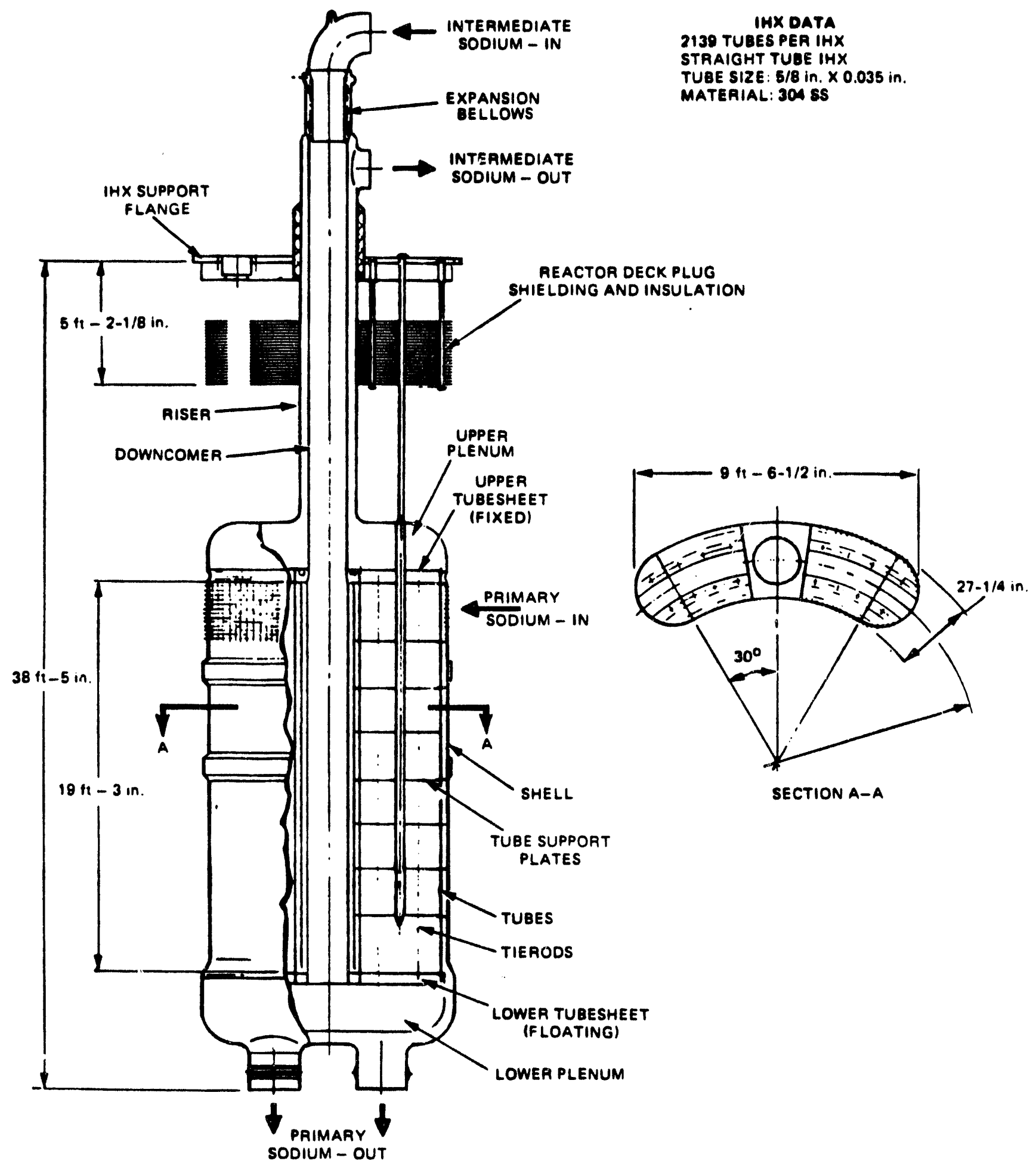

Figure 5.6 PRISM intermediate heat exchanger (IHX) 
Each pump is approximately $1.02 \mathrm{~m}$ (40 in.) in diameter

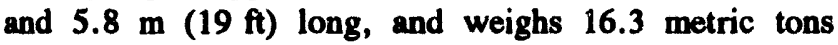
(18 tons).

The FM pump is shown in Figure 5.7. The pump inlet is at the bottom. Flow of the primary sodium through the EM pump is annular, between a center support cylinder and the stator. The stator is between the outer wall for sodium flow and the outer stator support cylinder of the pump. The EM pump is self-cooled in that the heat generated by electrical losses in the stator is transferred to the surrounding primary sodium. A riser section, extending from above the pump up to the closure head, contains the power and instrumentation cables. Because the EM pumps have no moving parts, conventional coastdown for a loss of power to the pumps is not possible. The EM pumps are connected in parallel with synchronous machines which, on loss of power, perform as generators to deliver electrical power to the pumps to maintain a flow "coastdown." Pump instrumentation is listed in Section 8.3 of this report. The instrumentation is used for controlling and analyzing pump performance and detecting failure of pump components.

\subsubsection{Synchronous Coastdown Machine}

The synchronous coastdown machine is an electric motor connected in parallel with the windings of the EM pump. Because the EM pumps have no moving parts, and therefore, no inherent coastdown, the synchronous machine is needed to simulate pump coastdown. The synchronous machine provides reactive power to the EM pump to correct the power factor during normal operation. Following loss of power to the EM pump, the synchronous machine converts the kinetic energy of its spinning rotor and flywheel into the electrical energy required by the EM pump to provide prima." flow coastdown. The coastdown performance for EM pump trip is show in Figure 5.8. The energy available for coastdown is related to the size, mass, and operating speed of the flywheel on the synchronous coastdov'n machine. The seismically isolated platform that supports the reactor and containment vessels also supports the synchronous coastdown machines; this precludes relative movement between the EM pumps and their synchronous coastdown machines.

\subsubsection{Scope of Review}

The PHTS is reviewed in terms of the design basis, system design, performance evaluation, tests, and instrumentation. The review focuses on the identification and acceptability of key safety issues, either based on analyses subunitted by GE in PSID Section 5.4 and PSID Appendix G, or on independent analysis by Brookhaven National Laboratory
(BNL) (Ref. 5.14). Instrumentation for the EM pump and synchronous coastdown machine is listed in Section 8.3 of this report. Detailed inspection plans for the EM pumps and the IHX have not been submitted; these will be reviewed at a later stage. Items regarding transient performance are discussed in Chapter 15 and Appendix B of this report.

\subsubsection{Review Criteria}

Section 3 of this report gives a general approach and criteria for PRISM review. Further guidance for review of PHTS systems comes from several generai design criteria and SRP sections.

The following GDC were considered in this review:

- GDC 10, "Reactor design": The PHTS shall be designed with margins to acceptable fuel design limits during normal operation and anticipated operational occurrences.

- GDC 14, "Reactor coolant pressure boundary": The PHTS shall be designed with extremely low probabilities of leakage and rapidly propagating failure.

- GDC 15, "Reactor coolant system design": Design conditions of the PHTS shall not be exceeded under rmal operation or anticipated operational rrences.

UC 30. "Ouality of reactor coolant pressure boundary": The PHTS shall be designed to the highest practical quality standards and shall provide a system for leak detection of sodium and cover gas.

- GDC 32. "Inspection of reactor coolant pressure boundary": The PHTS shall be designed to permit periodiz inspection and testing of components to assess structural and functional integrity.

The following SRP sections were considered:

- 5.4.1.1, "Pump Flywheel Integrity (PWR)"

- 5.2.3, "Reactor Coolant Pressure Boundary Materials"

\subsubsection{Safety Issues}

Koview of the PRISM PHTS was concentrated in areas where the design departs from LWR design. Important issues included the following:

- adequacy of $6895-\mathrm{kPa}(1000$-psi) IHTS design pressure - adequacy of the EM pump coastdown curve 

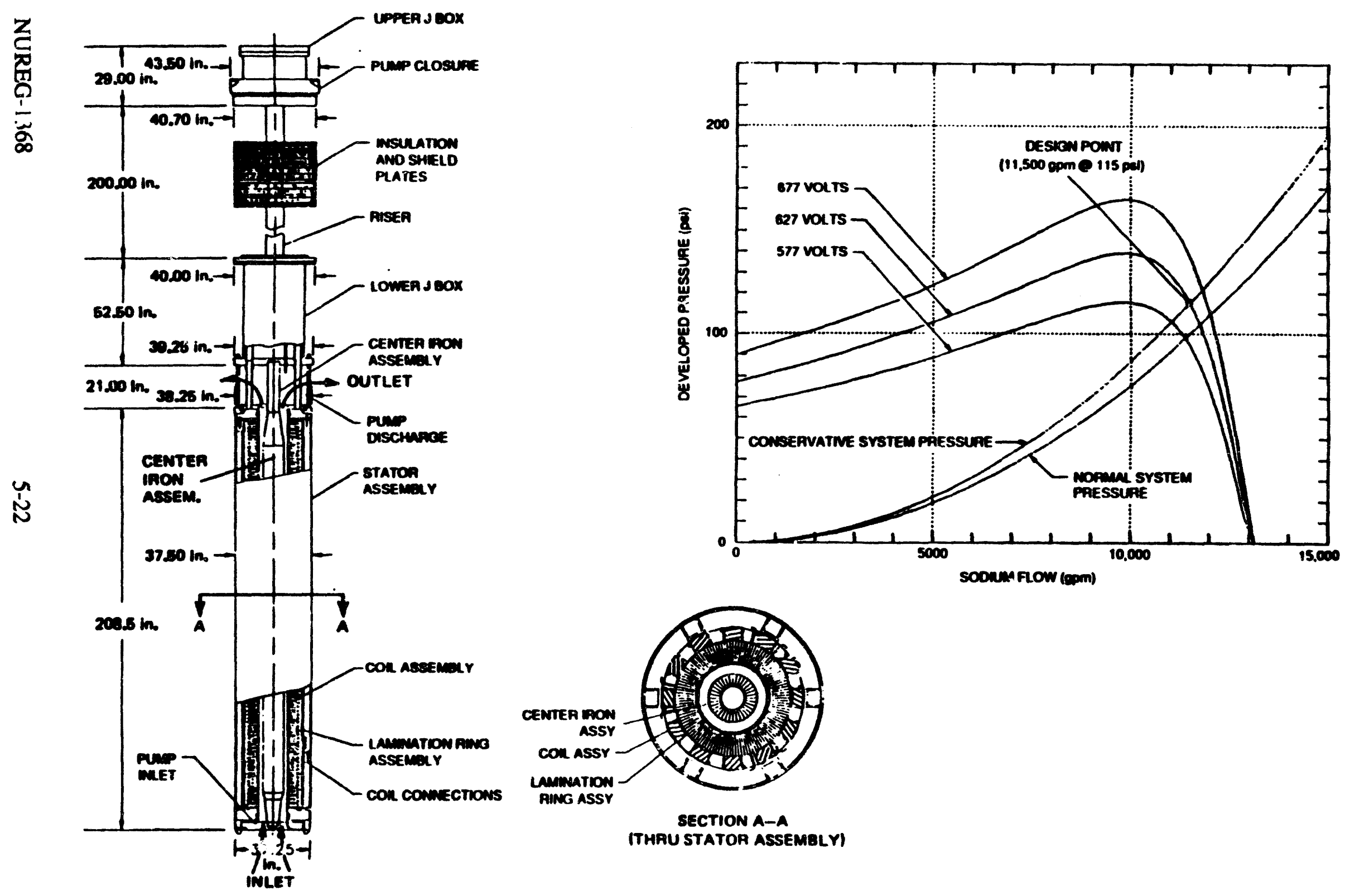

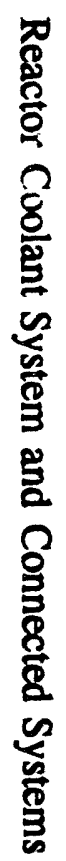

Figure 5.7 PRISM primary sodium EM pump 


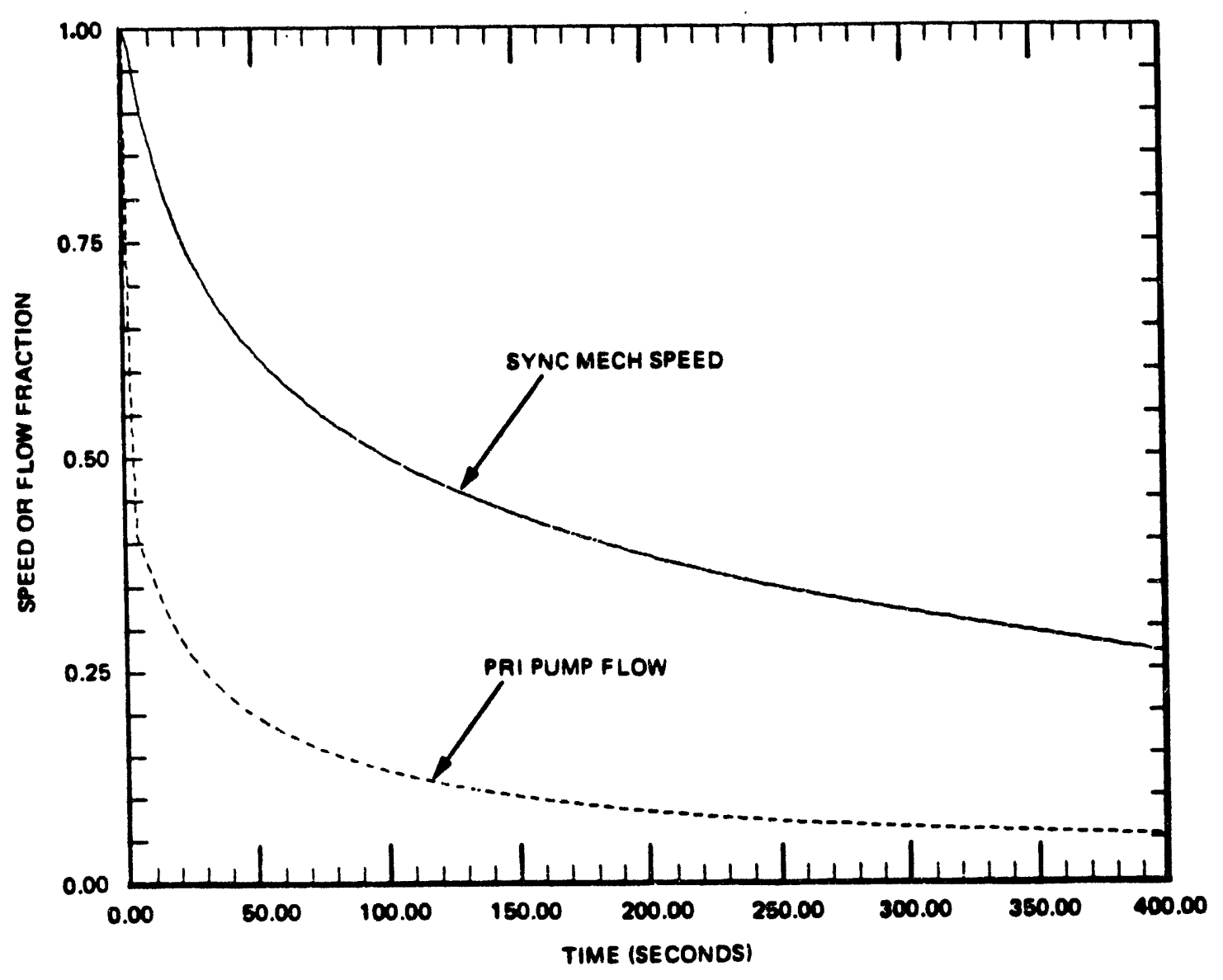

Figure 5.8 PRISM EM pump coastdown flow 
- design of the synchronous coastdown machine

- thermal-hydraulic analysis of the PHTS

- in-service inspection and testing of the PHTS

- use of the ASME high-temperature code cases

\subsubsection{Evaluation}

\subsubsection{IHTS Design Pressure}

While the IHTS is designed to withstand the full pressure of the water-steam system (6895 $\mathrm{kPa}(1000 \mathrm{psi})$ ), it is not clear from information presented in the PSID whether this would be the maximum pressure experienced by the IHTS. Additional pressure could develop from the energy released during a sodium-water reaction. The designer should submit more information on this issue.

\subsubsection{EM Pump and Pump Coastdown}

EM pump coastdown is important in both scrammed and unscrammed events for preventing sodium voiding which can lead to large reactivity insertions. In unscrammed transients, it is crucial to remove heat effectively for the first 2 minutes of the transient; during that time, pump coastdown is essential to insuring adequate heat removal. EM pump testing, as described in Section 5.6 of this report, will be used to evaluate the EM pumps. The PRISM response to a unprotected loss-of-flow (ULOF), with a loss-of-heat sink (LOHS), and with one pump failure to coastdown is examined in Bounding Event 4 (BE-4) in Chapter 15 of this report. The pump control system has also been designed so that reactor scram will be verified before the pumps are tripped.

\subsubsection{Synchronous Coastdown Machine}

The flywheel and rotor of the synchronous coastdown machine are designed to produce at least the coastdown characterized in the pump coastdown curve (Figure 5.8). This flow profile maintains the required flow-to-power ratio during core shutdown to minimize thermal shock, and also provides sufficient flow coastdown to prevent high-temperature challenges during the loss-of-flow events. Coastdown flow is quickly reduced to about 60 percent of full flow, to match the core power reduction. After this initial reduction, flow is raduced gradually to conserve the coastdown energy of the flywheel. The coastdown curve given by the designer has been verified independently by BNL in studies initiated by the NRC staff, and the designer will also be verifying the coastdown flow experimentally in the full-size EM pump prototype. The flow tests will cover the range of expected operating and extreme conditions. The designer has also stated that a redesign (enlargement or contraction) of the flywheel is possible if more or less coastdown energy is required.

\subsubsection{Thermal-Hydraulic Analysis}

For a pool-type reactor, the possibility of thermal stratification and other issues regarding mixing must be examined. The preapplicant has used the COMMIX code to examine the magnitude of stratification, stagnation, and other flow patterns in the PRISM primary system. The results showed uniform temperatures of $594 \mathrm{~K}\left(610^{\circ} \mathrm{F}\right)$ from the IHX outlet to the core inlet plenum, the entirety of the cold leg of the PHTS. At the core outlet, temperatures range from $758 \mathrm{~K}\left(905^{\circ} \mathrm{F}\right)$ for the hottest channel to $739 \mathrm{~K}\left(871^{\circ} \mathrm{F}\right)$ near the blanket. The UIS above the center of the core outlet considerably helps to mix the core outlet flow, as flow near the UIS bottom support plate is diverted to the refueling slot of the UIS and the annular region between the UIS and the fuel storage rack. Mixing occurs in the riser plenum so that temperature differences near the top of the plenum are reduced to about $5 \mathrm{~K}\left(9^{\circ} \mathrm{F}\right)$.

The UIS also acts to reduce flow velocities at the free surface of the riser plenum. This is accomplished through the UIS baffle plates, which will prevent the hot coolant leaving the driver and radial blanket assemblies from streaming directly upward to the top of the hot pool. Other velocity analysis shows that heat transfer through the sodium between the reactor vessel and the vessel liner can be effective with natural circulation patterns that are set up in this area. Two modes of natural circulation are established. In the lower portion of the vessel, natural circulation flows upward near the IHX and downward near the EM pumps. In the upper portion of the vessel, sodium circulates upward along the reactor vessel liner, and downward along the reactor vessel wall, due to the fact that the liner is hotter than the vessel.

GE and Argonne National Laboratory (ANL) are performing experiments in a 1/5-scale plexiglas water tank. Testing emphasizes examination of mixing patterns, coolability of in-vessel components, natural circulation, potential for flow reversal, and other adverse flow conditions. The tests also attempt to evaluate the effect of the UIS on thermal/flow behavior and further validate the COMMIX code. Few results of this testing have been published. ANL has stated that stratification in the model did not affect core coolability, and also said that COMMIX showed good agreement with measurements. Future testing will attempt to further substantiate these conclusions. Results of this testing will have to be evaluated at the next stage of review. 


\subsubsection{In-Service Inspection}

At a later stage of the review, the designer will also be required to submit more detail on the in-service inspection and testing programs for the EM pumps and the intermediate heat exchangers. Because these are nuclear Class 1 components, ISI must conform with Section XI of the ASME Boiler and Pressure Vessel Code. The EM pumps, IHXs, and primary system piping will be considered as internal components. Reactor internals are discussed in Section 5.3 of this report. Specifically, Division 3 of the ASME Code, "Rules for In-Service Inspection and Testing of Components of Liquid Metal Cooled Plants, " contains the inspection program for these components. Visual inspection of the EM pumps and IHX will be particularly important for the first PRISM plants for determining degradation, and it is not clear at this stage that the designers have any visual inspection planned for these components. Continuous monitoring is planned in terms of operating performance and will be the primary source of information on their operation. Another issue that will arise at a later review stage is the acceptability of a 60-year inspection plan, as opposed to the 40-year plan.

\subsubsection{ASME High-Temperature Code Cases}

The elevated-temperature ASME Code Case N-201 will need to be reviewed by the NRC staff upon receipt of a design certification application. The code case is not currently considered among acceptable high-temperature code cases as stated in the regulatory guides. Other hightemperature code cases $(\mathrm{N}-48, \mathrm{~N}-49, \mathrm{~N}-50, \mathrm{~N}-51)$ may also need to be reviewed. Code Case N-47, also used for guidance in design of components exposed to elevated temperatures, has not been accepted by the NRC.

\subsubsection{Research and Development}

\subsubsection{EM Pump}

Development of the EM pump for the PRISM consists of four phases: insulation-life testing, key-feature testing, stator-segment testing, and full-size prototype pump testing (Ref. 5.15).

Insulation-life testing establishes the service life of the mica insulation used in the stator windings. The planned service life of the EM pump is 30 years. This requirement is being demonstrated by testing insulation samples at elevated temperatures for leakage current. The designer has stated that the insulation will meet the 30-year-life requirement.
Key-feature testing will demonstrate the adequacy of the stator coils, the lamination rings, and stator mechanicalrestraint features. Methods for winding the stator coils, applying coil insulation, setting coil thickness, and fabricating the lamination rings have been demonstrated. Radial and axial support for the EM pump are also being confirmed.

A quarter-length segment of the stator has also been used to test the adequacy of the coils, coil insulation, and stator mechanical restraint under operating conditions for the PRISM. The outer shell of the pump was cooled by ambient air in this testing. Fabrication of the stator was demonstrated, as was its self-cooling capability. Insulation performance is also being measured. Future statorsegments test phases will simulate 10,000 hours of use at operating conditions.

A full-size/full-flow EM pump test is also planned. The test will correlate and verify pump operating characteristics with analytical results, and will also verify fabrication methods. There has been no independent confirmation of the designer's results.

\subsubsection{Thermal-Hydraulic/Vibration/Creep Fatigue Analysis}

Hydraulic model testing of the IHX will be conducted by the IHX vendor. The objectives of the IHX hydraulic model test are to ensure predictable heat transfer performance, flow stability, and overyll pressure loss characteristics and to ensure the absence of damaging tube vibration. The IHX and all its parts shall be designed so that they will not be damaged or caused tc malfunction either by flow-induced vibrations or by seismic vibrations. The IHX vendor will test flow vibration over the fuil range of operational velocities. Furthermore, the vit ration analysis shall cover vibrations and shock during shipment of the IHX. However, the dominant failure mode for the IHX is creep fatigue/creep damage in the upper, hotter portions of the IHX. The creep damage results from residual stresses created during temperature excursions in the reactor vessel. Engineering analysis that combines the effects of these degradation modes will also be carried out by the IHX vendor.

The COMMIX code was used to evaluate steady-state conditions in the PRISM, the flow patterns and velocities of the primary sodium, and flow patterns that exist between the vessel liner and the reactor vessel wall. COMMIX is also being used to examine flow stratifications that exist during norral PRISM operations, however, the code is limited in that it cannot model sodium interactions with the cover gas (gas entrainment). 
Temperatures of the sodium at many points in the primary flow path were also calculated by COMMIX. Some results of COMMIX testing are in Section 5.4.5.2 of this report.

In addition, the work using the 1/5-scale Plexiglas model of the PRISM (at ANL) could have safety-related applications. Using color dyes, ANL will examine possible problems with mixing and stratification. Some of the results could be important to evaluating the PRISM natural circulation response, which the designer has stated will also be tested in the prototype.

\subsubsection{Conclusions}

The quality group and safety classification for the components and systems included in the PRISM PHTS are commensurate with the importance of the safety function to be performed by these coniponents. The PHTS appears satisfactory to remove sufficient reactor heat under normal operating conditions. For scrammed accidents, the PRISM PHTS should perform very well in transporting heat away from the reactor.

The designer should submit more information to support the assumption that $6895 \mathrm{kPa}(1000 \mathrm{psi})$ is the maximum possible pressure to be experienced by the IHTS. Information on this issue should be submitted early, as the results could considerably affect the evaluation of the IHTS and the IHX tubes.

Coastdown performance of designer-submitted data on the EM pumps has been independently analyzed and verified by the staff, and the designer has plans for experimental verification of the coastdown flow over the full range of operating and extreme conditions. Although not described in detail, the testing plan seems adequate for verifying coastdown performance. The EM pump will also be tested extensively in the PRISM prototype reactor. EM pump acceptance will also depend on acceptance of the insulation material and the analytical principles used to determine the useful life of the insulation (Arrhenius principle). The results of the EM pump testing program as described in Section 5.4.6.1 of this report, and reliability assurance of pump coastdown, particularly relating to common-cause failure of pump coastdown, will affect final acceptance of the EM pumps and the PHTS.

The synchronous machine flywheel and rotor are designed to provide at least the coastdown characteristics shown in the pump coastdown curve (Figure 5.8). The coastdown curve given by the designer has been verified independently by BNL in studies initiated by the NRC staff, and the designer will also experimentally be verifying the coastdown flow in the full-size EM pump prototype. The flow tests will cover the range of expected operating and extreme conditions. Final acceptance of the synchronous machine flywheel and rotor and the coastdown curve will depend on the results of this testing.

Stratification problems relating to core coolability that arise because of transient events have not been analyzed to any great degree. The designer should evaluate initiators that may lead to degraded coolability due to flow stratification; however, COMMIX analysis and the UIS structure appear to preclude large-scale stratification in the steady state.

In-service inspection plans for the PRISM design need to be more fully developed at a later design stage, particularly in terms of visual inspection of major PHTS components (EM pumps, IHX). The designer has stated that ISI of PHTS components will be performed in compliance with Section XI of the ASME Code.

The elevated-temperature ASME Code cases will need to be reviewed by the NRC staff for acceptance upon receipt of a design certification application.

In the near term, the designer should examine the limits of the COMMIX code, particularly the inability to model different fluids in the same flow region. The effects of this limitation on analysis of gas entrainment and thermal stress analysis should be submitted.

\subsection{Intermediate Heat Transport System}

\subsubsection{Design Description and Safety Objectives}

The main components of the IHTS loop are the tube side of the two IHXs, the shell side of the steam generator, the intermediate pump, the IHTS expansion tank, connecting piping, and the IHTS isolation valves, located just outside the containment dome (Fig. 5.9). The IHTS interfaces with the SWRPRS. Rupture disks, designed to fail at $2240 \mathrm{kPa}(325 \mathrm{psi})$, are installed between the IHTS and SWRPRS to reduce the likelihood of high-pressure pulses in the IHTS coming from a sodium-water reaction. The active system of the isolation valves in combination with the passive system of the rupture disks is intended to eliminate the high-pressure pulses that result from steam generator tube failures. The SWRPRS and the steam generator are reviewed in Section 5.6 of this report. The IHTS piping and vessels are designed to ANSI Standard B31.1 and ASME Code Section VIII, respectively. Guard pipes surround the intermediate loop piping inside the containment dome to limit sodium fire and spill hazards in this area. The IHTS transfers the 


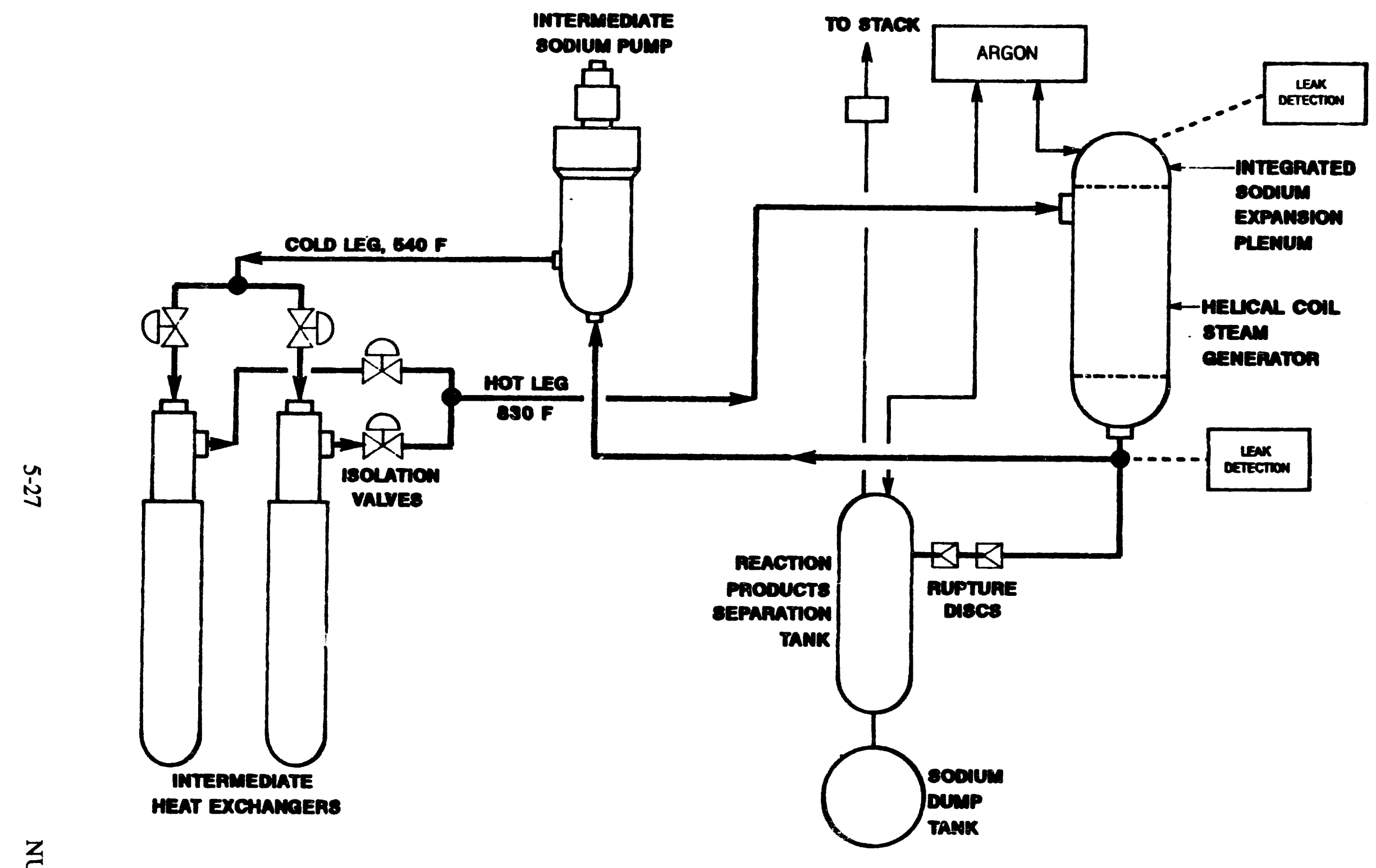

Figure 5.9 PRISM IHTS loop flow diagram 
reactor-generated heat from the IHX to the steam generator system under normal, shutdown, and upset conditions when available and can transport the reactor heat by the main intermediate pump, the backup pony pump, and residual heat through natural circulation to the balance-of-plant when the steam generator is operable, and to the ACS when the steam generator is not operable. The intermediate sodium is not radioactive and is separated from the primary radioactive sodium by the passive boundary of the IHX, which is reviewed in Section 5.4 of this report. The pressure in the IHTS is maintained at approximately $790 \mathrm{kPa}$ (100 psig), well above the nearatmospheric pressure in the primary system at the IHX elevation. The IHTS will contain process instrumentation and controls to monitor and control the IHTS over the full-power range during all normal and off-normal operating conditions. The entirety of the IHTS, except for the IHX, is not classified as safety-grade. Although not required for the non-safety-grade portions of the IHTS, ISI will be performed in accordance with the ASME Code, Section XI, Division 3.

The safety objectives of the IHX are to isolate radioactive primary sodium from intermediate sodium and to provide a mechanical barrier to the transport of radioactive sodium out of the containment boundary. Consequently, the designer has specified a zero leak rate for the IHX tubes. The IHTS will prevent the high pressures associated with a steam generator tube rupture from reaching the IHX tubes, along with its primary safety objective of reactor heat transport. The IHTS will be designed to remain operable following the OBE. Five OBEs, with 10 maximum peak response cycles each, are assumed to occur over the design life of the plant.

The intermediate pump is a vertically-oriented, single-stage, double-suction, free-surface, centrifugal pump. An auxiliary pony motor provides low-flow (10 percent) capability for residual heat removal. Automatic switching to the pony motor produces uninterrupted flows during coastdown. The pony motor also has an alternate power supply from the gas turbine generator. Adequate natural convection coolant circulation in the IHTS is to be provided under all conditions, except for an IHTS sodium leak.

\subsubsection{Scope of Review}

The IHTS is reviewed on a preapplication basis in terms of the system design, planned R\&D, performance evaluation, tests, inspections, and instrumentation. Design information comes from the PSID, Section 5.5 and Appendix G on design changes. The review focused on sodium leakage from the IHTS and possible threats to the IHX coming from the intermediate loop or the steam generator system, the most likely source being SWRs.

\subsubsection{Design Criteria}

GDC 15, 30, 31, and 32 of 10 CFR Part 50, Appendix A, which are directed toward maintaining the integrity of the primary coolant system, formed the primary review basis for the IHTS, as there is not an analogous system in LWRs.

\subsubsection{Safety Issues}

Review of the PRISM IHTS was concentrated in areas where the design departs from LWR design. Important issues are the response of the IHTS to SWRs, vibrations of the IHTS from the intermediate sodium pump, in-service inspection of the IHTS, and IHTS leakage-detection instrumentation.

\subsubsection{Evaluation}

Although not classified as safety grade, the IHTS performs two important functions for the PRISM. First, it removes operating and residual thermal power during normal and abnormal conditions. Second, it interfaces with the SWRPRS, which mitigates SWRs resulting from steam generator tube ruptures and consequently assists in maintaining IHX integrity.

\subsubsection{IHTS Response to Sodium-Water Reactions - IHTS Vibration}

The IHTS also contains isolation valves just outside the containment dome which close on a high-pressure signal and protect the IHX tubes from the products of SWRs which can corrode the IHX tubes. The IHTS, in conjunction with the SWRPRS, appears able to deal with the steam generator tube rupture scenario. Using a combination of active and passive systems (the IHTS isolation valves and the rupture disks, respectively), dangerous pressures at the IHX do not seem likely. Furthermore, all components and piping in the IHTS are designed for faulted-condition pressures equal to full-steam pressure, $6996 \mathrm{kPa}$ (1000 psig). Section 5.4 of this report addresses whether this is an appropriate IHTS design pressure. Section 5.6 of this report discusses the systems used to mitigate SWRs. Further documentation at the next stage of review will be required on IHTS components, particularly the gimbaled bellows, to assure that the IHTS design pressure is adequate.

It will also be necessary, at a later review stage, to evaluate natural frequencies of vibration of the IHTS, to 
preclude the intermediate pump from causing harmful resonance vibrations in the IHTS. Little information has been submitted on this topic.

\subsubsection{Leakage Detection Instrumentation}

Hydrogen leak detectors are located on the main loop piping at the steam generator outlet to allow early detection of a steam generator tube rupture. The IHTS contains numerous temperature and pressure sensors for the IHTS piping to detect leaks and monitor flow. All IHTS piping and components will have sodium-to-gas leak detection. Sodium aerosol or contact-type detectors monitor the insulation to pressure boundary annulus on all equipment. Sodium valves are equipped with contact-type detectors to monitor for valve-stem leakage, and major components have cable or spark plug detectors to monitor for the collection of pooled sodium underneath the components. To prevent the radioactive primary sodium from leaking into the intermediate sodium, the IHTS sodium pressure is maintained at a minimum $69 \mathrm{kPa}(10 \mathrm{psi})$, greater than the PHTS within the IHX. The IHTS is also equipped with radiation detectors that monitor for contamination by radioactive sodium. The IHTS instrumentation systems appear suitable to alert operators of a leak condition.

\subsubsection{In-Service Inspection}

Although not required for the non-safety-grade portion of the IHTS, in-service inspection will be in compliance with the ASME Code, Section XI, Division 3. Furthermore, all of the IHTS will be tested for leaks before being initially filled with sodium. The IHTS pressure boundary will then be continuously monitored by leak detection and visual inspection. Attachments for auxiliary systems to the IHTS will be examined at every refueling interval. Radiation monitors will be used in the IHTS hot leg to detect leakage of the primary sodium into the IHTS.

\subsubsection{Research and Development}

The most important component of the IHTS that requires functional testing is the intermediate sodium pump. Pump seizure failures should also be examined by the designer at a later review stage. The pump performance characteristics that will be continuously monitored include sodium flow rate, pump developed head, fluid temperature, discharge and suction pressure, shaft vibration, pump sodium level, pump cover gas pressure, seal vibration, bearing temperature, pump speed, and pump seal oil level. Testing of the IHX, the sole safety-grade system of the IHTS, is described in Section 5.4 of this report. The gimbaled joints used in the IHTS piping for seismic isolation, thermal expansion, and design loadings in the
PRISM will be developed and demonstrated in full-size testing. The IHTS was analyzed as part of the ACS residual heat removal system in Section 5.7 of this report.

\subsubsection{Conclusions}

Although not required for the non-safety-grade portion of the IHTS, in-service inspection will be performed in compliance with the ASME Code, Section XI, Division 3. This sho'ld be satisfactory.

The IHTS pressure boundary will also be continuously monitored by leak detection and visual inspection. On the basis of : s.formation submitted to this point, the PRISM appears to have the basis of a complete inspection program for leakage detection from the primary system to the secondary, and also for leakage from the IHTS. Inspection requirements for the IHX are reviewed in Section 5.4 of this report.

The IHTS, in conjunction with the SWRPRS, is designed to accommodate the steam generator tube rupture sienario. The SWRPRS and other means of controlling sodiumwater interaction are discussed in the following section.

At a later stage of the review, the natural vibration frequencies of the IHTS should be evaluated to preclude any damage from intermediate pump vibration.

The PRISM design appears adequate to prevent the steamsodium reaction from a steam generator tube failure from being forced through the IHTS sodium inlet into the IHX. However, this event should be more clearly and accurately analyzed at the design certification stage. The designer will need to clearly show the hydraulic forces that are involved in preventing reversal of flow and should identify all important components mentioned in the discussion of the event.

\subsection{Steam Generator System}

\subsubsection{Design Description and Safety Objectives}

The steam generator system (SGS) comprises the steam generator, the steam drum, the ixcirculation pump, the leak detection subsystem, and the water dump subsystem. Closely associated with this system are the non-safetygrade ACS discussed in PSID Section 5.7, and the SWRPRS. One SGS serves each reactor module, and the steam produced by three modules is headered together to supply a single turbine-generator (power block).

The steam generator is a vertically-oriented, helical coil, sodium-to-water counterflow, shell-and-tube heat 
exchanger. The unit can transfer $479 \mathrm{MWt}$, generating $6996 \mathrm{kPa}(1000 \mathrm{psig})$ steam at 91-percent quality and $558 \mathrm{~K}\left(545^{\circ} \mathrm{F}\right)$ with steam/water in upflow on the tube side, and $717 \mathrm{~K}\left(83.3^{\circ} \mathrm{F}\right)$ inlet sodium in downflow on the shell side. It is designed and fabricated to the requinements of ASME Code Section VIII, Division 2. Design specifications ans summarized in Table 5.1.

The components of the steam generator are shown in Figure 5.10. It is made from 2-1/4-Cr $-1-\mathrm{Mo}$ steel, and is $20.42 \mathrm{~m}$ (67 ft) in height and $3.66 \mathrm{~m}$ (12 ft) in diameter. The 54.25-m (178-ft)-long, 6.1-m (20-ft)-high tube bundle contains 323 single-walled tubes of $3 \mathrm{~cm}$ (1.25 inches) outside diameter and $2.67 \mathrm{~mm}$ (0.105 in.) wall thickness. The unit includes an internal cover gas space filled with argon to accommodate sodium expansion and mitigate the pressure transients during large SWRs. A cover gas hydrogen meter in the upper head detects small SWRs within the steam generator. Overpressure protection for the steam generator and the steam drum is provided by seven power-operated relief valves located on the steam drum and the main steamline. The valves can be automatically or manually operated to relieve steam pressure and can depressurize the system in less than a minute. The first set starts to open at a setpoint of $7686 \mathrm{kPa}$ (1100 psig).

Table 5.1 ALMR steam generator design specifications

\begin{tabular}{||l|l||}
\hline Characteristic & Specification \\
\hline Steam generator power & $479 \mathrm{MWt}$ \\
\hline Saturated cycle & $6895 \mathrm{kPa}(1000 \mathrm{psi})$ steam \\
\hline Steam outlet quality & $91 \%$ \\
\hline Steam-side design conditions & $7685 \mathrm{kPa}(1100 \mathrm{psi}) @ 589 \mathrm{~K}\left(600{ }^{\circ} \mathrm{F}\right)$ \\
\hline Sodium-side design conditions & $2170 \mathrm{kPa}(300 \mathrm{psig}) @ 742 \mathrm{~K}\left(875{ }^{\circ} \mathrm{F}\right)$ \\
\hline Sodium-side design-faulted condition & $6996 \mathrm{kPa}(1000 \mathrm{psig}) @ 742 \mathrm{~K}\left(875{ }^{\circ} \mathrm{F}\right)$ \\
\hline Material & $2-1 / 4-\mathrm{Cr}-1-\mathrm{Mo} \mathrm{steel}$ \\
\hline Number of tubes & 323 \\
\hline Heat transfer area & $1630 \mathrm{~m}(17,550 \mathrm{ft})^{2}$ \\
\hline Corrosion allowance: & \\
\hline Water side & $0.89 \mathrm{~mm}(0.035 \mathrm{in})$. \\
\hline Sodium side & $0.13 \mathrm{~mm}(0.005 \mathrm{in})$. \\
\hline Flow rates: & \\
\hline Water flow & $1.025 \times 10^{6} \mathrm{~kg} / \mathrm{hr}\left(2.26 \times 10^{6} \mathrm{lbm} / \mathrm{hr}\right)$ \\
\hline Steam flow & $9.30 \times 10^{5} \mathrm{~kg} / \mathrm{hr}\left(2.05 \times 10^{6} \mathrm{lbm} / \mathrm{hr}\right)$ \\
\hline Sodium flow & $8.30 \times 10^{6} \mathrm{~kg} / \mathrm{hr}\left(18.3 \times 10^{6} \mathrm{lbm} / \mathrm{hr}\right)$ \\
\hline Sodium inlet/outlet temperature & $717 \mathrm{~K} / 555 \mathrm{~K}\left(830^{\circ} \mathrm{F} / 540^{\circ} \mathrm{F}\right)$ \\
\hline Design life & $60 \mathrm{years}$ \\
\hline & \\
\hline
\end{tabular}


Reactor Coolant System and Connected Systems

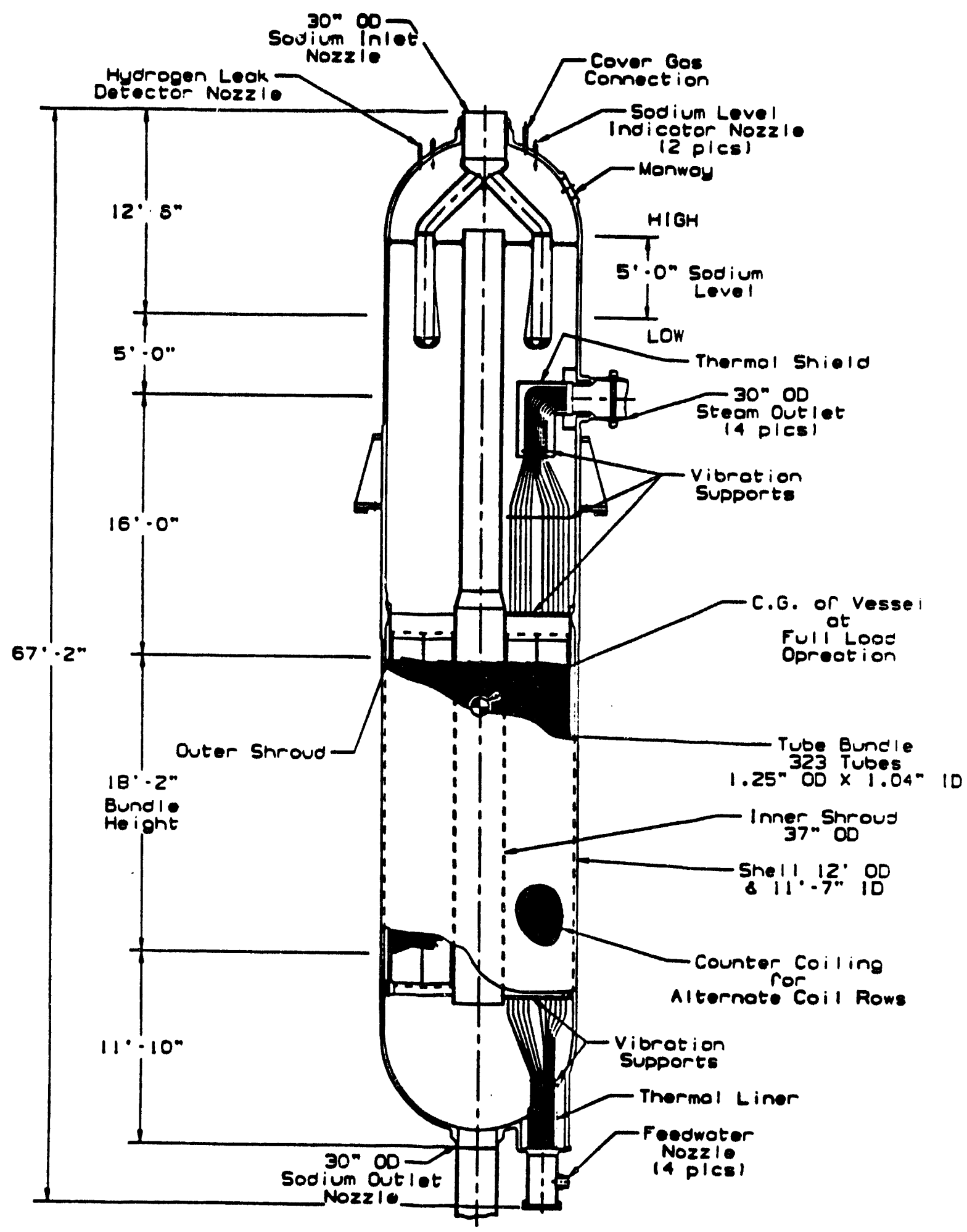

Figure 5.10 PRISM helical coil steam generator 
Hot sodium enters the steam generator vessel through a single sodium inlet nozzle at the center of the upper head and flows into a distribution plenum. The sodium is uniformly distributed and directed downward through distributor shoes (manifolds) located below the minimum operating sodium level. The sodium continues down through the upper plenum along the steam outlet tubes and the free flow area around the tube bundles. Once it leaves the bundles, sodium flows over the feedwater inlet tubes, then exits through the sodium outlet nozzle in the lower vessel head.

The inner shroud serves as a bypass channel to equalize pressure differentials between the inlet and outlet sodium nozzles. The bypass flow channel and the low tube bundle pressure drop are designed to protect the IHX tubes by preventing steam from being forced down the hot leg, into the IHX, by the differential pressure between the inlet and outlet sodium nozzles in the event the steam isolation valves fail to close during a steam generator tube leak.

A steam drum is located $4.57 \mathrm{~m}$ (15 ft) above the steam generator, at grade level, outside the steam generator building. It is fabricated from carbon steel SA516 GR 70 and is approximately $3.66 \mathrm{~m}(12 \mathrm{ft})$ in diameter, $10.36 \mathrm{~m}$ (34 ft) long, and contains two-stage separators and chevron dryers.

\section{Sodium-Water Reaction Pressure-Relief System}

In the event of a steam generator tube rupture, the steam generator depressurizes rapidly through a steam-side and water-side blowdown system which is initiated in conjunction with the sodium dump of the IHTS by the SWRPRS. The SWRPRS, shown in Figure 5.11, consists of two safety-grade $71.12-\mathrm{cm}$ (28-in.)-diameter rupture disks designed to rupture at $2241 \mathrm{kPa}$ (325 psi), a reaction products separation tank (RPST), two sodium dump tanks, a vent stack, and a hydrogen ignitor. The system can accommodate the reaction products, steam, and sodium flows associated with guillotine-type breaks of all the steam generator tubes, with an IHTS backpressure below $4826 \mathrm{kPa}$ (700 psi). Reaction products flow from the lower head of the steam generator through a $76.2-\mathrm{cm}$ (30-in.)-diameter SWRPRS line, through the rupture disks, to the RPST $(4.27-\mathrm{m}(14-\mathrm{ft})$-diameter, $7.01 \mathrm{~m}(23 \mathrm{ft})$ in height, SA-533 low alloy). The liquid and solid reaction products and displaced sodium are separated from gaseous reaction products within the RPST and drain into one of the horizontally oriented sodium dump tanks through two 24-inch-diameter drain lines. The sodium dump tanks (4.27-m (14-ft)-diameter, 10.06-m (33-ft)-long carbon steel) are interconnected by two $60.96-\mathrm{cm}$ (24-in.)- diameter sodium equalization lines and a $76.20-\mathrm{cm}$ (30-in.)-diameter gas equalization line so that the tanks operate as a single volume. Gaseous products are released through the stack and burned as they pass the flare tip ignitor. The designer expects the system to be able to reduce steam generator pressure from $6996 \mathrm{kPa}$ (1000 psig) to $2170 \mathrm{kPa}$ (300 psig) in less than 60 seconds during a tube rupture accident.

Leakage of water or steam or both into the sodium stream is monitored by hydrogen diffusion detectors located in the main sodium outlet and vent lines. Each sodium line contains redundant non-safety-grade detectors. Reactor scram and IHTS valve closure for this event will be accomplished by detection of sodium on the downstream side of the SWRPRS rupture disks as well as safety-grade IHTS pressure sensors located in the nuclear island (NI).

\subsubsection{Scope of Review}

The following submitted material was used in this review:

- Chapter 5 of the PRISM PSID

- responses to NRC comments contained in PSID Appendix $\mathrm{F}$

- Volume VI (Appendix G) of the PSID

- the Steam Generator Concept Selection Trade Study Report (Ref. 5.16)

- the Reliability, Availability, and Maintainability Program Plan (Ref. 5.17)

- supplemental information submitted during the review (Refs. 5.18 and 5.19)

Appendix G of the PSID contains information revising the stean. generator design from that originally submitted in PSID Chapter 5, as well as a discussion of the design-basis steam generator tube rupture event.

SRP Sections 5.4.2.1, "Steam Generator Materials," and 5.4.2.2, "Steam Generator T ibe Inservice Inspection," were considered in this review. These SRPs specifically require conformance to GDCs of $10 \mathrm{CFR}$ Part 50, Appendix $A$, relating to the performance of components serving as portions of the reactor coolant pressure boundary. Although the PRISM steam generators will not carry primary sodium, the safety significance of an SWR (as a threat to the IHX integrity) warrants regard for these $\mathrm{LWR}$ requirements. 


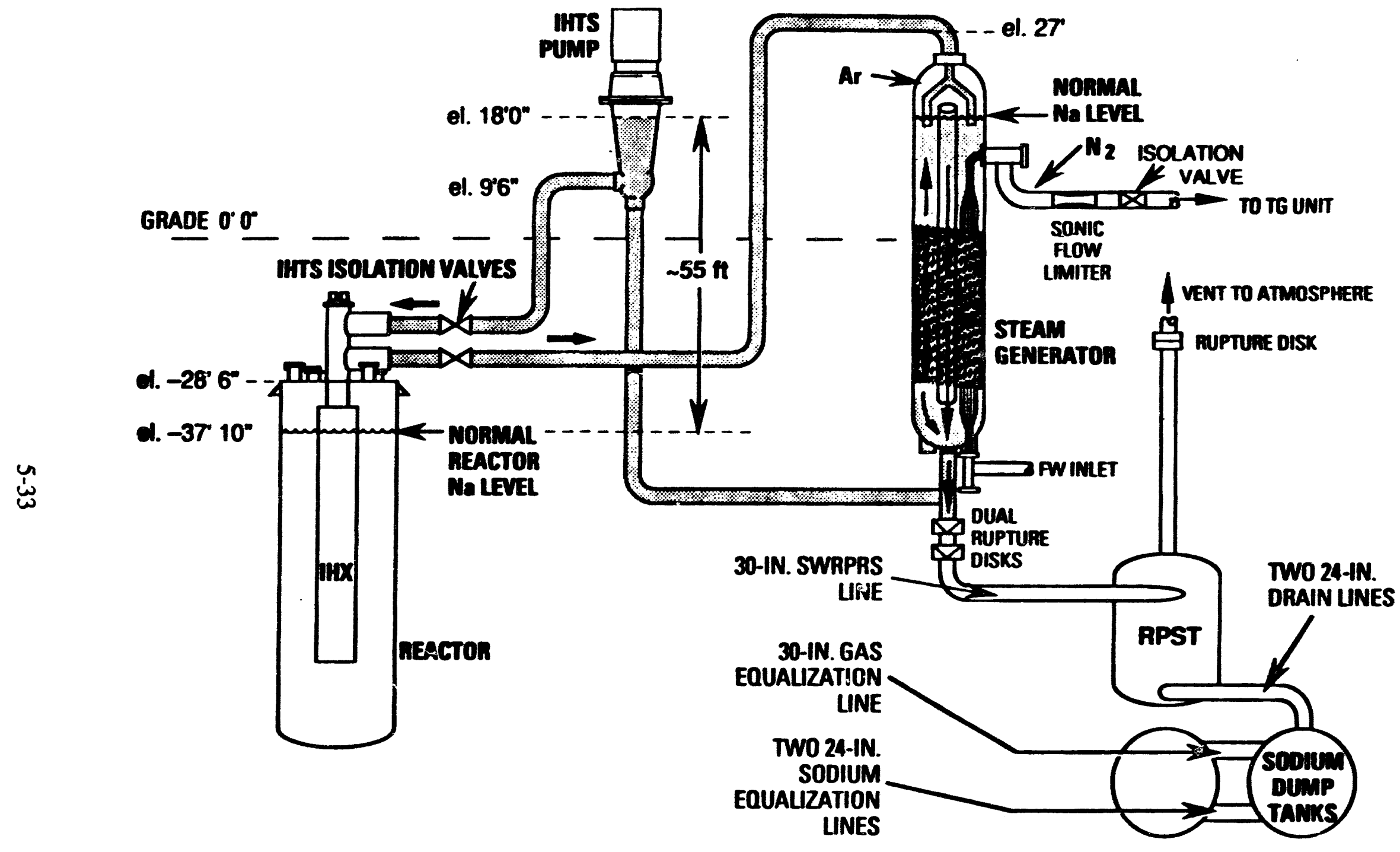

Figure 5.11 PRISM sodium-water reaction pressure relief system (SWRPRS) 
Design standards proposed by ANSI/ANS-54.1-1989, "General Safety Design Criteria for a Liquid Metal Nuclear Power Plant" (Ref. 5.20), were used to provide more specific guidance for review of areas involving unique characteristics of the PRISM. These criteria supplement the design criteria contained in 10 CFR Part 50, Appendix A.

Several design guidelines proposed by the Advanced LightWater Reactor Utility Requirements Document (ALWR Passive Plant) (Ref. 5.21) were referred to in this review. Although intended to address LWR safety or operability issues, these suggestions warrant consideration for their potential for reducing PRISM safety systems challenges. These points do not reflect regulatory positions, but are intended to provide early indication of expected industry design objectives for standard plants.

\subsubsection{Design Criteria}

The PRISM designers have stated that the following RGs will be fully complied with:

- 1.84, "Design and Fabrication Code Case Acceptability - ASME Section III, Division I" (Ref. 5.22)

- 1.85, "Materials Code Case Acceptability - ASME Division I" (Ref. 5.23)

The PRISM designers consider the following RG not applicable to the design:

- 1.83, "Inservice Inspection of PWR Steam Generator Tubes" (Ref. 5.24)

The steam generator will be fabricated to the requirements of the ASME Code, Section VIII, Division 2. The PRISM PSID further states that the steam generator system will be designed to withstand a $0.5 \mathrm{~g}$ peak ground acceleration eurthquake. The steam generator building will be designed as a seismic Category II structure, which is defined by the designer as being evaluated for a $0.5 \mathrm{~g}$ earthquake, and strengthened as necessary to ensure failure will not impair safety-related systems.

\subsubsection{Research and Developm. it}

Testing of the 70-MWt helical coil, prototype steam generator at the Energy Technology Engineering Center ETEC) was discontinued by the U.S. Department of Energy (DOE) in 1989 following $1.6 \times 10^{4}$ hours of operation. In PSID Appendix G, the designer reports that tests were completed for a broad range of conditions covering normal and off-normal unit opera ing conditions.
Post-test evaluations of $\mathbf{4 0}$ tubes are to be specified by the designer.

\subsubsection{Safety Issues}

As discussed in Chapter 10, "Evaluation of Steam and Power Conversion Systems" of this report, balance-of-plant influences on plant safety must be clearly addressed as the design progresses. In the PRISM design, the incorporation of the IHTS negates the role of the steam generator as a part of the primary coolant boundary. Further, the use of the RVACS as the safety-related means for removing decay heat relegates the SGS to a non-safety heat transfer role. Although not intrinsic to safety concerns, the SGS still has an indirect effest upon plant safety in its impact upon IHX integrity.

The steam generator tubes are the boundary between the secondary sodium in the IHTS and the higher pressure steam system. Interaction of sodium and water, which would occur as a result of a steam generator tube rupture, could present conditions in the IHTS (i.e., temperature, pressure, or chemical constituents) which could threaten the IHX unless protective systems perform as expected. Among the subsystems of the SGS designed to respond to such threats to the IHX are the SWRPRS, the leakdetection subsystem, and the water-dump subsystem. Of these, only the rupture disks of the SWRPRS are to be classified as safety-grade.

As discussed in Section 5.6.6 below, it is not clear that the designer's analysis of the proposed worst-case steam generator tube rupture event adequately considers the combined effects of safety system degradation and failure (including rupture disk malfunctions) along with the proposed failures of non-safety-grade systems. A thorough accounting of possible failure modes of SGSassociated safety and non-safety systems which could challenge IHX integrity is essential, since a containment bypass path would be established in the event an IHTS isolation valve failed to shut during a steam generator tube rupture event which damages the IHX.

Other specific areas requiring attintion before future reviews are the consequences of using a single-walled tube, helical coil design, the reliability of the design over its proposed lifetime, and safety classification of components required to mitigate an SWR.

\subsubsection{Evaluation}

The PRISM SGS outlined in the PSID has evolved from a design using straight double-walled tube construction with an integral steam drum, to a helical coil configuration 
using single-walled tubes with a separate steam drum. This fundamental design shift has necessitated a reexamination of the SGS.

Questions regarding failure modes associated with a tube rupture event and the safety classification of the SWRPRS and other SWR-related systems have greater significance in a single-walled tube design. A number of other issues unique to the steam generator were raised during this review and have less obvious safety impact, but should be considered early in the design process to preclude safety questions later. These include the suitability of singlewalled tubes, the implications of a helical coil design versus a straight tube design, and seismic classification of the system.

\section{Sodium-Water Reaction Response}

The reference steam generator design using single-walled tubes has a greater likelihood of leakage than the previous design. Along with this change, however, the design of the IHTS was modified to include safety-grade IHTS isolation valves. As discussed in Section 5.5.1 above, these valves provide protection to the IHX.

Analysis of the proposed worst-case steam generator tube rupture (see Chapter 15 of this report), includes plant response to the event without the IHTS valves shutting as required or the water-side dump operating. The ability of the plant to prevent a pressure challenge to the IHX seems to be predicated on the reliability of the SWRPRS to quickly relieve sodium-side pressure. The current design considers only a limited set of the SWRPRS failure modes (i.e., a pipe break just downstream of the rupture disks) in the analyses of plant response to a tube rupture event, Bounding Event 5 (see Chapter 15 for details). The major function of the SWRPRS to provide a relief path for SWR products is never questioned. The possibility of degradation of this essential relief path due to a deficiency in the non-safety-grade portion of the SWRPRS should be considered. Furthermore, reliability data for the rupture disks will be a required input to support their safety-grade classification.

Although not designed to seismic Category I, the steam generator building is to be evaluated for $0.5 g$ peak ground acceleration (part of the designer definition of seismic Category II). Further, the building will be designed so that any postulated failure of the structure will not affect the operability of the SWRPRS rupture disks or other safety systems. It is not clear how the designer intends to meet this goal, nor is it clear what sort of failures are considered challenges to the building integrity which could impede SWRPRS function. The design must include much more detailed analysis of postulated steam generator building failure modes and their consequences on SWRPRS operability.

Other means of dealing with the SWR situation seem adequate as long as component reliability problems are avoided. The non-safety-related leak detection system, relied upon only for indication and annunciation of small steam-water leaks into the intermediate sodium system, provides no automatic response capabilities. Redundant safety-grade IHTS pressure sensors located in the seismically isolated NI pc. uon of the plant, provide reactor scram and IHTS isolation signals in the event of a sodiumwater reaction. These same automatic responses are initiated by non-safety-grade sodium detectors located between the SWRPRS rupture disks. This leaves the IHTS pressure sensors as the only safety-grade protection signal for reactor scram and IHTS isolation in the event of a major SWR. The combination of the pressure sensor signal and the SWRPRS disks has the potential to provide sufficient protection. Designer evaluation of the designbasis tube rupture event included the assumed failure of the IHTS isolation valves to shut, thus accuunting for a single safety-grade component failure of the valves themselves, or of the pressure-sensing system to produce the required shutting signal. However, future reviews should examine the likelihood for non-safety-grade component failure in the SWRPRS so that the sodium relief, path is degraded or even fully blocked despite the proper functioning of the rupture disks. This scenario would present the possibility of a single failure occurring (IHTS isolation valves fail to shut) during a tube rupture without sufficient sodium relief the degradation or failure of a capacity due to non-safetygrade component. Further, an analytical basis will be required to justify the maximum expected IHTS pressure of $4826 \mathrm{kPa}$ (700 psi) during this event, considering chemical reaction and hydrodynamic effects. This is necessary to ensure that the IHX design pressure of $6895 \mathrm{kPa}$ (1000 psi) provides adequate margin from damage.

\section{Single-Walled Tubes}

The designer, GE, used the reliability estimates presented in the PRISM Trade Study Report (Ref. 5.16) to choose the helical coil steam generator design. The designer estimated that the failure rate of single-walled tubes in a helical coil configuration will be about 25 percent higher than that of double-walled straight tubes $\left(1.5 \times 10^{-3}\right.$ failures per year as opposed to $1.2 \times 10^{-3}$ failures per year). Although the failure rate per tube for single-walled helical tubes is higher than for straight double-walled tubes $\left(5.0 \times 10^{-6}\right.$ as opposed to $\left.0.66 \times 10^{-6}\right)$, the smaller number 
of tubes in the helical coil unit offsets much of this difference when considering reliability per unit. The data used for these estimates were gathered from performance experience in PWR steam generator tubes tempered by expert judgment about the effects of specific design configurations, materials used, and exposure to sodium as a heat transfer medium. Although this assessment is valuable as an initial comparison of design altematives, further analysis using liquid-metal fast-breeder reactor (LMFBR) steam generator performance could confirm this initial assessment.

Designer estimates of the material effects of sodium exposure to the tubes must be well confirmed to ensure their reliability. The major problem faced by $2-1 / 4-\mathrm{Cr}$ 1-Mo alloy in a sodium environment is decarburization and the resultant loss of strength (Refs. 5.25, 5.26, and 5.27). This phenomenon appears to be well documented and is probably not significant for the SGS expected sodium operating temperatures. However, decarburization during long-duration high-temperature transients (e.g., RVACSonly cooling events) should be considered. The long-term impact (i.e., expected component life) of other potential material effects should be considered, such as muss transfer of tube material, effects of impurities in the sodium stream, and changes in other mechanical properties due to expected transients which could shorten expectation of 60-year performance.

\section{Helical Coil Design}

The helical coil design offers perceived advantages over other design approaches, including the straight-tube steam generator. Among these are fewer tubes with larger diameters and greater wall thicknesses, fewer tube-totubesheet welds, easier accommodation of tube-to-tube and tube-to-shell thermal expansion differentials, smaller and thinner tubesheets, mitigation of departure from nucleate boiling (DNB) effects, increased DNB quality and heat transfer (see Refs. 5.25 and 5.28 for helical coil thermalhydraulic discussions), and easier accommodation of an expansion gas space. A prototype helical coil steam generator was tested to demonstrate these benefits. Areas to be addressed in future reviews include available inspection methods for this arrangement, long-term material and structural issues, mechanical effects from steamline breaks or other significant steam plant transients, failure propagation characteristics such as impingement wastage and overheat or blowout of tubes adjacent to the failure, and the magnitude of dynamic pressures resulting from a tube rupture event. Data gathered from operation of this prototype unit, and results of tests performed on it, should be available for future reviews to validate the benefits of the helical coil design and to address the issues listed above.

\section{Seismic Classification}

As discussed previously, the safety significance of the steam generator for the PRISM as compared to conventional LWRs is altered since it is not a portion of the reactor coolant boundary. The safety significance of the PRISM SGS and associated systems rests upon the capability to protect the IHX, a part of the reactor coolant boundary. GDC 2, "Design Basis for Protection From Natural Phenomena," states that systems important to safety must be designed to withstand natural phenomena without losing the capability to perform their safety functions. It is not clear that systems required to respond to an SGS sodium-water reaction, especially the relief path in the SWRPRS, are adequately protected from such natural phenomena as seismic events. The assignment of seismic Category II to the steam generator building must be defined in more detail so that the degree of adherence to GDC 2 may be more clearly determined in future reviews.

The staff compared the SGS with the proposed requirements of the Electric Power Research Institute contained in the Advanced Light-Water Reactor Utility Requirements Document (ALWR Passive Plant). Although intended for application to LWR designs, some of the criteria could be applied to the PRISM design. Section 4 of Chapter 3 of the EPRI document discusses steam generator requirements. Section 4.2.1 requires that the SGS be capable of producing the specified steam mass flow and pressure at full power with 10 percent of the tubes plugged. This possibility has not been addressed at this design stage, but is worth considering as the design matures. Section 4.2.8.1 details requirements for preventing steam generator dryout following a loss of feed, including the capability of the SGS to avoid dryout for 20 minutes following a low-level trip. Although the details of this item may not be applicable to the PRISM SGS (e.g., the necessity for secondary-side low-level trip), potential dryout raises material degradation concerns. The current design information has not addressed this potential problem. Future design refinements should ensure that provisions are made for secondary-side cleaning and adequate access openings as discussed in Sections 4.3.2.3 and 4.4.1.4.1 of the EPRI document. This is pertinent to ASME Code inservice inspection requirements (Ref. 5.29) which the designer has stated will be followed, and is especially important in a component required to operate for 60 years. 
The design criteria proposed by the American Nuclear Society in its, "General Safety Design Criteria for a Liquid Metal Nuclear Power Plant," have clear requirements for systems serving as barriers between sodium and sodiumincompatible materials. Section 3.1.4, "Protection Against Sodium and NaK Reactions," states that "two barriers shall be provided between reactor coolant and fluids not compatible with sodium unless the consequences of failure of a single barrier can be shown to be acceptable."

Although the PSID discussion of the design-basis SWR event for the PRISM provides some assurance of acceptable consequences for a tube rupture, compliance with this statement requires more analysis and consideration of SWRPRS-related systems failure modes and safety classification.

\subsubsection{Conclusions}

Modification of the SGS from a ștraight tube double-walled construction to a helical coil configuration using singlewalled tubes places more emphasis upon the IHX protection role of the steam generator and its associated systems. These systems, namely the SWRPRS, the water dump subsystem, and the leak detection subsystem, are required for IHX protection because they are important in the plant's response to a SWR. The issues raised during this preapplication review all relate to preventing an SWR and mitigating the event should it occur.

Issues specific to the steam generator mainly concern the tube design. Long-term chemical, metallurgical, and mechanical characteristics of 2-1/4 $\mathrm{Cr}-1$ Mo tubes in a sodium envirorment must be understood. Such characteristics of tube failure propagation as impingement wastage and overheat or blowout of tubes adjacent to the failure, and the magnitude of dynamic pressures resulting from a tube rupture event should be known in more detail to ensure that the IHX will not be threatened. Prototype unit operating data and results of tests performed on it should be available for future reviews to validate the design and to help answer such questions. Other LMR operating experience and test facility data should be considered during design efforts to more completely characterize expected SGS component performance.

A number of items concerning the ability of steam generator subsystems to respond to an SWR should be considered as the design matures. It is not clear that the required systems, especially the relief path in the SWRPRS, are adequately protected from seismic events. The assignment of seismic Category II to the steam generator building must be explained in more detail so that the degree of compliance with GDC 2 may be clearly determined. Possible degradation of the SWRPRS relief path in response to other failures should be considered, and reliability data for the rupture disks will be required to support their safety-grade classification. In addition, a more rigorous analytical basis will be required to justify the maximum expected IHTS pressure of $4826 \mathrm{kPa}$ (700 psi) during this event.

The basic SGS design has the potential to ensure its safety function of reactor coolant boundary protection (IHX) during a sodium-water interaction. While the items listed above raise important concerns for the SGS design, they appear to be capable of successful engineering solutions. Increased understanding of SWRPRS failure modes and adequate justification of system classifications in the design would contribute to resolution of these issues.

\subsection{Residual Heat Removal Systems}

\subsubsection{Design Description and Safety Objectives}

Residual heat removal in the PRISM design is accomplished through several alternative means: condenser cooling, active auxiliary cooling, and passive reactor vessel auxiliary cooling. The non-safety-grade condenser cooling and non-safety-grade ACS are used for normal shutdown events. The RVACS, a direct and constant natural circulation cooling of the reactor vessel, is safety grade and is relied upon for sufficient RHR during accidents involving the loss of the ACS and the condenser. A diagram of the three systerns is shown in Figure 5.12.

\subsubsection{RVACS Operation}

The RVACS operates continuously. Outside air at ambient temperature is drawn into the four RVACS inlet ducts the ducts are in a tornado-hardened housing about $4.57 \mathrm{~m}$ $(15 \mathrm{ft}$ ) above the grade - then flows down the silo walls. The airflow turns inward and upward at the bottom of the silo. Heat is drawn from the containment vessel wall and the collector surface separating the downflow and upflow air pathways. The collector surface receives heat by thermal radiation and convection, and is insulated on the outside. The air exits the RVACS at the outlet ducts, located near the inlet ducts. The air flows entirely by natural circulation. During normal operations, the heat transfer rate of the RVACS ranges between 0.7 and $0.9 \mathrm{MWt}$. In situations where the reactor vessel and containment vessel temperatures increase, the heat transfer rate of the RVACS increases to about $2.5 \mathrm{MWt}$. Also, during a temperature increase, expansion of the sodium inboard of the vessel liner raises the sodium level to RVACS overflow slots in the reactor vessel liner, and 


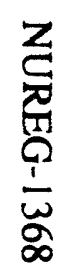

$\grave{\omega}_{\infty}^{u}$

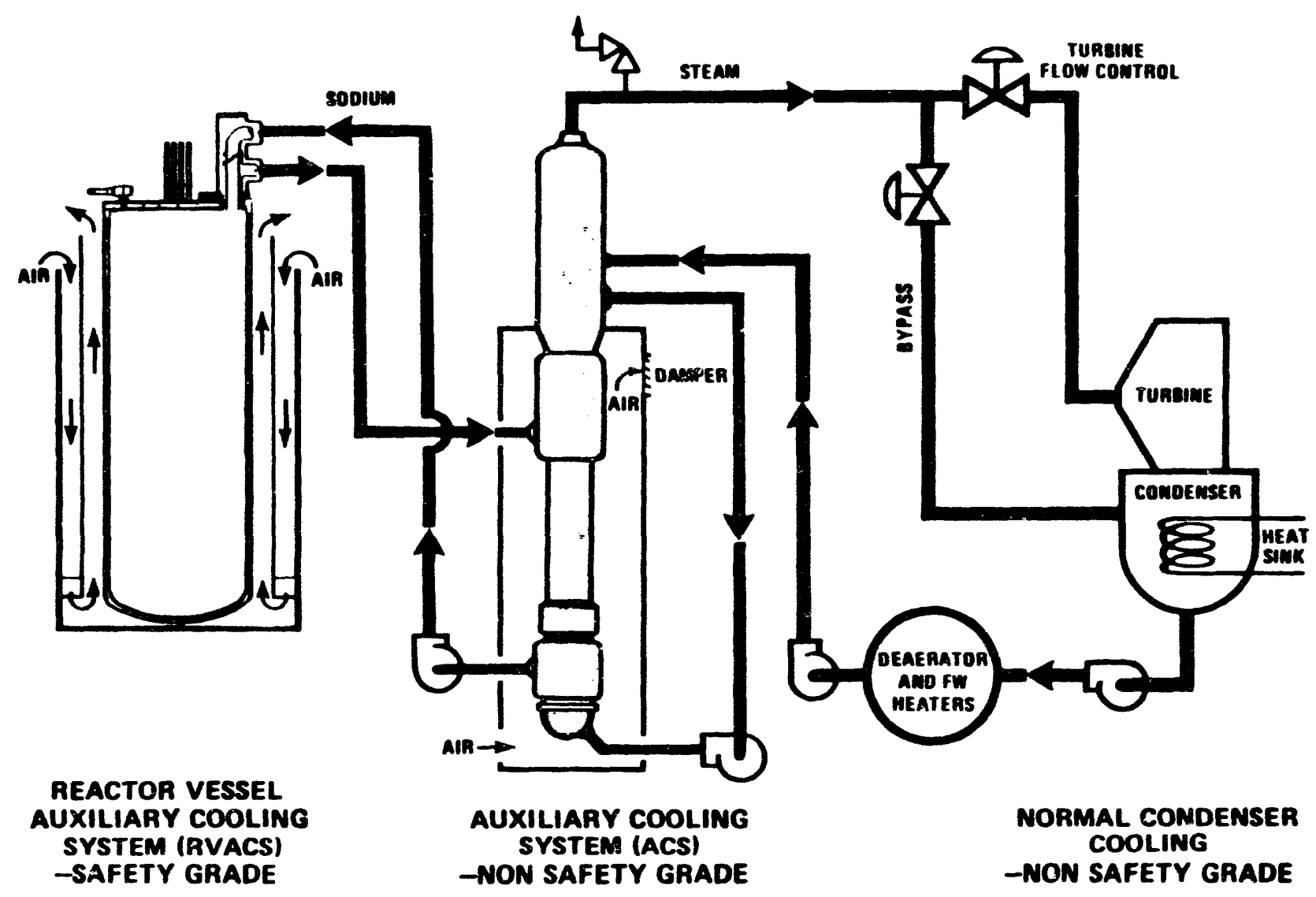

Figure 5.12 PRISM shutdown heat removal system 
natural circulation of the primary sodium commences. This increases heat transfer to the reactor and containment vessels, which augments RVACS heat removal.

\subsubsection{Auxiliary Cooling System Operation}

The ACS is based on natural circulation air-cooling of the steam generator. Operation is initiated by opening the inlet and outlet louvers in the steam generator building. The louvers can be opened remotely, or manually upon loss of power. When the louvers are opened, air flows in at the bottom of the steam generator shroud and passes upward along the outside of the steam generator to the top of the shroud and out the top of the steam generator building. For the ACS to effectively remove decay heat, the louvers must be open, and sodium must be circulating in the intermediate loop. It is not necessary to have water or steam in the steam generators, although an initial volume of water in the steam generator can be evaporated and vented from the steam generator, augmenting the ACS heat removal. The ACS system can operate with either forced or natural circulation flow in the IHTS, as stated in the PSID. The ACS is not safety grade, and is present in PRISM only to help the RVACS remove residual heat when the steam condenser is not available.

\subsubsection{Scope of Review}

The RVACS and the ACS are reviewed in terms of design basis, system design, performance evaluation, tests, inspections, and instrumentation. PSID Section 5.7 and PSID Appendix G were the basis for review for both the RVACS and the ACS. Independent analyses on design changes were also reviewed. The normal condenser cooling system is not considered in this section.

The ACS is a non-safety-grade system and is present in the PRISM mainly for investment protection, that is, to assist the RVACS in effecting a timely cooldown of the vessel. Little analysis of ACS performance by itself has been done. Some testing results analyzing the performance of the A.CS operating simultaneously with the RVACS has been completed, however, by the vendor. The ACS is also discussed in greater detail in Section 5.7.4 below.

\subsubsection{Review Criteria}

In Section 3.1.1 of this report, the staff gives a general approach and criteria for the PRISM review. Further guidance in reviewing the RHR systems is given in the SRP and the GDCs in Appendix A to 10 CFR Part 50.

The following SRP sections were considered in this review:
- 5.4.6, "Reactor Core Isolation Cooling System"

- 5.4.7, "Residual Heat Removal System"

Although the PRISM contains RHR systems quite different from those referred to in the SRP, analogies of certain acceptance criteria from SRP Sections 5.4.6 and 5.4.7 conceptually apply to the PRISM:

- RHR must remove all decay heat required for complete shutdown.

- RHR must remove heat such that fuel damage and sodium boiling are precluded.

- All R.VACS components must be seismic Class 1.

- Provisions must be made for sufficient instrumentation to determine the operability status of the RVACS.

- Reactor internals must not exceed ASME Service Level D limits for postulated RVACS accidents.

The following GDCs were considered in this review:

- GDC 1, "Quality Standards and Records": A quality assurance program for RHR systems w i 11 b e developed. A total quality assurance program will be developed for safety-grade systems like the RVACS.

- GDC 4, "Environmental and Dynamic Effects Design Bases": The RHR system is to be designed to perform its intended function for all reasonable environmental conditions and applicable dynamic effects.

- GDC 13, "Instrumentation and Control": Sufficient instrumentation is required for all parameters necessary to determine the operability and radiation leakage levels of the RVACS.

- GDC 34, "Residual Heat Removal": RHR shall transfer fission-product decay heat at acceptable ASME service limits and suitable redundancy in RHR components shall be provided.

- GDC 39 and 40, "Inspection and Testing of Containment Heat Removal System": Inspection and testing will take place through the continuous monitoring of RVACS heat renoval and periodic visual inspections of airflow channels of RHR systems. 


\subsubsection{Discussion of Safety Issues}

The design-basis RVACS event involves a reactor scram with only RVACS cooling. Analyses submitted by the designer show that the reactor vessel temperature will rise until the RVACS heat removal equals decay heat levels. The time for this equalization to occur is predicted to be about 30 hours. The analysis further predicts sodium temperatures in the vessel that would peak nominally at $880 \mathrm{~K}\left(1125^{\circ} \mathrm{F}\right)$, with a 95 -percent certainty that temperatures would be below $919 \mathrm{~K}\left(1195^{\circ} \mathrm{F}\right)$. These temperatures exceed the ASME Service Level B limit for structures (upset conditions), but are less than Service Leve! C temperatures. These results were confirmed generally in studies initiated by the staff. These elevated temperatures have the possibility of causing correspondingly higher temperatures in the reactor silo of $339 \mathrm{~K}\left(150^{\circ} \mathrm{F}\right)$ and $367 \mathrm{~K}\left(200^{\circ} \mathrm{F}\right)$. The materials used for the silo will require substantial justification owing to these elevated temperatures.

One mode of failure postulated for the RVACS is blockage of the inlet air passages. There are four inlet ducts for the RVACS per module and these ducts enter into a single annular downcomer outboard of the collector surface at the level of the closure head. Main causes for the postulated blockage include ice formation on the inlets, large objects, seismic events, sabotage, and flooding. The PRISM can respond to these events in a number of ways. First, the PRISM includes a sump system at the bottom of the RVACS, under the reactor vessel, to remove water during flooding events. Water that accumulates near the bottom of the vessel and causes blockage can be evaporated by the increased temperature of the containment wall during accident scenarios. The PRISM also incorporates screens and weathercaps for the RVACS inlets to keep large objects and rain from entering. With the PRISM system, there will also be continuous monitoring of the RVACS airflow rates, and inlet and outlet temperatures so that blockage of the RVACS can be recognized and resolved.

For a blockage of just the inlets, an alternative method of heat transfer becomes important. This method is shown in Figure 5.13. In this case, two of the four outlets would become inlets. Air would still circulate by natural convection; however, air would circulate downward near the cool sodium of the EM pumps, and would rise near the hotter sodium of the IHX. Hence, the two outlets near the EM pumps would become inlets, and the outlets near the IHXs would remain outlets. The designer has stated that maximum temperature at the core outlet would reach $904 \mathrm{~K}\left(1168^{\circ} \mathrm{F}\right)$, below Level C limits, and that uncertainties in the analysis might increase this temperature to $960 \mathrm{~K}\left(1268{ }^{\circ} \mathrm{F}\right)$, below Level $\mathrm{D}$ limits. However, analysis of this mode of heat transfer does involve considerable estimates about the air flow around the containment vessel. Blockage of all four outlets would be much more difficult, as ice formation is not possible, and there is no air suction on the outlets as there is on the inlets.

Bounding Event 3 (BE-3), reviewed in Chapter 15, deals with RVACS blockage. The underlying assumption for the RVACS response to this bounding event is that if the RVACS is 100-percent blocked, it must be unblocked in approximately 12 hours. If the RVACS is completely defeated for more than 12 hours, or if no other system can be brought on line in this time period, then temperatures in the core will rise above the ASME Service Level D limit for structures. The Level D limit in the elevated temperature Code Case $\mathrm{N}-47$ is $1099 \mathrm{~K}\left(1500^{\circ} \mathrm{F}\right)$; however, the preapplicant has used $978 \mathrm{~K}\left(1300^{\circ} \mathrm{F}\right)$ in place of the Level $\mathrm{D}$ limit in the conceptual design to allow a margin for uncertainties. However, Code Case N-47 has not been accepted by the NRC and will need to be evaluated during the next stage of review.

Surface degradation is another failure mode postulated for the RVACS. A high-emissivity surface is required on the outer side of the containment vessel for thermal radiation to the collector cylinder. This surface :s created in part by air oxidation at high temperatures. Independent studies initiated by the staff have confirmed the designers' findings indicating satisfactory RVACS performance over the applicable range of emissivities.

The design-basis RVACS transient exceeds ASME Service Level B limits as mentioned above, and the potential for damage to internal components during these transients is raised. The designer predicts a dependence on the RVACS only once in the 60-year life of the plant, and states that one RVACS transient does not reduce the life of the plant or its components. However, the PRISM design excludes safety-grade diesel generators, so it can be reasoned that the probability of station blackout, hence reliance on the RVACS, is higher for the PRISM than for other reactors. The designer is planning to prepare a thermal map of components within the reactor vessel in the prototype during the RVACS transient to determine the effects of these temperature excursions. Furthermore, during thermal mapping of the prototype, it would be quite useful to determine the extent of uneven cooling (hot spots) that may exist during RVACS transients.

The magnitude of the temperature excursions in situations where power is not available can be reduced by making the ACS more reliable. If the ACS is available whenever the 


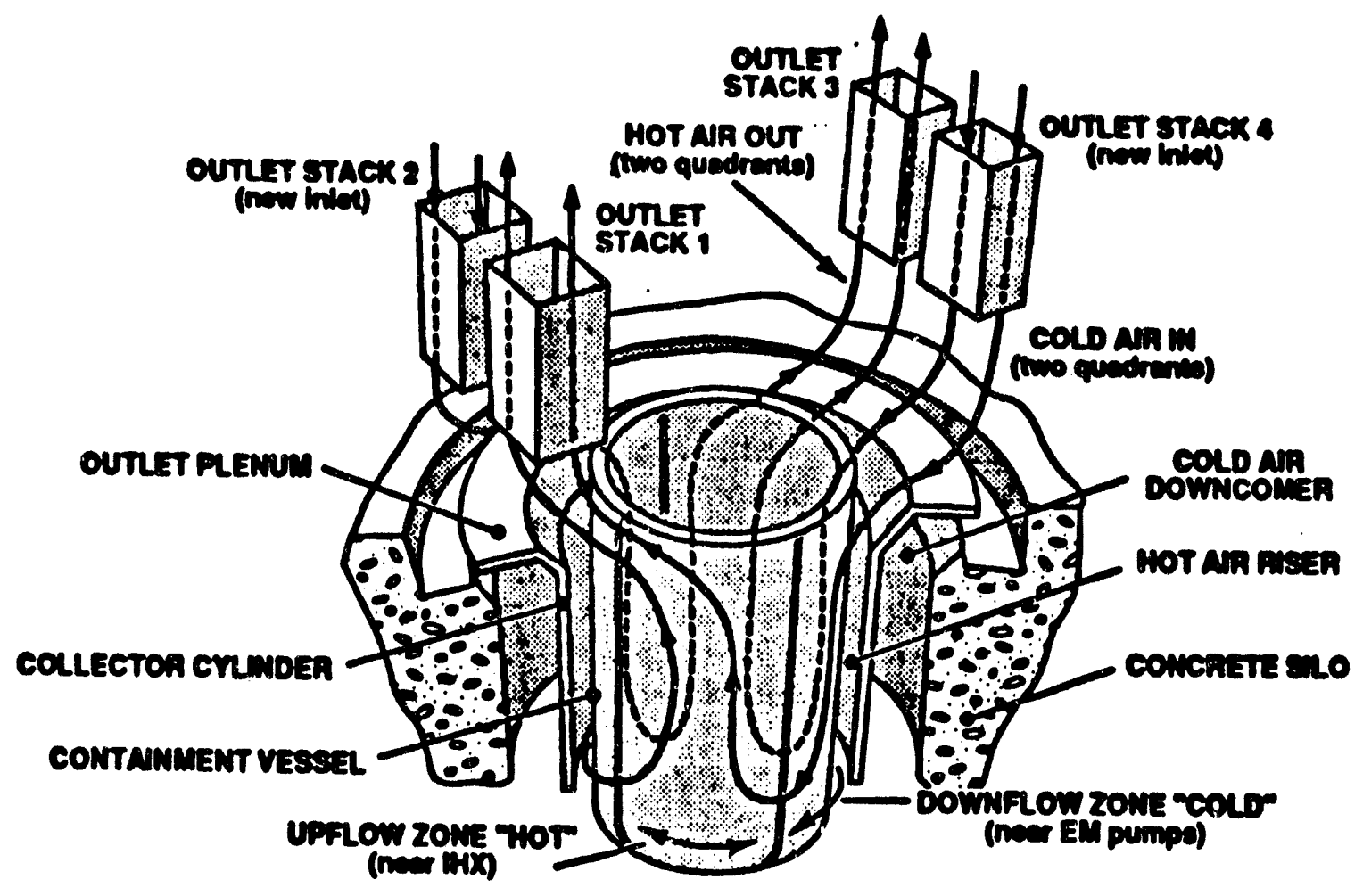

Figure 5.13 Alternative flow model for blockage of RVACS inlers 
RVACS is required, the peak temperatures in the designbasis event would be lowered from $880 \mathrm{~K}\left(1125^{\circ} \mathrm{F}\right)$ to $766 \mathrm{~K}\left(920^{\circ} \mathrm{F}\right)$, slightly above the operating temperature of $758 \mathrm{~K}\left(905^{\circ} \mathrm{F}\right)$. The ACS reliability can be increased by increasing the reliability of the one mechanism involved with the dominant failire mode, the louvers. Increasing redundancy or diversity or both of the louvers and their actuation systems is one option.

\subsubsection{Research and Development}

The performance of full-length annular segments of the air side of the RVACS has been tested at ANL under various operating conditions (Refs. 5.30 and 5.31). Heat transfer correlations were developed for the panels, and testing was done to determine alternative cooling patterns for a blocked RVACS system. These tests have generally supported the adequacy of the RVACS design. RVACS component testing is continuing at ANL. The RVACS will also be tested as part of the safety program for the first PRISM module. If the ANL test results continue to be consistent with predictions, there should be high confidence that the integral tests on the prototype reactor module would be successful. ACS performance should be confirmed during steam generator testing as well as on the prototype module test.

\subsubsection{Conclusions}

Taken together, the thres ystems that can provide RHR are quite reliable, and it appears difficult to disable all three systems. The RVACS is a system that seems able to achieve the required heat removal rates even under degraded conditions. The following conclusions can also be drawn about the RHR systems.

The RVACS appears able to handle the design-basis event and bring the reactor to the hot standby $\left(561 \mathrm{~K}\left(550^{\circ} \mathrm{F}\right)\right)$ condition. The 80 days required to reach hot standby using only the RVACS is considerably longer than for achieving the same state in LWRs and may be at issue as an orderly way to reach hot standby. Therefore, efforts to maximize ACS reliability are prudent, even though reasonable arguments of very high reliability for the RVACS could be made.

Blockage of the RVACS flow passages is the most credible failure mode for the RVACS, and a number of different methods of blockage have been postulated. The principle underlying the blockage scenarios and Bounding Event 3 is that if the RVACS becomes totally blocked, it must be unblocked or an alternate system must become available within about 12 hours. This appears to be sufficient time to unblock the RVACS or operate an alternate system.
Continuous RVACS monitoring becomes very important for detecting blockage in a timely fashion. Therefore, monitoring instruments for the RVACS should be arranged and alarmed in the control room in such a way that if there is a blockage or another problem with the RVACS, it will be recognized in the control room in a timely manner.

The PRISM designers will use thermal mapping techniques in the prototype in response to concerns about magnitude and frequency of high temperatures that accompany RVACS transients. During thermal mapping of the prototype, PRISM designers should also lonk for hot spots in the reactor that develop during the RVACS transient as a result of uneven natural circulation cooling. These temperature excursions can be nearly eliminated if the ACS is reliable enough to be available during the designbasis RVACS event. This can be achieved by increasing diversity/redundancy on the ACS louver system, and including a capability for local manual actuation of the louvers.

\subsection{References}

5.1 General Electric, PRISM-Preliminary Safety Information Document, GEFR-00793 UC-87Ta, November 1986.

5.2 General Electric, "ALMR Structural Materials," Presentation to the Advisory Committee on Reactor Safeguards, May 21, 1992, San Francisco, California.

5.3 U.S. Nuclear Regulatory Commission, "Standard Review Plan for the Review of Safety Analysis Reports for Nuclear Power Plants, LWR Edition," NUREG-0800, July 1982.

5.4 U.S. Nuclear Regulatory Commission, "Control of the Use of Sensitized Stainless Steel, " Regulatory Guide 1.44.

5.5 U.S. Nuclear Regulatory Commission, "Guidance for Construction of Class 1 Components in Elevated-Temperature Reactors," Regulatory Guide 1.87 .

5.6 American Society of Mechanical Engineers, Boiler and Pressure Vessel Code, 1989 edition, Code Case $\mathrm{N}-47, \mathrm{~N}-48, \mathrm{~N}-49, \mathrm{~N}-50, \mathrm{~N}-51, \mathrm{~N}-201$, "Rules for Construction of Nuclear Power Plant Components, " New York.

5.7 Borgstedt, H.U., et al., "The Influence of Liquid Sodium on the Creep-Rupture Behavior of SS AISI 
Reactor Coolant System and Connected Systems

316 L(N)," Proceedings of the International Conference on Fast Reactors and Related Fuel Cycles, October 28 - November 1, 1991, Kyoto, Japan.

5.8 Hanford Engineering Development Laboratory, Nuclear Systems Materials Handbook, (TID 26666), HEDL, Richland, Washington, 1975.

5.9 Lian, S., et al., "A Study of Mass Transfer Behaviors in the Austenitic Stainless Steels Exposed to Sodium at High-temperature, "Proceedings of the International Conference on Fast Reactors and Related Fuel Cycles, October 28 - November 1, 1991, Kyoto, Japan.

5.10 Suzuki, T., and Mutoh, I., "Effects of Metallic and Non-metallic Elements on Corrosion of Stainless Steels in a Flowing Sodium Environment," Proceedings of the International Conference on Fast Reactors and Related Fuel Cycles, October 28 November 1, 1991, Kyoto, Japan.

5.11 U.S. Nuclear Regulatory Commission, "Safety Evaluation Report Related to the Construction of the Clinch River Breeder Reactor Plant, " NUREG-0968, March 1983.

5.12 General Electric Nuclear Energy, "PRISM Reactor Structure Evaluation, " (GEFR - 00832), September 1988.

5.13 Betts, C., Boorman, C., Sheriff, N., "Thermal Striping in Liquid Metal Cooled Fast Breeder Reactors," 2nd International Topical Meeting on Nuclear Reactor Thermal-Hydraulics, Santa Barbara, California, Vol. 2, pp. 1292 to 1301, American Nuclear Society, LaGrange Park, Illinois, 1983.

5.14 U.S. Nuclear Regulatory Commission, "Evaluations of 1990 PRISM Design Revisions," NUREG/CR5815 (BNL-NUREG-52311), March 1992.

5.15 Kwant, W., et al., "Advanced, Self-Cooled Electromagnetic Pump Design and Development for the ALMR Primary System Application," Proceedings of International Conference on Fast Reactors and Related Fuel Cycles, October 28 November 1, 1991, Kyoto, Japan.

5.16 General Electric, "PRISM-Steam Generator Concept Selection Trade Study Report," (GEFR00827 UC-87Ta), July 1988.
5.17 General Electric, "PRISM-Reliability, Availability, and Maintainability Program Plan," (GEFR-00843 UC-87Ta), April 1989.

5.18 Salerno, L.N., General Electric, letter to Nicholas Grossman, Department of Energy, April 13, 1992" (XL897-92071), April 27, 1992.

5.19 Salerno, L.N., General Electric, letter to Nicholas Grossman, Department of Energy, September 1, 1992.

5.20 American National Standard Institute/American Nuclear Society, ANSI/ANS-54.1-1989, "General Safety Design Criteria for a Liquid Metal Nuclear Power Plant," ANS, LaGrange Park, Illinois.

5.21 Electric Power Research Institute-Advanced LightWater Reactor Utility Requirements Document, Vol. III, "ALWR Passive Plant," 1990.

5.22 U.S. Nuclear Regulatory Commission, "Design and Fabrication Code Case Acceptability - ASME Section III, Division 1, " Regulatory Guide 1.84.

5.23 U.S. Nuclear Regulatory Commission, "Materials Code Case Acceptability-ASME Section III Division 1," Regulatory Guide 1.85.

5.24 U.S. Nuclear Regulatory Commission, "Inservice Inspection of Pressurized Water Reactor Steam Generator Tubes, " Regulatory Guide 1.83.

5.25 U.S. Nuclear Regulatory Commission, "Draft Preapplication Safety Evaluation Report for Power Reactor Inherently Safety Module Liquid-Metal Reactor," NUREG-1368, September 1989.

5.26 KaKarala, C.R., and Boardman, C.E., "Advanced Liquid-Metal Reactor Helical Coil Steam Generator," reprint from Thermal Hydraulics of Advanced Heat Exchangers, Vol. 5, American Society of Mechanical Engineers, New York, 1990.

5.27 Lai, G.Y., "High-Temperature Corrosion of Engineering Alloys," ASM International, Materials Park, Ohio, 1990.

5.28 Shields, J.A., Jr., and Longua, K.I., "The Effects of Ten Years of Experimental Breeder Reactor Service on $2.25 \mathrm{Cr}-1$ Mo Steel," Nuclear Technology, Vol. 28, March 1976. 
5.29 Babcock \& Wilcox Company, "Heat Transfer in Coiled Tubes with Two Phase Flow," (4438), August 3, 1964.

5.30 American Society of Mechanical Engineers, Boiler and Pressure Vessel Code, 1989 edition, Section XI, Division 3, "Rules for Inspection and Testing of Components of Liquid-Metal Cooled Nuclear Power Plants," New York.

5.31 Hunsbedt, A., and Boardman, C.E., "ALMR Shutdown Heat Removal Operation Under Degraded Conditions," Proceedings of the International Conference on Fast Reactors and Related Fuel Cycles, October 28 - November 1, 1991, Kyoto, Japan.

5.32 Boardman, C.E., et al., "Convectively Cooled Pressure Containing Low Leakage Containment for the US ALMR," Proceedings of the International Conference on Fast Reactors and Related Fuel Cycles, October 28 - November 1, 1991, Kyoto, Japan.

5.33 U.S. Nuclear Regulatory Commission, "Preapplication Safety Evaluation Report for the
Sodium Advanced Fast Reactor (SAFR) LiquidMetal Reactor," NUREG-1369, December 1991.

5.34 U.S. Nuclear Regulatory Commission, "Advanced Liquid Metal Reactor (ALMR) Structural Materials, "Presentation to the Advisory Committee on Reactor Safeguards (ACRS), San Francisco, California, May 21, 1992.

5.35 U.S. Nuclear Regulatory Commission, "U.S. Advanced Liquid Metal Cooled Reactor (ALMR) Program Safety Approach, Design Summary, and Licensing Status," Presentation to the Advisory Committee on Reactor Safeguards, Bethesda, Maryland, August 6, 1991.

5.36 U.S. Nuclear Regulatory Commission, Code of Federal Regulations, Title 10, "Energy," Part 50, "Domestic Licensing of Production and Utilization Facilities," Appendix H, "Reactor Vessel Material Surveillance Program Requirements."

5.37 J.E. Quinn, General Electric, letter to S.P. Sands, NRC, "GE Comments on NUREG-1368 Preapplication Safety Evaluation Report for the Power Reactor Innovative Small Module (PRISM) Liquid-Metal Reactor," November 29, 1993. 


\section{ENGINEERED SAFETY FEATURES}

\subsection{Design Description and Safety Objectives}

The power reactor innovative small module (PRISM) design incorporates three features that are designed to prevent or mitigate the consequences of an accident: the containment system, the reactor vessel auxiliary cooling system (RVACS), and the head access area (HAA) guard pipes.

The RVACS, a passive shutdown heat removal system, is evaluated in Section 5.7 of this report.

The intermediate heat transport system (IHTS) piping is evaluated in Section 5.5 of this report. The piping has a second or guard pipe that will limit the hazards posed by sodium fires and spill hazards in the HAA. The guard pipes are discussed in this chapter.

The containment system, as modified in Preliminary Safety Information Document (PSID) Amendment 13 (Ref. 6.1), is discussed below, as are site suitability analysis and the proposed source term.

\subsubsection{Containment System}

The containment system is designed to provide a leak-tight boundary that will contain the accidental release of core fission products and primary coolant so that the 10 CFR Part 100 dose guidelines are not exceeded. The containment is designed to withstand the static and dynamic loads resulting from a primary-sodium leak accident. As proposed, the containment system for the PRISM design is not the conventional containment structure used at contemporary light-water reactors (LWRs). Rather, the containment boundary is composed of a containment vessel surrounding the reactor vessel connected to a low-leakage pressure-retaining containment dome above the reactor vessel head, and isolation valves in the intermediate heat transport system (IHTS) piping which penetrates the upper containment. This provides a low-pressure/low volume controlled leakage barrier around the primary system, and represents a departure from current design practice on LWRs and previous sodium-cooled reactor designs. The containment is examined in depth in Section 6.2 of this report.

Figure 6.1 shows the containment vessel and containment dome. The upper dome is a cylindrical carbon steel (SA516 Grade 70) torispherical dome comprising two sections, one resting upon the other. Leakage limits are set at less than 1 percent of the containment dome volume per day at design conditions of $134.4 \mathrm{kPa}(25 \mathrm{psig})$ and $645 \mathrm{~K}\left(700^{\circ} \mathrm{F}\right)$. The 1-inch-thick lower cylindrical portion of the dome is $3.67 \mathrm{~m}(12 \mathrm{ft})$ high and $14.63 \mathrm{~m}$ $(48 \mathrm{ft})$ in diameter. The upper cylindrical portion is
$7.32 \mathrm{~m}(24 \mathrm{ft})$ in diameter and $3.81 \mathrm{~cm}(1.5 \mathrm{in}$.) thick.

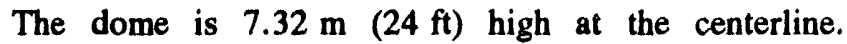
Personnel can access the dome through an airlock. All piping and instrumentation penetrations through the containment dome are located above the reactor primary system boundary and operating sodium level. The mainloop IHTS piping (50.8 cm (20 in.) diameter) is a closed system that penetrates the containment. Each IHTS line has a single safety-grade isolation valve outside the containment dome. In addition to equipment and personnel accesses, four maintenance access ports, and the four IHTS lines, a number of reactor system components penetrate the upper reactor containment:

- electromagnetic (EM) pump cabling

- reactor instrumentation

- five sodium processing lines (3-inch diameter)

- sodium pool cover gas processing line (1-1/2-inch diameter)

- heating, ventilation, and air conditioning (HVAC) refrigerant lines

All piping and instrument penetrations of the containment are located well above the operating primary sodium level. The penetrations are similar to those used in pressurizedwater reactor (PWR) containments, including the mainloop IHTS piping penetrations which have bellows and single isolation valves outside the containment dome. The IHTS isolation valves are designed to meet safety-grade requirements. Open-loop containment penetrations, such as the sodium and cover gas cleanup lines, use double isolation valves. There are no penetrations in the lower cylindrical containment vessel.

The IHTS main loop isolation valves will automatically shut upon detection of a major steam generator leak event in order to protect the intermediate heat exchangers (IHX) from the effects of a sodium/water reaction. The signals to shut the valves will come from two diverse indications: the first will be from the sodium detectors downstream of the sodium-water-reaction pressure-relief system (SWRPRS) rupture discs; the second from redundant safety-grade IHTS pressure sensors located within the nuclear island (NI).

The upper and lower containment boundaries are connected by a horizontal plate at the same elevation as the reactor vessel head. The 1-inch-thick cylindrical lower containment vessel is approximately $6.1 \mathrm{~m}(20 \mathrm{ft})$ in diameter, and made of $2-1 / 4-\mathrm{Cr}-1-\mathrm{Mo}$ steel. It has no 


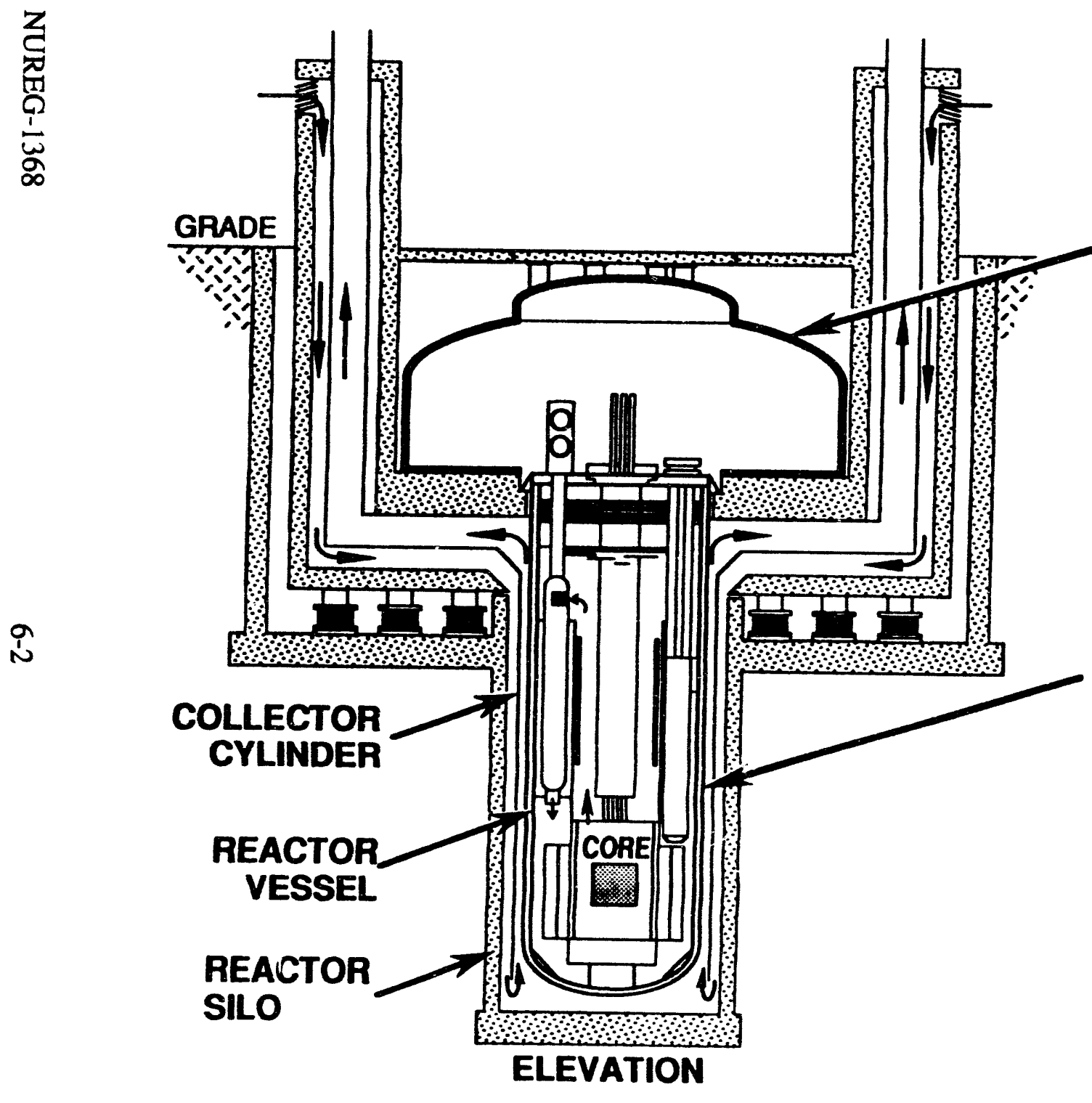

Containment Dome

- ASME Section III, Div. 1, Class MC

- Material - SA 516 Grade 70

- Design Requirements:

$<1 \%$ / day at 25 psig/700 of

Containment Vessel

- ASME Section III, Div. 1, Class MC"

- Material - 2 1/4 Cr - 1 Mo

- Design Requirements:

Zero Leak Rate at 60 psig/800 ${ }^{\circ} \mathrm{F}$

* - Reference 6.26 states that the containment vesse/ will be designed to ASME Section III, Div. 1, Class 1.

Figure 6.1 PRISM reactor containment 
penetrations and is designed to remain leak-tight at $253 \mathrm{kPa}(60 \mathrm{psig})$ and $700 \mathrm{~K}\left(800^{\circ} \mathrm{F}\right)$. The containment vessel is classified as a safety-related seismic Category I structure.

A $12.7 \mathrm{~cm}$ (5-in.) wide gap (annulus) between the reactor vessel and containment vessel is sized to limit the volume of sodium that could be contained between the reactor vessel and containment vessel. Since the primary sodium system is at low-pressure relative to the design pressure of the containment vessel, the annulus should be able to contain a primary sodium leak. The volume of the annulus ensures that the core, spent fuel, and intermediate heat exchanger inlets will remain covered with primary sodium should the reactor vessel leak. This gap is filled with argon gas at $90.4 \mathrm{kPa}$ (12 psig) and monitored with pressure sensors, as well as sodium liquid and aerosol detectors to detect leakags of either vessel.

\subsubsection{Containment During Maintenance}

Unlike an LWR, the PRISM reactor cannot be opened to the atmosphere during refueling or maintenance. The design maintains a sealed primary coolant boundary to prevent air from reaching the sodium pool and initiating a sodium fire. The containment dome is fitted with four ports to allow access for maintenance activities. These ports are sized to permit refueling and the removal and replacement of small equipment. Refueling operations are performed using a hardened refueling enclosure (RE), and the primary system remains closed by means of dual isolation valves. The $\mathrm{RE}$ extends the containment boundary as shown in Figure 6.2; however, the enclosure is vented and is designed to allow controlled leakage. Replacement of the IHX and EM pumps requires cutting and subsequent rewelding of the upper portion of the containment dome (expected to be done once during plant life). During normal reactor operation, the containment dome access ports are sealed with a mechanically secured seal plug.

Before a refueling or maintenance operation is performed, the primary system is cooled to $478 \mathrm{~K}\left(400^{\circ} \mathrm{F}\right)$ and the cover gas is replaced. A transfer adapter is positioned on the reactor closure head, providing a leak-tight transfer path between the reactor and the fuel or equipment transfer cask, which is in the RE, as shown in Figure 6.2. The transfer cask, transfer adapter, and their associated isolation valves serve as the primary system boundary during maintenance activities. During maintenance, the primary sodium purification system (PSPS, discussed in Chapter 9) which draws suction from the normal primary coolant system is used to remove impurities from the radioactive primary sodium. In effect, the PSPS becomes an extension of the primary coolant and containment boundaries and, as such, is designed as a safety-related system.

\subsubsection{Source Term and Site Suitability Analysis}

A stated goal of the designer is to develop source terms from mechanistic analyses and use these source terms to evaluate containment performance and off-site doses from events. The designer continues to refine its source term, but used these assumptions for design-basis analysis (Ref. 6.1):

- Release to the containment dome is assumed to occur at time zero of the event.

- A leak path forms in the reactor closure as a result of an unidentified cause, allowing cover gas to be released into the containment volume and air to enter the cover gas region, initiating a sodium fire.

- The complete core and in-vessel stored fuel melts, uniformly distributing fission products in the primary coolant.

- The sodium fire continues until all the oxygen in the containment dome is consumed.

The source term selected for containment performance analysis was estimated on the basis of oxide fuel information. The source term used for the design-basis analysis is provided in Table 6.1.

As discussed in the following section, containment performance has been assessed, and the findings were that doses from the design-basis accident (DBA) would be maintained within acceptable levels. This analysis was performed using computer codes, some modified to perform analyses for liquid-metal reactors. The designer used the CONTAIN Code to estimate the magnitude of radionuclide release, and the SMART Code to determine containment release levels and the resulting site boundary dose. Dose estimates were calculated for a period of one week, yielding values for dose at the site boundary at onehalf mile. Table 6.2 provides the results using weather conditions specified in Regulatory Guides (RGs) 1.3 and 1.4 (Ref. 6.2) for the first 8 hours. 


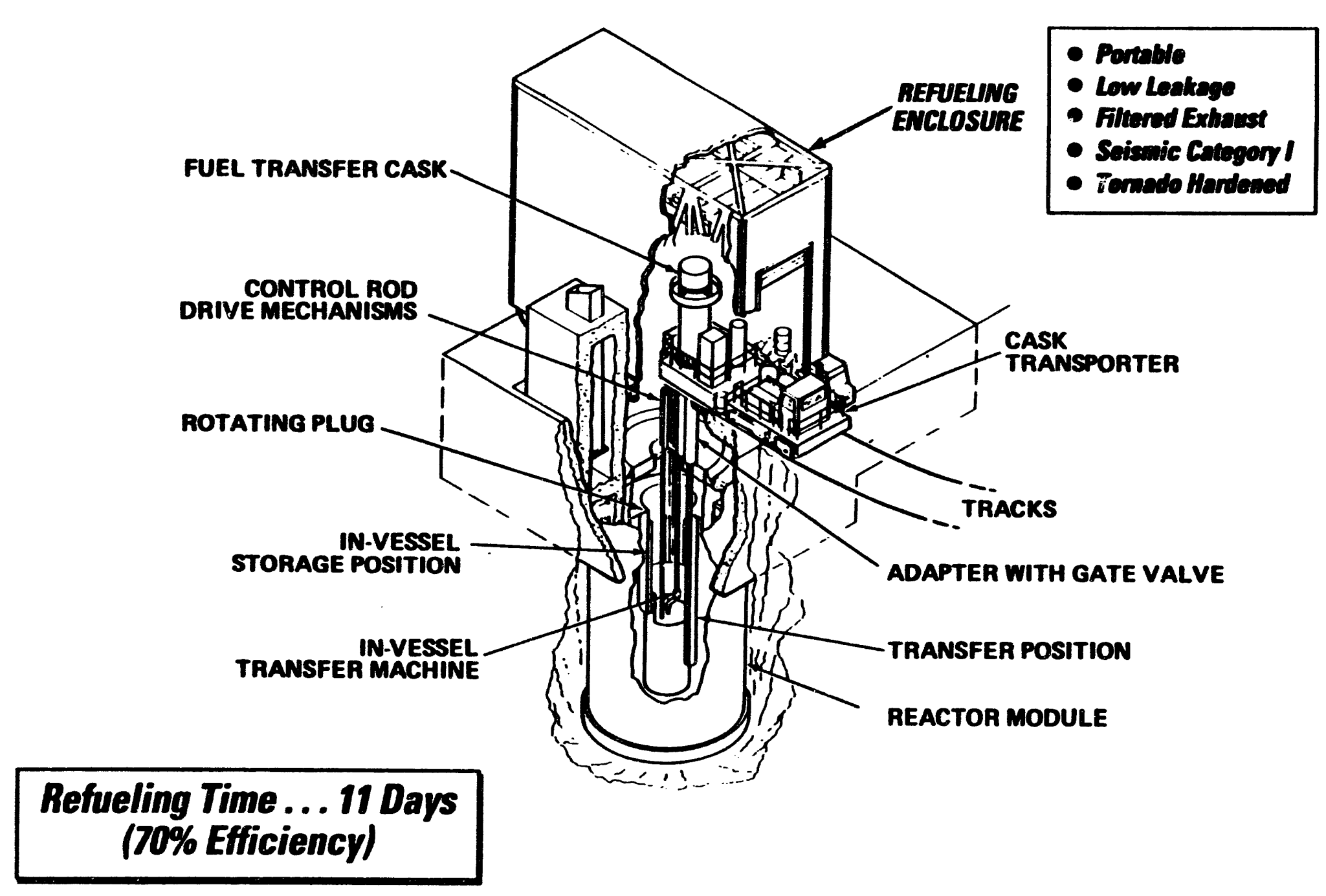

Figure 6.2 PRISM reactor refueling system arrangement 
Table 6.1 Source term used for design-basis analysis

\begin{tabular}{|c|c|c|}
\hline & \multicolumn{2}{|c|}{ Percent Reactor Inventory } \\
\hline Materials Released to Containment & Early Release (0-10 sec.) & Due to Fire (to 6 hrs.) \\
\hline Noble Gases (Xe, $\mathrm{Kr})$ & $100 \%$ & $0 \%$ \\
\hline Halogens $(\mathrm{Br}, \mathrm{l})$ & $0.1 \%$ & $0.8 \%$ \\
\hline Alkali Metals (Cs, Rb) & $0.1 \%$ & $1.6 \%$ \\
\hline $\mathrm{Te}, \mathbf{R u}$ & $0.1 \%$ & $0.004 \%$ \\
\hline $\mathrm{Sr}, \mathrm{Ba}$ & $0.01 \%$ & $0.0016 \%$ \\
\hline Fuel \& Other Fission Products & $0.01 \%$ & $0.0008 \%$ \\
\hline $\mathrm{Na}-22, \mathrm{Na}-24$ & None & $0.4 \%$ \\
\hline \multicolumn{3}{|l|}{ Energy Sources: } \\
\hline Sodium Fire (in Reactor) & None & $\begin{array}{l}\sim 773 \mathrm{~kg}(1700 \mathrm{lbs}) \text { sodium } \\
\text { consumed }\end{array}$ \\
\hline \multicolumn{3}{|l|}{ Leak Rate: } \\
\hline & $\begin{array}{l}<1 \% / \text { day @ } 172 \mathrm{kPa}(25 \mathrm{psig}), \\
645 \mathrm{~K}\left(700^{\circ} \mathrm{F}\right)\end{array}$ & $\begin{array}{l}<1 \% / \text { day @ } 172 \mathrm{kPa} \\
(25 \mathrm{psig}), 645 \mathrm{~K}\left(700^{\circ} \mathrm{F}\right)\end{array}$ \\
\hline
\end{tabular}

Table 6.2 Dose estimates for the first 8 hours

\begin{tabular}{|c|c|c|}
\hline Organ & Dose (rem) & \%PAG (Lower-Level) \\
\hline Whole Body & 0.19 & 18.6 \\
\hline Bone Marrow & 0.22 & 17.6 \\
\hline Lung & 0.51 & 40.7 \\
\hline Thyroid & 0.87 & 17.3 \\
\hline
\end{tabular}

Note: These values are the sum of inhalation and direct exposure doses, as well as exposure from ground deposition for one week, and are considered conservative by the designer.

\subsubsection{Containment Performance}

The PRISM advanced liquid-metal reactor (ALMR) design incorporates features intended to provide defense in depth for a range of severe accidents, including hypothetical core-disruptive accidents (HCDAs). The ability of the containment design to effectively provide protection from excessive fission-product release is largely based on the development of a mechanistic analysis of the source term, which is based on the present site suitability source term developed by $\mathrm{GE}$.

Preliminary assessments performed by the designer and confirmed independently indicate that, for the specified 
source term, the design should withstand the effects of extreme events. The proposed design-basis event is a large primary system breach (from an undefined initiating event), accompanied by a sodium pool fire. An assumed primary boundary breach leads to a release of fission products when the helium cover gas escapes to the containment volume and air enters the primary system. Contact of sodium with the air initiates a sodium fire which continues until all the available oxygen in the containment volume is consumed. The preliminary analyses of this event, using the designer's source term, show that the design provides margin for containment temperature and pressure conditions, and that the releases are within Protective Action Guideline limits (PAG) (Ref. 6.3).

The preapplicant also postulated a maintenance accident to demonstrate the capability of the maintenance containment configuration. During a postulated EM pump replacement, the transfer adapter is removed without installing the replacement EM pump. This would leave a large opening in the primary system, allowing air to enter the vessel, causing a sodium pool fire. The fire is terminated after an hour by nitrogen inerting of the vessel cover gas region (the containment atmosphere is not inerted directly). This is a function of the fire protection system described in Chapter 9. The vessel cover gas, containment volume, and refueling enclosure volumes are then purged through the refueling enclosure by the standby gas treatment system. More than 99 percent of the sodium aerosols are expected to be removed from the vented gas by the particulate filters on the standby gas treatment system. The designer's analysis of this event concludes that releases will be within the limits of 10 CFR Part 100 .

\subsubsection{Guard Pipes}

Guard pipes surrounding the IHTS and PSPS piping prevent intermediate sodium leakage into the head access area (HAA or upper containment volume) in case of a piping leak. The guard pipes are sealed at the reactor closure and the containment wall.

The designer states that the guard piping will be designed in accordance with American National Standards Institute (ANSI) B31.1, following RG 1.26 (Ref. 6.4). The design purpose of the guard piping in the HAA is to provide investment protection by assuring that neither radioactive primary sodium nor secondary sodium can enter the containment volume in the event of a leak in either of the sodium systems. Continuous leak monitoring of the interpipe (system piping/guard piping) annulus will be provided by sodium detectors, and insulation material will be situated within the inter-pipe annulus.

\subsubsection{Leak Testing and Inspections}

The designer plans to perform integrated leak tests on the upper containment dome to ensure that it meets leakage rate design criteria (Ref. 6.5). The test to be used will be a Type A integrated leakage test as defined in ANSI/American Nuclear Society (ANS)-56.3-1987 and is intended to meet the requirements of 10 CFR Part 50, Appendix J, as applicable to the PRISM design.

The integrity of the lower vessel is to be assured by continuous leak detection and periodic visual inspection (Ref. 6.5). Approximately one-third of this inspection will be performed every 3 years, so that 100 percent of the vessel welds are examined over a 10-year period. Most of the welds will be inspected from the outer surface using a remotely operated miniature television camera. Welds on the uppermost portion of the vessel will be examined from within the RVACS plena using a television camera. Details of these tests and inspections are not complete, however the preapplicant intends to satisfy the applicable code requirements listed above.

\subsection{Scope of the Review}

PRISM PSID, Chapter 6, "Engineered Safety Features, " and portions of Chapter 5, "Reactor Coolant and Connected Systems," which dealt with the containment vessel, as well as Section 9.5, "Auxiliary Liquid Metal Systems," describing the PSPS, Sections G.4.1 and G.4.16 of Volume VI, and Section F-6 of Volume V were used for the review of containment capability. Review emphasis and requests for additional information addressed proposed design changes and bounding event reanalysis, combustible gas sources and mitigation measures for the containment dome volume, containment configuration during maintenance, design code applicability of the containment dome, containment vessel temperature limits and margins to limits during degraded RVACS operation, fission product inventory and source term development.

The following standard review plan (SRP) sections (Ref. 5.6) provided guidance for review of this area: 3.2.2, "System Quality Group Classification; " 3.6.1, "Plant Design for Protection Against Postulated Piping Failures in Fluid Systems Outside Containment;" 3.6.2, "Determination of Rupture Locations and Dynamic Effects Associated With the Postulated Rupture of Piping;" 3.8.2, "Steel Containment;" 6.2.1, "Containment Functional Design;" 6.2.2, "Containment Heat Removal Systems;" 6.2.4, "Containment Isolation System;" and 6.2.5, "Combustible Gas Control in Containment." Branch Technical Position (BTP) RSB 5-1 (part of SRP Section 5.4.7 of Ref. 6.6), "Design Requirements of the Residual Heat Removal System," was used to clarify 
isolation guidance for zuxiliary systems containing primary coolant. These SRP sections specify conformance of the containment system to General Design Criteria (GDC) 1 , 2 , and 4 (which relate to design of equipment and systems important to safety), GDC 16 and 50 (which give the basic containment functional design requirements), GDC 38,39 , and 40 (which detail the containment heat removal system requirements), GDC 41,42 , and 43 (concerning combustible gas control in containment), and GDC 54 through 57 (relating to lines penetrating containment). GDC 64 requires means for monitoring the reactor containment atmosphere for release of radioactive contamination. These GDC are contained in 10 CFR Part 50, Appendix A.

Design standards proposed by ANSI/ANS-54.1-1989, "General Safety Design Criteria for a Liquid Metal Nuclear Power Plant" (Ref. 6.7), were used to provide more specific guidance for review of areas involving unique characteristics of PRISM. These criteria supplement the design criteria contained in $10 \mathrm{CFR}$ Part 50, Appendix A.

\subsection{Design Criteria}

In Section 1.8 of the PRISM PSID, the designer states that at least the intent of the following RGs will be met: - 1.11 "Instrument Lines Penetrating Primary Reactor
Containment" (Ref. 6.8)

- 1.29 "Seismic Design Classification" (Ref. 6.9)

- 1.57 "Design Limits and Loading Combinations for Metal Primary Reactor Containment System Components" (Ref. 6.10)

- 1.60 "Design Response Spectra for Seismic Design of Nuclear Power Plants" (Ref. 6.11)

- 1.61 "Damping Values for Seismic Design of Nuclear Power Plants" (Ref. 6.12)

- 1.63 "Electric Penetration Assemblies in Containment Structures for Nuclear Power Plants" (Ref. 6.13)

- 1.87 "Guidance for Construction of Class 1 Components in Elevated Temperature Reactors" (Ref. 6.14)

- 1.141 "Containment Isolation Provisions for Fluid Systems" (Ref. 6.15)
The review noted that the General Electric Company (GE) does not consider RG 1.7 (Ref. 6.16), "Control of Combustible Gas Concentration in Containment Following a Loss of Coolant Accident," to be applicable to PRISM. The staff has not determined the applicability of RG 1.7 (see Section 6.5.2 of this report).

Section G.4.1 of the PSID indicates that the containment vessel and dome are designed in accordance with Subsection NE of the American Society of Mechanical Engineers Boiler and Pressure Vessel Code (ASME Code), Section III, Division 1 for class MC components (Ref. 6.17). However, the preapplicant states in Reference 6.26 and in the PSID (Section 5.2.2.2 and response to Comment $f .9$ of Section 5 to Appendix F) states that the containment vessel will be designed according to Subsection NB of the ASME Boiler and Pressure Vessel Code, Section III, Division 1 for Class 1 components, as well as the elevated temperature code cases $\mathrm{N}-47$ through $\mathrm{N}-50$ since the vessel will be exposed to temperatures above $700 \mathrm{~K}\left(800^{\circ} \mathrm{F}\right)$.

Chapter 1 of the PSID outlines safety design criteria in Section 1.2.1.2. This includes the requirement that design of the containment will ensure that dose guidelines equivalent to $10 \mathrm{CFR}$ Part 100 are not exceeded. The containment, its penetrations, and the containment heat removal system (RVACS only) will accommodate conditions resulting from a sodium leak and fuel plenum fission gas release. The containment pressure boundary will be designed so that under all normal and postulated accident conditions, its materials behave in a non-brittle manner and it reflects consideration of service temperatures and other service conditions of the containment boundary during these operating conditions.

\subsection{Research and Development}

Reservations about the original containment design (e.g., no containment dome) were based upon the results of four bounding events (BEs) that were evaluated against proposed containment performance criteria. The updated proposed containment design is still unique, compared to conventional LWRis. The bounding events have been analyzed for the updated design indicating performance improvements. But the basis of containment performance requirements, the nature of the source term, is not yet thoroughly verified. The importance of these source term data to the containment design is discussed in Section 6.5.5.

In Appendix G of the PSID, GE has identified activities under the safety and licensing research and development plans which address containment evaluations. These include characterization of radionuclide transport, retention 
of radionuclides in the primary sodium, and other activities. This work, along with the planned Integral Fast Reactor (IFR) development effort, is required to provide the basis for the mechanistic source term upon which PRISM containment performance analyses are based. The source term is evaluated in Section 6.6 and accident analysis is discussed in Chapter 15 of this report.

Evaluation of available information indicates that further development work should be considered in order to provide the requisite confidence in the proposed containment design before applying for formal design certification. The IFR fuel development program is important to most of the information requirements. Characterization of the containment DBA depends upon expected metal fuel behavior under abnormal conditions. The ability of the core to withstand core melt and large reactivity insertion during accidents hinges upon the fuel characteristics. The IFR program is the means to provide information on the metal fuel.

Further information on vessel material performance will be needed to ensure that the containment vessel will serve as specified under postulated operating and accident conditions throughout the proposed plant lifetime. The effects on the containment boundary of long-term radiation exposure combined with possible exposure to hightemperatures, environmental effects, and other challenges must be well understood. The specific areas of vessel and dome material fracture toughness and long-term hightempurature effects (over the proposed plant lifetime) are discussed in this review. This added materials research and development effort could provide sufficient information to give adequate assurance of design attributes.

\subsection{Safety Issues}

The unique approach that the PRISM design uses to provide a containment function presents several design challenges. These include providing the ability to avoid conditions resulting in containment breach, ensuring containment boundary integrity for all postulated conditions, and ensuring that the containment can function during maintenance activities.

\subsubsection{Response to Challenges}

Should a core-melt or fuel-dislocation event occur, the size of the containment and its proximity to the reactor could result in a challenge to containment integrity. The proximity of the reactor vessel to the containment vessel could subject the containment vessel to the effects of a primary boundary breach. Such an event in the form of an ex-vessel core melt could damage the containment vessel, increasing the risk of allowing a path for fission-product release through the RVACS system. Avoiding this situation requires attention to the prevention of core damage. Recent design changes address this by

- incorporating provisions to prevent BEs of concern from leading to core damage

- adding features to preserve primary system integrity in case of HCDAs or core melt

- introducing the containment dome and IHTS isolation valves which, along with the containment vessel, will provide a containment system surrounding the primary system

The staff found that four BEs severely challenged the original containment design: $\mathrm{BE}-1$ (inadvertent withdrawal of all control rods with failure to scram), BE-3 (loss of all decay heat removal for 36 hours), BE-4 (instantaneous loss of flow from one primary pump with failure to scram), and BE-7 (flow blockage of a single fuel assembly). Along with design changes, the designer presented updated analyses of these events in slightly modified form. The staff analyzed three of these BEs independently (Ref. 6.18) to determine if fuel melting could be avoided (the detailed analyses are discussed in Chapter 15 of this report). The designer analysis of BE-1, redefined as two cases, $\mathrm{BE}-1 \mathrm{~A}$ and $\mathrm{BE}-1 \mathrm{~B}$, indicates that localized fuel melting would occur. The analyses of the other BEs indicate that the design changes preclude fuel melting. The staff's independent analyses of these events largely confirm the findings. Unknowns in the design and fuel behavior dictate that a significant margin be maintained to challenging containment integrity. Further, the containment DBA should include a substantial challenge to the containment vessel as well as to the dome. This could include direct containment heating from sodium or core-melt impingement or both. However, before a definitive conclusion can be drawn in a formal design certification review, further information is required from the significant research and development effort for the metal fuel.

\subsubsection{Containment Atmosphere and Combustible Gas Control}

Although the design includes a nitrogen purge system for the key "reactor" cover gas region, it does not include a direct means of containment atmosphere cleanup or containment volume combustible gas control during operation. GDC 41, "Containment atmosphere cleanup," requires that systems be provided to remove fission products or control combustible gas concentrations which could threaten containment integrity. This same 
requirement is stated in Section 3.5.11 of ANSI/ANS-54.1-1989, with the additional suggestion that sodium leak effects and the potential for oxygen reaction or hydrogen generation be considered. The preliminary PRISM design information indicates that the potential for combustible gas generation should be precluded by design. GDC 64 states that means should be available for monitoring the containment atmosphere for contamination. The issue of containment atmosphere monitoring and cleanup remains, and must be addressed in subsequent design review.

\subsubsection{Containment During Maintenance}

The proposal to use a temporary vented containment structure during refueling and maintenance activities differs from current LWR-related containment regulatory practice. As the design is refined and further event analyses are performed, the extent to which containment integrity will be required during maintenance will become more clear. The current level of design detail cannot be used to conclusively assess the adequacy of this approach, but this area will need to be addressed in any future formal applications.

\subsubsection{Material Characteristics}

The close proximity of the containment vessel to the reactor core, as well as the proposed 60-year lifetime of the PRISM plant, require that containment material properties be well understood for expected operational and accident conditions. Low fast-fluence levels are anticipated at the containment vessel (see response to Comment 5.29(d) of PSID Appendix F). Verification of these fluence levels will include consideration of core internal design changes (such as the gas expansion modules (GEMs)). Analysis must be performed to understand the performance of the steel to be used for the vessel. Also, during duty-cycle events that rely on RVACS-only cooling, temperatures in excess of the design value may be encountered by the vessel and its supporting structures. ASME Code Case N-47 analysis accounts for any creep effect, but not for the entire 60-year lifetime. Further, the combined effects of high-temperatures, irradiation, and undetermined corrosion effects must be considered.

\subsubsection{Source Term}

In the past, the magnitude and type of fission-product release to the containment have been determined according to the methods of Technical Information Document (TID)-14844 (Ref. 6.19). This source term has been integral to a conservative design approach that was used to account for unknowns in developing reactor technology, such as the type of material released from the fuel and paths it would follow to the environment. The effect of this approach has been to ensure that a high-strength, lowleakage structure is provided to preclude a large release to the environment. The availability of more detailed knowledge concerning LWR fission-product release and transport have begun a trend toward more realistic treatment of the source term.

Supporting information for the PRISM source term, metalfuel behavior under adverse conditions, as well as the overall source term itself, is still being developed (Ref. 6.5 discusses updates to the PSID Appendix 13 source term). Although methods of estimating the release of the containment atmosphere to the environment for a containment breach have been adapted to PRISM, the starting point for this effort is the source term. PRISM source-term formulation is not yet sufficient to perform a reliable assessment of the release of fission products to the containment atmosphere.

Until the Commission makes a final determination on the acceptability of mechanistic source-term analysis, and the designer has more complete metal-fuel failure data, which will permit a definitive source-term approach, the PRISM containment design cannot be conclusively assessed.

\subsubsection{Containment Isolation}

The means to isolate the containment received significant special attention for this review. The use of a single isolation valve for each IHTS line will need to be substantiated by additional information on the IHX reliability. Unknowns must be resolved concerning IHX long-term performance in the reactor vessel environment, IHX response to conditions inside the reactor vessel during accident sequences, and plans for inservice inspection and testing of the IHX before parallels to PWR steam system isolation schemes can be drawn. The operation of isolation systems will be examined at a later stage in the design review to ensure that they operate when required, perform their function for the duration of any challenge, and satisfy safety-grade design requirements.

\subsubsection{Containment Penetrations}

Design effort should carefully consider the classification and code applicability of containment penetrations and those components required to maintain leak-tight integrity. The designer acknowledges that specific details of the guard pipes to containment dome interfaces need to be developed. The design should clearly define the code applicability of each part of the containment system so that the suitability of the design can be determined. 


\subsection{Evaluation}

\section{Review Criteria}

The containment performance criteria to he applied during certification review continue to evolve. In addition to meeting onsite and offsite radionuclide release limits for the design-basis event categories detailed in Chapter 15, the design must conform to defin $\nsim$ release and leakage limits for beyond-design-basis events for a specified duration, following which leakage must at least be controlled.

\section{Fundamental Design}

The design of the PRISM containment, including the additions of the dome and IHTS isolation valves, differs from earlier reactor containment designs. The design follows the conventional philosophy of providing a lowleakage boundary for conditions postulated to challenge the containment. The PRISM containment is much smaller than conventional containments that are intended to deal with large energy releases from high-pressure primary systems. The containment boundary itself is much closer to the reactor than is normally the case. The testing and inspection plans involve leak testing of the upper dome, and a visual inspection and vessel annulus leak monitoring for the containment vessel. At this design stage, details of these tests and inspections are lacking, so future reviews will direct significant attention toward these requirements. Finally, the design relies upon passive cooling phenomena instead of on the dedicated active cooling systems used for LWR containments.

Uncertainties in the nature of challenges and their impact on the containment mean that a considerable work effort remains to achieve confidence that the Commission's safety goal objectives are met. Therefore, although the containment design appears to go far toward achieving this objective, more design data and research are required before the containment system can be evaluated for a design certification review. Source-term development and thorough containment system performance analysis based upon this additional information are needed to determine if the safety goal is achieved. These requirements are detailed in the remainder of this section.

\section{Response to Challenges}

Design improvements, outlined in Section 6.5.1, have reduced the potential of a large reactivity or fuel-melt event that could result in a large release. However, the close proximity of the containment boundary to the reactor itself could make a core dislocation or a reactor vessel breach a direct threat to the containment boundary. The preliminary metal-fuel of data on fuel-failure mechanisms and fission-product release introduces doubts about containment performance in such adverse situations. The results of ongoing fuel development work discussed in Section 6.4 should more clearly define the magnitude of risks of violating fuel integrity.

The design-basis containment challenge, as proposed by the designer, is a primary boundary breach, followed by a sodium pool fire. This scenario concentrates on effects in the upper containment. The design basis for the containment vessel is not discussed in the scenario. Shortand long-term material effects of a challenge to the containment vessel, to include direct containment heating from primary sodium impingement, should be included in design-basis considerations. This will help to quantify design margins for this important portion of the containment system.

GDC 50 requires the reactor containment to be able to accommodate any loss-of-coolant accident (LOCA). GDC 4 requires that structures important to safety, such as containment, have the capability to withstand effects of a LOCA, including dynamic effects from a pipe break (i.e., pipe whip or discharging fluid). SRP Sections 3.6.1 and 3.6.2 define PRISM sodium systems as high-energy systems, and provide guidance for determining dynamic effects of pipe breaks. The effects of the postuiated pipe break on the containment, environmental qualification (EQ) of electrical equipment, and containment atmosphere control and cooling should be considered. Even if the "leak before break" approach is accepted in future reviews, GDC 4 does not permit its application as justification to eliminate consideration of pipe break effects. Local dynamic effects of a PRISM pipe break may be less of a concern than for LWRs due to the comparatively lowpressure of the sodium systems; however, global effects such as EQ should be considered during design due to the temperature and chemical effects of a sodium leak. One particular concern is containment response following failure of the IHTS piping just outside containment. This could result in damage not only from the expected fire, but sodium/concrete interaction could produce combustible gas concentrations in confined spaces outside containment, posing a threat to the containment.

GDC 50 also directs that the design margin include consideration of the effects of potential energy sources not included in the determination of peak conditions. Although a sodium pool fire is a significant challenge for a PRISM reactor, it is not clear if other events could result in more severe conditions in containment. For instance, unknowns in pipe break characterization and results of combustible gas generation are examples of such conditions which could be factored into the containment design analysis. 
SRP Section 3.8.2 discusses the loading combinations to be considered for the containment such as, "normal operating loads with severe environmental loads and abnormal loads." Future reviews will determine if seiected load combinations are sufficient.

\section{Containment Atmosphere Cleanup}

The containment dome is a significant barrier to fissionproduct release and to external reactor hazards. However, the requirements of GDC 41 for containment atmosphere cleanup, as addressed in RG 1.7, as well as GDC 64 for means of monitoring containment atmosphere contamination, should be more clearly addressed in future design submittals. Additionally, the design appears to avoid the potential for a dangerous accumulation of combustible gases by eliminating virtually all sources of water to the containment volume. The analysis in Appendix $G$ to the PSID, using the modified CONTAIN Code, of a postulated sodium fire is largely confirmed by staff analysis (Ref. 6.18). Preliminary calculations show that combustion of the maximum possible hydrogen accumulation (from water vapor in the containment atmosphere) would yield only about 1 percent of the energy that would be released by the sodium fire. The requirement to reduce the containment atmosphere concentration of fission products, as well as the ability of the design to prevent hydrogen accumulation, will be considered in any future design reviews.

\section{Containment During Maintenance}

Maintenance activities for a liquid-metal reactor present a design challenge since the coolant cannot be allowed to cool to ambient temperature, and air contact with the coolant is not permitted since a sodium fire could result. The PRISM design presents a potentially workable means to meet these requirements, but the use of a temporary filtered containment structure will be evaluated in detail in any formal design application. A number of technical features that are to be used have not been evaluated. The seals between (1) the enclosure and the concrete deck and (2) the containment dome and deck require a demonstrated leakage rate not to be exceeded during any postulated event. The basis for the specified leak rate must be explained, and a test procedure must be devised to verify the leak rate. Heat and corrosive effects of sealing surfaces/mechanisms as a result of a sodium fire and possible seismic effects should be considered. The concrete deck, which normally serves as the reactor building roof, serves as a containment boundary during refueling. Additional design stipulations may be required so that the containment can satisfy structural, chemical, or other qualifications to ensure that releases are adequately controlled. The extension of the primary boundary by the transfer adapter and transfer cask is important since it prevents challenges to the containment from sodium fires. This feature will have to be able to serve the containment function under such external challenges as those required for the operating containment structure. An auxiliary concern for future design consideration are the details of monitoring and maintaining the reactor cover gas volume during maintenance.

In addition to the technical concerns outlined above, the use of a temporary containment on a recurring basis must be considered under routine regulatory practice. An involved procedure has been developed to perform expected maintenance procedures, but the details must be reviewed. This containment practice has not been used previously, so the regulatory requirements have to be developed.

Associated with containment practices during maintenance is the configuration of the PSPS. The PRISM PSID discusses a postulated sodium spill from this system during its operation while doing maintenance. Although more design detail will be required to fully assess this event, it appears that response to this event received adequate consideration for this level of conceptual design. However, the design did not describe means for ensuring that the system remains secured and isolated during power operation. The connection of a system that penetrates containment to the primary coolant system should follow such guidelines as those used for LWR residual heat removal (RHR) systems. The designer should consider the guidance contained in BTP RSB 5-1 (Ref. 6.6) which provides means to ensure that the RHR does not become a release pathway during normal plant operation.

\section{Materials}

Material performance issues are raised by the proposal to use a containment vessel in close proximity to the reactor vessel for a longer design life than previously accepted. Expected material properties of the containment vessel under long-term fast-neutron exposure should be considered. GDC 51 requires containments to have adequate fracture toughness to prevent brittle rupture.

The estimated fast-neutron end-of-life fluence at the containment vessel of $3 \times 10^{15} \mathrm{n} / \mathrm{cm}^{2}$ (Ref. 6.20) is much lower than the $10^{17} \mathrm{n} / \mathrm{cm}^{2}$ value at which Appendix $\mathrm{H}$ of 10 CFR Part 50 requires a material surveillance program for reactor vessel materials. This limit is based upon the expected neutron energy spectrum for LWRs, which is quite different from that of PRISM. A more appropriate measure of neutron irradiation may be based on displacement per atom (dpa). The staff is studying this area, so this issue will be revisited in future reviews. 
Furthermore, the effect of GEMs on the radial flux distribution (i.e., streaming) should be discussed. It may also be appropriate to consider the reactor vessel requirements of Appendix G, 10 CFR Part 50, for the containment vessel, since it would become the reactor coolant boundary in the event of a reactor vessel ieak.

The containment vessel, as well as its structural supports, would be exposed to high-temperatures during RVACS cooling events and to primary coolant sodium temperatures if called upon to contain a reactor vessel leak. The 2-1/4 $\mathrm{Cr}-1$ Mo steel is acceptable for service under Section III, Division 1 of the ASME Code for temperatures up to $645 \mathrm{~K}\left(700^{\circ} \mathrm{F}\right)$. The designer plans to incorporate ASME Code Case N-47-28 for elevated temperature application of the material. The staff has not fully reviewed these code cases under RGs 1.84 or 1.85 (Refs. 6.21 and 6.22). Therefore, this area will have to be reviewed at a later design stage. In addition to the Nuclear Regulatory Commission (NRC) code case acceptance, the designer acknowledges that tensile properties for the vessel material need to be determined for temperatures in excess of $922 \mathrm{~K}$ $\left(1200^{\circ} \mathrm{F}\right)$. Also, extrapolation of the code past the service life limit of 34 years will be a subject of future review (see Ref. 6.20).

Since the RVACS circulates air over the exterior surface of the containment vessel, the containment vessel is expected to corrode and, in fact, such corrosion is expected to enhance heat transfer to the environment. Exposure to environmental effects must be thoroughly analyzed for any detrimental effects on material properties. For instance, the oxide layer could spall as the containment vessel is subjected to thermal or stress cycles. This spalling would expose new material which would corrode and lead to subsequent spalling, degrading the vessel material.

\section{Source Term}

As discussed in Section 6.5.5, the nature of the TID-14844 source term has influenced conventional LWR containment requirements. Likewise, the basis for a design using a non-conventional containment is utilization of a mechanistic source term. The preliminary analysis of a hypothetical release presented in the PSID gives promise, and appears to be fairly accurate given the inputs available. These inputs, however, rely on extrapolated oxide-fuel data, not metal-fuel data. The assumptions made for sodium retention and release fractions for the groups of nuclides (see Section 6.1.3) seem reasonable in the light of experience cited in research literature, but will be examined in detail for any future design review.
Future accident and release analysis must include reliable information on the behavior of the metal fuel during normal and off-normal conditions, as well as fissionproduct release characteristics. Extensive research and development work (see Section 6.4 and Chapter 4) should provide this information.

\section{Containment Isolation}

The approach used for isolation of lines penetrating containment conforms to most of the requirements of the GDC of Appendix A to 10 CFR Part 50. However, the use of a single isolation valve for each IHTS line requires further examination. The designer draws a parallel between IHTS isolation and the single main steam isolation valves (MSIVs) used on some PWR steam systems (Ref. 6.23). The special considerations for a sodium design, along with the current level of design detail for the PRISM reactor cast serious reservations on this approach. The licensing of a PWR with single MSIVs on steam lines was done with the knowledge of sterm generator design, inspection, and maintenance plans, as well as an understanding of steam generator effects during accidents. The strict requirements imposed on PWR steam generators due to their role as part of the primary boundary provides confidence in their ability to serve as dependable barriers between the reactor coolant and the environment. Before a parallel can be drawn between PRISM reactors and PWRs, unknowns must be resolved concerning IHX longterm performance in the reactor vessel environment, IHX response to conditions inside the reactor vessel during accident sequences, and plans for inservice inspection and testing of the IHX (see Section 5.4.5.5).

During future design refinement, attention should be directed toward two points contained in the guidance in SRP Section 6.2.4, "Containment Isolation System" (Ref. 6.6). First, isolation valves take the positions that offer greatest safety upon a loss of actuating power. This depends on the function of the particular fluid system and its post-accident role. Secondly, the containment isolation reliability requirement of GDC 54 , which involves the use of diverse isolation signals, should be addressed. Means should be provided to ensure that isolation valves will not be inadvertently reopened, for example, when the isolation signal is cleared. Isolation valves should only be reopened deliberately, on an individual basis (i.e., valve-by-valve), not in group fashion.

\section{Containment Penetrations}

The designer acknowledges that specific details of the guard pipes to containment dome interfaces need to be developed. The current design specifies that the guard piping will be designed to ANSI 31.1 in accordance with 
RG 1.26. PSID Figure G.4.1-4 indicates that the guard piping extends beyond the containment and the expansion bellows. This implies that the guard piping, including this portion between the containment dome and the IHTS isolation valve, will be Quality Class D under the RG criteria. Another figure (submitted in Ref. 6.24) show/s that this guard pipe extension is a portion of the containment boundary and designed to ASME Section III, Class 1 requirements. Future design review submittal information should clearly delineate the code applicability of each part of the containment system so that the suitability of the design may be determined.

In this case, the guard piping that serves as part of the containment boundary should be Class 1 or Class 2 under Article NE-1000, Section III of the ASME Boiler and Pressure Vessel Code. This article states that, "Piping... which is part of the containment system... or which penetrate[s] or [is] attached to the containment vessel shall be classified as Class 1 or Class 2 by the [d]esign [s]pecification and meet the requirements of the applicable [s]ubsection." Article NCA-2000 defines the code classes for Division 1 components (such as the containment) and indicates the appropriate subsections of the Code to be applied to each class. Article NE-1000 contains sample diagrams which clearly indicate code applicability of the pictured components.

Future design effort should carefully consider the classification and code applicability of containment system components, especially those structural items required to maintain leak-tight integrity. As design details of expansion bellows and guard vessels for sodium system isolation valves are determined, the requirements of ASME Article NE-1000 should be considered. The intent to design the isolation valve guard vessels according to the requirements of ASME Section VIII seems to counter paragraph NE-1130 which includes all appurtenances attached to the containment vessel as part of the containment system (implying Section III requirements). Further, SRP Section 3.2.2, "System Quality Group Classification," indicates that metal containment components are to be considered under the NRC Quality Group B requirements. RG 1.26 lists ASME Boiler and Pressure Vessel Code Section III as the governing design criteria for Group B components.

This review included an examination of the PRISM design against the proposed requirements of the Electric Power Research Institute (EPRI) as stated in the "Advanced Light-Water Reactor Utility Requirements Document" (ALWR Passive Plant) (Ref. 6.25). Although intended for application to LWR plants, some of the general containment design criteria proposed by EPRI are relevant to PRISM.
EPRI suggests the use of a "physically based" source term similar to the mechanistic source term proposed by PRISM. The source term discussed in Section 1.2.3 of the EPRI document includes consideration of a large-scale core-damage event, leading to rapid fission-product release into the containment, with the potential for primary system boundary (reactor vessel head) penetration. An additional important EPRI consideration is that the plant probabilistic risk assessment (PRA), performed as part of the standardized certification process, be used to confirm the specific plant source term. This suggestion indirectly emphasizes the importance of understanding fuel failure progression, as well as other plant system responses.

The EPRI document includes other, more specific requirements of interest to the PRISM design. Section 6.3.2.5 requires that the design provide means to allow performance of a periodic check for gross leatage of the containment atmosphere during normal operation. Section 6.4.3.1 states that fission-product leakage should be controlled to meet PAGs for the physically based source term. Section 6.4.3.5 allows credit 'or fission-product holdup and removal in secondary structures (the reactor building) in order to meet the PAGs. Again, the nature of fission-product transport and release for PRISM metal fuel is of prime importance for such a design consideration.

EPRI combustible gas control requirements parallel a safety issue examined during this review. Section 6.5.2 of the EPRI document discusses requirements for combustible gas measurement and control within the containment atmosphere. This discussion includes a requirement that a natural circulation mixing of the containment atmosphere be possible when it is not inerted (Section 6.5.2.3). Although these concerns are based upon LWR experience, such consideration is prudent during the continued development of the PRISM design. The current design does appear to preclude a combustible gas accumulation hazard, but future design reviews should ensure that the potential for such hazard remains minimal.

The general safety design criteria of ANSI/ANS-54.1-1989 parallel existing regulatory requirements for containment, with some specific items to account for sodium reactor design. The standard includes separate definitions (Section 2.2) for a confinement system and reactor containment, which could prove useful in designation of design requirements for features such as the PRISM refueling enclosure. In Section 3.5.1, "Containment/Confinement System Design Basis," the standard requires that the system or systems designed to prevent fission-product release include design margin to reflect consideration of sources of energy to include potential exothermic chemical reactions (such as those between sodium and structural materials). Further, it 
requires consideration of the limited experience and experimental data available for defining accident phenowena, such as the limited fuel behavior data available for the PRISM metal fuel. Section 3.5.11, "Containment/Confinement Atmosphere Control," details criteria for combustible gas control specific to sodiumcooled reactor plants. Overall, the conceptual design of the PRISM containment follows the guidance of the containment-related sections of the standard. The portions referred to here apply to design areas requiring attention during future design development.

\subsection{Conclusion}

The PRISM containment design is conceptual in nature and lacks sufficient detail to draw firm conclusions about its overall suitability. However, a number of general safety questions arose during the review which require consideration before a formal application is submitted.

- The reactor response to BEs of concern is uncertain (see Section 6.5.1).

- Means to clean up a release to the containment atmosphere are provided only for refueling operations.

- The containment configuration during maintenance presents unique technical and regulatory challenges, including the use of a temporary containment enclosure and temporary extension of the primary boundary.

- Material performance characteristics for the containment vessel are important issues, specifically long-term neutron irradiation and high-temperature exposure due to the proposed plant lifetime and the location of the containment vessel relative to the reactor.

- Means of containment isolation require further consideration and more detailed information for future reviews. The plan to use single IHTS isolation valves must be supplemented with confirmation of IHX reliability and performance claims. The operation of the isolation valves must be examined under adverse conditions to ensure that their function will be fulfilled.

- The design of containment penetrations, especially the IHTS lines, needs to be more detailed so that the assigned quality grade suitability of these components may be determined. The use of guard pipes is sensible from the standpoint of fire mitigation and leakage control, but their interface with the containment boundary must be clearly defined.
- The overall influencing factor for the containment review remains the mechanistic source term. More information is needed to allow an assessment of fuel behavior and fission-product transport during abnormal operations and core upset events.

The resolution of these questions should help to provide ussurance that a PRISM containment of the type described in the PSID will function in the manner required to meet the Commission's safety goal. These concerns, as well as review of further design development, must be resolved before the staff can filly accept the proposed containment design.

\subsection{References}

6.1 General Electric, PRISM-Preliminary Safety Information Document, GEFR-00793 UC-87Ta, November 1986.

6.2 U.S. Atomic Energy Commission, "Assumptions Used for Evaluating the Potential Radiological Consequences of a Loss of Coolant Accident for Boiling Water Reactors/Pressurized Water Reactors," Regulatory Guides 1.3/1.4.

6.3 U.S. Environmental Protection Agency, Code of Federal Regulations, Title 40, "Protection of Environment," Part 190, "Environmental Radiation Protection for Nuclear Power Operations."

6.4 U.S. Nuclear Regulatory Commission, "Quality Group Classifications and Standards for Water, Steam, and Radioactive Waste Containing Components of Nuclear Power Plants, " Regulatory Guide 1.26.

6.5 Salerno, L.N., General Electric, letter to Nicholas Grossman, Department of Energy, April 27, 1992.

6.6 U.S. Nuclear Regulatory Commission, "Standard Review Plan for the Review of Safety Analysis Reports for Nuclear Power Plants, LWR Edition, " NUREG-0800, July 1982.

6.7 American National Standards Institute/American Nuclear Society, ANSI/ANS-54.1-1989, "General Safety Design Criteria for a Liquid Metal Nuclear Power Plant," ANS, LaGrange Park, Illinois.

6.8 U.S. Nuclear Regulatory Commission, "Instrument Lines Penetrating Primary Reactor Containment (Safety Guide 11) Supplement to Safety Guide 11, Backfitting Considerations," Regulatory Guide 1.11. 
6.9 U.S. Nuclear Regulatory Commission, "Seismic Design Classification," Regulatory Guide 1.29.

6.10 U.S. Nuclear Regulatory Commission, "Design Limits and Loading Combinations for Metal Primary Reactor Containment System Components," Regulatory Guide 1.57.

6.11 U.S. Nuclear Regulatory Commission, "Design Response Spectra for Seismic Design of Nuclear Power Plants," Regulatory Guide 1.60.

6.12 U.S. Nuclear Regulatory Commission, "Damping Values for Seismic Design of Nuclear Power Plants," Regulatory Guide 1.61.

6.13 U.S. Nuclear Regulatory Commission, "Electric Penetration Assemblies in Containment Structures for Nuclear Power Plants," Regulatory Guide 1.63.

6.14 U.S. Nuclear Regulatory Commission, "Guidance for Construction of Class 1 Components in Elevated Temperature Reactors," Regulatory Guide 1.87.

6.15 U.S. Nuclear Regulatory Commission, "Containment Isolation Provisions for Fluid Systems," Regulatory Guide 1.141.

6.16 U.S. Nuclear Regulatory Commission, "Control of Combustible Gas Concentrations in Containment Following a Loss-of-Coolant Accident," Regulatory Guide 1.7.

6.17 American Society of Mechanical Engineers, Boiler and Pressure Vessel Code, 1989 edition, Subarticles NCA, NE, NB, and Code Case N-47, "Rules for Construction of Nuclear Power Plant Components," New York.
6.18 U.S. Nuclear Regulatory Commission, "Evaluation of 1990 PRISM Design Revisions," NUREG/CR-5815 (BNL-NUREG-52311 R7), March 1992.

6.19 U.S. Atomic Energy Commission, "Calculation of Distance Factors for Power and Test Reactor Sites," Technical Information Document 14844, March 1962.

6.20 General Electric, "ALMR Structural Materials," Presentation to the Advisory Committee on Reactor Safeguards, San Francisco, CA, May 21, 1992.

6.21 U.S. Nuclear Regulatory Commission, "Design and Fabrication Code Case Acceptability - ASME Section III, Division 1," Regulatory Guide 1.84.

6.22 U.S. Nuclear Regulatory Commission, "Materials Code Case Acceptability - ASME Section III, Division 1," Regulatory Guide 1.85 .

6.23 Salerno, L.N., General Electric, letter to Nicholas Grossman, Department of Energy, June 12, 1992.

6.24 Salerno, L.N., General Electric, letter to Nicholas Grossman, Department of Energy, April 27, 1992.

6.25 Electric Power Research Institute - Advanced Light-Water Reactor Utility Requirements Document, Vol. III, ALWR Passive Plant, Chapter 2, "Power Generation Systems," 1990.

6.26 J.E. Quinn, General Electric, letter to S.P. Sands, NRC, "GE Comments on NUREG-1368 Preapplication Safety Evaluation Report for the Power Reactor Innovative Small Module (PRISM) Liquid-Metal Reactor," November 29, 1993. 


\section{INSTRUMENTATION AND CONTROL}

\subsection{Reactor Protection}

Normal reactor operations are conducted using the plant control system (PCS). The PCS contains a high level of automation for plant control, protection of the plant investment, and data handling transmission. The PCS functions utilize highly reliable redundant digital equipment and reliable power supplies. The nine nuclear steam supply systems, three turbine generators, and associated balance-of-plant (BOP) equipment in the standard PRISM plant can be controlled by means of the PCS from a single control center.

The PRISM design includes a reactor protection system (RPS) that is independent of the PCS. The RPS, in response to changes in monitored parameters, initiates reactor module safety-related trips to shut down the reactor. There are nine local and independent RPSs, one per reactor. Each local RPS consists of four identical sensor and electronic logic divisions, each located immediately adjacent to the reactor in equipment vaults. The RPS performs independent Class $1 \mathrm{E}$ conditioning and monitoring of sensors to determine plant status during and after an accident. All safety-related data handling and information transmission are provided locally by the RPS for the individual module.

The passive safety concept used in the PRISM design results in a minimum amount of plant instrumentation and control being classified as safety related. The staff focused its review effort on the conceptual design of the RPS and how it works with the other instrumentation and control systems. The staff will perform its detailed review of the RPS when a design certification application is submitted containing the design details and associated failure mode and effects analysis.

\subsubsection{Design Description and Safety Objectives}

The RPS is classified as safety related, Class $1 \mathrm{E}$, and is designed to protect the health and safety of the public. The actions initiated by a reactor trip include

- the release of all control rod absorber bundles for insertion by gravity

- activation of the post-trip control rod drive-in motors to ensure full control rod insertion under power

- initiation of electromagnetic (EM) pump coastdown following reactor scram confirmation

- a trip signal to the PCS for related investment protection action in the BOP
For each reactor, four divisions within the RPS monitor safety-related parameters and initiate safety system trips to shut down the reactor. Parameters such as primary sodium level, inlet and outlet core temperatures, core inlet pressure, and neutron flux will be monitored by four sensors each. Each of the four divisions monitors the three sensors from the other divisions with its own sensor acting as a spare. (For example, division $A$ monitors sensors $B, C$, and $D$ with sensor $A$ available as a spare should B, C, or D be taken out of service or fail.) Each division initiates a trip when two of three of the sensors exceed the setpoint. Subsequently, when any two of the four divisions trip, the breaker contacts interrupt the electrical current to the control rod latch coils to release all absorber bundles and shut down the reactor. (See Figure 7.1.)

The logic design of the RPS allows for improved flexibility in response to component failures and for maintenance and testing activities. When a failure occurs or maintenance and testing is being performed on all or part of a division, that division is declared inoperable and its trip breaker is deenergized. The three remaining sensors are shared by the remaining divisions, preserving the two-out-of-three logic necessary to deenergize a second trip breaker and shut down the reactor. Such flexibility preserves the level of reactor protection during routine activities and expected failure modes.

The RPS is designed with a high degree of fault tolerance; it has the capability for fault detection, confinement of faults, and isolation of fault effects. The system includes self-diagnostic features so that failures can be identified and equipment can be readily repaired or replaced. The RPS is designed to limit the consequences of initiating faults in its own module of the PRISM plant.

The RPS is made up of safety-related equipment from the sensor through and including the isolation device communicating with the PCS via the fiber-optic data handling and transmission system (DHTS). Each division sensor, its cabling, and its electronics is electrically and physically isolated from the other divisions. There are four physically separate isolated instrument vaults, one for each division. All signal-conditioning electronics and the RPS divisional logic are contained within these vaults. Safety-related indication of RPS parameters exists within the vaults. Manual trip is possible from each panel within the vaults, the control center, and the remote shutdown facility (RSF). 


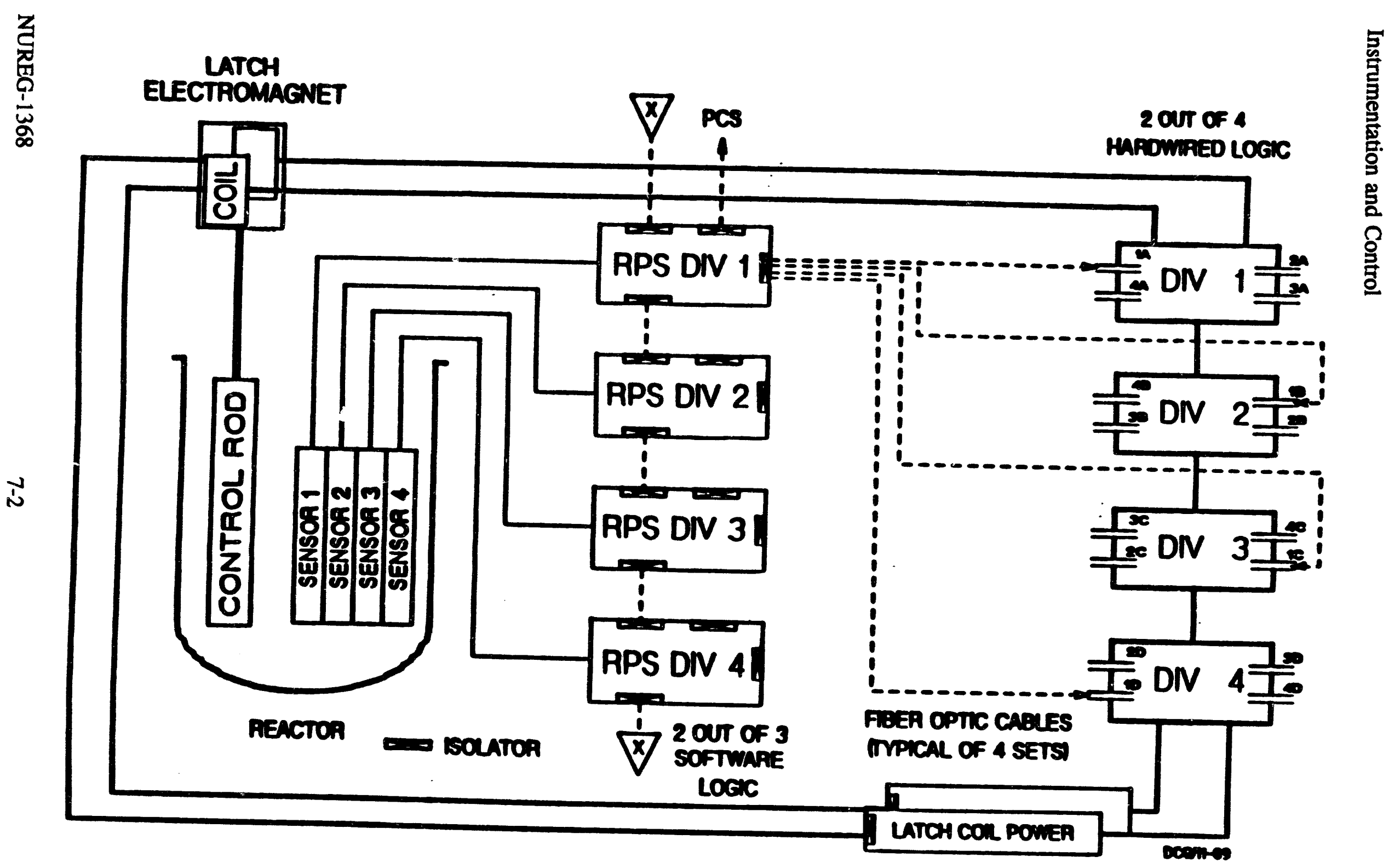

Figure 7.1 PRISM reactor protection system (RPS) configuration 


\subsubsection{Scope of Review}

The staff reviewed the RPS conceptual information to determine if it could meet the necessary design requirements of a system required for protection of the health and safety of the public. The staff also reviewed the RPS to establish that provisions would be included to prevent RPS degradation due to interactions with other plant instrumentation and control systems that are not safety related.

\subsubsection{Design Criteria}

A number of Nuclear Regulatory Commission (NRC) regulatory guides and industry standards apply to the reactor protection system. The guides and standards are as follows:

- NRC, "Instrument Lines Penetrating Containment," Regulatory Guide 1.11, February 1972.

- NRC, "Periodic Testing of Protection System Actuation Functions," Regulatory Guide 1.22, February 1972.

- NRC, "Quality Assurance Program Requirements (Design and Construction)," Regulatory Guide 1.28, Rev. 3, August 1985.

- NRC, "Quality Assurance Requirements for the Installation, Inspection, and Testing of Instrumentation and Electric Equipment," Regulatory Guide 1.30, August 1972.

- NRC, "Criteria for Safety-Related Electric Power Systems for Nuclear Power Plants, " Regulatory Guide 1.32, Rev. 2, February 1977.

- NRC, "Bypassed and Inoperable Status Indication for Nuclear Power Plant Safety Systems," Regulatory Guide 1.47, May 1973.

- NRC, "Application of the Single-Failure Criterion to Nuclear Power Plant Protection Systems," Regulatory Guide 1.53, June 1973.

- NRC, "Manual Initiation and Protection Actions," Regulatory Guide 1.62, October 1973.

- Initial Startup Test Program to Demonstrate Remote Shutdown Capability for Water-Cooled Nuclear Power Plants, " Regulatory Guide 1.68.2, Rev. 1, July 1978.

- NRC, "Qualification Tests of Electrical Valve Operators Installed Inside the Containment of Nuclear Power Plants, " Regulatory Guide 1.73, January 1974.
- NRC, "Physical Independence of Electric Systems," Regulatory Guide 1.75, Rev. 2, September 1978.

- NRC, "Environmental Qualification of Certain Electric Equipment Important to Safety for Nuclear Power Plants," Regulatory Guide 1.89, Rev. 1, June 1984.

- NRC, "Instrumentation for Light-Water-Cooled Nuclear Power Plants to Assess Plant Conditions During and Following an Accident, " Regulatory Guide 1.97, Rev. 3, May 1983.

- NRC, "Seismic Qualification of Electric and Mechanical Equipment for

Nuclear Power Plants," Regulatory Guide 1.100, Rev. 2, June 1988.

- NRC, "Instrument Set-points for Safety-Related Systems, "Regulatory Guide 1.105, Rev. 2, February 1986.

- NRC, "Periodic Testing of Electric Power and Protection Systems," Regulatory Guide 1.118, Rev. 2, June 1978.

- NRC, "Fire Protection Guidelines for Nuclear Power Plants," Regulatory Guide 1.120, Rev. 1, November 1977.

- NRC, "Qualification Tests of Electric Cables, Field Splices, and Connections for Light-Water-Cooled Nuclear Power Plants," Regulatory Guide 1.131, August 1977.

- NRC, "Criteria for Programmable Digital Computer System Software in Safety-Related Systems of Nuclear Power Plants," Regulatory Guide 1.152, November 1985.

- NRC, "Criteria for Power, Instrumentation, and Control Portions of Safety Systems, " Regulatory Guide 1.153, December 1985.

- NRC, "Guidance for Application of Regulatory Guide 1.47," BTP ISCB 21 of Standard Review Plan Section 7, Rev. 2, July 1981.

- NRC, "Guidance for Application of Regulatory Guide 1.22," BTP ISCB 22 of Standard Review Plan Section 7, Rev. 2, July 1981.

- IEEE, "Criteria for Class IE Power Systems for Nuclear Power Generating Stations, " IEEE Std. 308, Copyright 1980. 
- IEEE, "Standard for Electric Penetration Assemblies in Containment Structures for Nuclear Power Generating Stations," IEEE Std. 317, Copyright 1983.

- IEEE, "Qualifying Class 1E Equipment for Nuclear Power Generating Stations, " IEEE Std. 323, Copyright 1983.

- IEEE, "Type Tests of Continuous Duty Class 1E Motor for Nuclear Power Generating Stations," IEEE Std. 334, Copyright 1974.

- IEEE, "Installation, Inspection, and Testing Requirements for Class $1 \mathrm{E}$ Instrumentation and Electric Equipment at Nuclear Power Generating Stations," IEEE Std. 336, Copyright 1985.

- IEEE, "Criteria for Periodic Testing of Nuclear Power Generating Station Safety Systems," IEEE Std. 338, Copyright 1977, Reaffirmed 1984.

- IEEE, "Recommended Practices for Seismic Qualifications of Class 1E Equipment for Nuclear Power Generating Stations, " IEEE Std. 344, Copyright 1975, Reaffirmed 1980.

- IEEE, "Guide for General Principles of Reliability Analysis of Nuclear Power Generating Station Protection Systems," IEEE Std. 352, Copyright 1975, Reaffirmed 1980.

- IEEE, "Application of the Single Failure Criterion to Nuclear Power Generating Station Class 1E System," IEEE Std. 379, Copyright 1977.

- IEEE, "Criteria for Type Tests of Class 1E Modules Used in Nuclear Power Generating Stations," IEEE Std. 381, Copyright 1977, Reaffirmed 1984.

- IEEE, "Standard for Qualification of Safety-Related Valve Actuators," IEEE Std. 382, Copyright 1990.

- IEEE, "Standard for Type Test of Class 1E Electric Std. Cables, Field Splices, and Connections for Nuclear Power Generating Stations, " IEEE Std. 383, Copyright 1974, Reaffirmed 1980.

- IEEE, "Criteria for Independence of Class $1 \mathrm{E}$ Equipment and Circuits," IEEE Std. 384, Copyright 1981.

- IEEE, "Guide for the Design and Installation of Cable Systems in Power Generating Stations," IEEE Std. 422, Copyright 1986.
- IEEE, "Standard Quality Assurance Program Requirements for the Design and Manufacture of Class 1E Instrumentation and Electric Equipment for Nuclear Power Generating Stations," IEEE Std. 467, Copyright 1980.

- IEEE, "Standard Method for Identification of Documents Related to Class 1E Equipment and Systems for Nuclear Power Generating Stations, " IEEE Std. 494, Copyright 1974, Reaffirmed 1983.

- IEEE, "Criteria for Post Accident Monitoring Instrumentation for Nuclear Power Generating Stations," IEEE Std. 497, Copyright 1981.

- IEEE, "Guide for the Installation of Electrical Equipment to Minimize Noise Inputs to Controllers for External Sources," IEEE Std. 518, Copyright 1982, Reaffirmed 1990.

- IEEE, "Recommended Practice for the Design of Display and Control Facilities for Central Control Rooms of Nuclear Power Generating Stations," IEEE Std. 566, Copyright 1977.

- IEEE, "Requirements for Reliability Analysis in the Design and Operation of Safety Systems for Nuclear Power Generating Stations, " IEEE Std. 577, Copyright 1976.

- IEEE, "Criteria for Safety Systems for Nuclear Power Generating Stations (intended to replace IEEE Std. 279)," IEEE Std. 603, Copyright 1980.

- IEEE, "Design Qualification of Safety Systems Equipment Used in Nuclear Power Generating Stations," IEEE Std. 627, Copyright 1980.

- IEEE, "Preferred Power Supply for Nuclear Power Generating Stations," IEEE Std. 765, Copyright 1983.

- ANSI/IEEE/ANS, "Application Criteria for Programmable Digital Computer Systems in Safety Systems of Nuclear Power Generating Stations, " IEEE Std. 7.4.3.2, Copyright 1982, Reaffirmed 1990.

- IEEE, "Standard for Software Quality Assurance Plans," IEEE Std. 730, Copyright 1989.

- ANSI/ANS, "Design Basis Criteria for Safety Systems in Nuclear Power Generating Stations," ANSI/ANS Std. 4.1, Copyright 1978. 
- ANSI/ISA, "Transducer and Transmitter Installation for Nuclear Power Safety Applications, ANSI/ANS Std. S67.01, Copyright 1979, Reaffirmed 1987.

- ISA, "Response Time Testing of Nuclear SafetyRelated Instrument Channels in Nuclear Power Plants," ISA Std. S67.06, Copyright 1984.

These design criteria, particularly IEEE Std. 603 (which will supersede IEEE Std. 279 as the specification defining the requirements of Class 1E electrical systems), are required for design, manufacture, and construction activities. The staff will consider its review of the Electric Power Research Institute (EPRI) Requirements Document for advanced passive plants when it assesses the content, extent, and boundaries of safety-related systems that would be subject to these design criteria.

\subsubsection{Research and Development (R\&D)}

The RPS uses digital electronics and associated software. Extensive use or fiber-optics is also planned. Such stateof-the-art technology available for design is ahead of the technology that is well understood through experience and supported by application standards and, as a result, the specifics of a research and development (R\&D) program have not been identified. The NRC staff recommends that the PRISM design team should pay attention to possible further development in NRC and industry regarding this area, particularly with respect to isolation devices between the RPS and its ancillary systems (see Section 7.1.5.2).

The computer software validation and verification program will be reviewed at a later stage as the design progresses.

\subsubsection{Safety Issues}

\subsubsection{Second Shutdown System}

General Electric (GE) acknowledges the need for a highly reliable scram of the reactor. GE is relying on one shutdown system that does appear to be highly reliable. However, its susceptibility to common-mode failure needs a thorough review at a later design stage. The staff believes that the diverse means of shutdown provided by the passive reactivity feedbacks could be acceptable to meet the intent of General Design Criteria (GDCs) 26 and 27, provided that suitable recovery actions are developed to achieve subcriticality in a reasonable time and if an inservice testing program can be developed to verify over the life of the plant that the magnitude and nature of the feedbacks remains sufficient to respond to events in EC-I through EC-III without reliance on the RPS.
The ultimate shutdown system (USS) is a safety-grade system that releases balls of $\mathrm{B}_{4} \mathrm{C}$ into channels into the core. This system was added to the design in response to concerns about the adequacy of the passive reactivity feedbacks to shut down the reactor if the rods cannot be inserted as discussed above. Acceptance of passive reactivity feedback as a diverse means of reactor shutdown may depend upon a prototype demonstration to characterize and qualify the passive safety features. The use of the USS as a manual recovery action to achieve subcriticality is acceptable provided it is designed with sufficient reliability and redundancy.

The use of both the passive reactivity feedbacks and the USS as diverse means of achieving shutdown is acceptable pending review of the final designs when the design certification application is submitted.

\subsubsection{Isolation Devices}

The RPS has a number of interfaces with non-safetyrelated plant instrumentation and control systems as well as a number of points at which the independent divisions communicate with each other. At these points, various types of isolation devices will be employed. The final design for the RPS interfaces with other systems will have to meet the requirements of IEEE Std. 279 (or IEEE Std. 603). The PRISM design team should maintain contact with the NRC staff as the RPS design progresses to keep abreast of current staff guidance in this and other areas. The PRISM design team agreed to pay special attention to the testing and qualification of the isolation devices.

\subsubsection{Electromagnetic (EM) Pump Instrumentation and Control}

In response to staff questions on the safety design bases for the EM pump coastdown feature, GE provided the following

A reactor scram includes insertion of the control rods and a coastdown of the EM pumps. The primary design basis for initiating an EM pump coastdown as part of a reactor trip is to cover the loss-of-electrical-power design-basis event. EM pumps do not provide the mechanical inertia to sustain flow following a loss of electrical power as do mechanical pumps. The flow in an EM pump stops as rapidly as does the decay of the magnetic flux following an interruption of the electrical power. The sudden cessation of flow through the reactor core without rod insertion could lead to local overheating, cladding failure and possibly limited boiling within the inner fuel assemblies. 
Consequently, the primary flow is lowered at a rate to match approximately the inherent reactivity response. This is referred to as the primary flow "coastdown." With EM pumps, coastdown is provided by the inertia stored in a rotating synchronous machine. With the interruption of electrical power to the EM pumps and their synchronous machines, the machines begin to convert stored energy to electrical power which is delivered to the EM pumps to provide the requisite primary flow "coastdown."

Regarding the safety classification of the equipment associated with the EM pumps, GE stated that

The EM pump, the synchronous machine, and the dual RPS breakers in the power supply lines are all safety related and classified as electrical Class 1E equipment. The controller, the load commutated converter, and the ac power input source are not safety related. All safety-related actions of the EM pumps and the synchronous machine are detected by the RPS through the measurement of the pumps outlet pressure. Any problems with the input electrical power, the synchronous machine, or the EM pump will result in a reduction of the pump outlet pressure. Normally, the synchronous machine corrects the power factor of the EM pump. Hence, any problem that would degrade the performance of a synchronous machine will degrade the efficiency of the EM pump - and be sensed as a decrease in the pump outlet pressure.

Any EM pump, synchronous machine, controller/converter or electrical power source malfunction that influences the performance of the reactor will be sensed by the RPS pressure and temperature sensors and result in a reactor trip as the safety set-point is violated.

The electric power supply for each EM pump is monitored at the power conditioning unit. These sensors and logic are not classified as Class 1E. For further information in this area, refer to Section 8.3.

In response to concerns about maintaining forced coolant flow while at power, GE has modified the EM pump trip circuitry to delay pump trip and coastdown following a scram until indication of control rod insertion is received.

\subsubsection{Containment Isolation Function}

In Reference 7.16 GE described the containment isolation function, which is a portion of the RPS, as follows
Penetrations of the reactor closure that require isolation are limited to two $3^{\prime \prime}$ sodium processing lines and one 1-1/2" cover gas processing line. During reactor operation, these lines are closed with redundant manually operated isolation valves that are located immediately inboard and outboard of the containment dome shell. Position sensors are mounted on these valves to provide position information to the RPS. RPS logic prevents startup of the reactor if the position sensors indicate these isolation valves are open. These valves are prevented from opening during reactor operation by mechanical locking mechanisms and administrative procedures. An alarm will sound in the control room if these valves are inadvertently opened during reactor operation. The positions of these valves are also monitored following an accident. The preapplicant will meet the IEEE standards for Class 1E electrical equipment associated with the position indication function of these valves.

\subsubsection{Essential Auxiliary Support Systems}

Systems such as heating, ventilation, and cooling systems, that must function to ensure the capability of the safetyrelated instrument and control systems, must be identified to facilitate the review of the RPS.

\subsubsection{Sensor A.rray Configuration}

Any potential for spatial dependence of the sensors in relationship to their respective process variables must be analyzed and accounted for in the final design of the RPS.

\subsubsection{Information Systems Important to Safety}

Identification and qualification of information systems important to safety will need to be reviewed as the design progresses.

\subsubsection{Failure Mode Analysis and Testing Configuration}

A comprehensive failure mode analysis will be required before the design of the RPS can be accepted. Consideration should be given to the mechanics of maintenance and test activities and their effect on the level of protection offered by the RPS.

\subsubsection{Manual Scram Configuration}

The final design of the manual scrams at the RPS vaults, RSF, and control center will require final review and approval to assess their diversity, safety classification, and redundancy. This design should demonstrate a diverse 
capability to scram the reactor from the control center that does not require the PCS. It should also include safetygrade manual scrams from each of the RPS vaults and the RSF. In addition, the ability to actuate the USS from the control center and the RPS vaults in addition to the RSF needs to be addressed. A detailed review will be performed when a design certification application is submitted.

\subsubsection{Evaluation}

The staff has reviewed the conceptual design of the RPS, as proposed for the PRISM. The RPS will be a highly automated, digital system that uses fiber-optics for data handling and transmission. It will be completely isolated from the PCS.

The research and development program, now underway, is intended to provide the supporting information needed to review the final design during the design certification review. The program for validation and verification of the digital systems and the computer software will also be reviewed at that time.

\subsubsection{Conclusions}

GE has described its concept of the reactor protection system. After reviewing that design, the staff concludes that the RPS has the potential of being implemented in an acceptable manner. Final acceptance of the passive shutdown features will depend upon completion of additional R\&D and satisfactory development of a means for in-service testing/measurement of the reactivity feedback mechanisms and recovery actions to achieve subcriticality. Acceptable validation and verification program(s) for all digital electronic control hardware and software will be requested.

\subsection{Safety-Related Instrumentation}

\subsubsection{Design Description and Safety Objectives}

Safety-related instrumentation is used in the reactor protection, containment isolation, and accident monitoring systems. Reactor flows, fuel cladding integrity, reactor power, vessel closure leakage, vessel leakage, and reactor vessel auxiliary cooling system (RVACS) performance are monitored. Figure 7.2 shows the locations of the sensors used for these systems. The signals are used to provide indicators to the operators and to initiate reactor trips through the reactor protection system.

\subsubsection{Reactor Protection System Instrumentation}

The reactor protection system is activated by outputs from instrumentation monitoring the following parameters: core neutron flux, core outlet temperature, cold pool temperature, EM pump discharge pressure, and primary sodium level.

The power range flux monitor provides a signal from $1 \times 10^{-6}$ percent to 130 percent of full operating power. Output is proportional to neutron flux leaking from the core, which in turn is proportional to thermal power. The flux monitors are located in dry wells in the concrete silo and are surrounded by neutron thermalizing blocks and gamma shielding. The signal conditioning equipment complementing the monitors is located in the instrumentation vaults, connected to the monitors by cables in protected conduit. Power range flux is used to indicate excessive reactivity insertion, causing the RPS to take action to prevent overpower conditions. The non-safetyrelated, low-level-range flux detectors will be located in dry wells near the outer radius of the upper internals structure (UIS), $15.2 \mathrm{~cm}$ (6 in) above the top of the reactor core. These will measure core fission levels during shutdown and refueling.

Core outlet sodium temperature is measured from $255-1367 \mathrm{~K}\left(0-2000^{\circ} \mathrm{F}\right)$ and serves to protect the fuel from excessive cladding temperatures. Four thermowells penetrate the closure head and are attached to the UIS. Each is capable of holding four sensor elements, one dedicated as the primary sensor, the others as spares or for calibration. The sensors are located just below the spent fuel assemblies. Spent fuel storage positions are in the hot plenum above the top of the core barrel. These sensors indicate mixed mean outlet temperature of the sodium flowing from the core.

Cold pool temperature is sensed by four Class IE resistance temperature detectors (RTDs), one in each pump discharge plenum (Figure 7.2 shows these as pump discharge temperature). These RTDs provide RPS input in response to loss-of-heat-sink events and for off-normal events in the balance-of-plant.

A temperature sensor also measures sodium temperature in the hot pool. The purpose of the system is to prevent overheating of load-bearing structures, especially the reactor vessel, and to prevent excessive fuel pin cladding/fuel interface temperatures which could lead to eutectic formation and cladding damage. 


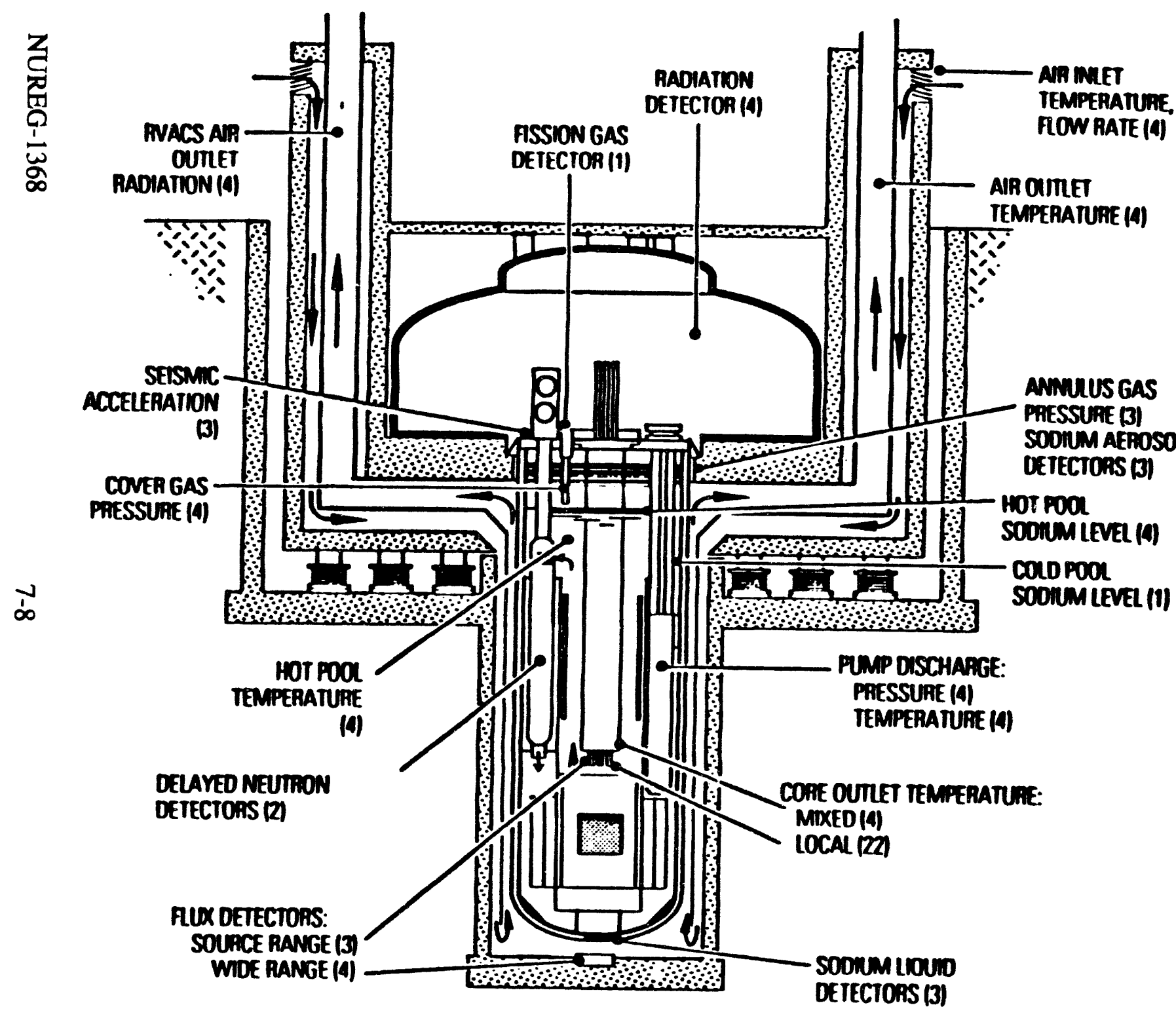

\begin{tabular}{|c|c|}
\hline $\begin{array}{l}\text { Monvtorimg } \\
\text { Functions }\end{array}$ & MSTRIMMENTATION \\
\hline $\begin{array}{l}\text { Reactor } \\
\text { Flow Parths }\end{array}$ & $\begin{array}{l}\text { - Hot } 8 \text { Cold Pool } \\
\text { Temperatures } \\
\text { - Local \& Mined } \\
\text { Core Outlet } \\
\text { Temperatures } \\
\text { - Hot } 8 \text { Cold Pool } \\
\text { Sodium Levels } \\
\text { - Pump Discharge } \\
\text { Pressure }\end{array}$ \\
\hline $\begin{array}{l}\text { Fuil Clad } \\
\text { integrity }\end{array}$ & $\begin{array}{l}\text { - Fission Gas } \\
\text { Monitoring } \\
\text { of Cover Gas } \\
\text { - Detored Neywon } \\
\text { Monitoring of } \\
\text { Primer Sodium }\end{array}$ \\
\hline Resctor Powor & - Alux Detectors \\
\hline $\begin{array}{c}\text { Closure } \\
\text { leakage } \\
.\end{array}$ & $\begin{array}{l}\text { - Upper } \\
\text { Containiment } \\
\text { Radiation Monitus } \\
\text { - Orive Mechanise } \\
\text { Bellows Leatage } \\
\end{array}$ \\
\hline $\begin{array}{l}\text { Peactor } \\
\text { Vessel } \\
\text { leakage }\end{array}$ & $\begin{array}{l}\text { - Anmulus Gas } \\
\text { Pressure } \\
\text { - Sodivm Liquid } \\
\text { Detecturs } \\
\text { - Sodium Aerosol } \\
\text { Detectors }\end{array}$ \\
\hline $\begin{array}{c}\text { RNACS } \\
\text { Pefformance }\end{array}$ & $\begin{array}{l}\text { - Air milet } 8 \text { Ounlet } \\
\text { Temperatures } 8 \\
\text { flow flate }\end{array}$ \\
\hline
\end{tabular}

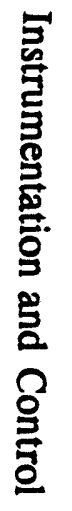

Figure 7.2 PRISM reactor module and RVACS monitoring instrumentation 
Sodium flow in the core is measured indirectly as EM pump discharge pressure and is used to initiate a reactor trip on low pump discharge pressure to prevent high fuel temperatures. The four pressure sensors are bellows type with strain gauge instrumented, diaphragm pressure transducers. Four instrument pipes connect the pump discharge with wet wells under the vessel closure head. The lower bellows assembly is located at the measurement point in the wet well and isolates the primary coolant from the instrument. Core flow is computed from the difference between the pump discharge pressure and the combination of the cover gas pressure and sodium static head as follows:

$$
\begin{aligned}
& \Delta P_{\text {core }}=P_{\text {pump diacharge }}-P_{\text {cover gas }}-\text { Static head } \\
& \text { Flow }=\text { Rated flow }\left[\Delta P_{\text {core }} \div \Delta P_{\text {ratod }}\right]^{0.53}
\end{aligned}
$$

In low-core-flow scenarios, such as RVACS-only cooling events, the differential pressure method will not be used because of the loss of detector sensitivity. In this case, core differential temperature will be used as an indication of core flow.

Hot pool sodium level is sensed by four Class IE-qualified inductive probes located within the EM pumps. The sensors are mounted in dry wells; one is mounted in each EM pump stem. The dry wells penetrate the closure head through the pump plugs and extend to just above the EM pump discharge plena. These sensors monitor the reactor module sodium level during all reactor operations with a range from above the maximum sodium level to below the minimum leak level.

\subsubsection{Containment Isolation System Instrumentation}

The intermediate heat transport system (IHTS) main loop isolation valves automatically close upon detection of steam generator tube leakage to protect the intermediate heat exchanger (IHX) from the effects of a sodium-water reaction. Actuation signals are generated from redundant safety-grade lHTS pressure sensors.

The $12.7 \mathrm{~cm}$ (5-in.) wide gap (annulus) between the reactor vessel and containment vessel is filled with argon gas at $184 \mathrm{kPa}$ (12 psig). Pressure sensors and sodium liquid and aerosol detectors are provided to detect leakage of either vessel.

\subsubsection{Accident Monitoring System Instrumentation}

The accident monitoring system incorporates information from several separate monitoring systems. These are trip actuation, reactor power generation, reactor heat removal, reactor vessel and containment integrity, and emergency elentrical power supply operability. The relationship of these systems to the RPS is depicted in Figure 7.3. These systems do not provide trip signals for the RPS, but they are Class 1E.

Trip actuation and trip function completion indicators inform the operator that required actions have been taken by any device with a trip function (reactor protection systems are described in Chapter 4). A limit switch associated with each control rod is monitored. The switch opens when the control rod has completed its full insertion travel following a scram actuation. The state of the rod shim and scram drive-in motors is monitored. The drivein motors, which are activated on a reactor scram, are intended to overcome a stuck rod as a backup to the normal scram function. The motors would continue to run until deenergized by a signal when the control rods hit the end-of-stroke limit switches. If the control rod is stuck and the motor can not move the rod to the limit switch, operator action would be needed to deenergize the motor.

The EM pump synchronous coastdown machines, the sources of emergency power to the pumps, are monitored during rundown to confirm expected performance. This monitoring system is described in Chapter 8.

Contributors to heat generation within the reactor vessel are the reactor core, the EM pumps, and stored fuel. Core heat output is determined by measurement of three parameters: mixed mean outlet temperature, mixed mean inlet temperature, and the core flow rate. Core outlet temperatures and core flow monitoring were discussed earlier in this section. Core inlet temperature is inferred from the measurement of EM pump outlet temperature. Each pump outlet has a single dry well containing four sensors which provides the measurement. Electrical input to the EM pumps is assumed to be totally converted to thermal energy. Heat produced by the pumps is calculated from electrical pumping power. Spent fuel elements can add as much as $0.2 \mathrm{MWt}$ to the heat generation rate. The core exit flow is assumed to then flow past the spent fuel bundles. Temperature will be measured at the spent fuel inlet storage section and at each IHX. These inputs supply the data required to determine spent fuel heat generation.

Residual heat removed through RVACS is estimated from the enthalpy change in the air flowing through the duct system. This is calculated from the air mass flow rate, humidity, and the temperature differential between inlet and outlet flows. RVACS air mass flow rate is to be monitored by a pitot tube dynamic and static air pressure measurement system with two sensors located in the exit chimney of each of the four RVACS stacks. Air mass flow from 0 to $36.3 \mathrm{~kg} / \mathrm{sec}(80 \mathrm{lbm} / \mathrm{sec})$ is measured. 


\section{ACCIDENT MONITORING}

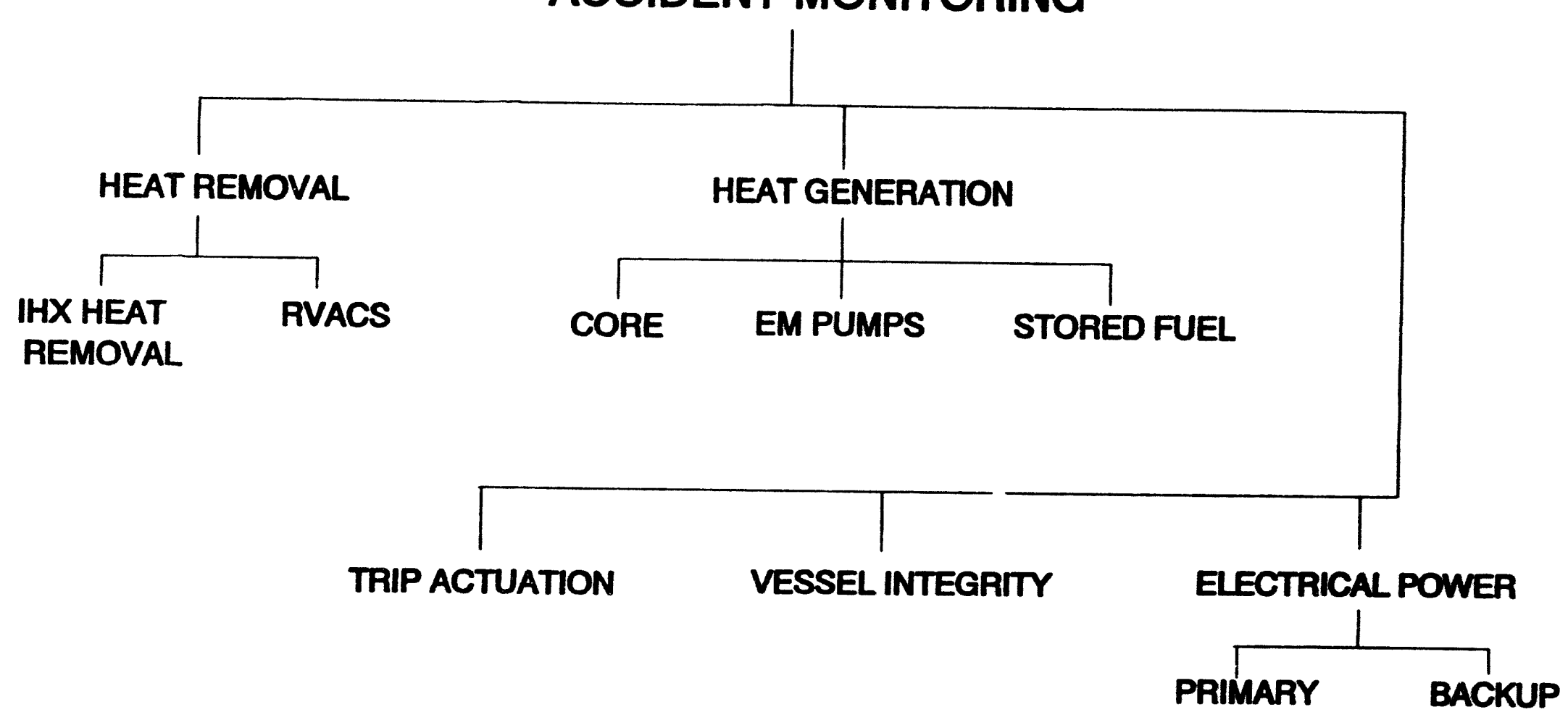

Figure 7.3 PRISM accident monitoring system diagram 
A thermistor-type device is used to measure the air temperature from \pm 2 percent of full scale, $255-533 \mathrm{~K}$ $\left(0-500^{\circ} \mathrm{F}\right)$ and the air velocity can be resolved to \pm 2 percent of full scale.

All portions of the RPS and accident monitoring system are dc powered from dual battery-backed sources. The batteries are maintained at full charge by safety-related battery chargers. The Class $1 E$ battery-backed sources are monitored by continuous measurement of voltage and current at critical points throughout each power source circuit. Indications are available on Class $1 \mathrm{E}$ displays in the RPS instrument vaults adjacent to the head access area (HAA) and in the remote shutdown facility. Diagnostic data is provided to the control room through Class $1 \mathrm{E}$ isolation devices.

\subsubsection{Scope of Review}

The following material was used for the review of safetyrelated instrumentation:

- Chapter 7 of the PRISM preliminary safety information document (PSID) (Ref. 7.1)

- Responses to NRC comments, PSID Appendix F

- Volume VI (Appendix G) of the PSID

- Reliability, Availability, and Maintainability Program Plan (Ref. 7.2)

- ALMR Technology Development Plan (Ref. 7.3)

- Supplemental information submitted during the review as responses to requests for additional information (Refs. 7.4, 7.5, and 7.6)

Appendix $G$ of the PSID describes some changes from the originally submitted design, including safety-grade reactor scram and post-accident monitoring capabilities in the RSF.

Standard Review Plan (SRP) (Ref. 7.7) Sections 3.11, "Environmental Design of Mechanical and Electrical Equipment"; 7.1, "Instrumentation and Controls"; 7.5, "Information Systems Important to Safety"; and 7.6, "Interlock Systems Important to Safety," were used as guides for this review. These SRPs ensure conformance to the GDCs of 10 CFR Part 50 (Appendix A), especially GDC 13, "Instrumentation and Control"; GDC 20, "Protection System Functions"; and GDC 23, "Protection System Failure Modes."
The design standards proposed by ANSI/ANS-54.1-1989, "General Safety Design Criteria for a Liquid Metal Nuclear Power Plant" (Ref. 7.8), were used to identify additional areas for review involving unique characteristics of the PRISM.

Several design guidelines proposed in the Advanced LightWater Reactor Utility Requirements Document (ALWR Passive Plant) (Ref. 7.9) were also considered in this review. Although intended to address light-water reactor (LWR) safety or operability issues, these guidelines warrant consideration based on their potential for reducing safety systems challenges in PRISM. They do not reflect regulatory positions, but are intended to provide early indication of expected industry design objectives for standard plants.

\subsubsection{Design Criteria}

In addition to the regulatory guides (RGs) and industry standards cited in Section 7.1.3, the PRISM designers have stated that the following RGs are applicable to the design:

- RG 1.45, "Reactor Coolant Pressure Boundary Leakage Detection" (Ref. 7.10)

\section{- RG 1.151, "Instrument Sensing Lines" (Ref. 7.11)}

The designers stated that the intent of RG 1.97, "Instrumentation for Light-Water-Cooled Nuclear Power Plants To Assess Plant and Environs Conditions During and Following an Accident," would be followed (listed in PSID Table 1.8-1). However, a number of references to this guidance in the PSID seem to demonstrate that even if modifications to this RG may be required for application to a liquid-metal reactor (LMR), the RG will serve an important role in the design of safety-related instrumentation systems for LMRs.

\subsubsection{Research and Development}

The ALMR Technology Development Requirements Plan discusses advanced instrumentation development plans. Current plans include validation and testing at EBR-II of the delayed neutron monitor (see Section 7.3), the hightemperature wide-range flux monitor, the qualification of a sodium ionization detector, and the qualification of pressure sensors for the reactor cover gas, primary sodium, and containment. No specific work scope has been specified for developing the technology for postaccident monitoring, but the development plan stated the intention of periodic reviews to determine if any future effort is needed in this area. 


\subsubsection{Safety Issues}

The review of safety-related instrumentation systems was limited by the minimal design detail available, a characteristic of this preapplication conceptual design stage. No distinct safety issues were identified. A number of concerns are noted in areas which will need to be evaluated in future review efforts. These are discussed in the following section.

\subsubsection{Evaluation}

The review of safety-related instrumentation focused on the requirements for post-accident monitoring. Although the review revealed no significant items of safety concern, a number of issues were raised warranting attention during future design efforts. This review did not include an examination of EM pump synchronous machine monitoring instrumentation, which is covered in Chapter 8.

\subsubsection{Accident Monitoring}

Future design efforts should ensure that accident monitoring guidance contained in SRP Section 7.2, RG 1.97, ANS 4.5-1980 (Ref. 7.12) (cited by RG 1.97), and the Three-Mile Island (TMI) action items (10 CFR 50.49(f)) are considered. Among the areas covered by these documents are range of the parameter covered, environmental qualification, duration of operation, and application of the single-failure criterion.

ANS 4.5-1980 has requirements for the ranges of parameters measured by instrumentation used to assess reactor coolant and containment boundary integrity. RG 1.97 states:

It is essential that the range selections be sufficiently great to keep instruments on scale or that one of a set of overlapping instruments will be on scale at all times. Further, it is prudent that a limited number of those variables that are functionally significant be monitored by instruments...with ranges that extend well beyond that which the selected variables can attain under limiting conditions.

The guidance then uses reactor containment pressure as an example of a parameter that should be monitored over a wide range. Other parameters that could be considered applicable are cover gas pressure, primary sodium temperature, and sodium flow.

SRP Section 3.11 requires that the designer identity the environmental design bases for equipment required to perform safety functions. The R\&D requirements plan pointed out that although post-accident monitoring had been considered, no specific research and development tasks were planned. The plan does include tasks for qualification of a number of sensors expected to be exposed to harsh environments such as reactor cover gas sensors, instruments exposed to primary sodium, and containment instrumentation. Although designer analyses include estimates of expected core and containment atmosphere conditions, it is not clear that these conditions have been factored into safety instrumentation design requirements. This development effort should include conditions for normal operation and accident situations to confirm operability for accident monitoring. The requirements of GDC 4, environmental and dynamic effects design bases, and the environmental considerations of $10 \mathrm{CFR} 50.49(\mathrm{c})(3)$ should be used to guide future design work. Additionally, 10 CFR 50.49(e) lists design considerations, including synergistic effects. This is an important point for a design such as PRISM that involves some untried or unconventional design features (e.g., RVACS).

The duration of operability for instrumentation important to monitoring plant conditions in a post-accident situation is an issue especially pertinent to PRISM considering the extended recovery times involved for some events (e.g., RVACS-only cooldown). ANS 4.5-1980 (Section 6.1.2) gives durations expected for instruments monitoring parameters for three variable categories. The categories, $A, B$, and $C$, are based on instrumentation requirements for different phases of accident response. Type A variables are used to initiate operator actions, Type B variables give the operator a means to assess the effectiveness of corrective actions, and Type $C$ variables indicate the potential for fission-product release. Differences exist between the approach used in the ANS standard and in RG 1.97. For instance, the RG defines variable categories in addition to those in the standard, and the time phases discussed in the standard are not used in the RG. However, the basic recommendation remains that instrumentation systems should be able to function as long as the information being provided is needed by the operators.

Appendix B to SRP Section 7.1 discusses the sing!e-failure criterion with respect tc protective systems. The design should account for any single failure, including instrumentation, which could affect protection system performance. This will be an area of signiticant importance for future reviews, since some aspects of the design appear to depend upon a limited number of parameters for protective action. One example is the response to a steam generator tube rupture that uses only one safety-grade instrumentation system (the IHTS 
pressure) to initiate a reactor scram for the event (see Chapter 5 for a more detailed discussion).

\subsubsection{Indirect Parameter Measurement}

SRP Section 7.1, "Instrumentation and Controls," addresses the issue of indirect measurement of variables. Referring to Section 4.8 of IEEE Std. 279 (Ref. 7.13), Appendix B of the SRP states that the use of an indirect parameter as an input for protective actions should be validated for all postulated events.

Primary sodium flow is measured indirectly in both forced and natural circulation regimes. During forced circulation, core flow is inferred from the pressure differential between the EM pump discharge and the cover gas. Analyses should ensure that determining flow in this manner is a valid approach for postulated events.

The proper operation of RVACS requires primary sodium flow, even if forced circulation is not available (see PSID, Appendix G, Section G.4.3.2.1). Residual heat removal (RHR) flow is a Type D parameter in RG 1.97, which further requires that it be available to monitor RHR operation. Thus, in addition to RVACS air flow, primary sodium flow in the reactor vessel should be considered a parameter required to verify proper RHR operation. The current design implies that core temperature instrumentation could also be used for determining natural circulation flow (see Ref. 7.4). This approach seems adequate with the information available at this design stage. However, future reviews will consider indirect measurement of natural circulation flow in detail. The necessity of measuring primary sodium flow magnitude, changes to flow, or flow blockages during RVACS operation will be examined relative to the guidance in RG 1.97.

\subsubsection{RVACS Instrumentation}

Redundancy and operability of RVACS flow sensors for off-normal events should be carefully considered. The instrumentation used to measure RVACS air flow must be able to measure the magnitude and direction of flow during an event with blocked flow paths, when expected flow patterns will be altered or even reversed. The unusual demands upon the RVACS flow measuring system, as well as its role as a vital safety system component, require that operability checks encompass all operating and accident regimes. Sections 4.9 and 4.10 of IEEE Std. 279 (discussed in Appendix B to SRP Section 7.1) discuss means for sensor checks and instrument testing and calibration. Future designs stould ensure that testing and calibration for these systems cover all postulated measurement conditions and parameter ranges.

\subsubsection{Measurement Redundancy}

The redundancy of variables used to assess the performance of safety functions should be examined in future reviews. RG 1.97 points out that a single variable may not be sufficient to ascertain the performance of a safety function. Further, it discusses the importance of multiple measurements of the same variable to account for spatial variations or variations due to system idiosyncrasies. Containment atmosphere temperature is a cited example, but the concept could be applicable to PRISM sodium leak detectors, RVACS temperatures, and sodium temperatures (to list only a few examples).

\subsubsection{Flux Monitoring}

PRISM uses a safety-grade wide-range flux-monitoring system and a non-safety-grade source range system. The reference PRISM design will monitor flux from $10^{-6}$ to 130 percent of full power, but it is not clear that the entire range will be covered by the safety-grade wide-range monitor. Final design of these systems should ensure that the guidance of RG 1.97 is followed for the range of neutron flux monitored by post-accident monitoring instrumentation. Safety-grade neutron monitoring for $10^{-6}$ to 100-percent full power should be available. The spatial dependence of the flux-monitoring systems should also be assessed. The location of the wide-range sensors under the vessel should be examined to ensure that power can be adequately measured, especially due to the possible effect of the gas expansion modules (GEMs) on the wide-range flux profile.

\subsubsection{Comparison to EPRI ALWR Requirements}

This review included an examination of the PRISM design against the proposed requirements of EPRI as stated in the Advanced Light-Water Reactor Utility Requirements Document (ALWR Passive Plant). Although intended for application to LWR plants, some of the general design criteria proposed by EPRI are relevant to PRISM.

The EPRI document treats instrumentation concerns within each major system chapter. Section 4.6.3.3 of the EPRI document discusses reactor pressure vessel level requirements and emphasizes the need for a dedicated level monitoring system which can reliably indicate level during shutdown maintenance activities when reactor coolant levels may be changed is especially applicable to PRISM. In Section 4.7.3.2.3, EPRI addresses core power instrumentation requirements for PWRs in a manner generally applicable to most reactor types. The need to account for spatial flux variations is emphasized in the discussion on in-core monitoring assemblies that can provide an axial flux profile. For the PRISM, the designer 
seems to intend to follow the guidance in Chapter 5 of the EPRI guidance (Sections 5.4.3, and 5.5.3) on display of passive decay heat removal system information in the control room and remote shutdown facility. Section 6.6.5.2 of the EPRI document is especially pertinent to this review since it addresses severe-accident equipment needs. The environmental qualification of instrumentation expected to be exposed to severe conditions is emphasized.

The general safety design criteria of ANSI/ANS-54.1-1989 parallel existing regulatory requirements for instrumentation, restating GDC 4 in its entirety and closely following other related LWR requirements. A notable difference, however, is the contrast between Section 3.1.5 of the standard, "Environmental and Missile Design Bases," and GDC 4, "Environmental and Dynamic Effects Design Bases." The standard does not discuss the exception for consideration of pipe break effects based on the probability of pipe rupture, although a sodium leak and resulting fire should be an environmental qualification consideration.

\subsubsection{Conclusions}

GE has described an accident-monitoring system that can satisfy the provisions of RG 1.97 and the requirements of 10 CFR Part 50. The staff focused its review on accidentmonitoring capabilities, since this is an area that is expected to be quite different for PRISM than for more familiar LWR designs. No significant safety issues were apparent from examination of the current design, but the staff is raising several concerns at this preapplication stage to ensure that they receive adequate consideration before a design certification review. The areas requiring further attention or design detail are: general accident monitoring requirements, indirect parameter measurement, RVACS instrumentation, redundancy of measurements, and flux monitoring systems.

\subsection{Other Instrumentation and Monitoring Systems}

\subsubsection{Design Description and Safety Objectives}

A number of instrumentation systems are provided to monitor the various reactor subsystems or to supply specialized diagnostic information. None are considered safety related. They include

- radiation monitoring

- fire protection

- impurity monitoring
- refueling neutron flux monitoring

- fuel element detection and location (FEDAL)

- loose parts monitoring (LPM)

\subsubsection{Scope of Review}

The staff reviewed the limited information submitted by the preapplicant. The staff performed only a cursory review of the conceptual designs of these non-safety-related systems. The PRISM design is currently at a stage at which the instrumentation and monitoring systems are not yet fully designed. When details of system descriptions and functions are developed in later stages of the application process, the staff will perform a more comprehensive review of these systems.

\subsubsection{Review Criteria}

In Appendix A to 10 CFR Part 50 (Ref. 7.14), GDC 13 states that instrumentation shall be provided to monitor variables and systems over their anticipated ranges for normal operation, for anticipated operational occurrences, and for accident conditions as appropriate to assure adequate safety. GDC 20 states that one function of a protection system is to sense accident conditions and to initiate the operation of systems and components important to safety. GDC 64 requires that means be provided for monitoring the reactor containment atmosphere spaces containing components for recirculation of fluids from loss-ofcoolant-accidents, effluent discharge paths, and the plant environs for radioactivity that may be released from postulated accidents.

Standard Review Plan Sections 7.1, "Instrumentation and Controls," and 7.5, "Information Systems Important to Safety," provided guidance for this review. The SRP describes the categories of instrumentation systems for light-water reactors and gives guidance and acceptance criteria for the review of these systems.

Regulatory Guide 1.97 (Ref. 7.15), provides guidance for the review of instrumentation systems designed to monitor plant variables during and following an accident. Although this guide pertains to current LWR technology, the staff may determine that some of the guidance is also applicable to PRISM technology.

Design standards proposed by ANSI/ANS 54.1-1989, "General Safety Design Criteria for a Liquid Metal Nuclear Power Plant, " were used to provide more specific guidance for review of areas involving unique characteristics of the PRISM design. These criteria supplement the design criteria in 10 CFR Part 50, Appendix A which constitute the requirements. 


\subsubsection{Research and Development}

There are no research and development plans for the instrumentation and monitoring systems not considered to be safety related.

\subsubsection{Safety Issues}

There are no safety issues identified for the instrumentation and monitoring systems not considered to be safety related.

\subsubsection{Evaluation}

\subsubsection{Radiation-Monitoring System}

The radiation-monitoring system measures radiation levels during all plant operating, shutdown, abnormal, and accident conditions. Monitors will be positioned in the areas surrounding the module, in the head access area, the safety-qualified equipment vaults, and at the site boundary. In Chapter 7 of the PSID, the preapplicant has identified the radiation-monitoring system as a non-Class $1 \mathrm{E}$ system and has not identified any of the equipment within the radiation-monitoring system as being safety related. Information systems important to safety are defined in Section 7.1 of the SRP as those systems that provide information for the safe operation of the plant during normal operation, anticipated operational occurrences, and accidents. They include those systems that provide information from which appropriate actions can be taken to mitigate the consequences of anticipated operational occurrences and accidents. Certain portions of the radiation-monitoring system are normally included in the category of information systems important to safety. The staff intends, at a later stage in the design, to review those portions of the radiation-monitoring system designed to assess plant and environs conditions during and following an accident using the guidance stated in RG 1.97.

\subsubsection{Fire-Protection System}

The fire-protection system should be designed in accordance with current light-water reactor regulations such as 10 CFR 50.48 and Appendix $R$ to 10 CFR Part 50. In Chapter 7.6 of the PSID, the applicant stated its intention to provide fire protection in accordance with 10 CFR 50.48 and 10 CFR Part 50, Appendix $R$ regulations. The fire-protection system for a sodium-cooled reactor will also require unique specifications. Fire-control systems and a means to detect sodium, $\mathrm{NaK}$ or their reaction products should be provided to limit and control the extent of reactions as necessary to ensure that the nuclear safety functions of structures, systems, and components are maintained. The staff will review fire protection in detail when the design is complete.

\subsubsection{Impurity-Monitoring System}

The reference design for primary system processing and impurity monitoring uses a permanent cold trap. The cold traps could be potential radiation and leakage hazards and should be designed accordingly. The system is used intermittently to purify sodium from one of three adjacent PRISM reactor modules (a power block). The purification system and associated impurity monitors are contained in a hardened building. This system appears to be in a preliminary design stage at this time. The primary system should be monitored to maintain purity within specified design limits. These limits should be based on consideration of chemical attack, fouling and plugging of passages, radioisotope concentrations, and detection of sodium-water interactions. The staff anticipates that this system would be designed employing such criteria as discussed in ANSI/ANS 54.1, "General Safety Design Criteria for a Liquid Metal Reactor Nuclear Power Plant."

\subsubsection{Refueling Neutron-Flux Monitoring System}

Low-level-range flux detectors are located in drywells near the outer radius of the upper internal structure and are located 6 inches above the reactor core to measure corefission power and subcriticality during shutdown and refueling. These detectors are shut off during normal power operation (Ref. 7.16). If these low-level-range flux detectors are required to ensure or monitor subcriticality during refueling, there should be redundancy in the system. If this system is designed with interlocks to prevent refueling accidents, then it should be designated as an instrumentation system that is required for safety.

\subsubsection{Fuel Element Detection and Location System}

The FEDAL system comprises the following three subsystems: (1) delayed neutron monitoring, (2) fission gas monitoring, and (3) pin gas tagging/tag recovery and analysis. Two delayed neutron-monitoring stations, a fission-gas monitor, and fuel pin gas tagging are employed in each reactor. A single tag gas recovery and analysis system serves all nine plant reactors.

The delayed neutron-monitoring subsystem monitors primary sodium to detect fuel exposed to primary sodium. The delayed neutron (DN) detectors are located in the intermediate heat exchanger drywell and monitor the primary sodium for the presence of sodium-borne fission products that decay by neutron emission (mainly bromine and iodine). The DN detector signals are processed to 
provide several continuous parameters which indicate the amount of fuel-to-sodium exposure.

The fission-gas monitor detects fuel pin breaches, counts the number of breaches in the core, and transmits the informetion for operator display. The fission-gas monitor samples the cover gas and through analysis of the gammaray spectra, determines the concentrations of selected fission gases. Data from the fission-gas monitor are processed to inform the operator about the state of the core in the reactor.

Pin-gas tagging, tag recovery, and analysis are used to locate fuel assemblies with a breached pin. Small amounts of gas having a unique isotopic composition are added to the fuel pins so that when there is a cladding failure the tag gas is released and the failed pin can be located by spectrometric analysis of the reactor cover gas. A total of 150 tags (one for each fuel and blanket assembly) are used. During reactor shutdown, the cover gas is recovered into a cover gas vehicle with a storage tank which connects to the reactor. The gas is then transported to the radwaste building where it is analyzed to determine breaches and their locations.

GE has stated that run-beyond-cladding-breach (RBCB) operation with a small number of breached fuel element cladding is not a safety concern; therefore, the FEDAL system is not classified as safety related. Operation with breached oxide fuel at EBR-II has shown that when sodium comes in contact with fuel inside the pin, the sodium reacts with the fuel and the resulting reaction products cover up the breach area. Experiments performed thus far using breached metal-fuel elements have indicated good compatibility of the metal-fuel system with sodium. Little erosion of metal has been observed. Fuel failure and its consequences are discussed in greater detail in Section $\mathbf{4 . 2}$ of this PSER.

\subsubsection{Loose Parts Monitoring}

It is a design objective in PRISM to use a commercially available LPM system that meets the intent of Regulatory Guide 1.333, "Loose Part Detection Program for the Primary System of Light-Water Reactors." The evaluation of this system and its conformance to the regulatory guide will be performed at a later stage in the design review.

\subsubsection{Conclusions}

Most of the instrumentation and monitoring systems discussed in this section are still in a preliminary design stage. Limited specific design information currently exists for these systems. The staff will review these systems in more detail at a later time. None of these systems are considered safety related. Portions of these systems could be designated as safety related or important to safety, particularly radiation monitoring (as it pertains to the function of providing information in order to mitigate accidents), refueling, criticality monitors, and portions of the fire detection systems.

\subsection{References}

7.1 General Electric, PRISM-Preliminary Safety Information Document, GEFR-00793 UC-87Ta, November 1986.

7.2 General Electric, PRISM-Reliability, Availability, and Maintainability Program Plan, GEFR-00843 UC-87Ta, April 1989.

7.3 General Electric (GE) Nuclear Energy, ALMR Technology Development Requirements Plan, GEFR-00845, Rev. 3 UC-87Ta, June 1992.

7.4 Salemo, L.N., General Electric, letter to Nicholas Grossman, Department of Energy, September 1, 1992.

7.5 Quinn, J.E., General Eloctric, letter to Nicholas Grossman, Department of Energy, November, 4, 1992.

7.6 Quinn, J.E., General Electric, letter to Nicholas Grossman, Department of Energy, February 2, 1993.

7.7 U.S. Nuclear Regulatory Commission, "Standard Reviev Plan for the Review of Safety Analysis Reports for Nuclear Power Plants, LWR Edition," NUREG-0800, July 1982.

7.8 American National Standards Institute/American Nuclear Society, ANSI/ANS 54.1-1989, "General Safety Design Criteria for a Liquid Metal Nuclear Power Plant," ANS, La Grange Park, Illinois.

7.9 Electric Power Research Institute-Advanced Light Water Reactor Utility Requirements Document, Volume III, "ALWR Passive Plant," Chapter 2, "Power Generation Systems," 1990.

7.10 U.S. Nuclear Regulatory Commission, "Reactor Coolant Pressure Boundary Leakage Detection Systems," Regulatory Guide 1.45 .

7.11 U.S. Nuclear Regulatory Commission, "Instrument Sensing Lines," Regulatory Guide 1.151. 
7.12 American National Standards Institute/American Nuclear Society, ANSI/ANS 4.5-1980, "Criteria for Accident Monitoring Functions in Light-WaterCooled Reactors," ANS, La Grange Park, Illinois.

7.13 Institute of Electrical and Electronics Engineers, IEEE Standard 279-1971, "Criteria for Protection Systems for Nuclear Power Generating Stations," Piscataway, New Jersey.

7.14 U.S. Nuclear Regulatory Commission, Code of Federal Regulations, Title 10, "Energy," Part 50, "Domestic Licensing of Production and Utilization
Facilities," Appendix A, "General Design Criteria for Nuclear Power Plants."

7.15 U.S. Nuclear Regulatory Commission, "Instrumentation for Light-Water-Cooled Nuclear Power Plants to Assess Plant and Environs Conditions During and Following an Accident," Regulatory Guide 1.97.

7.16 J.E. Quinn, General Electric, letter to S.P. Sands, NRC, "GE Comments on NUREG-1368 Preapplication Safety Evaluation Report for the Power Reactor Innovative Small Module (PRISM) Liquid-Metal Reactor," November 29, 1993. 


\section{ELECTRICAL SYSTEMS}

\subsection{Overall Electrical System}

\section{Design Description and Safety Objectives}

Power from the preferred offsite sources is delivered to each power block through high-voltage switchyard breakers. The breakers are arranged in a ring bus to accommodate multiple ties with the transmission network. If required, power from a secondary offsite source is available to the service power system through a separate high-voltage ring bus. The preferred and secondary offsite sources are connected to the power grid by separate and physically independent transmission lines.

The offsite sources furnish power to the 7.2-kilovolt $(\mathrm{kV})$ onsite ac power system through unit auxiliary transformers. The power is distributed to each reactor block through two dedicated 7.2-kV buses and four 480-V buses. Power may be routed to each power systena from the preferred or secondary offsite power supplies.

In the event of a loss of offsite power, a power-runback feature reduces reactor power and provides approximately 120 megawatts electric (MWe) from the turbine generators to accommodate loads of the three power blocks. Any single turbine generator is capable of furnishing the power requirements of the plant.

Upon loss of both the primary and secondary offsite power sources and a failure of the power-runback function, two non-safety-related gas turbine generators, normally in standby, are available to power essential loads through two separate 7.2-kV buses; thereby, serving all site requirements.

Uninterruptible power supplies (UPSs) connected to the non-safety-related $125-\mathrm{V}$ dc systems furnish power to loads in each turbine building, the common facilities for control and instrumentation functions, and the plant control system.

\subsection{Safety-Related Electrical Power System}

\subsubsection{Design Description and Safety Objectives}

The PRISM design places minimal safety-related requirements on the electrical systems because few safetyrelated systems require power (Ref. 8.1).

The Class 1E dc and Class $1 \mathrm{E}$ ac subsystems, the electromagnetic pump power supply, and the control rod latch coil and control rod drive motor power systems are considered safety-related electrical power systems.
Class 1E ac subsystems are powered by dedicated batterybacked (125-V dc) UPS systems through inverter and static transfer switch arrangements. Separate Class $1 E$ vital 120-V ac UPS systems in each reactor building produce reliable power for each individual reactor protection system. Separate UPSs, each with its own battery and battery charger, power each of the four reactor protection systems. Two spare battery chargers are shared between the $125-\mathrm{V} \mathrm{dc}$ buses, one serving channels $A$ and $C$, the other for B and D. Only Class $1 E$ loads are connected to Class 1E buses.

Power for the 48-V dc control rod latch coil and control rod drive-in motor circuits is furnished by batteries and chargers in the reactor buildings. Separate batteries power each of the four channels for each drive-in motor and latch coil system. Two spare battery chargers are available for each 48-V dc system. These are each shared between a pair of channels (channels $A$ and $C$, and channels $B$ and D).

The primary sodium electromagnetic (EM) pumps (see Section 8.3) are normally supplied from the 7.2-kV ac distribution system through input transformers and power conditioning units. Each EM pump has a separate power supply and a controlled coastdown system which is safetyrelated. Power for the controlled coastdown of the pump is supplied by a synchronous machine connected in parallel with the EM pump power. The synchronous machine-rated at $2000 \mathrm{kVA}-1110 \mathrm{~V}, 3$-phase, $20 \mathrm{~Hz}$, normally runs unloaded in an overexcited mode of operation and supplies reactive power (acting as a synchronous condenser). Upon loss of normal pump power, the stored kinetic energy in the synchronous machine is converted into electrical energy to provide a controlled-pump coastdown. Physical and seimic separation is maintained between cables connecting the synchronous machines and pumps.

\subsubsection{Scope of the Review}

The review focused on the safety-related portions of PRISM electrical power systems. The PRISM PSID Chapter 8, Section F8 of Appendices F and G were reviewed. At this conceptual design stage, limited detailed information is available on system characteristics. However, overall function and safety purposes were evaluated.

Standard Review Plan (SRP) (Ref. 8.2) Section 8.1, "Electric Power;" 8.2, "Off-site Power Systems;" 8.3.1, "AC Power Systems (On-site);" and 8.3.2, "DC Power Systems (On-site), " provided guidance for review of this area. These SRP sections specifically require that the 
electrical systems conform to General Design Criteria (GDC) 2, 4, 5, 17, 18, and 50 of 10 CFR Part 50.

Inconsistencies between general aspects of the PRISM design and basic guidelines proposed in the Electric Power Research Institute's (EPRI's) "Advanced Light-Water Reactor Utility Requirements Document" (Vol. III, "ALWR Passive Plant") (Ref. 8.3) were noted. These points do not reflect regulatory positions, but are intended to give early indication of conformance with expected industry design objectives for standard plants.

\subsubsection{Design Criteria}

The PRISM designers identified the following regulatory guides (RGs) as applicable to the electrical power systems:

- 1.6 "Independence Between Redundant Standby (On site) Power Sources and Between Their Distribution Systems" (Ref. 8.4)

- 1.32 "Criteria for Safety-Related Electric Power Systems for Nuclear Power Plants (Use of IEEE Std. 308-1971)" (Ref. 8.5)

- 1.63 "Electric Penetration Assemblies in Containment Structures for Nuclear Power Plants" (Ref. 8.6)

- 1.75 "Physical Independence of Electric Systems" (Ref. 8.7)

- 1.81 "Shared Emergency and Shutdown Electric Systems for Multi-Unit Nuclear Power Plants" (Ref. 8.8)

- 1.89 "Environmental Qualification of Electric Equipment Important to Safety for Nuclear Power Plants" (Ref. 8.9)

- 1.93 "Availability of Electric Power Sources" (Ref. 8.10)

- 1.100 "Seismic Qualification of Electric and Mechanical Equipment for Nuclear Power Plants" (Ref. 8.11)

- 1.118 "Periodic Testing of Electric Power and Protection Systems" (Ref. 8.12)

- 1.128 "Installation Design and Installation of Large Lead Storage Batteries for Nuclear Power Plants" (Ref. 8.13)
- 1.131 "Qualification Tests of Electric Cables, Field Splices, and Connections for Light-Water-Cooled Nuclear Power Plants" (Ref. 8.14)

- 1.153 "Criteria for Power, Instrumentation, and Control Portions of Safety Systems" (Ref. 8.15)

The PRISM designers also noted that the following two RGs do not specifically apply to the PRISM electrical power system:

- 1.9 "Selection, Design and Qualification of DieselGenerator Units Used as Standby (On site) Electric Power Systems at Nuclear Power Plants" (Ref. 8.16)

- 1.108 "Periodic Testing of Diesel Generator Units Used as On site Electric Power Systems at Nuclear Power Plants" (Ref. 8.17)

RGs 1.9 and 1.108 were excluded because the designers did not identify a need for a large safety-related power supply.

RGs applicable to this review, but not listed in Table 1.8-1 of the Preliminary Safety Information Document (PSID) are

- 1.155 "Station Blackout" (Ref. 8.18)

- 1.158 "Qualification of Safety-Related Lead Storage Batteries" (Ref. 8.19)

\subsubsection{Research and Development}

General Electric (GE) addressed concerns about the EM pumps and supporting equipment performance that had been raised during the preliminary review in Volume VI of the PSID, "Responses to Issues in Draft Preapplication Safety Evaluation Report (PSER), " Section G.4.7.3.7. GE stated that work would be performed to determine consequences of the synchronous machine supplying power to an electrically faulted pump. This work would include tests to ensure that the requirements of RG 1.63, "Electric Penetrations in Containment Structures, " are satisfied for electrical penetrations of the containment dome, including the requirement that an excessive fault current will not cause failure of the containment penetration integrity.

A test program for the EM pump and synchronous machine is planned, including controlled coastdown tests (PSID, Vol. VI, Section G.4.7.3.3). Components of the overall electrical system for the PRISM design are state of the art, so they do not need a research and development program. 


\subsubsection{Safety Issues}

A significant difference between the safety-related electrical system for the PRISM design and for operating reactor plants is the absence of Class $1 E$ emergency diesel power in the PRISM design. This design choice was made on the basis of the availability of passive shutdown and decay-heat-removal systems. The emergency diesels were made unnecessary because of the use of these passive reactivity shutdown features and the passive decay-heatremoval system called the reactor vessel auxiliary cooling system (RVACS). Without diesels, however, the likelihood of a station blackout event is increased for the PRISM design compared to operating light-water reactors (LWR).

Analyses for station blackout (Bounding Event (BF) 2), done by $G E$ and Brookhaven National Laboratories (RNL) (see PSER Chapter 15 and PSID Section G.4.16), shc wed that PRISM can safely withstand a loss of ac power for 36 hours without adverse core consequences. This blackout duration is well beyond the requirement of RG 1.155, "Station Blackout." However, other LWR station blackout requirements dictate that a multi-unit plant (sharing onsite ac sources) shall be able to reach hot standby or hot shutdown during a station blackout (10 CFR Section 50.63(c)(2) and 50.2). Also associated LWR regulatory guidance recommend that the core shall be able to reach cold shutdown in the event of a loss of offsite power (RG 1.81).

The PRISM reactor can be brought to hot standby, hot shutdown, or cold shutdown by RVACS without offsite power; however, the time to reach these core conditions will be very long (approximately 80 days) compared to the 36 hours in RG 1.139 and may be long compared to the "reasonable period of time" in Branch Technical Position RSB 5-1 of SRP 5.4.7.

\subsubsection{Evaluation}

The conceptual design of the onsite power system includes standby power sources and the distribution system required to supply power to safety-related components and systems. By following accepted design practice and expressing the intent to comply with applicable design and regulatory standards, the overall electrical power system should meet NRC requirements once the issues discussed below are resolved.

The passive systems included in the design are intended to enhance plant reliability without the need for an onsite emergency safety-grade ac power source. Reliance upon dc power sources to supply all vital ac and dc loads for station blackout event places greater safety emphasis on the de systems. The design should include battery capacity and reliability information to ensure that plant monitoring and a control capability are available throughout the event. Redundancy of battery sources appears sufficient, but ways to avoid common-mode failure should be considered.

Viability of the design without onsite safety-grade ac power is based upon the capability of a single passive decay heat removal system (i.e., RVACS). Although GE's analysis of the station blackout event (BE-2) shows that the core will sustain no damage, RVACS does not appear to be capable of bringing the reactor to a cold-shutdown condition in the short-term. RG 1.81, "Shared Emergency and Shutdown Electric Syste.ns for Multi-Unit Nuclear Power Plants," stipulates that each unit should have independent onsite emergency and shutdown electric systems, both ac and dc, capable of supplying the loads required for attaining cold shutdown, assuming a single failure and the loss of offsite power. RG 1.139, "Guidance for Residual Heat Removal" (For Comment) (Ref. 8.20), specifies that the design should have the capability of establishing reacto: cold-shutdown conditior: using only safety-grade systems, and that residual heat removal systems should be capable of bringing the reactor to a cold-shutdown condition within 36 hours after shutdown with only offsite power or onsite power available, assuming the most limiting single failure. The present PRISM design, with RVACS as the only safetygrade decay heat removal system, does not satisfy this guidance. Further, sonfidence in the operability of the passive decay heat removal system in all credible conditions should be established as a prerequisite to this deviation from the RGs.

Although the EM pump power system appears to be a workable design, confidence needs to be established about its capabilities and its failure modes need to be understood. Reliability of the synchronous machine and other power system components to provide controlled coastdown power in faulted conditions must be demonstrated. Means to monitor synchronous machine performance during operation, which were addressed by GE in PSID Volume VI, Section G.4.7, will need to be further detailed and subsequently examined.

The factors chosen to be tracked for early indication of machine degradation appear to give a good representation of performance during normal operation. However, the adequacy of these factors as indications of machine readiness will be examined when more detailed design information and test data are available. The possibility of common-mode failures of the synchronous machines will also be examined when more detailed design information and performance data are available. 
This review included a comparison of the PRISM design with the proposed requirements of EPRI as stated in the "Advanced Light-Water Reactor Utility Requirements Document" (ALWR Passive Plant) (Ref. 8.3). Although intended for application to LWR plants, some general criteria proposed in the document may apply to other reactor types.

The PRISM design does not use an onsite safety-grade ac power source (EPRI General Requirement 2.3.1.7), although standby, non-safety-related, onsite power systems are available. EPRI Requirement 1.5.2 specifies that these standby sources should be sized so that each can supply power to keep the plant in hot standby condition, and both can supply loads necessary to achieve normal cooldown. A number of related requirements are detailed in Chapter 11 of the EPRI Requirements Document, "Electric Power Systems," to ensure that the dc power system is capable of providing power for required loads in the event of a loss of ac power. EPRI Requirement 1.5 .3 gives a guideline that passive safety systems, including the associated dc power systems for monitoring and control, should function for at least 72-hours during a loss of ac power. This dictates that battery capacity (Requirement 7.2.3) meet the 72-hour requirement to supply selected safety loads. Other related design considerations include the ability to cope with extended operation (72-hours) of the dc and low-voltage ac systems without forced or ambient cooling (Requirement 7.2.4); the choice of battery types to reduce the chance of commonmode battery failures of the safety-grade power supply to less than 1 percent of all failures affecting separate divisions (Requirement 7.4.2.5); specification of battery charger capacity so that steady-state loads will be supplied under the maximum expected load conditions while recharging batteries from design minimum charge to 95 percent of fully charged within 24 hours. The requirements given here do not indicate a current or future regulatory stance, but show areas in which the present design does not appear to conform with perceived industry design trends.

As discussed in Section 8.2, due to the current level of design detail and the nature of the preapplication review, the majority of review attention was directed toward safety-related functions of electrical systems. However, in future reviews, the detailed design will be evaluated against the requirements of 10 CFR 50.49, "Environmental Qualification of Equipment Important to Safety," as well as the RGs, SRPs, and GDC of 10 CFR Part 50 (Ref. 8.21) listed in Sections 8.2 and 8.3. Particular emphasis will be directed toward requirements of GDC 17, including diversity and redundancy of breaker tripping and closing devices, fault protection and isolation, physical separation of circuits and components, and methods to test electrical jower system operation. The reviewers will also assess desig" details such as satisfactory means of lightning pintection, cathodic protection, lighting, and service power distribution.

\subsubsection{Conclusion}

The conceptual design of the PRISM electrical distribution system is based upon accepted power distribution practices. The detailed design is expected to meet NRC requirements. Issues remain involving the lack of an emergency ac power source, and the capability of the EM pump power system to supply coastdown to the EM pumps.

In particular, the viability of the design approach for emergency ac power is based upon the RVACS ability to meet decay heat removal requirements for loss of offsite power and station blackout. The design does not satisfy current LWR regulatory guidance because it cannot establish cold shutdown during a loss of offsite power. More information will be required to demonstrate dc system reliability and capacity. Future reviews will require demonstration of the ability of the synchronous machines to provide EM pump controlled coastdown power in faulted conditions, as well as details of means to monitor controlled coastdown.

\subsection{Electromagnetic Pump Power System}

The four primary sodium-coolant pumps are electromagnetic (EM) pumps and they are normally supplied power from the non-Class $1 \mathrm{E}$ ac distribution system. The non-Class $1 \mathrm{E}$ ac distribution system has a preferred offsite power supply and a secondary offsite power supply, as part of the common station service system. The secondary offsite power supply system also includes two non-safety-related standby gas-turbine generators, each rated at $2,000 \mathrm{~kW}$, that can feed the $7.2-\mathrm{kV}$ distribution systems. If the preferred and the secondary offsite power supplies are both lost, these generators can furnish power to common equipment essential to maintaining plant operation and preventing major equipment loss, but not to the EM pumps. The plant and, therefore, the EM pumps have no emergency ac power system.

\subsubsection{Design Description and Safety Objectives}

After a scram, a 2-to-3-minute long controlled coastdown of the EM pumps is required to prevent core temperatures from exceeding acceptable limits.

Power to the four EM pumps is normally supplied from a 7.2-kV, 3-phase, $60-\mathrm{Hz}$, ac distribution system through a dedicated input transformer and a highly reliable solid-state 
power conditioning unit. Each EM pump has a separate, independent power supply and coastdown system. The flow control regulator, which receives input from the nonsafety-related plant protection system, feeds the power conditioning unit to control the primary sodium flow. This unit also supplies power to the EM pump during startup and normal shutdown operation. On loss of this system, power to the EM pumps is required for a controlled coastdown for a period of about 2 to 3 minutes to prevent core temperatures from exceeding acceptable limits. This power comes from a synchronous motor-generator machine which, in normal operation, runs in a standby mode. The synchronous machine is self-excited; once the machine has started, the excitation current is generated through its own rotational motion without need for an external power supply. During startup of an EM pump, the ac power is needed for the initial excitation of the synchronous machine.

The EM pumps and synchronous coastdown machine performance are monitored for degradation during power operation.

The parameters used to monitor the performance of the EM pumps are listed in Table 8.1.

The parameters used to monitor the performance of the synchronous coastdown machines are listed in Table 8.2.

Table 8.1 EM pump performance monitoring parameters

\begin{tabular}{||l|l|}
\hline Parameter & Purpose \\
\hline \hline Pump discharge sodium pressure & Control performance and diagnostics \\
\hline $\begin{array}{l}\text { Insulation and core lamination temperatures } \\
\text { allowable limits }\end{array}$ & $\begin{array}{l}\text { Relate to coil and magnetic material properties for the detection } \\
\text { temperatures of impending failures, comparison allowable limits }\end{array}$ \\
\hline Duct temperature & Performance analysis, comparison to analytical predictions \\
\hline Sodium leakage & Detection of internal sodium leakage (failure of seal welds) \\
\hline Stator internal gas pressure & $\begin{array}{l}\text { Loss of inert gas from the stator pressure cavity, (leak } \\
\text { monitoring) }\end{array}$ \\
\hline
\end{tabular}

Table 8.2 Synchronous coastdown machine performance monitoring parameters

\begin{tabular}{||l|l||}
\hline Parameter & Purpose \\
\hline \hline Input/output voltage and current & Determine load and control for protection and diagnostics \\
\hline Output power & $\begin{array}{l}\text { Control and waveform analysis for performance monitoring, } \\
\text { diagnostics, maintenance, and the evaluation of power factor } \\
\text { correction, switching transients, etc. }\end{array}$ \\
\hline Shaft speed output frequency & Performance, diagnostics, and maintenance \\
\hline Shaft torque & Performance, diagnostics, and maintenance \\
\hline Rotor electrical voltage and current & $\begin{array}{l}\text { Measure output of the synchronous machine's pilot exciter and } \\
\text { regulator circuitry for control and diagnostics }\end{array}$ \\
\hline Vibration & Performance, diagnostics, and maintenance \\
\hline Bearing temperatures & Performance, diagnostics, and maintenance \\
\hline Winding temperature & Performance, diagnostics, and maintenance \\
\hline
\end{tabular}


The power conditioning unit is a three-stage solid-state device. The first stage is an ac-to-dc converter. The second stage filters the dc current and makes it available to the output section of the unit. The third stage is a set of solid-state switches that converts the dc output to a three-phase power source for the EM pump and its associated synchronous coastdown machine. The power conditioning unit forces a three-phase square wave current to flow through the EM pump windings. The rotating synchronous machine develops a sinusoidal counter electromotive force which develops a nearly sinusoidal voltage waveform on the EM pump stator.

The power conditioning unit is instrumented as listed in Table 8.3 to verify and monitor its performance.

All of the elements from the secondary side of the isolation transformer through the EM pump and the synchronous machine are electrically isolated from ground. The only ground point in the electrical power system for the primary heat transport system is a grounding resistor located in the power conditioning unit. A separate safety ground wire connects the frame of the synchronous machine, the magnetic core laminations and Faraday shield of the input transformer, the housing of the EM pump, and the metal enclosure of the power conditioning unit to the facility electrical ground at the power conditioning unit. This safety ground conductor protects personnel and equipment.

A ground fault detection and limitation system, consisting of a grounding scheme and a current measurement and lin iting resistor, is provided for the EM pump and the synchronous machine. This system performs the requisite protection functions, supplies the needed diagnostics for continuous on-line monitoring of the electrical insulation, and detects any deterioration. If a fault to ground occurs in either the EM pump or the synchronous coastdown machine, the current must flow through the fault into the grounding circuit, then through the grounding resistor to complete the circuit back to the source. The maximum current will be sized to prevent any single ground fault from supplying sufficient energy to burn through the EM pump duct. Operator alarms and pump trips are set to initiate protective actions, such as shuiting down the reactor, before any damage can occur.

If the ground leakage current is large enough, the nonsafety-related plant protection system automatically opens the power-conditioning unit breakers, thereby tripping the EM pump and allowing the synchronous coastdown machine to switch to its generator mode to provide flow coastdown. The resulting mismatch in the core flux-toflow ratio will produce a scr.um signal in the safety-related reactor protection system. Following positive indication of scram and control rod insertion, the remaining EM pumps will be tripped.

If a scram occurs during a ground fault, the reactor protection system opens all of the EM pump breakers (the scram logic andes circuitry to delay EM pump trip following a scram until positive indication of control rod insertion is received) and the synchronous coastdown machines switch to generator mode. When the EM pump breakers open, the ground fault is isolated and the current through the fault cannot return to the synchronous machine.

The power-conditioning unit, the EM pump synchronous coastdown machines, the EM pump breakers, and the overcurrent breakers are located below grade on the seismic island in separate reinforced-concrete, tomadohardened seismic Category I equipment vaults.

\section{Table 8.3 Power conditioning unit performance monitoring parameters}

\begin{tabular}{|l|l|}
\hline Parameter & Purpose \\
\hline Output voltage, current, and power & Determine load and control for protection and diagnostic purposes \\
\hline Output frequency & $\begin{array}{l}\text { Control and waveform analysis for performance monitoring, } \\
\text { diagnostics, and maintenance }\end{array}$ \\
\hline Ground fault current & $\begin{array}{l}\text { Measure insulation performance and detect: failure of insulation } \\
\text { system; output for a ground fault trip; identification of the phase } \\
\text { with which a ground fault is identified }\end{array}$ \\
\hline
\end{tabular}




\subsubsection{Scope of Review}

The review focused on the normal power supply system to the EM pumps and the safety related aspects of the EM pump synchronous coastdown machines. The electrical systems necessary to ensure the availability of the synchronous coastdown machines were reviewed, along with the design criteria and failure modes studies presented in the PSID Chapter 8 and Appendix G, to support the EM pump system design.

\subsubsection{Design Criteria}

The synchronous coastdown system is connected in parallel with the EM pump and is considered safety related. Normally, it is running unloaded in an overexcited mode of operation, supplying the reactive power requirements of the EM pump. Upon loss of the normal power supply to an EM pump, the stored kinetic energy in the synchronous machine is used to provide flow coastdown of the EM pump. The synchronous machine converts the kinetic energy of the spinning rotor and flywheel into electrical energy required by the EM pump to yield the necessary primary flow coastdown.

If normal power to the EM pumps should fail, the coastdown of the pump needs to be ensured. To accomplish this, the reactor protection system will, upon sensing loss of flow, open double safety-related breakers to isolate the power to the pump and associated synchronous machine from the rest of the power system to ensure coastdown power. The synchronous machine is designed and qualified as Class $1 \mathrm{E}$, and any sensor whose failure could impair the safety performance of the synchronous machine is Class $1 \mathrm{E}$ and is continuously monitored by the reactor protection system.

To ensure that the EM pump synchronous coastdown machines provide the necessary flow coastdown to remove decay heat, the reactor protection system scram logic includes circuitry to delay EM pump trip following a scram until positive indication of control rod insertion is received. After the reactor protection system senses that the core flux is rapidly decreasing, indicating that the rods are inserting into the core, a sigual is sent to open the EM pump circuit breakers. Opening the breakers shuts off normal ac power to the EM pumps, so the synchronous machines can produce a controlled coastdown.
The four EM pump synchronous cosstdown machines and their associated electrical equipment and instruments are each housed in four separate below-grade, reinforcedconcrete, tornado-hardened, seismic Category I equipment vaults. These vaults are located on the seismic island to isolate seismically, to support structurally, and to protect environmentally the EM pump flow controllers, the powerconditioning units, the safety-related synchronous coastdown machines, and related equipment.

The EM pump failure rates and risk estimates are given in Appendix A to this report. These evaluations include effects of systems interactions, environmental interactions, aging, maintenance, and performance monitoring.

The EM pump synchronous coastdown machine failure modes are identified in Table 8.4.

There are no system interactions among the four pump systems except for use of the same power supply system. The successful coastdown of each EM pump is fully dependent upon the successful operation of that EM pump and its associated synchronous coastdown machine, and its safety-grade Class 1E breakers. Backing up each circuit breaker are individual Class $1 \mathrm{E}$ current overprotection devices.

The only credible external common-cause failure that fails two or more coastdown systems simultaneously is a very strong earthquake. Since the coastdown equipment is seismically isolated, the effects of a strong earthquake will be considerably mitigated. Fire, smoke, and loss of heating and ventilation are not postulated to be major common-cause risk factors due to the separation and 3-hour fire barriers of the EM pump auxiliary equipment vaults, and the short time interval (2 to 3 minutes) during which the synchronous coastdown machine is required. Aging is not expected to be a concern because of the online p.rformance monitoring systems. Plant operation and maintenance requirements will include protection to prevent common-mode failures from such human actions as testing, calibration, and maintenance.

Common-mode failures, associated with the mechanical and physical design of the hardware and within the electrical supplies and control systems, that could result in the loss of more than one EM pump synchronous coastdown machine need to be evaluated when the system design is complete. 
Table 8.4 EM pump synchronous coastdown machine fallure modes

\begin{tabular}{||l|l|}
\hline Failure & Information Parameter \\
\hline Winding fails open & Input current and voltage; loop pressure and flow \\
\hline Winding turn-to-turn failure & Input current and voltage; loop pressure and flow \\
\hline Winding short to ground (ground fault) & Ground fault detection and diagnostics \\
\hline General insulation degradation & Ground fault detection and diagnostics \\
\hline Rotor diode failure & Current, voltage, loop pressure and flow \\
\hline Regulator failure & Current, voltage, loop pressure and flow \\
\hline $\begin{array}{l}\text { Pilot exciter fails to provide proper voltage and } \\
\text { current }\end{array}$ & Current, voltage, loop pressure and flow \\
\hline Bearing fails & Bearing temperature, vibration, rotor speed \\
\hline Excessive vibration & Bearing vibration \\
\hline Shaft torque incorrect & Shaft torque \\
\hline Shaft rotational speed improper & Shaft speed, current, voltage, and loop pressure and flow \\
\hline
\end{tabular}

\subsubsection{Research and Development}

A test program for the EM pump and synchronous machine is planned. The planned test program for the EM pump will test the components of a full-size EM pump and synchronous coastdown machine in a facility separate from the PRISM prototype test facility. The testing will be performed in sodium over a range of conditions. The test program should examine the coastdown performance of the synchronous machine and the effects of transition from an unloaded synchronous motor to a synchronous generator. The EM pump and synchronous coastdown machine will also be tested as part of the advanced liquid-metal reactor prototype test.

A 1/4-length, full-diameter stator segment of an EM pump was tested at Argonne National Laboratory (ANL) to estimate the thermal load, profile, and distribution expected in a plant-scale pump. The tests also included a full simulation of the electrical and mechanical stresses imposed on the coil insulation. A nominal sodium flow through the stator segment provided a prototype of the heat removal mode of operation. Although the duration of the stator segment test was short - the test lasted 3,600 hours - it gave confidence that the coil insulation is sufficiently developed to be used in a prototype full-size EM pump. In parallel with the stator segment test, ANL is conducting thermal aging and high-voltage testing of insulation samples and individual coils in ovens. These tests continued through fiscal year 1992. The findings of these tests, which include several insulation systems, temperatures from 773 to $973 \mathrm{~K}\left(960\right.$ to $\left.1,315^{\circ} \mathrm{F}\right)$, and constant voltages of either 1500 or $2000 \mathrm{~V}$, will be used to predict the insulation lifetime under normal operating conditions, that is, at lower temperatures and voltages.

\subsubsection{Safety Issues}

The primary failure mechanism of concern within the power systems is an electrical fault in the pump stator or in the power feeds. Such a failure could result from a breakdown of the electrical insulation system due to excessive temperatures, mechanical abrasion, or leakage of sodium into the stator housing. The windings are arranged so that the fault would first be to ground, and would be handled by the ground fault protection system.

The synchronous coastdown machine remains connected to the EM pump to provide the desired coastdown, and since the ground loop is also disconnected by opening the EM pump breakers, the ground fault will not impede the transfer of energy from the synchronous coastdown machine to the EM pump as long as the fault remains a simple fault to ground. Evaluations are being performed by the designers to determine what happens if the synchronous machine continues to supply power to the EM 
pump when the pump has an electrical fault. It is not expected that an unsafe level of damage will occur since the amount of power that the synchronous constdown machine can supply is limited. In addition, a possible second passive overcurrent protection device, which would be incorporated into the synchronous machine, will also be evaluated.

The possibility that operation of an EM pump during refueling could result in absorber bundle ejection or floatation was raised earlier in the review. The absorber bundle design requires that the bundle not be lifted by hydraulic forces when the bundle driveline is disconnected and the pumps are operating at full flow, and that the absorber bundle will fall into the core in a few seconds against full flow following a scram. GE analyses on the current design, absorber bundle geometries and pump flow rates, indicate a substantial difference between the lift force generated by the pump and the force needed to lift the absorber bundle; the forces are $4.9 \mathrm{kPa}(0.72 \mathrm{psi})$, and $45.5 \mathrm{kPa}(6.6 \mathrm{psi})$, respectively. Periodic scram testing will ensure absorber bundle drop against full-flow conditions.

The synchronous machine flywheel and rotor are designed to satisfy prescribed coastdown flow requirements. The flow profile, as a function of time, is selected by the designer to maintain the required flow-to-power ratio during core shutdown to minimize thermal shock and to furnish sufficient flow coastdown to prevent overtemperature challenges during loss-of-flow events. If the planned test program, as discussed in Section 8.3.4, indicates that the synchronous machine is not performing as required, the mechanical and physical design can be modified to obtain the necessary characteristics.

During an unprotected, loss-of-heat sink (ULOHS) event, the EM pumps are designed to trip to eliminate them as a source of heat to the reactor. A separate Class $1 E$ thermal shutoff system that backs up the reactor protection system automatically opens Class 1E pump circuit breakers when the cold sodium pool reaches a temperature of $810 \mathrm{~K}$ $\left(1,000^{\circ} \mathrm{F}\right)$. Tripping at this temperature ensures that the EM pumps will have sufficient electrical integrity to provide coastdown. The thermal shutoff system utilizes separate Class 1E thermocouples and temperaturemeasuring electronic chassis for each EM pump. The thermocouples measure the pump outlet temperature, which is normally within $3 \mathrm{~K}\left(5^{\circ} \mathrm{F}\right)$ of the inlet sodium temperature. When two of the four exceed the setpoint, a signal is sent to open the circuit breakers. Since the thermal shutoff system is separate from the reactor protection system, the chance that it also fails during a ULOHS events is judged by the designers to be remote. In the unlikely event that the EM pumps cannot be disconnected from their power supplies by the EM pump circuit breakers, the operator has hours in which to take action manually to turn off the pump before excessive sodium temperatures are caused by pump-heating.

A failure-modes anal; sis of the final design, including common-mode failures, of the EM pumps, synchronous coastdown machines, and the associated electrical supplies and control systems will be needed at a later review stage.

\subsubsection{Evaluation}

The ability to monitor the necessary parameters and to initiate electrical disconnection under all potential loss-ofpower conditions with safety-related equipment appears to be critical. If one EM pump and its coastdown are lost, the designer's analysis demonstrates that it is important to ensure coastdown of at least two of the three remaining EM pumps to avoid sodium boiling during an unprotected loss-of-flow transient. Coastdown of the remaining three EM pumps is required for this event only if all three gas expansion modules are also assumed to not function.

If the reactor scram is successful, it does not appear that the synchronous coastdown machines are needed to ensure fuel integrity.

To ensure that the EM pump synchronous coastdown machines can provide the necessary flow coastdown to remove heat, the reactor protection system scram logic includes circuitry to delay EM pump trip following a scram until positive indication of control rod insertion is received. When the reactor protection system senses that the core flux is rapidly decreasing, indicating that the rods are inserting into the core, it then sends a signal to open the EM pump circuit breakers. Opening these breakers shuts off power to the EM pumps, thereby initiating the controlled coastdown.

If a ground fault occurs in an EM pump or its synchronous machine, the non-safety-related plant protection system opens the power conditioning unit breakers and trips the EM pump, and the synchronous coastdown machine furnishes power for flow coastdown. If a coincident scram occurs, the reactor protection system opens the EM pump breakers and the synchronous coastdown machines supply coastdown power.

The normal power supply to the EM pumps is from the non-Class $1 \mathrm{E}$ ac distribution system through the highly reliable power conditioning unit. The safety-related synchronous coastdown machines meet the intent of GDC 2 ("Design Bases for Protection Against Natural Phenomena"), GDC 4 ("Environmental and Dynamic Effects Design Bases"), and GDC 5 ("Sharing of 
Structures, Systems, and Components") of 10 CFR Part 50 since they are protected against natural phenomena, are designed to account for environmental and dynamic effects, and do not share structures, systems, or components between nuclear power units. The common station service system does cross-connect the non-Class 1E ac power supplies (preferred and secondary) between modules; however, the power conditioning units and the circuit breakers provide appropriate isolation between each EM pump, and its associated EM pump synchronous coastdown machine. The power conditioning units and the EM pumps are instrumented to monitor performance and diagnose degradation problems or failures, consistent with GDC 18 ("Inspection and Testing of Electric Power Systems") of 10 CFR Part 50. The synchronous coastdown machines are also instrumented and meet the intent of GDC 18 for the inspection and testing of electrical systems important to safety. The safety-related synchronous coastdown machines are self-exciting during normal operations and do not require any extemal power source; therefore, GDC 17 ("Electric Power Systems") does not appear to be applicable to this machine.

The power supply to the EM pumps comes from a nonClass 1E ac distribution system, since the EM pumps are not required 10 remove decay heat (RVACS removes the decay heat). The synchronous cosstdown machine, however, is required to ensure adequate flow cosstdown if power to the EM pump is lost, so it is considered safety related and is Class $1 E$.

\subsubsection{Conclusion}

The information in the PSID is considered sufficient at this stage of the review to conclude that adequate testing will be provided to determine failures or degradations within the EM pump and synchronous coastdown machine power systems.

Testing of the EM pump design is ongoing and the results of these tests will be reviewed at a later stage in the design review. Separate effects testing of the EM pump and synchronous coastdown machine are planned. These tests need to examine the effects of transition from an unloaded synchronous motor to a synchronous generator when the EM pump breaker is tripped.

The instrumentation and sensors to monitor the performance of the power-conditioning unit, the EM pump, and the synchronous machine will be reviewed in more detail at a later design stage.

Additional studies by the designers evaluating the potential effects of ground faults in the EM pump power system will also be reviewed at a later date.
A failure-modes analysis of the final design, including common-mode failures, of the EM pumps, synchronous constdown machines, and the associated electrical supplies and control systems will be needed at a later review stage.

\subsection{References}

8.1 General Electric, PRISM-Preliminary Safety Information Document, GEFR-00793 UC-87Ta, November 1986.

8.2 U.S. Nuclear Regulatory Commission, "Standard Review Plan for the Review of Safety Analysis Reports for Nuclear Power Plants, LWR Edition," NUREG-0800, July 1982.

8.3 Electric Power Research Instituto-Advanced LightWater Reactor Utility Requirements Document, Vol. III, "ALWR Passive Plant," Chapter 2, "Power Generation Systems," 1990.

8.4 U.S. Nuclear Regulatory Commission, "Independence Between Redundant Standby (On site) Power Sources and Between Their Distribution Systems," Regulatory Guide 1.6.

8.5 U.S. Nuclear Regulatory Commission, "Criteria for Safety-Related Electric Power Systems for Nuclear Power Plants," Regulatory Guide 1.32.

8.6 U.S. Nuclear Regulatory Commission, "Electric Penetration Assemblies in Containment Structures for Nuclear Power Plants," Regulatory Guide 1.63.

8.7 U.S. Nuclear Regulatory Commission, "Physical Independence of Electric Systems," Regulatory Guide 1.75.

8.8 U.S. Nuclear Regulatory Commission, "Shared Emergency and Shutdown Electric Systems for Multi-Unit Nuclear Power Plants," Regulatory Guide 1.81 .

8.9 U.S. Nuclear Regulatory Commission, "Environmental Qualification of Electric Equipment Important to Safety for Nuclear Power Plants," Regulatory Guide 1.89 .

8.10 U.S. Nuclear Regulatory Commission, "Availability of Electric Power Sources," Regulatory Guide 1.93.

8.11 U.S. Nuclear Regulatory Commission, "Seismic Qualification of Electric and Mechanical Equipment for Nuclear Power Plants," Regulatory Guide 1.100. 
8.12 U.S. Nuclear Regulatory Commission, "Periodic Testing of Electric Power and Protection Systems," Regulatory Guide 1.118.

8.13 U.S. Nuclear Regulatory Commission, "Installation Design and Installation of Large Lead Storage Batteries for Nuclear Power Plants," Regulatory Guide 1.128.

8.14 U.S. Nuclear Regulatory Commission, "Qualification Tests of Electric Cables, Field Splices, and Connections for Light-Water-Cooled Nuclear Power Plants," Regulatory Guide 1.131.

8.15 U.S. Nuclear Regulatory Commission, "Criteria for Power, Instrumentation, and Control Portions of Safety Systems," Regulatory Guide 1.153.

8.16 U.S. Nuclear Regulatory Commission, "Selection, Design and Qualification of Diesel-Generator Units Used as Standby (On site) Electric Power Systems at Nuclear Power Plants," Regulatory Guide 1.9.
8.17 U.S. Nuclear Regulatory Commission, "Periodic Testing of Diesel Generator Units Used as On site Electric Power Systems at Nuclear Power Plants," Regulatory Guide 1.108.

8.18 U.S. Nuclear Regulatory Commission, "Station Blackout," Regulatory Guide 1.155.

8.19 U.S. Nuclear Regulatory Commission, "Qualification of Safety-Related Lead Storage Batteries," Regulatory Guide 1.158.

8.20 U.S. Nuclear Regulatory Commission, "Guidance for Residual Heat Removal," Regulatory Guide 1.139 .

8.21 U.S. Nuclear Regulatory Commission, Code of Federal Regulations, Title 10, "Energy," Part 50, "Domestic Licensing of Production and Utilization Facilities." 


\section{AUXILIARY SYSTEMS}

\subsection{Summary Descriptions}

As categorized by the PRISM designer, the auxiliary systems compromise (1) the fuel handling and storage system; (2) the water system; (3) process auxiliaries; (4) the heating, ventilation, air conditioning system; (5) the auxiliary liquid-metal system; (6) the sodium piping and equipment heating and insulation system; and (7) other auxiliary systems.

\subsubsection{Fuel Handling and Storage System}

The fuel handling and storage system is also known as the reactor refueling system (RRS). It is used (1) to receive, inspect, store, and prepare new assemblies for use; (2) to move assemblies between buildings; (3) to move assemblies within the vessel; (4) to store fuel temporarily; (5) to prepare assemblies for shipment; and (6) to control the inventory of assemblies. The RRS manipulates fuel blanket, control, and radial shield assemblies.

\subsubsection{Water System}

The water system comprises several subsystems. The subsystems and their functions are (1) the plant service water system to transfer heat from the balance-of-plant (BOP) auxiliary systems to the cooling towers; (2) the chilled water system to cool rooms; (3) the treated water system to supply makeup water, steam generator blowdown cleanup water, drinking water, and chemical feedwater; (4) the water source system to supply water to the cooling tower basin and the water treatment facility; and (5) the waste water treatment system to handle sanitation waste.

\subsubsection{Process Auxiliaries}

The process auxiliaries are (1) the inert gas receiving and processing system (IGRPS), (2) the impurity monitoring and analysis system, and (3) the compressed air system.

\section{Inert gas receiving and processing system}

The IGRPS provides liquified and ambient gas supply storage, delivers inert gases of specified composition and purity at regulated flow rates and pressures to use throughout the PRISM plant. The IGRPS also accepts the contaminated gasses through its vacuum and compressor facilities for storage and transfer to the gas radwaste system.

\section{Impurity monitoring and analysis system}

The impurity monitoring and analysis system provides sampling, monitoring, and analysis of the plant sodium systems and the plant nitrogen, helium, and argon gas systems in the PRISM plant, and acceptance sampling and analysis of incoming sodium, argon, helium, and nitrogen. Impurities in the sodium coolant, reactor cover gas, and intermediate sodium system argon are monitored to aid the reactor operator in maintaining proper sodium and cover gas purity levels and to provide information on potential degradation of components.

\section{Compressed air system}

The compressed air systems consist of three reciprocating air compressors, complete with intake filter-silencers, intercoolers, aftercoolers, and air receiver, prefilters, driers, afterfilters, and interconnecting piping and valves to distribute the compressed air throughout the plant.

\subsubsection{Heating, Ventilation, and Air Conditioning System}

The heating, ventilation, and air conditioning (HVAC) system controls the air temperature for both the nuclear island and the balance of plant. The system (1) controls temperature, humidity, pressure, and cleanliness of the air; (2) removes heat released by various pieces of equipment; (3) supplies directed air for cooling; (4) sustains ventilation and exhaust; and (5) helps to control airborne radioactivity.

\subsubsection{Auxiliary Liquid-Metal System}

The auxiliary liquid-metal system comprises the auxiliary intermediate liquid-metal system and the auxiliary primary liquid-metal system. The two systems are further subdivided into the sodium receiving and transfer subsystem (SRTS), the intermediate sodium processing subsystem (ISPS), and the primary sodiuri processing subsystem (PSPS).

The auxiliary intermediate liquid-metal system is used (1) to receive, melt, and transfer all sodium delivered to the site; (2) to prepare the intermediate sodium for offsite disposal; (3) to purify the IHTS and the SDT sodium; (4) to fill the IHTS loop or the SDT with sodium by using the ISPS electromagnetic (EM) pump; (5) to transfer sodium between the IHTS and the SDT; (6) to fill the reactor with sodium using the ISPS EM pumps; (7) to maintain sample connections for withdrawal of fresh sodium and IHTS-loop sodium for the impurity monitoring and analysis system; and (8) to supply sodium to the intermediate sodium plugging temperature indicator.

The auxiliary primary liquid-metal system is used (1) to purify the primary sodium in the reactor vessel and in the primary sodium storage vessel; (2) to maintain sodium transfer and storage facilities; (3) to remove heat from the 
coolant used in the primary cold traps; (4) to supply sodium to the primary sodium plugging indicator; and (5) to maintain primary sodium sample connections for the impurity monitoring and analysis system.

\subsubsection{Sodium Piping and Equipment Heating and Insulation System}

The sodium piping and equipment heating and insulation system is used to control the temperature of sodiumcontaining components, including the reactor vessel. The system is used to preheat the sodium process systems before initial fill and whenever needed. The system also maintains the sodium systems at a minimum temperature.

\subsubsection{Other Auxiliary Systems}

The other auxiliary systems are the plant fire protection systems (PFPSs), the communication system, and the plant lighting system. The design of these auxiliary systems and their safety objectives are detailed in Section 9.8.1, and the PFPS is given separate treatment in Section 9.9.

\subsection{Fuel Handling and Storage System (Reactor Refueling System)}

\subsubsection{Design Description and Safety Objectives}

The reactor refueling system (RRS) is designed for an 18month fuel-handling interval and a 60-year plant life. The refueling process will nominaily take 22 days.

The preap licant stated that the RRS will use "as low as reasonably achievable (ALARA)" radiation protection principles, and will meet 10 CFR Part 20 exposure limits. Further, the RRS will protect the health and safety of the public and the plant personnel, will maintain a leak-tight barrier, and will keep the fuel in a safe condition during all operations and accidents. The preapplicant stated that the system will function passively, without operator actions.

The preapplicant stated that the RRS will contain a release from the failure of 271 fuel pins, which is one fuel assembly of the original core design. The core, however, has been modified to a reference design of 331 fuel pins. The difference in the number of fuel pins will need to be addressed at a later stage of review.

The PRISM reactor will store up to 22 assemblies in the outlet plenum above the reactor core. The fuel assemblies are kept in the reactor vessel for at least one cycle to reduce the decay power level during fuel handling.

To refuel, the reactor is shut down and the sodium is cooled to $480 \mathrm{~K}\left(400^{\circ} \mathrm{F}\right)$. The portable refueling enclosure is secured above the reactor. The enclosure functions as a containment. The enclosure is evacuated to $0.85 \mathrm{kPa}(0.25 \mathrm{in} \mathrm{Hg})$ by gas treatment systems during refueling and maintenance operations. The helium cover gas in the containment is replaced with fresh helium to reduce the possibility of airborne radiation. An adapter is installed through the containment and the head access area roof and is attached to the transfer port. The fuel transfer cask, already loaded with a fresh fuel assembly, is then attached to the adapter.

A spent assembly is moved from the core to an in-vessel storage position by the in-vessel transfer machine (IVTM). The fuel from the fuel transfer cask is lowered to the invessel transfer position, then moved by the IVTM to an empty position within the core. The IVTM then moves a spent assembly from the core to an in-vessel storage position. The IVTM then moves a decayed spent fuel assembly from the in-vessel storage to the transfer position. Finally, the decayed spent fuel assembly is raised into the fuel transfer cask. This cycle is repeated for all fuel assemblies. The movement of the non-fuel assemblies (blanket, control, and radial shield assemblies) is similar, but they are not stored in the in-vessel storage for a cycle before being removed from the core.

The RRS comprises the reactor fuels handling system (RFHS), the transport system (TS), and the fuel receiving, storage, and shipping system (FRSSS).

The RFHS is designed to replace such core components as fuel, blanket, radial shield, and control assemblies. It is able to begin refueling 4 days after shutdown, and can complete all refueling within 22 days after shutdown. It will function with the primary coolant temperature at $480 \mathrm{~K}\left(400^{\circ} \mathrm{F}\right)$. It will be able to move failed fuel assemblies without special precautions. The RFHS main components are the in-vessel transfer machine, the rotatable plug drive, and the fuel transfer port.

The transport system comprises the fuel transfer cask (FTC), the cask transporter (CT), and the refueling enclosure (RE). It will move fuel between the fuel cycle facility and the reactor during the refueling outages.

The FRSSS will receive, store, and transfer the core assemblies to the co-located fuel cycle facility, and it will support the RFHS during refueling.

\subsubsection{Scope of Staff Review}

The review covered the RRS as presented in Chapter 9 of the PSID (Ref. 9.1). The following regulatory guidance was reviewed for general applicability to the PRISM design. Current SRPs and regulatory guides (RGs) were 
developed specifically for light-.vater reactors (LWRs). Similar guidance for liquid-metal reactors has not been developed. The PRISM RRS should meet the intent of the following standard review plan (SRP) sections (Ref. 9.2):

- 9.1.1, "New Fuel Storage"

- 9.1.2, "Spent Fuel Storage"

- 9.1.3, "Spent Fuel Pool Cooling and Cleanup System"

- 9.1.4, "Light Load Handling System (Related to Refueling)"

- 9.1.5, "Overhead Heavy Load Handling System"

- 9.4.2, "Spent Fuel Pool Area Ventilation System"

- 9.4.3, "Auxiliary and Radwaste Area Ventilation System"

The SRP sections require compliance with the following general design criteria (GDC) from Appendix A to 10 CFR Part 50, parts of which may apply to the PRISM RRS:

- 2, "Design Bases for Protection Against Natural Phenomena"

- 4, "Environmental and Missile Design Bases"

- 5, "Sharing of Structures, Systems, and Components"

- 44, "Cooling Water"

- 45, "Inspection of Cooling Water System"

- 46, "Testing of Cooling Water System"

- 61, "Fuel Storage and Handling and Radioactivity Control"

- 62, "Prevention of Criticality in Fuel Storage and Handling"

- 63, "Monitoring Fuel and Waste Storage"

\subsubsection{Design Criteria}

The preapplicant stated that, "The requirements in the NRC [SRP] Section 9.1.4, 'Fuel Handling System,' and NRC branch Technical Positions (BTPs) APCSBP-1, 'Overhead Crane Handling Systems for Nuclear Power Plants,' shall be used where applicable." The actual title of SRP Section 9.1.4 is "Light Load Handling System (Relaced to Refueling)." The cited BTP has been superseded by NUREG-0554 (Ref. 9.3), "Single-FailureProof Cranes for Nuclear Power Plants," and has been incorporated into SRP Section 9.1.5. In Table 3.2-1 of the PSID, the preapplicant identified the following equipment and structures of the reactor refueling systems as safety related. This table is reproduced here as Table 9.1.

\subsubsection{Research and Development Plans}

The RRS is in a preliminary stage of development. It is expected that there will be much research, development, and testing when a prototype of the PRISM reactor is built.

The preapplicant stated that the RRS or another supporting system will cool the core assemblies. The actual methods to be used need to be developed.

\subsubsection{Discussion of Safety Issues}

The staff raised the issue of containment early in the review. Part of the PRISM response was to design the refueling enclosure to act as secondary containment to mitigate refueling accidents.

\subsubsection{Evaluation}

The evaluation of the RRS was limited to identification of relevant codes and standards, and a cursory review of the proposed design and methodology. The review findings are given below.

The preapplicant submitted Table 9.1-7 in the PRISM PSID of unusual events to be considered in the design and analysis of the RRS. The table, however, appears incomplete; the preapplicant should also consider insertion of a hot fuel assembly into the fue! transfer cask and, therefore, the risk associated with this accident should be discussed.

The preapplicant stated that the RRS equipment and facilities will have an inherent means of cooling. The risk associated with failure of this means of cooling should be discussed.

The preapplicant stated that the refueling enclosure would act as secondary containment. The risk associated with failure of the secondary containment should be discussed.

The preapplicant stated that "LMFRB Safety Classifiration and Related Requirements," (Draft) American Nuclear Society ANSI/ANS 54.6 (Ref. 3a), October 1979, should be used to determine the safety classes of RRS equipment and facilities. The draft standard, however, was withdrawn by the American Nuclear Society. The 
preapplicant should submit a justification for its safety classification.

\subsubsection{Conclusions}

Since the PRISM design for the RRS is a conceptual design and the available information was limited, conclusions about acceptability cannot be made at this stage of the review.

The concepts of PRISM design for the RRS appear to be consistent with the objectives of the design for this stage of review.

Table 9.1 Safety-related equipment and structures for reactor refueling systems

\begin{tabular}{||l|l|c|c|c|}
\hline \multicolumn{1}{|c|}{ System } & \multicolumn{1}{|c|}{$\begin{array}{c}\text { Equipment or } \\
\text { Structure }\end{array}$} & $\begin{array}{c}\text { Safety } \\
\text { Class }\end{array}$ & $\begin{array}{c}\text { Quality Group } \\
\text { (QG) 2 or ASME } \\
\text { Code Sec/Class }\end{array}$ & $\begin{array}{c}\text { Seismic } \\
\text { Category }\end{array}$ \\
\hline Reactor fuel handling system & $\begin{array}{l}\text { In-vessel transfer } \\
\text { machine }\end{array}$ & 3 & QG-C & 1 \\
\hline Reactor fuel handling system & $\begin{array}{l}\text { Reactor fuel transfer } \\
\text { port adapter and gate } \\
\text { valve }\end{array}$ & 1 & III/1 & 1 \\
\hline Interim transport system & Fuel transfer cask & 3 & III/3 & 1 \\
\hline Mobile refueling enclosure & $\begin{array}{l}\text { Wall and roof steel } \\
\text { framing }\end{array}$ & 3 & QG-C & 1 \\
\hline Mobile refueling enclosure & Bridge crane & 3 & QG-C & 1 \\
\hline Reactor internal structures & In-vessel fuel storage & 1 & QG-A & 1 \\
\hline Reactor internal structures & $\begin{array}{l}\text { Core assembly } \\
\text { transfer station }\end{array}$ & 1 & QC-A & 1 \\
\hline
\end{tabular}

Notes:

1 Safety Class 1 (SC-1) applies to those components that are part of the primary coolant boundary; are used to perform scram functions under any plant conditions; or maintain core geometry or provide core support and whose failure could initiate a core disruptive accident.

Safety Class 2 (SC-2) applies to any component not in SC-1 that is required to maintain an adequate reactor coolant inventory following a primary coolant boundary leak; is part or an extension of the reactor containment boundary; is required to remove residual heat from the reactor core whose single failure following any plant condition constitutes _ IOSS of safety-function or that is not normal operating or cannot be tested adequately during normal power operation; the single failure of which could cause a loss of safety-function of other SC-2 components.

Safety Class 3 (SC-3) applies to those components not in SC-1 or SC-2 that are required to remove residual heat from the reactor core; the failure of which could result in the loss of safety-function of another component; that are extensions of the primary coolant boundary and are capable of being isolated from that boundary during all modes of normal reactor operation by two valves, each of which is either normally closed or capable of remote closure; the failure of which could result in the release to the environment of radioactivity and would result in potential offsite exposures that are comparable to the guideline exposure of 10 CFR Part 100.

2 QG-A corresponds to ASME Code Section III - Class 1, QG-B corresponds to ASME Code Section III - Class 2, QG-C corresponds to ASME Code Section III - Class 3. 


\subsection{Water System}

\subsubsection{Design Description and Safety Objectives}

The water systems, for the PRISM design, are divided into the following subsystems:

- Plant service water system

- Chilled water system

- Treated water system

- Water source system

- Waste water treatment system

The water systems, although required for generating electricity and for supporting a comfortable environment for personnel, are not required to assure nuclear safety.

\subsubsection{Scope of Staff Review}

Because of information available, the staff's review of the proposed water system was limited.

The following regulatory guidance was reviewed for general applicability to the PRISM design. Current SRPs and RGs were developed specifically for LWRs. Similar guidance for liquid-metal reactors has not been developed. The PRISM water system should meet the intent of the following SRP sections:

- 9.2.1, "Station Service Water System"

- 9.2.2, "Reactor Auxiliary Cooling Water Systems"

- 9.2.3, "Demineralized Water Makeup System"

- 9.2.4, "Potable and Sanitary Water Systems"

- 9.2.6, "Condensate Storage Facilities"

- 9.3.3, "Equipment and Floor Drainage System"

The SRP sections require compliance with the following GDC from Appendix A to 10 CFR Part 50 (Ref. 9.5), parts of which may apply to the PRISM water system:

- 2, "Design Bases for Protection Against Natural Phenomena"

- 4, "Environmental and Missile Design Bases"

- 5, "Sharing of Structures, Systems, and Components"

- 44, "Cooling Water"

- 45, "Inspection of Cooling Water System"

- 46, "Testing of Cooling Water System"

- 60, "Control of Releases of Radioactive Materials to the Environment"

\subsubsection{Design Criteria}

The preapplicant has not explicitly stated that the PRISM design will meet the intent of the cited SRP sections nor has the preapplicant identified any safety-related equipment or structures in the water system.

\subsubsection{Research and Development Plans}

The preapplicant submitted no research and development plans for the water system.

\subsubsection{Discussion of Safety Issues}

No safety issues associated with the water systems were identified at this time.

\subsubsection{Evaluation}

The PRISM water system designs are at a conceptual stage, and an in-depth evaluation is not practical or necessary at the preapplication stage of review.

The design is expected to use available technology, and the water system will not connect to any safety-related equipment, with the possible exception of the HVAC system.

Many of the SRP sections cited for the water system review apply to non-safety-related equipment. The PRISM design is expected to follow the SRP guidance.

\subsubsection{Conclusions}

The PRISM design for the water system appears to be consistent with the objectives of the design for this stage of review.

\subsection{Process Auxiliaries}

\subsubsection{Design Description and Safety Objectives}

The IGRPS is part of the containment for sodium systems during shutdown and will help to keep gas release below the limits stated in 10 CFR Part 50 (Appendix I).

The IGRPS is used (1) to receive, store, transfer, distribute, and process inert gas; (2) to supply helium cover gas for the reactor system; (3) to establish a helium atmosphere in the fuel cycle facility for receiving, storing, and shipping fuel; (4) to supply argon cover gas for the intermediate heat transfer system (IHTS) loops and the sodium dump tanks (SDTs); (5) to maintain a purge capability for IHTS maintenance; (6) to maintain a nitrogen purge capability for the sodium-water-reaction 
pressure-relief subsystem (SWRPRS) and for the steam generator system following a leak; (7) to establish vapor traps for all inert gases discharged from sodium systems; and (8) to sustain a vacuum for sodium transfer and gas analysis. The IGRPS is subdivided into the helium, argon, and nitrogen subsystems.

The impurity monitoring and analysis system is used (1) to monitor sodium impurity levels in the intermediate sodium systems during operation and to alarm on abnormal plugging (saturation) temperatures; (2) to monitor sodium levels in the primary sodium systems during refueling operations and to alarm on abnormal temperatures; (3) to sample sodium in the intermediate sodium systems during all normal plant operating conditions and to sample sodium in the primary sodium systems during refueling; (4) to sample and to analyze sodium from all sodium systems chemically and radio-chemically; (5) to collect, identify, and analyze helium cover gas from the reactor vessel, argon from the primary sodium storage vessel, argon and nitrogen from the SWRPRS, helium from the fuel receiving, storage, and shipping system, helium from the interim transport system, and argon from the IHTS; and (6) to collect, identify, and analyze samples of incoming nitrogen, helium, and argon.

The compressed air syster includes the service air system and the instrument air system. The service air system is used to supply compressed air to maintenance, tools, cleaning, and other pneumatic systems, and to feed the instrument air system. The instrument air system supplies filtered, oil-free, dry air to instrumentation, controls, pneumatic pistons, diaphragm valve operators, and airlocks in all areas of the plants.

The IGRPS stores liquified and vaporized gas, sends the gas through the plant, and receives contaminated gases.

Helium is used to inert the reactor, the reactor building, the spent fuel shipping cask, the fuel transfer cask, and the ports and floor valves. A truck serves as the helium gas distribution subsystem, bringing cylinders and bottles of cover gas to the reactor to supply the fuel-handling cells and to inert the fuel transfer casks and the shipping canisters.

Argon is used to inert the intermediate heat transfer and the auxiliary sodium systems. One argon subsystem services each power block. One separate argon gas distribution subsystem services the IHTS, IHTS cold traps, and sodium-water-reaction pressure-relief subsystem rupture disk. Also, argon is used to inert the reactor containment vessel, the primary sodium service vault, and the primary sodium storage vessel.
Stored as a liquid in tanks, the argon is vaporized and transferred to the steam generator building header. It supplies the SWRPRS rupture disks, the intermediate pump seals, intermediate pump oil tank pressure, and other systems. The IHTS argon supply system is sized to be able to supply IHTS argon needs of $2970 \mathrm{~m}^{3} /$ month (105000 scf/month). Argon gas is used to supply an inert atmosphere to the sodium expansion tank, the intermediate pump, the intermediate pump seal purge, the rupture disk purge, the SWRPRS sodium dump tank, the sodium receiving station, the auxiliary intermediate sodium system, the reactor containment vessel annulus, and the primary sodium storage tank.

The IGRPS supplies nitrogen gas to quench sodium-water reactions and to cool primary sodium processing subsystems. Nitrogen is used to inert the steam generator and the SWRPRS following a sodium-water reaction. The nitrogen is stored as a liquid in two separate gas generators. The two generators can each produce $2,300 \mathrm{~m}^{3}(80,000 \mathrm{scf})$, to be able to quench a sodiumwater reaction.

\subsubsection{Scope of Staff Review}

Because of the information available, the staff's review of the proposed process auxiliaries was limited.

The following regulatory guidance was reviewed for general applicability to the PRISM design. Current SRPs and RGs were developed specifically for LWRs. Similar guidance for liquid-metal reactors has not been developed. The PRISM process auxiliaries should meet the intent of the following SRP sections:

- 9.3.1, "Compressed Air System"

- 9.3.2, "Process and Post-Accident Sampling Systems"

The SRP sections require compliance with the following GDC from Appendix A to 10 CFR Part 50, parts of which may apply to PRISM process auxiliaries:

- 1, "Quality Standards and Records"

- 2, "Design Bases for Protection Against Natural Phenomena"

- 5, "Sharing of Structures, Systems, and Components"

- 13, "Instrumentation and Control"

- 14, "Reactor Coolant Pressure Boundary" 
- 26, "Reactivity Control System Redundancy and Capability"

- 41, "Containment Atmosphere Cleanup"

- 60, "Control of Releases of Radioactive Materials to the Environment"

- 63, "Monitoring Fuel and Waste Storage"

- 64, "Monitoring Radioactivity Releases"

\subsubsection{Design Criteria}

The preapplicant has not explicitly stated that it will meet the intent of the cited SRP sections.

Table 9.2 identifies the equipment and structures of the process auxiliaries that are safety related.

The preapplicant stated that each IGRPS component or subsystem shall be designed for codes and standards compatible with the system it is linked to. The preapplicant stated that piping which penetrates containments shall have double isolation valves, and that piping between isolation valves shall meet ASME Section III Class 2 requirements.

The preapplicant stated that, "Piping between isolation valves shall be designed to the lower level code classification of the connected components. The isolation valve shall be designed to the code classification of the connected component."

The preapplicant stated that non-safety-related piping and vessels will be designed to ASME Boiler and Pressure Vessel Code Section VIII, Division 1 (Ref. 9.6) and ANSI Standard B31.1 (Ref. 9.7), and that other piping will be designed to ANSI Std. B31.1.

The preapplicant stated that the IGRPS safety-related components, piping, and associated instrumcitation and controls will be designed to seismic Category I. Other components will be designed to Uniform Building Code Seismic Zone III.

Table 9.2 Safety-related equipment and structures for the process auxiliary systems

\begin{tabular}{|c|c|c|c|c|}
\hline System & $\begin{array}{c}\text { Equipment or } \\
\text { Structure }\end{array}$ & $\begin{array}{c}\text { Safety } \\
\text { Class }\end{array}$ & $\begin{array}{c}\text { Quality Group }{ }^{2} \text { or } \\
\text { ASME Code Sec/Class }\end{array}$ & $\begin{array}{c}\text { Seismic } \\
\text { Category }\end{array}$ \\
\hline \hline $\begin{array}{c}\text { Inert gas receiving and } \\
\text { processing system }\end{array}$ & Isolation valves & 1 & III/1 & 1 \\
\hline $\begin{array}{c}\text { Inert gas receiving and } \\
\text { processing system }\end{array}$ & Piping & 1 & III/1 & 1 \\
\hline
\end{tabular}

Notes:

1 Safety Class 1 (SC-1) applies to those components that are part of the primary cuolant boundary; are used to perform scram functions under any plant conditions; or maintain core geometry or provide core support and whose failure could initiate a core disruptive accident.

Safety Class 2 (SC-2) applies to any component not in SC-1 that is required to maintain an adequate reactor coolant inventory following a primary coolant boundary leak; is part or an extension of the reactor containment boundary; is required to remove residual heat from the reactor core whose single failure following any plant condition constitutes a loss of safety-function or that is not normal operating or cannot be tested adequately during normal power operation; the single failure of which could cause a loss of safety-function of other SC-2 components.

Safety Class 3 (SC-3) applies to those components not in SC-1 or SC-2 that are required to remove residual heat from the reactor core; the failure of which could result in the loss of safety-function of another component; that are extensions of the primary coolant boundary and are capable of being isolated from that boundary during all modes of normal reactor operation by two valves, each of which is either normally closed or capable of remote closure; the failure of which could result in the release to the environment of radioactivity and would result in potential offsite exposures that are comparable to the guideline exposure of 10 CFR Part 100.

2 QG-A corresponds to ASME Code Section III - Class 1,

QG-B corresponds to ASME Code Section III - Class 2,

QG-C corresponds to ASME Code Section III - Class 3. 
IGRPS components shall be classified as Class $C$ (ANSI Standard N45.2.1, "Cleaning of Fluid Systems and Associated Components During the Construction Phase of Nuclear Power Plants,") (Ref. 9.8) and they will be handled and received as specified in ANSI Standard N45.2.2, "Packaging, Shipping, Receiving, and Storage of Items for Nuclear Power Plants" (Ref. 9.9).

Pneumatic valve operators are supplied with instrument air. Safety Class 3 accumulators are included in the compressed gas system for selected active valves that fail in place so that these valves can be operated remotely for a period of 10 hours after loss of the air or nitrogen supply.

The impurity monitoring and analysis system piping, components, and associated controls and instrumentation shall be designed for seismic and other natural phenomena in accordance with the Uniform Building Code (UBC).

Fresh argon and nitrogen sampling shall be taken with a sampler meeting the MIL-S-27626 designated TTU-131/E (Ref. 9.10).

Cover gas purity is equivalent to RDT Standard M14-1T (Ref. 9.11),

\subsubsection{Research and Development Plans}

The preapplicant submitted no research and development plans for the process auxiliaries.

\subsubsection{Discussion of Safety Issues}

The staff raised a concern early in the review about the SWRPRS which involved the process auxiliaries. The staff recommended that both SWRPRS and the water/steam dump system should be safety grade. The PRISM design response was to make the SWRPRS rupture disks safety grade and the building seismic Category II.

There are two interactions between the inert gas systems and the SWRPRS, both of which should be examined for safety classification. The nitrogen distribution system supplies cover gas for the SWRPRS, and nitrogen purge gas for the steam generator system and SWRPRS following a large sodium-water reaction. The argon distribution subsystem provides evacuation and argon inerting to the space between the duplex rupture disks in the SWRPRS.

\subsubsection{Evaluation}

Piping between isolation valves should be designed to the upper level - not the lower level - code classification of the connected components. This is necessary since the presence of a lower classification pipe on a component effectively lowers the component classification.

\subsubsection{Conclusions}

Since the PRISM design for the process auxiliaries is a conceptual design, conclusions about acceptability cannot be made at this stage of the review.

\subsection{Heating, Ventilation, and Air Conditioning System}

\subsubsection{Design Description and Safety Objectives}

The HVAC system will be a typical HVAC system. It will use standard air-handling units, and standard heating and cooling systems. The system will reject heat to either the chilled water system or to outside air. It will rely on natural circulation, whenever possible.

The safety-grade RSF HVAC system will use freon as a coolant and, therefore, will not rely on the chilled water system.

\subsubsection{Scope of Staff Review}

Because of the information available, the review of the proposed plant heating, ventilation, and air conditioning system was limited.

\subsubsection{Review Criteria}

The following regulatory guidance was reviewed for general applicability to the PRISM design. Current SRPs and RGs were developed specifically for LWRs. Similar guidance for liquid-metal reactors has not been developed. However, HVAC systems are similar, whatever the reactor design. The PRISM HVAC system, therefore, should meet the intent of the following SRP sections:

- 9.4.1, "Control Room Area Ventilation System"

- 9.4.3, "Auxiliary and Radwaste Area Ventilation System $^{\text {" }}$

- 9.4.4, "Turbine Area Ventilation System"

- 9.4.5, "Engineer Safety Feature Ventilation System"

The SRP sections require compliance with the following GDC from Appendix A to 10 CFR Part 50, parts of which may apply to the PRISM HVAC system:

- 2, "Design Bases for Protection Against Natural Phenomena" 
- 4, "Environmental and Missile Design Bases"

- 5, "Sharing of Structures, Systems, and Components"

- 17, "Electric Power Systems"

- 19, "Control Room"

- 60, "Control of Releases of Radioactive Materials to the Environment"

- 61, "Fuel Storage and Handling and Radioactivity Control"

\subsubsection{Design Criteria}

The preapplicant stated that the HVAC system will meet applicable Occupational Safety and Health Agency (OSHA) noise criteria, and will conform to the applicable sections from the American Society of Heating, Refrigerating and Air Conditioning (ASHRAE), American Society for Testing and Materials (ASTM), the National Fire Protection Agency (NFPA), Sheet Metal and Air Conditioning Contractors National Association, the American National Standards Institute (ANSI), and Air Moving and Control Association.

The preapplicant stated that a safety-grade HVAC system with toxic-gas isolation and emergency outside-air filtration capability is included for the remote shutdown facility.

\subsubsection{Discussion of Safety Issues}

The staff raised a concern early in the review about the quality of the environment for the operator. Part of the PRISM designer's response was to upgrade the HVAC system of the control room, and to install a safety-grade HVAC system for the remote shutdown facility.

\subsubsection{Evaluation}

SRP Section 9.4.1 provides specific guidance on the HVAC system required for the control room. The philosophy of the PRISM designers is that for the PRISM reactor, operators are not important to safety and, therefore, require neither a safety-grade control room nor a safety-grade HVAC system.

The NRC is still considering the role of the operator. The need for a safety-grade control room is a policy issue before the Commission. The NRC staff cannot, therefore, determita the acceptability of a control room without a $\mathrm{sa}^{r}$, ‘rade HVAC system.

\subsubsection{Research and Development Plans}

The licensee submitted no research and development plans for the HVAC system.

\subsubsection{Conclusions}

The PRISM design for the HVAC system is not consistent with cuirent LWR requirements. Because the control room lacks a safety-grade HVAC system, the design does not satisfy the guidance given in SRP Section 9.4.1, "Control Room Area Ventilation System." This is, however, an open policy issue within the NRC.

\subsection{Auxiliary Liquid-Metal System}

\subsubsection{Design Description and Safety Objectives}

The auxiliary liquid metal system receives, transfers, and purifies all sodium used in the plant. This system consists of the sodium receiving and transfer subsystem (SRTS), the intermediate sodium processing subsystem (ISPS), and the primary sodium processing subsystem (PSPS). The SRTS handles new sodium delivered to the site, melts it in preparation for transfer to the intermediate or primary sodium systems, and transfers the melted sodium for use in the reactor. The ISPS has the following functions:

- Provides the capability to transfer the intermediate sodium for offsite disposal.

- Purifies the sodium in the IHTS or in the sodium dump tank (SDT) continuously or intermittently.

- Provides the capability to fill the IHTS and SDT using the ISPS EM pump.

- Provides the capability to transfer sodium from the IHTS to the SDT.

- Provides the capability to fill the reactor vessel initially with non-radioactive sodium using the ISPS EM pump.

- Provides sodium sample connections for the impurity monitoring and analysis system for fresh sodium and sodium in the IHTS.

- Provides sodium to the intermediate sodium plugging indicator.

The PSPS has the following functions:

- Purifies the primary sodium in the reactor vessel du: ing refueling and in the primary sodium storage vessel during reactor module replacement. 
- Provides sodium transfer and storage facilities (the primary sodium storage vessel) for the primary sodium in one reactor module.

- Provides heat removal for the coolant used in the primary cold traps.

- Provides sodium to the primary sodium plugging indicator.

- Provides primary sodium sample connections for Impurity Monitoring and Analysis System.

\subsubsection{Scope of Staff Review}

Because of the information available, the review of the auxiliary liquid metal system was limited.

\subsubsection{Review Criteria}

The following regulatory guidance was reviewed for general applicability to the PRISM design. Current SRPs and RGs were developed specifically for LWRs. Similar guidance for liquid-metal reactors has not been developed. The PRISM auxiliary liquid-metal system shou'd meet the intent of the following SRP sections:

- 9.2.6, "Condensate Storage Facilities"

- 9.3.3, "Equipment and Floor Drainage System"

The SRP sections require compliance with the following GDC from Appendix A to 10 CFR Part 50, parts of which may also apply to the PRISM auxiliary liquid-metal system:

- 2, "Design Bases for Protection Against Natural Phenomena"

- 4, "Environmental and Missile Design Bases"

- 5, "Sharing of Structures, Systems, and Components"

- 60, "Control of Releases of Radioactive Materials to the Environment"

\subsubsection{Design Criteria}

Table 9.3 identifies the equipment and structures of the auxiliary liquid-metal system that are safety related:

The preapplicant stated that the auxiliary intermediate liquid-metal system components will be designed to ASME Boiler and Pressure Vessel Code Section VIII and piping and fittings to ANSI B31.1, "Power Piping Code."

\subsubsection{Discussion of Safety Issues}

No safety issues associated with the auxiliary liquid-metal system have bisen identified at this stage of the review.

\subsubsection{Evaluation}

The PSPS penetrates the containment. The penetrating piping and the dual isolation valves should, therefore, be built to the same standards as the containment which is built to ASME Section III Class 1. To do otherwise effectively reduces the rating of the containment.

\subsubsection{Research and Development Plans}

The preapplicant submitted no research and development plans for the auxiliary liquid-metal system.

\subsubsection{Conclusions}

The PRISM design is conceptual and lacks sufficient detail to draw from conclusions as to whether this system will be designed to the same criteria as the containment. The PRISM design for the safety-related primary sodium processing system, particularly the safety classification of the pipes that penetrate the containment, will be evaluated at a later stage in the design review to ensure applicable regulatory requirements are satisfied.

\subsection{Sodium Piping and Equipment Heating and Insulation System}

\subsubsection{Design Description and Safety Objectives}

The function of the sodium piping and equipment heating and insulation system is to liquify and maintain the sodium as a liquid. The system comprises electrical trace-heating and reactor vessel preheating equipment, as well as pipe and vessel insulation.

The trace-heating equipment uses mineral-insulated-type cable wrapped around the component or zig-zagged around pipes. Thermocouple monitors and solid-state relays control the power to the cables, and thus control the heat rate. There are local and global control centers for the heating system, with the global system overriding the local.

The reactor vessel preheating system consists of two selfcontained blower heater packages.

The insulation for the systems consists of alumina silica sandwiched between layers of stainless steel. 
Table 9.3 Safety-related equipment and structures for the auxiliary liguid-metal system

\begin{tabular}{||c|c|c|c|c||}
\hline Subsystem & $\begin{array}{c}\text { Equipment or } \\
\text { Structure }\end{array}$ & $\begin{array}{c}\text { Safety } \\
\text { Class }\end{array}$ & $\begin{array}{c}\text { Quality Group 2 or } \\
\text { ASME Code Sec/Class }\end{array}$ & $\begin{array}{c}\text { Seismic } \\
\text { Category }\end{array}$ \\
\hline Primary sodium processing system & EM pump & 3 & III/3 $^{3}$ & 1 \\
\hline Primary sodium processing system & Cold trap module & 3 & III/3 & 1 \\
\hline Primary sodium processing system & Sodium drain tank & 3 & III/3 & 1 \\
\hline Primary sodium processing system & Sodium valves & 2 & III/2 & 1 \\
\hline Primary sodium processing system & Piping & 3 & III/3 & 1 \\
\hline
\end{tabular}

Notes:

1 Safety Class 1 (SC-1) applies to those components that are part of the primary coolant boundary; are used to perform scram functions under any plant conditions; or maintain core geometry or provide core support and whose failure could initiate a core disruptive accident.

Safety Class 2 (SC-2) applies to any component not in SC-1 that is required to maintain an adequate reactor coolant inventory following a primary coolant boundary leak; is part or an extension of the reactor containment boundary; is required to remove residual heat from the reactor core whose single failure following any plant condition constitutes a loss of safety-function or that is not normal operating or cannot te tested adequately during normal power operation; the single failure of which could cause a loss of safety-function of other SC-2 components.

Safety Class 3 (SC-3) applies to those components not in SC-1 or SC-2 that are required to remove residual heat from the reactor core; the failure of which could result in the loss of safety-function of another component; that are extensions of the primary coolant boundary and are capable of being isolated from that boundary during all modes of normal reactor operation by two valves, each of which is either normally closed or capable of remote closure; the failure of which could result in the release to the environment of radioactivity and would result in potential offsite exposures that are comparable to the guideline exposure of 10 CFR Part 100.

2 QG-A corresponds to ASME Code Section III - Class 1,

QG-B corresponds to ASME Code Section III - Class 2,

QG-C corresponds to ASME Code Section III - Class 3.

3 Portions that form the primary boundary.

\subsubsection{Scope of Staff Review}

The review was limited to a cursory look at the proposed RRS. A more in-depth review will be done after the preapplicant submits a more complete design.

\subsubsection{Design Criteria}

Current SRPs and RGs were developed specifically for LWRs. Similar guidance for liquid-metal reactors has not buen developed. Regulatory guidance for the PRISM sodium piping and equipment $h$ :ating and insulation system design will be developed at the next stage of review.

The preapplicant identified no equipment or structures of the piping and equipment heating and insulation system as safety related.
The equipment will heat the systems to $500 \mathrm{~K}\left(450^{\circ} \mathrm{F}\right)$ and maintain them at no less than $480 \mathrm{~K}\left(400^{\circ} \mathrm{F}\right)$. The equipment will not damage components during the heating process.

The preapplicant indicated that the design will keep thermal stresses to a minimum and will not affect safety functions of any systems, burden the HVAC system, or pose a personnel hazard.

\subsubsection{Discussion of Safety Issues}

No safety issues associated with the sodium piping and equipment heating and insulation system have been identified at this stage of the review. 


\section{Auxiliary Systems}

\subsubsection{Evaluation}

The use of heat tracing and insulation to maintain pipes at temperature is already accepted within the nuclear industry.

The preapplicant will be required to submit a more detailed design for evaluation.

\subsubsection{Research and Development Plans}

The preapplicant submitted no research and development plans for the sodium piping and equipment heating and insulation system.

\subsubsection{Conclusions}

The sodium piping and equipment heating and insulation system will be reviewed when the preapplicant submits a more detailed design.

\subsection{Plant Fire Protection System}

The plant fire protection system (PFPS) includes two systems, the sodium fire protection system (SFPS) and the non-sodium fire protection system (NSFPS). The PRISM design employs features addressing the unique fire protection requirements posed by the use of sodium in the plant. The NSFPS utilizes standard technology and was examined to ensure compatibility with the SFPS so that the special requirements of sodium fire protection and mitigation were addressed.

\subsubsection{Design Description and Safety Objectives}

The NSFPS will use water-supplied fire-fighting equipment on areas of the plant completely isolated from systems and components containing sodium. Total carbon dioxide flooding or local carbon dioxide application systems will be used for normally unoccupied electrical cable and equipment rooms. Total flooding systems of Halon 1301 will be used for the protection of electronic equipment rooms. The NSFPS includes the following subsystems: (1) fire protection water supply subsystem; (2) sprinkler, deluge, and water spray subsystems; (3) wet and dry standpipe subsystems; (4) carbon dioxide, Halon, and foam subsystems; and (5) portable fire extinguishers. The fireprotection water-supply subsystem will be capable of delivering $9,463 \mathrm{l} / \mathrm{per}$ minute $(2500 \mathrm{gpm})$ at $963 \mathrm{kPa}$ (125 psig). The equipment, instrumentation, and controls that make up the sprinkler and deluge subsystem will furnish protection to areas within plant buildings and on plant grounds that are suited to fire mitigation by sprinkler or spray systems. The dry standpipe and manual firefighting equipment will be located in non-alkali metal areas in the steam generator buildings and reactor support building areas with access to liquid-metal systems. The Halon facilities will furnish 5 to 6 volume percent of Halon for 10 minutes within the largest protected area. The carbon dioxide subsystem will achieve a 30-percent concentration in 2 minutes and a 50-percent concentration in 10 minutes for up to 20 minutes.

The SFPS will use passive catch pans and fire suppression decks to prevent continued sodium pool burning and will limit sodium burning to less than 10 percent of the mass of the spill. Small sodium fires will be suppressed by manually operated, portable fire extinguishers located throughout the nuclear island (NI) buildings.

Fire will be detected through the use of smoke, aerosol, and/or heat detectors which will actuate alarms to alert operators to the existence and location of fires. Where considered appropriate, heat detectors will be used to initiate automatic fire-suppression systems. Isolation features, including fire barriers, doors, dampers and lowleakage penetrations, will be used in the building and HVAC system design to impede the spread of fire and limit the distribution of airborne contaminants.

The sodium fire protection system is designed to

- Protect safety-related systems and components.

- Protect plant personnel from sodium fires.

- Limit the chemical reaction between sodium and concrete.

- Limit the formation and release of radioactive sodium aerosols.

- Limit the release of non-radioactive sodium aerosols

\subsubsection{Scope of Staff Review}

The staff used PRISM PSID (Ref. 9.1), Section 9.7.1, "Plant Fire Protection System," and Section F-6 of PSID Volume V (responses to NRC comments) for the review of PRISM fire protection systems. The review considered fire effects on safety systems, fire-detection features, special systems required to mitigate sodium fires, inert gas flooding system requirements, and simultaneous fires in multiple units.

Current regulatory documents were developed for LWRs, and do not specifically address LMR safety concerns. However, general guidance for the review was found in the SRP 9.5.1, "Fire Protection Program" and BTP CMEB-9.5-1, "Guidelines for Fire Protection for 
Nuclear Power Plants" (attached to SRP Section 9.5.1). This SRP and the BTP specify conformance of the fire protection system to 10 CFR 50.48 and GDC 3 and 5 of 10 CFR Part 50. GDC 3 specifies design objectives to be met by the fire protection system, GDC 5 is related to fire protection for shared safety-related structures. Fire protection requirements referring to BTP 9.5-1 and GDC 3 are furnished in 10 CFR 50.48 .

Design standards proposed by ANSI/ANS-54.1-1989, "General Safety Design Criteria for a Liquid Metal Nuclear Power Plant" (Ref. 9.12) and ANSI/ANS-54.8-1988, "Liquid Metal Fire Protection in LMR Plants" (Ref. 9.13), were used for more specific guidance for review of areas involving unique characteristics of the PRISM design. These criteria supplement the design criteria contained in 10 CFR 50.48 and 10 CFR Part 50 (Appendix A), which are requirements.

\subsubsection{Design Criteria}

In Section 1.8 of the PRISM PSID, the designer stated that RG 1.120, "Fire Protection Guidelines for Nuclear Power Plants" (Ref. 9.14), will be applicable (although minor modifications may be necessary to accommodate a liquidmetal system). Much of the guidance of RG 1.120 appears in BTP CMEB 9.5-1.

Section 9.7.1.1.2 of the PSID stated that the PRISM plant fire protection system will be designed so that it complies with National Fire Protection Association (NFPA) standards. Other system design requirements are specified, such as use of inert gas flooding systems for normally unoccupied electrical equipment rooms and use of a standby diesel-driven fire pump, many of which are addressed in review guidance cited in Section 9.3.2 (above).

\subsubsection{Discussion of Safety Issues}

No safety issues associated with the plant fire protection system were raised in this review.

\subsubsection{Evaluation}

The PRISM plant fire protection system outlined in the PSID has the potential to meet the general requirements for fire protection at nuclear power plants. However, the design presented for preapplication review lacks details needed to permit final conclusions to be reached on the effectiveness of the system to meet liquid-metal plant requirements. The technology applicable to sodium system fire safety should be consistent with that developed for the Fast Flux Test Facility and the Clinch River Breeder
Reactor, and should be readily available. Thus, no research and development effort is expected to be needed to finish the PRISM fire protection system design.

Future design refinements should consider fires involving facilities shared between units and fires due to man-made events. This guidance, from Section C (1) of BTP CMEB 9.5-1, includes design regard for a fire caused by such an event as an airplane crash, affecting more than one reactor unit on the site.

Although Section 9.4.1 of the PRISM PSID mentions that NFPA standards will be used in the design of the ventilation system, no specific mention is made with respect to special ventilation requirements for sodium combustion products. As mentioned in SRP Section 9.5.1, the means to remove smoke and other products of combustion should be established during the early stages of design. This is especially important for the PRISM design since the designer's strategy for mitigating small sodium fires emphasizes use of manual fire-fighting measures (PSID Section 9.7.1.2). The SRP lists other ventilation considerations, and references which NFPA standards should be used for future design efforts.

Other significant areas covered by NFPA requirements, as referenced by the SRP Section 9.5.1, which should receive design attention before future design review include fire detection systems, especially the means to provide reliable power to sensor and annunciator systems; water supplies to fire protection systems, mainly the pumping capacity, pump power source, and seismic qualification requirements; and Halon and carbon dioxide firesuppression system requirements which ensure that toxicity and corrosive effects are considered in the system design.

Along with safety design criteria paralleling existing fire protection system design requirements, ANSI/ANS-54.8 contains guidance for the design of features used for fire protection and mitigation in liquid-metal plants that are not covered in other codes and standards. For instance, details for catch pan design are discussed, as are the potential effects of sodium fire byproducts upon electrical equipment and structural components, as well as their danger to personnel. Such requirements should be carefully considered as the PRISM design proceeds.

This review included examination of the PRISM design with respect to the proposed requirements of the Electric Power Research Institute (EPRI) as stated in the Advanced Light Water Reactor Utility Requirements Document (ALWR Passive Plant) (Ref. 9.15). Although intended for application to LWR designs, some of the criteria could be applied to the PRISM design. Most of the requirements presented in Volume III, Chapter 9: Site Support Systems, 
paragraph 3, of the EPRI document parallel those currently applied to LWRs and those referred to in Section 9.9.2 of this report. A notable difference exists, however, under Section 3.4.2.1 of the EPRI document, which requires that at least 100 percent of the design fire pump capacity be available from a diesel-driven fire pump or pumps. Although the PRISM diesel-driven fire pump is capable of maintaining system pressure without the electric-driven pump (PSID Section 9.7.1.2), it is not clear that it can do so at the rated design flow of $9,463 \mathrm{l} / \mathrm{min}$. $(2,500 \mathrm{gpm})$.

\subsubsection{Conclusions}

The review of PRISM fire protection systems raised no safety issues, but also did not reach a conclusion on the suitability of the system to effectively satisfy liquid-metal plant fire protection requirements. The information available at this preapplication stage indicates that the final design could meet standard fire protection guidance as well as challenges posed by the presence of sodium in the plant. Specifics in the areas of fire detection, sodium-fire mitigation (e.g., catch pan design), ventilation features for sodium combustion byproducts, and means to deal with multi-unit fires (caused by man-made events) are among the issues to be considered during future reviews.

The sodium-fire protection system should build upon and utilize standard sodium-fire suppression and mitigation techniques developed, tested, and applied on previous liquid-metal designs. The staff believes that these features, if properly implemented, would constitute an acceptable means to preclude undue health hazards to the public, minimize equipment damage, and minimize release of sodium aerosols to the atmosphere.

The staff also believes that as the design progresses, the guidance of ANSI/ANS-54.1-1989, "General Safety Design Criteria for a Liquid Metal Nuclear Power Plant," and ANSI/ANS-54.8-1988, "Liquid Metal Fire Protection in LMR Plants, " should be incorporated into the design, and that PRISM at least meet their intent.

\subsection{References}

9.1 General Electric, PRISM-Preliminury Safety Information Document, GEFR-00793 UC-87Ta, November 1986.

9.2 U.S. Nuclear Regulatory Commission, "Standard Review Plan for the Review of Safety Analysis Reports for Nuclear Power Plants, LWR Edition," NUREG-0800, July 1982.
9.3 U.S. Nuclear Regulatory Commission, "SingleFailure-Proof Cranes for Nuclear Power Plants," NUREG-0554, May 1979.

9.4 American National Standards Institute/American Nuclear Society, ANSI/ANS 54.6-1979, "LMFBR. Safety Classification and Related Requirements," ANS, La Grange Park, Illinois.

9.5 U.S. Nuclear Regulatory Commission, Code of Federal Regulations, Title 10, "Energy," Part 50, "Domestic Licensing of Production and Utilization Facilities."

9.6 American Society of Mechanical Engineers ASME, Boiler and Pressure Vessel Code, Section III, Division 1.

9.7 American National Standards Institute/American Nuclear Society, ANSI/ANS B31.1, "Power Piping Code," ANS, La Grange Park, Illinois.

9.8 American National Standards Institute/American Nuclear Society, ANSI/ANS N45.21, "Cleaning of Fluid Systems and Associated Components During the Construction Phase of Nuclear Power Plants," ANS, La Grange Park, Illinois.

9.9 American National Standards Institute/American Nuclear Society, ANSI/ANS N45.2.2, "Packaging, Shipping, Receiving, and Storage of Items for Nuclear Power Plants," ANS, La Grange Park, Illinois.

9.10 U.S. Department of Defense, "Sampler, Cryogenic Liquid," MIL-S-27626, first issued September 12, 1966, Rev. D, Amend. 1, April 24, 1981.

9.11 U.S. Department of Energy, "Sodium Cover Gas Purchase Specifications," RDT Standard M14-IT (DOE/NE Standard M14-IT), first issued July 1972, Revised (Amend. 1) January 1975.

9.12 American National Standards Institute/American Nuclear Society, ANSI/ANS 54.1-1989, "General Safety Design Criteria for a Liquid Metal Nuclear Power Plant," ANS, La Grange Park, Illinois.

9.13 American National Standards Institute/American Nuclear Society, ANSI/ANS 54.8-1988, "Standard for Liquid Metal Fire Protection in LMR Plants," ANS, La Grange Park, Illinois. 


\section{Auxiliary Systems}

9.14 U.S. Nuclear Regulatory Commission, "Fire Protection Guidelines for Nuclear Power Plants," Regulatory Guide 1.120 (for comment), November 1977.
9.15 Electric Power Research Institute-Advanced LightWater Reactor Utility Requirements Document, Vol. III, "ALWR Passive Plant," 1990. 


\section{STEAM AND POWER CONVERSION SYSTEMS}

\subsection{Design Description and Safety Objectives}

\subsubsection{Summary Description}

A PRISM power block consists of three reactor modules, each with one steam generator that collectively supply one turbine generator set. The designer, General Electric, has stated in PSID (Ref. 10.1) Section 10.1 that the operation of the equipment, piping, and valves in the system do not affect the reactor modules and their safety features.

Steam from the three steam generators in a power block is combined and supplied at near-saturated conditions to the high-pressure inlet of the turbine generator. The exhaust steam enters the two low-pressure turbine sections after it passes through moisture separators and reheaters. The steam is exhausted from the low-pressure sections to the condenser, the two steam-jet air-ejector (SJAE) condensers, the steam packing exhauster (SPE) condensers, and the steam generator system (SGS) blowdown coolers, jefore it enters the feedwater and condensate system. For a simplified diagram of the secondary system, see Figure 10.1.

\subsubsection{Turbine Generators}

The PRISM design uses one turbine generator set for each power block. Each turbine is an 1800-rpm, tandemcompound, four-flow reheat machine. It consists of one single-flow, high-pressure cylinder and two double-flow low-pressure cylinder casings. The steam enters the turbine at a pressure of $6591 \mathrm{kPa}(956 \mathrm{psia})$ and a temperature of $556 \mathrm{~K}\left(540^{\circ} \mathrm{F}\right)$, and exhausts to a condenser vacuum of $8.5 \mathrm{kPa}$ (2.5 in. of mercury) absolute. Since the turbine casing is an integral component of rotating machinery, it will be excluded from meeting the American Society of Mechanical Engineers (ASME) Boiler and Pressure Vessel Code and will be built to manufacturer's standards.

The designer has specified such load demand change capabilities as normal daily load following from 100 percent to 50 percent of rated output at up to 2 percent per minute over 2 hours. After 20 minutes following prompt resynchronization from a total load rejection, the turbine can be reloaded to 100 percent power.

The turbine generators will be located so that turbine missiles will not be able to damage safety-related systems of the same power block. The designer states that the reactor buildings are within the low-trajectory, turbinemissile zone defined by Regulatory Guide (RG) 1.115 (Ref. 10.2) with respect to missiles generated by turbines of other power blocks. The plant will be protected against turbine missiles by assuring (1) turbine disk integrity through design, fabrication control, and inspection and maintenance measures; (2) turbine overspeed protection; and (3) underground siting of principal safety-related structures within the low-trajectory-missile zone.

Auxiliary systems will contain conventional shaft sealing, electrohydraulic control, lubrication, and instrumentation to the turbine unit.

\subsubsection{Main and Auxiliary Steam Systems}

Each PRISM power block includes a main steam system, a main steam dump system, and an extraction steam system. A single auxiliary steam system, supplied from auxiliary boilers, is common to all three power blocks. The main and auxiliary steam piping shall be constructed of carbon steel in accordance with American Society for Testing and Materials (ASTM) material specification A53 Grade B (Ref. 10.3).

The main steam system delivers steam from the steam generators to the high-pressure cylinder inlet of the turbine. This system also directs high-pressure turbine exhaust to the moisture separators/reheaters and then to the low-pressure turbine inlet cylinders. The main steam dump system allows steam flow to bypass the turbine and directly enter the condenser when required. This acts as a means of controlled heat release from the reactors through the steam generators for decay heat removal (DHR) and plant startup, and also helps to prevent reactor trips during rapid load rejections.

Feedwater heaters get steam from the extraction steam system which taps steam from points on the high-pressure and low-pressure turbines. This system has means to protect the turbine from water induction and offers overspeed protation. Various process uses are supplied by $1825 \mathrm{kPa}(250 \mathrm{psig})$ auxiliary steam sent to a single header by three auxiliary boilers. Each boiler can produce 50 percent of the total maximum auxiliary steam demand for the plant.

The main and auxiliary steam system piping, equipment, and components are specified as not nuclear safety-related, but are designed to serve for 60 years. The system has the capability for periodic surveillance testing and inservice inspection, and is capable of withstanding the dynamic forces of a turbine trip. 


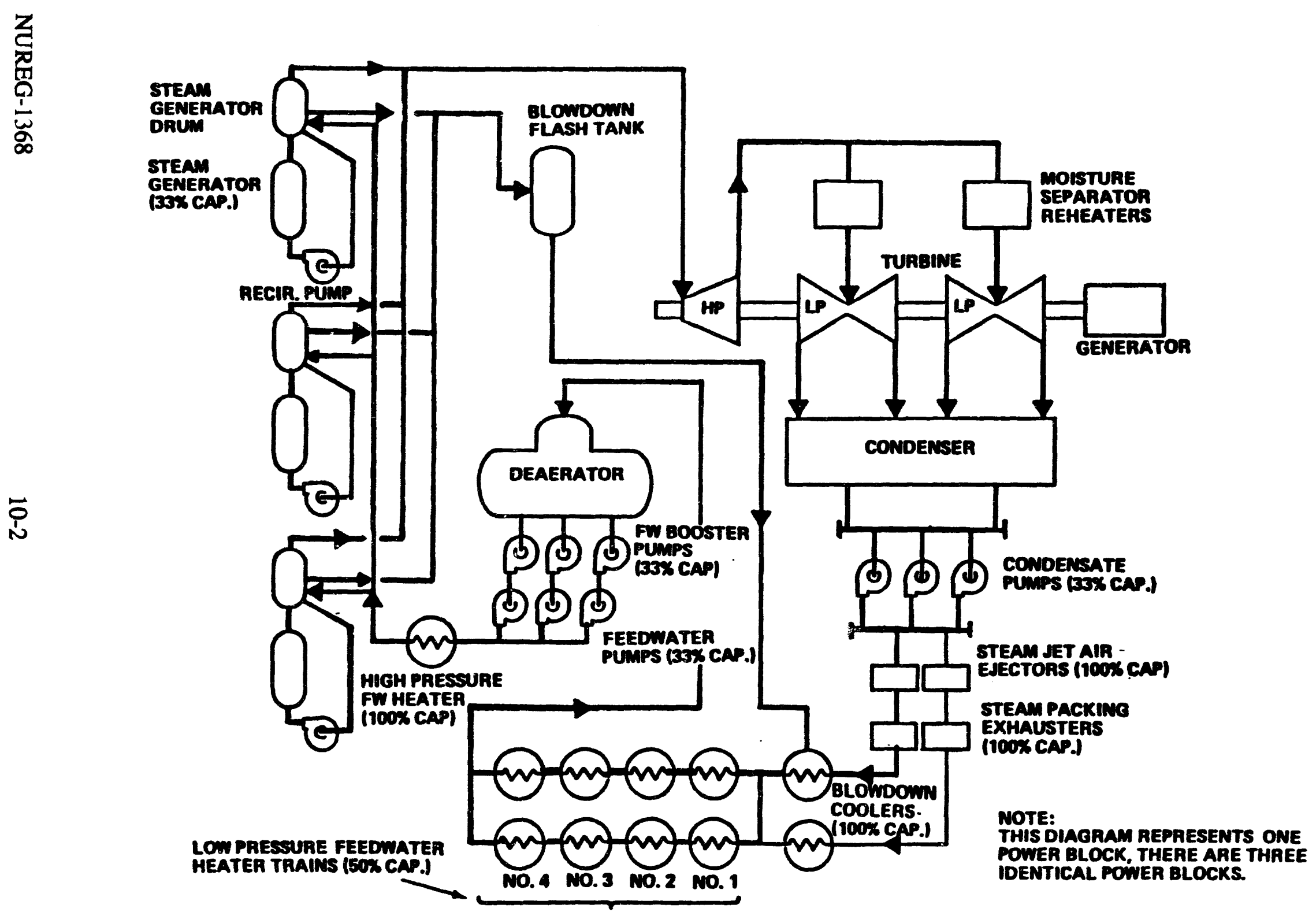

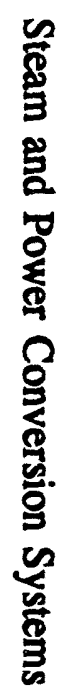

Figure 10.1 Steam and power conversion systems schematic 


\subsubsection{Feedwater and Condensate System}

Three subsystems (one for each power block) constitute the feedwater and condensate system: condensate subsystem, feedwater subsystem, and feedwater heater drain subsystem. A single auxiliary boiler feedwater and condensate system serves each power block. Major components of the feedwater and condensate system are depicted in Figure 10.1. These systems supply feedwater to the steam generators and auxiliary boilers, and have means to control and monitor feedwater quality to maintain chemistry specifications.

Exhaust from the turbine is condensed in the condenser, and condensate flows to the condenser hotwell. The condensate is then pumped through the SJAE and SPE condensers, the SGS blowdown coolers, and the four stages of low-pressure feedwater heaters to the deaerator. Condensate flows from the deaerator to the deaerator storage tank, which holds feedwater for the feed pumps. 'The feedwater then passes through one stage of highpressure heating where it reaches $489 \mathrm{~K}\left(420^{\circ} \mathrm{F}\right)$. Fluid is returned to the feedwater and condensate systems through the feedwater heater drain system or the condenser hotwell, or both.

\subsubsection{Water Chemistry Control}

Water chemistry is controlled in order to minimize corrosion in the steam generator system and to minimize fouling on the steam generator heat-transfer surfaces. Conditions will be maintained by feedwater deaeration, use of all-volatile chemical treatment, steam drum continuous blowdown, and demineralization of blowdown drains. The use of stainless steel feedwater heaters will minimize introduction of corrosion-product impurities into the steam generator. Recirculation water $\mathrm{pH}$ is to be maintained between 8.7 and 9.1 by adding ammonium hydroxide. Hydrazine will be used to scavenge oxygen not removed by the deaerator. Condensate dissolved oxygen content is to be maintained below 5 ppb.

\subsection{Scope of the Review}

Chapter 10 of the PSID and responses to NRC comments contained in Appendix F of the PSID were used in the review. Volume VI (Appendix G) of the PSID contained no design changes for the systems described in PSID Chapter 10, but associated research and development plans and safety analyses were covered. The designer states that operating the systems related to steam and power conversion does not affect the reactor modules and their safety features. Therefore, the staff focused its review on the overall operability of the system.
The following sections of the Standard Review Plan (SRP) (Ref. 10.4) were used for the review: 10.3, "Main Steam Supply System;" 10.4.2, "Main Condenser Evacuation System;" and 10.4.7, "Condensate and Feedwater System." These SRP sections specifically require conformance to General Design Criteria (GDC) set forth in 10 CFR Part 50, Appendix A (Ref. 10.5) concerning the performance of safety-related portions of the system, control of any release of radioactive materials to the secondary plant, as well as the DHR functions of the feed and condensate system (GDC 2, 4, $5,34,44,45,46,60$, and 64). The staff consulted Branch Technical Position (BTP) MTEB 5-3, "Monitoring of Secondary Side Water Chemistry in PWR Steam Generators," (attachment to SRP Section 5.4.2.1), to assess secondary chemistry control.

The staff referred to a number of design guidelines proposed by the Advanced Light-Water Reactor Utility Requirements Document (ALWR Passive Plant) (Ref. 10.6) in this review. Although many of these requirements are important only for LWR safety considerations, some of these proposals warrant consideration at least in terms of reducing safety system challenges for the PRISM design. These points do not reflect regulatory positions, but are intended to give early indication of expected industry design objectives for standard plants.

\subsection{Design Criteria}

The designer will comply fully with the following RGs:

- 1.26 "Quality Group Classifications and Standards for Water, Steam and Radioactive-WasteContaining Components of Nuclear Power Plants" (Ref. 10.7)

- 1.115 "Protection Against Low-Trajectory Turbine Missiles"

The main and auxiliary steam piping and the feedwater and condensate system piping will be designed, fabricated, and inspected in accordance with American National Standards Institute (ANSI) Standard B31.1 (Ref. 10.8). Valves shall be designed in accordance with the applicable ANSI Standard B16.5a (Ref. 10.9) pressure and temperature ratings.

\subsection{Research and Development}

The technology to be used in components of the steam and power conversion systems is not unique and does not require research and development. Development of an effective multi-module control system directly affects the 
function of this system, but is dealt with separately in Section 7.5. Development of the new steam generator design is important, since this will affect secondary plant chemistry control requirements.

At some future point in the design process, the safety immunity of the steam and power conversion systems should be substantiated with detailed event analyses. Accident analyses performed at this stage appear to envelope possible balance-of-plant (BOP) affects. For instance, a loss of feedwater flow should not cause more adverse conditions than cooldown on the reactor vessel auxiliary cooling system (RVACS) alone. However, staff review of additiona! information will be required to maintain the non-sarety status of these systems.

\subsection{Safety Issues}

The non-safety role of the steam and power conversion systems precludes raising safety issues in this area at this time. This review disclosed no potential impacts on plant safety. However, the information submitted by the designer is preliminary at this stage and, as discussed in Section 10.4, further development and analysis could modify this position.

\subsection{Evaluation}

Although the preliminary nature of the information available for these systems prevents a detailed assessment of their effect on safety-related functions during abnormal or upset conditions, three significant points were raised concerning BOP impact on reactor safety. First, the plant control system includes inputs from the BOP regarding such non-safety functions as the power runback feature for loss of all offsite power (see Section 8.1.1). Also, in Appendix D of the PSID, the preapplicant mentions feedwater and steam generator system inputs to the reactor control system that serve as a reactor trip function for loss of feedwater flow control events. It is not yet clear how such inputs will affect the plant protection system and reactor safety.

Additionally, means to protect safety structures from hazards posed by turbine missiles, as discussed in Section 10.1.2, must be assessed. Although RG 1.115 allows safety-related plant components to be located within the low-trajectory turbine-missile zone, sufficient design and analysis information must be submitted to substantiate a conditional low probability of safety system damage ( $<10$ E-3 per Regulatory Position C.4 of RG 1.115). Finally, the role of the secondary system DHR capability should be established. Although not explicitly required to ensure reactor safety, the consequences of a loss or degradation of secondary system DHR, while in progress, should be determined. The capability of a single safety-related DHR system such as RVACS must be determined for any postulated condition, including conditions established by a non-safety-related BOP.

In the course of this review, more general questions were posed concerning the extent to which the designer addressed the impact of BOP influences. Accident analysis beyond that presented in the PSID was referenced in response to one comment (see Comment 15.4 in PSID Appendix F), but little detail was presented. Although such analyses are not considered a requirement for preapplication review, the results of such work would enable the staff to determine if the non-safety classification is suitable for these systems. Such assessments for this design must be deferred until more design detail and accident analysis data are available.

The safety impact of the steam and power conversion portion of the plant is important since it is the basis for applying regulatory guidance and a number of related regulations for LWRs. As pointed out in Section 10.2, a number of the GDCs and SRPs apply to components and functions that relate to (1) safety-related portions of the system, (2) systems important to safety or influencing safety systems, (3) the capability to remove decay heat, or (4) the potential of the system to release radioactive materials to the environment. The design seems to satisfy most requirements of the review criteria cited here, based on inherent differences between ALMRs and LWRs. However, some areas could become safety issues should some aspects of the system be considered safety-related. It is not clear if the feedwater flow control and main steam isolation functions would satisfy current regulatory guidance. The impact of feedwater flow control malfunctions on the reactor system, discussed in SRP Section 10.4.7, are not yet detailed. More design information could clear up this question.

Although the designer does not consider it a serious safety challenge to plant systems, a steamline rupture is a serious safety challenge. Design review must include an evaluation of capabilities to deal with this event to ensure that plant safety will not be jeopardized. SRP Section 10.3 guidance for means to detect a main steamline break and initiate steam generator isolation are not discussed. The design should preclude blowdown of more than one steam generator with concurrent failure of a single active component.

Consideration of these control system questions should include GDC 24 of 10 CFR Part 50 Appendix A, "Separation of Protection and Control Systems," which requires that the interconnection of the protection and 
control systems be limited to avoid impairing the operability of safety systems.

The specifications for water chemistry control and the means used to achieve these conditions appear to follow the guidance of BTP MTEB 5-3 (referenced by SRP Section 5.4.2.1) for plants utilizing volatile chemistry control. A number of design details are yet to be determined and steam generator chemistry requirements are not yet fully specified. This area will require further scrutiny since the integrity of steam generator tubes must be maintained to avoid the consequences of a sodium-water reaction.

This review examined the PRISM design with respect to the proposed requirements of the Electric Power Research Institute (EPRI) as stated in the Advanced Light-Water Reactor Utility Requirements Document (ALWR Passive Plant). Although intended for application to LWR plants, some of the detailed BOP design criteria proposed by EPRI may be applicable to PRISM. Specifications range from material and fabrication techniques to system capacity, but only select points considered relevant to the PRISM design are mentioned here.

The general design description of the PRISM steam dump system appears to meet the EPRI requirements in Section 3.2.1.2 of Reference 10.6, "PWR Steam Bypass and Relief Capacity." As the design is completed, such detailed EPRI requirements as bypass flow capacity and actuation times should be considered in order to limit challenges to the steam system and demands upon steam relief capability.

Documents available on the PRISM design do not provide specific information on the main steam isolation valves (MSIVs). Section 3.2.2, "Main Steam Isolation Valves," of the EPRI document gives a number of general requirements and some specifications. Although the EPRI requirements address LWR containment and reactor safety factors, the MSIV structural and operability criteria should be considered for overall safety considerations. Specification of the valve actuation time during steamline breaks; as well as redundancy and separation of control system components, should also be considered.

EPRI feedwater and condensate system requirements emphasize such conditions of system reliabilis; as plant capacities with degraded system lineups and pump control features to maintain plant operation during system transients. The PRISM design could have an operational weakness in this area since a single high-pressure feedwater heater will be used. Although this does not seem to impose a safety challenge, operational flexibility may be limited at this component.
EPRI has proposed many other BOP requirements. Those discussed here are considered pertinent to the PRISM design. It must again be emphasized that these points do not indicate a present or future regulatory stance, but indicate design concerns that may predict significant industry trends.

\subsection{Conclusions}

The information submitted for the PRISM design specifies the general interface and design conditions for the steam and power conversion system. Although the overall design appears to satisfy the requirements for a non-safety-related system, further design detail and plant response analysis will be required for future reviews to ensure that safety is not affected.

Among the significant items of concern in this review are the interaction between BOP control systems and the reactor protection system, the means to protect safety structures from low-trajectory turbine missiles, and the role of secondary system DHR. Although these are not serious safety concerns at present, the staff will examine these areas in detail in future reviews to ensure that there will be no adverse impact on safety. Such important functions as feedwater control and main steam isolation must be considered in more detail to ensure that any malfunctions will not challenge the safety of reactor modules.

\subsection{References}

10.1 General Electric, PRISM-Preliminary Safety Information Document, GEFR-00793 UC-87Ta, November 1986.

10.2 U.S. Nuclear Regulatory Commission, "Protection Against Low-Trajectory Turbine Missiles, " Regulatory Guide 1.115.

10.3 American Society for Testing and Materials, ASTM A53, "Standard Specification for Pipe, Steel, Black and Hot-Dipped, Zinc-Coated, Welded and Seamless, " ASTM Standards, Vol. 01.01, "Steel Piping, Tubing, Fittings, American Society for Testing and Materials, " 1989.

10.4 U.S. Nuclear Regulatory Commission, "Standard Review Plan for the Review of Safety Analysis Reports for Nuclear Power Plants, LWR Edition," NUREG-0800, July 1982. 
10.5 U.S. Nuclear Regulatory Commission, Code of Federal Regulations, Title 10, "Energy," Part 50, "Domestic Licensing of Production and Utilization Facilities," Appendix A, "General Design Criteria for Nuclear Power Plants."

10.6 Electric Power Research Institute-Advanced LightWater Reactor Utility Requirements Document, Vol. III, "ALWR Passive Plant," Chapter 2, "Power Generation Systems," 1990.

10.7 U.S. Nuclear Regulatory Commission, "Quality Group Classifications and Standards for Water,
Steam and Radioactive-Waste-Containing Components of Nuclear Power Plants," Regulatory Guide 1.26.

10.8 American National Standards Institute/American Society of Mechanical Engineers, ANSI/ASME B31.1, Code for Pressure Piping, 1989, New York.

10.9 American National Standards Institute/American Society of Mechanical Engineers, ANSI/ASME B16.5a, Code of Pipe Flanges and Flanged Fittings, 1988, New York. 


\section{RADIOACTIVE WASTE MANAGEMENT}

\subsection{Source Terms}

The source term information the preapplicant will use for the design basis for expected releases will be provided at a later stage of review to demonstrate that the applicable requirements of $10 \mathrm{CFR}$ Part 20 (Ref. 11.1) and Appendix I to 10 CFR Part 50 (Ref. 11.2) will be met.

\subsection{Liquid Waste Management Systems}

The liquid radioactive waste system provides a means for collecting, processing, storing, and disposing of radioactive liquid wastes to control radiation within the plant. It is designed to yield reliable processing of collected liquid wastes to meet the requirements of 10 CFR Part 20 and the design objectives of Appendix I to 10 CFR Part 50. The liquid radioactive waste system is not safety related and is designed in accordance with Regulatory Guide (RG) 1.143 (Ref. 11.3). This system disposes of the treated wastes after monitoring radioactivity concentrations for conformance to 10 CFR Part 20.

The two systems within the liquid radioactive waste system are the intermediate-activity-level liquid (IALL) system and the low-activity-level liquid (LALL) system. In the IALL/LALL systems, the primary sources of wastes are (1) component and equipment cleaning and decontamination and (2) laboratory drains. These liquid wastes are collected and stored in collection tanks. From the collection tanks, wastes are periodically processed through a demineralizer train consisting of filters and mixed-bed demineralizers. The processed liquid wastes are stored in monitor tanks and sampled to ensure that they meet the water quality requirements and radicactivity levels for discharge. If the processed wastes do not meet the discharge requirements, they are reprocessed through the demineralizer train. Once they meet the discharge requirements, the process wastes are mixed with the cooling tower blowdown and discharged to the river.

The detergent and decontamination liquid (DDL) system is used to process low-activity liquids that contain detergents and other impurities that would rapidly degrade the IALL/LALL demineralizer resins. The primary sources of DDL wastes are laundry, showers, handwashes, and equipment and area contamination where detergents are used. The liquid wastes are collected and stored in collection tanks. From the collection tanks, the wastes are periodically processed through a filter and stored in a monitor tank. After sampling to ensure that the water quality requirements are met, the waste water can be recycled for further use or mixed with the cooling tower blowdown and discharged to the river. If the water quality requirements are not achieved, the wastes are reprocessed until they meet these requirements.
Acceptance criteria for radioactive liquid waste releases as a result of tank failures will be based on radionuclide concentrations at the nearest potable water supply not in excess of the values in Appendix B, Table II, Column 2 to 10 CFR Part 20. Analysis will be provided at a later design stage to show that these criteria can be met.

\subsection{Gaseous Waste Management Systems}

The gaseous-radioactive-waste system provides a means for collecting, processing, and disposing of radioactive gaseous wastes to control radiation within the plant. The system is designed to give reliable processing of collected radioactive gaseous wastes to meet the requirements of $10 \mathrm{CFR}$ Part 20 and the design objectives of Appendix I to 10 CFR Part 50. The gaseous-radioactive-waste system is not safety related and is designed in accordance with RG 1.143.

The primary source of radioactive gaseous wastes is the reactor cover gas. The PRISM reactor is designed to operate as a hermetically sealed system and is opened only for refueling or maintenance. Thus, there is no feed/bleed of reactor cover gas during operation. The helium cover gas is replaced before refueling with clean gas. A portable, vehicle-mounted, helium gas supply system is provided to evacuate, purge, and establish the reactor cover gas pressure at refueling. The system consists of a helium supply, filter, vacuum pump, receiver tank, vapor trap, compressor, and storage/transfer tank. The reactor cover gas is evacuated from the reactor before refueling to the receiver tank through the vapor tras using the vacuum pump. From the receiver tank, the cover gas is transferred to the helium storage/transfer tank using the compressor. The cover gas is replenished with clean helium. The radioactive reactor cover gas, collected by the mobile unit, is then transferred to the gaseousradioactive-waste system for processing. It is kept in storage for $\mathbf{4 5}$ days for the radioactivity to decay to allowable levels and then reused or discharged to the atmosphere through a monitored exhaust.

The acceptance criterion for gaseous waste releases as a result of a leak or failure of the waste gas system is a total body exposure to an individual not in excess of 0.5 rem at the nearest exclusion area boundary. At a later design stage, analysis needs to be provided to show the criterion can be met.

Ventilation systems are considered to be gaseous waste management systems with regard to the requirements of 10 CFR Part 20 and Appendix I to 10 CFR Part 50. Information on these systems will be provided at a later design stage. Applicable guidance concerning these systems is contained in RG 1.140 (Ref. 11.4). 


\subsection{Sclid Waste Management System}

The solid radioactive waste system provides means for collecting and disposing of radioactive solid wastes to control radiation within the plant. It is designed to provide reliable collection and transfer of radioactive solid wastes to meet the requirements of 10 CFR Parts 20 and 61 . Additional information will be provided at a later design stage regarding compliance with the requirements of 10 CFR Part 71. The solid radioactive waste system is not safety. related and is designed in accordance with RG 1.143. The primary sources of solid radioactive wastes are

- spent radwaste demineralizer resins

- spent radwaste filter cartridges

- sodium-bearing radioactive solids from equipment cleaning

- compactible solids such as rags

The solid wastes are collected, processed, and packaged for shipment to a Federal or State licensed burial site.

\subsection{Process and Effluent Radiological Monitoring Instrumentation and Sampling Systems}

The radiation monitoring system is designed to ensure radiation protection to plant personnel and the surrounding environment during all foreseeable operating and accident conditions. To meet this general requirement, the system design includes three basic equipment groups:

- area and airborne radiation instrumentation

- process radiation instrumentation

- effluent radiation instrumentation

The radiation monitoring system gives continuous area radiation monitoring within accessible cells located near radiation sources and where a significant increase in a gamma radiation level could occur (indicative of a process system failure). Continuous monitoring for airborne radioactivity is ccaducted (using mobile equipment) within the designated operating areas adjacent to potential radioactive sources.
Continuous radiation monitoring and sampling analysis of selected radioactive processes are performed. These monitors give early warning of process system malfunctions (abnormal conditions), provide a signal for process control (if required), and verify that the process product is suitable for release to the environment (if applicable).

Sampling and accompanying counting room analysis is performed at each plant effluent point that has the potential for radioactive release to determine the type and quantity of radioisotopes released to the environment. In addition, wide-range detectors are provided to monitor a wide spectrum of postulated design-basis accident conditions.

Acceptance criteria for the process and effluent radiological monitoring instrumentation and sampling systems are the relevant requirements of 10 CFR Part 20 as it relates to radioactivity monitoring of effluents to unrestricted areas.

\subsection{References}

11.1 U.S. Nuclear Regulatory Commission, Code of Federal Regulations, Title 10, "Energy," Part 20, "Standards for Protection Against Radiation."

11.2 U.S. Nuclear Regulatory Commission, Code of Federal Regulations, Title 10, "Energy," Part 50, "Domestic Licensing of Production and Utilization Facilities," Appendix I, "Numerical Guides for Design Objectives and Limiting Conditions for Operation to meet the Criterion 'As Low as Reasonably Achievable' for Radioactive Material in Light-Water-Cooled Nuclear Power Reactor Effluents."

11.3 U.S. Nuclear Regulatory Commission, "Design Guidance for Radioactive Waste Management Systems, Structures, and Components Installed in Light-Water-Cooled Nuclear Power Plants," Regulatory Guide 1.143.

11.4 U.S. Nuclear Regulatory Commission, "Design, Testing, and Maintenance Criteria for Normal Ventilation Exhaust System Air Filtration and Adsorption Units of Light-Water-Cooled Nuclear Power Plants," Regulatory Guide 1.140. 


\section{RADIATION PROTECTION}

Information on radiation protection methods and estimated occupational radiation exposures to operating and construction personnel during normal plant operations and anticipated operational occurrences (AOOs) is presented in Chapter 12 of the Preliminary Safety Information Document (PSID) (Ref. 12.1). The radiation protection measures incorporated for the standard power reactor innovative small module (PRISM) design are intended to ensure that internal and external occupational radiation exposures to plant operating personnel, contractors, administrators, visitors, and the general population as a result of station normal operating conditions, including AOOs, will be within the applicable limits of regulatory criteria and will be as low as is reasonably achievable (ALARA).

At the preapplication review stage, the staf.'s acceptance of the PRISM radiation protection program is based on the designer's assertion that doses to personnel will be maintained within the limits of 10 CFR Part 20 (Ref. 12.2). The PRISM radiation protection design and program features are consistent with the guidelines of Regulatory Guide (RG) 8.8 (Ref. 12.3). These radiation protection features will help to ensure that occupational radiation exposures are maintained ALARA during plant operation and during decommissioning.

The radiation protection measures incorporated in the design and the proposed radiation protection program described in the PSID provide reasonable assurance that occupational doses can be maintained ALARA and can be below the limits of 10 CFR Part 20.

\subsection{Ensuring That Occupational Radiation Exposures Are ALARA}

\subsubsection{Policy Considerations}

In the PRISM PSID, the preapplicant commits to ensure that the PRISM design will be designed, constructed, and operated in a manner consistent with RG 8.8, RG 8.10 (Ref. 12.4), and RG 1.8 (Ref. 12.5). The ALARA philosophy was applied during the initial design of the plant. These policy considerations will continue to be applied as the design is reviewed and modified.

During the next review stage, this section should include a description of the applicable responsibilities and the related activities to be conducted by the individuals having responsibility for radiation protection.

\subsubsection{Design Considerations}

The objectives of the radiation protection design are:

- Minimize the necessity for and the amount of time spent in radiation areas.

- Minimize radiation levels in routinely occupied areas and in the vicinity of plant equipment expected to require personnel attention.

- Limit occupational radiation exposure to less than 20 person-rem per year.

- Meet the requirements of 10 CFR Parts 20 and 50 during plant operations, shutdown, and refueling.

Some of the design considerations used to meet the plant objectives include modularization of radioactive components for ease of disassembly and removal to lower radiation areas for repair, remote operation (including use of special tools or equipment), use of labyrinth entrances to shielded cubicles, utilization of remote viewing devices, and provisions for venting, purging, and decontamination to reduce radiation levels in systems that may experience plateout. These design considerations are consistent with the guidelines of RG 8.8.

\subsubsection{Operational Considerations}

The Department of Energy's (DOE's) operational considerations include the development and implementation of plant operating plans and procedures for radiation exposure control as discussed in RGs 8.8 and 8.10. These operating plans and procedures cover system operation, maintenance, surveillance, testing, fuel handling, emergencies, radiation protection, and administration. Station procedures for work in radiological areas are prepared to ensure that

- Applicable activities are completed with adequate preparation and planning.

- Work is performed with appropriate radiation protection recommendations and support.

- Evaluations during post-work debriefings are used to identify improvements in future activities. 
The PRISM design is conceptual and lacks sufficient detail to draw firm conclusions about the overall suitability concerning radiation protection. However, the operational considerations presented in the PSID appear to be consistent with both RGs 8.8 and 8.10.

\subsection{Radiation Sources}

Section 12.2 of the PRISM PSID describes the sources of contained and airborne radioactivity that form the basis for in-plant radiation protection. The initial sources of radioactive materials derive from the fission process in the reactor fuel. Initial and derived radiation sources are prompt neutron and gamma radiation, fission products, and neutron activation products. Prompt radiation sources are located in the reactor vessel. Activation products and fission products from leaking fuel, however, can be transported and distributed to other plant systems. Equipment areas containing systems that are potential sources of leakage are provided with controlled ventilation systems. The use of activity and leakage control features, as well as controlled ventilation systems, ensures that airborne radioactivity levels in personnel access areas are maintained within the limits given in 10 CFR Part 20. The source terms appear to have been estimated conservatively; however, due to the conceptual nature of the design and the level of detail presented in the PSID, the preapplicant will need to furnish detailed source term information at a later stage of review.

\subsection{Radiation Protection Design Features}

In Section 12.3 of the PRISM PSID, the preapplicant describes the features that are included in the radiation protection design of the plant to maintain exposures at the ALARA level. Separate descriptions are presented for the categories of facility design features, shielding, ventilation, and monitoring instrumentation for area radiation and airborne radioactivity.

\subsubsection{Facility Design Features}

The acceptability of the facility design features for the standard PRISM design is based on DOE's application of the guidance contained in $R G$ 8.8. The radiation protection design features are intended to help maintain the occupational radiation exposures below the goal set by the user and, thus, to keep them within the limits of the regulatory criteria.

The standard PRISM design contains many features to minimize occupational radiation exposures. Plenum and duct arrangement reduces streaming potential by including offsets and eliminating open access ways into duct areas. Reactor modules are designed for in-place refueling and maintenance using a mobile refueling enclosure. The maximum design contact dose rate on the refueling enclosure is 0.25 rem per hour. Remote handling equipment is provided for transfer of solid waste into the storage areas and from the storage area to the transportation vehicles. Gaseous radioactive waste system components are located on a vehicle capable of moving between each of the reactors and the fuel cycle facility. The design vehicle contact dose rate is 0.25 millirem per hour. Areas in which radioactive spills could contaminate the floor are fitted with facilities for decontamination, washdown, and radioactive liquid collection. Additionally, floors in these areas are designed to prevent seepage and the spread of radioactive materials. Radioactive systems and equipment are designed and selected to minimize leakage. Collection headers and equipment drip pans are provided to minimize the spread of radioactivity.

The features incorporated in the standard PRISM design for maintaining occupational radiation doses ALARA during plant operation and maintenance will also serve to maintain radiation doses ALARA during decommissioning operations.

\subsubsection{Shielding}

The objective of the plant's radiation shielding is to provide protection against radiation for operating personnel (both inside and outside the plant) and for the general public during normal operation, AOOs, and accidents. The shielding is designed to meet the requirements of the radiation dose rate zone system that is based on frequency and duration of occupancy. The design of the radiation shielding considers the dose rate criterion for each zone based on maximum access from time estimates in each compartment within the zone.

The PRISM design has provided eight radiation zones as a basis for classifying occupancy and access restrictions on various areas within the plant. On this basis, maximum design dose rates are established for each zone and used as input for shielding of the respective zones. For example, design radiation levels in operating areas where personnel are expected to be working for a 40-hour week will be less than $\mathbf{0 . 2}$ millirem per hour. The areas that will have to be occupied on a predictable basis during normal operations and $A O O$ s are zoned so that exposures are below the limits of 10 CFR Part 20 and will b. ALARA. The zoning system and access control features will also meet the posted entry requirements of 10 CFR 20.203 or the Nuclear Regulatory Commission Standard Technical Specificarions.

The next stage of review should contain the results of a design review of station shielding to ensure the 
accessibility of vital areas after an accident (in accordance with the criteria of TMI Action Item II.B.2, NUREG-0737 (Ref. 12.6). These results should include post-accident source terms, a listing of plant systems containing highly radioactive materials following an accident, a set of postaccident radiation zone maps depicting the radiation levels in various areas of the plant 1 hour after the accident, a list of the vital areas that will require continuous or frequent occupancy following an accident, and a summary of the integrated doses to personnel in these areas for the duration of the accident. TMI Action Item II.B.2 is directly applicable to the PRISM design.

\subsubsection{Ventilation System}

The ventilation system for the PRISM design will be designed to ensure that plant personnel are not inadvertently exposed to airborne contaminants exceeding the limits given in 10 CFR Part 20. The PRISM designer intends to maintain personnel exposures ALARA by (1) maintaining airflow from areas of potentially low airborne contamination to areas of higher potential concentrations, (2) ensuring negative or positive pressures to prevent exfiltration or infiltration of potential contaminants, and (3) locating ventilation system intakes so that intake of potentially contaminated air from other building exhaust points is minimized. These design criteria are consistent with the guidelines of RGs 1.52 (Ref. 12.7) and 8.8.

\subsubsection{Area Radiation and Airborne Radioactivity Monitoring Instrumentation}

The PRISM area radiation monitoring system (ARMS) is provided to supplement the personnel and area radiation survey provisions of the plant radiation protection program to ensure compliance with the personnel radiation protection guidelines of 10 CFR Part 20, 10 CFR Part 50, 10 CFR Part 70 (Ref. 12.8), and RGs 8.2 (Ref. 12.9), 8.8, and 8.10.

\subsubsection{Area Radiation Monitoring System}

The ARMS is designed to (1) monitor the radiation levels in areas where radiation levels could become significant, and where personnel may be present, (2) alarm when the radiation levels exceed preset levels to warn of increased radiation levels, (3) provide a continuous record of radiation levels at key locations throughout the plant, and (4) provide criticality warning for new and spent fuel storage areas. The ARMS meets the criteria of Section II.F.1(3) of NUREG-0737 and RG 1.97 (Ref. 12.10), and is equipped with local and remote audible and visual alarms and a facility for central recording.

\subsubsection{Airborne Radioactivity Monitoring System}

Airborne radioactivity is monitored in compliance with 10 CFR Part 20 and RG 8.2. The design objectives of the airborne radioactivity monitoring system are to

- assist in maintaining occupational exposure to airborne contaminants ALARA

- check on the integrity of systems containing radioactivity

- wam of unexpected release of airborne radioactivity to prevent inadvertent overexposure of personnel

Airborne radioactivity monitors are installed in work areas where there is a potential for airborne radioactivity. These airborne radioactivity monitors have the capability to detect maximum permissible concentrations in air (MPCA) of the most restrictive particulate and iodine radionuclides in the area or cubicle of lowest ventilation flow rate. The design will provide portable continuous air monitors when needed to monitor air in areas that have no fixed airborne radioactivity monitors. All airborne and area radioactivity monitors are to be calibrated periodically. The objectives of the PRISM area and airborne radiation monitoring systems are in conformance with those portions of 10 CFR 20.201, 10 CFR 50.34, and 10 CFR 70.24, as well as RGs 1.97, 8.2, and 8.8 and American National Standards Institute Standard N13.1 (Ref. 12.11) related to airborne radioactivity monitoring.

\subsection{Dose Assessment}

A dose assessment, as described in RG 8.19 (Ref.12.12), has not been submitted at this stage of the design. This information will have to be submitted at the next stage of review.

\subsection{Operational Radiation Protection Program}

The PSID for the PRISM design does not contain a Section 12.5. As mentioned in Standard Review Plan (SRP) (Ref. 12.13) Section 12.5, this section should describe the health physics program with respect to organization, equipment, instrumentation, facilities, and procedures. Since the PSID is a preliminary document to the preliminary safety analysis report and since the PSID describes a standardized plant (not a plant at a specified site), most of the level of detail included in SRP Section 12.5 is not warranted at this stage of the review. However, during the final design approval review stage, Chapter 12 should contain (1) a description of the administrative organization of the health physics program, 
including the authority, responsibility, and training of each position identified; (2) the criteria for selecting portable and laboratory technical equipment and instrumentation for performing radiation and contamination surveys, area and airborne radioactivity monitoring, and personnel monitoring during normal plant operations and AOOs; and (3) a description (including location) of the health physics facilities, access control stations, laboratory facilities, decontamination facilities, and other contamination-control equipment and facilities.

\subsection{References}

12.1 General Electric, PRISM-Preliminary Safety Information Document, GEFR-00793 UC-87Ta, November 1986.

12.2 U.S. Nuclear Regulatory Commission, Code of Federal Regulations, Title 10, "Energy," Part 20, "Standards for Protection Against Radiation."

12.3 U.S. Nuclear Regulatory Commission, "Information Relevant to Ensuring That Occupational Exposures at Nuclear Power Stations Will Be as Low as Is Reasonably Achievable," Regulatory Guide 8.8.

12.4 U.S. Nuclear Regulatory Commission, "Operating Philosophy for Maintaining Occupational Radiation Exposures as Low as Is Reasonably Achievable," Regulatory Guide 8.10.

12.5 U.S. Nuclear Regulatory Commission, "Qualification and Training of Personnel for Nuclear Power Plants," Regulatory Guide 1.8.

12.6 U.S. Nuclear Regulatory Commission, "Clarification of TMI Action Plan Requirements," NUREG-0737, November 1980.
12.7 U.S. Nuclear Regulatory Commission, "Design, Testing, and Maintenance Criteria for Post Accident Engineered-Safety-Feature Atmosphere Cleaning System Air Filtration and Adsorption Units of Light-Water-Cooled Nuclear Power Plants," Regulatory Guide 1.52 .

12.8 U.S. Nuclear Regulatory Commission, Code of Federal Regulations, Title 10, "Energy," Part 70, "Domestic Licensing of Special Nuclear Material."

12.9 U.S. Nuclear Regulatory Commission, "Guide for Administrative Practices in Radiation Monitoring," Regulatory Guide 8.2.

12.10 U.S. Nuclear Regulatory Commission, "Instrumentation for Light-Water-Cooled Nuclear Power Plants to Assess Plant and Environs Conditions During and Following an Accident," Regulatory Guide 1.97.

12.11 American National Standard Institute/American Nuclear Society, ANSI/ANS 13.1-1981, "Sampling Airborne Radioactive Materials in Nuclear Facilities," ANS, LaGrange Park, Illinois.

12.12 U.S. Nuclear Regulatory Commission, "Occupational Dose Assessment in Light Water Reactor Power Plants Design Stage Man-Rem Estimates, " Regulatory Guide 8.19.

12.13 U.S. Nuclear Regulatory Commission, "Standard Review Plan for the Review of Safety Analysis Reports for Nuclear Power Plants, LWR Edition," NUREG-0800, July 1981. 


\section{CONDUCT OF OPERATION}

Planning for a radiological emergency, plant operations, and plant security are discussed and evaluated in this chapter. Key policy issues identified for the PRISM design and discussed in this chapter are emergency planning (Section 13.1), control room and remote shutdown facility design (Section 13.2.3), and the role of the operator and staffing (Section 13.2.4).

\subsection{Radiological Emergency Planning}

\subsubsection{Preapplicant's Proposed Planning}

Planning for a radiological emergency at a nuclear plant site entails offsite planning and onsite planning. The preapplicant has briefly discussed its emergency planning for the PRISM design in Section 13.1 and Appendix G.4.11 of the Preliminary Safety Information Document (PSID) (Ref. 13.1). The preapplicant submitted Appendix G.4.11 to address staff concerns identified during the review. The preapplicant stated that the detailed PRISM emergency plan would be submitted with the application for standard design certification and would fulfill the requirements of 10 CFR 50.47 and Appendix E to 10 CFR Part 50 (Ref. 13.2). The preapplicant did not address emergency planning for the offsite food ingestion pathway.

As proposed, the emergency plan would take advantage of the protection features inherent in the modular PRISM design. These are its relatively low power $(471 \mathrm{MWt})$, large heat capacity, low primary reactor coolant pressure, prompt reactivity shutdown and passive heat removal systems, seismic isolation, and containment barrier. These features should reduce the occurrence of core damage and large radioactivity release to extremely low probabilities. The emergency planning proposed for the design is supported by accident analyses and probabilistic risk assessment (PRA). The PRA showed that evacuation and sheltering of the public are not significant contributors to reducing the risk to the public from the operation of the plant design.

The preapplicant's proposed approach to offsite emergency planning differs significantly from that approved for operating light-water reactors (LWRs). The proposed approach, however, is similar to (1) that being proposed by the Electric Power Research Institute (EPRI) for the passive LWR advanced reactors (Ref. 13.3) and (2) the approach taken by the Commission for low-power research reactors (Ref. 13.4).

The preapplicant's proposed approach would establish a reactor design that would not require early notification, detailed planning for offsite evacuation and protective sheltering, and exercise of the offsite emergency plan.
The preapplicant has also proposed that the plume exposure pathway emergency planning zone (EPZ) would be within the plant site exclusion area boundary (EAB). The preapplicant asserts there are significant advantages to this approach.

These advantages would simplify offsite planning for the PRISM design by eliminating the need for extensive interaction between the licensee and State and local governments in developing a plan and implementing it. The preapplicant did address methods for alerting responsible individuals off site in the event of an accident.

The preapplicant stated that the PRISM is designed so that accidents, including severe accidents, have a very low probability, have long delay times to release radioactivity, and result in an extremely low probability of early health effects. The PRISM design is stated to meet the Commission's safety goals on prompt fatalities and longterm cancer fatalities on accident prevention alone. Radiological exposures from design-basis events (DBEs), as calculated by the preapplicant, indicate that the exposures are below the lower level protective action guides (PAGs) at the plant site EAB. These are the PAGs used by the Environmental Protection Agency (EPA) for deciding on whether to evacuate and shelter the public in response to a radiological accident at a nuclear power plant.

For these reasons, the preapplicant has stated that such planned offsite protective actions as early notification, evacuation, sheltering, and public drills are not needed to adequately protect the health and safety of the public during postulated accidents, including severe accidents. The onsite plan will be developed in accordance with the applicable requirements of NUREG-0654 (Ref. 13.5). Onsite planning will include emergency operating procedures (EOPs), prevention of core damage, and management of accidents, including core damage accidents. The preapplicant stated that the emergency plans would ensure the following:

- Adequate measures are taken to protect employees and the public.

- All individuals having responsibilities during an accident are properly trained.

- Procedures exist to provide the capabiiity to cope with a spectrum of accidents ranging from those of little consequence to those associated with a major radioactive release to the containment.

- Equipment is available to detect, assess, and mitigate the consequences of such accidents. 
- Emergency action levels and procedures are established to assist in making decisions.

\subsubsection{Scope of the Review}

The staff has reviewed the proposed approach to emergency planning and the supporting analysis presented in the PSID. The preapplicant submitted PRA analyses similar to those in NUREG-0396 (Ref. 13.6) to show the very low probability of exceeding the lower level PAGs of 1 rem wholebody and 5 rem thyroid at the site boundary.

\subsubsection{Discussion}

The staff considers emergency preparedness an essential part of the NRC "defense in depth" philosophy, in addition to safety classification and the three barriers to releases of radioactivity to the public. Briefly stated, this philosophy (1) requires a high quality in the design, construction, and operation of nuclear plants to reduce the likelihood of malfunctions; (2) recognizes that equipment can fail and operators can make mistakes and, therefore, requires safety systems of high reliability and sufficient training of operators to reduce the chances that malfunctions will lead to accidents that release fission products from the fuel; (3) recognizes that, in spite of these precautions, serious fuel damage exceeding that calculated for licensing the plant may happen and, therefore, requires containment structures and other safety features to prevent the release of significant amounts of fission products off site; and (4) recognizes that significant amounts of fission products, higher than expected from dose consequences for accidents evaluated during licensing of the plant, may be released to the public. Offsite planning offers reasonable assurance that protective measures can be taken in an emergency to protect the population around the nuclear power plant from releases from that plant. 10 CFR 50.47(a)(1) requires that no operating license will be issued to a nuclear power plant unless a finding is made that there is reasonable assurance that adequate protective measures can and will be taken in the event of a radiological emergency.

Currently, offsite protective actions are based on the PAGs for projected doses, which are 1-5 rem wholebody and 5-25 rem thyroid. At the lower level projected dose, protective actions should be considered. At the higher level projected dose, protective actions are warranted.

In the past, the Commission has limited offsite emergency activities to situations in which the lower level PAGs were expected to be exceeded. For example, emergency planning for low-power research reactors is restricted to the area around the reactor where the lower level PAGs may be exceeded. This is usually within the ownercontrolled area. For fuel cycle facilities, the final rule
(Ref. 13.7) exempts those facilities at which the lower PAGs will not be reached outside the owner-controlled areas. Therefore, there is a precedent for not requiring offsite emergency planning, beyond simple notification, where it is warranted by operation. The response of certain offsite agencies into the owner-controlled area (e.g., police, fire, medical) is traditionally considered a part of the onsite planning.

The staff believes that emergency planning requirements for advanced reactors can be evaluated on the basis of the characteristics of the designs. This principle is similar to that in the emergency planning rule (10 CFR 50.47), which states in 50.47 (c)(2) that the size of the EPZ for high-temperature gas-cooled reactors and for reactors with an authorized power level less than $250 \mathrm{MWt}$ can be determined on a case-by-case basis.

Reduced requirements for emergency planning could be based on the characteristics of a design that would prevent significant releases of nadioactive material to the public and would provide long times after accidents preceding releases for all but events of very low probability. The preapplicant has stated that the PRISM design has these characteristics. A possible basis for reduced requirements, that would be consistent with evaluating a range of events similar to those now evaluated for LWRs, could be developed using the PAGs as a guide for acceptability. A reduction in offsite emergency planning (beyond simple notification) could be considered if, for example

- The lower level PAGs are not predicted to be exceeded at the site boundary within the first 36 hours following any event in Event Categories (ECs) I, II, and III.

- A PRA for the plant that includes at least all events in EC-I through EC-III indicates that the cumulative frequency of exceeding the lower level PAGs at the site boundary within the first 36 hours does not exceed approximately $10^{-6}$ per ycar.

Unplanned (i.e., few details and no drills) or ad hoc evacuation and sheltering plans for the public that are aided by prompt notification of offsite authorities may be sufficient if these guidelines can be met. Communities already have plans for such events as hurricanes and flooding. These plans for such low-frequency events include means to evacuate and shelter the public and they are not exercised on an annual basis. Considering the history of ad hoc evacuations that were completed in from 2 to 8 hours, 24 hours may be sufficient for local agencies to take ad hoc protective actions (e.g., shelter or evacuate). If this could be established at a high-confidence level, then it might be determined that preplanning would not substantially reduce the risk to the public. The 
24 hours combined with 12 hours for plant personnel to diagnose the event and attempt corrective action before initiating evacuation and sheltering is the basis for the proposed 36-hour criterion. The criterion on cumulative frequency exceeding the PAGs should ensure that events of similar frequency to those considered in NUREG-0396 are considered for advanced reactors and that low risk is ensured for at least the time necessary to evacuate and shelter the affected public.

\subsubsection{Evaluation}

The preapplicant has proposed that formal offsite emergency planning for the PRISM design is not needed for (1) giving early notification, (2) detailed planning for evacua:ing and sheltering the public, and (3) exercising the offsite plan. The preapplicant did not state whether the early notification was for the public or for the State and local officials, or for both. There was no proposed reduction in the onsite emergency planning. The preapplicant did not address emergency planning for the food ingestion pathway. The preapplicant stated that the detailed emergency plan would be submitted with the application for the standard design certification.

In PSID Appendix G.4.11, the preapplicant stated that, although additional work and analyses were needed, the work completed indicated that the PRISM design could meet the proposed criteria. The staff has reviewed potential EC-I to EC-III events sufficiently (see Chapter 15 of this report) to conclude that the PRISN. design should meet the proposed criteria.

The preapplicant has proposed that the plume exposure pathway EPZ would be the plant site EAB, and also proposed to refrain from including offsite emergency plans on how to notify, evacuate, shelter, and drill the public. The staff believes thai this is equivalent to not requiring offsite emergency planning. The preapplicant has proposed that it would not prepare such plans, even for the contingency that actual plant releases may turn out to be higher than the maximum consequences calculated for licensing the plant. Because the Commission has a policy that offsite emergency planning is a requirement for the licensing and operation of a nuclear power plant and represents defense in depth, the preapplicant's proposal is considered as a request for a change in policy rather than as an adjustment of the EPZ size. Further, exemptions to existing regulatory requirements (e.g., 50.47(b)(5) for eariy notification of the public in the plume pathway and $50.47(b)(14)$ for periodic drills of the emergency plan) may have to be pursued. The preapplicant has not explained how the reduced emergency plan will fulfill all of the 50.47 requirements, including 50.47(b)(5) and 50.47(b)(14), although 50.47(c) allows the applicant to demonstrate that noncompliance with parts of $50.47(\mathrm{~b})$ may be acceptable.

A design's ability to prevent the significant release of radianctive material, or to provide a long delay time preceding a release for all but the most unlikely events, would be reflected in any NRC decision on relaxing emergency planning requirements. The staff believes that certain modifications from the emergency planning requirements in 10 CFR Part 50 and from the siting criteria in 10 CFR Part 100 may be appropriate for the PRISM design, considering its unique characteristics. These unique characteristics would determine the extent of offsite emergency planning requirements in the EPZ. However, the staff will require a high degree of assurance that all potential containment bypass accident sequences have a very low likelihood to occur before it will consider relaxing current requirements.

The staff has reviewed the emergency preparedness planning basis and approach presented for the PRISM design. The preapplicant must develop the more detailed event sequence and consequence analysis necessary for a detailed Level III PRA by the final design review stage to support demonstration of (1) sufficiently low !ikelihood of dose consequences to the public above the lower level PAGs, (2) sufficiently low likelihood of containment hypass sequences, and (3) sufficient delay in the release of activity from the core. Particular attention should be to the evaluation of the consequences of very low ubility events. The preapplicant must also address the emergency planning for the offsite food ingestion pathway.

\subsubsection{Conclusion}

The staff's position is that licensees who would operate advanced reactors should be required to develop offsite emergercy plans that contain detailed plans to evacuate and shelter the public, even if the likelihood of the need for these plans may bn considered small. Additionally, provisions for prompt notification and periodic emergency exercises, both on site and off site, should be included in these plans. These are required by existing NRC regulations for $L W R s$ and include the establishment of an offsite EPZ.

Information obtained from additional accident evaluations will serve as input to reevaluate the emergency planning requirements for the PRISM design, for the standard design certification review stage. Based, in part, upon these additional accident evaluations, the staff will consider whether some relaxation from current requirements for emergency plans may be appropriate at this later design 
review stage. The relaxations may include, but will not be limited to, notification requirements, size of the EPZ, and frequency of exercises. This evaluation will take into account the NRC policy decisions regarding emergency planning for the advanced passive LWRs.

\subsection{Plant Operations}

\subsubsection{General}

The preapplicant discussed the proposed operation of the PRISM reactor modules in Section 13.2, Section 7.2, and Appendices G.4.10 (control room), G.4.12 (role of operator), and G.4.13 (multi-module control) of the PSID.

The plant will be operated from one central control room and one operator will be in control of a power block of three reactor modules with their individual steam generators and one turbine-generator set.

This high ratio of reactor power systems to operators will be achieved by automating the procedures and diagnostic capability available to the operators through the use of multi-module controls. The control system and the protection system are described in Chapter 7 of this report. The preapplicant stated that the multi-module control of the plant would include the following automated controls:

- autumatic coordination of power block operation (overall plant control)

- automatic coordination of the nuclear steam supply system (NSSS) and balance of plant (BOP) and automatic apportionment of load to the turbinegenerator sets and to the reactor modules (power block control)

- automatic operation of all power train systems in the power range (25 percent to 100 percent load), including adjustments to the rod profile

- automatic turbine-generator warmup, rolling, and synchronization on demand

- automatic reactor warmup on demand

- automatic reactor startup on demand (from subcritical through 2-percent power)

- automatic startup of the power conversion portion of the plant (venting and draining of main steam, extraction, turbine and bypass control, feedwater, and condensate systems)
The extensive automated control proposed by the preapplicant will be implemented by what is called a "control engine," which consists of a set of distributed digital computers which are started and monitorad by the control room operator. See Section 13.2.5 below.

\subsubsection{Operating Modes}

Three normal operating modes are planned for the PRISM reactor: normal startup, load following, and shutdown. Normal startup is expected to consist of the startup of a single reactor module or a power block's turbine-generator set. A startup of an entire nine-module facility is stated to be a rare event. Normal startup semiautomatically sequences major plant system operation between pred rermined hold points. Operator permissives are required to continue the startup operation from each hold point. The preapplicant stated that this will free the operator from executing the laborious manua! control adjustments and from directly initiating each operational step.

If the turbine-generator set is not in operation, it will be brought to synchronous speed and loaded at its minimum stable loading of 10 percent of rated load when the total power block level of 12 percent of power is reached. During startup operations, main steam header pressure is maintained constant to permit individual modules to be brought to power without requiring isolation of their steam generators until steam generator outlet temperatures are matched. Once the turbine-generator loading is initiated, power is increased at the rate of 1 percent of rated power per minute. During startup, primary and intermediate system sodium flow rates will be maintained constant at full-rated-power flow conditions.

Normal operation of the plant is stated to be under base load conditions, or with the three resio: modules of each power block loadr $t$ equally. The plant $i$; capable of load following at the rate of 1-percent power per minute in the power range of 25 to 100 percent of rated power. The maximum power change rate is anticipated to be 20 percent of rated power per minute for a maximum change of 5-percent power.

Normal reactor shutdown is stated to be the reverse of normal startup but with fewer operator hold points and permissives required. An individur! reactor module may be shut down without interfering with the state of the other two modules. Normal shutdown decay heat removal uses the path through the main condenser out to the atmospheric heat sink. Should this path be unavailable, heat can be removed by the auxiliary cooling system which utilizes external air cooling of the steam generator for the reactor module. 


\subsubsection{Control Room and Remote Shutdown Facility}

As proposed by the preapplicant, the plant control room will contain the instrumentation and controls for up to three reactor power blocks and their power conversion systems. It is proposed as a seismic Category II, tornadohardened facility and, in response to staff concern, will have some operator habitability features. It will be located within the "protected area" (see Section 13.3). The preapplicant should explain which operator habitability features will protect the operators against smoke and other release of hazardous chemicals.

The control room contains the electronic display consoles for each power block; these are driven by what the preapplicant referred to as a redundant array of computationally powerful, high-speed, plant process computers. The number in the redundant array was not specified. The electronics, displays, and process computers are part of the plant control system (PCS) and are not safety related. The control room has no safetyrelated instrumentation or controls; however, all plant data, including reactor protection system (RPS) and postaccident monitoring (PAM) data, are sent to the control room. The safety-related data are isolated by Class 1E isolators and are available at the operator consoles through the process computers. A manual scram for each module exists in the control room and is also not safety related.

In the unlikely event of a natural disaster, or other severe accident that causes the control room to be uninhabitable, or should the non-safety-related instrumentation and controls be lost, the operator will proceed from the control room to the nearby separate alternative or remote shutdown facility (RSF). The RSF is also located in the protected area in the seismic Category I, tomado-hardened radwaste building, about $12 \mathrm{~m}$ (40 ft) from the control building. Access to the RSF control building is gained through a seismic Category II, tornado-hardened tunnel. The RSF has a safety-grade heating, ventilation, and air conditioning (HVAC) system with emergency outside air filtration; has the capability of being isolated during toxic gas release; and has 36 hours of uninterruptible backup power from batteries. The operator can communicate with onsite and offsite locations from the control room and the RSF.

The control of each module, including shutdown, can be accomplished from the RSF location or from the RPS equipment vaults located at each module using safety-grade instrumentation and controls. The RPS vaults are seismic Category I, tornado-hardened structures located on the seismically-isolated platform of the reactor facility. At a later review stage the preapplicant should address habitability protection for the operators in the RPS vaults.

The preapplicant classified the control room and the equipment in it as non-safety-grade, contending that no equipment failure or operator action or inaction from that location can interfere with safe plant operations. The preapplicant agrees that the operator has a safety role, but stated that the plant can automatically and safely be shutdown with safety-related systems without the operator taking any actions. The preapplicant stated that the control room offers adequate protection for the operator until the operator can reach the RSF or the RPS vaults (which would require an appropriate habitability system) giving the operator safety-grade protection from natural phenomena and environments that result from accidents. The operator has a manual scram for each module in the control room (non-Class 1E) and in the RSF (Class 1E); a manual scram is also available in the RPS vaults as are the scram breakers which can be manually opened.

The staff considers that the operators are a critical element in ensuring plant safety and that no increased burden should be placed on operators engaged in managing offnormal operations. The control room is the area in the plant where the operators are most familiar with the surroundings and would normally manage plant activities. The key plant documentation for the operators is usually kept in the control room. The staff may be reluctant to approve a design that would increase the frequency of evacuations of the control room during design-basis accident conditions or would hamper the control or monitoring of upset conditions as an event sequence progresses. The staff also believes that human performance will play a role in the safety of the advanced reactor plants and that the quality of support provided by a safety-related, seismic Category I, and electrical Class 1E control room is appropriate. This would include a Class $1 \mathrm{E}$ manual scram for each reactor module. This capability does exist in the RSF and the RPS vaults in the PRISM design. The staff position is that the control room should be designed to current LWR safety-related standards for natural phenomena and habitability to protect the operators and ensure their ability to control the plant.

The staff also believes that the RSF should be designed to complement the control room. There should be sufficient Class 1E instrumentation and controls in the RSF to effectively manage anticipated accidents that would result in a loss of the control room. The preapplicant has stated that this is the case for the PRISM RSF.

The preapplicant has proposed reduced control room habitability requirements for the PRISM design. A related 
policy issue was noted in the staff's April 2, 1993, paper (Ref. 13.8) to the Commission on the passive LWRs. EPRI proposed reduced control room habitability requirements, including reducing control room habitability time to 72 hours (instead of to the duration of the accident), as is required for current LWR operating plants. The staff position is that, pending resolution of this policy issue the control room and RSF for the PRISM design should meet the current LWR habitability requirements for operators during accidents.

\subsubsection{Role of the Operator and Staffing}

The staff has reviewed the preapplicant's proposed role of the operator and staffing for the PRISM design. In the preapplicant's view, the operator plays the following safety role:

- monitors and verifies performance of safety systems, and has the capability to initiate reactor shutdown by manual scram or manual activation of the ultimate shutdown system

- maintains communication with appropriate onsite and offsite personnel

- initiates recovery actions following an event

This is partially consistent with the staff's view of the role of the operator. The preapplicant stated that the safety systems of the PKuSM design offer primary protection of the plant and that the licensed operators' roles are primarily monitoring and backup to these systems. Although the operator can initiate a manual scram of each reactor module from the control room, the manual scram is non-Class $1 \mathrm{E}$ and the protection of the operator is limited. The staff believes that the operators represent an important source of knowledge concerning plant status, design, and behavior. This could prove extremely valuable in understanding, responding to, and recovering from an accident situation. Therefore, the operators should be protected from the effects of natural phenomena, accident environments, and potential intrusion.

In addressing the size of the crew necessary for operating the PRISM plant, the preapplicant stated that operating procedures and diagnostics will be automated to the extent that an operating staff of not more than three licensed operators, a senior operator as assistant shift supervisor, and a senior operator as shift supervisor will be required for the control room to manage a nine module plant. There would be three roving licensed reactor operators plus other roving non-licensed operation and maintenance personnel on site (Ref. 13.26).' The use of multi-module control for the operators in the control room is discussed in Section 13.2.5 below and Chapter 7 of this report.

In accordance with 10 CFR 50.54(m)(2)(iii), present-day LWR operating plants require a minimum of one shift supervisor, one licensed senior reactor operator (SRO), and two licensed reactor operators (ROs) per reactor, significantly more licensed operators than the preapplicant proposes for the PRISM design. The preapplicant has stated that the highly automated operating systems, the passive nature of the inherent reactivity response features and safety-related systems, and the large core and coolant heat capacities (and, therefore, slow response times during accidents) result in a design that responds to transients in a manner that demands less of the operator than do current LWR operating plants. The preapplicant has asserted that because of the passive safety features of the PRISM design, an operator may not be required to act for several days following an accident. The design has automatic safety systems that start up, shut down, and otherwise control the reactor. The passive safety systems are operating at all times and do not have to start up. The preapplicant has, therefore, suggested that the PRISM reactor could be operated with fewer licensed operators than are required in 10 CFR $50.54(\mathrm{~m})$.

The staff believes that operator staffing may be design dependent and intends to review the justification for a smaller crew size for the PRISM design by requiring the preapplicant to submit function and task analyses for normal operation and accident management.

These analyses must demonstrate, and tests and evaluations must confirm, the following:

(1) Smaller operating crews can respond effectively to a worst-case array of power maneuvers, refueling and maintenance activities, and accident conditions.

(2) An accident on a single unit can be mitigated with the proposed number of licensed operators, less one operator who is assumed to be incapacitated, and all other units can be taken to the equivalent of a coldshutdown condition for a LWR from a variety of potential operating conditions, including a fire (e.g., consider the effect of fire brigade duties on the number of available operators) in one unit.

(3) The units can be safely shut down with eventual progression to a safe long-term shutdown condition under each of the following conditions: (a) a complete loss of computer control capability, (b) a complete station blackout, or (c) a design-basis seismic event. 
The adequacy of these analyses shall be tested and demonstrated on a control room prototype.

\subsubsection{Multi-Module Control}

The preapplicant has stated that the control room has an operator console for each power block with electronics and displays. The electronics and displays will provide highly processed and well-integrated information to the operator through a highly interactive, user-friendly, man-machine interface driven by high-speed plant process computers and digital systems. This multi-module control, for the nine reactor modules at the PRISM plant, is part of the preapplicant's basis for reduced staffing for PRISM as compared to current LWR operating plants. This concept is new to the control of nuclear power reactors where current LWR operating plant controls, even using computers, are designed to control only one reactor. This is discussed in Chapter 7 of this report.

In its April 2, 1993, policy paper to the Commission (Ref. 13.8) on the passive LWR advanced reactor designs, the staff submitted positions on common-mode failures and analog backups for digital control and instrumentation systems. The staff requirements for advanced reactor designs, including the PRISM, wi:? be consistent with the Commission policy guidance on the passive LWR advanced reactor.

\subsubsection{Conclusion}

The staff has developed positions on issues concerning the control room and RSF design, and the role of the operator and staffing. The staff believes that, prior to pending policy decisions, the PRISM designers should adhere to the current LWR design requirements for control rooms and RSFs, including operator habitability. The staff will evaluate reduced operator staffing after the preapplicant submits and the staff reviews required function and task aralyses to justify the proposed staffing for normal operation and accident management.

The operating modes outlined in the PSID and planned for the PRISM design appear reasonable at this stage of the design. Adequate demonstration of the automated multimodule control system will be required. Plant operation with only one or two modules in a power block was not reviewed at this stage and needs to be included in the function and task analyses. Multi-module control is another area needing further evaluation by the staff at a later stage in the design review.

\subsection{Safeguards and Security}

\subsubsection{Design Description and Safety Issues}

The PRISM plant will have two separate but adjacent security areas in the owner-controlled exclusion area boundary: the BOP area and the nuclear island (NI) area.

The BOP area contains non-safety-related controls and power conversion structures and equipment, including three turbine buildings, below-grade pipe tunnels, steam generator buildings, circulating water pumphouses, cooling towers, the BOP guard house, and a warehouse, as shown in Figure 1.2 in Section 1 of this report. The BOP area has ordinary industrial-level security with unalarmed physical barriers to channel cooperative individuals to access points.

The NI area comprises the reactor modules with reactor systems and equipment containing radionuclides. This area also has the control building, a warehouse, the NI guard house, and a personnel services building. The NI warehouse is separate from the BOP warehouse. Each reactor module is housed in its own below-grade reinforced-concrete structure within the NI. The belowgrade sodium piping tunnels for the intermediate heat transport system (IHTS) and the electrical cabling for instrumentation and control connest between the NI and the BOP areas. Security access control points and one of two alarm stations are located within the NI guard house.

The NI security program consists of a nuclear level physical security organization, a protected area, one or more vital areas within the protected area, physical barriers, controlled access points, detection aids, communication capabilities, a testing and maintenance program, and an armed response force.

In this review, the staff did not give credit to the BOP area security or to plant equipment located outside the NI, based on a conservative assumption that those things would be vulnerable to a threat with the capabilities defined in 10 CFR 73.1.

\subsubsection{Physical Security Organization}

The NI physical security organization was not described. This is appropriate at the preapplication stage. 


\subsubsection{Physical Barriers}

Protected Area. In meeting the requirements of 10 CFR 73.55, Reference 13.9 described a barrier to the protected area that appears to meet or exceed the standards of 10 CFR 73.2(f)(1). Two chain-link fences of adequate height and a vehicle barrier are described. The preapplicant committed to illuminate the protected area with no less than 0.2 foot-candle (2.15 lux) with an uninterruptible power supply.

The security plan commits the plani owner/operator to keep the protected area around the reactor free from the clutter of construction and maintenance at all times once the module has been installed. Because the reactor modules are installed underground, the openness of the site will make it easier for patrols to detect unauthorized persons or vehicles.

Vital Areas. The preapplicant identified vital areas and vital equipment. According to Review Guideline 17 (Ref. 13.20), seismic Category I equipment would be sufficiently protected from radiological sabotage. All of this equipment is located within the NI protected area.

Reference 13.9 states that substantial barriers are incorporated into the design of structures housing vital equipment. Exterior walls, portals, ducts, and vents will be hardened to yield a penetration delay comparable to the time needed to penetrate 8 inches of reinforced concrete. Except for the reactor vessel auxiliary cooling system (RVACS) inlet/outlet stacks, all equipment identified as vital is located in below-grade structures and is surrounded by reinforced concrete.

Vital equipment that is not protected by vital area barriers comprises the RVACS air inlet and outlet structures. An analysis in Reference 13.9 indicates that disabling the RVACS (in conjunction with disabling other decay heat removal systems and ausing a loss-of-offsite-power transient) for a period of time sufficient to cause significant fuel damage is beyond the defined sabotage design-basis threat. Access to the containment vessel and reactor vessel can only be gained through RVACS vents and inspection ports, and the security system for the RVACS ventilation stacks contains intrusion detection sensors and alarms.

An uninterruptible power supply, protected as vital power, will produce onsite secondary power for security equipment and exterior lighting for the NI protected area for a minimum of 8 hours. The sodium-water-reaction pressure relief system (SWRPRS) inside the steam generator building is located outside the vital area, but a protective area will be established to protect the SWRPRS from sabotage and terrorist attack. This commitment is sufficient for the preapplication stage and should not be a factor in the licensability of PRISM as a standard design.

\subsubsection{Access Requirements}

In accordance with 10 CFR 73.55(d), all points of personnel and vehicle access to the protected area will be controlled. The individual responsible for controlling the final point of access into the protected area will be stationed in a bullet-resistant structure. As part of the program to control access, vehicles, personnel, packages, and material entering the protected area will be required to pass through metal and explosives detectors before gaining access to the protected area. In addition, barriers in the vehicle portals will protect against vehicle bombs. The design objectives are consistent with existing physical security regulations for access control.

The preapplicant stated that a photo-badge/key card system using encoded information will identify individuals who are authorized unescorted access to protected and vital areas and will be used to control access to these areas. Individuals will be identified by personnel recognition equipment (e.g., hand geometry, retinal patterns, or voice patterns).

\subsubsection{Detection Aids}

In satisfying the requirements of $10 \mathrm{CFR} 73.55(\mathrm{e})$, the preapplicant has committed to three types of sensors in each sector. Closed-circuit television (CCTV) will be used to observe and assess the cause of perimeter alarms. Illumination within the perimeter assessment area will be at a minimum level of 1.0 foot-candle (10.8 lux), which exceeds NRC requirements (Ref. 13.25). Cameras will be positioned to preclude obstruction by fencing or lighting.

Alarm mechanisms on doors to vital areas have not yet been selected. Doors will be of hardened construction to yield a delay comparable to at least 8 inches of reinforced concrete. Unreliable locking and alarm mechanisms on heavy doors in high traffic areas have sometimes signaled excessively. Door hardware must provide adequate delay while ensuring timely access and rapid exit for emergency situations. The preapplicant has stated that appropriate requirements will be established to ensure access and exit functions, but the specific alarm mechanisms and door hardware will be selected during the detailed design phase. This is not a significant issue at the preapplication stage because the preapplicant has stated that the appropriate requirements will be met in the final design stage and should not be a factor in the licensability of PRISM as a standard design. 


\subsubsection{Communications}

Security communication was not described. However, Reference 13.9 gives requirements for security communications that should satisfy the requirements of 10 CFR 73.55(f).

\subsubsection{Test and Maintenance Requirements}

The preapplicant did not describe physical security testing and maintenance. Since the PRISM design is conceptual and the available information was limited, conclusions about acceptability cannot be made at this stage of review.

\subsubsection{Response Requirements and Vulnerability Analysis}

In addressing the requirements of 10 CFR 73.55(h), the designer analyzed the ability of the armed response force to interpose ifself between vital areas (or vital equipment in the case of the exposed RVACS stacks) and any saboteur attempting entry. The preapplicant's analysis indicates that the response force would be capable of intercepting the adversaries and interrupting the postulated sabotage activities. However, at least one assumption used in the analysis may be unrealistic. Specifically, movement of the response force to the target area assumes a minimum time path without considering the effects of adversary weapons on the in-transit response force. Although the response force would not necessarily need to advance the assumed distance to engage adversaries armed with semiautomatic rifles, a site plan that placed the perimeter of the protected area farther from the vital areas and located members of the armed response force and their response weapons and equipment at or closer to the reactor buildings could help ensure a faster response.

The size of the armed response force deviates from the nominal force of 10 given in 10 CFR 73.55. The preapplicant stated that support from local law enforcement authorities was not included in the determination of the size of this onsite force. NUREG-0907, "Acceptance Criteria for Determining Armed Response Force Size at Nuclear Power Plants," includes factors that cannot be evaluated until a specific site has been selected. Therefore, it is premature at this concepiual design stage to assess the acceptability of the force size identified in References 13.9 and 13.13.

The preapplicant has stated that a vulnerability analysis (Ref. 13.13) in response to a design-basis threat was used to determine the size and location of the onsite response force needed to provide a sufficient response time to defeat the threat discussed above. The size and location of the onsite response force are not significant issues at the preapplication stage. This is an issue that must be based on the site and plant design. The final determination will be made at the combined 10 CFR Part 52 operating license stage and should not be a factor in assessing the licensability of PRISM as a standard plant design.

The design-basis threat used in the vulnerability analysis exceeds the threat in 10 CFR 73.1 by including vehicles for breaching barriers and carrying explosives. Although the PSID excludes rockets and high-level explosives from the scope of the design-basis threat, a commitment was made to address hand-carried rockets and explosives in a subsequent revision. Because of the large amount of carefully placed explosives deemed necessary to cause enough debris to block the RVACS vents, consideration of a rocket attack from outside the protected area is not anticipated to be a viable means of prohibiting decay heat removal.

\subsubsection{Employee Screening Program}

The preapplicant did not describe the screening program to ensure the trustworthiness of persons who are authorized unescorted access to the $\mathrm{NI}$ and to vital equipment. Considering the conceptual stage of the PRISM design and the limited information available of this program, conclusions about acceptability cannot be made at this stage of the review.

\subsubsection{Severe-Accident Policy Considerations}

The staff review of the acceptability of the protection afforded against the insider sabotage threat is deferred because Reference 13.9 states that the insider threat will be evaluated in a subsequent study to be performed in the preliminary design phase of PRISM. Also, Reference 13.10 states that Generic Safety Issue A-29, "Nuclear Power Plant Design for the Reduction of Vulnerability to Radiological Sabotage, " will be addressed in the next revision of Reference 13.9 and that the risk of tampering and vandalism will be reported in a PRA update. However, the preapplicant stated that an assessment of insider actions in Reference 13.13 concludes that fuel damage or theft, even from insider assistance, is not credible. The preapplicant concluded that, although insider assistance would help adversarial actions against vital areas, such assistance would be insufficient to overcome design features and security provisions of the plant.

Although the preapplicant has not established PRISM design criteria for protection against radiological sabotage, the passive safety features of the PRISM design provides 
advantages in protection against insiders and outsiders as compared to a current-generation LWR.

A number of redundant means of decay heat removal will protect the PRISM design against induced transients. A saboteur would find it difficult to totally disable the passive safety-grade RVACS, given the capabilities assumed in 10 CFR 73.1. The RVACS and the non-safety-related auxiliary cooling system (ACS) are each designed to operate and remove decay heat using natural circulation of air in the event of a station blackout and loss of instrumentation.

The staff concludes that the preapplicant has sufficiently addressed the insider sabotage threat for the preapplication stage. This area will be addressed later in the preliminary and final design stages of review.

\subsubsection{Scope of the Review}

The staff reviewed Sections 1.2 and 13.3 and Appendix G.4.14 of the PSID (Ref. 13.1) and References 13.9 to 13.13 . The preapplicant submitted References 13.9 to 13.13 under separate cover; these are controlled separately because they contain safeguards and security information that is protected by NRC regulations. The preapplicant submitted Appendix G.4.14 of the PSID on plant security in response to staff concerns raised early in the review process.

The staff performed a review that focused on the potential of the design to meet existing requirements and guidance for protection against radiological sabotage. These requirements and guidance are contained in the following NRC documents:

- 10 CFR Part 73, including Sections 73.1, 73.2, 73.55, and Appendices B and C (Ref. 13.14)

- Regulatory Guides 5.7 (Ref. 13.15), 5.12 (Ref. 13.16), 5.44 (Ref. 13.17), and 5.65 (Ref. 13.18)

- Review Guideline Numbers 10 (Ref. 13.19), 17 (Ref. 13.20), and 18 (Ref. 13.21)

- NUREG reports 0800 (Ref. 13.22), 0908 (Ref. 13.23), CR-0509 (Ref. 13.24), and CR-1327 (Ref. 13.25)

The review placed special attention on how the PRISM design would address the objectives of the Commission's Severe Accident Policy, which states: "The Commission also recognizes the importance of such potential contributors to severe accident risk as human performance and sabotage. The issues of both insider and outsider sabotage threats will be carefully analyzed and, to the extent practicable, will be emphasized in the design and in the operating procedures developed for new plants."

Also, Generic Issue A-29, "Nuclear Power Plant Design for the Reduction of Vulnerability to Sabotage," is one of the medium-priority generic safety issues for which the Commission expects new designs to demonstrate technical resolution by the standard design certification.

This review considers protection of the reactor facility from sabotage; it does not address protection against theft of nuclear material from onsite storage.

The preapplicant stated in Reference 13.1 that an assessment of insider actions concluded that fuel damage or theft, even with insider assistance, is not credible. The insider assistance would help adversarial actions against vital areas but would not be sufficient to overcome design features and security provisions to make this threat credible. This assessment is sufficient for the preapplication stage.

The staff's review of the acceptability of the protection afforded against the insider sabotage threat is deferred because Reference 13.9 stated that the insider threat will be evaluated in a study to be performed in the preliminary design review stage of the PRISM. Further, in Refenence 13.10, the preapplicant stated that Generic Safety Issue A-29, "Nuclear Power Plant Design for the Reduction of Vulnerability to Radiological Sabotage, " will be addressed in the next revision of Reference 13.9 and that the risk of tampering and vandalism will be reported in a future probabilistic risk assessment update for the PRISM plant.

\subsubsection{Conclusions}

The safeguards against radiological sabotage for the PRISM design are at an acceptable stage of development for the preapplication review of a conceptual design. The design is inherently less dependent than LWRs on proper functioning of security systems for protection against insider and outsider sabotage. There are no significant safeguards issues at this stage that could affect the licensability of PRISM as a standard design. 


\subsection{References}

13.1 General Electric, PRISM-Preliminary Safety Information Document, GEFR-00793 UC-87Ta, November 1986.

13.2 U.S. Nuclear Regulatory Commission, Code of Federal Regulations, Title 10, "Energy," Part 50, "Domestic Licensing of Production and Utilization Facilities."

13.3 Electric Power Kesearch Institute (EPRI), "ALWR Passive Plant," Revision 4, December 1992.

13.4 U.S. Nuclear Regulatory Commission, Code of Federal Regulations, Title 10, "Energy," Part 50, "Domestic Licensing of Production and Utilization Facilities," Section 50.54, "Conditions of Licenses."

13.5 U.S. Nuclear Regulatory Commission, "Criteria for Preparation and Evaluation of Radiological Emergency Response Plans and Preparedness in Support of Nuclear Power Plants, " NUREG-0654, January 1980.

13.6 U.S. Nuclear Regulatory Commission, "Planning Basis for Development of State and Local Government Radiological Emergency Response Plans in Support of Light-Water Nuclear Power Plants, " NUREG-0396, December 1978.

13.7 U.S. Nuclear Regulatory Commission, "Emergency Preparedness for Fuel Cycle and Other Radioactive Material Licensees," Federal Register, Vol. 54, No. 66, April 7, 1989, pg. 14051.

13.8 U.S. Nuclear Regulatory Commission, "Policy, Technical and Licensing Issues Pertaining to Evolutionary and Advanced Light-Water Reactor (ALWR) Designs, " SECY-93-087, April 2, 1993.

13.9 Bechtel National, Inc., "PRISM - Phase II Safeguards and Security Report," BNI-I 8603/UC-87Ta, dated June, 1986.

13.10 Bechtel National, Inc., "September 14, 1987 addendum," containing responses to an August 12, 1987, letter from B. M. Morris to F. X. Gavigan.
13.11 Bechtel National, Inc., "PRISM Second Addendum to the 'Safeguards and Security Assessment' a September 28, 1987, letter from B. M. Morris to F. X. Gavigan.

13.12 Brookhaven National Laboratory, letter from G. J. Van Tuyle to Ralph Landry, January 7, 1988.

13.13 Bechtel National, Inc., "ALMR Safeguards and Security Assessment," BNI-8902, November 1989.

13.14 U.S. Nuclear Regulatory Commission, Code of Federal Regulations, Title 10, "Energy," Part 73, "Physical Protection of Plants and Materials."

13.15 U.S. Nuclear Regulatory Commission, "Entry/Exit Control for Protected Areas, Vital Areas, and Material Access Areas," Regulatory Guide 5.7.

13.16 U.S. Nuclear Regulatory Commission, "General Use of Locks in the Protection and Control of Facilities and Special Nuclear Materials," Regulatory Guide 5.12.

13.17 U.S. Nuclear Regulatory Commission, "Perimeter Intrusion Alarm Systems, " Regulatory Guide 5.44.

13.18 U.S. Nuclear Regulatory Commission, "Vital Area Access Controls, Protection of Physical Security Equipment, and Key and Losk Controls," Regulatory Guide 5.65.

13.19 U.S. Nuclear Regulatory Commission, Review Guideline Number 10, "Compensatory Measures for the Loss of Normal Power Supply to Security Lighting, " memoraudum dated January 10, 1978.

13.20 U.S. Nuclear Regulatory Commission, Review Guideline Number 17, "Definition of Vital Areas," memorandum dated January 23, 1978.

13.21 U.S. Nuclear Regulatory Commission, Review Guideline Number 18, "Protected Area Control Function in Bulle'-Resisting Structure, " memorandum dated February 6, 1978.

13.22 U.S. Nuclear Regulatory Commission, "Standard Review Plan for the Review of Safety Analysis Reports for Nuclear Power Plants, " LWR Edition, NUREG-0800, July 1981. 


\section{Conduct of Operation}

13.23 U.S. Nuclear Regulatory Commission, "Acceptance Criteria for the Evaluation of Nuclear Power Reactor Security Plans," NUREG-0908, August 1982.

13.24 U.S. Nuclear Regulatory Commission, "Emergency Power Supplies for Physicul Security Systems," NUREG/CR-0509, November 1979.
13.25 U.S. Nuclear Regulatory Commission, "Security Lighting Planning Document for Nuclear Fixed Site Facilities," NUREG/CR-1327, April 1980.

13.26 J.E. Quinn, General Electric, letter to S.P. Sands, NRC, "GE Comments on NUREG-1368 Preapplication Safety Evaluation Report for the Power Reactor Innovative Small Module (PRISM) Liquid-Metal Reactor," November 29, 1993. 


\section{SAFETY TEST PROGRAM}

\subsection{Design Description and Safety Objectives}

The preapplicant is proposing to construct a prototype of the PRISM design and to conduct tests of this prototype with a safety test program. The objectives of the program are to demonstrate the safety characteristics of the PRISM design and to establish the data base required by 10 CFR Part 5? (Ref. 14.1) for certification of the design. This program is one part of the PRISM research and development (R\&D) program for the design and focuses only on the testing of the prototype. The R\&D program develops systems and components, such as the multimodule control system, for the final design which will be demonstrated later in the safety test program. Therefore, the R\&D program and the safety test program for PRISM will be reviewed together in this chapter to determine if the preapplicant has adequately provided for the analysis, experience, and testing needed to certify the PR'SM design in accordance with 10 CFR Part 52.

\subsubsection{Safety Test Program}

The safety test program is discussed in Chapter 14 and Appendices F.14 and G4.15 of the Preliminary Safety Information Document (PSID) submitted by the preapplicant for PRISM (Ref. 14.2). Appendix F provides the preapplicant's responses to NRC questions about the PRISM design. These questions and responses were generated before PSID Amendments 12 and 13 were submitted by the preapplicant in response to concerns raised by the staff on PRISM. The safety test program will be conducted during the final stages of the R\&D program and will go into effect near the end of the construction of the prototype. The preapplicant has implied that the program may continue after the NRC staff certifies the design. The main elements of the program are the prototype to be tested, the site to conduct the testing, and the test and evaluation plan.

The PRISM standard plant comprises nine 471-MWt reactor modules arranged in three separate power blocks. Each power block contains three reactor modules, three steam generators (one for each reactor module), and one turbine-generator. The proposed prototype is stated to be a single, full-scale, prototypical PRISM reactor module (i.e., one reactor) in a below-grade silo, with the associated support and isolation structures, and module instrumentation. The major elements of the prototype are the following:

- reactor vessel, deck, and rotatable plug

- associated support and isolation structures

- containment vessel

- two intermediate heat exchangers (IHX)
- four electromagnetic (EM) pumps

- four EM pump coastdown power supplies

- reactor core (471 $\mathrm{MWt}$ ) with metal fuel

- upper and lower internal structures

- fuel transfer machine

- control rod system

- control, reactor protection, and instrumentation systems

- seismic isolation system

- reactor vessel air cooling system (RVACS)

To minimize the investment in the prototype, it will consist of only one reactor module without the PRISM-design steam generator or turbine generator. The preapplicant does not consider the PRISM-design steam generator, turbine generator, or the multi-module controls to be safety related, and, therefore, they are not considered necessary for the safety testing of the design. The preapplicant states that the modular design of PRISM, with the safety-related portion separate from the non-safety-related portion of the plant, should permit the testing of a single reactor module, without the steam generator, turbine generator, and multimodule controls, to demonstrate the safety characteristics of a complete nine-module plant.

Instead of the PRISM-design steam generator and power conversion system, two different heat dump systems are under evaluation for rejecting the heat from the reactor module to the air during the prototype tests. These are (1) a steam generator system with steam delivered to a condenser cooled by water from a cooling tower and (2) a sodium-to-air heat exchanger system with heat from the intermediate loop rejected directly to the air. It is stated in Reference 14.2 that this choice of non-prototypic heat dump system is subject to change if a review shows that safety interactions with the balance of plant can not be adequately simulated in the prototype with either heat dump system.

After the safety characteristics of the design are demonstrated by the prototype testing which is intended to resolve the licensing issues for certification, the preapplicant will modify the prototype by adding a fully prototypical steam generator and turbine generator to enter what is called the power operation phase. The power operation phase has two functions: (1) permit operation of the module as a power producer to demonstrate availability, operating and maintenance reliability, and inspection characteristics; and (2) recover a majority of the capital investment in the prototype. The preapplicant may also change the prototype into a full three-reactor module power block after the prototype testing is complete before a nine-module plant is constructed. The preapplicant states that up to half of the 60-year design life of the prototype may be utilized for safety tests. 
The prototype tests are currently planned to be conducted at one of two existing reactor test facility sites at U.S. Department of Energy (DOE) national laboratories. The tests would be done at either the Fast Flux Test Facility site at Hanford in Washington State or the Experimental Breeder Reactor Number II (EBR-II) site at the Idaho National Engineering Laboratory (INEL) in Idaho. Existing facilities and services at either site would be shared with the PRISM prototype to reduce the cost of the prototype.

One goal of the safety test program is to perform tests of selected design-basis events (DBEs) and beyond-designbasis events (BDBEs) to demonstrate the design's passive safety characteristics. However, the preapplicant does not consider the prototype tests to be sufficient to validate the PRISM transient performance and provide the basis for PRISM standard design certification. Therefore, these tests will be in conjunction with other supporting scale model testing, component testing, and key feature testing to demonstrate the safety characteristics of the design. It is also stated that analyses and laboratory testing will be used to provide data for conditions that are not considered amenable to prototype testing, including interaction effects between the nuclear island and those parts of the plant which are not included in the prototype.

The safety test program is stated to be composed of three phases: (1) the conventional testing phase on systems and components, beginning before the construction of the prototype is completed and ending with the reactor power ascension and duty cycle tests; (2) the safety benchmark testing phase to measure and verify key design characteristics; and (3) the safety testing phase to demonstrate the response of the module to DBEs and BDBEs. Each testing phase is to provide assurance that this advanced reactor design is safe for the next testing phase.

The conventional testing phase is the testing that is applicable to any reactor startup and will be completed before starting any of the safety tests. It is divided into the following areas:

- Preoperational testing during the construction of the prototype to demonstrate the capability of structures, systems, and components (SSCs) to meet individual performance requirements, including safety-related requirements, in all operating modes and over the full design operating range, without taking the reactor critical.

- Baseline inservice inspections during the construction of the prototype to provide a preservice baseline at an isothermal refueling temperature against which all future inservice inspections can be compared.

- Hot functional testing to operate (1) "key" systems at near normal operating and abnormal conditions preceding fuel loading and power operation and (2) the reactor coolant system, in particular, at full reactor design inlet temperature and pressure to demonstrate key safety performance characteristics.

- Fuel loading testing to prepare and load fuel into the core and make all initial preparations for taking the core critical, including the calibration and testing of fuel handling equipment, radiation monitors, nuclear instrumentation, and radiation control equipment.

- Startup testing to characterize the core and "key" safety systems in a series of tests during precriticality, criticality, low power, power ascension to 100-percent power in pre-set stages, and selected module duty cycles.

The benchmark testing phase is to (1) measure and verify the passive reactor response characteristics (reactivity feedback) and structural responses and (2) verify the performance of the decay heat removal systems and the seismic response system. It is divided into the following areas:

- passive reactor response characteristics testing to establish baseline data on reactivity

- inherent structural seismic response characteristics testing to verify analytical predictions of dynamic seismic response behavior

- performance testing of the decay heat removal system to verify heat transfer characteristics and heat rejection rates for the safety-grade RVACS and the normal heat rejection systems

- seismic response verification testing to verify seismic isolation and integrity of the module, major components, and reactor internals

The safety testing phase, the final testing phase preceding the power operation phas for the prototype, is to demonstrate the safety response of the prototype modul to certain DBEs and BDBEs. The less severe events will be tested first to minimize the risk of damaging the prototype. The program will be designed to bound events to reduce the number of tests needea to be conducted on the prototype. Testing will be at a reduced power level in the module to prevent damage to the module but will allow for extrapolation of the results from the reduced power level 
to 100-percent power. Extremely unlikely events which could damage the prototype would be conducted at less than rated conditions or would be addressed by analyses and laboratory testing to prevent damage.

A preliminary list of the DBEs and BDBEs being considered (PSID Table G.4.15-1) by the preapplicant for testing the prototype includes the following:

- DBE testing, with a reactor scram, to envelope the design duty cycles for normal operation, anticipated scram events, and unlikely accidents, will include

- normal scram transients with flow coastdown

- reactivity addition with scram and flow coastdown

- loss of intermediate heat exchanger system at full flow

- BDBE testing, with an immediate or delayed scram, to bound a series of extremely-low-probability events will include

- reactivity addition at full flow without scram

- loss of intermediate heat exchanger system at full flow without scram

- loss of flow with flow coastdown without scram

- reactivity addition and loss of flow with flow coastdown without scram

- loss of flow and intermediate heat exchanger system with flow coastdown without scram

- reactivity addition and loss of power with flow coastdown without scram

- degraded RVACS and loss of intermediate heat exchanger system with flow coastdown and scram

During the safety testing phase, there will also be activities which the preapplicant has referred to as surveillance activities and post-testing reactor monitoring. The preapplicant states surveillance activities are being conducted to (1) develop reliability and operability monitoring, (2) demonstrate the on-line maintenance capability as it influences safety, and (3) demonstrate the in-service inspection capability. The post-testing reactor monitoring is established to develop a set of criteria, associated parameters capable of being monitored, and online monitoring that will form the basis for Technical
Specifications and will characterize the passive control of reactivity.

In addition to these tests on the prototype, there will also be scale model testing and laboratory tests which are discussed in Appendix 14A and Table G.4.15-2 of the PSID. These types of non-prototype testing will be conducted to minimize the cost of the testing and reduce the risk of damaging the prototype. Currently, these types of testing are being considered for the following: (1) performance testing of a degraded RVACS following a release of sodium (i.e., fire) inside the RVACS which is Service Level D Event D-5 of Appendix D of the PSID, (2) structural seismic response testing discussed in the benchmark testing phase (above) and seismic events beyond the safe-shutdown earthquake, (3) performance testing of a prototypical fuel assembly with the simulation of failure-initiating mechanisms, (4) steam generator tube failure followed by failure of the water/steam dump system, (5) large sodium leaks, and (6) station blackout without reactor scram for extended times.

To address the transition from the initial core to the equilibrium core, it is stated that a series of analyses will be done to predict the performance of these cures. Furthermore, work will be done to determine how the results of the tests on the initial core can be used to predict the behavior of transitional and equilibrium cores. The preapplicant stated, in response to NRC Comment 14.9 in Appendix F of the PSID, that the PRISM core for design certification will use U-Pu-Zr (i.e., uranium-plutoniumzirconium) fuel and has what is called a "zero" burnup swing because the core reactivity state does not change appreciably with burnup; however, this response may no longer be applicable with the changes identified in Amendments 12 and 13 of the PSID. The effects of fuel burnup are being investigated in the metal-fuel R\&D program (Section 4.2.4 of this report). Also, the testing of the prototype may be continued into a power operation phase, as discussed above, to confirm the transition effects from the initial core to the equilibrium core.

The preapplicant stated that a key feature of the prototype testing is this follow-on power operation phase which would (1) confirm interaction effects for equipment not included in the safety test program and (2) demonstrate the availability, operability, maintainability, reliability, and inspectability of the PRISM design. This would also include the effects of burnup on the core reactivity characteristics.

The use of a single reactor module raises questions concerning what may be needed to test the behavior of the multi-module control system for the three-module power block and the nine-module plant. In addressing this issue, 
the preapplicant has stated that the interaction among the three modules in a power block and among the three power blocks (i.e., a total of nine modules) in a plant would be simulated with a control program and confirmed in the power operation phase if a full power block is added, as discussed above, or with the first commercial plant.

Appendix 14B of the PSID discusses instrumentation and testing technique development for the safety test program. Instrumentation and testing techniques are considered important by the preapplicant to the safety testing phase of the safety test program, but they are not considered as an integral part of the program in that the entire development described in Appendix 14B is not required to be completed before the safety testing is started.

In PSID Section G.4.15.3.3, it was stated that the safety test program would be based on startup test programs for commercial power reactors, testing which was proposed for the sodium-cooled Clinch River Breeder Reactor Plant (CRBRP), and testing which has been performed at FFTF, EBR-II, and other liquid-metal reactors.

From the discussion on the power operation phase of the prototype tests in PSID Section G.4.15.6, it is uncertain whether the preapplicant expects the certification of the design to come at the end of the power operation phase or whether the power operation phase would continue after certification to collect further data on the design. The preapplicant did state that it expected up to half of the 60-year lifetime of the prototype would be involved with safety tests, many of which could be considered quite severe.

\subsection{Scope of Review}

The safety test program and the R\&D program were reviewed with the purpose of ensuring that the major objectives and features of these programs will support the standard design certification of PRISM in accordance with 10 CFR Part 52, the Nuclear Regulatory Commission's (NRC's) Advanced Reactor Policy Statement (Ref. 14.3;, Commission Paper SECY-91-074 (Ref. 14.4) on prototype testing for advanced reactor designs, and Standard Review Plan (SRP) Section 14.2 (Ref. 14.5) on the initial plant test program.

These programs cannot be reviewed separately because, although the preapplicant has not stated so, it appears that the preapplicant will be using both programs together to (1) demonstrate the design features and the safety characteristics of the design and (2) provide a part of the basis for the certification for the design. The preapplicant is developing the safety test program to tast the prototype as a part of the overall R\&D program (Ret. 14.6), but the preapplicant has stated that the R\&D program will be used to qualify certain equipment and systems outside of the prototype testing program and, therefore, outside of the safety test program. From the list of technology areas for the R\&D program in Section 14.4 of this report, it appears that the EM pumps, fuel transfer machine, multi-module control system, and steam generator will not be tested and verified in the safety test program. Therefore, it appears that what the safety test program does not demonstrate with the prototype, the $R \& D$ program is expected to prove or demonstrate.

The R\&D program was started in 1987 and work is being done to develop and demonstrate the PRISM design. On the other hand, the safety test program has not been started by the preapplicant and is still under development. It is not expected to be submitted to the NRC for review until at least the preliminary design review stage. The review of both of these programs cannot be con.pleted until the final design review stage when the specific testing necessary to support certification must be proposed for the PRISM design.

\subsection{Review Criteria}

\subsubsection{CFR Part 52}

Section 47(b)(2)(i) of Subpart B, "Standard Design Certification," of 10 CFR Part 52 provides criteria to determine if a design that (1) differs significantly from the current or evolutionary light-water reactor designs or (2) utilizes simplified, inherent, passive, or other innovative means to accomplish its safety functions has met certain requirements necessary prior to granting a standard design certification. This section of 10 CFR Part 52 provides criteria for determining what demonstration of the design safety features, including testing and testing facilities, and the possibility of a prototype plant, may be needed to support design certification. These criteria, in Paragraphs 52.47(b)(2)(i)(A)(1) through (4), Paragraph $52.47(b)(2)(i)(B)$, and $52.47(b)(2)(i i)$ are the following:

- Item 1 - Performance of each safety feature has becn demonstrated through either analysis, appropriate test programs, experience, or a combination thereof.

- Item 2 - Interdependent effects among the safety features of the design have been found acceptable by analysis, appropriate test programs, experience, or a combination thereof.

- Item 3 - Sufficient data exist on the safety features of the design to assess the analytical tools used for safety analyses over a sufficient range of normal operating 
conditions, transient conditions, and specified accident sequences, including equilibrium core conditions.

- Item 4 - The scope of the design is complete except for site-specific elements, such as the service water intake structure and the ultimate heal sink.

Items 5 and 6 below are an alternative set to Items 1 through 4 above:

- Item 5 - Acceptable testing of an appropriately sited, full-size prototype must include a sufficient range of normal operating conditions, transient conditions, and specified accident sequences, as well as including equilibrium core conditions.

- Item 6 - If Item 4 (above) is not met, then the testing of the prototype must demonstrate that the non-certified portion of the plant cannot significantly affect the safe operation of the plant.

And finally, whichever approach is chosen:

- Item 7 - The application for final design approval of a standard design must propose the specific testing necessary to support certification of the design, whether the testing is prototype testing or the testing required in the alternative by Items 1 through 4 .

\subsubsection{Commission's Advanced Reactor Policy Statement}

The Commission's Advanced Reactor Policy Statement (Ref. 14.3) does not require that a prototype of an advanced reactor design be constructed and operated to demonstrate the safety characteristics of the design for the standard design certification. The policy statement does state that "The Commission favors the use of the prototypical demonstration facilities as an acceptable way of resolving many safety-related issues."

Section 5.4.4 of NUREG-1226, "Development and Utilization of the NRC Policy Statement on the Regulation of Advanced Nuclear Power Plants" (Ref. 14.7), states that the NRC staff will have to be satisfied, for the design being reviewed, that there is a basis for each claim made for the design regarding system and equipment performance and reliability. For reactor designs that depart significantly from proven technology, the staff favors but does not require the use of a full-scale prototype test facility to demonstrate those features of the design that are fundamental to its safety performance. It is stated that as part of its review of the conceptual design, the staff will make a case-by-case judgment about the need for a prototype test considering such factors as

- departure from proven technology

- uncertainties in performance and how they can be reduced

- degree of defense-in-depth

- other R\&D programs planned to support the design

In the appendix to NUREG-1226, in the response to Question 6, the Commission 'ated that it requires proof of performance of certain safety-related components, systems, or structures before it will issue a license for that design. This proof will be design dependent and, therefore, the evaluation of a safety technology development program for an advanced reactor design and the possible need for a prototypical demonstration of that design, can be determined only by the review of that design. Therefore, the Commission favors the use of prototypical demonstration facilities as an acceptable way of resolving many safety related issues.

The definition of an advanced reactor, in the context of the Commission's Advanced Reactor Policy Statement, is a reactor design that differs significantly from the current light-water reactor designs which are under construction or in operation, or that utilizes simplified, inherent or other innovative means to accomplish its safety functions. This would include designs that are classified as evolutionary light-water reactors.

\subsubsection{Commission Paper SECY-91-074}

The NRC staff, in continuing to evaluate the need for a prototype to certify an advanced reactor design, submitted SECY-91-074, "Prototype Decisions for Advanced Reactor Designs," to the Commission on March 19, 1991. The staff stated in Enclosure 1 to the paper that it will use the criteria in 10 CFR 52.47(b)(2) to determine if the designer has sufficiently justified an advanced reactor design for a standard design certification. In Enclosure 2 to the Commission paper, the staff provided a process consisting of 19 steps to determine what type of testing and facilities may be needed for a standard design certification. This process would be applied to each performance or safety claim made for the design. The types of testing include tests of components, systems, simulators, non-nuclear and nuclear test loops, and prototypes. It is stated that the applicant for design certification may consider the least burdensome type of testing that offers the proof required to substantiate the performance and safety claims made for the design. 


\subsubsection{Standard Review Plan Section 14.2}

SRP Section 14.2 (Ref. 14.5) provides requirements on the initial plant test programs for a light-water reactor. The PRISM design is not a light-water reactor; however, the type of testing that should be done in the initial plant test programs to start up a plant or a prototype of a plant should be, for the most part, independent of the design. The specific equipment to be tested, the specific tests to be conducted, and the reactor power holdpoints will depend on the design; but the requirements for a test program (i.e., the program objectives, test procedures, use of operating experience, trial use of emergency operating procedures, initial fuel loading and criticality, test program sequence, and individual test descriptions in SRP Section 14.2) are generally independent of the reactor design.

The criteria in SRP Section 14.2 that appear to be applicable to any design including a sodium-cooled reactor are the following:

- A test program should establish the major phases of the program and the objectives for each phase consistent with Regulatory Guide (RG) 1.68 (Ref. 14.8).

- Test procedures should be written in a format consistent with RG 1.68 .

- The test program should be consistent with Appendix A to RG $\mathbf{1 . 6 8 .}$

- The test program should use operating and testing experience from other facilities.

- The test program should include the plant operating, emergency, and surveillance procedures, or should otherwise verify these procedures, to the extent practicable through use and the test program should verify operator training procedures.

- Procedures to guide the initial fuel loading and initial criticality should include precautions, prerequisites, and measures that are consistent with RG 1.68.

- The test program schedule and holdpoint requirements are for light-water reactor testing and do not apply to the PRISM; however, the following requirements should apply:

- Overlapping test program schedules should not result in significant divisions of responsibilities or dilutions of the staff provided to implement the test program.
- The sequential schedule for individual startup tests should establish, insofar as is practical, that test requirements will be completed for all plant SSCs that are relied upon to prevent, limit, or mitigate the consequences of postulated accidents before exceeding some low power level.

- Approved test procedures should be in a form suitable for review by regulatory inspectors at least 60 days preceding their intended use, and, for fuel loading and startup test procedures, at least 60 days preceding the fuel loading.

- Tests should be planned for the SSCs and design features that meet the criteria in RG 1.68. Abstracts of the planned tests should be provided and should include the objectives, prerequisites, test methods, test operating conditions, significant parameters and plant performance characteristics to be monitored, and acceptance criteria, in sufficient detail to establish the functional adequacy of what is being tested. If the test operating conditions are not representative of design operating conditions, the abstract should justify the test conditions to be used.

RG 1.68 is referred to several times in the criteria specified in SRP Section 14.2. The regulatory guide was written specifically for light-water reactors and in many cases specifies components, systems, and hold points for pressurized-water reactors and boiling-water reactors, at least some of which would not apply to a liquid-metal reactor. However, these specific references are representative of system functions that should be applicable to all reactor designs. The specific equipment to be tested and the specific tests to be conducted will depend on the design; but the requirements for test programs should not depend on the reactor design. Therefore, the guidance in RG 1.68 is considered applicable to such designs as PRISM, except where the guide refers to specific equipment, systems, schedules, or test power level holdpoints which are not applicable to PRISM.

The following guidance in the regulatory position section of RG 1.68 is considered applicable to the PRISM design:

- Proper sequence of tests as defined in Appendix A, so that the safety of the plant is never totally dependent on the performance of untested safety-related SSCs

- Criteria for selection of SSCs and design features to be tested, with a representative list for light-water reactors in Appendix A which can be compared to the PRISM design (Because the guide was not written for the firstof-a-kind light-water reactor, the selection must also 
include SSCs and design features which are innovative and unique.)

- Prerequisites to be completed before testing of the selected SSCs

- Scope, testing conditions, and length of the testing

- Guidance on the test procedures and the schedule to provide them to the NRC staff, with guidance on the preparation and content of the procedures given in Appendix C

- Schedule to conduct the test, with the minimum times specified applicable only to light-water reactors

- Participation of plant operating and technical staff in the development and conduct of the tests

- Trial testing of plant operating and emergency procedures

- Milestones and power hold points for testing, with the specific values applicable only to light-water reactors

- Test report format, with the reports retained as part of the plant historical record

The requirements specified in SRP Section 14.2 are repeated with more detail in the guidance given in RG 1.68 .

\subsection{Research and Development}

The PRISM R\&D program is discussed in Appendix G.3 of the PSID and in the Advanced Liquid Metal Reactor (ALMR) Technology Development Requirements Plan, GEFR-00845 (Ref. 14.6). This program is currently in effect and has been aiming since 1987 to have an advanced conceptual design in 1991 for the current preapplication stage, a preliminary design in 1993, and a prototype for the final design in 1999. The objectives of the program are to develop equipment and system technology for the PRISM design, collect data that support the safety characteristics of the design, and conduct the testing of the prototype of the design (i.e., the safety test program). The program is stated to be built on the data base from earlier U.S. liquid-metal reactors, such as FFTF, EBR-II, and CRBRP (never built), and from foreign reactors, such as Phenix and Super Phenix (France), MONJU (Japan), and PFR (Britain).

The development requirements for the R\&D program are given in GEFR-00845, except for the requirements on the fuel and fuel cycle for the PRISM design. The metal fuel is being developed and demonstrated by Argonne National Laboratory (ANL) in its Integrated Fast Reactor (IFR) Program but no details on this development are given in GEFR-00845. The development requirements on the fuel and fuel cycle are discussed in the ANL IFR Program plan. This plan was reviewed as part of the evaluation of accidents for the PRISM design in Chapter 15 and the details of the plan are discussed in Section 4.2.

The R\&D program is organized into three categories: (1) tasks important to safety, (2) tasks related to component development and design verification, and (3) tasks related to investment protection. These categories are shown in PSID Figure G.3.2-2 and Table 6-1 of GEFR-00845 to be organized into the following technology areas:

- advanced components and systems

- EM pumps, including the coastdown mechanism

- in-vessel fuel transfer machine

- control drive

- steam generator

- ultimate shutdown system

- advanced instrumentation and controls

- advanced instrumentation

- advanced plant controls

- robotics

- advanced technology

- seismic isolation

- shielding

- materials

- thermal-hydraulics

- reactor safety

- passive reactivity reduction

- passive shutdown heat removal

- safety and licensing support

- fuel cycle safety

- fuel safety

- fuel cycle safety

The ultimate shutdown system (above) has been added to the R\&D program since PSID Figure G.3.2-2 was submitted in Amendment 13. Safety and licensing support (above) will provide analysis tools and experimental data for safety evaluations and licensing, specifically for severe 
core accidents, hypothetical core disruption accident (HCDA) energetics, containment, sodium-water reactions, and sodium fires.

Table G.3.1-1 of the PSID summarizes the current results and status of 16 of the 17 major technology areas (except for robotics) as of May of 1990 . Loss-of-flow tests have been performed at EBR-II and FFTF. Table G.3.2-2 shows a breakdown of the R\&D work by the different organizations involved in the program.

Equipment and systems are being developed for the final design which will be qualified separately in the R\&D program from the safety test program. These include the electromagnetic pumps, steam generator, in-vessel fuel transfer machine, module instrumentation, plant controls, and seismic isolation. This development includes the consideration of reliability of the equipment and systems. The research and development for the steam generator includes a test of the helical coil steam generator, the leak detection system, and an evaluation of mechanisms limiting the life of the steam generator. It does not include an evaluation of the water dump system and the sodium-water reaction products relief system.

The performance of systems will be verified in the R\&D program. For example, performance of the RVACS, the only safety-grade shutdown heat removal system for the design, will be tested, and the heat transfer correlations will be experimentally verified. Analytical models and experimental data supporting the modeling of key phenomena important to safety are also being developed for the characterization of radionuclide transport from the core, and the retention of radionuclides in the sodium pool.

The testing in the program is organized into the following three phases: (1) the technology feasibility tests which support the conceptual design and have been completed already, (2) the key features tests or technology development tests which support the advanced conceptual design and are being completed, and (3) the components and subsystems tests or technology demonstration tests which support the final design and which have not been started. This testing, including the development of the fuel for the PRISM design, is to support the development of the final design for PRISM.

Most of the tasks in the R\&D program lead to the construction of the first prototype reactor module discussed in Sect on 14.1.1 (above). However, it is stated that there are development tasks, such as for advanced multi-module control systems, improved structural materials, and robotics for maintenance and repair work, that are not part of the prototype and may extend beyond the prototype testing and the standard design certification. Therefore, the R\&D program is not expected to be completed until after the testing of the prototype and the certification of the PRISM design.

\subsection{Safety Issues}

This section outlines safety issues which are discussed in greater detail in Section 14.6 (below). In each case, additional information is needed by the staff to address the issue. This information must be submitted by the final design review stage for the staff to identify the specific testing required for certification of the design in accordance with 10 CFR 52.47(b)(2)(ii).

\subsubsection{Risks Associated With the Prototype Tests}

The safety testing of the prototype carries some degree of risk, because the tests are evaluating a new advanced reactor design which has a higher power level than test reactors of a similar design, differs significantly from the current light-water reactor designs, and uses unreviewed simplified, passive, or other innovative means to accomplish safety functions. However, if tests are performed in a sequence so that the plant is not totally dependent on the performance of untested safety equipment, and there is proper planning and instrumentation coupled with planned safety and acceptance criteria, recovery actions, and validation of analytical predictions, the risk may be acceptable.

Structuring the safety test program in accordance with the applicable portions of SRP Section 14.2 and RG 1.68 is a necessary part of assuring the risk is acceptable. The lack of information on the proposed safety test program is discussed in Section 14.5.2 (below). Also, an appropriately sited prototype is another necessary part. An assessment of the risk to the public from potential accidents at the prototype needs to be provided by the preapplicant by the final design review stage. See Sections 14.6.1.4 and 14.6.4 (below).

\subsubsection{Lack of Detail on the Safety Test and R\&D Programs}

The preapplicant has not submitted sufficient information on the $R \& D$ program and the safety test program for the staff to review the programs and understand how they support the certification of the PRISM design. The preapplicant has not provided the following: (1) a description of that part of the PRISM plant which is to be certified including an explanation of how the non-certified art of the plant will not affect the safe operation of the plant; (2) a description of the proof needed to certify the PRISM design including how these two programs will 
provide this proof; (3) a description of how the power operation phase of the prototype tests would be related to the certification of the PRISM design; and (4) a description of the modifications to the programs which account for changes to the PRISM design submitted in Amendments 12 and 13 to the PSID. See Sections 14.6.1.1, 14.6.1.2, 14.6.1.5, 14.6.2, 14.6.3, 14.6.5, and 14.6.6 (below) for additional details.

\subsubsection{Justification of the Single-Module Prototype}

The proposed prototype will consist of one reactor module without the PRISM-design steam generator or power conversion system. The preapplicant has not sufficiently justified the proposed prototype for the PRISM design in terms of (1) the tests to be conducted on the prototype and (2) what the prototype will prove that the rest of the R\&D program has not demonstrated.

\subsubsection{Justification of the Systems for the Prototype}

The preapplicant has not sufficiently justified the selection of systems to be included in the prototype module. The proposed prototype may not include the PRISM-design steam generator and the multi-module control system. The preapplicant needs to justify which analyses, laboratory and R\&D testing, and simulations will be used to investigate the possible interaction effects between the reactor module and the balance of plant for the rodule which is not included in the prototype for testing. The lack of the PRISM-design steam generator and the multimodule control system in the prototype needs to be addressed further. See Section 14.6.1.3.

\subsubsection{Additional Development or Testing in the R\&D Program}

Although the EM pump coastdown mechanism and the RVACS are very important to the safety of the PRISM design, there appeared to be (1) no testing of the pump coast mechanism to determine its in-service operability during reactor power operation, excer: for that during the loss-of-flow testing of the prototype-the BDBE testing in the safety testing phase discussed in Section 14.1.1 -in the safety test program; and (2) no development of instrumentation to monitor RVACS performance in the control room during reactor power operation. The preapplicant will need to justify why the testing of the pump coastdown mechanism in the safety testing phase of the safety test program is sufficient to determine the inservice operability of the mechanism during reactor power operation.

In Reference 14.9, the preapplicant stated that RVACS instrumentation will be developed to monitor air flow rate, inlet air temperature, outlet air temperature, and air outlet radiation, and these readings will be continuously displayed in bother the control room and RSF. This addresses the staff's concern about the RVACS instrumentation in the control room.

\subsection{Evaluation}

The preapplicant has submitted details of the R\&D program for PRISM but has only submitted an outline of the safety test program in the PSID. There is a lack of specific information needed to review the safety test program. For example, there is no discussion of the organizations to conduct the tests, the specific equipment to be tested, the specific tests to be conducted, the objectives or safety claims to be demonstrated by the tests, the acceptance criteria for the tests, and how the tests will demonstrate the safety objectives of the equipment. Also, the preapplicant has not specified what parts of the PRISM design will be certified in accordance with 10 CFR Part 52. In PSID Appendix G.4.15.2.3, it was stated that certification will be requested for the power block and key support systems only, but the key support systems were not specified. Until the key support systems are specified, the staff will not know which parts of the design are to be certified and, thus, cannot determine the extent of testing required in the R\&D program and the safety test program to support the certification of the PRISM design.

Because of the conceptual nature of the design and the limited information available for some systems, it is acceptable for the preapplicant not to specify which parts of the design are to be certified or the specifics of the safety test program at the preapplication review stage. This information, however, is needed by the final design review stage when the preapplicant must submit, in accordance with 10 CFR 52.47(b)(2)(ii), the testing that it considers necessary to certify the design. The staff must then identify the specific testing that will be required for final design certification.

\subsubsection{Comparison to 10 CFR 52.47(b)(2)}

It is by comparing the R\&D program and the safety test program to 10 CFR 52.47(b)(2) that the NRC staff will determine if the proposed analysis, experience, and data base from other applicable designs or from testing of an advanced reactor, or from both, are sufficient to document the safety characteristics of the design and, therefore, to certify the design. The criterion for this decision is that there are no unanswered safety questions about the design. This criterion will depend on the specific design and the state of development of the design. 


\subsubsection{Demonstration of the Design for Certification}

PRISM is a pool-type, sodium-cooled reactor with one safety-grade heat removal system. This system, known as RVACS, allows air to remove heat conducted from the primary coolant through the reactor and containment vessels by natural convection. The design differs significantly from the current and evolutionary light-water reactor designs and uses simplified, inherent, passive, or other innovative means to accomplish its safety functions. Therefore, the PRISM design should meet the requirements in 10 CFR 52.47(b)(2)(i) to have its safety characteristics demonstrated either by (1) analyses, appropriate test programs, experience, or a combination thereof or (2) an appropriately sited, full-size prototype tested over a sufficient range of normal operating conditions, transient conditions, and specified accident sequences.

The preapplicant has an R\&D program to develop equipment and system technology for the PRISM design and to collect data to support the safety characteristics of the design. The preapplicant is proposing, through the $R \& D$ and the safety test programs, to test a prototype of the PRISM design to demonstrate its safety characteristics. Although the details of the safety test program have not been given and the extent of the PRISM design to be certified is not known, the discussion of the R\&D program and the safety test program shows that the testing should be extensive and should include tests that demonstrate safety features, interdependent effects, and provide data to assess analytical tools and models.

The preapplicant appears to propose, in addition to the prototype, (1) using analyses and laboratory testing to provide data for conditions not amenable to prototype testing, (2) incorporating data and experience from other sodium-cooled reactors in the United States and abroad in these programs, and (3) qualifying equipment and systems for the final design in the R\&D program separate from the safety test program and the testing of the prototype. Also, the preapplicant appears to be planning to address by analysis and non-prototype testing the impacts of the aspects of the balance of plant that will not be tested as part of the prototype and for which the applicant may not seek certification as part of the PRISM plant. Therefore, the preapplicant appears to be working to provide a combination of testing, including a prototype, analysis, and experience, to certify the PRISM design in accordance with the provisions of both 10 CFR $52.47(\mathrm{~b})(2)(\mathrm{i})(\mathrm{A})$ and (B). The preapplicant, however, has not described the extent to which the provisions of 10 CFR $52.47(\mathrm{~b})(2)(\mathrm{i})(\mathrm{A})$ and (B) will apply as the basis on which to justify the certification of the PRISM design.
After the safety characteristics of the design are demonstrated by prototype testing to resolve the licensing issues for certification, the prototype may be changed for what the preapplicant calls a "power operation phase" by adding a fully prototypic steam generator-turbine generator or a full three-reactor module power block. The preapplicant states that half of the 60-year design life of the prototype may be involved with safety tests. The preapplicant has not discussed how this power operation phase of the prototype tests would be related to the certification of the PRISM design.

\subsubsection{Non-Certified Part of the Design}

Neither 10 CFR 52.47(b)(2)(i)(A) nor 10 CFR 52.47(b)(2)(i)(B) requires that the portion of the plant design to be certified in accordance with 10 CFR Part 52 include the entire plant except for such site-specific elements as the service water intake structure and the ultimate heat sink. However, if 10 CFR 52.47(b)(2)(i)(B) is the basis for certification, it also states that if the scope of the plant to be certified is not complete, except for site-specific elements, then testing of the prototype must demonstrate that the non-certified part of the plarit can not significantly affect the safe operation of the plant. Because the portion of the plant to be certified by the preapplicant is not known, it is not possible to determine at this time if the safety test program will cover the interaction between that part of the design to be certified and that part not to be certified. Because the safety test program does not address this interaction, it would appear that the proposed testing of the prototype may not do this. This must be resolved by the final design review stage.

\subsubsection{Justification of the Prototype}

On the basis of the modular nature of the design, the preapplicant has proposed to have only one reactor module, without its attcndant reference design steam generator and power conversion system, serve as the prototype of a nine-module plant. The PSID states that all of the equipment for the proposed prototype will be prototypic of a plant except for the following:

- One of two heat dump systems will replace the steam generator system.

- The control system will be for only one reactor module instead of for a power block or nine modules.

- Diagnostic instrumentation which is not part of the PRISM design will be added to collect data during the prototype tests. 
To address the first two differences (above), the preapplicant has stated that analyses, laboratory testing, and simulations will be used to investigate the possible interaction effects between the reactor module and the balance of plant which is not included in the prototype.

The use of either of the two heat dump systems instead of the PRISM-design steam generator would affect the response of the design to a loss-of-heat-sink event. The key cases for the PRISM design where this is true are the unscrammed loss-of-heat-sink events such as transient overpressure events. Preliminary analyses of the unscrammed transients indicate that this class of unscrammed transient is perhaps the most benign because the reactor, with the large pool of sodium, has a long time to respond to such an event. Thus, of the unscrammed tests in the safety test program, the loss of heat sink appears to be the lowest in importance and, therefore, simulating the heat sink with a heat dump system instead of with the steam generator would appear to be a viable option. The preapplicant stated in Amendment 13 (Section G.4.15.3.2) of the PSID that the current reference plan for the prototype configuration is to use a sodium-toair heat exchanger system in place of a steam generator and steam-to-air heat exchanger system. The plan is open to change if further investigation shows that safety interactions between the reactor module and the heat sink cannot be adequately simulated. The proposed prototype heat dump systems would have different response characteristics to transients, as compared to the PRISMdesign steam generator, and the staff has raised questions concerning safety-related aspects of the steam generator and associated sub-systems (see Section 5.6 concerning SWRPRS). The preapplicant should address these items and justify what will be tested as the prototype heat sink.

For the multi-module control system, the preapplicant stated that the multi-module control system is neither safety related nor part of the reactor protection system, and that there will be extensive real-time simulations of the interactions among the three modules in a power block and among the three power blocks in a plant. The preapplicant also stated that there would be a confirmation of the multimodule simulations in either the power operation phase of the prototype if a complete power block is added or with the initial testing of the first commercial nine-module plant. This would appear to be a basis for a single reactor module to represent the PRISM multi-module plant design, but there are (1) no details of the analyses, testing, and simulations to be performed on the multi-module control system and (2) no justification for how these analyses, testing, and simulations would address the differences between the prototype module without the multi-module control system and the PRISM plant with the control system.

\subsubsection{Siting of the Prototype}

As currently planned, the prototype is proposed to be built at either the Hanford site (the Fast Flux Test Facility) or at the INEL site (the Experimental Breeder Reactor Number II test facility). These sites appear to meet the "appropriately sited" requirement of 10 CFR 52.47(b)(2)(ii) because the prototype would be at an existing reactor test facility which is away from the public. However, additional information on the location of the public with respect to these sites and the risk to this public from potential accidents at the prototype would need to be supplied by the preapplicant.

\subsubsection{Safety Testing of the Prototype}

In the safety testing phase of the safety test program, the preapplicant has proposed a preliminary list of ten proposed DBEs and BDBEs to be tested using the prototype. These proposed prototype tests should bound transient overpower events, loss-of-heat-sink events, lossof-flow events, and failure-to-scram events for the PRISM design; therefore, at this time no additional events for the prototype are considered necessary to demonstrate the safety characteristics of the design for certification. The preapplicant has stated that these events may be conducted at less than rated conditions to validate analytical and computer models and to prevent damage to the prototype. This is an acceptable approach to certification of the design; however, the details of this testing and how it will sufficiently demonstrate the safety characteristics of the design have not been submitted to the staff.

Concerning tests to verify the effect of burnup from the initial core to the equilibrium core on the safety characteristics of the core, the preapplicant has stated, in response to NRC Comment 14.9 in Appendix F of the PSID, that the PRISM core for design certification has what is called a "zero" burnup swing because the core reactivity state does not change appreciably with burnup. This, however, may no longer be correct with the changes identified in Amendments 12 and 13 of the PSID. The preapplicant has stated that the effects of fuel burnup will be investigated in the metal-fuel R\&D program, discussed in Section 14.1.2 (above), prior to the prototype test program. The preapplicant, however, must address the question of tests at different burnups during the prototype tests. 


\subsubsection{Work Scopes in the R\&D Program}

In the R\&D program, the work scopes for the technology areas in GEFR-00845 were reviewed to determine if any additional development work may be needed for the design. The EM pump coastdown mechanism and the RVACS are very important to the safety of the PRISM design, and their performance is being investigated in the R\&D program; however, the preapplicant should justify why the testing of the pump coastdown mechanism in the safety test program is sufficient to determine the in-service operability of the mechanism during reactor power operation.

Probably the most important technology area in the R\&D program for the final design is the reactor fucl that is discussed in Section 4.2. The extent of fuel testing in the safety test program will depend on what cannot be proven for the fuel in the other parts of the R\&D program. Additional tests beyond what is currently described in the safety test program may be required by the final design review stage for certification of the design.

\subsubsection{Conclusions}

By the final design review stage, the details of the safety test program will be reviewed together with the R\&D program to determine ; ooth programs are expected to provide the necessary nonstration of the PRISM design for certification. The reapplicant will need to provide or amplify the following information: (1) the part of the PRISM design to be certified and how the non-certified part will be shown not to significantly affect the safe operation of the plant; (2) the paragraphs of 52.47(b)(2)(i) which would be the basis for demonstrating the safety characteristics of the PRISM design for certification; (3) how the proposed analysis, experience, and testing (including the prototype testing) will support certification of the design; (4) the justification for proposing only one module to represent the multi-module site and whether the addition of a power conversion system and multi-modules would be part of the testing for the certification of the plant; and (5) the justification for the final proposed site for testing the prototype and for later adding a power conversion systen and additional modules to the prototype.

The preapplicant has stated that a certification basis agreement would be submitted to the NRC staff to clarify and summarize the information required to support an application for standard design certification. This agreement will define proposed standards and criteria for certification of the PRISM design, and the staff would use this to review the safety test and the R\&D programs.

\subsubsection{Comparison to the Commission's Advanced Reactor Policy}

The preapplicant has proposed to test a prototype to demonstrate the safety characteristics of the PRISM design. Because the PRISM design differs significantly from the current and evolutionary light-water reactor designs and uses simplified, inherent, passive or other innovative means of accomplishing its safety functions, the proposed use of a prototype is consistent with the Commission's Policy Statement (Ref. 14.3) on advanced reactors which favors a prototypical demonstration facility.

The prototype proposed by the preapplicant is not a fullsize prototype of the PRISM plant. In NUREG-1226, the staff states that it does not require a full-size prototype; however, there must be (1) a demonstration of the features of the design that are fundamental to its safety performance and (2) an integrated test of plant systems under prototypical conditions. The preapplicant has not provided sufficient detail of the safety test program to determine if the R\&D program and the safety test program will do this. This information must be provided by the final design review stage.

\subsubsection{Comparison to Commission Paper SECY-91-074}

The preapplicant has not submitted a comparison between the testing proposed for the prototype and the 19 steps listed in Enclosure 2 to Commission paper SECY-91-074 for determining the type of demonstration facilities that may be needed for the test approach under 10 CFR Part 52.47(b)(2)(i). This test approach is specified in $10 \mathrm{CFR} 52.47(\mathrm{~b})(2)(\mathrm{i})(\mathrm{A})(1)$ to $(4)$ and $52.47(b)(2)(i)(B)$ discussed in Section 14.3.1. This comparison to Enclosure 2 would be part of the preapplicant's justification that the testing proposed is sufficient to demonstrate the safety characteristics of the design to support the certification of the design. This comparison should be provided by the final design review stage.

\subsubsection{Comparison to SRP Section 14.2 and RG 1.68}

In PSID Section 1.8, it is stated that the initial testing of the PRISM design would meet the intent of RG 1.68. However, the preapplicant has not provided sufficient details of the safety test program, except that the test program will use operating and testing experience from other facilities, to determine to what extent the program will meet the intent of SRP Section 14.2 and RG 1.68. Examples of the details needed are the following: (1) an explanation by the preapplicant of the objectives of each analysis or test and how it will support the certification of 
the design and (2) a justification of the SSCs to be tested in terms of the remainder of the design that will not be tested. For example, SRP Section 14.2 and RG 1.68 list the SSCs to be tested and include those that will be used to process, store, control, or limit the release of radioactive materials from the plant; however, the R\&D program and the safety test program appear not to address these types of SSCs. This information needs to be submitted by the final design review stage.

\subsubsection{ALMR Technology Development Requirements Plan}

The preapplicant has submitted Revision 3 of the ALMR Technology Development Requirements Plan, GEFR-00845, dated June 1992. Although Phase IV of the program is the testing of the prototype, there are no details as to how these tests, including the work in the R\&D program, will support the certification of the design. The work scopes discussed in GEFR-00845 are presented without any explanation of how the development and the prototype testing will demonstrate the safety characteristics of the design and support the certification of the design. The preapplicant has not stated which characteristics of the PRISM design must be demonstrated for the standard design certification and how they will be demonstrated in the safety test program or in the other parts of the R\&D program.

\subsubsection{Changes to the Standard PRISM Design}

In Amendment 12 to the PSID, the preapplicant presented changes to the PRISM design, including safety-related equipment and systems. These changes are discussed in Table G.2.2-1 of PSID Section G.2.2. Examples of these changes are a containment structure added above the reactor vessel head and passive gas expansion modules added to the core. The discussion of the R\&D program and the safety test program in Amendments 12 and 13 have not addressed these changes to the PRISM design.

\subsection{Conclusions}

Safety issues concerning the R\&D program and the sifet: test program are discussed in Section 14.5 and are evaluated in Section 14.6. The preapplicant has not submitted sufficient information on these programs for the salf to complete its and and anderstend low the

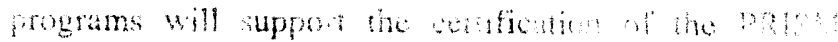

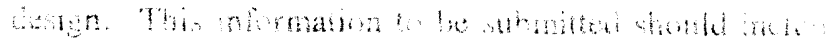

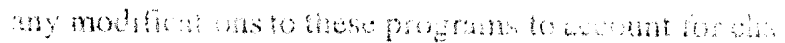

in the PRISM design since the draft PSER was issued by the NRC staff. This information must be submitted by the final design review stage in order for the staff to identify the specific testing required for certification of the design, in accordance with 10 CFR 52.47(b)(2)(ii).

\subsection{References}

14.1 U.S. Nuclear Regulatory Commission, Code of Federal Regulations, Title 10, "Energy," Part 52, "Early Site Permits; Standard Design Certifications; and Combined Licenses for Nuclear Power Plants, Subpart B, Standard Design Certification."

14.2 General Electric, PRISM-Preliminary Safety Information Document, GEFR-00793 UC-87Ta, November 1986.

14.3 U.S. Nuclear Regulatory Commission, "Advanced Reactor Policy Statement: 'Regulation of Advanced Nuclear Power Plants, Statement of Policy,'" 51 Federal Register 24643, July 8, 1986.

14.4 U.S. Nuclear Regulatory Commission, "Prototype Decisions for Advanced Reactor Designs," SECY-91-074, March 19, 1991.

14.5 U.S. Nuclear Regulatory Commission, Standard Review Plan, Section 14.2, "Initial Plant Test Program - Final Safety Analysis Report," NUREG-0800, Rev. 2, July 1981.

14.6 General Electric, ALMR Technology Developmient Requirements Plan, GEFR-00845, Rev. 3, UC-87Ta, June 1992.

14.7 U.S. Nuclear Regulatory Commission, "Development and Utilization of the NRC Policy Statement on the Regulation of Advanced Nuclear Power Plants," NUREG-1226, Section 5.4.4 and appendix, June 1988.

14.8 4. Nuclear Regulatory Commission, "nitial Test Prograns for Water-Cooled Nuctosi Power Plants," Segulatory Guide 1.68 .

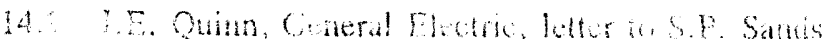

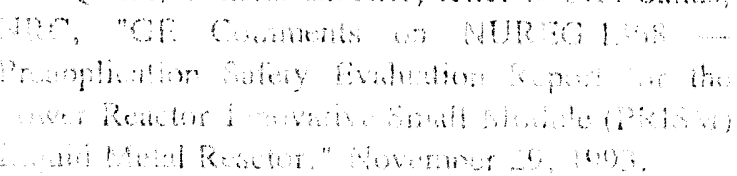




\section{ACCIDENT ANALYSIS}

\subsection{Introduction}

In this chapter, the staff reviews the PRISM safety analysis presented in Chapter 15 and Appendix G of the Preliminary Safety Information Document (PSID) (Ref. 15.1). Supplementing this review is the staff's review of the PRISM probabilistic risk assessment (PRA) discussed in Appendix A of this report and the staff's independent analysis of selected events discussed in Appendix B of this report.

\subsubsection{Design Description and Safety Objectives}

The methodology used by General Electric (GE) for defining the design-basis events (DBEs) for the PRISM reactor is described in Chapter 15 of the PSID. The procedure is systematic and draws upon PRA work performed in the conceptual stage of the design. The PRA is used to help ensure completeness in the identification of accident sequences and to rank the sequences in order of their importance on the basis of their expected occurrence frequency and offsite consequences. Each event is placed into a category of either a DBE or a beyond-design-basis event (BDBE). GE has considered all events occurring at a frequency of $10^{-6}$ or more per reactor-year to be DBEs. GE analyzes these events in a conservative manner. Less likely events are considered BDBEs (frequencies $<10^{-6}$ per reactor-year). GE considers these off-normal conditions of such extremely low probability that no event in this category is considered credible during the plant's lifetime. BDBEs can, however, have significant consequences. $\mathrm{GE}$ acknowledges some of these events may merit consideration in establishing the design. These BDBEs are discussed in Appendices E and G of the PSID.

\subsubsection{PRISM Approach to Safety}

GE cites five levels of safety in the PRISM design:

Passive ("Inherent") and Basic Design
$\underline{\text { Characteristics }}$

GE identifies the first level of safety as passive ("inherent") and related to or deriving from basic design characteristics. This means taking advantage of every aspect of the design from the type of coolant it uses down to the simplification of the engineered safety features employed. For example, sodium has excellent heat transport characteristics; it can be utilized at low pressure and yet be far below its boiling temperature. Building a power plant with nine completely separate small-size reactor modules allows each unit to have passive decay heat removal and a lower source term in the event of a catastrophic accident. The reactivity feedbacks are such that the power decreases significantly when off-normal events take place, thus producing a passive response to most unscrammed scenarios. Core inlet nozzles are designed to make total blockage of flow to an assembly nearly impossible. Passive heat removal systems such as the reactor vessel air cooling system (RVACS) have the potential to supply highly reliable decay heat removal. Finally, the metal fuel more effectively retains fission products but has a smaller Doppler reactivity feedback, compared to oxide fuel. The Doppler adds negative reactivity on a power increase, but its effect is less for the metal fuel. This, in turn, allows the temperature defect to be small and other passive feedbacks (for example, radial and axial expansion of the core) can control the core.

\section{Protection Against Anticipated and Unlikely Events}

GE states that this protection comes from a safety-grade reactor protection system (RPS), a non-safety-grade plant control system (PCS), the auxiliary cooling system (ACS) and safety-grade RVACS backup heat-removal systems, the containment vessel, and from the use of four electromagnetic (EM) pumps with synchronous machines to produce coastdown. The gas expansion modules (GEMs) for loss-of-flow events, the control rod stop system for reactivity insertion events, and the ultimate shutdown system (USS) give additional protection against anticipated and unlikely events.

\section{(3) Protection Against Extremely Unlikely Events}

The designer cites the ability of systems identified in the first and second levels of safety to defend the reactor against those accidents classified as extremely unlikely. Additionally, the reactor vessel and reactor module closure assembly are designed to contain radioactivity released by any fuel or cladding failure.

\section{(4) Protection Against Beyond-Design-Basis Events}

The fourth level of safety is the protection against BDBEs provided by the reactor's passive feedbacks. The reactor is protected against several of the most probable unscrammed events, such as loss of heat sink or loss of flow with coastdown. Not all events beyond the design basis are considered, only those falling in a range that is considered to be credible. A hypothetical core disruption accident (HCDA) is postulated to evaluate the integrity of the reactor coolant system and to test the mitigative effectiveness of the containment system.

Risk Assessment

The fifth level of safety, according to GE, is the use of PRA in evaluating the overall safety of the design and to point out areas requiring improvement. The PRISM 
designers are using the PRA throughout the development to keep the safety design process focused on issues of significance as measured by their impact on public risk. PRA is used to select DBEs and BDBEs and to assign reliability requirements for systems and components. The PRA is also the only evaluation in which the BDBEs are considered. Some extremely improbable events are considered in the PRA, and for these events, GE discusses the coolability of core debris and the possibility of energetics.

\subsubsection{Safety Evaluation Procedure}

GE's safety evaluation procedure of the PRISM plant consisted of locating the dominant risks in the plant design through the PRA. GE used the following steps to identify the events for inclusion in the design basis:

\section{(1) Event Selection}

In the PRISM approach to safety, the PRA was used to ensure completeness in the identification of accident sequences and to rank the sequences in the order of importance. The order of importance was based on the combination of occurrence frequency and offsite consequences. Thus the PRA provided the framework for the DBE selection.

\section{(2) Event Categorization}

GE placed each identified event into one of four DBE categories or the BDBE category using its nominal frequency as a criterion. The dividing line between DBEs and BDBEs is the frequency of $10^{-6}$ per reactor-year. The four DBE zategories as defined by $\mathrm{GE}$ are:

(a) Normal Operation - Any condition of system startup, design range operations, hot standby, or shutdown (frequency $\geq 10^{-1}$ per reactor-year)

(b) Anticinoted Event -.. Oft-normal condition that is axpected so sccur once or more dulia the plants lifetime $\left(10^{-1}>\right.$ frequtucy $\geq 10^{-2} \mathrm{per}$ reactor-year $)$

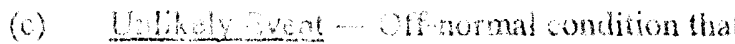

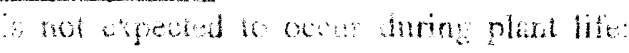
Hover we megred over a!

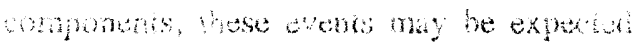

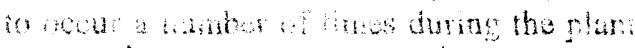

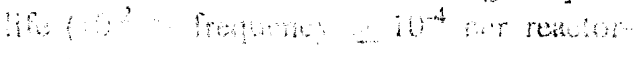
$y$

(d)

Extremely Unlikely Event - Off-normal conditions of such extremely low probability that no events in the category are expected, but represent limiting cases of failure that are identified as design bases $\left(10^{-4}>\right.$ frequency $\geq 10^{-6}$ per reactor-year). These frequency ranges are the same as those used by GE for the boiling-water reactor (BWR) and are similar to those recommended by American Nuclear Society (ANS) standards for the liquid-metal reactor (LMR) (Ref. 15.2).

The final category is the BDBE. This is an offnormal condition of such extremely low probability that $\mathrm{OE}$ considers no events in this category to be credible. However, these events may have potential consequences that merit their consideration in the design. These events have a frequency that is less than $10^{-6}$ per reactor-year. The HCDA is one example.

(3)

\section{(1)}

\section{Risk Assessment}

GE used the PRA to analyze all BDBEs and to assess conformance to NRC safety goals.

\subsection{Scope of Review}

The classification of DBEs and BDBEs and the of of PRA in the process were discussed at length with the staff from the Department of Energy and GE. Independent calculations by the Nuclear Regulatory Commission (NRC) staff generally support arguments about performance of the passive reactivity feedbacks and such key systems as RVACS.

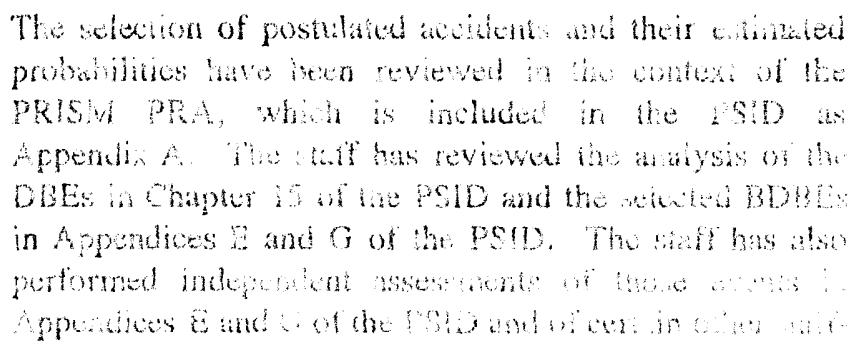


dentified bounding events, as presented in Appendix B of this report.

\subsection{Design Criteria}

It was considered necessary to review a spectrum of accidents beyond the traditional light-water reactor (LWR) design-basis accident (DBA) envelope for the PRISM design. Consideration of such a spectrum of accidents (1) ensures that advanced designs comply with the Commission's Safety Goal (Ref. 15.3) and Severe Accident (Ref. 15.4) policies, (2) sufficiently tests the capability of the design to allow use of mechanistic source terms for siting determinations and for decisions regarding containment design and emergency evacuation plans, and (3) ensures that the shift in emphasis in defense in depth from accident mitigation to accident prevention, as compared to LWRs, does in fact still produce a design with safety at least equivalent to that of current-generation LWRs. Therefore, a set of event categories corresponding to events that must be used for design, siting, containment performance, and emergency planning purposes needs to be defined. Events to be included in these categories should be selected deterministically, supplemented by insights gained from a PRA. The events selected can then be used as a basis for calculating source terms, for evaluating the safety characteristics of the proposed designs, and for assessing the adequacy of the containment systems and offsite emergency planning. The event categories frequency ranges, and the radiological consequence limits associated with the categories, used by the staff for the PRISM preapplication review and their associated descriptions are presented below.

\subsubsection{Event Category I (EC-I)}

This category of events for advanced reactors would be equivalent to the current anticipated operational nccurrences (AOOs) class of events considered for LWRs. The frequency range for these events is approximately $10^{-2}$ per plant-year, or greater, which corresponds to the frequency of events that may be expected to occur one or are times during the life of the plant. These events wold be analyzed in a manner similar to the analysis for LWRs to derwostrate comphinace with sppenuix I to $10 \mathrm{CPR}$ Part 50 (Rof. 15.5 ) and W CFR Part 100 (Ref. 15.6).

\footnotetext{
2.3.

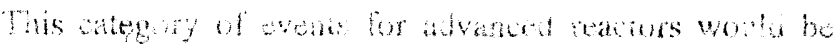

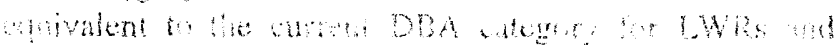

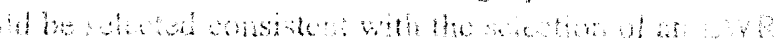

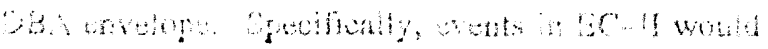

Be selected using traditional engineering judgment, complemented by PRA methods, that would include individual internal events down to a frequency of approximately $10^{-4}$ per plant-year $\left(10^{-4} / \mathrm{yr}\right.$ is based upon ensuring that any event expected to occur over the lifetime of a population of reactors -100 reactors operating for 100 years-is included). A lower value of $10^{-5}$ per plant-year will be used by the staff to increase the confidence that the collective risk of nost potential DBAs are considered in the design and to account for uncertainties, particularly for a preapplication review. (Currently, GE considers all individual events that might occur at a frequency higher than $10^{-6}$ per reactor-year to be DBEs. GE analyzes these events in a conservative manner.)

(2) Include a traditional selection of design-basis external events.

Be subject to the single-failure criterion and other traditional conservatisms (such as no credit for nonsafety-grade equipment). Events within this category would require conservative analysis as is presently done for LWRs.

\subsubsection{Event Category III (EC-III)}

This category of events for advanced reactors corresponds to those severe events beyond the traditional DBA envelope that should be used by designers in establishing the design bases for these reactors. The staff believes that the identification and use of such an event category is consistent with the Commission's Severe Accident Policy statement and is justified for the PRISM design, particularly where the use of a mechanistic calculation of source terms and a shift: emphasis from accident mitigation to accident prevcur 1 is proposed. The events in this category would be selected using engineering judigment, complemented by PRA. This is consistent with the guidance provided in the Commission's Safety Goal and Severe Accident policies, which encourage the use of PRA methods to supplement engineering judg-ment and deterministic (nonmechanistic) analyses. Specificaliy, events in EC-III would

(1) Include intemal events (less likely initiating erents

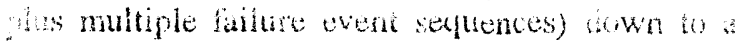
frequency of aprosinately $10^{-7}$ per plan yea

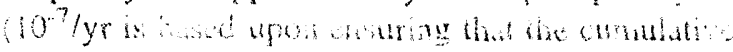

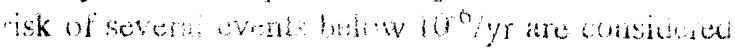

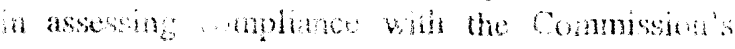

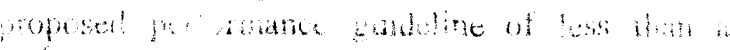

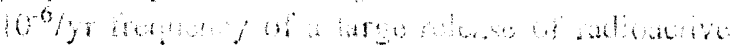

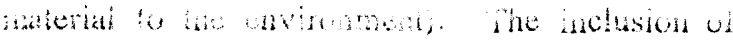


external events beyond those in EC-II would be consistent with their application to future LWRs, which is currently being developed as part of the implementation of the Commission's Severe Accident Policy.

(2) Include, using engineering judgment, additional bounding events to account for plant-specific uncertainties. Selected bounding events for the PRISM design are described in Table 15.1. Further specification of these events is provided in Table 15.2. The rationale for bounding event selection and use is described in the following Section 15.3.4.

In selecting the events to be included in EC-III, the design would be specifically reviewed to identify those events that have the potuntial for a large release, core melt, or reactivity excursion to ensure that adequate prevention or protection is furnisher' "ir these events. EC-III events should be analyzed on west-estimate basis, rather than on a known conservative basis as would be done for EC-II events.

\subsubsection{Bounding Event Selection}

In evaluating the PRISM design, the staff was faced with the task of defining the range of events that should be considered in the design. This task was made particularly important because the preapplicant was proposing a design with containment and emergency planning features significantly different than those applied to conventional LWRs, with primary justification for these features being the proposed capability of PRISM to prevent accidents that could lead to significant core damage and offsite release of radioactive material. Accordingly, a key test in evaluating the proposed PRISM design is to establish confidence in the ability of PRISM to prevent accidents that result in significant core damage or offsite release of radioactive material.

GE proposed selecting a range of events based upon PRA results (see Section 15.1.2). The staff believes that PRA can provide useful insights into event selection but that engineering judgment must ultimately be relied upon in event selection to account for uncertainties. Therefore, the staff has included in EC-III a set of bounding events for the PRISM design whose purpose is to account for uncertainties in design and reliability and acknowledge the difficulty in being able to identify, particularly at this stage of the design, all failure modes of a system or component. Specifically, the following appear to be the major sources of uncertainty affecting event selection:
(1) the limited performance and reliability data for the critical systems, mainly the passive decay heat removal system using air at atmospheric pressure to cool the reactor vessel, and the negative reactivity feedback mechanisms

(2) the lack of a final design which limits identification of initiating events, dominating sequences, and equipment reliabilities

(3) the incomplete state of supporting technology and analytical tools relevant to the new designs

extrapolation of research and development (R\&D) results to a full-size unit

significantly less design, construction, and operating experience compared to experience with LWRs

Accordingly, the set of bounding events selected for consideration at the conceptual design stage was intended to provide a sufficient test of the conceptual design so that accurate knowledge of the failure modes and failure probabilities of the safety features of the design would not be critical to assessing or understanding its safety.

Although the selected bounding events were not rigorously quantified in terms of probability, a judgment was made that their probability could reasonably be in the lower range of EC-III (i.e., 10 $10^{7} / \mathrm{yr}$ ), as show/n in Table 15.2. The following major assumptions were used in selecting the bounding events

- Select worst-case plant states (specified by system pressure, temperature, flowrate, etc.) as initial conditions for the challenges to the safety functions.

- Assume non-safety-grade equipment fails (either as an initiator or in response to the initiating event) in a way that exacerbates the accident to the maximum degree physically possible, unless a lesser degree can be justified. This will account for any uncertainties caused by using commercial-grade procurement and construction, and the lesser operational surveillance associated with the non-safety grade designation.

- Assume failure of unique safety-grade equipment for a period of time (bounds uncertainties in failure probabilities of safety-grade equipment).

- Allow a reasonable time (consistent with emergency planning provisions) to recover safety-grade equipment where no plant damage has occurred (anticipated transient without scram, station blackout, loss of all cooling). 
Description

1 Unprotected transient overpower (UTOP) events. Assume that the worst-case control rod withdrawal event occurs. Assume that all control rods remain full out (at the mechanical stops) for 12 hours and then the reactor is scrammed. Analyze this event for two cases on one module:

- A - All forced cooling remains functional.

- B - All cooling except the reactor vessel air cooling system (RVACS) is lost at the time the control rods are withdrawn.

2 Station blackout. Assume that scram occurs and natural circulation cooling is the only available mode of cooling for all modules on the site. Assume that 24 hours pass before ac power is restored.

3 Loss-of-heat-sink events. From full-power conditions, assume that all cooling via the normal cooling system and the auxiliary air cooling system is lost (loss of the intermediate loop). A scram is assumed to occur as soon as the reactor protection system detects off-normal conditions. Analyze this event for two cases:

- A - All airflow pathways in RVACS are assumed to be fully blocked for 12 hours. Assume sabotage on one module and analyze until the peak temperatures have passed.

- B - Assume a 75-percent, blockage of the RVACS airflow pathways for an indefinite period of time. Assume an earthquake that affects all modules and analyze until the peak temperatures or 12 hours have passed.

4 Unprotected loss-of-flow (ULOF) events. Assume an unscrammed ULOF event on one module and analyze this event for two cases:

- A - Assume that the flow through one pump stops suddenly and the others continue to operate normally. Analyze the event until new equilibrium power and flow rates have been established.

- B - Assume that the pumps are tripped and begin to coastdown. For this case, one of the pumps does not coastdown and it ceases pumping instantaneously. Analyze the first $\mathbf{1 0}$ minutes of the event.

5 Steam generator tube rupture event. Determine a justifiable number and the sequence of steam generator tube ruptures and analyze assuming failure to isolate or to dump water from the steam generator for 12 hours. Evaluate this event without forced cooling (one module).

6 Large sodium (Na) leaks (single module). Assume leaks in the intermediate heat transport system piping. Determine the size of the leak in accordance with the criteria for moderate-energy fluid system piping. Evaluate for sodium fires and leaks from the reactor vessel into the guard (containment) vessel.

7 Flow blockage. Assume blockage of flow to or from one fuel assembly.

8 External events. Evaluate external events that exceed those traditional analyzed as design basis events in a manner consistent with their application to current-generation light-water reactors. 


\section{Accident Analysis}

Table 15.2 Bounding events specification

\section{Description}

\section{Probability range estimate ${ }^{1}$}

BE-1 Assumed worst-case failure of nonsafety-grade control system (due to fire or other mechanism). Results in inadvertent withdrawal of all control rods, combined with failure to scram.

BE-2 Two- to sixteen-hour station blackout is assumed for light-water reactors (LWRs). Additional time added to compensate for lack of design detail.

BE-3 Severe external event could cause loss of offsite power and temporary loss of reactor vessel air cooling system (RVACS). Auxiliary cooling system is non-safety-grade.

BE-4 Loss of one synchronous machine is an anticipated event combined with anticipated transient without scram (ATWS).

BE-5 Steam generator (SG) and its water dump and isolation system are nonsafety-grade. Experience with SG tubes indicates multiple failures have occurred. Exact number to be determined later but should be at least 40 based upon prototype fast reactor (PFR) experience.

BE-6 Consistent with Clinch River Breeder Reactor (CRBR).

BE-7 Fabrication error results in blocked assembly being inserted into core.

BE-8 Severe external even analysis.
- Fire or control system failure, $10^{-1}-10^{-4} / \mathrm{yr}$

- Failure to scram - $10^{-5}-10^{-7} / \mathrm{yr}$

- Modules on site - 10 Range of prob. $=10^{-5}-10^{-10} / \mathrm{yr}$

- 2-16 hr station blackout - $10^{-5} / \mathrm{yr}$ for LWRs

- Additional 20-hr loss - $10^{-2}-10^{-3} / \mathrm{yr}$ Range of prob. $=10^{-7}-10^{-8} / \mathrm{yr}$

- External event causes loss of offsite power and blocks RVACS $<10^{-7} / \mathrm{yr}$

- Modules on site - 10 Range of prob. $=<10^{-6} / \mathrm{yr}$

- Instantaneous loss of flow through one primary pump $-10^{-2} / \mathrm{yr}$

- Failure to scram $-10^{-5}-10^{-7} / \mathrm{yr}$

- Modules on site - 10

$$
\text { Range of prob. }=10^{-6}-10^{-7} / \mathrm{yr}
$$

- Multiple SG tube ruptures have occurred in the past. Such ruptures would leave plant on RVACS cooling only.
- IHTS or reactor vessel leak = $10^{-6}-10^{-7} / \mathrm{yr}$ (per CRBR PRA)

- Modules on site -10 Range of prob. $=10^{-5}-10^{-6} / \mathrm{yr}$

Fabrication errors have occurred in the past. Experience shows

fabrication and loading errors cccur.

Under development for ALWRs; will be develoned for PRISM.

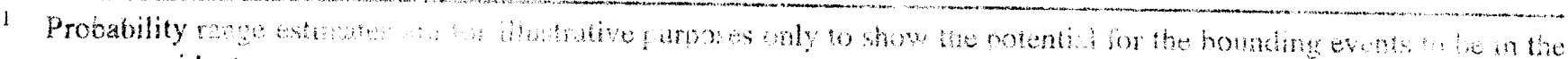
severe accidew: moss, 
- Assume multiple human errors or other initiating events consistent with events that have actually occurred.

- Assure at least an equivalent challenge to that applied to LWRs.

These assumptions resulted in the bounding events for the PRISM design (Table 15.1), which the staff considens appropriate given the current stage of the design. Further specification of the bounding events is given in Table 15.2. These bounding events should be reviewed in the future to determine if design changes, additional design detail, or R\&D program results suggest that a change is necessary.

The bounding events are also intended to be used for the assessment of containment performance and offsite emergency planning. Such assessment would include internal events of similar frequency to those events considered in the basis for the emergency planning zones and requirements for LWRs as described in NUREG-0396 (Ref. 15.7).

The staff recognizes that large uncertainties may exist in PRA results, especially in the lower frequency ranges. Therefore, in selecting and analyzing the events in categories EC-I, II, and III, consideration must be given to the treatment of uncertainties. Accordingly, where the event categories include in their definition a frequency value, this frequency value is intended to be a guideline only and is not to be considered a rigid limit for which compliance must be rigorously demonstrated.

In analyzing each event from the above event categories, a determination must be made as to whether or not the event applies to all reactor modules simultaneously or to one module only. In addition, in determining the events to be included in EC-I through EC-III, and in assessing the risk from a plant (where a plant consists of more than one module), the probability of certain events occurring must be increased to account for the multiple modules.

Tables 15.3 and 15.4 show the review criteria used to assess the PRISM design at the preapplication stage of review. These criteria are consistent with and very similar to those proposed by GE. It should be emphasized, however, that, as the design progresses, changes in the list of bounding events may be warranted to account for design changes, additional design detail, and R\&D program results.

\subsubsection{Source Term and Radiological Consequences}

Source terms could be developed for advanced reactors based on mechanistic analysis provided (1) those source terms are used in conjunction with dose guidelines consistent with those applied to LWRs, (2) the events considered in the mechanistic analysis are selected to bound credible severe accidents and design-dependent uncertainties, and (3) the performance of the reactor and fuel under normal and off-normal conditions is sufficiently well understood to permit mechanistic analysis. This would give a more realistic estimate of source terms and would give designers of advanced reactors incentive to develop designs that minimize releases. The following criteria are proposed for the preapplication review of the PRISM design for the calculation of a mechanistic siting source term:

(1) Using the EC-II spectrum defined previously, perform a conservative evaluation of EC-II scenarios and calculate a source term.

(2) Using the EC-III spectrum defined previously, perform a best-estimate evaluation of EC-III scenarios and calculate a source term.

Ensure that sufficient data exist (through an R\&D program or prototype testing) on reactor and fuel performance under EC-II and EC-III conditions to provide adequate confidence in the mechanistic analysis methods used.

(4) Ensure that none of the EC-II and EC-III scenarios are on a threshold where a slight change in assumptions or uncertainty can cause an unacceptable change in the source term.

The dose guideline specified for EC-II events is based upon maintaining a dose guideline equivalent to that for LWRs where mechanistically calculated source terms are used (i.e., where the LWR Standard Review Plan (Ref. 15.8) allows the use of mechanistically calculated source terms in analyzing accidents, it specifies offsite dose must be a small fraction of 10 CFR Part 100 guidelines, which is generally interpreted as $10-25$ percent of the 10 CFR Part 100 dose guidelines). For the preapplication review, the staff has chosen 10 percent of the 10 CFR Part 100 guidelines. The dose guidelines for EC-II is meant to ensure, at this stage of review, that the likelihood of meeting the LWR equivalent of a small fraction of the 10 CFR Part 100 guidelines is high and there is confidence in licensibility at a later review stage.

The dose guideline specified for EC-III events is based upon applying the same siting dose guideline as is applied to LWRs (10 CFR Part 100) to those events that are being analyzed in place of the traditional non-mechanistic LWR source term (i.e., EC-III events are the severe events which in an LWR have traditionally been predicted to result in a core melt and which, for LWRs, led to the 
Table 15.3 Summary of evaluation criteria

\begin{tabular}{|c|c|c|c|c|c|}
\hline \multirow[b]{2}{*}{$\begin{array}{l}\text { Design-basis event } \\
\text { category }\end{array}$} & \multirow{2}{*}{$\begin{array}{l}\text { Frequency } \\
\text { range (per } \\
\text { reactor year) } \\
(\text { Note 1) }\end{array}$} & \multicolumn{4}{|c|}{ Preapplication evaluation criteria } \\
\hline & & $\begin{array}{c}\text { Core } \\
\text { conditions }\end{array}$ & Structural limits & $\begin{array}{l}\text { Radiation } \\
\text { exposure to } \\
\text { plant } \\
\text { personnel } \\
\end{array}$ & $\begin{array}{l}\text { Offsite radio- } \\
\text { logical dose }\end{array}$ \\
\hline Normal operation & $F \geq 10^{-1}$ & See Table 15.4 & $\begin{array}{c}\text { ASME Code } \\
\text { service level "A" }\end{array}$ & 10CRF20 & $\begin{array}{c}\text { 10CFR50 } \\
\text { Appendix I }\end{array}$ \\
\hline $\begin{array}{l}\text { EC-I Anticipated } \\
\text { events }\end{array}$ & $10^{-1}>\mathrm{F} \geq 10^{-2}$ & See Table 15.4 & $\begin{array}{c}\text { ASME Code } \\
\text { service level "B:" }\end{array}$ & 10CFR20 & $\begin{array}{c}\text { 10CFR50 } \\
\text { Appendix I }\end{array}$ \\
\hline $\begin{array}{l}\text { EC-II Unlikely } \\
\text { events }\end{array}$ & $10^{-2}>\mathrm{F} \geq 10^{-4}$ & See Table 15.4 & $\begin{array}{l}\text { ASME Code } \\
\text { service level "C" }\end{array}$ & 10CFR20 & $\begin{array}{l}10 \% \text { of } \\
10 C F R 100 \\
\text { (Note } 3)\end{array}$ \\
\hline $\begin{array}{l}\text { EC-III Extremely } \\
\text { unlikely events }\end{array}$ & $10^{-4}>\mathrm{F} \geq 10^{-7}$ & See Table 15.4 & $\begin{array}{l}\text { ASME Code } \\
\text { service level "D" }\end{array}$ & (Note 2) & $\begin{array}{l}\text { 10CFR100 } \\
\text { (Note 3) }\end{array}$ \\
\hline
\end{tabular}

Note 1: Event frequencies are nominal values.

Note 2: Radiation exposure to plant personnel in main control room not to exceed 5 rem whole body, 30 rem inhalation, and 75 rem skin from any one event.

Note 3: For relaxation of emergency planning requirements, lower doses must be met.

\section{Table 15.4 Evaluation criteria - PRISM core conditions}

\begin{tabular}{|c|c|c|c|c|}
\hline \multirow{2}{*}{ Event category } & \multicolumn{2}{|c|}{ Peak transient temperatures, ${ }^{\circ} \mathrm{F}$} & \multicolumn{2}{|c|}{ Long-term temperatures, ${ }^{\circ} \mathrm{F}$} \\
\hline & Bulk coolant & Cladding ${ }^{*}$ & Bulk coolant & Cladding ${ }^{* *}$ \\
\hline Normal operation & 1,200 & 1,200 & 1,200 & 1,200 \\
\hline Anticipated events & 1,200 & 1,200 & 1,200 & 1,200 \\
\hline Unlikely events & 1,300 & 1,450 & 1,300 & 1,300 \\
\hline $\begin{array}{c}\text { Extremely unlikely } \\
\text { events }\end{array}$ & 1,300 & 1,450 & 1,300 & 1,300 \\
\hline
\end{tabular}

* - Temperatures at cladding centerline based on preventing breach by stress rupture.

** - Temperature at fuel-cladding interface based on preventing cladding breach by low-melting point formation (eutectic). 
establishment of the non-mechanistic TID-14844 (Ref. 15.9) source term).

The staff recognizes that the Safety Goal large release criteria would allow greater release than Part 100 at sufficient low probability. The dose guideline for EC-III is meant to ensure, at the preapplication stage, that the likelihood of meeting the Safety Goals is high and there is confidence that future licensability is assured.

To allow the use of mechanistic analysis for siting sourceterm selection, the staff proposed and GE adopted the following dose guidelines for siting assessment during the preapplication and preliminary design approval review stages.

\begin{tabular}{lll} 
Category & Dose Guidlines & Meteorology \\
EC-II & $10 \%$ of 10 CFR Part 100 & Conservative \\
EC-III & 10 CFR Part 100 & Conservative \\
\hline
\end{tabular}

These proposed criteria on siting source-term calculation and dose guidelines would be used in conjunction with the traditional assessment of site suitability using the guidelines of Regulatory Guide (RG) 4.7 (Ref. 15.10), "General Site Suitability Criteria for Nuclear Power Stations, " for such factors as population distribution and meteorology. These criteria are not intended to modify any of the other NRC siting guidelines described in RG 4.7.

\subsection{Research and Development}

Accident selection and event categorization are difficult for a new design where reliability data are not well established. The R\&D program for various portions of the PRISM system (for example, the EM pumps and the metal fuel) may influence event selection as program results are obtained. The plant response to transients that rely on the passive reactivity feedback characteristics of the metal core should be part of the Safety Test Program planned for the PRISM prototype test module.

Argonne National Laboratories (ANL) is currently testing large, heated panels to represent the containment vessel and collector panel walls of RVACS. Tests of the RVACS are also part of the PRISM Safety Test Plan. ANL is also testing the performance of the EM pumps.

The ongoing integral fast reactor (IFR) program, also known as the ANL metal-fuels program, will continue to generate data on failed fuel. To date, the ANL work on metal fuels has not been focused on source-term aspects. ANL has theoretical arguments supporting an assertion that only noble gases would reach the cover gas. A future applicant will need to acquire, through an R\&D program, supporting data for future licensing activities.

Exclusive of the PRA and analyses of the bounding events, there is little discussion of severe accidents and source terms throughout the PRISM PSID. However, for BE-1b, $B E-3$, and $B E-7$, some fuel melting is shown to be possible, and BE-4 and BE-7 could lead to energetic core disassembly events. If these events cannot be eliminated from EC-III by design, then many questions regarding fission-product retention in metal fuels and sodium, as well as the energetics of the metal fuel during fast transients, need to be answered through the R\&D program. The IFR program is addressing these issues. To address energetic events in a bounding manner, GE evaluated an analyses of a hypothetical core disruptive accident in Appendix $G$ of the PSID.

Sodium fires have been thoroughly investigated in the past and analysis of heat and aerosol generation is well characterized. A detailed review of fire protection in PRISM will be performed at a later review stage. A more difficult question might be the amount of fission products leaked into and retained by the sodium, but the ongoing metal-fuel program will add to this data base.

\subsection{Safety Issues}

The use of PRA to ensure completeness in the identification of accident sequences and to separate DBEs from BDBEs needs to be viewed with caution, particularly for an advanced design at the conceptual design stage. Several of the systems use natural physical phenomena or totally passive concepts for safety, which makes it difficult to assign reliabilities to these key systems. It is not difficult to appreciate the use of passive safety in the PRISM design, but it is extremely difficult to quantify it. Therefore, the line between DBEs and BDBEs cannot be based solely on PRA results. However, the preapplicant's approach to selecting DBEs and BDBEs for the PRISM does provide useful insight into the design.

Initially, GE and DOE only chose to analyze several key BDBE events. However, some other BDBE events have the potential to fail the PRISM reactor module that, in the staff's judgment, fall within EC-III. These events were called bounding events and were analyzed by GE and NRC as discussed in Section 15.6.7. The response of PRISM to these events lends confidence to the evaluation of containment and emergency planning features proposed for the PRISM design. 
Traditionally, U.S. reactor safety has been based on accident prevention and mitigation, using defense in depth, and diversity of systems. The PRISM safety is based primarily on prevention, again using defense in depth and diversity. The reactivity feedbacks, the safety-grade scram system, and the potential reliability of RVACS and ACS tend to support GE's position that serious accidents in PRISM can be prevented at a very high confidence level. GE originally reduced accident mitigation features in the design. A large containment building serves this role for LWRs, and GE argued that such a structure around PRISM could be counterproductive, as it could inhibit the use of one of the major safety features, the RVACS. In the revised design, a containment dome has been addeci to the upper portion of the reactor vessel, fully enclosing the upper structure without compromising the design or function of the RVACS, which surrounds the lower part of the reactor and containment vessels. The containment accident evaluation in response to an HCDA is discussed in Section 15.6.8.

With a new design, the data to support reliability claims is generally not available. Thus, what may look like a $10^{-12}$ event to GE may be treated as a $10^{-7}$ event in near-term licensing activities. GE has stated that only DBEs with failure-to-scram events need be considered. The staff has identified those events which it believes should be considered in the PRISM design, with emphasis at this stage of the review on the bounding events in EC-III (Table 15.1).

\subsection{Evaluation}

\subsubsection{Reactivity Insertion DBEs}

\subsubsection{Design Description and Safety Objectives}

The PRISM reactor was originally designed to have a burnup reactivity swing targeted at zero, so that the six control rods could be almost fully withdrawn at power with a remaining worth of about $6 \mathrm{C}$ each which is available for insertion by rod withdrawal at full power. This design tended to minimize the reactivity which is available for the transient overpower (TOP) event. In the revised design, the total worth of the control rods needed to be increased by approximately $\$ 1$ to account for reactivity characteristics of the metal fuel (axial growth, for example) that were not included in the original design analyses. The revised design now includes a control rod stop system which is currently designed to limit the reactivity insertion to $30 \mathrm{c}$, with an uncertainty of $10 \mathrm{c}$ or a maximum withdrawal of $40 \mathrm{c}$.

The event originally analyzed by GE was a sequential withdrawal of the six rods at 100 percent power, which results in the addition of $2 \mathrm{c} / \mathrm{sec}$ up to a total insertion of 36c for all rods withdrawn. The reactor was assumed to trip at 15 percent overpower, terminating the significant part of the transient. Key temperatures and other factors remained well within design limits. GE also analyzed the unscrammed reactivity insertion DBE, and again temperatures and other parameters remained within design limits. With a reactor trip, the reactivity insertion DBE is not a major challenge to PRISM.

\subsubsection{Scope of Review}

Both the staff and GE examined the unscrammed reactivity insertion event. The failure to scram on rod withdrawal event depends solely on passive response, i.e., only reactivity feedbacks protect the reactor. Independent analyses of the unscrammed event was done by the staff; these are presented in Appendix B along with GE result.

\subsubsection{Design Criteria}

For this event, GE uses the staff proposed release limits of 10 percent ("small fraction") of the 10 CFR Part 100 dose guidelines for the scrammed case and 100 percent of 10 CFR Part 100 for the unscrammed case.

\subsubsection{Research and Development Program}

The plant response to the transient covered in this section should be part of the Safety Test Program planned for the PRISM prototype test module.

\subsubsection{Safety Issues}

There are two issues here. First, is the size of the postulated TOP initiator correct? Second, is the GE analysis correct and are the consequences acceptable?

The rod stop system may provide a viable means of limiting the size of potential unprotected transient overpower (UTOP) initiators, but there may be safety deficiencies in the approach. Allowing the non-safetygrade plant control system (PCS) control over such an important safety system may not be the best choice. In order to be able to make a judgment regarding a proposed adjustment of rod stops, an operator will need reliable instrumentation and adequate training. Also, the determination of how far the stops should be moved up the rod must be done using a fairly elaborate calculation based on rod worth curves, burnup data, and detailed corephysics analysis. Moving all six rods up one-half inch is worth slightly less than $10 \mathrm{C}$, so the precision of the mechanical relocation does not seem a major concern. The reactivity insertion, or rod worth, will have to be verified; 
this will be reviewed at a later design stage when the control rod stop system is designed and reviewed in detail.

On the basis of independent analysis discussed in Appendix B, the staff concludes that GE's analysis is fairly accurate and that, in the short term, this event is of little consequence. For example, during the initial portion of the unscrammed event, GE projected a 95-percent increase in power; the independent calculation showed an 85-percent increase in power. There were many other similarities in the calculations, including most of the reactivity feedbacks. Thus, the GE analysis is a reasonable estimate of the PRISM system response to the postulated event. Regarding consequences, GE's analyses showed that throughout the event sequence, proposed acceptance criterion were met. Further, staff proposed safety tests of the prototype test module would be able to verify GE claims regarding this event sequence.

\subsubsection{Conclusions}

The reactivity insertion DBE, with scram, is not a major challenge to PRISM. For unscrammed reactivity insertion BDBEs fuel damage could occur long into the transient; this is discussed in Appendix B of this report. Any residual uncertainties can ultimately be resolved by the safety tests. Further information regarding this event is in Appendix B of this document.

\subsubsection{Undercooling DBEs (Loss of Normal Shutdown Cooling)}

\subsubsection{Design Description and Safety Objectives}

Normal shutdown cooling for the PRISM design is via condenser cooling. The first backup cooling system is the ACS, which supplies ambient temperature air from outside the plant to the outside surface of the steam generator. Should the intermediate heat transport system be unavailable (sodium-water reaction, for example) decay heat is removed by RVACS, which is the only PRISM decay heat removal system that is safety grade. This section focuses on the event in which only the RVACS is available for removing decay heat. GE uses a special purpose computer program to analyze the undercooling event.

In analyzing the postulated event, $G E$ assumes that the sodium flow through the intermediate heat transport system (IHTS) drops to zero in $2 \mathrm{sec}$ and that heat removal through the intermediate heat exchanger (IHX) drops accordingly. Two cases, using "expected" and "conservative" assumptions, are analyzed. For the expected case, nominal decay heat is used and the thermal emissivity of the reactor and containment vessels is assumed to be 0.77 . For the conservative case, 105-percent nominal decay heat is assumed and the reactor and containment vessel emissivity is reduced to 0.7 .

The GE analysis indicates a maximum sodium outlet temperature of $912 \mathrm{~K}\left(1182^{\circ} \mathrm{F}\right)$ for the conservative case, which is below the Service Condition C structural limit of $922 \mathrm{~K}\left(1200^{\circ} \mathrm{F}\right)$. Maximum temperatures come about 30 hours into the transient, when heat removal through the RVACS increases to meet the decay heat load.

\subsubsection{Scope of Review}

The performance of RVACS was independently verified using the PASCOL computer code (Ref. 15.11). Using GE values for thermal emissivity and other factors, the staff was able to reproduce the GE results for system performance. Sensitivity analyses using different emissivities were also performed. Because GE has chosen to make RVACS the only safety-grade decay heat removal system in the PRISM design, this system received the most attention in the staff review. The staff performed a calculation based on decay heat, heat capacity, and RVACS performance, in order to estimate reactor outlet sodium temperatures. As shown in Figure 15.1, neither ASME Limit C $\left(922 \mathrm{~K}, 1200^{\circ} \mathrm{F}\right)$ nor $\mathrm{D}\left(977 \mathrm{~K}, 1300^{\circ} \mathrm{F}\right)$ temperatures are exceeded for undegraded RVACS performance. Its performance under nominal conditions must be further verified, although independent analysis indicates that the RVACS will perform as conceived. Partial blockage of the air pathways via seismic event or sabotage has been postulated, but the RVACS can function even with large blockages. Furthermore, hours would be available to remove blockages during a heatup event.

Leakage of some sodium from the reactor vessel into the containment vessel has been postulated, and this does change RVACS performance in two ways. First, if enough sodium leaks out, the sodium level drops below the height needed for vessel liner overflow. This alters the heat transfer mechanism from the reactor vessel and will affect the RVACS performance. Second, having sodium between the two vessels improves the heat transfer because it partially fills a volume once occupied by a gas. Consequently, the RVACS performance is probably improved by such a leak, as the GE and ANL analyses show. Sensitivity studies will be necessary at a later design stage to assess the effect of leak size and location on the RVACS performance and the potential to produce hot spots in the reactor vessel. Finally, fouling of the heat transfer surface from sodium fires or dirt or corrosion appears not to be a major problem, as performance margins are very large. 


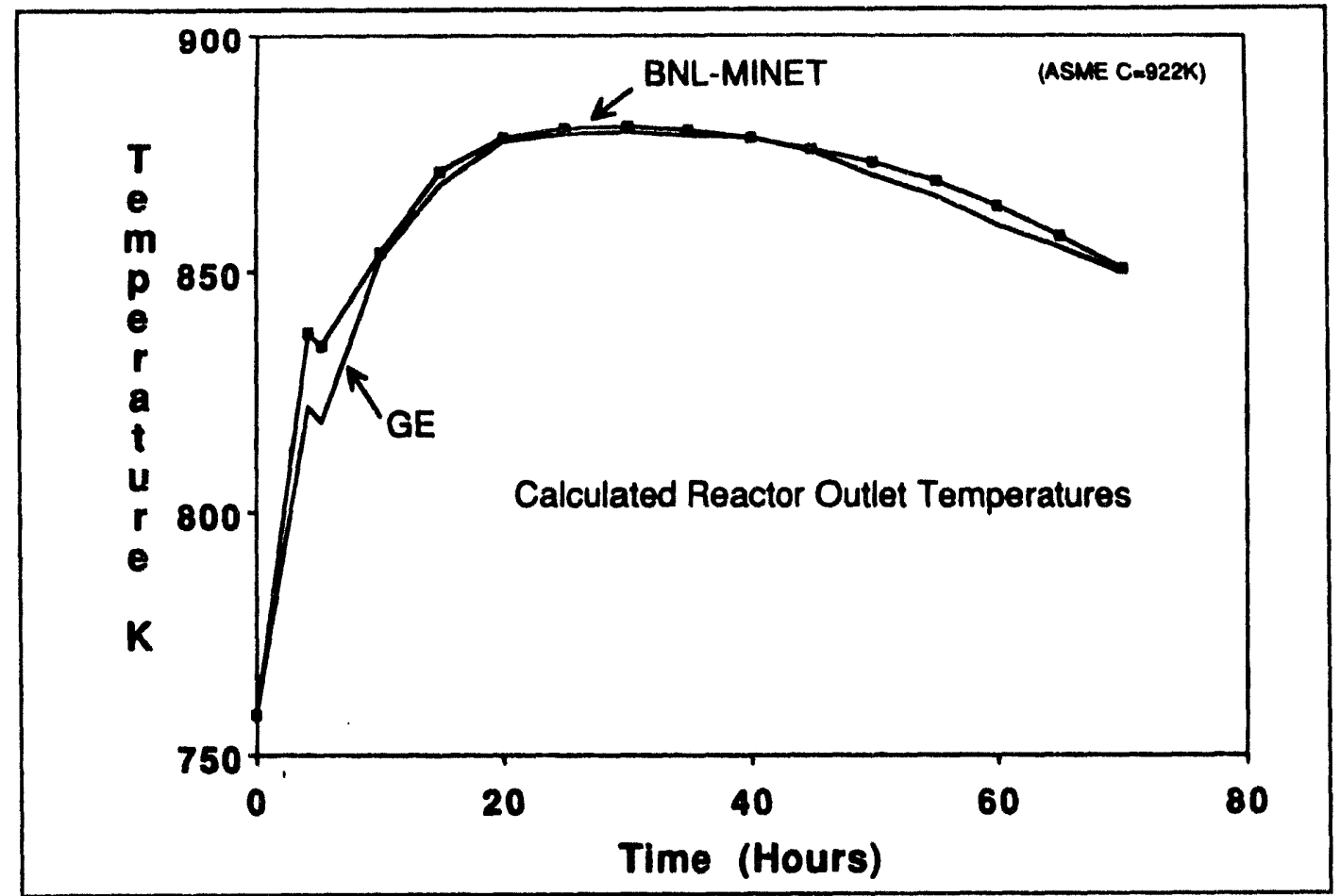

Figure 15.1 PRISM LOHS with RVACS performing normally

Independent analysis indicated that major air flow blockages in the RVACS could be tolerated without getting serious degradation in performance. The findings of an independent study on the sensitivity of RVACS performance are shown in Table 15.5. Comparison with the GE performance findings indicates good agreement. In addition, the sensitivity of RVACS performance to the airflow form loss is shown in Figure 15.2. The GE RVACS performance points are shown to indicate the corresponding form loss for their calculations. Further, the resistance through the airflow ducting was varied parametrically, and it was determined that partial flow blockages had little impact on heat removal (see Figure 15.2).

\subsubsection{Design Criteria}

For this event, GE uses the staff proposed release limits of 10 percent ("small fraction") of the 10 CFR Part 100 dose guidelines would be appropriate.

\subsubsection{Research and Development}

ANL is currently testing large, heated panels to represent the containment vessel and collector panel walls of
RVACS. Tests of the RVACS are also part of the PRISM Safety Test Plan.

\subsubsection{Safety Issues}

RVACS is a major factor in the overall safety of the PRISM reactor system, so close scrutiny is justified. Analyses performed to date indicate that the GE findings presented in this section are reasonable and that RVACS can indeed keep PRISM temperatures in an acceptable range during a loss of all cooling features other than RVACS. However, recovery actions from this event need to be developed to avoid thermal shock to the primary system upon recovery of forced circulation and normal decay heat removal.

\subsubsection{Conclusions}

The analysis shows that RVACS has the potential to remove PRISM decay heat effectively. As the GE parameters were judged to be conservative, it is likely that both GE and staff calculations underestimate RVACS performance. Further confirmation from the R\&D program and more detailed analysis will be required in later reviews, as RVACS is a key safety system in the PRISM design. 
Accident Analysis

Table 15.5 PRISM RVACS performance

\begin{tabular}{||l|c|c|c|c|c||}
\hline Parameter & \multicolumn{4}{|c|}{ PASCOL } & GEFR-00776 \\
\hline \hline Emissivity & 0.5 & 0.7 & 0.86 & 0.999 & 0.7 \\
\hline $\mathrm{Q}(\mathrm{Mw})$ & 1.86 & 2.45 & 2.85 & 3.21 & 2.42 \\
\hline $\mathrm{W}(\mathrm{kg} / \mathrm{sec})$ & 24.2 & 26.0 & 27.0 & 27.8 & 25.9 \\
\hline $\mathrm{T}_{\text {Our }}-\mathrm{T}_{\mathrm{IN}}\left({ }^{\circ} \mathrm{C}\right)$ & 75.1 & 92.2 & 103.2 & 113.4 & 91.7 \\
\hline
\end{tabular}

Notes: RVACS performance during decay heat removal operation as a function of steel emissivities $\left(\mathrm{K}_{\mathrm{IN}}=\mathrm{K}_{\mathrm{EX}}=4.0\right)$.

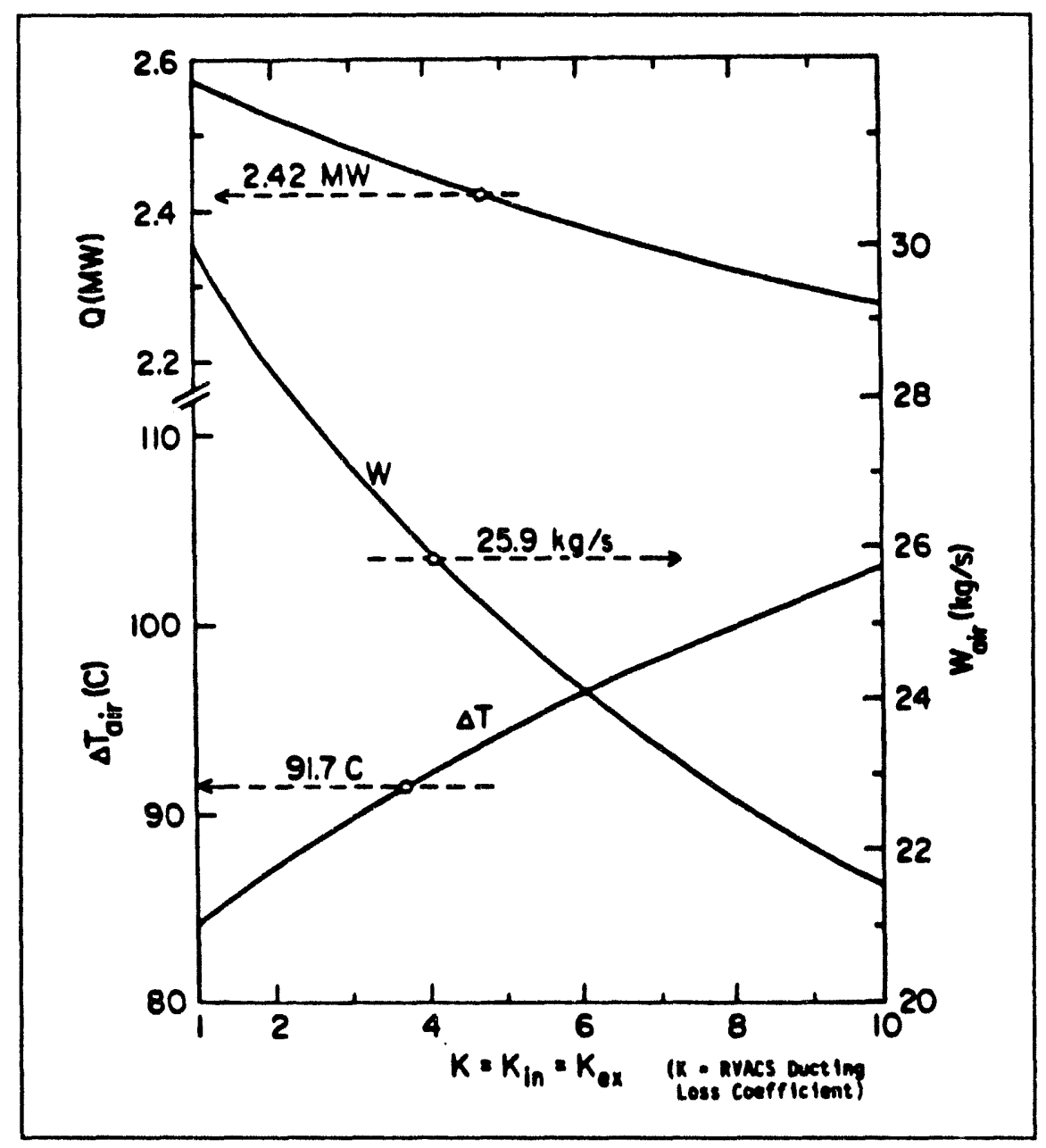

Figure 15.2 RVACS parametric study on air flow resistance 


\subsubsection{Fuel Failure (Local Fault) T'olerance}

\subsubsection{Design Description and Safety Objectives}

A combination of design features is described in order to minimize the possibility of local fuel failures and failure propagsion, and to detect failed fuel elements. These features include

(1) manufacturing quality assurance practices to prevent enrichment errors, oversized fuel elements, and bond defects

(2) various identification and discriminator schemes, along with monitoring and inventory control, to prevent mispositioning of fuel assemblies to forestall abnormal heat generation

(3) the metal-fuel concept given a demonstration of a reliable fuel with minimal failures $(0.01$ percent of equilibrium core)

the metal-fuel concept to provide good compatibility of sodium and fuel in the event of a cladding breach

(5) the high conductivity of the fuel element to minimize local temperature gradients due to geometric distortions or local accumulation of debris

the high thermal conductivity of the sodium, which is believed (in combination with other factors) to minimize or eliminate the possibility of pin-to-pin failure propagation as a result of the release of fission gas

(7) fission gas, tag gas, and delayed neutron monitoring for rapid detection/location of failed fuel elements

\subsubsection{Scope of Review}

The staff directed its review toward establishing the plausibility of the basic arguments presented by GE. The subassembly hardware was reviewed with respect to the question of mispositioning and the potential for subassembly flow blockage. The basic known properties of the metal-fuel system were assessed with respect to the expected reliability of the fuel and the potential for its insensitivity to local faults. Designs for the failed fuel monitoring system and the features utilized to prevent mispositioning of the core assemblies were not reviewed in detail at this stage of the design review. Such features are state of the art (i.e., used on Fast Flux Testing Facility (FFTF) and Clinch River Breeder Reactor) and they are not expected to be major areas of concern in the safety of the advanced LMR concepts.

\subsubsection{Design Criteria}

For these events, GE uses the staff proposed release limits of 10 percent ("a small fraction") of the 10 CFR Part 100 dose guidelines would be appropriate.

\subsubsection{Research and Development}

The ongoing IFR program, also known as the ANL metalfuels program, will continue to produce data on failed fuel.

\subsubsection{Safety Issues}

The status of development of the metal-fuel system is discussed in Section 4.2 of this report. The success of quality assurance (QA) programs with respect to manufacture of the ternary fuel has yet to be established. Similarly, HT-9 is a relatively new cladding material. Manufacturing and fabrication technologies are, therefore, relatively new. It follows that the staff must treat cluims about $\mathrm{QA}$ at this point as a case that has yet to be made. Research, however, is in progress, and there appear to be no major obstacles toward providing the requisite $Q A$ programs.

A basic contention of the PRISM PSID is that the PRISM design will have a highly reliable fuel system. It is argued that the number of fuel failures to be expected during normal operations is less than one per year $(0.01$ percent of equilibrium core). The statistical data base required to establish this case for the ternary fuel and PRISM fuel element design has yet to be established. A strong program of fuel irradiation is planned as part of the IFR program. The conversion of Experimental Breeder Reactor EBR-II to the ternary fuel and irradiation tests in FFTF will provide substantial experimental information. Research is in progress, and information is expected to be forthcoming.

The available evidence to date suggests that the metal fuel and sodium coolant are chemically compatible. Operation with failed fuel elements has not led to the observation of delterious behavior. No major corrosion or erosion processes were detected. The planned program of fuel irradiation will furnish additional data in the run-beyondcladding-breach experiments.

The arguments related to pin-to-pin propagation due to fission gas release are plausible. No independent calculations were done by the staff to substantiate the conclusion that no pin-to-pin propagation is expected. The fuel irradiation data base that will be accumulated in the 
coming year will provide additional possibilities of observing rapid gas release upon fuel element failure. Thus, far, the experience in EBR-II has led to no such observations.

The argument has been made that the metal-fuel system is relatively insensitive to such local fault conditions as bond defects or local deposition of debris. This argument is plausible because of the high conductivity of the metal fuel. However, the low fuel-clad eutectic temperature raises some doubts as to whether the metal fuel is so highly insensitive to local faults. Experiments are planned in the fuels irradiation program to gain additional data relevant to the question of local fault accommodation.

It has been argued that the likelihood of a complete subassembly blockage is extremely small. This is probably true for blockages caused by in-core debris. However, the staff believes that the potential for a fabrication error resulting in a blocked or partially blocked assembly exists, and subsequently, for the assembly getting inserted into the core, is credible within the EC-III event category. Accordingly, BE-7 for the PRISM design has been identified-the insertion of a blocked fuel assembly. The response of PRISM to this event is of concern because of the potential for sodium boiling, fuel motion, and a resulting positive reactivity feedback accident. In addition, previous work has not demonstrated that subassembly-tosubassembly failure will not propagate under such conditions. The current PRISM design does not have instrumentation to detect in-core flow blockages.

\subsubsection{Conclusions}

The review has focused on several design features that are implemented to minimize the occurrence of local faults and to ensure that local faults will be detected. Research in progress will provide experimental data to verify the local fault accommodation arguments presented by GE. The high conductivity of the fuel and the apparent compatibility of fuel and sodium lead to a good possibility of verifying the GE positions. It is also noted that the fuel-clad eutectic temperature is relatively low, so that some concern is warranted. At elevated temperatures, the HT-9 cladding begins to interact with the fuel to form a low-melt eutectic. The eutectic depends, in part, on the composition of the fuel in the outer radial zone, which in turn depends on the burnup level and the amount of component migration in the ternary metal fuel. It appears possible for significant eutectic formation to develop at temperatures as low as $903 \mathrm{~K}\left(1,165^{\circ} \mathrm{F}\right)$, which, if confirmed, would indicate some cladding damage during several postulated events. Recently obtained data from a high-burnup test pin, with a high linear heat generation rate (greater than the PRISM design value) suggests that the eutectic limit may be even lower, at least under some circumstances. The current irdication of eutectic formation value being used is $980 \mathrm{~K}$ $\left(1,300^{\circ} \mathrm{F}\right)$. A large research program is in progress and is expected to produce the relevant data. Flow blockage of a fuel assembly (due to fabrication error) remains a concern and could, in the present PRISM design, lead to fuel melting, sodium boiling, and the potential for an energetic reactivity accident and, as such, remains a concern. GE has developed a startup testing procedure to detect a blocked assembly before the power level is raised following refueling of the core, as discussed in Section 4.4.8.4 of this report.

\subsubsection{Primary Sodium Spills}

\subsubsection{Design Description and Safety Objectives}

GE analyzed a postulated primary sodium cold trap leak. The primary sodium service clean up system services one reactor at a time and cannot be activated unless the reactor has been shut down for at least 3 days. The DBA assumes that the entire cold trap primary sodium inventory of $3,785 l,(1,000$ gallons $)$ is spilled on the floor of the vault, which contains catch pans to mitigate sodium fires.

It was assumed that the reactor was operating with two failed pins. It was assumed that all of the fission products and $\mathbf{0 . 0 1}$ percent of the transuranics from the failed pins leak into the sodium and become uniformly dispersed in the coolant. On the basis of LWR experience, GE assumed a leakage rate from the fuel equal to $1.3 \times 10^{-8}$ $\sec ^{-1}$ for iodine and particulates. GE assumed sodium activity concentrations at the time of the accident equal to $4.7 \times 10^{-6} \mathrm{Ci} / \mathrm{cc}$ for $\mathrm{Na}-22$ and $0.031 \mathrm{Ci} / \mathrm{cc}$ for $\mathrm{Na}-24$, but offered no justification. It was also assumed that $3785 l$ $(1,000$ gallons) of primary sodium are in the cold trap when the spill occurs.

GE assumed that 95 percent of the spilled sodium was caught in the catch pans, 20 percent of the caught sodium burns, and 25 percent of the burning sodium becomes airborne. This airborne 4.75 percent is added to the 5 percent that is not caught, for a total of 9.75 percent airborne sodium. The activity in the cold trap is estimated to be $4,290 \mathrm{Ci}$ and the activity that becomes airborne is estimated to be $418 \mathrm{Ci}$. More than 99 percent of this activity is $\mathrm{Na}-22$ and $\mathrm{Na}-24$. The resultant doses computed at the site boundary for the whole-body riskequivalent dose is $0.69 \mathrm{rem}$. All doses are well below the 10 percent of the 10 CFR Part 100 dose limits.

\subsubsection{Scope of Review}

This area has not been reviewed in detail, but will be evaluated at a later stage in the design review when 
supporting design details and the findings from the R\&D program concerning source terms are completed.

\subsubsection{Design Criteria}

For this event, GE uses the staff proposed release limits of 10 percent ("small fraction") of the 10 CFR Part 100 dose guidelines would be appropriate.

\subsubsection{Research and Development}

Sodium fires have been thoroughly investigated in the past and analysis of heat and aerosol generation is well characterized. A more difficult question is the amount of fission products leaked into and retained by the sodium; the ongoing metal-fuel program will add to this data base.

\subsubsection{Safety Issues}

GE examined the obvious issue: What radioactive release would be expected from a cold trap spill? The source term associated with this DBE is small.

A second safety issue is whether postulated sodium fires can cause damage to key safety systems. GE has analyzed potential fouling of the RVACS surfaces and determined that it does not seriously degrade performance. As the design evolves further, this question should be examined more closely.

\subsubsection{Conclusions}

Unless the PRISM metal-fuel performance (fuel pin failures in an equilibrium core) is far worse than expected, this event is unlikely to result in a major release to the environment. As the design matures, this event should be examined further, particularly with respect to possible damage to safety systems resulting from sodium fires. It should be noted, however, that if the designers of PRISM incorporate state-of-the-art sodium fire detection and mitigation systems, the likelihood of a problem in this area should be minimized.

\subsubsection{Fuel-Handling and Storage Accidents}

\subsubsection{Design Description and Safety Objectives}

Each fuel assembly is stored within the reactor vessel for 20 months before it is removed. This allows decay heat generation in any given assembly to drop to levels at which dry handling is possible. The average power level from a given fuel assembly will be $600 \mathrm{~W}(1.2 \mathrm{~kW}$ maximum). A loss-of-coolant accident (LOCA) like the one that occurred at Chalk River, Canada, at the NRU reactor in May 1958, is not credible for this procedure, since the handling cask is passively cooled. The maximum fuel pin cladding temperature is predicted to reach $672 \mathrm{~K}\left(750^{\circ} \mathrm{F}\right)$ during the transfer.

The onsite fuel transfer is accomplished within a portable, passively cooled cask that is permanently attached to a rail cask transporter. The cask transporter can raise and lower the vertically held cask and also has a gate valve that allows it to seal to either the reactor vessel fuel transfer port or the adaptor at the fuel cycle facility. The onsite self-propelled fuel cask transporter is moved back and forth on tracks between the reactor and the fuel cycle facility (FCF). The cask is designed to withstand such events as the tornado-generated missile and the safe shutdown earthquake (SSE). Therefore, the leaking cask containing failed fuel pins is the limiting accident anticipated.

\subsubsection{Scope of Staff Review}

The staff reviewed this postulated accident with GE, DOE, and ANL personnel. The review concentrated on the assumptions and plant design features that affect the consequences of this event.

The assumed accident is a case in which five fuel pins within the cask fail as their temperature climbs from the $477 \mathrm{~K}\left(400^{\circ} \mathrm{F}\right)$ refueling temperature to $672 \mathrm{~K}\left(750^{\circ} \mathrm{F}\right)$ in the transfer cask. The failed pins leak their fission gases into the cask. The cask gate valve fails to properly seal, thereby allowing leakage. A leak of 5 percent/day is assumed. The resultant activity releases are calculated to be well below the 10 percent of 10 CFR Part 100 dose criteria.

\subsubsection{Design Criteria}

For this event, GE uses the staff proposed release limits of 10 percent ("small fraction") of the 10 CFR Part 100 dose guidelines would be appropriate.

\subsubsection{Research and Development Programs}

No R\&D program is needed for the fuel handling procedure. However, the reactor refueling system will be evaluated more thoroughly at a later design stage and during the safety test program.

\subsubsection{Safety Issues}

The major safety issue related to any part of the fuelhandling procedure is its potential to cause a significant release of radioactivity in the facility. The procedure described here calls for the spent fuel to remain inside the reactor vessel for 20 months. This means the decay heat 
generation in each assembly will be low when the fuel is being handled. This requirement also allows the fuel to be passively cooled in the cask, greatly reducing the risk of having a fuel failure.

\subsubsection{Conclusion}

The requirement of leaving spent fuel assemblies in the reactor vessel for almost 2 years makes handling the spent fuel less likely to result in releases due to fuel overheating. This also makes many aspects of the fuel handling easier. The method of moving the spent fuel between the reactor vessel and the fuel cycle facility by a self-propelled cask transporter should minimize the exposure to plant personnel.

\subsubsection{Other Design-Basis Events (Cover Gas Release)}

\subsubsection{Design Description and Safety Objectives}

The portable cover gas system services one PRISM reactor module at a time. Its first operation is to remove most of the cover gas from the reactor module via vacuum pumps and compressors that transfer the contaminated helium cover gas to a portable transfer tank before filling the evacuated cover gas space with clean helium. The activated cover gas is eventually transferred to the fuel cycle facility for processing before its reuse or release.

The postulated cover gas release accident is the nonmechanistic failure of a pipe or valve that releases the radioactive cover gas directly to the environment. The plant is assumed to have been operating 20 months preceding the accident at the technical specification limit of two fuel pin failures. It is also assumed that an additional fuel pin fails at shutdown, releasing all of its activity. The activity released from the fuel is assumed to be held in the sodium coolant except for the noble gas isotopes, which accumulate in the cover gas. The cover gas system is assumed to service the reactor 5 days after refueling shutdown.

The equilibrium cover gas activity, the activity from one additional failed pin, and the total activity released are $136.7,649.4$, and $725.2 \mathrm{Ci}$, respectively. GE adjusted the equilibrium cover gas activities by 5 days of radioactive decay before adding the contribution from the third failed pin (already decayed by 5 days) to calculate the total activity released. The resultant exclusion area boundary, whole-body, risk-equivalent dose is estimated to be about 6 mrem. The GE calculated doses are well below the 10 CFR Part 100 limits.

\subsubsection{Scope of Review}

This event was not reviewed in detail for this preapplication safety evaluation report. The refueling process and its associated risks will be evaluated further at a later stage in the design review.

\subsubsection{Design Criteria}

For a design-basis event, GE uses the staff proposed release limits around 10 percent ("small fraction") of the 10 CFR Part 100 dose guidelines.

\subsubsection{Research and Development Needs}

To date, the ANL work on metal fuels has not been focused on source-term aspects. ANL has arguments as to why only noble gases would reach the cover gas, but the lab may need to strengthen its arguments and develop supporting data through R\&D programs for future licensing activities.

\subsubsection{Safety Issues}

Although the cover gas release does result in an offsite dose, it is very small. As long as ANL can establish that only noble gases can normally reach the cover gas and that only two or three fuel failures are likely, this event is not likely to be a major safety concern.

\subsubsection{Conclusions}

As long as it can be shown that only noble gases are involved in a release of the cover gas, this event is not expected to be a major safety concern. Release of the cover gas is likely to result in a small release of radio. active gases.

\subsubsection{Bounding Events}

\subsubsection{Design Description and Safety Objectives}

The PRISM design has been described as passively safe. On this basis, the designers contend that core melt and sodium boiling do not have to be considered in the design. The staff has required analyses of a set of bounding events (Table 15.1) to ensure that a sufficiently challenging set of events is considered in assessing the acceptability of the design and in determining whether or not the PRISM design can be considered to have a level of safety at least equivalent to that of current-generation LWRs. 
The staff developed the bounding events (BEs) to take into consideration the uncertainties associated with the design, equipment reliability, and initial stages of supporting R\&D. The BEs address the following categories of events: reactivity additions, reactivity-insertion failures, heatremoval failures, sodium-water reactions and sodium fires, and external events (e.g., earthquakes and floods).

GE issued its response to the list of BEs in Appendices FE and $G$ to the PRISM PSID. The GE response includes probabilistic and deterministic analyses. The staff also performed independent analyses of selected boundary events, as presented in Appendix B of this report. A summary of the GE and staff analyses of the bounding events appears there.

\subsubsection{Scope of Ruview}

\section{BE-1: Unprotected Transient-Overpower(UTOP) Events}

The UTOP bounding events are addressed in Sections B.2.1, B.2.2, and B.3.4 of Appendix B to this report.

\section{BE-2: Station Blackout}

The loss of power and station blackout bounding events are addressed in Sections B.2.3 and B.3.5 of Appendix B to this report.

BE-3: Unprotected Loss of Heat Sink (ULOHS) Events

The ULOHS bounding events are addressed in Sections B.2.3 and B.3.6 of Appendix B to this report.

\section{BE-4: Unprotected Loss of Flow (ULOF) Events}

The ULOF bounding events are addressed in Sections B.2.5 and B.3.7 of Appendix B to this report.

\section{BE-5: Steam Generator Tube Rupture Event}

Liquid-metal reactor designs using a steam cycle for power production have had a sodium-to-water heat exchanger and that presented the potential for sodium-water chemical reactions. In the original PRISM design, GE proposed a double-wall tube steam generator, a quick-acting steam/water isolation and blowdown system, sodium side rupture disks, an IHX design pressure of $6,895 \mathrm{kPa}$ (1,000 psi), and intermediate loop sodium on the tube side of the IHX, thus isolating the IHX tube support plates from the pressures generated during a sodium-water reaction. The PRISM design provides significant protection against sodium-water reactions.
BE-5 includes ruptures of a "justifiable" number of steam generator tubes combined with failure to isolate or dump water from the steam generator. GE submitted a mixed quantitative/qualitative analysis of such an event. GE concluded that even under worst-case assumptions (assuming all tubes fail), the pressure in the IHX should remain below 4,826 kPa (700 psi).

Because the applicant has substituted a helical-coil singlewall tube steam generator for the older straight double-wall tube model, much of the analysis regarding possible sodium-water reactions has changed significantly from the previous design. The newer single-wall tubes are thought to be more likely to fail, but there is a design feature (central conduit) in the new unit that should help to mitigate such an event.

The major objective is to protect the IHX, which forms a boundary of both the primary coolant system and the containment system. The secondary sodium passes through the IHX tubes, and the applicant claims that a $6,895 \mathrm{kPa}(1,000 \mathrm{psi})$ pressure pulse (generated in the steam system from the steam generator tube failure) could be absorbed safely. The objectives in protecting the IHX are to prevent a larger pressure pulse and to prevent the sodium-water interface from passing into the IHX, where the ongoing chemical reaction could cause damage at the IHX tubes.

The IHTS isolation valves form one line of defense, as their closure, would protect the IHX from both pressure pulses and the sodium-water interface. These valves will be safety-grade and since they are active components, there is some concern regarding the level of reliability that can be ensured. These valves are provided for containment isolation.

The more reliable (and far more complex) defense comes from the passive rupture disks. Because of the rupture disks, the dump tanks, and some steam flow limiters, a large-scale sodium-water reaction can be accommodated without a major pressure buildup. The challenge is to ensure that the sodium-water interface cannot reach the IHX. As the reactions are developing in the steam generator, the pressure builds, and pushes the sodium level up into the argon cover gas in the top of the steam generator. Once the sodium level gets high enough, the sodium spills into a central conduit, which bypasses the helical coil tubes and lets out near the rupture disks. Because of this bypass feature, the sodium in the steam generator can be driven through the rupture disks without the argon cover gas pressure getting too high. Since any sodium in the lower portion of the steam generator and most of the sodium between the pump and the bottom of the steam generator will exit through the rupture disks, it 
is only the sodium-water mixture in the top of the steam generator that is a concern with respect to possibly passing into the IHX. Some of the sodium-water interface could push upward from the argon cover gas and back into the piping coming from the IHX (the hot leg). This would involve pushing sodium upward from the IHX to the IHTS pump, from which it would flow downward toward the rupture disks. Whether or not this could happen depends partly on the pressure differentials in the IHX and the IHTS. It seems fairly clear that one could design the piping to prevent this possibility, as long as the pressure drop through the steam generator is kept to reasonably low levels (which the conduit appears to accomplish).

Therefore, there appear to be two fairly reliable means to prevent a large sodium-water reaction from compromising the IHX tubes. However, one factor that seems to be at odds with a normal safety approach is the use of sequential (redundant) rupture disks (both must function for the drain process to begin). From a safety viewpoint, two parallel rupture disks would increase the likelihood of achieving a timely dump of the sodium. However, rupture disks tend to open at lower than designed rupture pressure rather than to remain closed above the design rupture pressure. Therefore, the applicant proposes sequentially redundant rupture disks to ensure they do not open by mistake and allow expulsion of the IHTS sodium. Still, the proper opening of the rupture disks is very important in responding to a large sodium-water reaction, so the staff recommends GE consider some parallel redundancy in the design as well.

The protection against the results of sodium-water reactions appears to be largely satisfactory, although some closer examination is advisable as the design matures. The designer's choice to use sequentially redundant rupture disks but not parallel-redundant rupture disks helps to prevent the inadvertent dumping of the sodium in the intermediate loop, but does not help in assuring the disks will open if a large reaction takes place.

\section{BE-6: Large Sodium (Na) Leaks (Single Module)}

Because PRISM is a pool-type system with primary system piping (extending only from the pump outlets to the reactor inlet plenum) completely within the reactor vessel, a primary loop pipe break is not a leak in the conventional sense, but, is rather, a flow short-circuit.

Leakage/breaking of an intermediate loop pipe could lead to a loss of IHTS inventory and to sodium fires. Given that RVACS performs the safety-grade heat-removal function and does not require the intermediate loop to function, the loss of IHTS inventory is not crucial to decay heat removal. Sodium fires can be a problem, but PRISM should employ state-of-the-art sodium fire mitigation systems. The most interesting question here is whether a major sodium fire could effectively foul the RVACS heattransfer surfaces and degrade performance. GE and ANL stated that they examined this question and determined that even if all of the combustion products plated out on the RVACS walls, the RVACS heat removal would still be adequate. This was not independently verified.

Finally, a leak of sodium from the reactor vessel into the gap between the two vessels results in a drop in sodium level and better heat transfer between the vessels. PRISM has been designed so that a leak of sodium into the gap leaves the sodium level in the reactor vessel above the IHX inlet ports, allowing continued sodium circulation in the primary system. Since the improved heat transfer between the vessels would help RVACS performance, it is likely that GE's claim that peak system temperatures under RVACS-only cooling are lower with a reactor vessel leak is probably correct.

\section{BE-7: Flow Blockage}

The event at the Fermi plant in 1966 involved a piece of zirconium liner that had broken loose and mo'el into the core inlet region, creating a partial flo "' b'cckage that caused fuel damage and might have led $t$ " much more serious event. As a result, the PRISM core let region is designed to prevent such a blockage. Awout the only means of developing a comparable blockage would require a piece of flexible material, such as aluminum foil, and would require a complete wrapping of that material 360 degrees around an assembly inlet. It is difficult to consider such a development as being even remotely possible.

The concern raised by the staff regarding PRISM is a manufacturing defect that might leave an assembly without the slots that allow the sodium to pass into the assembly. While unlikely, it is possible. The key point in the applicant's response is that the defect would be detected before the reactor was taken to full power, and that at low power any reactivity addition resulting from sodium voiding or fuel slumping could be accommodated without a major accident resulting. This response seems reasonable, assuming the applicant ensures that the proper instrumentation and procedures are used, but it also seems to indicate a shift in policy. In the past, the applicant has chosen to deemphasize the role of the operator in assuring the safety of PRISM, but in this case the applicant is indicating a reliance on a person or on a safety system (or on both) to detect a problem and to keep the problem from becoming much more serious. 
Flow blockage of a fuel assembly (due to fabrication error) could, in the present PRISM design, lead to fuel melting, sodium boiling, and the potential for an energetic reactivity accident and, as such, remains a concern. The fuel manufacturing QA program will need to be reviewed at a later stage in the design review. GE has developed a startup testing procedure to detect a blocked assembly before the power level is raised following refueling of the core, as discussed in Section 4.4.8.4 of this report.

\section{BE-8: External Events}

GE has not responded to $B E-8$, presumably because the phrase "consistent with those imposed on LWRs" left this item open ended.

For a reactor design utilizing a maximum degree of passive safety (and PRISM relies largely on passive safety), the likelihood of internally initiated events leading to core melts or to large releases will probably not dominate the risk. Thus, one would ultimately expect to find external events dominating the risk associated with passively safe reactor system designs. Therefore, while BE-8 remains undefined and GE did not respond to the staff's question, this is likely to be a major factor in the long-term evaluation of advanced reactors in general and PRISM in particular. It should be noted that GE has included in the design seismic isolators to provide a margin for earthquakes beyond the SSE.

\subsubsection{Design Criteria}

For a bounding-event sequence, GE use of release limits consistent with the guidelines of 10 CFR Part 100 would be appropriate. However, if reductions in offsite emergency planning are proposed, the release from these events might have to be lower than the 10 CFR Part 100 limits, perhaps more in line with the lower level Environmental Protection Agency (EPA) protective action guidelines (PAGs). For reference, Table 15.6 details the relationship between Appendix I, 10 CFR Part 100, and the PAG doses.

\subsubsection{Research and Development}

Exclusive of the PRA and analyses of the bounding events, there is little discussion of severe accidents and source terms throughout the PRISM PSID. However, for BE-1b, $B E-3$, and $B E-7$ some fuel melting is shown to be possible, and BE-4 and 7 could lead to energetic events. Therefore, if these events cannot be eliminated from EC-IIl by design, many questions regarding fissionproduct retention in metal fuels and sodium, the energetics of the metal fuel during fast transients, and accident progression following fuel melt will need to be answered through the R\&D program. These data would be reviewed at a later stage in the design review.

\subsubsection{Safety Issues}

GE has taken a position on PRISM that (1) a conventional containment structure is unnecessary and (2) ad hoc emergency planning is acceptable. These positions are defended largely through probabilistic arguments. However, the reliability of new and unproven passive systems is very difficult to estimate, particularly when assumed failure rates fall in the $10^{-6}$ range. As a result, the staff has proposed the set of bounding events to bound the uncertainties and to assist in assessing the acceptability of the design. Four of these events have the potential to lead to the release of large amounts of fission products. For BE-1b, a combined UTOP and failure of non-safety-grade cooling systems, a release beginning after only 2 hours is possible. For BE-3, failure of the safety-grade heatremoval system RVACS, a large release would occur in the 24-to-36-hour frame. BE-4 and BE-7 could lead to sodium boiling and possibly to energetic core disruption.

The situation regarding the passive reactor shutdown is far more complex, especially since the flow of data for PRISM-specific ternary metal fuel has only recently begun. ANL will likely obtain the performance that is required, even should adjustments in the fuel composition or density be required. However, the ternary metal-fuel behavior appears to be very complex and there is evidence of some undesirable redistribution of the uranium, zirconium, and perhaps the plutonium components.

Table 15.6 Offsite dose criteria

\begin{tabular}{|l|c|c|c|c|}
\hline & $\begin{array}{c}\text { Appendix I } \\
\text { (rem) }\end{array}$ & $\begin{array}{c}10 \text { CFR 100 } \\
\text { (rem) }\end{array}$ & $\begin{array}{c}10 \% \text { of 10 CFR 100 } \\
\text { (rem) }\end{array}$ & $\begin{array}{c}\text { Lower level PAGs } \\
\text { (rem) }\end{array}$ \\
\hline Whole body & 0.003 & 25 & 2.5 & 1 \\
\hline Thyroid (from Iodine) & 0.010 & 300 & 30 & 5 \\
\hline
\end{tabular}


The greatest challenge, for the current design characterization, appears to be the unprotected transientoverpower (UTOP) event, which boosts fuel centerline temperatures. A 40C initiator may be too large, given the current knowledge of the ternary fuel, and GE may need to adjust the rod stops more frequently so as to reduce the largest transient-overpower (TOP) initiator into the $30 \mathrm{C}$ range.

The main problem with the non-TOP unscrammed events is at the fuel-cladding interface. ANL seems confident that the rate of eutectic formation at the temperatures experienced during the unscrammed events is very slow, so minimal damage is to be expected. However, the behavior of the ternary metal fuel is very complex, and further experimental data will be needed before it can be concluded that the cladding damage will be minimal.

\subsubsection{Conclusions}

The reasonableness of the results of the GE bounding event calculations presented in PSID Appendices $E$ and $G$ have been largely confirmed by independent analyses and are considered credible. Several postulated events were analyzed using independent codes, such as Super System Code (SSC) (Ref. 15.12) and MINET (Ref 15.13). Review of the results indicates that due to the reactivity feedback characteristics of PRISM, there is the potential for the PRISM response to several postulated unscrammed events to be benign and some degree of passive shutdown safety is to be expected.

The recent design revisions have been quite significant. The increase in reactor power (for economic reasons) may have reduced some safety margins. Some changes were also required to compensate for a more current assessment of the ternary metal fuel. These changes include a reactor redesign, and the addition of the GEMs and the control rod stop system.

As a result of these changes, it is believed that the PRISM system design has been improved, but that a more detailed evaluation of the ternary metal fuel has revealed some significant problems. It must be recognized that the ANL experience with the high plutonium ( 26.5 percent) ternary metal fuel has been quite limited, and that some problems should be expected. It is expected that the R\&D program will address current issues about plutonium migration and low eutectic temperatures.

The addition of the GEMs appears to have improved the passive shutdown for the unprotected loss-of-flow (ULOF) events (BE-4). As long as there is at least a partial coastdown provided by the synchronous machines, PRISM would survive the ULOF category events. The EM pump coastdown machines are a critical safety feature and a high likelihood of successful operation must be demonstrated.

The PRISM passive shutdown has always appeared to perform well for the ULOHS events (BE-3), and nothing has changed significantly with the revised design. If there are problems here, they will develop only if the event continues for a long time, and the addition of the ultimate shutdown system makes this very unlikely.

\subsubsection{Hypothetical Core Disruption Accident (HCDA)}

\subsubsection{Design Description and Safety Objectives}

The containment concept originally developed for PRISM was unconventional, which may be expected given the differences between PRISM and current LWRs. There are several contributing factors. The sodium coolant system is at low pressure under normal operating conditions, so the need to use a large containment to absorb stored energy from a massive LOCA is not present. There are major advantages associated with keeping the core covered with sodium, so there is a strong desire to build a guard/containment vessel system to catch any leaks within a relatively small volume and ensure that the sodium level will not fall too low. With sodium in the reactor vessel and a moderate power production in the reactor, a natural draft air-cooling system capable of removing afterheat can be designed, assuming that outside air can be brought into proximity with the reactor vessel. As a result, the applicant's original containment concept for PRISM bore little resemblance to containments designed for conventional LWRs.

In trying to convince the staff that its original concept was appropriate for the PRISM containment, the applicant relied heavily upon the argument that the chance of a major accident and radioactive release was very small. Although these arguments had merit, there remains too much uncertainty regarding the metal fuel (among other things) for these arguments to be completely persuasive. As a result of these concerns, the applicant chose to upgrade the PRISM containment. The revisions fall into three categories. First, provisions were added to "ensure that none of the Event-Category III (EC-III) bounding events of concern leads to core damage or sodium boiling, "; that is, the improvements were intended to limit the probability of such accidents to less than $10^{-6}$ (1 chance in 1 million) per plant-year. Second, design features were added to ensure the vessel and vessel closure would resist core melts and possible HCDAs. Third, GE added a containment dome above the head access area (HAA) and added isolation valves in the IHTS, trying to ensure that the probability of a 1-rem radiation dose at the site 
boundary over a 36-hour period following a severe accident is less than $10^{-6}$ per plant-year.

It is noted that the revised containment concept is still consistent with the objectives pointed out above, i.e., it is still relatively small and is consistent with natural draft aircooling the vessel. Further, it may be the correct concept for the PRISM design, depending on whether it could, in fact, withstand postulated HCDA events.

GE described the assumptions used in specifying the system and the accident scenario for the containment evaluation. A key assumption regarding the sodium fire is that the sodium pool is in direct contact with the containment atmosphere, which should give a maximum rate of burning. The assumed containment dome leak area is 0.0005 in. ${ }^{2}$, resulting from an unknown failure in the upper head structures (rotatable plug).

\subsubsection{Scope of Review}

GE sponsored calculations by the Westinghouse Hanford Corporation (WHC) to analyze the containment system performance during the proposed design-basis event (the HCDA and sodium fire), using the CONTAIN Code (Ref. 15.14). While Hanford staff members had experience using the CONTAIN Code for this type of application (for FFTF), they relied upon the people who developed the CONTAIN Code at Sandia National Laboratory for up-to-date versions of the code, as well as updated input descriptions. An incorrect data specification led to what appears to have been a relatively small and conservative error in the CONTAIN results included in Appendix G of the PSID. The impact of this error is discussed in Section 15.6.8.6.

The CONTAIN Code was used to predict conditions within the containment dome and the quantities of the various isotopes released from the containment during the several hours of transient time analyzed. Since the CONTAIN Code does not include the capability to calculate the radiological consequences of any release from the containment, GE used the SMART (Ref. 15.15) Code to estimate the radiological consequences of the releases predicted by CONTAIN.

Because of the large uncertainties associated with both the size of the possible HCDA initiator and the behavior of the fission products in the fuel and in the sodium pool, the staff did not commit major resources to evaluating this event in detail. However, the impact of a large sodium fire on the containment is of interest and enough is known about the system design and the phenomena involved to make its analysis significant and credible. Therefore, a scoping study was undertaken by the staff to determine whether that portion of the CONTAIN analysis appears to be correct, what the impact on the containment might be, and how the predictions depend on key assumptions in the analysis.

A modified Bethe-Tait (Ref. 15.16) core disassembly model was developed for the analysis of the PRISM design (Ref. 15.17). The purpose of this analysis was to compare the HCDA potential with the $500-\mathrm{MJ}$ assumption used by GE for the maximum energy imparted into the coolant system in the PRISM HCDA capability analysis.

\subsubsection{Design Criteria}

It is difficult to come up with a reasonable source term for the advanced liquid-metal reactor (ALMR) (PRISM). Initially, the applicant argued that the chances of an HCDA or a core melt were so low that only some minor release should be assumed as a design-basis event. After considerable discussion, the applicant has now moved toward using a source term based on a substantial HCDA that triggers a major sodium fire in the containment dome.

GE added a containment dome above the HAA and added isolation valves in the IHTS, trying to ensure that the probability of a 1-rem radiation dose at the site boundary over a 36-hour period following a severe accident is less than $10^{-6}$ per plant-year.

\subsubsection{Research and Development}

The R\&D needs are related to the metal-fuel development program (i.e., IFR program) and include the fuel axial extrusion process which limits the energy resulting from the HCDA. The behavior and transport of the fission products from the fuel pins, through the sodium coolant and cover gas region, into the containment dome, and finally into the environs is also under investigation as part of the IFR program.

\subsubsection{Safety Issues}

A modified Bethe-Tait (Ref. 15.16) core disassembly model was developed for the NRC by BNL for the analysis of the PRISM design (Ref. 15.17). The model was applied over a range of reactivity insertion from $\$ 10 / \mathrm{sec}$ to $\$ 2,000 / \mathrm{sec}$, to determine maximum peak pressures, temperatures, and energies during postulated HCDAs. The energy release was calculated as the work potential of the adiabatic expansion of the metal-fuel vapor generated during the event. This relationship is shown in Figure 15.3. With this plot and the knowledge that GE has tentatively rated the PRISM reactor vessel at $500 \mathrm{MJ}$, 


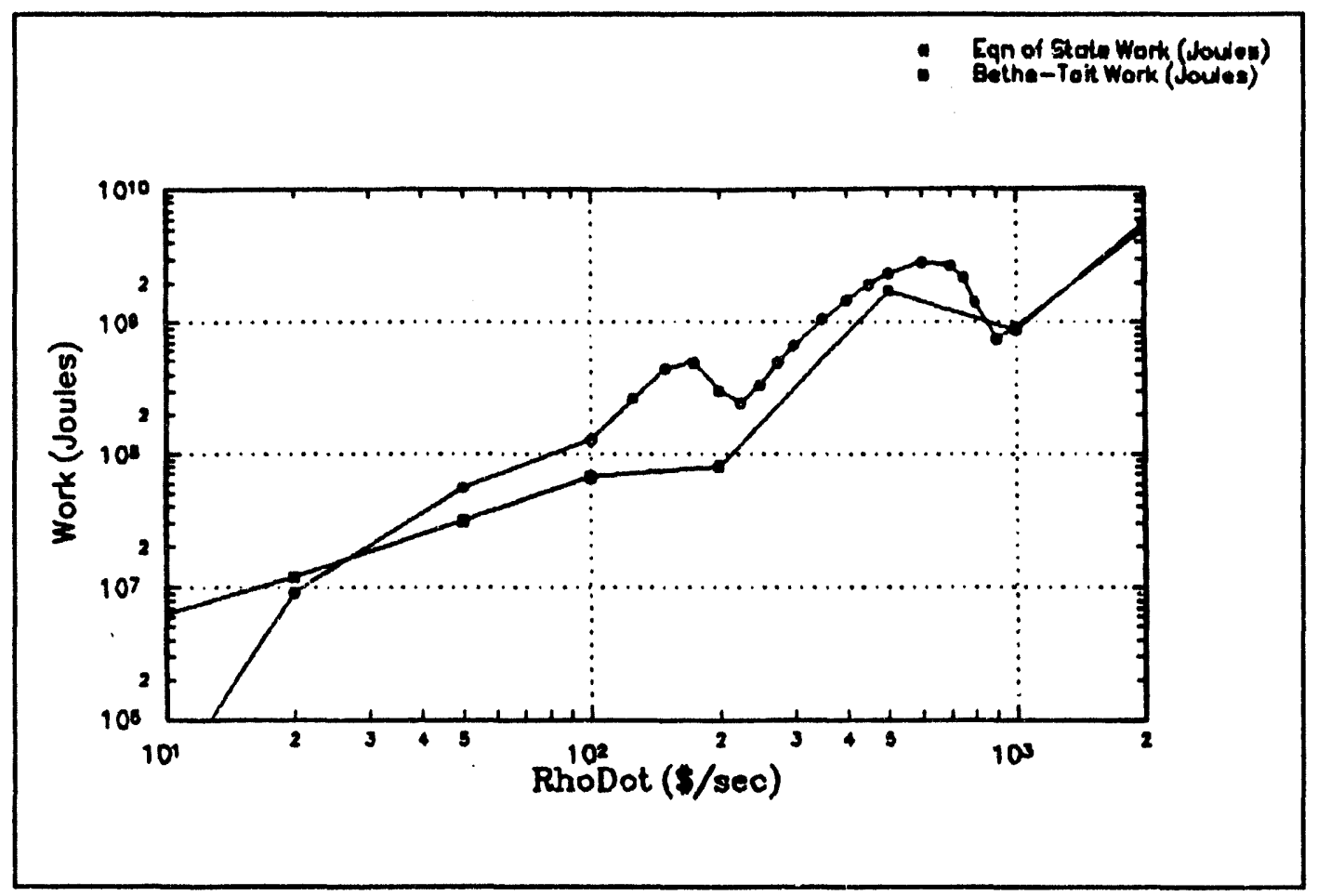

Figure 15.3 Predicted adiabatic expansion work versus reactivity insertion rates for a metal-fuel
core

the BNL analysis indicates that this corresponds to a reactivity insertion rate of $\$ 185 / \mathrm{sec}$. This maximum rate can be used to assess the margin to reactor vessel failure for the two most severe classes of transients that have the potential to develop into HCDAs, the UTOP and the ULOF events.

The UTOP event was predicted to result in an energy release of $190 \mathrm{MJ}$ and the ULOF event produced $160 \mathrm{MJ}$, both less than the $500 \mathrm{MJ}$ value used by GE. The equivalent reactivity insertion rates for these events is about $\$ 110-\$ 115 / \mathrm{sec}$. The $\mathrm{BNL}$ analysis also indicates that a large fraction of the fuel will be in a molten state during most of the power excursion. Once the fuel pins fail, molten fuel becomes very mobile within the reactor concern for the PRISM reactor and additional evaluations of the HCDA may be required at a later stage of the design review.

Although it is believed to be a positive development for the applicant to acknowledge that some worst-case events cannot be entirely ruled out, the effort to analyze the mitigative capabilities of the design suffers from some major gaps in the data. First and foremost, without data on fuel extrusion for rapid power excursions, it is very difficult to estimate when the excursion would be terminated. This would be difficult data to acquire, although there is currently a test program to develop similar data for oxide fuel. Second, the major factors preventing the release of harmful fission products will be (1) retention in the fuel due to its comparatively low melting temperature and (2) retention in the sodium pools of such key fission products as iodine. Again, there are relatively little data to support these arguments, even though such behavior seems likely.

The applicant defines the containment design-basis source term with the releases defined over the initial $10 \mathrm{sec}$ (the HCDA) and over the period from $10 \mathrm{sec}$ through $6 \mathrm{hr}$ (the sodium fire). The significance of the 6-hr cutoff is not explained, although the containment pressure turns negative (relative to outside the containment) in this time frame, i.e., once the oxygen has been consumed in the fire. During the first $10 \mathrm{sec}$, it is assumed that all of the noble gases are released, that 0.1 percent of the halogens (iodine), the alkali metals (cesium), tellurium, and ruthenium escape, and that 0.01 percent of the strontium, barium, fuel, and other fission products are released. Over the longer interval, an additional 0.8 percent of the halogens, 1.6 percent of the alkali metals, 0.004 percent 
of the tellurium and ruthenium, 0.0016 percent of the strontium and barium, and 0.0008 percent of the fuel and other fission products are assumed to be released. I' is also assumed that 0.4 percent of the sodium over the 10-sec-to-6-hr period is released, presumably corresponding to the amount burned, and the assumed containment leak rate of less than 1 percent/day at $274 \mathrm{kPa}$ $(25 \mathrm{psig})$ and $644 \mathrm{~K}\left(700^{\circ} \mathrm{F}\right)$.

It should be noted that the processes involved can be very complex, and involve a combination of chemical reactions and radioactive decay. For example, the fission products $\mathrm{Br}-89$ and $\mathrm{l}-138$ are both soluble in sodium, and can be released from the fuel and transported efficiently in the coolant. However, each isotope decays within a few seconds, to $\mathrm{Kr}-89$ and $\mathrm{Xe}-138$, respectively. These noble gases will esrupe to the cover gas, before decaying a few minutes later to $\mathrm{Rb}-89$ and $\mathrm{Cs}-138$, respectively, which would likely settle out on some surface. Thus, the process by which the fission products can escape the fuel, the sodium pool, the cover gas, and perhaps even further is very complex, and a substantial effort may be required before a reasonably accurate source term can be developed.

The basis for the numbers provided is data from oxide fuel in sodium pools. There are three problems related to the use of such data to extrapolate for metal fuel. First, the models for oxide fuel are largely empirical, and there is little basis for extrapolating from equations that are mostly fitted data. Second, the metal fuel melts at a relatively low temperature, so that many fission products would remain in solid form, i.e., as solid particles in molten liquid fuel. As a result, they are more likely to stay with the fuel, which is helpful. Third, the metal fuel includes zirconium rather than oxygen, so the sodium-fuel chemistry would be different. As a further complication, if the initiating event is an HCDA, some of the fuel could reach very high temperatures, so a portion of the fission products could become molten or could even conceivably vaporize. The numbers are very uncertain.

The key factor that would terminate a power excursion would be the rapid axial extrusion of the fuel, which is expected to expand rapidly up into the fission gas plenum, effectively expanding the core and increasing neutron leakage, i.e., shutting down the reactor. To be effective, this expansion needs to take place very quickly. The fastest data that ANL has for metal-fuel axial expansion is for a period of about $8 \mathrm{sec}$ (the TREAT facility). In contrast, data from the international in-pile CABRI (Ref. 15.18) test program (co-sponsored by the NRC through early 1985) describes oxide-fuel axial expansion on a millisecond scale.

\subsubsection{Evaluation}

\section{Total Energy Released by a Sodium Fire}

The most crucial factor in this analysis of the containment is the sodium combustion, which forms sodium monoxide when there is no excess oxygen available:

$$
2 \mathrm{Na}+1 / 2 \mathrm{O}_{2} \rightarrow \mathrm{Na}_{2} \mathrm{O}+2195 \mathrm{cal} / \mathrm{g},
$$

and sodium peroxide if there is excess oxygen available:

$$
2 \mathrm{Na}+\mathrm{O}_{2} \rightarrow \mathrm{Na}_{2} \mathrm{O}_{2}+2500 \mathrm{cal} / \mathrm{g},
$$

The amount of energy released per unit mass of the reaction product is $9.2 \mathrm{MJ} / \mathrm{kg}(3,955 \mathrm{BTU} / \mathrm{lb})$ for the sodium monoxide and $10.5 \mathrm{MJ} / \mathrm{kg}(4,505 \mathrm{BTU} / \mathrm{lb})$ for the sodium peroxide. Since there is much more sodium available than oxygen, it would seem that more sodium monoxide would form than sodium peroxide. On the basis of the GE CONTAIN analysis, it appears that for each pound of oxygen consumed, a little more than two pounds of sodium are consumed (this trend roughly holds true through the transient). This implies that approximately twice as many moles of sodium monoxide are being formed as is sodium peroxide. Since the event began with about $273 \mathrm{~kg}$ (602 lb) of oxygen in the containment dome, this implies that about $529 \mathrm{~kg}(1,166 \mathrm{lb})$ of sodium monox:de and about $333 \mathrm{~kg}(734 \mathrm{lb})$ of sodium peroxide are formed. This should release about 7.9 million BTUs (British thermal units) of heat. Integrating the area under the combustion energy curve during the transient, gives between 7,400 and $8,400 \mathrm{MJ}$ ( 7 and 8 million BTUs). This indicates the CONTAIN calculation is at least consistent with respect to the chemical reactions.

As a conservative variation, it could be assumed that all of the oxygen is used to form sodium monoxide. This would create about $1058 \mathrm{~kg}(2,333 \mathrm{lb})$ of sodium monoxide, releasing about $9,700 \mathrm{MJ}$ (9.2 million BTUs) of energy. Therefore, even if all the oxygen went into forming sodium monoxide, the increase in energy release would be only around 16 percent, which would not appeai to pose a major problem with respect to the apparent safety margins for this event.

\section{Rate of Combustion}

Although the total energy produced by the sodium fire is important, it is the rate of combustion that directly impacts peak temperatures and pressures within the containment dome. Models used for analyzing sodium pool fires are quite complex, as they must simulate the air and sodium flow patterns around the sodium-air interface. In adcition, such models typically contain some input data that is 
somewhat judgmental in nature, so the user may have more control over key parameters ("dials") than might be desirable. However, there has been quite a bit of validation work done to confirm the performance of sodium pool fire models used to support the CONTAIN Code (Ref. 15.14). Therefore, barring some user-input errors, the sodium fire analysis used in the applicant's simulation is probably fairly accurate.

As a further check for this combustion rate, a "rule of thumb" cited in Reference 15.19, i.e., "Typical burning rates for pool fires in air are around $25 \mathrm{~kg}$ (55 lbs) $\mathrm{Na} /$ meter squared/hour," was utilized by BNL. Since the sodium pool diameter is $5.64 \mathrm{~m}(\mathbf{1 8 . 5} \mathrm{ft})$, this implies an initial energy release rate of about $2.16 \mathrm{MJ} / \mathrm{sec}$ $(2,048 \mathrm{BTU} / \mathrm{sec})$, assuming that all the sodium goes to creating sodium monoxide. The peak combustion energy generation is about $1.33 \mathrm{MJ} / \mathrm{sec}(1,400 \mathrm{BTU} / \mathrm{sec})$, which reflects several geometric considerations that are not in the "rule of thumb" estimate. Because this energy-generation rate is not out of line with respect to this very rough estimate, and because the sodium pool fire models used with CONTAIN have a fairly good validation base, it seems likely that $1.33 \mathrm{MJ} / \mathrm{sec}(1,400 \mathrm{BTU} / \mathrm{sec})$ value is at least approximately correct.

\section{Temperature Transient Characteristics}

The initial inventory of air in the containment is roughly $1,180 \mathrm{~kg}(2,601 \mathrm{lb})$, and the heat capacity of air around $477 \mathrm{~K}\left(400^{\circ} \mathrm{F}\right)$ is about 1,028 joules $/ \mathrm{kg} / \mathrm{K}$ $\left(0.245 \mathrm{BTU} / \mathrm{lbm}-{ }^{\circ} \mathrm{F}\right)$. At the original rate of energy generation of $1,400 \mathrm{BTU} / \mathrm{sec}(1.47 \mathrm{MJ} / \mathrm{sec})$, the air in the containment would increase from $37.8^{\circ} \mathrm{C}$ to $287.8^{\circ} \mathrm{C}$ or $250 \mathrm{~K}\left(100^{\circ} \mathrm{F}\right.$ to $550^{\circ} \mathrm{F}$ or $\left.450{ }^{\circ} \mathrm{F}\right)$, in a little under $3.5 \mathrm{~min}$. This then explains why the air temperatures increase so rapidly.

\section{Pressure Transient Characteristics}

The ideal gas law dictates the relationship between temperature and pressure, assuming the volume and mass hold constant. In this case, the pressure in $\mathrm{Pa}$ is equal to 325 times the temperature in $K$. Thus, initially, the pressure of 1 atmosphere is consistent with the temperature of $311 \mathrm{~K}\left(100^{\circ} \mathrm{F}\right)$. Once the sodium fire heats the atmosphere to $561 \mathrm{~K}\left(550^{\circ} \mathrm{F}\right)$, the pressure should reach approximately $183 \mathrm{kPa}$ (26.45 psia), assuming the amount of oxygen consumed by the fire can be neglected for the first 4 minutes. From the ideal gas law, this pressure is about $183 \mathrm{kPa}$ (11.75 psig), which is a little higher than the peak pressure of $169 \mathrm{kPa}$ (9.8 psig) from the GE CONTAIN analysis (which would include the consumption of oxygen in the fire).
As the air in the containment dome is heated, some heat starts to transfer to the internal structures and through the dome to the outside air. Once that rate of heat transfer equalizes with the rate of energy being generated by the sodium fire, the air temperature will peak. With the dome having a heat transfer area of about $336 \mathrm{~m}^{2}\left(3,617 \mathrm{ft}^{2}\right)$ and the equipment "slab" having a heat transfer surface area of about $107 \mathrm{~m}^{2}\left(1,152 \mathrm{ft}^{2}\right)$, the temperature required to release the energy from the initial portion of the fire would be about $544 \mathrm{~K}\left(520^{\circ} \mathrm{F}\right)$. As was discussed in the previous subsection, a temperature of $561 \mathrm{~K}\left(550^{\circ} \mathrm{F}\right)$ would give a pressure a little below $183 \mathrm{kPa}$ (11.75 psig). Therefore, the temperature peaking around $561 \mathrm{~K}\left(550^{\circ} \mathrm{F}\right)$ is entirely reasonable.

It should be noted that the containment is designed to leak less than 1 percent/day at $274 \mathrm{kPa}$ (25 psig) and $644 \mathrm{~K}$ $\left(700^{\circ} \mathrm{F}\right)$. Although several approximations are made in comparing against the CONTAIN calculations, none of these approximations suggest errors large enough to increase the containment pressure and temperature nearly that high. Even if several worst-case assumptions were combined, it seems unlikely that the design-basis sodium fire would push the containment pressure above $274 \mathrm{kPa}$ (25 psig).

Once the heat-transfer process catches up with and then passes beyond the heat-generation rate from the sodium fire, the system temperatures can level off and begin to decrease as the fire starts to exhaust the supply of oxygen. In addition, as the oxygen portion of the air is gradually consumed, the pressure decreases. Going back to the ideal gas law, and estimating the pressure of only the nitrogen portion of the air at the elevated temperature of $436 \mathrm{~K}$ $\left(325^{\circ} \mathrm{F}\right.$ ) (from Figure G.4.1-9 of the PSID at 6 hours), would result in $105 \mathrm{kPa}$ (15.2 psia). This is $105 \mathrm{kPa}$ ( $0.5 \mathrm{psig}$ ), which compares well with the containment dome pressure of 0.1 psig at 6 hours from the GE CONTAIN analysis.

Although the short-term pressure transient can be estimated, it is more difficult to confirm the trend through the 6 hours of transient. However, the dominant processes are rate dependent, i.e., the rate of change is proportional to the inventory. This should lead to classic exponential decay curves. In fact, most of the curves from the CONTAIN Code calculations fit this description. The only oddity during this long period shows up as a kink in the slope (of several curves) after about 55 minutes. The reason for this kink can be traced to the water mass in the containment. At 100 -percent relative humidity in the containment at the start of the transient, with the ambient temperature of $310 \mathrm{~K}\left(100^{\circ} \mathrm{F}\right)$ and an estimated water vapor pressure of $6.62 \mathrm{kPa}(0.96 \mathrm{psia})$, the resulting mass is $51.4 \mathrm{~kg}(113.3 \mathrm{lb})$. Due to an error made by $\mathrm{GE}$ in the 
input deck, the initial water vapor inventory from the CONTAIN Code calculation is $71.3 \mathrm{~kg}$ (157 lb), which is 39 percent too high. In either case, the water vapor reacts with the sodium to form sodium bydroxide:

$$
2 \mathrm{Na}+2 \mathrm{H}_{2} \mathrm{O} \rightarrow 2 \mathrm{NaOH}+\mathrm{H}_{2}
$$

This reaction acts to remove the water vapor from the containment atmosphere during the first hour. Once the water vapor has been removed, the rate of the drop in pressure slows, which creates the bends in the various curves at 55 minutes. Because there is 39 percent too much water vapor in the CONTAIN calculation, the impact and duration of this process is exaggerated somewhat. However, there is far more oxygen and nitrogen in the containment atmosphere, so a 39-percent error in water vapor inventory is probably not very significant.

\subsubsection{Conclusion}

The scoping review performed on the results from the GE CONTAIN calculation indicates that the analysis seems reasonable. The user-input mistake in specifying the amount of water vapor in the containment dome is the type of error that occurs fairly frequently when a large computer code is being modified, and is unlikely to have changed the results significantly. The scoping analysis shows there are large margins to accommodate errors and uncertainties, in that the pressure increase could more than double before there would be any cause for concern. Therefore, at this time, it appears that the PRISM containment dome could accommodate a worst-case sodium pool fire, and with fairly large safety margins.

With respect to the fission-product release fractions and site boundary doses, there is far greater uncertainty involved. The applicant shows projected doses at the site boundary ranging from 1 percent to 40 percent of the PAGs. However, these low doses are due to the relatively small amount of fission products and fuel that escape from the sodium pool into the containment dome. The data base supporting those release rates is not complete, so these predicted doses involve a great deal of engineering judgment and should be used with care. A major concern here is that the models for fission-product release from oxide fuel are largely empirical, so the extrapolation to metal fuel is based more on speculation than on understanding. However, GE and ANL arguments regarding the likely retention of fission products within the metal fuel and the sodium pools appear to be reasonable assumptions.

It appears probable that a large HCDA could be accommodated in the PRISM reactor vessel, but it may be some time before that can be established with confidence.
Some essential data regarding fuel expulsion during rapid transients simply do not exist. The fastest data available are for an 8-second period transient overpower event. In contrast, data for oxide fuel are available over a fewmillisecond period (Ref. 15.18).

Because of the lack of the key metal-fuel data, the applicant adapted some HCDA analysis that was performed previously for the FFTF reactor, and evaluated how the PRISM vessels and structures would stand up to that event. The applicant's analysis indicates that the PRISM reactor vessel and closure can safely accommodate HCDA loads resulting from energetics on the order of $500 \mathrm{MJ}$ without loss of structural integrity, disengagement of the rotatable plug from the reactor closure, or expulsion of sodium. Independent examination, by Battelle at Brookhaven National Laboratory's request, of the applicant's analysis has not revealed any apparent errors. Therefore, it does appear likely that the PRISM system could withstand this large HCDA postulated for the FFTF.

In comparing the postulated HCDAs for different fuel types, a recent paper (Ref. 15.20) from the Indira Gandhi Center for Atomic Research is particularly useful. This paper focuses on worst-case scenarios, with arbitrarily large reactivity insertions in 500-MWe sodium-cooled reactors, using metal, oxide, and carbide fuel. The researchers make several interesting points:

- The lower operating and melting temperatures for metal fuel decreases any concerns about fuel-coolant interaction ( $\mathrm{FCl}$ ), which is essentially benign for metal fuel.

- The large difference between the melting and boiling temperatures in the metal fuel will tend to keep the core together longer, and would result in larger melt fractions (perhaps 100 percent).

- Because the fraction of metal-fuel melting is much higher, the potential reactivity insertion in metal fuel (due to slumping) is also higher.

- For rear civity insertions under about $\$ 75 / \mathrm{sec}$, the metal core releases more energy than the oxide and carbide cors. However, for insertions above $\$ 100 / \mathrm{sec}$, the ensrgy release for the metal core is significantly lower.

Zerhaps the most crucial finding from Reference 15.20 is that the energy release from a $\$ 200 / \mathrm{sec}$ ramp is only about $300 \mathrm{MJ}$, and is increasing only gradually as the reactivity insertion rate increases. For the 155-MWe PRISM core, the release would be less, and certainly less than the 500-MJ estimate made for the FFTF and utilized by the applicant for determining HCDA loads. Thus, the analysis 
in Reference 15.20 supports the applicant's contention that the PRISM vessel and head could survive a large HCDA event. The modified Bethe-Tait analysis also supports this conclusion. The consequences of the HCDA and resulting sodium fire on containment performance indicates that the design values of $264 \mathrm{kPa}(25 \mathrm{psig})$ and $644 \mathrm{~K}\left(700^{\circ} \mathrm{F}\right)$ would not be exceeded. The peak pressure is estimated to be about $183 \mathrm{kPa}$ (12 psig) and the peak temperature is estimated to be $561 \mathrm{~K}\left(550^{\circ} \mathrm{F}\right)$.

\subsubsection{Severe Core Accident Considerations}

\subsubsection{Design Description and Safety Objectives}

The designer (GE) has stated that the PRISM design provides for both prevention and mitigation of severe core accidents. Prevention is provided by the reactor protection system, by strong negative reactivity feedback with rising temperatures, and with passive shutdown features (the GEMs and the USS) and passive decay heat removal (the RVACS). With these design features, it appears that PRISM can withstand EC-III events including ATWS events and the bounding events identified in Section 15.6.7 of this report without unacceptable fuel failure. There also appears to be margins to ASME Code design limits for structural integrity. Mitigation is provided by the containment dome.

Several design changes are now under consideration to enhance the ability of the reactor to contain the consequences of an HCDA and/or a core melt accident within the primary system boundary. Several specific hardware features, to address HCDA energetics and core melt, under consideration, shown in Figure 15.4, are:

- a shear ring between the fixed closure and the rotatable plug to retain the plug under impact loading from a sodium slug accelerated towards the upper head during an HCDA

- a self-locking refueling port

- an upper internals structure with a slotted cylinder

- a redundant structure (backup plate) placed under the inlet plenum to retain a core melt in a coolable geometry if the core debris leaks through any openings that may develop in the inlet plenum lower plate

GE does not consider containment of an HCDA and/or core melt accident within the primary system boundary to be a design or licensing requirement; however, attainment of the capability appears feasible to the designer, and additional work is planned to determine if it actually is feasible. Design changes to provide this capability may or may not be incorporated depending on the outcome of this work compared to alternative methods to achieve the desired degree of safety.

\subsubsection{Scope of Review}

Appendix G (Section 4.19) of the PSID covers two analytical efforts that attempt to use simple engineering principals to show that two worst case scenarios may not be as damaging as might be anticipated. This work reflects some degree of ingenuity, and provides some reassurance, although additional work is needed to conclude that the results are correct.

The first scenario is the HCDA. It is assumed by GE that the analysis that was performed to assess the magnitude of possible power excursions in FFTF, which uses oxide fuel, could be used to estimate an upper bound on the maximum excursion that could develop in PRISM. The ramp rates, which were in excess of $\$ 100 /$ second, ind the energy releases, a few hundred megajoules, are quite high and could be considered conservative at least for the FFTF oxide core. The analysis presented in Reference $\mathbf{1 5 . 2 0}$ suggests that the energy release from a metal core should be smaller than that from an oxide core, for reactivity insertions above $\$ 100 /$ second. However the $500 \mathrm{MJ}$ HCDA was analyzed to assess the structural integrity of the primary system boundary (the reactor vessel, the closure head and the IHX).

The second scenario is core melt. Because a sodium cooled reactor is not designed to operate in its most reactive configuration, any fuel relocation could well result in a significantly supercritical mass. As a result, a molten metal fuel core would be very difficult to predict. It is possible that the fuel could gradually relocate and accumulate down on the core support plate, and that is the condition that GE/ANL chose to analyze.

\subsubsection{Design Criteria}

The structural design criteria for the primary system boundary and the reactor vessel internal structures are based on American Society of Mechanical Engineers (ASME) Level D limits. The bolt capacities are based on the material yield strength than the ASME stress limit in order to assure pressure retention.

The core melt retention capability studies are primarily concerned with recriticality of the melt, the temperatures reached by the melt and the retaining structures, and the dissolving of iron from the retaining structures into the melt. Structural analysis of the structures retaining the melt and design modifications to enhance this capability are also included. 

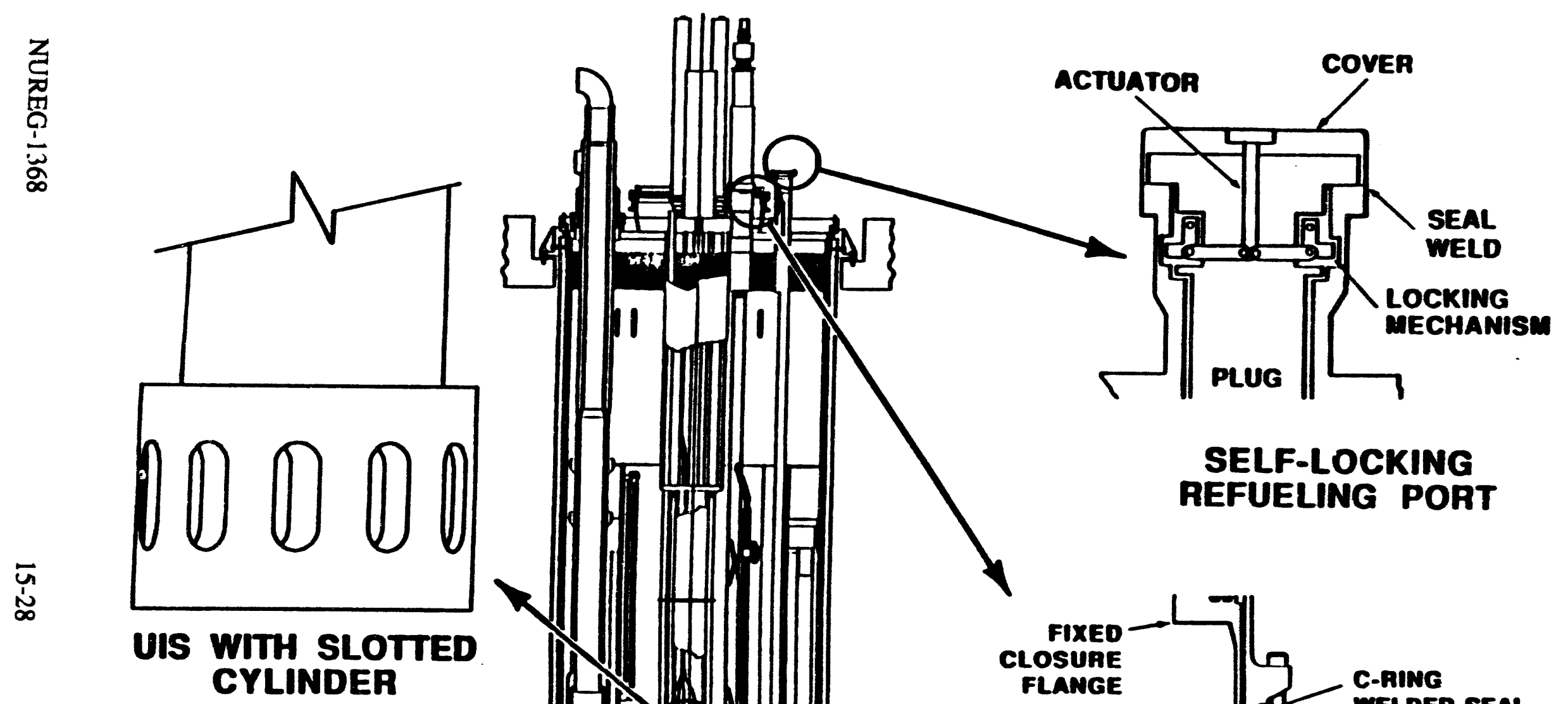

竞

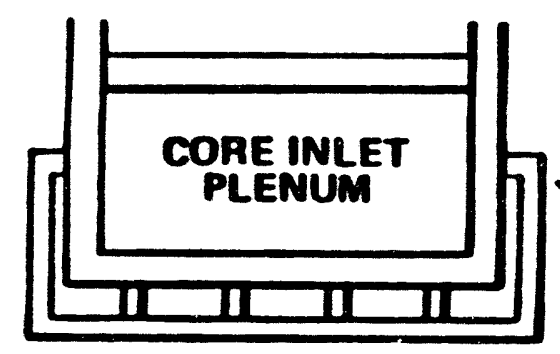

CORE SUPPORT STRUCTURE WITH BACKUP PLATE

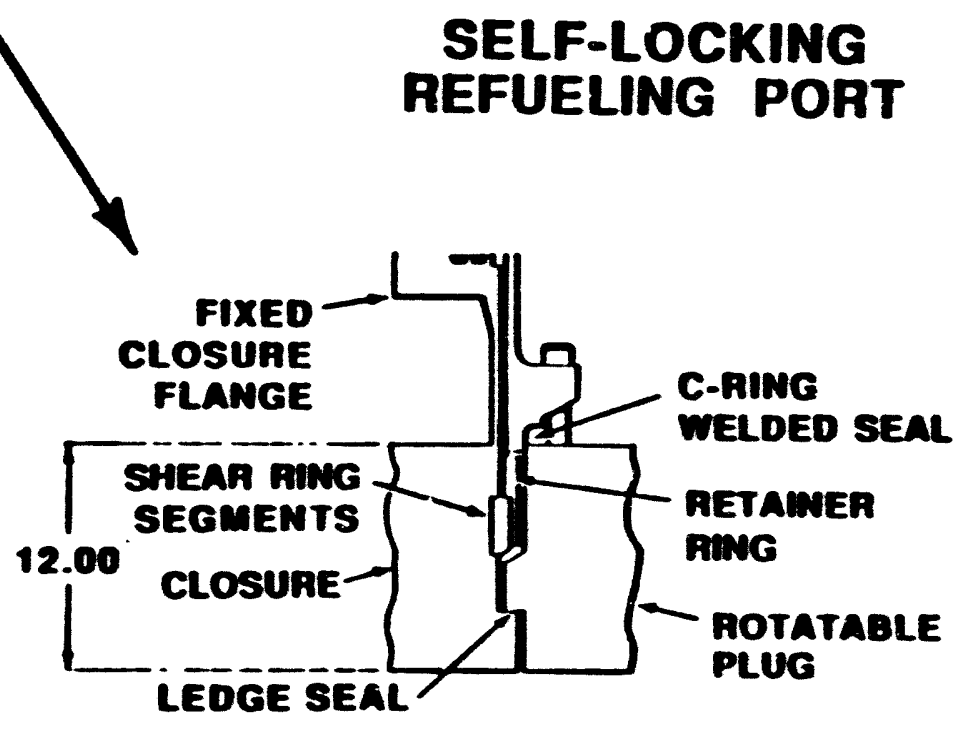

\section{rotatable plug}

SHEAR RING

Figure 15.4 PRISM reactor changes to enhance accident mitigation capability 


\subsubsection{Research and Development}

Metal core HCDAs are anticipated to have low energies because of the low melt temperature, high mobility and reduced tendency of the metal fuel to form blockages relative to oxide fuel. Based on scoping analyses, a limit of $40 \mathrm{MJ}$ (as compared to the $500 \mathrm{MJ}$ used) was stated for the total work energy in the PRISM metal core (Amendment 6 to the PSID). However the expected fuel behavior and low work energy remain to be demonstrated. A demonstration is planned in Phase III (1991-1995) of the IFR program described in Section 1.5 of this report at the Argonne National Laboratory. Included in the program are:

- development of analytical models of metal fuel response to severe accident conditions

- ex-reactor experiments on fuel dispersal in a transient overpower event including fuel/fission product retention in sodium

- multi-pin transient tests in the TREAT reactor

- validation of the analytical models using the ex-reactor data and the results from transients in EBR-II, FFTF as well as in TREAT.

Current understanding of in-vessel retention of core melt is based on preliminary scoping analysis and experiments. Preliminary experiments at ANL have investigated metal fuel fragmentation. The results indicate that a very porous debris will form that should be coolable by natural convection of sodium within the PRISM reactor vessel without producing core melt. A demonstration is planned in Phase III (1991-1995) of the IFR program at the ANL. Included in the program are ex-reactor tests concerning:

- downward melt relocation in the fuel assembly

- melt breakup, quench, and solidification in the sodium-filled regions under the core

- effect of iron in the melt compositions ranging from $\mathrm{UFe}_{2}$ to various compositions of U-FE-Zr

- coolability of core debris accumulated on horizontal surfaces in the sodium pool

- fuel dispersal in a transient overpower event

- retention of fuel and fission products within the sodium.

\subsubsection{Safety Issues}

The structural calculations don't include any radiationinduced embrittlement that might develop. One example would be the core barrel, which will see increased fluence in the sectors directly out from the 3 GEMs, and could undergo embrittlement as a result.

A key factor in some of the scenarios that could result in core melts is failure of RVACS to remove the decay heat. However, the preapplicant is assuming that when the molten core is settled on the core support structure, the heat is going to be removed via the RVACS (this appears to be implied by Figure G.4.19-11). This points to a possible weakness in the PRISM containment design, i.e., if the cooling systems that are there to prevent core melt fail, it may not be possible to cool the containment vessel, so the containment may also fail.

\subsubsection{Evaluation}

The Appendix $G$ analysis indicates that the PRISM vessel and structures could likely absorb the large energy release predicted for FFTF. The staff independent estimates tend to confirm this, i.e., the large HCDA postulated for FFTF could probably be accommodated in PRISM without large scale failures resulting. However, the structural calculations don't include any radiation-induced embrittlement that might develop. The structures were predicted to remain essentially elastic under the HCDA loads. The primary system boundary appears to be able to contain HCDAs with work potential up to $500 \mathrm{MJ}$ without a structural failure, disengagement of the rotatable plug, or sodium expulsion. Seals, including the canopy seal over the closure/plug interface, will be maintained under slug impact. The canopy seal will also hold the residual pressures following the slug impact if the HCDA bubble is quenched as expected during its expansion through the pool sodium. The canopy wall can be thickened or the seal can be redesigned if additional studies show problems with the proposed design.

Because a sodium cooled reactor is not designed to operate in its most reactive configuration, any fuel relocation could well result in a significantly supercritical mass. As a result, a molten metal fuel core would be very difficult to predict. It is possible that the fuel could gradually relocate and accumulate down on the core support plate, and that is the condition that GE/ANL chose to analyze.

The analysts considered four scenarios, including relocation of the active fuel alone, the active fuel and its cladding, the fuel and blanket materials (with cladding), and virtually the entire core. There is no specific mention of any sodium, although some experiments indicate that 
molten metal fuel is very porous and would certainly contain a considerable amount of sodium. Estimates of the infinite neutron multiplier, $k_{\infty}$, for each of the four compositions were made by GE/ANL. The first two composites, i.e., materials coming only from the active fuel region, have $k_{\infty}(s)$ in the range of 1.9. While this is high, there is a great deal of fissile plutonium in the PRISM active fuel, and a $k_{\infty}$ even higher than 1.9 may be possible. The remainder of the analysis involves geometric considerations, assuming the melt spreads evenly on the core support plate, and involves estimating critical heights that would have to be attained before $k_{\text {eff }}$ reached 1.0. GE/ANL concluded that the critical height cannot be reached for each of the four composites, due largely to the degree of spreading on the support plate. GE also points out that if there existed a real hazard of achieving a critical mass on the plate that they could add neutron poisons to the region just in case.

In response to questions regarding the transition phase, the preapplicant analyzed a case where the fuel assemblies melted and the fuel then accumulated in the lower shields. Using some worst case assumptions, the preapplicant predicted a maximum $k_{\text {eff }}$ of 1.28 . The preapplicant then showed that by using some natural $\mathrm{B}_{4} \mathrm{C}$ in the region, the maximum $k_{\text {eff }}$ could be reduced to a sub-critical value (less than 1.0).

Having determined that the mass lying on the core support would most likely be subcritical, GE proceeded to analyze the long term heat removal and materials damage. Presumably they have assumed porous fuel with sodium in the pores, although this is not specifically stated. GE did include some analysis of the damage to the core support structure due to the prolonged exposure to the fuel, and states that they had to add a 2-inch backup plate (Figure 15.5) to compensate.

A key factor in some of the scenarios that could result in core melts is failure of RVACS to remove the decay heat. However, the preapplicant is assuming that when the molten core is settled on the core support structure, the heat is going to be removed via the RVACS (this is implied by Figure G.4.19-11, anyway). This points to a possible weakness in the PRISM containment design, i.e., if the cooling systems that are there to prevent core melt fail, it may not be possible to cool the containment vessel, so the containment may fail also.

\subsubsection{Conclusions}

The Appendix $\mathbf{G}$ analysis indicates that the PRISM vessel and structures could likely absorb the large energy release predicted for FFTF. Our independent estimates tend to confirm this, i.e., the large HCDA postulated for FFTF could probably be accommodated in PRISM without large scale failures resulting. However, the structural calculations don't include any radiation-induced embrittlement that might develop. One example would be the core barrel, which will see increased fluence in the sectors directly out from the three GEMs, and could undergo embrittlement as a result.

Since the projected FFTF HCDA energy release estimate may well bound that expected for PRISM, it is entirely possible PRISM could survive such an event without catastrophic failure of the vessels or key structures. The structures were predicted to remain essentially elastic under the HCDA loads. The primary system boundary appears to be able to contain HCDAs with work potential up to $500 \mathrm{MJ}$ without a structural failure, disengagement of the rotatable plug, or sodium expulsion. Seals, including the canopy seal over the closure/plug interface, will be maintained under slug impact. The canopy seal will also hold the residual pressures following the slug impact if the HCDA bubble is quenched as expected during its expansion through the pool sodium.

The preapplicant's analysis showing subcriticality of a molten core when distributed on the below-core support plate is useful. However, there is great uncertainty involved with the process of relocating the fuel from the original core to the support plate. The preapplicant is assuming that when the molten core is settled on the core support structure, the heat is going to be removed via the RVACS (this is implied by Figure G.4.19-11). This points to a possible weakness in the PRISM containment design, i.e., if the cooling systems that are there to prevent core melt fail, it may not be possible to cool the containment vessel, so the containment may fail also.

\subsection{Conclusions}

GE's approach of separating DBEs from BDBEs solely on the basis of PRA for a new reactor design like PRISM is inappropriate for the preapplication review. Therefore, the staff has identified deterministically certain events which are intended to bound uncertainties in the design and which should be considered for design purposes as bounding EC-III events, as described in Section 15.3.3. For this review of the PRISM PSID, the staff can accept GE's list of DBEs for EC-II events. The bounding events, which are considered in the EC-III category, are listed in Table 15.1

The PRISM designers have approached safety creatively by placing emphasis on accident prevention and reducing mitigative hardware. However, acceptance of this approach will require a design for which a high confidence can be achieved that accidents that lead to core melt or 


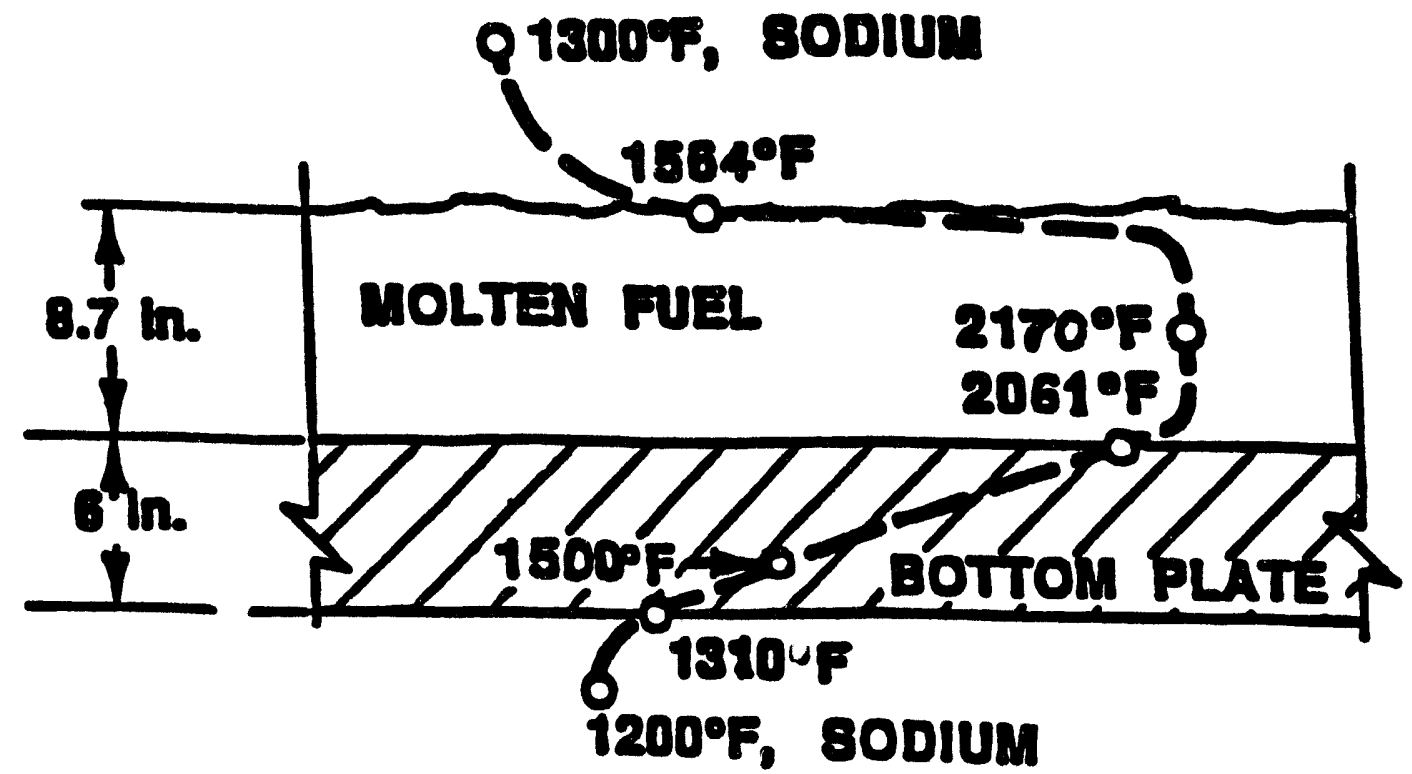

A - Without Backup Plate

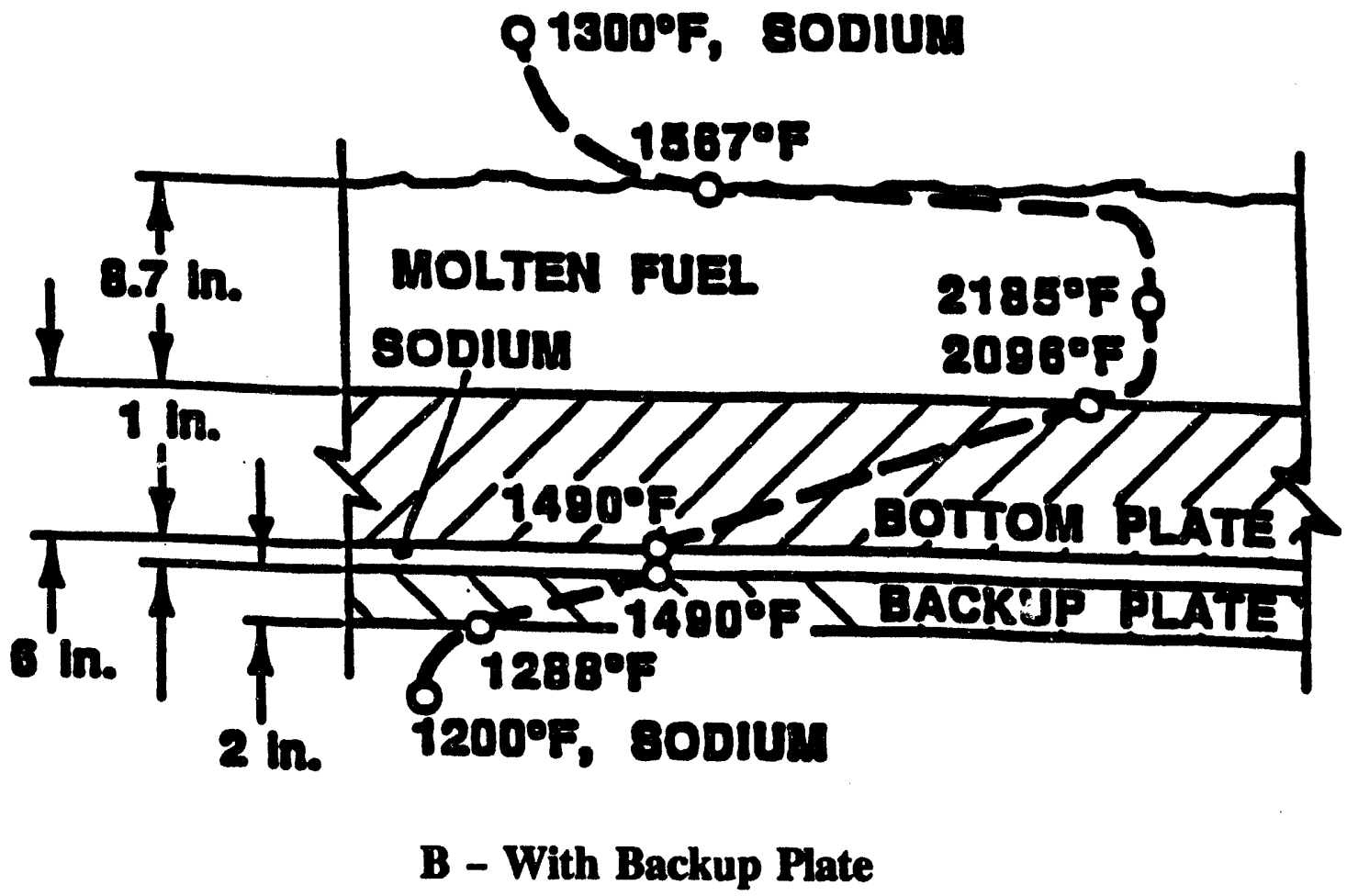

Figure 15.5 PRISM temperature distributions in the melt and the core support bottom plate 
positive reactivity feedback situations can be prevented. The events identified by GE for analysis, as supplemented by the staff's review and preapplication accident evaluation criteria, result in the analysis of PRISM and a preliminary assessment of its licensability.

The reactivity insertion DBE is not a major challenge to PRISM in the short term (first several hours). In the longer term, however, fuel damage could occur as discussed in Section 15.6.1. Any residual uncertainties can ultimately be resolved by the safety tests. Further information regarding this event is given in Section 15.6.1 and Appendix B of this report.

The analysis in Section 15.6.2 shows that RVACS has the potential to renove PRISM decay heat effectively. As the GE parameters were judged to be conservative, it is likely that both GE and staff's independent calculations underestimate RVACS performance. Further confirmation from the R\&D progiam and more detailed analysis will be required in later reviews, as RVACS is a key PRISM safety system.

The review has focused on several design features that are implemented to minimize the occurrence of local faults and to ensure that local faults will be detected. Research and development progress is expected to produce experimental data to verify the local fault accommodation arguments presented by GE. The high conductivity of the fuel and the apparent compatibility between the fuel and sodium lead to the expected verification of the GE arguments. It is also noted that the fuel-clad eutectic temperature is relatively low, so that some concern is warranted. A large research program now in progress is expected to produce the relevant data. Flow blockage of a fuel assembly (due to fabrication error) could, in the present PRISM design, lead to fuel melting, sodium boiling, and the potential for an energetic reactivity accident and, as such, remains a concern.

Unless the PRISM metal-fuel performs far worse than expected, a primary sodium spill event is unlikely to result in a major release to the environment. As the design matures, the primary sodium spill event should be examined with respect to possible damage to safety systems resulting from sodium fires. It should be noted, however, that if PRISM incorporates state-of-the-art sodium-fire detection and mitigation systerus, the likelihood of a problem in this area should be minimized.

The requirement for leaving spent fuel assemblies in the reactor vessel for almost 2 years makes handling the spent fuel less likely to result in releases due to fuel overheating. This also makes many aspects of the fuel handling easier. The method of moving the spent fuel between the reactor vessel and the fual cycle facility by a self-propelled cask transporter should minimize the exposure to plant personnel.

Release of the cover gas is likely to result in a small release of radioactive gases. As long as only noble gases are involved, this event is not going to be a major safety concern.

Since certain of the bounding events identified by the staff for inclusion in EC-III have the potential to lead to core melt or energetic reactivity accidents, or both, the acceptability of the PRISM design (particularly the containment and offsite emergency planning proposals) is of concern.

The scoping review performed on the solutions to the GE CONTAIN calculation indicate that the analysis seems reasonable. The user-input mistake in specifying the amount of water vapor in the containment dome is the type of error that occurs fairly frequently when a large computer code is being modified, and is unlikely to have changed the results enough to cause concern. The scoping analysis shows there are large margins to accommodate errors and uncertainties, in that the pressure increase could more than double before there would be any cause for concern. Therefore, at this time, it appears that the PRISM containment dome could accommodate a worstcase sodium pool fire with fairly large safety margins.

With respect to the fission-product release fractions and site boundary doses, there is far greater uncertainty involved. The preapplicant shows projected doses at the site boundary ranging from 1 percent to 40 percent of the PAGs. However, these low doses are due to the relatively small amount of fission products and fuel that escape from the sodium pool into the containment dome. The data base supporting those release rates is not complete, so these predicted doses involve a great deal of engineering judgment and should be used with care. A major concern here is that the models for fission-product release from oxide fuel are largely empirical, so the extrapolation to metal fuel is based more on observation than on understanding. However, GE and ANL arguments regarding the likely retention of fission products within the metal fuel and the sodium pools appear to be reasonable.

There is a reasonably good chance that a large HCDA could be accommodated in the PRISM reactor vessel, but it may be some time before that can be established with confidence.

The analyses presented for the preapplication review have been performed for nominal operating conditions at 100 percent power. Shutdown and low-power operations 
will need to be addressed in future risk assessments and analyses to support design certification.

\subsection{References}

15.1 General Electric, PRISM-Preliminary Safety Information Document, GEFR-00793 UC-87Ta, November 1986.

15.2 American National Standards Institute, Inc. / American Nuclear Society, ANSI/ANS-4.1-1978, "Design Basis Criteria for Safety Systems in Nuclear Generating Stations," A.NSS, LaGrange Park, Illinois.

15.3 U.S. Nuclear Regulatory Commission, "Safety Goals for the Operation of Nuclear Power Plants, " 51 Federal Register 28044, August 4, 1986.

15.4 U.S. Nuclear Regulatory Commission, "Policy Statement on Severe Reactor Accidents Regarding Future Designs and Existing Plants," 51 Federal Register 32138, August 8, 1985.

15.5 U.S. Nuclear Regulatory Commission, Code of Federal Regulations, Title 10, "Energy," Part 50, "Domestic Licensing of Production and Utilization Facilities."

15.6 U.S. Environmental Protection Agency, Code of Federal Regulations, Title 40, "Protection of Environment, " Part 190, "Environmental Radiation Protection for Nuclear Power Operations."

15.7 U.S. Nuclear Regulatory Commission, "Planning Basis for the Development of State and Local Government Radiological Emergency Response Plans in Support of LWRs," NUREG-0396, December 1978.

15.8 U.S. Nuclear Regulatory Commission, "Standard Review Plan for the Review of Safety Analysis Reports for Nuclear Power Plants, LWR Edition," NUREG-0800, July 1981.

15.9 DiNunno, J.J., et al., U.S. Atomic Energy Commission, "Calculation of Distance Factors for Power and Test Reactor Sites," Technical Information Document (TID-14844), March 1962.

15.10 U.S. Nuclear Regulatory Commission, "General Site Suitability Criteria for Nuclear Power Stations, " Regulatory Guide 4.7, Rev. 1, November 1975.
15.11 U.S. Nuclear Regulatory Commission, "Summary of Advanced LMR Evaluations - PRISM and SAFR," NUREG/CR-5364 (BNL-NUREG-52197), October 1989.

15.12 U.S. Nuclear Regulatory Commission, "Super Systems Code (SSC, Rev. 0) An Advanced Thermohydraulic Simulation Code for Transients in L M F B R s , " N U R E G / C R-3169 (BNL-NUREG-51659), April 1983.

15.13 U.S. Nuclear Regulatory Commission, "MINET Code Documentation," NUREG/CR-3668 (BNL-NUREG-51742), December 1989.

15.14 Sandia National Laboratories, "User's Manual for CONTAIN 1.1 - A Computer Code for Severe Nuclear Reactor Accident Containment Analysis, " SAND 87-2309, Albuquerque, New Mexico, 1987.

15.15 Brookhaven National Laboratory, "A Simplified Model for Calculating Early Off-Site Consequences from Nuclear Reactor Accidents," BNL-NUREG-52153, July 1988.

15.16 Nuclear Development Associates, "An Estimate of the Order of Magnitude of the Explosion When the Core of a Fast Reactor Collapses, " British Report UKAEA-RHM (56/113), Classified, 1956, and Nuclear Development Associates Report NDA-14-170, 1957.

15.17 Brookhaven National Laboratory (BNL), "HCDA Analysis of PRISM With a Modified Bethe-Tait Model," Department of Nuclear Energy, BNL, August 1992.

15.18 Heusener, G., et al., "The CABRI Programmes Motivations and Achievements, "Proceedings of the 1990 International Fast Reactor Safety Meeting, Snowbird, Utah, August 1990.

15.19 International Atomic Energy Agency, "Status of Liquid-Metal Cooled Fast-Breeder Reactors," Technical Report No. 246, pg. 448, Vienna, Austria, 1985.

15.20 Singh, O.P., et al., "Energetics of a Hypothetical Core Disruptive Accident for Different Fuels for a Medium Sized Reactor," Proceedings of the International Conference on Fast Reactors and Related Fuel Cycles, October 28 - November 1, 1991, Kyoto, Japan. 


\section{TECHNICAL SPECIFICATIONS}

The technical specifications are not reviewed at this stage of the preapplication review. 


\section{QUALITY ASSURANCE}

\subsection{Quality Assurance Program}

The quality assurance (QA) program described for the PRISM replicates the one for the advanced BWR (ABWR), "Nuclear Energy Business Group BWR Quality Assurance Program Description," NEDO-11209-04A, Revision 5, March 1985.

The complete description of the QA program for the ABWR will need to be evaluated at the next stage of review for applicability to the PRISM design before it can be approved by the NRC. It is reasonable to expect that the QA program will be equally acceptable for the PRISM conceptual design and subsequent phases.
There is a different data base supporting LWR safety analyses from that supporting LMR analyses. Therefore, further information will be required on how the appropriate data base will be developed and validated. The applicant will have to describe the QA program to be used for the PRISM design.

In addition, should the licensing process for the PRISM proceed as expected toward design certification, the QA program necessary to ensure conformance of each production reactor module with the prototype module will have to be described, reviewed, and approved. 


\section{APPENDIX A}

PROBABILISTIC RISK ASSESSMENT 


\section{A.1 Purpose and Objectives of the Conceptual PRISM Probabilistic Risk Assessment (PRA) Review}

This section presents the staff's evaluation of the PRISM PRA, as detailed in Appendix $A$ and supplemented in Appendix G of the Preliminary Risk Assessment (PSID) (Ref. A.1), within the framework of criteria given in the Commission's Safety Goal Policy (Ref. A.2) and Advanced Reactor Policy Statements (Ref. A.3). The safety goals set the risk-based criteria, and the advanced reactor policy expects, but does not require, that future designs will have enhanced margins of safety over current generation lightwater reactors (LWRs).

In order to determine if the conceptual PRISM design can meet the above criteria, three review objectives were established:

- evaluate the PRA methodology and assumptions for accuracy and completeness

- identify the weaknesses and limitations of the PRA

- bring to the forefront for evaluation and scrutiny the systems and features relied upon most for protection against severe accident vulnerabilities

The PRISM design is conceptual and, therefore, lacks operational experience and data. A limited amount of experimental data from research performed at the Fast Flux Test Facility (FFTF), EBR-II, and the TREAT reactor were used to partially validate computer codes that model PRISM's transient behavior. The codes themselves, however, are in a state of continuing development, and code limitations coupled with lack of data have resulted in the need for exercising engineering judgment throughout the PRA. Although the designers claim that conservative judgments were made, those judgments can only be validated after sufficient operating experience with prototype and commercial reactors is gained.

\section{A.2 Introduction}

\section{A.2.1 Overview}

The PRISM PRA is a Level 3 conceptual PRA that includes the systems, containment, and consequence analysis. The PRA is done for a single module on the plant site. The assumed location for population distribution is the GESSAR II site. The current PRA does not consider

- startup accidents and accidents at power levels other than full power
- miltimodule interactions

- external events other than (limited) seismic events

These excluded areas need to be considered in future PRA activities when more details are available.

\section{A.2.2 Description of 1990 Design Changes}

\section{A.2.2.1 Increase in Reactor Power Level and System Power Production}

The reactor power level and the nine-reactor-system power production were increased from $425 \mathrm{MWt}$ and $1245 \mathrm{MWe}$ to $471 \mathrm{MWt}$ and $1395 \mathrm{MWe}$, respectively. This was done primarily for economic reasons at the direction of the U.S. Department of Energy (DOE). General Electric Company (GE) did not re-size the key decay heat removal system, reactor vessel auxiliary cooling system (RVACS), and this leads to higher temperatures during postulated accident conditions. In addition, the normal system operating temperatures are $17 \mathrm{~K}\left(30^{\circ} \mathrm{F}\right)$ higher, so all event analyses had to be revised (see Appendix B of this SER), accounting for hotter initial conditions.

\section{A.2.2.2 Ultimate Shutdown System (USS)}

While the passive reactor shutdown mechanism, based on reactivity feedbacks, has significant safety advantages, it usually leaves the reactor in a critical condition and, therefore, exposed to further changes in system conditions. With the addition of the USS, GE has provided an alternate means of shutting down the reactor. USS activation causes many small spheres of $\mathrm{B}_{4} \mathrm{C}$ to fall through a tube into the center of the core, in response to an operator-actuated shutdown command. This action results in a subcritical reactor producing only decay heat. The device fills an important gap in the PRISM safety defenses. That is, the passive shutdown no longer has to function indefinitely, because a neutronic shutdown can be anticipated within some reasonable time.

\section{A.2.2.3 Gas Expansion Modules (GEMs)}

A key question regarding the passive shutdown mechanism is whether it can act to reduce reactor power quickly enough to prevent sodium boiling or fuel damage. The crucial test is the unprotected loss-of-flow (ULOF) case, which results in a relatively quick reduction in coolant flow to the reactor. Initially, the applicant believed that the reactivity feedbacks and their associated uncertainties were such that the passive shutdown could function effectively without GEMs in response to the postulated ULOF. 
GEMs are simple devices, resembling large inverted test tubes. Under full pumping conditions, the gas in the tube is compressed so that sodium occupies the portion of the GEM that resides within the active core region and traps the gas in the GEMs above the core. When the pumps stop and the system dynamic pressure falls, the gas region expands into the core, speeding the decrease in reactor power through increased leakage of neutrons.

\section{A.2.2.4 Mechanical Stops on Control Rods}

A key safety question regarding the passive shutdown, particularly with the use of metal fuel and its small Doppler reactivity feedback, is how much reactivity can be added to the core by withdrawing the control rods and whether the resulting power increase can be safely accommodated. In the original PRISM reactor design, GE and the metal fuel experts at Argonne National Laboratory (ANL) felt they could limit the burnup reactivity swing to be less than 35c, including a degree of uncertainty. More recent fuel data and fuel cycle analysis indicates that the burnup reactivity swing, due in part to significant axial expansion in the fuel, could be larger than was first believed. As the passive accommodation of reactivity additions is limited to roughly $40 \mathrm{c}$, some means was needed to limit the amount that could be inserted during the period when the control rod insertion could be much higher, for example $\$ 1$. This was done by placing electronically controlled mechanical rod stops on the control rods and positioning them to limit how much rod could be removed from the core by the rod positioning system. These stops would be adjusted a few times during burnup to ensure that the possible reactivity insertion would be limited to a manageable level. Assuming the control rods are at mid-core (limiting), the maximum feedback for the movement of all six rods would be $75 \mathrm{c}$ per inch. Thus, a relatively large measurement error of $31.75 \mathrm{~mm}(1 / 8-i n$.) would introduce a less-than-10c error, relatively little reactivity uncertainty from the measurement error. However, the uncertainty associated with predicting the reactivity worth of all the rods at the new maximum withdrawal position could be significantly larger, so it remains to be determined if a $10 c$ uncertainty margin is sufficient.

\section{A.2.2.5 Below-Core Structure}

The original PRISM design relied almost exclusively on accident prevention and placed little emphasis on mitigation. More recently, however, GE and ANL have been addressing accident mitigation concerns, and the revision to the below-core structure is intended to better accommodate a core-melt event. The data base regarding metal fuel failure under melt conditions or during postulated power excursions is incomplete, so it is difficult to evaluate the performance of such a structure under severe accident conditions. The analysis suggests that such a below-core structure would accommodate a melt and would probably result in a less-than-critical mass. However, at present, it is very difficult to predict how the metal fuel will behave during the transition period, as it relocates from the core configuration to the below-core structure. It is not clear how soon such data will become available, but it may take a few years to develop this data base.

\section{A.2.2.6 Accommodation of Hypothetical Core Disruptive Accident (HCDA)}

The key factor that would terminate a power excursion is the rapid axial extrusion of the fuel, which is expected to push rapidly (pop) up into the fission gas plenum, effectively expanding the core and increasing neutron leakage, thereby shutting down the reactor. To be effective, this expansion needs to take place very quickly. The fastest data that ANL has for metal fuel axial expansion is on the order of about 8 seconds (the TREAT facility). In contrast, data from the international in-pile CABRI (Ref. A.4) test program (co-sponsored by the U.S. Nuclear Regulatory Commission (NRC) through early 1985) describes oxide fuel axial expansion on a millisecond scale.

The applicant's analysis and some cross-comparisons of key parameters suggest that the PRISM structures could accommodate a fairly large HCDA event (see Section 15.6.8). Thus, it is likely that the applicant will establish that the PRISM vessels, head, and containment designs can withstand some design-basis HCDA without failing catastrophically.

\section{A.2.2.7 Seismic Design}

GE has moved two key systems, the electromagnetic (EM) pump synchronous coastdown machines and the reactor protection system (RPS) electronics, into the seismically isolated region. Seismic isolation offers some protection against horizontal ground acceleration, and the isolation of these two key safety systems seems to be a significant improvement. In particular, the concerns regarding cables running between the non-isolated synchronous coastdown machines and the isolated EM pumps have been eliminated.

\section{A.2.2.8 Containment Improvements and Dome}

GE has improved the PRISM containment design, making more of the system leak-tight and adding a containment dome over the reactor head. In addition, isolation valves were added in the intermediate heat transport system 
(IHTS) in an effort to strengthen the design regarding accident mitigation. The second vessel, called either a guard vessel or a containment vessel, is cooled by outside air as part of the RVACS heat removal system. This has clear advantages for preventing serious accidents in the PRISM reactor. The behavior of fission products and actinides from the metal fuel in either molten metal fuel or a sodium pool has never been well characterized. Therefore, it isn't known how many and how much of the most hazardous components would escape from the fuel and the sodium pool and make their way into the containment dome. Further, it is not clear whether the containment design basis should be a core melt, a sodium fire, or an energetic event.

\section{A.2.2.9 Helical Coil Steam Generator}

The applicant has substituted a single-wall tube, helical coil steam generator in place of an older double-wall tube concept which was based on the steam generators used in EBR-II. The older design was very conservative, and leakages between the sodium and water/steam were quite unlikely. The newer design may be more likely to suffer such a leak, but has the additional capability to accommodate any resulting sodium expansion and a capability to bypass the sodium-water reaction byproducts.

\section{A.2.2.10 IHTS Auxiliary Cooling Systen (ACS) Modifications}

The applicant has added a forced circulation capability to this system, which removes heat from the outside of the steam generator. This is an "investment protection" system, and the forced circulation capability will likely reduce the time required to cool down the reactor in the event of a loss of normal cooling. As this is not a safetygrade system, its impact on the PRA was not evaluated in detail. However, the addition of a forced circulation capability would seem to be helpful to safety, since the system can still function under natural circulation.

\section{A.2.2.11 Reactor Fuel Redesign}

The applicant has made various changes in pin size, fuel loading, power densities, and burnup, in addition to the three GEMs and one USS that were added to the core. Most of these changes were made in response to some new information on the ternary metallic fuel, as well as a more thorough examination of reactor performance at different times in the fuel cycle. With these devices, the response of the reactor to unscrammed events may be better. A detailed study of the potential impact of the GEMs and USS on the overall design risk will need to be performed at a later stage in the design review.

\section{A.2.2.12 Impact of Changes on PRA}

The 1990 design changes fall into one of four categories:

(1) Changes directed at decreasing risk from external events:

- seismic isolation of the EM pump synchronous machines and the RPS

- tornado hardening of the portable refueling closure, steam generator building, and control building

- upgrading the portable refueling enclosure to seismic Category I, and the steam generator building and control building to seismic Category II

(2) Changes directed at reducing the frequency of core damage:

- ura of GEMs to provide extra passive negative reactivity feedback for loss of flow accidents

- use of a diverse reactor shutdown system

- use of control rod withdrawal limiters (rod stops)

(3) Changes directed at preventing the release of radioactive material from the reactor vessel.

- design of the reactor head with the goal of accommodating the dynamic and static loading of a HCDA

- design of the reactor internals with the goal of accommodating a whole core meltdown and retaining it inside the reactor in a coolable and stable configuration

(4) Changes directed at preventing the release of radioactive material to the environment:

- use of low-leakage, pressure-retaining containment dome designed to retain its integrity under an HCDA, followed by a sodium fire which consumes all the containment oxygen, while maintaining the offsite dose below the protective action guidelines (PAGs) and limits in 10 CFR Part 100 (Ref. A.16). 


\section{A.3 Methodology and Data}

\section{A.3.1 Overview}

The PRISM PRA employed standard event-tree, fault-tree, and plant-system models to assess accident sequence frequencies. This methodology is well accepted by the PRA community. Best-estimate values (no uncertainty distribution) were used throughout the quantification process. LWR experience (Refs. A.5 and A.6) and the Clinch River PRA (Ref. A.7) provided the data used to estimate initiating event frequencies and component failure probabilities. Sequences were formed in the usual way by propagating system failure probabilities through the system-based event trees. The event trees ultimately terminate in either safe shutdown or 1 of 23 accident types. Branch-point probabilities were determined using fault-tree modeling, although the fault trees have very little detail on which to base system reliabilities. Only three systems were quantified using fault-tree methodology: the reactor protection system, the reactor shutdown system, and the EM pump coastdown system.

Each accident type has an associated phenomenological core response event tree. Event-tree sequences lead to 1 of 12 core damage states, each state having an associated containment event tree. The containment tree outputs are binned into 1 of 13 containment release categories. The release categories formed the input for the MACCS code (Ref. A.8), which calculates early and latent fatalities. The RISKSP code (Ref. A.9) was used to calculate overall risk. The codes themselves were not evaluated as part of this PRA review.

The PRISM risk model structure is shown in Figure A.1.

\section{A.3.2 Initiating Events}

It appears that the more important initiating events (Table A.1) associated with LMRs were identified and properly represented on the system event trees. Altogether, 21 initiating events were identified with frequencies that range from 5.5 events/yr for forced shutdown, to $10^{-13}$ events/yr for vessel failure. However, because the PRA attempts to encompass the very low probability end of the initiator spectrum, for example, $10^{-13}$ events/yr, a far greater effort is needed to justify completeness. Relying on past studies that truncate at orders-of-magnitude higher frequencies is not adequate.

Depending on the initiating event, a mean time to recover (MTTR) that ranged from 8 hours for substantial loss of flow to 4,380 hours for vessel fracture was estimated (Table A.1). The MTTR is directly related to the shutdown heat removal system mission time, which ultimately affects the accident sequence frequencies (the shorter the recovery time, the higher the reliability). The licensee did not document how the times were estimated. One issue that could affect the MTTR is the ueed for a safety-related seismically qualified control room (see Chapter 13) from which operators could communicate during an accident. PRISM's current design does not maintain such a safety-related control room and, therefore, no credit was given for it.

The PRISM PRA considers three general classes of initiators:

- reactivity insertions (excluding seismic)

- seismic events

- heat removal faults

These initiators tend to bound many of the concerns related to liquid sodium reactors. However, the impact of support-system-level failures, such as loss of dc power, instrument air, and service water, and interactions among support systems have not been addressed in detail because of lack of design detail. Specific issues regarding initiating events are:

- Factory manufacturing, preoperational testing, low primary pressure, and lack of vessel penetrations should reduce the probability of catastrophic reactor vessel failure. Nevertheless, it is unlikely that the primary vessel failure rate of $10^{-13} / \mathrm{yr}$ proposed by GE can be substantiated. A realistic assessment is, therefore, needed.

- The frequency of station blackout for PRISM was estimated by GE to be $3 \times 10^{-5} / \mathrm{yr}$. This frequency is comparable with current LWRs. PRISM, however, does not have Class $1 E$ emergency diesel generators and must run back reactor power and pick up house load during loss of offsite power. In addition, common-cause or cascade failures on the runback system were not modeled explicitly. The frequency of station blackout may, therefore, be much bigher than that reported in the original PRISM PRA.

The PRISM reactor was designed to passively accommodate loss-of-power events, and its performance under station blackout conditions should be acceptable. The requirement for safety-grade (Class 1E) power is low, approximately 60 kilowatts for a nine-module plant, and can be supplied entirely from batteries. The lack of Class $1 E$ diesel generators may actually be an advantage of this design, because the probability of a diesel generator starting up on demand need not be treated in the PRA. 

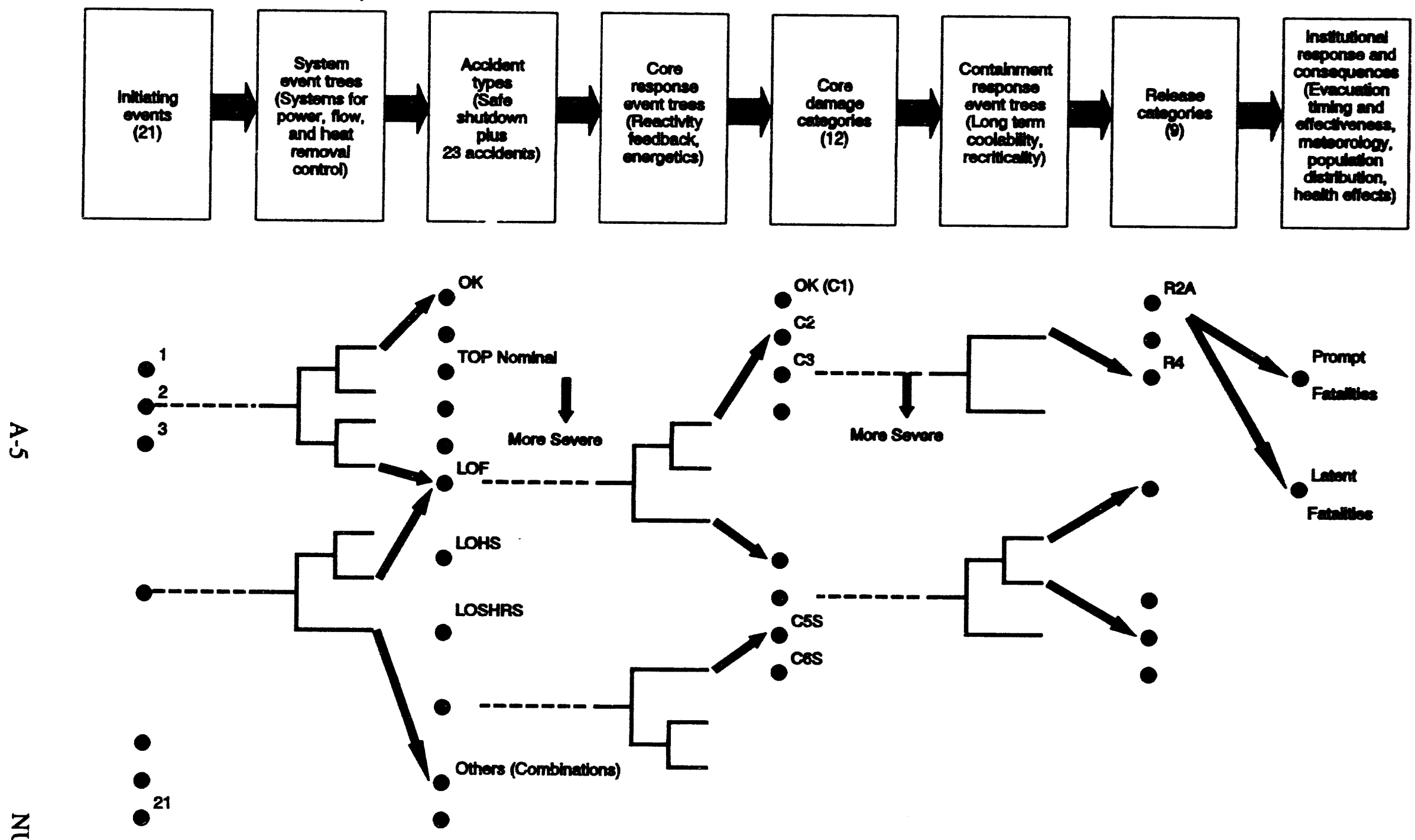

Figure A.1 PRISM risk model structure 
Probabilistic Risk Assessment

Table A.1 Initiating event frequency and mean time to recover

\begin{tabular}{|c|c|c|c|}
\hline $\begin{array}{l}\text { Event } \\
\text { no. }\end{array}$ & Initiating event & $\begin{array}{l}\text { Frequency } \\
\text { (per year) }\end{array}$ & $\begin{array}{l}\text { Shutdown heat removal } \\
\text { mission time (hours) }\end{array}$ \\
\hline 1 & Reactivity insertion $7 \mathrm{C}$ to $18 \mathrm{c}$ & $1.0 \times 10^{-4}$ & 600 \\
\hline 2 & Reactivity insertion $18 \mathrm{c}$ to $36 \mathrm{C}$ & $1.0 \times 10^{-4}$ & 600 \\
\hline 3 & Reactivity insertion $>36 \mathrm{C}$ & $1.0 \times 10^{-6}$ & 4,380 \\
\hline 4 & Earthquake $0.3 g$ to $0.375 g$ & $1.0 \times 10^{-4}$ & 120 \\
\hline 5 & Earthquake $0.375 g$ to $0.825 g$ & $1.9 \times 10^{-5}$ & 4,380 \\
\hline 6 & Earthquake $>0.825 g$ & $7.1 \times 10^{-7}$ & 4,380 \\
\hline 7 & Vessel failure & $1.0 \times 10^{-13}$ & 4,380 \\
\hline 8 & Local core coolant blockage & $1.8 \times 10^{-6}$ & 4,380 \\
\hline 9 & Reactor vessel leak & $1.0 \times 10^{-6}$ & 4,380 \\
\hline 10 & Loss of one primary pump & $1.6 \times 10^{-1}$ & 600 \\
\hline 11 & Loss of substantial primary coolant flow & $5.0 \times 10^{-2}$ & 8 \\
\hline 12 & Loss of operating power heat removal & $8.0 \times 10^{-2}$ & 86 \\
\hline 13 & Loss of shutdown heat removal via BOP & $8.0 \times 10^{-3}$ & 24 \\
\hline 14 & Loss of shutdown heat removal via IHTS & $1.0 \times 10^{-2}$ & 600 \\
\hline 15 & IHTS pump failure & $5.0 \times 10^{-2}$ & 600 \\
\hline 16 & Station blackout & $3.0 \times 10^{-5}$ & 1,200 \\
\hline 17 & Large $\mathrm{Na}-\mathrm{H}_{2} \mathrm{O}$ reaction & $6.0 \times 10^{-8}$ & 4,380 \\
\hline 18 & $\begin{array}{l}\text { Spurious scram and transients inadequately } \\
\text { handled by PCS }\end{array}$ & 0.6 & 600 \\
\hline 19 & Normal shutdown & 0.6 & 600 \\
\hline 20 & Forced shutdown & 5.5 & 240 \\
\hline 21 & RVACS blockage & $1.0 \times 10^{-8}$ & 86 \\
\hline Sum & & 6.398 & \\
\hline
\end{tabular}


Although GE has stipulated that, oven at higher froquencies, station blackout would not contribute significantly to risk, the high primary system temperatures associated with blackout conditions (see Section 5.7) may laad to damage to the reactor vessel, supporting structures, and safety systems needed for mitigation of other accidents. Whether PRISM should be allowed to have a station blackout frequency higher than current LWRs remains an open item whose resolution will depend on the ability and reliability of the ACS to control temperatures, the design capability of plant equipment to withstand such an event, and the ability to inspect the reactor components following the event.

- The ability of the plant control system (PCS) and balance-of-plant (BOP) systems to run back power in 9 out of 10 transients will need to be demonstrated. This could affect several sequences in addition to station blackout noted above.

- In the original design, a double-tube construction of the steam generator tubes has the potential for reducing the frequency of a large tube-rupture accident, but PRISM's $6 \times 10^{-8} / \mathrm{yr}$ event frequency appears to significantly underestimate the frequency of a large tube rupture. The steam generators are not seismic Category I, and common-cause failures that could result from fatigue, thermal shock, flow-induced vibration, and wear and aging have not been modeled.

A single-wall tube, helical coil steam generator now replaces an older double-wall tube concept. The older design was very conservative, and leakages between the sodium and water/steam were quite unlikely. The newer design may be more likely to suffer such a leak, but has the additional capability to accommodate any resulting sodium expansion and a capability to bypass the sodium-water reaction byproducts. The new steam generator's impact on the PRA will be reviewed in detail later in the design review.

- PRISM's estimated frequency for inadvertent control rod withdrawal at $10^{-4} / \mathrm{yr}$ is about two orders of magnitude less than that for LWRs. The data source used in the fault-tree quantification was not provided.

These items should be addressed at the next design stage.

\section{A.3.3 System Event-Tree, Fault-Tree Analysis}

Each initiating event, Events 1 through 18 of Table A.1, has a corresponding system response event tree in which only front line systems appear. Except for large seismic events greater than $0.825 \mathrm{~g}$ (event 6 in Table A.1), where the reactor protection system is replaced by the seismic isolation function, each tree contains the following:

- Reactor protection system (RPS): This system senses the need to shut down and initiates the proper signals for power, flow, and heat removal.

- Reactor shutdown system (RSS): This system includes the control rods, control rod drive motors, and magnetic latches.

- Inherent reactivity feedback features: These features include the control rods, their drivelines and guide tubes, the core restraint system, above and below core pads, and the grid plate.

- Primary pumps: These include the primary EM pumps and their electrical power supply.

- Pump coastdown system: This system includes the synchronous coastdown machines and their connecting cables.

- Operating power heat removal system: This system includes the BOP systems.

- Shutdown heat removal system: This system includes the intermediate heat exchanger (IHX) and RVACS. GE did not include the non-safety-grade ACS in their PRA.

Initiating Events 19 through 21 represent events that are controlled by the plant control system (PCS) or by manual scram of the reactor. Therefore, their event trees include only the shutdown heat removal capability to remove decay heat.

Depending on the types of system failures, each of the 21 initiating events result in 1 of 23 accident types. Identified alphanumerically (the larger the number the greater the severity), each accident type was binned into one of five generic accident groups:

S - protected loss of the IHX shutdown heat removal system (LOSHR)

P - unprotected transient overpower (UTOP)

F - unprotected loss of flow (ULOF)

H - unprotected loss of heat sink (ULOHS)

G - unprotected combined (transient overpower/loss of power) UTOP/LOF 
The numerical severity levels are:

1 - protected (reactor shut down by RSS) loss of the shutdown heat removal system (LOSHR)

2 - unprotected (reactor not shut down by the RSS) transient overpower (TOP)

3 - unprotected loss of flow (LOF)

4 - unprotected loss of heat sink (ULOHS)

5 - unprotected combined TOP with LOF or TOP with ULOHS

The LOF and combined TOP/LOF accidents were predicted in the PRA to have the highest frequencies at approximately $6 \times 10^{-8} / \mathrm{yr}$ and $2 \times 10^{-8} / \mathrm{yr}$, respectively. The LOSHR and ULOHS accidents had lower frequencies at about $10^{-10} / \mathrm{yr}$. Loss of primary flow (LOF) initiated by primary pump failures and large seismic events were the dominant contributors to the LOF and TOP/LOF accident frequencies, which also dominate both the prompt and latent fatalities.

The fault trees used to estimate the system reliabilities lack the detail needed to substantiate the high reliabilities claimed in the PRISM PRA. Support system failures, system interactions, and human errors are essentially unmodeled. Common-cause beta facturs are assumed small and fragility data are derived by judgment. In most cases, the original PRISM PRA did not provide specific sources of data used in the fault trees, and there was reason to believe that some of the basic event probabilities have been underestimated. In Appendix G of the PSID, GE compared the common-cause factors and beta factors used in the PRISM PRA to values referenced by Electric Power Research Institute (EPRI) for the advanced lightwater reactor, and concluded that the values used in the PRISM study are comparable to, or more conservative than, those recommended by EPRI.

In Appendix G of the PSID, the applicant provided additional justification for the data used in the fault trees. The applicant points out some fundamental differences between the PRISM advanced liquid-metal reactor (ALMR) and conventional LWR systems operation and configuration, which should reduce the significance of dependent failures resulting from common-cause, human errors and dependence on support systems. These include:

- Safety systems needed for reactor shutdown and decay heat removal in the ALMR are either continuously operating and monitored (RVACS, for example) or are almost continuously operating and monitored (the RPS and control rods, for example). In contrast to conventional LWRs, where the majority of safety systems are in an inactive standby mode, the ALMR safety systems are expected to reveal any degradation or failure prior to the time their use is demanded, thus, leadiug to a higher availability when needed.

- Monitoring of safety equipment, failure isolation, diagnostics of abnormal conditions, and reactor protection are all done automatically in the ALMR without operator (human) intervention, thus reducing the man-machine interface significantly.

- No support systems are needed for the operation of RVACS, for reactor trip by the latch mechanism, for the ultimate shutdown (USS) mechanism, for cooling the EM pumps, or for the operation of the EM pump synchronous coastdown machines. Electric power for the diverse control rod drive-in mechanism is very small, and is needed for only 2 minutes.

GE acknowledges that these observations do not replace the need to continue to evaluate the safety of the PRISM design and perform detailed analyses covering all questions of dependencies from human interactions, system interactions, and support system interactions. Plans are in place to apply state-of-the-art methodologies and the latest data, as the design evolves and the system interfaces become more clearly defined. Importance analyses will continue to be used to focus the effort on those issues that might have a significant impact on risk.

The generic accident groups do, however, highlight the significance of several important systems: reactor protection system, primary EM pump coastdown system, reactor vessel air cooling system, reactivity control and shutdown system, seismic isolation system, and the passive reactivity feedback features. Limitations in quantifying these systems' reliabilities are discussed in Section A.4.

\section{A.3.4 Sensitivity Study on Initiating Event Frequencies}

The staff noted early in the review that the claimed frequency of 4 of the 21 initiating events-catastrophic reactor vessel failure, station blackout, steam generator tube rupture, and inadvertent control rod withdrawal-appear to be low when compared to currentgeneration LWRs. GE evaluated the importance of the uncertainty in an initiating event in Appendix $G$ to the PRISM PSID. This importance is defined as the increase in the event frequency that would be required to double the risk from the event. The larger this factor, the less important the event. The results of the GE study are summarized in Table A.2. The most sensitive event is the 
large earthquake, with a factor of 2.35 increase in frequency needed to double the risk.

Table A.2 Risk sensitivity to uncertainty in initiating event frequencies

\begin{tabular}{|c|c|c|c|}
\hline Rank & Initiating event & $\begin{array}{l}\text { Estimated } \\
\text { frequency } \\
\text { (per year) }\end{array}$ & $\begin{array}{l}\text { Factor } \\
\text { increase } \\
\text { allowable } \\
\text { before risk } \\
\text { is doubled }\end{array}$ \\
\hline 1 & 6 Earthquake $>0.825 \mathrm{~g}$ & $7.0 \times 10^{-7}$ & 2.35 \\
\hline 2 & 10 Loss of one primary pump & $1.6 \times 10^{-1}$ & 20 \\
\hline 3 & 11 Loss of substantial primary coolant flow & $5.0 \times 10^{-2}$ & 60 \\
\hline 4 & 12 Loss of operating power heat removal & $8.0 \times 10^{-2}$ & 200 \\
\hline 5 & 5 Earthquake $0.375 g$ io $0.825 g$ & $1.9 \times 10^{-5}$ & 1,600 \\
\hline 6 & 2 Reactivity insertion $18 \mathrm{C}$ to $36 \mathrm{C}$ & $1.0 \times 10^{4}$ & $4 \times 10^{4}$ \\
\hline 7 & 21 RVACS blockage & $1.0 \times 10^{-8}$ & $2 \times 10^{7}$ \\
\hline 8 & 20 Forced shutdown & 5.5 & $4 \times 10^{7}$ \\
\hline 9 & 19 Normal shutdown & 0.6 & $1 \times 10^{8}$ \\
\hline 10 & 3 Reactivity insertion $>36 \mathrm{C}$ & $1.0 \times 10^{-6}$ & $3 \times 10^{8}$ \\
\hline 11 & All other events & & $>10^{10}$ \\
\hline
\end{tabular}


The staff had concerns about an apparent low frequency estimate, that the four events identified above, all fall into the "all other events" group, for which group an increase in frequency on the order of $10^{10}$ is needed to double the risk from these events. GE investigated these four events further with the following results:

- The catastrophic reactor vessel failure in the original PRA referred to a complete circumferential rupture of the vessel from fatigue. Fracture mechanics analyses led to the extremely low frequency estimate of $10^{-13}$ per vessel year. Revised analyses, in support of Appendix G of the PSID, indicate that extreme seismic events and leaks in both the reactor vessel and the guard vessel dominate the conditional vessel failure probability. The random catastrophic vessel failure is excluded from the revised list of initiating events to be used by GE for future studies on the basis of being insignificant. However, vessel failure will be included in a future PRA as a failure given a severe earthquake.

- An independent assessment on the frequency of station blackout was performed for GE, for the PRISM PSID Appendix $G$ response, using a newly developed data base. The results were nearly identical to the original value. It was noted that the safety systems do not depend on the availability of electric power; consequently, significant errors in the estimated frequency should have negligible impact on the risk estimates.

- In the original PRA, the steam generator tube rupture used in the beyond-design-basis, composite event analysis involved multiple tube ruptures and failure of the multiple protective systems designed to terminate the resulting sodium-water reaction. The new steam generator design will be evaluated in future studies.

- The reactivity insertion events were reevaluated with a new data base for the PRISM PSID Appendix G submittal. The current estimate of the frequency of these initiating events is about an order of magnitude higher than the original estimates, but is still lower than those of a typical LWR.

\section{A.4 System Analysis}

\section{A.4.1 Reactor Protection System}

The PRISM module is protected by two shutdown systems:

(1) The reactor protection system (RPS) is a safetyrelated system that monitors primary plant parameters and trips the reactor whenever primary parameters are exceeded.
(2) The plant control system (PCS) is a non-safetyrelated system normally used to control reactor power. This system monitors secondary plant parameters and can provide a trip signal to the RPS should certain parameters be exceeded.

The RPS can signal the PCS to cut back power or make adjustments to other plant systems during certain transient conditions. An RPS reactor trip is accomplished by deenergizing the magnetic latch mechanisms, that release the control rods from their drive assemblies. In addition, a reactor trip will energize safety-related control rod drivein motors to ensure rod insertion and provide a diverse and redundant means of rod insertion. Computerized monitoring and periodic testing is expected to improve reliability.

There are four RPS divisions (two-out-of-three logic with one on standby), each housed in separate instrument vaults. The RPS fault trees were not fully developed, and common-cause failures, although included, were not modeled explicitly. The very low failure-per-demand probabilities (as low as $4 \times 10^{-10}$ for some sequences) are about five orders of magnitude less than those used for LWRs. Specific issues are

- The reliance of all four division setpoints on a fifth file maintrined independently by the PCS will need further analysis. This alone could be a significant commoncause contributor to the scram system.

- The ability to maintain no common elements, functions, or electrical interconnections between each of the instrumentation vaults will have to be substantiated at a later design stage.

- Potential system interactions between the RPS, PCS, and other PRISM modules could exist but remain unmodeled at this time.

- Human errors related to improper test and maintenance on the RPS and PCS have not been modeled.

\section{A.4.2 Primary Pump Coastdown System}

To prevent sodium boiling in the reactor core following trip of the primary EM pumps, a controlled primary flow coastdown is required. The PRISM primary pumps are electromagnetic and, therefore, do not have inertial coastdown capability. Synchronous coasidown machines are used to supply electrical power to the pumps during the coastdown period. In the original design, failure of one of the four coastdown machines had the potential to lead to sodium boiling for unprotected events if the other three pumps did not coast down normally. In the revised 
design, the GEMs have beer added to the system and their reuctivity feedback following a loss-of-flow event reduces the need for reliance on an external electrical source for coastdown. Instantaneous loss of primary flow (no coastdown) and failure to scram will lead to severe consequences, the magnitude of which is very difficult to predict. Assurance must be maintained that primary pumps will not trip before neutronic shutdown. By adding logic to the RPS to detect rod insertion before pump trip, GE has reduced the risk of pump trip before reactor shutdown, probably by two orders of magnitude. Excluding large earthquakes, no credible common-cause failures of the syachronous machines were postulated in the PRA. A subjective beta factor of 0.005 was chosen for failure of three of the four synchronous coastdown machines to supply power to the EM pumps and, when multiplied by the probability of individual synchronous machine system failure on demand, estimated as $5 \times 10^{7}$, results in a common-cause failure on demand contribution of less than $10^{-9}$. Coupled with a $10^{-9}$ scram failure probability, the sequence is essentially insignificant. Such a low failure probability cannot be justified because of lack of data and details. The staff identified the following areas that require further study:

- system interactions between the synchronous machines, their power supply and control system, primary pump power supply, other power blocks, and other modules

- environmental interactions and the impact on the synchronous machine from such common-cause events as smoke, fire, inadvertent fire suppression, flooding, and loss of heat, ventilation, and air conditioning (HVAC)

- effects of aging on the coastdown system

- human errors during periodic maintenance and testing of the coastdown system

- ability to test and monitor system status during normal operation

In Appendix G of the PSID, GE supplied additional material to address these concerns. There are no system interactions among the four pump systems other than obtaining power from the same site power supply system. The successful coastdown of each EM pump is fully dependent upon the successful operation of that EM pump and its associated synchronous coastdown machine, and its safety-grade Class $1 E$ breakers which open to disconnect the system from the normal power supply system. Backing up each circuit breaker are individual Class $1 E$ overcurrent protection devices.
The only credible external common-cause failure that fails two or more coastdown systems simultaneously is an earthquake of very large magnitude. Since the coastdown equipment is seismically isolated, the effects of a large earthquake are considerably mitigated. Fire, smoke, and loss of heating and ventilation are not postulated to be major common- cause risk factors due to the separation and 3-hour fire barriers of the EM pump auxiliary equipment vaults, and the short time interval (2 minutes) during which the synchronous coastdown machine is required. Aging is not expected to be a concern because of the on-line performance monitoring systems. Plant operation and maintenance requirements will include protection to prevent common-mode failures from such human activities as testing, calibration, and maintenance.

Common-mode failures, associated with the mechanical and physical design of the hardware and within the electrical supplies and control systems, that could result in the loss of more than one EM pump synchronous coastdown machine, need to be evaluated at a later design stage when the system design is complete.

The synchronous machines have been moved to the nuclear island and are seismically isolated and, therefore, their susceptibility to damage from earthquake shock and falling debris has been reduced. Failure of the synchronous machines during a seismic event is one of the leading contributors to PRISM's risk. Although seismically initiated events dominate the plant risk, only limited documentation of the seismic analysis is available at this time. In particuiar, GE estimated that the conditional probability of pump-coastdown failure given a seismic event between $0.375 \mathrm{~g}$ and $0.825 \mathrm{~g}$ is approximately $2 \times 10^{8}$, while for seismic events greater than $0.825 g$ GE estimated a conditional probability of approximately $6 \times 10^{-1}$. This discontinuity unrealistically biases the risk from seismic events and needs to be corrected. Fragility data and detailed analysis are needed to substantiate the risk estimates.

\section{A.4.3 Shutdown Heat Removal System}

Residual decay heat must be removed by the shutdown heat removal system (SHRS) following reactor scram. The SHRS consists of three paths by which decay heat can be removed:

(1) through the intermediate heat transport system (IHTS), the steam generator, and then by steam flow through the turbine or turbine bypass to the main condenser 
(2) through the IHTS, the steam generator, and then by natural circulation of air over the shellside surface of the steam generator (ACS)

through the reactor vessel, the containment vessel, and then by natural circulation of air through the safety-related reactor vessel air cooling system (RVACS)

Excluding large external events and RVACS blockage, GE estimated the probability of shutdown heat removal system failure on demand ranges to be $4.4 \times 10^{-7}$ or less, depending on the event sequence. These extremely low failure probabilities are attributed to

- diversity and redundancy in decay heat removal

- ability to continuously monitor the operability status of the SHRS

- long response times that allow for repairs

- higher balance-of-plant decay heat removal reliability, which allows cutback from three feedwater pumps to one and from two main condensers to one

The extremely low RVACS failure probability has essentially eliminated internal loss-of-heat-sink (LOHS) accidents from the dominant sequences. Although appealing because of its passive behavior, RVACS has no operational history. Lack of operating experience and inability to specifically identify RVACS failure modes does not allow eliminating LOHS sequences based solely on analytically established probability. Furthermore, RVACS efficiency depends on the environmental conditions present at the site. High temperatures are expected during conditions where the RVACS alone removes decay heat. Such high temperatures could affect the capability of the vessel and supporting structure for continued operation while degradir.: other systems needed for subsequent plant operation, for example, primary pumps. Other issues are discussed below.

Common-cause and cascade failures of the feedwater train and main condenser were not modeled in shutdown heat removal via BOP and will limit the reliability of the secondary-side heat removal system. An in-depth analysis of the BOP including support systems, and interactions among systems is needed to substantiate the PRA quantification. The ACS, for example, was not modeled explicitly, although it requires operator action.

\section{A.4.4 Reactivity Control and Shutdown Systen}

The reactivity control and shutdown system consists of six rods, any one of which could successfully shut down the reactor. GE used simple fault trees to estimate the probability of system failure, which ranged from $2.9 \times 10^{-7}$ to $5.8 \times 10^{-9}$ per demand, depending on the initiating event. Subjective common-cause beta factors used in the PRA must be substantiated at a later design stage. GE attributes the low failure rates associated with the PRISM design to the need for only 1 of 6 rods to shut down the reactor, as compared to 47 of 48 in an LWR; a mean time to failure estimate of 10 to 1,000 times longer than in an LWR; increased redundancy in trip breakers; and an unavailability estimated at $10^{-4}$ of that in an LWR. The demand failure probability of the scram motor at $10^{5}$ is deemed optimistic at this time and, depending on the mode of failure, could degrade the passive feedback features discussed in Section A.4.6.

\section{A.4.5 Seismic Isolator System}

A unique feature in the PRISM design is the ability to isolate the reactor vessel during a seismic event. Although the reactor itself is designed to $0.3 g$, seismic isolators (designed to $1.0 \mathrm{~g}$ ) reduce the horizontal motion of the reactor vessel from the earth's horizontal oscillatory motion during an earthquake, thereby increasing the seismic margin. Although not explicitly stated in the PSID, the reactor silo will also be designed to $1.0 \mathrm{~g}$, according to GE engineers.

For a seismic initiating event greater than $0.825 g$, GE includes the seismic isolator function explicitly in the system response tree. GE subjectively chose a failure probability of $1.35 \times 10^{-3}$. GE did not explicitly model maintenance, aging, and other potential common-cause failure mechanisms of the isolator's natural-rubber bearings.

\section{A.4.6 Passive Reactivity Feedback}

As primary temperature increases, sodium density decreases, adding positive reactivity to the core. Other passive feedback effects, however, limit the rate and extent of increase in power by adding negative reactivity. Instantaneous or prompt negative feedback results from Doppler absorption and fuel axial expansion. Delayed r gative feedback results from control rod motion, fuel subassembly bowing or dilation of the subassembly load pads, and expansion of core support grid plates. 
Under certain "failure to scram" conditions, prompt negative reactivity feedback alone cannot overcome the positive sodium reactivity addition. An instantaneous LOF without scram and primary pump constdown (which is needed to maintain sodium temperature : below the boiling point) would result in voiding (due to sodium boiling) the core in only a few seconds. Core voiding could lead to core disassembly and the release of a large amount of radioactivity. The plant can be protected against such an event only by ensuring a low probability of failure to scram and a high reliability for the coastdown system.

Delayed feedback is conditional and depends on control rod movement and structural integrity. Stuck control rods and structural failures caused by such external events as earthquakes can defeat or severely limit feedback effects. Passive feedback is, therefore, dependent on the initiating event and the ability to keep the control rods free in their guide tubes.

For other than seismic events, the probability of passive feedback failure has been quantified as follows:

- If the reactivity control and shutdown system has failed, 0.1 per demand. This estimate was based on a fault tree that indicated that 10 percent of such failures resulted in stuck rods, a condition that partially negates reactivity feedback. (GE engineers claim that the PRA is extremely conservative in this estimated failure probability, although probabilistic modeling and documentation to substantiate this claim were not submitted.)

- If the control rods are free to move in their guide tubes, $10^{-6}$ per demand. The only mode of failure identified is structural failure that would prevent fuel assemblies from moving or extending in the right geometry.

For seismic events, the failure probability of the passive feedback features increases with $g$-loading. For earthquakes greater than $0.825 \mathrm{~g}, \mathrm{GE}$ assumes that the passive feedback features fail.

A generic failure probability of $10^{-6}$ for the passive feedbacks for all nonseismic demands appears optimistic. Passive feedbacks are much more effective during transients that extend over longer periods of time (loss of heat sink) than for those that occur rapidly (loss of flow). Such behavior was not reflected in the PRA.

Finally, it should be recognized that, since the passive feedback features on which PRISM must ultimately depend during the dominant-risk severe accidents rely to a large extent on structural motion, a means for in-service testing over the life of the plant needs to be developed to ensure such structural motions are maintained as the plant ages.

\section{A.4.7 Sensitivity Studies on Frequency of Accident Types}

Similar to the importance analysis presented in Section A.3.4 for initiating events, GE performed an importance analysis of the uncertainty in the frequency of accident type by calculating the risk-doubling factor. The results are presented in Table A.3. The combined UTOP/ULOF event was found to be the most sensitive accident. The frequency of the event comes almost entirely from the large earthquake initiating event. Next in importance is the ULOF accident type which results from two types of sequences: (1) one involves EM pump trip with failure to scram and failure to coastdown and (2) the other includes EM pump trip with successful coastdown but stuck control rods so that no credit can be taken for negative reactivity from control rod expansion. The second sequence dominates the risk. The unavailability of the synchronous coastdown machines has to increase by a factor of at least $10^{7}$ to bring the first sequence near the second in frequency.

\section{A.5 Phenomenological Analysis}

Although an objective of the PRISM design was to eliminate core melt and core energetic accidents from consideration in the design (via prevention), the PRISM PRA nevertheless analyzed such events in an effort to quantify risk.

\section{A.5.1 Core Response Event Trees}

Basically, GE used two types of core response event trees. The first type corresponds to ULOF and ULOHS accident types. During these types of accidents, heatup of the primary sodium occurs first, followed by passive negative feedback. Should passive feedback fail to shut down the reactor, eutectic formation and cladding penetration, sodium voiding, meltdown, and severe energetics could result. The second type of core response event tree corresponds to transient overpower (TOP) and combined TOP/LOF events. Scram is required for shutdown, although passive feedbacks alone could stabilize reactor power at an elevated level, and allow recovery.

Associated with the 23 accident types are the core response event trees. The response trees lead to 12 core damage categories: C1-C6 and C1S-C6S, six with and six without shutdown heat removal, respectively. The categories define the amount of fuel and fission products released, the extent of vessel or vessel seal damage, and sodium temperature. Basically, the core response trees model the 
Table A.3 Risk sensitivity to uncertainty in accident-type frequencies

\begin{tabular}{|c|c|c|c|}
\hline Rank & Accident type & $\begin{array}{l}\text { Estimated } \\
\text { frequency } \\
\text { (per year) }\end{array}$ & $\begin{array}{c}\text { Factor } \\
\text { increase } \\
\text { allowable } \\
\text { before risk is } \\
\text { doubled }\end{array}$ \\
\hline 1 & G4 Combined severe UTOP and ULOF & $2.1 \times 10^{-8}$ & 2.5 \\
\hline 2 & F3 Severe ULOF & $6.6 \times 10^{9}$ & 13 \\
\hline 3 & G4S Combined , G4 and LOSHR & $9.6 \times 10^{-10}$ & 49 \\
\hline 4 & H3 Severe ULOHS & $7.0 \times 10^{-11}$ & 1,540 \\
\hline 5 & G3 Combined severe UTOP and ULOF & $6.0 \times 10^{-11}$ & $2 \times 10^{3}$ \\
\hline 6 & S5 LOSHR with degraded core flow & $3.0 \times 10^{-11}$ & $3 \times 10^{3}$ \\
\hline 7 & LOSHR with normal core flow & $5.0 \times 10^{-12}$ & $2 \times 10^{4}$ \\
\hline 8 & P3 Severe UTOP & $<10^{-12}$ & $7 \times 10^{6}$ \\
\hline 9 & F1 Design-basis ULOF & $<10^{-12}$ & $7 \times 10^{8}$ \\
\hline 10 & All other events & $<10^{-12}$ & $>10^{9}$ \\
\hline
\end{tabular}

* - Type definitions:

F1 Unprotected flow coastdown

F3 Unprotected loss of flow with failure of flow coastdown or degraded inherent reactivity feedback

P1 Unprotected reactivity insertion $7 \mathfrak{C}$ to $18 \mathrm{C}$

P2 Unprotected reactivity insertion $18 \mathrm{C}$ to $36 \mathrm{C}$

P3 Unprotected reactivity insertion $>36 \mathrm{C}$

P4 Unprotected reactivity insertion $>36 \mathrm{C}$ with degraded inherent reactivity feedback

H2 Unprotected loss of heat sink at nominal power

H3 Unprotected loss of heat sink at elevated power

G3 Combined (P2 and F3) with (P3 and F1)

G4 Combined (P3 and F3) with (P4 and F1) 
earlier stages of accident progression where neutronic activity could lead to energetic situations and early vessel breach. The later stages are treated in the containment response event trees (Section A.5.2).

For events with shutdown heat removal capability, the core response trees $(\mathrm{C} 1-\mathrm{C} 6)$ contain'six branch points:

- reactor shuts down, before cladding failure as a result of fuel-cladding eutectic formation

- core flow is unimpeded by flow blockage or fissionproduct gas release

- reactor shuts down as a result of fuel sweepout following cladding failure

- reactor shuts down before significant damage occurs

- amount of energy released is insignificant

- energetic release does not result in damage to the reactor vessel (primary coolant) boundary

For events without shutdown heat removal capability, the core response trees (C1S-C6S) contain five branch points:

- no cladding failure occurs as a result of fuel-cladding eutectic formation

- no sodium boiling or voiding occurs

- core flow is unimpeded by flow blockage or fissionproduct gas release

- amount of energy released is insignificant

- energetic release does not damage the reactor vessel (primary coolant) boundary

If the passive feedbacks fail, then a similar situation as that postulated for the LOF and ULOHS scenarios (sodium voiding and energetics) would result. The only core damage category projected by GE to lead to an uncoolable core debris condition is C6 (large core melt). The dominant contributors to $\mathrm{C} 6$ are the LOF sequences that involve failure to scram and failure of the passive feedback features. The sequences lead to sodium boiling and neutronic excursions because of PRISM's positive void coefficient. According to the PRA, the C6 core condition leads to melting 100 percent of the fuel with 10 percent forming a vapor. The largest uncertainty in the PRA stems from the engineering judgment used to estimate the energy associated with such an energetic release. The energy so chosen ultimately affects the vessel behavior, source term, and consequences.

The system event trees account for possible structural damage or misalignment which could prevent structural components from expanding to provide the expected negative reactivity feedback. The core event trees accommodate the dependence of the effectiveness of the passive reactivity feedback on the accident type and severity. Table A.4 shows the conditional probability of failure to provide sufficient reactivity feedback to prevent fuel cladding eutectic formation and sodium boiling that were used by GE for the different accident types and severity. GE is reevaluating these conditional failure probabilities to include the addition of the GEMs in the design, which should enhance the passive negative reactivity feedback under ULOF conditions. The new probabilities will be reviewed at a later stage in the design review.

In general, GE did not perform mechanistic analyses to support this portion of the PRA, but exercised judgments based on experimental work performed on the oxide fuel core at the FFTF, and then extrapolated findings to the metallic core used in the PRISM design. Differences between oxide fuel and metal fuel behavior under transient conditions introduce an additional source of uncertainty. Metal fuels tend to release the noble gases and volatile materials at lower temperatures than do oxide fuels. There is virtually no prior experience with modeling metal fuel LMRs under LOF conditions and, since physical arguments based on perceived physical properties of the system and generic physical principles can be misleading, the PRA at this stage of development is considered to contain substantial uncertainties. Additional experimental work will be needed to resolve these uncertainties.

\section{A.5.2 Containment Response Event Trees}

Each of the 12 core damage categories have an associated containment response event tree. The containment trees model the later stages of accident progression, which take a long time to develop and can lead to core meltdown or late energetics. The branch points on the tree determine the following phenomenological core and vessel behavior during the accident:

- debris coolability

- early vessel thermal failure (due to high temperature)

- core uncovery resulting from sodium boiloff

- energetic recriticality 


\section{Probabilistic Risk Assessment}

GE binned the output sequences into the following nine containment release categories that subsequently determine the magnitude and timing of the radioisotopes released:

- R2A - 25-percent early core melt transient, early debris not coolable

- R3 - 100-percent early core melt transient with energetic expulsion, debris coolable, no melt-through
- R4A - 100-percent early core melt transient with energetic expulsion, early debris not coolable

- R6A - no early transient, loss of SHRS and core uncovery, no late energetic expulsion

- R6U - early transient, minor core damage, otherwise same as R6A

Table A.4 Conditional probability of eutectic formation and sodium boiling

\begin{tabular}{|c|c|c|c|}
\hline & Accident & $\begin{array}{l}\text { Conditional probability } \\
\text { of eutectic formation }\end{array}$ & $\begin{array}{c}\text { Conditional probability } \\
\text { of sodium boiling } \\
\text { given } \\
\text { eutectic formation }\end{array}$ \\
\hline F1 & Unprotected flow coastdown & 0.01 & 0 \\
\hline F3 & $\begin{array}{l}\text { Unprotected loss of flow with failure of } \\
\text { flow coastdown or degraded inherent } \\
\text { reactivity feedback }\end{array}$ & 1 & 0.5 \\
\hline P1 & Unprotected reactivity insertion $7 \mathrm{c}$ to $18 \mathrm{C}$ & 0.01 & 0 \\
\hline P2 & Unprotected reactivity insertion $18 \mathrm{C}$ to $36 \mathrm{C}$ & 0.05 & 0.001 \\
\hline P3 & Unprotected reactivity insertion $>36 \mathrm{c}$ & 0.5 & 0.01 \\
\hline P4 & $\begin{array}{l}\text { Unprotected reactivity insertion }>36 \mathrm{C} \text { with } \\
\text { degraded inherent reactivity feedback }\end{array}$ & 0.99 & 0.01 \\
\hline $\mathrm{H} 2$ & $\begin{array}{l}\text { Unprotected loss of heat sink at nominal } \\
\text { power }\end{array}$ & 0.01 & 0 \\
\hline H3 & $\begin{array}{l}\text { Unprotected loss of heat sink at elevated } \\
\text { power }\end{array}$ & 1 & 0.5 \\
\hline G3 & Combined (P2 and F3) with (P3 and F1) & 0.7 & 0.1 \\
\hline G4 & Combined (P3 and F3) with (P4 and F1) & 1 & 0.9 \\
\hline
\end{tabular}

* Type definitions:

F1 Unprotected flow coastdown

F3 Unprotected loss of flow with failure of flow coastdown or degraded inherent reactivity feedback

P1 Unprotected reactivity insertion $7 \mathrm{c}$ to $18 \mathrm{c}$

P2 Unprotected reactivity insertion $18 \mathrm{C}$ to $36 \mathrm{C}$

P3 Unprotected reactivity insertion $>36 \mathrm{C}$

P4 Unprotected reactivity insertion $>36 \mathrm{C}$ with degraded inherent reactivity feedback

H2 Unprotected loss of heat sink at nominal power

H3 Unprotected loss of heat sink at elevated power

G3 Combined (P2 and F3) with (P3 and F1)

G4 Combined (P3 and F3) with (P4 and F1) 
- R6S - early transient, 25-percent core melt, otherwise same as R6A

- R8A - no early transient, loss of SHRS and core uncovery, late energetic expulsion

- R8U - same as R6U but with late energetic expulsion

- R8S - same as R6S but with late energetic expulsion

Category R4A had the highest release frequency at $2.2 \times 10^{-8} / \mathrm{yr}$, and is the dominant contributor to both the early and latent fatalities. Core damage state $\mathrm{C} 6$ is the main contributor to this release category. According to the PRA, there is basically a 90 -percent chance that a C6 core damage state would lead to early containment vessel failure and a large release of radioactivity, that is, release Category R4A. The remaining 10 percent results in coolable geometry (release Category R3).

R4A has the largest source term because of the severity of the sequence at an early time, that is, core disruption with 10 percent of the core expelled initially into the containment and a subsequent 100 -percent core melt with containment vessel failure. Other core melt sequences involve cooldown or similar behavior over longer periods of time, for example, 64-99 hours before containment vessel melt-through. The longer time periods effectively reduce the consequences and risk. Assumptions made at this stage in the PRA have a significant effect on the predicted consequences. On the basis of the original design, these included:

- the assumption that expulsion of sodium from the vessel will always be upward and into the head access area (HAA)

- the assumption that the releases will be attenuated by aerosol agglomeration and settling in the head access area (Leakage at a rate of 100 -percent volume/day is assumed.)

- the assumptions related to the energetic sequences that would result in only (1) 10-percent vaporization of the fuel of which 5 percent is expelled into the HAA and (2) the noncatastrophic failure of the HAA

Mechanistic analyses do not support these assumptions. The energetics involved have large uncertainties (see Section A.5.1), that affect the assumptions made at this stage in the PRA.
In the revised design, a leak-tight containment dome has been added to the upper head region of the reactor vessel. In Appendix $\mathbf{G}$ of the PSID, GE re-evaluated the accident consequences for the hypothetical core disruptive accident (HCDA), to bound the risk. The staff has also performed an evaluation of the HCDA (Ref. A.10), as discussed in Chapter 15 of this SER. Included in this evaluation is an assessment of the source term used by $\mathrm{GE}$ for the consequence analyses.

The HAA (the space above the containment dome and the upper part of the concrete reactor silo), now only important during refueling operations, is not a leak-tight barrier, and the amount of protection it would actually provide could only be termed speculative at this conceptual design stage. As a result of the design changes, the HAA will need to be reviewed in detail at a later stage in the design review, with emphasis on refueling accidents.

\section{A.5.3 Consequences}

Public consequences, presented in the original PSID, were calculated by GE for the WASH-1400 (Ref. A.6) site 6, eastern U.S. coastal site (GESSAR II site). For evacuation cases, standard strategies based on expected population movement during an unplanned evacuation were assumed. For people not being evacuated, strategies were assumed on the basis of relocation and expected groundshine dose.

The consequences presented were for oxide fuel, even though metal fuel is proposed for the PRISM design. In order to estimate the impact of metal fuel on the consequences, GE performed a sensitivity study. The releases were accelerated by a factor of 1.5 , and the solids released were increased by 15 percent because of assumed fuel-concrete-water reaction. For the R4A no-evacuation case, prompt fatalities were shown to increase from 7 to 124 , and latent fatalities increased from 1,520 to 3,320 . Other releases also resulted in risk increases, but were much smaller contributors to overall risk. Except for the early energetic releases, all other accident sequences result in a gradual heatup and boiloff of sodium. There is the potential for late energetics in these boiloff sequences, but these accidents result in a 3-day to 4-day grace period, which provides adequate time for evacuation.

For the risk-dominant LOF and TOP/LOF sequences, three areas were identified for which the staff believes the $\mathrm{GE}$ assumptions appear too optimistic. The staff will require further analysis in these areas

- fission-product holdup in the HAA that leads to attenuation of the radioactivity released from the vessel 
- release fractions of barium and strontium that could be higher than those used in the GE treatment of energetic recriticalities

- 10-percent core vaporization due to the assumed energetics

In Appendix G of the PSID, GE provided a sensitivity study to address uncertainties from lack of metal fuel data and to address the lack of a detailed mechanistic analysis. Three source terms were analyzed with the SMART (Ref. A.11) computer program:

- WASH-1400 Release Category PWR1 with the 3,412 MWt PWR radioisotopic inventory of the SMART code library

- Release Category PWR1 with the PRISM end of equilibrium cycle inventory

- a PRISM release category which is more consistent with the release scenario expected from a metal core under a hypothetical, protected indefinite loss of all decay heat removal (LODHR) (both IHX and RVACS) capability event

The release categories for these bounding events are presented in Table A.5. Three analyses were performod for different weather patterns, (1) moderately stable weather (Type F), (2) neutral weather (Type D), and (3) extremely unstable weather (Type A). The resulting probability of early fatality as a function of distance are shown in Figures A.2.A, A.2.B, and A.2.C, respectively. It is noted that no containment attenuation or delay were assumed for the source term. The results indicate that the small radioactive inventory, the fission-product retention capability of sodium, and its thermal capacity have a significant impact on reducing public risk.

\section{A.6 Summary}

Public risk from the operation of a single PRISM module has been estimated in the PRISM PRA to be several orders of magnitude less than the NRC safety goal's quantitative health objectives. Societal risk, or probability of latent cancer fatality per one year of operation (out to 10 miles) was estimated by GE to be approximately $9.0 \times 10^{-12} / \mathrm{yr}$, and $1.0 \times 10^{-11} / \mathrm{yr}$, with and without evacuation, respectively. This risk is much smaller than the proposed NRC safety goal of $1.9 \times 10^{-6} / \mathrm{yr}$. The individual risk or probability of prompt fatality per 1 year of operation out to 1 mile was reported to be less than $10^{-13} / \mathrm{yr}$, and $3.0 \times 10^{-10} / \mathrm{yr}$, with and without evacuation, respectively. This is also small compared to the safety goal of $5 \times 10^{-7} / \mathrm{yr}$. The large release frequency was reported to be approximately $2.0 \times 10^{-8} / \mathrm{yr}$, compared to a proposed guideline of $1 \times 10^{-6} / \mathrm{yr}$.

According to the PRA, PRISM's total core melt frequency is less than $3.0 \times 10^{-8} / \mathrm{yr}$. The major contributors to core melt all lead to energetic core disassembly accidents and Release Category R4A. The total frequency of this class of accidents is approximately $2.0 \times 10^{-8} / \mathrm{yr}$. In addition to having the highest release frequency, R4A also has the highest consequences. This results in a sudden jump or "cliff" in the risk spectrum because the more benign lossof-heat-sink releases are much lower in frequency. Low frequencies are attributed to the reliability of the shutdown heat removal system, having failure probabilities according to GE as low as $3.0 \times 10^{-17}$ per demand for some internal events, to $4.4 \times 10^{-5}$ per demand for large seismic events, that is, earthquakes having peak ground acceleration greater than $0.825 \mathrm{~g}$.

Seismic events are the largest component of the risk from the PRISM plant. However, the risk-dominant sequences, for both the early and latent fatalities, result from earthquakes greater than $0.825 \mathrm{~g}$ ground acceleration which, by itself, would cause a large offsite hazard. For such large seismic events, the seismic isolators are assumed to degrade, leading to the potential for

- reactivity insertion because of subsequent core compaction and relative control rod motion

- failure of the reactor shutdown system

- failure of the inherent feedback features as a result of in-vessel structural damage or failure of the coastdown machines

For internal events, both prompt and latent fatalities are dominated by sequences initiated by loss of primary sodium flow through the core. These sequences include failure of the primary EM pumps, failure to scram because of stuck control rods, and failure of the passive feedbacks. The frequency of this type of accident sequence is estimated by GE at approximately $6.0 \times 10^{-9} / \mathrm{yr}$. The advanced reactor policy statement expects that future designs will have enhanced margins of safety compared to current generation LWRs. Several innovative design features should enhance safety of the PRISM design relative to large $L W R$ designs

- smaller core size that limits energetics, core inventory, and decay heat

- below-grade reactor cavity silo that protects against external threats 
Table A.5 Release categories for GE bounding calculation

\begin{tabular}{|c|c|c|c|c|c|c|c|c|c|c|c|c|}
\hline Case & Ref & $\begin{array}{l}\text { Release } \\
\text { time } \\
\text { (hr) }\end{array}$ & $\begin{array}{c}\text { Duration } \\
\text { of release } \\
\text { (hr) }\end{array}$ & $\begin{array}{l}\text { Noble } \\
\text { gases }\end{array}$ & I & Cs & Te & $\begin{array}{l}\text { Sr, } \\
\text { Ra }\end{array}$ & $\mathbf{R u}$ & La & Ac & $\mathrm{Na}$ \\
\hline 1,2 & PWR1 & 2.5 & 0.5 & 0.9 & 0.705 & 0.4 & 0.4 & 0.05 & 0.4 & 0.003 & 0.003 & 0.05 \\
\hline \multirow[t]{3}{*}{3} & $\begin{array}{c}\text { LODHR } \\
\text { First } \\
\text { puff }\end{array}$ & 20 & 7.5 & 1.0 & 0.05 & 1.0 & 0.02 & 0.01 & 0.001 & 0.001 & 0.001 & 1.0 \\
\hline & $\begin{array}{c}\text { Second } \\
\text { puff }\end{array}$ & 27.5 & 72.5 & 0 & 0.95 & 0 & 0.98 & 0.1 & 0.01 & 0.01 & 0.01 & 0 \\
\hline & Total & & & 1 & 1 & 1 & 1 & 0.11 & 0.011 & 0.011 & 0.011 & 1 \\
\hline
\end{tabular}

Case 1: Based on a 3,411 MW(t) PWR with WASH-1400 PWR1 release fractions.

Case 2: Based on the WASH-1400 PWR1 release category with the ALMR end of equilibrium inventory.

Case 3: Based on a $470 \mathrm{MW}(t)$ ALMR with a release scenario from a metal core under a hypothetical, protected loss of all decay heat removal (LODHR) capability event.

\begin{tabular}{|c|c|}
\hline Noble Gases & - krypton and xenon \\
\hline & - iodine \\
\hline Cs & - cesium \\
\hline $\mathrm{Te}$ & - tellurium \\
\hline Sr, Ra & - strontium and radium \\
\hline $\mathbf{R u}$ & - ruthenium \\
\hline $\mathrm{La}$ & - lanthanum \\
\hline Ac & - actinium \\
\hline $\mathrm{Na}$ & - sodium \\
\hline
\end{tabular}


Probabilistic Risk Assessment
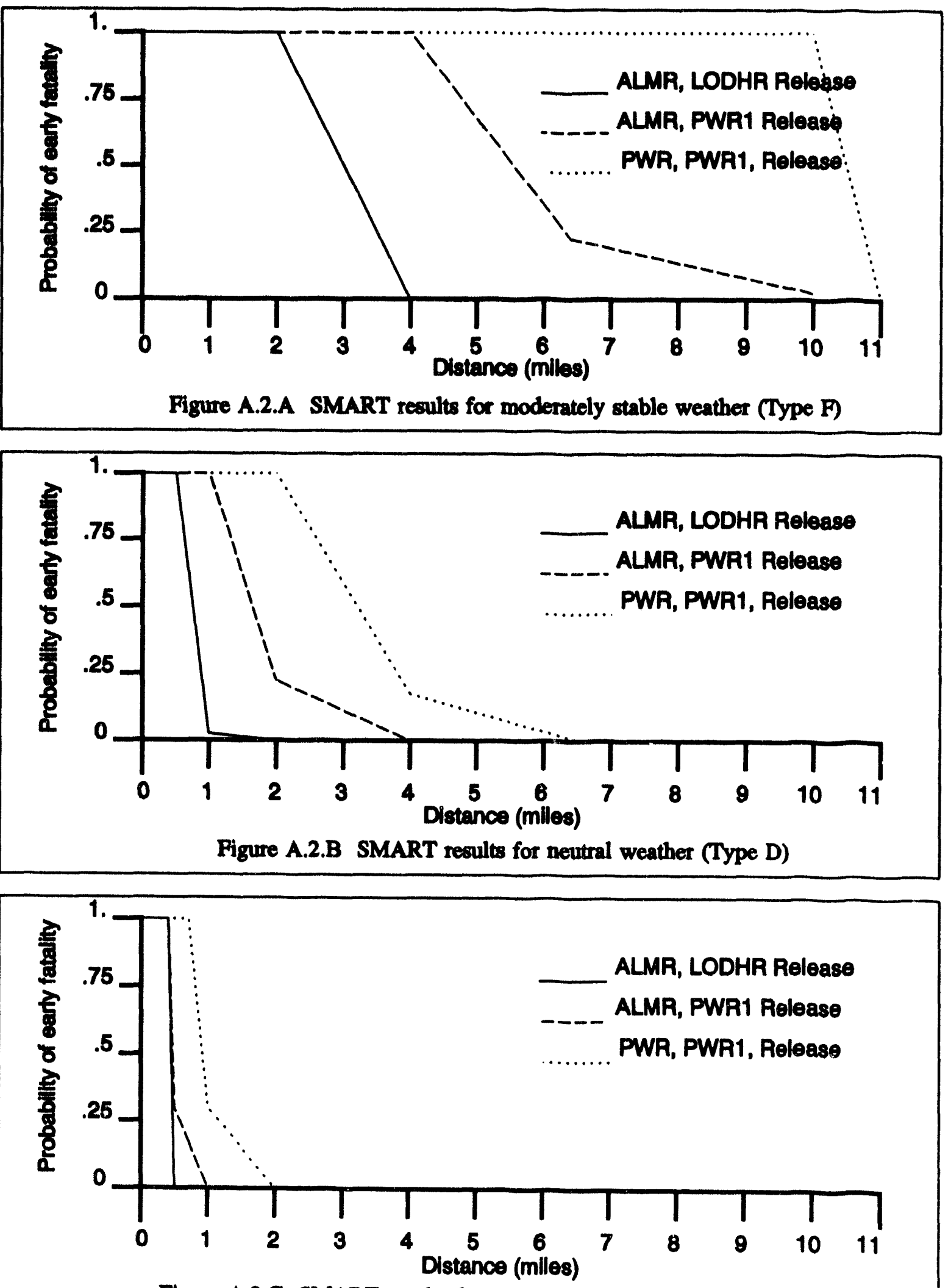

Figure A.2.C SMART results for extremely unstable weather (Type A) 
- seismic isolators that help protect the reactor from horizontal ground accelerations

- passive decay heat removal, which offers high reliability and redundancy to secondary-side decay heat removal

- passive reactivity feedback features that reduce the probability of an anticipated transient without scram (ATWS) event leading to core damage

- large sodium pool with high thermal capacity that allows for longer grace periods

- low (atmospheric) primary pressure that reduces the threat of a large loss-of-coolant accident (LOCA)

- ability to test PRISM response to challenging events via prototype reactor module

The overall risk benefit of these innovative design features over the current generation of reactor systems is somewhat reduced, however, because some important safety-related systems, that is, emergency feedwater and safety-related control room, have been eliminated or downgraded because of these features. In addition, the PRISM design lacks a second active, diverse shutdown system as is presently required for LWRs. However, the passive reactivity feedbacks could be an acceptable alternative, provided that sufficient confidence is established in these unique features to support their reliability estimates.

In comparison to LWRs, the following reliability estimates appear optimistic:

- station blackout frequency of $3.0 \times 10^{-5} / \mathrm{yr}$, considering that the PRISM design does not have safety-related emergency diesels, and that the proposed procedures for mitigating station blackout have not been fully evaluated at this stage of the design review

- steam generator tube rupture initiating event at $6 \times 10^{-8} / \mathrm{yr}$ (LWRs are above $10^{-3}$ )

- vessel failure at $10^{-13} / \mathrm{yr}$ (LWRs are $10^{-7} / \mathrm{yr}$ )

- reactor protection system failure probabilities as low as $4 \times 10^{-10}$ per demand (LWRs are above $10^{-5}$ )

Other estimates in which LWR experience is not available for comparison necessitate the need for additional test data or analyses to substantiate probabilities claimed by the preapplicant:
- primary EM pump coastdown failure probability of $5 \times 10^{-7}$ per demand

- shutdown heat removal failure probabilities as low as $3 \times 10^{-16}$ per demand

- seismic isolator failure probability of $1.35 \times 10^{3}$ for a seismic event with peak ground acceleration of $0.83 \mathrm{~g}$ or greater

- failure of the passive feedbacks at $10^{-6}$ per demand

In addition, the EM primary pumps raise a special concern because their loss or degradation (full or partial) without scram could result in an energetic accident the consequences of which are difficult to predict.

Uncertainties were not quantified at this stage of development, but are assumed to be large. Major sources of uncertainties stem from

- lack of design detail on which to estimate system reliabilities (Information is needed on support systems, common-cause failures, and human factors.)

- limited test data, and experience with regard to PRISM's unique features:

- synchronous coastdown machines

- seismic isolators

- natural convection decay heat removal system

- passive feedback features

- unmodeled human interface, including operator recovery action, and test and maintenance activities

- lack of data needed to support the engineering judgments used to address the phenomenological analysis (Mechanistic analysis using metal fuel has not been performed.)

- lack of data and analyses to support the assumptions used to estimate the source term

In general, with limited test data, limiting operating experience, and limited analysis, the ability to predict PRISM's behavior over such a broad range of accident conditions as proposed in this PRA remains questionable. 


\section{A.7 Conclusions}

\section{A.7.1 Overview}

The PRISM PRA gives a preliminary overviow of the plant's vulnerabilities, and indeed has gone a long way in attempting to quantify them. Seismic events and primary pump failures dominate the LOF sequences, and are believed to be the dominant contributors to risk. On the basis of limited experimental data and the preapplicant's available engineering judgment, the TOP and LOHS sequences appear to contribute less to overall risk.

Redundancy, diversity, and passive safety features designed into the PRISM reactor resulted in very low PRA risk estimates. These estimates appear to meet the quantitative health objectives and large release criteria given in the Commission's safety goal policy, and they display enhanced margins of safety as anticipated by the advanced reactor policy statement. There are caveats, however, when using these estimates as a means of judging PRISM's safety capacity that must be taken into consideration. These are

- The PRA lacks the detail and data required to substantiate sometimes optimistic estimates of system reliability. Major weaknesses include essential unmodeled common-cause failures, human factors, and support system failures. It is also believed that some of the basic initiating event probabilities have been underestimated.

- External events other than seismic have not been quantified and will contribute to the final risk estimates. Seismic analysis is limited to the hazard curve assumed for the GESSAR II site. Fragilities are based on engineering judgment.

- System interactions among safety systems, support systems, and other modules have not been assessed.

- Source-term estimates may be low for some scenarios as a result of extrapolating from oxide fuel to metal fuel.

- Retention of fission products in the metal fuel, sodium pool, cover gas region, and containment dome appears optimistic and needs to be substantiated.

- A mechanistic analysis of the accident sequences has not been performed. Generic assumptions made in the PRA may not accurately represent some of the more important accident sequences.
- The safety goal policy statement specifies that mean values should be used when demonstrating compliance with the quantitative health objectives and large release criteria, whereas PRISM's PRA spocifies "best estimate." Uncertainties have not been quantified, nor are they well understood at this conceptual design stage.

- The role of the operator is not apparent from the PRA. Credit in the form of operator recovery has been taken, although it has not been established what actions will be taken or if operators will even be available to perform such actions.

- In order to substantiate the very low risk estimates reported in the PRISM PRA, a greater effort will be needed to achieve reasonable completeness at the lower end of the probability frequency spectrum.

\section{A.7.2 Assescment of 1990 Design Changes}

\section{A.7.2.1 Increase in Reactor Power Level and System Power Production}

The increase in power level and other adjustments to the estimated decay heat curves resulted in a significant (15 to 20 percent) increase in the decay heat that must be removed through RVACS in the case of a loss of heat sink event. Previously the safety margins were quite high, and even simple models could demonstrate the effectiveness of RVACS. With the higher decay heat loads, a more precise analysis of RVACS performance was needed. Fortunately, this was possible using slight modifications of existing analytical tools; the agreement of the revised analyses with the applicant's calculational results is very close (see Appendix B, Section B.3.6). While the safety margins are reduced, the RVACS performance appears to be more than adequate, and this is not viewed as a major problem area.

\section{A.7.2.2 Ultimate Shutdown System (USS)}

The staff's previous analyses of the postulated unscrammed events were terminated after a few minutes because (1) the most demanding conditions of the transient were believed to be reduced and (2) there were shortcomings in the physical models in the super system code (SSC) (Ref. A.12) when utilized beyond the first several minutes. With the introduction of the USS, it seems unlikely that an unscrammed transient would be allowed to continue indefinitely. Thus, the analysis of such postulated events beyond a few minutes may no longer be necessary, depending on how long it is assumed to take the operators to actuate the USS, since it takes about 1 minute for shutdown after the USS is artivated. 


\section{A.7.2.3 Gas Expansion Modules (GEMs)}

The GEMs are important contributors to the mitigation of postulated unscrammed events involving loss of pump flow, and must be modeled explicitly. Therefore, models were added to the SSC representation of the PRISM reactor, and factored into the analyses of all postulated unscrammed events (Ref. A.13). It is noted that the potential impact of the GEMs is so significant that their usage in the FFTF was sufficient to ensure that an oxidefuel core could survive an unscrammed loss of flow. The impact on the PRISM ULOF analysis is substantial.

The staff assessed GEMs modeling in the SSC. An experimental program at the FFTF provided validation data for the GEM performance and reactivity feedback characteristics. Preliminary results from this evaluation indicated the following:

- Diffusion theory should not be used to determine the worth of a GEM. The streaming effect of neutrons requires the use of transport theory or Monte Carlo methods. At the FFTF, the GEM worth was calculated to be $\$ 1.70$ using diffusion theory; the measured worth was calculated as $\$ 1.31$.

- GEM worth can be substantiated before a reactor is brought to power using subcritical tests at startup.

- GEM worth and insertion rate are function of temperature because of the sodium level within the device. At a reactor average temperature of $500 \mathrm{~K}$ $\left(440^{\circ} \mathrm{F}\right)$ in the FFTF, the GEM worth was $\$ 1.31$. At $583 \mathrm{~K}\left(590^{\circ} \mathrm{F}\right)$ it was $\$ 1.40$.

- The worth of the GEM was different for each FFTF fuel cycle. Fission-product accumulation might be the cause. The GEM worth variation over the life of a fuel cycle needs to be verified.

- The GEM worth determined in the FFTF was developed as a function of GEM sodium level and independent of the reactor temperature (not at power). This effect may not be the case because the neutron energy spectrum effects, fission product effects, and the GEM sodium density effects were not in the FFTF analyses.

There are some potential drawbacks associated with the GEMs, including the obvious questions about their failure to operate when needed, which could happen if some of the gas leaked out during normal operation, filling the GEM with sodium. Alternately, if the pumps are not turned on until after the reactor is critical, a significant power increase would result. Further, addition of the
GEMs raises questions about shielding (more neutrons escape through the gas) and possible reactivity insertions should the gas escape and migrate into the central regions of the core. The positioning of the GEMs in relationship to the positioning of ex-core instrumentation needs to be addressed at a later design stage. One issue to be addressed is the effect of the changing neutron field due to GEMs activation on ex-core instrumentation for power measurements.

\section{A.7.2.4 Mechanical Stops on Control Rods}

The applicant argues that by adjusting the rod stops at proper intervals, the potential TOP initiator can be kept below a $40 \mathrm{C}$ reactivity insertion (30C plus $10 \mathrm{C}$ of margin for error). While judgment as to whether $40 C$ is indeed a credible upper bound needs to be reserved until a later stage in the design review, when the rod stop system design is complete and the control rod worth can be evaluated, $40 \mathrm{c}$ was used for the UTOP initiator for the revised analyses.

\section{A.7.2.5 Below-Core Structure}

No attempt was made to perform detailed analysis of core melt or core disruptive events because the data base for molten metal fuel is incomplete. Arguments made by the applicant regarding the geometry of the melt when imposed on the below-core structure seemed consistent, with a major consideration being the porosity of the fuel which is a key factor in cooling the melt.

\section{A.7.2.6 Accommodation of Hypothetical Core Disruptive Accident (HCDA)}

There is no data base to indicate how quickly the metal fuel will undergo extrusion, which is a rapid form of axial expansion and the key factor in limiting the size of the HCDA. Arguments made by the applicant regarding extrapolating from oxide fuel sound reasonable, but more data is required before a final judgment can be made regarding accommodation of an HCDA in the PRISM design.

\section{A.7.2.7 Seismic Design}

The impact of changes in the seismic design would be clear in any revision of the PRISM PRA. However, the applicant did not perform such a revision and the staff did not attempt to project what such a revision would look like. There was no impact from the changes, for example, regarding movement of the synchronous machines into seismic isolation, on the deterministic analyses of postulated events. 


\section{A.7.2.8 Containment Improvements, Including the Containment Dame}

The applicant provided an analysis of a postulated sodium fire, which included the simulation of conditions in the containment as well as a source-term calculation. Simple calculations confirmed the trends in conditions within the containment, and also revealed a small error in GE's analysis using the CONTAIN Code (Ref. A.14) (see Section 15.6.8 of this report). However, the source-term calculation depends strongly on assumptions regarding how many and how much of the key isotopes escape from the fuel, the sodium, and the cover gas, and into the containment. The impact of the containment dome is believed to be fairly small in comparison to these other factors, with respect to limiting the source term.

\section{A.7.2.9 Helical Coil Steam Generator}

Because of the projected effectiveness of the RVACS in removing decay heat, the focus of heat removal reliability has not been on the steam generator. By this design change, the applicant may have increased the likelihood of a sodium-water reaction, which would be reflected in a revision to the PRA. However, the design features of the new unit may help to mitigate such an accident. Neither the old steam generator nor the new design was explicitly factored into the evaluation. The staff may require inclusion in a later PRA revision.

\section{A.7.2.10 IHTS Auxiliary Cooling System (ACS) Modifications}

GE decided that, because the ACS is not a safety-grade system, it would not be factored into the deterministic analyses. If it were factored in, it would likely be the natural circulation mode of operation that would be considered, as opposed to the new forced-cooling operational mode.

\section{A.7.2.11 Reactor Fuel Re-Design}

The revisions to the PRISM reactor design were fairly extensive and all analyses for unscrammed events had to be repeated. Because of the addition of the GEMs and new information regarding performance of the ternary metal fuel, the principal area of concern has shifted from the unscrammed LOF events to postulated transient-overpower events.

\section{A.7.3 Impact of 1990 Design Changes}

The initial PRA included with the PRISM PSID gave some insights regarding the design, especially with respect to the relative importance of some of the key safety systems.
Many of these systems were different from anything previously evaluated. In several cases, there was no existing data base from which to extrapolate. The RVACS, which is the only safety-grade decay heat removal system, has no apparent failure mode other than very large earthquakes and very effective acts of sabotage. In addition, key data are missing regarding the behavior of the metal fuel during severe accidents. As a result, the initial PRA contained several estimates having very large uncertainties.

Design updates were provided in Appendix G of the PSID. The applicant pointed out several instances of design changes strengthening the case regarding the safety of PRISM, and in some instances the staff would concur. The applicant also attempted to improve on the PRA, and to use sensitivity studies to argue that some of the areas that contain large uncertainties are not very important. This should be viewed with caution, however, as some of the failure rates assumed by the applicant may contain enough uncertainty to distort the sensitivity study itself.

Several design changes are cited, and most appear to improve the PRISM safety picture. Key changes are discussed in the sections that follow.

\section{A.7.3.1 Seismic Isolation of the Synchronous Machines}

This appears to be a significant improvement, as these machines must provide a highly reliable "coastdown" for the EM pumps (which have no built-in coastdown). The previous arrangement had the cables between the EM pumps and the corresponding synchronous machines crossing between zones that were seismically isolated and those that were not. This appeared to be a significant safety problem, and its elimination should reduce the risk.

\section{A.7.3.2 Strengthening Buildings and Enclosures}

The refueling enclosure, steam generator building, and the control building have been tornado hardened. In addition, the refueling enclosure has been upgraded to seismic Category I, and the steam generator building and control building have been upgraded to seismic Category II. Clearly, these are improvements that are potentially important to safety, and should reduce the risk due to external events. In particular, providing better protection for the operator is viewed as a significant improvement.

\section{A.7.3.3 Gas Expansion Modules (GEMs)}

It is not clear whether the addition of GEMs will ultimately be considered a plus or a minus for the PRISM design. They will add significant negative reactivity (leakage) when the EM pumps slow or stop, and are, 
therefore, helpful for postulated unscrammed loss-of-flow events (ULOFs). They also insert reactivity when the pumps are started. However, for the previous design, GE and ANL believed the passive shutdown mechanism would be adequate without GEMs. Newer fuel and design information indicated that the GEMs might be needed in order to survive a ULOF, and the GEMs were added to the design. There is always the possibility that they will not always perform as expected, so their addition to PRISM might trigger some new accident initiators or complications or both. It is even possible that the GEMs might actually increase the overall risk, even though they are currently required for the passive shutdown mechanism of the ULOF event.

\section{A.7.3.4 Ultimate Shutdown System (USS)}

The addition of the USS should reduce risk, particularly of unscrammed events. There are some questions regarding performance of the USS, but these should be resolved without much difficulty. Previously stated concerns regarding the adequacy of the passive shutdown mechanism as a "second and diverse means of reactor shutdown" are now largely resolved, particularly for the long, slow events that allow time for both operator action and for the USS to shut down the reactor.

\section{A.7.3.5 Control Rod Stops}

Previously, claims by GE and ANL suggested that the burnup reactivity swing should be limited to a few conts. After some additional fuel performance data were obtained and more detailed analyses were performed, the designers determined that a burnup reactivity swing in excess of $\$ 1$ was to be anticipated. As the passive shutdown is adequate for only a $30 \mathrm{C}$ to $40 \mathrm{C}$ reactivity insertion, the preapplicant was forced to add the rod stops, which periodically must be adjusted to provide for burnup and to ensure that the maximum UTOP initiator is small enough to allow the passive response to function properly. The need to use rod stops to prevent a larger UTOP increases risk, as failure to limit the reactivity insertion to less than $40 \mathrm{C}$ (with uncertainty) could result in fuel damage. Their incorporation in the design at this early stage appears to be a benefit. The rod stop mechanism and its impact on the overall PRA will be assessed again at a later stage in the design review.

\section{A.7.3.6 Designing To Accommodate HCDAs}

This is potentially an important risk reduction, as this class of accidents could have rapid and possibly severe ssequences. If the PRISM system could indeed withstand a worst-case HCDA and maintain structural integrity, the likelihood of early fatalities from any postulated accidents would be very small. The primary reservation here is that the data for that metal fuel extrusion would terminate the reactivity excursion is very limited, so the size of potential HCDAs is not well known. In addition, there now appears to be the possibility of the solidus temperature being exceeded in the center of the core but not near the top of the core, which could preclude the extrusion from occurring as required to terminate an HCDA event. One independent analysis (Reference A.15) suggests the energy release in a metal fuel HCDA would be significantly less than the 500-MJ currently assumed by the applicant, suggesting that the PRISM system could survive a large HCDA event. A recently completed study by the staff (Ref. A.10) also indicates that the 500-MJ value currently used by GE may be conservative.

\section{A.7.3.7 Designing To Accommodate Core Meltdown}

GE's modifications to the lower core support structure may make safe, that is, noncritical, accommodation of a whole core meltdown within the lower region of the vessel more likely, and thus decrease risk somewhat. However, there are important uncertainties. First, the core must change from the normal configuration and move to the support region without achieving recriticality. Secondly, vessel cooling would be primarily from the RVACS. However, most scenarios resulting in core melt involve failure of this system, so it seems unlikely that the RVACS would be available to cool the molten core. Therefore, this design modification may or may not reduce risk significantly.

\section{A.7.3.8 Containment Dome}

With the addition of a containment dome, PRISM more closely resembles a conventional U.S. power reactor, but the incremental reduction in risk is probably far less than achieved from an LWR containment. This is due primarily to the capability to retain fission products in either the molten fuel or the sodium pool, which should reduce the type and amount of radionuclides reaching the containment atmosphere during an accident. However, the dome is helpful for mitigating sodium fires and delaying the release of fission prod:cts in a worst-case accident.

\section{A.7.3.9 Sensitivity Studies}

The original PRISM PRA contained some failure probabilities that were difficult to justify. For example, failure rates for the scram system in the range of 1 in a billion, and for RVACS in the range of 1 in a trillion, were inappropriate. These can be well-designed systems that should have low failure rates.

Concerns regarding these assumed failure rates were discussed with the applicant on many occasions. The 
applicant's PRA experts indicated their intent to revise the PRISM PRA. However, the materials included in the latter part of Appendix G of the PSID indicate that some philosophical differences remain. In particular, some of the extremely low assumed failure rates may have distorted the basis for the sensitivity studies (see Sections A.3.4 and A.4.7).

A fairly simple summary PRA can be developed based upon three major factors: reactor shutdown, shutdown heat removal, and retention of fission products. The two systems that stand out are the scram system and the RVACS. Of slightly less importance are the passive ("inherent") reactor shutdown, the USS, the alternate heat removal systems (normal and ACS), and the tendency of the fission products to remair in either the molten fuel or the sodium pool. To some degree, statements by the applicant are fairly consistent with these estimates. However, with such large uncertainties reganding the failure probabilities of key systems, neither the preapplicant nor the staff should focus too closely on the "bottom-line" risk estimates.

Issues that remain open and that will require additional review as the design develops include

- The reliabilities for passive systems, such as RVACS, are not known and could vary by several orders of magnitude depending on the evaluator.

- For such new and radically different designs, the PRA will include many numbers that can not be adequately supported by available test data or operational exporience. Estimates of core damage frequencies and large release probabilities could be off by two or three orders of mugnitude. Further, even sensitivity studies could contain errors large enough to distort the results.

Other key issues and questions that will have to be addressed at a later stage in the design review include

- Although the addition of GEMs improves the passive shutdown response for ULOF events, are there instances where the GEMs could add reactivity or fail to function when needed? What would be the outcome of auch failures and could these be prevented?

- Introduction of the GEMs could affect various types of analysis. Their contribution during the basic unscrammed events (ULOF, ULOHS, UTOP) is significant and generally helpful. However, the GEMs will become an integral part of the core, and will have to be factored into many types of analysis, including reliability-based analysis.
- With the introduction of the control rod stops to limit potential UTOP initiators, a means needs to be developed to determine a limit (i.e., 30c), and to define the accuracy of the rod stop positioning. If the accuracy of the rod stop positioning is poor in comparison to the acceptable UTOP limit, then a safety issue would exist regarding the rod stops.

- Regarding accommodation of HCDAs, there is not sufficient data to confidently predict the size of an HCDA in a metal fiw ALMR. Therefore, the likelihood of an HCDA being accommodated within the PRISM vessel may remain an open issue at least until more analytical or test data become available.

- With respect to the andyses of severe accidents, some bounding analysis can be helpful until better data become available. However, there remains a great deal of work to be completed in this area, and this will continue to be true for at least 2 or 3 years.

- New data on the temary metal fuel indicates there is much more to be learned, especially with respect to phase transitions. The ternary fuel is clearly different from the U-Zr fuel, and the data base is being built at this time. This is a key issue, especially during overpower events.

On the basis of the issues that require additional review and the questions that remain, it is the staff's judgment that only limited uses can be made of the PRA at this stage of the design review. As stated elsewhere in this SER, the PRA should not be the only document used for accident selection and judgments about the safety of the PRISM design. Much engineering judgment, supported by an R\&D program and prototype testing results will be required as the design and review proceeds. The items identified at this stage of the review should be addressed at a later design stage. Large uncertainties in the front end of the PRA exacerbate the large uncertainties in the phenomenological treatment of the core response and consequence analysis. Deterministic engineering judgment has, therefore, played a dominant role in the staff's review of the PRISM design.

\section{A.8 References}

A.1 General Electric, PRISM - Preliminary Safety Information Document, GEFR-00793 UC-87Ta, November 1986.

A.2 U.S. Nuclear Regulatory Commission, "Safety Goals for the Operation of Nuclear Power Plents," 51 Federal Register 28044, August 4, 1986. 
A.3 U.S. Nuclear Regulatory Commission, "Policy Statement on Regulation of Advanced Nuclear Power Plants," 51 Federal Register 24643, August 29, 1986.

A.4 Heusener, G., et al, "The CABRI Programmes Motivations and Achievements, "Proceedings of the 1990 International Fast Reactor Safety Meeting, Snowbird, Utah, August 1990.

A.5 U.S. Nuclear Regulatory Commission, "Nuclear Plant Reliability Data Systems, " NUREG/CR-2232, September 1981.

A.6 U.S. Nuclear Regulatory Commission, "Reactor Safety Study-An Assessment of Accident Risk in U.S. Commercial Nuclear Power Plants," WASH-1400, October 1975.

A.7 U.S. Department of Energy, "Clinch River Breeder Reactor Plant Probabilistic Risk Assessment," Technology for Energy Corporation, Knoxville, TN, September 1984.

A.8 Sandia National Laboratory, "MELCOR Accident Consequences Code System (MACCS)," Sandia National Laboratories, NUREG/CR-4691, Vols. 1-3, SAND.86-1562, February 1990.

A.9 El-Sheikh, K.A., "Probabilistic Risk Assessment of the Advanced Liquid Metal Reactor," GEFR-00873, November 1989.

A.10 Brookhaven National Laboratory, "HCDA Analysis of PRISM With a Modified Bethe-Tait Model," Department of Nuclear Energy, BNL, August 1992.
A.11 Brookhaven National Laboratory, "A Simplified Model for Calculating Early Off-Site Consequences from Nuclear Reactor Accidents," BNL-NUREG-52153, July 1988.

A.12 U.S. Nuclear Regulatory Commission, "Super System Code (SSC, Rev. 0) An Advanced Thermohydraulic Simulation Code for Transients in L M F B R s , " N U R E G / C R-3169 (BNL-NUREG-51659), April 1983.

A.13 Brookhaven National Laboratory, "Assessment of the Pump Restart Tests in FFTF Using SSC," Department of Nuclear Energy, BNL, September 1992.

A.14 Sandia National Laboratory, "User's Manual for CONTAIN 1.1 - A Computer Code for Severe Nuclear Reactor Accident Containment Analysis," SAND 87-2309, Albuquerque, New Mexico, November 1987.

A.15 Singh, O.P., et al., "Energetics of a Hypothetical Core Disruptive Accident for Different Fuels for a Medium Sized Reactor," Proceedings of the International Conference on Fast Reactors and Related Fuel Cycles, October 28 - November 1, 1991, Kyoto, Japan.

A.16 U.S. Nuclear Regulatory Commission, Code of Federal Regulations, Title 10, "Energy," Part 100, "Reactor Site Criteria." 


\title{
APPENDIX B
}

\section{INDEPENDENT ANALYSES OF SELECTED EVENTS}

\author{
ANALYZED BY GE
}


This appendix focuses principally on the revised bounding events (BEs) analyses submitted by General Electric (GE) after GE made significant design changes, particularly those events pertaining directly to the reactor. The newly added gas expansion modules (GEMs) and control rod stops, and how these may affect the safety of the PRISM system, are also discussed. The GE analyses are documented in Appendix G to the PRISM Preliminary Safety Information Document (PSID) (Ref. B.1).

In the draft preapplication safety evaluation report (PSER) (Ref. B.2), some concerns were expressed regarding the expected PRISM system response to some of the postulated BEs, particularly in light the of PRISM containment design and the stated objective of avoiding the need for preplanned offsite emergency evacuation procedures. Because previous evaluations of the events in PSID Chapter 15 and the postulated beyond-design-basis-events (BDBEs) (Ref. B.3) did not indicate major problems, it was the BEs that stood out as potential problems. Thus, in Appendix G GE chose to address only the BEs, and to focus on how changes in the PRISM design and newer information on the metal-fuel performance affects the outcome of the postulated BEs. It is noted that these changes also would change the analyses of events analyzed in PSID Chapter 15 and PSID Appendix E (the BDBEs). However, the safety margins for these events were previously quite large and it is unlikely that these margins would be reduced significantly by any of the recent changes. In the case of the BDBEs, there is considerable overlap between these events and the NRC BE-1A, -1B, and -2 (as interpreted by GE). The NRC defined BEs are discussed in Chapter 15 of this report. GE's decision to focus on the BEs rather than on the BDBEs covered in PSID Appendix E is acceptable for preapplication review.

There are four BEs of concern: (1) BE-18: the unprotected transient over-power (UTOP) event with the reactor vessel auxiliary cooling system (RVACS) providing the only cooling, (2) BE-38: the long adiabatic heatup event, (3) BE-4: the unprotected loss-of-flow (ULOF) event missing one pump coastdown, and (4) the fuel assembly blockage event. The blocked fuel assembly was addressed through design changes and have not been analyzed at this stage of the review.

\section{B.1 Design Description and Safety Objectives}

Two design changes that affect the $B E$ analyses have been incorporated into the PRISM ALMR design. GEMs are used, located on the periphery of the core, to add negative reactivity on loss-of-flow events. A control rod stop system is now used to limit reactivity insertion for the transient overpower event. The safety objectives are based on maintaining metal fuel and structural integrity and maintaining margins to sodium boiling for anticipated transient without scram (ATWS) events.

\section{B.1.1 Gas Expansion Modules (GEMs)}

The GEMs were added to provide additional negative reactivity in response to loss-of-pumping events. Previously, it was believed that the inherent and passive reactivity feedbacks of the reactor would be sufficient for the passive shutdown mochanism to prevent damage in a ULOF event. However, new information on the performance of the ternary metal fuel and more careful analysis of the various anticipated fuel loadings indicated that additional negative reactivity might be needed in a ULOF event, thus GEMs were added.

The GEM is essentially an empty assembly duct, filled with an inert gas sealed at the top, open at the bottom, and connected to the core high-pressure inlet coolant plenum. When the pumps are operating, sodium is pumped into the GEM, and the trapped gas is compressed into a region above the active core. Sodium then occupies that portion of the GEM adjacent to the fueled region of the core. When the pumps are off, the gas region expands into the core region, allowing more neutrons to escape from the core (scattering back into the reactor is reduced). Such devices were successfully tested in the Fast-Flux Test acility (FFTF) during a series of ULOF tests. Recent GEM tests in the FFTF are being evaluated by the staff to develop a model for use in future PRISM independent safety analyses.

The predicted sodium levels in the GEMs for various (static) conditions are shown in Figure B.1. For full pumping and flow, such as cases $B$ and $C$ in the figure, the gas space is well above the core. For cases where there is little or no sodium flow, such as case D and E, the sodium level is below the active core. The refueling condition, case $A$, has not been considered in any detail, but most refueling operations are at relatively cool, subcritical conditions so that the effect of any spurious reactivity insertions should be far less threatening than if they occurred at power.

The GEM effect during postulated transient conditions is highest for the unscrammed loss-of-flow events, especially during the pump coastdown phase. They appear to be highly effective and helpful during such an event and even provide additional margin in case the synchronous machines are less effective than predicted, or if one or two might fail entirely. 
Appendix B

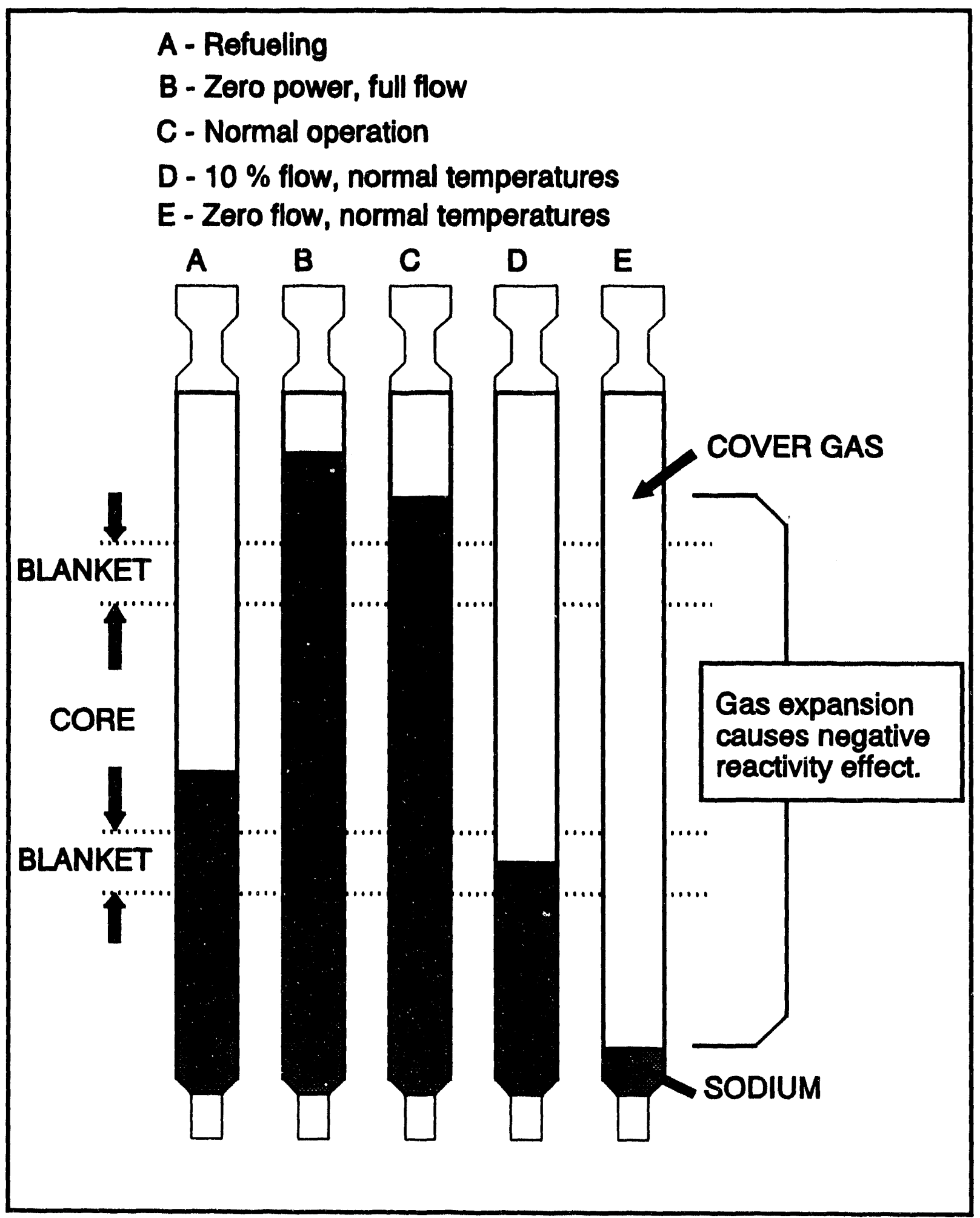

Figure B.1 Operation of the gas expansion module tested in the Fast-Flux Test Facility 
There are potential safety issues associated with the addition of these devices. First, can they be tested in position on a routine basis? The preapplicant indicates that the GEMs can be tested while the reactor is subcritical by varying the pump speeds. In principle, such testing can be performed safely and the results should be fairly accurate, based on the change in subcritical neutron multiplication factors. Second, are GEMs reliable and can deterioration in performance be detected during operation? It appears that the preapplicant has at least three options for monitoring the GEMs: by using tag gas that can be detected if leaked, by monitoring the neutron flux on the outer (away from the center of the core) side of the GEM duct, and by subcritical testing of the GEM worth during plant outages. Third, could the GEMs inadvertently insert $70 \mathrm{c}$ of reactivity at a crucial time? The preapplicant claims that it will be nearly impossible to reach full power critical without the pumps being on and, therefore, the gas must be compressed into the region above the core under full-power conditions. However, this argument is based largely on operating procedures and human factors, and the risk from having GEMs in the core will have to be evaluated in future probabilistic risk assessment (PRA) studies.

In summary, the preapplicant states that it must yet carefully weigh the risks versus the benefits from having the GEMs in the design; however, the preapplicant believes using the GEMs will significantly improve the PRISM response to ULOF events.

\section{B.1.2 Control Rod Stops}

The PRISM control rod stop system (CRSS) is one of the more important safety systems in the current design because it limits the potential magnitude of UTOP initiators. Although the designer recognizes the expected high reliability of other key safety systems, the CRSS is especially important because of the potentially rapid and severe development of reactivity events in cores of liquidmetal reactors (LMRs).

Since it is difficult at this time to develop meaningful probabilistic risk numbers for a system such as the PRISM in which key safety systems are new, untested, and largely passive; weaknesses in the system must be determined using engineering judgment. For the PRISM design documented in PSID Appendix G, the analysis points directly to the UTOP event. A combination of small Doppler feedback, zirconium,' uranium, and perhaps plutonium migration, and low solidus temperatures creates the vulnerability for the metal-fuel core. The best defense against the UTOP vulnerability is to ensure that only small reactivity insertions are possible. In the current PRISM design, this is achieved through the rod stops.
The current UTOP limit of $40 \mathrm{C}$ (including $10 \mathrm{C}$ to cover uncertainties) may be too high, as discussed in BE-1B (below). However, if this is reduced into the range of $30 \mathrm{C}$ to $35 \mathrm{c}$, then the UTOP predictions may move into an acceptable range. Therefore, it is quite possible the rod stops may be adjusted more frequently to limit reactivity insertion to less than $40 \mathrm{c}$.

The CRSS performs an out-motion blocking function and will not affect rod insertion, either forced or gravity driven. The rod stops are moved periodically when the top of the control rods move within some selected distance of the rod stops. The plant control system determines when the rod stops should be moved and by how much, but cannot actually move the rod stops without operator permission. The operator can deny permission to move the rod stops, but cannot move the rod stops to an alternate position. Also, all normal rod movement (excluding scram) is temporarily stopped while the stops are adjusted.

GE offers some arguments as to why this approach should be safe and acceptable. It states that the data used by the plant control system (PCS) to determine the next move is verified using reactor protection system (RPS) data (a safety-grade system). Also, if the operator does not approve the proposed relocation, the operator can prevent rod movement. Because the burnup swing is negative, failure to move the rod stops will eventually lead to an extremely gradual reactor shutdown (but will not affect the scram capability).

Although the CRRS provides a viable means of limiting the size of potential UTOP initiators, there may be room for improvement. Allowing the non-safety-grade PCS control over such an important safety system may not be the best choice. If the operator is to be able to make a judgment regarding the proposed adjustment, then reliable instrumentation and adequate training are needed. Also, how far up the rod stops should be moved must be determined using a fairly elaborate calculation based on rod worth curves, burnup data, and detailed core-physics analysis. Movement of all six rods one-half inch is worth slightly less than $10 \mathrm{C}$, so the precision of the mechanical relocation does not seem a major concern.

GE may be able improve on the CRRS it currently proposes by transferring the function to adjust the rod stops to either the RPS or another dedicated safety system. If the operators are to have the power to veto a proposed adjustment, they must have a clear and reliable picture of the current conditions. Finally, a simple algorithm could be developed to determine the proposed adjustment in position. Such an algorithm, which might be based on the effect of recent adjustments in control rod position, should be highly reliable. 


\section{B.1.3 Damage and Failure Limits}

In PSID Section G.4.16.3.2, GE cites the damage and failure liwits for the cladding, sodium, structure, and, to some degree, the fuel. For the sodium (boiling) and structure (ASME codes), these limits are easily quantified. The situation for the HT9 cladding is not as clear and involves both sreep rupture and eutectic formation failure modes. For the ternary fuel, the limits are very hard to qualify and vary throughout the fuel lifetime and across each fuel pin. There is a time factor involved in some of the failure limits, especially the cladding and structural temperature limits.

\section{Sodium Boiling}

The saturation temperature for the sodium depends on the pressure, which varies with sodium depth and pumping (increases system pressure and pressure drops). In the PRISM, the in-core sodium boiling temperature is about $1344 \mathrm{~K}\left(1960^{\circ} \mathrm{F}\right)$ if the pumps are operating and $1233 \mathrm{~K}$ $\left(1760^{\circ} \mathrm{F}\right)$ if the pumps are off.

\section{Structural Integrity}

The ASME Code Level D limits are $1033 \mathrm{~K}\left(1400^{\circ} \mathrm{F}\right)$ over the short term (less than an hour) or $980 \mathrm{~K}\left(1300^{\circ} \mathrm{F}\right)$ over the longer term, i.e., more than an hour. The structural temperatures generally will be similar to the reactor outlet sodium temperature although they will lag sodium temperature significantly during the early portion of a transient.

\section{Cladding Failure}

HT9 has some excellent properties, especially with respect to surviving in a high neutron flux and energy environment. However, at elevated temperatures, HT9 loses some of its creep strength and also begins to interact with the fuel to form a low-melt temperature eutectic. The preapplicant has explicitly factored these failure modes into its analytical tools and compares the cladding damage in mils against the nominal cladding thickness of 20 mils. As a preliminary design limit, GE has limited the cladding attack to less than 10 percent of the wall thickness, to 2 mils. The preapplicant's analyses of the BE shows a maximum cladding attack of 0.22 mil for BE-1B and a trivial amount for the other $\mathrm{BE}$.

\section{Fuel Melting}

GE and Argonne National Laboratory (ANL) share the following position:
Fuel melting, per se, is not a cause of pin failure. TREAT tests have demonstrated that extensive fuel melting does not affect the basic pin failure mechanism. Failure by cladding creep rupture, with cladding thinning by fuel-cladding liquid phase formation, is the appropriate mechanistic cladding breach criterion....

If the relocation of fuel into the coolant channel and beyond were the sole concern, this position could be acceptable. However, the PRISM reactor is not configured to give the highest possible reactivity. Movement of a significant amount of fuel toward the center of the core would increase reactivity and could lead to severe damage. The reference metal fuel initially has only 75 percent smear density (area ratio of fuel to inside area of cladding) after the fuel swells and closes the gap during the first 1-1/2 to 2 percent atom burnup. Therefore, molten fuel early in life can relocate within the cladding, which could cause an increase in reactivity of the core.

\section{Fuel and Cladding Behavior and Uncertainties}

Both the ternary metal fuel and the HT9 cladding are in a development stage, and there are little data available at significant burnup levels. Therefore, the temperature limits (eutectic formation and perhaps others) are not well known. Since ANL personnel have been working with metal fuels for more than three decades, their estimates regarding fuel performance must be considered expert opinion at this time. There are several areas for which more data is required; these are:

- Fuel-cladding chemical interaction forms a eutectic with a minimum melting temperature at the fuel-cladding interface caused mainly by iron diffusion into the fuel. This effect is compounded by lanthanide migration, plutonium migration, zirconium migration, and the kinetics at the fuel/cladding interface. This minimum eutectic temperature must be determined for the prototypical fuel.

- The maximum fuel-cladding liquid penetration rate from the eutectic formation must be determined from irradiated fuel, where the lanthanide, zirconium, plutonium, and iron diffusion is accounted for.

- The effect of lanthanide penetration into the cladding must be determined.

- The migration of the fuel components to form multiple annular zones having too much or too little uranium, zirconium, or perhaps plutonium (the plutonium migration appears to be modest) must be determined. 
- Estimation of fuel solidus and liquidus temperatures depends on component migration with burnup, and this has not been fully characterized. Similarly local thermal conductivity and expansion will depend on component migration.

- The effect of fuel reprocessing contamination on fuel composition and performance needs better resolution, especially regarding its effect on thermal conductivity, isotope migration, fuel-cladding interaction, and zone formation.

- The EBR-II metal-fuel data were collected on samples with a high volumetric heating rato. Data at different heating rates are needed to determine if this gives a conservative estimation of the fuel's failure mechanisms.

A conservative assessment of literature available on the eutectic data and physics suggests a cladding temperature limit of about $900 \mathrm{~K}\left(1160^{\circ} \mathrm{F}\right)$, about $75 \mathrm{~K}\left(135^{\circ} \mathrm{F}\right)$ lower than GE assumes. Recently obtained data from a high bumup test pin, with a high linear heat generation rate (greater than the PRISM design value) suggest that the eutectic limit may be even lower, at least under some circumstances. However, throughout much of this appendix results are compared against the preapplicant's limits of $980 \mathrm{~K}\left(1300^{\circ} \mathrm{F}\right)$, on the assumption that the next batch of data will support the ANL current best estimate. It must be recognized that this fuel is still under development and evaluations are based on currently available data.

The fuel temperature is an important parameter for fast transients, on the order of seconds to a few minutes. If the fuel temperature exceeds the solidus temperature then there is the possibility that the resulting molten fuel region may influence fuel relocation; for example, relocation may occur in the molten region instead of through axial extrusion. The changes in the local fuel density, power density, and thermal conductivity also may affect the transient characteristics.

The cladding temperature is an important parameter for slow transients, on the order of several minutes to hours. The eutectic penetration occurs over time (at temperature). The coolant (sodium) temperature is another important parameter for slow transients. The ability to remove decay heat, through the reactor vessel auxiliary cooling system (RVACS) for example, to maintain structural integrity (ASME Level C for long term, and Level D for short term) is dependent on the coolant temperature.

The peak fuel, peak cladding, and peak coolant temperatures will be presented for each of the BE analyses.
These values can be compared to the proposed limits, as discussed, and a determination can be made on the possibility of fuel, cladding, or structural damage that might occur for the ovent. These data are provided in Table B.1.

\section{B.2 Summary and Interpretation of GE's Revised Analyses}

The analyses of the BEs are performed with the events being initiated while the reactor is at 100 percent power, with a core inlet temperature of $610 \mathrm{~K}\left(640^{\circ} \mathrm{F}\right)$ and a mixed mean outlet temperature of $758 \mathrm{~K}\left(905^{\circ} \mathrm{F}\right)$. Beginning of equilibrium cycle conditions are used, when the power in the driver assemblies is the greatest. The peak assembly represents fresh fuel but, for conservatism, the fuel conductivity is based on irradiated fuel because the conductivity of fresh fuel drops rapidly during the first $\mathbf{1 . 5}$ to 2 atom percent burnup. GE uses the ARIES plant transient computer program to analyze these events.

\section{Analysis of Bounding Events}

\section{B.2.1 BE-1A: All-Rods Withdrawal Without Scram, With Normal Cooling}

This event postulates that a malfunction in the reactivity controller causes the shim motor to continue to withdraw the control rods until the driveline reaches the rod stop, with the absence of the RPS function for scramming the reactors. A $40 \mathrm{C}$ reactivity insertion is assumed oven though the rod stops are positioned to limit the insertion to approximately $30 \mathrm{c}$. The insertion rate is $2 \mathrm{c}$ per minute, corresponding to the maximum speed of the shim motor as it sequentially withdraws one rod at a time. All normal heat removal systems continue to operate at full capacity.

All six rods are fully withdrawn to the rod stops in 20 seconds. The maximum power reaches 172 percent of nominal power in about 30 seconds. At this time Doppler and thermal expansion reactivity feedbacks turn the power rise around and the power stabilizes at about 120 percent of full power by 100 seconds into the event. The peak fuel, cladding, and bulk coolant temperatures reach maximum levels of $1292 \mathrm{~K}\left(1855^{\circ} \mathrm{F}\right), 979 \mathrm{~K}\left(1303^{\circ} \mathrm{F}\right)$, and $951 \mathrm{~K}\left(1252^{\circ} \mathrm{F}\right)$ at 31 seconds.

\section{B.2.2 BE-1B: All-Rods Withdrawal Without Scram, With RVACS Coc'ing Only}

This event is analyzed in the same manner as BE-1A except that the intermediate heat transport system is lost so that only RVACS is available to remove heat from the reactor vessel. Because GEMs will rapidly provide a large negative reactivity feedback if the electromagnetic (EM) 
Table B.1 Summary of peak temperatures reached during bounding events

\begin{tabular}{|c|c|c|c|c|c|c|}
\hline \multicolumn{2}{|c|}{ Event Description } & \multirow{2}{*}{$\frac{\begin{array}{c}\text { Peak cladding } \\
\text { temperature } \\
\left({ }^{\circ} \mathrm{F}\right)\end{array}}{1303}$} & \multirow{2}{*}{$\begin{array}{c}\begin{array}{c}\text { Peak coolant } \\
\text { temperature } \\
\left({ }^{\circ} \mathbf{F}\right)\end{array} \\
1252\end{array}$} & \multirow{2}{*}{$\begin{array}{c}\begin{array}{c}\text { Leak mixed } \\
\text { mean core } \\
\text { outlet }\end{array} \\
\text { temperature } \\
\left({ }^{\circ} \mathbf{F}\right)\end{array}$} & \multirow{2}{*}{$\begin{array}{l}\begin{array}{c}\text { Cladding loss } \\
\text { by liquid phase } \\
\text { formation } \\
\text { (mils) }\end{array} \\
<0.005\end{array}$} & \multirow{2}{*}{$\begin{array}{c}\begin{array}{c}\text { Margin to } \\
\text { sodium } \\
\text { boiling } \\
\left({ }^{\circ} \mathbf{F}\right)\end{array} \\
708\end{array}$} \\
\hline $1 \mathrm{~A}$ & $\begin{array}{l}\text { All-rods UTOP, } \\
\text { normal cooling }\end{array}$ & & & & & \\
\hline 1B & $\begin{array}{l}\text { All-rods UTOP, } \\
\text { RVACS only }\end{array}$ & 1495 & 1479 & 1344 & 0.22 & 281 \\
\hline 2 & $\begin{array}{l}\text { ULOF + LOHS } \\
\text { for } 36 \text { hours }\end{array}$ & 1312 & 1291 & 1191 & $<0.001$ & 469 \\
\hline 3 & $\begin{array}{l}\text { Loss of decay heat } \\
\text { removal }\end{array}$ & & & & & \\
\hline $3 \mathrm{~A}$ & $\begin{array}{l}75 \% \text { RVACS } \\
\text { blockage for } 36 \\
\text { hours }\end{array}$ & 1215 & 1215 & 1215 & None & 580 \\
\hline 3B & $\begin{array}{l}100 \% \text { blockage for } \\
12 \text { hours, } 25 \% \\
\text { unblocked }\end{array}$ & 1290 & 1290 & 1290 & None & 500 \\
\hline 4 & $\begin{array}{l}\text { ULOF + LOHS, } \\
\text { one pump seized } \\
\text { on coastdown }\end{array}$ & 1355 & 1335 & 1193 & $<0.001$ & 425 \\
\hline 5 & $\begin{array}{l}\text { Rupture of steam } \\
\text { generator tubes } \\
\text { with failure to } \\
\text { isolate or dump } \\
\text { water }\end{array}$ & \multicolumn{5}{|c|}{$\begin{array}{l}\text { Ref: PSID Section G.4.8 } \\
\text { The IHTS and SG system have been designed in a manner that provides passive } \\
\text { protection of the interfacing primary system boundary at the IHX. A failure of } \\
\text { the active protection system, such as failure of the redundant steam and feedwater } \\
\text { isolation valves to close and terminate the event as designed, will not result in } \\
\text { IHX failure. }\end{array}$} \\
\hline 6 & Large sodium leak & \multicolumn{5}{|c|}{$\begin{array}{l}\text { Ref: PSID Amendment } 11 \\
\text { Double ended guillotine rupture of IHTS pipe } \\
\text { Beactor vessel leak (critical leak) } \\
\text { Because of the low-stress, low-energy nature of the IHTS, a leak-before-break } \\
\text { situation is expected to exist for pipe breaks. Reactor vessel leaks are included as } \\
\text { a design-basis event. Analyses will be provided at a later date. }\end{array}$} \\
\hline 7 & $\begin{array}{l}\text { Assembly flow } \\
\text { blockage }\end{array}$ & \multicolumn{5}{|c|}{$\begin{array}{l}\text { Ref: PSID, Section G.4.6 } \\
\text { See Section } 4.4 .5 \text { of this report. }\end{array}$} \\
\hline 8 & External events & \multicolumn{5}{|c|}{ Awaiting definition by NRC staff. } \\
\hline
\end{tabular}


pumps are stopped, GE conservatively assumed that the EM pumps will continue to run until the pump outlet temperatures reaches the pump trip set point $811 \mathrm{~K}$ $\left(1000^{\circ} \mathrm{F}\right)$.

The peak power reaches 172 percent nominal a little earlier, at 21 seconds, because of the additional negative reactivity feedback associated with the loss of the heat sink. The peak fuel, cladding, and bulk coolant temperatures reach maximum levels of $1303 \mathrm{~K}\left(1885^{\circ} \mathrm{F}\right)$, $1086 \mathrm{~K}\left(1495{ }^{\circ} \mathrm{F}\right)$, and $1002 \mathrm{~K}\left(1344^{\circ} \mathrm{F}\right)$ at 80 seconds. The bulk coolant temperature decreases, then begins to increase again after about 1400 seconds as the vessel heats up and begins to move the core away from the control rods. The temperature increases to $966 \mathrm{~K}\left(1280^{\circ} \mathrm{F}\right)$ at 9000 seconds.

If the EM pumps are tripped at the beginning of the event, the maximum power will only reach 103-percent nominal, and the peak fuel and cladding temperatures will be much lower, $1137 \mathrm{~K}\left(1586^{\circ} \mathrm{F}\right)$ and $1006 \mathrm{~K}\left(1351^{\circ} \mathrm{F}\right)$, respectively.

\section{B.2.3 BE-2: Unprotected Loss of Flow, Loss of Heat Sink, for 36 Hours}

BE-2, as originally defined, is a station blackout event lasting 36 hours. GE has modified this to include no scram and loss of normal heat removal (from the intermediate heat exchanger and balance of plant). This event is now referred to as a "BE-2'."

Power and flow drop rapidly at the start of event because of the large negative reactivity insertion from the actuation of the GEMs on loss of flow. The peak fuel, cladding, and peak coolant temperatures reach maximum levels of $1115 \mathrm{~K}\left(1547^{\circ} \mathrm{F}\right), 984 \mathrm{~K}\left(1312^{\circ} \mathrm{F}\right)$, and $973 \mathrm{~K}\left(1291^{\circ} \mathrm{F}\right)$ respectively, at 3 seconds. The gystem continues to slowly heat up and Doppler and core radial expansion reactivity feedbacks finally turn the power excursion around. The peak bulk outlet temperatures reaches $917 \mathrm{~K}\left(1191^{\circ} \mathrm{F}\right)$ at 41,000 seconds.

\section{B.2.4 BE-3: Loss of Decay Heat Removal Capability}

The original PRISM design emphasized prevention over mitigation and did not include a containment structure over the reactor vessel head. This lack of a conventional containment structure lent additional importance to preventing fuel damage; therefore, a very stringent bounding event involving loss of the single safety grade decay heat removal system was defined. With the subsequent addition of the containment dome, the decay heat removal bounding event was modified to be more realistic and allow for some recovery actions. Two events were defined for analyses:

- BE-3A: 75-percent blockage of decay heat removal capability for 36 hours

- BE-3B: complete loss of decay heat removal capability for 12 hours followed by 25-percent unblockage of RVACS

GE analyzed the two transients by means of a thermal nodal network model, which accounts for

- radiation from the reactor vessel to the containment vessel

- radiation from the containment vessel to the collector cylinder

- radiation from the collector cylinder to the silo wall

- natural circulation of air through the RVACS air passages, assuming appropriate amounts of blockage

- conduction outward through the silo wall and surrounding earth

Although of minor importance, the heat rejection from the bottom of the reactor vessel is included. Heat losses through the top closure and from the intermediate heat transport system are neglected.

The maximum bulk core outlet temperature for BE-3A, assuming no unblockage after 36 hours, is $930 \mathrm{~K}$ $\left(1215^{\circ} \mathrm{F}\right)$ at about 40 hours. The results for BE-3B, 100-percent blockage initially, are somewhat more severe, with the peak bulk outlet temperature reaching $972 \mathrm{~K}$ $\left(1290^{\circ} \mathrm{F}\right)$ at 25 hours, following the partial unblockage at 12 hours.

\section{B.2.5 BE-4: Unprotected Loss of Flow, Loss of Heat Sink, With Seizure of One Primary Pump}

GE redefined this event to include the loss of heat sink in addition to the complete loss of one EM pump and its associated synchronous coastdown machine. The other three synchronous coastdown machines are assumed to operate as designed. The flow coastdown through the core is reduced in comparison to BE-2'.

The peak fuel, cladding, and peak coolant temperatures reach maximum levels of $1123 \mathrm{~K}\left(1562^{\circ} \mathrm{F}\right), 1010 \mathrm{~K}$ $\left(1355^{\circ} \mathrm{F}\right)$, and $997 \mathrm{~K}\left(1335^{\circ} \mathrm{F}\right)$, at 3 seconds. The system continues to slowly heat up until Doppler and core radial expansion reactivity feedbacks turn the power 
excursion around. The pleak bulk outlet temperature reaches $918 \mathrm{~K}\left(1193^{\circ} \mathrm{F}\right)$ at 41,000 seconds.

\section{B.2.6 Sumumary}

GE summarizes its analyses of the BEs in PSID Section G.4.16.2, reproduced hero as Table B.1. For BE-5 through -7, GE refers to PSID Section G.4.8.3 for the steam generator tube rupture (BE-5), PSID Amendment 11 for large sodium leuks (BE-6), and PSID Section G.4.6 for the postulated assembly flow blockage (BE-7). GE defers its response for "External Events" (BE-8) "until receiving further input from the NRC staff" (i.e., a list of postulated external events).

Table B.1 contains peak cladding and coolant temperatures, the peak mixed-mean core outlet sodium temperature, the estimated cladding loss (mils), and the minimum margin to sodium boiling for each of the first few BEs, that is, BE-1A, $-1 B,-2,-3 A,-3 B$, and -4 . GE did not include the peak fuel temperatures in this table, which is consistent with the stated position that it is the potential failure mode through cladding failure that is the greater concern, and the position that some localized fuel melting during highly improbable events should be acceptable. It is noted that GE predicted the penk fuel temperatures during BE-1A and $-1 B$ (the $40 C$ UTOP cases) to be above the solidus temperature. In BE-1A, 1B, BE-2, and $\mathrm{BE}-4$, the peak cladding temperature is above the $980 \mathrm{~K}\left(1300^{\circ} \mathrm{F}\right)$ design specification threshold temperature where rapid eutectic cladding failure is predicted to occur if the temperature is sustained.

In order to better comprehend key portions of Table B.1 and other information contained within PSID Section G.4.16, Figure B.2 was constructed. Included are the peak fuel, cladding, and coolant temperatures from GE's analyses for BE-1A, $-1 B$, and $-2^{\prime}$ (GE analyzed a more-challenging variation on the $B E-2$ recommended by the NRC staff), and BE-4, along with some key information regarding failure limits. In the interest of presenting a good overview on one figure, some liberties with the cladding damage range and the fuel solidus temperature range have been taken, and more than the optimum amount of information is presented in this single figure. However, the array of information provided by ANL regarding metal-fuel performance and failure modes is extensive, and Figure B.2 is generally consistent with the information provided.
It is clear from Figure B.2 that some fuel would be heated above the solidus temperature for BE-1A and $-1 B$. For the UTOP events, the power production in the pins increases by about 70 percent, so the pin center-line temperatures can increase very substantially. As the peak fuel temperatures for BE-1A and BE-1B are above the solidus temperature for the zirconium fuel, there is little doubt that some localized melting would take place. A decision will be required at the design certification stage, in terms of how much, if any, localized fuel melting will be acceptable.

The peak cladding and sodium temperatures for events BE-1A and BE-1B show that the system gets significantly hotter if only RVACS is available to remove the heat. These higher temperatures are needed to radiate the heat out through the vessels, and result in a lower power production in the core. As a result, the increase in fuel temperatures is significantly less than the increase in cladding and sodium temperatures. For BE-1B, GE estimated a cladding wastage of 0.22 mil (Table B.1), which is about 1 percent. This amount of damage, if correct, should probably be acceptable for such an unlikely event. The peak sodium temperature is well below boiling and does not appear to be problem for the UTOP events.

The ULOF-ULOHS (BE-2') and ULOF-3/4 coastdown (BE-4) events on the right side of Figure B.2 result in significantly lower fuel temperatures. There may be a very slight amount of cladding damage for these events, especially if conservative limits are applied. The sodium is well below boiling, with or without pumping. A major factor in limiting the peak temperatures is the use of the GEMs to insert a large amount of negative reactivity once the pumps trip off line.

The GE results presented in PSID Section G.4.16.2, as summarized in Figure B.2 point directly to the postulated UTOP events as the safety concerns within the category of "bounding events." Independent analyses performed at Brookhaven National i aboratory (BNL) (Ref. B.5) tend to confirm this, although BNL's peak fuel temperatures are somewhat higher, and the subsequent cladding damage greater. Despite ANL's optimism that it can demonstrate that metal fuel can survive these events, GE may have to consider reducing the potential UTOP initiator below $40 \mathrm{C}$ (including uncertainties), perhaps by moving the control rod stops more frequently. Biecause the preapplicant seems to have a few options available to reduce the potential UTOP initiators, the results summarized in Figure B. 2 are not viewed as an insurmountable problem. 


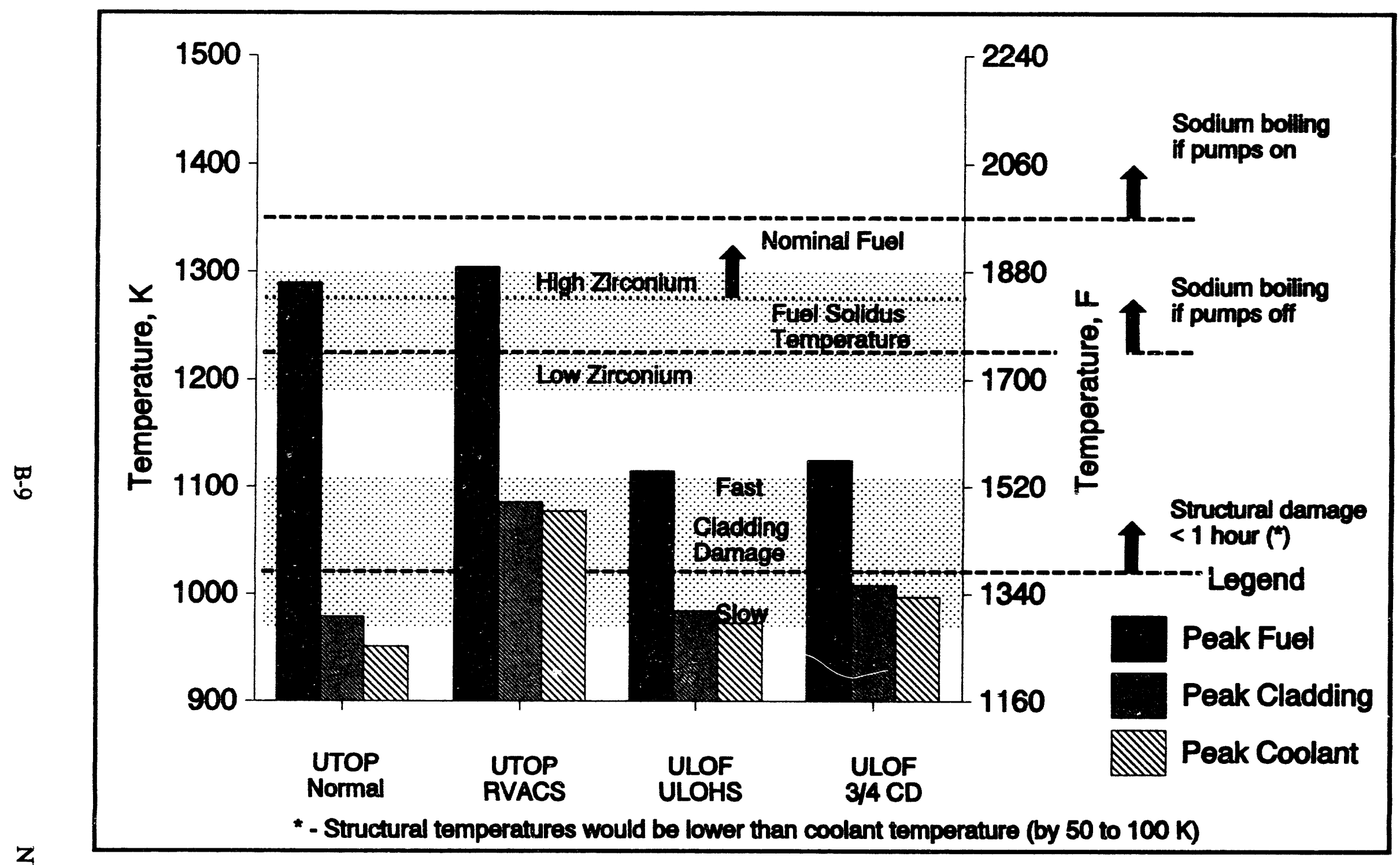

Figure B.2 Summary of GE Bounding Events 1A, 1B, 2', and 4 


\section{B.3 Independent Analyses of Selected Bounding Events}

BNL performed revised independent analyses of several postulated events, including BE-1A, $-2,-3 A,-3 B$, and -4 , using the SSC and MINET codes. The analysis of BE-1B will require some model modifications, which have not yet been implemented. However, there are enough direct comparisons between the staff analyses and those provided by GE to project the likely results for 1B. Because GE incorrectly represented reactivity insertion (the rod worth for the control rod drive-line expansion was too high), its predictions for all the unscrammed events are slightly cooler (a few degrees K) than they should be. Thus, it is expected that GE's results for BE-1B are fairly accurate, although the fuel should be slightly hotter and a little more cladding damage should be expected.

The review of these events by the staff included two different efforts. The first part involved reviewing GE's calculations presented in PSID Appendices E and G. This amounted to studying the transients analyzed by GE to ascertain whether a coherent package of transients was analyzed.

- For the second part of the review, the staff conducted an independent set of calculations to analyze the passive safety features claimed by the designers. BNL performert these calculations using the SSC and MINET comput

simulate the reactor system and independently

postulated transients. SSC was modified to $h_{\text {t. }}$.o reactivity feedbacks associated with a metal-fueled core. From the information in the PSID, computer models were created with minimal interactions with the PRISM designers, except when information was missing (i.e., the models are not identical).

The point kinetics reactivity coefficients were taken from the data supplied by the vendor. Efforts were made to review the coefficients supplied by the designers and to compare them with previously published values for other liquid-metal reactors (LMRs). No apparent inconsistencies were identified. In addition, it was possible to make estimates of some of the feedback coefficients, and these estimates agreed with the values given. It is realized that the passive response of the reactor is dictated by these coefficients and that they must be recalculated at a later stage in the review by an independent source (using different computational tools) for the worth of each of the feedbacks to be evaluated in a truly independent fashion. However, the use of the preapplicant's reactivity coefficients is believed to be appropriate at this stage in the review process.

\section{B.3.1 Analytical Approach}

Most of the staff's independent analyses were performed using two well established codes, SSC (Ref. B.6) and MINET (Refs. B.7 and B.8). SSC was developed for analyzing various LMR systems under transient conditions. Ho vever, it was necessary to add some models to SSC for analyzing the PRISM, as discussed in the next section. MINET is a highly flexible systems code that could be used to analyze the postulated long-term heatup events, as well as features of the pump coastdown events. Between SSC and MINET, most of the modeling requirements were fulfilled. Any gaps were covered using special-purpose models. It is noted that work is in progress to reconfigure SSC, MINET, and other analytical tools to create a more complete integral representation of the PRISM system.

\section{B.3.2 SSC Modeling}

A full-plant SSC model was used to represent PRISM in the independent analyses, as illustrated in Figure B.3. Several major components were represented, as shown. For the reactor, seven channels were used to represent the drivers, the internal blankets, the radial blankets, the control assemblies, the reflector region, the shield assemblies, and a hot driver assembly. The bypass flow also was modeled. Twelve axial nodes were used for each assembly, with two nodes used for the lower shield region, six nodes for the active core, and four nodes for the gas plena. Each axial node includes four radial rings in the fuel region plus one for the cladding.

Data used for representing the intermediate heat exchanger (IHX), the pumps, the steam generators, and other key coolant system components were taken from the PSID (Ref. B.1) or were obtained directly from the preapplicant. The EM pump representation was simplified because SSC has no explicit provision for representing the EM pump. (Such a model has been developed and tested in MINET, but has not yet been incorporated into SSC.) Therefore, the primary system flow rate was imposed as a transient boundary condition based on calculational results from both GE's analyses and results generated using the MINET.

SSC was originally developed to analyze oxide fuel LMRs. To facilitate modeling of the metal fuel used in PRISM, several modifications were implemented, as documented in References B.3 and B.4. In addition to these changes, additional modifications were required to model the revised PRISM core design. The principal change wias the addition of a model for the GEMs. Three of these assemblies were added to PRISM in order to supplement the negative reactivity feedback that develops once the pumps have been tripped. When the pumps trip and the 
pressure drops, the sodium within the GEMs at the active core elevation is displaced by expanding helium gas, thus increasing the leakage of neutrons from the core and subtracting about $69 \mathrm{C}$ of reactivity, assuming all three GEMs function properly. The operational mode of the GEMs is illustrated in Figure B.1.

The GEM is essentially an empty assembly duct, sealed at the top, open at the bottom, and connected to the core support plate in the inlet plenum of the core. A hexagonal cross-section duct, with a wall thickness slightly greater than the standard fuel and blanket duct, forms the unit. When the pumps are at full flow, the plenum pressure (minus the static head to the GEM level) compresses the gas in the GEM cavity to be above the core. The sodium within the GEM causes more neutrons to be scattered and deflected back into the core, as compared to when the gas is adjacent to the core. When the flow decreases, the trapped helium expands and drops the sodium level into the core region. As a result, fewer neutrons are scattered back into the core region. The reactivity effect increases as the gas expands into the core and remains constant once the gas-liquid interface drops below the core region. At this point, the maximum negativity reactivity of $69 \mathrm{c}$ (i.e., $23 \mathrm{c}$ each) is imposed.

\section{B.3.3 MINET Representalion}

The MINET is a highly flexible and modular systems code based on a momentum integral network formulation. Although several different system representations were used in analyzing the PRISM, they were all variations of the layout shown in Figure B.4. The core representation includes user-specification of the heating term (decay heat once scram occurs), because, the reactivity feedback modeling currently available in MINET is not sufficiently detailed for analyzing the passive shutdown mechanism. Models for the pipes and pools conserve mass, energy, and momentum along a length of piping (called segments). The pump representation was extended to model in detail the PRISM EM pumps, including the coastdown response. The IHX was simulated as a full heat exchanger in some cases, and as a user-input "heated pipe" in other cases. The RVACS heat loss was specified as a time/temperaturedependent heat loss in volume 108. Some auxiliary piping and valve modules were used to facilitate simulation of postulated pipe rupture events. As a result, the valve modules identified as 501 and 502 in Figure B.4 have no physical equivalent in the PRISM, and they are present only so the user can allow the sodium flow to leak; otherwise they can be closed off.
While the MINET models could be used to simulate several types of transient events, the applications thus far have focused in two areas. First, and most extensively, MINET has been used to simulate long-term heatup events. During these events, a scram occurs and normal and ACS cooling are lost, leaving only the RVACS to remove the decay heat. After a few hours, the sodium becomes hot enough for the RVACS to spill over, which means transferring sodium from volumes 101 to 108 in the MINET representation illustrated in Figure B.4. Over the long term, the system gradually heats up to a degree where the heat loss to the up-flowing RVACS air equals (and then exceeds) the decay heat production, which may be a day or so after the event begins. The second MINET application has been for postulated pipe rupture and pump seizure (cuastdown failure) events. A complex model of the EM pumps and the synchronous coastdown machines was implemented in MINET.

\section{B.3.4 Unprotected Transient Overpower Events}

An unprotected transient overpower (UTOP) accident results when positive reactivity is inadvertentiy inserted into the core and there is a failure to scram. The limiting case assumption is that all the control rods are accidently removed. This event is bounded by the amount of reactivity available in the control rods. In an oxide fuel core (i.e., $\mathrm{UO}_{2}$ ), the temperature and power defect and built-in excess reactivity for the burnup swing (excluding axial expansion) is generally several dollars' worth, making the event very severe, should it occur. The metalfuel core in PRISM has, on the other hand, a small temperature and power defect $(-\$ 1.2)$, negligible burnup swing (excluding axial expansion) $(-4 \mathfrak{C})$, and excess reactivity to account for the fuel axial expansion $(-\$ 1.10)$. The amount of reactivity available for a UTOP is rediced by adding control rod stops in the PRISM so that only a limited amount of excess reactivity $(4 \mathfrak{C} C$, including $10 C$ to cover uncertair ies) can be added. The nominal excess reactivity, at full power, at the beginning of the fuel cycle is $\$ 2.15$ and at the end of fuel cycle it is $\$ 1.05$.

Because of the small Doppler feedback, the UTOP scenario can be very challenging for a metal-fuel core. The hard neutron spectrum of a metal core has relatively few neutrons in the prominent U-238 resonances; thus giving the PRISM reactor a small Doppler feedback. This is the usual mechanism to limit ai. overpower event of the axial core. Instead, the PRISM design must rely on neutronic feedbacks from radial expansion, control rod expansion, and fuel axial expansion to limit the peak power. As the temperature increases, its effect on the neutronic reactivity is relied upon to limit the energy production to an acceptable level. 
Appendix B

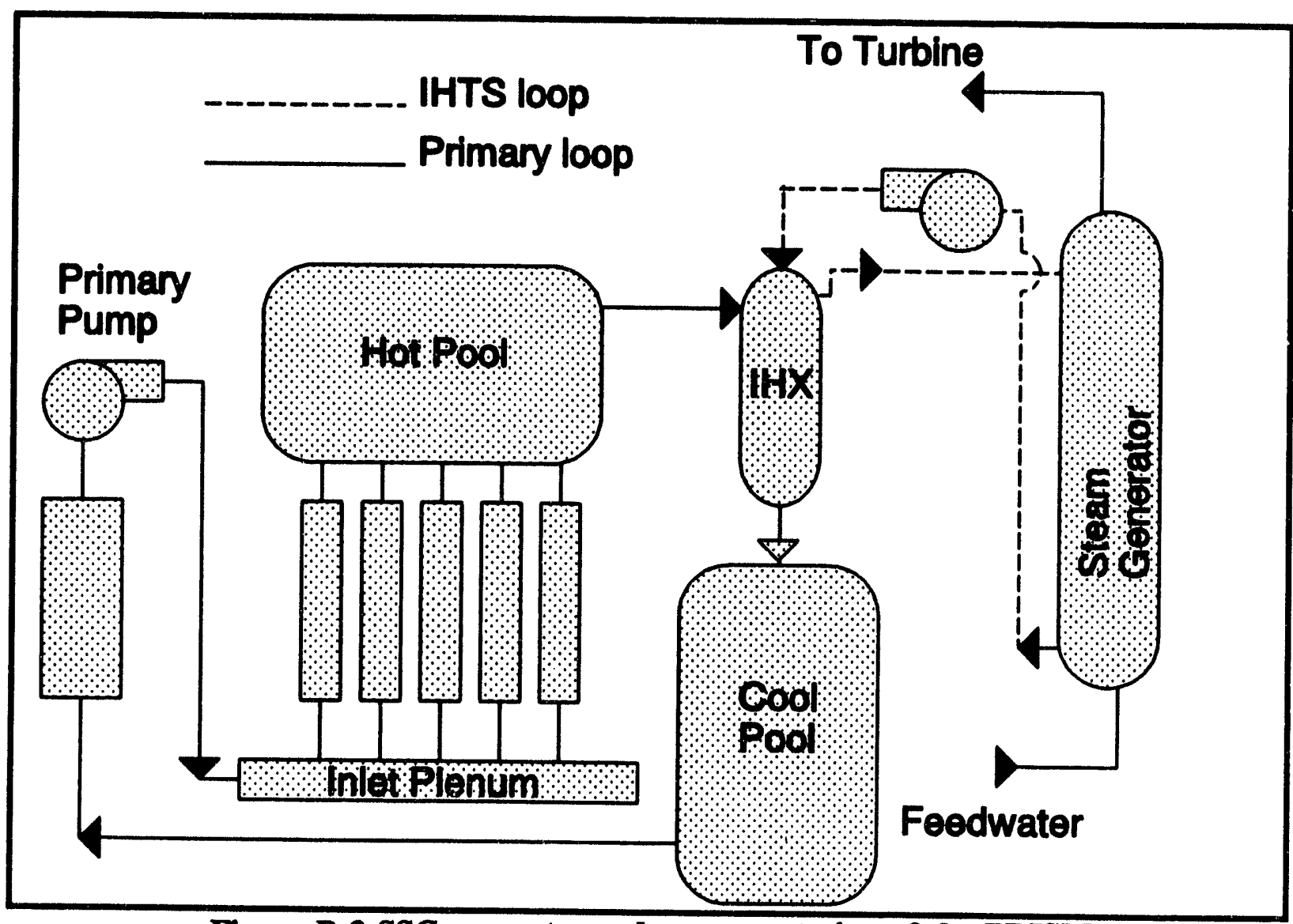

Figure B.3 SSC computer code representation of the PRISM

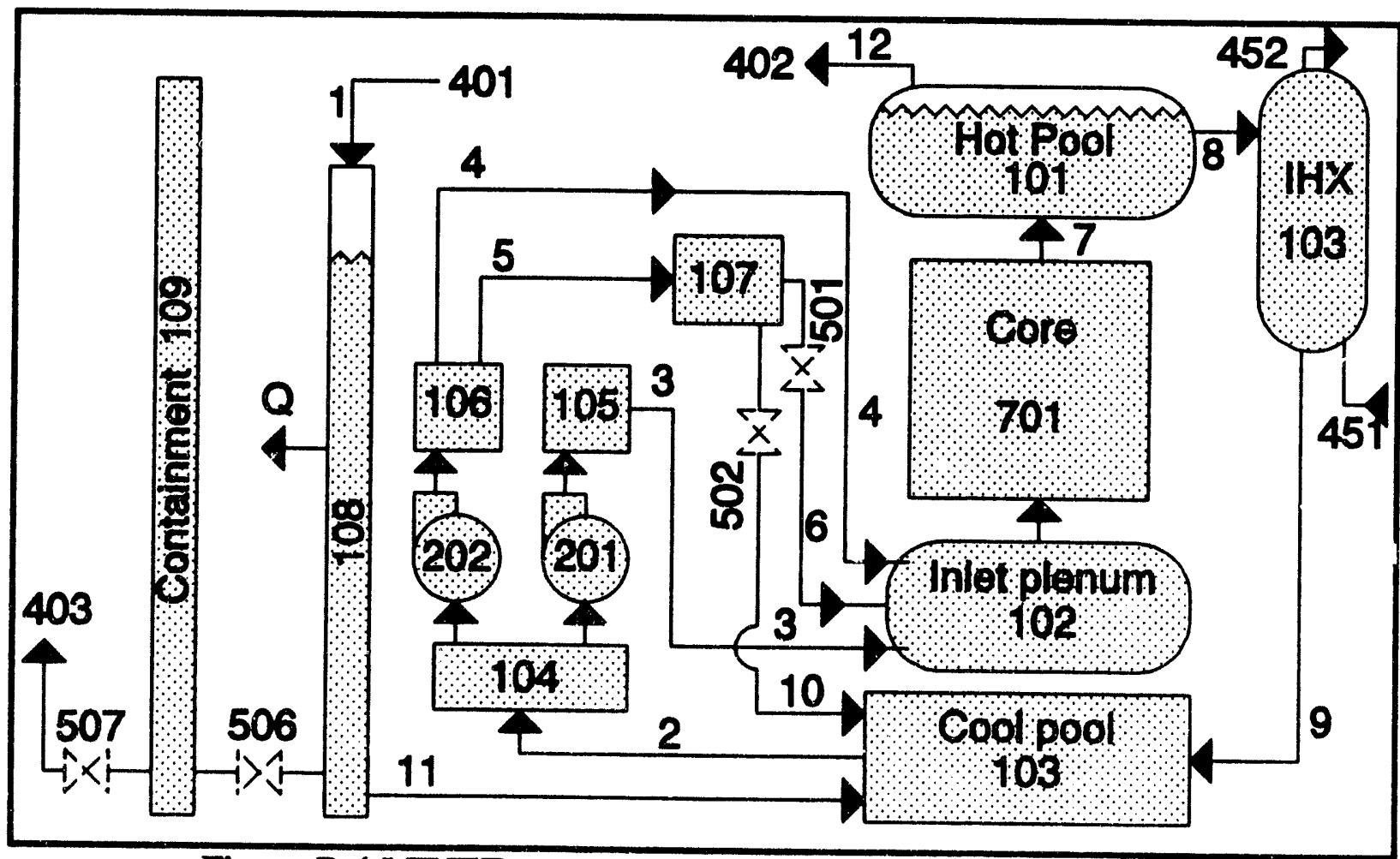

Figure B.4 MINET computer code representation of the PRISM 


\section{B.3.4.1 BE-1A: UTOP With Normal Cooling}

The event is initiated from full power. The control rods are assumed to begin withdrawing with a speed of $2 \mathrm{c}$ per second. The control roc stops are set to limit the withdrawal worth to 30c. However, GE has adopted $40 \mathrm{C}$ as the transient overpower (TOP) initiator to account for uncertainties and to be conservative. Thus, the PRISM TOP is assumed to insert $2 \mathrm{C}$ per second for 20 seconds, for a total of $40 \mathrm{c}$, representing the withdrawal of all the control rods.

The initial conditions used and important system parameters are listed in Table B.2. A majority of the initial conditions were taken from the PSID amendment for the 1989 version of the PRISM, with the remainder from direct communications with the vendor.

Two UTOP cases were analyzed. The first calculation represented a case where SSC is set up to replicate the ARIES calculations discussed in the PSID. This was done to verify that the models give comparable results for similar assumptions. The second calculation represents the PRISM system if more conservative assumptions are made about the fuel behavior.

\section{Nominal Case: UTOP with Nominal Fuel Properties}

The withdrawal of all of the control rods is represented by an insertion of $+2 \mathrm{c}$ per second for 20 seconds. The EM pumps are assumed to continue to operate at nominal conditions. The control rods are thus removed to the rod stop position without causing activation of the reactor protection system.

The plots from the analysis are shown in Figures B.5 through B.12. The power reaches a peak of 1.7 times the rated power by 23 seconds, and begins to level off at 1.22 times the rated power by 7 minutes, as shown in Figure B.5. The increase in power raises the average core outlet sodium temperature (Figure B.6) to a maximum of $870 \mathrm{~K}\left(1106^{\circ} \mathrm{F}\right)$. This increase in the core outlet sodium temperature also improves the performance of the IHX. The total rise in core outlet temperature is $112 \mathrm{~K}\left(202^{\circ} \mathrm{F}\right)$. Eventually the core outlet sodium temperature is reestablished at around $833 \mathrm{~K}\left(1040^{\circ} \mathrm{F}\right)$, which is $75 \mathrm{~K}$ $\left(135^{\circ} \mathrm{F}\right)$ above the initial temperature.

The changes in the reactivity can be seen in Figures B.7 through B.9. The total (net) reactivity feedback, shown in Figure B.7, starts out positive because of the reactivity from the control rods being removed, but turns downward once the negative reactivity feedbacks increases enough to counter the positive insertion. The rise in fuel temperatures first increases the Doppler absorption of the neutrons and then triggers the fuel's elongation. These two feedbacks add about $-23 \mathrm{C}$ at the time of peak power. Higher sodium temperatures create a harder neutronic spectrum, which generates a positive reactivity feedback of about $+6 \mathrm{C}$ at the time of peak power. The higher sodium temperatures cause the thermal expansion of the control rod drive line and radial expansion, which are negative reactivities feedbacks, as indicated in Figures B.8 and B.9. The control rod drive lines have time constants of around 30 seconds and are slow to act as compared to the radial expansion. Radial expansion, shown in Figure B.9, is composed of the grid plate and the above-core load pad (ACLP) expansion, which are shown in Figure B.8. The radial expansion adds the crucial amount of reactivity that eventually limits the power increase to 1.7 times rated power and contributes to the power reduction that follows. The control rod drive-line expansion reactivity continues to increase (negative) in worth and drives the total reactivity to zero after around 80 seconds. Although the reduced power decreases the worth of several of the reactivities, the control drive line continues to expand, causing the total reactivity to become slightly negative and re-stabilizing the power near 1.22 times the rated level.

The predicted behavior of the component reactivities is very similar between GE's ARIES calculations and the SSC calculations. The two predictions are compared in Table B.3. One point of contention was the worth of the control rod drive line, which ARIES was predicting to reach a worth of about $30 \mathrm{c}$, while SSC predicted about 20c. Upon investigation, GE agreed that the ARIES worth curve was set erroneously for the smaller (old) height core and the staff prediction was correct. GE will have to modify the plots in the PSID. Also, the ARIES modeling used the single assembly bowing model, which gives about $5 \mathrm{c}$ to $8 \mathrm{C}$ of negative reactivity that is not factored into the SSC calculation. This effect was intentionally left out of the SSC calculation because the quantification of the radial bowing is very difficult and the feedback is always negative when the temperatures are rising; omitting it is believed to be both conservative and prudent. (However, the bowing feedback will not be a significant issue until there is a case identified where one needs the bowing contribution to predict a safe response to a postulated event.)

The results from the UTOP spike and increase in power level on the fuel can be seen in Figures B.10 through B.12, where the peak temperatures are shown. The thermal conductivity is set to that of the nominal fuel so that SSC can be consistent with the ARIES calculation. (This is changed in the next SSC calculation.) 
Table B.2 Initial and key operating parameters

\begin{tabular}{||l|c|c|}
\hline \multicolumn{1}{|c|}{ Description } & PRISM & SSC \\
\hline Power (MW) & 471 & 471 \\
\hline Cover gas (kPa) & 99.3 & 99.3 \\
\hline Primary sodium flow (kg/s) & 2513 & 2507 \\
\hline Primary sodium inlet temperature (K) & 610.9 & 610.9 \\
\hline Primary sodium outlet temperature (K) & 758.1 & 758.0 \\
\hline Inlet plenum pressure (kPa) & 744.6 & 744.6 \\
\hline Pump rise (kPa) & 614.3 & 614.3 \\
\hline Fuel assembly length (m) & 4.978 & 4.978 \\
\hline Core height (m) & 1.3462 & 1.3462 \\
\hline Peak fuel pin/average fuel pin & 1.31 & 1.31 \\
\hline Fuel pin OD (m) & 0.00668 & 0.00668 \\
\hline Driver fuel pins/assembly & 331 & 331 \\
\hline Intermediate sodium flow (kg/s) & 2293 & 2275 \\
\hline IHX-IHTS inlet temperature (K) & 555.4 & 557.0 \\
\hline IHX-IHTS sodium outlet temperature (K) & 716.5 & 720.0 \\
\hline
\end{tabular}

Table B.3 Peak temperatures predicted by SSC and ARIES

\begin{tabular}{|l|c|c|}
\hline \multicolumn{1}{|c|}{ Parameter } & ARIES & SSC \\
\hline Peak power & 1.72 & 1.7 \\
Peak sodium (Na) temperature (K) & 951 & 944 \\
Peak clad temperature (K) & 979 & 960 \\
Peak fuel temperature (K) & 1292 & 1298 \\
& & 1164 \\
Average Driver Peak Temperature (K) & $\ldots-$ & 1340 \\
Na saturation temperature (K) & $\ldots-$ & \\
\hline
\end{tabular}


Appendix B

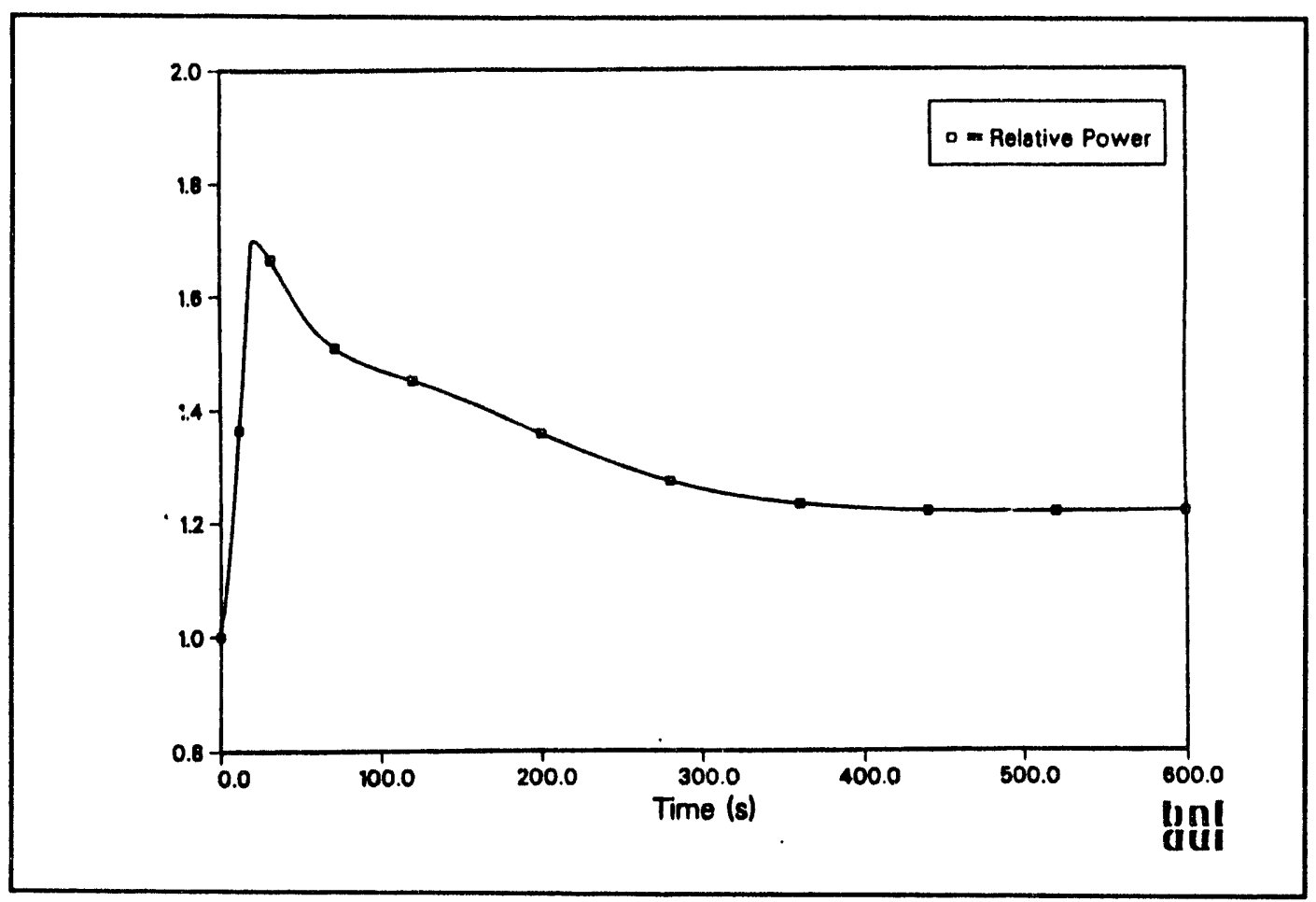

Figure B.5 Relative power prediction from the SSC computer code for the PRISM during a 40C UTOP for assumptions similar to the ARIES computer code

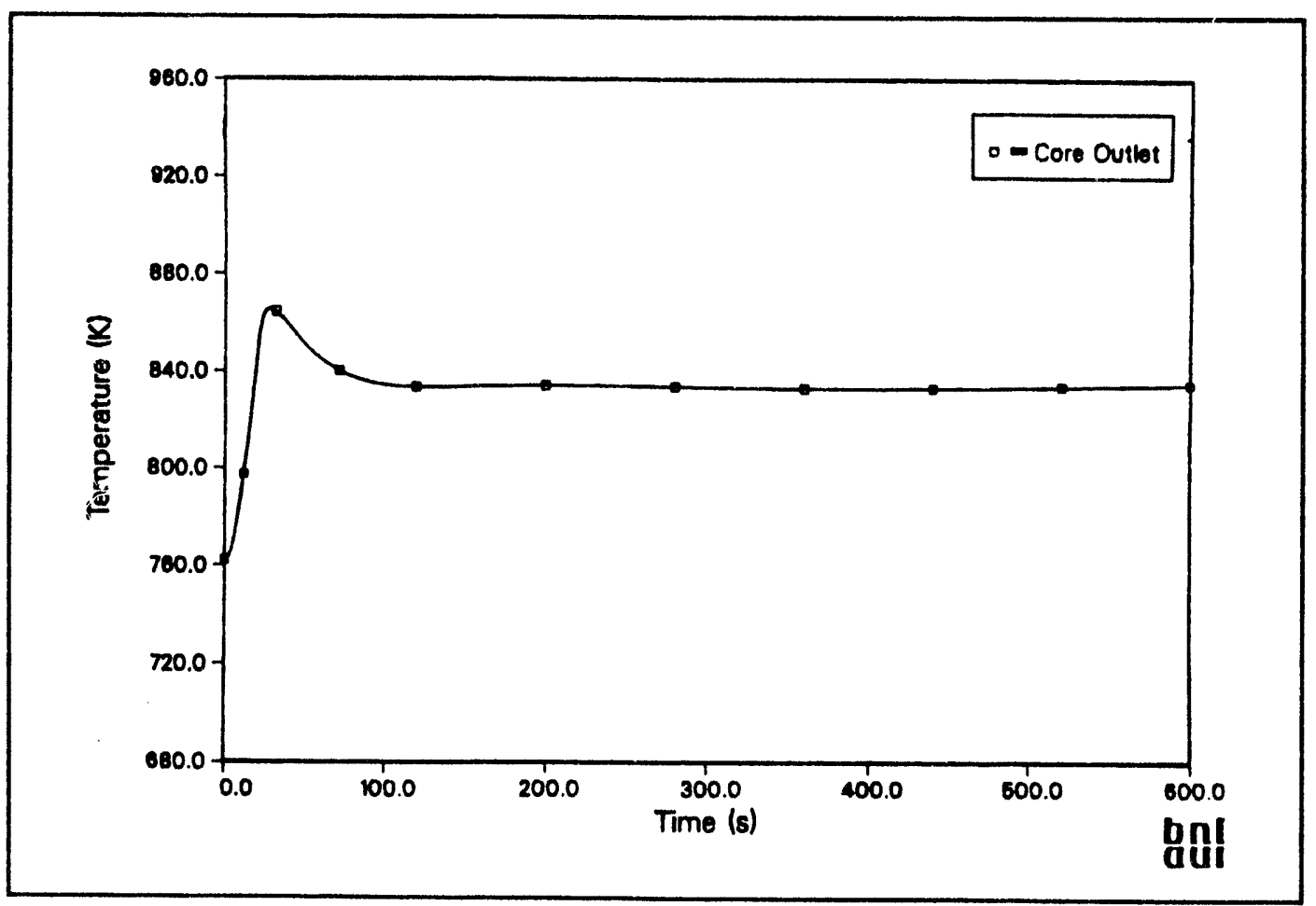

Figure B.6 Average core outlet temperature prediction from the SSC computer code for the PRISM during a 40C UTOP for assumptions similar to the ARIES computer code 
Appendix B

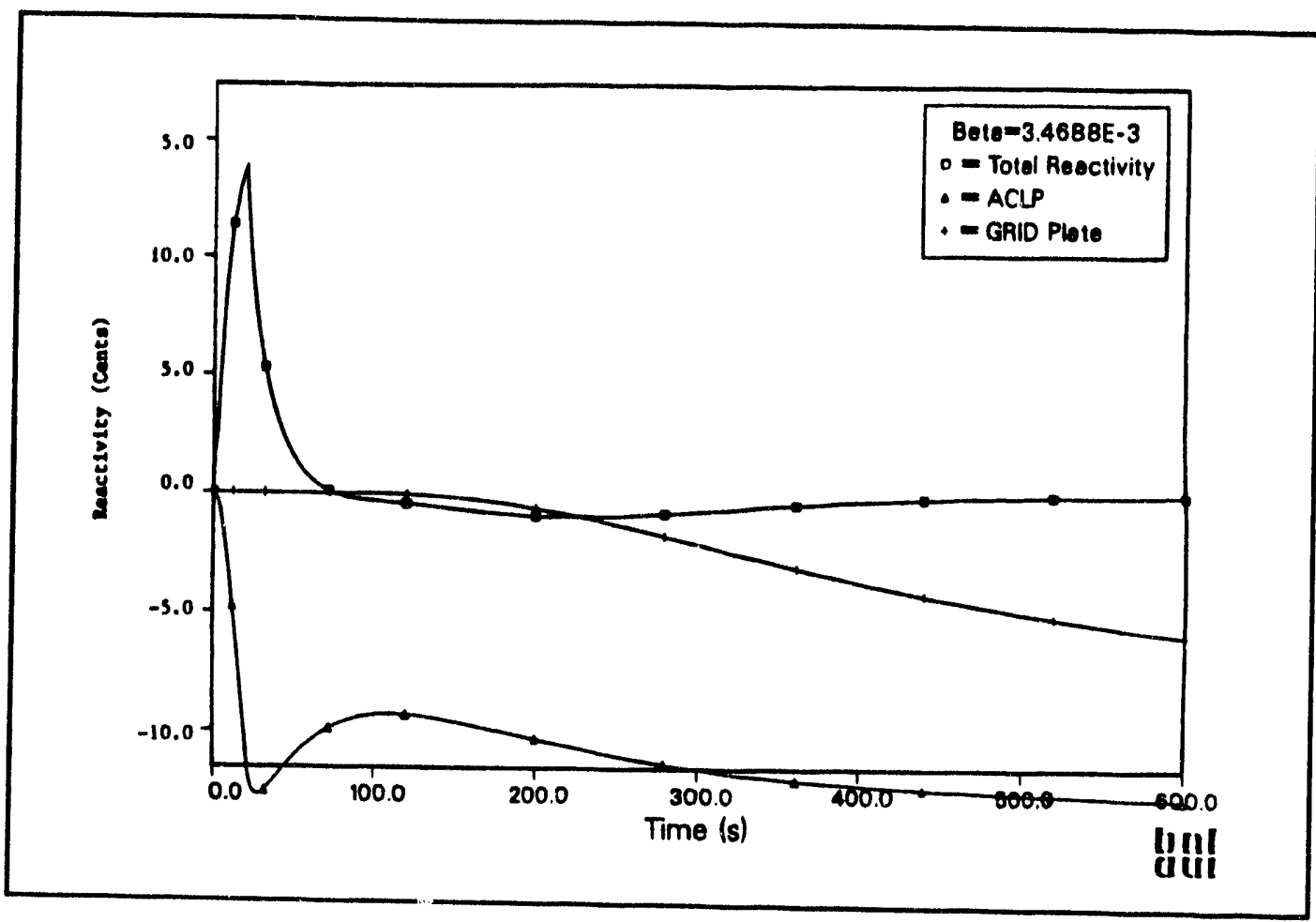

Figure B.7 Reactivity feedbacks (total, ACLP, grid plate) predicted for the 40C UTOP from the SSC computer code using conditions similar to the ARIES computer code

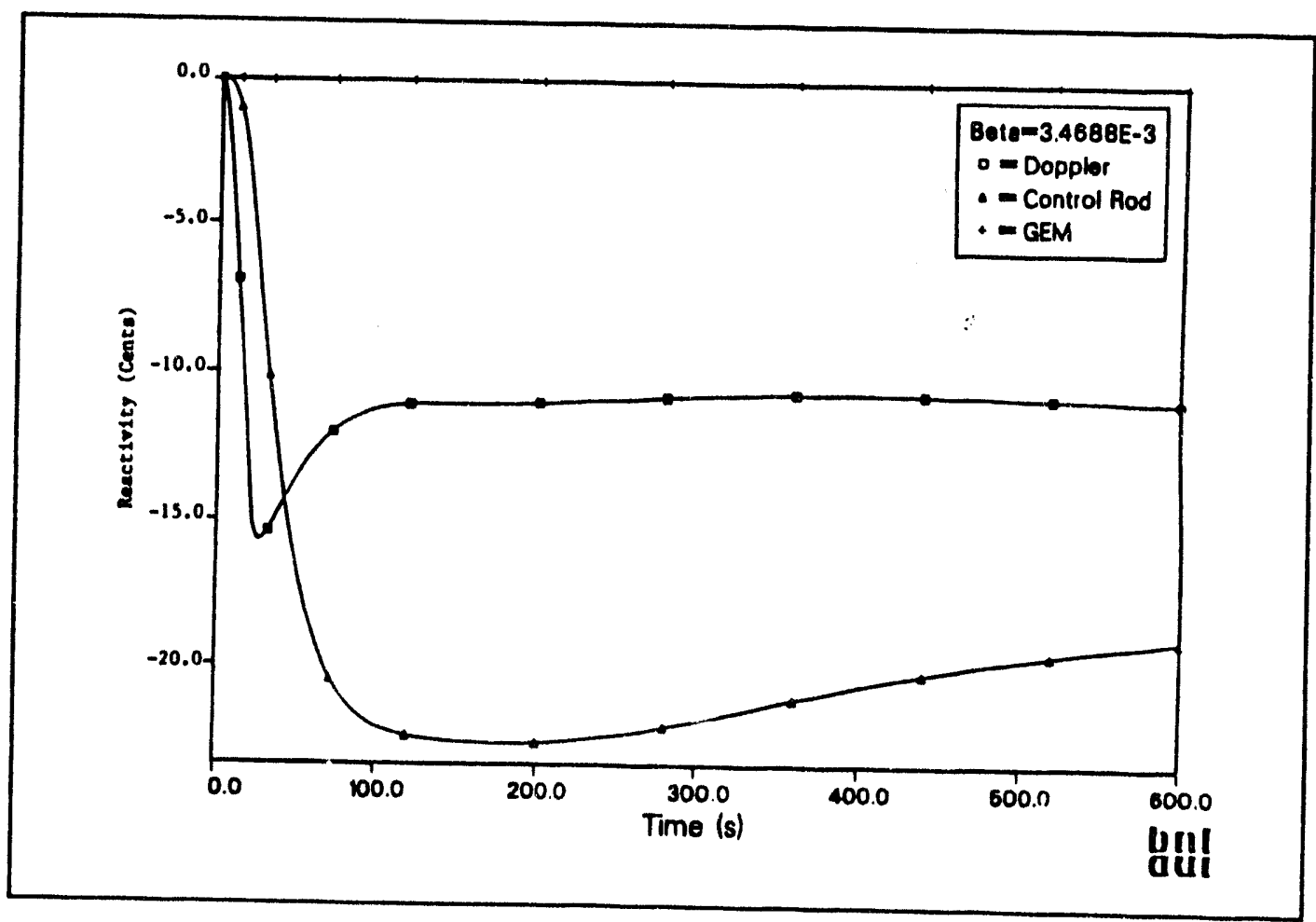

Figure B.8 Reactivity feedbacks (Doppler, control rod, GEMs) predicted for the 40C UTOP from the SSC computer code using conditions similar to the ARIES computer code 


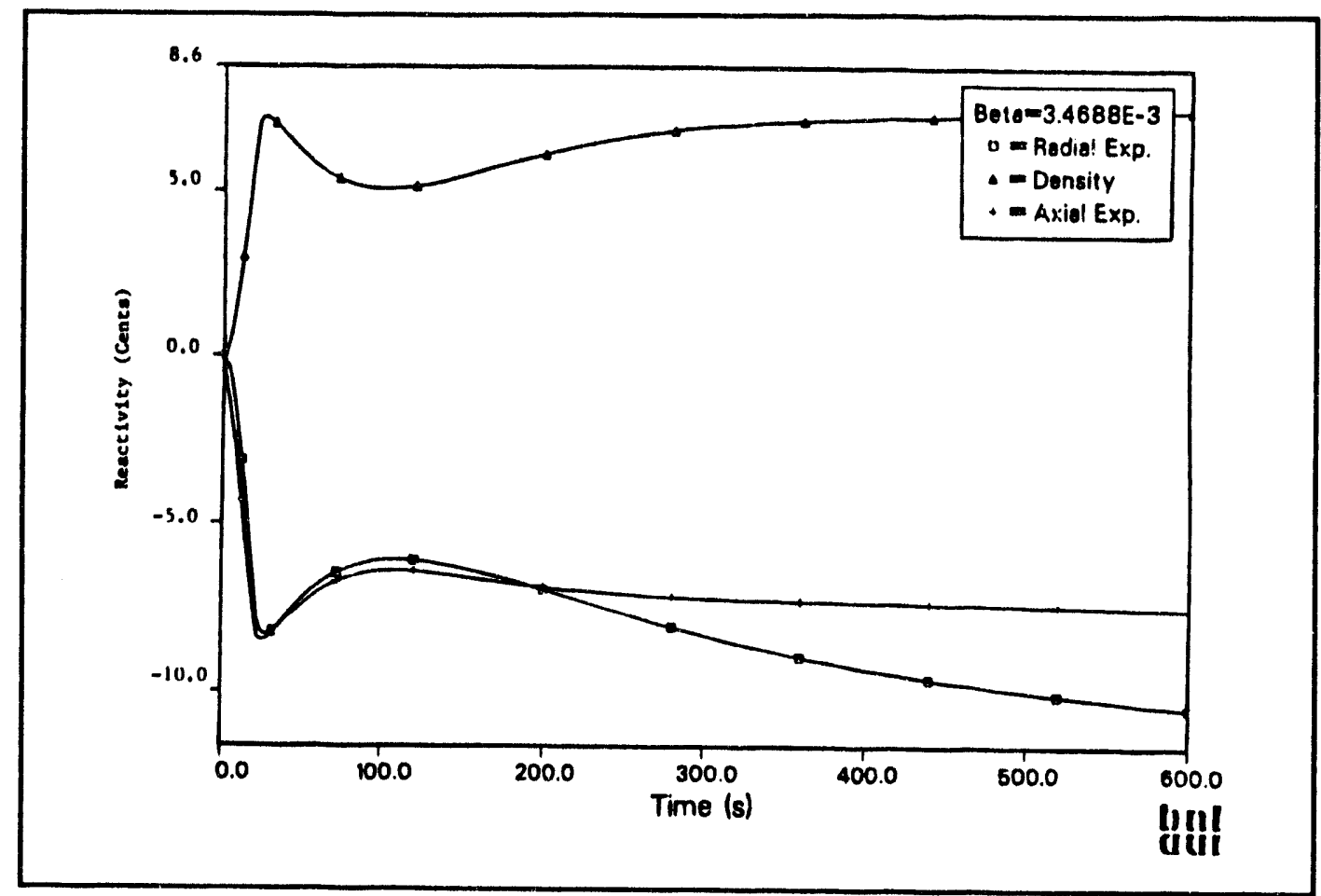

Figure B.9 Reactivity feedbacks (radial expansion, density, axial expansion) predicted for the 40C UTOP from SSC using conditions similar to the ARIES

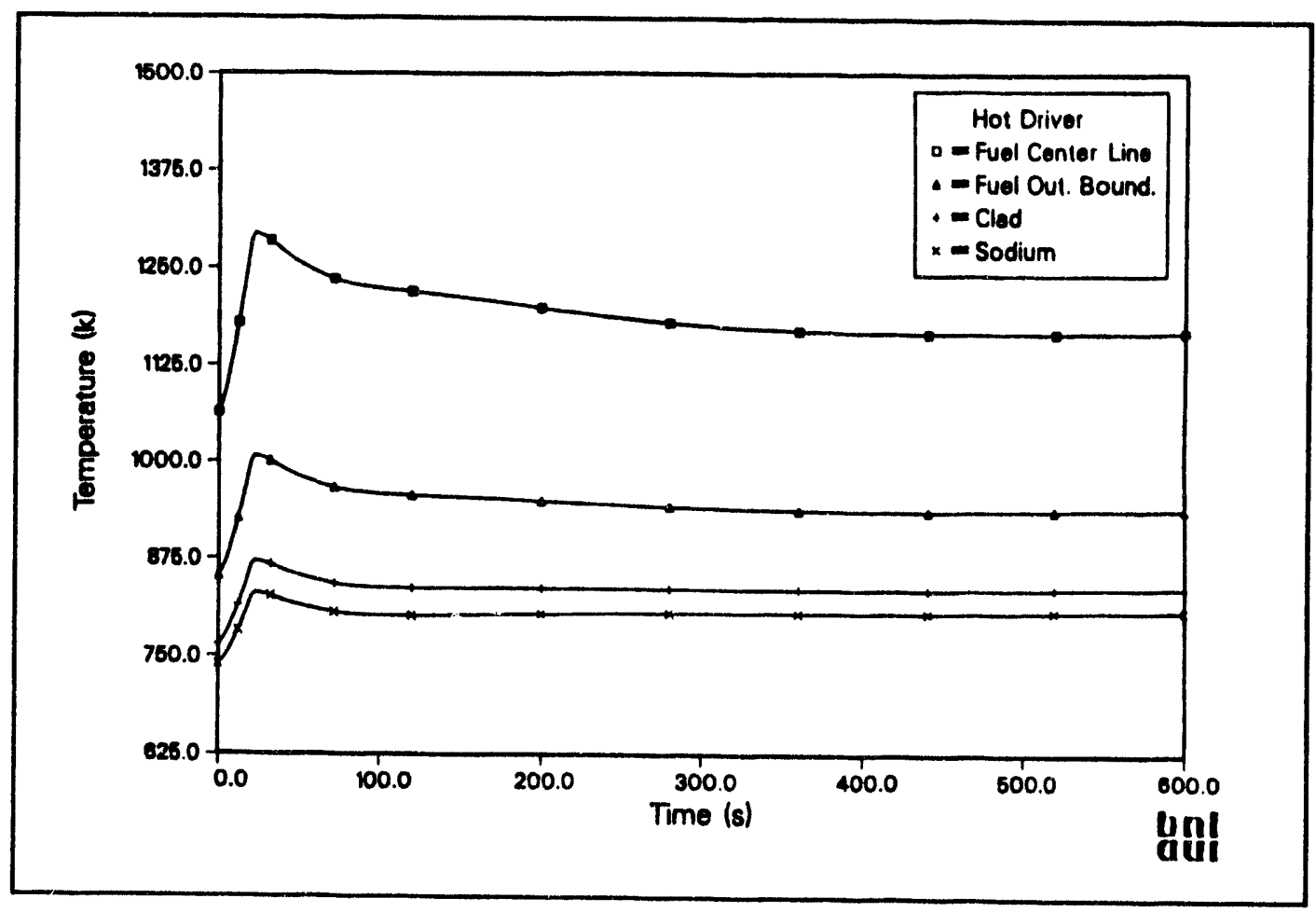

Figure B.10 Predicted fuel temperature distribution from the SSC computer code for the third node from the top (i.e., $0.898 \mathrm{~m}-\mathbf{v} .674 \mathrm{~m}$ ) for a 40C UTOP using nominal ternary fuel thermal conductivities 
Appendix B

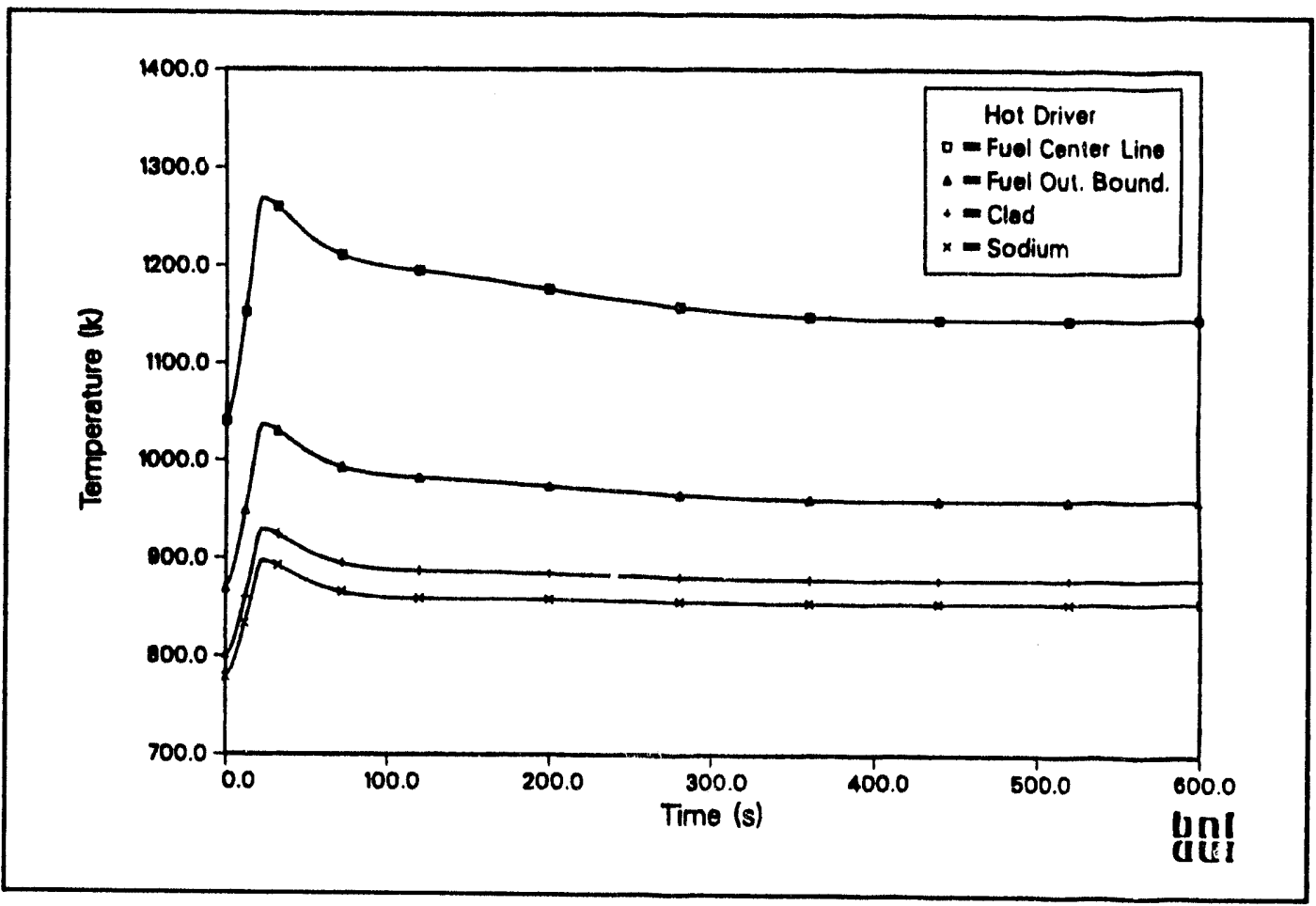

Figure B.11 Predicted fuel temperatures distribution from the SSC computer code for the second node from the top (i.e., $1.122 \mathrm{~m}-0.897 \mathrm{~m}$ ) for a 40c UTOP using nominal ternary fuel thermal conductivities

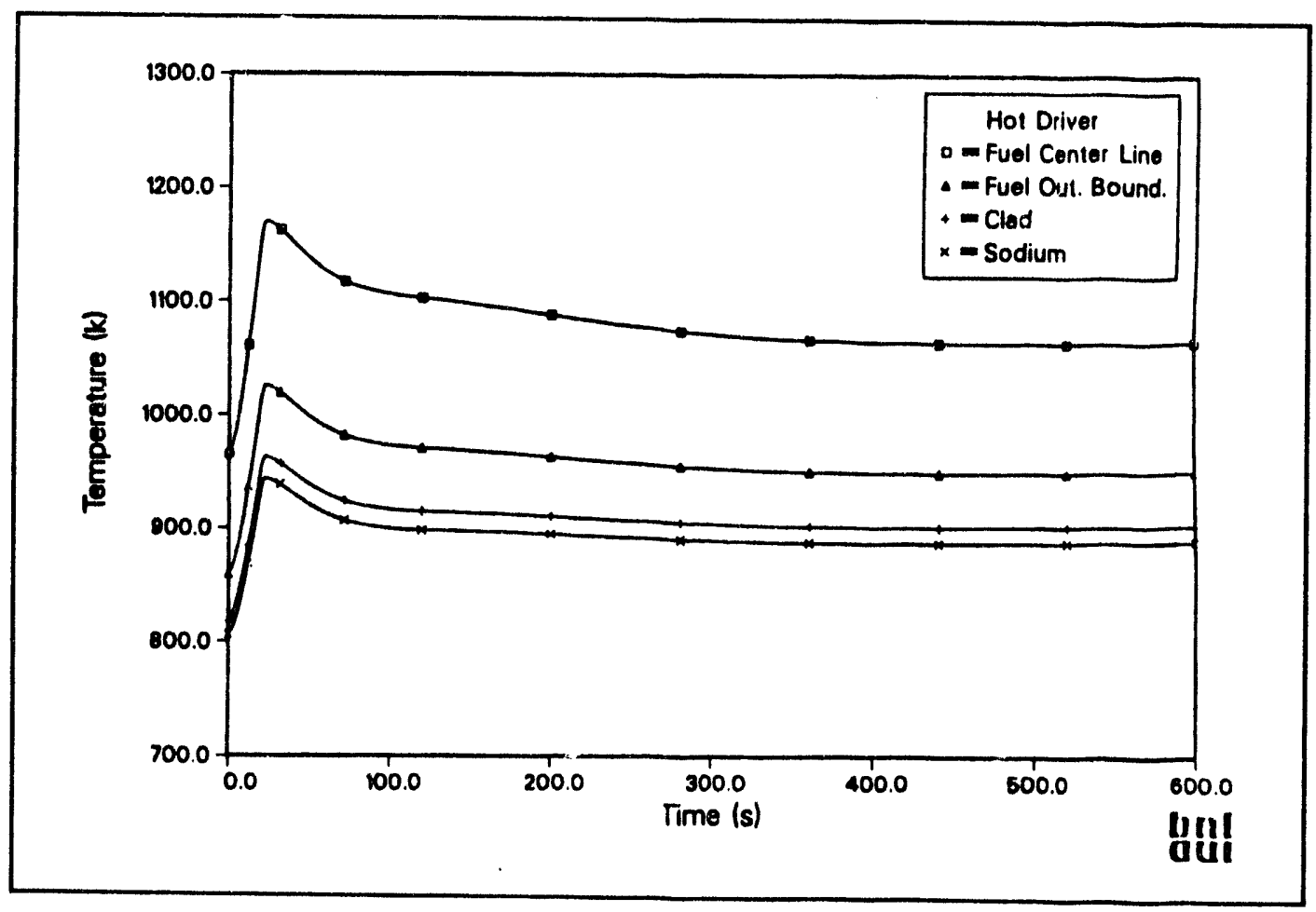

Figure B.12 Predicted fuel temperature distribution from the SSC computer code for the top $0.224 \mathrm{~m}$ (i.e., $1.346 \mathrm{~m}-1.122 \mathrm{~m}$ ) of the fuel pin for a $40 \mathrm{c}$ UTOP using nominal ternary fuel thermal conductivities 
The figures show that the peak temperatures are in the core center (axially) rather than near the top, as was the case in the previous PRISM design analyses. Excess reactivity, teeded to compensate for the axial expansion reactivity loss and other factors, requires the control rods to be inserted deeper in the core than previously (also causing the need for the control rod stops), resulting in stronger bottom power peaking. The fuel center line temperature plotted in Figure B.10 shows that the temperature reaches $1298 \mathrm{~K}\left(1875^{\circ} \mathrm{F}\right)$, which is above the $1273 \mathrm{~K}\left(1830^{\circ} \mathrm{F}\right)$ solidus temperature for the nominal fuel. This solidus temperature is not thought to be conservative because local melting temperatures can be affected by isotope migration, which can reduce the solidus and liquidus temperatures.

Fuel melting was predicted in both the ARIES and SSC calculations. The extent of melting depends on the peaking factors used and the thermal properties. GE has estimated a peaking factor (i.e., peak driver pin compared to the average driver pin) of 1.31 , which was used in both codes. However, this directly affects the maximum temperature, and there is no direct confirmation that this peaking factor is appropriate. The thermal properties are still under review and have not yet been finalized for the present fuel in PRISM. The estimated behavior of the isotopes and their migration have not been resolved either. Significant migration of the uranium and zirconium components occurs in the Experimental Breeder Reactor II (EBR-II) fuel and is predicted for the PRISM fuel. High zirconium levels reduce the solidus temperature and the thermal conductivity. Plutonium also may migrate, which could greatly reduce both the solidus temperature and the thermal conductivity, especially if the effect on local volumetric heating rates within the fuel is considered.

Because the metal-fuel development program is ongoing, particularly with respect to the ternary fuel, several key factors have not been determined yet. The fuel is very dynamic when compared to oxide fuel, since the fuel experiences swelling, element migration, sodium logging, interporosity connections, fission-product formation, and permanent axial expansion. The thermal conductivity is affected by all these factors, and irradiated fuel shows a minimum conductivity at 2-percent atom burnup when sodium logging (sodium filling the porosity within the fuel region) and interporosity connections have not been completed. The $\mathrm{i}^{-i}$. mum conductivity is generally taken as $0.5 \pm 0.1$ times nominal, while the long-term value is $0.7 \pm 0.1$, because of the sodium logging. It is believed that the fuel thermal conductivity is the least certain factor in the thermal hydraulic analysis for the PRISM. The conservative minimum value, 0.5 times nominal, is used in both the GE and the staff analyses.
Conservative Case: UTOP With Reduced Thermal Conductivity

Two principal changes were made for this variant case. First, the control rod drive line was previously assumed to be washed by the sodium exiting from the surrounding channels in the lower part of the hot pool to be consistent with ARIES. This was changed to use the average sodium exiting the core and the average of the hot pool because local thermal-hydraulic behavior during these events is not known. Further, the exact behavior of the flow around the upper internals structure (UIS) has not been determined. The second change was the reduction in the thermal conductivity for the hot channel, based on possible migration of the plutonium and zirconium and weighted by the volumetric heating rates. Plutonium migration may be insignificant, in compurison to the zirconium and uranium migration, but more data are needed before it can be concluded that there is little or no plutonium migration. Some of the resultant thermal conductivity values are shown in Table B.4.

The power peak increases to 1.8 times the rated power and later stabilizes at 1.2. The average core outlet sodium temperature reaches a peak of $880 \mathrm{~K}\left(1125^{\circ} \mathrm{F}\right)$. The reactivities show the same trends as before, except that the control rod drive line is slower to respond. In this more conservative analysis it is washed by the average sodium temperatures above the core rather than the hotter local exit temperatures immediately adjacent to the control rod drive line. This slower response allows the peak power to reach 1.8 before the negative reactivity feedbacks start noticeably reducing the power level. It is noted that sodium density feedback is the only active positive reactivity feedback (with temperature).

The fuel temperatures for the top three nodes in the hot channel are shown in Figures B.13, through B.15. The peak temperatures and power predicted during this calculation are shown in Table B.5. The peak center line temperature in Figure B. 13 reaches $1400 \mathrm{~K}\left(2,060^{\circ} \mathrm{F}\right)$, which is far above the solidus temperature for the nominal fuel (i.e., $1273 \mathrm{~K}$ or $1830{ }^{\circ} \mathrm{F}$ ), let alone for the case with the reduced solidus temperature from zirconium migration, which is about $1200 \mathrm{~K}\left(1700^{\circ} \mathrm{F}\right)$ when zirconium is about 2-atom percent in the center ring. Peak temperatures for the next axial level up in hot channel are shown in Figure B.14, with the fuel temperature peaking near $1364 \mathrm{~K}\left(1995{ }^{\circ} \mathrm{F}\right)$, which exceeds the solidus temperature for both nominal- and zirconium-reduced fuel. However, the top node (Figure B.15) is much cooler at $1258 \mathrm{~K}$ $\left(1805^{\circ} \mathrm{F}\right)$, which indicates that prefailure extrusion that projects molten fuel into the gas plenum from trapped molten pockets expelled by pressurized fission gas, will not 


\section{Appendix B}

Table B.4 Referenced thermal conductivities

\begin{tabular}{|c|c|c|}
\hline Temp ${ }^{\circ}(\mathbf{K})$ & Nominal $(\mathbf{W} / \mathbf{m K})$ & Reduced $(\mathbf{W} / \mathbf{m K})$ \\
\hline 800 & 7.3 & 2.5 \\
1000 & 9.5 & 4.6 \\
1300 & 12.9 & 9.8 \\
\hline
\end{tabular}

Table B.5 Peak values for UTOP variant case

\begin{tabular}{|l|r|}
\hline Parameter & \multicolumn{1}{|l|}{ Value } \\
\hline Relative power & 1.8 \\
Fuel centerline temperature (K) & $1,400.0$ \\
Sodium temperature (K) & 963.0 \\
Clad temperature (K) & 981.0 \\
Average driver fuel assembly (K) & $61,185.0$ \\
\hline
\end{tabular}

occur because the top-of-fuel temperatures are not hot enough (i.e., close to the solidus temperature). Thus, this expected negative reactivity feedback from nearly molten fuel would be unlikely to help mitigate this event. The sodium margin to saturation temperature is shown in Figure B.16.

In summary, two SSC calculations were performed for the postulated UTOP event. The first used conditions and models similar to the ARIES code calculation. The results showed good agreement when both codes included similar modeling assumptions. The second SSC calculation for the UTOP event used the reduced thermal conductivity to account for uncertainties and irradiation effects. Also, the average upper pienum pool temperatures were used to wash against the control rod drive lines just above the core, as opposed to the flow from surrounding channels, as was used in the ARIES calculation.

All three calculations predict that some fuel melting will occur. When uncertainties in the thermal conductivity are included, the results suggest that much of the upper portion of the peak pin could experience localized melting.

While SSC does not represent phase changes or any other fuel melting phenomena, the high temperatures predicted indicate that the potential for significant melting is very real. These calculations were performed at the 2-atom percent burnup level, corresponding to the lowest value of thermal conductivity in the burnup cycle, and at that time the fuel would not have swollen out to the cladding, except at the center (axial) location. Rather, the fuel-clad contact would occur according to the axial power shape, which would make the center close first, followed by the bottom and finally by the top of the fuel.

Some of these concerns have been discussed with GE and ANL. While the preapplicant believes that further data on the metal-fuel behavior will reduce the concerns, GE has provided a brief list of changes that could be made to the PRISM to alleviate these concerns. These changes are as follows:

- move the control rod stops more frequently and by smaller increments.

- make multiple rod withdrawals extremely improbable.

- increase B.10 enrichment in control rods so driveline expansion is more effective.

- change pin characteristics.

- reduce plutonium content.

While each of these steps may have strengths and shortcomings, it is clear that GE has several options. Therefore, although the 40C UTOP indicates fuel damage the preapplicant has several options for reducing or eliminating the vulnerability. 


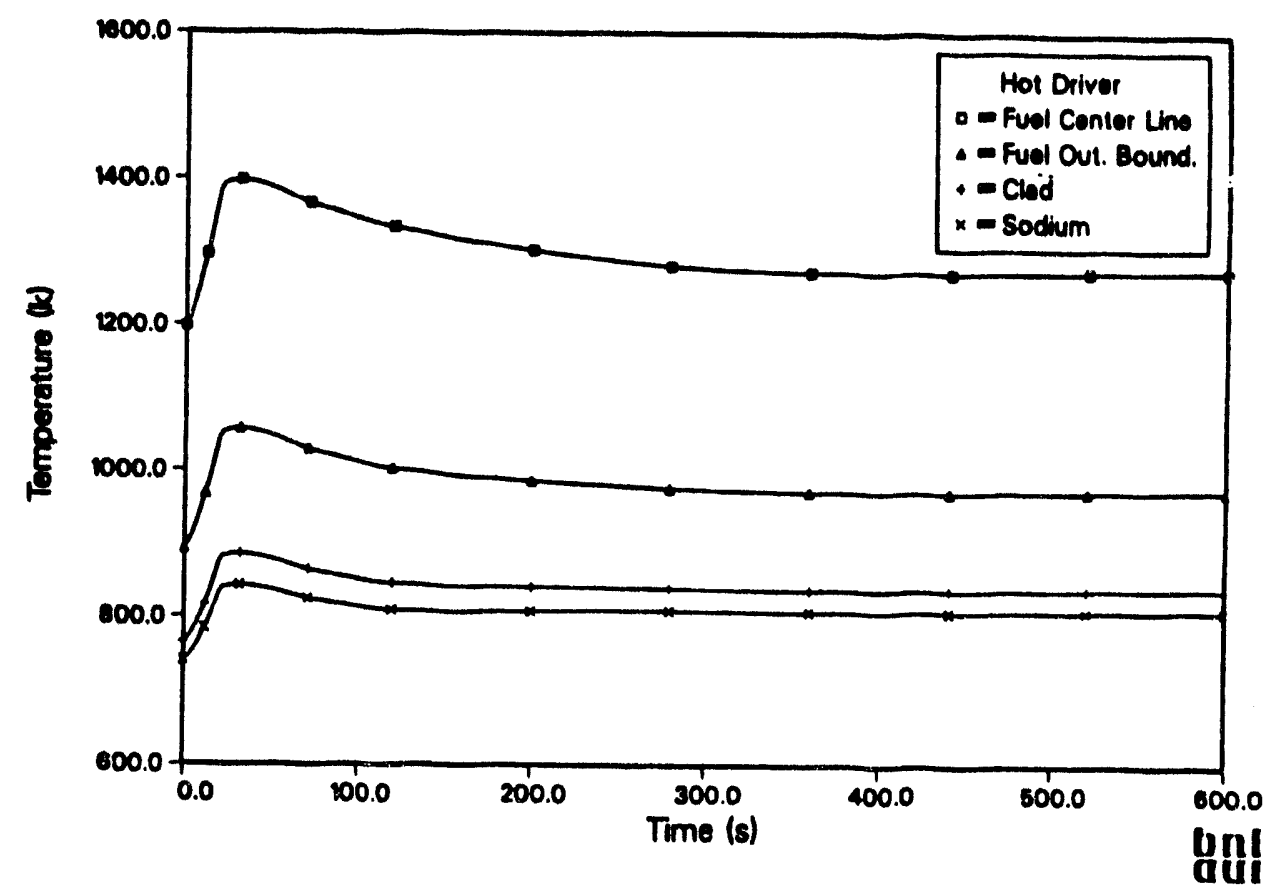

Figure B.13 Predicted fuel temperatures distribution from the SSC computer code for the third node from the top (i.e., $1.122 \mathrm{~m}-0.897 \mathrm{~m}$ ) for a 40C UTOP using reduced ternary fuel thermal conductivities

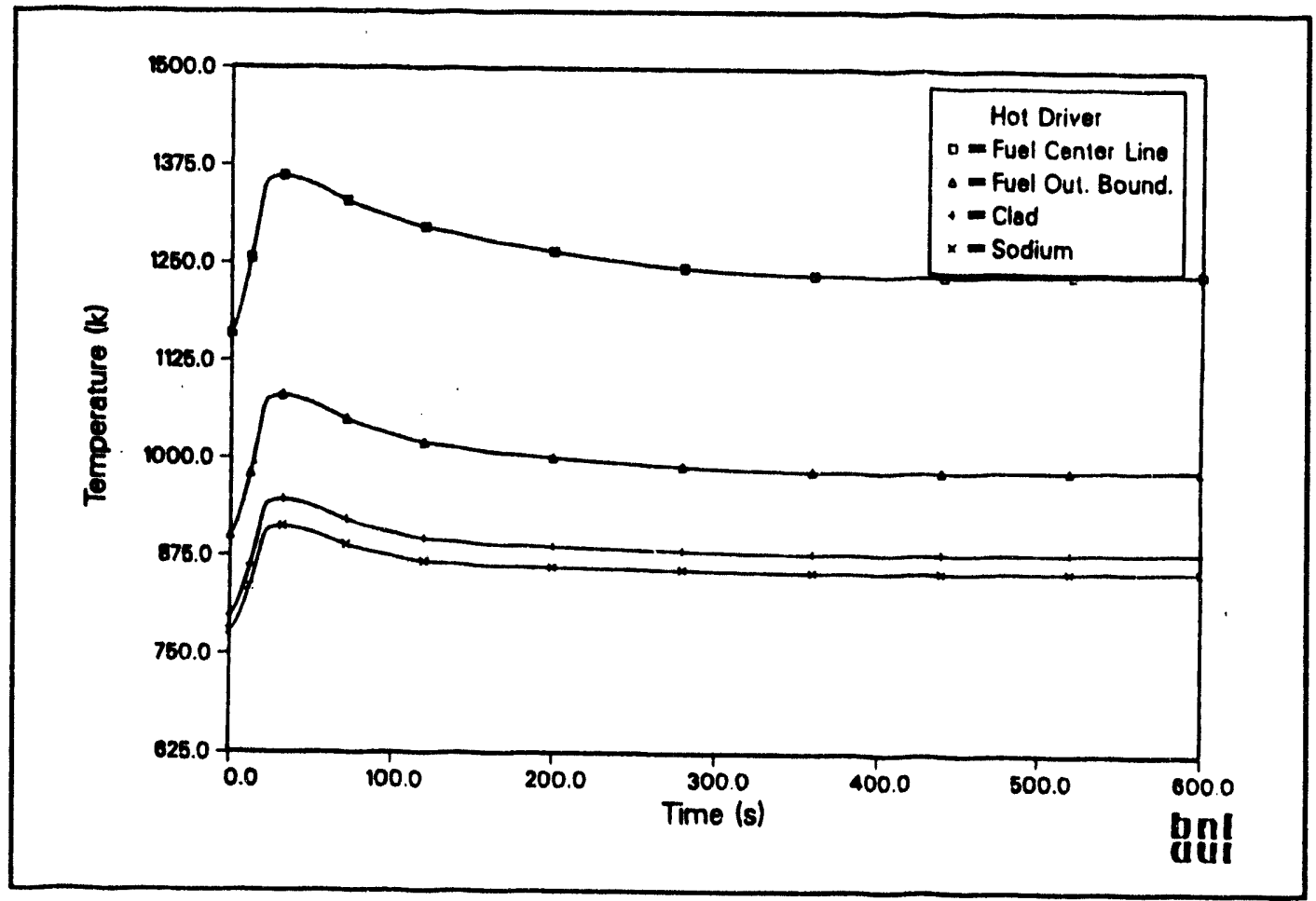

Figure B.14 Predicted fuel temperature distribution from the SSC computer code for the top $0.224 \mathrm{~m}$ (i.e., $1.346 \mathrm{~m}-1.122 \mathrm{~m}$ ) of the fuel pin for a $40 \mathrm{c}$ UTOP using reduced ternary fuel thermal conductivities 
Appendix B

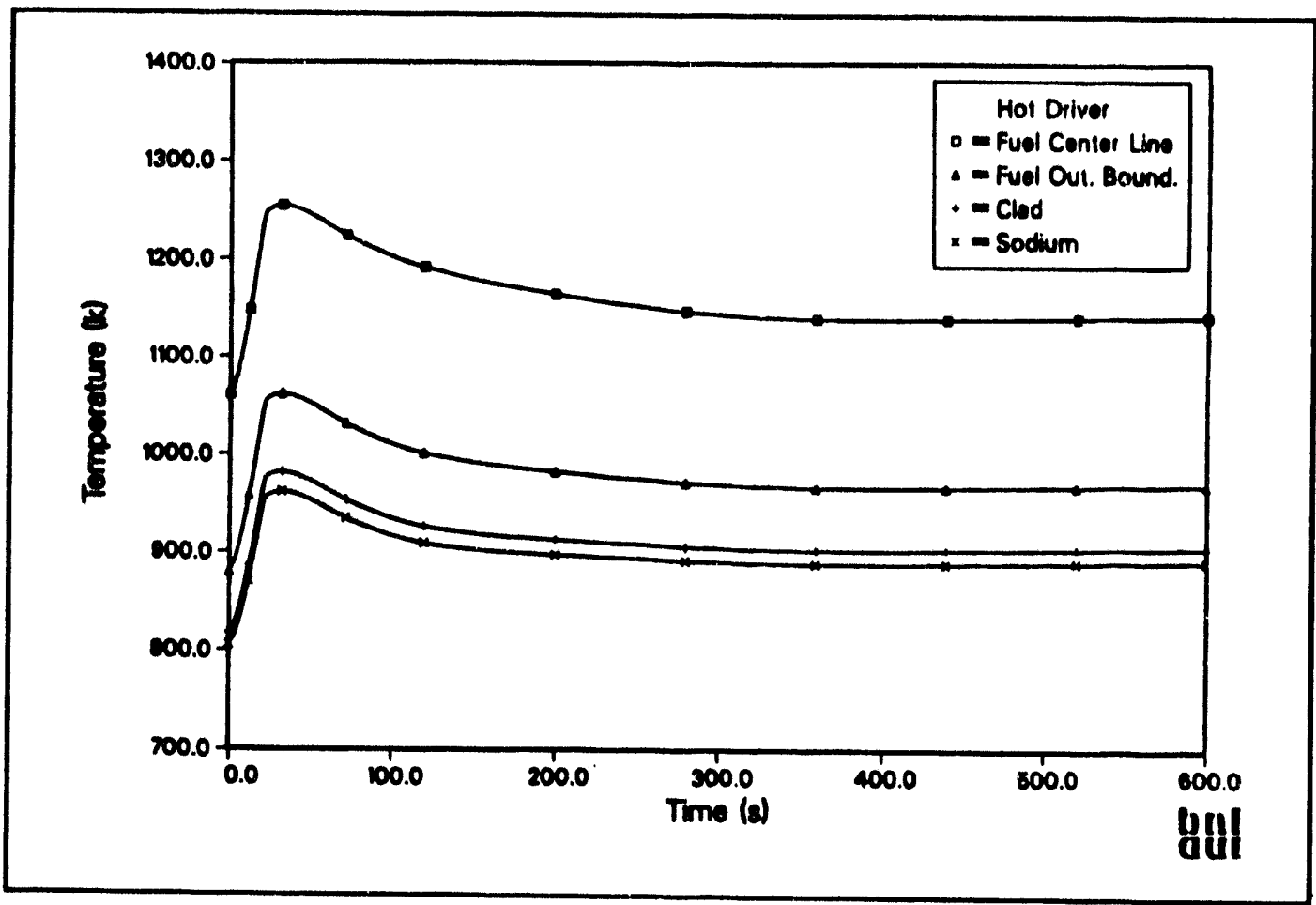

Figure B.15 Predicted sodium saturation temperaturc margin from the SSC computer code for a 40C UTOP using reduced ternary fuel thermal conductivities

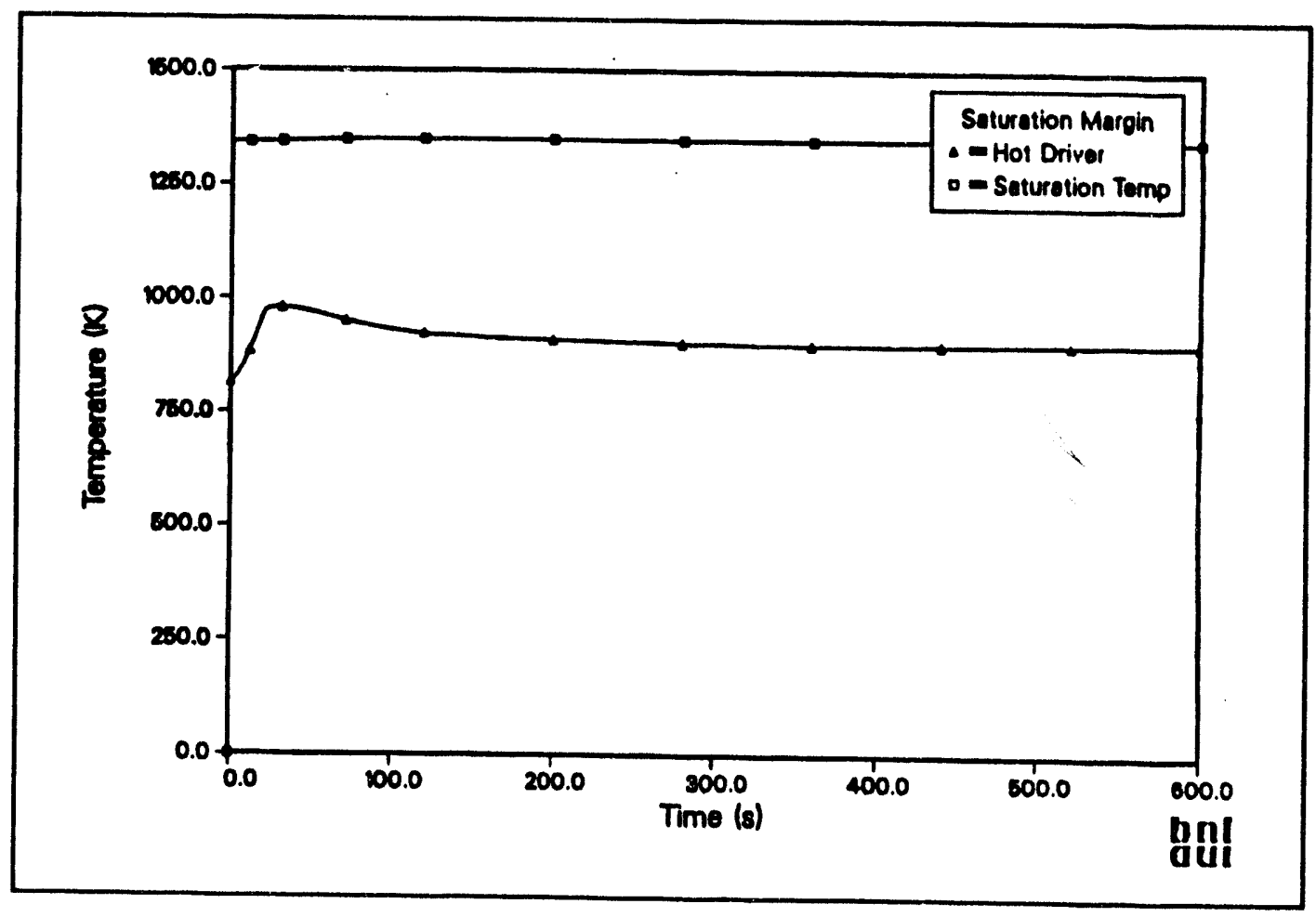

Figure B.16 Predicted sodium level in the GEMs from the SSC computer code for a 40C UTOP using reduced ternary fuel thermal conductivities 


\section{B.3.4.2 BE-1B: UTOP With Only RVACS Cooling}

To analyze this lengthy unprotected event, the preapplicant used the long-term heatup calculation from MINET coupled with a long-term reactivity transient analysis from SSC. This capability is planned as part of the advanced LMR transient analysis package (ALTAP), which is to be created from SSC, MINET, and couple of smaller special purpose computer models.

While this event could not be fully simulated, some judgments can be made based on GE's calculations and the independent analyses for related cases. First, the independent calculations for the long-term heatup events (MINET code) are very similar to those provided by GE. This is true for the reference RVACS heatup event, which is the scrammed version of the event considered here. Therefore, it can be assumed that the rate of heat removal in the GE analysis of BE-1B is reasonably accurate. Second, with the exception of GE's error in the reactivity worth of control rod motion (GE inadvertently used the reactivity worth curve for the previous PRISM reactor design), GE's results for the unprotected events are in good agreement with the SSC calculations (when nominal fuel conditions are used, consistent with GE's calculations). Therefore, it was expected that the GE analysis of BE-1B would predict lower reactor power and temperatures, but by a relatively small amount. A crosscomparison can be made on the basis of the results from two GE calculations for BEs-1A and $1 B$, as summarized in Figure B.2. It is noted that the peak cladding and sodium temperatures are significantly higher for $\mathrm{BE}-1 \mathrm{~B}$, as the systems' temperatures have to be considerably higher than in BE-1A for the RVACS to be able to effectively dump the heat. However, when the sodium and cladding temperatures are much higher, the power production must fall significantly. This is indicated by the fact that the peak fuel temperature in BE-1B is not much higher than that in BE-1A.

Thus, there are several good reasons to believe the GE results are fairly accurate, with two qualifications: First, the predicted powers and temperatures will be slightly lower as a result of the control rod modelling error. Second, GE's results neglect any plutonium migration, which cannot be ruled out with the present data base. Should future data indicate the plutonium is relocating toward the fuel pin, then tue predicted peak temperatures could be significantly higher and the possible fuel damage could be serious.

Either way, it must be concluded that the results for BE-1B are a reason for concern because significant fuel melting is likely. However there are several options available to remedy this problem, with the most obvious being to simply move the control rod stops more frequently. Therefore, while the analysis of BE-1B indicates a potential safety problem, the preapplicant has options to resolve the problem fairly easily with appropriate design changes.

\section{B.3.4.3 Variation on BE-1: UTOP With LOF}

Although not specified as one of the postulated BEs, the UTOP with the EM pumps tripped simultaneously is an interesting, although unlikely, event. This event was difficult to accommodate passively with the previous PRISM design, but the addition of the GEMs has had a major effect on the predicted response for this event.

The initial conditions are the same as the previous cases, as specified in Table B.2. The transient begins with the simultaneous trip of the pumps and the withdrawal of the control rods. The four EM pumps coastiown. The control rod withdrawal is worth $2 \mathrm{c}$ per second for 20 seconds, for a total of 40c. The secondary loop and IHX remain operational during this event.

The decrease in flow and increase in reactivity causes a fast heatup of the system. At about 300 seconds, the power and flow begins to stabilize, and natural circulation is established. Also, lower temperature sodium reaches the core, from the operating IHX, and decreases the reactor outlet sodium temperature.

The initial response comes mostly from the three GEMs. As the pumps coastdown, the sodium level in the GEMs drops, adding negative reactivity as the pump outlet pressure decreases. This holds down the power-to-flow ratio, so enough coolant flow is available to remove the heat generated. The fuel and channel ducts increase in temperature, expanding, and adding negative reacti ity from radial expansion. However, the GEMs dominate the other reactivity feedbacks, causing the power to decrease. The power level settles around 10 percent of rated power, with the reactivity feedbacks from the GEMs and the temperatures of the structures having reached a new (critical) equilibrium point.

The reactor outlet sodium temperature in the hot channel is predicted to be $1015 \mathrm{~K}\left(1367^{\circ} \mathrm{F}\right)$. The corresponding fuel temperature is the initial value, and thus is near the center of the core. The various temperatures in the hot driver channel, near the core center and the core outlet, are shown in Figures B.17 and B.18, respectively. The internal and radial blanket temperatures increase from the normal operating levels, but no fuel temperature limits are even approached. Figure B.19 shows that the margin to boiling in the ULOF/TOP is $215 \mathrm{~K}\left(390^{\circ} \mathrm{F}\right)$. The sodium level in the GEMs, which drops quickly as the pumps 
constdown, is shown in Figure B.20. With the addition of the GEMs, it is now apparent that the PRISM could withstand a ULOF/TOP of 40c. The power would transition to about 10 percent of the rated level. No fuel damage is predicted for this case because of the negative reactivity feedbacks from the GEMs following loss of flow.

\section{B.3.4.4 Peak UTOP Temperatures}

The peak temperatures predicted in the UTOP event calculations are shown in Figure B.21, which also shows the pertinent temperature limits. As was discussed, the peak temperatures for the BE-1A 40C UTOP with the normal cooling were very similar, as long as GE's assumptions are used. Thus, the two sets of bars in the left half of Figure B.21 are quite similar. Both calculations indicate some fuel melting in the hottest part of the core, although the damage would be fairly localized if nominal fuel is assumed. If zirconium migration is considered, the fuel damage would be more extensive. However, if the peak cladding and sodium temperatures appear to be acceptable, the PRISM could probably survive the fuel melting if there was little or no effective compaction of the fuel material in the pins (a compaction would lead to increased reactivity and power production). However, if the lower cladding damage limit of $903 \mathrm{~K}$ $\left(1165^{\circ} \mathrm{F}\right)$ applies, then significant cladding damage could occur.

Peak temperatures for the same event, if we assume plutonium migration, are indicated by the third set of bars in Figure B.21. The peak fuel temperatures are very high, although the peak cladding and sodium temperatures are little changed. Even if the cladding remains intact, it appears that the fuel damage would be widespread and severe, assuming that plutonium migration is a real characteristic of the ternary fuel. Should further experiments indicate significant plutonium relocation, it may be necessary for GE to reduce the maximum credible TOP initiator.

The final case in Figure B.21 is an instance where the design changes have resulted in enhanced safety, as this was previously one of the more hazardous unprotected events.

\section{B.3.5 BE-2: Loss of Electric Power}

As defined by the NRC staff, BE-2 includes an assumed reactor scram, which occurs when the power is lost. The preapplicant stated that this event is not interesting, and proceeded to analyze an unprotected version of BE-2. GE's choice to analyze an unprotected version of BE-2 is convenient because it offers an opportunity to reconsider some of the prior BDBEs covered in PSIn Appendix E, but not re-analyzed as part of PSID Appendix G. The staff has analyzed a few variations of BE-2.

\section{B.3.5.1 Loss of Power With Scram}

BE-2, a loss of power with scram, does not seriously challenge the PRISM reactor system, as it is designed to passively accommodate such an event. A loss of power will cause the control rods to fall into tiu core, quickly and effectively shutting down the reactor. A loss of power also will result in the trip and coastdown of the system pumps. This would imply that the water inventory in the steam generators and steam drums would be available as a heat sink. Further, the ACS should provide natural draft air cooling of the exterior of the steam generators. Thus, with natural circulation in the primary and intermediate loops, there should be very substantial cooling. In addition, the RVACS is an entirely passive system, and by itself the RVACS is effective enough to prevent damige.

The performance of the PRISM system with scram and with the RVACS providing the only cooling was analyzed with MINET. Two cases were evaluated, corresponding to BE-3A and -3B from Table B.1. For BE-3A, the peak sodium temperatures develop after 24 hours into the event and are more than $40 \mathrm{~K}\left(72^{\circ} \mathrm{F}\right)$ below the ASME Code Level $\mathrm{C}$ limit $\left(922 \mathrm{~K}\right.$ or $\left.1200^{\circ} \mathrm{F}\right)$ for the reactor vessel, as shown in Figure B.22. For BE-3B, the peak sodium temperatures are the near the ASME Code Level D limit ( $997 \mathrm{~K}$ or $1335^{\circ} \mathrm{F}$ ), as shown in Figure B.23.

\section{B.3.5.2 Loss of Power Without Scram - Variant Cases}

The preapplicant chose to analyze a combined loss-of-flow and loss-of-heat-sink without scram, which is roughly equivalent to a loss of all pumping without scram, neglecting the reduced rate of heat removal through the intermediate loop based on natural circulation. An independent analysis of a similar event was performed by the staff, as discussed in the next section. The variant cases covered in the two sections that follow represent a loss of primary pumping (i.e., ULOF), and a loss of all heat removal through the intermediate loop (i.e., LOHS) which might occur if a large sodium-water reaction caused the dumping of the intermediate loop sodium. 
Appendix B

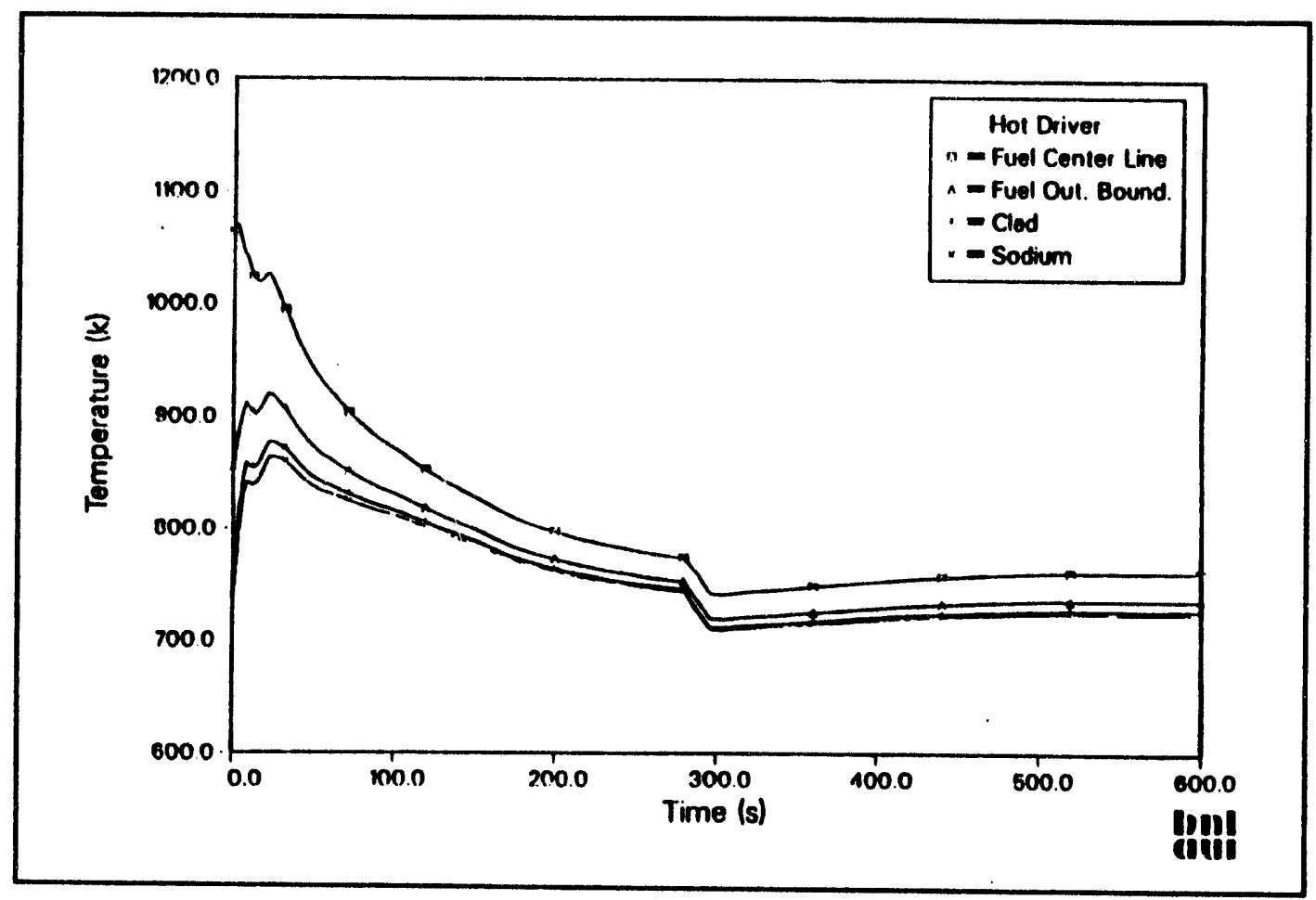

Figure B.17 Predicted fuel temperature distribution from the SSC computer code for the third node from the top (i.e., $0.897 \mathrm{~m}-0.673 \mathrm{~m}$ ) during a 40C UTOP/LOF

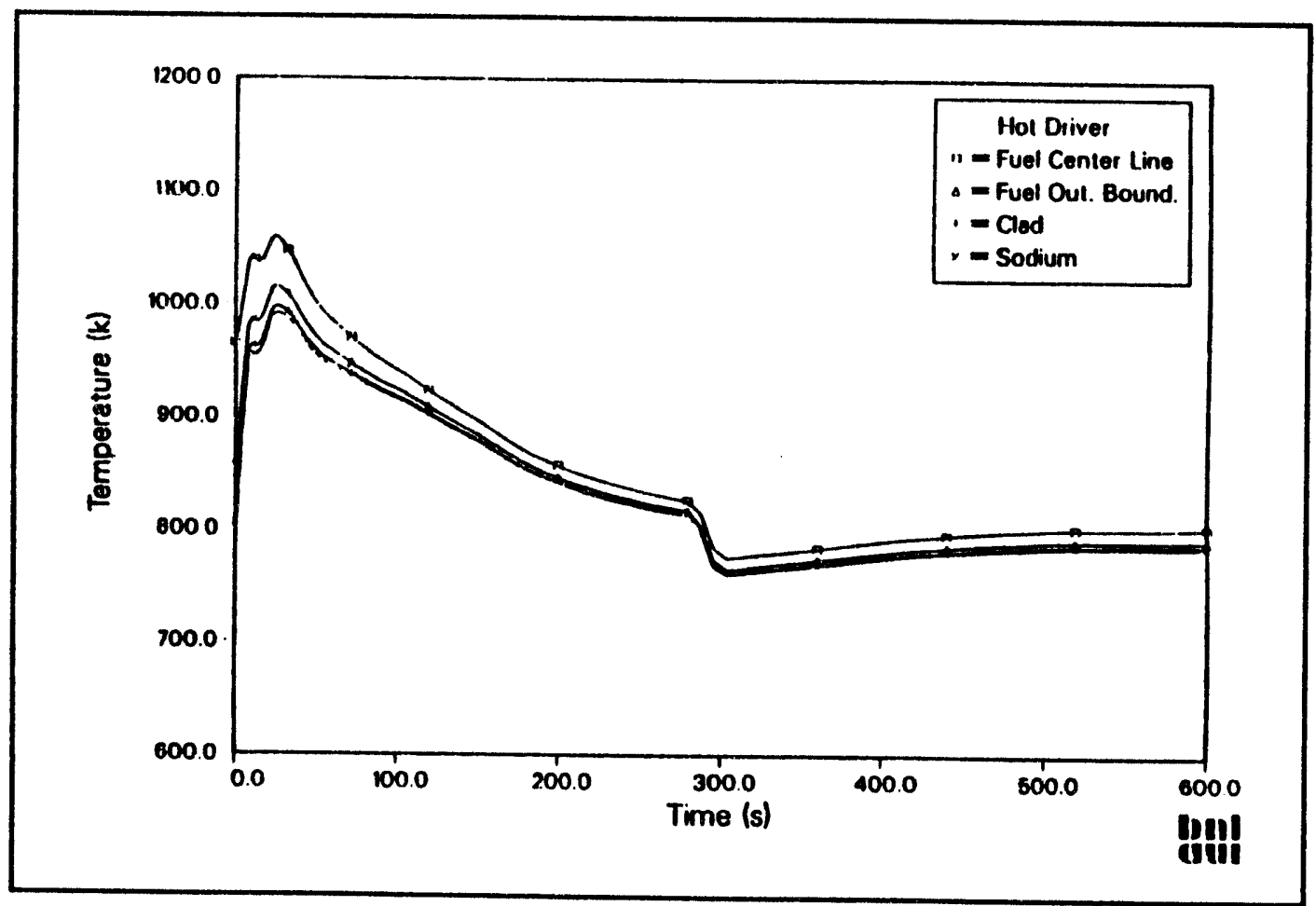

Figure B.18 Predicted fuel temperature distribution from the SSC computer code for the top $0.224 \mathrm{~m}$ (i.e., $1.346 \mathrm{~m}-1.122 \mathrm{~m}$ ) during a 40C UTOP/LOF 
Appendix B

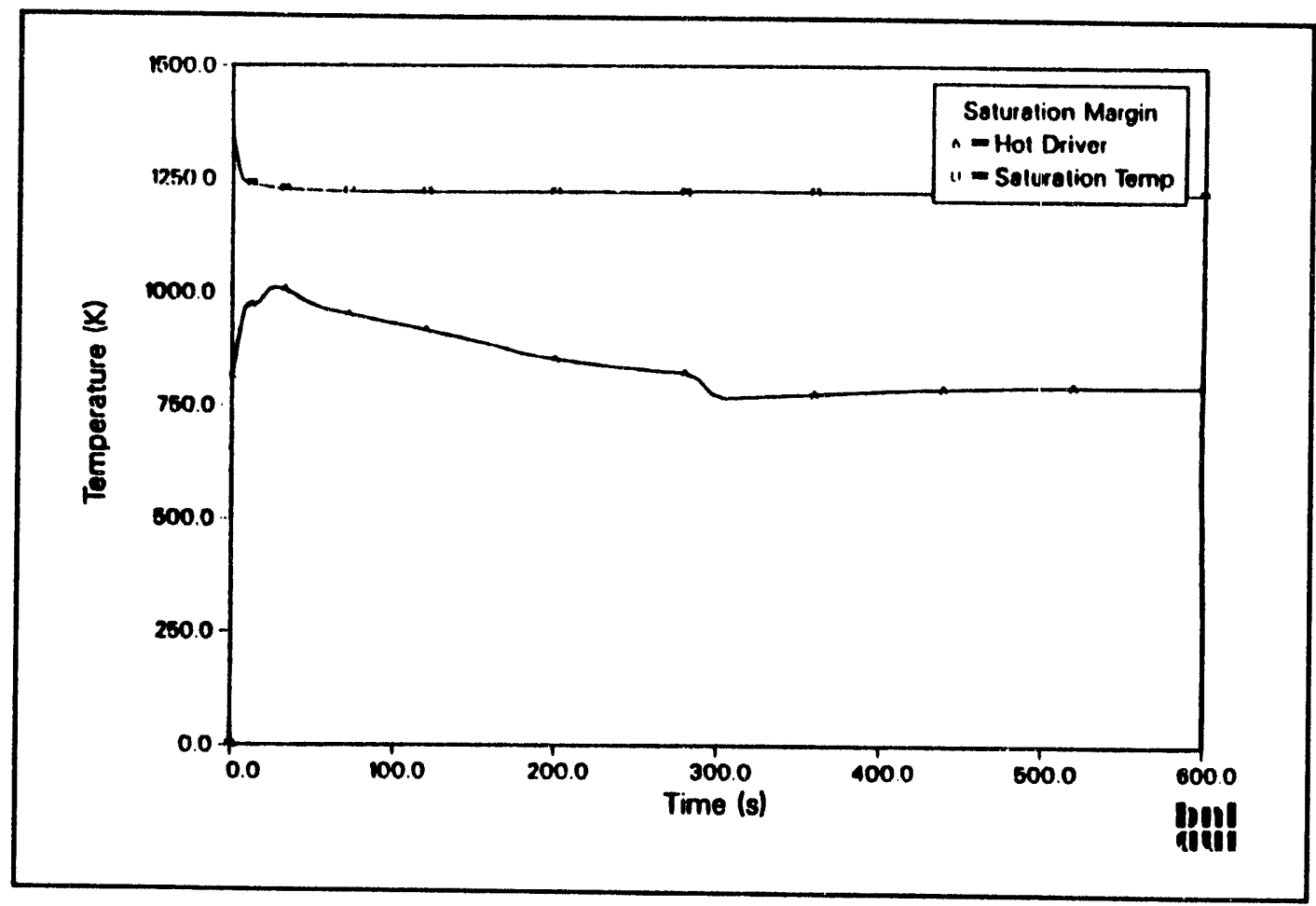

Figure B.19 Predicted sodium saturation margin from the SSC computer code for a $40 \mathrm{C}$ UTOP/LOF

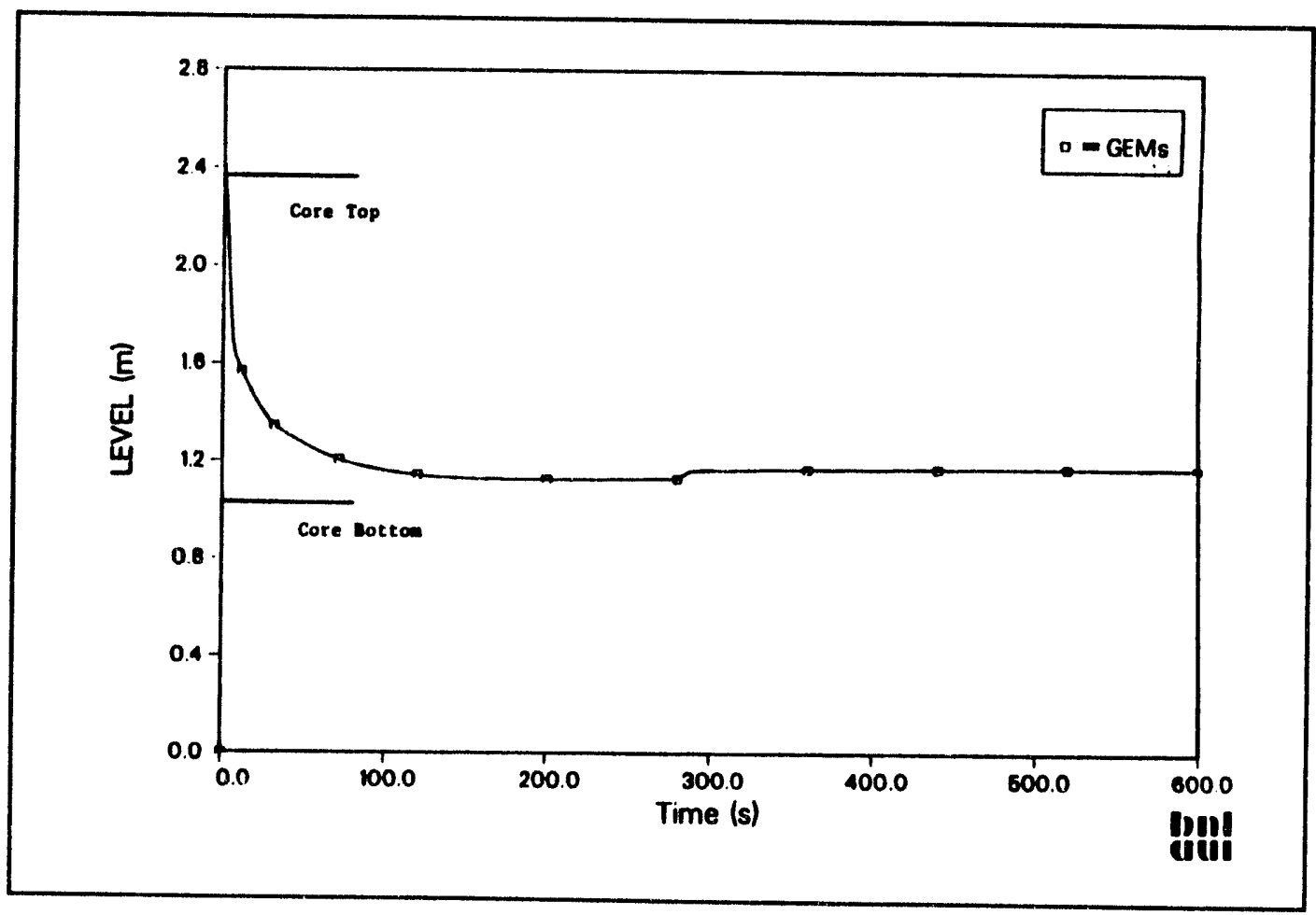

Figure B.20 Predicted sodium level in the GEMs from the SSC computer code for a $40 \mathrm{C}$ UTOP/LOF 


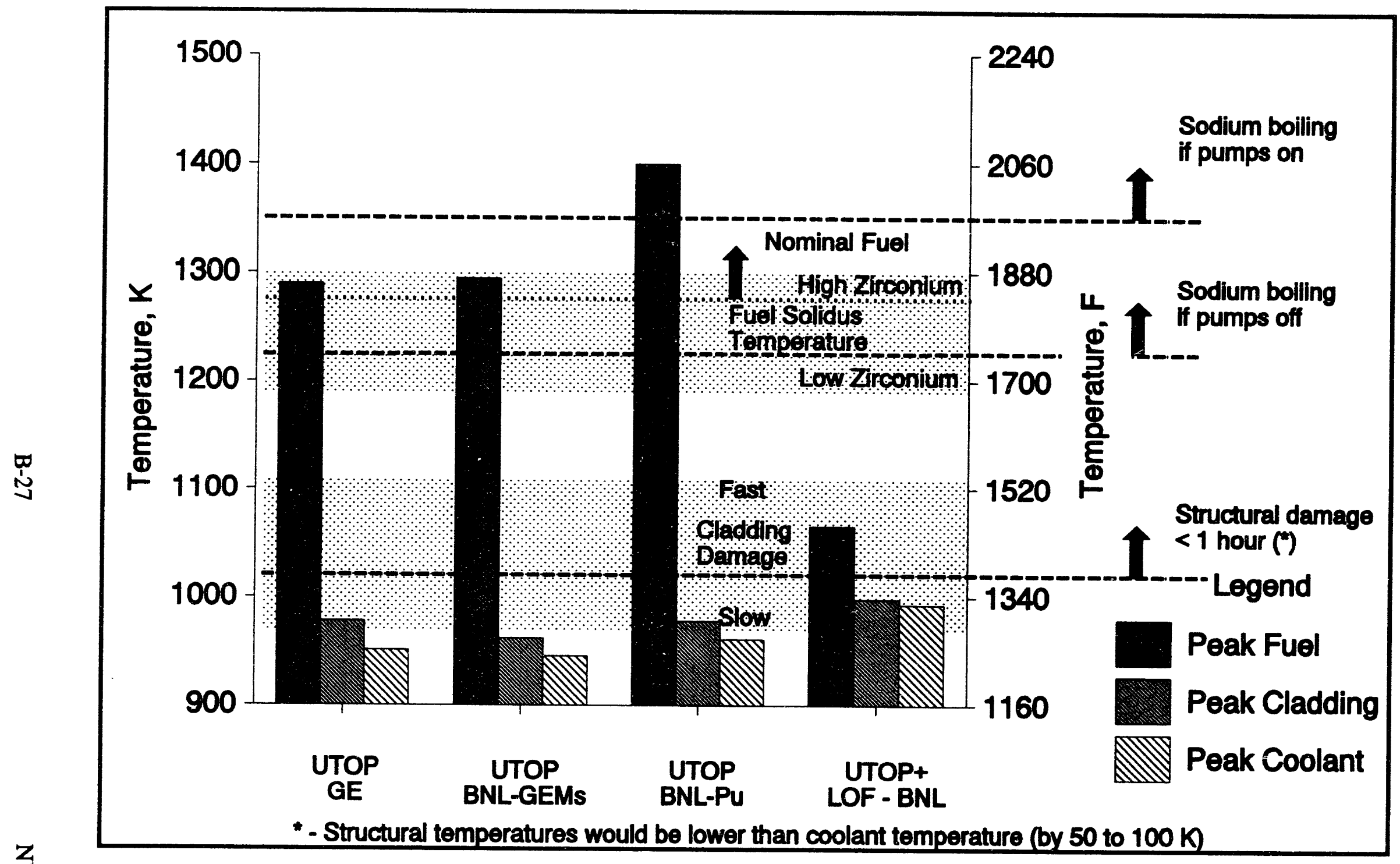

Figure B.21 Temperature summary for UTOP events 
Appendix B

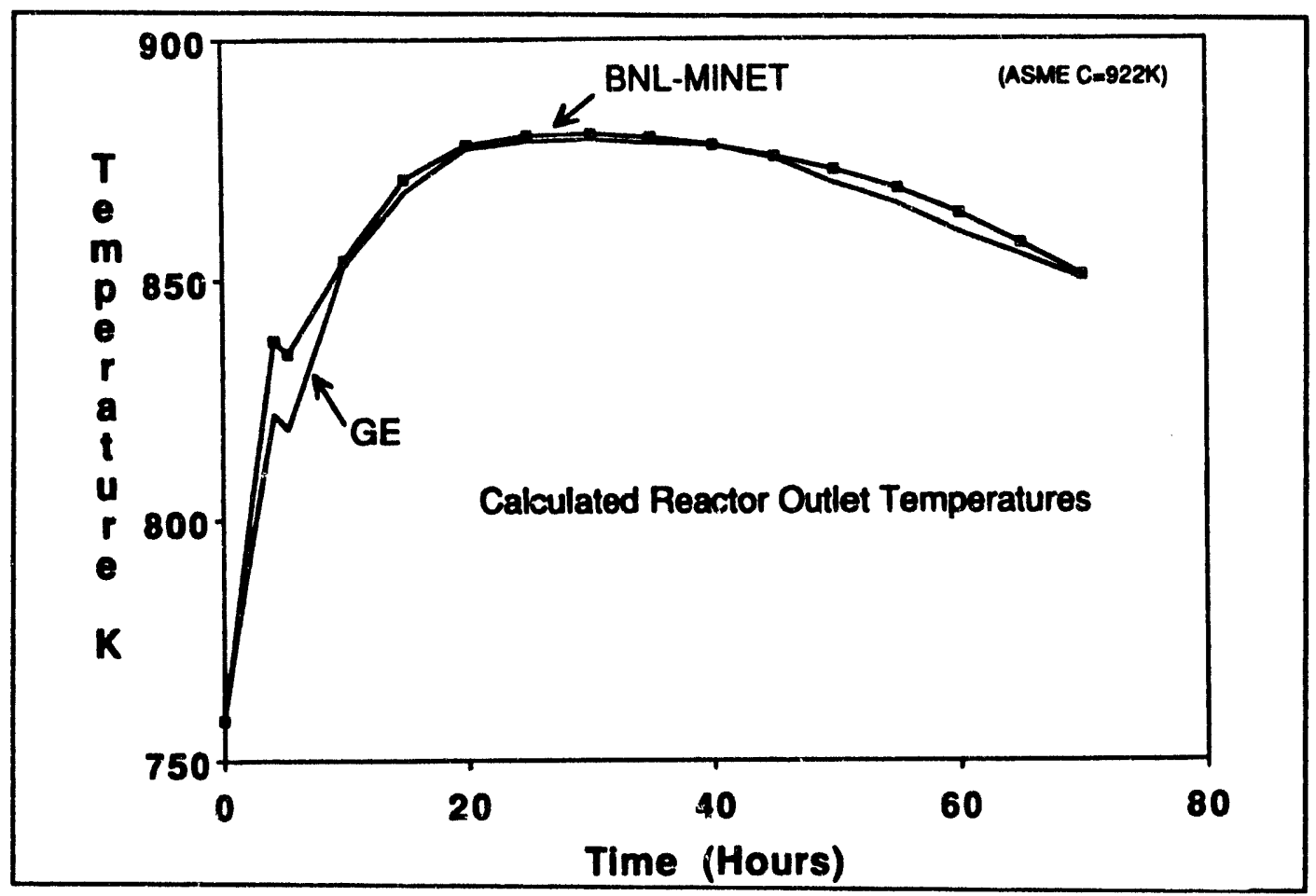

Figure B.22 PRISM LOHS with RVACS performing normally (Bounding Event 3A)

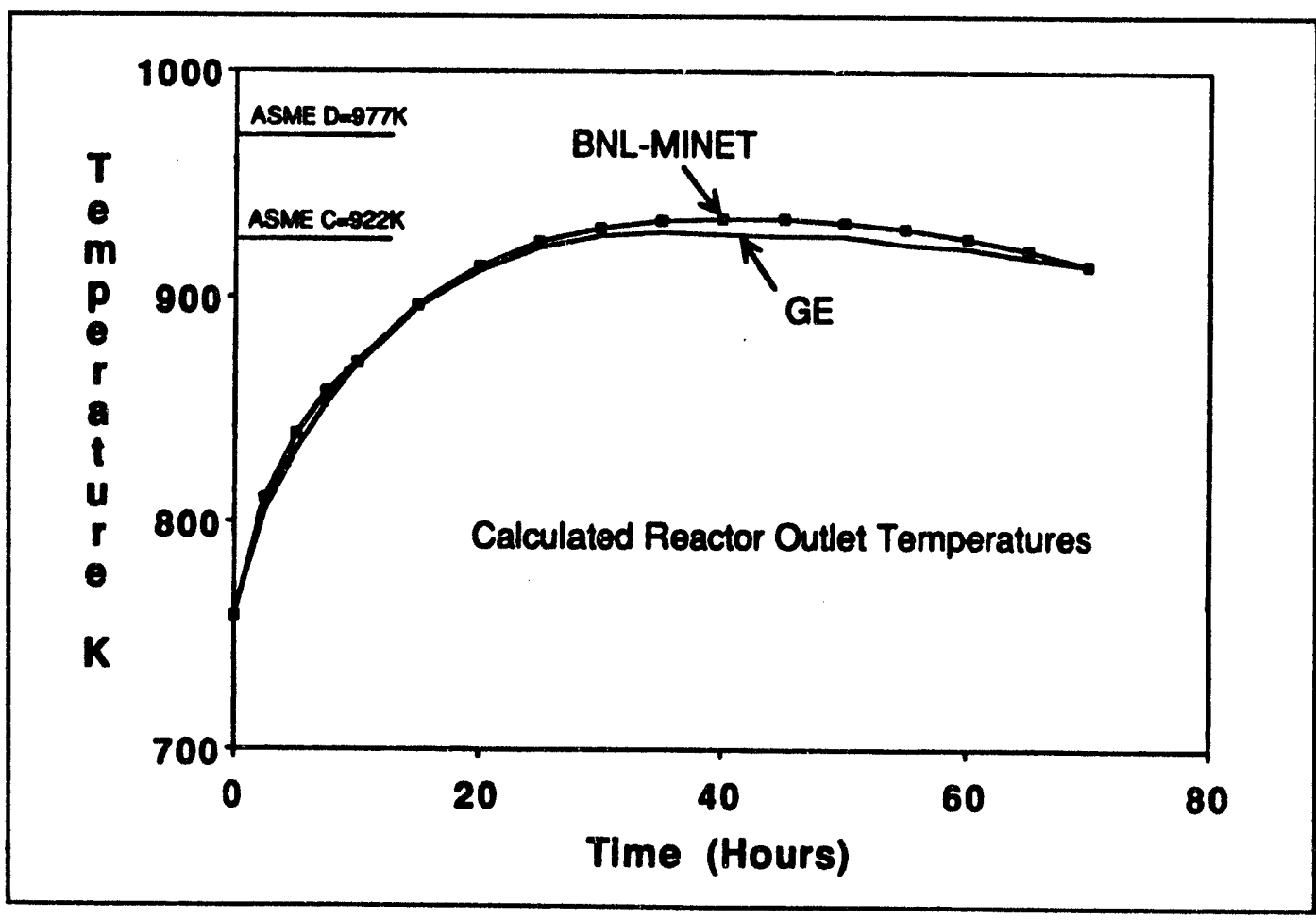

Figure B.23 PRISM LOHS with RVACS air flow ducting 75-percent blocked (Bounding Event 3B) 


\section{B.3.5.3 Combined ULOF/LOHS}

This transient is initiated from full-power conditions, as defined in Table B.1. The transient is initiated by the EM tripping and beginning to coastchown, while the IHXs stop removing heat from the primary loop. The reactor does not scram.

As in all flow coastdown transients, the likelihood of the fuel remaining undamaged is directly related to the power to flow ratio. As long as enough coolant flow is available to remove the generated heat, the fuel temperature can be maintained at acceptable levels. Figure B.24 shows that the reactor power level in the PRISM decreases with the flow rate. By 300 seconds, the power level drops to about the decay heat level. The neutronic feedbacks, which reduce the puwer, are related to the power-to-flow ratio, which determines the sodium temperature in the core. The core outlet temperature reaches $950 \mathrm{~K}\left(1250^{\circ} \mathrm{F}\right)$ at the end of the 1000 seconds, as shown in Figure B.25.

In Figure B.26, the total reactivity is plotted. At the end of 1000 seconds, the net reactivity is near $-\$ 1.15$. Figure B.27 shows three of the components of the total reactivity. The sodium reactivity feedback reaches about $+15 \mathrm{C}$, while the axial expansion reaches about $-5 \mathrm{c}$, and the radial expansion goes to $-16 \mathrm{c}$. The components of the radial expansion are the above-core load pads (ACLPs) and core grid plate, which are plotted in Figure B.26. The large thermal mass of the system delays the grid plate heatup. The dominant feedback during this event is the negative feedback from the GEMs, as shown in Figure B.28. The Doppler feedback, also plotted in Figure B.28, shows a positive response because the GEMs reduce the power so quickly that the fuel actually cools down and does not heat up enough to produce a negative reactivity feedback until after 400 seconds into the transient.

The three GEMs have a total reactivity worth of $-69 \mathrm{c}$. During the ULOF, the gas region drops into the core region as the pressure in the inlet plenum decreases. The fast insertion of negative reactivity reduces the power, keeping the power-to-flow ratio favorable, so the heat can be removed without damaging the fuel. The drop in the GEM sodium level can be seen in Figure B.29, with the corresponding reactivity insertion included in Figure B.28. It can be seen that the GEMs quickly add $-66 \mathrm{c}$ by 100 seconds, reducing the power nearly as quickly.

The fuel temperatures drop very quickly at the core center. During the transient, the peak fuel temperatures shift to the core exit, where the peak sodium temperatures cause the highest fuel temperature. In Figure B.30, the temperatures at the exit of the hot channel are shown. The fuel reaches a temperature of $990 \mathrm{~K}\left(1325^{\circ} \mathrm{F}\right)$ by 1000 seconds, and is in a range where eutectic penetration would begin. Finally, the margin to boiling is shown in Figure B.31, which indicates the closest margin to boiling is near the end of the simulation period, and is $215 \mathrm{~K}\left(390^{\circ} \mathrm{F}\right)$ from boiling. This margin may decrease, depending on the duration of the heatup.

\section{B.3.5.4 ULOF Only}

The ULOF is initiated by a trip and coastdown of the EM pumps from full power. The initial conditions corresponding to full power are as shown in Table B.1. Two cases were examined, namely with and without GEMs.

With GEMs Case: The power immediately begins to drop, as shown in Figure B.32, and reaches decay heat by 500 seconds, since there is enough negative reactivity at these temperatures to keep the core subcritical. The core average sodium outlet temperature, shown in Figure B.33, reaches a peak of $830 \mathrm{~K}\left(1035^{\circ} \mathrm{F}\right)$. The GEMs insert about $-58 \mathrm{c}$ by 200 seconds, but do not reach their full worth until 600 seconds. This effect is caused by the increasing temperature and pressure of the cover gas, during the beginning part of the event, and higher density sodium coming in from the (still functioning) IHX. The radial expansion components, that is, the ACLPs and core bottom grid plate, turn positive since the GEN, s push the power and temperatures down. The Doppler and control rod drive line (caused from vessel expansion) reactivity feedbacks turn slightly positive. The axial and radial expansion reactivity feedbacks are positive, while the usually positive reactivity feedback from sodium density becomes a few cents negative because average sodium temperature is reduced as referenced from nominal operating conditions. While the reactivities feedbacks respond differently to achieve the power reduction, as compared to the previous transients, enough negative reactivity is inserted to drive the core subcritical, and the power transitions down to the decay heat level by 500 seconds. The margin to boiling with the GEMs is approximately $300 \mathrm{~K}\left(540^{\circ} \mathrm{F}\right)$.

Without GEMs Case: The ULOF without GEMs would be a power reduction from the temperature-dependent reactivity. The predicted power is plotted along with the power predicted for the case with GEMs, shown in Figure B.32. Without the GEMs, the power is slightly higher and decreases somewhat slower because temperature increases must activate the reactivity. The average core outlet sodium temperature increases to $935 \mathrm{~K}\left(1125^{\circ} \mathrm{F}\right)$ $\left(830 \mathrm{~K}\right.$ or $1035^{\circ} \mathrm{F}$ with GEMs) and levels out at about $850 \mathrm{~K}\left(1070^{\circ} \mathrm{F}\right)$, as shown in Figure B.33. These higher 
Appendix B

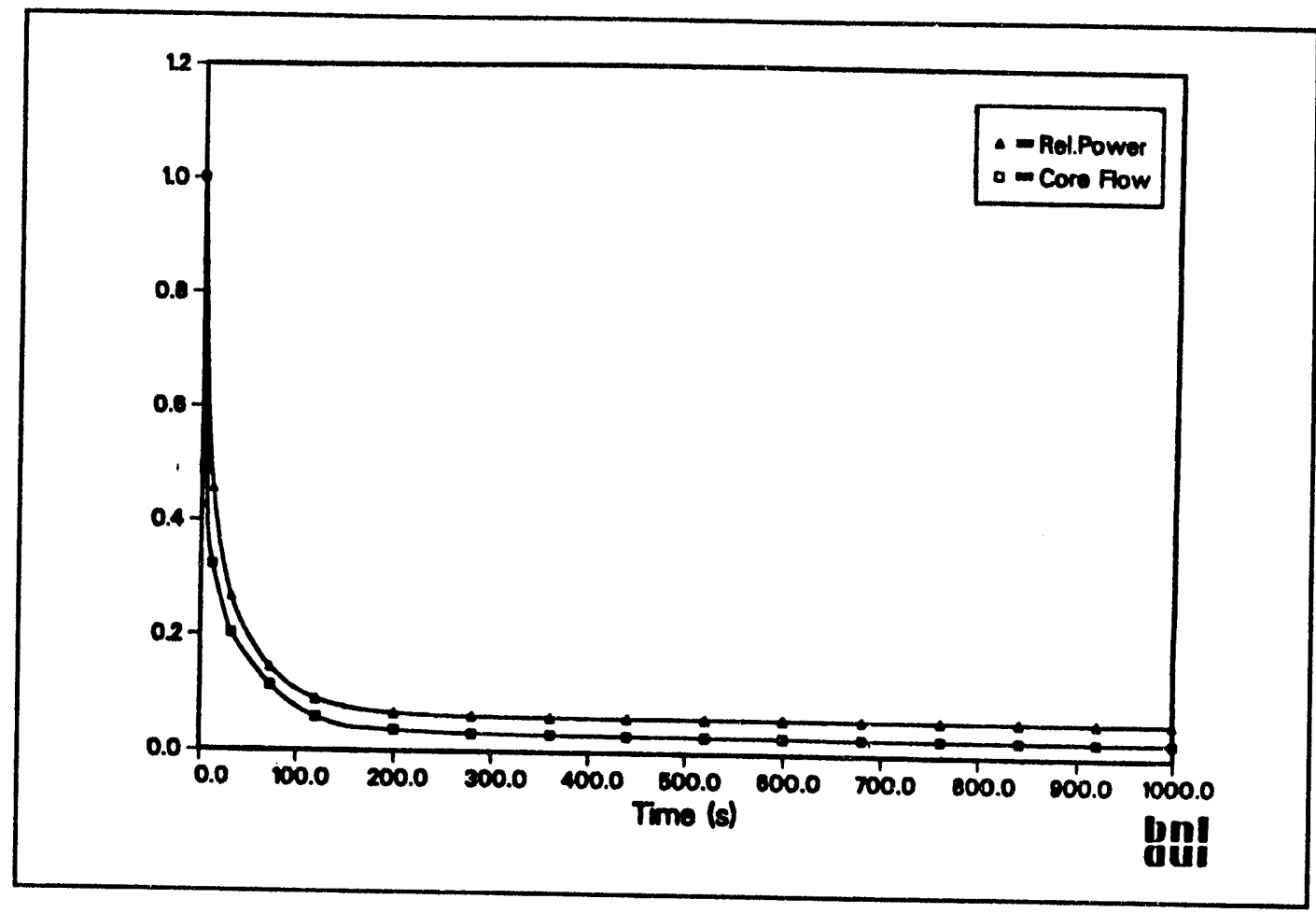

Figure B.24 Predicted relative power and core flow from the SSC computer code during a ULOF/LOHS

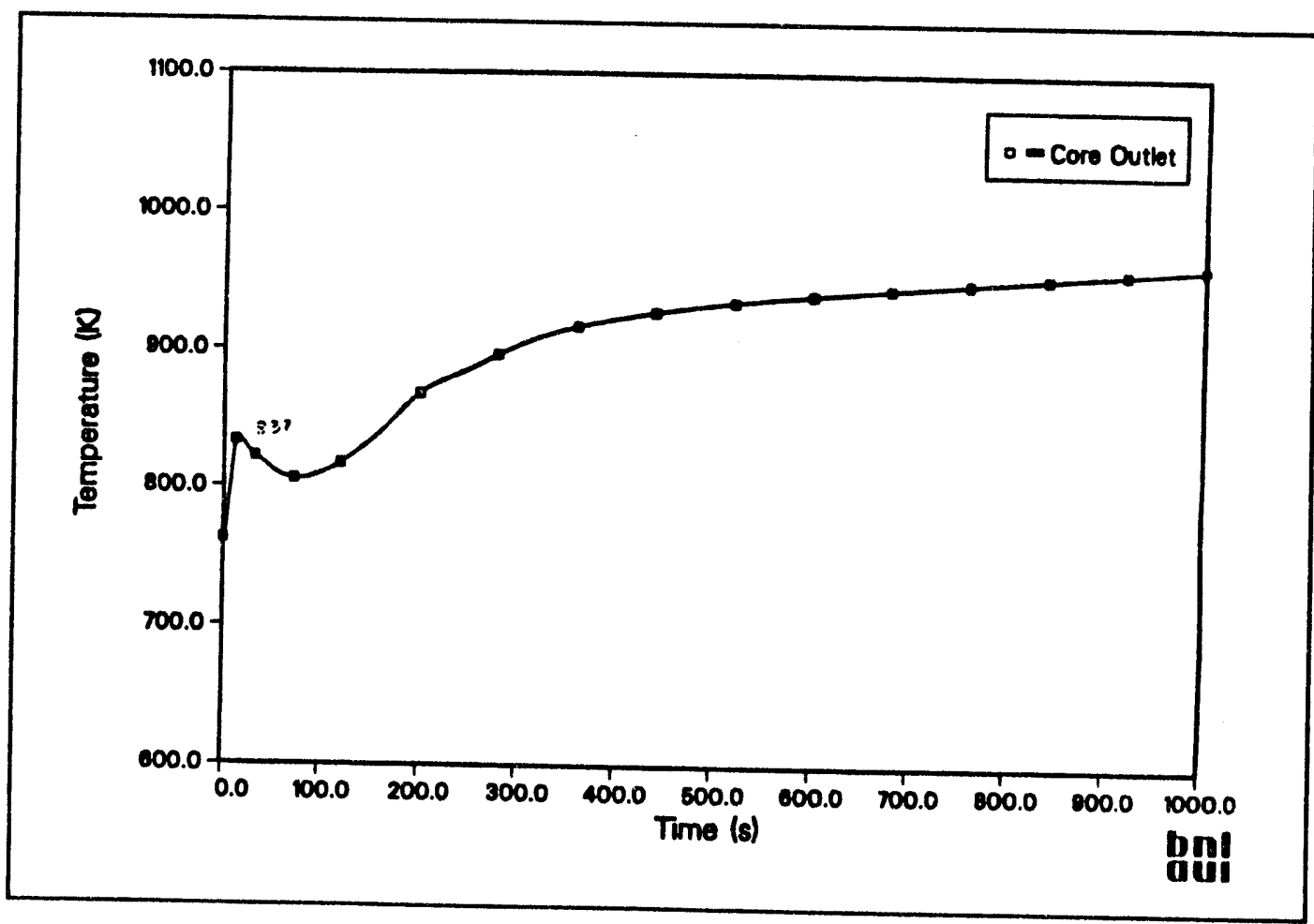
Figure B.25 Predicted average core outlet temperature from the SSC computer code during a
ULOF/LOHS 
Appendix B

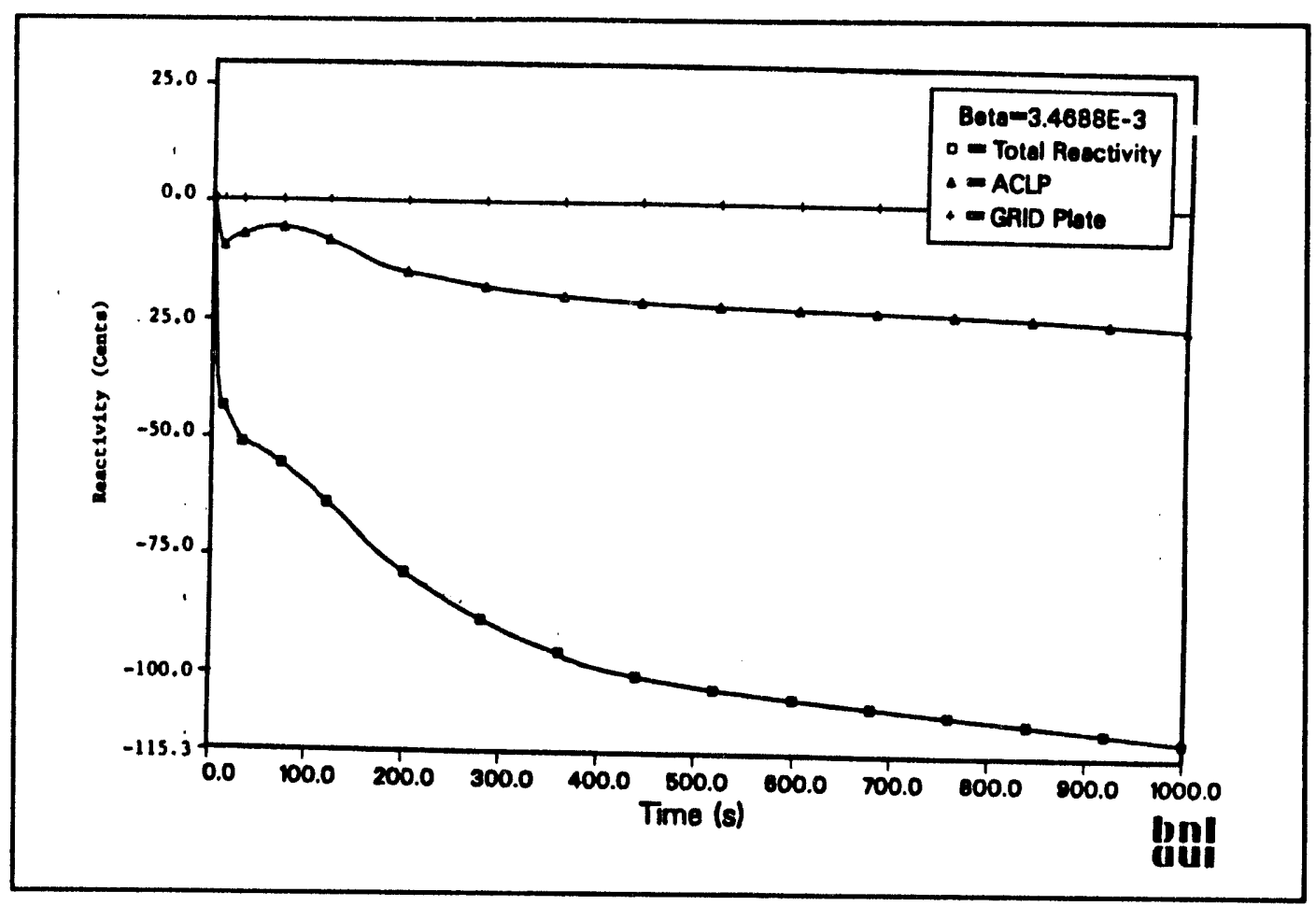

Figure B.26 Predicted total, above-core load pad and core support grid plate reactivity feedback from the SSC computer code during a ULOF/LOHS

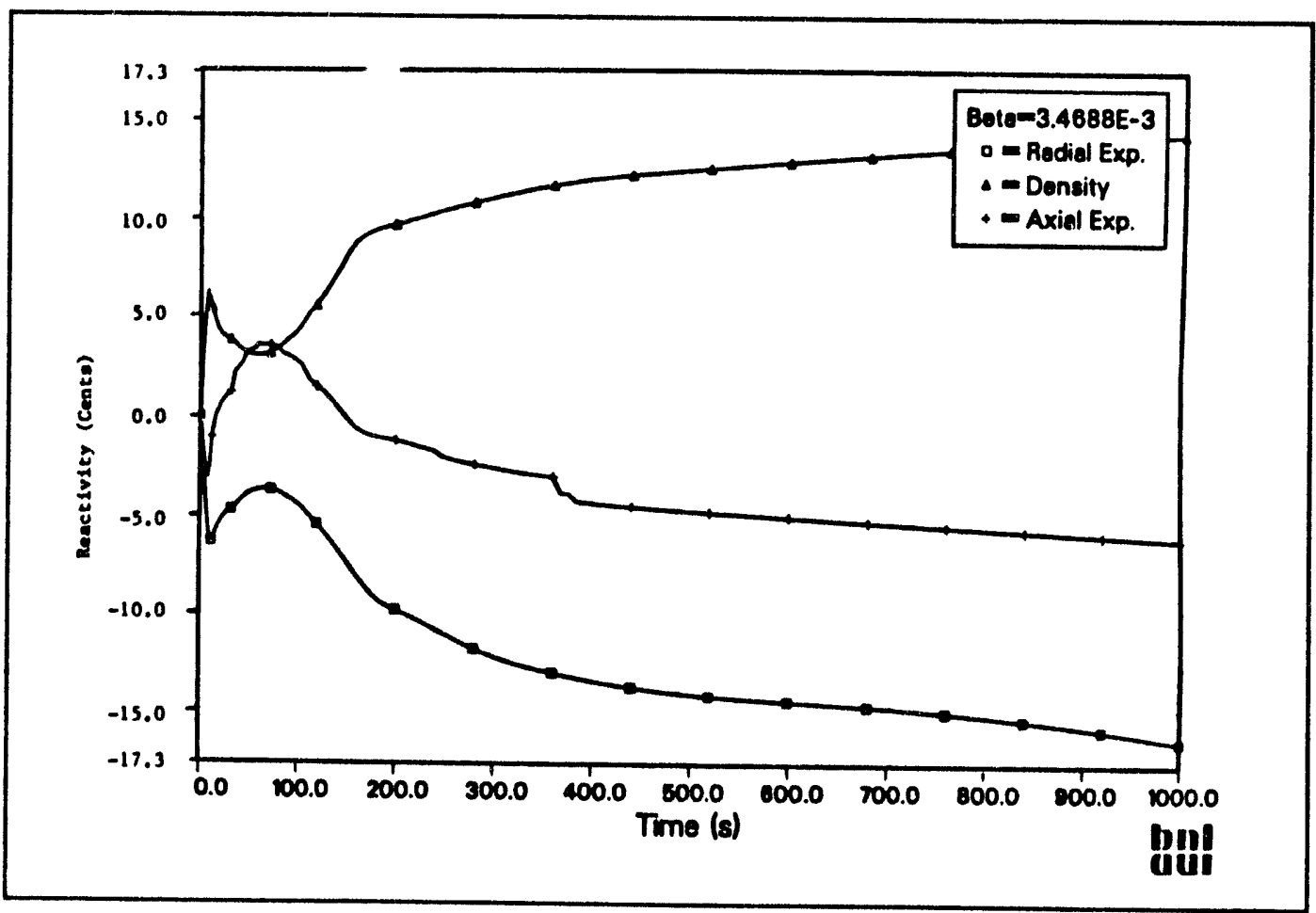

Figure B.27 Predicted radial expansion, sodium density, and axial expansion reactivity feedback from the SSC computer code during a ULOF/LOHS 
Appendix B

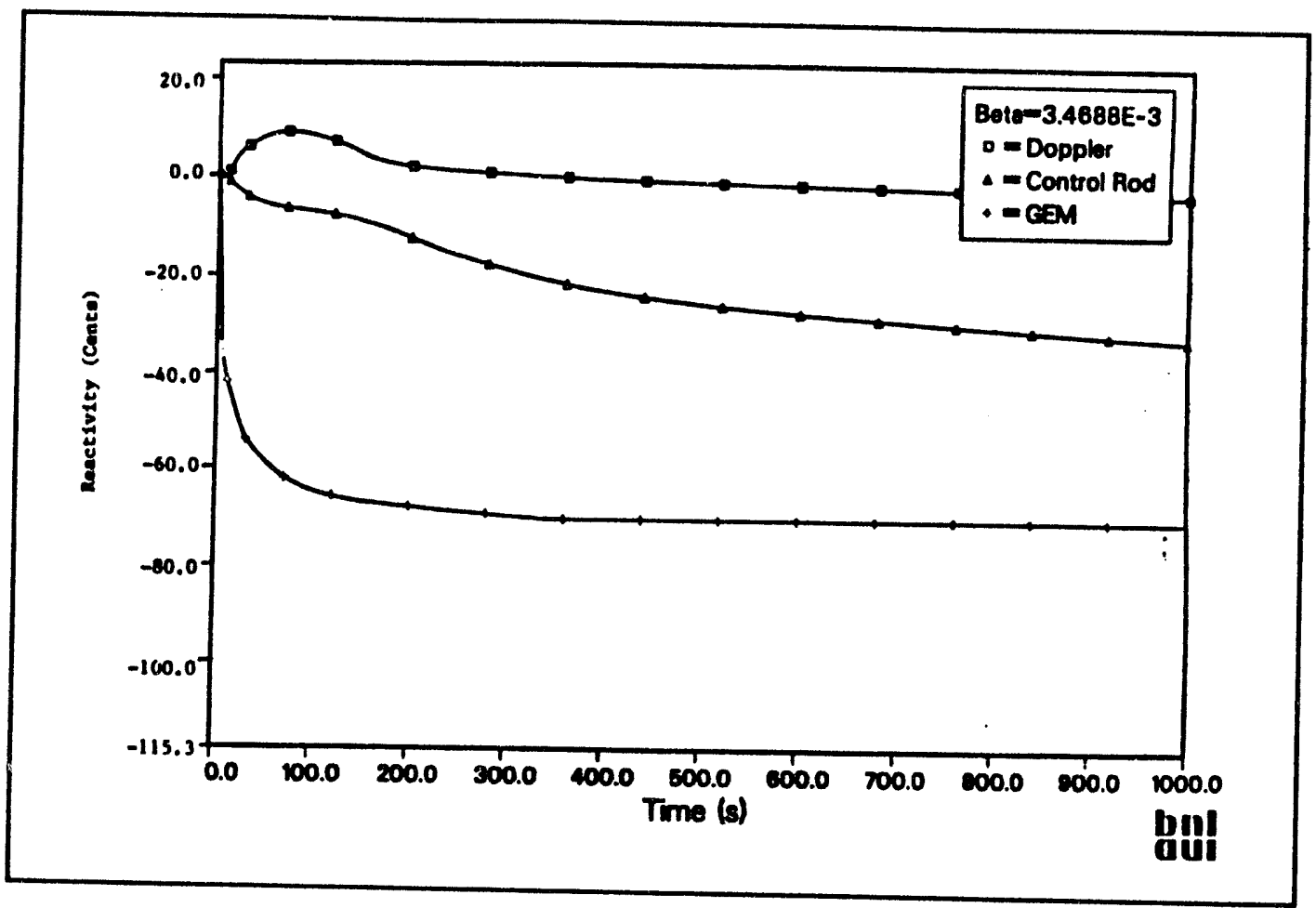

Figure B.28 Predicted Doppler, control rod expansion, and gas expansion module reactivity feedback from the SSC computer code during a ULOF/LOHS

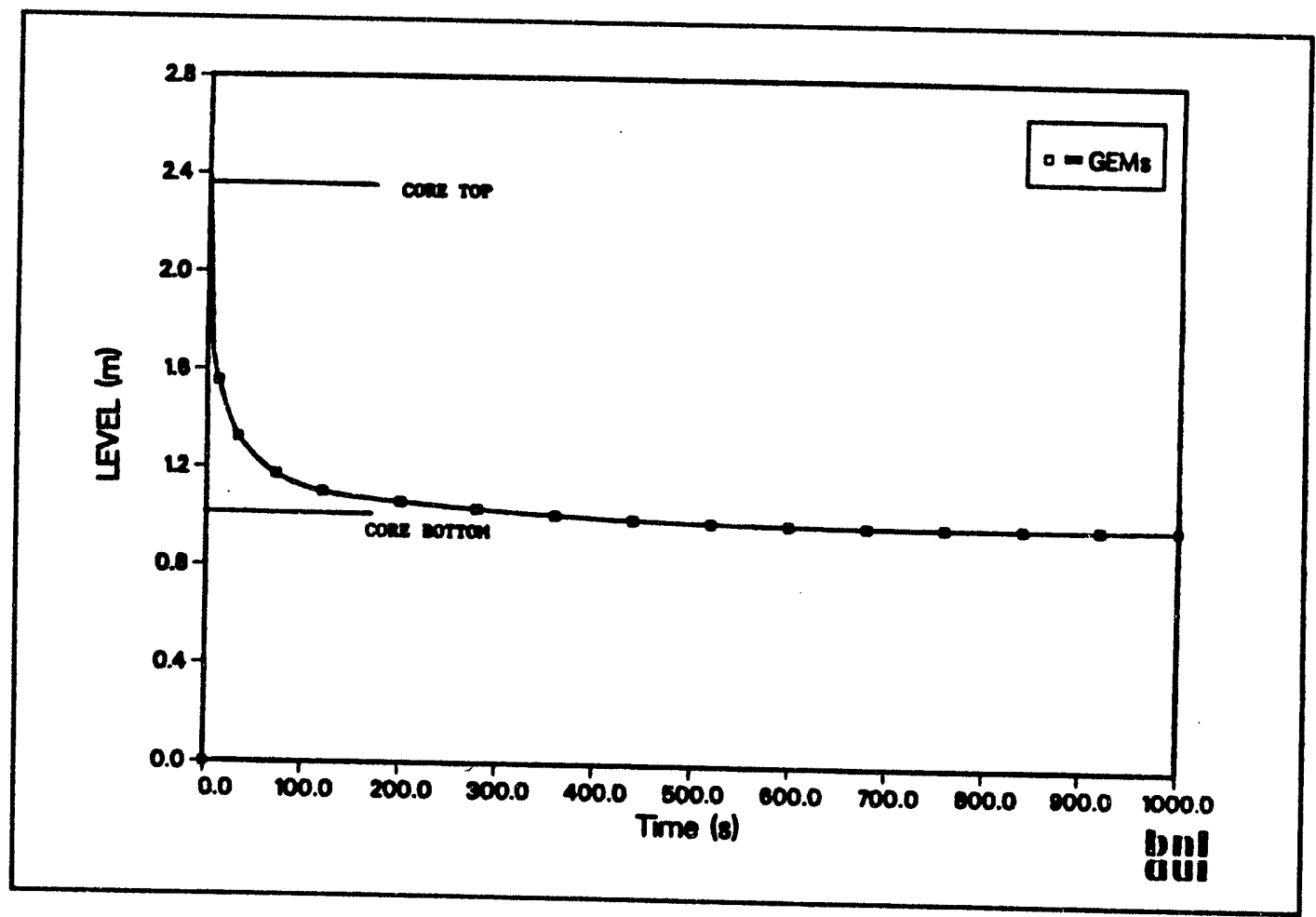

Figure B.29 Predicted sodium level in the GEMs from the SSC computer code during a
ULOF/LOHS 
Appendix B

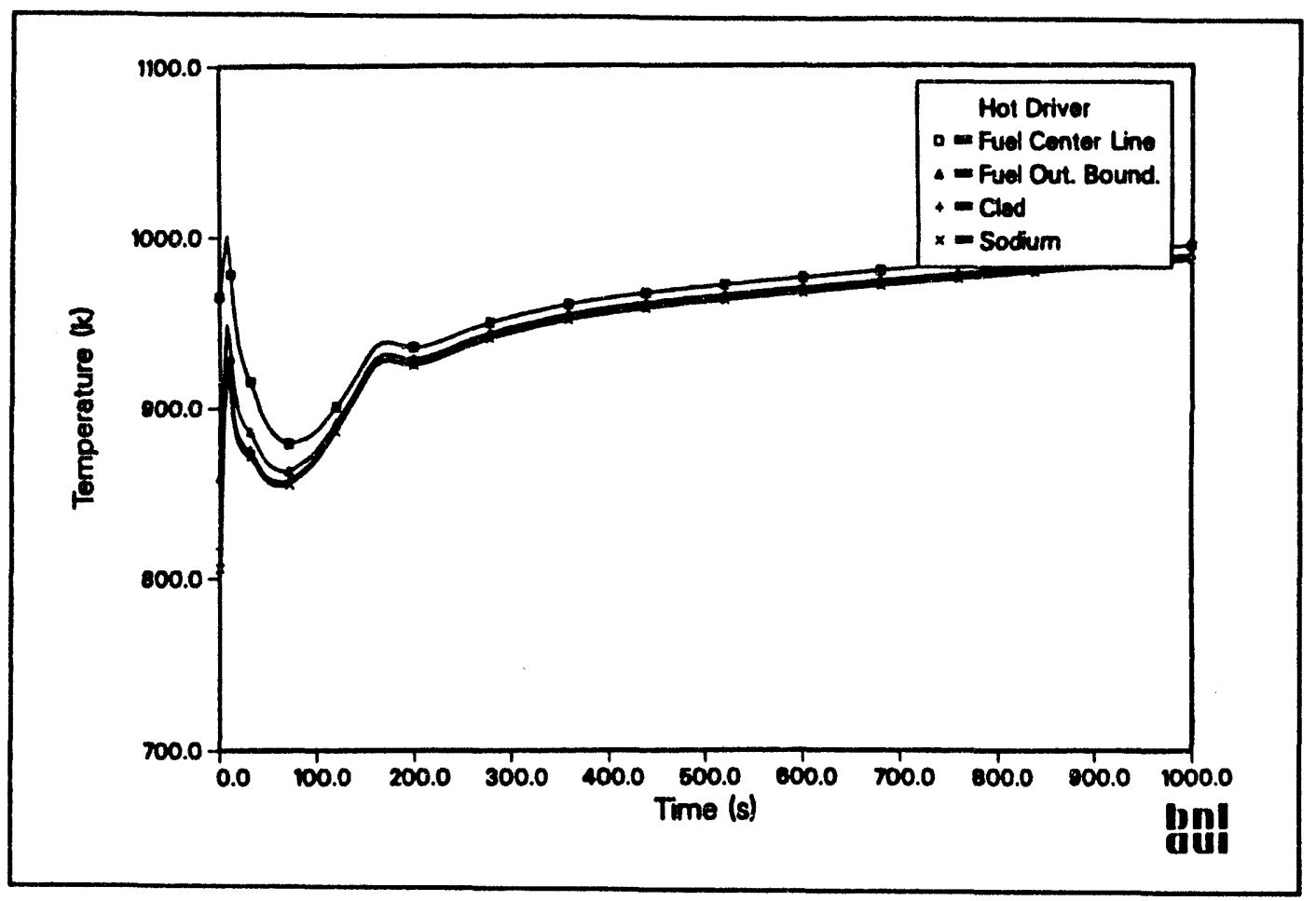

Figure B.30 Predicted fuel temperature distribution from the SSC computer code for the top node (i.e., $1.346 \mathrm{~m}-1.122 \mathrm{~m}$ ) during a ULOF/LOHS

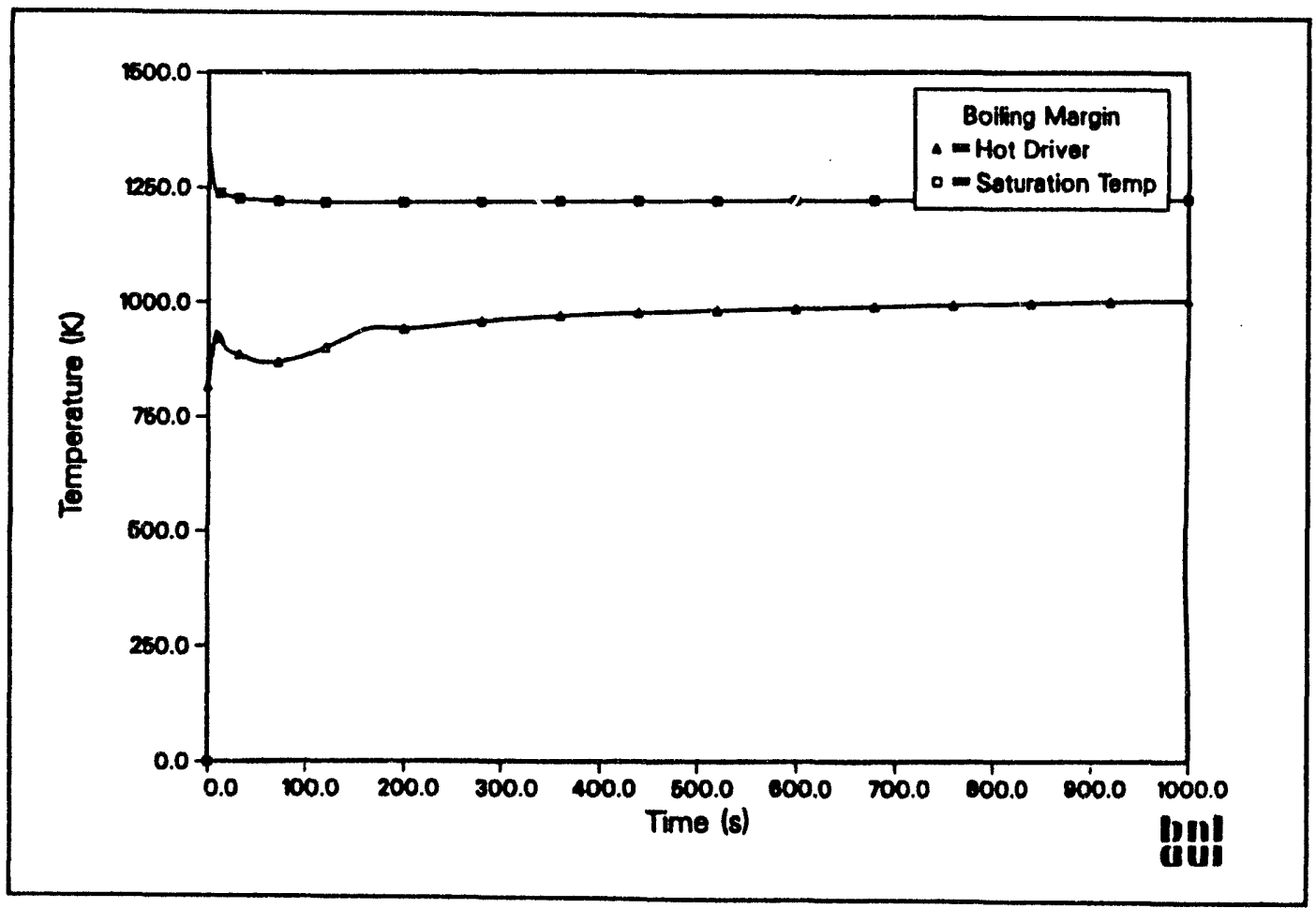

Figure' B.31 Predicted sodium saturation margin from the SSC computer code during a ULOF/LOHS 
Appendix B

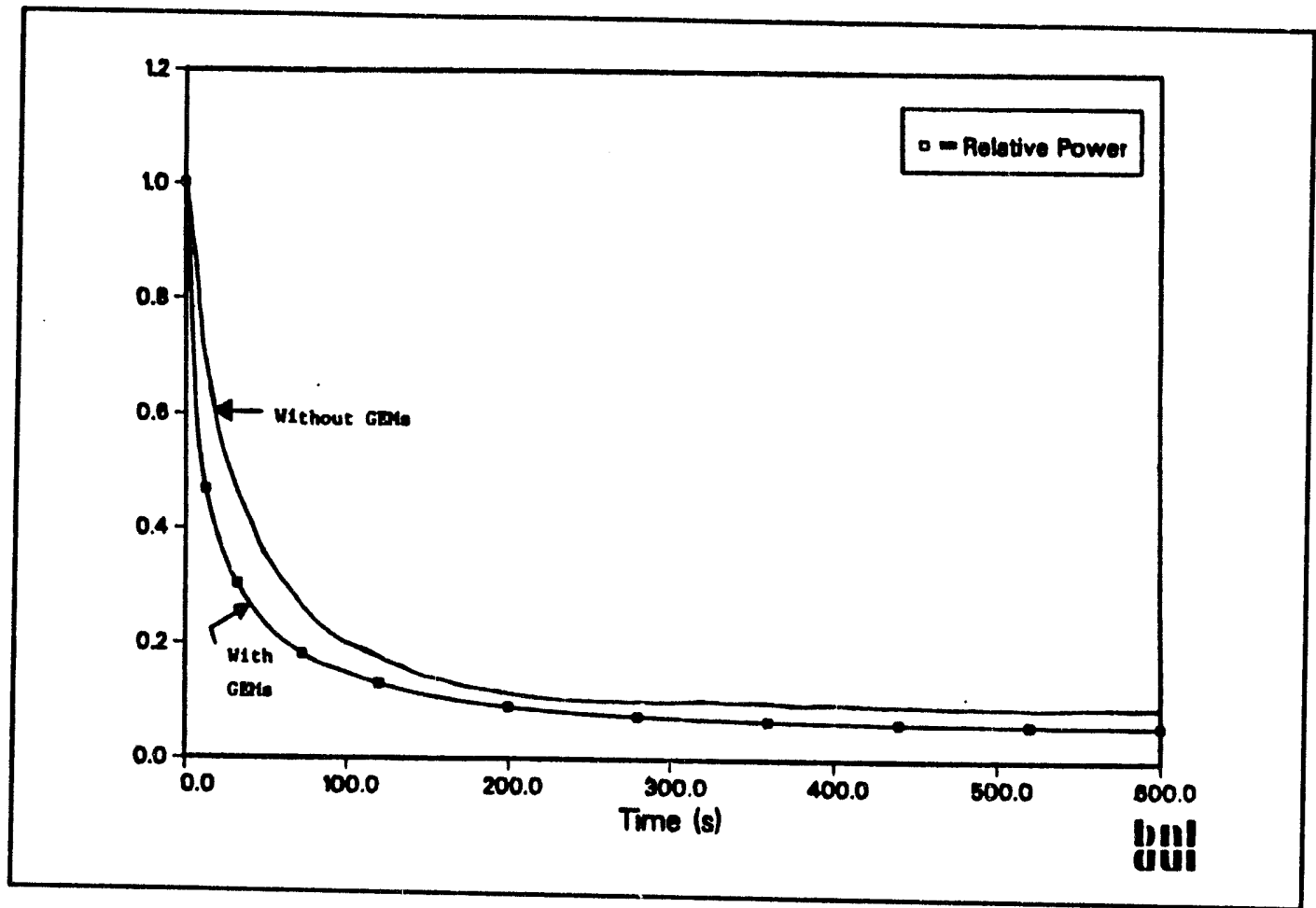

Figure B.32 Predicted relative power from the SSC computer code for a ULOF with and without GEMs

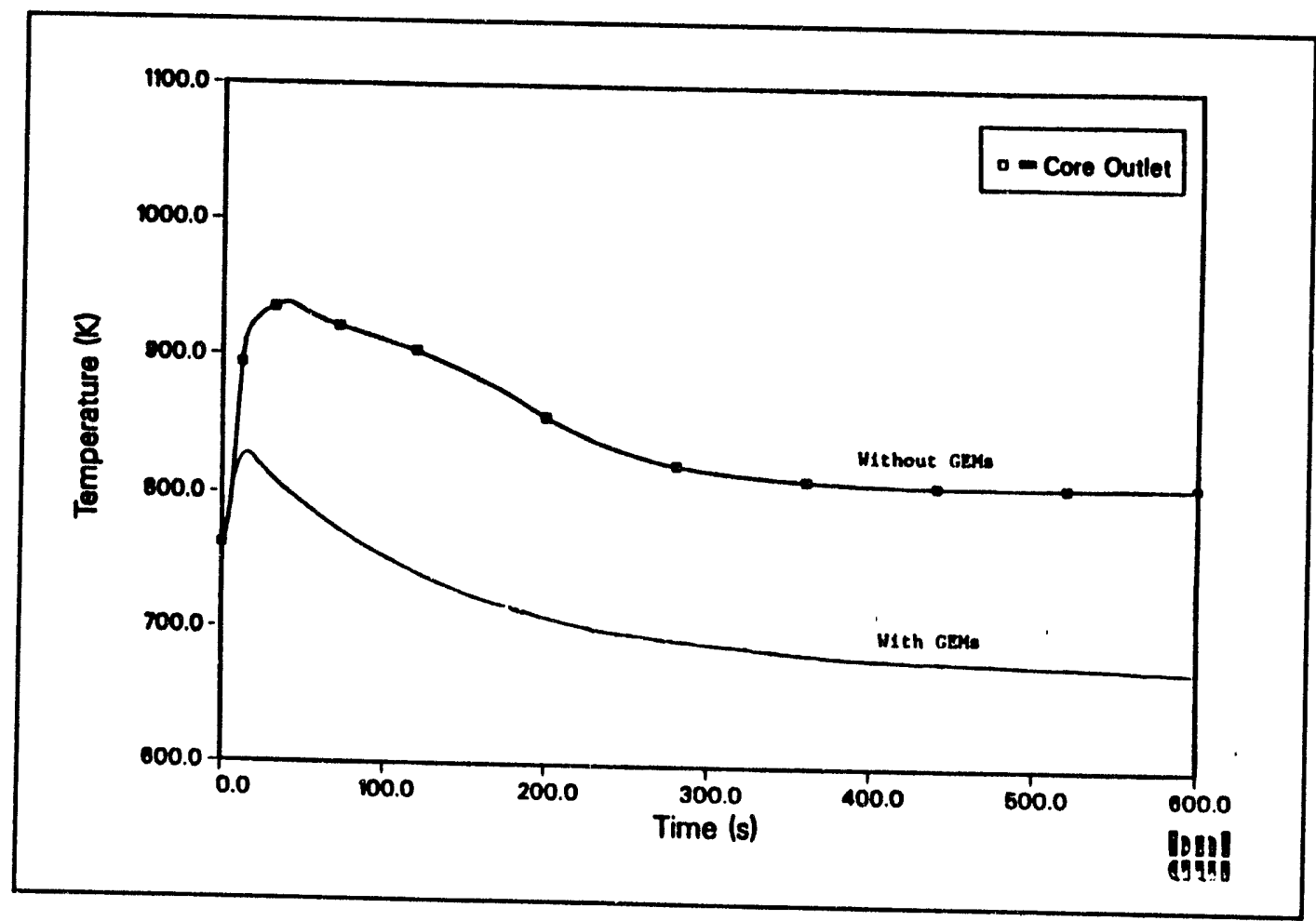

Figure B.33 Predicted average core outlet temperature from the SSC computer code for a ULOF with and without GEMs 
temperatures are needed to match the heat loss and the power production, which is higher than decay heat levels. The net reactivity peaks near $-27 \mathrm{c}$. The ACLP contribution is negative, since the core without GEMs must heat up significantly. The sodium heats up as the sodium flow rate reduces, raising system temperatures. The Doppler, axial expansion, radial expansion, and control rod drive line reactivities feedbacks initially turn negative, with only the sodium reactivity feedback positive. The net is a negative reactivity feedback initially, and the power level is later reestablished at about 10 percent of rated power. The increases in temperature also change temperatures within the fuel. The increase in system temperatures causes an increase in the peak center-line temperature before the power begins to fall. However, the peak fuel temperatures reach only $1150 \mathrm{~K}\left(1610^{\circ} \mathrm{F}\right)$ for the case without the GEMs. This is far below the solidus temperature for the fuel alloy (i.e., $1249 \mathrm{~K}$ or $1790^{\circ} \mathrm{F}$ ), even factoring in the three annular rings that develop within the fuel pellet from zirconium migration. Without the GEMS, the peak sodium temperature is only $160 \mathrm{~K}$ $\left(290^{\circ} \mathrm{F}\right)$ from boiling.

Conclusions for the ULOF Cases: The SSC predictions show that the PRISM would be able to withstand the ULOF, both with and without the aid of the GEMs. The GEMs can dominate the neutronic reactivity feedbacks and can bring the power down to the decay heat level within 500 seconds, with a margin to sodium boiling of about $300 \mathrm{~K}\left(540^{\circ} \mathrm{F}\right)$. The fuel temperatures decrease, and fuel damage is not a significant risk for this event. The case without the GEMs shows the usual heatup of the structures, which activates the reactivity feedbacks, thus reducing the power. This causes the power to stabilize around 10 percent of rated power and temperatures to be about $150 \mathrm{~K}\left(270^{\circ} \mathrm{F}\right)$ higher than when the GEMs are functioning (i.e., $\sim 850 \mathrm{~K}$ versus $\sim 700 \mathrm{~K}$ or $\sim 1070{ }^{\circ} \mathrm{F}$ versus $\left.\sim 800^{\circ} \mathrm{F}\right)$.

The GEMs can be helpful in three respects. Firsi, they add to the safety margin regarding sodium boiling, and this is a crucial threshold to avoid. Second, if one or more of the pump coastdowns are less than anticipated (e.g., if one of the synchronous machines seizes), then the GEMs could help avoid a potentially serious accident. Third, during an extended unprotected event, the reactor vessel expands and pulls the control rods out somewhat from the core, and the GEMs help to overcome this delayed reactivity addition, which can be quite significant.

\section{B.3.5.5 ULOHS Only}

The event is initiated from full-power conditions, as listed in Table B.2. The secondary loop heat transfer is arbitrarily terminated, so that all heat generated is retained in the primary vessel. The vessel heatup is assumed to be adiabatic. The EM pumps continue to operate normally, and the plant protection system is assumed to not scram the reactor. As discussed previously, the thermal conductivity used is the reduced case, as shown in Table B.3, in order to account for the uncertainties in the data collected to date and to reflect the fuel's behavior under irradiation.

Within 10 seconds of the IHX being shut off, the temperature of the sodium entering the IHX is the same as that leaving the IHX. The power level transitions to a decay heat level by 500 seconds. The sodium temperature in the core inlet ia plenum is starting to increase by 80 seconds. The slow heatup of sodium results from the large sodium pools and the metal mass, giving the primary sodium a big thermal sink.

The increase in sodium temperature results in the net reactivity dropping down to about $-27 \mathrm{c}$ by 600 seconds. This is what is left over after overcoming the power defect because the absolute temperature of the system has increased. The radial expansion is the dominant reactivity feedback in this event, and drives the net feedback, with the grid plate expansion shown to be the largest contributor to the negative feedback. The hot inlet sodium thermally expands the grid plate and reduces the fuel density by spreading the assemblies of the core, causing more fast neutron leakage. These higher temperatures also increase the axial thermal expansion feedback, contributing about $-8 \mathrm{c}$. The higher temperatures increase the positive reactivity feedback from the sodium density to about $14 \mathrm{c}$. The Doppler reactivity feedback is worth only about $-5 \mathrm{c}$. The control rod drive line expansion has a maximum reactivity worth of only $-7 \mathrm{c}$ by 200 seconds. By 200 seconds, the rods are already being withdrawn as a result of vessel expansion, which pulls the cantilevered rods back out of the core once the $r$ sel expansion outpaces the control rod drive line expa sion. However, over the long term, the grid plate expansion and other thermal expansion feedbacks largely counteract the effect.

The temperatures in the hot driver are shown in Figures B.34 and B.35. The temperature decreases after about 75 seconds. This figure is representative of all the mid-core temperatures. Some of the fuel center-line temperatures below the core center increase because of the increase in the sodium inlet temperature. Since the reactor power transitions to decay heat levels, the fuel temperatures are not a concern for this event. The margin to sodium voiding is about $560 \mathrm{~K}\left(1010^{\circ} \mathrm{F}\right)$, which is quite large and not a reason for concern.

Thus, the LOHS event does not appear to pose a significant challenge to the PRISM passive shutdown. The peak fuel temperatures all decrease, and show no fuel 


\section{Appendix B}

damage during the first 600 seconds. The only concern might be the extent of this transient and any impact on the service limits.

\section{B.3.5.6 Comparing the ULOF and ULOHS Cases}

The peak fuel, cladding, and sodium temperatures for the various unprotected loss of flow and/or heat sink, along with key temperature limits are shown in Figure B.36. GE's results for BE-2' are represented in the first set of bars, which directly correspond to those in Figure B.2. Peak temperatures from the equivalent staff calculations are shown in the second set of bars. The difference in peak fuel temperatures remains unresolved. The peak fuel temperatures in the staff calculation occur at the beginning of the transient, because tripping of the pumps triggers a quick response from the GEl/s, which brings the power down before the system can begin to heat up. It is unclear why the fuel temperatures increase in the preapplicant's analysis. With respect to the peak cladding and coolant temperatures, both analyses indicate similar temperature increases, which could lead to some cladding damage, depending on how the sparse data available are interpreted.

The staff results for the ULOF event, with and without the GEMs functioning, are represented by the third and fourth sets of bars. The peak temperatures with the GEMs functioning properly pose little concern. However, without the GEMs, there could be significant cladding damage.

The fifth case, the unprotected loss of heat sink does not appear to be a significant safety concern, unless it continues indefinitely. Certainly, the peak temperatures are very modest over the near term, as indicated in Figure B.36.

\section{B.3.6 LOHS Events With Partial Blockage of RVACS Ducting}

Because RVACS is the only safety-grade heat removal system for the PRISM, it has been closely scrutinized for potential failure modes. While some degradation in system performance is possible (heat transfer surfaces may change) and some partial failures (reactor vessel leaks, for instance) are conceivable, the failure mode that seems most significant would be a blockage of the air-flow ducting. However, these four independent air ducts are very large and difficult to fully block, except via a massive earthquake or an extremely thorough act of sabotage.

Because RVACS is such a crucial system, it is felt that some degree of failure should be assumed for further analysis. (This failure is in addition to a loss of normal cooling and loss of ACS, which are not safety systems, but have excellent natural cooling capabilities regardless.)
Initially, a very lengthy adiabatic heatup without RVACS was analyzed, which led to predictions of severe damage about 1 day into the event. However, the priginal definition of this event pre-dated some revisions in the preapplicant's positions regarding containment and the safety function of the operator (thereby reducing the likelihood and consequences of such an unlikely event).

\section{B.3.6.1 75-percent Blockage of Air-Flow Ducting}

The peak reactor outlet sodium temperatures are as shown in Figure B.37. The GE results and the staff results indicate that system temperatures peak around $925 \mathrm{~K}$ $\left(1205^{\circ} \mathrm{F}\right)$ about 40 hours into the event. The principal concern is that the ASME Code Level C limits for system structures are around $922 \mathrm{~K}\left(1200^{\circ} \mathrm{F}\right)$. However, Level $\mathbf{C}$ limits are primarily an investment concern because if these limits are exceeded then the process of restarting the unit would involve a detailed reevaluation. In addition, the cladding temperatures for this event (close to the sodium temperatures) could cause significant damage to the fuel.

\section{B.3.6.2 Full Blockage of Ducting for 12 Hours, Then 25 Percent Reopened}

The peak sodium temperatures are included in Figure B.37. Both the GE results and the staff results indicate peak temperatures in the range of $975 \mathrm{~K}$ (1296 ${ }^{\circ} \mathrm{F}$ ), about 25 hours into the event. These peak temperatures are near ASME Code Level D limits (977 K or $1300^{\circ} \mathrm{F}$ ), and some damage to the structures may result. There also may be some localized cladding damage in the hotter portions of the reactor.

\section{B.3.7 LOF Events With Coastdown Failures}

As an EM pump has virtually no inertia, it is necessary for GE to use synchronous machines to provide an artificial coastdown. These safety-grade machines, which are little more than flywheels coupled with motor-generator units, are operated continuously so that there will be a coastdown if there is a power loss or other malfunction. As the synchronous machine is coasting down, the rotational energy is converted to electrical power for the EM pumps, which then experience gradual reduction in pumping power.

Because the passive reactor shutdown requires some time to bring the fission power down, the absence of pump coastdowns can be a major safety concern. Therefore, the synchronous machines and the cables are crucial safety components. The designer's decision to move these machines into the seismically isolated zone is believed to be a major improvement. Further, the addition of the 
Appendix B

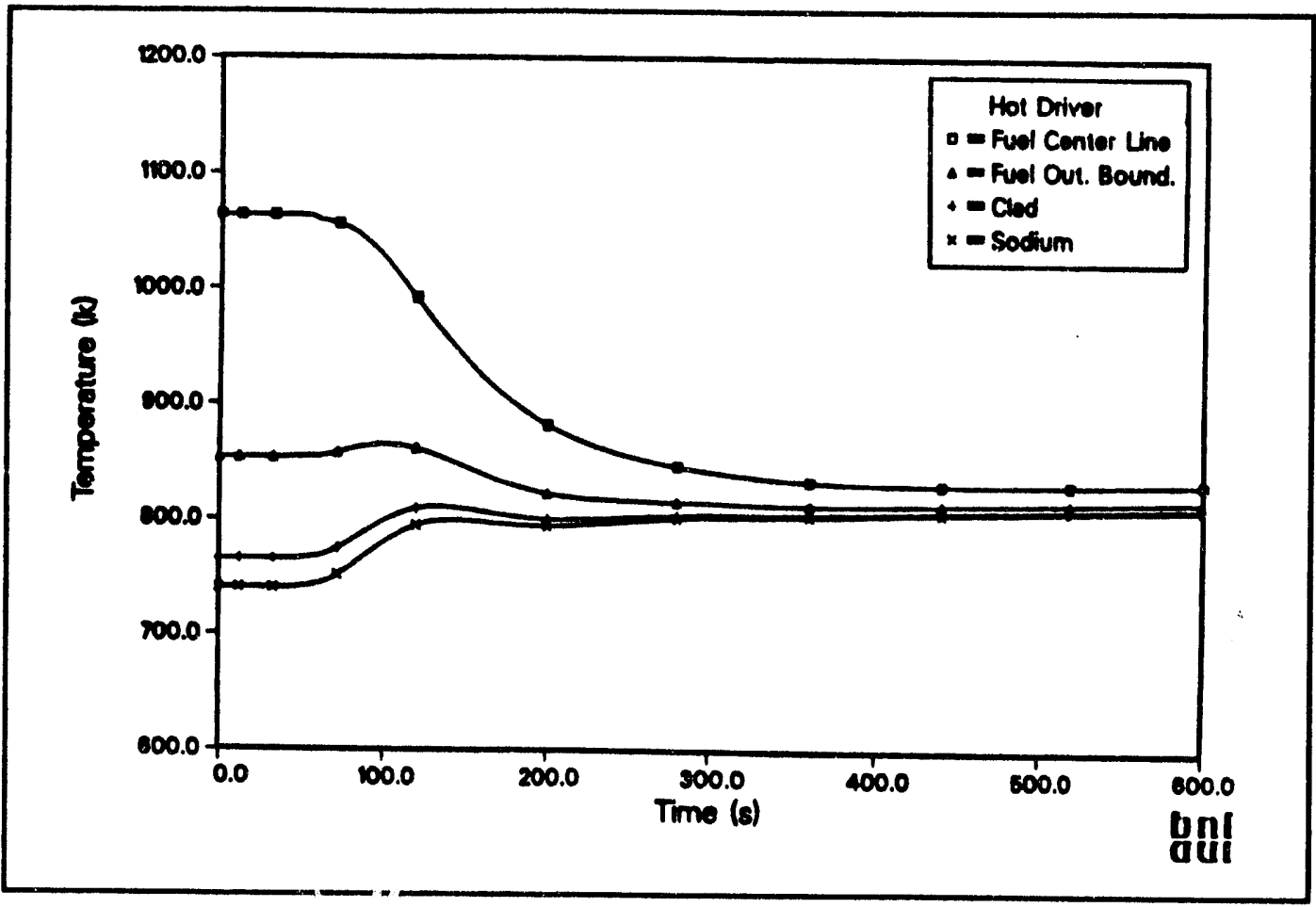

Figure B.34 Predicted fuel 1 - perature distribution from the SSC computer code for the third node from the $t$, (i.e., $0.897 \mathrm{~m}-0.673 \mathrm{~m}$ ) for a ULOHS

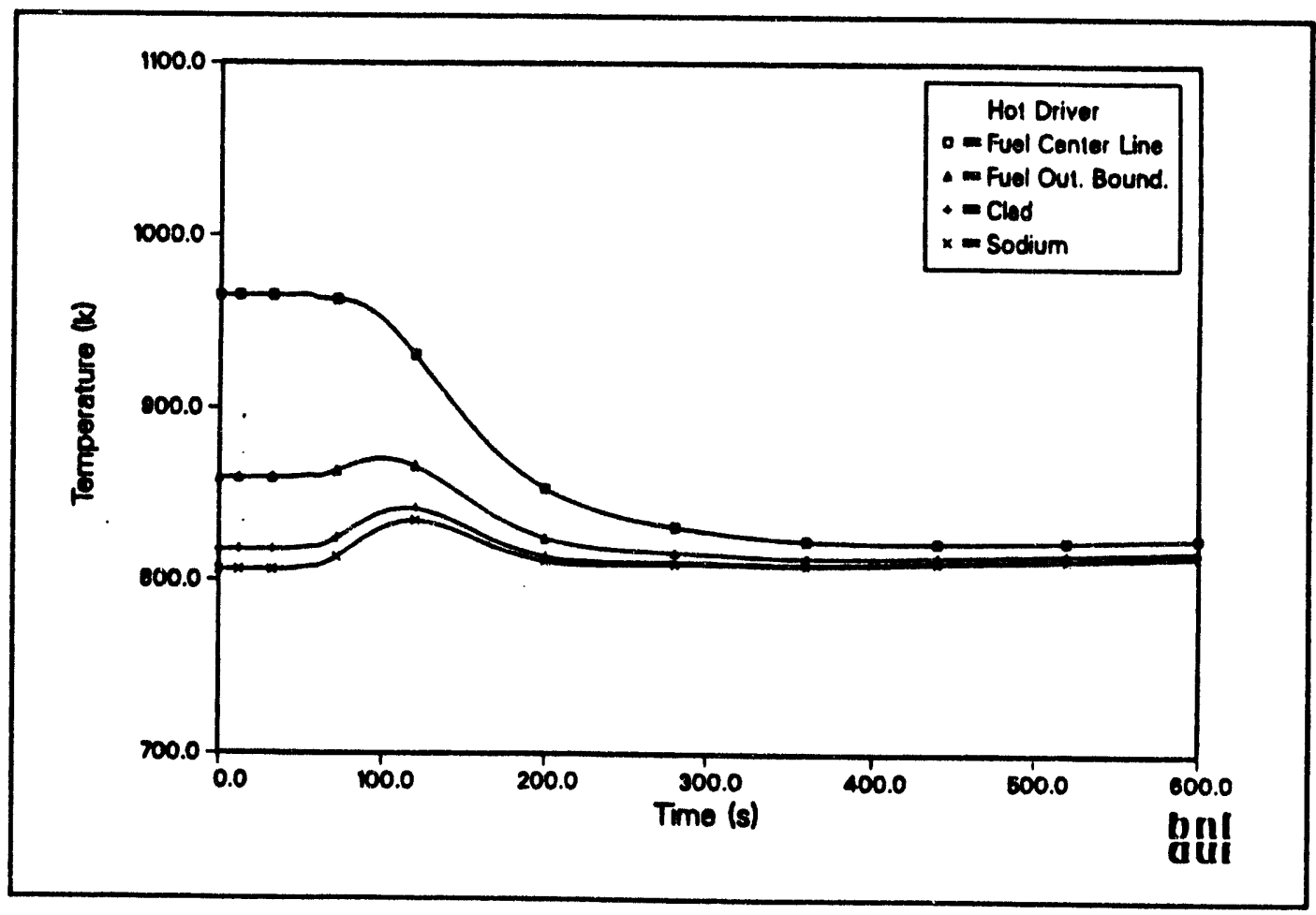

Figure B.35 Predicted fuel temperature distribution from the SSC computer code for the top node (i.e., $1.346 \mathrm{~m}-1.122 \mathrm{~m}$ ) for a ULOHS 


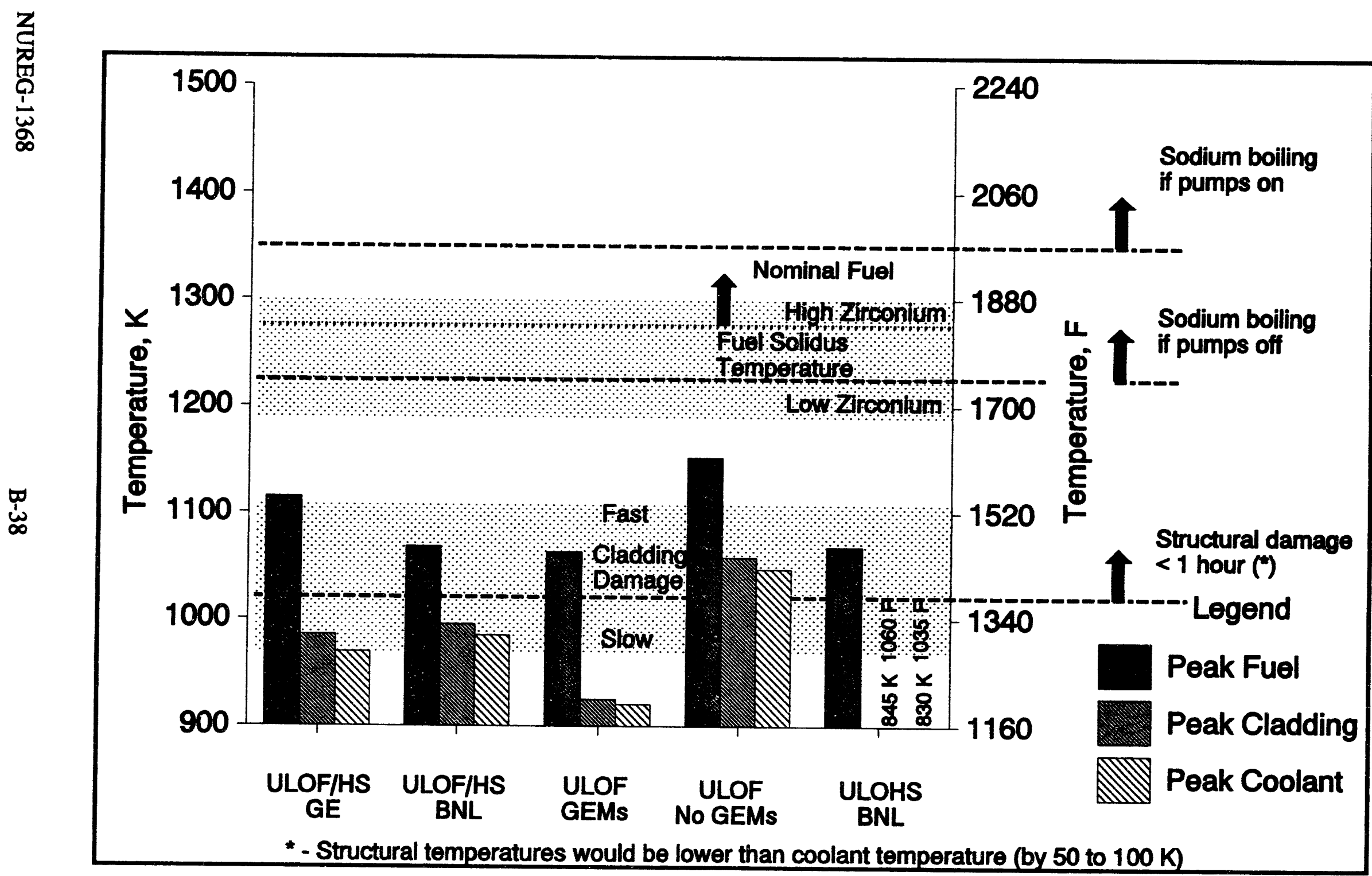

Figure B.36 Temperature summary for unprotected loss-of-flow and/or loss-of-heat-sink events 


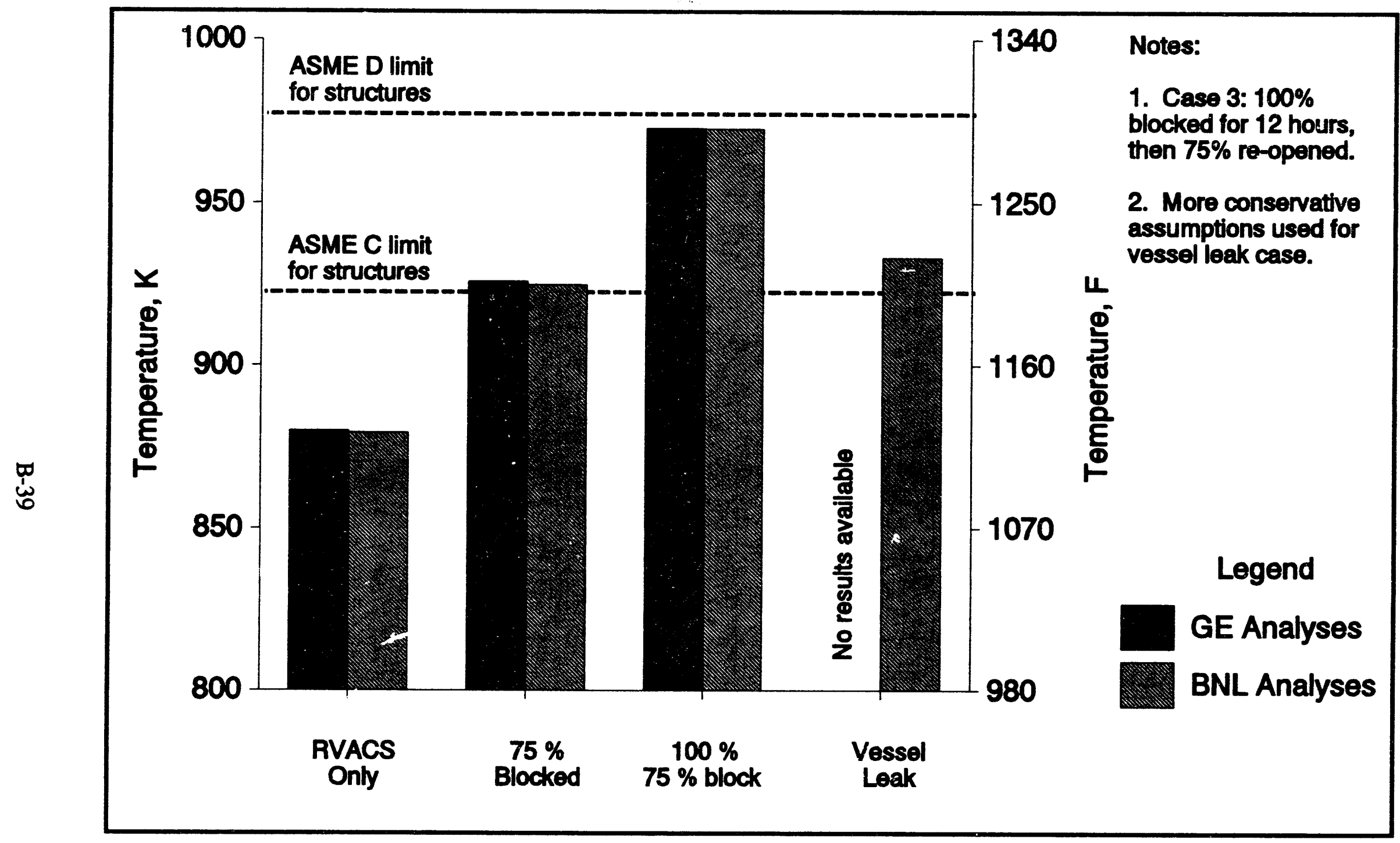

Figure B.37 Temperature summary for unprotected loss-of-heat-sink with RVACS only events 
GEMs has been helpful, as the large and rapid negative reactivity feedback that results when the pumps are tripped improves the effectiveness of the passive shutdown.

Even though the designer's modifications in this area have addressed some concerns, possible pump coastdown failure modes remain an area of concern. In this section, three cases are considered: (1) the loss of one constdown during a ULOF event, (2) the instantaneous loss of one pump at full power, and (3) the instantaneous loss of all pumps at full power. It is emphasized that the third case is thought to be exceedingly unlikely and is considered here mostly because of the GEMs.

\section{B.3.7.1 ULOF on Three of Four Pump Coastdowns}

In this case, a normal ULOF event is assumed with one pump coastdown missing entirely. This is $\mathrm{BE}-4$, so the calculations can be compared against those provided by the preapplicant in PSID Appendix G.

Analysis of this event was complicated by the need to calculate the sodium flow rate through the reactor power using the MINET computer code, and to calculate the reactor power using the SSC computer code. Because the reactor power level and the sodium flow rate are closely coupled, a number of passes were needed to ensure the two calculations were consistent.

In the MINET modeling, the pumps were represented individually, using the fairly detailed pump head and torque curves provided by GE. Some of the complexity is caused by the stoppage of one pump, which creates an open pipe-like pathway for the sodium to short-circuit back to the inlet of the other pumps. The results can be observed in Figures B.38 through B.41. Normally, the flow through each pump quickly drops from $630 \mathrm{~kg}$ per second to about $300 \mathrm{~kg}$ per second, and then coasts down, as shown in Figure B.38. Instead, the flow per pump goes to about $500 \mathrm{~kg}$ per second, and the coastdown from there is more protracted, as shown in Figure B.39. These changes are caused by the flow reversing through the failed pump, as shown in Figure B.40. With that line open, the circuit flow resistance is sharply reduced, leading to surging in the pumps that are coasting down, and the reduced torque that causes the coastdown to be stretched out. As a result, the coastdown of sodium flow rate through the reactor, shown in Figure B.41, is not nearly as severe as one might anticipate.

The flow coastdown predicted by MINET was used to drive the SSC calculations. The calculated power from the
SSC prediction is shown in Figure B.42. The reasons for the fast power reduction are shown in Figures B.43 through $B .45$, which include the various reactivity feedbacks at work. In this case, the reactivity from the GEMs, which is shown in Figure B.45, dominates the others, especially over the first several seconds. This is triggered by the rapid drop in the sodium level within the GEMs, which drops quickly as the pumping is cut back sharply.

Peak temperatures calculated for this event are shown in Figures B.46 through B.419. The peak fuel temperatures in the hot driver near the axial center of the core, shown in Figure B.46, are at the beginning of the event.

The first 12 hours of this event involve an adiabatic heatup of the primary system, with temperatures climbing more than $200 \mathrm{~K}\left(360^{\circ} \mathrm{F}\right)$ during that tiue. If the adiabatic heatup were to continue, severe damage would occur before the end of 24 hours. However, the likelihood of the PRISM system ever experiencing an adiabatic heatup, given that all three heat removal systems function well under natural circulation, seems extremely small. Further, 12 hours is a lengthy period for someone to restore partial functioning of one or more of the heat removal systems. Therefore, generally speaking, the adiabatic heatup category of events seem unlikely to dominate the risks in operating a PRISM unit.

This is because the negative reactivity from the GEMs drops the power quickly and brings the fuel temperatures down with it. The sodium temperatures near or at the outlet of the core, also are shown in Figures B.47 through B.49. The sodium temperatures peak at the initiation of the event, but reduce with the flow rate.

The only real safety concern here would be the cladding temperatures, and this depends on what assumptions are made regarding the cladding damage limits. This event would have to continue for a long time for significant cladding damage to occur, and even then damage would be localized to the hotter parts of the core. Therefore, this event now looks fairly mild, with the GEMs making a significant contribution to reducing its severity.

While an analysis of the highly improbable case where two pump coastdowns are missing was not performed, it is possible to extrapolate from other cases. It is expected that some localized fuel naelting and significant cladding damage would occur, but sodium boiling would be very unlikely. 
Appendix B

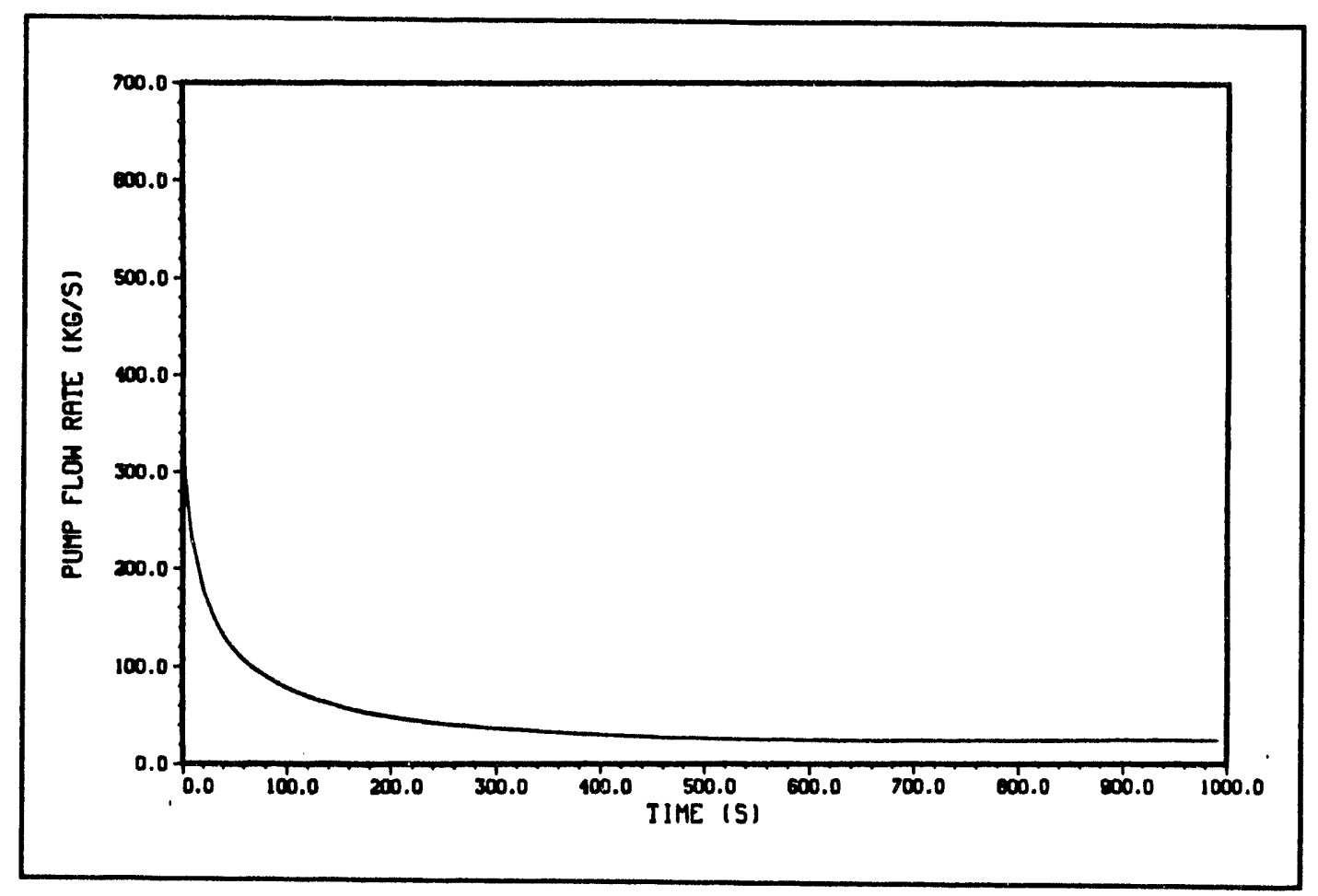

Figure B.38 Predicted pump flow rate from the MINET computer code for a ULOF/LOHS with four EM pumps

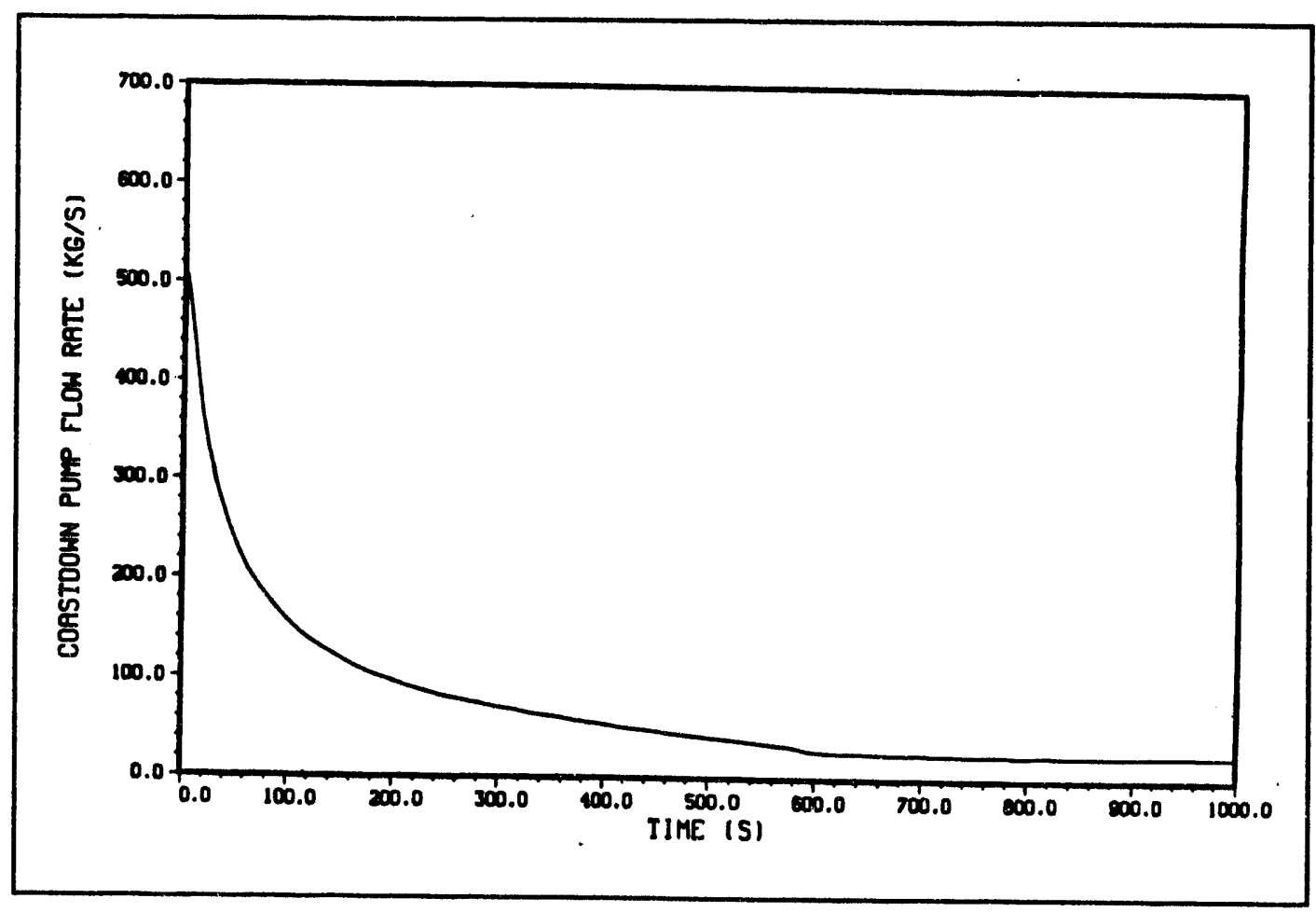

Figure B.39 Predicted pump flow from the MINET computer code for a ULOF/LOHS with a pump seizure and three pumps coastdown 
Appendix B

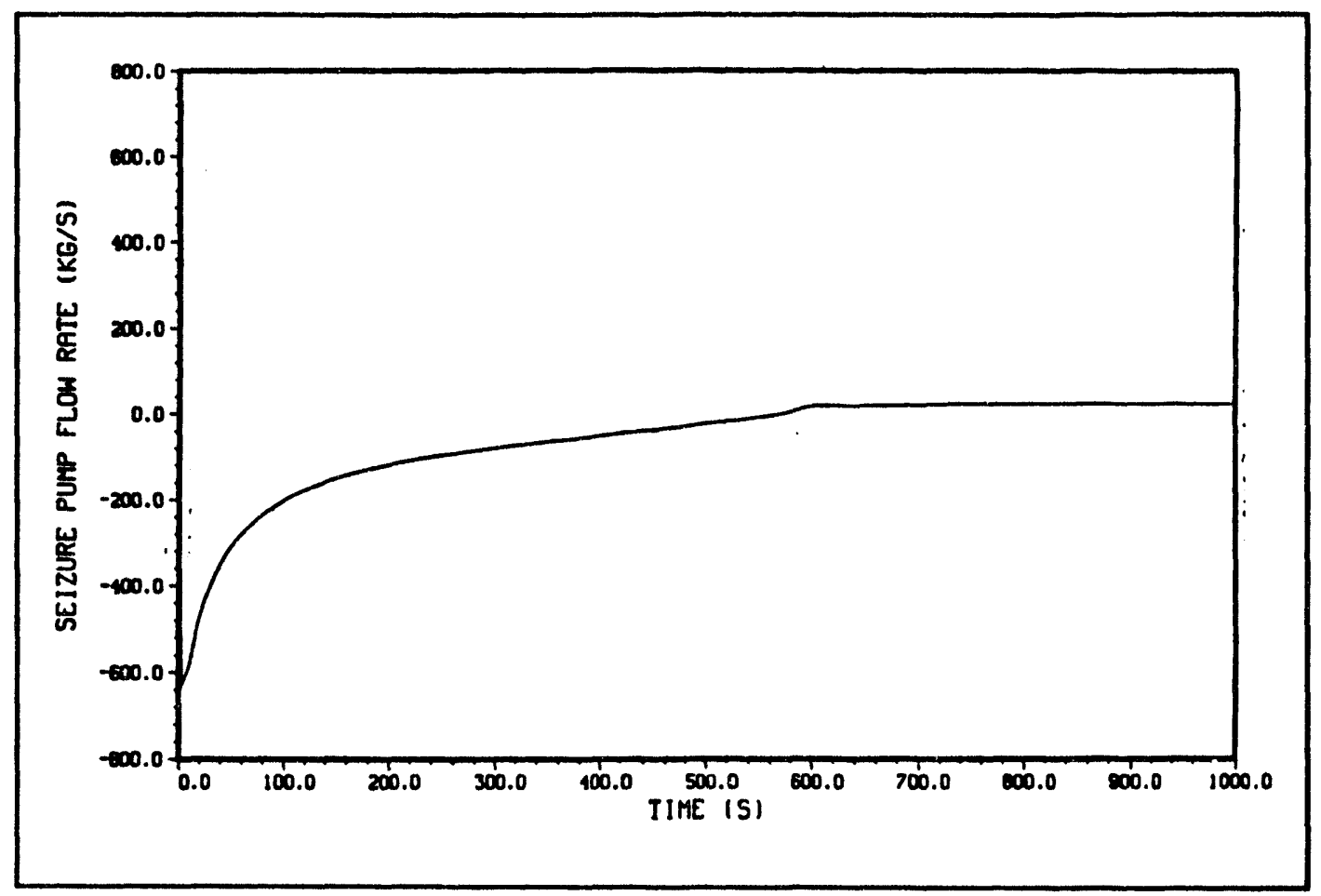

Figure B.40 Predicted flow in a seized EM pump for a ULOF/LOHS with three pumps coastdown

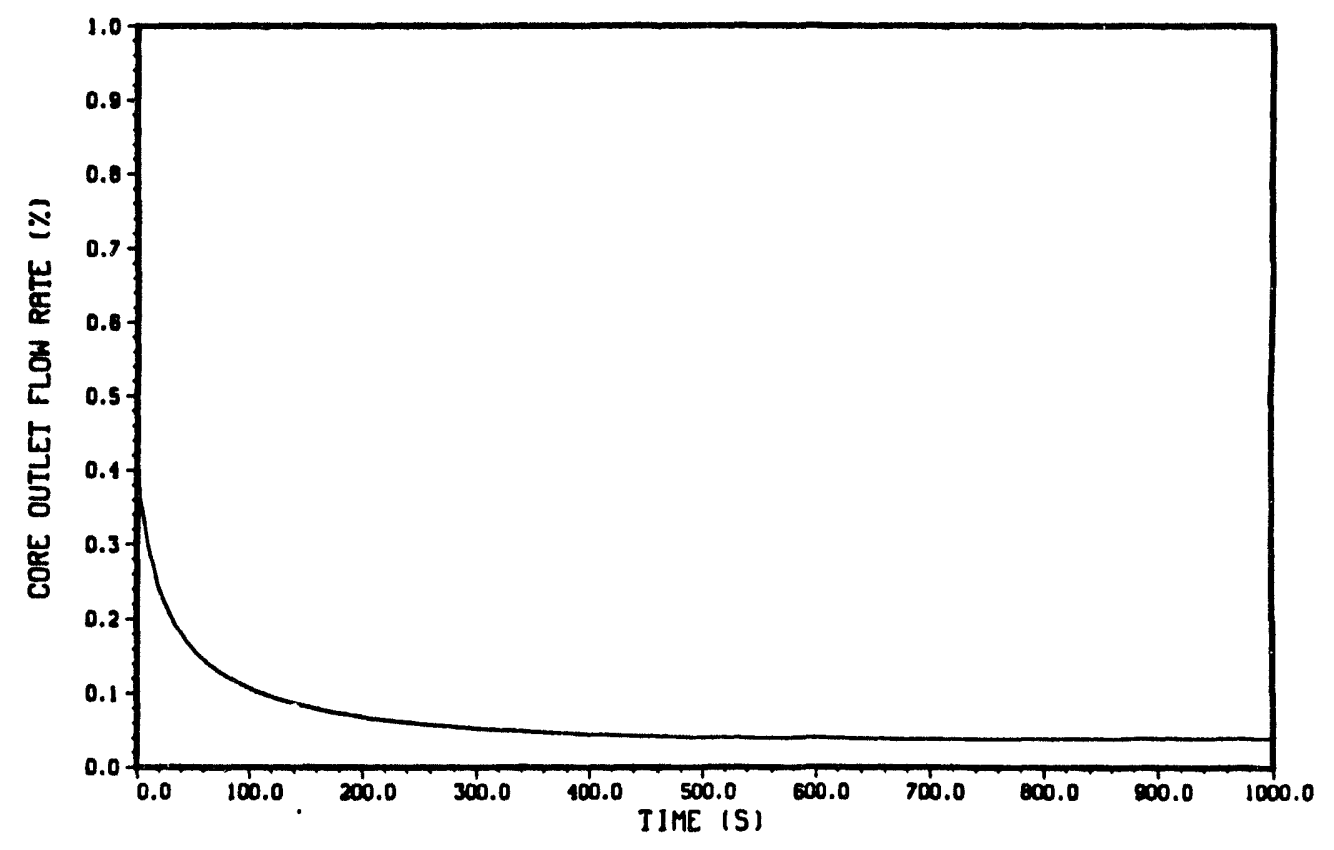

Figure B.41 Predicted core outlet flow from MINET for a ULOF/LOHS with one pump seizure and three pumps coastdown 


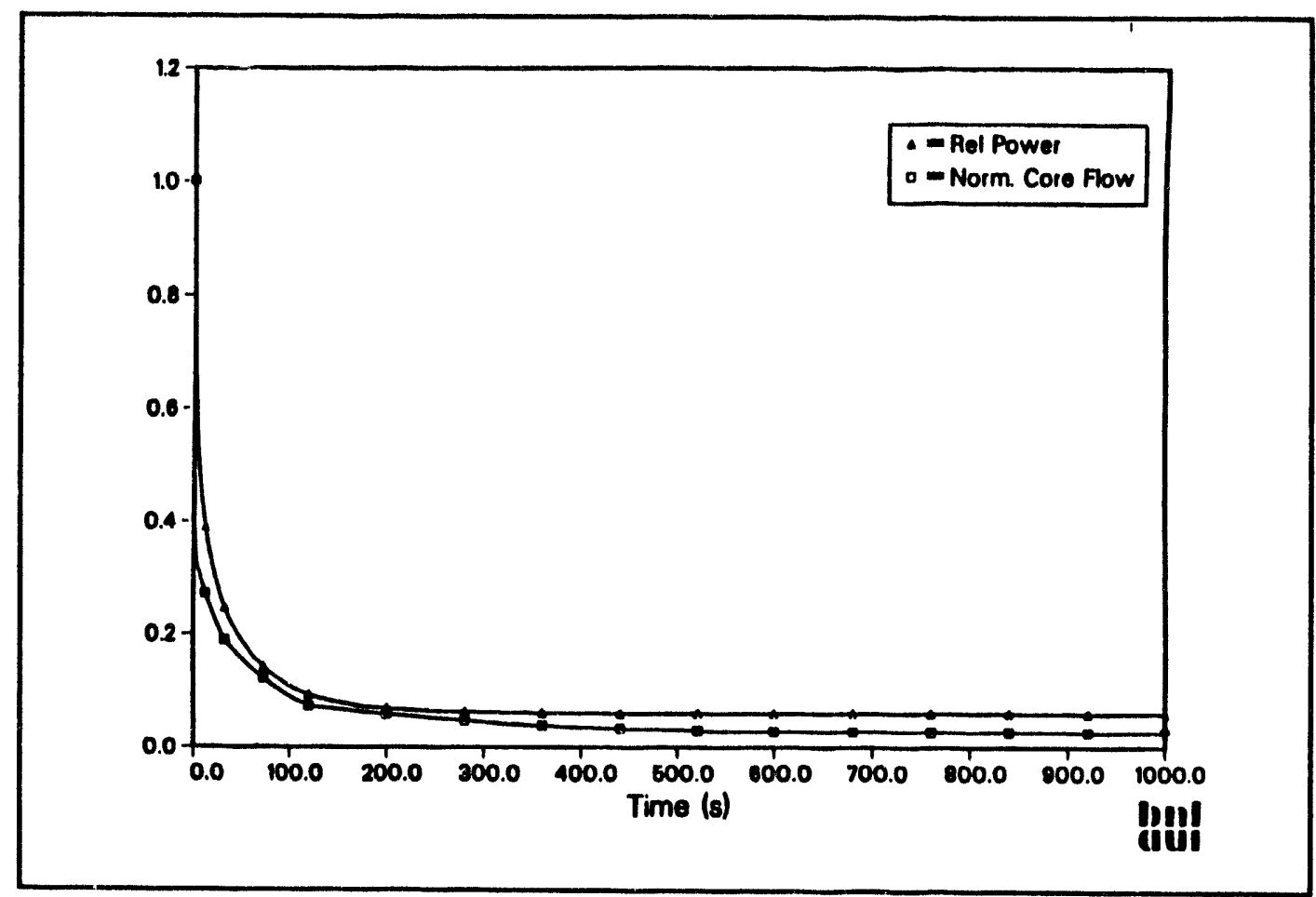

Figure B.42 Predicted relative power and normalized core flow from the SSC computer code for a ULOF with one pump seized

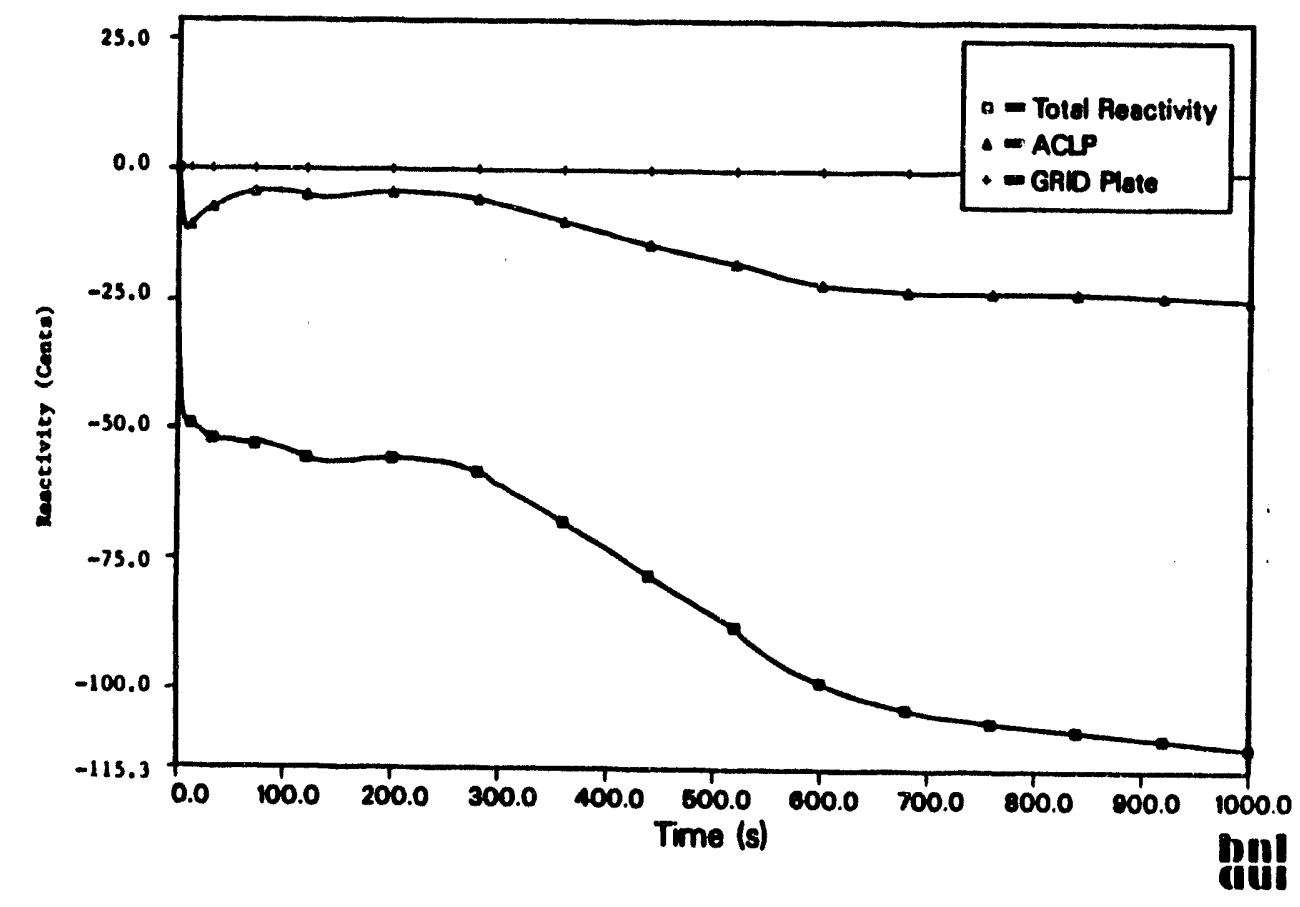

Figure B.43 Predicted total, above-core pad, and grid plate reactivity feedback from the SSC computer code for a ULOF with one pump seized 
Appendix B

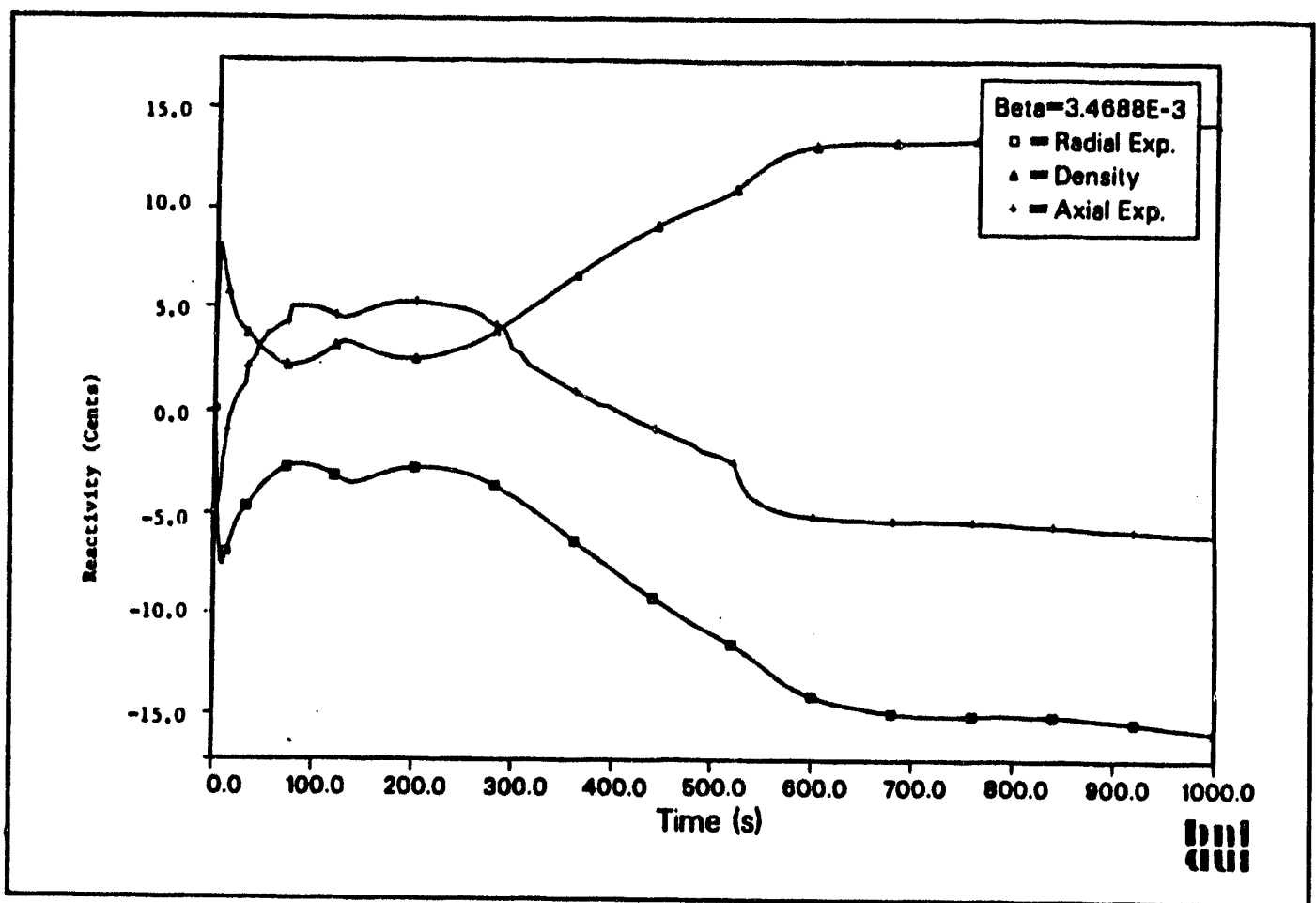

Figure B.44 Predicted core radial expansion, sodium density, and axial expansion reactivity feedback from the SSC computer code for a ULOF with one pump seized

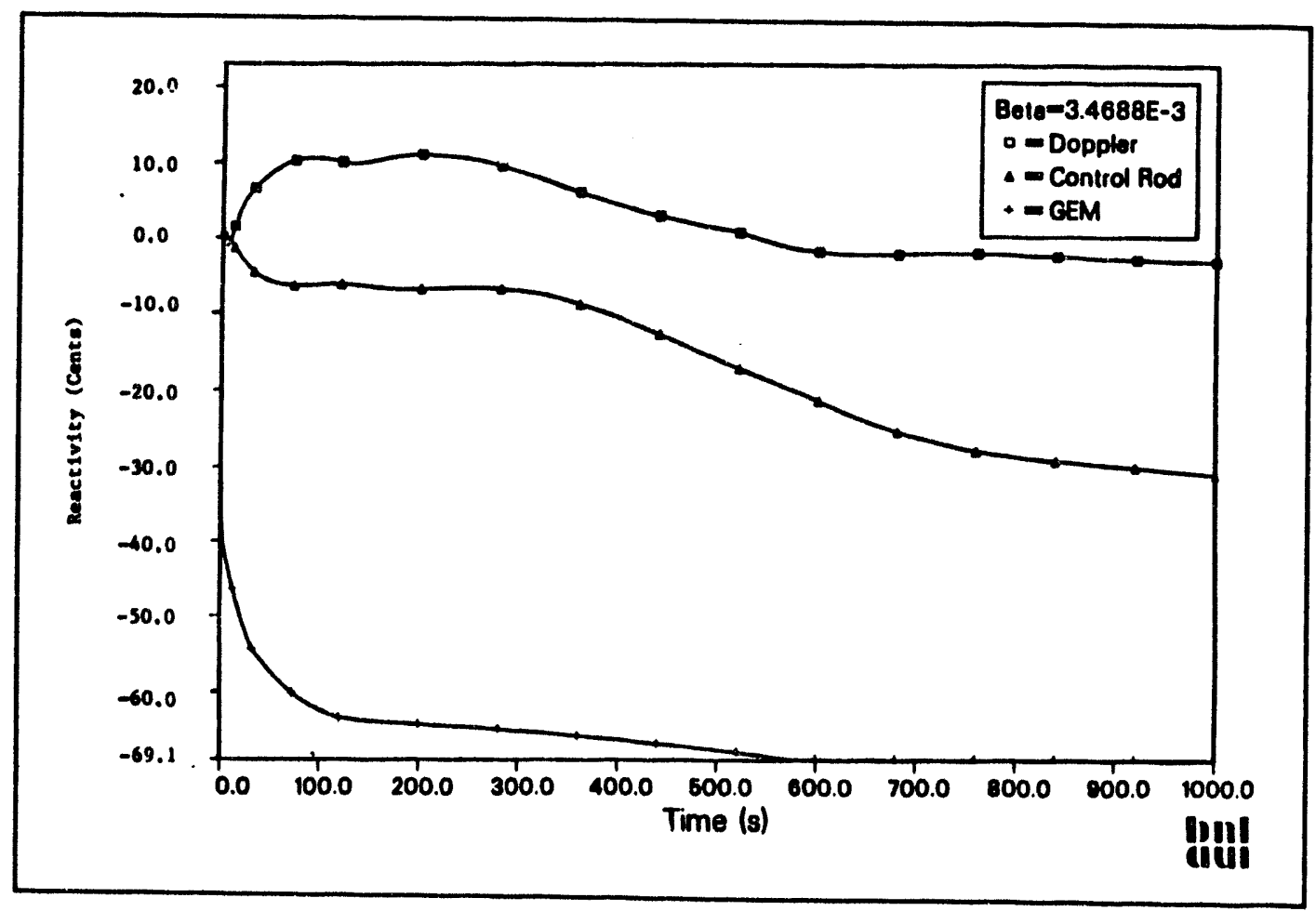

Figure B.45 Predicted Doppler, control rod drive line thermal expansion and GEM reactivity feedback from the SSC computer code for a ULOF with one pump seized 
Appendix B

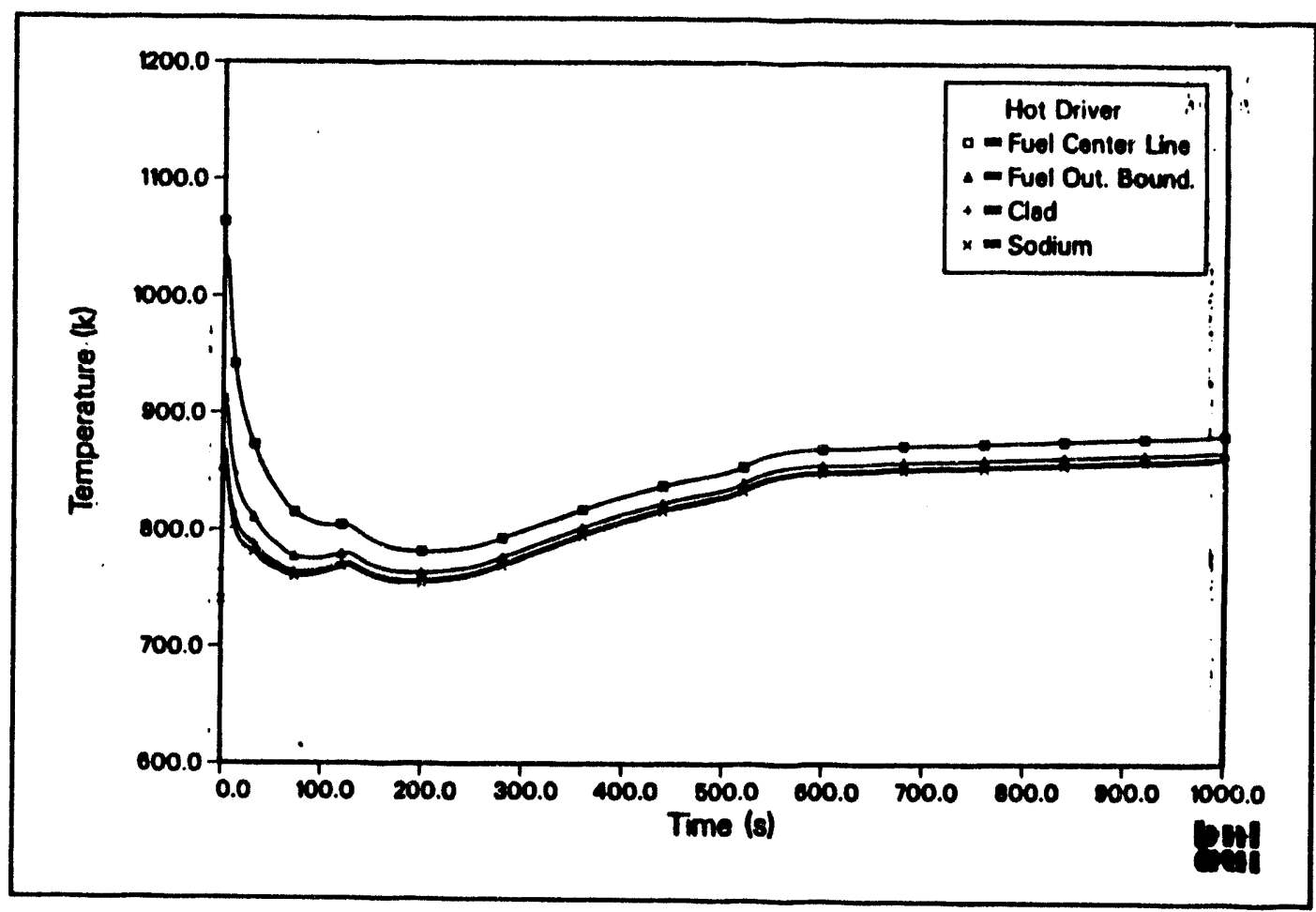

Figure B.46 Predicted fuel temperature distribution for the third from the top node (i.e., 0.897 $\mathrm{m}-\mathbf{0 . 6 7 3} \mathrm{m}$ ) of a fuel pin from the SSC computer code for a ULOF with one pump seized

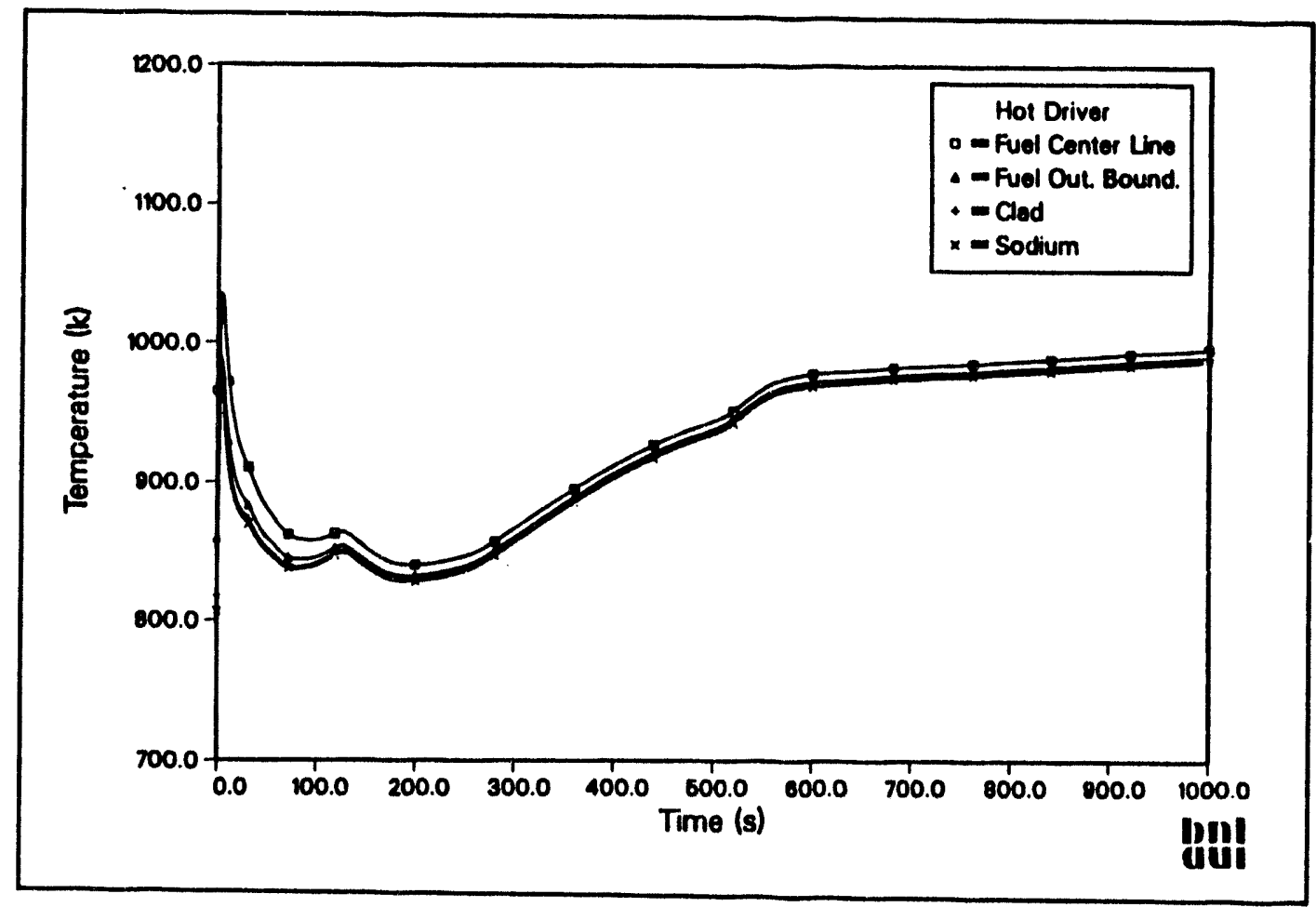

Figure B.47 Predicted fuel temperature distribution for the top node (i.e., $1.346 \mathrm{~m}-1.122 \mathrm{~m}$ ) of a fuel pin from the SSC computer code for a ULOF with one pump seized 
Appendix B

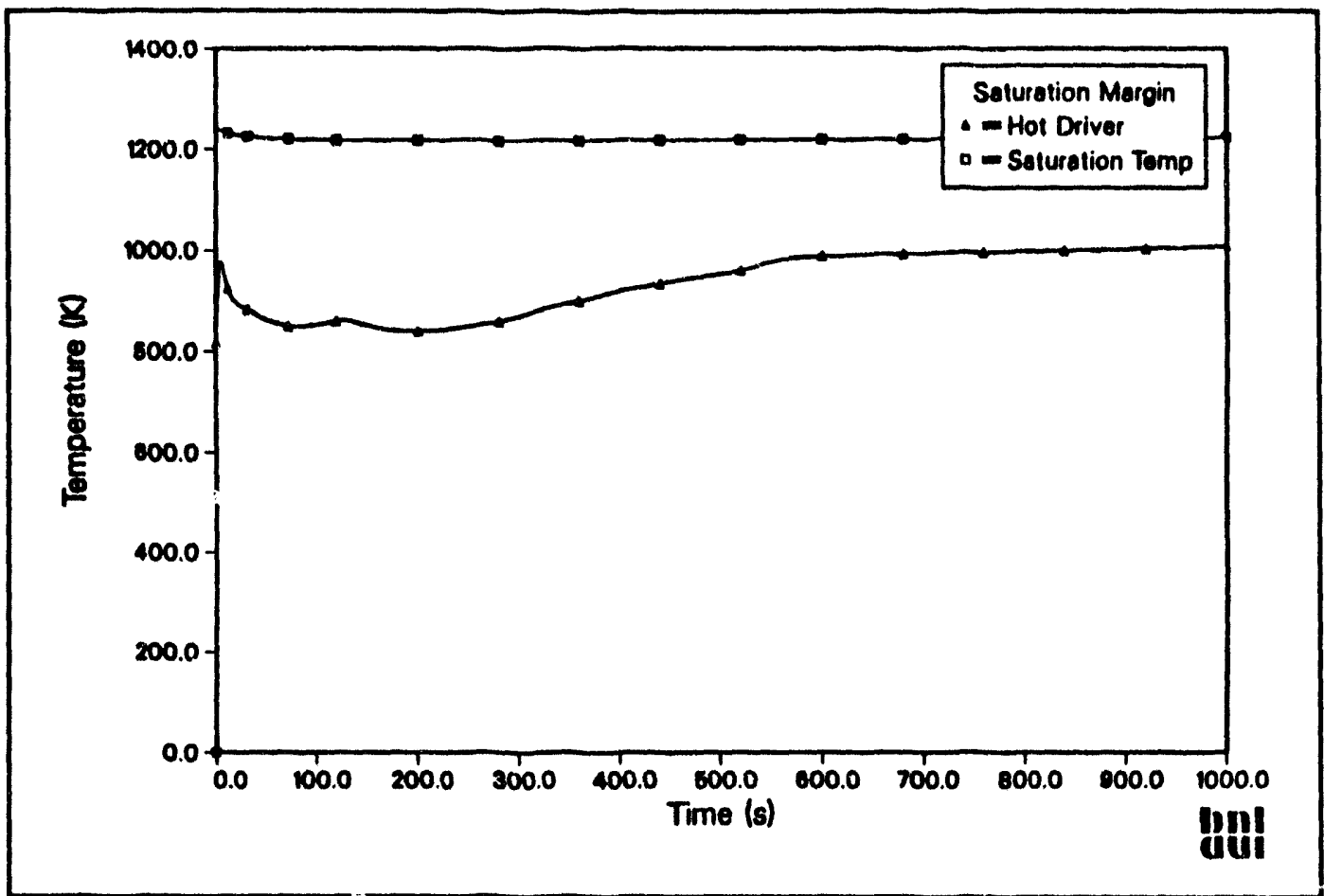

Figure B.48 Predicted margin to sodium saturation from the SSC computer code for a ULOF with one pump seized

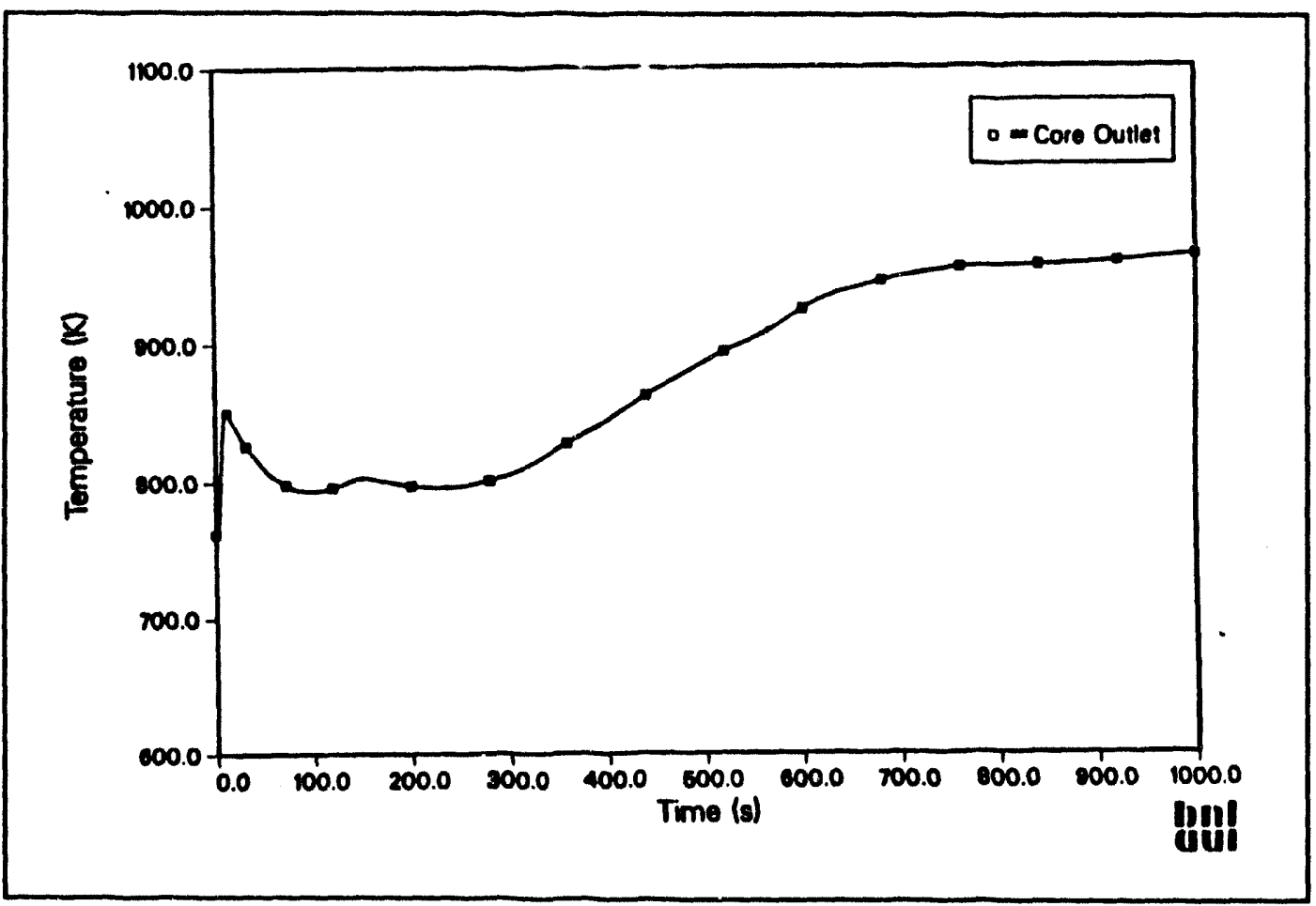

Figure B.49 Core exit average sodium temperature from the SSC computer code for a ULOF with one pump seized 


\section{B.3.7.2 Instantaneous Stoppage of One Pump Without Scram}

In principle, a pump could fail in such a way that no coastdown would occur, although it is questionable that this could develop with warning signs. However, it is possible that any warning signs would be overlooked. If a failure to scram the reactor is also imposed, the probabilities become very low. However, an external event, particularly a very large earthquake, causing multiple failures could conceivably initiate this type of event.

The normalized sodium flow rate through the reactor, as specified for SSC, and the normalized power production, as calculated by SSC, are shown in Figure B.50. The reactivity feedback from the GEMs, roughly $-25 \mathrm{c}$, develops quickly and dominates the other reactivities feedbacks. This is because the sudden loss of a pump drops the pressure quickly, dropping the sodium level in the GEMs.

The resulting fuel temperatures are shown in Figure B.51. With reduced pumping and less power production, temperatures fall significantly. However, since the power does not remain as low as the coolant flow, the temperature rise across the core and the temperature fall across the IHX increases. Also, as shown in Figure B.51, although the drop in temperatures are quite sudden, the peak maximum temperatures are reached within the first 5 seconds.

The analyses, using both the MINET and SSC codes, indicate that this event is largely benign. Clearly the GEMs have a major effect if one pump is stopped suddenly.

\section{B.3.7.3 Instantaneous Stoppage of All Pumps Without Scram}

The probability of this event is less than the already defined BEs and could best be described as "exceedingly unlikely." In principle, a massive earthquake (larger than the design basis earthquake) might be postulated that causes the loss of all energy flow (including that from the synchronous machines) to the EM pumps and completely incapacitates the scram system. In addition, all this must occur simultaneously and the operator must fail to trigger the ultimate shutdown system (USS).

The reason for analyzing this event was to answer an intriguing "what if?" question, particularly in light of the recent addition of the GEMs. It was believed that there was some chance that the GEMs might bring the power down quickly enough to prevent sodium boiling.
However, the analysis currently shows that for this event the sodium would boil after about 10 seconds and that a power excursion would likely result.

The first task in the analysis was to determine the rate of flow reduction to the reactor. The same MINET representation, as previously discussed, was used except this time pump flows were cut to zero within 4 seconds. The calculated reactor flow rate is shown in Figure B.52. The flow rate curve labeled "General Electric, ARIES" is from a very preliminary calculation and should not be regarded as final. However, it is interesting that the flow rate estimated by GE decreases much more slowly than that from the MINET calculation. The inertia that is apparently in the GE calculation is not fully understood. The sudden flow reduction predicted by MINET is believed to be more realistic. However, if the curve predicted by the preapplicant is correct, that would surely make for a slower transient and sodium boiling would be delayed at the very least.

The SSC calculations were driven, using the pump head, to have the same sodium flow rate shown in Figure B.52 (MINET code). The resultant reactor power and sodium flow, as calculated by SSC, are shown in Figure B.53. Initially the power decreases, although not nearly as fast as the flow decreases. By 20 seconds, the power is increasing and a power excursion driven by sodium boiling develops after about 25 seconds. The reactivities feedbacks are shown in Figures B.54 through B.56. The total reactivity (Figure B.54) is initially dominated by the feedback from the GEMs (Figure B.56), which quickly add $63 \mathrm{c}$ of negative reactivity, but is later dominated by the sodium density and void feedback (Figure B.55). The sodium appears to be largely subcooled through the first 14 seconds, but the large-scale sodium boiling is developing thereafter. Most of the other reactivities feedbacks are much smaller, although the Doppler reactivity feedback is accelerating at the end. The one crucial reactivity feedback that would have to limit the severity of the event is the axial expansion of the fuel. However, the model is based on thermal expansion and does not include the rapid "prefailure extrusion" (rapid axial fuel expansion) that ANL predicts for rapid temperature increase.

Some other key characteristics are shown in Figures B.57 through B.59. Not surprising, the sodium levels in the GEMs drop quickly, as shown in Figure B.57. Peak temperatures in the hot driver clearly show sodium boiling at 9 seconds, and sodium boiling is developing in the average drivers by 16 seconds, as shown in Figure B.59. 
Appendix B

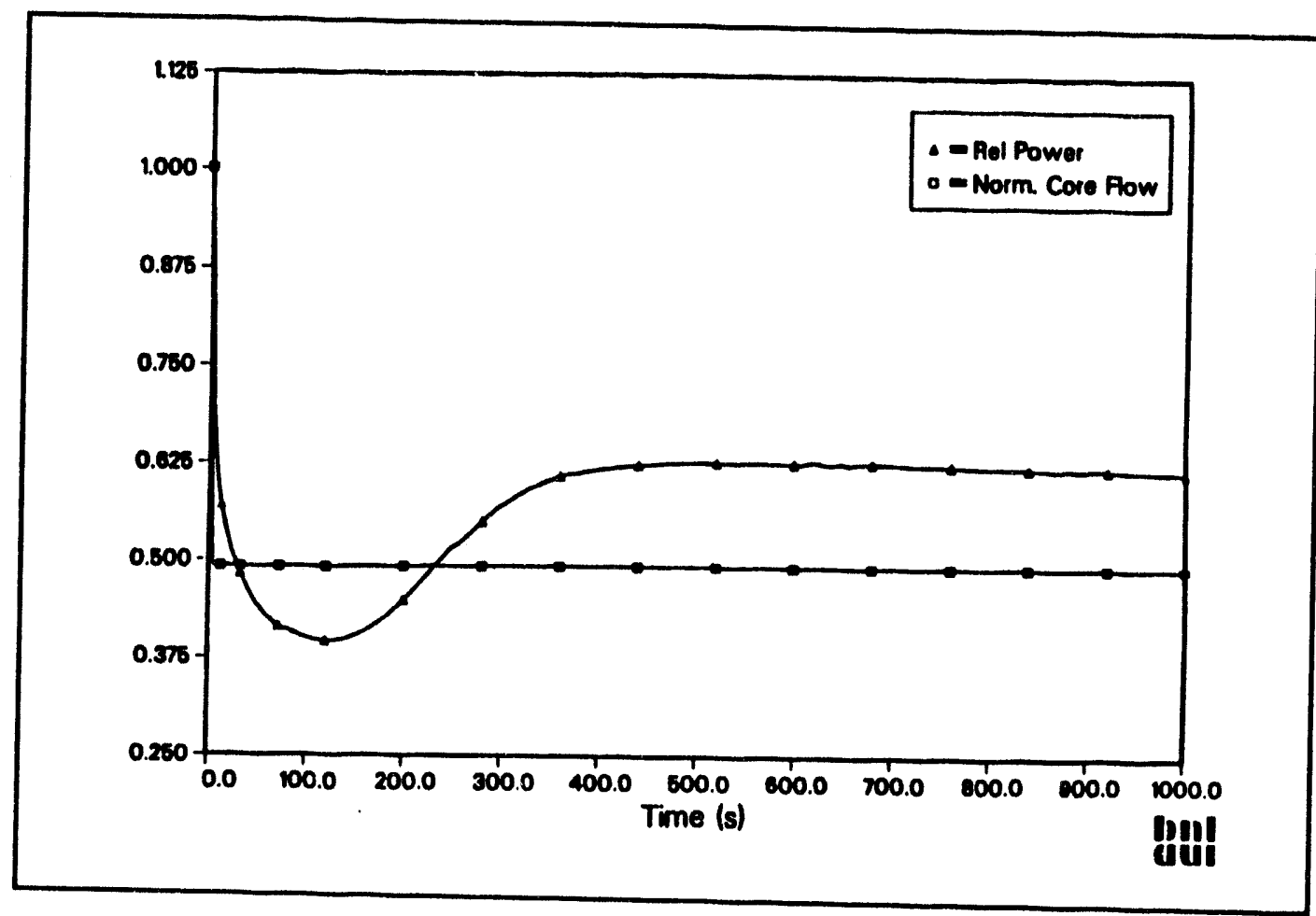
Figure B.50 Predicted relative power and normalized core flow from the SSC computer code
for a pump seizure

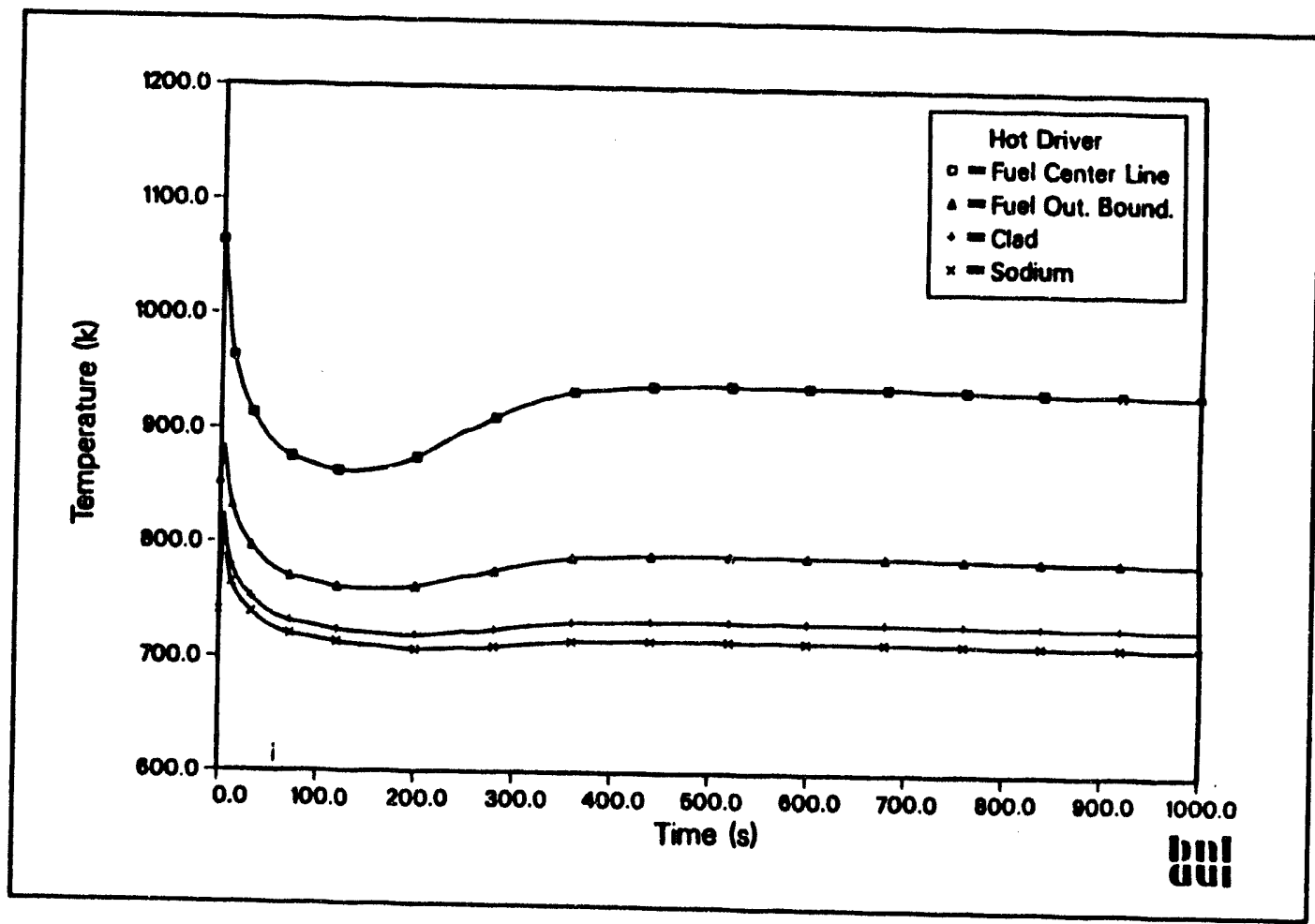

Figure B.51 Predicted fuel temperature distribution from the SSC computer code for the third node from the TOP (i.e., $0.897 \mathrm{~m}-0.673 \mathrm{~m}$ ) for a pump seizure 
Appendix B

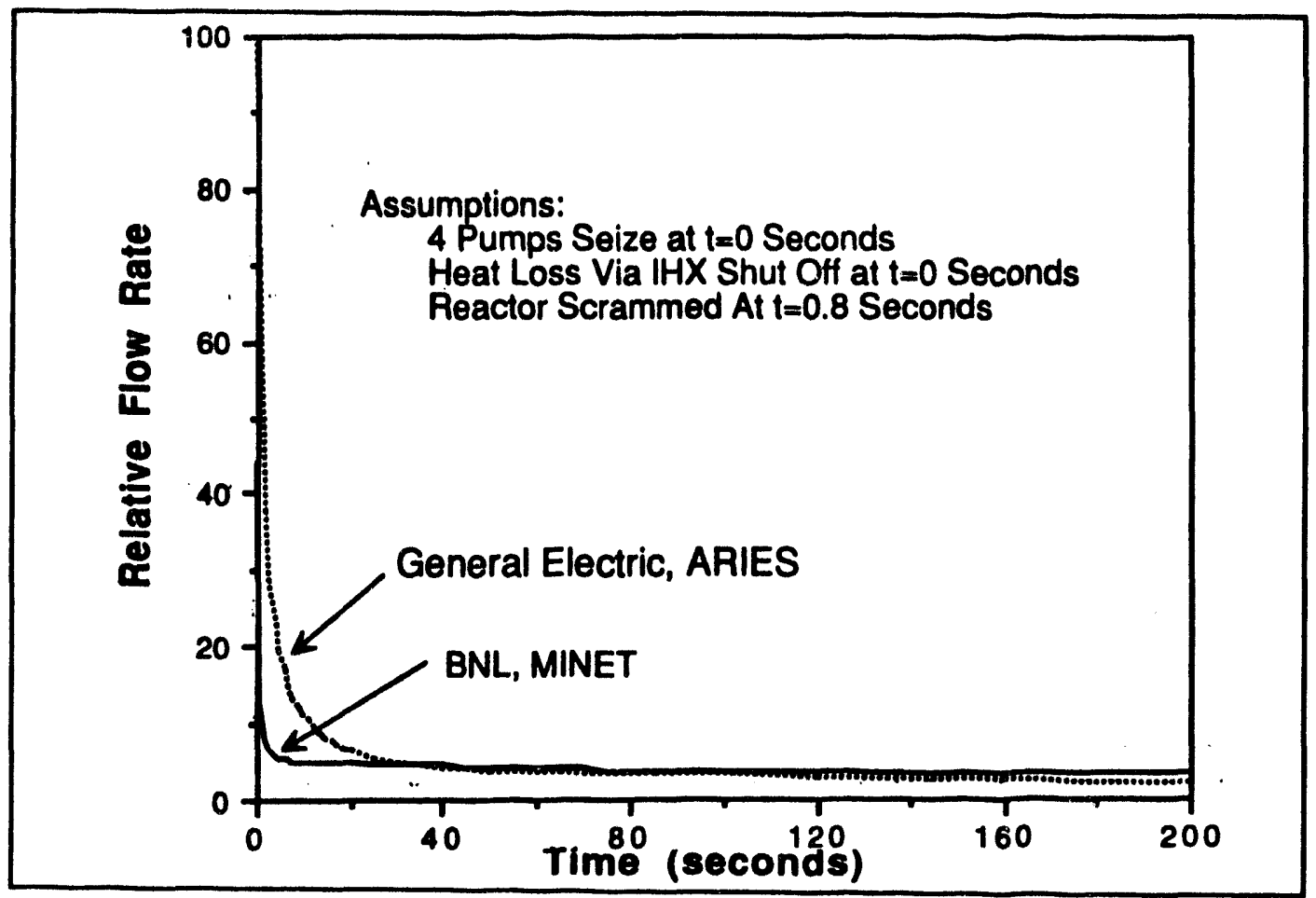

Figure B.52 PRISM core sodium flow from the SSC computer code for a total EM pump failure

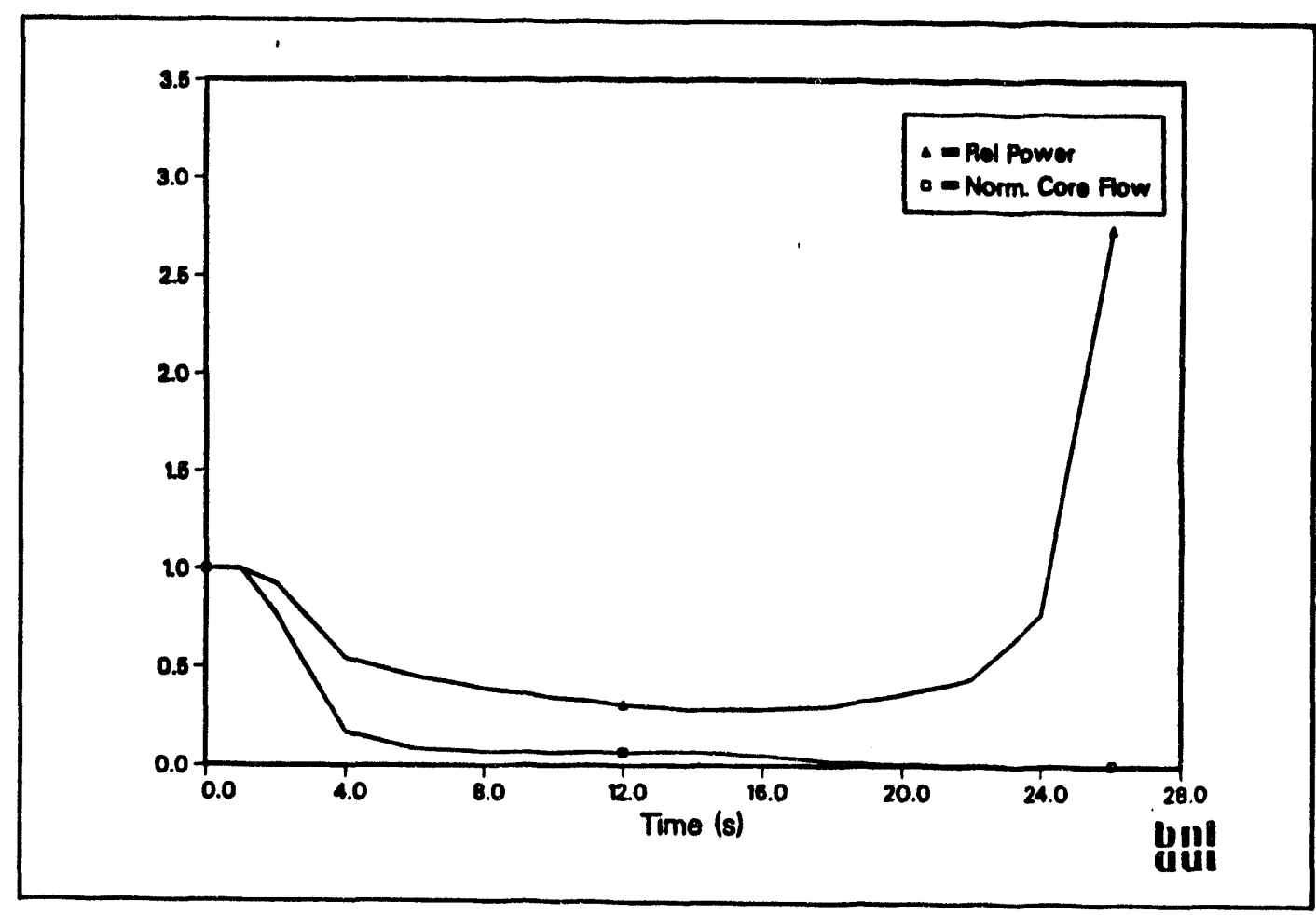

Figure B.53 Predicted relative power and normalized core flow from the SSC computer code for a total EM pump failure 
Appendix B

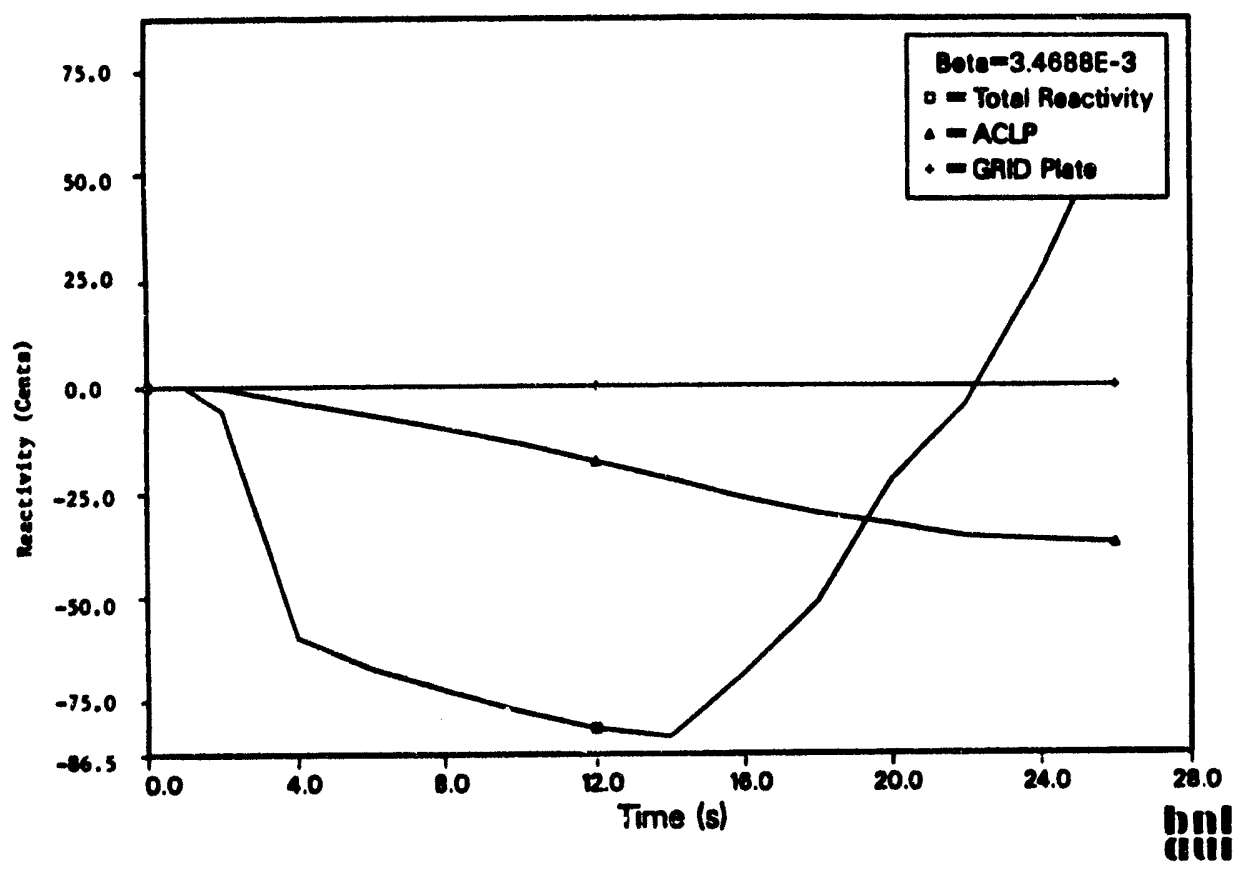

Figure B.54 Predicted total, above-core pad and core-support grid plate reactivity feedback from the SSC computer code for total EM pump failure

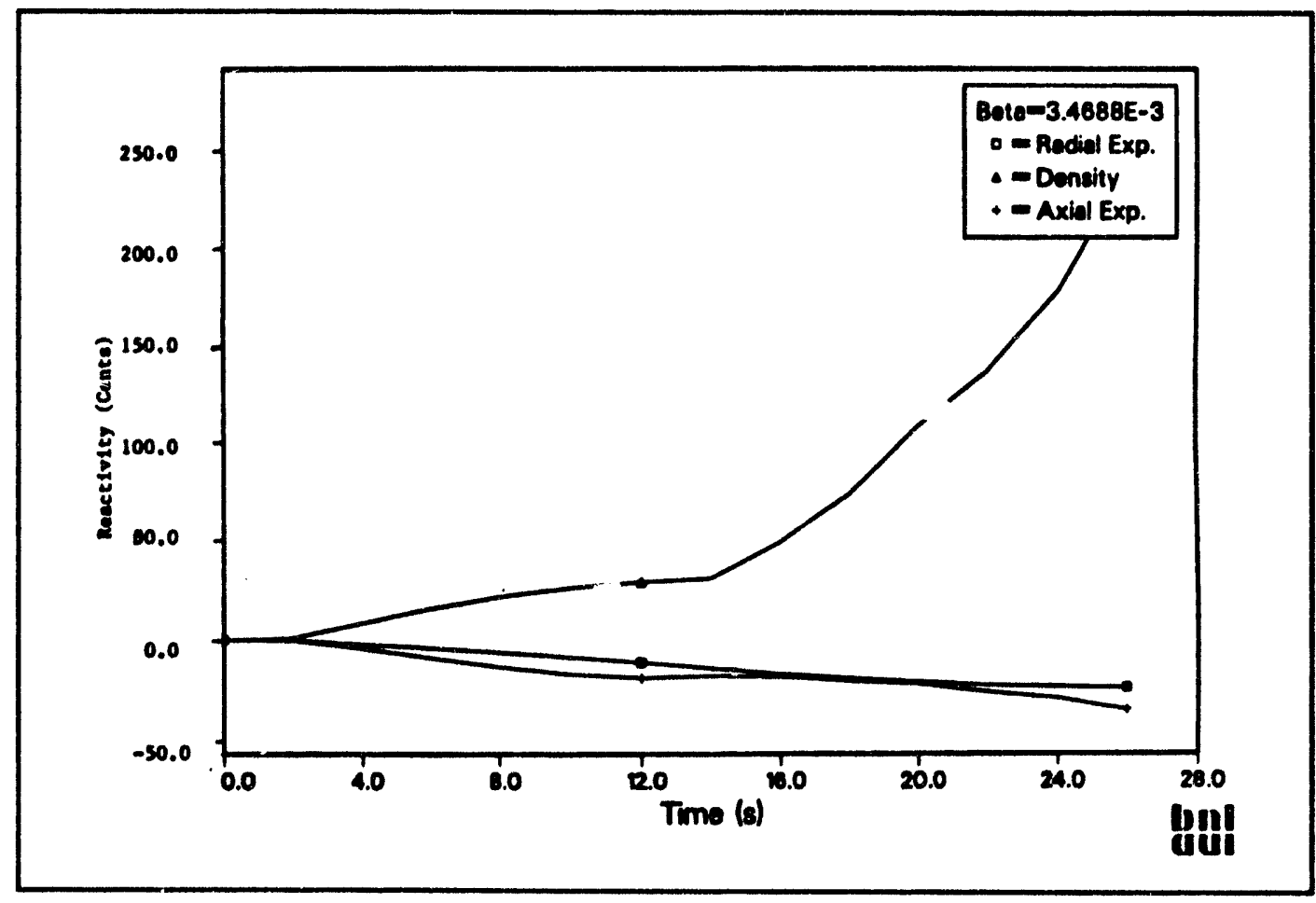

Figure B.55 Predicted core radial expansion, sodium density, and axial expansion reactivity feedback from the SSC computer code for a total EM pump failure 
Appendix B

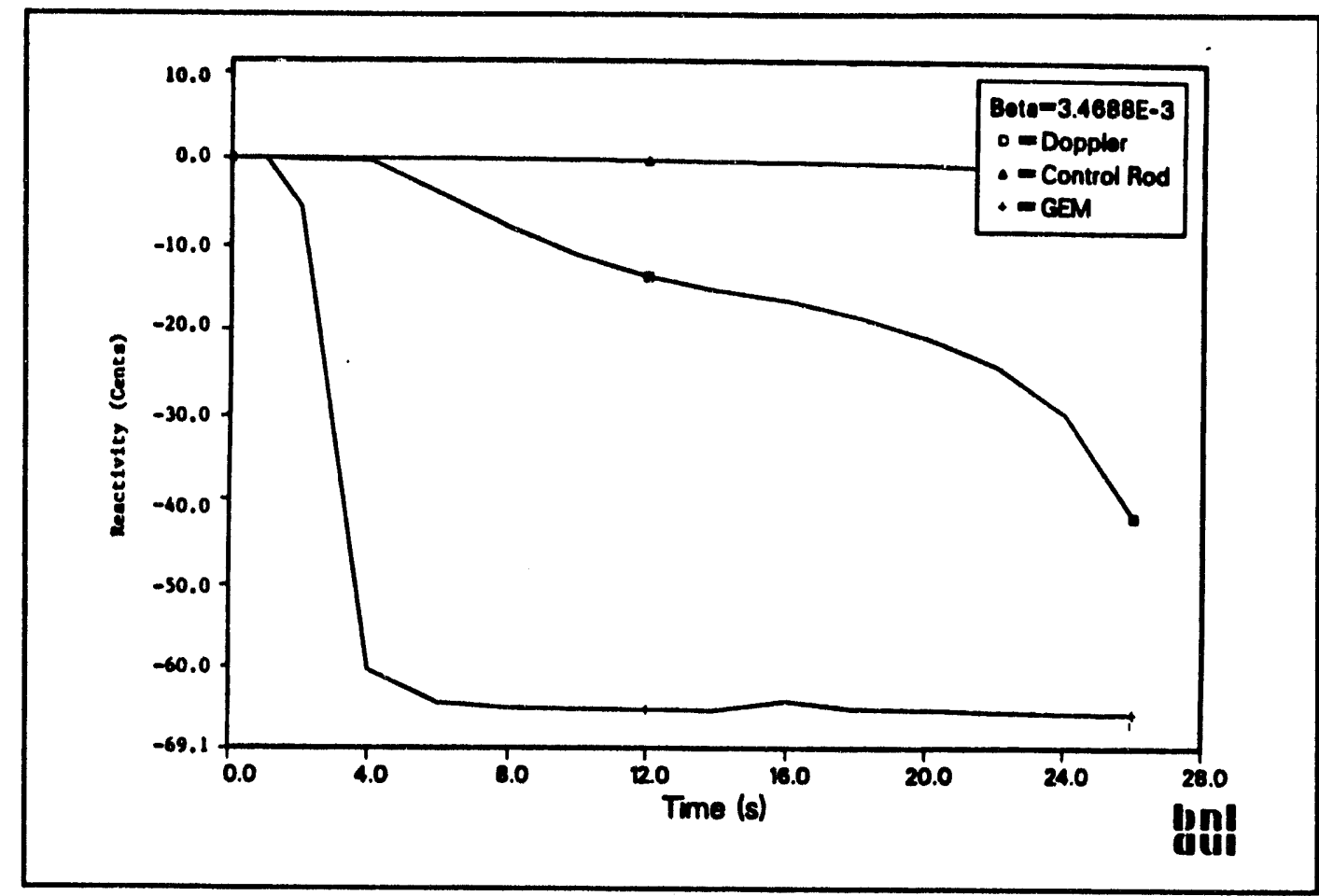

Figure B.56 Predicted Doppler, control rod drive line thermal expansion, and GEM reactivity feedback from the SSC computer code for a total EM pump failure

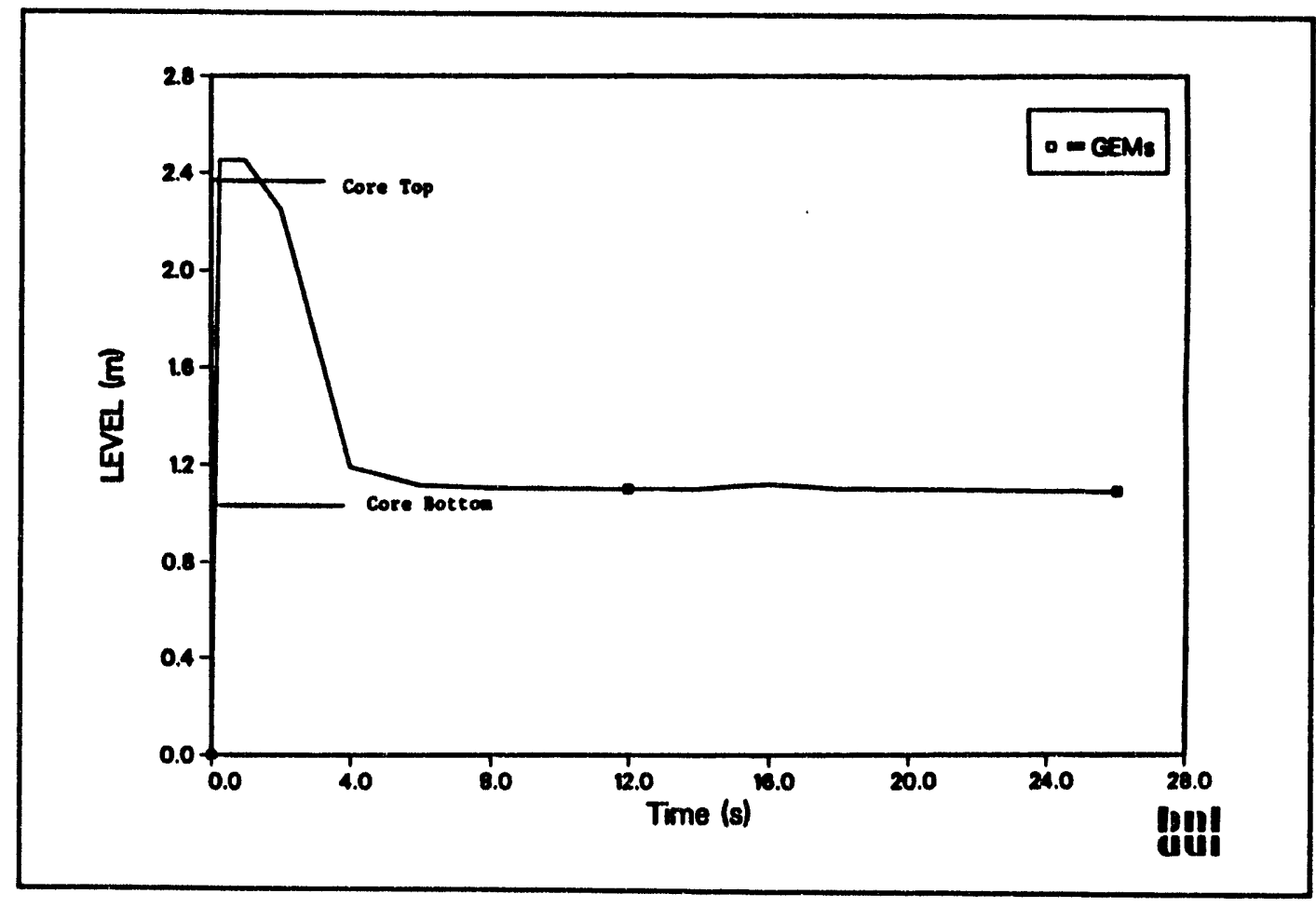

Figure B.57 Predicted sodium level in the GEMs from the SSC computer code for a total EM pump failure 
Appendix B

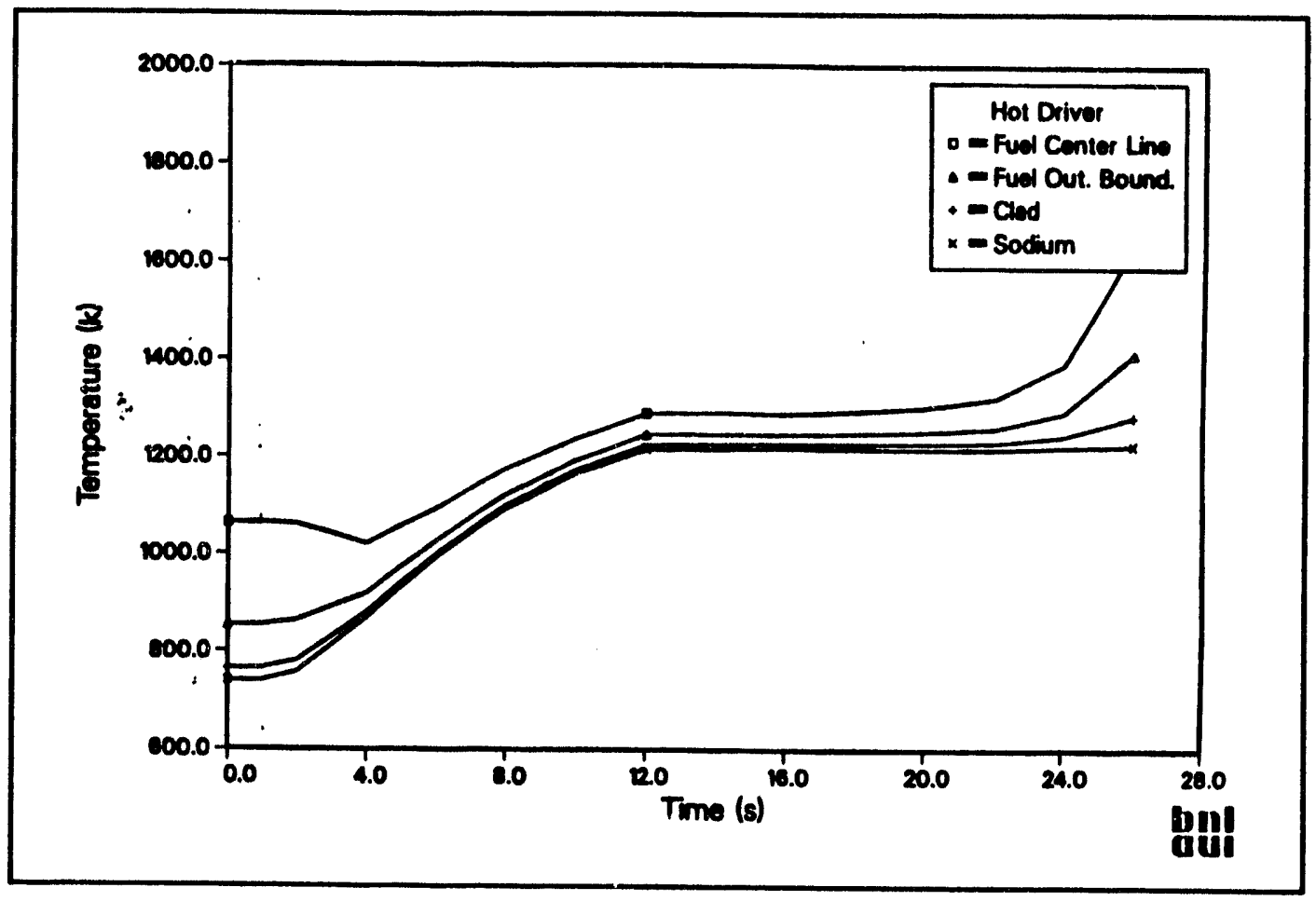

Figure B.58 Predicted fuel temperature distribution from the SSC computer for the third node from the TOP (i.e., $0.897 \mathrm{~m}-0.673 \mathrm{~m}$ ) for a total EM pump failure

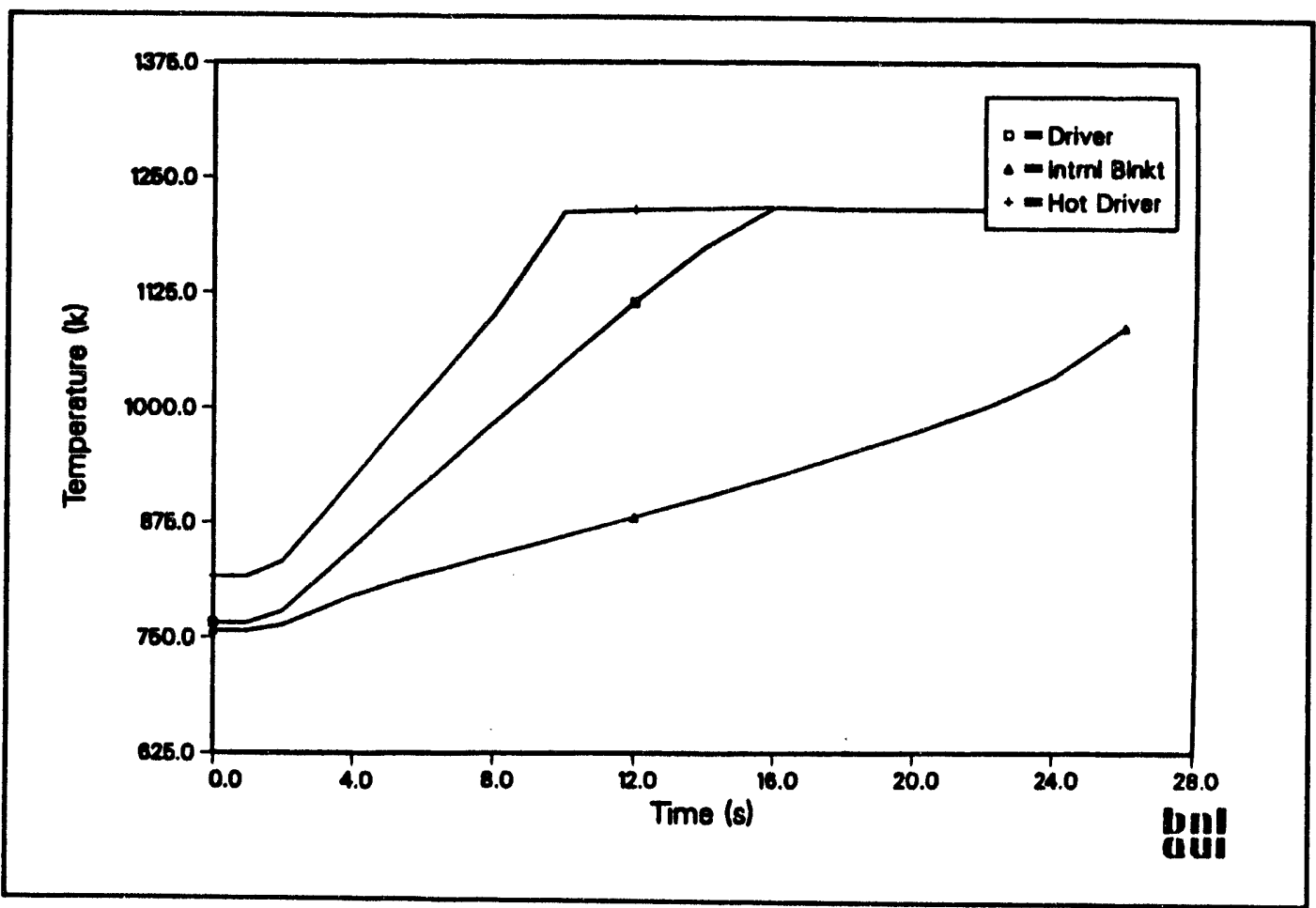

Figure B.59 Channel exit sodium temperature from the SSC computer code for a total EM pump failure 
Assuming the prediction of the sodium flow rate through the core (Figure B.52) is correct, this is clearly an event that must be avoided. The preapplicant recognizes the importance of ensuring a pump coastdown and appreciates that steps must be taken to ensure this event has an almost zero likelihood.

A second way of avoiding such a severe event is to ensure high scram reliability. An analysis of the no-coastdown event was performed using the same BNL codes, but this time with a scram coming 0.8 second after the pumps trip. The case was predicted with and without GEMs. In both cases, there is a large margin to sodium boiling and the peak fuel temperatures are acceptable. Cladding damage would be minor. Thus, it is not essential to get the pump coastdowns if the scram is successful.

\section{B.3.7.4 Cross-Comparison of ULOF Variations}

Peak temperatures from the four calculations, including one by GE (PSID Appendix G) and three by the staff, are cross-compared in Figure B.60. The two sets of bars on the left match up well with three out of four pump coastdowns for the ULOF as was expected since both use the same initial assumptions. The discrepancy in the peak fuel temperature is believed to result from GE's prediction that the fuel temperatures start upward before falling. This behavior cannot be accounted for; it is believed that the reactivity feedback from the GEMs should bring the power down faster than the fuel can heat up as a result of the lower sodium flow. The difference in fuel temperature is not significant and there are substantial safety margins for each calculation. There will be some cladding damage in this case, but it should not be extensive unless the event continues for a long time.

The third set of temperature bars in Figure B.60 is a sudden pump stoppage (seizure) without scram. These peak temperatures are fairly low, and this event does not appear to be threatening.

The fourth set of temperatures is for the assumed, although highly improbable, instantaneous stoppage of all four pumps without scram. The temperatures shown are taken from the last part of the calculation that SSC code could complete.

Overall, the addition of GEMs appears to improve the response for this category of events. Losing a pump or a single pump coastdown no longer appeared to be a major concern. However, the last case illustrates that the need for the pump coastdowns is very genuine and that anything that could eliminate all four pumps entirely and simultaneously must be guarded against. Finally, while the GEMs can be very helpful in this respect, there is the additional burden of monitoring the sodium level within the GEMs to ensure their ability to act promptly and effectively.

\section{B.4 Research and Development}

The research and development (R\&D) program outiined by GE covers many of the higher priority needs and includes some indications that there will be increased emphasis on examining factors important to accident mitigation. It is clear that most of the R\&D support will be in the metalfuels area, particularly a hot fuel examination facility (HFEF/South) and further testing in EBR-II.

Although GE did not discuss its planned R\&D for key severe accident issues, such as rapid axial expulsion and the behavior of molten metal fuel in sodium pools, it is clear that GE, along with the U.S. Department of Energy (DOE) and ANL, plans to increase the efforts in these areas. It is recognized that it will be difficult to develop such data and major results will not be expected in the near term.

While analyses of the postulated events discussed in this appendix are supportive of the $G E$ arguments regarding the PRISM passive reactor shutdown, there are substantive uncertainties in these calculations related to the EM pump performance and the metal-fuel performance. These uncertainties can be best resolved during the safety tests on the prototype facility.

\section{B.5 Safety Issues}

The following safety issues have been identified previously, in Chapters 4,5 , and 8 of this report, and are repeated here for convenience.

- Since postulated UTOP events may lead to some localized fuel melting, additional analyses or testing by the preapplicant will be necessary to determine how much, if any, localized fuel melting is acceptable in the ternary metal fuel.

- At elevated temperatures, the HT9 cladding begins to interact with the fuel to form a low-melt eutectic. The eutectic depends, in part, on the composition of the fuel in the outer radial zone, which in turn depends on the burnup level and the amount of component migration in the ternary metal fuel. It appears possible for significant eutectic formation to develop at temperatures as low as $903 \mathrm{~K}\left(1165^{\circ} \mathrm{F}\right)$, which, if confirmed, would indicate some cladding damage during several postulated events. The current design threshold temperature for eutectic formation is $980 \mathrm{~K}$ $\left(1300^{\circ} \mathrm{F}\right)$. 


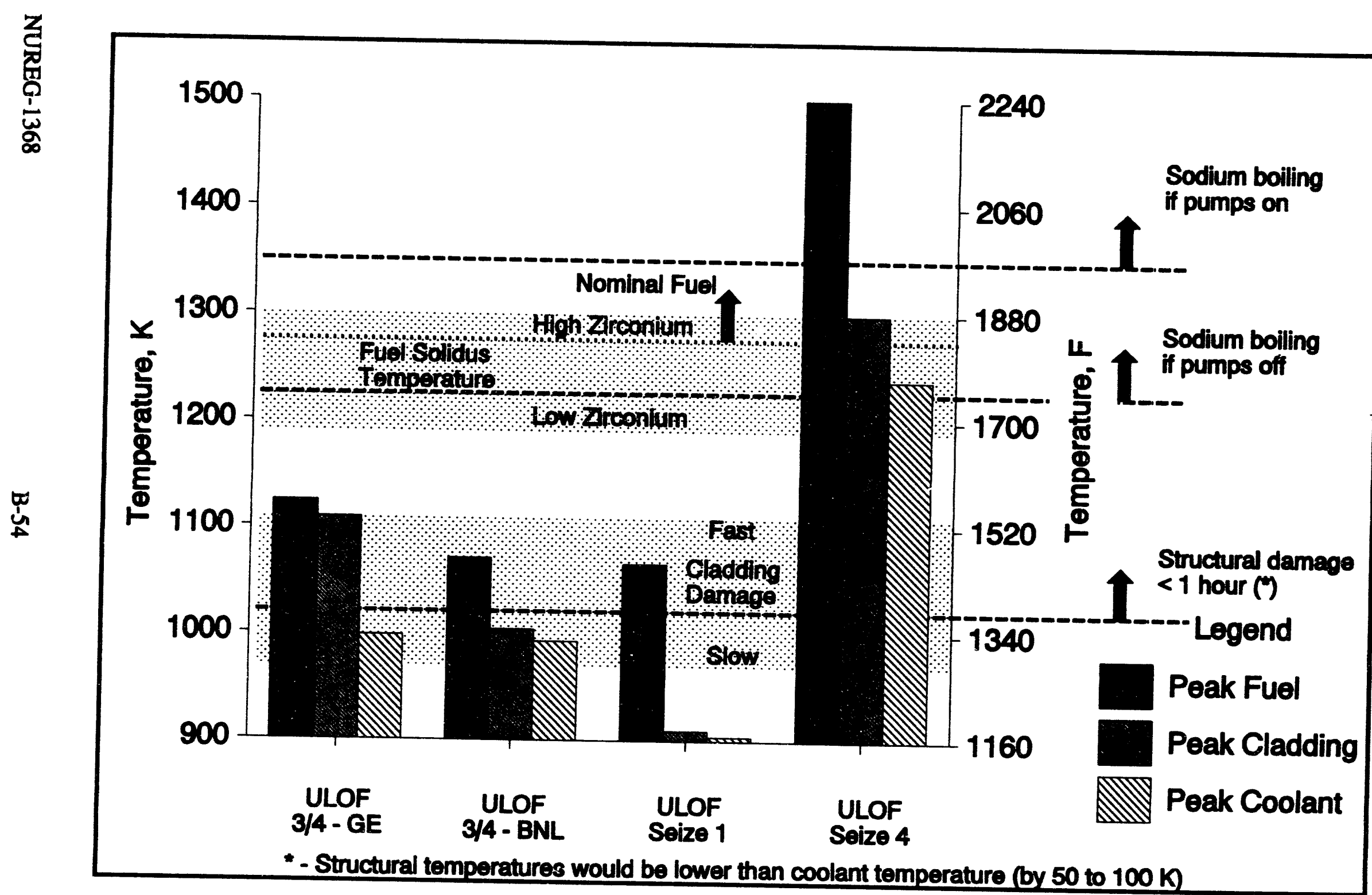

Figure B.60 Temperature summary for loss-of-flow events 
- The component migration in the fuel is not fully understood, although additional research results are scheduled to be available over the next year.

- The current postulater UTOP event is $40 \mathrm{c}$, and could result in some fuel damage, center-line melting, but no cledding failure. If the preapplicant chooses to reduce the maximum UTOP initiator, it will be necessary to review the method and results.

- Failure of all the pump coastdown devices during the ULOF class events could result in a core disruptive accident. While the failure of more than one of the constdown devices is expected to be very infrequent, precautions should be taken to make sure the chances of such multiple failures are very small.

- The GEMs are very helpful for ULOF events. However, there are potential safety issues associated with the GEMs. First, can they be tested in position on a routine basis? The preapplicant indicates that they can test the GEMs by varying the pump speeds, while the reactor is subcritical. In principle, such testing could be performed safely and the results should be fairly accurate on the basis of the change in subcritical neutron multiplication factors. Second, are they reliable and can deterioration in performance be detected during operation? It appears that the preapplicant has at least three options for monitoring the GEMs: using tag gas that can be detected if leaked, monitoring the neutron flux on the outer (away from the center of the core) side of the GEM duct, and subcritical testing the GEM worth during plant outages. Third, could the GEMs inadvertently insert $70 \mathrm{C}$ of reactivity at a crucial time? The preapplicant claims that it will be nearly impossible to reach full power critical without the pumps being on; therefore, the gas must be compressed into the region above the core under full-power conditions. However, this argument is based largely on operating procedures and human factors and will require additional evaluation at a later review stage.

- The rod stop system may provide a viable means of limiting the size of potential UTOP initiators, but there may be room for improvement in a couple of areas. Allowing the non-safety-grade plant control system (PCS) control over such an important safety system may not be the best choice. If the operator is to be able to make a judgment regarding the proposed adjustment he/she will need reliable instrumentation and adequate training. Also, the determination of how far up the rod stops should be moved must be done using a fairly elaborate calculation based on rod worth curves, burnup data, and detailed core-physics analysis.
Movement of all six rods $127 \mathrm{~mm}(0.5-\mathrm{in}$.) is worth slightly less than 10c, so the precision of the mechanical relocation does not seem a major concern.

\section{B.6 Evaluation}

\section{B.6.1 Can the GE Andyses for PRISM Be Replicated?}

Independent calculations led to similar predictions regarding the PRISM response to postulated unprotected events. This is encouraging, as the two independent calculations are indicating similar behavior, particulariy when modeling differences are considered. One weakness is that both codes are using the same reactivity parameters, although there are good reasons to believe that these reactivity numbers are approximately correct.

\section{B.6.2 Do We Agree With the GE Interpretation of the Analyses?}

GE has made an effort to bound the uncertainties in the reactivity parameters. However, GE has not considered uncertainties in pump coastdowns and other key system parameters such as temperatures, power level, and flow rates at the start of a transient or accident. The uncertainties may be somewhat larger than GE assumes, particularly for the loss-of-flow events.

\section{B.6.3 Have Key Events Been Overlooked?}

The capability of the PRISM to respond passively to various unprotected challenges is a design advantage. However, the existence of a large positive void worth is a clear vulnerability, and the preclusion of sodium boiling for the BEs via the passive shutdown characteristics is essential to accepting the current design. For the PRISM, the use of synchronous machines to provide EM pump constdown creates a potential vulnerability. Various ULOF events have been analyzed to determine the vulnerability to unlikely events related to EM pump coastdown failure.

\section{B.6.4 Gas Expansion Modules}

The GEMs were added to provide additional negative reactivity in response to loss-of-pumping events. It was thought that the passive reactivity feedhacks of the reactor would be sufficient for the passive shutdown mechanism to prevent damage in a ULOF event. The GEMs were added after new information on the performance of the ternary metal fuel and more careful analysis of the various anticipated fuel loading indicated that additional negative reactivity might be needed in a ULOF event. 


\section{Appendix B}

Behavior of the GEMs and their effectiveness under postulated transient conditions are discussed under Section B.3.7 "LOF Events With Constdown Failures." The GEMs improve the capability of PRISM to withstand ULOF events. They appear to be highly effective and helpful during such an event, even providing extra margin in case the synchronous machines are less effective than predicted, or in case one or two might fail entirely.

In summary, the preapplicant states it must still carefully weigh the risks against the benefits of having the GEMs in the design. With the GEMs in use, the PRISM response to ULOF events is improved. On the other hand, there may be some risks associated with their utilization, although none have yet been specifically identified.

\section{B.6.5 Control Rod Stops}

The PRISM control rod stop system is one of the more important safety systems in the current design because it limits the potential magnitude of UTOP initiators. Although the designer recognizes the expected high reliability of other key safety systems, the control rod stops are especially important because of the potentially rapid and severe development of reactivity events in LMR cores.

While it is difficult to develop meaningful probabilistic risk numbers for a system such as PRISM, in which key safety systems are new, untested, and largely passive, weaknesses in the system can be determined by engineering judgment. For the PRISM design documented in PSID Appendix G, the analysis points directly to the UTOP event. It is a combination of small Doppler feedback, zirconium migration, uranium migration, and perhaps plutonium migration, and low solidus temperatures that creates the vulnerability of the metal-fuel core. The best defense against the UTOP vulnerability is to ensure that only small reactivity insertions are possible. In the curnent PRISM design, this is achieved via the rod stops.

The current UTOP limit of $40 \mathrm{C}$ (including $10 \mathrm{C}$ to cover uncertainties) may be a bit too high, as shown in Section B.3.4. However, if this is reduced into the range of $30 \mathrm{C}$ to $35 \mathrm{c}$, then the UTOP predictions may move into an acceptable range. Therefore, it is quite possible the rod stops may be adjusted more frequently so as to limit reactivity insertion to less than $40 c$.

\section{B.7 Conclusions}

The reasonableness of the results of the GE calculations presented in PSID Appendix E and PSID Appendix $G$ have been largely confirmed by independent analyses and are considered credible. Review of the results indicates that because of the reactivity feedback characteristics of the IRISM, there is the potential for the PRISM response to several postulated unprotected events to be benign; therefore, some degree of passive shutdown safety is to be expected.

The recent design revisions have been quite significant. The increase in reactor power (for economic reasons) may have reduced some safety margins. Some changes also were required to compensate for a more current assessment of the ternary metal fuel. These changes include a reactor redesign and the addition of the GEMs and the control rod stop system.

As a result of these changes, it is believed that the PRISM system design has been improved, but that a more detailed evaluation of the ternary metal fuel has revealed some significant problems. The ANL experience with the high plutonium ( 26.5 percent) ternary metal fuel has been quite limited; therefore, some problems should be expected. Given time, ANL could resolve some of the current issues about plutonium migration and low eutectic temperatures.

Several postulated events were analyzed using such independent computer codes as SSC and MINET. In most cases, GE calculational results could be duplicated and most of the differences between the two predictions are understood.

Generally speaking, the PRISM RVACS has consistently stood up to close scrutiny, and it appears to be a very robust system. It is difficult to adequately factor this system into a PRA because most failure modes are barely credible. The most plausible failure mode may be a single failure (blockage of one duct or a leak in the reactor vessel, for example) in combination with previously unnoticed degradation in some key performance characteristics. While this combination may be unlikely, it may be more likely than either a double-vessel failure or the complete blockage of all four air ducts.

The situation regarding the passive reactor shutdown is far more complex, especially since the flow of data for PRISM-specific ternary metal fuel has only recently begun. ANL, presumably, will eventually obtain the performance that is required, including adjustments in the fuel composition or density if required. However, the ternary metal-fuel behavior appears to be very complex and there is evidence of some undesirable redistribution of the uranium, zirconium, and perhaps the plutonium, components.

The greatest challenge for the current design characterization appears to be the UTOP event, which boosts fuel center-line temperatures. A $40 \mathrm{C}$ initiator may 
be too large, given the current knowledge of the ternary fuel, and GE may need to adjust the rod stops more frequently to reduce the largest TOP initiator into the $30 \mathrm{C}$ range. GE clearly has some options in this area.

Because of the GEMs, the passive shutdown now appears to work much better for the ULOF events. As long as there is at least a partial cosstdown provided by the synchronous machines, the PRISM response to the ULOF category of events should be acceptable. The high reliability of the EM pump constdown machines must be demonstrated.

The PRISM passive shutdown has always appeared to perform well for the LOHS events, and nothing has changed significantly with the revised design. If there are problems here, they will develop only if the event continues for a long time, and the addition of the USS makes this very unlikely.

The main problem with the non-TOP unprotected events is at the fuel-cladding interface. ANL seems confident that the rate of eutectic formation at the temperatures experienced during the unprotected events is very slow, so minimal damage is to be expected. However, the behavior of the ternary metal-fuel is very complex and further experimental data will be needed before it can be concluded that the cladding damage will be minimal.

\section{B.8 References}

B.1. General Electric, PRISM-Preliminary Safesy Information Document, GEFR-00793 UC-87Ta, November 1986.
B.2. U.S. Nuclear Regulatory Commission, "Draft Preapplication Safety Evaluated Report for Power Reactor Inherently Safe Module Liquid Metal Reactor," NUREG-1368, September 1989.

B.3. U.S. Nuclear Regulatory Commission, "Summary of Advanced LMR Evaluations - PRISM and SAFR," NUREG/CR-5364 (BNL-NUREG-52197), October 1989.

B.4. Van Tuyle, G.J., et al., "Analyses of Unscrainmed Events Postulated for the PRISM Design, " Nuclear Technology, 91, August 1990.

B.5. U.S. Nuclear Regulatory Commission, "Evaluation of 1990 PRISM Design Revisions," NUREG/CR-5815 (BNL-NUREG-52311), March 1992.

B.6. U.S. Nuclear Regulatory Commission, "Super System Code (SSC, Rev. 0) An Advanced Thermohydraulic Simulation Code for Transients in LMRBRs," NUREG/CR-3169 (BNL-NUREG-51659), April 1983.

B.7. U.S. Nuclear Regulatory Commission, "MINET Code Documentation," NUREGiCR-3668 (BNL-NUREG-51742), December 1989.

B.8. Van Tuyle, G.J., "A Momentum Integral Network Method for Thermal-Hydraulic Systems Analysis," Nuclear Engineering and Design, 91:17-28. 


\section{APPENDIX C}

\section{ADVISORY COMMITTEE ON REACTOR SAFEGUARDS LETTER}




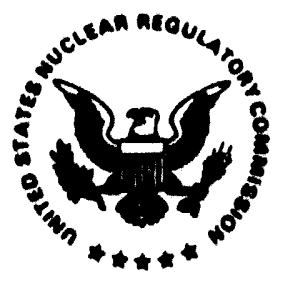

UNITED STATES

NUCLEAR REGULATORY COMMISSION

Appendix C ADVISORY COMMITTEE ON REACTOR SAFEGUARDS

WASHINGTON, D. C. 20858

November 10,1993

The Honorable Ivan Selin

Chairman

U.S. Nuclear Regulatory Commission

Washington, D.C. 20555

Dear Chairman selin:

SUBJECT: SECY-93-289, "ISSUANCE OF THE DRAFT PREAPPLICATION SAFETY EVALUATION REPORT (PSER) FOR THE POWER REACTOR INNOVATIVE SMALL MODULE (PRISM) LIQUID-METAL REACTOR"

During the 403 rd meeting of the Advisory Committee on Reactor Safeguards, November 4-6, 1993, we heard presentations by representatives of the NRC staff and General Electric Nuclear Energy on the subject SECY paper that proposes the issuance of a draft inal Preapplication safety Evaluation Report (PSBR) for the Power Reactor Innovative Small Module (PRISM) Reactor for comment. We also had the benefit of the documents referenced.

Consistent with the Commission's advanced reactor policy, the staff has, to the extent reasible, used existing regulations to formulate criteria and procedures for review of this design. Where necessary the staff has created additional criteria and procedures, following the guidance furnished by the Commission in the staff Requirements Memorandum dated July 30, 1993, that dealt with key policy issues for advanced reactors. Because the staff review was based on a conceptual design, the PSER did not, nor was it intended to, result in an approval of the design. Instead it identified certain key safety issues, provided some guidance on applicable licensing criteria, assessed the adequacy of the preapplicant's research and development programs, and concluded that no obvious impediments to licensing the PRISY design had been identified.

Although our own review of the PSER was less detailed than would have been appropriate for a safety evaluation report on an actual application, we believe that the staff has satisfactorily fulfilled its role in the preapplication process. We agree with the staff's proposal to provide the PSER to the U.S. Department of Energy. 
Appendix C

Dr. William $J$. Shack did not participate in the Committee's deliberation regarding this matter.

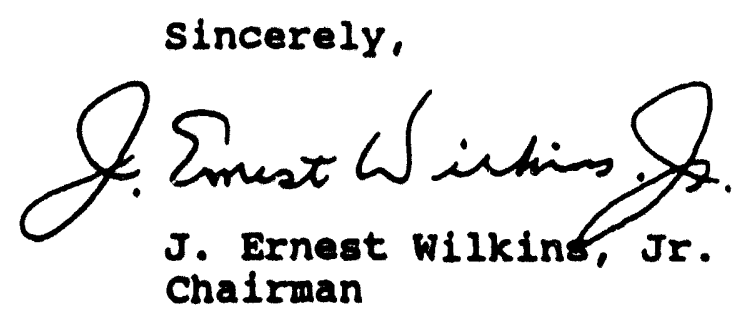

\section{Reterences:}

1. SECY-93-289, dated October 19, 1993, Memorandum from James $M$. Taylor, NRC Executive Director for Operations, for the Commissioners, Subject: Issuance of the Draft Preapplication Safety Evaluation Report (PSER) for the Power Reactor Innovative Small Module (PRISK) IIquid-ketal Reactor

2. U.S. Nuclear Regulatory Commission, NUREG-1368, "Preapplication Safety Evaluation Report (PSER) for the Power Reactor Innovative Small Module (PRISM) Liquid Metal Reactor," October 1993

3. Staff Requirements Memorandum dated July 30, 1993, from S. Chilk, secretary of the Commission, NRC, to J. M. Taylor, NRC Executive Director for Operations, Subject: sEcy-93-092 Issues Pertaining to the Advanced Reactor (PRISM, MHTGR, and PIUS) and CANDU 3 Designs and Their Relationship to Current Regulatory Requirements 


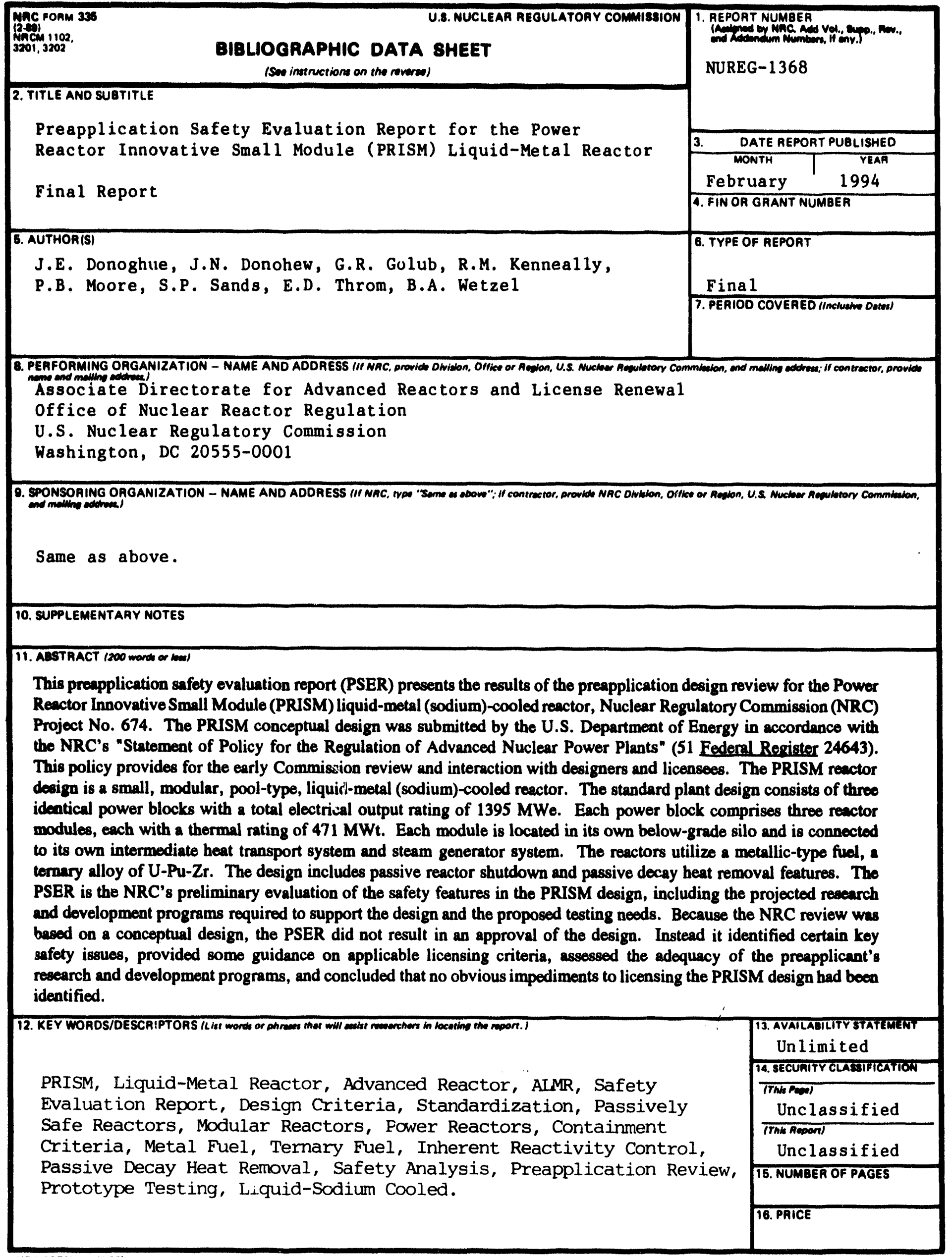




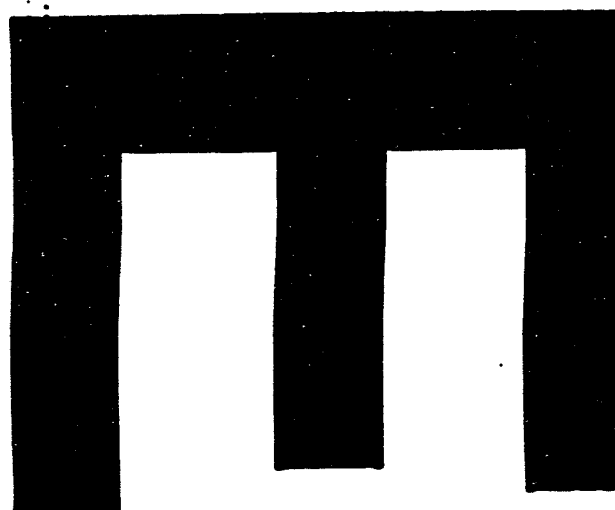

$\cdots$

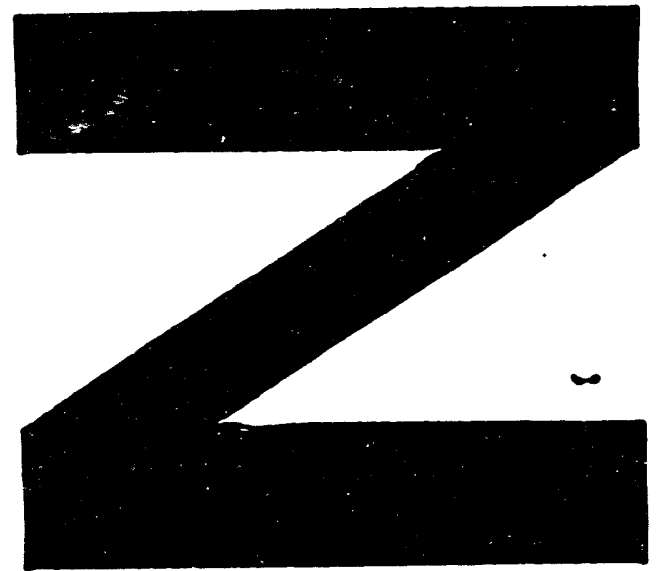

2
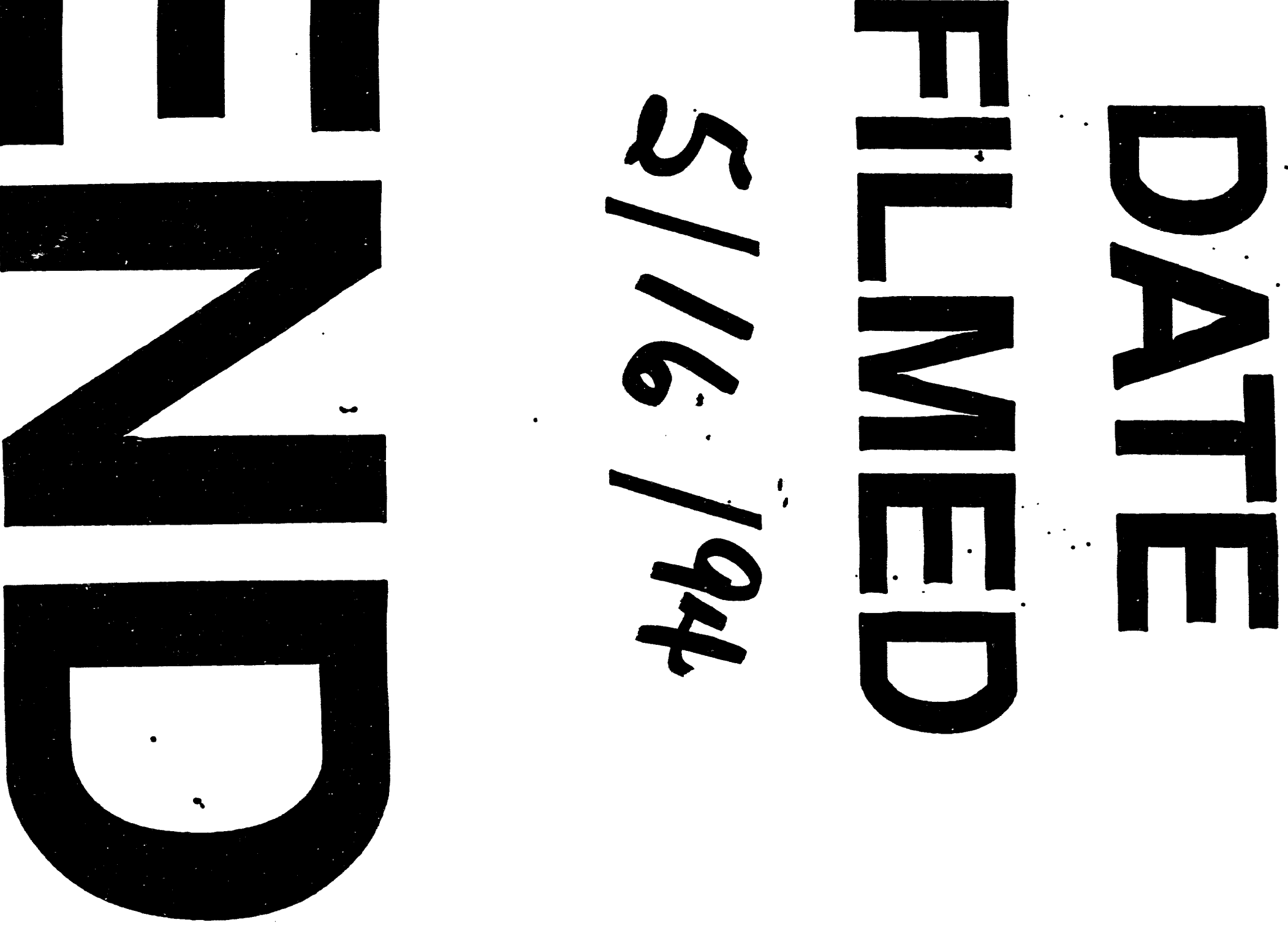
